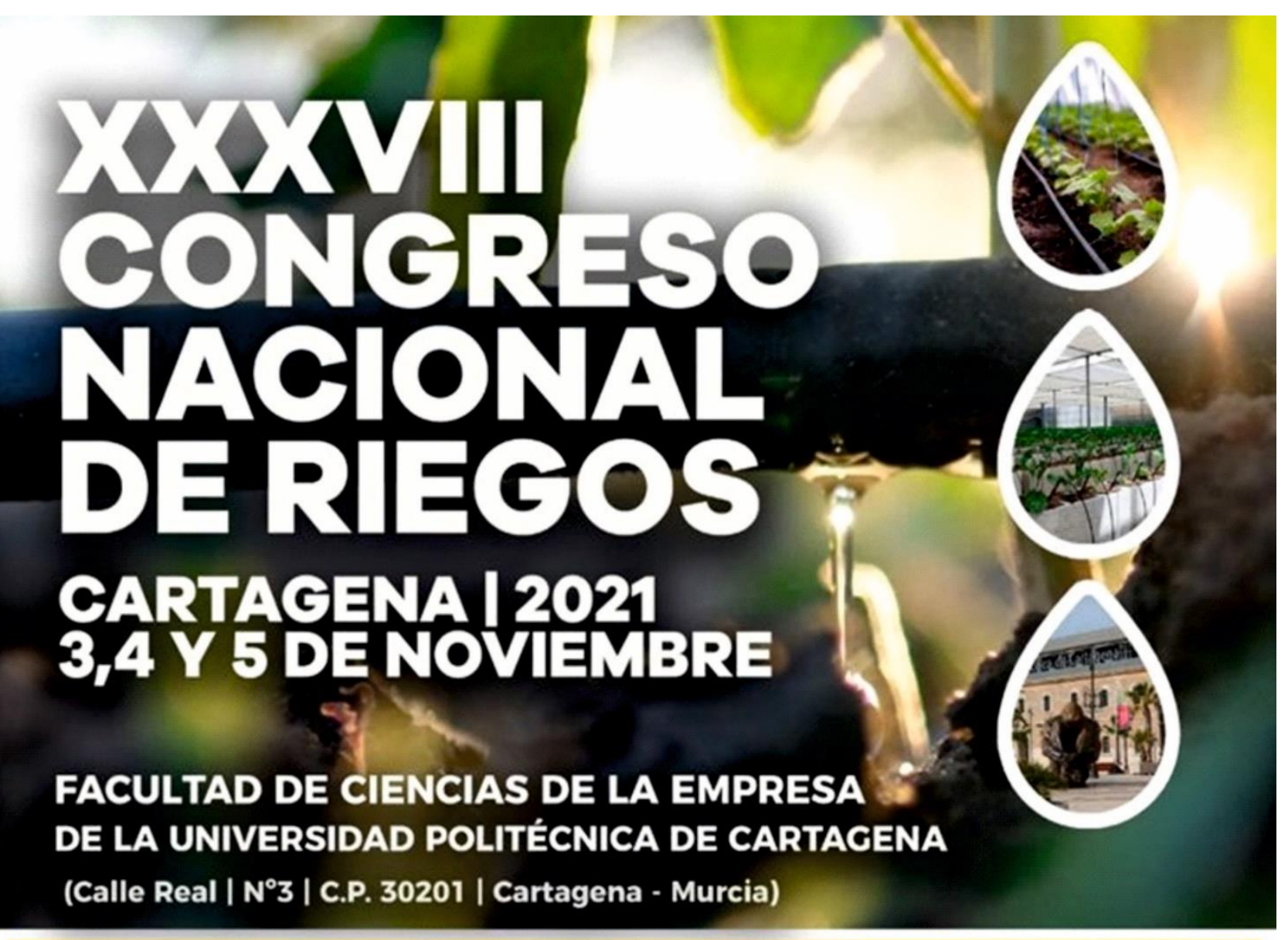

\title{
ORGANIZADORES:
}

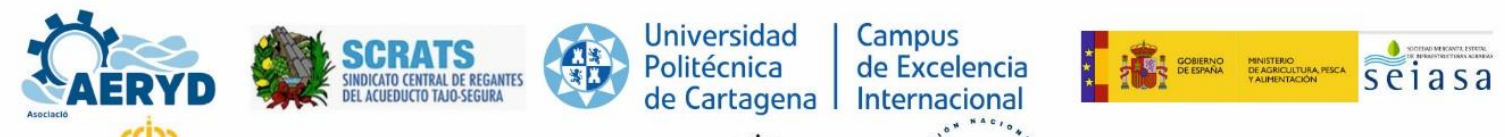
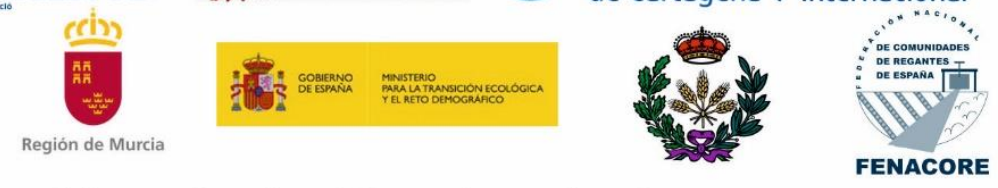

$\frac{1}{\nabla} \underset{\text { Grantrap protesional Servicio publico }}{\text { Grupo }}$

PATROCINADORES Y COLABORADORES:

174UD 2 mOLECOR
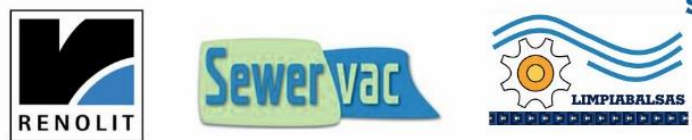

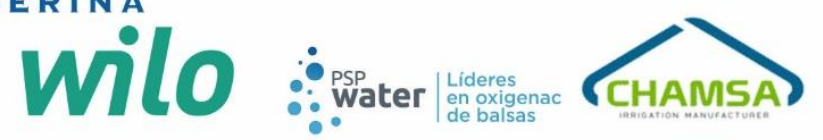

M $\mathrm{H}$ MH

A $\overline{\text { Aвogados }}$

(4) NOKS ES Inidroten

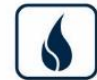

nutricontrol

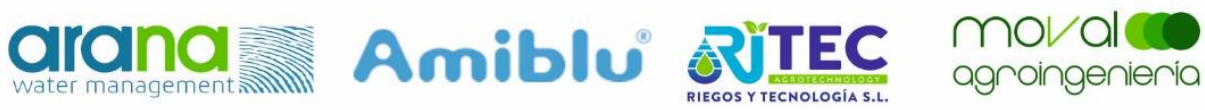

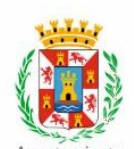

Ayuntamiento
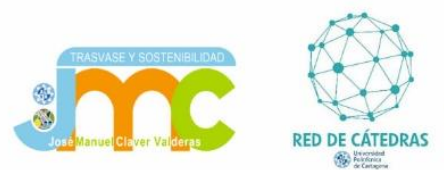

悡 COGITARMIE

(S) sotrafa

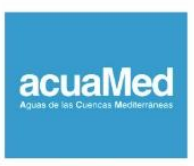

$\approx$

Comunidad de Regantes 


\section{Congreso Nacional de Riegos}

\section{CARTAGENA 2021}


Edita:

Universidad Politécnica de Cartagena

Ediciones UPCT

Plaza del Hospital, 1

30202 Cartagena

Teléfono: 968325908

ediciones@upct.es

Maquetación:

Asociación Española de Riegos y Drenajes (AERYD), José Francisco Maestre Valero y Victoriano M artínez Alvarez

DOI: 10.31428/10317/10078

HANDLE: http://hdl.handle.net/ 10317/10078

ISBN: 978-84-17853-40-2 


\title{
XXXVIII CONGRESO NACIONAL DE RIEGOS
}

Cartagena, 3, 4 y 5 noviembre 2021

\section{https://aeryd.es/events/xxxviii-congreso-nacional-cartagena/}

\section{BOLETIN FINAL}

\section{ENTIDADES ORGANIZADORAS}

ASOCIACIÓN ESPAÑOLA DE RIEGOS Y DRENAJES - AERYD

SINDICATO CENTRAL DE REGANTES DEL ACUEDUCTO TAJO SEGURA - SCRATS

UNIVERSIDAD POLITÉCNICA DE CARTAGENA - UPCT

SOCIEDAD ESTATAL DE INFRAESTRUCTURAS AGRARIAS - SEIASA

MINISTERIO PARA LA TRANSICIÓN ECOLÓGICA Y EL RETO DEMOGRÁFICO - MITECO

COMUNIDAD AUTÓNOMA REGIÓN DE MURCIA - CARM

FEDERACIÓN NACIONAL DE COMUNIDADES DE REGANTES - FENACORE COLEGIO OFICIAL DE INGENIEROS AGRÓNOMOS REGIÓN DE MURCIA - COIARM

EMPRESA DE TRANSFORMACIÓN AGRARIA, S.A. - TRAGSA

\section{EMPRESAS PATROCINADORAS-EXPOSITORAS}

\author{
SISTEMA AZUD, S.A. \\ SEWERVAC-IBERICA, S.L. \\ MOLECOR TECNOLOGÍA, S.L. \\ EPG Y SALINAS, S.L. \\ EMPRESA DE TRANSFORMACIÓN AGRARIA, S.A. \\ PSP WATER, S.L. \\ HIDROTEN, S.A. \\ AMIBLU PIPES SPAIN, S.A. \\ WILO IBERICA S.A. \\ RENOLIT IBÉRICA, S.A. \\ MALLO Y HOYOS ABOGADOS S.L.
}


ARANA WATER MANAGEMENT S.L.

RIEGOSALZ S.L.

NOKSEL ESPAÑA, S.A.

SERINA SERVICIOS DE INGENIERIA Y ARQUITECTURA S.L.

GRUPO CHAMARTIN S. A.

PREFABRICADOS DELTA S.A.

RIEGOS Y TECNOLOGÍA S.L

NUTRICONTROL, S.L.

\section{ENTIDADES COLABORADORAS}

AYUNTAMIENTO DE CARTAGENA

COMUNIDAD DE REGANTES DEL CAMPO DE CARTAGENA

CÁTEDRA TRASVASE Y SOSTENIBILIDAD - JOSÉ MANUEL CLAVER VALDERAS

RED DE CÁTEDRAS UPCT

SOTRAFA S.A.

COLEGIO OFICIAL DE INGENIEROS TÉCNICOS AGRÍCOLAS DE LA REGIÓN DE MURCIA ACUAMED

MOVAL AGROINGENIERIA S.L 


\title{
COMITÉ ORGANIZADOR
}

\author{
Presidentes: \\ Da. Beatriz Miguel Hernández, Rectora de la UPCT. \\ D. Lucas Jiménez Vidal, Presidente del SCRATS.
}

\section{Secretarios:}

Central: Secretaría AERYD.

Local: D. Alejandro Pérez Pastor. Catedrático de la UPCT.

\section{Vocales:}

D. José Ma González Ortega, Presidente de la AERYD.

D. Alfonso Botía Ordaz, Secretario General del SCRATS.

D. Roberto Ocón Pérez de Albéniz, Gerente de Regadíos Grupo TRAGSA.

D. Miguel Valero Ganau, Jefe de Obras, Proyectos y Explotación de SEIASA (Valencia).

D. José Sandoval Moreno, Director General del Agua de la CARM.

D. Francisco Javier García Garay, Comisario de Aguas de la CHS.

D. Andrés Antonio Martínez Bastida, Decano del COIARM.

D. Mariano Soto García, Secretario General de la CRCC.

D. Victoriano Martínez Álvarez, Catedrático de la UPCT. 


\section{COMITÉ CIENTÍFICO-TÉCNICO}

\section{GRUPO A: Investigación, desarrollo e innovación en riego y drenaje.}

Coordinador: Dr. Rafael Domingo Miguel (UPCT).

Dra. María del Carmen Ruíz Sánchez (CEBAS-CSIC).

Dr. Bernardo Pascual España (Universidad Politécnica de Valencia).

Dr. José Manuel Miras Avalos (Centro de Investigación y Tecnología Agroalimentaria de Aragón).

Dr. Alfonso Moriana Elvira (Universidad de Sevilla).

Dr. Roque Torres Sánchez (Universidad Politécnica de Cartagena).

Dr. Luis Gonzaga Sanesteban García (Universidad Pública de Navarra).

\section{GRUPO B: Ingeniería y gestión de regadíos}

Coordinador: Dr. Victoriano Martínez Álvarez (UPCT).

Dr. Luis Juana Sirgado (Universidad Politécnica de Madrid).

Dr. Manuel Valiente Gómez (Universidad de Castilla La Mancha).

Dr. Emilio Camacho Poyato (Universidad de Córdoba).

Dr. Gerard Arbat Pujolras (Universidad de Girona).

Dr. José Francisco Maestre Valero (Universidad Politécnica de Cartagena).

Dr. Juan Manzano Juárez (Universidad Politécnica de Valencia).

\section{GRUPO C: Balsas de Riego}

Coordinador: Dr. José María González Ortega (TRAGSA)

Dr. Francisco J. Sánchez Romero (Universidad Politécnica de Valencia).

Dr. Juan Bautista Torregrosa Soler (Universidad Politécnica de Valencia).

Dr. Francisco Zapata Raboso (Generalitat Valenciana).

D. Andrés Antonio Martínez Bastida (Colegio Oficial de Ingenieros Agrónomos de la Región de Murcia).

D. Sebastián Delgado Amaro (Consejería de Agua, Agricultura, Ganadería, Perca y Medio Ambiente).

D. Miguel Majuelos Moraleda (Sociedad Mercantil Estatal de Infraestructuras Agrarias).

D. Escolástico Aguiar González (Balten).

D. José Luis Cuenca Lorenzo (Tencate). 


\section{Congreso Nacional de Riegos \\ CARTAGENA 2021

\section{GRUPOS TEMÁTICOS - RELACIÓN DE TRABAJOS}

\section{GRUPO A: INVESTIGACIÓN, DESARROLLO E INNOVACIÓN EN RIEGO Y DRENAJE}

\begin{tabular}{|c|c|c|}
\hline Referencia & Tipo & Título y autores \\
\hline A-01-2021 & Oral & $\begin{array}{l}\text { Determinación del estado hídrico en viña a través de imágenes RGB y } \\
\text { multiespectrales adquiridas por un VANT. } \\
\text { López García, P., Ortega Álvarez, J.F., Moreno Hidalgo, M.A., Ballesteros González, R. }\end{array}$ \\
\hline A-02-2021 & Oral & $\begin{array}{l}\text { Caracterización técnico-económica de la reducción de boro en agua } \\
\text { marina desalinizada mediante resinas de intercambio iónico. } \\
\text { Imbernón, A., Martínez-Álvarez, V., Gallego-Elvira, B., Martín-Gorriz, B., Molina-del Toro, R., } \\
\text { Jodar-Conesa, F.J., Maestre-Valero, J.F. }\end{array}$ \\
\hline A-03-2021 & Oral & $\begin{array}{l}\text { Estudio de la gestión de las estrategias de riego en los olivares } \\
\text { tradicionales. } \\
\text { Molina-Moral, J.C., Moriana Elvira, A., Pérez-Latorre, F.J. }\end{array}$ \\
\hline A-04-2021 & Oral & $\begin{array}{l}\text { Necesidades de agua de riego en una explotación comercial de almendro } \\
\text { mediante teledetección. } \\
\text { Pérez García, Yeray, Campoy Urrea, Jaime, Calera Belmonte, Alfonso. }\end{array}$ \\
\hline A-05-2021 & Oral & $\begin{array}{l}\text { Riego deficitario en granado. Relaciones hídricas y crecimiento del fruto } \\
\text { Domingo Miguel, R., Blaya Ros P.J., Quartarella T., Martínez López, M., Moreno Hernández G., } \\
\text { Giménez Gallego, J. Torres Sánchez, R. }\end{array}$ \\
\hline A-06-2021 & Póster & $\begin{array}{l}\text { Estudio de indicadores de suelo y planta para la programación del riego en } \\
\text { cerezos jóvenes. } \\
\text { Blaya-Ros, P.J., Blanco Montoya, V., Torres-Sánchez, R., González-Teruel, J.D., Espósito, M.E., } \\
\text { Domingo Miguel, R. }\end{array}$ \\
\hline A-07-2021 & Oral & $\begin{array}{l}\text { Evaluación de la programación del riego de parcelas de cítricos mediante } \\
\text { predicciones meteorológicas. } \\
\text { Carricondo Anton, J.M., Jiménez-Bello, M.A., Sala Piqueras, A., Martínez Gimeno, M.A., Bonet } \\
\text { L., Pérez-Pérez, J.G., Intrigliolo D. }\end{array}$ \\
\hline A-08-2021 & Oral & $\begin{array}{l}\text { Estudio comparativo del manejo del riego por goteo en almendro en marco } \\
\text { de plantación intensivo y súperintensivo en el Centro Nacional de } \\
\text { Tecnología de Regadío (CENTER). } \\
\text { Sánchez de Ribera González, Alejandro, Cervantes Díaz-Toledo, Alfonso; Madurga del Cura, } \\
\text { Cristina2; Muñoz Sopeña, Daniel; Rodríguez Fernández, Diego; Zazo Salinero, Teresa. }\end{array}$ \\
\hline A-09-2021 & Oral & $\begin{array}{l}\text { Integración de modelos hidráulicos, de distribución de agua y de cultivo } \\
\text { para el análisis holístico de sistemas de riego por aspersión fija. } \\
\text { Morcillo García, Manuel, Moreno Hidalgo, Miguel Ángel, Rocío Ballesteros Gonzalez, Jesús } \\
\text { Montero Martínez, Amaro del Castillo Sánchez-Cañamares. }\end{array}$ \\
\hline A-10-2021 & Poster & $\begin{array}{l}\text { Efectos de la supresión del riego durante la postcosecha de nectarinos } \\
\text { extra-tempranos en la acumulación de reservas, producción y calidad del } \\
\text { fruto. } \\
\text { Conesa, M.R., Conejero, w., Vera, J., Ruiz-Sánchez, M.C. }\end{array}$ \\
\hline A-11-2021 & Oral & $\begin{array}{l}\text { Evaluación de sensores de contenido de agua en el suelo para gestionar } \\
\text { riegos de precisión. } \\
\text { Vera, J., Conejero, W., Conesa, M.R., Mira-García, A.B., Ruiz-Sánchez, M.C. }\end{array}$ \\
\hline A-12-2021 & Oral & $\begin{array}{l}\text { Aplicación de la termografía con dron para la evaluación de la eficiencia } \\
\text { del riego por aspersión. } \\
\text { López Rodríguez, M,Salvatierra Bellido, B, Jarén Morilla, C }\end{array}$ \\
\hline A-13-2021 & Oral & $\begin{array}{l}\text { Mejora del manejo del riego por surcos en el Bajo Guadalquivir. } \\
\text { Salvatierra Bellido, B., Jarén Morilla, C., López Rodríguez, M. }\end{array}$ \\
\hline A-15-2021 & Oral & $\begin{array}{l}\text { Preciriego: Un proyecto de colaboración público-privada para adaptar la } \\
\text { irrigación de precisión al riego por goteo de los cultivos leñosos. } \\
\text { Gonzalez, L., Intrigliolo, D., Ortega, J.F., Ballesteros, R., Ramirez-Cuesta, J.M., del Castillo, A., } \\
\text { García, F.J., Munuera, M.T., Moreno, M.A. }\end{array}$ \\
\hline A-16-2021 & Oral & $\begin{array}{l}\text { Reutivar: App para la programación óptima de fertirriego con agua } \\
\text { regenerada. } \\
\text { González Perea, R., Alcaide Zaragoza, C., Fernández García, l., Camacho Poyato, E., Rodríguez } \\
\text { Díaz, J.A. }\end{array}$ \\
\hline A-17-2021 & Oral & Efecto de la frecuencia de riego en parámetros cuantitativos y cualitativos \\
\hline
\end{tabular}




\begin{tabular}{|l|l|l|}
\hline & & $\begin{array}{l}\text { de la Vitis vinifera cV. Syrah. } \\
\text { Montoro Rodríguez, A., Picazo Denia, H., Mañas Jiménez, F. }\end{array}$ \\
\hline A-18-2021 & Oral & $\begin{array}{l}\text { Plataforma de supervisión y control de riego localizado en cultivos } \\
\text { leñosos. } \\
\text { Domínguez-Niño, J.M., Munuera, M.T., Nortes, P., Masdemont, B., Buitrago, J.M., Ponce, L., } \\
\text { Tornero, J.F., García, F.J. }\end{array}$ \\
\hline A-19-2021 & Poster & $\begin{array}{l}\text { Integración de nuevas soluciones plásticas con propiedades antioxidantes } \\
\text { en sistemas de irrigación destinados a la reutilización de agua en } \\
\text { agricultura de precisión. } \\
\text { Munuera, M.T., Nortes, P., Domínguez-Niño, J.M., Ponce, L., Masdemont, B., Buitrago, J.M. }\end{array}$ \\
\hline A-20-2021 & Oral & $\begin{array}{l}\text { Utilidad de la termografía para evaluar cambios fisiológicos en árboles de } \\
\text { pomelo regados con agua regenerada y riego defici-tario combinado. } \\
\text { Romero-Trigueros, C., Bayona, J.M., Parra, M.., Nortes, P.A.., Nicolás, E. }\end{array}$ \\
\hline
\end{tabular}

\section{GRUPO B: INGENIERÍA Y GESTIÓN DE REGADÍOS}

\begin{tabular}{|c|c|c|}
\hline Referencia & Tipo & Título y autores \\
\hline B-02-2021 & Oral & $\begin{array}{l}\text { Límite de la zona saturada bajo riego por goteo superficial. Modelo } \\
\text { analítico y empírico. } \\
\text { del Vigo, A., Zubelzu, S., Juana, L. }\end{array}$ \\
\hline B-03-2021 & Oral & $\begin{array}{l}\text { La digitalización del campo. Uso de Teledetección y nuevas tecnologías } \\
\text { como herramientas sostenibles en la gestión de regadíos modernizados. } \\
\text { Proyectos I+D+i OPTIREG y DEMETER. } \\
\text { Fernández Pesado, Pedro Javier; Rubio Melón, Ángel; Escudero Barbero, Rosario; Sánchez } \\
\text { Hernández, Blanca; Calero Gil, Rodrigo. }\end{array}$ \\
\hline B-04-2021 & Oral & $\begin{array}{l}\text { Optimización de sistemas de bombeo fotovoltaico a depósitos con criterio } \\
\text { técnico-económico. } \\
\text { Carricondo-Antón, JM., Jiménez-Bello, MA., Manzano Juárez, J., Royuela Tomas, A., González } \\
\text { Altozano, P. }\end{array}$ \\
\hline B-05-2021 & Poster & $\begin{array}{l}\text { Predicción del volumen bombeado semanalmente con diferente número } \\
\text { de bombas en una estación con energía fotovoltaica. } \\
\text { Carricondo-Antón, JM., Jiménez-Bello, MA., Manzano Juárez, J., Royuela Tomas, A., González } \\
\text { Altozano, P. }\end{array}$ \\
\hline B-07-2021 & Oral & $\begin{array}{l}\text { Recuperación de humedad del suelo sobre campos agrícolas basada en la } \\
\text { integración de fotogrametría de UAV e información de teledetección } \\
\text { satelital. } \\
\text { Amal Chakhar, David Hernández-López, Rocío Ballesteros, Miguel A. Moreno. }\end{array}$ \\
\hline B-08-2021 & Oral & $\begin{array}{l}\text { Mapeo de áreas regadas usando datos geoespaciales y teledetección } \\
\text { ción en el municipio de Caudete de las Fuentes (Valencia). } \\
\text { López-Pérez, Esther, Sanchis-lbor, C., Jiménez Bello, M.A., Rubio-Martin, A., Macian-Sorribes } \\
\text { H., García-Prats, A., Manzano-Juárez, J., García-Molla, M., Pulido-Velázquez, M. }\end{array}$ \\
\hline B-09-2021 & Oral & $\begin{array}{l}\text { Tecnología de sensores inalámbricos para el manejo del fertirriego en el } \\
\text { viñedo en Galicia. } \\
\text { Rodríguez-Fernández, M., Fandiño, M., Cancela, J.J. }\end{array}$ \\
\hline B-10-2021 & Oral & $\begin{array}{l}\text { Estudio de envejecimiento real en tuberías de PRFV en servicio, en redes } \\
\text { de distribución de agua para riego. } \\
\text { Berganza López, B., Chillón Moreno, JM, González Prolongo, s. }\end{array}$ \\
\hline B-11-2021 & Oral & $\begin{array}{l}\text { Efecto de la modificación de la tubería de salida en filtros de arena con } \\
\text { brazos colectores. } \\
\text { Pujol Sagaró, T., Arbat Pujolràs, G., Puig Bargués, J., Duran Ros, M., Pujol Planella, J., Ramírez } \\
\text { de Cartagena Bisbe, F. }\end{array}$ \\
\hline B-12-2021 & Oral & $\begin{array}{l}\text { Evaluación del uso de predicciones climáticas para la operación de } \\
\text { bombeos mediante energía fotovoltaica de inyección directa. } \\
\text { Carricondo-Antón, JM, Jiménez-Bello, MA, Manzano Juárez, J, Royuela Tomas, A, Sala } \\
\text { Piqueras, A. }\end{array}$ \\
\hline B-13-2021 & Oral & $\begin{array}{l}\text { Estudio comparativo del comportamiento de los contadores mecánicos } \\
\text { frente a los caudalímetros electromagnéticos y de ultrasonidos. } \\
\text { Madurga del Cura, Cristina, Cervantes Díaz-Toledo, Alfonso, Muñoz Sopeña, Daniel, Rodríguez } \\
\text { Fernández, Diego, Sánchez de Ribera González, Alejandro, Zazo Salinero, Teresa. }\end{array}$ \\
\hline
\end{tabular}




\section{Congreso Nacional de Riegos CARTAGENA 2021}

\begin{tabular}{|l|l|l|}
\hline B-14-2021 & Poster & $\begin{array}{l}\text { Auditorías técnicas de los sistemas de telecontrol implantados en las } \\
\text { CCRR realizadas por el Centro Nacional de Tecnología de Regadíos } \\
\text { (CENTER). }\end{array}$ \\
\hline B-15-2021 & Oral & $\begin{array}{l}\text { Cervantes Díaz-Toledo, Alfonso, Madurga del Cura, Cristina, Muñoz Sopeña, Daniel, Rodríguez } \\
\text { Fernández, Diego, Sánchez de Ribera González, Alejandro, Zazo Salinero, Teresa. }\end{array}$ \\
\hline $\begin{array}{l}\text { Norma de Interoperabilidad de los sistemas de telecontrol y su aplicación } \\
\text { práctica en el Centro Nacional de Tecnología de Regadíos (CENTER). } \\
\text { Cervantes Díaz-Toledo, Alfonso, Madurga del Cura, Cristina, Muñoz Sopeña, Daniel, Rodriguez } \\
\text { Fernández, Diego, Sánchez de Ribera González, Alejandro, Zazo Salinero, Teresa. }\end{array}$ \\
\hline B-16-2021 & Oral & $\begin{array}{l}\text { Nuevo enfoque en la metodología de transferencia en los regadíos. } \\
\text { Jarén Morilla C., Salvatierra Bellido B., López Rodríguez M. }\end{array}$ \\
\hline B-18-2021 & Oral & $\begin{array}{l}\text { Evaluación económica del impacto sobre la agricultura de regadío del } \\
\text { Vinalopó-Alacantí de la sustitución de recursos subterráneos por recursos } \\
\text { del trasvase Júcar-Vinalopó. } \\
\text { Calatrava, J., Martínez-Granados, Richart, V.J. }\end{array}$ \\
\hline B-19-2021 & Oral & $\begin{array}{l}\text { Desarrollo de una plataforma loT para la gestión del riego de precisión } \\
\text { Puig Pérez-Barquero F., Rodríguez Díaz, J.A., González Perea, R., Camacho Poyato, E. }\end{array}$ \\
\hline & $\begin{array}{l}\text { Rentabilidad del uso de agua marina desalinizada en la producción de } \\
\text { tomate de invernadero en Almería } \\
\text { Martínez-Granados, D., Marin-Membrive, P., Calatrava, J. }\end{array}$ \\
\hline
\end{tabular}

\section{GRUPO C: BALSAS DE RIEGO}

\begin{tabular}{|l|l|l|}
\hline Referencia & Tipo & Título y autores \\
\hline C-01-2021 & Oral & $\begin{array}{l}\text { Estudio comparativo de punzonamiento en láminas sintéticas para } \\
\text { impermeabilización de balsas. } \\
\text { Climent Vicent, Pau, Moreno Marín, Francisco José, Murillo Silva, Claudio. }\end{array}$ \\
\hline C-02-2021 & Oral & $\begin{array}{l}\text { Aumento de la durabilidad de láminas de PVC-P utilizadas para la } \\
\text { impermeabilización de balsas de riego con tecnologías de lacado. } \\
\text { Climent Vicent, Pau, Moreno Marín, Francisco José, Murillo Silva, Claudio, Hans Tanghe }\end{array}$ \\
\hline C-03-2021 & Oral & $\begin{array}{l}\text { Evolución de las geomembranas de PVC-P instaladas en las balsas de la } \\
\text { Isla de Tenerife. Importancia de los plastificantes en la vida útil de la } \\
\text { geomembrana. } \\
\text { Vara Mora, Tatiana, Cabrera Romero, Ma Dolores, Solera Martínez, Rosario, Mateo Sanz, Beatriz. }\end{array}$ \\
\hline C-04-2021 & Oral & $\begin{array}{l}\text { Reimpermeabilización, casos prácticos. } \\
\text { Vara Mora, Tatiana, Dolores Cabrera, Ma Dolores, Solera Martínez, Rosario, Mateo Sanz, Beatriz. }\end{array}$ \\
\hline C-05-2021 & Oral & $\begin{array}{l}\text { Criterios técnicos para la construcción y explotación de balsas de SEIASA. } \\
\text { Hernández Redondo, Jose Ángel, Majuelos Moraleda, Miguel }\end{array}$ \\
\hline C-06-2021 & Oral & $\begin{array}{l}\text { Reflexiones sobre la elaboración e implantación de Planes de Emergencia } \\
\text { en Balsas } \\
\text { Sánchez-Romero, F.J., Pérez-Sánchez, M., Redón-Santafé, M., Torregrosa Soler J.B., Ferrer } \\
\text { Gisbert, C., Ferrán Gozálvez, J.J., Ferrer Gisbert, A., Zapata Raboso, F.A. }\end{array}$ \\
\hline C-07-2021 & Oral & $\begin{array}{l}\text { Contribución a la caracterización geométrica de balsas como herramienta } \\
\text { para el cálculo de indicadores } \\
\text { Sánchez-Romero, F.J., Pérez-Sánchez, M., Redón-Santafé, M., Torregrosa Soler J.B., Ferrer } \\
\text { Gisbert, C., Ferrán Gozálvez, J.J., Ferrer Gisbert, A., Zapata Raboso, F.A. }\end{array}$ \\
\hline C-08-2021 & Oral & $\begin{array}{l}\text { Nuevas Funciones de las Balsas de Riego en una Transición } \\
\text { hacia una agricultura más sostenible, en la Provincia de Alicante. } \\
\text { Zapata Raboso, F.A., Cabañero Fernández, J., Ferrán Gozálvez, J.J., Ferrer Gisbert ,A , Ferrer } \\
\text { Gisbert, C., Mascarell Gómez, A., Pérez Sánchez, M., Redón-Santafé, M., Sánchez Romero F.J., } \\
\text { Torregrosa Soler J.B., Vinaches Ramis, J. }\end{array}$ \\
\hline
\end{tabular}




\section{GRUPO TEMAS A:}

\section{Investigación, desarrollo e innovación en riego y drenaje}

Agrohidrología y agronomía del riego: Relaciones agua-suelo-planta-atmósfera. Necesidades hídricas de los cultivos. Balance de agua. Coeficientes de cultivo. Estrategias de riego en áreas con escasez de agua. Respuesta de los cultivos a riegos deficitarios. Nuevos métodos y tecnologías de medición del agua de riego, herramientas de cálculo y modelos de simulación.

Salinidad, Drenaje, Efectos Ambientales y Agua de riego: Adecuación de las características del suelo al método de riego. Efecto del clima y de su posible cambio en las prácticas e infraestructuras de riego. Impacto del regadío y drenaje en el entorno natural. Las prácticas de riego y sus efectos sobre la mejora de la capacidad de reserva de agua en el suelo. Lixiviación de sales y otros elementos. Recuperación de suelos salinos.

Calidad del agua de riego: Escasez de agua de buena calidad. Aprovechamiento de aguas subterráneas para riego. Utilización para el riego de aguas depuradas, regeneradas o desalinizadas. Efecto de estas aguas sobre el suelo, cultivos y acuíferos. Riesgos de la utilización de aguas residuales regeneradas en los seres vivos. 


\title{
Determinación del estado hídrico en viña a través de imágenes RGB y multiespectrales adquiridas por un VANT
}

\author{
López García, P. ${ }^{1}$, Ortega Álvarez, J.F. ${ }^{1}$, Moreno Hidalgo, M.A. ${ }^{1}$, Ballesteros González, R. ${ }^{1}$
}

Instituto de Desarrollo Regional, Universidad de Castilla-La Mancha, Albacete, España; Patricia.Lopez@uclm.es; Jose.Ortega@uclm.es; MiguelAngel.Moreno@uclm.es; Rocio.Ballesteros@uclm.es

Resumen: La teledetección se ha convertido en una herramienta muy utilizada en la agricultura de precisión. La existencia de sensores ligeros, calibrados geométrica y radiométricamente, ha hecho que los vehículos aéreos no tripulados (VANTs) sean una de las plataformas más utilizadas en teledetección por obtener datos de muy alta resolución espacial y temporal. En el marco de la viticultura de precisión, haciendo uso de VANTs para la obtención de imágenes aéreas de la cubierta vegetal que proporcionen información agronómicamente útil para hacer un manejo y una gestión del riego sostenible y eficiente frente a la escasez hídrica existente principalmente en zonas áridas y semiáridas, se llevó a cabo un estudio en un viñedo localizado en Fuente-Álamo (Albacete) durante 2018 y 2019. Para obtener un amplio rango de condiciones de estado hídrico de la vid, varias estrategias de riego fueron aplicadas incluyendo regímenes con diferentes niveles de salinidad del agua, estableciendo diferencias en el estado hídrico de la cepa. Los vuelos se hicieron a lo largo del ciclo fenológico usando sensores convencionales (o RGB -red, green, blue-) y multiespectrales a bordo de un VANT, obteniendo ortoimágenes. Estas ortoimágenes fueron segmentadas para incluir solo la vegetación obteniendo el grado de cobertura verde como un parámetro geométrico representativo del desarrollo vegetal del cultivo. El potencial hídrico de tallo fue medido a mediodía con cámaras de presión, y la integral de estrés hídrico fue calculada a partir de estas medidas de estado hídrico, como una variable representativa del efecto acumulado de la intensidad y duración del estrés hídrico desde el comienzo del ciclo de desarrollo hasta el momento de la medida. Modelos de regresión lineal simple usando índices de vegetación basados en la respuesta espectral de la vegetación y el grado de cobertura verde fueron evaluados para predecir la integral de estrés hídrico. Técnicas de regresión no lineal usando redes neuronales artificiales con bandas de los sensores multiespectral y RGB y el grado de cobertura verde como variables predictoras de la integral de estrés hídrico también fueron empleadas. Ambos modelos mostraron que los datos del rango visible (pese a la menor reflectividad de la vegetación en este rango espectral) fueron más útiles para predecir la integral de estrés hídrico que los datos del rango multiespectral, que consideran la reflectividad en el red-edge y en el infrarrojo cercano, proporcionando mejores resultados los modelos no lineales de redes neuronales artificiales con valores de $\mathrm{R}^{2}$ próximos a 1 y errores relativos de $1.5 \%$ o ligeramente superiores. La mayor resolución espacial, calidad radiométrica, facilidad de uso de la cámara RGB, su menor precio y fácil procesamiento de las imágenes RGB hace que estos sensores, utilizados en menor medida con usos agrícolas, sean una buena opción para usarse en la predicción del estado hídrico en viña.

Palabras clave: estrés hídrico; imágenes multiespectrales; imágenes RGB; VANT; viña 


\title{
XXXVIII Congreso Nacional de Riegos CARTAGENA 2021
}

\section{Determination of water status in vineyard using RGB and mul- tispectral images acquired by a UAV}

\author{
López García, P. ${ }^{1}$, Ortega Álvarez, J.F.1, Moreno Hidalgo, M.A. ${ }^{1}$, Ballesteros González, R. ${ }^{1}$
}

Instituto de Desarrollo Regional, Universidad de Castilla-La Mancha, Albacete, Spain; Patricia.Lopez@uclm.es; Jose.Ortega@uclm.es; Migue1Angel.Moreno@uclm.es; Rocio.Ballesteros@uclm.es

\begin{abstract}
Remote sensing has become a widely used tool in precision agriculture. The existence of light sensors, geometrically and radiometrically calibrated, has made unmanned aerial vehicles (UAVs) one of the most used platforms in remote sensing. They obtain very high spatial and temporal resolution data. Within the framework of precision viticulture, the use of UAVs to obtain aerial images of the vineyard provide agronomically useful information to carry out sustainable and efficient irrigation management under a scenario of constant water scarcity mainly in arid and semi-arid areas. In this context, a study was carried out in a vineyard located in Fuente-Álamo (Albacete) during 2018 and 2019. To obtain a wide range of water status conditions of the vine, various irrigation strategies were applied including regimes with different levels of water salinity, establishing differences in the water status of the vine. The flights were made throughout the phenological cycle using conventional (or RGB -red, green, blue-) and multispectral sensors aboard a UAV, obtaining orthoimages. These orthoimages were segmented to include only the vegetation, obtaining the green canopy cover (GCC) as a representative geometric parameter of the plant development. The midday stem water potential was measured with pressure chambers, and the water stress integral was calculated from these measures of water status, as a representative variable of the cumulative effect of the intensity and duration of water stress since the beginning of the development cycle up to the time of measurement. Simple linear regression models using vegetation indices based on the spectral response of the vegetation and the GCC were evaluated to predict the water stress integral. Nonlinear regression techniques using artificial neural networks with bands of the multispectral and RGB sensors and the GCC as predictor variables of the water stress integral were also used. Both models showed that the data from the visible range (despite the lower reflectivity of the vegetation in this spectral range) were more useful to predict the water stress integral than the data from the multispectral range, which considers the reflectivity in the rededge and near infrared, providing better results the non-linear models of artificial neural networks with values of $\mathrm{R}^{2}$ close to 1 and relative errors of $1.5 \%$ or slightly higher. The higher spatial resolution, radiometric quality, ease of use of the RGB camera, its lower price and easy processing of RGB images make these sensors, with less extended use in agriculture, a good option to be used in the prediction of the water status in vineyard.
\end{abstract}

Keywords: multispectral images, RGB images, UAV, vineyard, water stress 


\section{Congreso Nacional de Riegos CARTAGENA 2021}

\section{Introducción}

El estado hídrico del viñedo es el determinante principal tanto en el desarrollo de la cepa como en la composición del vino [1] potencialmente afectados por factores edáficos y ambientales. En zonas áridas y semiáridas, el riego (considerando frecuencia, volumen de agua aplicado y su nivel de sales) juega un papel importante en la determinación del estado hídrico de la cepa [2]. Así, la programación de riego es un factor clave en el equilibrio entre producción y calidad, y en el contexto de escasez de agua, para el manejo sostenible de los recursos hídricos disponibles para usos agrícolas que cada vez son más limitados debido al incremento de la competencia entre los diferentes usos económicos, restricciones ambientales y los efectos del cambio climático [3]. En el marco de la viticultura de precisión, que busca mejorar la eficiencia en la gestión de los recursos disponibles en términos de calidad, producción y sostenibilidad basada en la variabilidad espacial del viñedo dentro de la parcela [4], se emplea el riego deficitario controlado que consiste en reemplazar solo parte de la evapotranspiración potencial del viñedo durante periodos fenológicos previamente establecidos teniendo efectos positivos sobre la calidad de la producción final [5], con una mínima reducción de la producción. La implementación del riego deficitario controlado requiere el control del estado hídrico de la cepa para establecer el momento óptimo de riego. Hay diferentes técnicas para lograr este control, desde métodos que determinan el estado hídrico directamente sobre la planta como es el caso de la conductancia estomática y el potencial hídrico, entre otros, hasta métodos basados en sensores que recogen un gran número de medidas indirectas a lo largo del tiempo, tales como medidas de transpiración, fluctuaciones en el diámetro del tronco o temperatura de la cubierta vegetal o de hoja. Sin embargo, estas medidas son laboriosas, requieren de dispositivos pesados de precio elevado y realizan medidas puntuales pueden no ser representativas de la variabilidad espacial del estado hídrico de la parcela en su conjunto [6].

Hay varias herramientas que son utilizadas por la viticultura de precisión. Una de ellas es el uso de la teledetección, imágenes obtenidas con satélites, aeroplanos, y vehículos aéreos no tripulados (VANTs). Esta información es utilizada para obtener información espacial del cultivo [7]. Los VANTs, con sensores ligeros y de alta calidad geométrica y radiométrica, permiten obtener datos de alta resolución temporal y espacial [8]. Los datos de reflectancia espectral de los sensores a bordo han sido empleados para el control de parámetros biofísicos y bioquímicos, tales como la biomasa, contenido de pigmentos en hoja, el estado hídrico del cultivo, coeficiente de cultivo y la evapotranspiración [9]-[13]. Los datos espectrales son normalmente empleados como una combinación matemática de dos o más bandas para generar índices de vegetación basados en las regiones del visible o RGB (red, green, blue), red-edge e infrarrojo cercano del espectro electromagnético (Pôças et al. 2015). La parte visible del espectro es caracterizada por la baja reflectancia de la cubierta, debido a la fuerte absorción de los pigmentos foliares, principalmente clorofila y carotenoides. La región del infrarrojo cercano es caracterizada por la alta reflectancia y el dominio térmico de la cubierta es caracterizado por su temperatura, de modo que los estomas se cierran bajo una situación de estrés, la transpiración se ralentiza y la temperatura de la hoja aumenta. Por tanto, la temperatura de la hoja o de la cubierta vegetal puede ser utilizada como un indicador de estrés en la planta [16].

Recientes estudios para detectar el estrés hídrico de la viña han usado medidas en el térmico obtenidas de las imágenes aéreas, con una elevada dificultad en la obtención de productos precisos. Otros autores utilizaron índices de vegetación multiespectrales, pero pocos usaron índices de vegetación en el visible, ya que esta región del espectro se caracteriza por la baja reflectancia [14], [17]-[20]. Sin embargo, en este estudio además de índices de vegetación multiespectrales, el incremento de la resolución espacial conduce al uso de índices de vegetación RGB como predictores del estado hídrico de la viña. Esta aproximación permite el uso de sensores de menor coste (cámaras RGB), la obtención de productos 


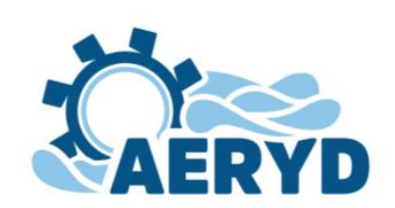

\section{Congreso Nacional de Riegos CARTAGENA 2021}

geomáticos con mayor resolución espacial y un tratamiento fotogramétrico más sencillo comparado con los productos de los sensores multiespectral y térmico.

El grado de cobertura verde (GCV) es un parámetro geométrico que proporciona información sobre el desarrollo vegetativo o el vigor de la cubierta, y es obtenido de las imágenes aéreas. Normalmente se relaciona con el índice de área foliar, la biomasa, la altura de la planta y el volumen de la cubierta vegetal, entre otros parámetros [13], [21]. En este estudio, el GCV será utilizado como predictor del estado hídrico del viñedo junto con la información espectral.

Además de modelos estadísticos de regresión lineal simple y múltiple, el empleo de algoritmos basados en técnicas de inteligencia artificial para tratar conjuntos de datos obtenidos de la teledetección es una buena alternativa debido a su habilidad para aplicar tanto modelos lineales como no lineales [6]. El aprendizaje automático es un tipo de técnica de inteligencia artificial que usa métodos computacionales para aprender directamente del conjunto de datos sin depender de ecuaciones establecidas resolviendo problemas altamente no lineales con la mínima intervención humana [22]. Entre los algoritmos utilizados de aprendizaje automático, las redes neuronales artificiales (RNAs) son ampliamente utilizadas en la simulación de estrés hídrico y otros estudios en agricultura (Poblete et al. 2017, Romero et al. 2018).

Por tanto, el principal objetivo de este estudio es desarrollar modelos predictivos basados en RNAs, que integren información de la cubierta vegetal en el rango del espectro visible y multiespectral de muy alta resolución espacial obtenida con un VANT para evaluar la distribución espacial del estado hídrico del viñedo. Para obtener un amplio rango de condiciones de estado hídrico, se evaluaron varios regímenes de riego, incluyendo regímenes con diferentes niveles de sales, para considerar las diferentes fuentes potenciales de variación en el estado hídrico de la cepa.

\section{Materiales y métodos}

La parcela de viña en la que se llevó a cabo el estudio experimental se encuentra en el término

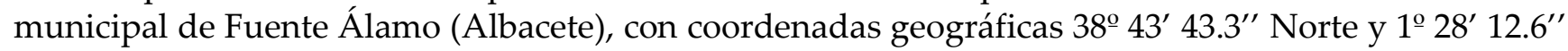
Oeste, con una altitud de $820 \mathrm{~m}$, de 6,5 ha de superficie, ocupando el ensayo 0,6 ha. La parcela se ubica dentro de una zona regable de la Sociedad Agraria de Transformación (SAT) Las Colleras (Figura 1).

A)

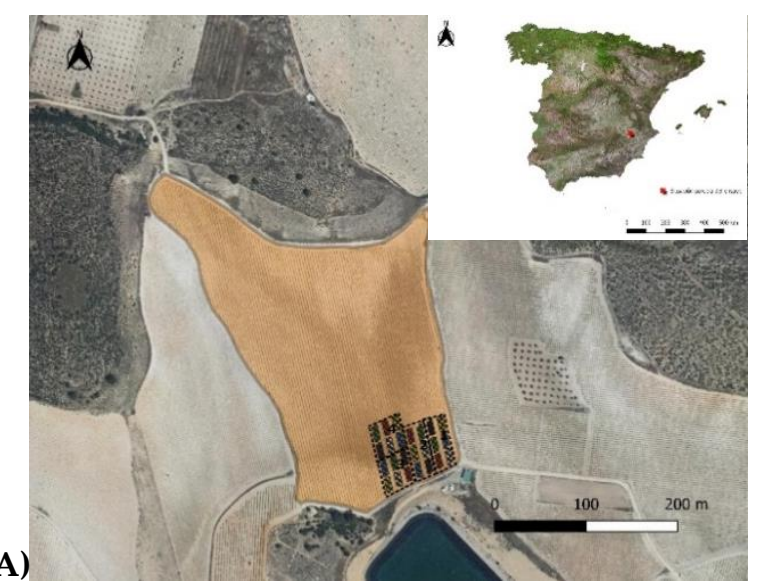

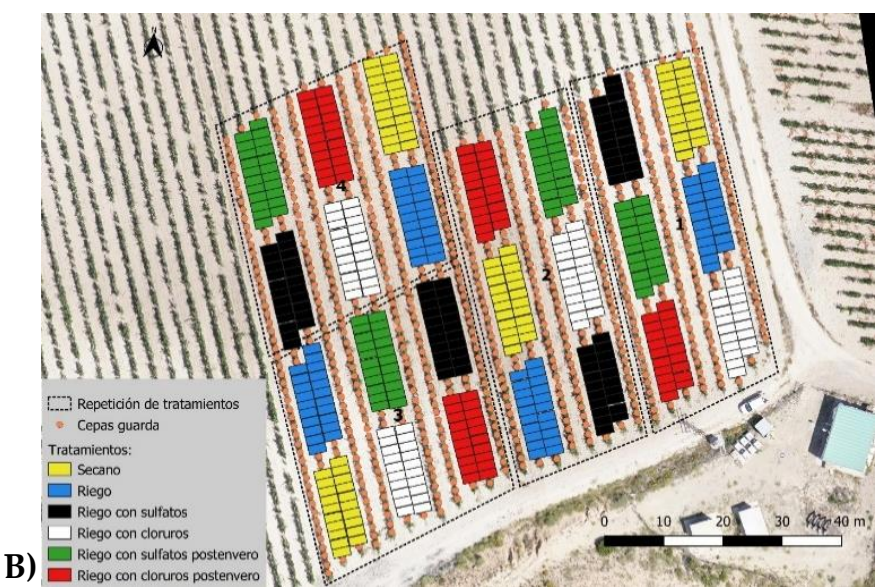

Figura 1. A) Localización del viñedo comercial en Fuente-Álamo (Albacete), y B) distribución de los tratamientos y repeticiones en el diseño experimental. Cada rectángulo coloreado corresponde con una cepa. 


\section{Congreso Nacional de Riegos CARTAGENA 2021}

Se trata de un viñedo de la variedad Monastrell, plantado en 2007, injertado sobre 110-R, con un marco de plantación de $3 \mathrm{~m}$ entre filas y 1,5 m entre cepas dentro de cada fila. El diseño de plantación es en espaldera, orientación Norte-Sur y riego por goteo con goteros autocompensantes de $4 \mathrm{l} / \mathrm{h}$ a $1 \mathrm{~m}$ de distancia. En este viñedo se realizó un ensayo de riego con aguas de diferente calidad (Figura 1 B) durante la campaña de 2018 y 2019. Seis tratamientos (T1-T6) y cuatro repeticiones de cada tratamiento integraron el diseño experimental. Los tratamientos fueron los siguientes: secano (T1), riego con agua de buena calidad (T2), riego con sulfatos añadidos (T3), riego con cloruros añadidos (T4), y T5 y T6 fueron tratamientos de riego con sulfatos y cloruros añadidos, respectivamente, pero iniciando el riego comenzado el envero de la uva. Debido a la escasez hídrica, las restricciones hídricas limitaron el agua disponible para el riego a $1000 \mathrm{~m}^{3} / \mathrm{ha}$, dotación que se aplicó en todos los tratamientos. En la campaña de 2019 el diseño experimental fue simplificado ya que T5 y T6 no se aplicaron porque no se observaron diferencias en cuanto a características agronómicas y de calidad de la uva con respecto a los otros tratamientos de sales añadidas (T3 y T4).

Se midió el potencial hídrico de tallo a mediodía para evaluar el estado hídrico de la viña utilizando una cámara de presión (Model 600, PMS Instrument Company, Albany, OR, EEUU) seis veces en 2018 y siete veces en 2019 en dos hojas de cada tratamiento y repetición. Las medidas de potencial hídrico de tallo se efectuaron los mismos días en los que las imágenes aéreas fueron obtenidas (Tabla 1). El potencial hídrico de tallo caracteriza el estado hídrico de la viña en el momento puntual de la medida, sin embargo, la respuesta espectral de la cubierta vegetal muestra el efecto acumulado de la duración e intensidad del déficit hídrico desde el comienzo del ciclo de desarrollo hasta el momento de la medida. Por tanto, el efecto acumulado del estrés hídrico puede ser representado por la integral de estrés hídrico $\left(S_{\Psi}\right)$, que se calcula como el sumatorio de las medidas del potencial hídrico a lo largo del periodo de estudio [25]. Su cálculo se muestra en la ecuación (1):

$$
S_{\Psi}=\left|\sum_{i=0}^{i=t}\left(\bar{\Psi}_{i, i+1}-c\right) n\right|
$$

Donde: $\bar{\Psi}_{\mathrm{i}, \mathrm{i}+1}$ es la media de dos medidas consecutivas de potencial hídrico; c, es el valor de potencial hídrico menos negativo registrado durante la campaña; y n, es el número de días entre una medida y la siguiente.

Tabla 1. Fechas de medida del potencial hídrico de tallo y de ejecución del vuelo con dron, y estado fenológico del viñedo.

\begin{tabular}{cccc}
\hline Fechas de muestreo & Estado fenológico & Fechas de muestreo & Estado fenológico \\
\hline $15 / 06 / 2018$ & Botones florales (H-I) & $19 / 06 / 2019$ & Comienzo de cuajado (J) \\
$02 / 07 / 2018$ & Cuajado (J) & $04 / 07 / 2019$ & Fin de cuajado (J) \\
$27 / 07 / 2018$ & Racimo cernido (L) & $16 / 07 / 2019$ & Tamaño guisante de la baya (K) \\
$14 / 08 / 2018$ & Comienzo de envero (L-M) & $29 / 07 / 2019$ & Racimo cernido (L) \\
$23 / 08 / 2018$ & Envero (M) & $14 / 08 / 2019$ & Envero (M) \\
$19 / 09 / 2018$ & Maduración (N) & $28 / 08 / 2019$ & Comienzo de maduración (N) \\
& & $18 / 09 / 2019$ & Maduración (N) \\
\hline
\end{tabular}

La imágenes multiespectrales y RGB de alta resolución obtenidas con los sensores SEQUOIA (Parrot, París, Francia) y Sony Ilce-5100 (Sony Corporation, Tokio, Japón) a bordo de un cuadricóptero md4-1000 (Microdrones Inc., Kreuztal, Alemania) se trataron fotogramétricamente para obtener una ortoimagen georreferenciada para toda la parcela con tamaño de pixel de $8 \mathrm{~cm}$ (en el caso de la 


\section{Congreso Nacional de Riegos CARTAGENA 2021}

ortoimagen multiespectral) y $2 \mathrm{~cm}$ (en el caso de la ortoimagen RGB). Estas ortoimágenes se trataron con una versión modificada del programa de visión computacional de cálculo del índice de área foliar [26], obteniendo ortoimágenes con vegetación segmentada (sin suelo y sombras, entre otros) utilizadas para determinar el GCV y varios índices de vegetación (Figura 2).

A)
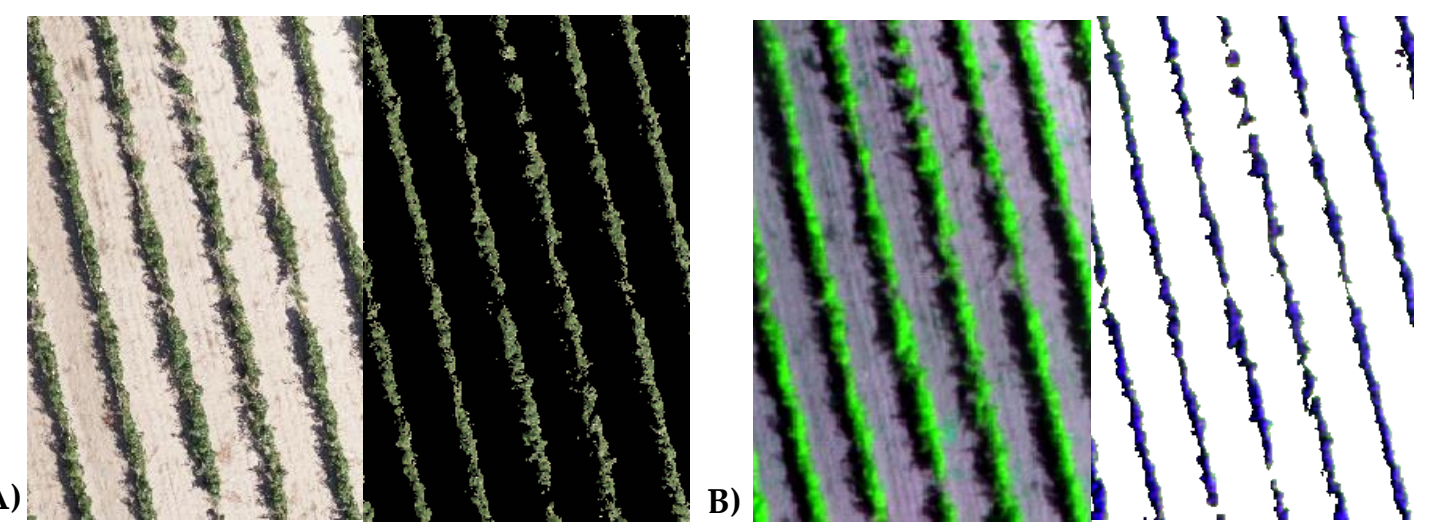

Figura 2. Segmentación de la vegetación en: A) ortoimagen RGB, y B) ortoimagen multiespectral.

El complemento NETLAB del programa MATLAB (Mathworks Inc., Natick, MA, EEUU) se usó para desarrollar y calibrar modelos de RNAs para predecir la $S_{\Psi}$ con distintas combinaciones de bandas. En este estudio, se utilizó una RNA perceptrón multicapa. La estructura de este tipo de RNA está formada por nudos o neuronas interconectadas. Cada conjunto de nudos constituye una capa, y hay tres tipos de capas: a) una capa de entrada, donde cada neurona corresponde a una variable de entrada diferente (en este estudio, el conjunto de bandas separadas de los sensores multiespectrales y RGB y el GCV para cada tratamiento y repetición; b) una capa oculta, donde los datos son procesados; y c) una capa de salida, donde se proporcionan los resultados estimados de la $S_{\Psi}$. Las interconexiones entre neuronas se conocen como pesos sinápticos. Se seleccionó un algoritmo de RNA de retropropagación durante el proceso de calibración para obtener los valores de los pesos sinápticos [22], [27]. Previamente se evaluó el efecto de los tratamientos salinos sobre la reflectancia espectral de la cubierta vegetal y no se observaron diferencias significativas entre ninguna campaña o fechas de muestreo. Por lo tanto, los modelos de RNAs que utilizan las bandas de sensores multiespectrales y RGB para generar la $S_{\Psi}$ se calibraron y validaron para todos los tratamientos juntos. En ambos años, los datos de entrada fueron las tres bandas normalizadas separadas de la cámara RGB para los modelos de RNA RGB y las cuatro bandas separadas para el sensor multiespectral. Se generaron otros dos modelos de RNAs agregando el GCV como dato de entrada. Para cada fecha de muestreo en cada campaña, los datos de entrada totales de las bandas y el GCV junto con los datos de $S_{\Psi}$ medidos se dividieron aleatoriamente en dos grupos con la misma desviación estándar y media para la calibración (60\% del conjunto de datos de entrada total) y validación ( $40 \%$ del conjunto de datos de entrada total). Se implementó un proceso iterativo para lograr este objetivo. La RNA aplicada a los datos de entrada tuvo seis neuronas ocultas y un centenar de iteraciones, que se obtuvieron mediante la metodología desarrollada por [28] para evitar efectos de sobrealimentación del modelo.

Para evaluar la precisión y el funcionamiento de los modelos de RNAs para cada fecha de muestreo en los diferentes años estudiados (2018 y 2019), se emplearon los datos estadísticos sobre el proceso de validación (que utilizó el $40 \%$ de los datos aleatorios), como el coeficiente de determinación $\left(\mathrm{R}^{2}\right)$, el error cuadrático medio (RMSE) y el error relativo (ER), entre los valores de $S_{\Psi}$ medidos y simulados. 


\section{Resultados y discusión}

En las Tablas 2 y 3, para la campaña de 2018 y de 2019, respectivamente, se muestran los resultados de validación de los modelos de RNAs utilizados para predecir la $S_{\Psi}$, empleando como variables predictoras las bandas del espectro visible o multiespectral de los sensores con los que se adquieren las imágenes aéreas de toda la parcela y el GCV. Para 2018, la combinación de bandas independientes RGB actuó mejor como predictora que la combinación de bandas del sensor multiespectral, excepto el 15 de junio. Comparando para una fecha (27/07/2018) los distintos modelos de RNAs aplicados empleando distintos predictores, se observa que utilizando únicamente las bandas independientes del sensor multiespectral se obtiene un valor de $\mathrm{R}^{2}$ de 0.82 que incrementa a 0.97 si además se incluye el GCV multiespectral, no ocurre lo mismo con el ER, que en lugar de disminuir aumenta de $3.27 \%$ a $3.38 \%$, y el RMSE que se mantiene en $0.46 \mathrm{MPa}^{*}$ días, tendencia que se repite para las demás fechas excepto para el 14/08/2018. En cuanto al empleo de las bandas del visible, se obtiene un valor de $\mathrm{R}^{2} 0.98$ que incrementa a 0.99 si además se incluye el GCV, el ER disminuye de $3.06 \%$ a $2.03 \%$, y el RMSE también disminuye de $0.39 \mathrm{MPa}^{*}$ días a $0.27 \mathrm{MPa}^{*}$ días. Tendencia que se repite para las demás fechas. A nivel general, comparando en todas las fechas todos los modelos aplicados, se observa que los modelos que utilizan las bandas RGB y el GCV obtienen mejores parámetros estadísticos (mayores valores de $\mathrm{R}^{2}$ y menores errores). Esto también ocurría en el trabajo previo en el que se analizaron modelos de regresión lineal simple empleando índices de vegetación obtenidos en el rango del espectro multiespectral y visible como predictores [29].

Tabla 2. Resultados de validación ( $R^{2}$ : coeficiente de determinación, RMSE: error medio cuadrático, y ER: error relativo) para los modelos de regresión de redes neuronales artificiales (RNAs) usando bandas RGB y multiespectrales y el grado de cobertura verde $(\mathrm{GCV})$ para simular la integral de estrés hídrico $\left(\mathrm{S}_{\Psi}\right)$ para cada fecha de vuelo en la campaña de 2018. Los valores estadísticos que se muestran en negrita indican el modelo que mejor funciona en cada fecha de muestreo.

\begin{tabular}{|c|c|c|c|c|c|c|c|c|c|c|c|c|c|}
\hline & \multicolumn{3}{|c|}{$\begin{array}{c}\text { RNA con bandas RGB y } \\
\text { GCV }\end{array}$} & \multicolumn{3}{|c|}{ RNA con bandas RGB } & & \multicolumn{3}{|c|}{$\begin{array}{c}\text { RNA con bandas } \\
\text { multiespectrales y GCV } \\
\text { multiespectral }\end{array}$} & \multicolumn{3}{|c|}{$\begin{array}{l}\text { RNA con bandas } \\
\text { multiespectrales }\end{array}$} \\
\hline & $\mathrm{R}^{2}$ & $\begin{array}{c}\text { RMSE } \\
\text { (MPa*días) }\end{array}$ & $\begin{array}{l}\text { ER } \\
(\%)\end{array}$ & $\mathrm{R}^{2}$ & $\begin{array}{c}\text { RMSE } \\
\text { (MPa*días) }\end{array}$ & $\begin{array}{l}\text { ER } \\
(\%)\end{array}$ & & $\mathrm{R}^{2}$ & $\begin{array}{c}\text { RMSE } \\
\text { (MPa*días) }\end{array}$ & $\begin{array}{l}\text { ER } \\
(\%)\end{array}$ & $\mathrm{R}^{2}$ & $\begin{array}{c}\text { RMSE } \\
\text { (MPa*días) }\end{array}$ & $\begin{array}{l}\mathrm{ER} \\
(\%)\end{array}$ \\
\hline $15 / 06 / 2018$ & 0.75 & 0.02 & 4.88 & 0.72 & 0.03 & 6.36 & $15 / 06 / 2018$ & 0.75 & 0.02 & 4.87 & 0.66 & 0.02 & 3.97 \\
\hline 02/07/2018 & 0.85 & 0.24 & 4.75 & 0.84 & 0.28 & 5.66 & $27 / 07 / 2018$ & 0.97 & 0.46 & 3.38 & 0.82 & 0.46 & 3.27 \\
\hline $27 / 07 / 2018$ & 0.99 & 0.27 & 2.03 & 0.98 & 0.39 & 3.06 & $14 / 08 / 2018$ & 0.92 & 1.13 & 4.38 & 0.88 & 1.26 & 5.15 \\
\hline $14 / 08 / 2018$ & 0.99 & 0.58 & 2.48 & 0.94 & 0.88 & 3.65 & $23 / 08 / 2018$ & 0.9 & 1.95 & 6.31 & 0.92 & 1.78 & 6.24 \\
\hline $23 / 08 / 2018$ & 0.99 & 0.51 & 1.56 & 0.99 & 0.72 & 2.17 & $19 / 09 / 2018$ & 0.94 & 2.53 & 5.2 & 0.82 & 2.5 & 5 \\
\hline
\end{tabular}

Para 2019 (Tabla 3), la combinación de bandas independientes RGB actuó mejor como predictora que la combinación de bandas del sensor multiespectral, excepto el 16 y 29 de julio, y el 14 de agosto. Comparando para una fecha (29/07/2019) los distintos modelos de RNAs aplicados empleando distintos predictores se observa que utilizando únicamente las bandas independientes del sensor multiespectral se obtiene un valor de $\mathrm{R}^{2}$ de 0.88 que incrementa a 0.97 si además se incluye el GCV multiespectral, sin embargo, el ER incrementa de $6.39 \%$ a $7.8 \%$, y el RMSE se mantiene en aproximadamente 0.7 $\mathrm{MPa}^{*}$ días, tendencia que no se repite para las demás fechas, pues los errores disminuyen. En cuanto al 


\section{Congreso Nacional de Riegos CARTAGENA 2021}

empleo de las bandas del visible, se obtiene un valor de $\mathrm{R}^{2}$ de 0.96 que disminuye ligeramente a $0.95 \mathrm{si}$ además se incluye el GCV, el ER disminuye de $7.42 \%$ a $7.11 \%$, y el RMSE también disminuye de 0.82 MPa*días a $0.66 \mathrm{MPa}^{*}$ días. Tendencia que se repite para las demás fechas, excepto para el 4 y el 16 de julio. A nivel general, comparando en todas las fechas todos los modelos aplicados, se observa que para cada fecha de muestreo presentan mejores parámetros estadísticos distintos modelos, por ejemplo, para el 16 de julio como mejor modelo predictor sería el que utiliza las bandas multiespectral y el GCV multiespectral, sin embargo, para el 29 de julio el mejor modelo sería el que utiliza las bandas RGB y el GCV. Lo que sí se podría descartar son los modelos que emplean solo las bandas multiespectrales, pues en ninguna fecha de muestreo han presentado el mejor comportamiento. Si bien, estos resultados no permiten generalizar para obtener un modelo predictor, pues en 2018 en todas las fechas de muestreo los modelos que empleaban las bandas RGB y el GCV funcionaron mejor, no ocurriendo lo mismo para 2019, donde los mejores modelos tienen características diferentes, aunque funcionan dentro de parámetros admisibles en los dos años.

Tabla 3. Resultados de validación ( $R^{2}$ : coeficiente de determinación, RMSE: error medio cuadrático, y ER: error relativo) para los modelos de regresión de redes neuronales artificiales (RNAs) usando bandas RGB y multiespectrales y el grado de cobertura verde (GCV) para simular la integral de estrés hídrico $\left(S_{\Psi}\right)$ para cada fecha de vuelo en la campaña de 2019. Los valores estadísticos que se muestran en negrita indican el modelo que mejor funciona en cada fecha de muestreo.

\begin{tabular}{|c|c|c|c|c|c|c|c|c|c|c|c|c|}
\hline & \multicolumn{3}{|c|}{ RNA con bandas RGB y GCV } & \multicolumn{3}{|c|}{ RNA con bandas RGB } & \multicolumn{3}{|c|}{$\begin{array}{c}\text { RNA con bandas } \\
\text { multiespectrales y GCV } \\
\text { multiespectral }\end{array}$} & \multicolumn{3}{|c|}{$\begin{array}{l}\text { RNA con bandas } \\
\text { multiespectrales }\end{array}$} \\
\hline & $\mathrm{R}^{2}$ & $\begin{array}{c}\text { RMSE } \\
\text { (MPa*días) }\end{array}$ & ER (\%) & $\mathrm{R}^{2}$ & $\begin{array}{c}\text { RMSE } \\
\text { (MPa*días) }\end{array}$ & ER (\%) & $\mathrm{R}^{2}$ & $\begin{array}{c}\text { RMSE } \\
\text { (MPa*días) }\end{array}$ & $\begin{array}{l}\mathrm{ER} \\
(\%)\end{array}$ & $\mathrm{R}^{2}$ & $\begin{array}{c}\text { RMSE } \\
\text { (MPa*días) }\end{array}$ & $\begin{array}{l}\text { ER } \\
(\%)\end{array}$ \\
\hline $16 / 07 / 2019$ & 0.98 & 0.39 & 6.45 & 0.93 & 0.39 & 6.15 & 0.97 & 0.16 & 2.34 & 0.99 & 0.28 & 4.6 \\
\hline 29/07/2019 & 0.95 & 0.66 & 7.11 & 0.96 & 0.82 & 7.42 & 0.97 & 0.69 & 7.8 & 0.88 & 0.7 & 6.39 \\
\hline $14 / 08 / 2019$ & 0.98 & 0.65 & 3.76 & 0.97 & 1.1 & 5.6 & 0.99 & 0.29 & 1.57 & 0.98 & 0.74 & 4.14 \\
\hline 28/08/2019 & 0.99 & 0.54 & 2.36 & 0.98 & 0.98 & 3.68 & 0.99 & 0.84 & 3.31 & 0.98 & 1.32 & 4.74 \\
\hline
\end{tabular}

\section{Conclusiones}

El uso de algoritmos de aprendizaje automático, tales como los modelos de RNAs, demostró ser una potente herramienta para el procesamiento de los datos de teledetección obtenidos de VANTs para desarrollar modelos de predicción de $S_{\Psi}$ en los distintos momentos del ciclo de desarrollo del viñedo, ya que los ajustes fueron mejor que aquellos obtenidos de los modelos de regresión lineal simple. Para todas las fechas de muestreo de 2018 y cuatro fechas de 2019, se obtuvieron mejores resultados utilizando bandas RGB como entrada para los modelos de RNAs. El uso de cámaras RGB convencionales aumenta la aplicabilidad de la metodología propuesta debido al menor coste de los sensores RGB, en comparación con los sensores multiespectrales y térmicos, y al procesamiento fotogramétrico más 


\section{Congreso Nacional de Riegos CARTAGENA 2021}

sencillo de las imágenes. Las imágenes RGB de alta resolución permiten la segmentación precisa de la vegetación, lo cual es esencial para evitar los efectos del suelo y obtener valores de GCV precisos.

En este estudio no se generaron modelos de aplicación general, ya que se requeriría una amplia gama de medidas de campo para calibrar un modelo que pudiera aplicarse a una parcela completa. Sin embargo, con unas pocas mediciones de campo, el estado hídrico de una parcela completa se puede estimar con el enfoque propuesto, aunque los mejores modelos en ambos años tengan características diferentes, pues todos funcionan dentro de parámetros admisibles. Los estudios futuros intentarán predecir el estado hídrico en una fecha específica en cualquier año utilizando un modelo calibrado generalizable desarrollado previamente al integrar el número de estaciones analizadas

\section{Referencias}

1. D. I. Jackson and P. B. Lombard, "Environmental and Management Practices Affecting Grape Composition and Wine Quality - A Review," Am. J. Enol. Vitic., vol. 44, no. 4, 1993.

2. J. M. Mirás-Avalos and D. S. Intrigliolo, "Grape Composition under Abiotic Constrains: Water Stress and Salinity," Front. Plant Sci., vol. 8, p. 851, May 2017.

3. J. Hunink et al., "A simplified water accounting procedure to assess climate change impact on water resources for agriculture across different European river basins," Water (Switzerland), vol. 11, no. 10, 2019.

4. A. Matese and S. F. Di Gennaro, "Technology in precision viticulture: A state of the art review," Int. J. Wine Res., vol. 7, no. 1, pp. 69-81, 2015.

5. J. M. Miras-Avalos and E. S. Araujo, "Optimization of vineyard water management: Challenges, strategies, and perspectives," Water (Switzerland), vol. 13, no. 6, pp. 1-32, 2021.

6. S. S. Virnodkar, V. K. Pachghare, V. C. Patil, and S. K. Jha, Remote sensing and machine learning for crop water stress determination in various crops: a critical review, no. 0123456789. Springer US, 2020.

7. M. N. Boukoberine, Z. Zhou, and M. Benbouzid, "A critical review on unmanned aerial vehicles power supply and energy management: Solutions, strategies, and prospects," Appl. Energy, vol. 255, no. August, p. 113823, 2019.

8. L. Pádua et al., "UAS, sensors, and data processing in agroforestry: a review towards practical applications," Int. J. Remote Sens., vol. 38, no. 8-10, pp. 2349-2391, 2017.

9. P. J. Zarco-Tejada et al., "Assessing vineyard condition with hyperspectral indices: Leaf and canopy reflectance simulation in a row-structured discontinuous canopy," Remote Sens. Environ., vol. 99, pp. 271-287, 2005.

10. C. Acevedo-Opazo, B. Tisseyre, H. Ojeda, S. Ortega-Farias, and S. Guillaume, "Is it possible to assess the spatial variability of vine water status?," OENO One, vol. 42, no. 4, p. 203, Dec. 2008.

11. J. Berni, P. J. Zarco-Tejada, L. Suárez, and E. Fereres, "Thermal and narrowband multispectral remote sensing for vegetation monitoring from an unmanned aerial vehicle," IEEE Trans. Geosci. Remote Sens., vol. 47, no. 3, pp. 722-738, Mar. 2009.

12. J. Baluja et al., "Assessment of vineyard water status variability by thermal and multispectral imagery using an unmanned aerial vehicle (UAV)," Irrig. Sci., vol. 30, no. 6, pp. 511-522, Nov. 2012.

13. R. Ballesteros, J. F. Ortega, D. Hernández, and M. Á. Moreno, “Characterization of Vitis vinifera L. canopy using unmanned aerial vehicle-based remote sensing and photogrammetry techniques," Am. J. Enol. Vitic., vol. 66, no. 2, pp. 120-129, May 2015. 


\section{Congreso Nacional de Riegos CARTAGENA 2021}

14. I. Pôças et al., "Predicting grapevine water status based on hyperspectral reflectance vegetation indices," Remote Sens., vol. 7, pp. 16460-16479, 2015.

15. M. Romero, Y. Luo, B. Su, and S. Fuentes, “Vineyard water status estimation using multispectral imagery from an UAV platform and machine learning algorithms for irrigation scheduling management," Comput. Electron. Agric., vol. 147, pp. 109117, Apr. 2018

16. J. M. Costa, O. M. Grant, and M. M. Chaves, “Use of thermal imaging in viticulture: current application and future prospects," in Methodologies and Results in Grapevine Research, S. Delrot, Ed. Springer Science+Business Media B.V., 2010, pp. 136-147.

17. M. Möller et al., “Use of thermal and visible imagery for estimating crop water status of irrigated grapevine,” J. Exp. Bot., vol. 58, no. 4, pp. 827-838, 2007.

18. J. R. Rodríguez-Pérez, D. Riaño, E. Carlisle, S. Ustin, and D. R. Smart, “Evaluation of hyperspectral reflectance indexes to detect grapevine water status in vineyards," Am. J. Enol. Vitic., vol. 58, no. 3, pp. 302-317, Sep. 2007.

19. M. Rossini et al., "Assessing canopy PRI from airborne imagery to map water stress in maize," ISPRS J. Photogramm. Remote Sens., vol. 86, pp. 168-177, 2013.

20. P. J. Zarco-Tejada et al., "A PRI-based water stress index combining structural and chlorophyll effects: Assessment using diurnal narrow-band airborne imagery and the CWSI thermal index," Remote Sens. Environ., vol. 138, pp. 38-50, 2013.

21. R. Ballesteros, J. F. Ortega, D. Hernandez, and M. A. Moreno, “Onion biomass monitoring using UAV-based RGB imaging,” Precis. Agric., vol. 19, no. 5, pp. 840-857, 2018.

22. C. M. Bishop, Pattern recognition and machine learning. New York, USA: Springer, 2006.

23. T. Poblete, S. Ortega-Farías, M. A. Moreno, and M. Bardeen, “Artificial neural network to predict vine water status spatial variability using multispectral information obtained from an unmanned aerial vehicle (UAV)," Sensors, vol. 17, no. 11, 2017.

24. G. Krishna et al., "Comparison of various modelling approaches for water deficit stress monitoring in rice crop through hyperspectral remote sensing," Agric. Water Manag., vol. 213, no. August 2018, pp. 231-244, 2019.

25. I. Buesa, D. Pérez, J. Castel, D. S. Intrigliolo, and J. R. Castel, “Effect of deficit irrigation on vine performance and grape composition of Vitis vinifera L. cv. Muscat of Alexandria," Aust. J. Grape Wine Res., vol. 23, no. 2, pp. 251-259, Jun. 2017.

26. J. I. Córcoles, J. F. Ortega, D. Hernández, and M. A. Moreno, “Estimation of leaf area index in onion (Allium cepa L.) using an unmanned aerial vehicle," Biosyst. Eng., vol. 115, no. 1, pp. 31-42, 2013.

27. M. Kubat, An Introduction to Machine Learning, Second. Springer, 2017.

28. R. Ballesteros, J. F. Ortega, and M. Á. Moreno, “FORETo: New software for reference evapotranspiration forecasting," J. Arid Environ., vol. 124, pp. 128-141, 2016.

29. P. López-García et al., "Assessment of Vineyard Water Status by Multispectral and RGB Imagery Obtained from an Unmanned Aerial Vehicle," Am. J. Enol. Vitic., p. ajev.2021.20063, Jun. 2021. 


\title{
Caracterización técnico-económica de la reducción de boro en agua marina desalinizada mediante resinas de intercambio iónico
}

\author{
Imbernón, A. ${ }^{1}$, Martínez-Álvarez, V. ${ }^{1}$, Gallego-Elvira, B. ${ }^{1}$, Martín-Gorriz, B. ${ }^{1}$, Molina-del Toro, R. ${ }^{2}$, Jodar-Conesa, F.J. \\ ${ }^{3}$, Maestre-Valero, J.F. ${ }^{1}$ \\ 1 Universidad Politécnica de Cartagena (UPCT); alberto.imbernon@edu.upct.es \\ Universidad Politécnica de Cartagena (UPCT); victoriano.Martinez@upct.es \\ Universidad Politécnica de Cartagena (UPCT); belen.gallego@upct.es \\ Universidad Politécnica de Cartagena (UPCT); b.martin@upct.es \\ EcoHidro Agua y Medio Ambiente (ECOHIDRO); ruben.molina@ecohidro.es \\ Agrícola Conesa Marín; franconesa@live.com \\ Universidad Politécnica de Cartagena (UPCT); josef.maestre@upct.es
}

Resumen: La Cuenca del Segura (Sureste de España) se caracteriza por una marcada escasez hídrica, lo que ha suscitado el frecuente uso de recursos hídricos no convencionales, como el agua marina desalinizada (AMD), para el riego y abastecimiento. El AMD, a pesar de su baja conductividad eléctrica comprendida entre 0,36 y $0,90 \mathrm{dS} / \mathrm{m}$, se caracteriza por una elevada concentración de boro, cloruro y sodio. El boro, aun siendo un elemento esencial para los cultivos, se puede presentar en el AMD en una concentración tóxica y puede suponer un riesgo para las cosechas. Existen diversos métodos para la reducción y eliminación de boro en AMD, entre los que se encuentran las resinas de intercambio iónico (RII). La principal característica de una resina es su selectividad específica por un elemento, la cual está determinada por su composición química y estructura molecular. Gracias a esta selectividad, y de manera contraria a otros métodos como las membranas de ósmosis inversa, método más extendido en el mundo en la actualidad, la resina no produce un agua prácticamente desmineralizada. En este estudió se evaluó el efecto de un equipo de RII, con selectividad por el boro, en la reducción de dicho elemento en AMD, así como su coste y su eficiencia energética. Los resultados obtenidos indicaron que la resina empleada, Amberlite PWA10, eliminó el boro del AMD de forma eficaz, y mostró una elevada eficiencia desde el punto de vista energético. Sin embargo, el elevado coste de inversión del equipo y los costes operativos de mantenimiento pueden resultar su principal inconveniente.

Palabras clave: Recursos hídricos no convencionales; Selectividad química; Toxicidad por boro; Riego sostenible. 


\title{
Technical and economic characterization of boron reduction in desalinated seawater using ion exchange resins
}

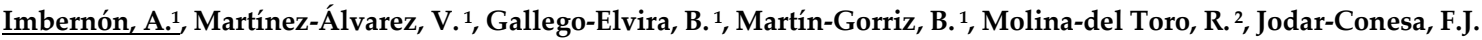 \\ 3 , Maestre-Valero, J.F. 1 \\ Universidad Politécnica de Cartagena (UPCT); alberto.imbernon@edu.upct.es \\ Universidad Politécnica de Cartagena (UPCT); victoriano.Martinez@upct.es \\ Universidad Politécnica de Cartagena (UPCT); belen.gallego@upct.es \\ Universidad Politécnica de Cartagena (UPCT); b.martin@upct.es \\ EcoHidro Agua y Medio Ambiente (ECOHIDRO); ruben.molina@ecohidro.es \\ Agrícola Conesa Marín; franconesa@live.com \\ Universidad Politécnica de Cartagena (UPCT); josef.maestre@upct.es
}

\begin{abstract}
The Segura River Basin (Southeast of Spain) is characterized by a marked water shortage, which has led to the frequent use of non-conventional water resources, such as desalinated seawater (DSW), for irrigation and human supply. DSW, despite its low electrical conductivity between 0.36 and $0.90 \mathrm{dS} / \mathrm{m}$, is characterized by a high boron, chloride and sodium concentration. Boron, although represents an essential element for crops, can be present in DSW in a toxic concentration and can pose a risk to some crops. Ion exchange resins (IERs) is one of the extant methods for the reduction and removal of boron in DSW. The main characteristic of a resin is its specific selectivity for an element, which is determined by its chemical composition and molecular structure. Thanks to this selectivity, and contrary to other methods such as reverse osmosis membranes, considered the most widespread method in the world today, the resin does not produce practically demineralized water. In this study, the effect of an IER equipment, with selectivity for boron, in reducing this element in DSW was evaluated, as well as its cost and energy efficiency. The results obtained indicated that the resin used, Amberlite PWA10, removed the boron from DSW efficiently, and showed high efficiency from the energy point of view. However, the high investment cost of the equipment and the operational maintenance costs could be its main drawback.
\end{abstract}

Keywords: Non-conventional water resources; Chemical selectivity; Boron toxicity; Sustainable irrigation. 


\section{Introducción}

La Cuenca del Segura se caracteriza por una marcada escasez de recursos hídricos, la cual promueve el desarrollo de técnicas para la obtención de agua, destinada al consumo humano y al riego. Entre ellas destacan (i) la reutilización de agua tras su depuración y regeneración, y especialmente, (ii) el empleo de agua marina desalinizada (AMD). No obstante, esta última posee singularidades que pueden limitar su uso directo para el riego agrícola [1], destacando su escaso contenido nutricional y, especialmente, la presencia de una elevada concentración de iones boro, cloruro y sodio. Habitualmente, la concentración de boro en el AMD supera los umbrales de toxicidad para cultivos leñosos, ya que la franja que separa una concentración adecuada y una tóxica es muy estrecha [2]. La bibliografía sitúa el umbral de fitotoxicidad por boro en cítricos en $0,5 \mathrm{mg} / \mathrm{L}$, aunque este valor depende de factores como el $\mathrm{pH}$ y el contenido de materia orgánica presente en el suelo, entre otros [3-5]. Entre la gran variedad de métodos que existen en la actualidad para la eliminación de boro en AMD, destaca el sistema de resinas de intercambio iónico (RII) [6,7], en el que, en la capacidad para la reducción de boro por parte de la resina, influyen factores como el propio tipo de resina empleada y diversas características del agua de alimentación, como su caudal, concentración de boro, $\mathrm{pH}$ o temperatura. Cuando una resina que posee un grupo funcional $\mathrm{N}$-metilglucamina se selecciona para la eliminación de boro en AMD, el ion borato $\left(\mathrm{BO}^{3-}\right)$ presente en el agua tratada forma un complejo con dos grupos hidroxilos de la resina, mayormente favorecido en medios neutros o ligeramente alcalinos. Si la resina se encuentra en un medio muy ácido, su capacidad para formar un complejo con el boro se reduce, al presentarse en el agua como $\mathrm{H}_{3} \mathrm{BO}_{3}$, mientras que en un medio de elevada alcalinidad dicha eficiencia en la eliminación de boro se puede ver favorecida, siempre que no supere umbrales máximos característicos para cada tipo de resina [6-8]. Respecto a la temperatura, Darwish et al. [7] estudiaron la reducción de boro mediante el paso de agua destilada, con concentraciones elevadas de ácido bórico disuelto en ella, mediante una columna de resina Amberlite IRA743. Concluyeron que por debajo de $40{ }^{\circ} \mathrm{C}$, la temperatura no comprometió el funcionamiento de la resina. Por otro lado, un aspecto a considerar es el limitado tiempo de funcionamiento de las resinas hasta su regeneración, pues, tras éste, pierden la capacidad de retención de boro debido a su saturación iónica y deben someterse a un proceso de regeneración [8,9]. El tiempo hasta este punto varía según el tipo de resina empleada, su capacidad total de adsorción de boro, el caudal de agua de alimentación o la concentración de dicho ion presente en el agua de alimentación. Chillón Arias et al. [8] estudiaron el comportamiento de tres resinas en la reducción de boro en AMD y determinaron que el proceso de regeneración fue necesario para lograr una eliminación total de boro, tras alcanzar un tiempo de funcionamiento comprendido entre $50 \mathrm{y} 56 \mathrm{~h}$. Por otro lado, Darwish et al. [7], y Yilmaz et al. [10], comprobaron además que este proceso de regeneración fue satisfactorio mediante dos etapas, empleando ácido clorhídrico $(\mathrm{HCl})$ y sosa cáustica $(\mathrm{NaOH})$. La etapa con $\mathrm{HCl}$ arrastra el boro retenido por la resina, mientras que la etapa con $\mathrm{NaOH}$ neutraliza su estructura y la devuelve a su estado iónico inicial. Nadav [9] demostró, además, que esta segunda etapa en la regeneración mejora la uniformidad del potencial químico de la resina, respecto a una regeneración de una sola etapa, y evitando una pérdida de la vida útil de la resina más acelerada.

En términos económicos, el coste final elevado de un equipo de RII puede ser muy variable, en función de, principalmente, el tamaño de la instalación y el tipo de resina seleccionada $[9,11,12]$. 


\section{Congreso Nacional de \\ Riegos}

Su coste energético es reducido en comparación a otros métodos, como la ósmosis inversa (OI), que requiere de elevadas presiones para lograr bajas concentraciones de boro. Sin embargo, el principal factor que conduce a la elección del método de OI en detrimento de la RII, parece ser la elevada asociación de los costes de instalación, de reactivos y de mantenimiento de este último equipo, el cual, a pesar de ser más eficaz técnica y energéticamente, posee una inversión mayor.

En este contexto, el objetivo de este estudio fue la caracterización, técnica y económicamente, de la reducción de la concentración de boro en AMD a nivel de parcela, empleando para ello un equipo de resinas de intercambio iónico.

\section{Materiales y métodos}

\subsection{Proceso de reducción de boro mediante columna de RII.}

El ensayo experimental, llevado a cabo en Torre Pacheco (Murcia), se basó en el empleo de un equipo prototipo de RII (Modelo: HidroPURE DR20). La resina empleada fue Amberlite PWA10, resina de intercambio aniónico débil, cuyo grupo funcional, N-metilglucamina, se caracteriza por una elevada especificidad por el ion boro. El sistema trabajó a una presión de 2,5-3 bar, y, según el fabricante, la resina funcionaba eficientemente en un rango de $\mathrm{pH}$ de 5-8 y a una temperatura inferior a $40^{\circ} \mathrm{C}$. Por otro lado, el caudal máximo de producción para el prototipo es de $1,2 \mathrm{~m} / \mathrm{h}$ y el tiempo de funcionamiento previo a saturación iónica, menor a $60 \mathrm{~h}$.

De esta forma, con el fin de realizar una evaluación técnico-económica de dicho sistema de RII, se planificaron dos pruebas en las que la temperatura promedio fue de $16^{\circ} \mathrm{C}$ para la prueba $1, \mathrm{y}$ $28^{\circ} \mathrm{C}$ para la prueba 2 . La duración de ambas pruebas fue de $156 \mathrm{~h}$, y en ellas no se realizó ningún ajuste de presión de bombeo hacia la columna de resina, o del valor de $\mathrm{pH}$, salvo en el inicio de cada prueba, las cuales comenzaron en un pH de 5,5 (Prueba 1) y 11 (Prueba 2).

El AMD empleada en el ensayo fue suministrada desde la Instalación Desalinizadora de Agua de Mar (IDAM) de Escombreras, y fue almacenada en un depósito regulador para asegurar el suministro continuo al sistema. El agua de alimentación se caracterizó por un rango de $\mathrm{pH}$ entre 8,1 y 8,5 , y una concentración de boro promedio de $1,05 \mathrm{mg} / \mathrm{L}$.

Previo a su paso por la columna de resina, el agua de alimentación sufrió un pretratamiento (Figura 1), compuesto por cartuchos de microfiltración y carbón activo, y por un lecho de zeolita, para eliminar posibles partículas de determinado tamaño $(>1 \mu \mathrm{m})$ : 


\section{Congreso Nacional de Riegos}

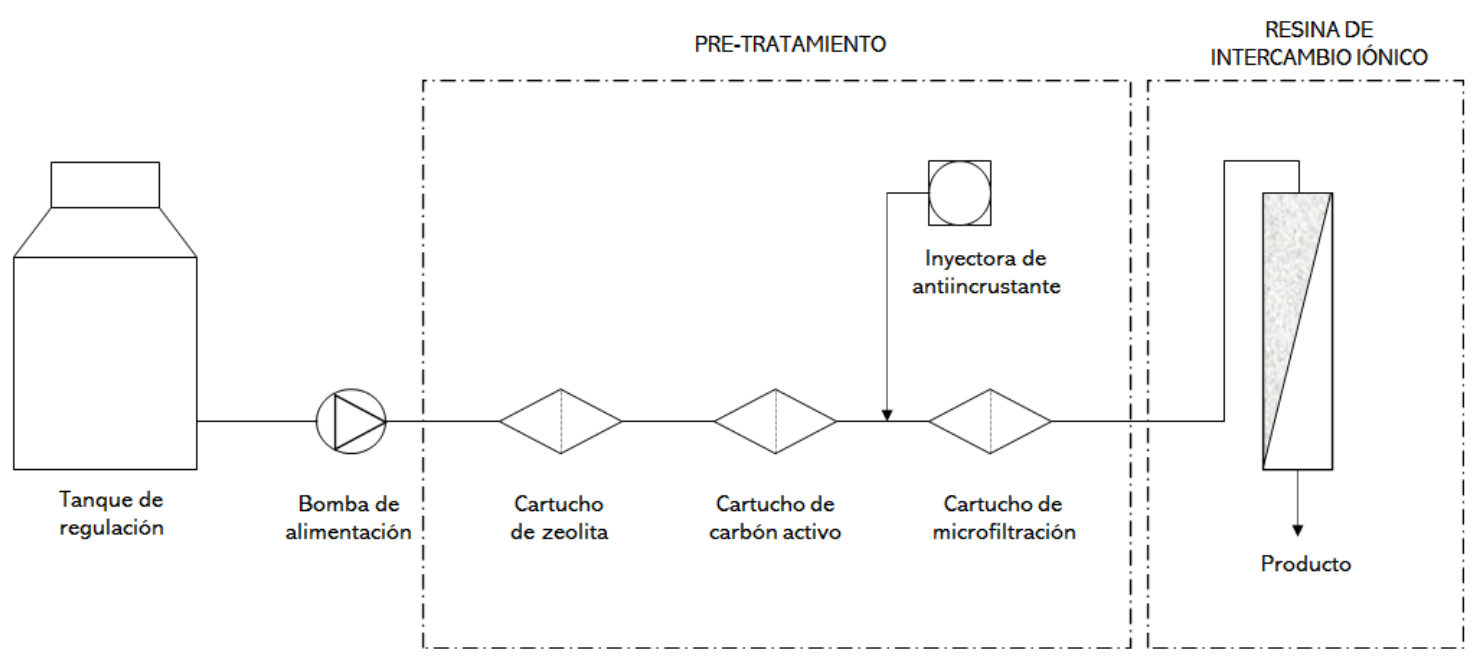

Figura 1. Diagrama de flujo de corrientes del sistema de resinas de intercambio iónico descrito. Proyecto Retos Colaboración SEARRISOST - RTC - 2017-6192-2.

Tras este pretratamiento, el agua se impulsó al lecho de resina (44 L) contenido en la columna. El caudal de agua de alimentación se situó en $1 \mathrm{~m}^{3} / \mathrm{h}$, dando lugar a un flujo (volúmenes de agua por volumen de lecho de resina) de $22,7 \mathrm{BV} / \mathrm{h}$, y a un agua producto con una concentración reducida de boro.

Una vez llevada a cabo la prueba 1, tras 156 h, la resina se sometió a un proceso de regeneración, con el fin de desplazar el boro adsorbido por la misma y devolverla a su estado iónico inicial. Para dicha regeneración se dispuso de dos depósitos de $50 \mathrm{~L}$, con el fin de adicionar los compuestos empleados en el proceso $(\mathrm{HCl}$ y $\mathrm{NaOH})$, compuesto por dos etapas, una primera en la que se inyectó $\mathrm{HCl}$ para desplazar el boro, y una segunda en la que se adicionó $\mathrm{NaOH}$ para neutralizar la resina. El agua producto originado durante la regeneración, se almacenó en un nuevo tanque de regulación.

\subsection{Monitorización de datos.}

Para evaluar la eficiencia técnica y económica del equipo, la caracterización de su funcionamiento se llevó a cabo mediante la toma de muestras de agua producto, cada $3 \mathrm{~h}$, durante el proceso completo de reducción de boro. Tras la toma de muestras, se determinaron las siguientes variables: caudal de agua producto, presión de bombeo hacia la resina, temperatura del AMD, $\mathrm{pH}$ de AMD producto ( $\mathrm{pH}$ metro CRISON GLP21), conductividad eléctrica de AMD producto (conductímetro CRISON GLP31), intensidad de cada fase que alimentaba el sistema, mediante una pinza amperimétrica y tensión de la red eléctrica.

Las muestras de agua (AMD y AMD producto) se analizaron en laboratorio: mediante un cromatógrafo iónico (METROHM 861 Advanced Compact IC) para obtener la concentración de iones y cationes (Cl-, NO3-, $\mathrm{PO} 43-$-, $\mathrm{SO} 42-, \mathrm{Na}+, \mathrm{NH} 4+, \mathrm{K}+, \mathrm{Ca} 2+, \mathrm{Mg} 2+)$ y un espectrómetro ICPMasas (Agilent Technologies 7900) para obtener la concentración de microelementos (B, Mn, Fe, $\mathrm{Cu}, \mathrm{Zn})$. 


\section{Congreso Nacional de Riegos}

Finalmente, en la evaluación económica, se tuvieron en cuenta (i) el coste de operación, compuesto por los costes de amortización, energéticos, de reactivos y de mantenimiento, $\mathrm{y}$, por otro lado, (ii) el coste de cultivo, compuesto por el coste del agua de alimentación, y el de acondicionamiento del agua tratada para el fertirriego del cultivo, todo en $€ / \mathrm{m}^{3}$. Con el fin de estimar los costes a mayor escala, éstos se calcularon para el prototipo empleado en el ensayo a pie de parcela (caudal producto de $1 \mathrm{~m}^{3}$ ), y para un equipo teórico de mayor producción $\left(20 \mathrm{~m}^{3}\right)$.

No obstante, las comparaciones realizadas son orientativas, debido, fundamentalmente a diferencias en el coste de los equipos, según su tamaño y configuración, su mantenimiento, y otros factores, como el precio de la luz, que se ve sometido a continuas fluctuaciones.

\section{Resultados y discusión}

\subsection{Evaluación técnica}

El agua fue bombeada a una presión en torno a 3 bar durante el proceso, sin sufrir variaciones a lo largo del mismo ni denotar disminuciones de caudal, que se mantuvo en $1 \mathrm{~m}^{3} / \mathrm{h}$. El valor de pH en el agua producto, que comenzó en 5,5 en la prueba 1, y en 11 en la prueba 2, debido al ciclo completo de regeneración tras la prueba 1, evolucionó desde el comienzo del funcionamiento del equipo hasta su estabilización (Figura 2), alcanzando el mismo valor que el pH del agua de alimentación $(\mathrm{pH} 8,3)$ tras aproximadamente $23 \mathrm{~h}$. La CE del agua producto permaneció inalterada respecto al AMD de entrada, no viéndose afectada por la presencia de resina, comportamiento observado en otras resinas, como Amberlite IRA743 o Dow XU-43504 [7,8]

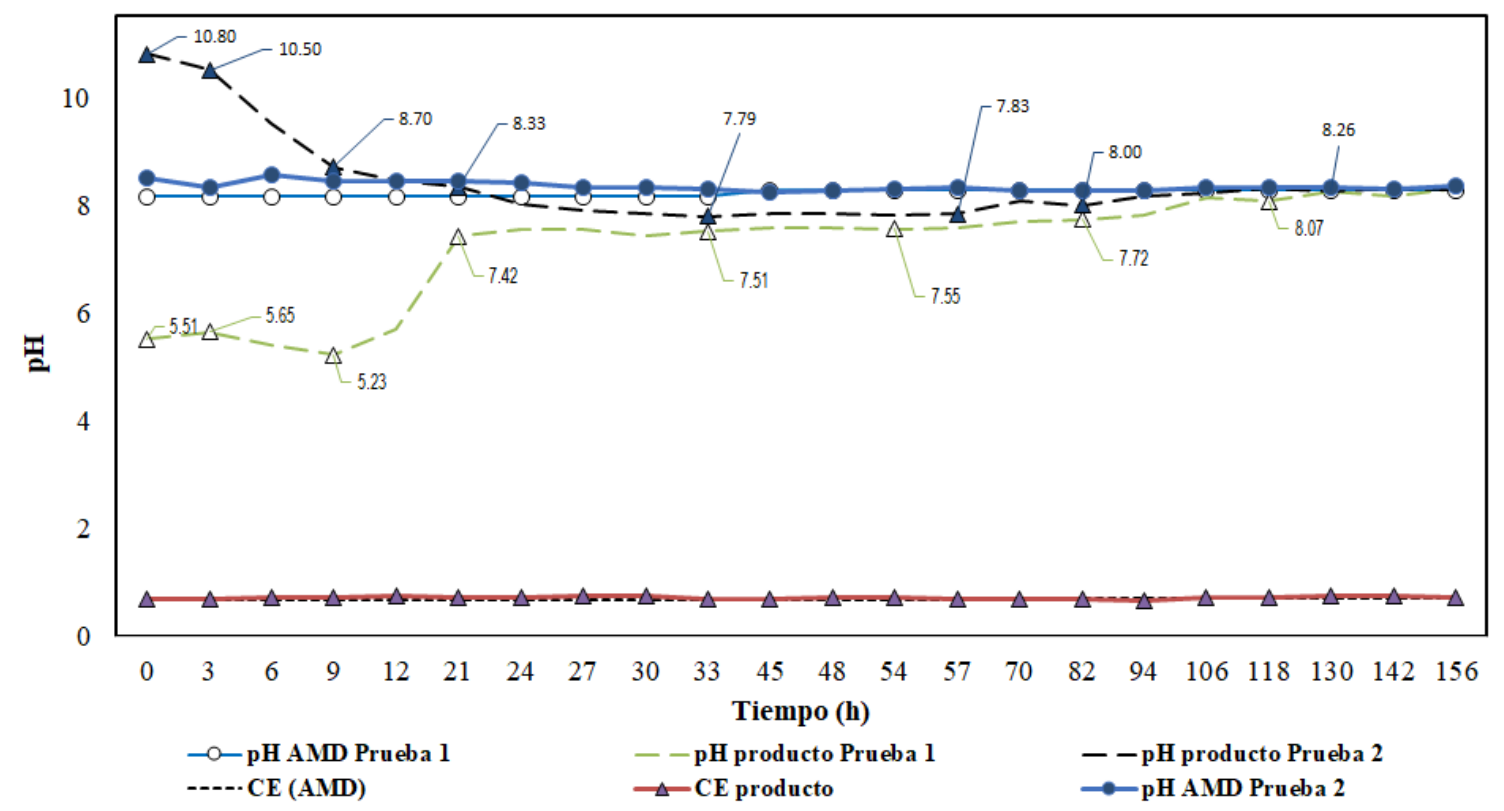

Figura 2. Evolución de pH y CE en AMD y agua producto.

Mediante el análisis de los principales aniones y cationes presentes en el AMD producto, se evaluó la selectividad de la resina por el ion boro, observando que la concentración de los mismos no sufrió ninguna variación respecto al AMD de alimentación, comportamiento común para otras 


\section{Congreso Nacional de Riegos}

resinas con elevada selectividad específica [8,12]. Por otro lado, la concentración de boro en la prueba 1 (Figura 3) se situó en $0 \mathrm{mg} / \mathrm{L}$ durante las primeras $56 \mathrm{~h}$ de funcionamiento del equipo, una evolución muy similar a otras resinas ya estudiadas, como Amberlite IRA743 o Purolite S108 [7-9], que mantuvieron esta concentración de boro, durante 56 y 52 h, respectivamente. En la prueba 2 este tiempo disminuyó hasta $47 \mathrm{~h}$, presumiblemente debido a alcalinización del agua producida por el $\mathrm{NaOH}$, hasta valores de $\mathrm{pH}$ de 11, que dieron lugar a un peor comportamiento por parte de la resina en la adsorción de boro.

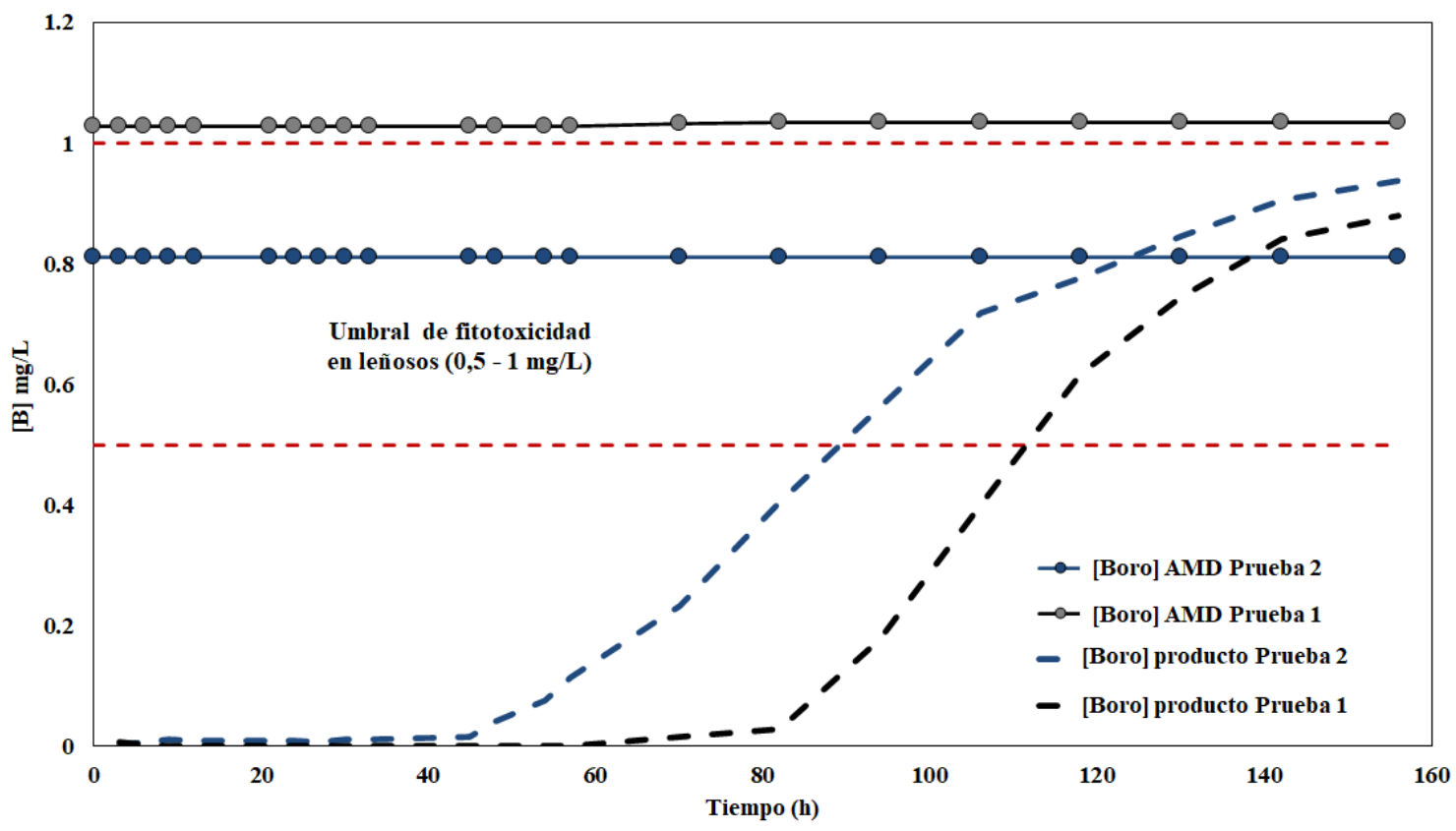

Figura 3. Evolución de [B] en el agua producto.

Posteriormente, la concentración aumentó progresivamente hasta el umbral de fitotoxicidad en cítricos $(0,5 \mathrm{mg} / \mathrm{L})$ tras, aproximadamente, $110 \mathrm{~h}$ en la prueba 1 y $88 \mathrm{~h}$ en la prueba 2 . Este valor continuó aumentando en ambas pruebas hasta 0,9 mg/L al final del proceso, tras un total $156 \mathrm{~h}$. Su comportamiento distó del de otras resinas, (AmberliteIRA743 y Dow XU-43594), que lograron una concentración menor a $0,5 \mathrm{mg} / \mathrm{L}$ durante 75 y $66 \mathrm{~h}$ [8], en torno a $35 \mathrm{~h}$ menos que Amberlite PWA10, mostrando una mejor tasa de adsorción de boro y comprobando la gran selectividad específica por el ion, así como su eficiencia durante el proceso. No obstante, dicho comportamiento depende de un gran conjunto de parámetros, por lo que no es recomendable realizar una comparativa entre estas resinas y los resultados obtenidos en las pruebas con AmberLite PWA10, debido a las diferencias existentes dichos parámetros, como la concentración de boro en el agua de alimentación, el volumen de resina de la columna o tamaño promedio de partícula de resina. Darwish et al. [7] estudiaron la adsorción de boro mediante diferentes diámetros de Amberlite IRA743 y demostraron que la mayor tasa de adsorción de boro se produjo con las partículas de menor tamaño empleadas $(1-45 \mu \mathrm{m})$, respecto a las de mayor tamaño (700 $\mu \mathrm{m})$. 
En cuanto a la evaluación económica, el resumen de costes se presenta en la Tabla 1.

Tabla 1. Resumen de costes de operación y cultivo para equipos HidroPURE DR20 con RII.

\begin{tabular}{c|c|cc}
\hline \multicolumn{2}{c|}{ Costes desglosados $\left(\boldsymbol{\epsilon} / \mathbf{m}^{\mathbf{3}}\right)$} & Prototipo & Diseño 1 \\
\hline \multirow{4}{*}{ Costes de operación } & Costes de amortización & 0,846 & 0,065 \\
& Costes energéticos & 0,090 & 0,001 \\
& Costes de mantenimiento & 0,400 & 0,025 \\
& Costes de reactivos & 0,146 & 0,335 \\
\hline \multirow{2}{*}{ Coste de cultivo } & Coste total de operación & $\mathbf{1 , 4 8 2}$ & $\mathbf{0 , 4 2 6}$ \\
\hline & Coste del agua desalinizada & 0,620 & 0,620 \\
& Coste de acondicionamiento para fertirrigación & 0,085 & 0,085 \\
\hline & Coste total de cultivo & $\mathbf{0 , 7 0 5}$ & $\mathbf{0 , 7 0 5}$ \\
\hline & Coste global $\left(\boldsymbol{\epsilon} / \mathbf{m}^{\mathbf{3}}\right)$ & $\mathbf{2 , 1 8 7}$ & $\mathbf{1 , 1 3 1}$ \\
\hline
\end{tabular}

El coste de amortización del equipo abarcó más del 57\% en el caso del prototipo, y el coste de mantenimiento resultó elevado debido a la tasa de reposición anual de la resina (5\%). Estos costes son mayores respecto a un sistema de ósmosis inversa [8,13]. Destaca también elevado el coste de cultivo, debido fundamentalmente al precio actual del AMD $(0,62 € / \mathrm{m} 3)$, y al coste para acondicionar el agua para el riego del cultivo, fruto de la desmineralización producida en el proceso de OI en la IDAM. No obstante, el coste total de operación se vio compensado por el bajo coste energético, aunque con un valor un $16,5 \%$ superior a un equipo de ósmosis inversa de similares características [13]. Por otro lado, el efecto escala disminuyó notablemente el coste global, reduciéndolo un $50 \%$ respecto al prototipo en parcela.

También destaca el elevado número de ciclos de regeneración, el cual puede verse disminuido mediante el empleo de un embalse regulador. Un ciclo habitual de regeneración debe realizarse antes de que el agua producto posea una concentración de boro igual o superior al umbral de fitotoxicidad del cultivo irrigado. Sin embargo, la producción de agua filtrada por la resina, cuya concentración de boro aumenta a medida que se produce su saturación iónica, y su posterior almacenamiento en un embalse regulador, da lugar a un efecto de dilución que disminuye la concentración total de dicho ion en el agua almacenada. Esto permite retrasar el ciclo de regeneración, como se observa en la Figura 4, donde tras 156 h, el agua producto acumulada en dicho embalse tendría una concentración de boro inferior a $0,5 \mathrm{mg} / \mathrm{L}$, lo cual conlleva una notable disminución en el coste de reactivos, al realizar un menor número de ciclos de regeneración, lo que, a su vez, da lugar a un coste de operación menor. 


\section{Congreso Nacional de Riegos}

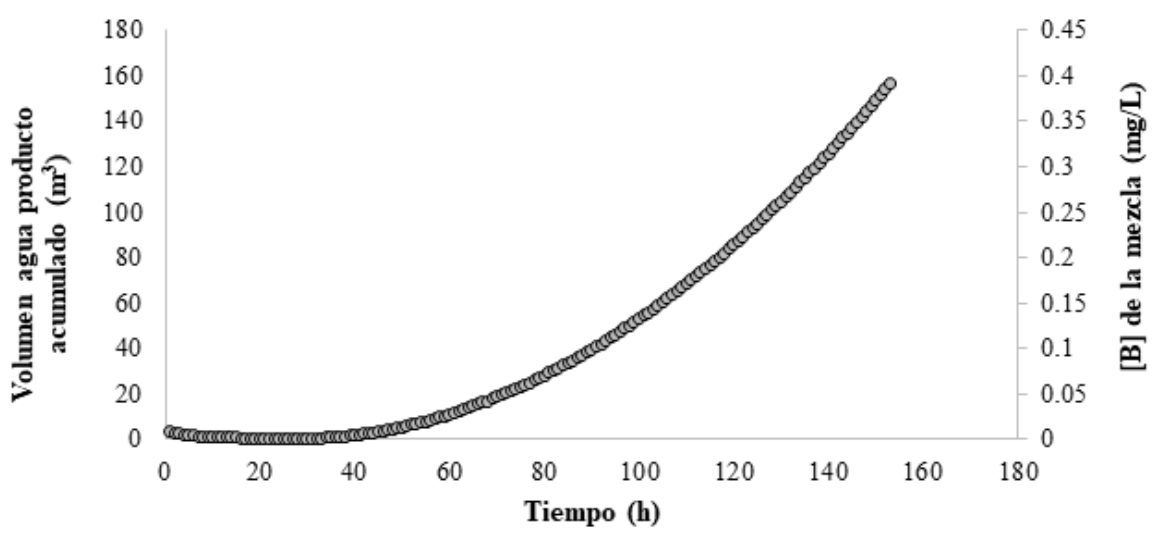

Figura 4. Evolución de la concentración de boro en un embalse regulador teórico para el almacenamiento del agua producto de RII.

\section{Conclusiones}

En este estudio se evaluó técnica y económicamente el empleo de un equipo de resinas de intercambio iónico para la reducción de la concentración de boro en AMD, a nivel de parcela.

En primer lugar, se demostró que la resina Amberlite PWA10 fue capaz de adsorber el ion boro del AMD satisfactoriamente. Manifestó una selectividad específica elevada y mantuvo la concentración de dicho ion en $0 \mathrm{mg} / \mathrm{L}$, en promedio, durante $52 \mathrm{~h}$ de funcionamiento, $\mathrm{y}$, por debajo del umbral de fitotoxicidad de cítricos $(0,5 \mathrm{mg} / \mathrm{L})$ durante aproximadamente $99 \mathrm{~h}$. La conductividad eléctrica del agua producto permaneció en un valor prácticamente idéntico al presentado en el AMD durante el funcionamiento del equipo, así como el resto de iones presentes en el agua de alimentación.

Desde un punto de vista económico, el equipo de RII resultó eficiente desde el punto de vista energético, gracias a la baja presión de trabajo y a la capacidad de la resina para operar con un adecuado rendimiento a temperatura fresca y moderada, dando lugar a unos costes energéticos bajos.

No obstante, las RII presentaron un coste de operación elevado, debido principalmente a los componentes de amortización y mantenimiento. La necesidad de realizar un mayor número de ciclos de regeneración de la resina variará en función de la sensibilidad al boro del cultivo, así como por el volumen de agua producto requerido. No obstante, esta cifra se puede ver disminuida gracias al efecto de dilución que un elevado volumen de agua puede ejercer sobre la concentración de boro presente en la misma, en caso de ser almacenado en un embalse regulador.

Como conclusión general, se determinó que la viabilidad y rentabilidad del sistema reductor de boro mediante RII está supeditada a, principalmente, el tipo de agua empleada y su concentración de boro, el nivel de reducción deseado para dicho ion, la rentabilidad del cultivo, y finalmente, la posibilidad de realizar mezclas de aguas, las cuales permitan una disminución de los costes de agua, proceso de producción y acondicionamiento para el riego. 


\section{Congreso Nacional de Riegos}

\section{Bibliografía}

1. Martínez-Álvarez, V., \& Martín-Gorriz, B., (2014). Antecedentes y problemática de la aplicación de agua marina desalinizada al riego agrícola. Universidad Politécnica de Cartagena.

2. Seda Kayaci, S. Birgül Tantekin-Ersolmaz, M. Göktuğ Ahunbay, William B. Krantz, (2020). Technical and economic feasibility of the concurrent desalination and boron removal (CDBR) process, Desalination, Volume 486.

3. Jones, J. (1998). Plant Nutrition Manual. Chapter 1. Functions of plants. Pag (6-8).

4. Alarcón, A. (2001). El boro como nutriente esencial. Universidad Politécnica de Cartagena. Edafología y Química Agrícola.

5. García-Sánchez, F., Simón-Grao, S., Martínez-Nicolás, J., Alfosea-Simón, M., Liu, C., Chatzissavvidis, C., Pérez-Pérez, J., Cámara-Zapata, J. (2020). Multiple stresses occurring with boron toxicity and deficiency in plants. Journal of Hazardous Materials. Volume 397.

6. P. Glueckstern, M. Priel, (2007). Boron removal in brackish water desalination systems, Desalination, Volume 205, Issues 1-3, Pages 178-184.

7. Bin Darwish, N., Kochkodan, V., Hilal, N., (2015). Boron removal from water with fractionized Amberlite IRA743 resin, Desalination, Volume 370, Pages 1-6.

8. Chillón Arias, M.F., Bru, L.V., Pico, D.P., Galvañ, P.V., (2011). Comparison of ion Exchange resins used in reduction of boron in desalinated water for human consumption. Desalination 278, 244-249.

9. Erdem Yilmaz, A., Boncukcuoglu, R., Tolga Yilmaz, M., Muhtar Kocakerim, M., (2005). Adsorption of boron from boron-containing wastewaters by ion exchange in a continuous reactor. Journal of Hazardous Materials, Volume 117, Issues 2-3, Pages 221-226.

10. Nadav, N., (1999). Boron removal from seawater reverse osmosis permeate utilizing selective ion exchange resin. Desalination, Volume 124, Issues 1-3, Pages 131-135.

11. Dardel. F., (2019). Ion Exchange. Maximun temperature and organic load for anion resins. Francois de Dardel.

12. Jacob, C. (2006). Seawater desalination: Boron removal by ion exchange technology. University of Montpellier II, France. Rohm and Haas Co.

13. Jódar-Conesa, F. J., (2021). Evaluación técnica-económica del uso de ósmosis inversa para la reducción de boro en agua marina desalinizada y su posterior uso en riego de cultivos sensibles. Trabajo Fin de Estudios, Universidad Politécnica de Cartagena. 


\title{
Estudio de la gestión de las estrategias de riego en los olivares tradicionales.
}

\author{
Molina-Moral, J.C. ${ }^{1}$, Moriana Elvira, A ${ }^{2}$, Pérez-Latorre, F.J. ${ }^{1}$
}

Dpto. Área Mecánica de Fluidos, Campus Científico Tecnológico Linares. Universidad de Jaén.; jcmm001@red,ujaen.es; fjperez@ujaen.es

2 Dpto. Agronomía ETSIA, Universidad de Sevilla; ammoriana@us.es

Resumen: El riego en el olivar tradicional permite aumentar el rendimiento, pero supone un coste adicional que debe optimizarse. La provincia de Jaén (España) es el lugar del mundo donde el riego de este tipo de olivar es más importante. La gran homogeneidad existente en los sistemas de riego localizados y la tipología de las instalaciones y equipos instalados en estos cultivos tradicionales en esta provincia, permite estudiar y caracterizar diferentes estrategias para el diseño de proyectos de riego que no afecten al rendimiento del cultivo, cuando se disminuye la dosis de aplicación.

El objetivo de este trabajo es caracterizar el riego del olivar en una amplia región. Para ello, se estudia la variación del contenido de agua en el suelo de una finca típica de olivos bajo diferentes escenarios de precipitación, demanda evaporativa, tasa de aplicación y disponibilidad temporal de agua de riego para estimar las necesidades y estrategias de riego más adecuadas.

El estudio se ha realizado con los datos disponibles de 18 estaciones agroclimáticas con las que se han establecido patrones de precipitación máxima, media y mínima.

Se consideraron tasas de aplicación diaria en instalaciones típicas de 3,2 (1 sector), 1,6 (2 sectores) y 1,1 (3 sectores) mm día-1, combinadas con tres tipos de disponibilidad de agua: diaria, sólo durante 20 días al mes y con ausencia total en agosto. Los resultados se analizaron desde el punto de vista del momento de inicio del estrés hídrico, las necesidades de riego, las horas de funcionamiento del sistema y la dosis de riego.

Los resultados sugieren que la estrategia de riego de 2 sectores con ausencia de riego en agosto podría ser económicamente la de mayor interés para el olivicultor. Por otro lado, se obtiene que la estrategia que garantiza un mejor perfil hídrico en el suelo es la que corresponde a la implantación de la sectorización en un solo sector y la aplicación de la estrategia de riego E3: RDI, calendario de marzo a septiembre con riego deficitario controlado en agosto.

Palabras clave: cambio climático, endurecimiento del hueso, estrés hídrico, disponibilidad de agua. 


\title{
XXXVIII Congreso Nacional de Riegos CARTAGENA 2021
}

\section{Study of the management of irrigation strategies in traditional}

\section{olive groves.}

\author{
Molina-Moral, J.C. ${ }^{1}$, Moriana Elvira, A², Pérez-Latorre, F.J. ${ }^{1}$
}

Dpto. Área Mecánica de Fluidos, Campus Científico Tecnológico Linares. Universidad de Jaén.; jcmm001@red,ujaen.es fjperez@ujaen.es;

2 Dpto. Agronomía ETSIA, Universidad de Sevilla; amoriana@us.es

\begin{abstract}
Irrigation in traditional olive groves increases yields, but entails an additional cost that must be optimised. The province of Jaén (Spain) is the place in the world where irrigation of this type of olive grove is most important. The great homogeneity existing in the localised irrigation systems and the typology of the installations and equipment installed in these traditional crops in this province, allows the study and characterisation of different strategies for the design of irrigation projects that do not affect the crop yield when the application dose is reduced.
\end{abstract}

The aim of this work is to characterise olive orchard irrigation in a wide region. For this purpose, the variation of water content in the soil of a typical olive groove farm under different scenarios of precipitation, evaporative demand, application rate and temporal availability of irrigation water is studied in order to estimate the most appropriate irrigation needs and strategies.

The study has been carried out using data available from 18 agro-climatic stations with which maximum, average and minimum rainfall patterns have been established.

Daily application rates in typical installations of 3.2 ( 1 sector), 1.6 ( 2 sectors) and 1.1 ( 3 sectors) mm day1 were considered, combined with three types of water availability: daily, only for 20 days per month and with total absence in August. The results were analysed in terms of time of onset of water stress, irrigation requirements, hours of system operation and irrigation dose.

The results suggest that the 2-sector irrigation strategy with no irrigation in August could be economically the most interesting for the olive grower. On the other hand, it is obtained that the strategy that guarantees a better water profile in the soil is the one that corresponds to the implementation of sectorization in a single sector and the application of the E3 irrigation strategy: RDI, from March to September calendar with controlled deficit irrigation in August.

Key words: climate change, stone hardening, water stress, water availability. 


\section{Congreso Nacional de Riegos CARTAGENA 2021}

\section{Introducción}

A partir de los años 90 del siglo pasado, se produjo un aumento de la superficie de olivar en todo el mundo; la mayoría de estas nuevas superficies eran de regadío y más densos [1]. Sin embargo, las explotaciones olivareras tradicionales siguen siendo las más comunes. Además, estas plantaciones tradicionales de baja densidad son los más importantes en las zonas agrícolas áridas, comúnmente asociadas a la baja disponibilidad de agua. España es el primer productor mundial de aceite de oliva y es el país con mayor superficie [1], lo que supone una gran diversidad de sistemas de cultivo. Jaén es la provincia española que mayor superficie dedica a esta especie, con 482.427 hectáreas, de las cuales 243.888 hectáreas son de regadío, [2] (MAPA, 2018). Al contrario de lo que ocurre en otras partes del mundo, la mayor parte de la superficie de regadío en esta zona es de olivar tradicional de baja densidad (88\% de los olivares de regadío frente al 12\% de los intensivos [3].

La sostenibilidad del agua está relacionada con dos condiciones principales. Por un lado, la conservación de los recursos hídricos en calidad y cantidad a largo plazo [4] y por otro aquellas políticas que supongan la fijación de la población en las zonas rurales. De este modo, las gestiones agrícolas sostenibles se aplicarán cuando se obtengan suficientes ingresos económicos de la explotación [5]. El riego de las plantaciones tradicionales es un muy buen ejemplo. El aumento esperado del rendimiento podría mejorar la gestión sostenible en los olivos tradicionales de secano, que suele estar limitada por los bajos beneficios. Por otro lado, las previsiones de cambio climático auguran una menor pluviometría y una mayor variabilidad que puede afectar a las etapas fenológicas más sensibles del cultivo como son la floración y la maduración [6]. Entonces, las necesidades hídricas aumentarían y las plantaciones tradicionales de olivos de secano, que hoy en día tienen un rendimiento aceptable, podrían reducir fuertemente sus beneficios y se abandonarían. Los que suponen que los agricultores consideran el riego como la solución a largo plazo a los problemas de bajos ingresos y toda la sociedad podría considerar como herramienta para aumentar la sostenibilidad de estos sistemas agrícolas.

El olivo es un cultivo frutal tradicional de secano, uno de los más resistentes a las condiciones de estrés hídrico. Las funciones de producción sugieren una alta productividad del agua de riego con un gran incremento del rendimiento, con un bajo aumento de la evapotranspiración del cultivo [7]. Sin embargo, los trabajos en olivares de baja densidad no han presentado esta clara respuesta [8]. Los olivares tradicionales de baja densidad se sitúan en zonas con poca cantidad de recursos hídricos. Por tanto, aumentar la superficie de riego de un sistema agrícola no puede ser una estrategia sostenible. Además de la escasez de agua, estas zonas suelen tener problemas de disponibilidad de agua a lo largo de la temporada (con una temporada de riego corta o un tiempo de riego corto). Esto supone un problema adicional en la programación y diseño de los sistemas de riego. Aunque el olivo es una especie resistente a la sequía, no todos los estados fenológicos a lo largo de la estación son igual de resistentes e incluso una combinación en la duración y el nivel de estrés hídrico podría ser importante [9]. Los periodos de floración, cuajado y acumulación de aceite son los más sensibles a las condiciones de estrés hídrico, [10]. Por otro lado, niveles relativamente severos de estrés hídrico durante la fase de endurecimiento del hueso no reducen el rendimiento final [7]. Por lo tanto, se podría considerar el riego deficitario, estimando el momento en el que se van a realizar estas condiciones de estrés hídrico. Por otro lado, los olivares tradicionales, aun contando con este aumento de rendimiento, tendrían una capacidad de inversión en riego muy reducida, puesto que, los sistemas de riego actuales tienen limitaciones en la capacidad de bombeo y en las dosis de agua aplicada. Esto podría ser una limitación importante en la programación del riego.

El objetivo de este trabajo es estimar la reserva hídrica del suelo en las condiciones de una plantación tradicional de baja densidad de olivos considerando varias limitaciones a nivel de finca y posibles 


\section{Congreso Nacional de Riegos CARTAGENA 2021}

escenarios en el comportamiento de las lluvias. De esta forma, los resultados aportarán una visión holística de la sostenibilidad del riego en este sistema agrícola. Se han considerado las condiciones climáticas de la provincia de Jaén (España) por ser la zona de olivar tradicional más importante del mundo. Con el fin de incluir las limitaciones más comunes para la programación del riego, además de la cantidad de agua, se han tenido en cuenta el tiempo de riego disponible a lo largo de la temporada y la organización del sistema de riego.

\section{Materiales y métodos (Trabajo de innovación: descripción de la innovación)}

\section{1. Área de estudio.}

La zona de estudio comprende la provincia de Jaén (España), que tiene una superficie de 13.489 $\mathrm{km} 2$, en la que el olivar es el cultivo frutal más importante de la superficie (582.427 hectáreas), de las cuales 249.888 hectáreas son de regadío (alrededor del $43 \%$ ). Esta zona es la mayor productora mundial de aceitunas y aceite con más de 60 millones de olivos, y una producción media total en la última década de 2.214.021 toneladas de aceitunas, y 480.025 toneladas de aceite de oliva, [2], lo que supone que este cultivo es el primer y principal motor a nivel socioeconómico en la provincia.

\subsection{Características de la instalación de riego.}

En la actualidad, se presentan varios sistemas en las zonas olivareras. A partir de los años 90 del siglo pasado, el aumento de la densidad en los olivares ha ido en aumento y se ha cambiado parte de los tradicionales, de secano y baja densidad, por los de regadío de muy alta densidad, [5]. Sin embargo, las plantaciones de baja densidad siguen siendo los más importantes en superficie, así el olivar tradicional, con marcos de plantación de 9 a 12 metros y densidades entre 80-120 plantas/ha [12]. Según el Plan Director del Olivar, [13], la densidad media de plantación en la provincia de Jaén es de 117 plantas/ha. Algunas de estas explotaciones tradicionales han pasado de ser de secano a ser de regadío. El sistema de riego más habitual es el de dos goteros por árbol, lo que permite una dosis de $16 \mathrm{~L} \mathrm{h-1}$ por planta [14-15]. Por otro lado, la disponibilidad de agua es muy limitante y comúnmente, existen serias restricciones en cantidad y tiempo de riego [16]. Para maximizar la superficie regada, se divide la cantidad máxima de riego diario entre 2 o 3 sectores, para aumentar la superficie regada [17]. Así pues, la cantidad de agua disponible se divide entre 1, 2 o 3 partes para regar la plantación completa (por lo que se denomina a partir de aquí 1,2 o 3 sectores). En cuanto al tipo de sectorización utilizado, Peragón y otros [18], realizaron una encuesta en las comunidades de regantes de la provincia, mostrando que más del $90 \%$ de las instalaciones tienen una sectorización en 3 sectores.

De esta forma, la parcela agrícola tipo considerada está formada por olivares maduros con una distancia común entre árboles de $10 \times 10$ m, lo que nos da una densidad de 100 olivos por hectárea, con un sistema de riego por goteo que consiste básicamente en una elevación desde una captación de agua hasta un depósito de agua y posterior rebombeo a la explotación olivarera, con la instalación de una red de tuberías primarias, secundarias, terciarias y de goteo que terminan en dos goteros autocompensantes por árbol de 8 litros/hora de caudal instantáneo $(0,44$ 1/ha). Con el sistema de riego propuesto como caso de estudio, la programación del riego se limitó en función de un número máximo de horas disponibles para el riego (20 horas día-1). Así, la dosis máxima a aplicar depende de la realización de una determinada sectorización en 1, 2 ó 3 sectores y permite utilizar el agua disponible el 100\%, 50\% y $33 \%$ del tiempo. Esto supone limitar la capacidad de riego de los olivares a 3,2 mm día-1 (1 sector), 1,6 mm día-1 (2 sectores) y 1,1 mm día-1 (3 sectores). Para cada una de estas estrategias se caracterizó mensualmente la reserva disponible en el suelo. En las programaciones de riego se consideró que al 


\section{Congreso Nacional de Riegos CARTAGENA 2021}

inicio del año agrícola (octubre) se utilizaba una reserva de $10 \mathrm{~mm}$ (cantidad muy cercana a la realidad en condiciones naturales en la zona estudiada). Se consideró que la eficiencia de aplicación del sistema de riego utilizado, correspondiente a un sistema de riego por goteo localizado, era del 95\%.

\subsection{Variables climáticas.}

Los datos climatológicos se realizaron a través de la Red de Información Agroclimática de Andalucía, [19], constituida por estaciones meteorológicas automáticas estratégicamente ubicadas. A partir de ellos se calculó los datos de los años agrícolas (octubre-septiembre) durante el periodo 2001-2020. En total, se han considerado 18 estaciones agroclimáticas activas distribuidas en 7 regiones agrícolas. Los resultados de evapotranspiración de referencia (ETo) utilizados son los calculados por la Red de Información Agroclimática de Andalucía (RIAA), que la determina utilizando los datos climáticos estándar recogidos en el modelo matemático Penman-Montheith, según establece la FAO [20]). La precipitación efectiva se estimó como aquella que produce el 75\% de la infiltración del agua de lluvia en el suelo [21]).

El análisis de las variables climáticas correspondientes a la precipitación y evapotranspiración consistió en realizar un estudio de variabilidad de los valores extremos (máximos y mínimos) y de los valores medios [22], determinando los valores medios mensuales y el total anual para cada una de las estaciones agroclimáticas consideradas (Figura 1). Este procedimiento permite clasificar las estaciones agroclimáticas considerando sólo aquellas que presentan valores similares, por encima o por debajo de los resultados obtenidos. Para acercarse a la realidad, se ha calculado también el valor de la mediana para eliminar el sesgo de los valores extremos.

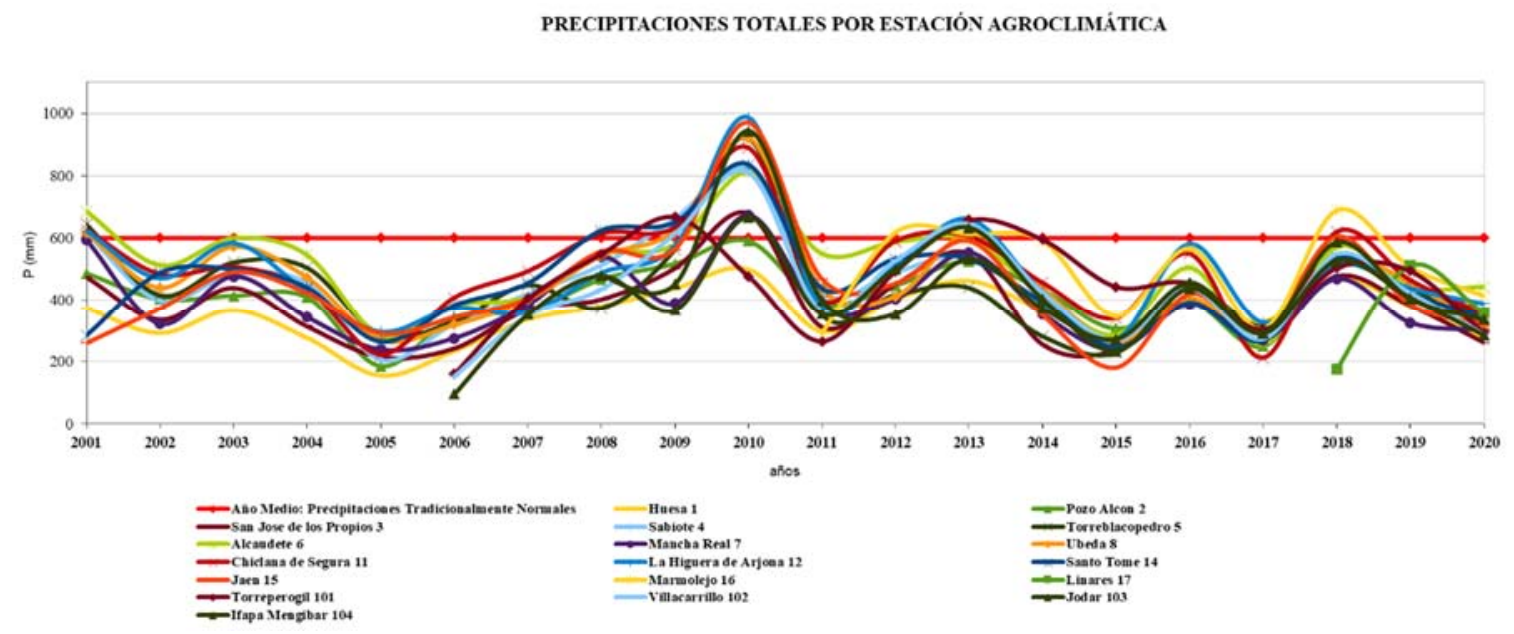

Figura 1: Precipitación anual por estación agroclimática.

De este modo, se clasificaron las estaciones agroclimáticas en relación con la variable de la precipitación según los resultados, y se consideraron tres escenarios basados en los datos reales de la precipitación en toda la serie histórica:

- Escenario 1; Cuando la precipitación media mensual es superior a la media, se elige como dato la mediana de la precipitación máxima, considerando como años de mayor precipitación aquellos que superan los $581 \mathrm{~mm}$.

- Escenario 2; La media de las precipitaciones mensuales. 


\section{Congreso Nacional de Riegos CARTAGENA 2021}

- Escenario 3; Cuando la precipitación media mensual está por debajo de la media, se elige como dato la mediana de la precipitación mínima, considerando como años de menor precipitación los que están por debajo de $292 \mathrm{~mm}$.

\subsection{Constantes de referencia: tipo de suelo, profundidad de las raíces, cobertura del dosel y grado de desarrollo} del cultivo.

La determinación de las necesidades de riego y el momento de entrada en estrés hídrico se establecieron siguiendo el método del balance hídrico, de forma que se considera que el agua consumida es la suma del agua de riego y de las precipitaciones, [23]). En este balance, el agua útil o disponible en el suelo para la planta estará entre los límites superior e inferior.

En el caso del estudio, el tipo de suelo elegido fue franco-arcilloso (por ser el más común en la zona), con las siguientes características: punto de marchitez (PT) $(\mathrm{cm} 3 / \mathrm{cm} 3)$ 0,17; capacidad de campo $(\mathrm{CF})(\mathrm{cm} 3 / \mathrm{cm} 3)$ 0,36; densidad aparente del suelo $(\mathrm{cm} 3 / \mathrm{cm} 3)$ 1,33 [24]. La humedad disponible para la planta se estimó utilizando un nivel de agotamiento permisible (ADL) del 75\%, que es el nivel usualmente recomendado [25]. Se estableció una profundidad radicular útil de $1,0 \mathrm{~m}$. según diferentes trabajos [7-9]. La evapotranspiración de los cultivos (ETc) se estimó según la metodología propuesta por Allen y otros [26]

- $\quad \mathrm{ETc}=\mathrm{ETo}^{*} \mathrm{Kc}{ }^{*} \mathrm{Kr}$. [1]. Dónde [1]: ETo: Evapotranspiración del cultivo de referencia.

- Kc: Coeficiente adimensional del cultivo.

- Kr: Coeficiente adimensional de reducción de la evaporación.

Los valores de Kc utilizados (Tabla 1) son los sugeridos por Pastor y otros, [15]. En el caso de estudio, se ha considerado que el valor del coeficiente de reducción $\mathrm{Kr}$ tomará un valor de 1, ya que el cultivo sombreará más del 50-60\% de la superficie del suelo, según Castel y Fereres, [27]). En cuanto a la fenología del cultivo en la zona, la fecha media de plena floración tuvo lugar en mayo), y el inicio del endurecimiento del hueso está fechado en julio, [26].

Tabla 1: Variación mensual del coeficiente Kc.

\begin{tabular}{|l|l|l|l|l|l|l|l|l|l|l|l|l|}
\cline { 2 - 11 } \multicolumn{1}{c|}{} & Ene. & Feb. & Mar. & Abr. & May. & Jun. & Jul. & Ago. & Sep. & Oct. & Nov. & Dic. \\
\hline Kc & 0,5 & 0,5 & 0,65 & 0,65 & 0,65 & 0,6 & 0,6 & 0,6 & 0,6 & 0,65 & 0,65 & 0,5 \\
\hline
\end{tabular}

\subsection{Programa de cálculo.}

Para el cálculo de la programación y dosis de riego se utiliza la metodología del balance hídrico, tal y como se recoge en el no 56 de la FAO [26]). El programa utilizado es una adaptación del programa de cálculo y determinación de las "Necesidades Hídricas del Olivar" del IFAPA, ([19], de acceso abierto, previo registro, y publicación online en Internet desde 2015 (https://www.juntadeandalucia.es/agriculturaypesca/ifapa/servifapa/recomendador-olivar), en el que se introdujeron las variables mencionadas, con los datos medios de la estación más lluviosa y más seca del total de 18 estaciones agroclimáticas.

\subsection{Estrategias de riego.}

Los escenarios anteriores se caracterizaron además en función de la disponibilidad de agua, seleccionando los más comunes en la zona de estudio: 


\section{Congreso Nacional de Riegos CARTAGENA 2021}

- Estrategia 1 (IDD): Riego todos los días del mes, [14]). Esta simulación pretende reflejar aquellas instalaciones de riego sin limitaciones de tiempo ni de disponibilidad de agua durante el periodo de riego (marzo - septiembre), donde el uso del agua es de máxima eficiencia todo el tiempo.

- Estrategia 2 (ID20): Riego 20 días al mes. Se trata de instalaciones con limitaciones temporales o de disponibilidad de agua (aproximadamente el 30\%). Esta estrategia es similar a la anterior, pero dejando los fines de semana libres, similar a un calendario laboral convencional, [29]).

- Estrategia 3 (RDI): Riego deficitario regulado. Estas instalaciones no disponen de agua durante un periodo de tiempo determinado que coincide con el periodo de parada estival del olivar. Existen diferentes estudios de estrategias de riego deficitario en diferentes cultivos [30]), así como en olivar en los que se proponen importantes recortes de riego, tanto en olivar tradicional [31]) como en olivar intensivo o superintensivo ([7-32]. En la zona de estudio, en la práctica, estos cortes se establecen en el periodo comprendido entre julio y agosto. La aplicación del riego en condiciones de estrés hídrico moderado produce un aumento tanto de la calidad del aceite de oliva como de la tasa de acumulación, [33-34]En el caso particular de este estudio, el mes de agosto se ha establecido sin riego.

\section{Resultados}

\subsection{Precipitación}

Los años medios de todas las estaciones presentaron un patrón de precipitaciones muy similar, con un periodo húmedo entre septiembre y mayo, con máximos en noviembre y marzo, y un periodo muy seco durante el final de la primavera y el principio del verano. También se han obtenido los valores extremos de precipitación y sus tendencias, en los que se observa que, en general, el rango entre los valores extremos de precipitación es mayor en los años húmedos que en los secos, la figura 2 muestra la variabilidad de los datos a lo largo de los años medios (a) y los valores máximos y mínimos encontrados.

En la figura 2, se destacan varios hechos. En primer lugar, las precipitaciones tienen una distribución variable tanto en los años lluviosos como en los secos. En segundo lugar, el intervalo o rango entre las precipitaciones máximas y mínimas suele ser mayor en los años lluviosos que en los secos. En tercer lugar, la mayor parte de las precipitaciones máximas se sitúan por debajo de los $600 \mathrm{~mm}$, mientras que para las mínimas tenemos que éstas en la mayoría de las ocasiones no llegan a los $300 \mathrm{~mm}$, aunque muestran una tendencia a acercarse significativamente a partir de 2016. Los datos de estas 18 estaciones agroclimáticas se utilizaron para obtener los escenarios de precipitación, media y mínima.

MAXIMAS Y MINIMAS PRECIPITACIONES CON TENDENCLAS

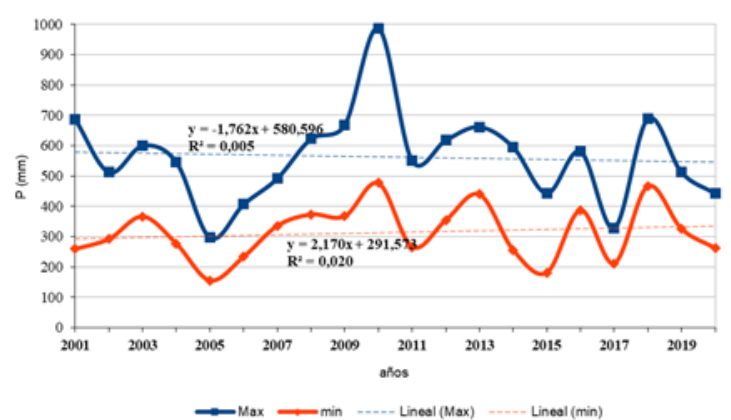

Figura 2: Precipitaciones máximas y mínimas y tendencias. 


\subsection{Evapotranspiración}

En cuanto a la evapotranspiración de referencia (ETo), existe una variación interanual en los valores recogidos, con un mayor rango durante los meses de primavera-verano y menor durante el periodo de otoño-invierno.

Su determinación es más compleja que la de la precipitación ya que depende de dos procesos; la evaporación desde el suelo y desde la superficie cubierta por el cultivo, y por otro lado el fenómeno de la transpiración desde las hojas. Esta situación hace que la evapotranspiración no sólo se vea afectada por los valores climatológicos sino también por las características del suelo y los factores de la planta. En el caso del estudio, al tratarse de un solo cultivo y calcularse con datos meteorológicos para cada una de las estaciones agroclimáticas, se adoptaron valores normales. Esta hipótesis se confirma al determinar la distribución de probabilidad de los valores mensuales de evapotranspiración, que presentan una menor desviación estándar en los resultados (Figura 3). En la estimación de la reserva hídrica del suelo se utilizaron los datos medios de la ETo.

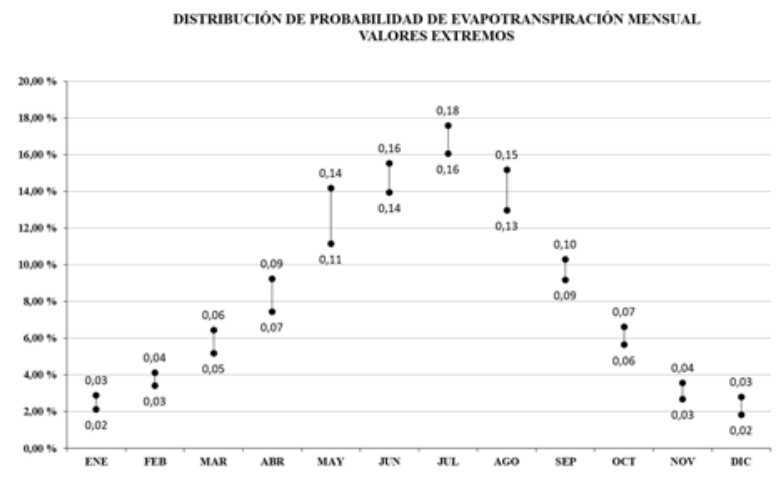

Figura 3: Distribución de probabilidad de la evapotranspiración. Valores extremos.

\subsection{Estrategia 1: Programa de riego deficitario de marzo a septiembre, regando todos los días del mes. (IDD).}

La Figura 4 muestra el patrón de reserva de agua del suelo considerando tres escenarios diferentes de precipitación y tres números diferentes de sectores. En los años lluviosos (Figura 4a), la reserva de agua se agotó de julio a agosto en la estrategia de 2 sectores, y de julio a septiembre en las estrategias de 3 sectores. No aparece estrés hídrico en la estrategia de 1 sector. La cantidad de agua aplicada también varió entre estas estrategias (Tabla 2): Para tres sectores se utilizó 161,2 mm, mientras que para un sector consumió 305,09 mm. La estrategia de 2 sectores presentó una cantidad intermedia con $212 \mathrm{~mm}$. El tiempo de riego también varió, pero en sentido contrario, desde 3182 horas al año (3 sectores) hasta 2013 horas al año en 1 sector, con un valor intermedio de 2790 horas de riego en 2 sectores.

Para la situación de precipitaciones medias (Figura $4 \mathrm{~b}$ ) no hay ningún periodo de estrés hídrico cuando se riega 1 sector. En los riegos de 2 y 3 sectores, el agotamiento de la reserva de agua del suelo se produce en la misma época (julio), aunque en el primer caso dura dos meses y en el segundo se prolonga hasta el final de la campaña de riego. En cuanto a la cantidad de agua aplicada, los resultados para 1 sector fueron de $397,3 \mathrm{~mm}$, para 2 sectores de $316,7 \mathrm{~mm}$ y para 3 sectores de $217,5 \mathrm{~mm}$. En cuanto al tiempo de riego, el resultado es mayor a medida que aumenta el número de sectores, de modo que para 1 sector fue de 2614 horas, para 2 sectores de 4168 horas y para 3 sectores de 4293 horas 


\section{Congreso Nacional de Riegos CARTAGENA 2021}
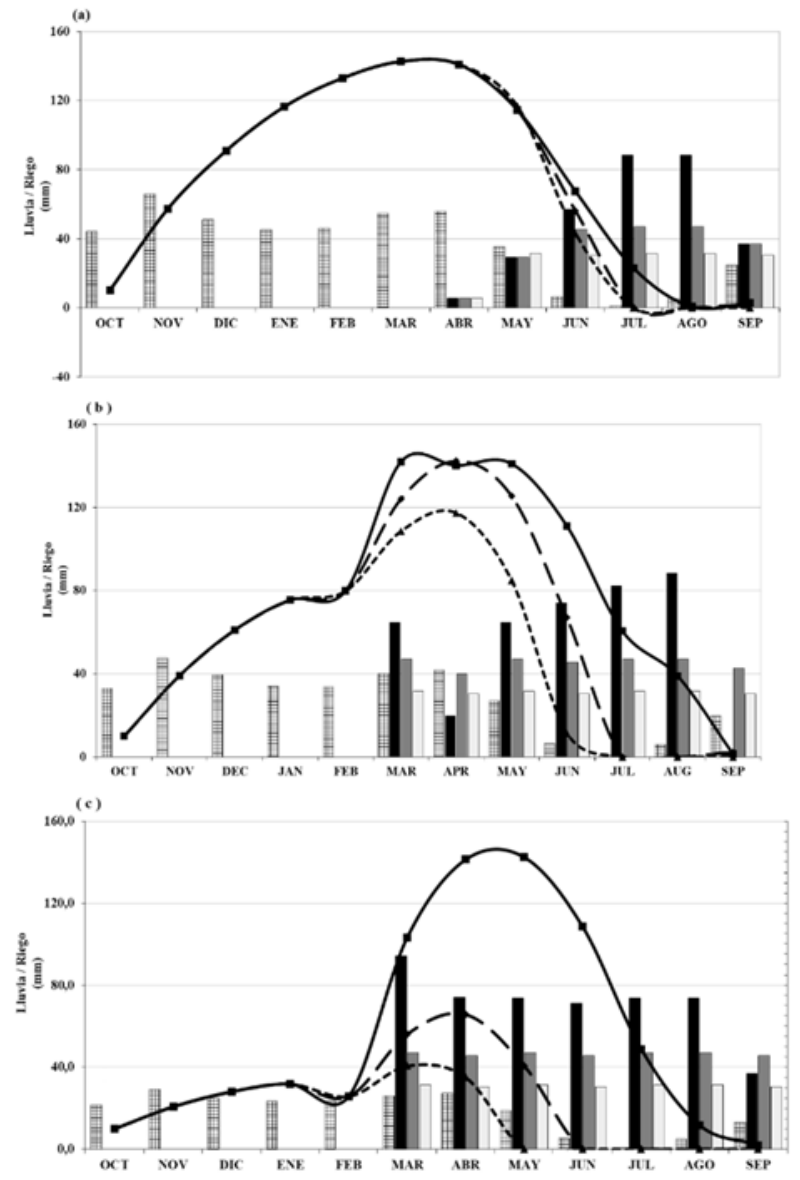

Figura 4: Patrón de la reserva de agua del suelo en el riego diario en condiciones de lluvia máxima (a), media (b) y mínima (c). Línea sólida, estrategia de 1 sector; línea de guiones largos, estrategia de 2 sectores; línea de guiones, estrategia de 3 sectores. Barras con patrón cuadrado, precipitación efectiva; barras sólidas, riego en la estrategia de 1 sector; barras claras, riego en la estrategia de 2 sectores; barras blancas, riego en la estrategia de 3 sectores.

Por último, en el supuesto más limitante (Figura 4c), el escenario de precipitaciones mínimas, no se estimó ningún período de estrés hídrico para 1 sector, pero en los demás estos períodos aumentaron. La estrategia de 2 sectores presentaría un periodo de estrés hídrico de junio a septiembre, mientras que la estrategia de 3 sectores sería aún mayor con un agotamiento del agua del suelo de mayo a septiembre. El consumo de agua aumentaría claramente (Tabla 2): en la estrategia de 1 sector sería de 497,5 mm, en la de 2 sectores de 325,3 $\mathrm{mm}$ y en la de 3 sectores de 217,5 $\mathrm{mm}$. El tiempo de riego estacional también aumentaría en todas las estrategias con 3273 horas en 1 sector y más tiempo en 2 sectores (4280 horas) y 3 sectores (4293 horas).

\subsection{Estrategia 2: Programa de riego deficitario de marzo a septiembre, riego en 20 días del mes. (ID20).}

El escenario de precipitaciones máximas presentó un periodo de estrés hídrico en todas las estrategias sectoriales. En la estrategia de 1 sector, el estrés hídrico se estimó sólo en agosto. Pero en las estrategias de los sectores 2 y 3, estos periodos fueron más amplios en los dos meses de julio a septiembre. El agua aplicada pasa de 262,2 $\mathrm{mm}$ en 1 sector a 107,4 $\mathrm{mm}$ en 3 sectores, lo que supone una gran reducción, superior al 50\%. (Tabla 2). El tiempo de riego fue máximo en la estrategia de 3 sectores con 


\section{Congreso Nacional de Riegos CARTAGENA 2021}

2119 horas por temporada y mínimo en 1 sector (1725 horas). La estrategia de 2 sectores fue intermedia pero cercana al valor máximo con 2075 horas.

El escenario de precipitaciones medias presentó los mismos resultados que la temporada de lluvias sobre el periodo de estrés hídrico. Sin embargo, la reducción de las precipitaciones de la estación media en comparación con la lluviosa aumentó el agua aplicada en torno al 40\% (370,5 mm en 1 sector, 210,9 $\mathrm{mm}$ en 2 sectores y 142,3 $\mathrm{mm}$ en 3 sectores) (Tabla 2). El aumento del tiempo de riego fue menor entre la estación de lluvias y la de precipitaciones medias (alrededor del 30\%), con un máximo en 3 sectores de 2809 horas y un mínimo en 1 sector de 2438 horas (en 2 sectores se estimó en 2775 horas).

Por último, el escenario de precipitaciones mínimas cambió claramente los resultados en comparación con los dos anteriores. La estrategia de todos los sectores presentó periodos de estrés hídrico, el sector 1 sólo de julio a agosto, pero los sectores 2 y 3 de mayo a septiembre. Esta disminución de las precipitaciones aumentaría el consumo de agua en todos los sectores de la estrategia hasta los valores máximos en 1 sector de la estrategia $(412,3 \mathrm{~mm})$ y el mínimo de 3 sectores $(142,3 \mathrm{~mm})$, con un valor intermedio en 2 sectores $(212,8 \mathrm{~mm})$.

\subsection{Programa de riego deficitario de marzo a septiembre con riego controlado en agosto. (RDI).}

El escenario de precipitaciones máximas, la estrategia de todos los sectores presentó un periodo de estrés hídrico. En 1 sector, el estrés hídrico se estimó sólo en agosto, pero en los otros dos el período fue más amplio, de julio a septiembre en 3 sectores, pero de julio a agosto en 2 sectores. En estas condiciones, el agua aplicada fue máxima en 1 sector con 284,1 mm y mínima en 3 sectores $129,7 \mathrm{~mm}$, con un valor intermedio en 2 sectores con 182,6 mm (Tabla 2). El tiempo de riego se estimó en 1869 horas (1 sector), 2403 horas (2 Sectores) y 2560 (3 Sectores).

El escenario de precipitaciones medias el periodo de estrés es más largo en 3 sectores (tres meses), que en 2 sectores ( 2 meses), y en 1 sector ( 1 mes), aunque en 1 sector se produce durante el mes de agosto, mientras que en las estrategias de 2 y 3 sectores comienza en julio. A medida que aumentamos el número de sectores tenemos una disminución del agua aplicada y un aumento del tiempo de riego. La estrategia del sector 1 presentó un agua aplicada de $377,8 \mathrm{~mm}$, mientras que los sectores 2 y 3 fueron de $266,8 \mathrm{~mm}$ y $186 \mathrm{~mm}$, respectivamente. Por otro lado, el tiempo de riego varió entre 2485 horas (para 1 sector) y 3671 horas (para 3 sectores), presentando un valor intermedio para 2 sectores de 3510 horas.

Por último, en condiciones de lluvia mínima (Figura 9c), los periodos de estrés hídrico aumentaron en todas las estrategias. Fueron de junio a septiembre en 2 sectores y de mayo a septiembre en 3 sectores. Sólo en la estrategia de 1 sector, el periodo de estrés hídrico no aumentó y se estimó únicamente durante el mes de agosto. El agua aplicada aumentó claramente con 472,9 mm en 1 sector, 278,2 mm en 2 sectores y $186 \mathrm{~mm}$ en 3 sectores. Este nivel de agua aplicada produjo un aumento del tiempo de riego de 3111 horas en 1 sector, 3660 horas en 2 sectores y 3671 horas en 3 sectores.

\section{4.- Discusión.}

Los resultados de los diferentes escenarios presentaron una amplia gama de consumos de agua y periodos de estrés hídrico que podrían afectar al beneficio de las explotaciones olivareras. Los agricultores en la mayoría de los escenarios considerados manejarían una programación de riego deficitaria debido a las grandes limitaciones de disponibilidad de agua, en tiempo y cantidad. La selección de una estrategia de riego tiene que considerar, principalmente, dos factores: cuándo se produciría este periodo de estrés hídrico y la cantidad de agua aplicada. Los resultados esperados en cuanto a rendimiento cambiarían en gran medida según el momento de este periodo de estrés hídrico. El estrés hídrico más temprano se estimó en mayo para el escenario de precipitaciones mínimas en la estrategia de 3 


\section{Congreso Nacional de Riegos CARTAGENA 2021}

sectores en todas las programaciones de riego y en la estrategia de 2 sectores cuando se modeló la programación ID20. El mes de mayo es la fecha habitual de plena floración en esta zona. Hay varios trabajos que han descrito este periodo fenológico como el más sensible a la sequía [7-35]). Aunque estas condiciones son muy poco frecuentes en la cuenca mediterránea, y por ello el olivo es un cultivo frutal de secano, los cambios climáticos podrían aumentar el número de temporadas en las que esto ocurra [36]). Por lo tanto, la estrategia de 3 sectores era la menos sostenible, ya que los recursos hídricos se desperdiciarían en los escenarios de precipitaciones más limitantes e incluso se esperarían diferencias bajas con las condiciones de secano.

Varios de los escenarios considerados podrían retrasar el periodo de estrés hídrico a después de la plena floración y así escapar de la mayor reducción del rendimiento. Este es el caso de las condiciones de lluvia mínima en la estrategia de 2 sectores con riego diario y programación de RDI. El periodo de endurecimiento del hueso se considera el periodo más resistente a la sequía en el olivo [37]. Es común sugerir 49-56 días después de la floración completa como la fecha más probable para el inicio de este período [38], que, para el área de estudio, podría estimarse que comienza alrededor de principios de julio. Luego, en junio, es probable que el estrés hídrico se produzca durante el crecimiento del endocarpio. En esta etapa fenológica se ha estimado una reducción del rendimiento en torno al $20 \%$ en un nivel de estrés hídrico moderado [32-39]). Pero, un nivel de estrés hídrico severo podría incluso afectar al rendimiento de la siguiente temporada [40]. Entonces, estas estrategias podrían ser adecuadas si garantizan una gran reducción del agua aplicada y el olivicultor podría asumir esta importante reducción del rendimiento. El periodo de estrés hídrico por endurecimiento del hueso, probablemente alrededor de julio en esta zona, reduciría el efecto sobre el rendimiento. El nivel de estrés hídrico fuerte a mediados de verano no afectó significativamente al rendimiento en varios olivares de riego, pero las tendencias fueron similares a la anterior con una reducción del rendimiento del 20\% (7-41). Sin embargo, estos resultados se obtuvieron en olivares más densos y se esperaría un menor nivel de estrés hídrico en el tradicional. En condiciones de estrés hídrico moderado la reducción del rendimiento sería casi nula, más aún si se esperan lluvias otoñales antes de la cosecha [7-41]. Además, la acumulación de aceite podría no verse afectada con el estrés hídrico durante este periodo [42]). Entonces, todas las programaciones de riego en el escenario de 1 sector serían adecuadas y también las de 2 sectores si no se dan condiciones de lluvia mínima. Esta discusión se centra en las aceitunas destinadas a la almazara ya que se recuperan con las lluvias de otoño, pero no en las aceitunas de mesa ya que el tamaño del fruto es muy sensible al estrés hídrico y es muy importante en este tipo de producción [43].

La disponibilidad de agua cambia fuertemente entre las plantaciones de olivos e, incluso, entre las estaciones, ya que se puede aplicar una restricción severa durante los períodos de sequía. En España, la cantidad máxima de riego estacional es limitante y una disponibilidad común de agua en los huertos de olivos es de $150 \mathrm{~mm}$ [3]. Esta agua aplicada es mucho menor que la estimada en todas las estrategias de los sectores 1 y 2 (Tabla 2). Este resultado sugiere que la sostenibilidad del riego en la explotación olivarera tradicional es muy limitante si no se consideran programaciones de riego precisas adicionales. En estas condiciones de muy baja disponibilidad de agua, el riesgo de no obtener mejoras en comparación con el olivar sin riego sería muy posible. Moriana y otros autores, [8] (2007) no encontraron diferencias significativas en un olivar tradicional de Cornicabra a una distancia de $12 * 12 \mathrm{~m}$ con cantidades de agua más restrictivas que en el presente trabajo $(75 \mathrm{~mm})$ y alcanzando niveles de estrés hídrico signficativamente mayores que el riego con el $100 \%$ de ETc durante el endurecimiento del hueso. Entonces, esta cantidad de agua podría utilizarse para asegurar un estado hídrico óptimo o casi óptimo en la etapa fenológica más limitante (es decir, la plena floración) y no para un riego deficitario sostenible. En tales condiciones, la determinación precisa del estado del agua podría ser muy importante [44]). 


\section{Congreso Nacional de Riegos CARTAGENA 2021}

Tabla 2: Resumen del agua aplicada $(\mathrm{mm})$, de la reserva de agua $(\mathrm{mm})$ y del tiempo de riego estacional (horas) en las tres condiciones de precipitación (estación lluviosa, media y seca), con los tres calendarios de riego (diario, 20 días al mes y sin riego en agosto (RDI)) en la estrategia de los 3 sectores.

\begin{tabular}{|l|l|l|l|l|l|l|l|l|l|}
\cline { 2 - 9 } \multicolumn{2}{c|}{} & \multicolumn{3}{c|}{ S1: IDD } & \multicolumn{3}{c|}{ S2:ID20 } & \multicolumn{3}{c|}{ S3:RDI } \\
\cline { 2 - 10 } & $\mathbf{1}$ sector & 2 sector & $\mathbf{3}$ sector & 1 sector & 2 sector & 3 sector & 1 sector & 2 sector & 3 sector \\
\hline $\begin{array}{l}\text { Agua aplicada (mm) } \\
\text { con máximas lluvias }\end{array}$ & 305,9 & 212,0 & 161,2 & 262,2 & 157,7 & 107,4 & 284,1 & 182,6 & 129,7 \\
\hline $\begin{array}{l}\text { Tiempo de riego con } \\
\text { lluvias máximas (h) }\end{array}$ & 2013 & 2790 & 3182 & 1725 & 2075 & 2119 & 1869 & 2403 & 2560 \\
\hline $\begin{array}{l}\text { Reserva de agua (mm) } \\
\text { con lluvias máximas }\end{array}$ & 899,1 & 863,7 & 850,6 & 902,7 & 848,3 & 818,1 & 1051,8 & 899,1 & 850,6 \\
\hline $\begin{array}{l}\text { Agua aplicada (mm) } \\
\text { con lluvias medias }\end{array}$ & 397,3 & 316,7 & 217,5 & 370,5 & 210,9 & 142,3 & 377,7 & 266,8 & 186,0 \\
\hline $\begin{array}{l}\text { Tiempo de riego con } \\
\text { lluvias medias (horas) }\end{array}$ & 2614 & 4168 & 4293 & 2438 & 2775 & 2809 & 2485 & 3510 & 3671 \\
\hline $\begin{array}{l}\text { Reserva de agua (mm) } \\
\text { con lluvias medias }\end{array}$ & 900,1 & 727,0 & 587,6 & 800,1 & 580,5 & 511,1 & 908,2 & 718,4 & 587,6 \\
\hline $\begin{array}{l}\text { Agua aplicada (mm) } \\
\text { con mínimas lluvias }\end{array}$ & 497,5 & 325,3 & 217,5 & 412,3 & 212,8 & 142,3 & 472,9 & 278,2 & 186,0 \\
\hline $\begin{array}{l}\text { Tiempo de riego en con } \\
\text { lluvias mínimas (h) }\end{array}$ & 3273 & 4280 & 4293 & 2713 & 2800 & 2809 & 3111 & 3660 & 3671 \\
\hline $\begin{array}{l}\text { Reserva de agua (mm) } \\
\text { con lluvias mínimas }\end{array}$ & 674,6 & 279,0 & 191,9 & 403,9 & 189,6 & 159,4 & 715,6 & 279,0 & 191,9 \\
\hline
\end{tabular}

\section{5.- Conclusiones.}

La sostenibilidad del riego en los olivares tradicionales debe tener en cuenta varios aspectos para asegurar una gestión eficiente del agua. La conservación de los recursos hídricos es el más importante, pero también debe considerarse el uso de estos recursos naturales para mejorar los beneficios de los olivicultores. El trabajo actual demuestra que la estrategia de riego más común en una de las zonas tradicionales de producción de aceitunas más importantes del mundo no es adecuada. La estrategia de los 3 sectores presentó el periodo más largo de estrés hídrico y, lo más importante, en las etapas fenológicas más críticas cuando se produjo el escenario de lluvias mínimas. Entonces, adaptar el agua actual disponible a un riego deficitario sostenible que, en el escenario de menor pluviometría, incluso reduce fuertemente el rendimiento, es un desperdicio de agua y de dinero del agricultor. Esto supone que los olivares tradicionales tienen que cambiar a estrategias de 1 ó 2 sectores con programación diaria o RDI. Sin embargo, estas estrategias suponen un gran aumento del agua aplicada que podría no ser sostenible, principalmente en el escenario de precipitaciones mínimas. En estas condiciones, las estrategias de 1 ó 2 sectores podrían considerar una programación de riego precisa y concentrada que al menos asegure unas condiciones cercanas a las óptimas en las etapas fenológicas más sensibles.

\section{Referencias}




\section{Congreso Nacional de Riegos CARTAGENA 2021}

1. FAOSTAT, Datos sobre Alimentación y Agricultura, 2020. Organización de las Naciones Unidas para la Alimentación y la Agricultura. http://www.fao.org/faostat/es/\#data/QC/visualize.

2. MAPA, Ministerio de Agricultura, Pesca y Alimentación, 2018. “Anuarios de Estadística Agraria”. Parte Tercera. Capitulo 07.07-12. https://www.mapa.gob.es/es/estadistica/temas/publicaciones/anuario-de-estadistica/default.aspx.

3. C.H.G., Confederación Hidrográfica del Guadalquivir, 2019. “Datos y capas de riegos en la provincia de Jaén”. https://www.chguadalquivir.es/inicio.

4. Khan S,, Tariq R,, Yuanlai C., and Blackwell J., 2004. “Can irrigation be sustainable?” En: New Directions for a Diverse Planet. Proceedings of the 4th International Crop Science Congress. Brisbane, Australia. www.cropscience.org.au

5. Schoonhoven, Y., and Runhaar, H., 2018. "Conditions for the adoption of agro-ecological farming practices: a holistic framework illustrated with the case of almond farming in Andalusia". International Journal of Agricultural Sustainability 16(3):1-13. DOI:10.1080/14735903.2018.1537664.

6. Lorite, I.J.; Gabaldón-Leal, C.; Ruiz-Ramos, M.; Belaj, A.; de la Rosa, R.; León, L.; Santos, C. , 2018. “Evaluation of olive response and adaptation strategies to climate change under semi-arid conditions". Agricultural Water Management 247261. DOI: https://doi.org/10.1016/j.agwat.2018.04.008.

7. Moriana, A., Orgaz, F., Pastor, M., and Fereres, E., 2003. "Yield Responses of a Mature Olive Orchard to Water Deficits". Journal of the American Society for Horticultural Science. 128(3): pp, 425-431. DOI:10.21273/JASHS.128.3.0425.

8. Moriana, A., Gomez, A., Desamparados, S., Perez, D., Olmedilla, N, Ribas, F., and Fregapane, G., 2007. "Influence of different irrigation strategies in a traditional Cornicabra cv. olive orchard on virgin olive oil composition and quality". Food Chemistry Vol 100, Issue 2:568-578. DOI: https://doi.org/10.1016/j.foodchem.2005.09.075.

9. Giron, I., Martín, M.J., Corell, M., et al, 2016. “Umbrales Sostenibles de Estrés Hídrico durante el Endurecimiento del Hueso en la Producción de Aceituna de Mesa". Conference Paper at XXXIV Congreso Nacional de Riegos. Sevilla.

10. Diaz, A., Fernandez, J.E., Perez, A., et al., 2018. The olive tree under water stress: fitting the pieces of response mechanisms in the crop performance puzzle. Water Scarcity and Sustainable Agriculture in Semiarid Environment. Tools, Strategies, and Challenges for Woody Crops. Academic Press. pp. 439-479. ISBN: 978-0-12-813164-0

11. MAPA, Ministerio de Agricultura, Pesca y Alimentación, 2019. “Encuesta sobre Superficies y Rendimientos Cultivos. Resultados 2019", ESYRCE. Apartado 3.3. N.I.P.O.: 003-19-051-9. https://www.mapa.gob.es/es/estadistica/temas/estadisticas-agrarias/boletin2019 tcm30-536911.pdf/.

12. Penco, J.M., 2020. “Aproximacion a los costes del cultivo del olivo". Desarrollo y conclusiones del estudio AEMO. Spanish Association of Olive Municipalities. https:/www.aemo.es/slides/slide/estudio-de-costes-aemo-2020-241. Last access: 08/04/2021.

13. CAP, 2015. "Plan Director del Olivar". Consejería de Agricultura, Ganadería, Pesca y Desarrollo Sostenible. Decreto 103/2015, de 10 de marzo. BOJA № 54, (19/03/2015).

14. Rojas, R., Roldán, J., López, R., Alcaide, M., and Camacho, E, 1996. “El riego del olivar en la provincia de Jaén (II): programación de riegos". Ingeniería del Agua. 3(1). DOI:10.4995/ia.1996.2691.

15. Pastor, M., Orgaz, F., Vega, V., Hidalgo, J., Castro, J., Nieto, J., Aguilar, J. Fernandez, E., Morales, J., and Soria, L., 1998. "Programación del riego y la fertilización en olivares de la provincia de Jaén". Junta de Andalucia. Consejería de Agricultura y Pesca de la Junta de Andalucía. ISBN: 84-89802-30-0.

16. Granados, A., 2013. "Criteria for dimensioning irrigation networks that are robust to changes in crop alternatives". Doctoral thesis. ETSI Caminos, Canales y Puertos. Universidad Politecnica de Madrid. Reg_ 16101. DC: http://oa.upm.es/16101/. OAI: oai:oa.upm.es:16101.

17. Alduan, A., and Monserrat, J., 2009. “Estudio comparativo entre la organización a la demanda o por turnos en redes de riego a presión". Ingeniería del agua, [S.1.], v. 16, n. 3, p. 235-242, sep. 2009. ISSN 1886-4996. DOI: https://doi.org/10.4995/ia.2009.2951.

18. Peragón, J.M., Delgado, A., Rodríguez, J.A., and Pérez, F.J., 2016. “A GIS-based decision tool for reducing salinization risks in olive orchards". Agricultural Water Management. 33-41. pp 166. DOI:10.1016/j.agwat.2015.12.005

19. R.I.A.A, 2020. Red de Información Agroclimática de Andalucía. I.F.A.P.A., (Instituto de Investigación y Formación Agraria y Pesquera). Consejería de Agricultura, Ganadería, Pesca y Desarrollo Sostenible: https://www.juntadeandalucia.es/agriculturaypesca/ifapa/riaweb/web/.

20. FAO, Organización de las Naciones Unidas para la Alimentación y la Agricultura, 2006. “Evapotranspiración del cultivo. Guías para la determinación de los requerimientos de agua de los cultivos". pp. 89134.http://www.fao.org/3/x0490s/x0490s00.htm

21. CAP, 2001. "Programación de riegos en olivar". Consejería de Agricultura, Ganadería, y Pesca. Serie: Olivicultura y Elaiotecnia. ISBN: 84-89802-33-5.

22. Andrades, M.S., and Muñez, C., 2012. "Fundamentos de climatología”. Universidad de La Rioja. Coleccion: Material didáctico. Agricultura y Alimentación. 2ª edicion. ISBN: 978-84-695-2799-3 


\section{Congreso Nacional de Riegos CARTAGENA 2021}

23. Chaves, V.M., 2006. “Manejo del riego por goteo en olivo y respuesta de la planta al regimen hídrico". Memoria del XLIII Curso Internacional de Edafología y Biología Vegetal. Departamento de Sostenibilidad del Sistema Suelo-Planta-Agua. Instituto de Recursos Naturales y Agrobiología de Sevilla (IRNASS). Consejo Superior de Investigaciones Cientificas, (CSIC).. http://hdl.handle.net/10261/134075.

24. Fereres, E., and Villalobos, F.J., 2016. "Deficit Irrigation. Principles of Agronomy for Sustainable Agriculture”. Springer International Publishing. pp. 281-294. ISBN: 9783319834450. doi:10.1007/978-3-319-46116-8 21.

25. Orgaz, F., Hidalgo, J., Castro, J.A., et al., 1999. “Respuesta del olivar tradicional a diferentes estrategias y dosis de agua de riego". Investigación agraria Producción y protección vegetales. 14 (3). pp. 393-404.

26. Allen, R.G., Pereira, L.S., Raes, D., and Smith, M., 1998. “Crop evapotranspiration. Guidelines for computing crop water requirements". FAO Irrigation and drainage paper 56. Food and Agriculture Organization, Rome.

27. Castel, J.R., and Fereres, E., 1982. "Responses of Young Almond Trees to Two Drought Periods in the Field". Journal of Horticultural Science. 57(2). pp. 175-187. DOI:10.1080/00221589.1982.11515038.

28. Aguilera, F.,and Ruiz, L., 2009. “Periodo de floración del olivo (Olea europaea L.) en la provincia de Jaén”. Departamento de Biología Animal, Biología Vegetal y Ecología. Universidad de Jaén. Conference presented at Expoliva.

29. Larios, J.M., 2008. "Respuesta del olivo a tratamientos con riego deficitario". Instituto de Recursos Naturales y Agrobiologia de Sevilla, (IRNASS). Consejo Superior de Investigaciones Cientificas, CSIC. Doctoral Thesis. http://hdl.handle.net/10261/139518.

30. Lopez, G., Arbones, A., Girona, J., and Marsal, J., 2008. “Response of peach trees to regulated deficit irrigation during stage II of fruit development and summer pruning". Spanish Journal of Agricultural Research. DOI: 10.5424/sjar/2008063-340.

31. Hidalgo, J.J., and Vega, V., 2008. “Estrategias de riego deficitario controlado en un olivar de aceituna de mesa cv Manzanilla. Resultados de los 3 primeros años de un ensayo de larga duración". Conference Paper at XXVI Congreso Nacional de Riegos; AERYD, Asociación Española de Riegos y Drenajes: Huesca, 24-26 de junio. pp. 31-32.

32. Gómez del Campo, M., 2013. "Summer deficit irrigation in a hedgerow olive orchard cv. Arbequina: relationship between soil and tree water status, and growth and yield components". Spanish Journal of Agricultural Research. 11(2). pp. 547-557. http://dx.doi.org/10.5424/sjar/2013112-3360.

33. Lavee, S., Hanoch, E., Wodner, M., and Abramowitch, H., 2007. "The effect of predetermined deficit irrigation on the performance of cv. Muhasan olives (Olea europaea L.) in the eastern coastal plain of Israel". Scientia Horticulturae, 2007. (112). pp. 156-163. doi:10.1016/j.scienta.2006.12.017.

34. D'Amato, R., Proietti, P., Onofri, A., et al., 2017. “Biofortification (Se): Does it increase the content of phenolic compounds in virgin olive oil (VOO)?". Plos One. 12(4):e0176580. doi:10.1371/journal.pone.0176580

35. Rapoport, HF., Hammami, SBM., Martins, P., Perez-Priego, O., and Orgaz, F., 2012. "Influence of water deficits at different times during olive tree inflorescence and flower development". Environmenatl and Experimental Botany 77:227-233

36. López Bernal, A., Testi, L., and Villalobos, F.J., 2019. “Olivar y cambio climático, predicciones de un modelo de simulación". Vida rural, ISSN 1133-8938, № 470, págs. 38-42.

37. Goldhamer, D.A., 1999. “Regulated Deficit Irrigation for California Canning Olives”. Acta Horticulturae.(474). pp.369372. DOI:10.17660/ActaHortic.1999.474.76.

38. Hammami, S., Manrique, T., and Rapoport, H., 2011. “Cultivar-based fruit size in olive depends on different tissue and cellular processes throughout growth". Scientia Horticulturae. (130). pp. 445-451. DOI:10.1016/j.scienta.2011.07.018.

39. Gucci, R., Lodolini, E., and Rapoport, HF., 2007. "Productivity of olive trees with different water status and crop load". Journal of Horticultural Science \& Biotechnology 82, 648-656.

40. Gucci, R., Caruso, G., Gennai, C., Esposto, S., Urbani, S., and Servili, M., 2019. "Fruit growth, yield and oil quality changes induced by deficit irrigation at different stages of olive fruit development". Agricultural Water Management 212, 88-98.

41. Ahumada, L., Ortega, S., Searles, P., and Retamales, J., 2017. "Yield and Water Productivity Responses to Irrigation Cutoff Strategies after Fruit Set Using Stem Water Potential Thresholds in a Super-High Density Olive Orchard". Frontiers Research Foundation. Frontier in Plant Science. pp. 8-11. DOI:10.3389/fpls.2017.01280.

42. López-Bernal, A., Fernandes-Silva, A.A., Vega, V.A., Hidalgo, J.C., León, L., Testi, L., and Villalobos, FJ., 2021. “A fruit growth approach to estimate oil content in olives". Europ. J. Agron. 123. DOI: 0.1016/j.eja.2020.126206

43. Girón, I.F., Corell, M., Galindo, A., Torrecillas, E., Morales, D., Dell'Amico, J., Torrecillas, A., Moreno, F., and Moriana, A., 2015. "Changes in the physiological response between leaves and fruits during a moderate water stress in table olive trees". Agricultural Water Management 148:280-286

Ben-Gal, A., Ron, Y., Yermiyahu, U., Zipori, I., Naoum, S., and Dag, A., 2021. "Evaluation of regulated deficit irrigation strategies for oil olives: A case study for two modern Israeli cultivars". Agric. Water Manage. 245, doi 10.1016/j.agwat.2020.106577. 


\title{
Necesidades de agua de riego en una explotación comercial de almendro mediante teledetección
}

\author{
Pérez García, Yeray ${ }^{1}$, Campoy Urrea, Jaime ${ }^{1}$, Calera Belmonte, Alfonso ${ }^{1}$ \\ Grupo de Teledetección y SIG. Instituto de Desarrollo Regional. Universidad de Castilla-La Mancha. Campus Universitario SN. Albacete \\ (España); Yeray.Perez@alu.uclm.es; Jaime.Campoy@uclm.es; Alfonso.Calera@uclm.es
}

\section{Resumen:}

La superficie dedicada al cultivo del almendro (Prunus dulcis) en regadío se ha duplicado en España en los últimos 5 años. La alta respuesta del rendimiento de este cultivo a la cantidad de agua aplicada junto con su elevada rentabilidad ha propiciado que actualmente el cultivo del almendro se convierta en una alternativa al cultivo de cereales y otros leñosos en muchas zonas del territorio nacional. No obstante, la expansión del cultivo en zonas con escasez de agua hace necesario el desarrollo y la aplicación de herramientas que permitan conocer sus necesidades de agua con la suficiente precisión, resolución espacial y temporal, con el objetivo de optimizar los recursos hídricos, realizar una gestión más rentable y sostenible con el entorno. De esta manera, las series temporales de imágenes de NDVI de satélite surgen como una herramienta valiosa que permiten caracterizar la evolución espacial y temporal de la cubierta vegetal y estimar con precisión la evolución del coeficiente de cultivo a lo largo del ciclo de crecimiento siguiendo las relaciones establecidas en la literatura científica.

El objetivo del presente estudio es determinar la evapotranspiración del cultivo del almendro y sus necesidades de agua de riego a través de la implementación del modelo de balance diario de agua en el suelo explorado por las raíces descrito en el manual de FAO 56 y asistido por teledetección. La metodología propuesta integra el coeficiente basal de cultivo $\left(\mathrm{K}_{\mathrm{cb}}\right)$ derivado de la serie temporal de imágenes de satélite en el balance de agua. Dicha metodología está bien documentada en la literatura científica para otros cultivos, aunque permanece casi inexplorada y con escasa experiencia previa para el cultivo del almendro.

El estudio se ha realizado en una explotación de almendro con riego localizado situada en el término municipal de Abarán (provincia de Murcia) durante la campaña 2019. Las necesidades de agua de riego estimadas con el modelo propuesto son evaluadas frente a datos reales de riego aplicados por el agricultor.

Los resultados obtenidos revelan el desempeño de la metodología propuesta para estimar con precisión las necesidades de agua de riego del cultivo del almendro a lo largo de la campaña de estudio, capturando diferencias en los requerimientos de agua del cultivo entre las parcelas analizadas. La aplicación de la metodología en situaciones reales permite al agricultor ajustar el suministro de agua a las demandas del cultivo, y ampliar su conocimiento sobre el uso del agua realizado en la explotación. Esta información resulta de gran utilidad para la toma de decisiones orientadas a la mejora de la planificación de riegos, elaboración de estrategias de riego deficitario controlado (RDC) y a una optimización de la gestión y uso de los recursos hídricos.

Palabras clave: NDVI ; almendro ; regadío ; satélite ; coeficiente de cultivo ; evapotranspiración 


\title{
Irrigation water requirements in an almond commercial farm using a remote sensing-based approach
}

\author{
Pérez García, Yeray ${ }^{1}$, Campoy Urrea, Jaime ${ }^{1}$, Calera Belmonte, Alfonso ${ }^{1}$
}

1 Grupo de Teledetección y SIG. Instituto de Desarrollo Regional. Universidad de Castilla-La Mancha. Campus Universitario SN. Albacete (España); Yeray.Perez@alu.uclm.es; Jaime.Campoy@uclm.es; Alfonso.Calera@uclm.es

\section{Abstract:}

The irrigated area cultivated with almond trees (Prunus dulcis) has doubled in Spain in the past 5 years. Almond is becoming a very extended tree crop in Spain, due to the high response of this crop to water used jointly with the likewise good market perspectives. Thus, almond is a viable alternative to traditional crops, such as cereals and other woody crops. However, the crop is expanding into waterscarce areas. In this manner, precise irrigation management tools are required to adequate the water applied to the actual crop requirements with suitable temporal and spatial resolutions. Adequate estimates of the net irrigation water requirements allow to improve the water use efficiency and therefore, achieving more profitable and sustainable management. Thus, time series of remote sensing satellite images allow to describe the spatial and temporal evolution of the canopy and estimate with reasonable accuracy the evolution of transpiration coefficient during the whole growing season using the wellrecognized relationships reported in the scientific literature.

This work aims at estimating the almond tree evapotranspiration and the net irrigation water requirements applying a Remote Sensing-based Soil Water Balance. This approach integrates basal crop coefficient $\left(\mathrm{K}_{\mathrm{cb}}\right)$ derived from time series of satellite images into the daily soil water balance at the root depth, which is widely explained in the FAO 56 manual. This methodology is well-documented in literature for other crops, although limited information is available for almond.

The study was realized in a drip irrigated almond commercial farm located in Abarán (province of Murcia), during the campaign 2019. The net irrigation water requirements estimated using the methodology proposed were assessed with regard to actual applied irrigation data provided by the farmer.

The results obtained in the present study reveal the potential of the methodology proposed to accurately estimate the net irrigation water requirements of almond tress during the study campaign. Moreover, the approach proposed was to able to capture differences of water requirements between the analyzed plots.

The operational application of this methodology will allow the farmer to know the actual crop water demand and adjust the water inputs to the crop water requirements. The information obtained is useful for making management decisions aimed at improving irrigation scheduling, developing controlled deficit irrigation (CDI) strategies and optimizing the management and use of water resources.

Keywords: NDVI ; almond tree ; irrigated ; satellite ; crop coefficient ; evapotranspiration 


\section{Introducción}

La actividad agraria es el sector que mayor consumo de agua demanda, por encima de los usos domésticos, industrial y de servicios. Sin embargo, la escasez de agua es el factor más limitante que condiciona el desarrollo de los cultivos y la producción de alimentos en muchas zonas del mundo.

En la actualidad, el cultivo del almendro (Prunus dulcis) se presenta como una alternativa rentable al cultivo de cereales y otros leñosos. España posee la mayor superficie dedicada a este cultivo en el mundo con 687225 ha, de la que el 84,7\% del área se maneja en condiciones de secano [1]. Sin embargo, la superficie dedicada al cultivo del almendro en regadío se ha duplicado en España en los últimos 5 años, debido a la alta respuesta del rendimiento de este cultivo a la cantidad de agua aplicada junto con su alta rentabilidad en la actual coyuntura de mercado.

Para afrontar el reto de optimizar los recursos hídricos en zonas con condiciones de escasez de agua es necesario el desarrollo y la aplicación de herramientas que permitan conocer la demanda de los recursos hídricos de los cultivos con la suficiente precisión, resolución espacial y temporal. Actualmente, la alta disponibilidad, frecuencia y resolución espacial de las imágenes multiespectrales de los satélites Sentinel 2A (S2A) y Sentinel 2B (S2B), pertenecientes al programa Copernicus de ESA, permiten obtener series temporales densas de imágenes capaces de describir de forma precisa el ciclo de crecimiento del cultivo.

De esta manera, las series temporales de imágenes NDVI de satélite constituyen una herramienta valiosa y operativa que permiten caracterizar la evolución temporal y espacial de los cultivos en tiempo real, y estimar con precisión diferentes parámetros biofísicos a lo largo del ciclo de crecimiento, como el coeficiente basal de cultivo $\left(\mathrm{K}_{\mathrm{cb}}\right)$, a través de relaciones robustas y ampliamente asentadas en la literatura científica. La determinación del $\mathrm{K}_{\mathrm{cb}}$ a través de medidas de reflectividad de la cubierta vegetal procedente de sensores remotos y su integración en el balance diario de agua en suelo, permite estimar de forma continua la evapotranspiración del cultivo [2] y sus necesidades de agua.

El objetivo general del presente trabajo es estimar la evapotranspiración del cultivo del almendro y sus necesidades de agua de riego mediante la implementación del modelo de balance diario de agua en el suelo explorado por las raíces descrito en el manual de FAO 56 [3] y asistido por teledetección. Esta información resulta relevante para ajustar las aplicaciones de riego a las necesidades reales del cultivo.

El estudio se ha realizado en una explotación de almendro con riego localizado situada en el término municipal de Abarán (provincia de Murcia) durante la campaña 2019. Las necesidades de agua de riego estimadas con el modelo propuesto son evaluadas frente a datos reales de riego aplicados por el agricultor. Además, para el desempeño de la metodología propuesta se han empleado series temporales de imágenes NDVI de alta resolución derivadas de los satélites S2A y S2B.

\section{Materiales y métodos}

- $\quad$ Zona de estudio

El estudio se ha realizado en la finca de Casablanca, que se localiza en la comarca Vega Alta del Segura, en el término municipal de Abarán (provincia de Murcia, ver Figura 1.

El clima en la zona de estudio es el Mediterráneo, caracterizado por una acusada variación estacional. De acuerdo a los datos obtenidos desde la estación agrometeorológica de Jumilla (Román) (latitud: $38^{\circ} 19^{\prime} 5^{\prime \prime} \mathrm{N}$; longitud: $1^{\circ} 19^{\prime} 32^{\prime \prime} \mathrm{O}$; altitud: $340 \mathrm{~m}$ ) procedente de la red SIAR (Servicio Integral de Asesoramiento al Regante), para el periodo de tiempo de 23 años (1998-2021) la temperatura media anual fue de $16,7^{\circ} \mathrm{C}$. Julio es el mes más cálido del año con una temperatura media mensual de $26,8^{\circ} \mathrm{C}$, en contrate enero es el mes más frío con una temperatura media de $8,2^{\circ} \mathrm{C}$. El 


\section{ACERYD}

CARTAGENA 2021

periodo medio libre de heladas está comprendido desde el 28 de marzo al 1 de diciembre, con una duración de 248 días. La precipitación media durante el mismo periodo fue de $328 \mathrm{~mm}$.

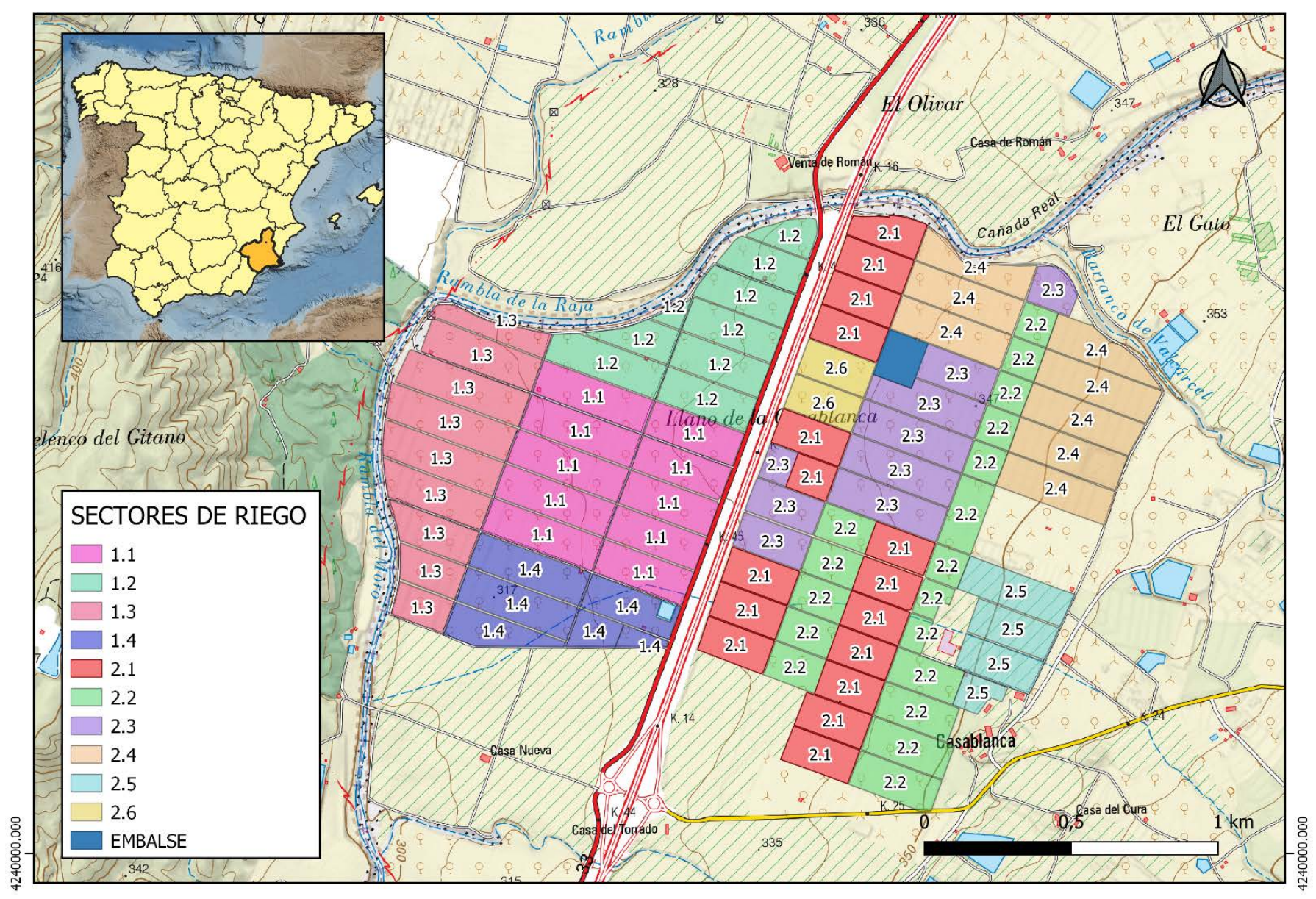

Figura 1. Localización de la zona de estudio, y distribución de los sectores de riego de la finca Casablanca (Abarán, Murcia).

Tabla 1. Cuadro descriptivo de los sectores.

\begin{tabular}{|c|c|c|c|c|}
\hline Código & Año & Variedad & $\begin{array}{c}\text { Marco } \\
\text { plantación }\end{array}$ & Ha \\
\hline $1.1 \_6 \times 6$ & 2012 & 33\%ANTOÑETA 66\%FERRAGNES & $6 \times 6$ & 43.15 \\
\hline $1.2 \_5 \times 3$ & 1987 & 10\%CRISTOMORTO 30\%FERRADUEL 60\%FERRAGNES & $5 \times 3$ & 28.55 \\
\hline $1.3 \_5 \times 3$ & 1987 & 10\%CRISTOMORTO 30\%FERRADUEL 60\%FERRAGNES & $5 \times 4$ & 10.81 \\
\hline $1.3 \_5 \times 4$ & 1987 & 10\%CRISTOMORTO 30\%FERRADUEL 60\%FERRAGNES & $5 \times 3$ & 27.40 \\
\hline $1.4 \_5 \times 4$ & 1987 & 10\%CRISTOMORTO 30\%FERRADUEL 60\%FERRAGNES & $5 \times 4$ & 12.89 \\
\hline $1.4 \_6 \times 6$ & 2009 & 100\%ANTOÑETA & $6 \times 6$ & 6.11 \\
\hline $2.1 \_6 \times 6$ & 2009 & 100\%ANTOÑETA & $6 \times 6$ & 43.37 \\
\hline $2.2 \_6 \times 6$ & 2009 & 100\%ANTOÑETA & $6 \times 6$ & 38.24 \\
\hline $2.3 \_6 \times 6$ & 2015 & 33\%ANTOÑETA 66\%FERRAGNES & $6 \times 6$ & 31.02 \\
\hline $2.4 \_6 \times 6$ & 2019 & 100\%ANTOÑETA & $6 \times 6$ & 35.96 \\
\hline $2.6 \_5 \times 4$ & 1987 & 20\%CRISTOMORTO 40 FERRADUEL 40\%FERRAGNES & $5 \times 4$ & 5.97 \\
\hline
\end{tabular}


La explotación objeto de estudio tiene una superficie total de 440 hectáreas, de las cuáles 350 ha se dedican al cultivo del almendro en regadío y 90 ha al cultivo de cereales en secano. La finca cuenta con dos pozos y un embalse para el abastecimiento de agua de riego. Además, dispone de dos naves para el almacenamiento de la almendra tras la recolección.

En la Figura 1 se muestra la localización de la explotación objeto de estudio y la distribución de los sectores de riego. La finca dispone de 10 sectores de riego. Cada sector recibe una aplicación de agua dependiendo de sus características, principalmente el marco de plantación, y la aplicación de agua es homogénea dentro de cada sector. La Tabla 1 muestra las principales características de los sectores de riego (código, año de plantación, variedad cultivada, marco de plantación, superficie). El sector 2.5 no se incluye en el estudio al ser una plantación muy reciente realizada en el año 2020.

Las primeras plantaciones se hicieron en el año 1987; se diseñaron en un marco de plantación con calles de 5 metros y una separación entre árboles de 3 metros, siendo pioneros al mecanizar todo el proceso de recolección de la almendra a través del sistema americano, en el que la almendra se recoge barriendo el suelo. Este diseño todavía sigue presente en la explotación en los sectores 1.2 y parte del 1.3. También se diseñó con otro marco de plantación, separando un metro la separación entre árboles en los sectores 1.3, 1.4 y 2.6 siendo la separación entre árboles de 4 metros y la de las calles 5 metros.

En las nuevas plantaciones, realizadas a partir del 2009, con la aparición del sistema de recolección con paraguas invertido que consiguió mecanizar todo el proceso de la recolección, el marco de plantación ha sido a cinco de oros o tresbolillo irregular a 6 metros.

En lo que respecta al riego aplicado, el agricultor posee un registro diario de las horas de riego empleadas en cada sector, en la cual se ha basado nuestro estudio. A efectos de validación de las dosis aplicadas, se han realizado dos evaluaciones de riego en campo, en el sector 1.1 y 1.2, como representativos de cada uno de los diseños agronómicos existentes en la finca, con el objetivo de conocer la pluviometría media del sistema de goteros y la uniformidad de emisión. Los resultados obtenidos en esta evaluación muestran que la pluviometría de los emisores se acerca a la nominal, con un buen desempeño de la instalación.

Por último, el agricultor ha facilitado información en cuanto la profundidad del suelo según su experiencia en campo y también se ha realizado un análisis de suelo necesario para conocer el agua disponible, la capacidad de campo y el punto de marchitez en el perfil del suelo.

- $\quad$ El Modelo de balance de agua FAO 56 asistido mediante teledetección

El modelo de balance de agua descansa en el principio de conservación de la masa para el agua contenida en la capa de suelo explorado por las raíces del cultivo. Un modelo ampliamente utilizado es el que se describe en detalle en el manual FAO 56 [3], que utiliza un paso de tiempo diario y en el que la evapotranspiración del cultivo (ET) se calcula mediante el procedimiento ET $=\mathrm{K}_{\mathrm{c}}$. ETo, coeficiente de cultivo, $\mathrm{K}_{\mathrm{c}}$, multiplicado por la evapotranspiración de referencia, ETo. Una versión avanzada de FAO 56 es la que utiliza el coeficiente dual, en el que se desglosa el coeficiente de cultivo en un coeficiente de cultivo basal, $\mathrm{K}_{\mathrm{cb}}$, y un coeficiente de evaporación, $\mathrm{K}_{\mathrm{e}}$, lo que permite calcular por separado la componente de transpiración, $\mathrm{T}=\mathrm{K}_{\mathrm{cb}} \cdot \mathrm{ETo}$, y la componente de la evaporación del suelo desnudo, $\mathrm{E}=\mathrm{K}_{\mathrm{e}} \cdot \mathrm{ETo}$. 


\section{Congreso Nacional de Riegos CARTAGENA 2021}

Cuando el contenido de agua en el estrato de suelo explorado por las raíces cae por debajo de un cierto valor umbral el cultivo puede entrar en estrés hídrico. La aparición de estrés implica una reducción del ritmo al cual transpira el cultivo, debido al cierre de estomas por el insuficiente contenido de agua en suelo. En FAO 56 el estrés hídrico se modela mediante un parámetro denominado coeficiente de estrés hídrico, $\mathrm{K}_{\mathrm{s}}$, que tiene el valor de 1 en ausencia de estrés. En presencia de estrés, cuando el contenido de agua en suelo cae por debajo de un umbral que depende del cultivo, el valor de $\mathrm{K}_{\mathrm{s}}$ es menor que 1, y disminuye de forma proporcional a cómo disminuye el contenido de agua en suelo.

El modelo FAO 56 se denomina "asistido por teledetección" [4] cuando el coeficiente de cultivo basal se deriva de la serie temporal de imágenes de satélite que describen la evolución del cultivo. Esto se hace principalmente a través de su relación con los denominados índices de vegetación [5], que se calculan desde las imágenes multiespectrales. En este trabajo se utiliza la relación lineal, $\mathrm{K}_{\mathrm{cb}}=1.44 \cdot \mathrm{NDVI}-0.10$, obtenida sobre un cultivo de viña [6]. Dado que el modelo opera en paso de tiempo diario, los valores del NDVI son interpolados linealmente para obtener valores interpolados.

- $\quad \underline{\text { Suelo }}$

La Tabla 2 muestra el valor de las propiedades hídricas del suelo utilizados en este caso de estudio, teniendo en cuenta las características conocidas del suelo y analíticas disponibles.

Tabla 2.- Propiedades hídricas del suelo en el modelo FAO 56 asistido por satélite utilizado en este estudio.

\begin{tabular}{cccc}
\hline Parámetro & Valor & Unidad \\
\hline Profundidad & Franco arcillosa & $\mathrm{m}$ \\
Textura & & 0,346 & - \\
\cline { 1 - 1 } Capacidad de campo & 0,183 & $\mathrm{~m}^{3} / \mathrm{m}^{3}$ \\
\cline { 1 - 1 } Marchitez permanente & 200 & $\mathrm{~mm}$ \\
\hline Agua disponible total en la zona radicular (ADT) & & $\mathrm{mm}$ \\
\hline
\end{tabular}

- $\quad$ Imágenes de satélite

Para el año 2019, que es del que se muestran los resultados en este trabajo, se han procesado un total de 24 imágenes libres de nubes, adquiridas por los satélites gemelos Sentinel 2A y Sentinel 2B, con una resolución espacial de $10 \mathrm{~m} \times 10 \mathrm{~m}$. Estas imágenes han sido procesadas y normalizadas para obtener la reflectividad en superficie y calcular de ellas el NDVI, de acuerdo a la metodología utilizada por la Sección de Teledetección y SIG del Instituto de Desarrollo Regional en la Universidad de Castilla-La Mancha

Finalmente se ha calculado el valor promedio de NDVI para cada sector en cada una de las imágenes disponibles; este valor promedio se obtiene mediante la realización de una operación SIG de agregación espacial de los valores de NDVI correspondientes a todos los píxeles de cada uno de los sectores, aplicando un "buffer" que elimine aquellos pixeles cuyo centro geométrico se encuentre a menos de $7 \mathrm{~m}$ de la línea que delimita el sector.

Operando de la misma forma, se han analizado los años 2020 y 2021, aunque los resultados no se muestran en el presente estudio.

Una cuestión importante es si el valor del NDVI se debe a la cubierta de los árboles o pudiera ser alterado por la presencia de arvenses; en la explotación en estudio las malas hierbas se controlan muy cuidadosamente, como se pudo comprobar en las visitas a campo, aunque es inevitable que 
pueda incrementar levemente este valor en los meses de primavera u otoño después de las lluvias. Se asume pues que el valor del NDVI corresponde esencialmente a la cobertura vegetal verde de los árboles.

\section{- $\quad$ Meteorología}

Los datos meteorológicos utilizados, Evapotranspiración de referencia $\left(\mathrm{ET}_{\mathrm{o}}\right)$ y precipitación, se obtienen a escala diaria desde la estación agrometeorológica procedente de la red SIAR (Servicio Integral de Asesoramiento al Regante) más cercana a la finca (MU125, Jumilla-Román, Murcia).

\section{Resultados y discusión}

\section{Patrón temporal de la evolución del NDVI}

La Figura 2 muestra la evolución temporal del NDVI correspondientes al año 2019, para cada uno de los 11 sectores, en la que se han indicado las fechas de floración y cosecha. El patrón temporal el refleja un crecimiento rápido del NDVI después de la floración, crecimiento que alcanza un máximo en abril, decreciendo suavemente hasta la senescencia y pérdida de hoja.

En la gráfica se representa el periodo vegetativo de 2019, donde se puede apreciar una tendencia con valores más altos en los sectores con los marcos de plantaciones más densos con 667 y 500 árboles por hectárea (1.4_5x4,1.2_5x3, 1.3_5x3, 1.3_5x4 y 2.6_5x4), alcanzando valores de NDVI de 0,64 para el mes de abril. Siendo también el valor más alto para el resto de sectores el mes de abril con densidades de 248 árboles por hectárea (1.1_6x6, 1.4_6x6, 2.1_6x6, 2.2_6x6, 2.3_6x6 y 2.4_6x6) con un valor de NDVI de 0.53 . También se puede apreciar las diferencias del sector $2.4 \_6 \times 6$, cultivo implantado ese mismo año, con el resto de sectores o el sector 2.3_6x6 con 4 años de vida, donde todavía no ha alcanzado su máximo desarrollo.

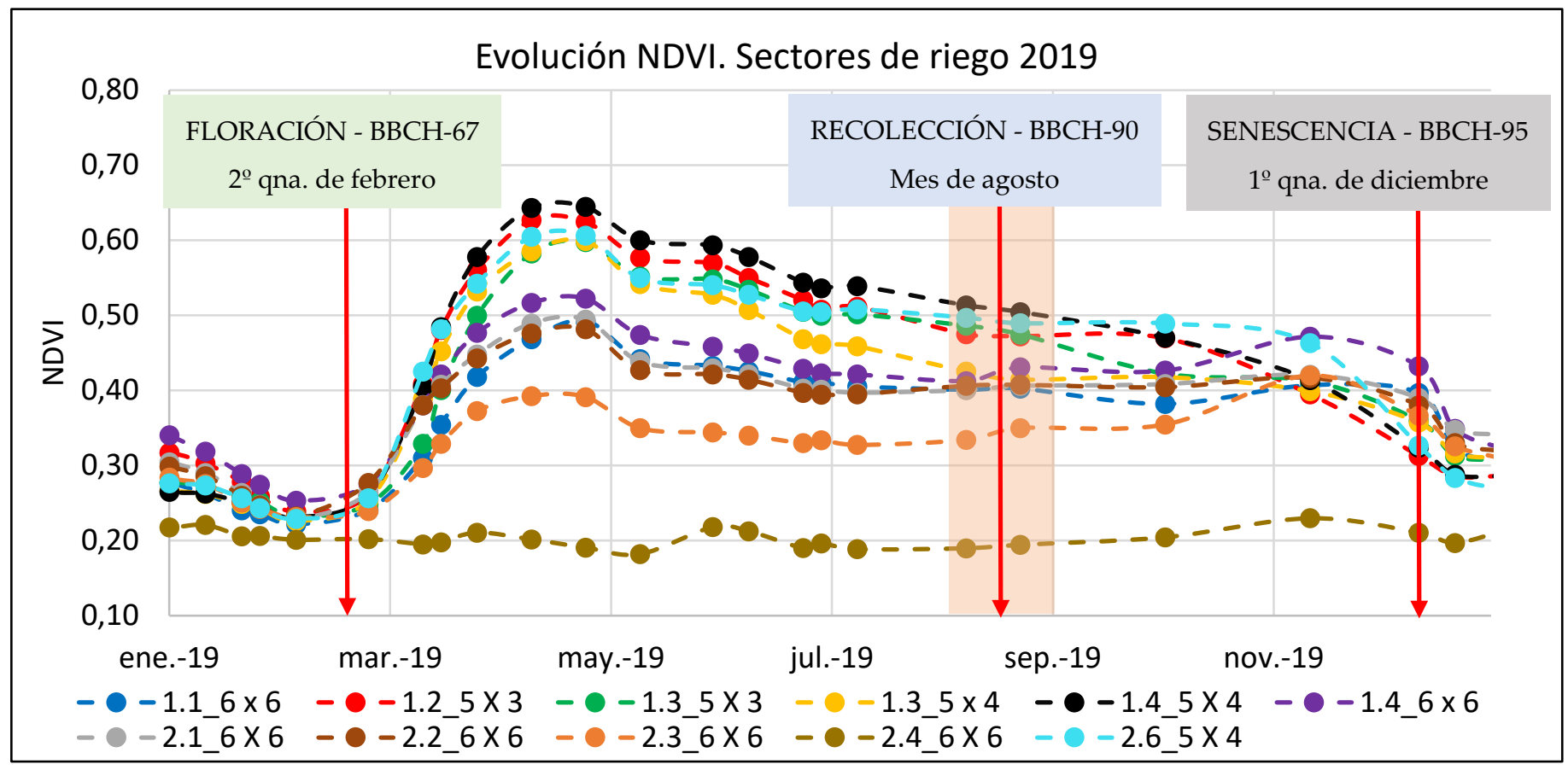

Figura 2. Evolución temporal NDVI. Serie temporal de imágenes de satélite (S2A, S2B), 2019. 


\section{Congreso Nacional de Riegos CARTAGENA 2021}

Las diferencias de los patrones temporales entre los sectores muestran que las series temporales de imágenes de satélites son capaces de capturar las diferencias en el desarrollo y en el crecimiento del cultivo entre los distintos sectores de riego.

\section{Balance de agua}

El balance de agua ha permitido calcular las necesidades de agua de riego totales en la campaña considerando un manejo en ausencia de estrés, lo que se ha comparado con la aplicación de agua por parte del agricultor. Los resultados de esta comparación se muestran en la Figura 3.

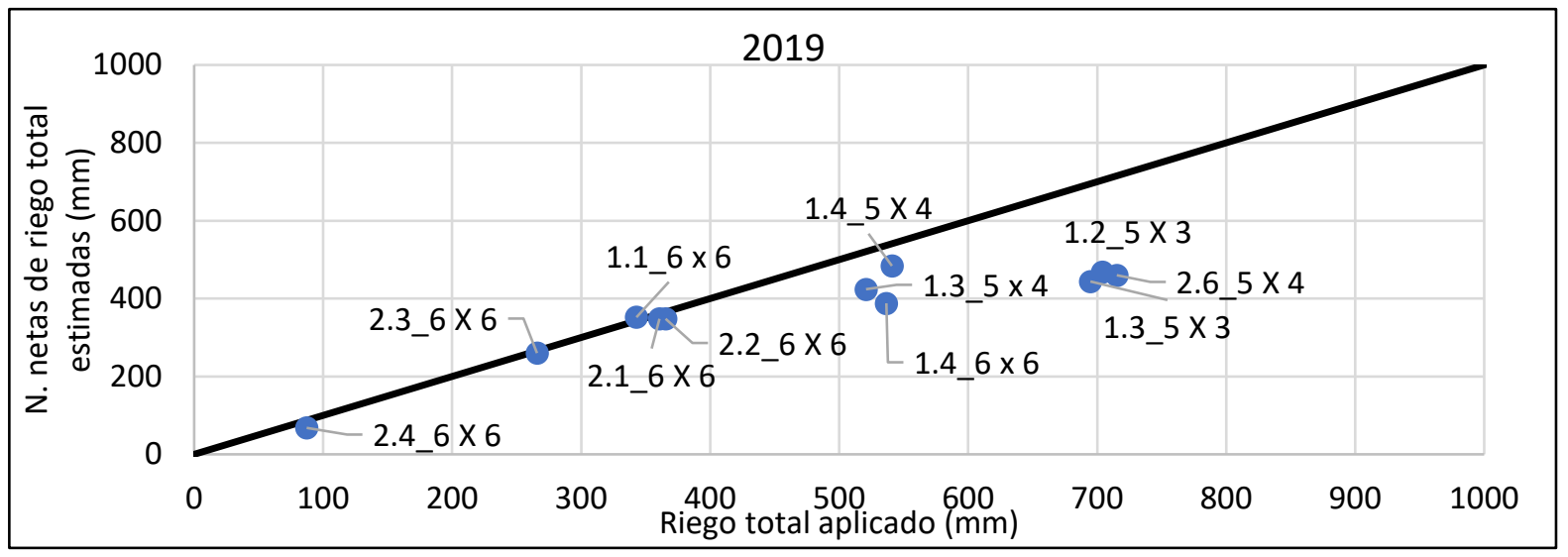

Figura 3. Necesidades netas de riego total estimadas vs riego total aplicado en sectores de riego, año 2019.

En la Figura 3 se comparan los datos de los riegos aportados por el agricultor y los riegos estimados por el modelo, para el año 2019 en todos los sectores de riego. Tal y como se puede apreciar, las necesidades netas de riego totales estimadas con la metodología propuesta son muy similares al riego total aportado por el agricultor en la mayoría de los sectores de riego $\left(1.3 \_5 \times 4,1.4 \_6 \times 6,1.4 \_5 \times 4,1.1 \_6 \times 6\right.$, $2.2 \_6 \times 6,2.1 \_6 \times 6,2.3 \_6 \times 6$ y 2.4_6x6). Sin embargo, se distinguen claras discrepancias entre las estimaciones y las aplicaciones de riego totales en algunos sectores (1.2_5x3, 1.3_5x3 y 2.6_5x4). En estos sectores que coinciden con los marcos de plantación de mayor densidad, el modelo estima unas necesidades totales menores a las aportadas por el agricultor.

Un paso adicional a este análisis es considerar la distribución temporal de las necesidades de agua de riego. Se ha elegido para este análisis el sector 1.2 como representativo de los sectores que presentan una mayor diferencia entre las cuantías totales de agua aplicada y las necesidades estimadas, que son aquellos que presentan también una mayor cobertura vegetal, con el marco de $5 \mathrm{~m} \times 3 \mathrm{~m}$ y 667 árboles/ha.

Para ello se ha realizado de nuevo el balance de agua utilizando las aplicaciones de agua realizadas por el agricultor como un dato de entrada adicional al modelo. En este caso el modelo permite estimar el contenido de agua en el suelo, de acuerdo con el resto de parámetros utilizados y que se han descrito anteriormente.

En la Figura 4 se representa la estimación del agotamiento del agua en el suelo, definido como la diferencia entre la capacidad total de agua en suelo disponible para las plantas $(200 \mathrm{~mm})$ menos el contenido de agua en suelo en cada día del ciclo de cultivo. El modelo permite estimar también la percolación, que se define como el agua que sale de la capa explorada por las raíces hacia capas más profundas, lo que sucede en determinados momentos debida a la aparición de precipitaciones con el perfil del suelo con un alto contenido de agua. La línea de $80 \mathrm{~mm}$, esto es el $40 \%$ de la capacidad total, corresponde al umbral de agua fácilmente utilizable, de acuerdo a lo indicado en FAO 56 para el almendro. 


\section{Congreso Nacional de Riegos CARTAGENA 2021}

En el caso de este sector se da un tanto la paradoja de que se aplica un mayor aporte de agua por el agricultor, $668 \mathrm{~mm}$, que la cuantía estimada como óptimo, $469 \mathrm{~mm}$, y aun así parece puede producirse algún estrés hídrico en algún momento del ciclo.

La Figura 5 muestra la diferente distribución temporal de las recomendaciones de agua de riego que el modelo estima como óptimas, al imponerse la condición que el coeficiente de estrés se mantenga con un valor alrededor de 1 . Asimismo, se le impone la condición de una dosis máxima de $6 \mathrm{~mm} /$ día, que es la capacidad nominal del sistema de riego.

La diferencia entre las necesidades estimadas y el agua realmente aplicada se explica fundamentalmente por una mejor gestión del agua en el suelo que evita posibles percolaciones en la primavera. Obviamente el modelo no contempla aquellas prácticas de manejo ligadas a la fertilización ni a prácticas de limpieza de tuberías, etc., que tienen una dinámica propia, no ligada estrictamente a satisfacer las necesidades de agua.

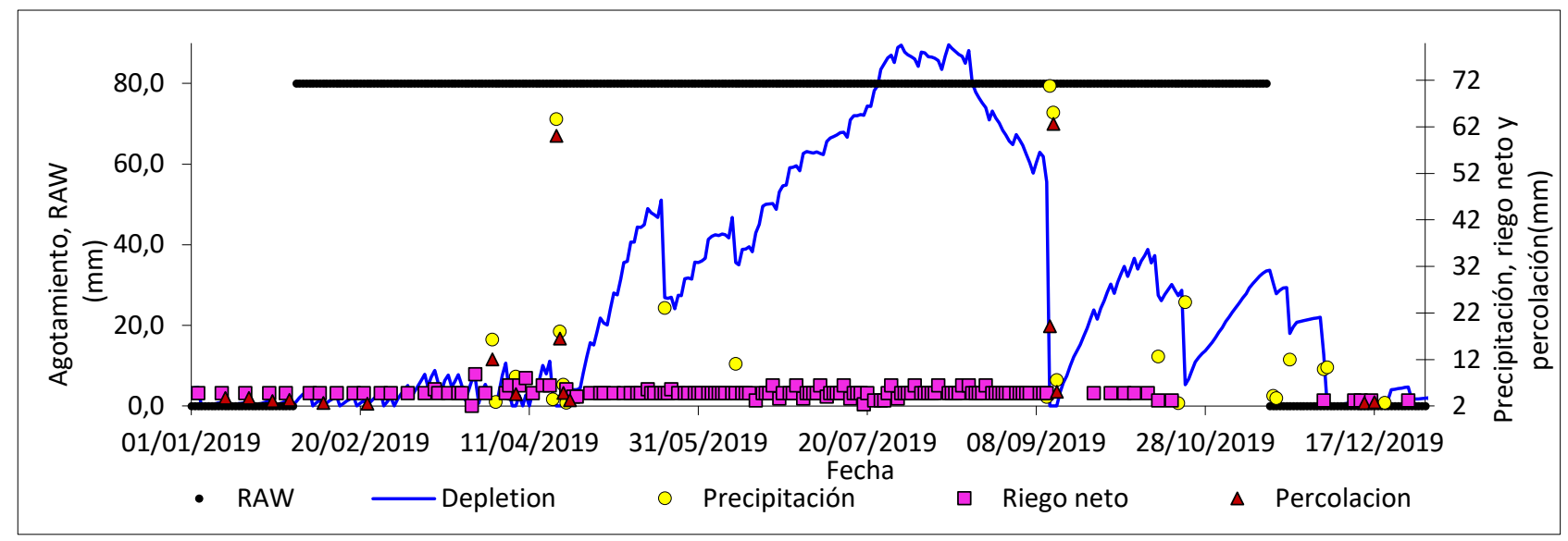

Figura 4. Agotamiento en la zona radicular calculado por el método del coeficiente dual para el sector 1.2, junto con al riego aplicado por el agricultor y la precipitación registrada en la estación meteorológica de Jumilla-Román (Murcia)

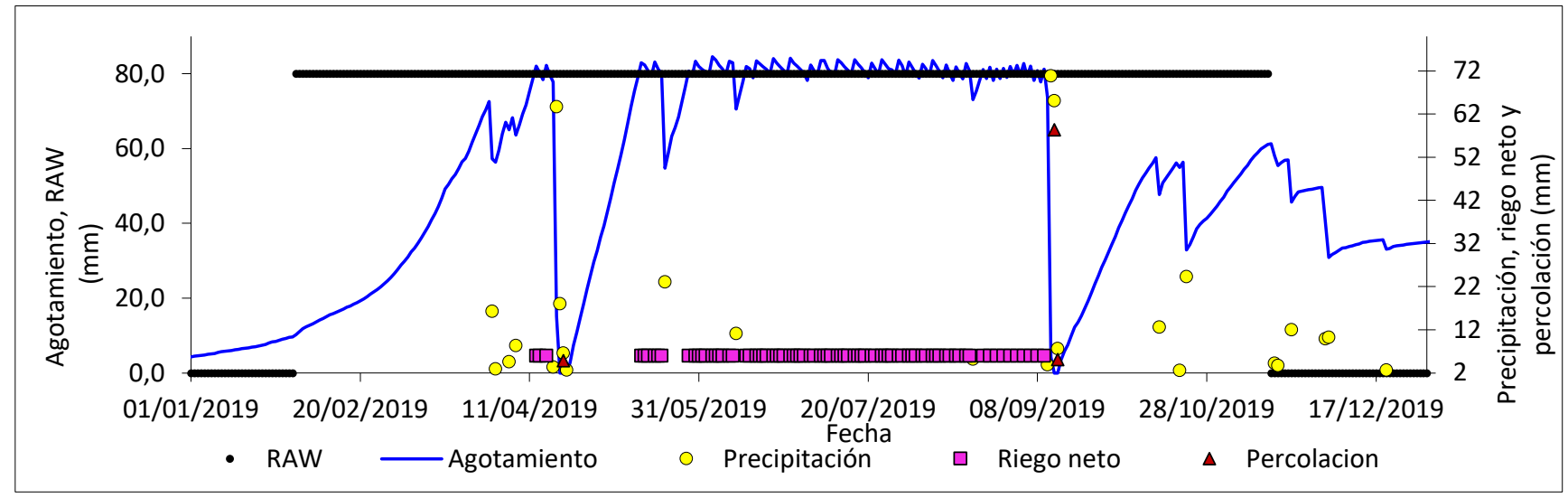

Figura 5. Agotamiento en la zona radicular calculado por el método del coeficiente dual para el sector 1.2, junto con al riego estimado por el modelo y la precipitación registrada en la estación meteorológica de Jumilla-Román (Murcia)

\section{Conclusiones}

El balance agua FAO 56 asistido por satélite, en el que el coeficiente de cultivo basal se deriva de imágenes multiespectrales, es en la actualidad una herramienta operativa para una aproximación a la 
determinación de las necesidades de agua del almendro, tanto en la cuantía total de agua a aplicar durante el ciclo de crecimiento, como en cuanto a determinar cuándo y cuánto regar bajo las condiciones establecidas por el sistema de riego y cuantía de agua disponible.

Desde el año 2017 hasta el presente se tiene acceso libre y gratuito, prácticamente en tiempo real, a las imágenes de los satélites gemelos Sentinel 2A y Sentinel 2B, del programa Copernicus de la Comisión Europea. Las imágenes ofrecen una resolución espacial de tamaño de pixel de $10 \mathrm{~m} \times 10 \mathrm{~m}$, y la constelación de satélites posibilita un período de revisita de 3 a 5 días, lo que permite disponer de suficientes imágenes libres de nubes para describir la evolución del cultivo con una alta frecuencia temporal.

Operando con estas imágenes, el modelo de balance de agua FAO 56 asistido mediante teledetección proporciona unas estimaciones de necesidades de agua de riego que se corresponden razonablemente bien con el riego total aplicado por el agricultor.

Sin embargo, la distribución temporal de las aportaciones de agua de riego admite potencial de mejora, que puede ser analizado mediante las herramientas descritas en este trabajo. En este sentido se ha puesto en marcha un proceso de colaboración con el agricultor para integrar en el modelo las condiciones de manejo del agua específicas en cuanto a la disponibilidad de agua y objetivos agronómicos, al objeto de maximizar el agua disponible.

\section{Referencias}

1. MAPA, 2020. Anuario de estadística, 2019, 2020. Ministerio de Agricultura, Pesca y Alimentación, Madrid, España.

2. Neale, C. M. U., Bausch, W. C., \& Heermann, D. F. (1989). Development of reflectance-based crop coefficients for corn. Transactions of the American Society of Agricultural Engineers, 32(6), 1891-1899.

3. Allen, R. G., Raes, D., \& Smith, M. (1998). Crop Evapotranspiration: Guidelines for Computing Crop Requirements. In Irrig. Drain. Pap. No. 56, FAO, Rome, Italy.

4. Calera, A., Campos, I., Osann, A., D’Urso, G., \& Menenti, M. (2017). Remote sensing for crop water management: From ET modelling to services for the end users. Sensors, 17(5), 1-25.

5. Pôças, I., Calera, A., Campos, I., \& Cunha, M. (2020). Remote sensing for estimating and mapping single and basal crop coefficientes: A review on spectral vegetation indices approaches. Agricultural Water Management, 233(December 2019), 106081.

6. Campos, I., Neale, C. M. U., Calera, A., Balbontín, C., \& González-Piqueras, J. (2010). Assessing satellite-based basal crop coefficients for irrigated grapes (Vitis vinifera L.). Agricultural Water Management, 98(1), 45-54. 


\title{
Riego deficitario en granado. Relaciones hídricas y crecimiento del fruto
}

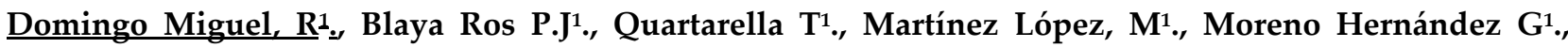 \\ Giménez Gallego, J1'. Torres Sánchez, R¹.
}

1Universidad Politécnica de Cartagena. rafael.domingo@upct.es; pedro.blaya@upct.es; t.quartarella@studenti.uniba.it; marianoupct@gmail.com; gmorenohdez6@gmail.com; jaime.gimenez@upct.es; roque.torres@upct.es

Resumen: con la convicción de que los agrosistemas mediterráneos tienen que afrontar la necesidad de convivir con la escasez de agua, y que resulta muy difícil, si no imposible, poder satisfacer las necesidades máximas de agua de la mayoría de los cultivos; diseñamos un ensayo de riego deficitario (RD) en granado "Wonderful" bajo malla, para estudiar las relaciones hídricas y poder ajustar los volúmenes de riego y elegir la estrategia de manejo más adecuada bajo las condiciones de cultivo.

El ensayo se inició en 2021 en una plantación de granado "Wonderful" bajo malla de sombreo 30\%, perteneciente al Grupo Paloma (Mazarrón). Los árboles formados en vaso abierto y a marco de $5 \mathrm{~m} \mathrm{x}$ $3,5 \mathrm{~m}$, presentaban un diámetro de tronco entre $11,5-12,2 \mathrm{~cm}$ y un porcentaje de área sombreada del $43 \%$. El riego por goteo constó de un único lateral por hilera de árboles y 3 emisores autocompensantes de $4 \mathrm{~L} / \mathrm{h}$ por árbol. El agua de riego, de pozo, presentó un $\mathrm{pH}$ de $7,9, \mathrm{CE}_{25^{\circ} \mathrm{C}}$ de 2,6 $\mathrm{dS} \mathrm{m}^{-1}$ y una concentración de cloruros y sodio de 10,9 y 11,9 meq L-1, respectivamente. Los tratamientos en curso son: i) control (CTL) con riego al 115\% ETc, ii) riego deficitario sostenido (RD) regado al 75\% CTL, iii) riego deficitario controlado (RDC) con riego al 40 - 100 - 70\% CTL durante las fases: floración, cuajado y crecimiento inicial del fruto (junio) - tramo II de la fase de rápido crecimiento del fruto - fase final del período de crecimiento y maduración del fruto, y iv) finca (FCA) regado de acuerdo al criterio del técnico de la empresa. El diseño experimental es de bloques al azar y tres repeticiones por tratamiento.

Los resultados de la campaña de riego actual, periodo marzo-primera semana de julio, indican un ahorro de agua respecto a CTL del 20; 25 y 53\% para FCA, RD y RDC, respectivamente. La evolución del fruto y diámetro medio es similar en los cuatro tratamientos ( $\mathrm{d}=62 \mathrm{~mm}$-DDA 187). Aunque no hubo diferencias de potencial matricial del agua en el suelo $\left(\Psi_{\mathrm{m}}\right)$, debido a su alta variabilidad, si se dieron de potencial de tallo a mediodía $\left(\Psi_{t}\right)$ para RDC desde principios de junio hasta el cambio de riego al 100\% de CTL, primera semana de julio. De igual modo que en $\Psi_{\mathrm{m}}$, no se observaron diferencias de conductancia estomática $\left(\mathrm{g}_{\mathrm{s}}\right)$ a excepción de los días previos al cambio de riego en RDC. Aunque son resultados preliminares y se requiere de los resultados que deriven de los años posteriores, éstos sugieren una buena adaptabilidad del granado al déficit hídrico, al mantener una evolución y tamaño de fruto similar, el cual es una de las principales características de calidad de la granada a nivel comercial. Dada la excelente aceptación de la variedad Wonderful para exportación, tanto el volumen de riego actualmente aplicado como las características principales del fruto son resultados alentadores.

Palabras clave: potencial de tallo a mediodía; intercambio gaseoso; dinámica de crecimiento, Punica granatum L. 


\title{
Estudio de indicadores de suelo y planta para la programación del riego en cerezos jóvenes
}

\author{
Blaya-Ros, P.J.'; Blanco, V. ${ }^{1}$, Torres-Sánchez, R. ${ }^{1}$, González-Teruel, J.D. ${ }^{1}$, Espósito, M.E. ${ }^{2}$, Domingo, R. ${ }^{1}$
}

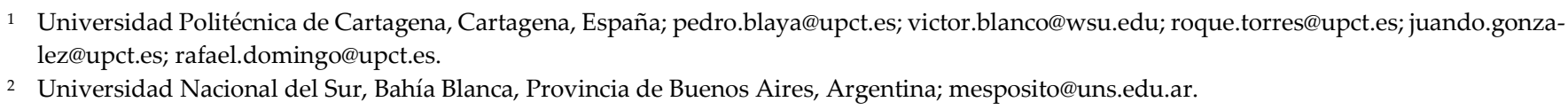

2 Universidad Nacional del Sur, Bahía Blanca, Provincia de Buenos Aires, Argentina; mesposito@uns.edu.ar.

Resumen: En zonas áridas y semiáridas existe una necesidad constante de mejorar la eficiencia del uso del agua. En este sentido, el empleo de indicadores puede convertirse en una herramienta eficaz para confeccionar programas de riego más precisos. Durante el verano de 2018 y 2019, con el objetivo de estudiar la sensibilidad y la variabilidad de distintos indicadores de suelo y planta, se llevó a cabo un ensayo en cerezos jóvenes (Prunus avium L. 'Lapins'). Tres tratamientos de riego aplicados fueron: control (CTL) regado para asegurar condiciones no limitantes de agua en el suelo, y dos tratamientos deficitarios, MS y SS, los cuales fueron regados como CTL hasta finales de junio, momento a partir del cual se alternaron 2 ciclos consecutivos de supresión - reanudación del riego. Los árboles fueron recupera-

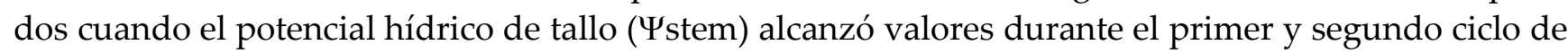
supresión de -1,3 y -1,7 MPa para MS y -1,6 y -2,3 MPa para SS. Los indicadores de suelo y planta estudiados fueron afectados por el déficit hídrico impuesto. La tasa de crecimiento diaria del tronco (TGR) y la máxima contracción diaria del tronco (MDS) mostraron una respuesta rápida al cambio de riego; sin embargo, ambos indicadores tuvieron una alta variabilidad. En este sentido, MDS mostró la mayor intensidad de señal, aunque la sensibilidad de este indicador fue mitigada por su coeficiente de variación $(\mathrm{CV})$. Por otro lado, el contenido volumétrico de agua del suelo $(\theta \mathrm{v})$ y la temperatura de la copa (Tc) exhibieron una alta sensibilidad debido a la baja variabilidad. $\Psi$ stem, indicador usado como referencia, mostró una estrecha relación con el resto de los indicadores estudiados, excepto con TGR. La relación observada entre MDS y $\Psi$ stem fue lineal hasta alcanzar valores de $\Psi$ stem de -1,3 MPa. Los resultados obtenidos sugieren que $\Psi$ stem es un indicador sensible al estrés con un bajo CV; Tc, la diferencia de temperatura de la copa y del aire y el índice de estrés del cultivo pueden ayudar a determinar, de forma rápida y sencilla, el estado hídrico del cultivo; y MDS podrías ser utilizado hasta valores de estrés moderados para la elaboración de programas de riego en cerezos jóvenes.

Palabras clave: Programación del riego, indicadores de estrés hídrico; variabilidad; sensibilidad; Prunus avium L.; Potencial hídrico de tallo; Temperatura de la copa. 


\title{
Feasibility of soil and plant indicators for irrigation scheduling in cherry trees
}

\author{
Blaya-Ros, P.J. ${ }^{1}$; Blanco, V. ${ }^{1}$, Torres-Sánchez, R. ${ }^{1}$, González-Teruel, J.D. ${ }^{1}$, Espósito, M.E. ${ }^{2}$, Domingo, R. ${ }^{1}$ \\ Universidad Politécnica de Cartagena, Cartagena, España; pedro.blaya@upct.es; victor.blanco@wsu.edu; roque.torres@upct.es; juando.gonza- \\ lez@upct.es; rafael.domingo@upct.es. \\ 2 Universidad Nacional del Sur, Bahía Blanca, Provincia de Buenos Aires, Argentina; mesposito@uns.edu.ar.
}

\begin{abstract}
In arid and semi-arid areas there is a constant need to improve water use efficiency. In this sense, the use of indicators can become an effective tool to design more accurate irrigation programs. During the summer of 2018 and 2019, with the aim of studying the sensibility and variability of different soil and plant indicators, an experiment was carried out in young 'Lapins' cherry trees (Prunus avium L.). Three irrigation treatments were applied: control treatment (CTL) irrigated to ensure non-limiting soil water conditions; moderate water stress (MS) subjected to two drying cycles whose duration was dependent on the time elapsed until the trees reached values of midday stem water potential (Ystem) of -1.3 and $-1.7 \mathrm{MPa}$ for the first and second cycle, respectively; and severe water stress (SS) similar to MS, but with reference values of -1.6 and $-2.5 \mathrm{MPa}$. In-between drought cycles, the MS and SS trees were irrigated daily as the CTL trees until reaching $\Psi$ stem values like the CTL trees. The soil and plant indicators studied were affected by the water deficit. Trunk growth rate (TGR) and maximum daily shrinkage (MDS) showed a rapid response to irrigation alteration; however, both indicators had high variability. In this sense, MDS showed the highest signal intensity, although its sensitivity was reduced by its coefficient variability $(\mathrm{CV})$. On the other hand, the volumetric water content $(\theta \mathrm{v})$ and the canopy temperature (Tc) showed a high sensitivity due to low variability. $\Psi$ stem, the indicator used as a reference, showed a close relationship with other indicators, except for TGR. The relationship obtained between MDS and $\Psi$ stem was linear until reaching values of $\Psi$ stem of -1.3 MPa. These results obtained suggest that $\Psi$ stem is a stress-sensitive indicator with a low $\mathrm{CV}$; Tc, the difference between the canopy and the air and crop water stress index can help to determine, quickly and easily, the crop water status; and MDS could be used up to moderate stress values for deficit irrigation scheduling in young cherry trees.
\end{abstract}

Keywords: Irrigation scheduling, water stress indicators; variability; sensitivity; Prunus avium L.; stem water potential; canopy temperature. 


\section{Congreso Nacional de Riegos CARTAGENA 2021}

\section{Introducción}

En las zonas áridas y semiáridas, la frecuencia e intensidad de los periodos de sequía se han incrementado debido al cambio climático, lo que podría provocar una reducción de la disponibilidad hídrica. Esta situación ha generado la necesidad de optimizar el uso del agua en el sector agrícola en estas zonas, principal consumidor de los suministros hídricos. Sin embargo, para aumentar la eficiencia en el uso del agua es necesario conocer, de forma directa o indirecta, el estado hídrico de la planta.

Números indicadores del estado hídrico del suelo y de la planta han sido utilizados para la confección y supervisión de programas de riego. Los indicadores de suelo son ampliamente empleados a nivel comercial para la programación del riego, debido a que pueden determinar de forma indirecta el estado hídrico de la planta, además de ser fácilmente interpretables y automatizables [1]. Por el contrario, debido a su mayor dificultad de interpretación y medida, los indicadores del estado hídrico de la planta son aplicados principalmente en el ámbito de la investigación. El potencial hídrico de tallo y de hoja han sido los indicadores de referencia para estimar el estado hídrico de la planta [2]. Si bien, su aplicabilidad en campo es compleja, debido a que es una técnica muy laboriosa y no automatizable. Por esta razón, aumentó el interés en la utilización de las fluctuaciones de diámetro de tronco en la programación del riego en frutales. Los cambios en el diámetro del tronco se han utilizado con éxito en múltiples frutales [3,4], debido a que son capaces de monitorizar el estado hídrico del cultivo de forma continua. Por otro lado, la termografía infrarroja ha emergido como una herramienta no destructiva y capaz de estimar de forma precisa el estado hídrico de los cultivos a distintas escalas [5]. La temperatura de la copa (Tc) es regulada principalmente por la tasa transpirativa de la planta y, por lo tanto, por la apertura estomática.

Teniendo en cuenta lo anteriormente comentado, se llevó a cabo durante dos años un experimento en cerezos (Prunus avium L.) sometidos a varios ciclos de supresión-recuperación del riego con el objetivo de estudiar la sensibilidad, la variabilidad y la adecuación de distintos indicadores de suelo y planta para su aplicación en el manejo del riego.

\section{Materiales y métodos}

El estudio se llevó a cabo durante junio - septiembre de 2018 y 2019 en la Estación Experimental Agroalimentaria 'Tomás Ferro' (ETSIA-UPCT), ubicada en Cartagena. El material vegetal empleado fueron cerezos ( $P$. avium L. 'Lapins') injertados sobre 'Mirabolano'. Los árboles tenían 3 años de edad al inicio del ensayo y estaban dispuesto en un marco de plantación de 3,5 m x 2,25 m. El sistema de riego constó de un único lateral de riego por hilera de árboles con tres emisores autocompensantes de 2,2 $\mathrm{L} \mathrm{h}^{-1}$ por planta. El agua de riego presentó una conductividad eléctrica $\left(\mathrm{CE}_{25^{\circ} \mathrm{C}}\right)$ de $1,1 \mathrm{dS} \mathrm{m}^{-1} \mathrm{y}$ fue de buena calidad en general.

El diseño experimental fue de bloques al azar, con 3 repeticiones por tratamiento. Los tratamientos de riego fueron: i) CTL, control, regado para satisfacer el $115 \%$ de las necesidades hídricas del cultivo, ii) MS, déficit moderado-severo, regado como CTL hasta finales de junio, momento a partir del cual se alternaron 2 ciclos consecutivos de supresión-reanudación del riego. El riego se reanudó tras alcanzar un potencial hídrico de tallo ( $\Psi$ stem) de $-1,3 \mathrm{MPa}$ en el primer ciclo de sequía y de -1,6 MPa en el segundo; y iii) SS, déficit severo, similar a MS, pero con recuperaciones a -1,6 MPa y -2,3 MPa. Los periodos de recuperación se dieron por finalizados cuando los valores de $\Psi$ stem de los tratamientos deficitarios alcanzaron valores de $\Psi$ stem similares a los de los árboles CTL.

Las variables meteorológicas fueron proporcionadas por la estación agroclimática CA12 del Servicio de Información Agraria de la Región de Murcia (SIAM - https://siam.imida.es/). La dosis de riego fue calculada semanalmente a partir de la evapotranspiración del cultivo (ETc), según la metodología 
FAO: $\mathrm{ETc}=\mathrm{ET}_{0} \times \mathrm{K}_{\mathrm{c}} \times \mathrm{K}_{\mathrm{L}}$, donde $\mathrm{ET}_{0}$ es la evapotranspiración de referencia [6]; $\mathrm{K}_{\mathrm{c}}$, coeficiente de cultivo [7]; $\mathrm{K}_{\mathrm{L}}$, coeficiente corrector [8].

El contenido volumétrico de agua del suelo $(\theta \mathrm{v})$ en el perfil $0-0,8 \mathrm{~m}$ fue monitorizado con un sensor capacitivo (Diviner2000, Entelechy Pty. Ltd., Golden Grove, Australia). Para ello, se instalaron dos tubos de acceso por repetición $(n=6)$ a $23 \mathrm{~cm}$ del emisor central. $\theta \mathrm{v}$ fue medido cada 2 - 7 días en el periodo de 8:00 - 10:00 h UT durante ambos años experimentales.

El estado hídrico de la planta fue monitorizado a través del potencial hídrico de tallo ( $\Psi$ stem), las microvariaciones del diámetro del tronco (VDT) y de la temperatura de copa (Tc). Istem fue medido al mediodía con una cámara de presión (mod. SF-PRES-70, SolFranc Tecnologías, S.L., Spain) cada 3 7 días en 2 hojas por repetición cercanas al tronco y envueltas con plástico y papel de aluminio [2].

VDT se obtuvieron mediante 6 sensores (2 por repetición) de desplazamiento lineal (LVDT, Solartron Metrology, modelo DF $\pm 2,5 \mathrm{~mm}$, Bognor Regis, UK). A partir de las medidas de las fluctuaciones del diámetro del tronco se obtuvieron los siguientes parámetros [9]: diámetro máximo diario del tronco (MXTD), diámetro mínimo diario del tronco (MNTD), máxima contracción diaria (MDS), calculada como la diferencia entre MXTD y MNTD, y tasa de crecimiento diaria del tronco (TGR), determinada como la diferencia entre MXTD de dos días consecutivos.

Tc fue medida al mediodía con una cámara térmica (Flir One, Flir Systems, Wilsonville, OR, USA) en los mismos días que $\Psi$ stem. Dos imágenes fueron tomadas por repetición $(n=6)$ a una distancia de 1,5 m de la copa y en la parte soleada del árbol [10]. La emisividad fue de 0,95 y las fotografías fueron analizadas en el programa informático Flir Tools application (Flir One, Flir Systems, Wilsonville, OR, USA). Para atenuar el impacto de las variables climáticas, se determinaron dos índices térmicos: (i) la diferencia entre la temperatura de la copa y la del aire $(\Delta \mathrm{T})$; y ii) el índice de estrés hídrico del cultivo (CWSI, crop water stress index) [11]:

$\Delta \mathrm{T}=\mathrm{Tc}-\mathrm{Ta}$

CWSI $=\frac{\Delta \mathrm{T}-\Delta \mathrm{T}_{\mathrm{wet}}}{\Delta \mathrm{T}_{\mathrm{dry}}-\Delta \mathrm{T}_{\mathrm{wet}}}$

donde, Tc es la temperatura de la copa; Ta es la temperatura del aire; $\Delta$ Tdry $\Delta$ Twet es la diferencia entre la temperatura de la copa y la del aire cuando el cultivo tiene los estomas completamente cerrados y $\Delta$ Twet cuando están completamente abiertos. $\Delta$ Twet y $\Delta$ Tdry fueron determinadas de acuerdo con las recomendaciones propuestas por Blaya-Ros et al. [12].

Se determinó el coeficiente de variación (CV), la intensidad de señal (IS) y la sensibilidad de los indicadores del estado hídrico. IS de $\Psi$ stem, MDS, Tc fue calculada como la relación entre los valores (V) de los tratamientos deficitarios (RD) y CTL (IS $=\mathrm{V}_{\mathrm{RD}} \cdot \mathrm{V}_{\mathrm{CTL}^{-1}}$ ) y para $\theta \mathrm{v}$ como IS $=\mathrm{V}_{\mathrm{CTL}} \cdot \mathrm{V}_{\mathrm{RD}}{ }^{-1}$. La sensibilidad se determinó mediante las expresiones:

Sensibilidad: $S=\frac{I S}{C V}$ propuesta por Goldhamer y Fereres [9].

Sensibilidad corregida: $S^{*}=\frac{\mathrm{IS}-1}{\mathrm{CV}}$ propuesta por de la Rosa et al. [13].

El análisis de los datos se realizó mediante ANOVA, utilizando el programa informático SPSS Statistics (SPSS Inc., 24.0 Statistical package; Chicago, IL, USA) y la prueba de rango múltiple de Duncan. Las regresiones lineales entre los indicadores se realizaron con Sigmaplot Plus v.12.5 (Systat Software, San Jose, CA, USA). 


\section{Resultados y discusión}

El régimen de riego influyó en el estado hídrico del suelo (Figuras 1b, 1b) y de la planta (Figura 1c, 1d). En el tratamiento CTL, el contenido volumétrico de agua del suelo medio a $25 \mathrm{~cm}$ de profundidad $(\theta \mathrm{v})$ fue de $37,1 \%$ durante ambos años de estudio. Del mismo modo, los árboles de CTL mostraron un

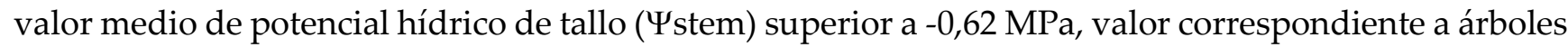
bajo condiciones no limitantes de agua en el suelo [14]. Los árboles de MS y SS presentaron valores de $\theta \mathrm{v}$ y $\Psi$ stem similares a los árboles del tratamiento CTL antes de que el riego fuera restringido. Cuando el riego fue suprimido, $\theta \mathrm{v}$ disminuyó progresivamente a medida que avanzaba el déficit, alcanzando valores mínimos, en el tratamiento MS, de 29,6 \% en 2018 y 29,0 \% en 2019. El tratamiento SS alcanzó un mayor déficit hídrico durante los periodos de supresión, logrando valores mínimos de $27,1 \%$ en 2018 y 26,0 \% en 2019. Los valores de $\Psi$ stem de ambos tratamientos deficitarios disminuyeron de forma gradual hasta alcanzar los umbrales establecidos en cada periodo de supresión del riego. De acuerdo con Blanco et al. [14] y Marsal et al. [15], valores de $\Psi$ stem inferiores a -1,5 MPa pueden repercutir negativamente a la producción y la calidad de la fruta [15].
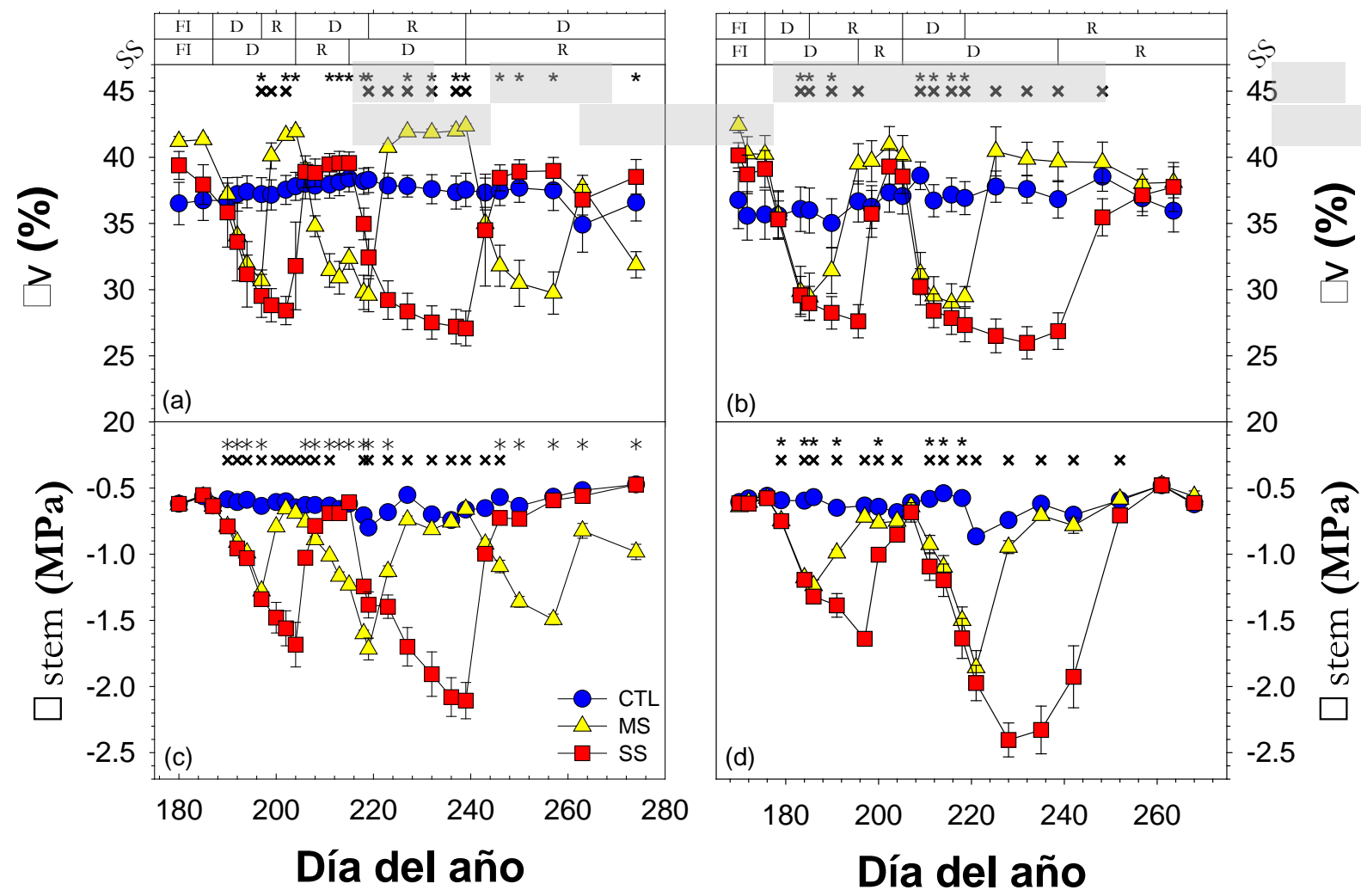

Figura 1. Evolución $(\mathrm{a}, \mathrm{b})$ del contenido volumétrico de agua del suelo a $25 \mathrm{~cm}$ de profundidad $(\theta \mathrm{v})$ y $(\mathrm{c}, \mathrm{d})$ del potencial hí-

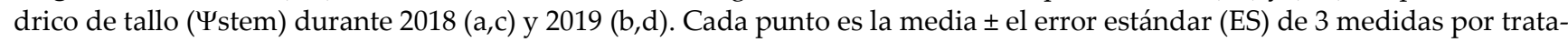
miento para $\theta \mathrm{v}$ y 6 medidas por tratamiento para $\Psi$ stem. Los asteriscos y las cruces indican diferencias significativas entre MS y CTL y entre SS y CTL según el test de Rango Múltiple de Duncan $(p<0,05)$. Las barras horizontales superiores indican los periodos de los ciclos supresión-recuperación del riego que definieron a los tratamientos MS y SS. 'FI' es el periodo previo al inicio de los ciclos de supresión-recuperación, en el que ambos tratamientos deficitarios fueron regados como CTL;

' $\mathrm{D}$ ', periodo de supresión de riego; ' $\mathrm{R}$ ', periodo de recuperación de los árboles. 


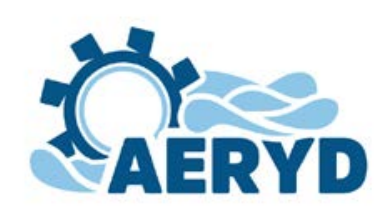
CARTAGENA 2021

Los parámetros derivados de las fluctuaciones del diámetro de tronco, la máxima contracción diaria del tronco (MDS) y la tasa de crecimiento diaria del tronco (TGR), mostraron una rápida respuesta al déficit hídrico (Figura 2). MDS y TGR se vieron fuertemente influenciados por el estrés hídrico. Los tratamientos deficitarios mostraron un aumento de los valores de MDS durante los ciclos de supresión. Por el contrario, los valores de TGR, obtenidos por los tratamientos deficitario, fueron significativamente inferiores a los árboles de CTL. SS alcanzó unos valores máximos de MDS de 235 y $255 \mu \mathrm{m}$ para el primer ciclo de supresión y 400 y $441 \mu$ m para el segundo ciclo de supresión durante 2018 y 2019, respectivamente. Los árboles del tratamiento CTL mostraron unos valores medios de MDS de $96 \mu \mathrm{m}$ en ambos años de experimentación. Los valores de TGR disminuyeron a medida que el ciclo avanzaba, pasando de $290 \mu \mathrm{m} \mathrm{día}^{-1}$, obtenidas a finales de junio, a las $90 \mu \mathrm{m}^{-1}$ obtenidas a finales del estudio, lo que podría indicar una disminución de la elasticidad del tronco [16]. Como se puede observar en la figura $2 a$ y $2 b$, hubo una gran influencia interanual en los valores de MDS, lo que podría ser atribuido al crecimiento del tronco.
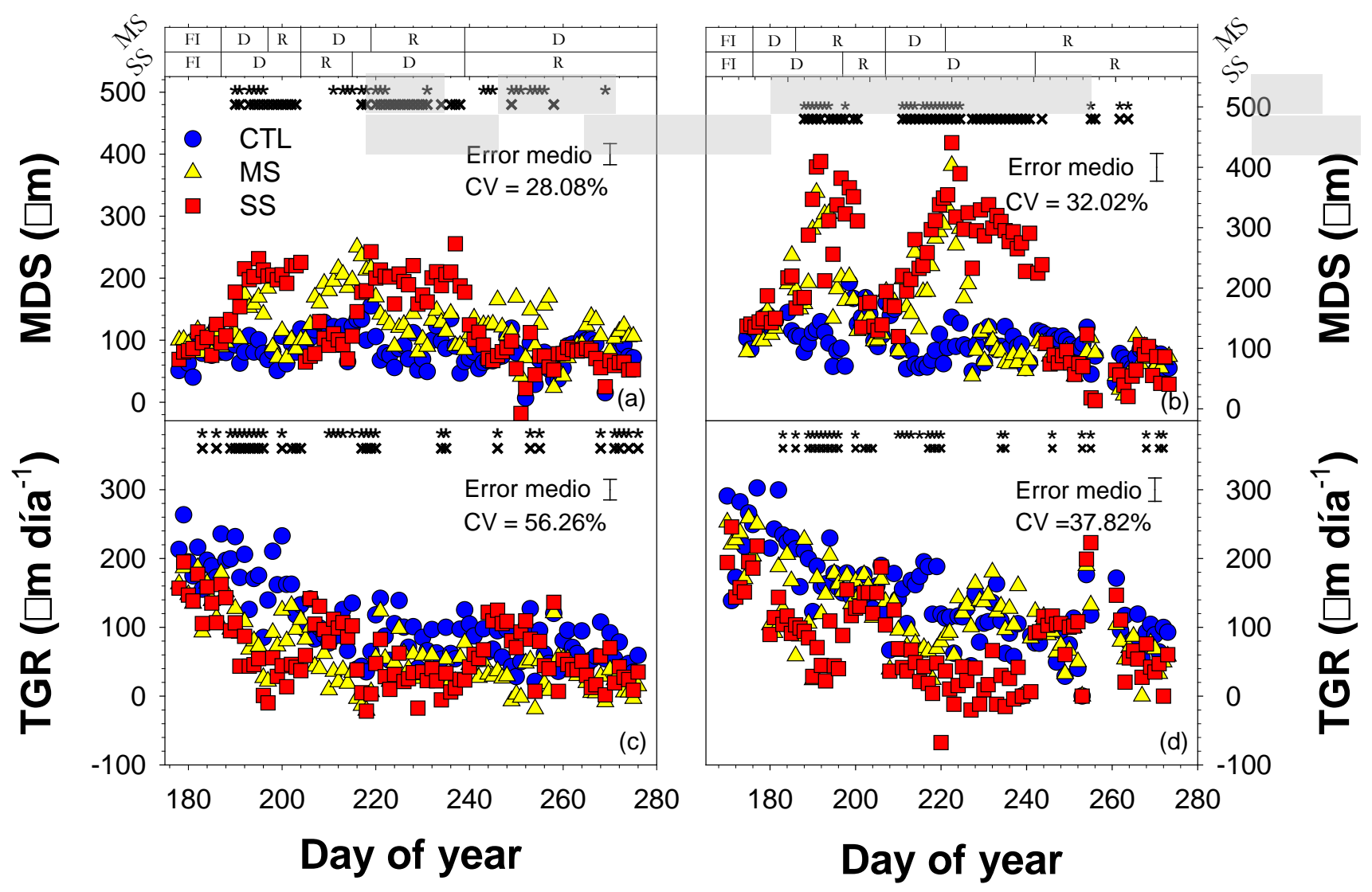

Figura 2. Evolución $(a, b)$ de la máxima contracción diaria del tronco (MDS) y (c,d) de la tasa de crecimiento diaria del tronco (TGR) durante $2018(\mathrm{a}, \mathrm{c})$ y 2019 (b,d). Cada punto es la media \pm ES de 6 medidas por tratamiento. Los asteriscos y las cruces indican diferencias significativas entre MS y CTL y entre SS y CTL según el test de Rango Múltiple de Duncan ( $p<0,05)$. Las barras horizontales superiores indican los periodos de los ciclos supresión-recuperación del riego que definieron a los tratamientos MS y SS. 'FI' es el periodo previo al inicio de los ciclos de supresión-recuperación, en el que ambos tratamientos deficitarios fueron regados como CTL; 'D', periodo de supresión de riego; ‘ $\mathrm{R}$ ', periodo de recuperación de los árboles. 
Una respuesta similar fue obtenida por Tc y los índices térmicos derivados, $\Delta \mathrm{T}$ y CWSI, al déficit hídrico en 2019 (Figure 3). Los árboles de CTL mostraron una alta tasa transpirativa durante ambos años de estudio, lo que dio lugar a que Tc fuera inferior a Ta $\left(\Delta \mathrm{T}\right.$ media $=-0,77^{\circ} \mathrm{C}$; Figura $\left.3 \mathrm{~b}\right)$. Aunque los árboles CTL mostraron una alta tasa de transpiración, ésta no fue capaz de mantener los valores de CWSI cercanos a 0, máxima apertura estomática. Esto podría indicar que, aunque el agua en el suelo no fue un factor limitante, la resistencia al flujo del agua aumentó [10]. Por el contrario, los tratamientos deficitarios experimentaron un incremento significativo de los valores de Tc (Figura 3a), motivado por una disminución de la disponibilidad hídrica del suelo (Figura 1a, 1b). Este aumento de temperatura posiblemente fue consecuencia de una menor disipación del calor a través de la evaporación del agua [17]. Del mismo modo, los índices térmicos, $\Delta \mathrm{T}$ y CWSI, presentaron valores significativamente superiores a los mostrados por los árboles de CTL (Figura 2c). Los valores de $\Delta \mathrm{T}$ alcanzados por los árboles de SS estuvieron cercanos al límite superior establecido por Blaya-Ros et al. [12], confirmando la intensa regulación estomática. El estrés hídrico también se vio reflejado en los valores de CWSI (Figura 2c), provocando un aumento de los valores de CWSI hasta alcanzar valores próximos a 0,5 y 0,9 durante el primer y el segundo periodo de sequía.
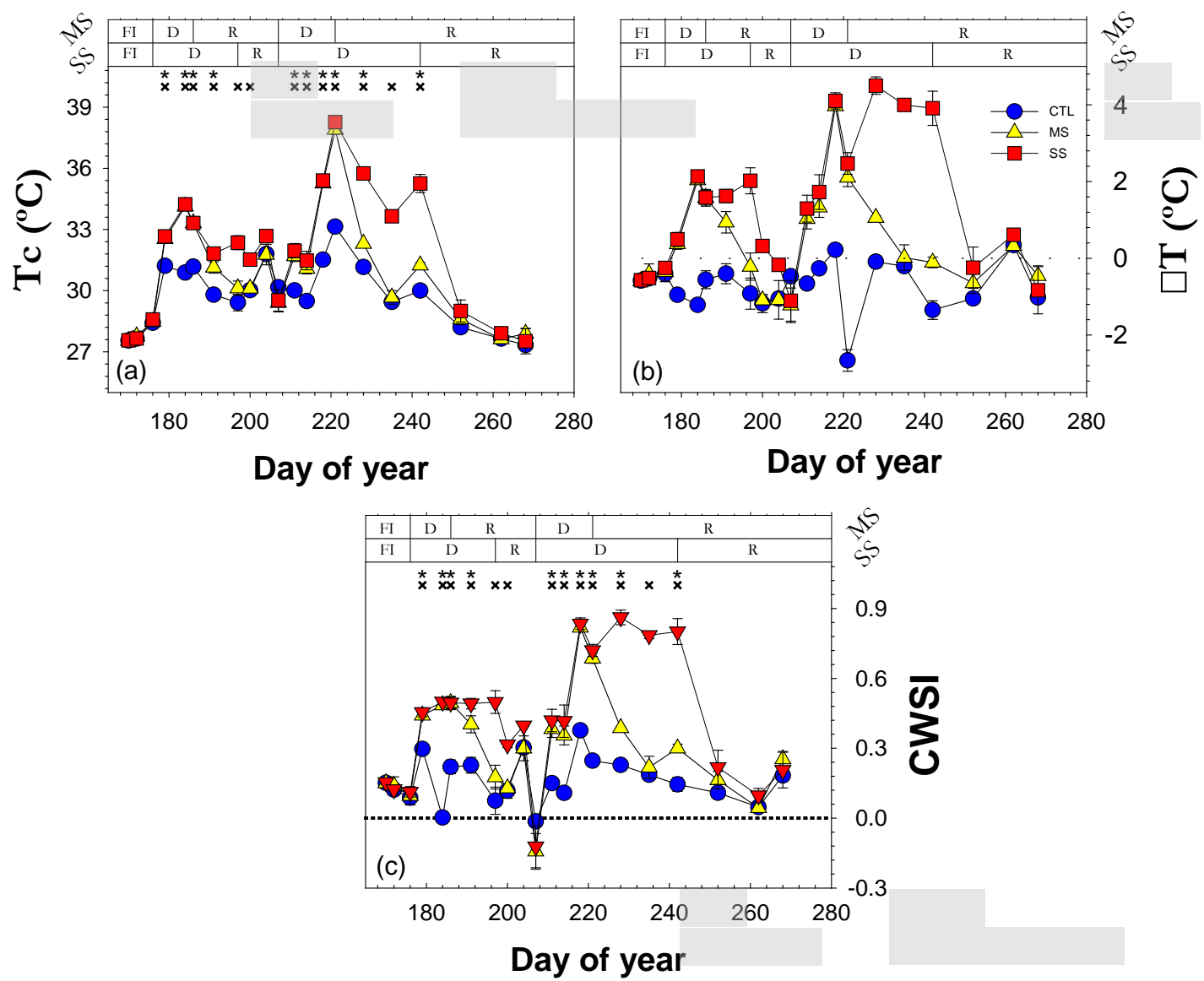

Figura 3. Evolución (a) de la temperatura de la copa (Tc), (b) de la diferencia de temperatura copa-aire (DT) y (c) del índice de estrés del cultivo (CWSI) durante 2019. Cada punto es la media \pm ES de 6 medidas por tratamiento. Los asteriscos y las cruces indican diferencias significativas entre MS y CTL y entre SS y CTL según el test de Rango Múltiple de Duncan (p< 0,05). Las barras horizontales superiores indican los periodos de los ciclos supresión-recuperación del riego que definieron a los tratamientos MS y SS. 'FI' es el periodo previo al inicio de los ciclos de supresión-recuperación, en el que ambos tratamientos deficitarios fueron regados como $C T L$; ' $D$ ', periodo de supresión de riego; ' $R$ ', periodo de recuperación de los árbo- 
La tabla 1 muestra una alta relación entre $\Psi$ stem y el estado hídrico del suelo, determinado por $\theta \mathrm{v}$, lo que indicaría que $\Psi$ stem se ve fuertemente influenciado por la reserva hídrica del suelo. Del mismo modo, Istem mostró una estrecha relación con MDS; sin embargo, esta relación tuvo dos partes claramente diferenciadas: i) una fase lineal para valores de $\Psi$ stem entre $-0,5 \mathrm{MPa}$ y $-1,3 \mathrm{MPa}$, en que una reducción en $\Psi$ stem implica un incremento de MDS; y ii) fase suavemente curvilínea para valores Istem inferiores a -1,3 MPa, donde se da una consolidación de los valores de MDS. En cerezo 'Prime Giant', Blanco et al. [14] observaron que en valores de $\Psi$ stem próximos a -1,3 MPa se producía un agotamiento importante de las reservas hídricas de la planta, y, por lo tanto, de su capacidad de contracción diaria. TGR fue el indicador que menor relación mostró con $\Psi$ stem, resultados similares a los obtenidos por Moriana et al. [18] en olivo, donde observaron que $\Psi$ stem obtenía una mayor relación con MDS que con TGR. Tc y los índices térmicos derivados, $\Delta \mathrm{T}$ y CWSI, obtuvieron un coeficiente de correlación de Pearson superior a 0,8 con $\Psi$ stem, lo que estaría en concordancia con los datos obtenidos en olivo por García-Tejero et al. [19].

Table 1. Coeficiente de correlación de Pearson para las relaciones lineales entre las distintas variables medidas durante el periodo experimental.

\begin{tabular}{l|ccccccc}
\hline & Istem & CWSI & $\Delta \mathbf{T}$ & Tc & MDS & TGR & $\theta \mathbf{v}$ \\
\hline CWSI & $-0,87$ & 1,00 & - & - & - & - & - \\
$\Delta \mathbf{T}$ & -0.88 & 0.85 & 1.00 & - & - & - & - \\
Tc & -0.81 & 0.85 & 0.71 & 1.00 & - & - & - \\
MDS & -0.78 & 0.81 & 0.73 & 0.72 & 1.00 & - & - \\
TGR & 0.56 & -0.46 & -0.51 & -0.47 & -0.40 & 1.00 & - \\
$\theta \mathbf{v}$ & 0.83 & -0.75 & -0.81 & -0.66 & -0.72 & 0.51 & 1.00 \\
\hline
\end{tabular}

El análisis de los distintos indicadores reveló que MDS y $\Psi$ stem tuvieron la mayor sensibilidad durante ambos años de estudio (Figure 4). Aunque MDS mostró unos valores ligeramente superiores a

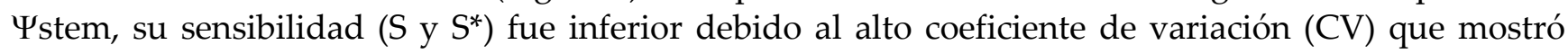
durante el experimento. Blanco et al. [14] observó una respuesta de MDS idéntica en cerezos adultos, donde MDS y $\Psi$ stem obtuvieron unos valores de IS similares; sin embargo, la sensibilidad de MDS fue inferior debido a la alta variación del indicador. Tc y $\theta \mathrm{v}$ mostraron una baja intensidad de señal ante el déficit hídrico, lo que dificultaría su uso para la elaboración de programas de riego utilizando IS. No obstante, ambos indicadores mostraron una alta sensibilidad (S) debido a que registraron un CV bajo, posiblemente debido al rango de medida de estos de ambos indicadores y la su variación dentro de este. Por el contrario, ambos indicadores, Tc y $\theta v$, mostraron una sensibilidad corregida ( $\left.S^{*}\right)$ [13] inferior a MDS y $\Psi$ stem. 

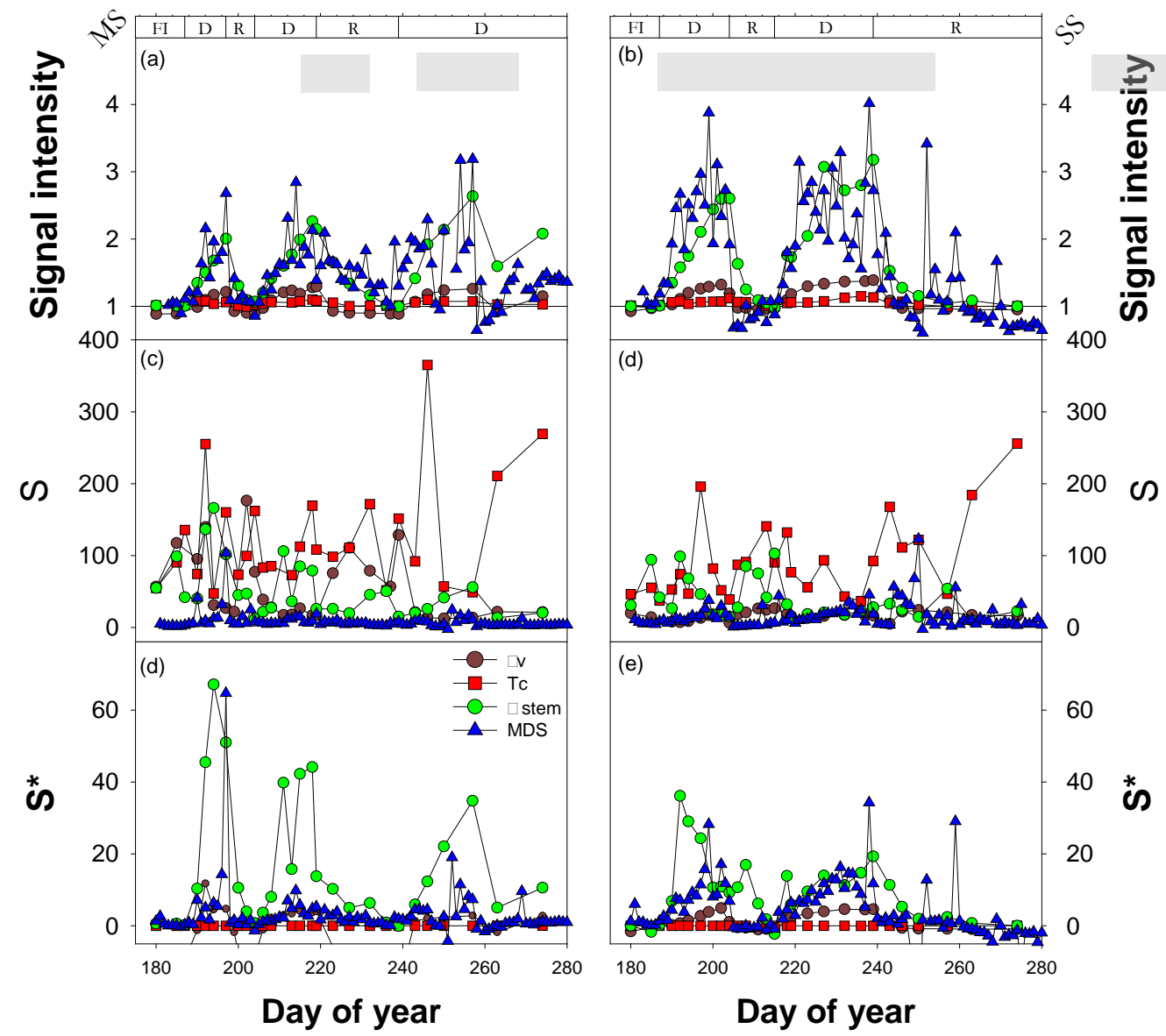

Figura 4. Evolución (a) de la intensidad de señal, (b) de la sensibilidad (S) y (c) de la sensibilidad corregida (S*) durante 2018. Las barras horizontales superiores indican los periodos de los ciclos supresión-recuperación del riego que definieron a los tratamientos MS y SS. 'FI' es el periodo previo al inicio de los ciclos de supresión-recuperación, en el que ambos tratamientos deficitarios fueron regados como CTL; ' $\mathrm{D}$ ', periodo de supresión de riego; ' $\mathrm{R}$ ', periodo de recuperación de los árboles.

\section{Conclusiones}

Los resultados expuestos evidencian que MDS y $\Psi$ stem consiguieron la mayor intensidad de señal durante ambos años de estudio. Sin embargo, la sensibilidad ( $S$ y $S^{*}$ ) de MDS se vio afectada por su alto $\mathrm{CV}$, por lo que haría falta disponer de un mayor número de sensores por parcela para aumentar la precisión de este indicador. La sensibilidad calculada a partir de las dos expresiones (S y $\left.S^{*} ;[9,13]\right)$ para $\theta \mathrm{v}$ y Tc fue contradictoria, obteniendo el método tradicional $(S)$ valores superiores a los registrados por el método corregido $\left(\mathrm{S}^{*}\right)$. Por lo cual, la expresión corregida $\left(\mathrm{S}^{*}\right)$ sería más adecuada para calcular la sensibilidad de los indicadores de estrés hídrico, dado que tiene en cuenta IS y CV.

Todos los indicadores e índices estudiados, a excepción de TGR, podrían usarse para estimar Istem con precisión y evaluar el nivel de estrés al que está sometido el cultivo. MDS podría utilizarse para elaborar programas de riego en niveles de estrés ligero-moderado, desaconsejando su uso en niveles de estrés moderados-severos ( $\Psi$ stem $<-1,3 \mathrm{MPa}$ ). $\Delta \mathrm{T}$ y CWSI mostraron una estrecha relación con Istem; sin embargo, no sería recomendado su uso para la confección de programas de riego mediante el método de la intensidad de señal. No obstante, podrían emplearse para estudiar y evaluar la respuesta de cerezos jóvenes al déficit hídrico y, por lo tanto, para supervisar programas de riego basados en niveles de estrés diferentes. 


\section{Referencias}

1. Jones, H. G. Monitoring plant and soil water status: established and novel methods revisited and their relevance to studies of drought tolerance. J. Exp. Bot. 2007, 58, 119-130.

2. Schackel, K. A.; Ahmadi, H.; Biasi, W.; Burchner, R.; Goldhamer, D. A.; Gurusinghe, S.; Hasey, J.; Kester, D.; Krueger, B.; Lampinen, B.; et al. Plant water status as an index for irrigation need in deciduous fruit trees. Hort Technol. 1996, 7, $23-29$.

3. Puerto, P.; Domingo, R.; Torres, R.; Pérez-Pastor, A.; García-Riquelme, M. Remote management of deficit irrigation in almond trees based on maximum daily trunk shrinkage. Water relations and yield. Agric. Water Manag. 2013, 126, 33-45.

4. Ortuño, M. F.; Conejero, W.; Moreno, F.; Moriana, A.; Intrigliolo, D. S.; Biel, C.; Mellisho, C. D.; Pérez-Pastor, A.; Domingo, R.; Ruiz-Sánchez, M. C.; et al. Could trunk diameter sensors be used in woody crops for irrigation scheduling? A review of current knowledge and future perspectives. Agric. Water Manag. 2010, 97, 1-11.

5. García-Tejero, I. F.; Gutiérrez-Gordillo, S.; Ortega-Arévalo, C.; Iglesias-Contreras, M.; Moreno, J. M.; Souza-Ferreira, L.; Durán-Zuazo, V. H. Thermal imaging to monitor the crop-water status in almonds by using the non-water stress baselines. Sci. Hortic. 2018, 238, 91-97.

6. Allen, R.G.; Pereira, L.S.; Raes, D.; Smith, M. FAO Irrigation and drainage paper In Crop. Evapotranspiration-Guidelines for Computing Crop. Water Requirements; Food and Agriculture Organization: Rome, Italy, 1998.

7. Marsal, J. FAO irrigation and drainage paper In Crop. Yield Response Water. Sweet Cherry; Food and Agriculture Organization: Rome, Italy, 2012; pp. 449-457

8. Fereres, E.; Pruitt, W.O.; Beutel, J.A.; Henderson, D.W.; Holzapfel, E.; Schulbach, H.; Uriu, K. Evapotranspiration and drip irrigation scheduling. In Drip Irrigation Management; Leaflet 21259; Division of Agricultural Sciences, University of California: Los Angeles, CA, USA, 1981; pp. 8-13.

9. Goldhamer, D. A.; Fereres, E. Irrigation scheduling protocols using continuously recorded trunk diameter measurements. Irrig. Sci. 2001, 20, 115-125.

10. Jackson, R. D.; Kustas, W. P.; Choudhury, B. J. A reexamination of the crop water stress index. Irrig. Sci. 1988, 9, $309-317$.

11. Jackson, R.D.; Idso, S.J.; Reginato, R.J.; Pinter, P.J. Canopy temperature as a crop water stress indicator. Water Resour. Res. 1981, 17, 1133-1138.

12. Blaya-Ros, P. J.; Blanco, V.; Domingo, R.; Soto-Valles, F.; Torres-Sánchez, R. Feasibility of low-cost thermal imaging for monitoring water stress in young and mature sweet cherry trees. Appl. Sci. 2020, 10.

13. de la Rosa, J. M.; Conesa, M. R.; Domingo, R.; Pérez-Pastor, A. A new approach to ascertain the sensitivity to water stress of different plant water indicators in extra-early nectarine trees. Sci. Hortic. 2014, 169, 147-153.

14. Blanco, V.; Domingo, R.; Pérez-Pastor, A.; Blaya-Ros, P. J.; Torres-Sánchez, R. Soil and plant water indicators for deficit irrigation management of field-grown sweet cherry trees. Agric. Water Manag. 2018, 208, 83-94.

15. Marsal, J.; Lopez, G.; del Campo, J.; Mata, M.; Arbones, A.; Girona, J. Postharvest regulated deficit irrigation in 'Summit' sweet cherry: fruit yield and quality in the following season. Irrig. Sci. 2010, 28, 181-189.

16. Conesa, M. R.; Torres, R.; Domingo, R.; Navarro, H.; Soto, F.; Pérez-Pastor, A. Maximum daily trunk shrinkage and stem water potential reference equations for irrigation scheduling in table grapes. Agric. Water Manag. 2016, 172, 51-61.

17. Jones, H. G. Use of infrared thermometry for estimation of stomatal conductance as a possible aid to irrigation scheduling. Agric. For. Meteorol. 1999, 95, 139-149.

18. Moriana, A.; Girón, I. F.; Martín-Palomo, M. J.; Conejero, W.; Ortuño, M. F.; Torrecillas, A.; Moreno, F. New approach for olive trees irrigation scheduling using trunk diameter sensors. Agric. Water Manag. 2010, 97, 1822-1828.

19. García-Tejero, I. F.; Hernández, A.; Padilla-Díaz, C. M.; Diaz-Espejo, A.; Fernández, J. E. Assessing plant water status in a hedgerow olive orchard from thermography at plant level. Agric. Water Manag. 2017, 188, 50-60. 


\title{
XXXVIII Congreso Nacional de Riegos CARTAGENA 2021
}

\section{Evaluación de la programación del riego de parcelas de cítricos}

\section{mediante predicciones meteorológicas}

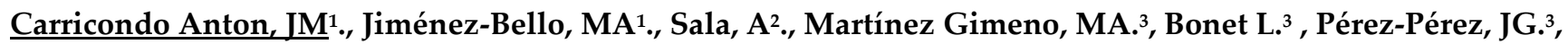 \\ Intrigliolo D.S. ${ }^{4}$
}

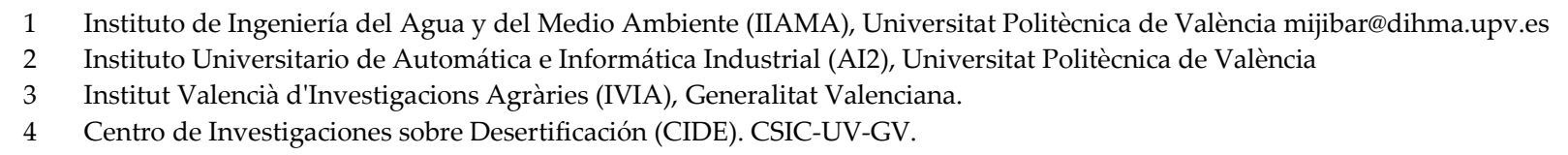

Resumen: Para realizar una programación del riego más ajustada a la demanda hídrica, se puede estimar la evapotranspiración potencial (ETo), tal como describe el método FAO 56, con anterioridad al riego mediante predicciones meteorológicas (PM). En este trabajo se han utilizado PM del Global Forecast System (GFS) y Météo-France. Del Sistema de Información Agroclimática para el Regadío (SIAR) se ha obtenido los datos meteorológicos de la zona de estudio. El objetivo ha sido conocer si el uso de distintas PM mejora la programación del riego que se realiza de manera habitual, además de determinar la mejor ventana temporal (VT) para realizar la programación de riego. El caso de estudio corresponde a 307 ha de cítricos de una Comunidad de Regantes en Picassent (Valencia). Se propone un modelo basado en la simulación de estimación de la ETo mediante PM y se compara frente a los riegos realizado por los agricultores de la zona de estudio. Para reducir la incertidumbre entre la PM y las mediciones realizadas en estaciones meteorológicas se ha aplicado el Filtro de Kalman (FK) a cada variable de la PM. Para estimar la humedad del suelo se ha utilizado un modelo hidrológico simplificado teniendo en cuenta la evapotranspiración del cultivo, el riego, la precipitación efectiva y el drenaje. Los errores relativos en la estimación de la ETo se han obtenido para 2 periodos temporales, el primero desde el 1 de abril hasta el 30 de septiembre y el segundo durante todo el año 2019. Como ejemplo, el sistema que menores errores presenta es GFSк (con FK), reduciendo los errores respecto de la ETo calculada mediante mediciones en estaciones meteorológicas del 9.9\% al 6.3\% para 1 y 7 días respectivamente. El error medio semanal de la ETo mediante datos históricos para la misma época fue del $18.8 \%$. Al aplicar el modelo hidrológico simplificado para calcular la humedad del suelo, esta se mantuvo por encima de un valor umbral de no estrés del cultivo para todos los escenarios. El volumen de agua drenado anualmente aumenta al reducir el número de días predichos para todos los escenarios, esto es debido a que al reducir la VT aumenta el volumen regado manteniendo una humedad del suelo próxima a la humedad objetivo. La programación del riego sobre la base de las PM se ha comparado con una llevada a cabo de forma empírica por agricultores de la zona obteniéndose un drenaje de $468.6 \mathrm{~mm}$ año-1 frente a las PM de GFSк a 7 días de VT que presenta $55.9 \mathrm{~mm}^{-1} \mathrm{ano}^{-1}$ para un suelo franco arenoso arcilloso. La VT de programación que evita una mayor pérdida por percolación profunda para un terreno franco arcillo arenoso es la de 7 días para la PM de GFSк. No obstante, en próximos estudios, se analizará la integral de estrés para determinar si las distintas programaciones de riego afectan al rendimiento del cultivo. Palabras clave: Evapotranspiración de referencia; Programación riego; Prediccion necesidades riego. 


\title{
XXXVIII Congreso Nacional de Riegos
} CARTAGENA 2021

\section{Evaluation of the irrigation scheduling of citrus plots by means of}

\section{meteorological predictions}

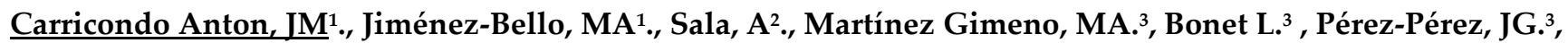 \\ Intrigliolo D. ${ }^{4}$ \\ 1 Instituto de Ingeniería del Agua y del Medio Ambiente (IIAMA), Universitat Politècnica de València mijibar@dihma.upv.es \\ 2 Instituto Universitario de Automática e Informática Industrial (AI2), Universitat Politècnica de València \\ 3 Institut Valencià d'Investigacions Agràries (IVIA), Generalitat Valenciana. \\ 4 Centro de Investigaciones sobre Desertificación (CIDE). CSIC-UV-GV.
}

To perform an irrigation scheduling more adjusted to water demand, the reference evapotranspiration (ETo) can be estimated, as described in the FAO 56 method, prior to irrigation using meteorological predictions (PM). In this work, the PMs of the Global Forecast System (GFS) and Météo-France have been used. From the Agroclimatic Information System for Irrigation (SIAR) the meteorological data of the study area has been obtained. The objective was to know if the use of different PM improves the irrigation scheduling that is carried out on a regular basis, in addition to determining the best time window (VT) to carry out the irrigation scheduling. The case study corresponds to 307 ha of citrus trees in a Water User Associaion in Picassent (Valencia). A model is proposed based on the simulation of estimation of ETo by PM and this is compared to the management carried out by farmers in the sutdy area. To reduce the uncertainty between PM and measurements made in meteorological stations, the Kalman Filter (FK) has been applied to each PM variable. To calculate soil moisture, a simplified hydrological model has been used where the crop evapotranspiration, effective precipitation and drainage have been taken into account. The relative errors in the estimation of ETo have been obtained for 2 time periods, the first being from April 1 to September 30 and the second throughout the year 2019. As an example, the system that presents the least errors is GFSK (with FK), reducing errors with respect to the ETo calculated through measurements in meteorological stations, when the ETo is estimated weekly with accumulated days for the time of maximum needs from $9.9 \%$ to $6.3 \%$. \% for 1 and 7 days respectively. The weekly mean error of the ETo using historical data for the same period was $18.8 \%$. When applying the simplified hydrological model to calculate soil moisture, it has been kept above a threshold value of no crop stress for all scenarios. The volume of water drained annually increases by reducing the number of days predicted for all scenarios, this is due to the fact that reducing the VT increases the volume irrigated while maintaining soil moisture close to the target humidity. Irrigation programming based on PM has been compared with one carried out empirically by farmers in the area, obtaining a drainage of $468.6 \mathrm{~mm}_{\text {year }}{ }^{-1}$ compared to PM of GFSK at 7 days of VT that presents 55.9 mm year${ }^{1}$ for a sandy clay loam soil. The programming VT that avoids a greater loss by deep percolation for a sandy clay loam soil is the 7 days for the PM of GFSK. However, for future studies, the stress integral will be analyzed to determine if the different irrigation schedules affect the water status of the crop.

Keywords: Reference evapotranspiration; Irrigation programming; Prediction of irrigation needs. 


\section{Congreso Nacional de Riegos CARTAGENA 2021}

\section{Introducción}

Para aumentar la eficiencia de riego, es esencial conocer las necesidades del cultivo que hasta ahora se calculan de manera usual por la metodología descrita por Penman-Monteith [1]. Para poder determinar correctamente las necesidades de cada cultivo sería de gran utilidad conocer la ETo con anterioridad al riego para poder realizar una programación que suministre el agua necesaria a cada planta. El método de Penman-Monteith ha sido empleado utilizando predicciones de riego [2,3], aunque en estos trabajos no se ha combinado con un modelo agrohidrológico.

Existen diferentes servicios de predicciones meteorológicas, cada uno con sus características particulares. Para poder determinar cuáles son las que tienen menos incertidumbre para la zona de estudio, en este trabajo se han utilizado las previsiones meteorológicas del Global Forecast System (GFS) (www.nco.ncep.noaa.gov) del National Centers for Environmental Prediction del gobierno de US, y el servicio meteorológico francés Météo-France (MF) (www.meteofrance.com). Cabe destacar que cada sistema de datos meteorológicos posee un grid y unos datos libres con diferentes ventanas temporales (VT) siendo de $0.25^{\circ}$ y hasta 16 días de previsión para GFS, $0.1^{\circ}$ y hasta 4.75 días para MF. Para mejorar la calidad de los datos en diferentes trabajos se han utilizados técnicas estadísticas, como es el Filtro de Kalman [4], consiguiendo reducir la incertidumbre de las predicciones meteorológicas. Del Sistema de Información Agroclimática para el Regadío (SIAR) se ha obtenido los datos meteorológicos de la zona de estudio.

El objetivo de este trabajo es conocer si el uso de diferentes servicios meteorológicos, con y sin aplicar sistemas estadísticos para reducir la incertidumbre entre las medidas reales y las predicciones mejoran la programación del riego, además de determinar la mejor VT para realizar esta. Se ha particularizado en el caso de los cítricos. Para ello se compararán dos tipos de programación del riego, siendo el primero la utilización de las ETo calculadas con datos de predicciones meteorológicas. El segundo es el más empleado habitualmente con una ventana semanal, basado en qué se aporta la dosis

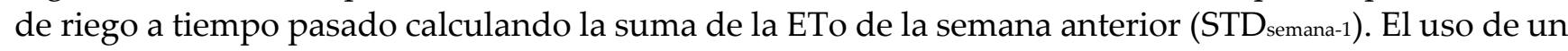
modelo agrohidrológico permite cuantificar el contenido de agua del suelo dependiendo del tipo de este.

\section{Materiales y métodos}

El caso de estudio es la comunidad de regantes de Sector XI del canal Júcar-Turia (39'22'38,39' N y $0{ }^{\circ} 28^{\prime} 22,51^{\prime \prime} \mathrm{O}$ ), próxima al municipio de Picassent (Valencia). Esta comunidad de regantes cuenta con una red de riego presurizada que funciona mediante peticiones de los agricultores, el cultivo principal son cítricos adultos y la técnica de riego empleada es el riego localizado. De todas las parcelas se han seleccionado tres parcelas representativas del caso de estudio (P1, P2 y P3), las cuales han sido monitorizadas.

\subsection{Descripción del modelo}

Esta metodología pretende reducir el error entre las necesidades de riego del cultivo y la dosis que se aportan mediante la mejora de la programación del riego. Se propone un modelo donde el cálculo de la evapotranspiración de referencia (ETo) se realiza mediante predicciones meteorológicas. Las necesidades de riego se calcularán mediante datos procedentes de 2 servicios climáticos, siendo el primero el Global Forecast System (GFS) y el segundo e Météo-France (MF). Se realizan predicciones meteorológicas con una VT de 1, 4 y 7 días para GFS y de 1 y 4 días para MF para todo el año 2019. Se asume que se realizan riegos todos los días la media de la ventana calculada. Las PM pueden ser usadas directamente para el cálculo de las necesidades de los cultivos, pero para reducir la incertidumbre entre 


\section{Congreso Nacional de Riegos CARTAGENA 2021}

la predicción meteorológica y las mediciones realizadas se puede aplicar el Filtro de Kalman a cada variable de la predicción meteorológica.

Las predicciones de NR mediante predicciones meteorológicas se estudian frente a las predicciones de las NR calculadas mediante el procedimiento tradicional basado en restablecer las necesidades de

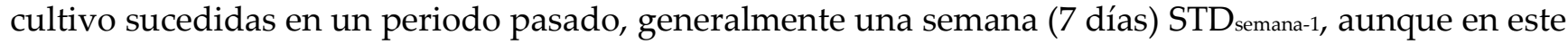
estudio se estudiara también para 1 y 4 días STD dia-1 y STD dia-4 respectivamente.

Una vez obtenidas las necesidades de riego para cada escenario se calcula el balance hídrico que depende de las texturas de suelo

\subsection{Cálculo de Necesidades de Riego (NR).}

Las NR se han calculado utilizando la metodología de Penman Monteith para el cálculo de la ETo. Una vez calculada la ETo se determina las necesidades de evapotranspiración del cultivo (ETc), para cítricos con porcentajes de cubierta vegetal mayores al 70\% [5] y a la ETc se le resta la precipitación efectiva.

$$
\begin{aligned}
& E T c=E T o \cdot K c \cdot f c_{m e s} \\
& N R=E T c-P_{e}
\end{aligned}
$$

Donde ETo es la evapotranspiración de referencia, Kc es el coeficiente de cultivo, fcmes es el factor de corrección mensual para cítricos, ETc es la evapotranspiración del cultivo (cítricos) y Pe es la precipitación efectiva.

La ETo se calcula mediante dos métodos: a) por predicción, mediante las PM de la Temperatura media $\left({ }^{\circ} \mathrm{C}\right)$, humedad relativa $(\%)$, velocidad del viento a 2 metros de altura $\left(\mathrm{ms}^{-1}\right)$ y la radiación solar observada de onda corta descendente $\left(\mathrm{Wm}^{-2}\right)$; (b) en el segundo método o método estándar, se determina las NR para la próxima semana utilizando la ETo de la semana anterior, empleando los datos meteorológicos de la estación agroclimática más próxima a la zona de estudio.

\subsubsection{Determinación de parámetros climáticos predichos para el cálculo de las NR mediante el FK.}

El problema de las predicciones es que tienen una incertidumbre o error generado en el propio modelo de estimación de esas predicciones. Para reducir la incertidumbre entre el modelo predictivo y la medida realizada en estaciones meteorológicas se ha empleado un Filtro de Kalman. Las ecuaciones de dicho filtro tienen dos etapas [6]. Cuando se dispone de una medida se ejecuta el paso "corrector" dado por:

$$
\begin{gathered}
K_{k}=P_{k}^{-} H_{k}{ }^{T}\left(H_{k} P_{k}^{-} H_{k}{ }^{T}+R\right)^{-1} \\
\hat{x}_{k}=\hat{x}_{k}^{-}+K_{k}\left(z_{k}-H_{k} \hat{x}_{k}^{-}\right) \\
P_{k}=\left(I-K_{t} H_{k}\right) P_{k}^{-}
\end{gathered}
$$

Donde $P_{k}^{-}$es la matriz de varianza del estado o el error de estimación, $H_{-} k$ es la matriz de medición, $K \_k$ es la ganancia de Kalman, $z \_k$ es la observación real en el instante $\mathrm{k}, x$ es el estado inicial estimado y $R$ es la matriz de varianza del ruido de medición.

Una vez se obtiene el vector corregido para las mediciones de los datos y del modelo pasado, se determina la predicción futura ajustando el modelo de los siguientes días, mediante las ecuaciones de simulación [6] lo que se suele denominar etapa de "predictor" en la literatura:

$$
\begin{gathered}
\hat{x}_{k}^{-}=A \hat{x}_{k-1} \\
P_{k}^{-}=A P_{k-1} A^{T}+Q
\end{gathered}
$$




\section{Congreso Nacional de Riegos CARTAGENA 2021}

Donde $P_{k}^{-}$es la matriz de varianza del estado o el error de estimación, $\hat{x}_{k-1}$ es el estado estimado en la iteración anterior. Si se deseara simular a varios pasos en el futuro sin observaciones intermedias, se supone en el predictor (3) $P_{k}=P_{k}^{-}$y sin ejecutar las ecuaciones del corrector (2).

Alimentando a cuatro filtros de Kalman, se obtienen (recursivamente) los cuatro parámetros de la corrección para cada una de las variables de temperatura, humedad, viento a $2 \mathrm{~m}$ y radiación solar de onda corta. Mediante los 4 parámetros se calcula la ETo mediante la metodología de Penman Monteith. Una vez determinadas las NR para los escenarios con GFS (GFS std (sin aplicar FK), GFSk (aplicando FK)) para las VT de 1, 4 y 7 días, y para los escenarios con MF (MF std, (sin aplicar FK), MFK (aplicando FK)) para las VT de 1 y 4 días se calculan estos escenarios compensando los errores entre las mediciones y las predicciones del periodo predicho anterior. Obteniendo escenarios con errores compensados (-C) con GFS (GFS-C std y GFS-CK) para 1, 4 y 7 días, y los escenarios con MF (MF-Cstd y MF-CK) para 1 y 4 días. Con ello las NR para los escenarios GFS std, GFSk, $\mathrm{MF}_{\text {std, }} \mathrm{MF}_{\mathrm{K}}$ para las VT de 1, 4 y 7 días se calculan

$$
\begin{aligned}
& \mathrm{GFS}_{V T}=\mathrm{GFS}_{V T}-P_{e_{V T}} \\
& \mathrm{MF}_{V T}=\mathrm{MF}_{\mathrm{VT}}-P_{e_{V T}}
\end{aligned}
$$

y de los escenarios GFS-C std, $_{\text {GFS-C }}$, MF-C std $_{\text {y }}$ MF-C $C_{\kappa}$ para las VT 1, 4 y 7 días se calculan

$$
\begin{aligned}
& \mathrm{GFS}-\mathrm{C}_{V T}=\mathrm{GFS}_{V T}-P_{e_{V T}}-\left(G F S_{V T}-E T c_{M_{V T}}\right) \\
& \mathrm{MF}-\mathrm{C}_{V T}=\mathrm{MF}_{V T}-P_{e_{V T}}-\left(M F_{V T}-E T c_{M_{V T}}\right)
\end{aligned}
$$

Donde Pevt es la precipitación efectiva de la VT anterior, ETcmvt es la ETc calculada mediante mediciones de parámetros meteorológicos de la VT anterior.

Se utilizan las siguientes condiciones:

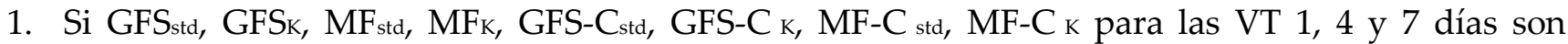
inferiores a $0 \mathrm{~mm}$, no se producirá riego durante el periodo de la siguiente predicción.

2. Si la humedad del suelo $\left(\mathrm{W}_{\mathrm{t}}\right)$ más las NR (GFS std, GFS $, \mathrm{MF}_{\text {std, }} \mathrm{MF}_{\mathrm{K}}, \mathrm{GFS}-\mathrm{C}_{\text {std }}, \mathrm{GFS}-\mathrm{C}_{\mathrm{K}}, \mathrm{MF}-\mathrm{C}_{\text {std, }}$ MF$\mathrm{C}_{\mathrm{K})}$ para las VT 1, 4 y 7 días es mayor a la Capacidad de Campo (CC), no se producirá riego durante el periodo de la siguiente predicción.

\subsubsection{Determinación de las NR mediante sistema estándar.}

Los NR estándar (STD semana+1, $_{\text {, }}$ TD $_{\text {dia }+4 \text { y }}$ STD $_{\text {dia }+1}$ ) se determinan tradicionalmente asumiendo la ETo de la semana pasada ( $\mathrm{Li}$ et al., 2018), aunque en este estudio además se ha realizado con VT de 1 y 4 días. Del mismo modo que en el caso anterior, se ha compensado el error la ETo del periodo anterior

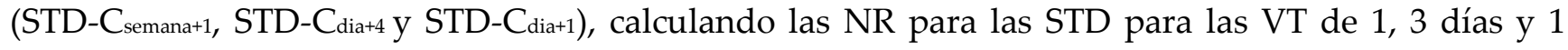
semana mediante las siguientes ecuaciones:

$$
\begin{aligned}
& \mathrm{STD}_{\mathrm{VT}}=\mathrm{STD}_{\mathrm{VT}}-P_{\left.e_{\mathrm{VT}}\right)} \\
& \mathrm{STD}-\mathrm{C}_{\mathrm{VT}}=\mathrm{STD}_{\mathrm{VT}}-P_{e_{V T}}-\left(\mathrm{STD}_{\mathrm{VT}}-E T c_{M_{V T}}\right)
\end{aligned}
$$

Se utilizan las siguientes condiciones:

1. Si STD o STD-C para las VT 1, 4 y 7 días son inferior a $0 \mathrm{~mm}$, no se producirá riego durante el siguiente periodo de riego.

2. Si la humedad del suelo $\left(\mathrm{W}_{\mathrm{t}}\right)$ más STD o STD-C para las VT 1, 4 y 7 días es mayor a la CC, no se producirá riego durante el periodo siguiente. 


\section{Congreso Nacional de Riegos CARTAGENA 2021}

\subsection{Humedad en el suelo}

El seguimiento de la humedad del suelo determinará una perspectiva de la eficiencia del uso del agua cuantificando la perdida de agua por drenaje e intentando mantenerla humedad mínima en el suelo para que las plantas no sufran estrés. La determinación de humedad del suelo $\left(\mathrm{W}_{\mathrm{t}}\right)$ se establece, mediante la ecuación:

$$
W_{t}=W_{\text {dia }(-1)}-E T c_{M}+I+P_{e}-D P
$$

Donde $W_{\text {dia(-1) }}$ es la humedad del suelo del día anterior $(\mathrm{mm})$,ETcm es la ETc calculada mediante mediciones en estaciones meteorológicas $(\mathrm{mm})$, I es el riego $(\mathrm{mm})$, Pe es la precipitación $(\mathrm{mm})$ y DP es el drenaje en profundidad $(\mathrm{mm})$. En este modelo se ha simplificado no teniendo en cuenta la escorrentía superficial ni la capilaridad al tratarse de un riego localizado.

La textura de suelo de las tres parcelas es franco arcilloso arenoso (FAA). Para comprobar cómo afecta la textura a los tipos de programación, se estudiarán dos texturas adicionales donde se pueden desarrollar el cultivo de los cítricos, una más arcillosa (Arcillo limoso (AL)) y otra más arenosa (Franco arenoso (FA). El cálculo de DP se realiza cuando la humedad al suelo está entre Saturación (SAT) y CC teniendo en cuenta las texturas y Conductividades hidráulicas (Ksat). Los suelos se describen en la Tabla 1.

$$
D D=0.0866 \cdot K^{2} a t^{0.35} \cdot(S A T-F C)
$$

Para el estudio de la humedad del suelo en los diferentes escenarios se estudia con la textura del suelo de las parcelas del caso de estudio (FAA) y las texturas FA y AL. La profundidad del sistema radicular es de $50 \mathrm{~cm}$. Los parámetros de las texturas (SAT, FC, Punto de marchitamiento (PM) y Ksat) se establecen según [7].

Tabla 1. Datos de suelos usados.

\begin{tabular}{|l|c|c|c|c|}
\cline { 2 - 5 } \multicolumn{1}{c|}{} & SAT vol$(\%)$ & CC vol(\%) & PM vol(\%) & Ksat (mm/day) \\
\hline Franco arenoso & 41 & 22 & 10 & 1200 \\
\hline Franco arcilloso arenoso & 47 & 32 & 20 & 225 \\
\hline Arcillo limoso & 54 & 50 & 32 & 100 \\
\hline
\end{tabular}

\section{Resultados y discusión}

\subsection{Errores de ETo por días de predicción}

Los errores en la estimación de la ETo para las distintos métodos y ventanas temporales comparada con la ETo registrada en la estación meteorológica, se han obtenido para 2 periodos de tiempo, siendo el primero desde el 1 de abril hasta el 30 de septiembre y el segundo durante todo el año 2019. Los errores descienden al aumentar el número de días de predicción de ETo, ya que los errores se compensan de un día para otro. Los errores relativos para MF descienden cuando se estima la ETo de 1 y 4 días acumulados para la época de máximas necesidades del $10.12 \%$ al $6.5 \%$ para $\mathrm{MF}_{\mathrm{k}}$ y del $16.44 \%$ al $12.96 \%$ para $\mathrm{MF}_{\text {std. }}$ Sin embargo, cabe reseñar que los errores relativos para GFS, $\mathrm{GFS}_{\text {std }}$ descienden cuando se estima la ETo de 1 y 5 días acumulados para la época de máximas necesidades del $9.88 \%$ al 5.6\% para GFS y del $11.69 \%$ al $6.85 \%$ para el GFS std, ya que los datos de GFS son horarios las primeras $120 \mathrm{~h}$. El sexto y séptimo día de predicción GFS abastece de datos cada 3 horas, siendo esta reducción de datos la causante del aumento del error relativo medio semanal para la época de máximas necesidades en predicciones a 7 días los errores del 6.31\% para GFS $\mathrm{k}$ del $7.62 \%$ para el GFS std. La determinación del 


\section{Congreso Nacional de Riegos CARTAGENA 2021}

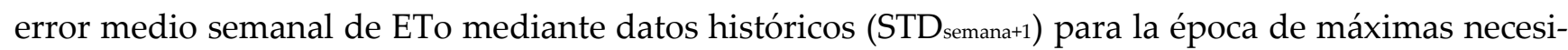
dades no presenta una disminución al acumular días siendo el error relativo medio semanal un 18.8\% mientras que para todo el año 2019 el error medio semanal asciende a $25.6 \%$. En la figura 1 se pueden observar los errores para el año 2019.

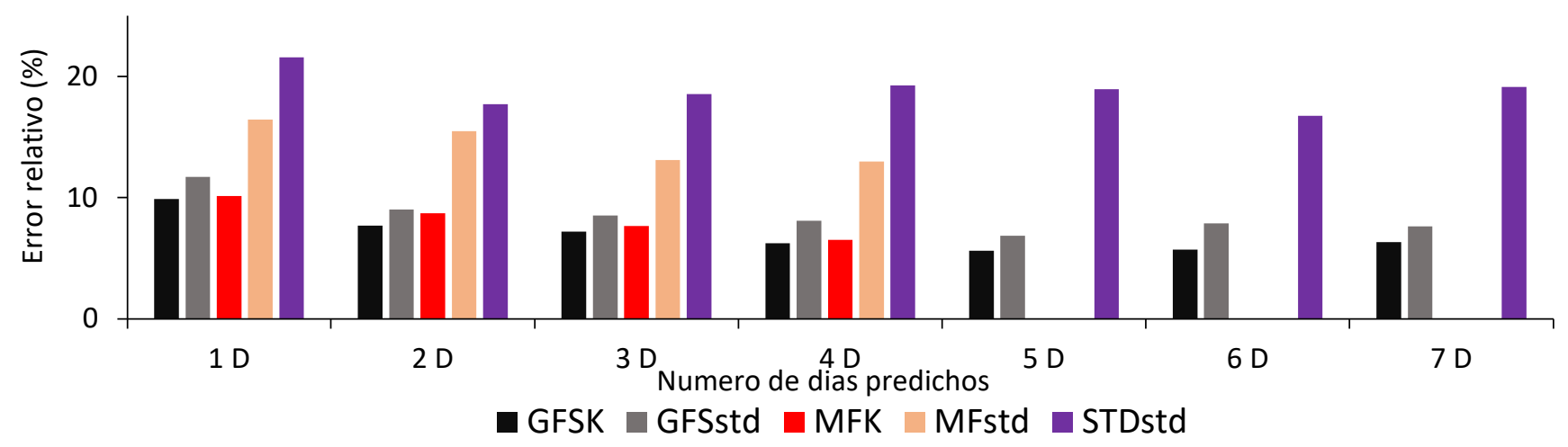

Figura 1. Errores de ETo para el periodo de maximas necesidades según si la programación se hace entre 1 a 7 días para GFSk, GFSstd, STD y de 1 a 4 días para MFstd y MFk (\%).

Al confrontar las ETc medidas frente a las ETc predichas o estimadas se obtienen los siguientes $\mathrm{R}^{2}$ para cada escenario para las VT de 1, 4 y 7 días (ver Tabla 2).

Tabla 2. $\mathrm{R}^{2}$ de ETo predichas y estimada con datos historicos frente a ETo medida para las VT de 1,4 y 7 dias.

\begin{tabular}{|c|c|c|c|c|c|c|c|c|c|c|c|c|c|}
\hline & 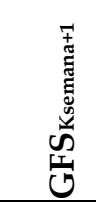 & 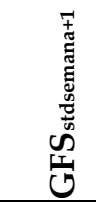 & 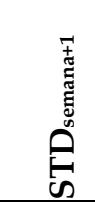 & 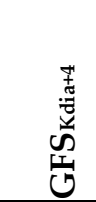 & 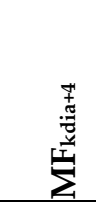 & 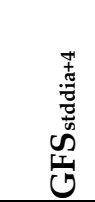 & 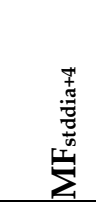 & 苞 & 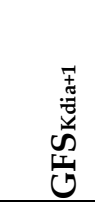 & 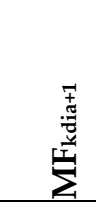 & 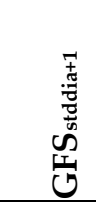 & 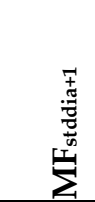 & 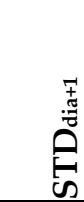 \\
\hline $\mathrm{R}^{2}$ & 0,85 & 0,82 & 0,57 & 0,90 & 0,89 & 0,86 & 0,84 & 0,59 & 0,91 & 0,91 & 0,88 & 0,86 & 0,77 \\
\hline
\end{tabular}

Las mayores $\mathrm{R}^{2}$ se obtienen al disminuir la VT obteniendo $\mathrm{R}^{2}$ de $0,91,0,9$ y 0,85 para las VT de 1, 4 y 7 dias respectivamente. El servicio meteorológico qué mayor $\mathrm{R}^{2}$ presenta frente a los datos medidos es GFSk.

\subsection{Efectos de los escenarios en la humedad del suelo}

En este apartado se estudia la evolución de la humedad para las texturas de suelo determinadas frente a los escenarios para las VT de 1, 4 y 7 días, además de simular el estado de la humedad parcelas agrícolas (P1, P2 y P3) gestionadas por usuarios del caso de estudio. La figura 2 muestra la evolución de la humedad en un suelo FAA para la predicción de ETo generada con el servicio climático GFS, al cual se le ha aplicado el FK y se ha compensado la predicción con el error de la anterior, para las VT de 1, 4 y 7 días, con ello, se puede observar la diferencia de humedad en la programación con diferentes VT. Como se indica la humedad que se produce con la predicción de GFS-C_kdia+1 mantiene la humedad más próxima a la humedad objetivo (CC), que la predicción GFS-C_kdia+4 y a su vez, esta mantiene la humedad más próxima a la humedad objetivo que la predicción GFS-C_ksemana+1. Esto es debido, en este último caso, a que la humedad desciende debido a que esta más la predicción es mayor a la humedad objetivo (CC) no se produce riego durante la siguiente predicción. Con el fin de evitar que los niveles de humedad no disminuyeran por debajo de un determinado valor para la VT 7 de días, se podría programar el riego hasta la humedad objetivo y reprediendo el riego cuando se llegara a una humedad objetivo inferior. Esta sería una de las mejoras a introducir dento de las simplificaciones adoptadas. 


\section{Congreso Nacional de Riegos CARTAGENA 2021}

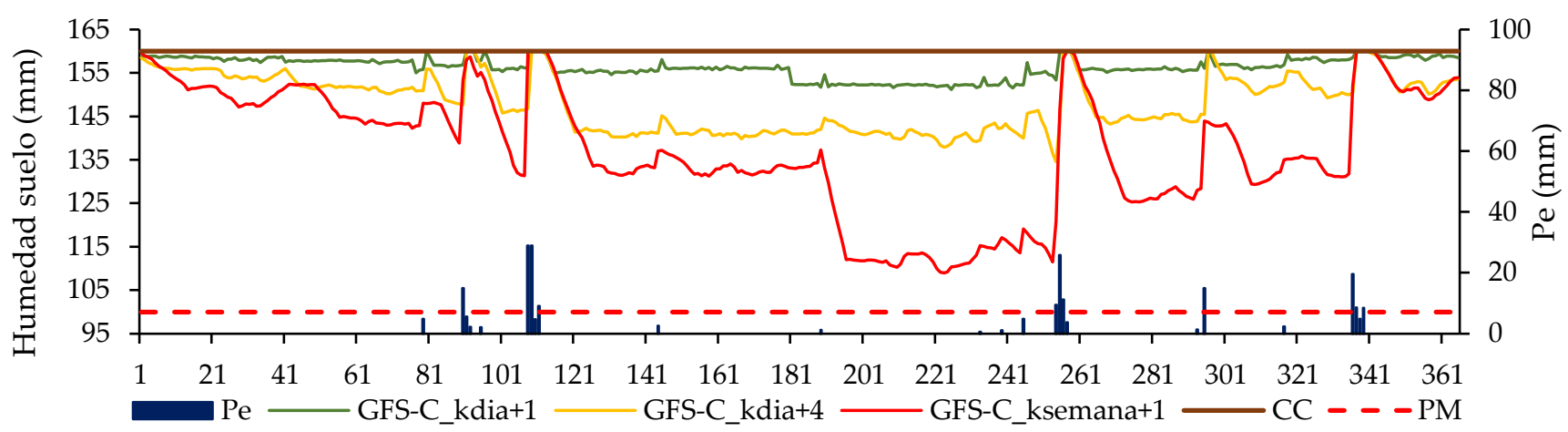

Figura 2. Evolución de la humedad del suelo (mm) en el año 2019, para el servicio climático de GFS, habiendo aplicado el FK y compensando su error con la predicción anterior para las VT de 1, 4 y 7 y la Pe (mm) del año 2019 para un suelo FAA.

El riego llevado a cabo por los usuarios, produce variaciones en la humedad del suelo dependiendo de la dosis de riego que se aplica. Cómo se observa en la figura 3, los riegos determinan que la humedad esté cerca de la humedad objetivo (CC) produciendo un elevado drenaje, y no teniendo en cuenta la precipitación, la cual drena en su mayoría.

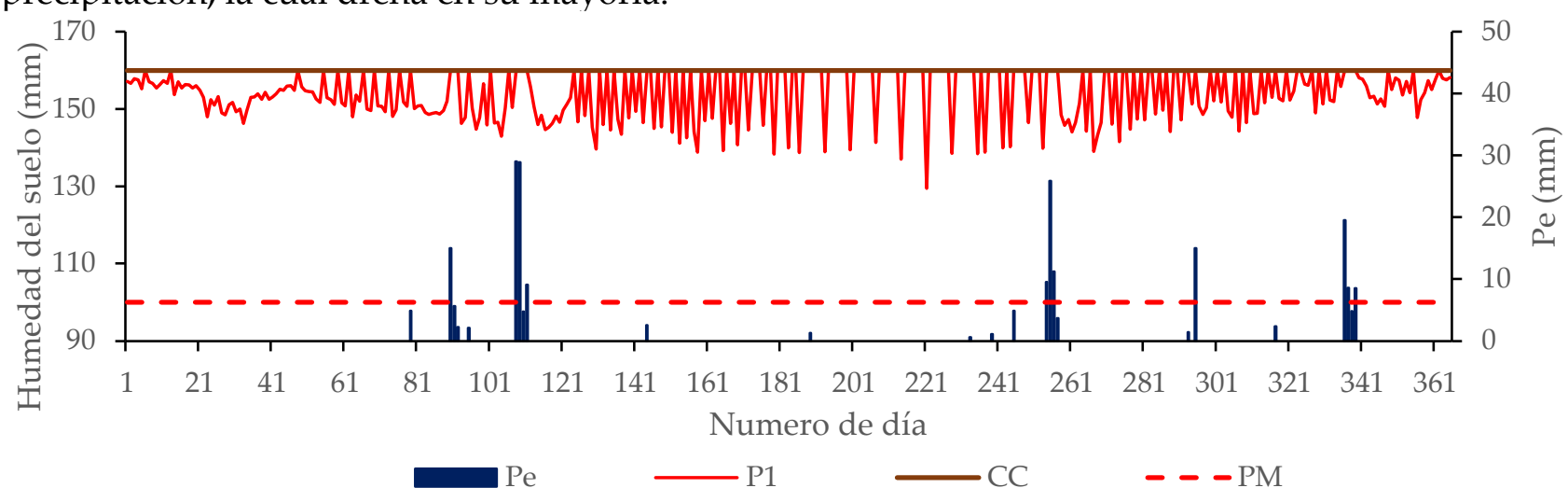

Figura 3. Evolución de la humedad del suelo (mm) producida por el riego para la parcela P1 y la Pe (mm) del año 2019.

Los resultados de los escenarios para las VT de 1, 4 y 7 días se dividen en dos apartados, por un lado, las predicciones de las necesidades del cultivo compensando el error con la predicción anterior y por otro lado sin compensarla. En el apartado que se describen los resultados de los escenarios sin compensar el error de la predicción anterior, se introducen las tres parcelas ya que los usuarios no compensan los errores pasados.

\subsubsection{Efectos de los escenarios en la humedad del suelo con escenarios no compensados.}

$\mathrm{Al}$ aumentar el número de días de predicción se reduce la cantidad de riego $\left(\mathrm{mm} \mathrm{año} \mathrm{o}^{-1}\right)$. Esto es debido a que hay mayor número de semanas que no riegan porque la humedad del suelo más las NR son superiores a la humedad objetivo. En cuanto a las parcelas seleccionadas por los usuarios, la parcela P1 se le aporta 927,8 $\mathrm{mm}_{\text {año }}{ }^{-1}$, estando muy por encima de las dosis para los escenarios predichos con datos meteorológicos y mediante datos históricos, y de las parcelas P2 y P3 a las que se les aportan 543,8 y $423,3 \mathrm{~mm}_{\text {año }}{ }^{-1}$ respectivamente, como se puede ver en la figura 4 . Por otro lado, el drenaje aumenta al reducir el número de días predichos para todos los escenarios, también el posible estrés que sufra el 


\section{Congreso Nacional de Riegos CARTAGENA 2021}

cultivo, y como cabía esperar es mayor en suelos más arenosos que de arcillosos. Para el riego producido por el agricultor la parcela P1 presenta drenajes de 841.9, 468.6 y $352.8 \mathrm{~mm}$ año ${ }^{-1}$ para los suelos FA, FAA y AL respectivamente siendo drenajes muy superiores al resto de escenarios predichos y estimados.
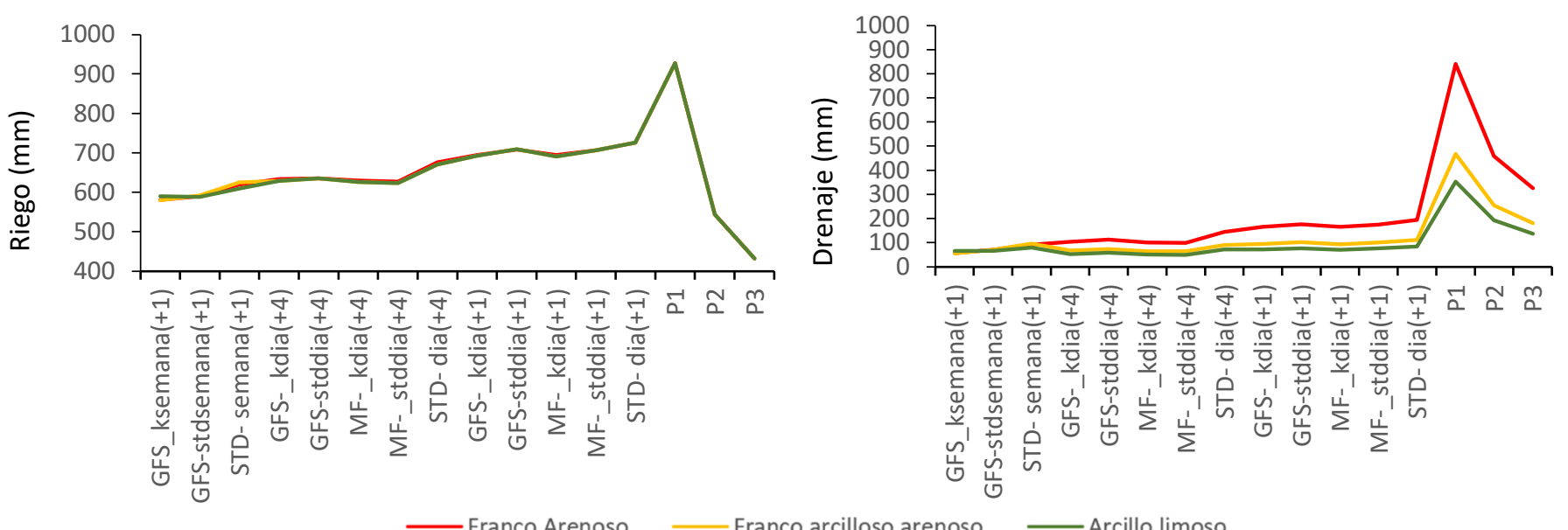

Figura 4. Riego y drenaje con errores no compensados con VT de 1, 4 y 7 días para la parcela tipo y de las 3 parcelas agrícolas $(\mathrm{mm})$, para 3 tipos de textura de suelo. La escala de las gráficas es diferente.

\subsubsection{Efectos de los escenarios en la humedad del suelo con escenarios compensados}

Como en los escenarios con errores no compensados al aumentar el número de días de VT de 1 a 4 o 7 días, se reduce la cantidad de NR anual. Esto es debido a que hay mayor número de semanas que no riegan en predicciones a 7 días que en predicciones a 4 días y estas a su vez a las predicciones a 1 día, porque la humedad del suelo más las NR son superiores a la humedad objetivo. Por otro lado, el drenaje aumenta al reducir el número de días predichos debido al aumento de la NR y al situar la humedad más próxima a la CC para todos los escenarios; el drenaje es mayor en suelos más arenosos que de arcillosos como se puede ver en la figura 5.

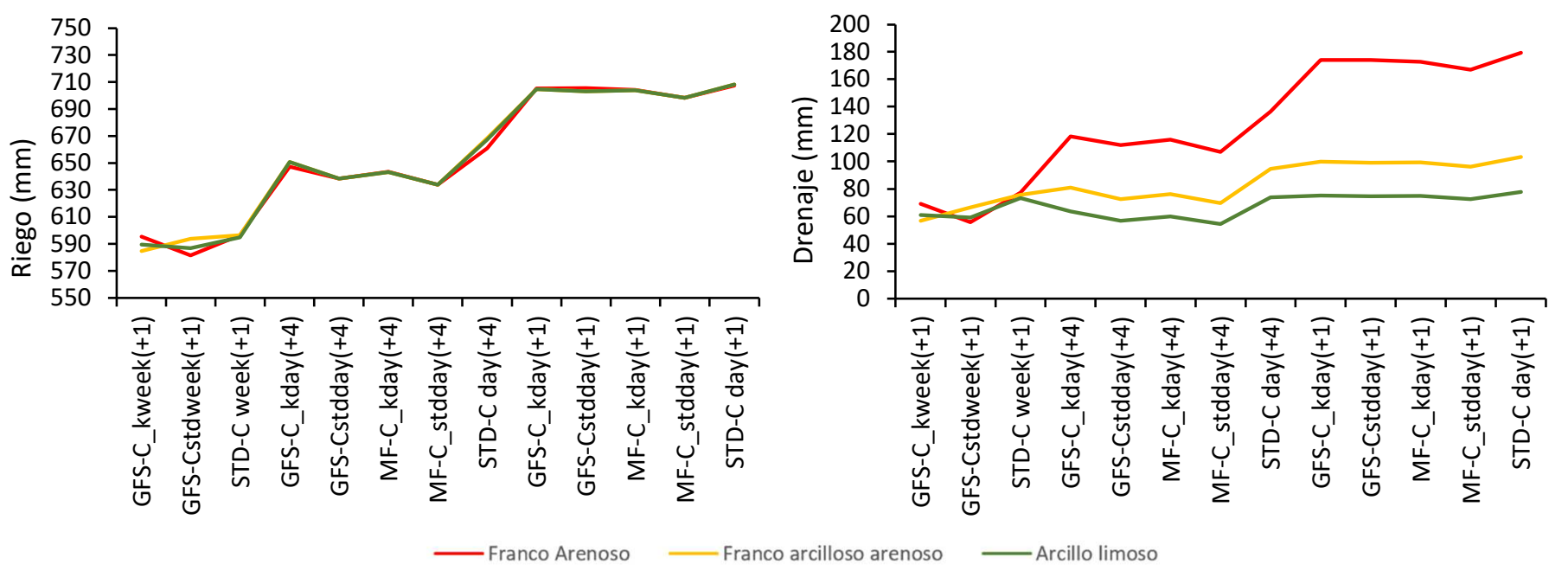

Figura 5. Riego y drenaje con errores no compensados para VT de 1, 4 y 7 días y 3 tipos de textura de suelo (mm). La escala de las gráficas es diferente. 


\section{Congreso Nacional de Riegos CARTAGENA 2021}

\section{Conclusiones}

Los servicios climáticos GFS y MF se pueden utilizar para la programación de riego con un menor error que al trabajar con la metodología tradicional de utilizar la ETo de la semana anterior para compensar la ETc sucedida. Al aplicar el Filtro de Kalman se redujo la incertidumbre entre las medidas y las predicciones al disminuir el error entre la ETo predicha o estimada frente a la determinada mediante medidas de parámetros climáticos en las estaciones meteorológicas. La VT que mejor mantiene la humedad del suelo próxima a la humedad objetivo es la de 1 día para todos los escenarios, aunque la VT de 7 días es la que más eficiente es en cuanto al volumen a aportar anualmente y la que menor drenaje produce, bajo la suposición de no regar si la predicción más la humedad del día anterior se superará la CC.

La relación o coeficiente entre el volumen de agua drenado y el volumen aportado (riego y precipitación) para un suelo franco arcillo arenoso considerando la programación de riego empírica de los agricultores es del 40,8\%, 33,3\% y del 27,6\% para las fincas P1, P2 y P3 respectivamente y del 7\% cuando se utiliza las necesidades de riego son calculadas mediante la predicción meteorológica GFS Kemana +1.

Aunque todos los escenarios simulados han mantenido la humedad del suelo por encima del punto de marchitamiento, habría que validar agronómicamente los distintos escenarios modelizados para verificar cómo influye finalmente la programación del riego sobre el estado hídrico de la planta y la producción final.

\section{Agradecimientos}

Este estudio ha sido parcialmente financiado por el proyecto ADAPTAMED (RTI2018-101483-BI00), financiado por el Ministerio de Ciencia e Innovación de España y con fondos de la UE FEDER

\section{Referencias}

1. Allen, R.G.; Pereira, L.S.; Raes, D.; Smith,M. Crop evapotranspiration guide- lines for computing crop water requirements., (1998).

2. D. Vanella, D.S. Intrigliolo, S. Consoli, G. Longo-Minnolo, G. Lizzio, R.C. Dumitrache, E. Mateescu, J. Deelstra, J.M. Ramírez-Cuesta, Comparing the use of past and forecast weather data for estimating reference evapotranspiration, Agric. For. Meteorol. 295 (2020) 108196. https://doi.org/10.1016/j.agrformet.2020.108196.

3. I.J. Lorite, J.M. Ramírez-Cuesta, M. Cruz-Blanco, C. Santos, Using weather forecast data for irrigation scheduling under semi-arid conditions, Irrig. Sci. 33 (2015) 411-427. https://doi.org/10.1007/s00271-015-0478-0.

4. Kalman, R. A New Approach to Linear Filtering and Prediction Problems, Trans. ASME - J. Basic Eng. 82 (1960) 35-45. https://doi.org/10.1115/1.3662552.

5. Castel, J. Water use of developing citrus canopies in Valencia, Proceeding Int. Soc. Citric.IX Congres (2000)223-226.

6. Albertos, P.; Sala, A. Multivariable control systems : an engineering approach, (2004).

7. FAO. AquaCrop training handbooks Book I . Understanding AquaCrop, (2015) 49. 


\section{Estudio comparativo del manejo del riego por goteo en almen- dro en marco de plantación intensivo y súperintensivo en el Centro Nacional de Tecnología de Regadío (CENTER)}

\section{Sánchez de Ribera González, Alejandroํㅜㄹ, Cervantes Díaz-Toledo, Alfonso²; Madurga del Cura, Cristina²; Muñoz} Sopeña, Daniel²; Rodríguez Fernández, Diego²; Zazo Salinero, Teresa²

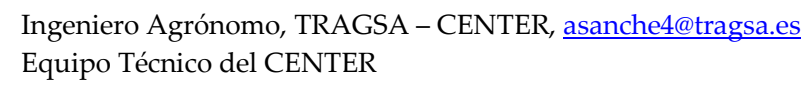

Resumen: El riego por goteo superficial y subterráneo hacen posible que el aporte de agua se haga de un modo preciso, tanto en la cantidad como en la localización del mismo. Se produce un bulbo húmedo que, dependiendo del manejo y del caudal de los emisores, es uniforme a lo largo de ramal, haciendo que mejore la eficiencia de aplicación y, por tanto, la disponibilidad de agua para las plantas.

Desde el Centro Nacional de Tecnología de Regadío se intenta ayudar y concienciar al sector que, para ciertos cultivos como puede ser frutales y leñosos en general, el uso de este tipo de sistemas de riego, así como el uso de las nuevas tecnologías para su manejo, puede ayudar a reducir costes e inputs en el cultivo, manteniendo o incluso aumentando sus rendimientos, además de reducir considerablemente el agua consumida.

El objetivo de este estudio es comparar, mostrar y valorar distintos modelos de sistemas de riego localizado tanto subterráneo como superficial combinado con distintos modos de manejo, bien en modo tradicional o en modo automático, incluyendo sondas y sensores en la toma de decisiones de los riegos, sin que influya el tratamiento agrícola de la planta, que se hará de forma conjunta y por igual, como puede ser el aporte de nutrientes (que se hará por fertirrigación), tratamiento de malas hierbas, enfermedades, poda etc.

En este caso se ha elegido una variedad comercial de almendro específica para implantar 12 parcelas de estudio: 6 parcelas en marco de plantación intensiva de $4 \times 6$ metros y 6 parcelas en marco de plantación superintensiva de $1,25 \times 3,5 \mathrm{~m}$.

Para todas las tuberías emisoras elegidas se realiza una evaluación hidráulica que incluye tanto el coeficiente de uniformidad antes de su instalación y en algunos casos durante su funcionamiento, así como la determinación de la relación presión-caudal suministrada por cada gotero bajo condiciones controladas de temperatura del agua en el Laboratorio de Ensayo de Materiales y Equipos de Riego del CENTER, de acuerdo a la norma UNE-ISO 9261.

Los resultados obtenidos en los distintos años de evolución del cultivo servirán para comparar y valorar los distintos métodos de manejo elegidos y poder mostrar su eficiencia.

Palabras clave: Goteo, Emisor, superficial, subterráneo, almendro, ensayos, CENTER 


\section{Comparative study of the management of drip irrigation in al- mond trees in an intensive and super-intensive plantation framework at the National Center for Irrigation Technology (CENTER).}

Sánchez de Ribera González, Alejandro ${ }^{1}$ Cervantes Díaz-Toledo, Alfonso²; Madurga del Cura, Cristina²; Muñoz Sopeña, Daniel2; Rodríguez Fernández, Diego²; Zazo Salinero, Teresa².

1 Agricultural engineer, TRAGSA - CENTER, asanche4@tragsa.es

2 CENTER Technical team

Abstract: Supply water in a precise way is possible thanks to the surface and underground drip irrigation. Depending on the management and flow of the emitters, a uniform wet bulb is produced along the line of the pipe, improving the efficiency of the application and the availability of water for the plants.

The National Centre for Irrigation Technology (CENTER) tries to help and raise awareness in the sector. In Crops such as fruit trees and woody trees in general, this type of irrigation systems and the new technologies for their management can help to reduce costs and inputs in the crop. It also maintains or even increases productions and reduces considerably the water consumed.

The aim of this study is to compare, show and evaluate different models of localized irrigation systems, underground and surface systems, combined with different management techniques, traditional and automatic mode. Sensors have been also included to make irrigation decisions. The agricultural treatments of the plant are the same for every system and it includes works like applications of nutrients (fertigation mainly), treatments of weeds, diseases, pruning, etc.

The almond variety chosen is a specific commercial variety. The project includes 12 study plots: 6 in an intensive plantation frame of $4 \times 6$ meters and 6 in a super-intensive plantation frame of $1.25 \times 3.5 \mathrm{~m}$.

All emitter pipes used are tested in accordance with the UNE-ISO 9261 standard in the Laboratory of the CENTER. It includes the uniformity coefficient and the pressure-flow relation test supplied by each dripper. All the tests are being performed under controlled conditions of water temperature.

The results obtained in the different years of evolution of the crop will make it possible to compare and evaluate the different management methods chosen and to show their efficiency.

Keywords: Drip, Emitter, superficial, underground, almond tree, tests, CENTER 


\section{Introducción}

El almendro es uno de los cultivos leñosos que más ha evolucionado en España en los últimos años. Su cultivo ha pasado de ser el cultivo de supervivencia de suelos pobres con producciones de entre 150 y 200 kilos por hectárea $(\mathrm{kg} / \mathrm{ha})$, a las plantaciones intensivas o súper intensivas en regadío que multiplican las producciones, llegando incluso a alcanzar cifras de entre 2500 a $3000 \mathrm{~kg} / \mathrm{ha}$, siendo por lo tanto un cultivo cuyo rendimiento está muy ligado a las dosis de agua aplicadas.

Desde el Centro Nacional de Tecnología de Regadíos, perteneciente a la S.G. de Regadíos, Caminos Naturales e Infraestructuras Rurales del Ministerio de Agricultura, Pesca y Alimentación, siempre se busca fomentar y mejorar las buenas prácticas de aplicación de riegos y apoyar estudios que impliquen comparar distintas formas de aportación hídrica. Este estudio tiene como objetivo comparar, mostrar y valorar distintos modelos de sistemas de riego localizado tanto subterráneo como superficial que a su vez se han combinado con distintos modos de manejo: convencional y automático.

Para evitar incluir más variables que distorsionen esta valoración, se intentará que no influya el tratamiento agrícola de la planta, realizándolo de forma conjunta y por igual, en función de los datos de suelo, y las muestras preliminares de nutrientes, perfiles, $\mathrm{pH}$, etc... Se unificarán tratamientos como: el abonado y la fertilización (que se hará principalmente por fertirrigación), el tratamiento de malas hierbas, el tratamiento de enfermedades, plagas, podas etc...

Este estudio se ha iniciado con la colaboración de varias empresas para la implantación del sistema de riego, las cuales han aportado sus ramales y emisores acorde con sus necesidades. Y una vez que entre en producción el almendro, serán las encargadas de manejar el riego de la parcela correspondiente.

\section{Materiales y métodos}

Para este proyecto se ha establecido una plantación de 2 ha de almendros en regadío subdividida en 12 parcelas, con marcos de plantación y variedad de cultivos acorde a dos modos de plantación que se van a comparar:

- Modo intensivo: consta de seis parcelas de cuatro líneas de cultivo cada una, con un marco de plantación de $4 \times 6$ metros y la variedad de almendro Penta. Cada línea de cultivo tiene un total de 16 árboles por lo que cada parcela de intensivo consta de un total 64 árboles.

- Modo súper intensivo: consta de seis 6 parcelas con seis líneas de cultivo y un marco de plantación de 1,25x 3,5metros y la variedad elegida también es Penta bajo un patrón de ciruelo enanizante "rootpac20" que hace que la planta no se desarrolle tan rápidamente en altura y la formación del seto es más favorable. Cada línea de cultivo tiene un total de 46 árboles por lo que cada parcela de súper intensivo consta de un total de 276 árboles.

Cuando sea época de recolección estos dos modos de plantación también permitirán comparar las formas de recolección y la maquinaria necesaria para ello. 


\section{CXeAro}

\section{Congreso Nacional de Riegos CARTAGENA 2021}

A continuación, se muestra un plano de la situación de la parcela.

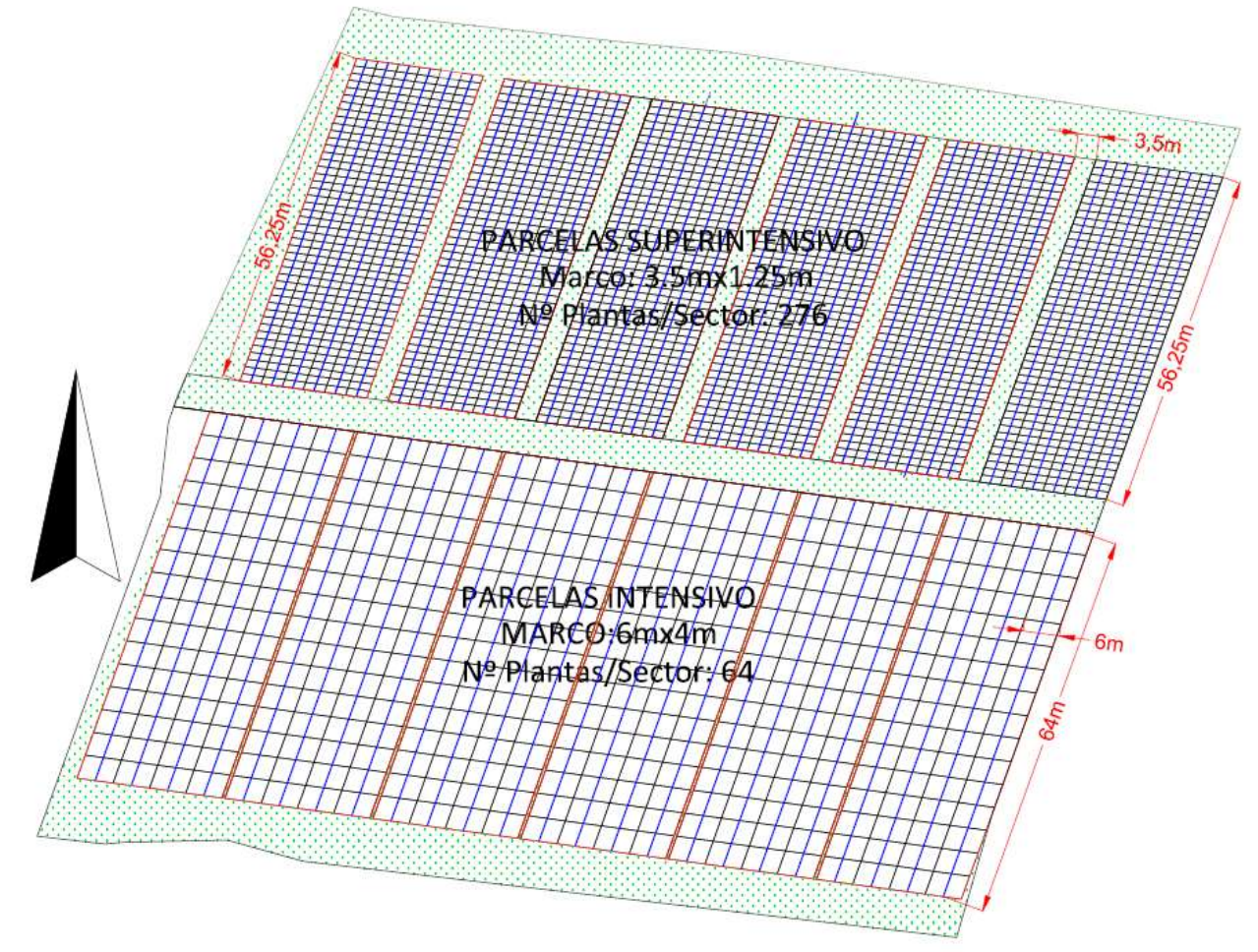

Figura 1. Esquema de distribución de las parcelas.

La variedad elegida para la implantación se ha realizado después de estudiar varias variables como son:

- La ubicación geográfica: el Centro Nacional de Tecnología de Regadíos (CENTER) se encuentra situado en la ribera del río Henares, en el término municipal de San Fernando de Henares, Madrid.

- Los datos agroclimáticos de los últimos 15 años, obtenidos de la estación situada en el propio CENTER perteneciente a la red SIAR.

- El perfil de suelos: aunque se ha elegido para el estudio una parcela de cultivo ya analizada anteriormente se han tomado varios muestreos en las zonas más representativas para poder así, realizar un manejo del riego inicial, lo más eficiente posible.

Tabla 1. Resumen estudio análisis del suelo

\begin{tabular}{ccccccc}
\hline Zona & $\begin{array}{c}\text { Hzte } \\
(\mathbf{c m})\end{array}$ & $\begin{array}{c}\text { Tipo de } \\
\text { suelo }\end{array}$ & PH & \%m.o. & \%CC & $\begin{array}{c}\text { \%Pto } \\
\text { marchitez }\end{array}$ \\
\hline \multirow{2}{*}{$\begin{array}{c}\text { Superin- } \\
\text { tensivo }\end{array}$} & 20 & & 8,5 & 1,0 & 17,0 & 10,4 \\
& 40 & Franco & 8,7 & 0,5 & 18,3 & 10,7 \\
\hline \multirow{3}{*}{ Intensivo } & 60 & & 8,7 & 0,4 & & \\
& 20 & Franco & 8,5 & 1,0 & 22,7 & 12,8 \\
& 40 & limoso & 8,5 & 0,5 & 20,2 & 9,8 \\
\hline
\end{tabular}


Con los estudios realizados, aunque predomina el suelo franco, se ha detectado una zona un poco más arenosa (60-70\%) sobre todo en horizontes más profundos que hay que tener en cuenta para realizar un manejo del riego lo más adecuado posible. Para estas zonas concretas se realiza un seguimiento especial.

Los datos de porcentaje de materia orgánica en el suelo indican el valor del aporte inicial necesario para la implantación del cultivo, como así se ha hecho.

Los valores de $\mathrm{pH}$ nos sirven para conocer el comportamiento del suelo y ver la incidencia que tiene en la planta y las raíces, ya que de ello va a depender que se asimilen mejor o peor los nutrientes.

Los valores de capacidad de campo y punto de marchitez dan una aproximación de la humedad mínima que debe tener el suelo para que, sin estar saturado, siempre tenga agua disponible la planta para su buen desarrollo durante los periodos de crecimiento y las distintas fases (brotación, cuajado y crecimiento de los frutos).

- Nutrientes en el suelo: también se ha realizado un muestreo en varios puntos para conocer el estado inicial, determinar las carencias del suelo en cuanto a macro y micro nutrientes y poder realizar los aportes necesarios. Los resultados más representativos se muestran a continuación:

Tabla 2. Resumen muestras nutrientes en el suelo

\begin{tabular}{ccc}
\hline Nutriente & M1 (mg/kg suelo) & M2(mg/kg suelo) \\
\hline $\mathrm{N}$ & 1,38 & 13,34 \\
$\mathrm{~N}-\mathrm{NO}_{3}$ & 6,1 & 59,07 \\
$\mathrm{P}$ & 17,63 & 25,22 \\
$\mathrm{~K}$ & 577,69 & 892,43 \\
$\mathrm{Ca}$ & 4794,82 & 5501,99 \\
$\mathrm{Mg}$ & 384,46 & 555,78 \\
$\mathrm{Na}$ & 65,54 & 90,34 \\
\hline
\end{tabular}

Con todos estos datos analizados, se decidió que la variedad debía presentar una época de floración muy tardía, para poder eludir las posibles heladas primaverales de la zona. Es por eso que tras valorar las diferentes posibilidades, se ha elegido como variedad principal Penta.

Desde el principio de la plantación que se realizó en Junio/Julio del año 2020 se ha hecho un seguimiento tanto a la planta como al riego. 
Respecto al riego en esta campaña se ha hecho hincapié en el buen desarrollo de la planta, ya con todos los emisores implantados desde el mes de junio de 2021.

Las distintas parcelas estudiadas se corresponden con las siguiente distribución del riego:

Tabla 3. Resumen del riego instalado Caudal $(1 / \mathrm{h})$ y separación entre emisores $(\mathrm{m})$ en cada parcela de ensayo.

\begin{tabular}{|c|c|c|c|}
\hline $\begin{array}{c}\text { № } \\
\text { Parcela }\end{array}$ & $\begin{array}{l}\text { Intensivo } 4 \text { filas } \\
6 \times 4 \mathrm{~m}\end{array}$ & $\begin{array}{c}\text { Súperintensivo } 6 \text { filas } \\
\text { de } 3,5 \times 1,25 \mathrm{~m}\end{array}$ & $\begin{array}{c}\text { № } \\
\text { Parcela }\end{array}$ \\
\hline 11 & $\begin{array}{l}\text { Qe: } 1,6 \text { 1/h; Se: } 0,6 \mathrm{~m} \\
\text { Riego superficial }\end{array}$ & $\begin{array}{l}\text { Qe: } 2 \text { 1/h; Se: } 0,5 \mathrm{~m} \\
\text { Riego enterrado }\end{array}$ & 12 \\
\hline 9 & $\begin{array}{l}\text { Qe: } 1,6 \text { l/h; Se: } 0,6 \mathrm{~m} \\
\text { Riego enterrado }\end{array}$ & $\begin{array}{l}\text { Qe: 1,6 1/h Se: 0,6m } \\
\text { Riego superficial }\end{array}$ & 10 \\
\hline 7 & $\begin{array}{l}\text { Qe: } 1,5 \text { l/h; Se: } 0,6 \mathrm{~m} \\
\text { Riego enterrado }\end{array}$ & $\begin{array}{c}\text { Qe: } 1,5 \text { 1/h Se: } 0,6 \mathrm{~m} \\
\text { Riego enterrado }\end{array}$ & 8 \\
\hline 5 & $\begin{array}{l}\text { Qe: } 1,5 \text { 1/h; Se: } 0,6 \\
\text { Riego enterrado m }\end{array}$ & $\begin{array}{c}\text { Qe: } 1,5 \text { 1/h Se: } 0,6 \mathrm{~m} \\
\text { Riego enterrado }\end{array}$ & 6 \\
\hline 3 & $\begin{array}{l}\text { Qe: } 2 \text { 1/h; Se: } 0,75 \mathrm{~m} \\
\text { Enterrado2 }{ }^{\mathrm{o}} \text { año }\end{array}$ & $\begin{array}{c}\text { Qe: } 1,6 \text { 1/h Se: } 0,6 \mathrm{~m} \\
\text { Riego enterrado } 2^{\circ} \text { año }\end{array}$ & 4 \\
\hline 1 & $\begin{array}{c}\text { Qe: } 1,6 \text { 1/h; Se: 0,5m } \\
\text { Riego superficial }\end{array}$ & $\begin{array}{l}\text { Qe: 1,6 1/h Se: 0,5m } \\
\text { Riego superficial }\end{array}$ & 2 \\
\hline
\end{tabular}

Desde el principio, se ha ido registrando los siguientes datos de cada parcela que ayudaran a evaluar los distintos sistemas implantados:

- Tubería instalada en cada sector. Si se ha enterrado o no y desde cuándo.

- Control de los riegos y lectura de contadores: dentro de la programación de riegos, controlar y revisar consumos por parcela. Detección de fugas y posibles emisores obturados.

- Presión de riego. Se regula a la entrada de cada parcela, mediante una válvula hidráulica reductora, la presión de riego recomendada para cada tipo de tubería emisora instalada.

- Registro de precipitaciones: se lleva un histórico de las precipitaciones que se han producido y la efectividad de las mismas, en las distintas épocas.

- Lectura de sondas de humedad y otros sensores de las parcelas que están instalados.

- Datos de fertirrigación: se lleva registro de los aportes de abonado que se han realizado en cada momento para controlar el aporte de nutrientes. Como se ha comentado anteriormente este aporte es común a todas las parcelas para que no sea un condicionante a la hora de comparar manejos de riego. Estos aportes se han calculado basándose en estudios, publicaciones [1-2] y asesoramiento de técnicos expertos en la materia, que, junto con los análisis realizados, han recomendado los aportes asignados. Esto se continuará haciendo durante los años sucesivos. 


\section{Congreso Nacional de Riegos CARTAGENA 2021

Paralelamente se va a evaluar distintos sistemas de manejo con distintas colaboraciones:

1. El manejo tradicional o convencional, que, mediante los modelos estadísticos y métodos empíricos, los coeficientes de cultivo (FAO), mezclado con los datos climáticos y de suelo, establecen las dosis de riego.

2. El manejo en modo automático en el que se tiene en cuenta todo lo anterior, pero a su vez, se programa el riego incluyendo los datos suministrados principalmente por sondas de humedad y otros tipos de sensores.

Para ayudar a ser más exhaustivos, todas las tuberías emisoras y los emisores instalados en campo se están ensayando en el banco de emisores del Laboratorio Central para Ensayo de Materiales y Equipos de Riego del CENTER, de forma que se tenga perfectamente determinado el coeficiente de uniformidad y la curva caudal presión (Q-P). Ver ejemplo Fig.5.

Cada parcela de riego está conectada por un sistema de telecontrol que aparte de abrir y cerrar la válvula hidráulica reductora, acumula la lectura de pulsos del contador, da información de la presión en la tubería principal y acumula el gasto total de las 12 parcelas.

También se tendrán en cuenta, cuando la planta empiece a producir almendra, otros aspectos importantes como pueden ser:

- Fecha de entrada en producción

- Rendimientos de producción por ha dependiendo de las dosis aplicadas.

- Otros aspectos como, el coste de mano de obra según los costes por hora y ha, el personal requerido de mantenimiento, costes de recolección y tiempo invertido, etc...

\section{Resultados y discusión}

Después de un año de seguimiento, se lleva registro de todos los consumos, presiones y gastos por parcela descritos anteriormente. A continuación, se muestran los consumos por parcela registrados:

Tabla 4. Resumen del gasto medio registrado por parcela $(\mathrm{l} / \mathrm{h})$

\begin{tabular}{cccc}
\hline Parcela & Gato (1/h) Intensivo & Gasto (1/h) Súperinten. & Parcela \\
\hline 11 & 1365 & 2025 & 12 \\
9 & 1365 & 1350 & 10 \\
7 & 1280 & 1687,5 & 8 \\
5 & 1280 & 1688 & 6 \\
3 & 1365 & 900 & 4 \\
1 & 1638 & 2160 & 2 \\
\hline
\end{tabular}




\section{Congreso Nacional de Riegos CARTAGENA 2021}

También se tiene registrados resultados de:

- Datos de los sensores y las sondas de humedad instaladas. Los resultados obtenidos permiten conocer el estado del terreno y ayuda a la toma de decisiones tanto a nivel instantáneo, como a nivel global de campaña, así como a estudiar la evolución y el comportamiento de la parcela. Por ejemplo:

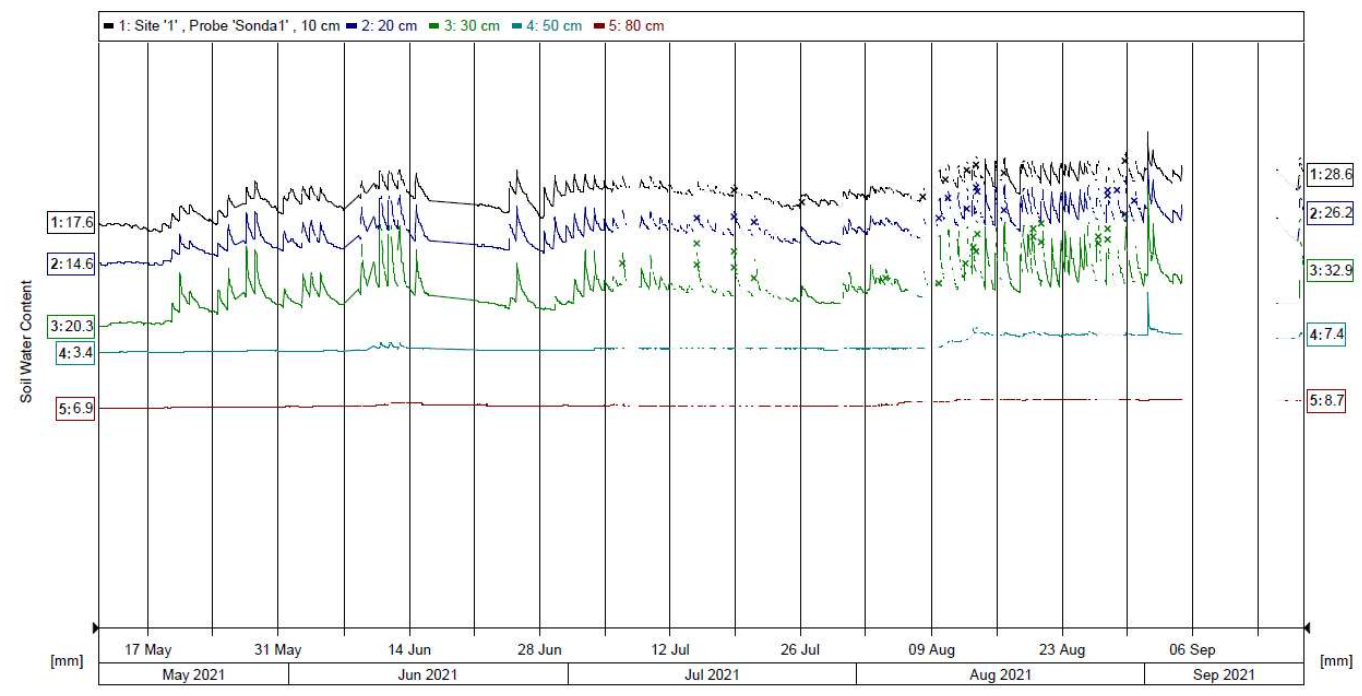

Figura 2. Visualización de la campaña de riego visto desde una sonda de humedad.

- Perímetro del tallo de árboles elegidos para el muestreo de cada parcela de ensayo.

- Altura de la planta, aunque se han realizado varias podas de formación.

- Aspecto general en cuanto a vigor color y estado general, sobre todo para localizar posibles plagas y enfermedades, y realizar las reposiciones de marras necesarias.

A continuación se muestra la evolución de las parcelas desde su plantación en junio de 2020 hasta septiembre de 2021.

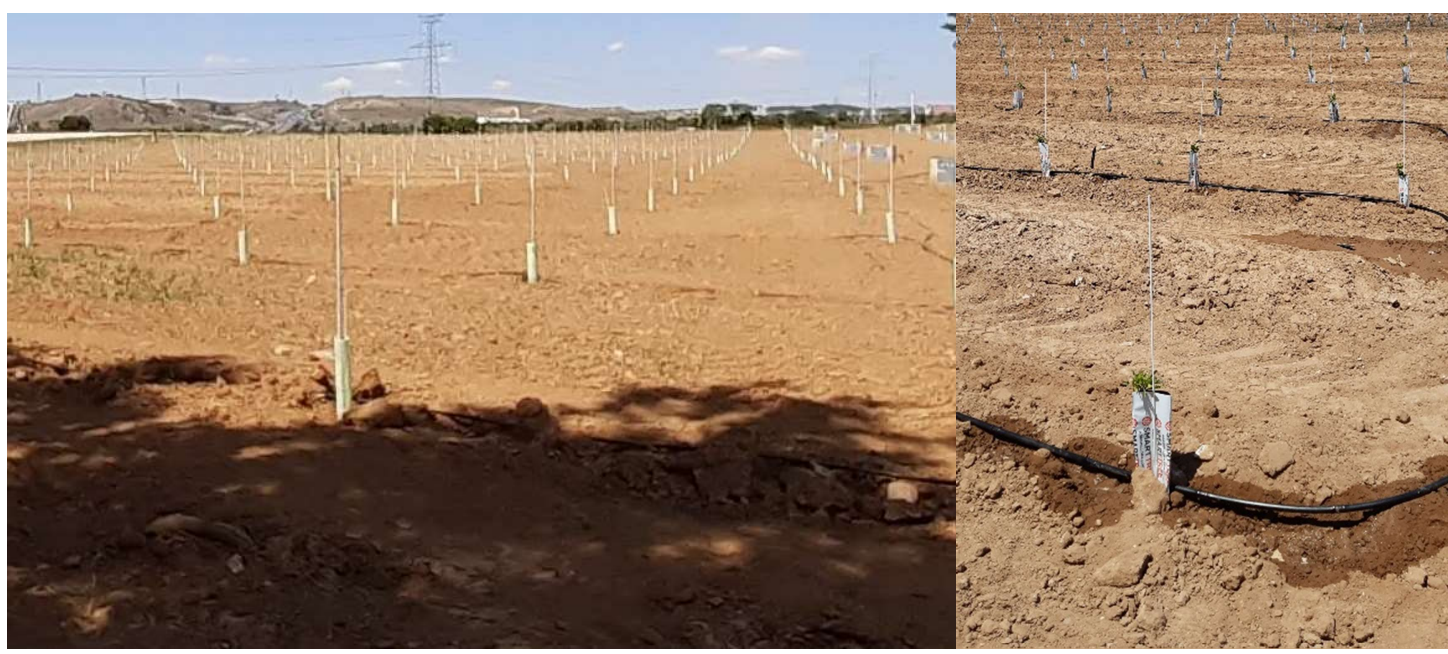

Figura 3. Estado del cultivo despues de su plantación. 


\section{COAERYD}

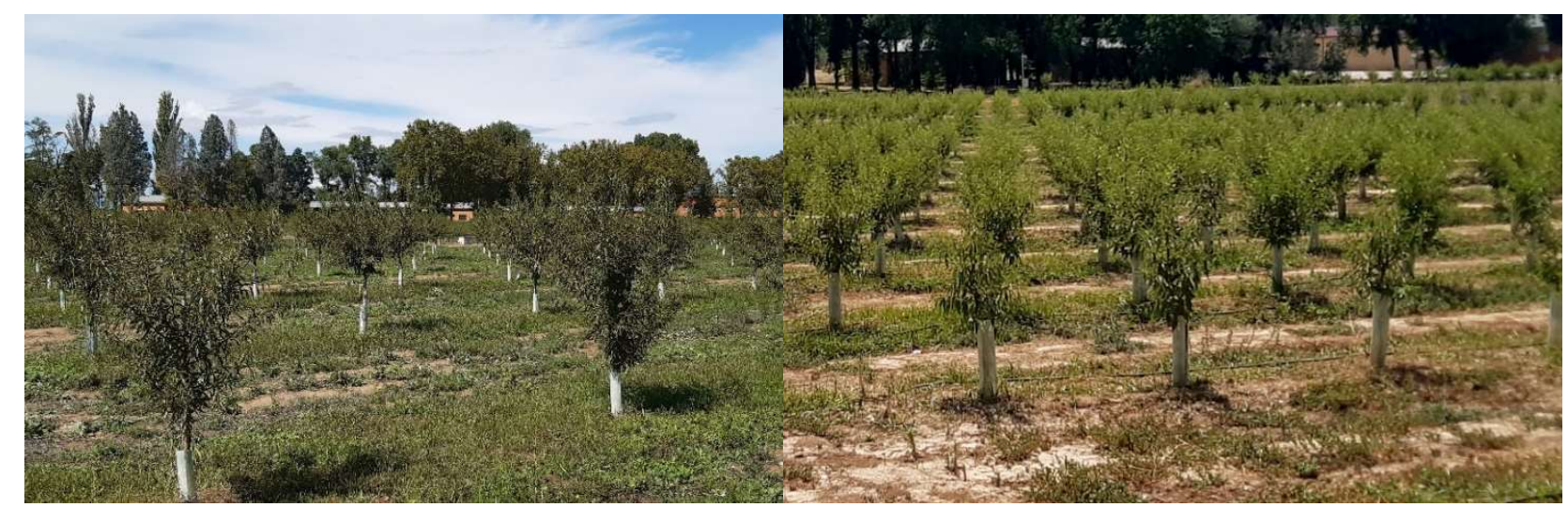

Figura 4. Estado del cultivo en la actualidad.

- Datos de ensayo de los emisores, a continuación, se muestra un ejemplo de la curva caudal-presión de uno de los emisores instalados, perteneciente a una tubería emisora compensante.

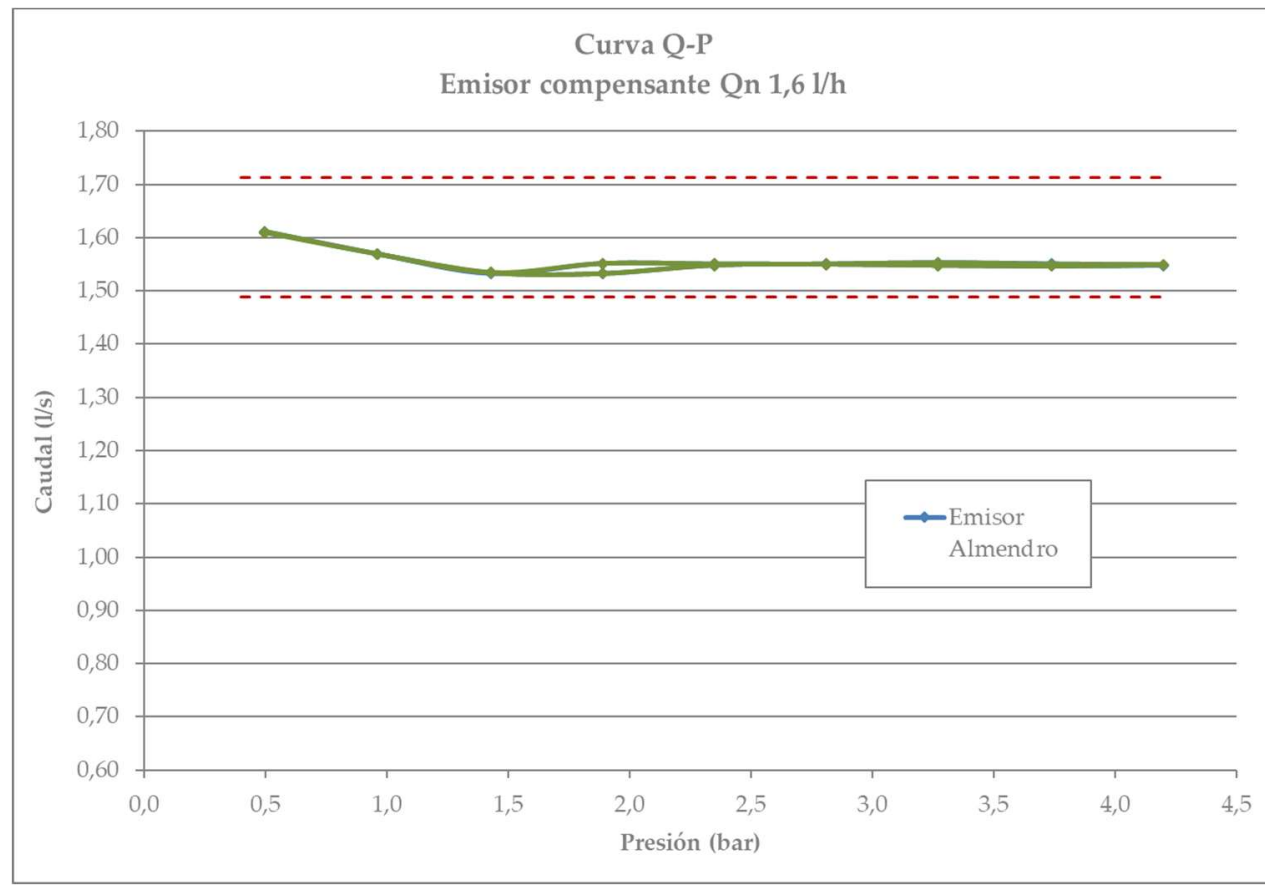

Figura 5. Curva caudal-presión emisor compensante instalado en campo rango de compensación (0.4-3.5 bar). 


\section{Conclusiones}

Aunque se está en el arranque del proyecto y solo se lleva una campaña completa de riego, se empiezan a ver algunas cuestiones importantes de cara a la implantación y evolución de un cultivo de este tipo, como puede ser las siguientes:

1. Los estudios previos de parcela: ubicación, suelo, nutrientes, etc... se hacen muy necesarios para la implantación correcta de un cultivo como el almendro, ya que condicionan no solo la variedad sino también el sistema de riego y su manejo.

2. El control de malas hierbas, en los estados iniciales, es una tarea complicada y difícil de realizar, que, aunque no es objeto de este proyecto, se hace difícil no reflejarlo en las conclusiones debido a la labor inicial que supone. Se recomienda realizar un control exhaustivo para evitar su descontrol, bien mezclando herbicidas que no dañen el almendro en su fase inicial, cosa que se hace complicada en su manejo y efectividad final, bien desbrozado de manera constante cuando sea necesario, también teniendo cuidado con no dañar la planta, o bien mezclando eficazmente las dos anteriores.

3. La buena proyección y dimensionado de la plantación evita bastantes gastos posteriores que surgen en la puesta en marcha de la instalación, y que pueden afectar directamente al desarrollo homogéneo de las plantas.

4. En el caso del almendro, un buen manejo de riego inicial se hace necesario para un buen desarrollo de la planta, de forma que muchos factores de este manejo influyen, como puede ser: el enterrado o no de la tubería emisora desde el inicio, la limpieza recurrente de sectores después de alguna rotura o desajuste de la tubería emisora, la colocación de purgadores para mejorar el funcionamiento, etc...

5. La falta de algunos nutrientes, la radiación solar (zonas de sombra en algunos puntos) y errores en el manejo del riego, inciden de manera directa en el desarrollo homogéneo del cultivo.

Es por esto que un buen manejo y la elección del sistema de riego correcto desde el inicio, es importante y necesario para hacer prosperar el cultivo y facilitar las cosas al usuario del sistema de riego.

\section{Referencias}

1. Guía de gestión integrada de plagas Almendro Ministerio de Agricultura, Pesca y Alimentación.

2. Guía práctica fertilización racional de cultivos en España. parte II, Ministerio de Medio Ambiente y Medio Rural y Marino 


\title{
Integración de modelos hidráulicos, de distribución de agua y de cultivo para el análisis holístico de sistemas de riego por aspersión fija
}

\author{
Morcillo García, Manuel ${ }^{1}$, Moreno Hidalgo, Miguel Ángel², Ballesteros González, Rocíoº, Montero Martínez, \\ Jesús $^{4}$, del Castillo Sánchez-Cañamares Amaro ${ }^{5}$
}

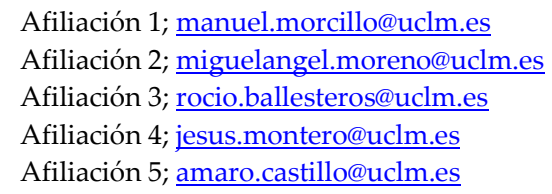

Resumen: En un contexto de recursos limitados, donde, debido al continuo aumento de la población mundial, cada vez hay una mayor demanda de alimentos, lo que se traduce en una mayor explotación de los recursos disponibles, como el agua, que, sumado al elevado consumo de energía para su extracción y aplicación, hacen necesario la modernización de los sistemas de riego y desarrollo de nuevas metodologías y herramientas que permitan gestionar los recursos de una manera más eficiente, obteniendo unas producciones óptimas. En este caso concreto, se ha centrado en los sistemas de riego por aspersión, los cuales se utilizan en cultivos con una gran demanda hídrica y necesitan, además de un correcto diseño y dimensionamiento, una adecuada gestión para el uso eficaz del agua de riego.

Por ello, el objetivo perseguido ha sido la integración de modelos hidráulicos (para evaluar la distribución de presiones y caudales del sistema de riego), de distribución de agua (para determinar la distribución de agua aplicada en el suelo) y de simulación de cultivos (para evaluar el efecto de la distribución de agua sobre la producción del cultivo). Este modelo integrado y holístico permitirá ayudar en el proceso de toma de decisiones sobre el diseño, dimensionado y gestión de sistemas de riego. Para mostrar la potencialidad del modelo integrado se ha aplicado a un caso real, evaluando un diseño realizado por una empresa de riegos privada (utilizando criterios clásicos), llevada a cabo en una parcela de Tarazona de la Mancha (Albacete) con cultivo de cebolla (Allium cepa L.).

La herramienta desarrollada permitirá determinar la producción de cebollas en cada metro cuadrado de la parcela, dada por la distribución de agua en el suelo y una zonificación por las características del mismo, obteniendo los índices; productividad del agua $\left(\mathrm{kg} / \mathrm{m}^{3}\right)$ y productividad de la energía $(\mathrm{kg} / \mathrm{kWh})$, permitiendo determinar la pluviosidad optima del sistema de riego con la que ser más eficientes con los recursos utilizados, pero sin afectar a producción del cultivo. Además, en base a los resultados obtenidos, se puede customizar el sistema de riego de forma localizada, abriéndose un abanico de posibilidades; como mejorar la uniformidad de riego, aplicar más agua en las zonas con mayor potencial productivo, entre otros, en un contexto de riego de precisión. Por lo que se puede concluir que la herramienta desarrollada tiene un elevado potencial, permitiendo ayudar en el proceso de toma de decisiones sobre el diseño, dimensionamiento y gestión de sistemas de riego por aspersión.

Palabras clave: Riego; Aspersión; Precisión; Integración; Modelos. 


\title{
Integration of hydraulic, water distribution and crop models for holistic analysis of fixed sprinkler irrigation systems
}

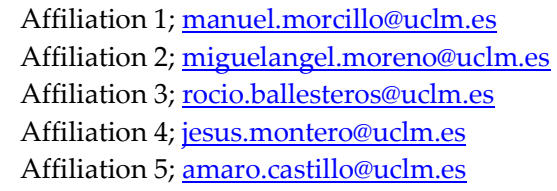

Morcillo García, Manuel ${ }^{1}$, Moreno Hidalgo, Miguel Ángel², Ballesteros González, Rocíoº, Montero Martínez, Jesús ${ }^{4}$, del Castillo Sánchez-Cañamares Amaro ${ }^{5}$

\begin{abstract}
In a context of limited resources, where, due to the continuous increase in the world population, there is an increasing demand for food, which translates into greater exploitation of available resources, such as water, which, added to the high consumption of energy for its extraction and application, make it necessary to modernize irrigation systems and develop new methodologies and tools that allow to manage resources in a more efficient way, obtaining optimal productions. In this specific case, it has focused on sprinkler irrigation systems, which are used in crops with high water demand and require, in addition to proper design and sizing, adequate management for the effective use of irrigation water. Therefore, the objective pursued has been the integration of hydraulic models (to evaluate the distribution of pressures and flows of the irrigation system), water distribution (to determine the distribution of water applied to the soil) and simulation of crops (to assess the effect of water distribution on crop production). This integrated and holistic model will help in the decision-making process on the design, dimensioning and management of irrigation systems. To show the potential of the integrated model, it has been applied to a real case, evaluating a design made by a private irrigation company (using classical criteria), carried out in a plot of Tarazona de la Mancha (Albacete) with onion cultivation. (Allium cepa L.).
\end{abstract}

The developed tool will determine the production of onions in each square meter of the plot, given by the distribution of water in the soil and a zoning by its characteristics, obtaining the indices; water productivity $\left(\mathrm{kg} / \mathrm{m}^{3}\right)$ and energy productivity $(\mathrm{kg} / \mathrm{kWh})$, allowing to determine the optimal rainfall of the irrigation system with which to be more efficient with the resources used, but without affecting crop production. In addition, based on the results obtained, the irrigation system can be customized locally, opening a range of possibilities; how to improve irrigation uniformity, apply more water in areas with greater productive potential, among others, in a context of precision irrigation. Therefore, it can be concluded that the developed tool has a high potential, allowing to help in the decision-making process about the design, dimensioning and management of sprinkler irrigation systems.

Keywords: Irrigation; Sprinkling; Accuracy; Integration; Models. 


\section{Congreso Nacional de Riegos CARTAGENA 2021}

\section{Introducción}

Se espera que la población mundial aumente en 2.000 millones de personas en los próximos 30 años. Para alimentar a esta población cada vez más numerosa, la producción de alimentos deberá aumentar en gran medida, por lo que será necesario producir más con menos. Las proyecciones muestran que, para alimentar una población mundial de 9.700 millones de personas en 2050, sería necesario aumentar la producción de alimentos en un 70\% [1]. La producción de alimentos y el uso del agua están relacionados de forma inseparable. El agua siempre ha sido el principal factor que limita la producción agrícola en gran parte del mundo. Con la competencia cada vez mayor por recursos hídricos no renovables en todo el mundo y la creciente demanda de productos agrícolas, nunca ha sido tan apremiante la necesidad de mejorar la eficiencia y productividad del uso del agua para la producción de cultivos.

El agua de riego es esencial para la producción de cultivos, y cualquier escasez tiene un impacto en los rendimientos finales. Por lo tanto, los agricultores siempre han tendido a regar en exceso (en el caso de cultivos de alto margen bruto), un enfoque que va en contra de la conservación de recursos escasos. En la actualidad, debido a la expansión global de las áreas regables y la disponibilidad limitada de agua de riego, existe la necesidad de optimizar el riego para maximizar en la medida de lo posible el rendimiento de los cultivos [2]. Para dicha optimización en el uso del agua, se demanda una correcta planificación del riego, ya que sólo se requerirá de un evento de riego cuando la cantidad de lluvia sea insuficiente para compensar las pérdidas de agua por evapotranspiración. El objetivo principal del riego es la aplicación del agua en el momento preciso y con la cantidad precisa de agua.

Para mejorar la eficiencia y la productividad del uso del agua para la agricultura, es necesario la modernización de los sistemas de riego, donde los sistemas de riego tradicionales como el riego por superficie o gravedad se vean sustituidos por sistemas más modernos como el riego localizado o por aspersión.

Es cierto que esta modernización también lleva consigo un aumento de la demanda energética, que unido a los aumentos de las tarifas eléctricas hacen que se incrementen en gran medida los costes. Además, la energía utilizada genera importantes emisiones de gases de efecto invernadero (GEI), que contribuyen a acelerar el cambio climático [3]. Por ello, se necesita optimizar las instalaciones de riego, pero no solamente desde el punto de vista productivo, si no también desde un punto de vista de sostenibilidad, por lo que siempre se deben considerar criterios tanto ambientales como económicos. Por tanto, es necesario desarrollar herramientas y modelos que puedan contribuir directamente a mejorar el uso del agua y la energía en el riego, con un enfoque holístico para el diseño y la gestión de la infraestructura del riego [4].

En cuanto a los diferentes sistemas de riego, debido a las características del sistema de riego por aspersión, es el sistema más adecuado para cultivos con una elevada densidad de plantación, como por ejemplo maíz, bulbos, tubérculos, cereales y leguminosas. La idoneidad del riego por aspersión depende de factores de diseño y de funcionamiento. Como efectos derivados de la aplicación de agua mediante sistemas de aspersión se encuentran: la relación entre la velocidad de aplicación (pluviometría del sistema) y la capacidad de infiltración de agua del suelo, produciéndose escorrentía si la primera supera a la segunda, el posible deterioro de la superficie del terreno por el impacto de las gotas si estas son muy grandes, la uniformidad de distribución en superficie y su gran dependencia de la acción del viento, intensidad y dirección [4]. Para minimizar los posibles efectos adversos que pueden ocasionar los sistemas de aspersión, se ha de realizar un diseño y dimensionado óptimo.

Debido a que las redes de distribución de agua en aspersión son sistemas complejos cuyo modo de funcionamiento escapa muchas veces al control de los operadores. El desarrollo no planificado de la red, unido al comportamiento altamente no lineal de sus componentes, obligan hoy en día a utilizar 


\section{Congreso Nacional de Riegos CARTAGENA 2021}

modelos de simulación por ordenador [5]. El programa informático más utilizado para la simulación de redes hidráulicas es EPANET, el cuál es capaz de realizar una simulación de período prolongado del comportamiento hidráulico y de la calidad del agua dentro de redes de tuberías presurizadas [6]. El problema de estos modelos hidráulicos es que se llega a nivel emisor en los modelos más avanzados, pero realmente no se evalúa lo que ocurre cuando el agua sale por los aspersores. Existen programas como SIRIAS (SImulación de RIego por ASpersión), que es capaz de simular la distribución de agua de los aspersores bajo la influencia del viento, utilizando la teoría balística [7], y SORA (SOlapamiento en Riego por Aspersión), que muestra la superposición para cualquier marco de riego [7]. El software SORA sólo solapa 4 aspersores y no tiene en cuenta que estos puedan tener distinta presión. Para su aplicación en una parcela real de riego, se presenta la necesidad de escalar el estudio a nivel sector y que contemple la capacidad de que cada uno de los emisores pueda tener distinta presión. En el caso de los cultivos, existen modelos informáticos que pretenden simular su comportamiento ante diferentes escenarios de manejo. Estas herramientas se han desarrollado con el conocimiento científico de la fisiología de las plantas, la ciencia del suelo, la agroclimatología y su relación con el manejo de los cultivos en campo [8]. Actualmente existen distintos modelos de cultivo, entre los que destacan AquaCrop [9], Cropsyst [9] y Sticks [9], entre otros. El software AquaCrop simula el crecimiento, la productividad y el uso de agua de un cultivo día a día, según se vea afectado por condiciones cambiantes en la disponibilidad de agua y las condiciones ambientales [10].

Actualmente no existen modelos integrales que evalúen el efecto de la distribución de presiones en el sistema de riego y la distribución de agua sobre la producción en cada punto de la parcela, en un contexto de agricultura de precisión. Estos modelos integrados permiten evaluar las decisiones realizadas en el diseño y dimensionado de los sistemas de riego de una forma global, hasta llegar a la producción en cada parte de la parcela, con las consecuencias, económicas asociadas.

Así, el objetivo de este trabajo es integrar modelos hidráulicos, de distribución de agua y de cultivo para el análisis holístico de sistemas de riego por aspersión fija. Para conseguir este objetivo se aplicará la metodología desarrollada a una parcela comercial localizada en el término municipal de Tarazona de La Mancha, Albacete.

\section{Materiales y métodos}

\subsection{El caso de estudio.}

La parcela de estudio se encuentra ubicada en el término municipal de Tarazona de la Mancha (Albacete), tiene una superficie de 2,82 ha y cuenta con un sistema de riego por aspersión en un marco de 17,5 m x 17,5 m, con aspersores circulares UNIRAIN F46 de dos boquillas (5/32"+3/32") con vaina prolongadora del chorro y aspersores sectoriales UNIRAIN P45LP de una boquilla (5/32") con vaina prolongadora del chorro, donde el agua de riego es abastecida por la comunidad de regantes SAT no 8770 "Soreta". La parcela se encuentra a su vez dividida en 2 sectores de riego, el sector 1 tiene una superficie de 1,52 ha y cuenta con 60 aspersores (45 circulares y 15 sectoriales), mientras que el sector 2 tiene una superficie de 1,30 ha y cuenta con 54 aspersores (39 circulares y 15 sectoriales). En cuanto al cultivo establecido en el año de estudio, se trata de cebolla (Allium cepa L.) de siembra, la cual se ha sembrado en camas de $1 \mathrm{~m}$ de ancho, contando cada una con 6 filas y una separación entre bulbos de $15 \mathrm{~cm}$, con un total de 59 camas a lo largo de la parcela.

Por la variabilidad del suelo a lo largo de la parcela, se ha realizado una zonificación, ya que, dependiendo de las características del mismo, el cultivo se desarrollará de manera diferente, afectando de forma distinta la cantidad de agua de riego aplicada. En primer lugar, se ha medido la conductividad eléctrica del suelo mediante una sonda EM38, realizando un total de 1.063 mediciones sobre una malla 


\section{Congreso Nacional de Riegos CARTAGENA 2021}

de $5 \mathrm{~m} \times 5 \mathrm{~m}$ y total de 279 mediciones sobre una malla de $10 \mathrm{~m} \times 10 \mathrm{~m}$. Paralelamente, se han tomado un total de 7 muestras de suelo repartidas por toda parcela, las cuales han sido analizadas en el Instituto Técnico Agrario Provincial de Albacete (ITAP). En base al estudio de la conductividad eléctrica y a las muestras de suelo analizadas se ha dividido la parcela en 4 zonas diferentes.

\subsection{Caracterización y modelización hidráulica del sistema de riego.}

En primer lugar, se ha modelado el sistema de riego en el programa Epanet, donde, para poder ubicar cada uno de los elementos que componen el sistema de riego, se ha georreferenciado cada uno de los aspersores de la parcela con un GPS Leica Zeno 20 (de precisión centimetrica). La ubicación de cada uno de estos puntos se ha llevado a AutoCAD, donde se han añadido el resto de elementos (tuberías y válvulas) siguiendo el plano de instalación del sistema de riego. Con un programa creado en entorno MATLAB, se ha obtenido finalmente el diseño del modelo hidráulico de Epanet para cada uno de los sectores de riego, integrado el diseño del sistema de riego de AutoCAD (indicando los diferentes diámetros de las tuberías en función del color asignado) y el Modelo Digital del Terreno (MDT) con paso de malla de $5 \mathrm{~m}$ descargado del Centro de Descargas del CNIG (Centro Nacional de Información Geográfica), con el objetivo de conocer la cota del suelo y así poder ubicar en altura cada uno de los elementos.

Para determinar el coeficiente de descarga de los aspersores, estos fueron ensayados en la Estación de Seguimiento de Maquinaria Agrícola (ESEMA), donde se realizaron el mismo número de ensayos para los dos tipos de aspersores (circulares y sectoriales), con presiones de $20 \mathrm{mca}, 25 \mathrm{mca}, 30 \mathrm{mca}, 35$ mca, $40 \mathrm{mca}, 45 \mathrm{mca}, 50 \mathrm{mca}$ y $55 \mathrm{mca}$. Realizando un total de 50 ensayos, debido a que se realizaron repeticiones con distintas unidades, con el objetivo de disminuir el posible error (tanto de medida, como de variabilidad entre unidades de un mismo modelo de aspersor), obteniendo para cada una de dichas presiones el caudal emitido, mediante un caudalímetro electromagnético (permitiendo obtener la curva presión-caudal introducida a cada aspersor en el modelo hidraulico de Epanet) y la curva radial de distribución de agua, con pluviómetros de área conocida colocados a 0,6 m de separación.

Se ha realizado una calibración del modelo de Epanet, con el objetivo de introducir al programa las rugosidades optimas en cada tuberia y ajustarlo de una forma precisa al comportamiento real del sistema, para ello se han utilizado transductores de presión colocados estratégicamente en la parcela y conectados a unos Datalogger desarrollados y fabricados en por la sección del Instituto de Desarrollo Regional (IDR) Precisión Agroforestal y Cartográfica (PAFyC) de la Universidad de Castilla-La Mancha (UCLM), permitiendo almacenar datos de presión cada segundo. Para dicha calibración se ha colocado en cada sector y evento de riego, un total de 4 transductores de presión, los cuales se encuentran funcionando de forma simultánea. En el primer sector se ha colocado el primer transductor en cabecera (con el objetivo de almacenar todos los datos de presión inicial), el segundo se ha colocado en el último aspersor del primer ramal (para la calibración del ramal con mayor presión), el tercero se ha colocado en la válvula correspondiente al último ramal (para la calibración de la tubería secundaria) y el cuarto se ha colocado en el último aspersor del ramal donde se encuentra la situado el transductor de la válvula (para la calibración del ramal con menor presión). En cuanto al segundo sector se ha seguido la misma estrategia, pero en este caso se han realizado más determinaciones en otros puntos, moviendo el segundo transductor al segundo y tercer aspersor más desfavorable.

Con los datos obtenidos por los datalogger para cada sector, se ha creado un programa en entorno MATLAB utilizando la dll de Epanet, el cual introduce la presión en cabecera en cada segundo durante todo el riego objetivo y realiza para cada una de estas presiones tantas simulaciones en Epanet como es necesario, modificando en cada una de ellas la rugosidad de tres tipos de tuberías previamente 


\section{Congreso Nacional de Riegos CARTAGENA 2021}

asignadas (tuberías primarias y secundarias, tuberías porta-aspersores y aspersores), de manera que, se comparan (para todas las simulaciones) los resultados de presiones simuladas en los aspersores donde se han colocado los transductores de presión, con el valor real de dichas presiones medido en campo, realizando un proceso de optimización, el cual determina de manera estadística el valor de rugosidad de cada uno de los diferentes elementos integrados que minimiza el error, obtenido así una precisa calibración del modelo hidráulico de Epanet.

La planificación de riegos del cultivo de cebolla la ha llevado a cabo el propio agricultor de la parcela, apoyado por una sonda de humedad colocada por la empresa Nutricontrol, además, dicha empresa ha instalado un programador web de riegos, el cual, ademas de permitir controlar los solenoides que abren y cierran la válvula principal y la de los dos sectores de riego, registra en su plataforma web los valores de caudal y presión en cabecera de cada uno de los eventos de riegos, con intervalos de tiempo de registro de entre 10 y 20 minutos. Estos datos, ampliados con los registros del datalogger instalado en cabecera, se han utilizado para registrar las presiones y caudales de cada uno de los eventos de riego.

\subsection{Determinación de la distribución de agua en la parcela}

Para la simulación de la distribución de agua en el suelo de cada aspersor, se ha utilizado el programa informático SIRIAS, el cual es capaz de simular la distribución de agua bajo la influencia del viento, utilizando teoría balística para simular la trayectoria de las gotas descargadas, de manera que, integrando las variables del viento intensidad y dirección, permite obtener una distribución de agua distorsionada por el viento [11]. Además, el programa tiene en cuenta las perdidas por evaporación y arrastre derivadas del proceso del riego. Para ello, a SIRIAS se le han introducido las curvas radiales ensayadas (tanto de los aspersores circulares como de los sectoriales), realizando simulaciones cada 1 mca, con un rango de presiones desde $25 \mathrm{mca}$ a $55 \mathrm{mca}$, donde para cada una de las presiones se han simulado todas las condiciones de viento posibles, con rangos de intensidades cada $1 \mathrm{~m} / \mathrm{s}$, desde una hipótesis sin viento $(0 \mathrm{~m} / \mathrm{s})$ hasta un máximo de $6 \mathrm{~m} / \mathrm{s}$ y con intervalos de dirección del viento cada $10^{\circ}$, obteniendo una base de datos de 6.727 posibilidades de presión y variabilidad de viento para cada tipo de aspersor (13.454 en total).

Para poder realizar una simulación de la distribución de agua en un sector completo y real de riego, el grupo de investigación PAFyC ha desarrollado el programa SORA 2021, programado en entorno MATLAB, el cual es capaz de realizar una simulación de la distribución del agua de riego en cada metro cuadrado de la parcela, distinguiendo entre sectores de riego, donde, la presión en cabecera es cambiante (en este caso, se ha utilizado para toda la campaña de riegos una media de presiones cada 30 minutos, usando los registros de la plataforma de Nutricontrol y del datalogger propio ubicado en cabecera) y en base a esto, integrado el modelo hidráulico de Epanet (con la dll), cada aspersor tendrá una presión diferente para el período de tiempo de riego simulado, además, el programa integra las variables del viento (intensidad y dirección), utilizando datos climáticos de viento cada 30 minutos (coincidiendo con los tiempos de riego y la media de presiones) obtenidos de la estación de la red SIAR de Motilleja, ubicada a $18 \mathrm{~km}$ de la parcela. Para esta simulación, el programa utiliza la base de datos de simulaciones de SIRIAS, la cual contiene todas las posibilidades de presiones y dirección e intensidad de viento, en este caso se han tratado todos los aspersores del sector como circulares, puesto que los puntos a analizar se encuentran fuera del radio de la superficie mojada de dichos aspersores. De manera que, se ha realizado la simulación del sector 1, obteniendo el agua aplicada durante toda la campaña de riegos en cada metro cuadrado de suelo. Tras dividir el valor obtenido entre el número total de horas de riego, se ha obtenido la pluviosidad. 


\subsection{Monitorización del cultivo y determinación de la producción}

Para el seguimiento del cultivo, se realizaron un total de 5 vuelos de dron, espaciados en el tiempo a lo largo del ciclo de cultivo, portando una cámara RGB (con un tamaño de pixel de $1 \mathrm{~cm}$ ) y 2 cámaras multiespectrales (Micasense RedEdge MX y Parrot Sequoia), aunque en este caso solo se han utilizado las ortoimágenes multibanda de la cámara Micasense Red Edge MX (con un tamaño de pixel de $5 \mathrm{~cm}$ ) con la que se ha determinado el índice de vegetación de diferencia normalizada (NDVI). Antes de realizar los 3 últimos vuelos, se colocaron estratégicamente en cada una de las 4 zonificaciones por tipo de suelo unos marcos metálicos de $1 \mathrm{~m} \times 1 \mathrm{~m}$ (coincidiendo con el ancho de las camas de la cebolla), los cuales se pueden diferenciar en las ortoimágenes, en estos marcos se realizó un muestreo de biomasa, donde se contaron el número de cebollas y se cogió una muestra de 5 bulbos (con el calibre más representativo del marco), las cuales fueron pesadas en fresco y posteriormente secadas en una estufa para obtener la materia seca.

Para poder comparar la producción del cultivo en cada uno de los cuatro puntos con el resto de parámetros, solamente se tuvo en cuenta el peso en fresco de las 5 cebollas muestreadas el día 13/08/2021 en cada una de las zonas de la parcela, donde el bulbo ya había alcanzado su máximo desarrollo y todavía el cuello de la cebolla se encontraba turgente.

Con 3 de los 4 marcos de $1 \mathrm{~m} \times 1 \mathrm{~m}$ (correspondientes a las 3 zonas por tipo de suelo que se encuentran en el sector 1) se ha realizado una comparación entre el NDVI (obtenido con la cámara multiespectral Micasense RedEdge MX el día 13/08/2021, coincidiendo con la realización del muestreo), la producción de cebollas obtenida en el muestro y la pluviosidad media en ese metro cuadrado concreto, con el objetivo de encontrar una relación entre la pluviosidad, el índice NDVI y la producción.

\section{Resultados y discusión}

Se ha obtenido la distribución de agua en el suelo mediante el programa SORA 2021, pero solo se ha tenido en cuenta en el sector 1, siendo suficiente para comprobar la influencia del riego en el desarrollo del cultivo, ya que, el principal objetivo para este trabajo es comprobar de forma visual que la pluviosidad de las diferentes zonas se ajusta al índice NDVI (Figura 1) y relacionar la pluviosidad, el NDVI y la producción (utilizando el peso de las muestras recogidas), en los marcos de $1 \mathrm{~m} \times 1 \mathrm{~m}$ donde se realizaron los muestreos de biomasa (Figuras 2, 3 y 4). 


\section{AREYD}

CARTAGENA 2021

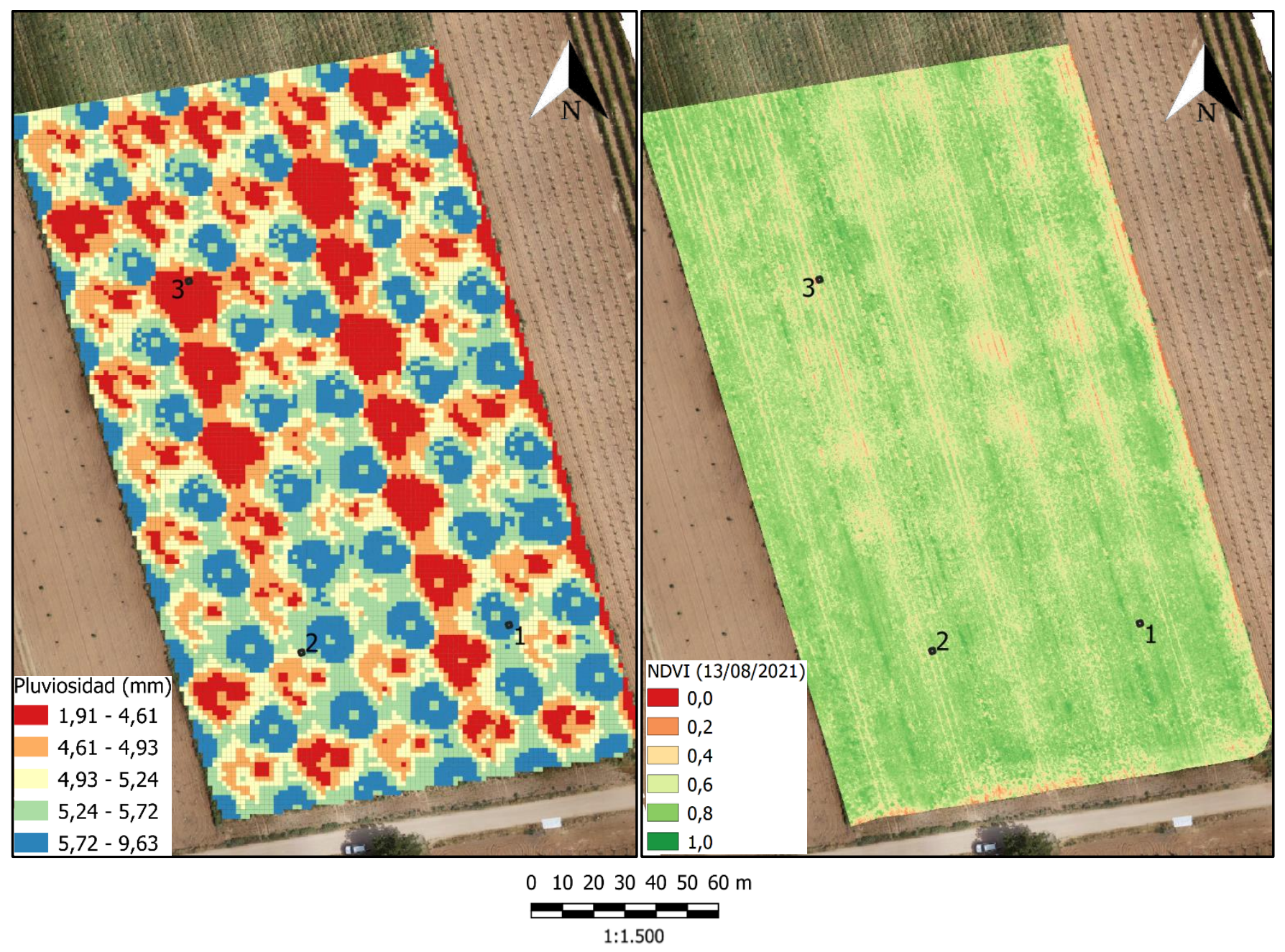

Figura 1. Pluviosidad del sistema de riego (izquierda) e índice NDVI el día 13/08/2021 (izquierda). Los puntos muestran las zonas de control de producción.

En la figura 1 se puede observar de forma visual que las zonas con menor y mayor pluviosidad coinciden directamente con las zonas de menor y mayor índice NDVI, incluso sin tener en cuenta la zonificación por características de suelo. En cuanto al mapa de pluviosidad, para la comparación con el índice NDVI hay que descartar el área de influencia de la primera línea de aspersores del lateral izquierdo y de la zona inferior de la parcela, debido a que los aspersores de esas dos líneas son sectoriales y la simulación se ha realizado teniendo en cuenta todos los aspersores como circulares (por lo que en dicha zona la cantidad de agua aplicada es mayor). En posteriores actualizaciones del programa SORA 2021 se introducirá la base de datos SIRIAS de los aspersores sectoriales, siendo el programa capaz de distinguirlos y utilizar la curva radial correspondiente. También se añadirá el sector 2 de riego, con el objetivo de analizar toda la parcela. 


\section{Congreso Nacional de Riegos}

CARTAGENA 2021

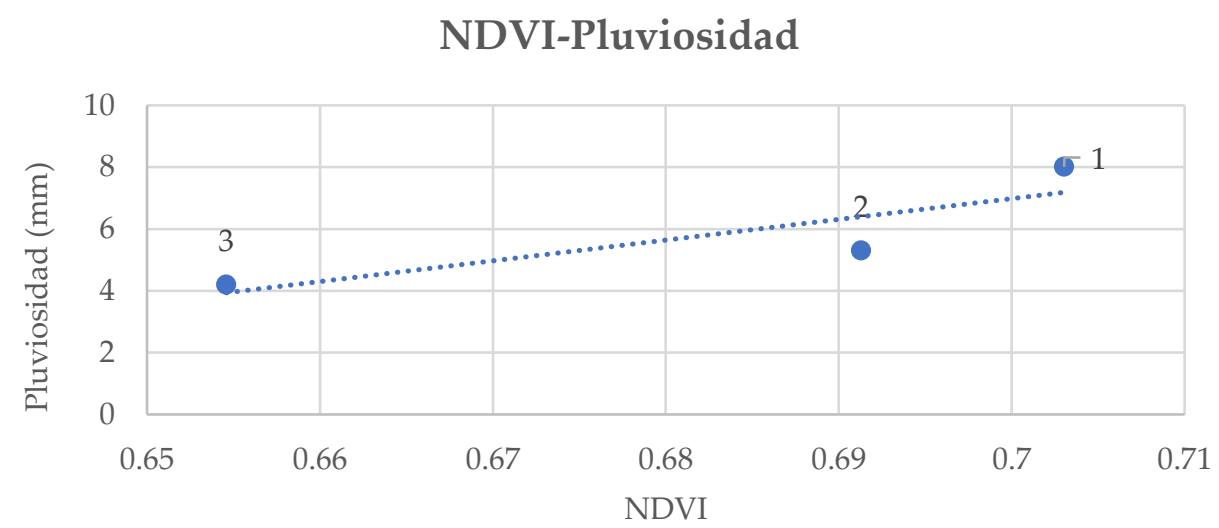

Figura 2. Relación entre el índice NDVI y la pluviosidad en cada uno de los marcos de muestreo.

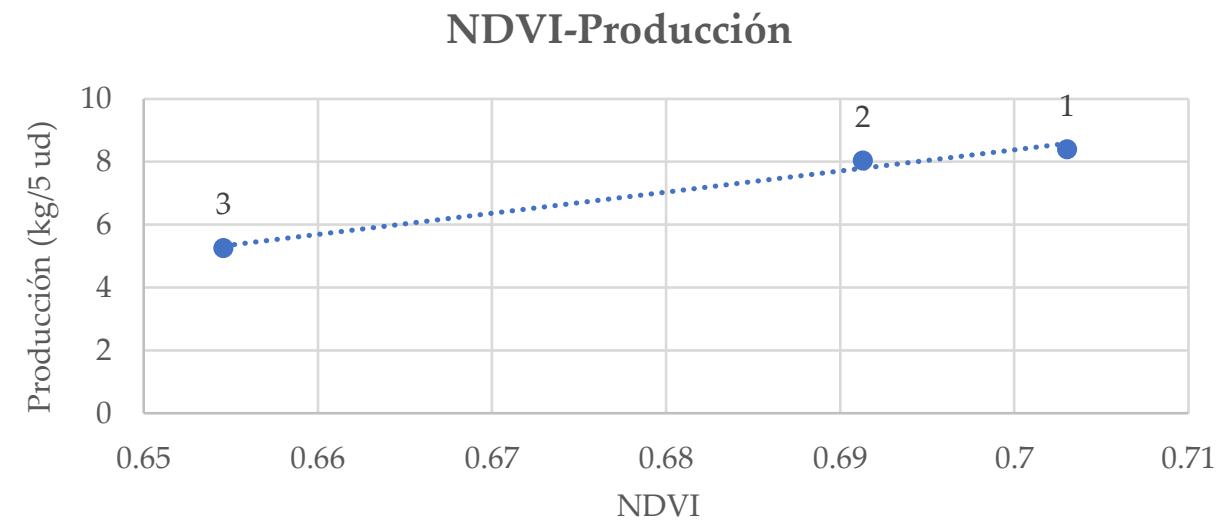

Figura 3. Relación entre el índice NDVI y la producción obtenida en cada uno de los marcos de muestreo.

\section{Pluviosidad-Producción}

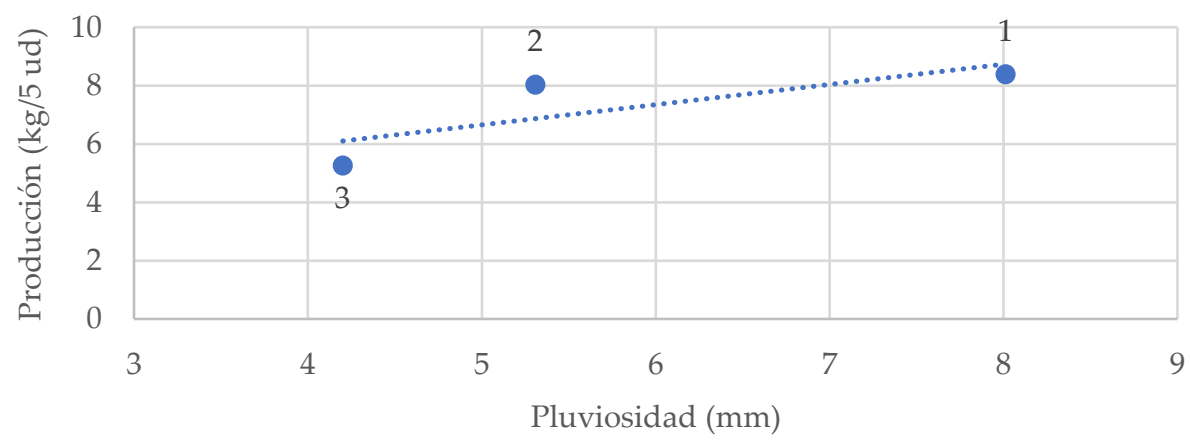

Figura 4. Relación entre la pluviosidad y la producción obtenida en cada uno de los marcos de muestreo. 


\section{Congreso Nacional de Riegos CARTAGENA 2021}

En cuanto a la comparación de la pluviosidad, producción y NDVI en los marcos de muestreo (Figuras 2, 3, y 4), se puede observar a través de una línea de tendencia que existe una relación directa entre el agua de riego aplicada (obtenida mediante la simulación) y el desarrollo del cultivo, teniendo en cuenta que cada uno de los marcos se encuentra en una zonificación de suelo diferente, donde por potencial productivo del suelo, el cultivo se desarrollará de distinta forma.

Para la caracterización del cultivo y la futura calibración en el programa AquaCrop, se realizó seguimiento fenológico con 19 muestreos, controlando además el correcto desarrollo del cultivo y sus diferente etapas fenológicas (en la escala $\mathrm{BBCH}$ ). Los mismos días que se realizaron los seguimientos fenológicos, se llevó a cabo un vuelo con un dron DJI Mini 2, para obtener imágenes RGB del cultivo y determinar así el grado de cobertura, obteniendo curva Kc del cultivo. Por lo que el siguiente paso es realizar la calibración del cultivo en AquaCrop y las simulaciones de cultivo correspondientes a cada sector de riego y zonificación por tipo de suelo, con el objetivo de obtener los kilogramos por metro cuadrado de parcela, obteniendo los índices; productividad del agua $\left(\mathrm{kg} / \mathrm{m}^{3}\right)$ y productividad de la energía $(\mathrm{kg} / \mathrm{kWh})$.

\section{Conclusiones}

El modelo integrado es capaz de simular un sector real de riego, teniendo en cuenta las variaciones de presión en cabecera, la no uniformidad de presiones en los diferentes aspersores y la dirección e intensidad del viento. Como prueba de que la simulación se ajusta a la realidad, se ha obtenido una evidente relación visual entre la pluviosidad en cada metro cuadrado con el índice NDVI, además, se ha conseguido relacionar directamente la pluviosidad con la producción de cebollas muestreadas en los diferentes puntos.

\section{Referencias}

1. FAO 2009. Cómo alimentar al mundo 2050. Foro de expertos de alto nivel: URL_http://www.fao.org/fileadmin/templates/wsfs/docs/synthesis_papers/C\%C3\%B3mo_alimentar_al_mundo_en_2050.pdf. Consultado: 20 de junio de 2021.

2. Moutonnet, P. Yield response factors of field crops to deficit irrigation. Food and Agriculture Organization of the United Nations (FAO). Deficit irrigation practices. 2002, pp. 11-15.

3. Carrillo-Cobo, M. T.; Camacho-Poyato, E.; Montesinos, P.; Rodríguez Díaz, J. Assessing the potential of solar energy in pressurized irrigation networks. The case of Bembézar MI irrigation district (Spain). Spanish journal of agricultural research 2014, volume $12 n^{\circ}$ 3, pp. 838-849.

4. Tarjuelo, J. M.; Rodriguez-Diaz, J. A.; Abadía, R.; Camacho, E.; Rocamora, C.; Moreno, M. A. Efficient water and energy use in irrigation modernization: Lessons from Spanish case studies. Agricultural Water Management 2015, volume 162, pp. 67-77.

5. Martínez Alzamora, F. EPANET. Una potente herramienta para el análisis de redes de distribución de agua a presión. Revista Hidropres. Tecnología de Captación, Gestión y Tratamiento Del Agua., 2003, pp. 30-37.

6. Rosman, L. A. Epanet 2 manual de usuario. US Environmental Protection Agency, Cincinnati, Ohio, 2001; pp. 1-2.

7. Montero, J.; Tarjuelo, J.; Carrión, P. SIRIAS: A simulation model for sprinkler irrigation. Irrigation Science, 2001, volume $20 n^{\underline{0}}$ 2, pp. 85-98.

8. Boote, K. J.; Jones, J. W.; Hoogenboom, G.; White, J. W. The role of crop systems simulation in agriculture and environment. International Journal of Agricultural and Environmental Information Systems (IJAEIS), 2010, volume $1 n^{\circ}$ 1, pp. 41-54.

9. Montoya Sevilla, F. Calibración y validación de modelos para la simulación de patata (Solanum tuberosum L.) bajo diferentes tratamientos de riego con pivot en condiciones semiáridas. Tesis doctoral, Universidad de Castilla-La Mancha, Albacete, 2013.

10. Steduto, P.; Hsiao, T. C.; Fereres, E.; Raes, D. Respuesta del rendimiento de los cultivos al agua. Estudio FAO: Riego y Drenaje (FAO), 2012, spa no 66, pp. 1-3.

11. Carrión, P.; Tarjuelo, J.; Montero, J. SIRIAS: a simulation model for sprinkler irrigation. Irrigation Science, 2001, volume $20 n^{\circ}$ 2, pp. 73-84. 


\title{
Efectos de la supresión del riego durante la postcosecha de nectarinos extra-tempranos en la acumulación de reservas nu- tricionales, producción y calidad del fruto
}

\author{
Conesa, M.R., Conejero, W., Vera, J., Ruiz-Sánchez, M.C.
}

Departamento de Riego, CEBAS-CSIC, Campus de Espinardo, 25, 30100 Murcia; mrconesa@cebas.csic.es; wenceslao@cebas.csic.es; jvera@cebas.csic.es; mcruiz@cebas.csic.es

Resumen: En nectarinos extra-tempranos cultivados en condiciones mediterráneas, se evaluó la idoneidad del largo periodo de postcosecha (mayo-octubre) para desarrollar estrategias de riego deficitario controlado. Para ello, se establecieron 4 tratamientos de riego: (i) Control (T-CTL): regado al 100\% ETc durante todo el año; (ii) Estrés 1 (T-E1): supresión del riego en la postcosecha temprana (junio y julio); (iii) Estrés 2 (T-E2): supresión del riego en la postcosecha tardía (agosto y septiembre), y iv) Estrés 3 (T-E3): supresión del riego durante todo el período postcosecha (junio-septiembre). Salvo en las fases de estrés, todos los tratamientos recibieron idénticas dosis de riego que T-CTL. La producción total y el número de frutos por árbol fue mayor en T-CTL y T-E1, que en el resto de tratamientos de estrés. Además, el tratamiento T-E2 registró el mayor porcentaje de frutos agrietados. El análisis de reservas en raíz mostró valores significativamente más altos de arginina y fósforo en los árboles del tratamiento T-E1 seguido de T-CTL. No se observaron diferencias significativas entre tratamientos en los parámetros de calidad físico-química estudiados. Estos resultados sugieren que el periodo de postcosecha tardía (agosto-septiembre), es más sensible que el de postcosecha temprana (junio-julio) al déficit hídrico severo, pues disminuye la acumulación de reservas nutricionales, afectando al rendimiento del cultivo.

Palabras clave: arginina; almidón; déficit hídrico; fósforo; postcosecha; rendimiento 


\title{
Effects of withholding irrigation during the postharvest period of extra-early nectarine trees on the accumulation of nutritional reserves, yield and fruit quality.
}

\author{
Conesa, M.R., Conejero, W., Vera, J., Ruiz-Sánchez, M.C.
}

Departamento de Riego, CEBAS-CSIC, Campus de Espinardo, 25, 30100 Murcia; mrconesa@cebas.csic.es; wenceslao@cebas.csic.es; jvera@cebas.csic.es; mcruiz@cebas.csic.es

\begin{abstract}
In extra-early nectarines grown under Mediterranean conditions, the suitability of the long post-harvest period (May-October) to develop deficit irrigation strategies was evaluated. For this purpose, 4 irrigation treatments were established: (i) Control (T-CTL): irrigated at 100\% ETc throughout the year); (ii) Stress 1 (T-E1): withhoding irrigation during early postharvest (June and July); (iii) Stress 2 (T-E2): withhoding irrigation during late postharvest (August and September), and (iv) Stress 3 (T-E3): withhoding irrigation during the whole postharvest period (June-September). Except for the stress phases, all treatments received identical irrigation doses as T-CTL. Total yield and number of fruits per tree were higher in T-CTL and T-E1. In addition, T-E2 treatment showed the highest percentage of cracked fruits. The reserves analysed in root samples showed significantly higher values of arginine and phosphorus in T-E1 treatment followed by T-CTL. No significant differences were observed between treatments in the physico-chemical quality parameters studied. These results suggest that the late post-harvest period (August-September) is more sensitive than the early post-harvest period (June-July) to severe water deficit, as it reduces the accumulation of nutritional reserves, affecting crop yield.
\end{abstract}

Keywords: arginine; phosphorus; postharvest; starch; water deficit; yield 


\section{Congreso Nacional de Riegos CARTAGENA 2021}

\section{Introducción}

La aridez de los agro-sistemas mediterráneos requiere aplicar técnicas que optimicen el uso del agua, minimizando el impacto sobre las cosechas y la calidad de los frutos. Para ello, el riego debe adaptarse a cada cultivo en función de su fenología [1-3]. En este sentido, el conocimiento del comportamiento hídrico del árbol en cada fase fenológica, es esencial para identificar los periodos conocidos como críticos, en los que restricciones en el riego pueden tener efectos adversos, siendo este concepto la base del denominado Riego Deficitario Controlado (RDC) [4].

En frutales de hueso, las fases de floración y cuajado, así como la última fase de rápido crecimiento del fruto son especialmente sensibles a la falta de agua, siendo la fase de endurecimiento del hueso donde se pueden aplicar restricciones en el riego sin afectar al rendimiento del cultivo [5,6] Así mismo, en variedades de maduración temprana y extra-temprana, caracterizadas por tener cortos periodos de crecimiento del fruto y una larga postcosecha, se considera ésta última como el periodo más adecuado para la aplicación de déficit hídrico [7-9]. Sin embargo, dado que la producción de un año depende, además, de lo acontecido durante el período de postcosecha anterior (de elevada demanda hídrica en condiciones mediterráneas), resulta conveniente ajustar la programación del riego para evitar que un déficit hídrico severo afecte en los procesos de inducción y diferenciación florales, y en consecuencia ocasione una menor fructificación en la campaña siguiente.

La arginina es uno de los 20 aminoácidos esenciales que se sintetizan en todas las especies vegetales y se considera la principal fuente de reserva nitrogenada en frutales de hoja caduca, como el nectarino, pudiendo ser considerada como un indicador metabólico general del cultivo [10]. Su utilización por parte del árbol, depende de las reservas de almidón que posea. El equilibrio entre ambos, es fundamental para el buen desarrollo de los estadios de brotación y cuajado del fruto. Por otro lado, una adecuada absorción y almacenamiento de fósforo en la raíz determina el desarrollo del fruto y demás órganos vegetales [11].

El objetivo de este trabajo fue evaluar los efectos de la supresión del riego en determinados momentos de la fase de postcosecha de nectarinos extra-tempranos, sobre la acumulación de reservas nutricionales (arginina, almidón y fósforo), producción y calidad del fruto, a fin de identificar la idoneidad de este periodo para aplicar estrategias de RDC.

\section{Materiales y métodos}

\subsection{Condiciones de la parcela experimental}

El ensayo se realizó durante la postcosecha (mayo-octubre) del ciclo de crecimiento 2020-2021 en una parcela de 0,5 ha de nectarinos extra-tempranos (Prunus persica (L.) Batsch cv. 'Flariba'), de 10 años de edad, injertados sobre GxN-15 y distribuidos a un marco de plantación de 6,5 $\mathrm{m} \times 3,5 \mathrm{~m}$, en la finca experimental del CEBAS-CSIC, situada en Santomera-Murcia ( $\left.38^{\circ} 06^{\prime} \mathrm{N}, 1^{\underline{0}} 02^{\prime} \mathrm{O}\right)$. El suelo de textura franco-arcillosa presentaba una densidad aparente de $1,43 \mathrm{~g} \mathrm{~cm}^{-3}$ y bajos niveles de materia orgánica (1.3\%) y capacidad de intercambio catiónico $\left(97,9 \mathrm{mmol} \mathrm{kg}{ }^{-1}\right)$. El contenido de agua en el suelo $\left(\Theta_{\mathrm{v}}\right)$ a capacidad de campo (CC) y punto de marchitez (PM) fue del 29 y 14\%, respectivamente. El agua de 


\section{Congreso Nacional de Riegos CARTAGENA 2021}

riego procedía de la Comunidad de Regantes Azarbe del Merancho, y sometida a procesos de limpieza y desalación en la propia finca, presentaba una conductividad eléctrica $\left(\mathrm{CE}_{25^{\circ} \mathrm{C}}\right) \mathrm{de} 1 \mathrm{dS} \mathrm{m} \mathrm{m}^{-1} \mathrm{y} \mathrm{pH}$ de 8 .

El sistema de riego consistió en una única línea porta-emisores, con 4 emisores de $4 \mathrm{~L} \mathrm{~h}^{-1}$ dispuestos a 50 y $130 \mathrm{~cm}$ a ambos lados del tronco. Los árboles recibieron 83-56-109 $\mathrm{kg} \mathrm{ha}^{-1} \mathrm{y}$ año-1 de $\mathrm{N}$, $\mathrm{P}_{2} \mathrm{O}_{5}$ y K $\mathrm{K}_{2} \mathrm{O}$, respectivamente, mediante fertirriego [12]. Las prácticas culturales (control de malas hierbas, tratamientos fitosanitarios, aclareo y poda) fueron las habituales para frutales de hueso de la zona. Los datos climáticos (evapotranspiración de referencia (ETo), según la ecuación de Penman-Monteith [13], y precipitación) procedían de una estación climática automática, situada en la propia finca (http://www.cebas.csic.es/general_spain/est_meteo.html).

\subsection{Tratamientos}

- Periodo de preacondicionamiento (mayo): Todos los árboles se regaron al 100\% de la evapotranspiración del cultivo (ETc), en función de los valores de ETo de la semana previa y los coeficientes de cultivo (Kc) locales de Abrisqueta et al. [14] = Tratamiento Control (T-CTL).

- Periodo de estrés (junio-septiembre): Se establecieron 3 tratamientos de estrés, por supresion del riego: Estrés 1 (T-E1): durante la postcosecha temprana (junio y julio); Estrés 2 (T-E2): durante la postcosecha tardía (agosto y septiembre); y Estrés 3 (T-E3): durante toda la fase postcosecha (junio-septiembre).

- Periodo de recuperación (octubre): Todos los árboles se regaron como T-CTL (100\% ETc).

El diseño estadístico fue de bloques al azar con 4 repeticiones de 6 árboles por repetición (24 árboles por tratamiento) empleando los 4 centrales para las medidas.

\subsection{Medidas}

- Estado hídrico del suelo: medidas discretas, al final de cada periodo, del contenido de agua en el suelo $\left(\Theta_{\mathrm{v}}\right)$ a $15 \mathrm{~cm}$ de profundidad, con sensor Acclima-TDR (Time Domain Reflectometry), junto al emisor situado a $50 \mathrm{~cm}$ del tronco, en 8 árboles representativos por tratamiento (2 árboles/repetición), siguiendo las recomendaciones de Vera et al. [15].

- Estado hídrico del árbol: medidas semanales del potencial hídrico foliar antes del alba ( $\Psi_{\text {a }}$ y de tallo a mediodía solar $\left(\Psi_{\mathrm{t}, \mathrm{md}}\right)$, con cámara de presión (Soil Moisture Equipment Corp., Model 3000) en 4 hojas tratamiento ( 1 hoja por árbol/repetición) siguiendo las recomendaciones de Hsiao [16].

- Reservas nutricionales: contenido de arginina, almidón y fósforo en raíces, por un laboratorio acreditado (AGQ-Labs: http://www.agq.com.es/). En la parada invernal (10 diciembre 2020) se obtuvieron muestras de raíces suberizadas (4-8 mm grosor) en 8 árboles por tratamiento (2 por repetición), en zanjas de $30-50 \mathrm{~cm}$ de profundidad realizadas con retroexcavadora (Optimal Modelo OP03) a $10 \mathrm{~cm}$ de la hilera de árboles, entre el primer y segundo emisor.

- Producción: La recolección se realizó el 1 de mayo de 2021, controlándose el peso total, número de frutos por árbol y porcentaje de frutos agrietados en todos los árboles del ensayo (24 árboles/tratamiento). Previamente, se eliminaron los frutos 'no comercializables'. 


\section{Congreso Nacional de Riegos CARTAGENA 2021}

- Calidad del fruto: En muestras de 60 nectarinas por tratamiento (15 frutos/repetición), se evaluó la calidad físico-química: (i) Peso fresco, con balanza de precisión (Mettler PE 360 DeltaRange, Suiza); (ii) diámetro ecuatorial, con calibre digital (Mitutoyo, CD-15D); (iii) firmeza, con texturómetro (AGROSTA® 100Field, Francia); (iv) color, con colorímetro (Minolta CR-10, Osaka, Japón) según el sistema de coordenadas CIE L*a*b*, calculando la saturación del color (Chroma) $\left[\mathrm{C}^{*}=\left(\mathrm{a}^{2}+\mathrm{b}^{2}\right)^{1 / 2}\right]$ y el tono o matiz (ángulo Hue) $\left[\mathrm{h}^{*}=\arctan \left(\mathrm{b}^{*} / \mathrm{a}^{*}\right)\right] ;(\mathrm{v})$ sólidos solubles totales (SST) $\mathrm{y}$ acidez titulable $(A T)$, con medidor digital (Atago PAL-BX/ACID F5 Master Kit- Multifrutas, Japón), cuyos resultados fueron expresados como ${ }^{\circ}$ Brix y $\mathrm{mg}$ ácido málico $\mathrm{L}^{-1}$ de jugo, respectivamente. A partir de estos últimos, se calculó (vii) índice de madurez (IM) =SST/ AT.

\subsection{Análisis estadístico}

El análisis de varianza (ANOVA) se realizó con el programa SPSS versión 13.0 para Windows, así como la prueba de comparación múltiple de Duncan, a un nivel de confianza del 95\%.

\section{Resultados y discusión}

\subsection{Riego y Climatología}

Durante el periodo de estudio, la climatología típicamente mediterránea registró una ETo de $1097 \mathrm{~mm}$ y una precipitación de $206 \mathrm{~mm}$, distribuida de forma irregular como es característico de la zona [3] (Tabla 1). El tratamiento T-CTL recibió un volumen de agua total de $616 \mathrm{~mm}$, similar al recomendado para nectarino extra-temprano con riego localizado en la Región de Murcia [17]. Los tratamientos T-E1 (supresión del riego postcosecha temprana) y T-E2 (supresión del riego postcosecha tardía), supusieron una reducción del riego aplicado respecto a T-CTL del 46,5 \% y del 41,5\%, respectivamente, mientras que en T-E3, la reducción fue del 92\% (Tabla 1).

Tabla 1: Evapotranspiración de referencia $\left(\mathrm{ET}_{0}\right)$, precipitación y riego en los tratamientos de riego durante la post- y pre-cosecha de la estación de crecimiento 2020/2021.

\begin{tabular}{|c|c|c|c|c|}
\hline & Post-Cosecha $^{1}$ & Pre-Cosecha ${ }^{2}$ & Total & $\begin{array}{c}\text { \% Reducción } \\
\text { T-CTL }\end{array}$ \\
\hline $\mathrm{ET}_{0}(\mathrm{~mm})$ & 931 & 166 & 1097 & \\
\hline Precipitación (mm) & 28 & 178 & 206 & \\
\hline \multicolumn{5}{|l|}{ Riego (mm) } \\
\hline T-CTL & 589 & 27 & 616 & \\
\hline T-E1 & 303 & 27 & 329 & $46,5 \%$ \\
\hline T-E2 & 333 & 27 & 360 & $41,5 \%$ \\
\hline T-E3 & 23 & 27 & 50 & $92 \%$ \\
\hline
\end{tabular}




\section{Congreso Nacional de Riegos CARTAGENA 2021}

\subsection{Estado hídrico del suelo y la planta}

Los valores medios de $\Theta_{\mathrm{v}}$ al final de los periodos de preacondicionamiento y recuperación fueron similares en todos los tratamientos, debido a la ausencia de déficit hídrico (Figura 1A), oscilando entre 29-34\%, próximos a capacidad de campo. Al final del estrés en la postcosecha temprana (T-E1) y tardía (T-E2) se observó una reducción $\approx 75 \%$ en los valores de $\Theta_{v}$ respecto a T-CTL. El tratamiento T-E3, registró valores similares a los tratamientos T-E1 y T-E2, con valores de $\Theta_{\mathrm{v}} \approx 7-9 \%$ (Figura 1A).

Las figuras $1 \mathrm{~B}$ y $\mathrm{C}$ muestran los valores medios del $\Psi_{\mathrm{a}}$ y $\Psi_{\mathrm{t}, \mathrm{md}}$ al final de cada periodo de riego. Bajo condiciones de ausencia de deficit hídrico, $\Psi_{\mathrm{t}, \mathrm{md}}$ osciló en un rango de 0.59-0.88 $\mathrm{MPa}$, lo que indicó que el suministro hídrico fue adecuado [8, 17, 18]. Al final del periodo E1 (supresión del riego en la postcosecha temprana), los tratamientos T-E1 y T-E3 mostraron diferencias significativas respecto a T-CTL, con valores medios de $\Psi_{\mathrm{t}, \mathrm{md}}$ de $-1,86$ y $-2,27 \mathrm{MPa}$, respectivamente. Al final del periodo E2 (supresión del riego en la postcosecha tardía), los tratamientos T-E2 y T-E3 mostraron una reducción del $60 \%$ en los valores de $\Psi_{\mathrm{t}, \mathrm{md}}$ respecto al T-CTL, con valores medios de -1,72 MPa (T-E2) y -2,00 MPa (T-E3). Girona et al. [19] y Naor et al. [20] establecieron un valor umbral de $\Psi_{\mathrm{t}, \mathrm{md}}$ de -1,5 MPa para garantizar la fertilidad y floración del melocotonero y de -2,0 MPa para limitar la aparición de frutos dobles. Cabe destacar que $\Psi_{\text {a }}$ minimizó las diferencias entre tratamientos, al compararlo con $\Psi_{\mathrm{t}, \mathrm{md}}$. Sin embargo, la tendencia estacional entre $\Psi_{\mathrm{a}}$ fue similar a $\Psi_{\mathrm{t}, \mathrm{md}}$, lo que se comprobó en la relación encontrada entre ambos parámetros $\left[\Psi_{\mathrm{t}, \mathrm{md}}=-0,90+1,21 \Psi_{\mathrm{a}}, \mathrm{r}^{2}=0,67^{* * *}\right]$ (datos no mostrados). Conesa et al. [21] establecieron al $\Psi_{\mathrm{t}, \mathrm{md}}$ como indicador más fiable para determinar el estado hídrico de nectarinos extra-tempranos.
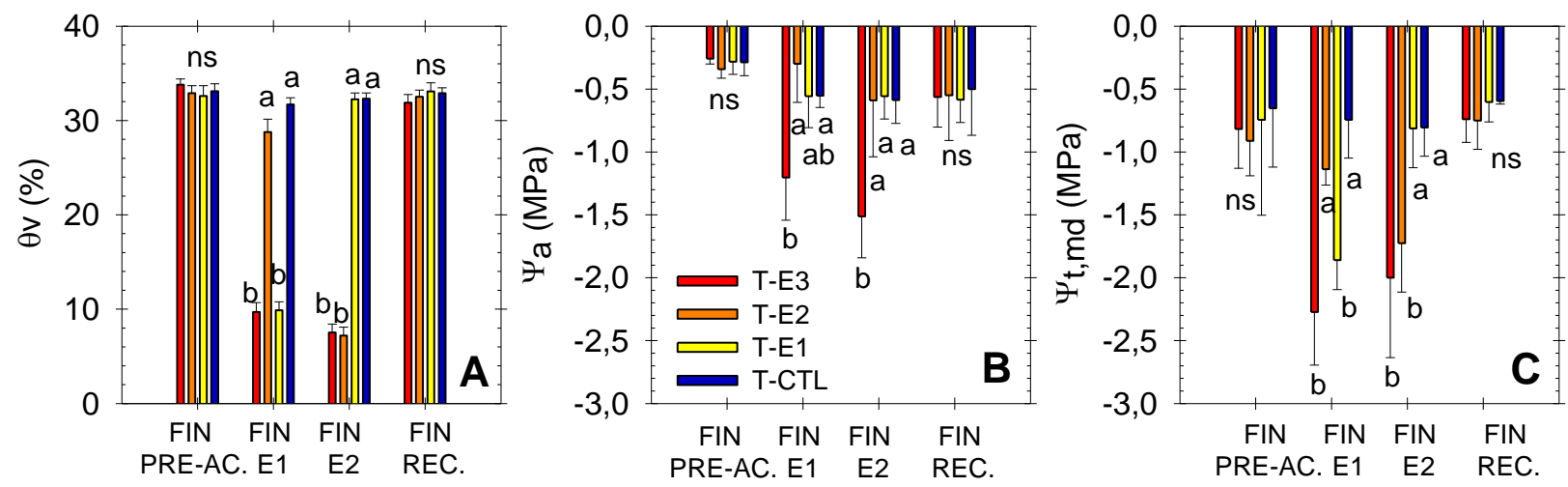

Periodos de riego

Figura 1. Valores al final de los periodos de pre-acondicionamiento (PRE-AC.), estrés 1 (E1), estrés 2 (E2) y recuperación (REC.) de: (A) contenido volumétrico de agua en el suelo $\left(\Theta_{v}\right),(B)$ potencial hídrico foliar antes del alba $\left(\Psi_{a}\right)$ y (B) potencial hídrico de tallo al mediodía ( $\Psi_{\mathrm{t}, \mathrm{md}}$ ) en los tratamientos de riego. Cada barra es la media de 8 medidas con Acclima-TDR y 4 hojas \pm error estándar. Las letras distintas indican diferencias significativas entre tratamientos, según el test de Duncan $(p<0.05)$; ns: no significativo.

\subsection{Producción}

La producción total fue significativamente inferior en T-E2 (supresión del riego postcosecha tardía) y T-E3 (supresión del riego postcosecha completa), con una reducción respecto a T-CTL del 50\% 


\section{Congreso Nacional de Riegos CARTAGENA 2021}

y 75\%, respectivamente. Del mismo modo, el número de frutos fue significativamente reducido en T-E2 y T-E3. No se encontraron diferencias entre T-E1 y T-CTL, hecho que pone de manifiesto la capacidad de aplicar estrategias de RDC durante la postcosecha temprana (junio-julio). Cabe destacar que el tratamiento T-E2 registró el mayor porcentaje de frutos agrietados $(>50 \%)$, aunque éste no fue significativo, podría apuntar a una mayor sensibilidad para reducir el riego en este periodo (postcosecha tardía). Se conoce que un manejo inadecuado del riego durante la postcosecha temprana de frutales de hueso puede afectar a los procesos de inducción y diferenciación floral [22], por ello, los dos meses posteriores a la recolección son considerados críticos [9]. Sin embargo, nuestros resultados demuestran que el periodo de postcosecha tardía (agosto-septiembre) fue el más sensible al déficit hídrico severo, en términos productivos.

Tabla 2. Producción de nectarina, $\mathrm{n}^{\mathrm{o}}$ frutos por árbol y porcentaje de frutos agrietados en los tratamientos de riego.

\begin{tabular}{cccc}
\cline { 2 - 4 } & $\begin{array}{c}\text { Producción }^{\mathrm{z}} \\
\left.\text { (kg árbol }^{-1}\right)\end{array}$ & $\begin{array}{c}\text { Número frutos } \\
\text { (frutos árbol }^{-1} \text { ) }\end{array}$ & $\begin{array}{c}\text { Frutos } \\
\text { agrietados }\end{array}$ \\
\hline T-CTL & $23,90 \mathrm{a}$ & $319 \mathrm{a}$ & 28 \\
T-E1 & $18,66 \mathrm{a}$ & $223 \mathrm{ab}$ & 39 \\
T-E2 & $15,90 \mathrm{~b}$ & $205 \mathrm{~b}$ & 52 \\
T-E3 & $13,59 \mathrm{~b}$ & $168 \mathrm{~b}$ & 35 \\
\hline ANOVA & $*$ & $* *$ & $\mathrm{~ns}$ \\
\hline
\end{tabular}

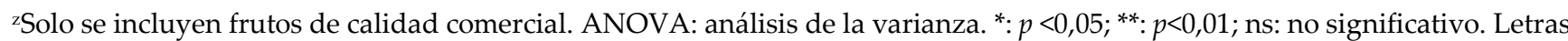
diferentes en cada columna indican diferencias significativas entre tratamientos según el test de Duncan $(p<0,05)$.

\subsection{Calidad del fruto}

No se observaron diferencias significativas entre tratamientos, en ninguno de los parámetros de calidad físico-química estudiados (Tabla 3), si bien los datos de SST y el IM estuvieron por debajo del límite de consumo, debido al carácter astringente de la variedad de nectarino estudiada [18].

Tabla 3. Peso fresco, diámetro ecuatorial, firmeza, parámetros de color $\left(\mathrm{L}^{*} \mathrm{C}^{*} \mathrm{~h}^{\circ}\right)$, sólidos solubles totales (SST), acidez titulable (AT) e índice de madurez (IM) en los tratamientos de riego.

\begin{tabular}{lccccccccc}
\hline & $\begin{array}{c}\text { Peso fresco } \\
\mathbf{( g )}\end{array}$ & $\begin{array}{c}\text { Diámetro } \\
\mathbf{( m m )}\end{array}$ & $\begin{array}{c}\text { Firmeza } \\
\mathbf{( N )}\end{array}$ & $\mathbf{L}^{*}$ & $\mathbf{C}^{*}$ & $\mathrm{~h}^{\circ}$ & ${ }^{\circ}$ Brix) & $\mathbf{( m g ~ \mathbf { L } ^ { - 1 } )}$ & $\mathbf{I M}$ \\
\hline T-CTL & 140,92 & 65,56 & 88,94 & 36,97 & 36,14 & 21,90 & 8,60 & 1,10 & 7,83 \\
T-E1 & 142,66 & 65,76 & 90,04 & 37,42 & 37,33 & 23,22 & 8,71 & 1,04 & 8,41 \\
T-E2 & 136,03 & 63,89 & 85,94 & 37,61 & 36,16 & 24,20 & 9,08 & 1,08 & 8,38 \\
T-E3 & 134,65 & 63,96 & 87,08 & 37,87 & 38,11 & 24,37 & 8,26 & 1,05 & 7,91 \\
\hline ANOVA & $\mathrm{ns}$ & $\mathrm{ns}$ & $\mathrm{ns}$ & $\mathrm{ns}$ & $\mathrm{ns}$ & $\mathrm{ns}$ & $\mathrm{ns}$ & $\mathrm{ns}$ & $\mathrm{ns}$ \\
\hline
\end{tabular}

ANOVA: análisis de la varianza. ns: no significativo 


\section{Congreso Nacional de Riegos CARTAGENA 2021}

\subsection{Reservas nutricionales}

En general, los valores obtenidos de reservas en raíces fueron bajos, en relación a los que se consideran normales para la especie estudiada (Prunus sp.). El contenido de fósforo fue mayor en los tratamientos T-CTL y T-E1 (Figura 2A). El contenido de almidón fue similar en todos los tratamientos de riego (Figura 2B). La arginina registró los valores más altos en el tratamiento T-E1 seguido de T-CTL $>$ T-E2> T-E3 (Figura 2C). Diversos estudios han mostrado los beneficios de la aplicación exógena de arginina como fuente de reserva de nitrógeno sobre el rendimiento productivo y la calidad de los frutos [23-25]. Eslami et al. [26] observó una reducción en la caída fisiológica de frutos de pistacho y abcisión foliar, tras la aplicación exógena de arginina. En este sentido, los valores altos de arginina y fósforo en raíz obtenidos en T-E1 y T-CTL, explicarían el incremento en el rendimiento prodictiven de estoc tratamientoc (Tahla ?)
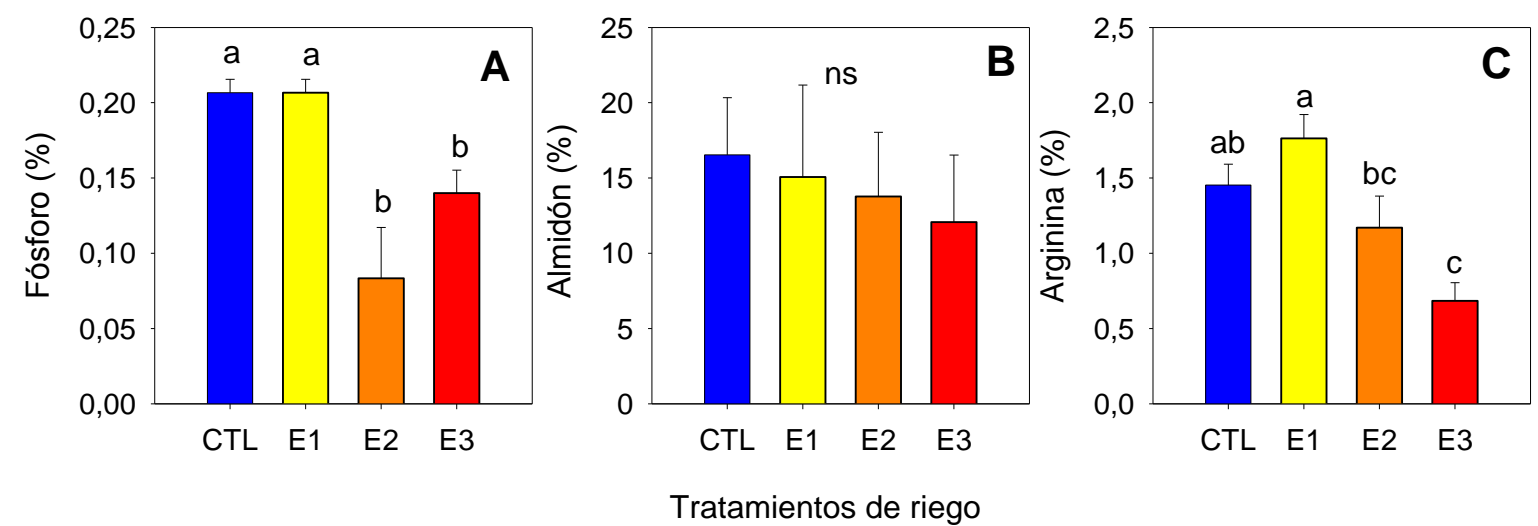

Figura 2. (A) fósforo, (B) almidón, y (C) arginina en raíces de los tratamientos de riego. Cada barra es la media de 8 muestras \pm error estándar. Las letras distintas indican diferencias significativas entre tratamientos según el test de Duncan ( $p<0.05)$; ns: no significativo.

\section{Conclusiones}

En nectarino extra-temprano cultivado en condiciones mediterráneas, el periodo de postcosecha temprana (junio-julio) es clave en la aplicación de estrategias de RDC por su influencia en los procesos de inducción y diferenciación foliar. Sin embargo, nuestros resultados indican que el periodo de postcosecha tardía (agosto-septiembre) fue el más sensible al déficit hídrico severo al reducir la acumulación de reservas nutricionales en las raíces, especialmente arginina y fósforo, lo que afectó al rendimiento productivo.

\section{Agradecimientos}

El trabajo se ha financiado con el proyecto PID2019-106226RB-C2-1 (Plan Nacional-AEI) y 19903/GERM/15 (Fundación Séneca, Región de Murcia). M.R. Conesa agradece la ayuda posdoctoral disfrutada del programa Juan de la Cierva (FJCI-2017-32045).

\section{Referencias}

1. Naor, A. Irrigation scheduling and evaluation of tree water status in deciduous orchards. Hortic. Rev. 2006, 32, 111-116.

2. Katerji, N.; Mastrorilli, M.; Rana, G. Water use efficiency of crops cultivated in the Mediterranean region: Review and analysis. Eur. J. Agron. 2008, 28, 493-507. 


\section{Congreso Nacional de Riegos CARTAGENA 2021}

3. Fernández-García, I.; Lecina, S.; Ruiz-Sánchez, M.C.; Vera, J.; Conejero, W.; Conesa, M.R.; Dominguez A.; Pardo, J.J.; Léllis, B.C.; Montesinos, P. Trends and challenges in irrigation scheduling in the semi-arid area of Spain. Water. 2020,12 (3), 785.

4. Chalmers, D.J.; Mitchell, P.D.; Van Heek, L.A.G. Control of peach tree growth and productivity by regulated water supply, tree density, and summer pruning. J. Am. Soc. Hortic. Sci. 1981, 106, 307-312.

5. Fereres, E.; Soriano, M.A. Deficit irrigation for reducing agricultural water use. J. Exp. Bot. 2006, 58, 147-159.

6. Ruiz-Sánchez, M.C.; Domingo, R.; Castel, J.R. Review. Deficit irrigation in fruit trees and vines in Spain. Span J Agric Res. 2010, 8(S2), 5- 20.

7. Mounzer, O.H.; Conejero, W.; Nicolás, E.; Abrisqueta, I.; García-Orellana, Y.; Tapia, L.M.: Vera, J.; Abrisqueta, J.M.; Ruiz-Sánchez, M.C. Growth pattern and phenological stages of early maturing peach trees under a Mediterranean climate. HortSci. 2008, 43(6), 1813-1818.

8. De la Rosa, J.M.; Domingo, R.; Gómez-Montiel, J.; Pérez-Pastor, A. Implementing defcit irrigation scheduling through plant water stress indicators in early nectarine trees. Agric Water Manag. 2015, 152, 207-216.

9. Ruiz-Sánchez, M.C.; Abrisqueta, I.; Conejero, W.; Vera, J. Deficit irrigation management in early-maturing peach crop. En: Water Scarcity and Sustainable Agriculture in Semiarid Environment. Tools, Strategies, and Challenges for Woody Crops. ISBN 978-0-12-813164-0. Elsevier. Chapter 6. 2018, 111-126 pp.

10. Kliewer, W.M.; Cook, J.M. Arginine Levels in Grape Canes and Fruits as Indicators of Nitrogen Status of Vineyards. Am. J. Enol. Vitic. 1974, 25, 111-118.

11. Fox, R.L. External Phosphorus Requirements of Crops. En: Chemistry in the Soil Environment, Vol. 40. (Eds). R. H. Dowdy,J. A. Ryan,V. V. Volk,D. E. Baker, ISBN:9780891183068. American Society of Agronomy and Soil Science Society of America, Inc. (ASA Special Publications). Chapter 12. 1981, 105-189 pp.

12. Vera, J.; De la Peña, J.M. FERTIGA: Programa de fertirrigación de frutales. CEBAS-CSIC, Murcia, Spain. 1994, 69 pp.

13. Abrisqueta, I.; Abrisqueta, J.M.; Tapia, L.M.; Munguía, J.P.; Conejero, W.; Vera J.; Ruiz-Sánchez, M.C. Basal crop coefficients for early-season peach trees. Agric. Water Manage. 2013, 121, 158-163.

14. Allen, R.G.; Pereira, L.S.; Raes, D.; Smith, M. Crop Evapotranspiration: Guidelines for Computing Crop Water Requirements; Food and Agriculture Organization of the United Nations: Rome, Italy. 1998.

15. Vera, J.; Conejero, W.; Mira-García, A.B.; Conesa, M.R.; Ruiz-Sánchez, M.C. Towards irrigation automation based on dielectric soil sensors. J. Hortic. Sci. Biotech. 2021. https://doi.org/10.1080/14620316. 2021.1906761

16. Hsiao, T.C. Measurement of tree water status. En: Steward, B,. A., Nielsen, D.R. (Eds), Irrigation of Agricultural Crops. Agronomy Monograph No.30. American Society of Agronomy. Madison. WI. 1990. 243-279 pp.

17. Vera, J.; Conejero, W.; Conesa, M.R.; Ruiz-Sánchez, M.C. Irrigation factor approach based on soil water content: A nectarine orchard case study. Water 2019 11, 589.

18. Conesa, M.R.; Conejero, W.; Vera, J.; Agulló, V.; García-Viguera, C.; Ruiz-Sánchez, M.C. Irrigation management practices in nectarine fruit quality at harvest and after cold storage. Agric. Water Manage. 2021, 243, 106519.

19. Girona, J.; Gelly, M.; Mata, M.; Arbonés, A.; Rufat, J.; Marsal, J. Peach tree response to single and combined deficit irrigation regimes in deep soils. Agric. Water Manage. 2005, 72, 97-108.

20. Naor, A.; Stern, R.; Peres, M.; Greenblat, Y.; Gal, Y.; Flaishman, M.A. Timing and severity of postharvest water stress affect following-year productivity and fruit quality of field-grown 'Snow Queen' nectarine. J. Am. Soc. Hortic. Sci. 2005, 130, 806812.

21. Conesa, M.R.; Conejero, W.; Vera, J.; Ramírez-Cuesta, J.M.; Ruiz-Sánchez, M.C. Terrestrial and remote indexes to assess moderate deficit irrigation in early-maturing nectarine trees. Agronomy. 2019, 9 (10), e630.

22. Faust, M. Physiology of temperate zone fruit trees. John Wiley \& Sons, Inc. Estados Unidos de América. 1989. 215pp.

23. Abdul-Qados, A.M.S. Effect of arginine on growth, yield and chemical constituents of wheat grown under salinity condition. Acad. J. Plant Sci. 2009, 2(4), 267-278.

24. Mohseni, F.; Pakkish, Z.; Panahi, B. Arginine impact on yield and fruit qualitative characteristics of strawberry. Agric. Conspec. Scient. 2017, 82(1), 19-26.

25. Naser, A.S.M.T.G.; Azeez, H.A.S.D.R. Effect of arginine and some nutrients in the vegetative and fruit growth of Zaghinia Apricot tress (Prunus armeniaca L.). Mesopotamia Journal of Agriculture, 2019. 47 pp.

26. Eslami, M.; Nasibi, F.; Kalantari, K.M.; Khezri, M.; Oloumi, H. Effect of Exogenous Application of L-arginine and Sodium Nitroprusside on Fruit Abscission and Physiological Disorders of Pistachio (Pistacia Vera L.) Scions. Int. J. Hortic. Sci. 2019, 6 (1), 51-62. 


\title{
Evaluación de sensores de contenido de agua en el suelo para gestionar riegos de precisión
}

\author{
Vera, J., Conejero, W., Conesa, M.R., Mira-García, A.B., Ruiz-Sánchez, M.C. \\ Departamento de Riego, CEBAS-CSIC, Campus de Espinardo, 25, 30100 Murcia; jvera@cebas.csic.es; wenceslao@cebas.csic.es; mrcone- \\ sa@cebas.csic.es; abmira@cebas.csic.es; mcruiz@cebas.csic.es
}

Resumen: La escasez de agua y la necesidad de abastecer de alimentos de mayor calidad nutricional y organoléptica a una demanda cada vez más exigente y sensible por los sistemas de producción ha propiciado una gran tecnificación del riego. Esta tecnificación incluye el riego localizado, la fertigación y las mejoras en la toma de decisiones basadas en las necesidades hídricas del cultivo en cada etapa fenológica. Una de esas mejoras es la incorporación de sensores de contenido de agua para monitorizar la humedad del bulbo. En este trabajo se compara la respuesta de dos tipos de sensores comerciales de contenido volumétrico de agua en el suelo basados en la estimación de la constante dieléctrica: EnviroPro (capacitivo) y Acclima-TDR (Time Domain Reflectometry), instalados a 0,2, 0,4 y 0,6 $\mathrm{m}$ de profundidad y a 0,1 $\mathrm{m}$ del gotero, en una parcela de limeros (Citrus latifolia Tan. cv. Bearss) cultivados en meseta, en la finca experimental del CEBAS-CSIC (Santomera, Murcia) en un suelo franco-arcilloso. La gestión del riego localizado consistió en establecer umbrales de inicio y parada del riego basados en un agotamiento máximo permisible de agua en el perfil del suelo (MAD, de sus siglas en inglés Maximum Allowable Depletion) del 30\%. EL MAD considera una fracción de la reserva de agua útil, que varía desde capacidad de campo (CC) hasta el punto de marchitez (PM), parámetros estrechamente ligados a la textura del suelo. Los valores de contenido de agua en el suelo determinados con Acclima-TDR fueron ligeramente superiores a los obtenidos mediante el modelo matemático (dependiente de los porcentajes de arena, limo, arcilla y materia orgánica, y de la compactación del suelo): $0,35 \mathrm{~m}^{3} \mathrm{~m}^{-3}$ para capacidad de campo y $0,30 \mathrm{~m}^{3} \mathrm{~m}^{-3}$ para el $30 \%$ de MAD. Sin embargo, las lecturas correspondientes medidas con EnviroPro fueron de 0,54 y $0,38 \mathrm{~m}^{3} \mathrm{~m}^{-3}$ respectivamente. Además, las tendencias observadas en las curvas de agua en el suelo no fueron paralelas durante el ensayo, con una respuesta a la humectación y su redistribución más rápida en el caso de los sensores de capacitancia. De estos resultados cabe concluir que la gestión del riego de precisión requiere sensores cuyas características de exactitud, precisión y volumen de suelo explorado sean compatibles con el rango de MAD establecido (en este caso $0,04 \mathrm{~m}^{3} \mathrm{~m}^{-3}$ ), lo que se consiguió con los sensores TDR.

Palabras clave: Acclima-TDR; agua útil; EnviroPro; humedad del suelo; riego de precisión; MAD 


\title{
XXXVIII Congreso Nacional de Riegos CARTAGENA 2021
}

\section{Evaluation of soil water content sensors for precision irrigation management}

\author{
Vera, J., Conejero, W., Conesa, M.R., Mira-García, A.B., Ruiz-Sánchez, M.C. \\ Irrigation Departament, CEBAS-CSIC, Campus de Espinardo, 25, 30100 Murcia; jvera@cebas.csic.es; wenceslao@cebas.csic.es; mrcone- \\ sa@cebas.csic.es; abmira@cebas.csic.es; mcruiz@cebas.csic.es
}

\begin{abstract}
Water scarcity and the need to supply food of higher nutritional and organoleptic quality to an increasingly demanding and sensitive demand for production systems has led to a great technification of irrigation. This includes drip irrigation, fertigation and improvements in decision-making based on the crop water requirements at each phenological stage. One of these improvements is the use of water content sensors to monitor soil water status. This work compares the response of two types of commercial soil volumetric water content sensors based on dielectric constant estimation: EnviroPro (capacitive technique) and Acclima-TDR (Time Domain Reflectometry technique), installed at $0.2,0.4,0.6$ and $0.8 \mathrm{~m}$ depth and at $0.1 \mathrm{~m}$ from the dripper, in a plot of lime trees (Citrus latifolia Tan. $\mathrm{cv}$. Bearss) grown on ridges in the experimental field station of CEBAS-CSIC, in a clay loam soil. The management of drip irrigation consisted of establishing thresholds values, for start and stop irrigation, based on a Maximum Allowable Depletion (MAD) value of $30 \%$. MAD considers a fraction of the available water, which varies from field capacity (FC) to wilting point (WP), parameters that depend mainly on soil texture. The soil water content values determined with Acclima-TDR sensors showed light discrepancies with those derived from mathematical model (based on the percentages of sand, silt, clay and organic matter). In this case, the corresponding mean values were 0.35 and $0.30 \mathrm{~m}^{3} \mathrm{~m}^{-3}$ for FC and 30\% MAD, respectively, while they were 0.54 and $0.38 \mathrm{~m}^{3} \mathrm{~m}^{-3}$ for EnviroPro probes. In addition, the trends observed in the soil water content curves were not parallel during the studied period, with a faster response to wetting and water re-distribution in the capacitance sensors. From these results it can be concluded that precise irrigation management requires sensors whose accuracy, precision and soil volume exploration characteristics was compatible with the established MAD range (0.04 $\mathrm{m}^{3} \mathrm{~m}^{-3}$ in our conditions). This was accomplished with the TDR sensors.
\end{abstract}

Keywords: Acclima-TDR; available soil water; EnviroPro; precision irrigation; soil water content; MAD 


\section{Congreso Nacional de Riegos CARTAGENA 2021}

\section{Introducción}

La limitación de disponibilidad de recursos hídricos para el riego ha propiciado la tecnificación de riego localizado y el fertiriego, lo que junto con la información derivada de la monitorización del estado hídrico del suelo y de la planta ha acuñado el concepto de Riego de Precisión.

Paralelamente, el estado hídrico del suelo ha servido de referencia para manejar el riego, tanto por el estado energético, mediante tensiómetros, como por el contenido de agua, estimado con sensores [1]. Este último ha experimentado un gran auge en los últimos 30 años gracias al desarrollo de la microelectrónica de sensores inalámbricos y la transmisión de datos al usuario para la toma de decisiones [2].

La tecnología más extendida de monitorización del contenido de agua en el suelo $\left(\theta_{\mathrm{v}}\right)$ se basa en la estimación de la humedad volumétrica a partir de la constante dieléctrica, empleando técnicas capacitivas, como es el caso de los sensores EnviroScan, EnviroPro, Aquacheck, C-probe, Decagon, Teros, o Arifruit. Estos sensores permiten observar el perfil de humedad a diferentes profundidades y derivar el stock hídrico de agua en el suelo. Típicamente la traza de $\theta_{\mathrm{v}}$ entre dos riegos muestra un patrón de escalera descendente en el que durante el día se produce el descenso y por la noche se estabiliza. Esta tendencia ha servido para establecer valores umbrales de inicio y parada del riego de forma gráfica.

Sin embargo, para la determinación cuantitativa del stock hídrico es necesario un laborioso trabajo de calibración que depende del tipo de suelo, su densidad aparente, contenido de materia orgánica y propiedades estructurales.

Otra tecnología para estimar el contenido de agua en el suelo es la reflectometría en el dominio del tiempo (de sus siglas en inglés TDR, time domain reflectometry), desarrollada por Topp [3] y que estima con mayor precisión el tiempo de propagación de un pulso eléctrico en el suelo y permite obtener la constante dieléctrica virtualmente independiente de la textura, salinidad y demás propiedades del suelo. Sin embargo, el coste de estos equipos y su consumo energético no han conseguido un uso extensivo en la agricultura de regadío. Recientemente, esta tecnología se ha miniaturizado mediante nano-electrónica (sensores Acclima), alcanzando una precisión igual o mayor a la de sus predecesores con un coste similar al de los sensores capacitivos.

En este trabajo se presentan los resultados de un ensayo de riego en limeros cv. Bearss cultivados en meseta en una parcela de la finca experimental del CEBAS-CSIC en Santomera (Murcia), monitorizada con sensores capacitivos (EnviroPro) y sensores TDR (Acclima-TDR).

\section{Materiales y métodos}

El ensayo se llevó a cabo durante los meses de verano de 2021 en la finca experimental del CEBAS-CSIC en Santomera (Murcia), en una parcela de 1,2 ha de limeros (Citrus latifolia Tan., cv. Bearss) de 5 años de edad, injertados sobre Citrus macrophylla L., cultivados en meseta, con un marco de plantación de $6 \mathrm{~m} \times 5 \mathrm{~m}$. El suelo es pedregoso, altamente calcáreo (45\% de carbonato cálcico), de textura franco-arcillosa: Arena $40 \%$ p/p, Limo $28 \%$ p/p, Arcilla 32\% p/p con una composicion de 17\% esmectita, $29 \%$ polirgoskita, $41 \%$ illita-mica, $8 \%$ caolinita y $5 \%$ clorita (arcillas tipo 2:1, lo que favorece el desarrollo de grietas en el suelo) y el contenido de materia orgánica fue bajo (1,4\%). El sistema de riego localizado consistió en una doble línea porta-goteros separada $1 \mathrm{~m}$, con 4 goteros autocompensantes de $4 \mathrm{~L} \mathrm{~h}^{-1}$ por árbol, situados equidistantes a 0,75 m del tronco.

La parcela se equipó con los siguientes sensores de contenido de agua en el suelo: EnviroPro, sonda encapsulada capacitiva de 0,8 m tipo "drill and drop" (Entelechy Pty Ltd, Australia) y 


\section{Congreso Nacional de Riegos CARTAGENA 2021}

Acclima-TDR modelo 315H (Acclima, Inc., USA). Ambos sensores se instalaron a 0,1 m del gotero más cercano al tronco y a las profundidades de 0,2, 0,4, 0,6, 0,8 $\mathrm{m}$ (Figura 1) en 4 árboles representativos de la parcela experimental.

A

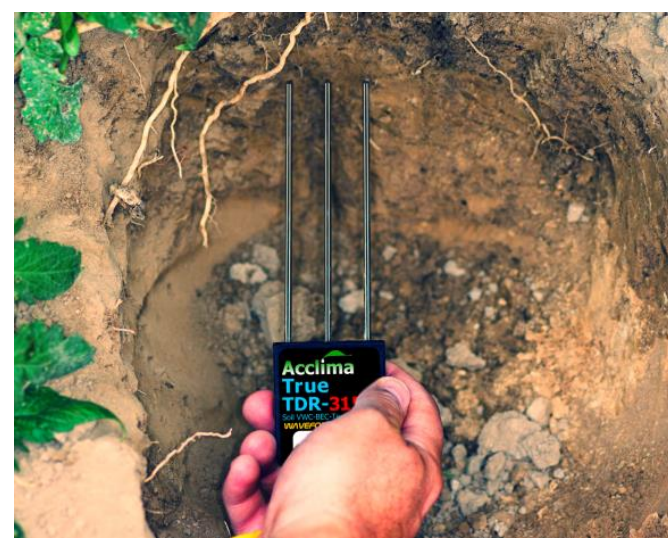

B

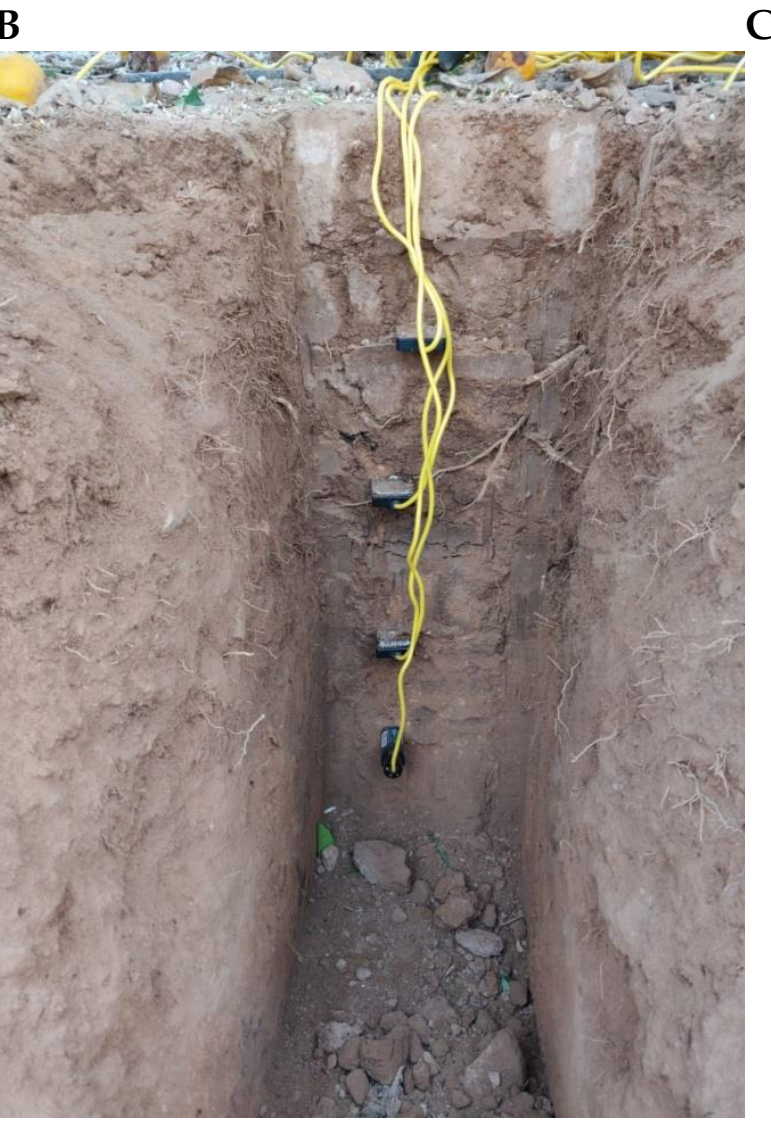

C

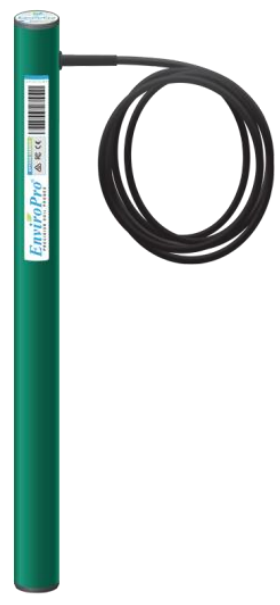

Figura 1. (A) Sensor Acclima-TDR utilizado; (B): Disposición vertical de los sensores Acclima-TDR en el perfil de suelo seleccionado; (C): Sonda EnviroPro de 0,8 m de longitud utilizada.

La programación del riego se realizó de forma automática mediante una red inalambrica de sensores y actuadores (WSAN, Wireless Sensor and Actuator Network). Los sensores permitieron monitorizar en continuo $\theta_{\mathrm{v}}$ en el perfil $0-0,8 \mathrm{~m}$ del suelo y actuar en la apertura/cierre de las electroválvulas. Para ello se establecieron valores umbrales de $\theta_{\mathrm{v}}$ correspondientes a un $30 \%$ de MAD y capacidad de campo para el inicio y fin del riego, respectivamente. El MAD (de sus siglas en inglés Maximum Allowable Depletion) considera una fracción de la reserva de agua útil del suelo, definida como CC menos PM; ambos parámetros estrechamente ligados a la textura del suelo. El sistema de telemetría tomaba lecturas cada $5 \mathrm{~min}$. y registraba el promedio cada $15 \mathrm{~min}$. Las unidades de radio-transmisión enviaban datos al servidor web addVANTAGE (ADCON Telemetry, Austria) para el procesamiento y la visualización de los datos.

De forma previa a la toma de datos, en el caso de la sonda EnviroPro se realizó un ensayo de calibración en laboratorio. Para ello se tomó una muestra de suelo de la parcela que fue tamizado ( $2 \mathrm{~mm})$ y secado en estufa a $105{ }^{\circ} \mathrm{C}$ durante $48 \mathrm{~h}$. El suelo seco se introdujo en cilindros de PVC de $150 \mathrm{~mm}$ de diámetro interno y $190 \mathrm{~mm}$ de altura, compactándose a 1,3-1,6 t m³, haciendo uso para ello de una 


\section{Congreso Nacional de Riegos CARTAGENA 2021}

prensa hidráulica de puente (MECAMAQ). Periódicamente se fueron añadiendo 100 cc de agua de riego hasta producir el drenaje de la columna de suelo.

En el caso del sensor Acclima-TDR, que no precisa de calibración, mide directamente $\theta_{\mathrm{v}}$ a partir de la constante dieléctrica y de la aplicación de la ecuación de Topp [3], ya que no está afectado por la composición mineral ni la estructura del suelo.

\section{Resultados y discusión}

La aplicación del modelo matemático de Saxton y Rawls [4] en las condiciones texturales de diseño obtuvo valores de $0,46 \mathrm{~m}^{3} \mathrm{~m}^{-3}$ (saturación), 0,33 $\mathrm{m}^{3} \mathrm{~m}^{-3}$ (CC) y $0,20 \mathrm{~m}^{3} \mathrm{~m}^{-3}(\mathrm{PM})$, siendo los valores de referencia para la comparación de los distintos sensores estudiados (Figuras 2, 3 y 4).

La curva de calibración realizada en laboratorio de la sonda EnviroPro mostró una relación lineal $y=0,83 x+14,37\left(r^{2}=0,91^{* *}\right)$, donde $y$ es el valor de $\theta_{\mathrm{v}}$ del sensor y $x$ el valor de $\theta_{\mathrm{v}}$ real correspondiente. La densidad aparente del suelo fue determinante en los valores observados por la sonda EnviroPro (Figura 2). Hasta un valor de $\theta_{\mathrm{v}}$ de $0,2 \mathrm{~m}^{3} \mathrm{~m}^{-3}$, las pendientes fueron muy diferentes entre sí, sin un orden lógico por el grado de compactación, posiblemente debido a la presencia de arcillas expandibles que facilitaron la aparición de grietas impidiendo una buena uniformidad de agua en el perfil del cilindro de suelo empleado en la calibración. A partir de valores de humedad superiores, la respuesta de la sonda varió hasta un 50\% según la densidad aparente del suelo, si bien la pendiente en todas las curvas de retención de humedad fue prácticamente la misma, limitadas tan solo en el nivel máximo de agua admisible, mayor cuanto menor fue la densidad aparente.

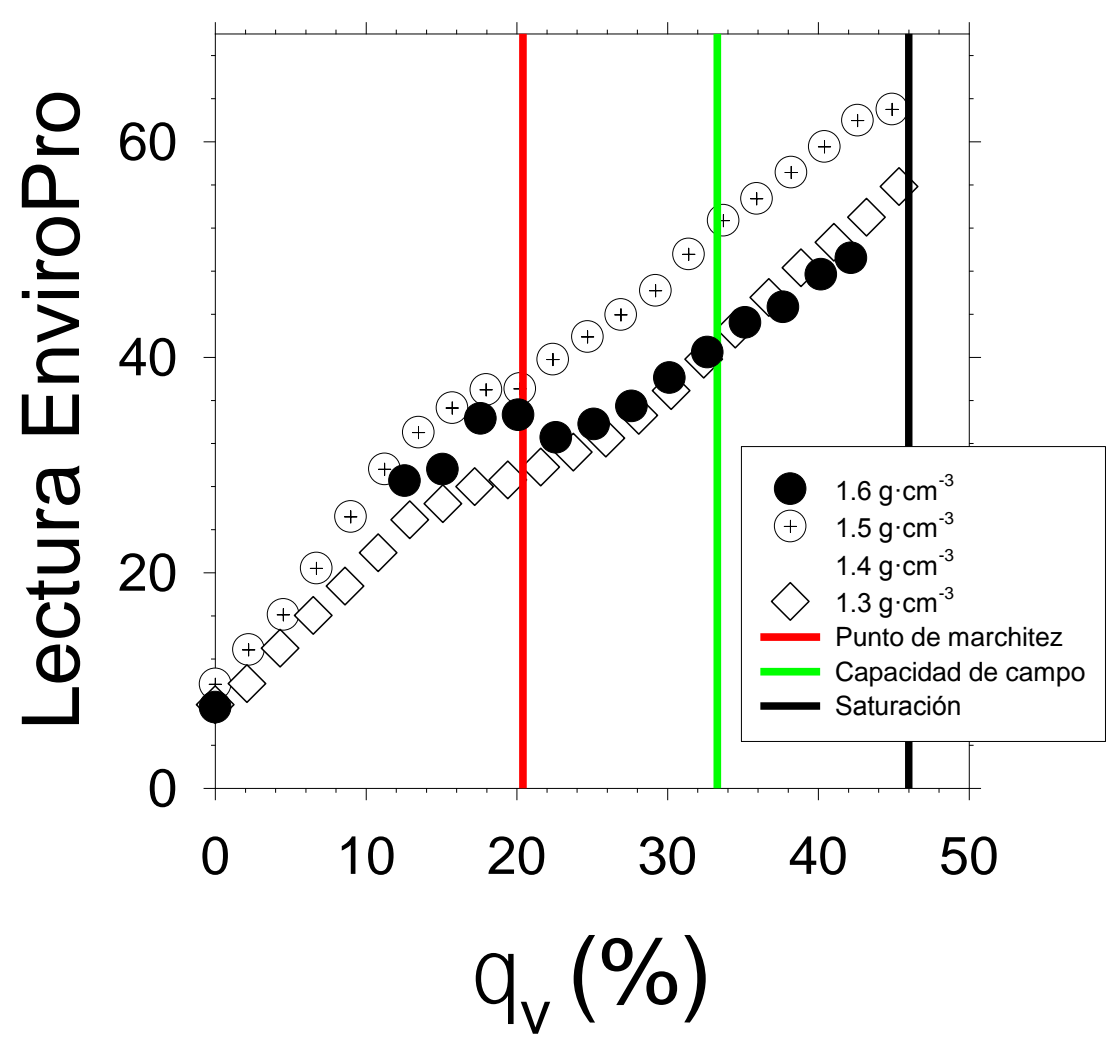

Figura 2. Calibración en laboratorio de sensores EnviroPro, utilizando columnas de PVC (150 mm diámetro y 190 mm alto) rellenas de suelo franco-arcilloso de diferente densidad aparente. 


\section{Congreso Nacional de Riegos CARTAGENA 2021

Las medidas de $\theta_{\mathrm{v}}$ realizadas en campo con sondas EnviroPro, previamente calibradas, generaron un valor de CC de $0,54 \mathrm{~m}^{3} \mathrm{~m}^{-3}$, discrepando de los valores observados en laboratorio (Figura 3). Igualmente, se constató la debilidad en la determinación cuantitativa de $\theta_{\mathrm{v}}$ para el valor de MAD = $30 \%$, que correspondía al umbral establecido como criterio de control para el inicio del riego (Figura 3). Este hecho evidencia los errores derivados de la interpretación de valores absolutos cuando se utiliza esta sonda.

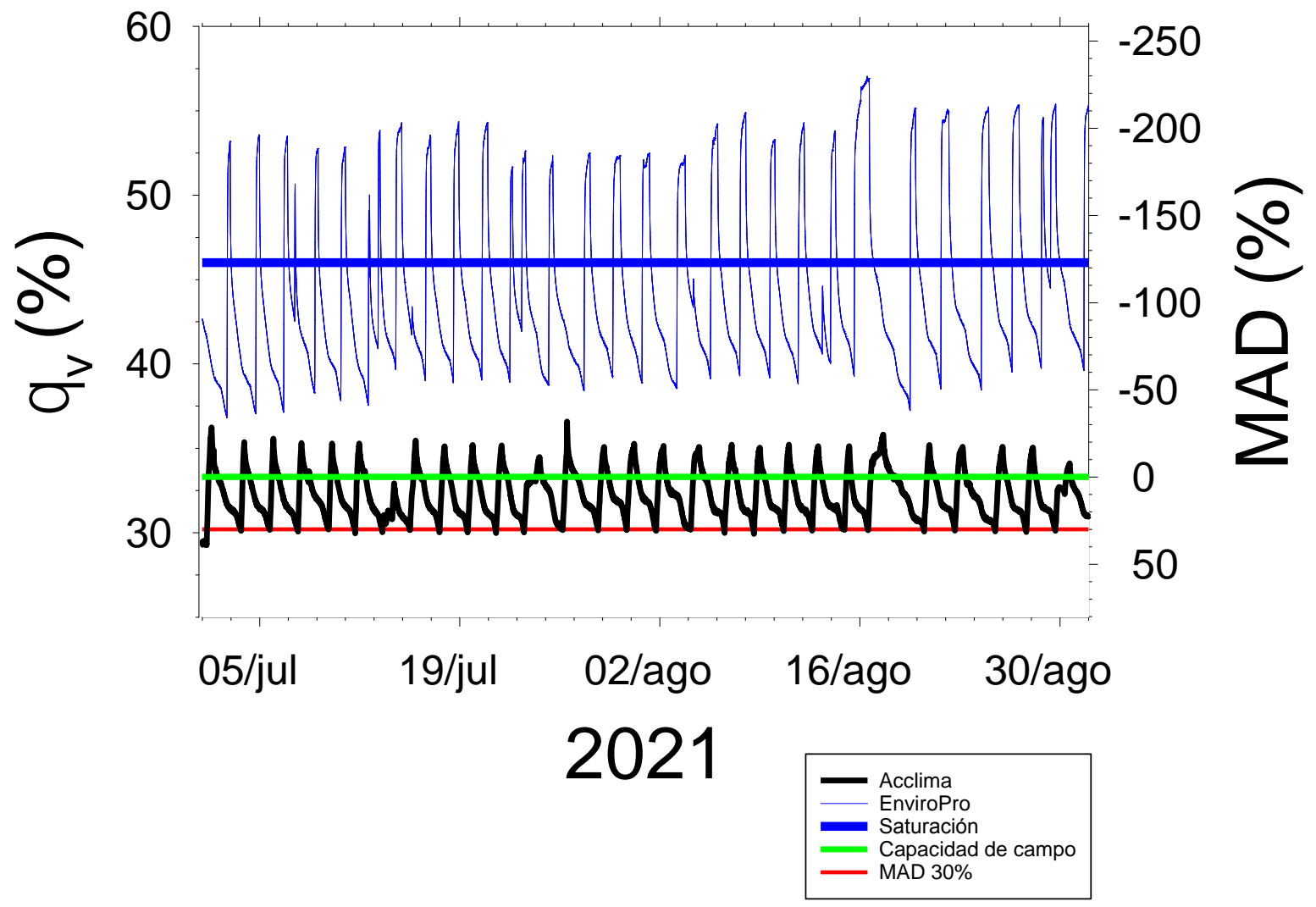

Figura 3. Evolución del contenido medio de agua en el suelo $\left(\theta_{\mathrm{v}}\right)$ monitorizado con sensores EnviroPro y Acclima-TDR en el perfil 0-0,6 m de suelo de la parcela experimental. Las líneas horizontales indican los valores umbrales de $\theta_{\mathrm{v}}: 30 \% \mathrm{MAD}$ y capacidad de campo, para iniciar y detener el riego, respectivamente, y el valor de saturación.

Adicionalmente, el concepto de "tendencia" de la curva de $\theta_{\mathrm{v}}$ fue durante muchos años el criterio empleado para iniciar el riego, ya que éste muestra de forma clara las extracciones de agua por la planta y/o el drenaje durante el periodo diurno y su estabilización durante la noche (Figura 4). 


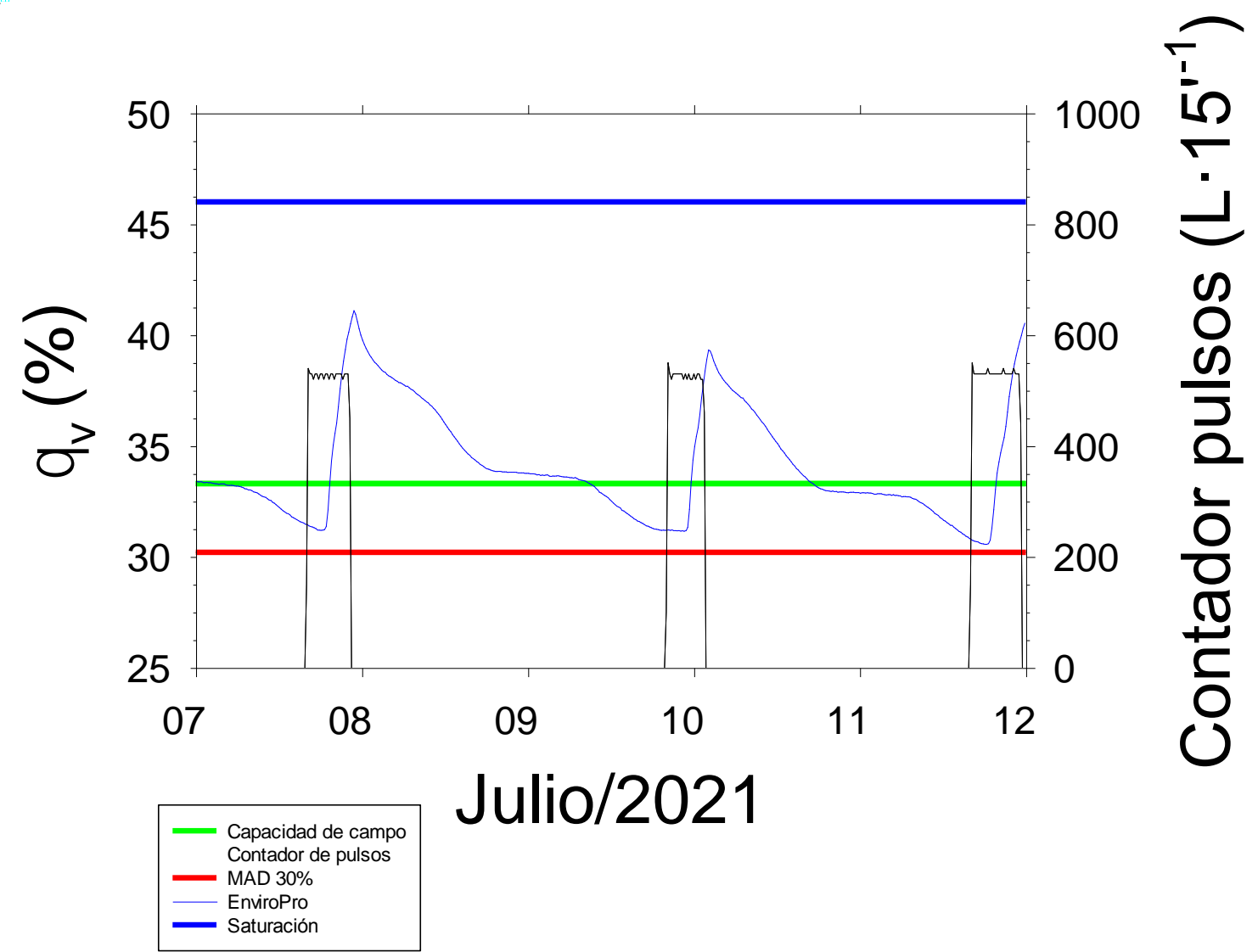

Figura 4. Evolución del contenido volumétrico medio de agua $\left(\theta_{\mathrm{v}}\right)$ en el perfil 0-0,6 m, medido con sonda EnviroPro y los eventos de riego (barras). Las líneas horizontales indican los valores 30\% MAD, capacidad de campo y saturación.

Las medidas de $\theta_{\mathrm{v}}$, realizadas con sensores Acclima-TDR en campo, mostraron valores de CC de $0,35 \mathrm{~m}^{3} \mathrm{~m}^{-3}$, demostrando una ligera diferencia con los valores del modelo de Saxton y Rawls (Figura 3). Este valor de CC fue utilizado como umbral para finalizar el riego en las condiciones experimentales.

Las discrepancias entre las medidas de saturación y capacidad de campo, realizadas en laboratorio y en condiciones de campo, han sido demostradas por Evett et al. [5], quienes propusieron el valor de $\theta_{\mathrm{v}}$ máximo observado en campo como referencia a partir de la cual establecer la dinámica de extracción de agua por la planta durante el ciclo de cultivo.

La exactitud de la medida del contenido de agua en el suelo para satisfacer un MAD del 30\% supuso, en las condiciones experimentales, una franja muy estrecha de $\theta_{\mathrm{v}}\left(0.04 \mathrm{~m}^{3} \mathrm{~m}^{-3}\right)$, lo que condiciona la viabilidad del riego de precisión.

No obstante, es importante señalar que la adopción del concepto de MAD para establecer umbrales de inicio del riego permite la generalización de los niveles de agotamiento de agua en el suelo independientemente de sus características, y su viabilidad ha sido constatada por medio de la determinación de valores de potencial hídrico de tallo, indicadores de un adecuado suministro hídrico en las plantas de limero estudiadas [6]. 


\section{Congreso Nacional de Riegos CARTAGENA 2021}

\section{Conclusiones}

- La calibración de las sondas capacitivas EnviroPro requiere un trabajo laborioso especifico de campo para cada una de las condiciones texturales de suelo. Ello se demostró con las importantes discrepancias observadas en los valores de $\theta_{\mathrm{v}}$ derivados de la calibración realizada en laboratorio. En el caso de los sensores Acclima-TDR, el trabajo previo de laboratorio no es necesario y la lectura realizada en campo mostró valores de $\theta_{\mathrm{v}}$ exactos, salvo en algún caso, por defectos en la instalación del sensor ocasionados por la presencia de piedras.

- El valor de CC obtenido con sondas EnviroPro resultó más diferente del derivado del modelo de Saxton y Rawls que el obtenido con sensores Acclima-TDR.

- El concepto de MAD para el riego de precisión permite la generalización de los niveles de agotamiento de agua en el suelo independientemente de sus características, así como su validación mediante el potencial hídrico de tallo.

- El ensayo de campo realizado permite concluir que ambos sensores (capacitivos y TDR) permiten observar la tendencia de $\theta_{\mathrm{v}}$ en el perfil del suelo. Sin embargo, el riego de precisión requiere de valores reales, exactos y precisos de $\theta_{\mathrm{v}}$ para su aplicación.

- El valor de MAD establecido supuso un valor de $\theta_{\mathrm{v}}=0,04 \mathrm{~m}^{3} \mathrm{~m}^{-3}$ inferior a $C C$, lo que resulta inconsistente cuando se utilizan sensores con un error superior a este valor.

- La nueva generación de sensores TDR encapsulados supone una mayor exactitud y precisión en la medida de $\theta_{\mathrm{v}}$, con respecto a sus antecesores. Además, exploran un volumen de suelo mayor y tienen un precio similar al de los sensores capacitivos.

\section{Agradecimientos}

El trabajo se ha financiado con el proyecto PID2019-106226RB-C2-1 (Plan Nacional AEI) y 19903/GERM/15 (Fundación Séneca, Región de Murcia). M.R. Conesa agradece la ayuda posdoctoral disfrutada del programa Juan de la Cierva (FJCI-2017-32045).

\section{Referencias}

1. Merriam, J.L. A management control concept for determining the economical depth and frequency of irrigation. Transactions of ASAE 1966, 9: 492-498. doi:10.13031/2013.40014

2. Vera J., Conejero, W., Mira-Garcia, A.B., Conesa, M.R., Ruiz-Sánchez, M.C. Towards irrigation automation based on dielectric soil sensors. J. Hort. Sci. and Biotech. 2021, https://doi.org/10.1080/14620316.2021.1906761

3. Topp, G.C., Davis, J.L., Annan, A.P. Electromagnetic determination of soil water content: Measurements in coaxial transmission lines. Water Resources Research, 1980, 16, 574-582. doi:10.1029/WR016i003p00574T

4. Saxton, K.E., Rawls, W. Soil water characteristics. Hydraulic properties calculator. 2009 https://hrsl.ba.ars.usda.gov/soilwater/Index.htm

5. Evett, S.R., Stone, K.C., Schwartz, R.C., O'Shaughnessy, S.A., Colaizzi, P.D., Anderson, S.K., Anderson, D.J. Resolving discrepancies between laboratory-determined field capacity values and field water content observations: implications for irrigation management. Irrig. Sci. 2019, 37(6)

6. Mira-Garcia, A.B., Conejero, W., Vera, J., Ruiz-Sánchez, M.C. Leaf water relations in lime trees grown under shade netting and open-air. Plants. 2020, 9, 510; doi:10.3390/plants9040510 


\title{
Aplicación de la termografía sobre dron a la evaluación de la eficiencia del riego por aspersión.
}

\author{
Cristina Jarén Morilla ${ }^{1}$, Salvatierra Bellido Benito ${ }^{1}$, Manuel López Rodríguez $^{1}$
}

Instituto de Investigación y Formación Agraria de Andalucía, Rancho de la Merced (IFAPA, sede Chipiona-Cádiz; cristina.jaren@juntadeandalucia.es, benito.salvatierra@juntadeandalucia.es, manuel.lopez.rodriguez@juntadeandalucia.es

Resumen: En las instalaciones de riego, el control de la uniformidad en el agua aplicada da una medida (más o menos directa) sobre los caudales en cada parte de la superficie cultivada, la falta de uniformidad en el riego causa elevadas pérdidas de agua por percolación y la generación de contaminación difusa. En la mayoría de las ocasiones el objetivo elegido es determinar si los caudales y presiones son uniformes (no varían o cuanto varían) entre un sector y otro de la instalación de riego, sin considerar en su totalidad otros elementos, como el suelo y el clima, que pueden afectar esta uniformidad. Tradicionalmente el uso de los pluviómetros así como la realización de medidas de humedad directamente en el suelo transformados en coeficientes que permiten cuantificar esta uniformidad. Estos métodos, salvo que se trate de pequeñas instalaciones, se aplican sobre una muestra de la misma siendo sus resultados extensibles al total. El uso de cámaras termográficas, ahora cada vez más asequible economicamente puede ser una herramienta útil para medir de forma rápida y precisa en toda la superficie regada.

Partiendo de parcelas con bajo grado de humedad en el suelo se ha comparado las medidas teóricas y de pluviómetros y muestreo en parcelas regadas por aspersores, con los resultados obtenido mediante la técnnica termografica sobre dron, en diferentes circunstancias de tiempo de riego.

Los resultados obtenidos nos muestran que el método es viable y de gran aplicabilidad para evaluar la eficiencia del uso del agua en las parcelas regadas, mejorando la misma en el diseño y manejo delriego y disminuyendo con ello los impactos negativos en el medio.

Palabras clave: Riego 1; coeficiente de uniformidad 2; termografía 3; medio-ambiente 4. 


\title{
Application of thermography on drone to the evaluation of the effi- ciency of sprinkler irrigation.
}

\section{Cristina Jarén Morilla ${ }^{1}$, Salvatierra Bellido Benito $^{1}$, Manuel López Rodríguez ${ }^{1}$}

1 Instituto de Investigación y Formación Agraria de Andalucía, Rancho de la Merced (IFAPA, sede Chipiona-Cádiz; cristina.jaren@juntadeandalucia.es, benito.salvatierra@juntadeandalucia.es, manuel.lopez.rodriguez@juntadeandalucia.es

\begin{abstract}
In irrigation facilities, the control of the uniformity in the applied water gives a measure (more or less direct) on the flows in each part of the cultivated area, the lack of uniformity in the irrigation causes high losses of water by percolation and the generation of diffuse pollution. In most cases, the objective chosen is to determine if the flows and pressures are uniform (they do not vary or how much they vary) between one sector and another of the irrigation installation, without fully considering other elements, such as soil and climate., which can affect this uniformity. Traditionally the use of rain gauges as well as the realization of humidity measurements directly in the soil transformed into coefficients that allow to quantify this uniformity. These methods, except in the case of small installations, are applied to a sample of the same, their results being extensible to the total. The use of thermal imaging cameras, now more and more economically affordable, can be a useful tool to measure quickly and accurately on the entire irrigated area.
\end{abstract}

Starting from plots with a low degree of humidity in the soil, theoretical measurements and rain gauges and sampling in plots watered by sprinklers have been compared with the results obtained through the thermographic technique on drone, in different circumstances of irrigation time.

The results obtained show us that the method is viable and highly applicable to evaluate the efficiency of the use of water in irrigated plots, improving it in the design and management of irrigation and thereby reducing the negative impacts on the environment

Keywords: Irrigation 1; uniformity coefficient 2; thermography 3; environment 4. 


\section{Introducción}

En las instalaciones de riego, la uniformidad da una medida (más o menos directa) sobre los caudales aplicados en cada parte del cultivo. En la mayoría de las ocasiones el objetivo elegido es determinar si los caudales y presiones son uniformes (no varían o cuanto varían respecto a la medida) entre un sector y otro de la instalación de riego, como medida de la uniformidad del agua aplicada.

Tradicionalmente el uso de los pluviómetros y su tratamiento han permitido obtener unos coeficientes que cuantifican esta uniformidad. Los parámetros más utilizados son el coeficiente de variación(CV), la uniformidad de distribución referida al 25\% del área menos regada (UD) y el coeficiente de Uniformidad (CU) de Christiansen (1942). Este último es el que con más frecuencia se utiliza en el riego por aspersión (Dechmi,F. Et al), aunque en nuestro ámbito la uniformidad de distribución aparece con más frecuencia.

La interpretación de los mismos varía según las fuentes, pero una aproximación normalmente aceptada sería para la UD aplicado a los sistemas de riego localizados se admite que valores de $90 \%-100 \%$ la uniformidad es excelente; $80 \%$ - 90\% uniformidad buena; 70\% - 80\% aceptable; $<70 \%$ inaceptable. En el caso de los riegos por aspersión, un coeficiente de uniformidad $>80 \%$ indicaría una uniformidad de distribución buena. Para este tipo de sistemas de riego, Keller y Bliesner (1990) consideran hasta un CU del $75 \%$ como relativamente baja. Según Cuenca (1989), la eficienca potencial de las coberturas totales estaría entre un $70 \%$ en diseños para bajo viento y un $82 \%$ en diseños para alto viento.

Andalucía es la Comunidad Autónoma con mayor superficie ${ }^{1}$ de regadío 29,18\% (1.117.858 has) del total nacional. De esta superficie sólo el 11,67\% (65.992 has) se riega por aspersión. Pero su uso se concentra en zonas donde predominan los cultivos herbáceos anuales llegando a superar el $50 \%$ de la superficie regada (ejem. Marismas de Lebrija).

En el riego por aspersión la toma de muestra para evaluar la uniformidad es complicada y costosa sobre todo en grandes instalaciones agrícolas. Estos métodos en el mejor de los casos y salvo que se trate de pequeñas instalaciones, hacen su aplicación sobre una muestra de la misma en el tiempo y el espacio, siendo sus resultados extensibles al total del tiempo de duración del cultivo y a la superficie ocupada, presentando complicaciones en la representatividad y la interpretación de la muestra.

La termografía es una técnica que permite determinar temperaturas a distancia y sin necesidad de contacto físico con el objeto a estudiar. Desarrollada en el S.XX, es ya habitual en los sectores industriales, de construcción y energéticos. Recientemente, la incorporación de cámaras termográficas a los drones está poniendo estas técnicas al alcance de un mayor número de sectores, aprovechando la mejora de tecnología y el abaratamiento de costes de la misma, abriendo un campo de aplicaciones muy interesante en la agricultura. 
En este ensayo se aplican las técnicas de termografía sobre dron para la evaluación de la uniformidad de un riego por aspersión en condiciones de campo.

\section{Materiales y métodos.}

Los ensayos se realizaron sobre dos parcela al aire libre con suelo artificial enarenado, en la finca del Instituto de Investigación y Formación Agraria y Pesquera (IFAPA) de la Junta de Andalucía en su centro de Chipiona. Se regó con agua superficial suministrada por la CRR Costa Noroeste de Cádiz, en varias pruebas entre los meses de mayo a septiembre del año 2021 .

La instalación de riego por aspersión con un marco de 12×12 metros, (siendo ésta la unidad de comparación) constaba de aspersores Unirain F46 con boquilla 9/64 con vaina prolongadora, situados a 0,8 m sobre el suelo, una presión de trabajo 250 y $450 \mathrm{kPa}$ y tiempos de riego de $1 \frac{1}{2}$ y 1 hora

Se dispuso de una cámara térmica Zenmuse H20T (La carcasa del cardán DJI Zenmuse H20T se compone de cuatro sensores separados: Cámara gran angular: un sensor CMOS de 1/2,3 pulgadas que emite $12 \mathrm{MP}$ con un campo de visión de 82,9 $9^{\circ}$. Cámara con zoom: un sensor CMOS de $20 \mathrm{MP}$ de 1/1,7 pulgadas que incluye un zoom óptico híbrido x23 (200x máximo) que ofrece $4 \mathrm{~K} 30 \mathrm{p}$ en video. Telémetro láser: permite medir la distancia de un objeto desde el dron de 3 a 1200 metros con una precisión de unos 0,2 metros. Sensor térmico radiométrico: la resolución de 640 por 512 píxeles ofrece una frecuencia de actualización de 30p y tiene una sensibilidad térmica de $\leq 50 \mathrm{mk@f1.0} \mathrm{(NEDT).).} \mathrm{La} \mathrm{misma} \mathrm{va} \mathrm{montada} \mathrm{sobre} \mathrm{un} \mathrm{dron,} \mathrm{Martice}$ 300 RTK (para aplicaciones industriales. Ofrece hasta 55 minutos de vuelo, un intervalo de transmisión máximo de hasta $8 \mathrm{~km}$, funciones avanzadas de IA, 6 sensores direccionales y de posicionamiento.)

Se calculó la curva característica del aspersor tipo elegido en una instalación aislada del propio centro y tomando la caracterización del mismo en trabajos de más profuniddad realizados en el propio centro (Salvatierra, B et alt, 2010)

Sobre dos parcelas de 12×12 metros secas en profundidad se dio un riego, desde los vértices de la misma, de media y una hora de duración. Se realizaron controles con pluviómetros de la lluvia caída en la parcela, 31 pluviómetros uniformemente distribuidos, con un diámetro de abertura de 0,15 m y 0,17 m de altura. Con barrenas se controló la penetración del agua en el suelo de las parcelas muestreando 100 puntos en cada una de ellas, en una cuadrícula de 1,5x1,5 m. Y por último se tomaron imágenes con dron de las parcelas, antes y después del riego, con un pixel de 0,038 x 0,038 m. de resolución, aproximadamente 99.000 datos muestreados de la parcela de $12 \times 12$.

\section{Resultados y discusión}




\section{Congreso Nacional de Riegos CARTAGENA 2021}

En una instalación aislada del viento se obtuvo la curva característica del aspersor utilizado, en dos regímenes de presión, 250 y 450 $\mathrm{kPa}$, Figura nำ.

Con la curva característica se calculó la superficie mojada teórica y la lluvia recibida en la misma, definiendo perímetros mojados de 1,52,5-4-6-9-12-14 metros de radio y sus intersecciones, y presiones de trabajo de 250 y $450 \mathrm{kPa}$., Figuras 2 y 3 .

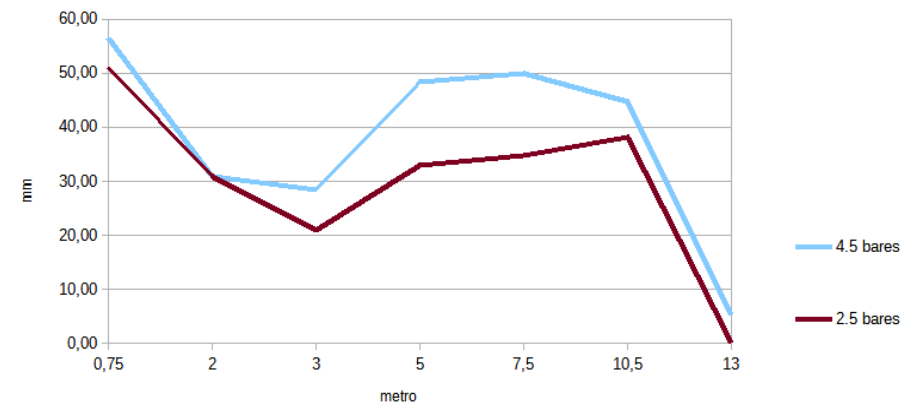

Figura 1. Aspersor UNIRAIN F46 con boquilla 9/64 y vaina prolongadora
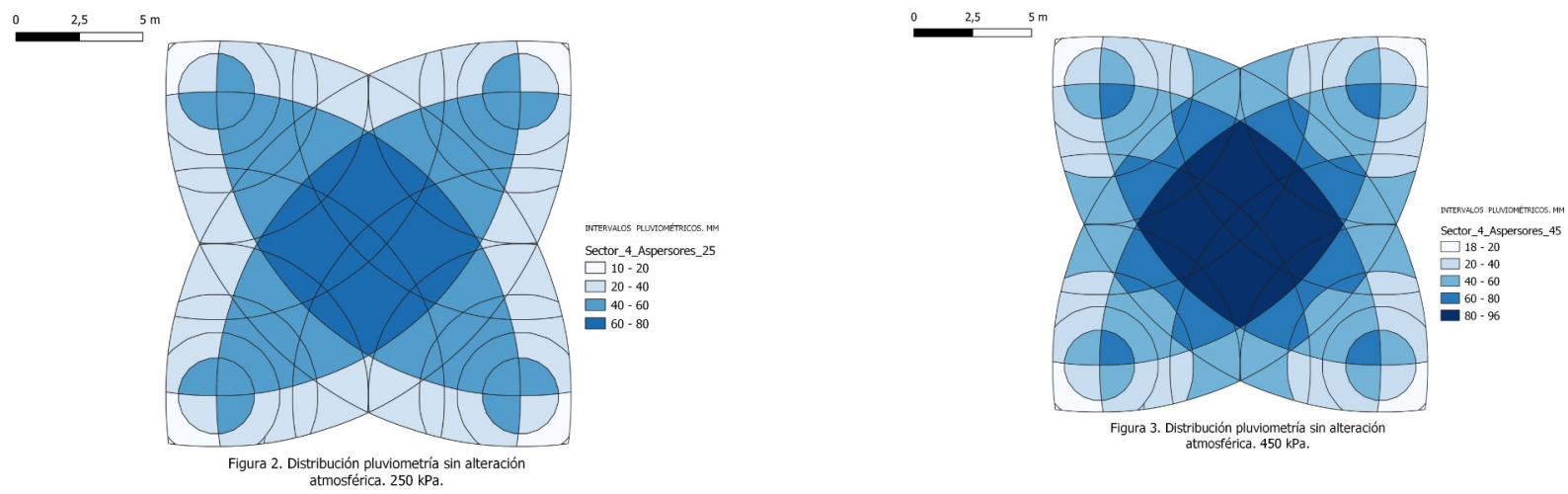

El coeficiente de uniformidad de Christiansen teórico fue de 74,15 y el 73,98\% y una uniformidad de distribución de 63,71 y 67,71 \% para las presiones de 250 y $450 \mathrm{kPa}$ respectivamente. Logicamente valores bajos pero que se justifican por lo reducido de la parcela (4 aspersores) y el acusado efecto borde.

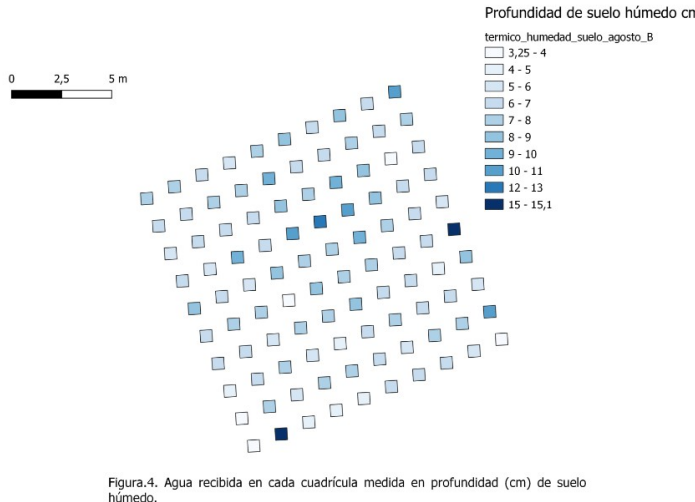

Se tomaron muestras del suelo húmedo después del riego en las dos parcelas ( $1 / 2$ y 1 hora), Figura. 4 para $1 / 2$ hora, midiendo el peso del perfil húmedo y la profundidad alcanzada por el frente húmedo, después del riego.

Los coeficientes obtenidos fueron para $1 / 2$ y 1 hora respectivamente CU $79,88 \%$ y UD 70,19\%, mientras que en la segunda parcela los valores fueron de $71,34 \%$ y $62,79 \%$. 
Se obtuvo el coefiente de uniformidad a partir de pluviómetros distribuidos en las dos parcelas regadas. Respectivamente los valores para cada coeficiente fueron CU 61,47 y $74,52 \%$ y UD 54,36 y $69,26 \%$. Valores más bajos de los normales para los aspersores y boquillas utilizados, pero como se dijo, justificados teniendo en cuenta las dimensiones del ensayo y el efecto borde acumulado respecto a una instalación de tamaño mayor.

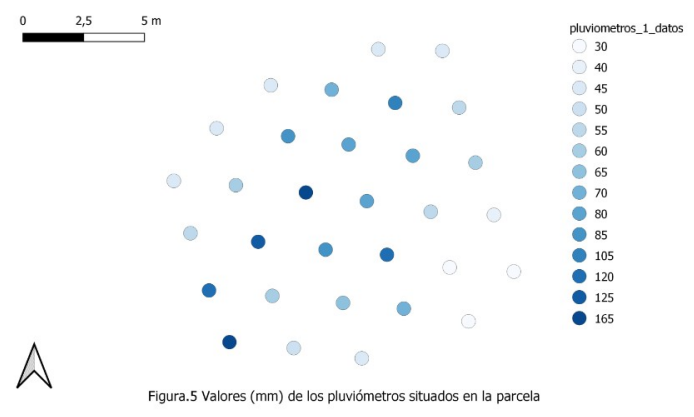

Para las imágenes de termografía tomadas (Figuras 6, 7 y 8), la distribucion de las temperaturas tomadas en cada pixel $(0,035 \times 0,035 \mathrm{~m})$ de la imagen comprendida entre los aspersores, se muestra en la figura 9.
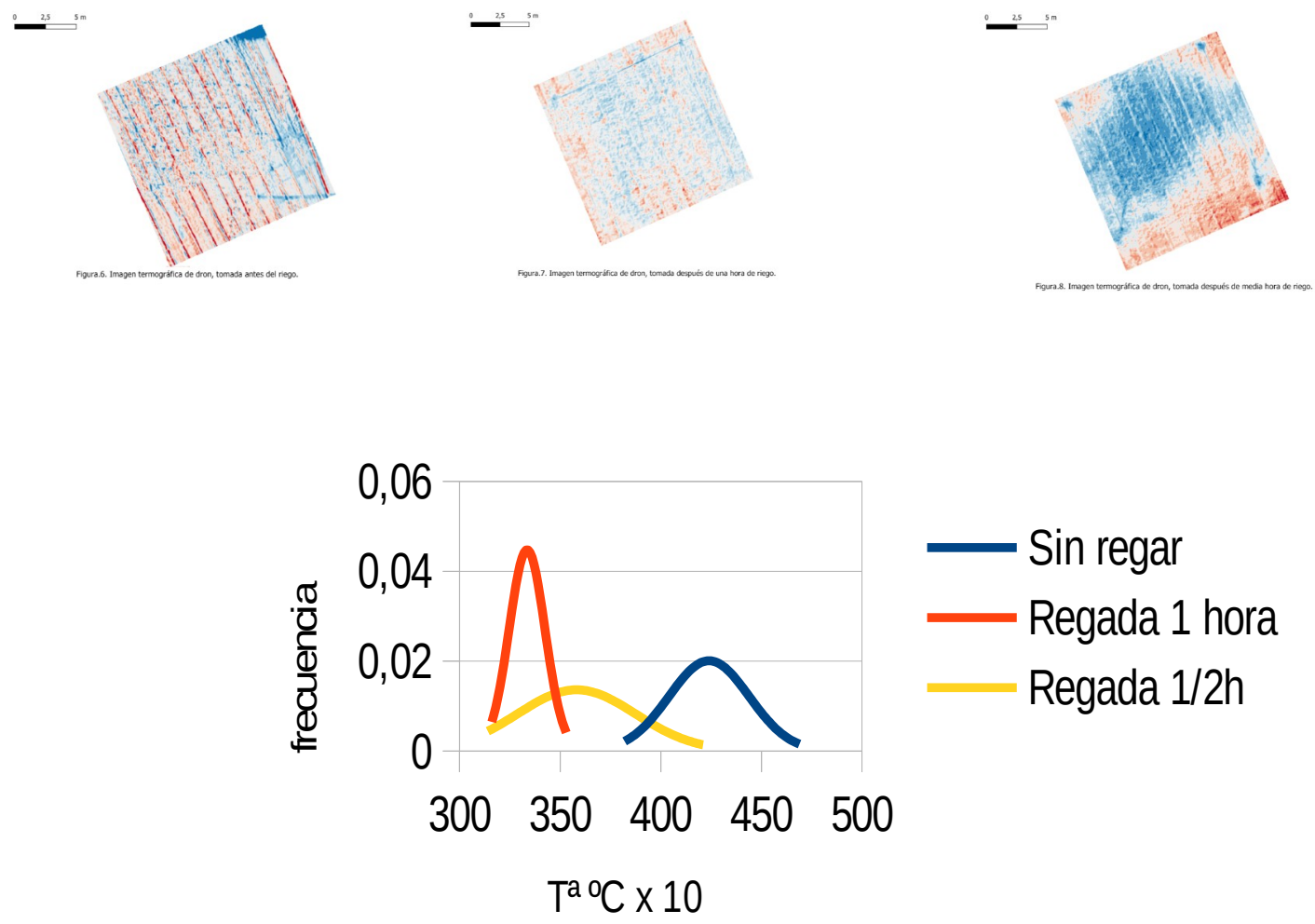

Figura.9. Distribución de valores de la termografía. 
Tabla 1. Valores termográficos de las imágenes según tratamiento

\begin{tabular}{cccc}
\hline Tratamiento & P. sin riego & $\begin{array}{c}\text { P. 1 hora de } \\
\text { riego }\end{array}$ & $\begin{array}{c}\text { P. 1/2 hora de } \\
\text { riego }\end{array}$ \\
\hline $\mathrm{T}^{\mathrm{a}}$ promedio & 42,3 & 33,3 & 35,8 \\
Desv. estandart & 19,8 & 8,9 & 29,3 \\
\hline
\end{tabular}

Tabla 2. Valores de coeficientes obtenidos según tratamiento

\begin{tabular}{ccccc}
\hline Método & Teóricas & $\begin{array}{c}\text { Pluvió } \\
\text { metros }\end{array}$ & $\begin{array}{c}\text { Humedad } \\
\text { de suelo }\end{array}$ & $\begin{array}{c}\text { Termografía } \\
\mathbf{1} \text { 2_1 horas }\end{array}$ \\
\hline CU de Christiansen & $74 \%$ & $61-74 \%$ & $71-79 \%$ & $92 \_98 \%$ \\
UD q q $25 \%$ & $63-68 \%$ & $54-69 \%$ & $63-71 \%$ & $88 \_96 \%$ \\
\hline
\end{tabular}

El balance de energía en la superficie de un suelo está fuertemente influenciada por la posición diurna del Sol, por la composición del suelo, la labor y por el contenido de agua entre otros.

El balance de energía, Radiación neta del suelo $\left(\mathrm{R}_{\mathrm{ns}}\right)$ se expresa como:

$$
R_{n s}=H_{s}+G_{s}+\lambda E_{s}
$$

donde $H_{s}$ es el calor sensible, $G_{s}$ calor del suelo y calor latente $\lambda E_{s}$ en un suelo seco este término sería nulo.

Si se riega en un momento determinado del día en un suelo desnudo homogéneo (composición, color, humedad, labores,...) y condiciones microclimáticas iguales (no sombras, cortavientos, etc...), la zona regada experimentará una variación de la temperatura respecto a la no regada debido a una variación del calor sensible (al estar el agua a diferente temperatura que el suelo) y a las pérdidas de calor latente. Estos cambios energéticos pueden ser medidos en términos de variación de temperatura de la superficie del suelo.

Una vez que el riego ha concluido, si el mismo ha sido eficaz, ha garantizado que en toda la superficie se haya depositado una cantidad suficiente de agua (figura 7), esto hace que la superficie del suelo pase de una $T_{\text {as }}$ a una menor temperatura $T_{\text {ah }}$ (figura 9). Si el riego no es homogéneo y no deposita la misma cantidad de agua en un punto del suelo que en otro, antes de su saturación superficial (menor tiempo de riego) se provoca un gradiente de temperaturas más disperso (figura 8), siendo esta medida un buen indicador de 


\section{Congreso Nacional de Riegos CARTAGENA 2021}

la mayor o menor bondad del sistema de riego, pudiendo resalizarse esta medida en la totalidad de la superficie de riego y no sólo en una muestra, sin alterar la superficie de cultivo.

\section{Conclusiones}

Este sistema es una herramienta asequible y fácil de implementar para evaluar la eficiencia de un sistema de riego por aspersión, proporcionando un conocimiento que permita minimizar la lisiviación y las zonas subregadas, actuando sobre las pérdidas de nutrientes y una minimización de la llegada de éstos al ciclo del agua. Al poder análisar el total de la superficie en riego, puede ayudar a evaluar tanto el diseño como el manejo de la instalación de riego por aspersión. La rapidez y comodidad de su uso permite repetir las medidas en diferentes condiciones climáticas (viento) mejorando la eficiencia de estos sistemas de riego por aspersión.

La dispersión que se obtiene en los primeros estadíos del riego debe ser una buena herramienta para comparar diferentes instalaciones, manejo y diseño, del riego por aspersión.

\section{Referencias}

1. Christiansen J.E., (1942). Irrigation by Sprinkling. Univ. Of California. Agric. Exp. Sta. Bull. 670, 124pp.

2. Dechmi, F. (P), Playán Jubillar, E., Faci González, J.M., Bercero, A. Uniformidad de los Sistemas de riego por aspersión en el polígono de la Loma de Quinto (Zarragoza). Unidad de Suelos y riegos, Laboratorio de Agronomía y Medio Ambiente. SIG-DGA Zaragoza.

3. Cuenca, R.H. (1989). Irrigation system design: an ingeneering approaxh. Englewood Cliffs, New Jersey, Prentice-Hall, Inc. 552 pp.

4. Keller, J \& Bliesner, RD. (1990). Sprinkle and Trickle Irrigation. AVI Book. Van Nostrand Reinhold. New York. USA.

5. 1. Análisis de los Regadíos Españoles. Año 2020. Fuente: Encuesta sobre Superficies y Rendiemintos de Cultivos (ESCYRCE).

6. Salvatierra, B. 2010. Uniformidad de riego de las instalaciones de riego por aspersión, Boletín trimestral de Información al Regante. № 14 . Enero, marzo, pp 7-8.

7. Salvatierra, B. 2012. Evaluaciones y manejo de las instalaciones de riego por aspersión en la remolacha azucarera en Andalucía. Revista AIMCRA 111, pp 3-9.

8. Salvatierra-Bellido, B., Montero-Martínez, J., Pérez-Urrestarazu, L. 2018. Development of an automatic test bench to assess sprinkler irrigation uniformity in different wind conditions. Computers and Electronics in Agriculture 151, 31-40. doi: 10.1016/j.compag.2018.05.036

9. Rafael Fernández Gómez, Nicolás A. Oyonarte Gutiérrez, Juan P. García Bernal,, Mª del Carmen Yruela Morillo, Mercedes Milla Milla, Ricardo Ávila Alabarces, Pedro Gavilán Zafra, 2010. Manual de Riego para Agricultores Módulo 3: Riego por Aspersión. Junta de Andalucia.

10. Laserna Arcas, S.1, Montero Martínez, J. 2, Sheikhesmaeili, O. 3, Alcázar Bascuñana, E.4. análisis de la uniformidad de riego en Sistemas de aspersión semiportátil con aspersores de gran tamaño. 


\title{
Mejora del manejo del riego por surcos en el Bajo Guadalquivir.
}

\author{
Salvatierra Bellido, B. ${ }^{1}$, Jarén Morilla, C. ${ }^{1}$, López Rodríguez, M. ${ }^{1}$
}

Instituto de Investigación y Formación Agraria de Andalucía, Rancho de la Merced (IFAPA, sede Chipiona-Cádiz; benito.salvatierra@juntadeandalucia.es, cristina.jaren@juntadeandalucia.es, manuel.lopez.rodriguez@juntadeandalucia.es

Resumen: El riego por surcos es todavía un método utilizado en muchas zonas regables por las características intrínsecas a las mismas, bien por la ausencia de costes energéticos o bien por no haber acometido proyectos de presurización de redes de distribución de agua. El problema principal del manejo del riego en general es conseguir eficiencia y a la vez reducir la constante lixiviación de nitratos. El riego por gravedad representa en Andalucía un 15\% de la superficie de regadío y concentrada una gran parte en el Bajo Guadalquivir en zonas no modernizadas. En el año 2011 se empezo a estudiar la eficiencia del riego por surcos en el Bajo Guadalquivir desde el Instituto de Andaluz de Investigación y Formación Agraria, Pesquera, Alimentaria y de Producción Ecológica (IFAPA) dónde desde Centro de Chipiona se hizo la primera evaluación de riego por surcos sobre un cultivo de algodón. Con estos datos de partida obtenidos, el objetivo marcado es conseguir una mejor eficiencia de aplicación del agua en el riego por surcos, junto con la mayor eficiencia en la aplicación del abonado nitrogenado mejorando la rentabilidad de las explotaciónes. Para ello, se implementa en un ensayo la tecnología del riego por surcos por pulsos para reducir el consumo de agua y disminuir las tasas de lixiviación de nitratos a través de la fertirrigación en esta modalidad de riego. Para ello, se ha contado con una parcela colaboradora con características representativa de la zona, dónde se compara en el cultivo del algodón con dos manejos diferentes. Por un lado, el riego convencional por surcos con abonado convencional a voleo frente al riego por pulsos con fertirrigación automatizada. Cuando se riega por pulsos en el riego por surcos se aplica un caudal por cada surco mayor, además de que cada pulso de riego se realiza el avance sobre suelo saturado y por consiguiente con un mayor grado de impermeabilidad en la zona ya regada. El sistema permite la inyección del abonado en función a la fase de riego más idónea. La aplicación de esta tecnología ha supuesto: Una mayor eficiencia de riego con un ahorro de agua del $25 \%$ para las condiciones del ensayo. Esta situación de ahorro de agua también permitirá mayor frecuencia de riego, redundando sobre mejores rendimientos de los cultivos. Igualmente en el manejo del abonado se consigue un aumento en la eficiencia del abonado nitrogenado con un ahorro del 34\% aproximadamente en las condiciones del ensayo. Finalmente, los resultados obtenidos mejorarán y la aplicación de esta técnica mejorarán la productividad y sostenibilidad de los cultivos con esta modalidad de riego por surcos.

Palabras clave: Riego; surcos; pulsos; fertirrigación. 


\title{
XXVIII Congreso Nacional de Riegos CARTAGENA 2021
}

\section{Improvement of furrow irrigation management in the Lower Guadalquivir.}

\author{
Salvatierra Bellido, B. ${ }^{1}$, Jarén Morilla, C. ${ }^{1}$, López Rodríguez, M. ${ }^{1}$
}

Instituto de Investigación y Formación Agraria de Andalucía, Rancho de la Merced (IFAPA, sede Chipiona-Cádiz; benito.salvatierra@juntadeandalucia.es, cristina.jaren@juntadeandalucia.es, manuel.lopez.rodriguez@juntadeandalucia.es

\begin{abstract}
Furrow irrigation is still a method used in many irrigable areas due to their intrinsic characteristics, either due to the absence of energy costs or because they have not undertaken pressurization projects for water distribution networks. The main problem of irrigation management in general is to achieve efficiency while reducing the constant leaching of nitrates. Irrigation by gravity represents $15 \%$ of the irrigated area in Andalusia and a large part is concentrated in the Lower Guadalquivir in non-modernized areas. In 2011, the efficiency of furrow irrigation in the Lower Guadalquivir began to be studied by the Instituto de Andaluz de Investigación y Formación Agraria, Pesquera, Alimentaria y de Producción Ecológica (IFAPA), where the Center of Chipiona made the first evaluation of furrow irrigation on a cotton crop. With these starting data obtained, the objective is to achieve a better efficiency in the application of water in furrow irrigation, together with greater efficiency in the application of nitrogen fertilizer, improving the profitability of the farms. For this, the technology of surge furrow irrigation is implemented in a trial to reduce water consumption and reduce nitrate leaching rates through fertigation in this irrigation modality. For this, a collaborating plot with representative characteristics of the area has been counted on, where it is compared in the cultivation of cotton with two different operations. On the one hand, conventional furrow irrigation with conventional broadcast fertilizer versus surge irrigation with automated fertigation. When irrigating by surge irrigation, a flow is applied for each larger furrow, in addition to each irrigation pulse the advance is carried out on saturated soil and therefore with a greater degree of impermeability in the already irrigated area. The system allows the injection of the fertilizer according to the most suitable irrigation phase. The application of this technology has meant: Greater irrigation efficiency with a water saving of $25 \%$ for the test conditions. This situation of saving water will also allow a greater frequency of irrigation, resulting in better crop yields. Likewise, in the handling of the subscriber, an increase in the efficiency of the nitrogen subscriber is achieved with a saving of approximately $34 \%$ under the test conditions. Finally, the results obtained will improve and the application of this technique will improve the productivity and sustainability of the crops with this modality of furrow irrigation.
\end{abstract}

Keywords: Irrigation; furrow; surge; fertigation. 


\section{Congreso Nacional de Riegos CARTAGENA 2021}

\section{Introducción}

El riego por surcos es una variante del sistema de riego por gravedad que predomina en muchas zonas de España y que actualmente es uno de los más sostenible energéticamente. La superficie de riego por gravedad en España aún tiene presencia en el regadío español con unas 908.075 ha de las cuales Andalucía representa el $18,7 \%$ con 169.875 ha [1].

La mejora de la eficiencia en el uso del agua en el riego por surcos (Walter, 1989) está muy ligada al diseño previo y definitivo de las condiciones de la parcela: tipo de suelo, pendiente y longitud del recorrido del agua. Pero existen otras variables como caudal de riego y la humedad inicial antes de un riego, que pertenecen al manejo del riego en cada momento y son de carácter circunstancial. La variación de estas últimas para la mejora de la eficiencia de riego requieren de conocimientos técnicos muy cualificados.

Desde el Instituto Andaluz de Investigación y Formación Agraria, Pesquera, Alimentaria y de la Producción Ecológica (IFAPA) y desde el Centro Rancho de la Merced, se están desarrollando líneas de trabajo para mejorar la eficiencia del riego, del abonado y la fertirrigación en cultivos herbáceos de regadío al aire libre. La mayoría de la superficie de riego por surcos está incluida en estos sistemas de cultivo y por tanto requiere de un estudio específico para hacer más sostenible este sistema de riego . Desde los proyectos de transferencia de tecnología en el regadío y de optimización del abonado nitrogenado, se ha concluido con la puesta a punto un sistema de riego innovador, que hace más eficiente el riego por gravedad, a la vez que permite la aplicación de abono con mínimas tasas de percolación profunda.

El riego por gravedad es el único método que prescinde del consumo energético y es por tanto el más económico, pero a su vez es uno de los sistemas menos tecnificados y dónde la baja eficiencia de aplicación del agua merma mucho las cosechas por la distribución irregular del agua y la lixiviación de los nitratos. Por tanto, investigar sobre este sistema de riego mejorará la eficiencia de aplicación [2] consiguiendo disponer de producciones similares a las de un riego a presión.

Por todo y desde el IFAPA se ha analizado, en condiciones experimentales sobre el cultivo del algodón, la introducción de mejoras en el riego por surcos, dónde se ha utilizado el riego por surcos en la modalidad de aplicación por pulsos de riego [3] y con inyección del abono a través de este sistema de riego.

\section{Objetivo}

El fin último de este trabajo es conseguir un manejo más sostenible del riego por surcos. Dónde los objetivos específicos son los siguientes:

1. Conseguir mayor eficiencia en el riego por sucos;

2. Conseguir mayor eficiencia en el abonado en el cultivo del algodón y todos los cultivos regados con este sistema en general;

3. Hacer más sostenible cualquier cultivo con este sistema, tanto desde el punto de vista ambiental y como de rentabilidad.

\section{Materiales y métodos}

\subsection{Materiales}

Para el estudio se contó con una parcela en la zona regable del Bajo Guadalquivir, en la Comunidad de Regante de Las Marismas en la provincia de Sevilla. Para ello se utilizó una parcela de 4 ha de 


\section{Congreso Nacional de Riegos CARTAGENA 2021}

superficie la cual se dividió en dos subpardes de 2 ha cada una y con propiedades similares. Dicha parcela fue escogida como representativa y proporcionada a través de un convenio del IFAPA con el Colectivo de Algodoneras Del Sur De Andalucía S.L. (COALSA). El suelo es muy homogéno de textura arcillosa y con una conductividad eléctrica en extracto $1 / 5$ que oscilaba desde los $0,244 \mathrm{dS} / \mathrm{m}$ en los primeros 30 centímetros a los $0,859 \mathrm{dS} / \mathrm{m}$ en los siguientes 30 centímetros, y partiendo de un nivel de nitratos en el suelo de $132 \mathrm{mg} / \mathrm{kg}$ a los $40 \mathrm{mg} / \mathrm{kg}$ respectivamente. Toda la parcela está drenada con drenes subterráneos a una profundidad de $0,8 \mathrm{~m}$ y una equidistancia de $5 \mathrm{~m}$. La dirección de los drenes es la misma a las líneas de cultivo (de Sur a Norte).

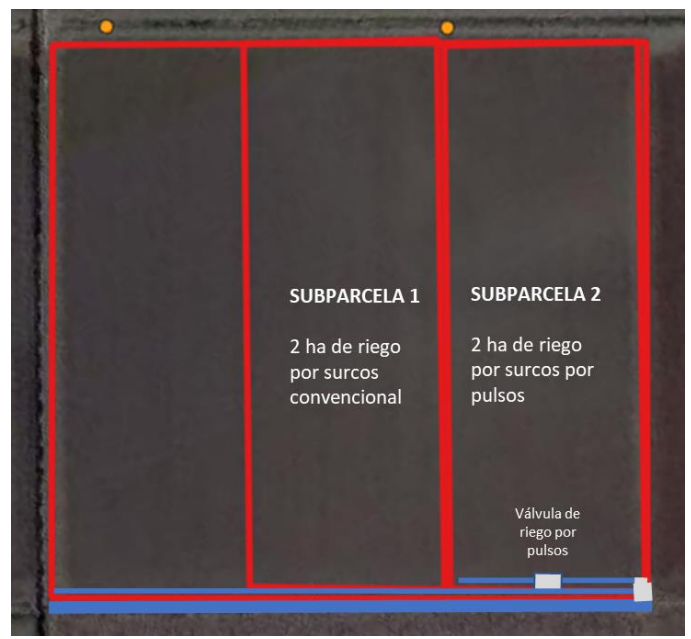

Figura 1. Croquis de las dos parcelas experimentales de riego por sucos. De derecha a izquierda la subparcela de manejo más sostenible y la subparcela de riego convencional. Los puntos en amarillos son los puntos colectores de drenaje hacia un canal colector de drenaje.

Sobre las dos parcelas se cultivó algodón con los objetivos de cubrir las necesidades de riego a través de riego por surcos en ambas subparcelas.

El cultivo se siembra el 2 de abril de 2021 y se recolecta el 21 de septiembre del mismo año. Ambas subparcelas tienen el mismo manejo excepto las prácticas de riego y abonado, por las que son objeto de este estudio. Por tanto, se distinguen dos manejos distintos:

- Subparcela 1. En dicha parcela se lleva a cabo el manejo convencional de riego y abonado que se hace tradicionalmente en la zona y que se describe más adelante

- Subparcela 2. En esta por el contrario se aplica una técnica innovadora de riego por surcos: riego por pulsos. Y la práctica del abonado se hace a través de la fertirrigación

Para la subparcela 2 se ha utilizado una válvula de riego para riego por surcos que proporciona riego por pulsos. Es decir, este elemento en forma de pieza en " $\mathrm{T}$ " (figura 2) se encarga de aplicar agua sobre los surcos de forma intermitente sobre dos tuberías de plastocanal situadas a ambos lados de la válvula. La función de la válvula es conmutar cada cierto tiempo, el agua recogida por la acequia de distribución, hacia un lado u otro. La frecuencia y tiempo de cambio está gobernada por unos algoritmos predefinidas en el autómata de la válvula. Aunque en cualquier momento puede ser modificado por el usuario.

Todo el sistema es autónomo y automático, ya que se alimenta energéticamente a través de una placa fotovoltaica y una batería que asegura el funcionamiento en ausencia de luz.

El objetivo del sistema es regar de mara óptima para evitar la mayor cantidad de infiltración en cabecera y hacer el riego lo más uniforme posible. Esto se consigue saturando de manera rápida los 


\section{Congreso Nacional de Riegos CARTAGENA 2021}

tramos iniciales en los primeros avances del agua y caudales el doble a un riego por surco convencional, de esta manera conseguimos rápidamente un suelo más impermeable asegurando avances más rápidos en los siguientes pulsos y de manera progresiva.

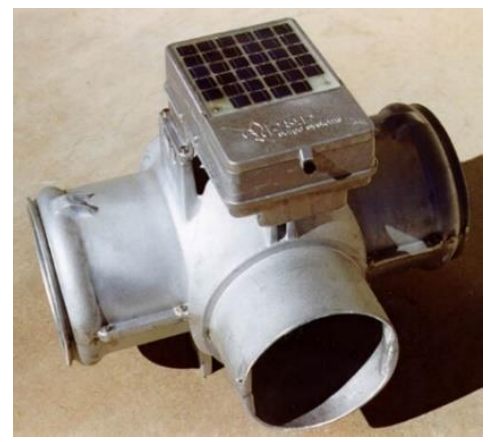

Figura 2. Imagen de la válvula para el riego por pulsos en riego por surcos.

Simultáneamente el dispositivo puede llevar asociado un equipo de fertirrigación (figura 3), a la vez que puede ser programado para ello. Dicha programación optimiza el reparto de abono en una fase posterior a la fase de avance del agua en el surco. A dicha fase se le denomina fase de remojo e inyecta el abono con pulsos de riego con una mayor frecuencia.

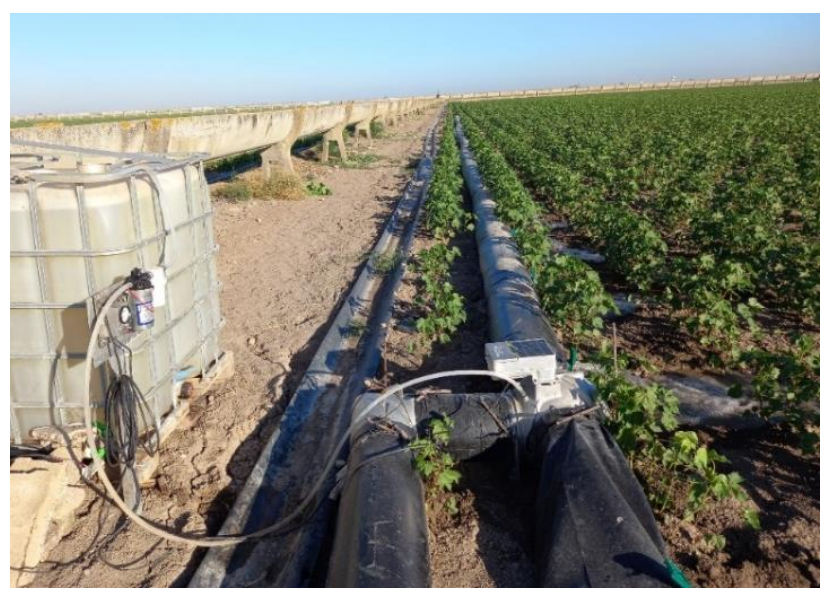

Figura 3. Imagen del sistema en funcionamiento con el sistema de fertirrigación incorporado.

En la figura anterior se muestra la instalación del ensayo de algodón realizado en el año 2021 sobre la parcela experimental y con el cultivo del algodón. La válvula de riego por surcos soporta a cada lado de ella dos tuberías de plastocanal de $400 \mathrm{~mm}$ de diámetro y de una longitud cada una de 22,5 m. Sobre estas tuberías flexibles se han instalados compuertas para cada suco con una equidistancia de 1,5 $\mathrm{m}$ regando calles alternas del cultivo.

\subsection{Métodos}

Una vez dispuesto el sistema de riego por pulsos en la subparcela 2 de riego por surcos y el cultivo ya implantado en la fase de nascencia se propuso la siguiente metodología.

Al tratarse de dos parcelas experimentales únicas, con diferentes variables de manejos y dado el tamaño de estas (subparcela 1 y 2), fue imposible disponer de un diseño experimental alternativo que 


\section{Congreso Nacional de Riegos CARTAGENA 2021}

permitiese un tratamiento estadístico posterior. Por tal motivo se llevó a cabo un seguimiento del desarrollo del cultivo a través de imágenes satélites. De esta manera se pudieron analizar los resultados con mayor precisión.

Una vez definido el objetivo de manejo de cada parcela, se expone a continuación los tipos de operaciones realizadas sobre cada una.

- Subparcela 1. El manejo del riego y el abonado corrió a cargo del agricultor y reproduciendo el sistema de cultivo representativo de la zona regable. En este caso el riego se realizaba con una sola tubería de plastocanal similar al sistema de riego por pulsos, pero con taladros en la tubería a la altura de cada surco (alternos a las líneas de cultivo igualmente). El manejo de abonado consistió en un abonado de fondo 5 días antes de la siembra y un abonado de cobertera justo antes del segundo riego. Las dosis de todas las aplicaciones se muestran en el apartado de resultados.

- Subparcela 2. En este caso el riego fue por pulsos y adaptado a la frecuencia impuesta por la petición de agua solicitada a la comunidad de regantes por parte del agricultor. Y el abonado en este caso, y por asegurar el inicio del cultivo no fuera a llover y no se pudiera fertirrigar se aplicó un abonado de fondo con menor dosis que el agricultor. Y posteriormente se fertirrigó en función a las curvas de absorción de nutrientes del cultivo y adaptada a la frecuencia de los riegos.

\section{Resultados y discusión}

Después de todo el cultivo y sobre una campaña de riego completa, los resultados han arrojado una gran cantidad de información que merece ser analizada por partes como consecuencia de la comparación de un manejo tradicional de los factores riego y abonado frente a un manejo optimizado.

\subsection{Riego}

Los parámetros de riego recogido de ambas subparcelas se recogen a continuación para definir las diferencias entre ambos manejos desde el punto de vista sólo de la aplicación del agua.

Se ha evaluado el caudal instantáneo de riego de cada chorro de agua obteniendo valores similares en todos los riegos y con los siguientes valores medios.

Tabla 1. Caudal instantáneo de cada chorro del riego por surcos.

\begin{tabular}{lcc}
\hline & $\begin{array}{c}\text { Subparcela 1 (manejo } \\
\text { convencional) }\end{array}$ & $\begin{array}{c}\text { Subparcela 2 (manejo } \\
\text { sostenible por pulsos) }\end{array}$ \\
\hline Caudal por chorro $(1 / \mathrm{s})$ & 0,8 & 1,5 \\
\hline
\end{tabular}

Por tanto, el caudal instantáneo en ambas parcelas fue similar y de $48 \mathrm{l} / \mathrm{s}$ ya que en el riego por surcos el caudal sólo iba hacia la mitad de la parcela de manera alterna e intermitente a cada zona.

El calendario de riego aplicado es el mismo en cada subparcela ya que se adpató a los turnos ya definidos por la comunidad de regantes con peticiones previas de los agricultores de la agrupación de parcelas dónde se situaba la parcela experimental. A continuación se sintetizan no sólo las fechas de los mismos sino además: el déficit de agua en el suelo [4] justo antes de cada riego y el porcentaje de reducción de tiempo de riego del manejo por pulsos frente al manejo convencional. Esta información se generó en el primer caso realizando un balance de agua en el suelo teniendo en cuenta la demanda evapotranspirativa del cultivo y el segundo caso comparando el tiempo en el que se completaba el 


\section{Congreso Nacional de Riegos CARTAGENA 2021}

riego en cada una de las subparcelas y por tanto mostrando la reducción del tiempo que se generaba regando por pulsos.

Tabla 2. Calendario de riegos, el Agua en el Suelo (DAS) justo antes del riego y el porcentaje de reducción de tiempo de riego en el riego por pulsos.

\begin{tabular}{cccc}
\hline RIEGO & Fecha & $\begin{array}{c}\text { DAS } \\
{[\mathrm{mm}]}\end{array}$ & $\begin{array}{c}\text { Porcentaje de reducción del tiempo de riego } \\
{[\%]}\end{array}$ \\
\hline $1^{*}$ & $13 / 04 / 2021$ & 25,7 & - \\
2 & $07 / 06 / 2021$ & 62,6 & 35,9 \\
3 & $29 / 06 / 2021$ & 85,5 & 17,1 \\
4 & $20 / 07 / 2021$ & 151,8 & 24,8 \\
5 & $04 / 08 / 2021$ & 108,8 & 22,8 \\
\hline
\end{tabular}

* Este riego fue convencional en ambas parcelas para no generar riesgos de nascencia del cultivo al agricultor

Exceptuando el primer riego, sobre cual no fue aplicada la técnica del riego por surcos, todos los riegos generaron una reducción de tiempo de riego. El riego 3, no consiguió una reducción de tiempo similar a los demás riegos, debido a que el sistema tuvo una falta de energía en la mitad del tiempo de riego y se apagó, a partir de ahí regamos manualmente. El motivo fue claramente porque la válvula fue guardada previamente al riego en un lugar cerrado no cargando la batería del riego anterior.

Por tanto y considerando esta irregularidad, se consiguió una reducción media de tiempo del $25 \%$ en el peor de los casos, y por tanto el dato merece un análisis de impacto en la mejora del riego por surcos. Dicha reducción de tiempo de riego es trasladable directamente a la reducción de volumen de agua.

En el siguiente gráfico se muestra la distribución de los riegos en función del Déficit de Agua en el Suelo (DAS) de partida y la reducción del tiempo de riego en el riego por pulso utilizado en la subparcela 2 frente al riego convencional aplicado en la subparcela 1

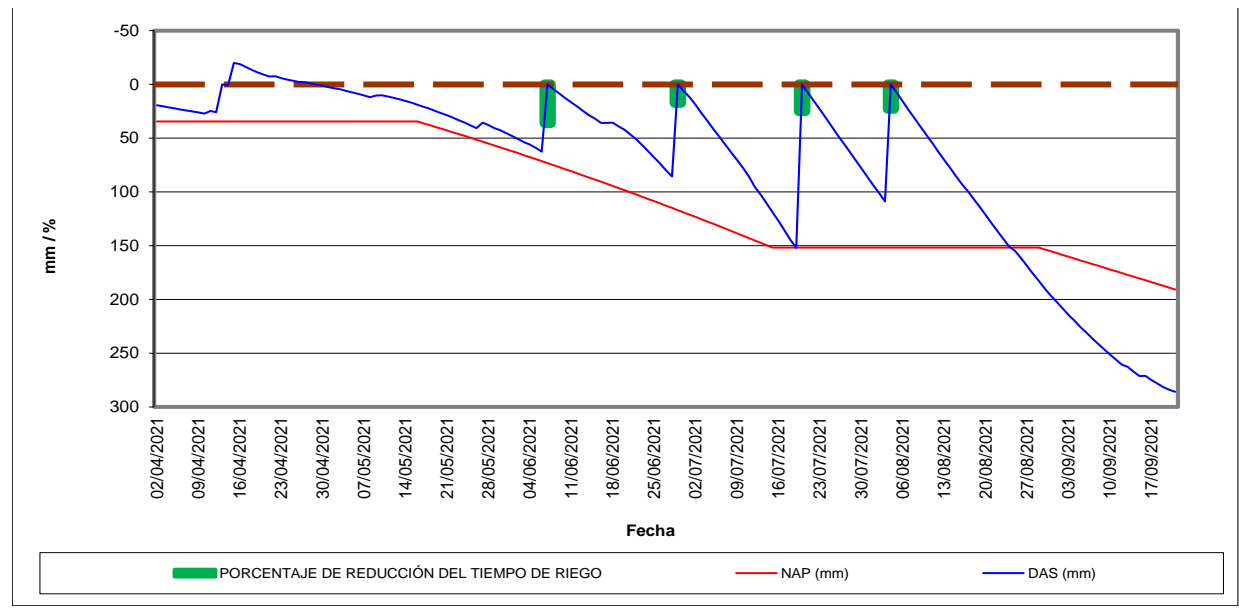

Figura 4. Gráfico del balance de agua en el suelo dónde se representa el DAS justo antes del riego el Nivel de Agotamiento Permisible (NAP) por el cultivo de algodón y el porcentaje de reducción de tiempo de riego en el riego por pulsos.

Habiendo medido los tiempos de riegos en cada subparcela y teniendo en cuenta el caudal instantáneo, los consumos de agua fueron los siguientes:

Tabla 1. Volúmenes de agua aplicados. 


\section{Congreso Nacional de Riegos CARTAGENA 2021

\begin{tabular}{ccc}
\hline & $\begin{array}{c}\text { Subparcela 1 (manejo } \\
\text { convencional) } \\
{\left[\mathrm{m}^{3} / \mathrm{ha}\right]}\end{array}$ & $\begin{array}{c}\text { Subparcela 2 (manejo } \\
\text { sostenible por pulsos) } \\
{\left[\mathrm{m}^{3 / \mathrm{ha}]}\right.}\end{array}$ \\
\hline $\begin{array}{c}\text { Volumen de agua } \\
\text { aplicado }\end{array}$ & 5.458 & 4.365 \\
\hline
\end{tabular}

* Estos volúmenes se han podido aplicar debido a la disponibilidad del agricultor en detrimento de riegos deficitarios en otros cultivos de agua en la explotación.

Un análisis a nivel de parcela del ahorro conseguido implicaría disponer directamente de un riego más sobre el cultivo. Pero además, esta circunstancia llevaría posiblemente a una mayor eficiencia de riego, al aumentar la frecuencia de los riegos. Esto produciría también una mayor producción del cultivo, incluso pudiendo llegar a mejorar la producción del algodón en riego por aspersión, puesto que la distribución del agua en el suelo podría ser más uniforme.

Y un análisis a mayor escala supondría que para un volumen ahorrado próximo a los $1.000 \mathrm{~m}^{3} / \mathrm{ha}$ y para una superficie estimada de riego por surcos en Andalucía de 50.000 ha se podría llegar a un ahorro de aproximadamente $50 \mathrm{hm}^{3}$

\subsection{Abonado}

Los parámetros de abonado recogidos en ambas subparcelas atiende a los criterios recogidos anteriormente.

- Sobre la subparcela 1 (parcela testigo) se distribuye el abono en una aplicación de fondo con dosis de abonado similar a la tradicional mas una sola aplicación de cobertera antes del segundo riego

- Sobre la subparcela 2 (parcela piloto) se distribuye en una aplicación de fondo reducida, con respecto a la parcela testigo mas cinco aplicaciones a través de fertirrigación y después de cada riego. Todas las aplicaciones se realizan según la curva de absorción de cada macronutriente del cultivo de algodón [5], dónde se aplicaba anticipadamente el equilibrio y dosis de abonado para el periodo posterior entre riego y riego.

El balance de distribución y dosis abono aplicado en unidades de fertilizantes se recoge en la siguiente tabla.

Tabla 3. Distribución de abonado en ambas subpacerlas.

\begin{tabular}{ccccccc}
\hline Tipo de aplicación & \multicolumn{3}{c}{ TESTIGO (subparcela 1) } & \multicolumn{2}{c}{ PILOTO (subparcela 2) } \\
\hline Macronutriente & $\mathbf{N}$ & $\mathbf{N}$ & $\mathbf{P}$ & $\mathbf{K}$ & $\mathbf{P}$ & $\mathbf{K}$ \\
Fondo & 32 & 24 & 60 & 15 & 96 & 32 \\
Cobertera/fertirrigación & 128 & 81 & 15 & 57 & - & - \\
$\quad$ TOTAL & $\mathbf{1 6 0}$ & $\mathbf{1 0 5}$ & $\mathbf{7 5}$ & $\mathbf{7 2}$ & $\mathbf{9 6}$ & $\mathbf{3 2}$ \\
\hline
\end{tabular}

Por tanto, en aplicación de nitrógeno se consigue un ahorro del 34,4 \% además del 21,6\% en fósforo.

El manejo sostenible mediante la fertirrigación también aportó las siguientes ventajas.

Un ahorro en la aplicación 


\section{Congreso Nacional de Riegos CARTAGENA 2021}

Una mayor eficiencia en la aplicación del abonado nitrogenado y por tanto una disminución de lixiviados. Todo ello teniendo en cuenta: el fraccionamiento de las aplicaciones, la aplicación sobre un suelo saturado y más impermeable y con la reducción de volumen agua de agua en el riego.

\subsection{Producción}

Para verificar la viabilidad del sistema de riego se ha evaluado tanto el cultivo como la estimación de la producción final. Para ello, no sólo se recolectaron de manera independiente ambas parcelas, sino que además, y para verificar el comportamiento de los suelos y del cultivo, se hizo un seguimiento con satélite. Para ello se recogieron valores de NVDI característicos de ambas parcelas dónde se incluye los valores máximos y mínimos de cada una.

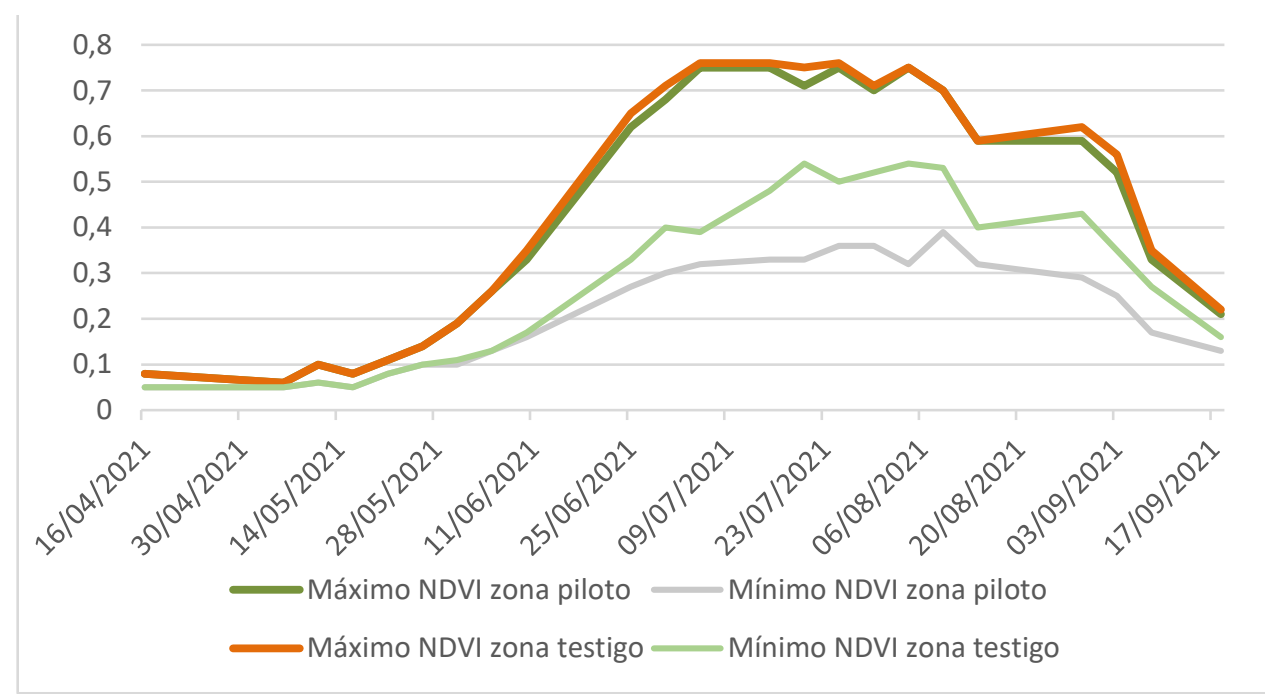

Figura 5. Gráfico de valores máximos y mínimos de NVDI en las dos subparcelas

En dicho gráfico aparecen dos irregularidades con respecto a la evolución del índice de vegetación NVDI de las parcelas. Los valores mínimos de la parcela piloto son muy bajos debido a la irregularidad del estado del suelo en esa parcela. Esta información se justifica en la siguiente figura.
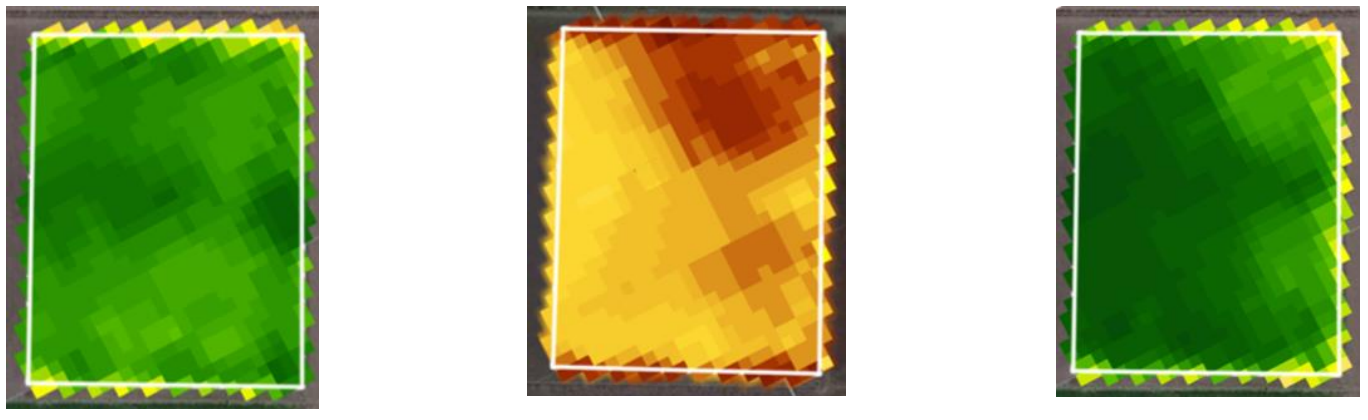

Índice vegetación NDVI de menor a mayor.

Fecha: 21/07/2018 Cultivo: Algodón Valores de NVDI máximo, medio y mínimo: $0.67,0,6$ y 0,4
Fecha: 05/06/2021 Cultivo: Algodón Imagen anterior al riego por pulsos dónde el primer riego fue el tradicional en toda la parcela
Fecha: 20/07/2021 Cultivo: Algodón. Valores de NVDI máximo, medio y mínimo: $0,71,0,65$ y 0,48

Figura 6. Imágenes de NVDI de circunstancias concretas sobre la parcela de ensayo. 


\section{Congreso Nacional de Riegos CARTAGENA 2021}

La irregularidad de la fertilidad del suelo es manifiesta desde una campaña anterior de algodón en el año 2018, tal como se aprecia en la imagen de la izquierda, donde todo fue regado con el mismo sistema de riego. Por tanto esa misma configuración se traslada a la campaña de 2021 como se puede verificar en la segunda imagen sobre el algodón de 2021 y antes de instalar la válvula de riego por pulsos, dónde el riego dado con el sistema tradicional en toda la parcerla manifiesta también dicha irregularidad. Por tanto, y a pesar de obtenerse una producción bruta en la zona testigo de $3.800 \mathrm{Kg} / \mathrm{ha}$ frente a una producción de la zona testigo ligeramente inferior $(3600 \mathrm{Kg} / \mathrm{ha})$, dichas producciones hubieran sido exactamente iguales con la fertilidad del suelo más homogénea. Esto fue comprobado con una corrección realizada a partir de muestras de pesadas parciales recogidas en puntos de similares valores de NVDI.

Por todo y adoptando en el cultivo del algodón un manejo más sostenible dónde se utilice el riego por pulsos y la fertirrigación en riego por surcos, se pueden conseguir buenas producciones con un ahorro mínimo de agua del $25 \%$ de agua del 34\% de nitrógeno. Sin embargo, se necesita continuar para conseguir más información que definan de manera más particularizada todos los parámetros del riego y así conseguir un techo de ahorro. En la bibliografía, y en casos experimentales parecidos se consigue un valor promedio del $35 \%$ de ahorro frente al manejo tradicional, con tasas de reducción de infiltración hasta de un $70 \%[6]$.

\section{Conclusiones}

Como resumen final se podría mencionar lo siguiente:

- El sistema de riego por surcos demuestra que puede ser un riego viable con posibilidades de mejora en la eficiencia de aplicación de riego.

- El sistema de pulsos de forma automatizada consigue considerables ahorros de agua en toda una campaña de riego de un cultivo herbáceo.

- El uso de la fertirrigación incorporada a la válvula automatizada de riego, permite una mayor eficiencia en la aplicación de abonos nitrogenados y facilita su aplicación sin generar costes añadidos.

- Es posible hacer más sostenible cualquier cultivo aplicando el este sistema automatizado no sólo desde el punto vista de rentabilidad sino desde el punto de vista ambiental.

- Un año de ensayo no es suficiente para llegar a un manejo óptimo del sistema. Por tanto, es necesario repetir en otras situaciones para conseguir mayores ahorros de agua y menores tasas de infiltración a las conseguidas inicialmente sobre el riego por surcos convencional.

\section{Referencias}

1. Ministerio de Agricultura, Pesca y Alimentación (MAPA). Informe sobre Regadíos en España. 2018. Gobierno de España

2. Walker, W.R. Guidelines for designing and evaluating surface irrigation systems. 1989. FAO Irrigation and Drainage Paper 45. Food and Agriculture Organitation of the United Nations. Rome, Italy.

3. C.W. Wood, L.J. Krutz, L. Falconer, H.C. Pringle III, B. Henry, T. Irby, J.M. Orlowski, C. J. Bryant, D.L. Boykin, R.L. Atwill, D.M. Pickelmann. Surge Irrigation Reduces Irrigation Requirements for Soybean on Smectitic Clay-Textured Soils. 2017. Crop Management. August 17.

4. Allen, Richard G., et al. Crop evapotranspiration-Guidelines for computing crop water requirements. 1998. FAO Irrigation and drainage paper 56. Food and Agriculture Organitation of the United Nations. Rome, Italy. Vol. 300, no 9.

5. Jana Harish, D.D. Pawar, K.D. Kale, R.R. Hasure and S.K. Dingre. Nutrient Availability in Bt. Cotton under Drip Fertigation. 2018. International Journal of Current Microbiology and Applied Sciences, April 7(04):3373-3379

6. Riza Kanber, Harun Köksal, Sermet Önder, Selim Kapur, Sebahattin Sahan. Comparison of surge and continuous furrow methods for cotton in the Harran plain. 2001. Agricultural Water Management 47, 119-135 


\section{Preciriego: Un proyecto de colaboración público-privada para adaptar la irrigación de precisión al riego por goteo de los culti- vos leñosos.}

González-Gómez, L. ${ }^{1}$ Intrigliolo, D.S. ${ }^{1,2}$, Ortega, J.F. ${ }^{3}$, Ballesteros, R. ${ }^{3}$, Ramirez-Cuesta, J.M. ${ }^{2}$, del Castillo, A. ${ }^{3}$, López-García, P. ${ }^{3}$, García,_F.J. ${ }^{4}$, Munuera, M.T. ${ }^{5}$, Moreno, M.A. ${ }^{3}$

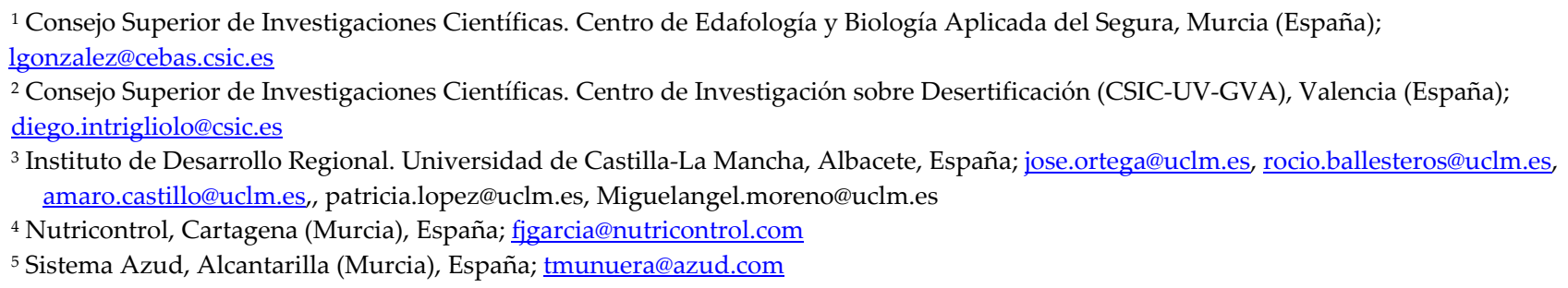

Resumen: En las últimas décadas se han realizado grandes avances para ajustar la dosis de riego a aplicar las necesidades hídricas promedio de una parcela, tendiendo hacia un riego de precisión. El siguiente reto que aborda el proyecto Preciriego es tener en cuenta la variabilidad en las parcelas para ajustar el riego a las posibles diferencias existentes. Mientras en cultivos herbáceos más extensivos y bajo riego por aspersión con Pivots este desafío ha sido ya abordado, se han realizado menos trabajos en cultivos leñosos y riego por goteo. En esta comunicación se integran técnicas de teledetección de rango cercano utilizando drones y modelos hidráulicos de precisión para llevar a cabo una zonificación de un viñedo comercial para definir tres zonas con distintos índices de vigor vegetativo. Posteriormente, se ha aplicado un riego diferencial para cada zona de modo que, manteniendo la dosis promedio establecida de unos 1000 m3/ha, la misma ha sido aplicada de forma diferencial en función del vigor de las cepas. Para ello se ha variado el diseño agronómico del riego, utilizando distintas distancias entre goteros en función de la zonificación realizada. De este modo, sin tener que sectorizar ni aplicar tiempos o frecuencias de riego distintas para cada zona, la pluviosidad de la instalación fue distinta. Dicha estrategia de riego de precisión ha sido validada en campo, demostrando que las zonas de mayor vigor vegetativo han aprovechado mejor la mayor dotación de riego empleada teniendo una mayor producción frente a otras zonas con menor desarrollo vegetativo donde se ha considerado que la productividad de las cepas podía estar limitada por otros factores al margen del riego. Otra de las ventajas del sistema de riego de precisión radica en la automatización de la programación llevada a cabo desarrollada mediante nuevos programadores con posibilidad de tele-lectura y fácil instalación en parcela. La puesta en práctica de los sistemas de riego de precisión sigue adelante en el proyecto Preciriego con otros ensayos en marcha en cultivos leñosos y hortícolas al aire libre.

Palabras clave: eficiencia en el uso del agua, drones, evapotranspiración, vid, zonificación. 


\title{
XXXVIII Congreso Nacional de Riegos CARTAGENA 2021
}

\section{Preciriego: A public-private collaboration project to adapt pre- cision irrigation to drip irrigation of woody crops.}

\author{
González-Gómez, L. ${ }^{1}$, Intrigliolo, D.S. ${ }^{1,2}$, Ortega, J.F. ${ }^{3}$, Ballesteros, R. ${ }^{3}$, Ramirez-Cuesta, J.M. ${ }^{2}$, del Castillo, A. ${ }^{3}$, Ló- \\ pez-García, P. ${ }^{3}$, García,_F.J. ${ }^{4}$, Munuera, M.T. ${ }^{5}$, Moreno, M.A. ${ }^{3}$

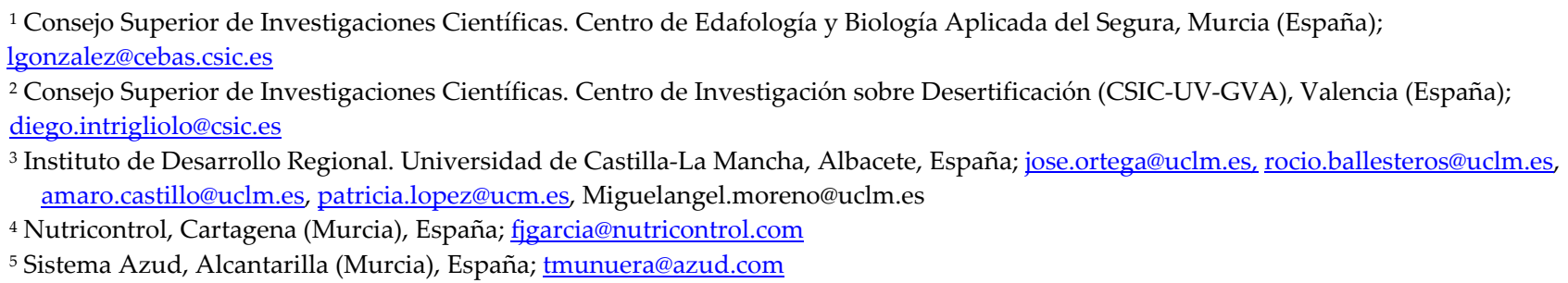

\begin{abstract}
Recently important advances have been made to adjust the irrigation dose to apply the average plot water needs tending towards precision irrigation. The next challenge that the Preciriego project addresses is to take into account the variability in the plots to adjust the irrigation to the possible existing differences. While in more extensive herbaceous crops and under sprinkler irrigation with Pivots this challenge has already been addressed, less work has been done with woody crops under drip irrigation. In this communication, close-range remote sensing techniques are integrated using drones and precision hydraulic models to carry out a zoning of a commercial vineyard to define three zones with different vegetative vigour indexes. Subsequently, a differential irrigation has been applied for each zone so that, maintaining the established average dose of about $1000 \mathrm{~m} 3$ / ha, water was applied differentially depending on the vine vigour. For this, the agronomic irrigation design has been varied, using different distances between drippers depending on the zoning carried out. In this way, without having to sectorize or apply different irrigation times or frequencies for each zone, the watering application for each zone was different. This precision irrigation strategy has been validated in the field, showing that the areas with the highest vegetative vigour have made better use of the greater irrigation application, having a higher production compared to other areas with less vegetative development. In the low vigour areas, it has been considered that the vine productivity could be limited by factors other than irrigation. Another advantage of the precision irrigation system lies in the automation of the programming carried out by means of new programmers with the possibility of remote-reading and easy installation on the plot. The implementation of precision irrigation systems continues in the Preciriego project with other trials underway in woody and horticultural crops.
\end{abstract}

Keywords: water use efficiency, drones, evapotranspiration, grapevine, zoning. 


\section{Congreso Nacional de Riegos CARTAGENA 2021}

\section{Introducción}

En la actualidad el uso eficiente de los recursos hídricos es un importante reto al que deben enfrentarse agricultores y gestores agrarios, con especial relevancia en zonas semiáridas que presentan una marcada limitación y escasez en la disponibilidad de agua como sucede en el sureste español. Así pues, las estrategias de riego de precisión toman un papel determinante en el manejo agronómico de las parcelas agrícolas. La agricultura de precisión requiere la tecnología necesaria para la distribución de los insumos así como el conocimiento de la distribución espacial de los requisitos de los cultivos [1].

La creación de mapas capaces de capturar la variabilidad intra e inter-parcelaria permite distribuir los riegos en base a las características intrínsecas de las propias parcelas, influenciadas por las propiedades de su suelo, la climatología y el manejo agronómico realizado sobre ellas. Existen numerosas técnicas que han abordado la creación de estos mapas como aquellas basadas en la conductividad eléctrica del suelo, las que emplean modelos de crecimiento de cultivos o modelos hidráulicos de precisión, el empleo de cosechadoras con monitores de rendimiento, o por ejemplo aquellas que utilizan datos obtenidos desde sensores remotos como satélites o drones entre otros. En este último contexto, la teledetección ha demostrado su potencial y efectividad para llevar a cabo la monitorización espacio-temporal de la vegetación [2] a través de una amplia multitud de índices de vegetación (IVs) derivados de las imágenes obtenidas desde dichos sensores remotos. Los IVs son sensibles a los cambios ocurridos en la vegetación en términos de desarrollo fisiológico, puesto que pueden reflejar las adversidades sufridas por el cultivo que afectan a su crecimiento y desarrollo, al reducir la densidad clorofílica o su biomasa, lo que provocará una disminución del IV [3,4]. Este hecho ha favorecido su uso como indicadores de diversos parámetros biofísicos como son la fracción de cobertura vegetal, el índice de área foliar, la fracción de la radiación fotosintéticamente absorbida, el coeficiente de cultivo, la altura de la planta, el contenido en clorofila, o el contenido en agua entre otros [5-7]. De ellos, el Índice de Vegetación de Diferencia Normalizada (NDVI) [8] es el IV más popular y más ampliamente usado desde comienzo de los años 70 hasta hoy en día, siendo capaz de describir de manera adecuada el vigor vegetativo de las cubiertas vegetales.

La automatización de la programación en los sistemas de riego de precisión permite llevar a cabo un manejo más preciso y controlado que garantice el aporte adecuado de las necesidades hídricas específicas de los cultivos. En este sentido, cada vez es más demandado el empleo de sistemas de control inteligente y remoto que no solo permita tomar lecturas de sensores, integrar programaciones sencillas de riego y actuar sobre los emisores, sino que además sea capaz de interpretar los datos e integrar esta información en los modelos de ayuda a la toma de decisiones definidos para regular en tiempo real sobre el riego que realmente se debe aplicar.

El presente trabajo tiene por objetivo la evaluación en términos de producción, de una zonificación de precisión a través de un ensayo de riego diferencial por goteo realizada en base a la variabilidad del vigor vegetal presente en una parcela de viña en espaldera, enmarcada dentro del proyecto Preciriego (sistema experto para el diseño y control de un sistema de riego a presión, personalizado y de precisión)

\section{Materiales y métodos}

El trabajo desarrollado se llevó a cabo durante la campaña 2020 sobre una parcela comercial de viña en espaldera y riego por goteo, de la variedad Monastrell (Vitis vinífera L.), ubicada en el término municipal de Fuente-Álamo, provincia de Albacete $\left(38^{\circ} 43^{\prime} 47^{\prime \prime} \mathrm{N}, 1^{\circ} 28^{\prime} 18^{\prime \prime} \mathrm{O}\right)$. La parcela fue plantada en el año 2007 utilizando el portainjerto $110 \mathrm{R}$. Las cepas presentan un marco de plantación de 3 m entre calles y 1.5 m entre cepas, con una orientación de la filas norte-sur. Tiene una superficie de 7.3 ha y se divide en 3 sectores hidráulicos, aunque el ensayo se llevó a cabo sobre el sector 1 (Figura 1) de 0.9 ha 


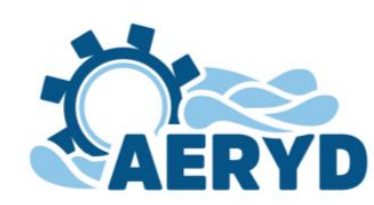

XXXVIII Congreso Nacional de Riegos

y 31 líneas o filas de viña. Según la clasificación climática de Köppen-Geiger, la climatología en el área de estudio es del tipo Bsk (estepario frío). La temperatura media anual es de $14.9^{\circ} \mathrm{C}$ y la precipitación promedio anual es de $294 \mathrm{~mm}$. El suelo de la parcela es franco arenoso, con un $\mathrm{pH}$ alto de 8.86 y ligeramente alcalino.

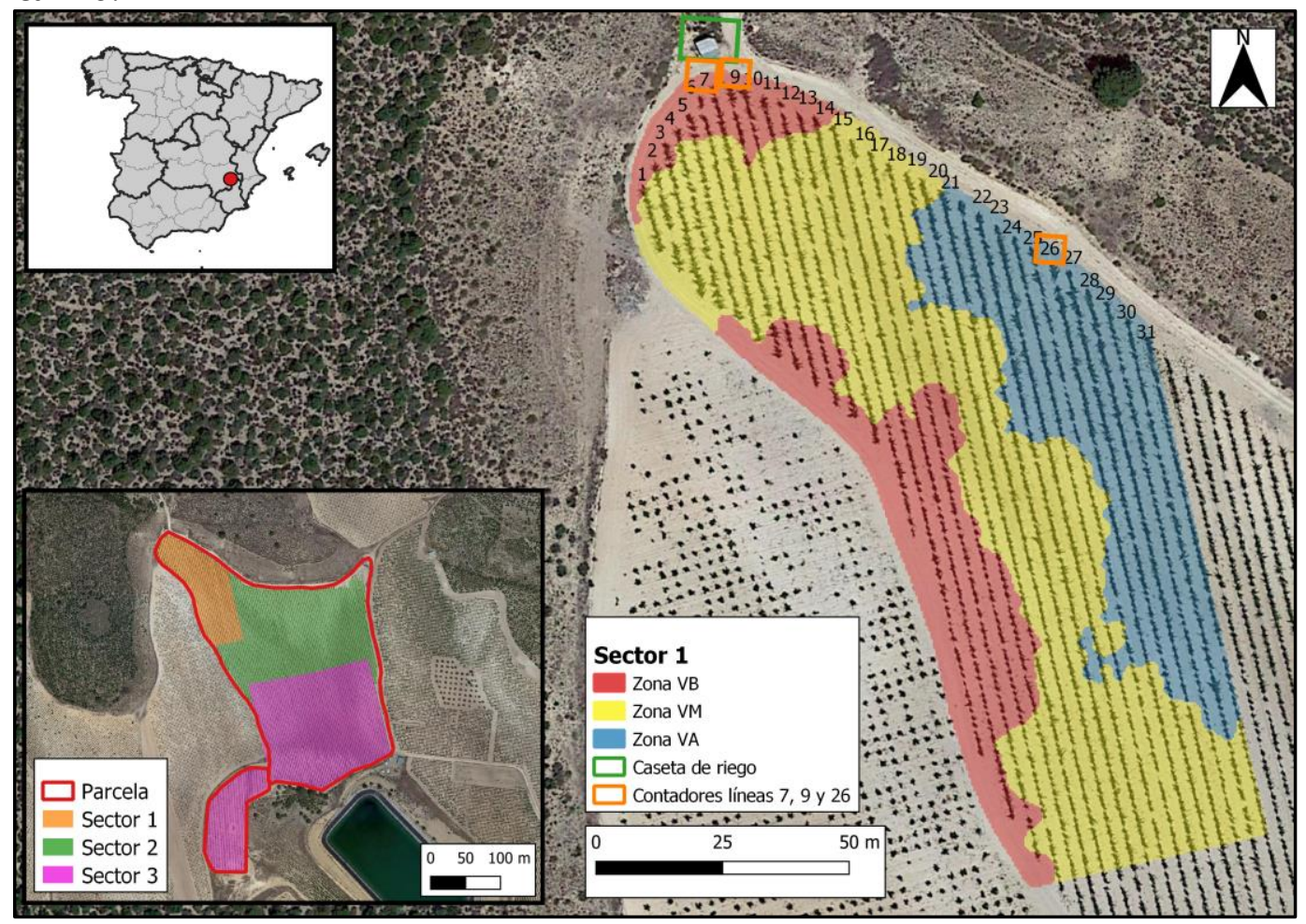

Figura 1. Parcela de viña ubicada en Fuente-Álamo ( $38^{\circ} 43^{\prime} 47^{\prime \prime} \mathrm{N}, 1^{\circ} 28^{\prime} 18^{\prime \prime} \mathrm{O}$, Albacete). Detalle mapa de zonificación del sector 1 .

La variabilidad presente en el sector 1 de la parcela objeto de estudio, se obtuvo a partir de un mapa de zonificación realizado mediante una imagen de muy alta resolución espacial $(5 \mathrm{~cm})$ adquirida con una cámara multiespectral Micasense instalada sobre un dron y tomada el día 19 de junio del 2019. Se segmentó la vegetación separándola así del suelo, y eliminando con ello el alto efecto que los suelos ejercen en cultivos leñosos como la vid. Para ello, se utilizó la versión modificada del programa LAIC (Leaf Area Index Calculation) [9], llamado "MS-GEO-LAIC Multiespectral”, desarrollado por el grupo Precisión Agroforestal y Cartográfica (PAFyC) de la Universidad de Castilla-La Mancha (UCLM). A partir de la diferencia normalizada de las bandas del rojo y del infrarrojo cercano se calculó el NDVI sobre la vegetación y se realizó un análisis cluster k-means. Posteriormente se aplicó un filtro de sal y pimienta, agrupando píxeles y eliminando pequeñas islas, obteniendo finalmente una zonificación en 3 clases de vigor alto (VA), medio (VM) y bajo (VB) (Figura 1).

Para poder llevar a cabo el riego diferencial, manteniendo de manera homogénea los mismos tiempos y momentos de riego entre las zonas definidas en el sector 1 de la parcela (Figura 1), en cada una de ellas se instalaron goteros autocompensantes del mismo caudal, de $3.51 \mathrm{ha}^{-1}$, pero con distinta separación entre ellos. Por ello, los goteros se dispusieron a $1.25 \mathrm{~m}$ en la zona VB, a $1 \mathrm{~m}$ en la zona VM, y a $0.75 \mathrm{~m}$ en la zona VA. La programación del riego estuvo limitada por la dotación hídrica máxima en la parcela, siendo esta de aproximadamente $1000 \mathrm{~m}^{3} \mathrm{ha}^{-1}$. La programación de los riegos se inició la semana del 21 de julio y terminó la semana del 22 de septiembre. Los riegos semanales se programaron 


\section{Congreso Nacional de Riegos CARTAGENA 2021}

en base a las necesidades hídricas estimadas durante la semana previa. Siguiendo la metodología de FAO 56 [10], para el cálculo del riego se estimaron las necesidades hídricas semanales en base a la evapotranspiración del cultivo $\left(E T_{c}\right)$, considerando por un lado la demanda evaporativa de la atmósfera por medio de la evapotranspiración de referencia $\left(\mathrm{ET}_{\mathrm{o}}\right)$ y por otro lado, el cultivo analizado y su estadio fenológico a través del coeficiente de cultivo $\left(\mathrm{K}_{\mathrm{c}}\right)$ (Ecuación 1). La ETo se obtuvo diariamente desde la estación meteorológica de la Red SIAR (Sistema de Información Agroclimática para el Regadío) más cercana a la parcela objeto de estudio, estando ubicada en la población de Ontur (Albacete). Siguiendo las recomendaciones de $\mathrm{FAO} 56$, los valores de $\mathrm{K}_{\mathrm{c}}$ deben de ajustarse a la localización y a las condiciones climáticas del área analizada. Por ello, se han empleado valores históricos de $\mathrm{K}_{\mathrm{c}}$ en la parcela ya ajustados a las condiciones locales y del cultivo [11].

$$
E T_{c}=E T_{o} \times K_{c}
$$

Las necesidades de riego netas (NRN) se obtienen restando a la $\mathrm{ET}_{\mathrm{c}}$ la precipitación efectiva $\left(\mathrm{P}_{\mathrm{e}}\right)$, calculada asumiendo que el $70 \%$ de la lluvia registrada sobre la parcela es aprovechada por el cultivo (Ecuación 2).

$$
N R N=E T_{c}-P_{e}
$$

En base a las NRN y considerando la eficiencia de la instalación de riego y la fracción de lavado se obtuvieron las necesidades de riego brutas (NRB). En nuestro caso, se multiplicaron las NRN por un coeficiente de corrección de 1.05 (Ecuación 3).

$N R B=N R N \times 1.05$

Para calcular la duración de los riegos semanales, las NRB se dividen entre la pluviosidad del sistema. Dicha pluviosidad es estimada multiplicando el número de goteros por su caudal, y dividiéndolo entre la superficie total, obteniendo así una pluviosidad de $1.22 \mathrm{~mm} \mathrm{~h}^{-1}$.

Para poder contabilizar el agua real aplicada se instaló un contador general en la caseta de riego y otros 3 contadores al comienzo de las líneas número 7, 9 y 26, pertenecientes a las zonas VB, VM y VA, respectivamente (Figura 1). Además, en cada una de las 3 zonas se instalaron sondas de humedad y temperatura con sensores a diferentes profundidades $(5,15,30,45 \mathrm{y} 60 \mathrm{~cm})$, para poder observar principalmente en el caso de las sondas de humedad el comportamiento relativo en el tiempo de la humedad en suelo. A través de la instalación del equipo "NTC Datalogger" la aplicación del riego se automatizó, así como la visualización y descarga de datos de las sondas y los contadores.

Desde mediados de junio y hasta finales de septiembre, y en intervalos aproximados de 15 días, se llevaron a cabo, en 8 fechas diferentes, medidas de potencial hídrico del tallo ( $\left.\Psi_{\text {tallo }}\right)$ utilizando cámaras de presión Scholander (Model 600, PMS Instrument Company, Albany, OR, USA) con el objetivo de analizar el estado hídrico de las cepas. Se seleccionaron 20 cepas representativas de la zona VB, 14 de la zona VM y otras 14 de la zona VA. Las hojas elegidas de cada cepa fueron envueltas en bolsas de plástico cubiertas de aluminio al menos $1 \mathrm{~h}$ antes de llevar a cabo las medidas, las cuales fueron realizadas entre las 12:00-14:00 h del mediodía solar.

Dos días antes de la vendimia del agricultor, el 23 de septiembre, se realizó un muestreo de vendimia y de bayas, para poder obtener datos de producción y de madurez fenólica y tecnológica en las 3 zonas analizadas del sector 1 . También se muestrearon diversas cepas de los sectores 2 y 3 , comparando así los datos obtenidos con los del sector 1 objeto del ensayo. En los muestreos de producción se recogieron los racimos de 130 cepas, de las cuales, 80 pertenecían al sector 1 ( 25 zona VB, 30 zona VM, y 25 zona VA), 25 al sector 2 y otras 25 al sector 3 . En cuanto a los muestreos de madurez fenólica y tecnológica, se recogieron de manera aleatoria 3000 bayas en diferentes cepas de los 3 sectores de la parcela. En concreto se realizaron 3 repeticiones de aproximadamente 200 bayas en cada una de las 3 zonas del sector 1, y otras 3 repeticiones de aproximadamente 200 bayas tanto en el sector 2 como en el sector 3 . 


\section{Congreso Nacional de Riegos CARTAGENA 2021}

Las diferencias entre las 3 zonas del sector 1, así como las diferencias entre estas 3 zonas y los otros 2 sectores de riego (el 2 y el 3), han sido analizadas a través de un análisis de varianza (ANOVA), realizado mediante el programa Statistix 9 (Analytical Software, Tallahassee, USA). Las diferencias significativas encontradas se han analizado por medio del test HSD (Honest Significant Difference) de Tukey (=0.05).

\section{Resultados y discusión}

\subsection{Zonificación de la parcela y diseño hidráulico}

El mapa de variabilidad y zonificación del sector 1 de la parcela analizada que atiende al desarrollo vegetativo diferenciado por medio del análisis del NDVI ha permitido distinguir 3 zonas: la zona de menor vigor vegetativo, VB, la zona de vigor intermedio, VM, y la zona de mayor vigor, VA (Figura 1). En base a ello, en el diseño hidráulico del sector 1 los goteros se dispusieron a $1.25 \mathrm{~m}$ en la zona VB, a $1 \mathrm{~m}$ en la zona VM, y a $0.75 \mathrm{~m}$ en la zona VA. Así pues, la estrategia consistió en aplicar mayor cantidad de agua a la zona más vigorosa al tener los goteros instalados a una menor distancia entre ellos, y por el contrario aplicar menor cantidad de agua, con una mayor separación entre goteros, a la zona menos vigorosa y por tanto a priori con menores necesidades hídricas.

\subsection{Análisis estado hídrico}

La Figura 2 muestra el seguimiento del estado hídrico del viñedo a través de las mediciones quincenales del $\Psi_{\text {tallo }}$ desde mediados de junio hasta finales de septiembre. La gráfica muestra como el estado hídrico del viñedo disminuyó a lo largo de la campaña en las 3 zonas del sector 1, pero situándose en valores de débil a moderado déficit hídrico [12]. En concreto, los valores de $\Psi_{\text {tallo }}$ de la zona VB oscilaron entre los -0.36 MPa hasta los -0.81 MPa días antes de la vendimia. Con valores y una evolución temporal muy similar, el $\Psi_{\text {tallo }}$ de la zona VM osciló entre los $-0.39 \mathrm{MPa}$ hasta los $-0.81 \mathrm{MPa}$. La zona VA fue la que registró los menores valores de $\Psi_{\text {tallo, }}$ los cuales fueron desde - $0.43 \mathrm{MPa}$ hasta $1.01 \mathrm{MPa}$. Así pues, la zona con mayor vigor vegetativo fue la que presentó los menores valores de $\Psi_{\text {tallo. }}$ Esta zona VA presentó diferencias significativas con respecto a las otras dos desde mediados de julio hasta el final de la campaña de riego, con la salvedad de la penúltima medida tomada.

Complementario al análisis del estado hídrico de las plantas por medio de medidas puntuales de

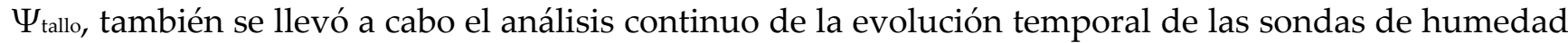
capacitativas desde julio hasta el final de la campaña de riego (Figura 3). La sonda ubicada en la zona VB presentó un problema en su instalación que interfirió en las medidas realizadas y por ello sus datos fueron descartados. La evolución temporal de la humedad mostró movimiento de agua en suelo principalmente hasta los 15 primeros cm en la zona VM y hasta los $30 \mathrm{~cm}$ en la zona VA. A mayor profundidad, aunque si muestra movimiento, no se observa percolación de agua hacia capas más profundas que indiquen un riego excesivo y/o mal distribuido en el tiempo (Figura 3).

Los volúmenes de agua registrados por los contadores instalados en cada una de las 3 zonas del sector 1 al comienzo de las líneas 7, 9 y 26, así como el del contador general instalado en la caseta de riego (Figura 1), se muestran en la Figura 4 comparados frente a los volúmenes programados durante la campaña. En los contadores de línea, se muestra que tras los 4 primeros riegos y con excepción de algún riego puntual, las dosis teóricas se ajustaron con bastante precisión a las reales. En el conjunto de toda la campaña de riego, la diferencia entre el riego teórico y el registrado a través de los contadores fue de un $6.2 \%$, $7.1 \%$ y un $9.6 \%$, en las líneas 7 (zona VB), 9 (zona VM) y 26 (zona VA), respectivamente. El contador general no mostró el caudal real registrado hasta el día 25 de agosto, coincidiendo con el 


\section{Congreso Nacional de Riegos CARTAGENA 2021}

riego número 20. Para el periodo de tiempo disponible, la diferencia entre el riego teórico y el registrado a través del contador general fue de un $2 \%$.

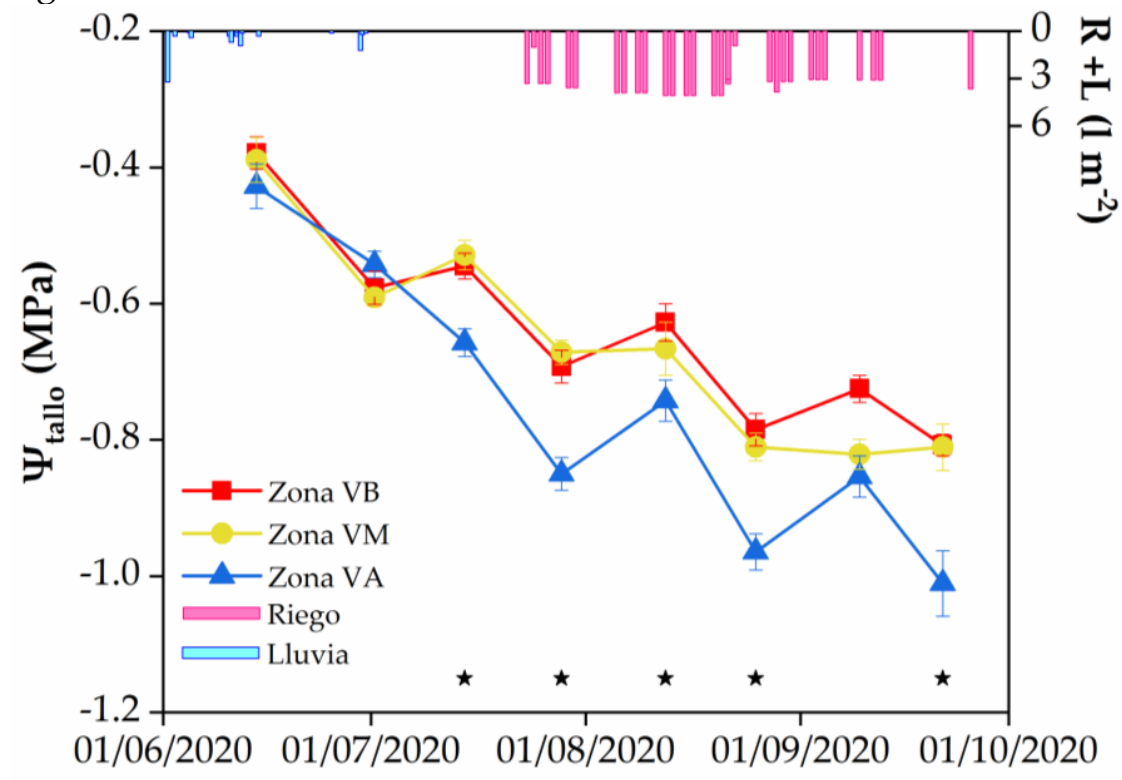

Fecha

Figura 2. Potencial hídrico de tallo ( $\left.\Psi_{\text {tallo }}\right)$, en MPa, en las 3 zonas del sector 1. VB: vigor bajo. VM: vigor medio. VA: vigor alto. $\mathrm{R}+\mathrm{L}$ : riego teórico + lluvia. Las barras representan el error estándar para las medidas. Los asteriscos muestran las diferencias significativas entre zonas $(\mathrm{p}<0.05)$ a través del Test HSD de Tukey.

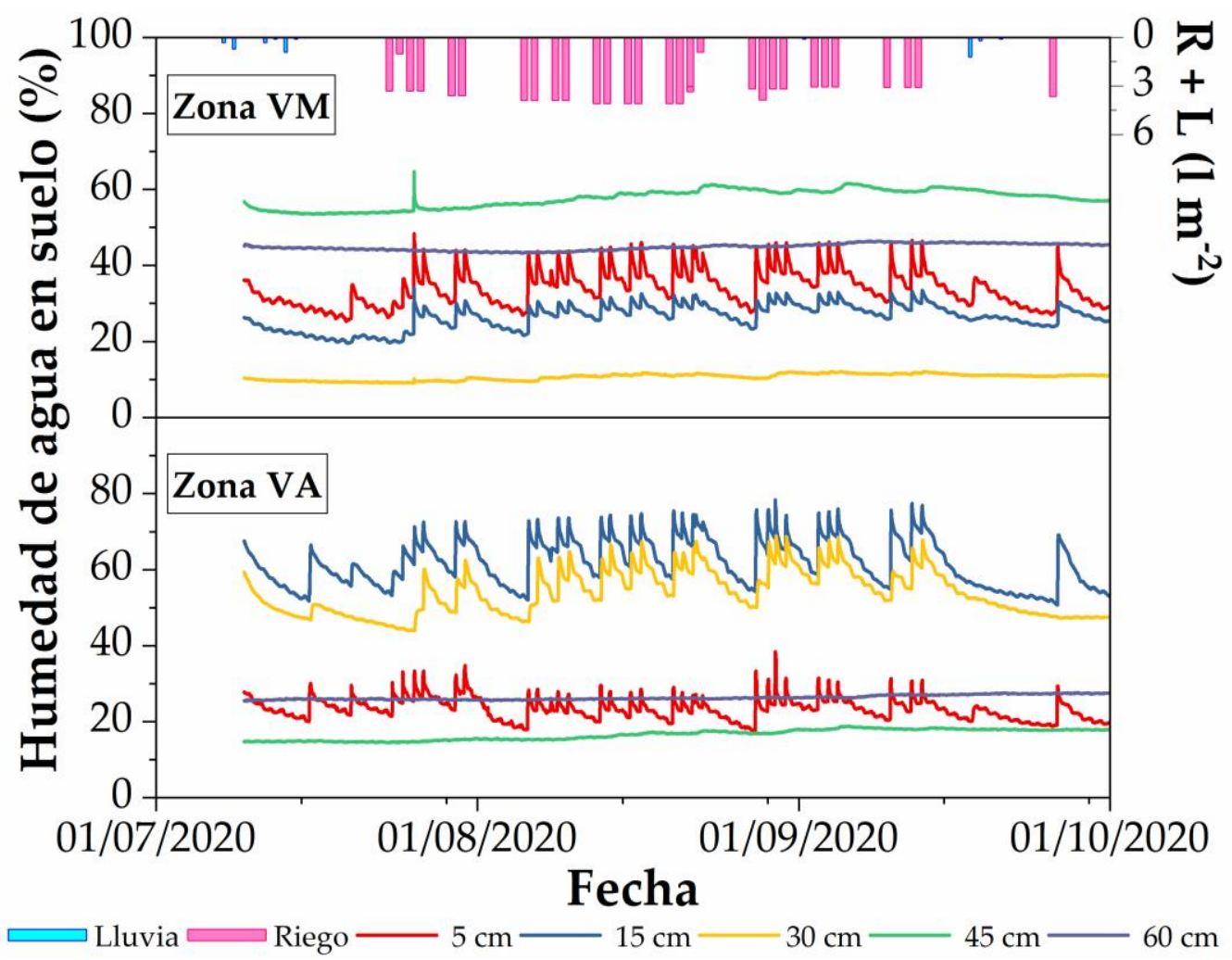

Figura 3. Humedad de agua en suelo a través de las sondas de humedad instaladas en la zona VM (vigor medio) y en la zona VA (vigor alto) a diferentes profundidades $(0-5,15,30,45$ y $60 \mathrm{~cm})$. $\mathrm{R}+\mathrm{L}$ : riego teórico + lluvia. 


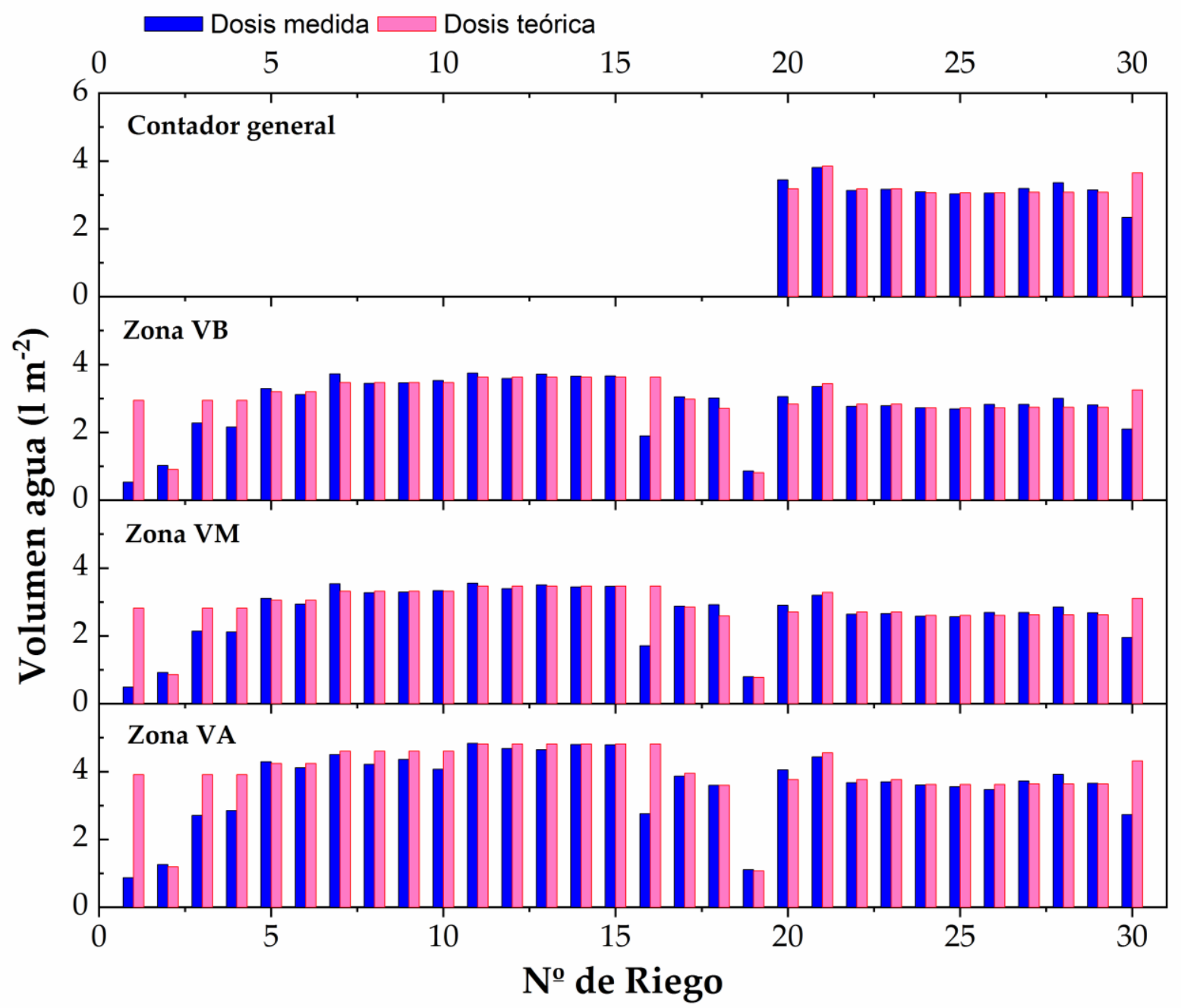

Figura 4. Volumen de agua medido mediante contadores frente a volumen de agua teórico programado. VM: vigor medio. VA: vigor alto.

\subsection{Análisis muestreos de vendimia}

La Tabla 1 muestra los datos de producción promedia por cepa y por hectárea obtenidos entre los muestreos llevados a cabo dos días antes de la vendimia, así como el peso promedio de las bayas. Aparecen diferencias significativas entre las zonas del sector 1, donde la zona VA presenta una mayor producción $\left(5.78 \mathrm{~kg}\right.$ cepa $\left.^{-1}, 12836 \mathrm{~kg} \mathrm{ha}^{-1}\right)$ que las zonas VB y VM, ambas dos con resultados muy similares entre ellas (3.31-3.33 $\mathrm{kg}$ cepa-1 ${ }^{-1}$ 7351-7399 $\left.\mathrm{kg} \mathrm{ha}^{-1}\right)$. Por lo tanto, la zona más vigorosa en base al mapa de variabilidad del sector 1 analizado obtuvo una mayor producción final como se podía esperar. Esto es así a pesar del menor estado hídrico registrado en esta zona (Figura 2). La comparación de la producción de las zonas del sector 1 con respecto a los sectores 2 y 3 muestra diferencias significativas entre las zonas VB y VM del sector 1 con respecto a los sectores 2 y 3 . Sin embargo, el promedio de todo el sector $1\left(4.14 \mathrm{~kg} \mathrm{cepa}^{-1}, 9195 \mathrm{~kg} \mathrm{ha}^{-1}\right)$ no presentó diferencias significativas con respecto a los sectores 2 y 3. Por lo tanto, puede considerarse como acertada la estrategia de suministrar más agua a la zona con mayor potencial productivo. En cuanto al peso de las bayas no se observan diferencias significativas en ningún caso. 


\section{Congreso Nacional de Riegos CARTAGENA 2021}

Tabla 1. Datos promedios de producción por cepa y por hectárea, y de peso de bayas. VB: vigor bajo. VM: vigor medio. VA: vigor alto. Las letras minúsculas indican diferencias significativas entre las zonas del sector 1 . Las letras mayúsculas indican diferencias significativas entre las 3 zonas del sector 1 y los sectores de riego 2 y 3.

\begin{tabular}{ccccc}
\hline Sector & Zona & $\begin{array}{c}\text { Producción } \\
\left.\text { (kg cepa }^{-1}\right)\end{array}$ & $\begin{array}{c}\text { Producción } \\
\left.\text { (kg ha }^{-1}\right)\end{array}$ & $\begin{array}{c}\text { Peso de la } \\
\text { baya } \mathbf{~ g ) ~}\end{array}$ \\
\hline 1 & VB & $3.31 \mathrm{~b} ; \mathrm{B}$ & $7351 \mathrm{~b} ; \mathrm{B}$ & $1.83 \mathrm{a} ; \mathrm{A}$ \\
1 & VM & $3.33 \mathrm{~b} ; \mathrm{B}$ & $7399 \mathrm{~b} ; \mathrm{B}$ & $1.67 \mathrm{a} ; \mathrm{A}$ \\
1 & VA & $5.78 \mathrm{a} ; \mathrm{A}$ & $12836 \mathrm{a} ; \mathrm{A}$ & $1.85 \mathrm{a} ; \mathrm{A}$ \\
2 & & $4.98 \mathrm{~A}$ & $11070 \mathrm{~A}$ & $1.75 \mathrm{~A}$ \\
3 & & $4.50 \mathrm{AB}$ & $9990 \mathrm{AB}$ & $1.76 \mathrm{~A}$ \\
\hline
\end{tabular}

\subsection{Análisis madurez fenólica y tecnológica}

En cuanto a la composición de la uva no se apreciaron diferencias estadísticamente significativas en la madurez tecnológica de la uva (Tabla 2) entre las distintas zonas y sectores de la parcela. Sin embargo, sí se pudo observar como las bayas de la zona VB (menos vigorosa) tenían un índice de polifenoles totales mayor que el resto de zonas y de los otros 2 sectores.

Tabla 2. Datos madurez fenólica y tecnológica. VB: vigor bajo. VM: vigor medio. VA: vigor alto. IPT: Índice de Polifenoles Totales. SST: Sólidos Solubles Totales. Las letras minúsculas indican diferencias significativas entre las zonas del sector 1. Las letras mayúsculas indican diferencias significativas entre las 3 zonas del sector 1 y los sectores de riego 2 y 3 .

\begin{tabular}{|c|c|c|c|c|c|c|}
\hline Sector & Zona & $\begin{array}{l}\text { Antocianos } \\
\left(\mathrm{mg} \mathrm{g}^{-1}\right)\end{array}$ & $\begin{array}{c}\text { IPT } \\
\left(\mathrm{mg} \mathrm{g}^{-1}\right)\end{array}$ & $\begin{array}{c}\text { Promedio } \\
\text { SST ( }{ }^{\circ} \text { BRIX) }\end{array}$ & $\begin{array}{c}\text { Promedio } \\
\mathrm{pH}\end{array}$ & $\begin{array}{c}\text { Promedio Ac. Total } \\
\left(\mathrm{g}^{-1}\right) \text { tartárico } \\
(\mathrm{pH}=8.2)\end{array}$ \\
\hline 1 & VB & $2.658 \mathrm{a} ; \mathrm{A}$ & $1.284 \mathrm{a} ; \mathrm{A}$ & 23.30 a; $\mathrm{A}$ & $3.47 \mathrm{a} ; \mathrm{A}$ & $5.96 \mathrm{a} ; \mathrm{A}$ \\
\hline 1 & $\mathrm{VM}$ & $2.745 \mathrm{a} ; \mathrm{A}$ & $1.141 \mathrm{~b} ; \mathrm{B}$ & $22.73 \mathrm{a} ; \mathrm{A}$ & $3.52 \mathrm{a} ; \mathrm{A}$ & $5.84 \mathrm{a}: \mathrm{A}$ \\
\hline 1 & VA & $2.602 \mathrm{a} ; \mathrm{A}$ & 1.040 b; B & $21.67 \mathrm{a} ; \mathrm{A}$ & $3.50 \mathrm{a} ; \mathrm{A}$ & $6.01 \mathrm{a} ; \mathrm{A}$ \\
\hline 2 & & $2.490 \mathrm{~A}$ & 1.103; B & $22.40 \mathrm{~A}$ & $3.52 \mathrm{~A}$ & $5.79 \mathrm{~A}$ \\
\hline 3 & & $2.610 \mathrm{~A}$ & 1.042; B & $21.48 \mathrm{~A}$ & $3.52 \mathrm{~A}$ & $6.07 \mathrm{~A}$ \\
\hline
\end{tabular}

\section{Conclusiones}

Se ha validado en campo un sistema de riego de precisión, demostrando que las zonas de mayor vigor vegetativo han aprovechado mejor la mayor dotación de riego empleada teniendo una mayor producción frente a otras zonas con menor desarrollo vegetativo donde se ha considerado que la productividad de las cepas podía estar limitada por otros factores al margen del riego. Otra de las ventajas del sistema de riego de precisión desarrollado radica en la automatización de la programación llevada a cabo desarrollada mediante nuevos programadores con posibilidad de tele-lectura y fácil instalación en parcela. La puesta en práctica de los sistemas de riego de precisión sigue adelante en el proyecto Preciriego con otros ensayos en marcha en cultivos leñosos y hortícolas al aire libre. 


\section{Congreso Nacional de Riegos CARTAGENA 2021}

\section{Agradecimientos}

Esta investigación ha sido financiada por los proyectos de investigación Precieriego (RTC-2017-6365-2) y ClimAlert (SO3/P4//F0862). Se agradece la ayuda de campo prestada por el personal técnico y en particular por el Ing. Técnico Diego Guerra Alcázar (CEBAS-CSIC).

\section{Referencias}

1. Campos, I.; González-Gómez, L.; Villodre, J.; Calera, M.; Campoy, J.; Jiménez, N.; Plaza, C.; Sánchez-Prieto, S.; Calera, A. Mapping within-field variability in wheat yield and biomass using remote sensing vegetation indices. Precis. Agric. 2019, 20, 214-236, doi:10.1007/s11119-018-9596-z.

2. Khaliq, A.; Comba, L.; Biglia, A.; Aimonino, D.R.; Chiaberge, M.; Gay, P. Comparison of satellite and UAV-based multispectral imagery for vineyard variability assessment. Remote Sens. 2019, 11, doi:10.3390/rs11040436.

3. Tucker, C.J. Red and Photographic Infrared 1,lnear Combinations for Monitoring Vegetation; 1979; Vol. 8;.

4. Tucker, C.J.; Holben, B.N.; Elgin, J.H.; McMURTREY III, J.E. Remote Sensing of Total Dry-Matter Accumulation in Winter Wheat; 1981; Vol. 11;

5. Alganci, U.; Ozdogan, M.; Sertel, E.; Ormeci, C. Estimating maize and cotton yield in southeastern Turkey with integrated use of satellite images, meteorological data and digital photographs. F. Crop. Res. 2014, 157, 8-19, doi:10.1016/j.fcr.2013.12.006.

6. Bausch, W.C.; Neale, C.M.U. Crop Coefficients Derived from Reflected Canopy Radiation: A Concept. Trans. ASAE 1987, 30, 0703-0709, doi:10.13031/2013.30463.

7. Pinter, P.J.; Hatfield, J.L.; Schepers, J.S.; Barnes, E.M.; Moran, M.S.; Daughtry, C.S.T.; Upchurch, D.R. Remote Sensing for Crop Management; 2003;

8. Rouse, J.W.; Hass, R.H.; Schell, J.A.; Deering, D.W. Monitoring the vernal advancement and retrogradation (green wave effect) of natural vegetation. 1973.

9. Córcoles, J.I.; Ortega, J.F.; Hernández, D.; Moreno, M.A. Estimation of leaf area index in onion (Allium cepa L.) using an unmanned aerial vehicle. Biosyst. Eng. 2013, 115, 31-42, doi:10.1016/J.BIOSYSTEMSENG.2013.02.002.

10. Allen, R.G.; Pereira, L.S.; Raes, D.; Smith, M. Crop evapotranspiration: Guidelines for computing crop requirements. Irrig. Drain. Pap. No. 56, FAO 1998, 300, doi:10.1016/j.eja.2010.12.001.

11. Martínez Moreno, A. Efectos del riego deficitario con aguas salinas en la producción y composición de la uva y la calidad del vino (PhD Thesis), Universidad de Murcia, 2020.

12. Leeuwen, C. van; Trégoat, O.; Choné, X.; Bois, B.; Pernet, D.; Gaudillère, J.-P. Vine water status is a key factor in grape ripening and vintage quality for red Bordeaux wine. How can it be assessed for vineyard management purposes? OENO One 2009, 43, 121-134, doi:10.20870/OENO-ONE.2009.43.3.798. 


\title{
Reutivar: App para la programación óptima de fertirriego con agua regenerada
}

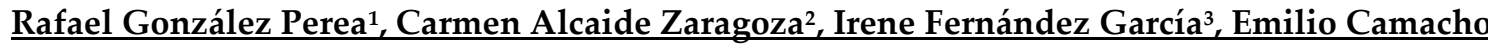 \\ Poyato $^{4}$, Juan Antonio Rodríguez Díaz1 \\ 1Departamento de Agronomía. Universidad de Córdoba. Campus Rabanales, Edif. Leonardo da Vinci, 14071. Córdoba. \\ g72goper@uco.es. \\ ${ }^{2}$ Departamento de Agronomía. Universidad de Córdoba. Campus Rabanales, Edif. Leonardo da Vinci, 14071. Córdoba. \\ g12alzac@uco.es. \\ ${ }^{3}$ Departamento de Ingeniería eléctrica, Universidad de Córdoba. Campus de Rabanales, Edif. Leonardo da Vinci. \\ g52fegai@uco.es. \\ ${ }^{4}$ Departamento de Agronomía. Universidad de Córdoba. Campus Rabanales, Edif. Leonardo da Vinci, 14071. Córdoba. \\ ecamacho@uco.es. \\ ${ }^{5}$ Departamento de Agronomía. Universidad de Córdoba. Campus Rabanales, Edif. Leonardo da Vinci, 14071. Córdoba. \\ ma2rodij@uco.es.
}

Resumen: El olivar es un cultivo de gran repercusión económica en toda España, siendo el país con la mayor superficie del mundo dedicada a éste. Esta importancia se acentúa en Andalucía, donde es el cultivo más representativo e icónico en la región. De hecho, debido a la superficie que ocupa, el olivar es el cultivo que más agua consume en toda la Cuenca Hidrográfica del Guadalquivir. En cuanto a su fertilización, ésta suele ser poco precisa y, con frecuencia, basada en prácticas culturales y en la experiencia del agricultor. Esto conlleva que se realicen aplicaciones de fertilizantes innecesarias, ocasionando la contaminación de suelos y aguas subterráneas. En este escenario, la utilización de agua regenerada para riego de olivar surge como alternativa a las fuentes de agua tradicionales. Sin embargo, uno de los problemas asociados al riego con este tipo de agua es la gestión de la fertilización, pues ésta ya incorpora una importante cantidad de nutrientes, que es además variable a lo largo del año. Por ello, en este trabajo, se ha desarrollado una aplicación móvil (Reutivar-App) para la programación conjunta y en tiempo real del riego y la fertilización del olivar considerando el riego con agua regenerada. Reutivar-App está destinada a técnicos y agricultores e integra metodologías complejas y ya consolidadas, pero en un formato muy amigable. La aplicación tiene en cuenta tanto registros agroclimáticos históricos como predicciones climáticas, características hidráulicas del sistema de riego, dotación de agua concedida, análisis foliares y análisis de calidad del agua periódicos. Como resultado, genera una recomendación semanal del tiempo de riego y la cantidad de fertilizante óptimos a aplicar. Dichos resultados ponen de manifiesto que se puede hacer un uso mucho más eficiente del agua y el fertilizante y que, gracias a los nutrientes que este tipo de aguas aporta, el uso de fertilizantes adicionales puede ser innecesario, implicando importantes beneficios tanto medioambientales como económicos.

Palabras clave: App; programación de fertirriego; reutilización aguas regeneradas; olivar. 


\section{INTRODUCCIÓN}

En España, alrededor del $70 \%$ del agua dulce total distribuida va destinada a la agricultura de regadío (FAO, 2012) lo cual hace a esta actividad especialmente vulnerable ante periodos de sequía. Según el World Resources Institute (2015), España experimentará un estrés hídrico severo para 2040, convirtiéndose así en uno de los países con mayor presión sobre los recursos hídricos a nivel mundial. Además, si en este contexto se tienen en cuenta también las previsiones futuras de aumento de la demanda de agua y del déficit potencial de humedad del suelo en diferentes zonas regables (Plan Hidrológico Guadalquivir, 2016), en los próximos años la agricultura de regadío tendrá que evolucionar para hacer frente a estos desafíos. Esta situación es especialmente crítica en zonas como Andalucía, donde la agricultura de regadío juega un papel fundamental. El cultivo más representativo y simbólico de Andalucía es el olivar, pues ha marcado su paisaje y su cultura y constituye, además, la base de la economía de muchas poblaciones. El olivar, debido a su extensión, y aun siguiendo estrategias de riego deficitario, es el cultivo con mayor demanda hídrica de la Demarcación Hidrográfica del Guadalquivir (más de $580 \mathrm{hm}^{3} /$ año), lo que supone algo más del $20 \%$ del total agrícola. Por otro lado, la fertilización de este cultivo se realiza generalmente de forma poco precisa, siguiendo prácticas culturales tradicionales y sin control sobre la humedad del suelo o del agua aplicada. Esto provoca aplicaciones de fertilizantes en exceso, especialmente de nitrógeno, lo que ocasiona problemas de contaminación del suelo y de las aguas. Este problema puede agravarse en el caso de riego con aguas residuales depuradas, pues estas ya incorporan una cantidad importante de nutrientes la cual, además, es variable a lo largo del año. Sin embargo, la utilización de este tipo de aguas, gestionadas correctamente y con ayuda de los nuevos avances en tecnología y comunicación, puede convertirse en una solución estratégica a la problemática planteada.

Los impactos asociados al uso de aguas regeneradas utilizadas para riego de olivar han sido considerados por varios autores, centrando su atención en los impactos en el suelo (Batarseh et al., 2011; Petousi et al., 2015; Segal et al., 2011), en el desarrollo del árbol (Ayoub et al., 2016; Bedbabis et al., 2010) y en la calidad del aceite (Palese et al., 2006; Bedbabis et al., 2010; Bourazanis et al., 2016), concluyendo que el uso de estas aguas, siempre que se haga de manera controlada y se realicen los pertinentes análisis regularmente, no afecta a ninguno de los parámetros evaluados.

Por otro lado, diferentes autores han desarrollado aplicaciones enfocadas a la gestión del uso del agua y la fertilización. Bueno-Delgado et al. (2016) y Pagán et al. (2015) propusieron una metodología para determinar el tipo de fertilizante que debería emplearse desde el punto de vista económico, teniendo en cuenta la calidad del agua de riego. Sin embargo, en ambos trabajos es necesario conocer la solución nutritiva ideal como parámetro de entrada, la cual el agricultor suele desconocer. Pérez-Castro et al. (2017) desarrollaron un método para determinar la cantidad de fertilizantes que se debe aplicar según el tipo de cultivo y las condiciones del sistema, pero solo es aplicable a cultivos hortícolas en invernadero. En cuanto a la mejora de la gestión del uso del agua, González Perea et al. (2017) implementaron los principios de riego de precisión para el cultivo de fresa en una aplicación de fácil manejo para el agricultor, lo que conllevó importantes ahorros de agua. Mérida García et al., (2018) presentaron un modelo de gestión óptima del riego de olivar mediante energía solar que ajustaba el riego según las necesidades de riego del cultivo en tiempo real. Sin embargo, no existe ninguna herramienta de gestión, de fácil manejo, que integre todos los elementos anteriormente citados: gestión del uso del agua y el fertilizante, es decir, un fertirriego de precisión para el cultivo de olivar usando aguas regeneradas. 


\section{OBJETIVOS}

El objetivo de este trabajo es el desarrollo de una aplicación de escritorio y para dispositivos móviles, destinada a los agricultores, que realice la programación en tiempo real del fertirriego de precisión del olivar regado con aguas regeneradas mediante en el uso de las Tecnologías de la Información y la Comunicación (TICS), maximizando la eficiencia en el uso del agua y el fertilizante y asegurando la sostenibilidad del olivar de regadío.

\section{MATERIALES Y MÉTODOS}

\subsection{Caso de estudio}

El estudio se ha llevado a cabo en el Sector I de la Comunidad de Regantes (C.R.) de Tintín, localizado en Montilla (Córdoba), concretamente en una finca comercial de olivar tradicional. En esta zona, el clima es mediterráneo, con una precipitación media anual $\left(P_{t}\right)$ de $590 \mathrm{~mm}$, principalmente en primavera y otoño. La temperatura media anual $\left(T_{m}\right)$ es de $16.9^{\circ} \mathrm{C}$ y la evapotranspiración de referencia media $\left(E T_{0}\right)$ es $3 \mathrm{~mm}$ día ${ }^{-1}$. La finca está compuesta por árboles adultos (Olea europea L., cv Hojiblanca y Olea europea L., cv Nevadillo azul) espaciados a $8 \mathrm{~m}$ x 8m para la producción de aceite. El agua de riego, procedente de la EDAR de Montilla, se almacena en una balsa y desde allí se distribuye a los regantes mediante una estación de bombeo localizada aguas abajo de dicha balsa. El sistema de riego empleado es riego por goteo subterráneo, con goteros de $2.2 \mathrm{~L} / \mathrm{h}$ y espaciados $1 \mathrm{~m}$.

\subsection{Caracterización de la finca}

La caracterización de la finca contempló la caracterización hidráulica del sistema de riego, del suelo, del estado nutricional de los árboles y de la calidad del agua de riego. La caracterización hidráulica parte del levantamiento de la finca y su posterior digitalización. A continuación, se realizó la simulación hidráulica del sistema de riego en EPANET (Rossman, 2000) para obtener la eficiencia de riego de la parcela. Respecto a la caracterización del suelo, se tomaron ocho muestras de suelo en cuatro puntos diferentes, considerando cambios en la morfología, color y pendiente. Dos de esos puntos se localizaron bajo el árbol y los dos restantes correspondieron a muestras de suelo procedente de las calles. En cada punto seleccionado se tomaron dos muestras, una en la capa de suelo de 0-15 cm y la otra en la de 15-30 cm para evaluar textura, $\mathrm{pH}$ y contenido de nutrientes. Para la caracterización del estado nutricional del árbol se realizaron análisis foliares en el mes de julio. Se tomaron dos muestras, correspondientes a las dos variedades de olivo presente en la finca, formadas por 100 hojas de 50 árboles cada una. Finalmente, para la evaluación de la calidad de agua de riego se tomaron muestras en parcela del agua aplicada cada dos semanas y se analizaron posteriormente en el laboratorio.

\subsection{Descripción del modelo}

El objetivo del modelo es proporcionar en tiempo real a los agricultores, la cantidad de agua y fertilizante necesaria a aportar, ajustando estos valores a las necesidades reales del cultivo para mejorar la sostenibilidad del sistema productivo. El modelo, denominado REUTIVAR, se ha desarrollado en Android OS y está formado por cinco módulos independientes e interconectados: 1) características de la plantación, 2) datos climáticos, 3) limitación mensual de uso de agua, 4) programación del riego y 5) programación de la fertilización (Figura 1). Los módulos que conforman el modelo se describen a continuación.

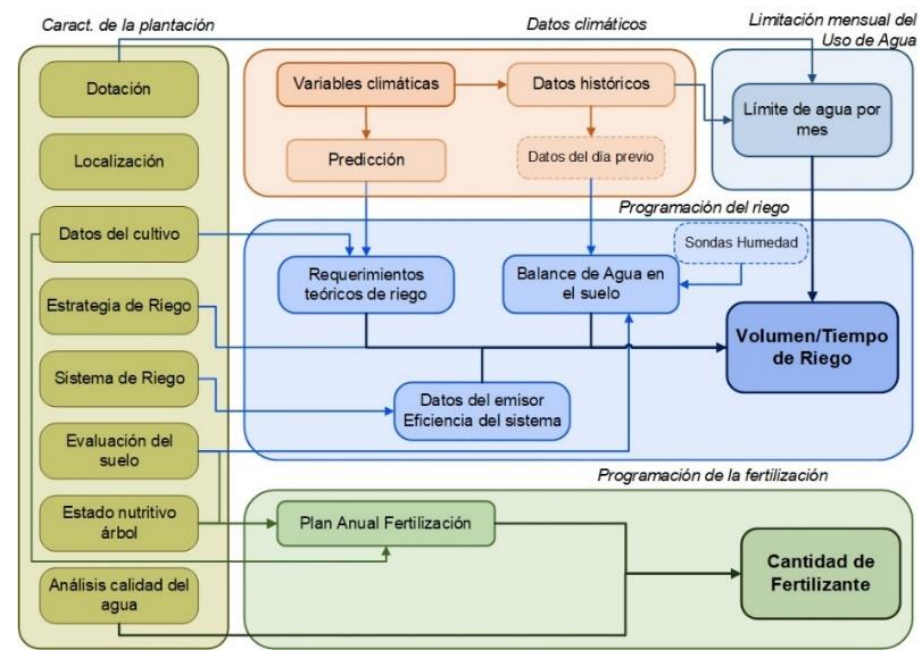

Figura 1. Esquema general del modelo REUTIVAR 


\subsubsection{Características de la plantación}

En este módulo se introducen los datos generales de la plantación tales como localización de la parcela, características texturales del suelo, ciclo del cultivo, coeficiente de cultivo, dotación de riego concedida, características del sistema de riego (caudal, separación entre goteros, etc.), estrategia de riego, días de la semana que se quiere regar, análisis del estado nutritivo del árbol (mediante análisis foliares) y análisis de la calidad del agua de riego.

\subsubsection{Datos climáticos}

Este módulo contempla dos aspectos: predicción meteorológica y registros agroclimáticos históricos, los cuales dependen de la localización de la parcela de cultivo. En primer lugar, se obtiene, de forma diaria, la predicción meteorológica de la zona de estudio para una semana utilizando AEMET OpenData, la API REST (Application Programming Interface. REpresentational State Transfer) que pone a disposición la Agencia Estatal de Meteorología (AEMET, 2015). Los datos que se obtienen son: precipitación $(P)$, temperatura media $\left(T_{m}\right)$, temperatura máxima $\left(T_{m a x}\right)$, temperatura mínima $\left(T_{\min }\right)$, humedad relativa máxima $\left(H R_{\max }\right)$, humedad relativa mínima $\left(H R_{\min }\right)$, velocidad del viento $\left(u_{2}\right)$ e índice de nubosidad $(n u)$. A partir de estos parámetros y mediante la ecuación de FAO Penman-Monteith (Allen, 1998), se obtiene el valor de la evapotranspiración de referencia, ETo.

Así mismo, se determina la estación agroclimática más cercana a la localización seleccionada de las disponibles en la Red de Estaciones Agroclimáticas de Andalucía. De esta estación, mediante técnicas de web scraping, se obtienen los valores diarios de $\mathrm{P}$ y ETo de todos los años disponibles de la estación $y$, diariamente, se almacenan estos mismos datos del día anterior. Toda esta información se incorpora en una base de datos integrada en la aplicación, la cual se usa para la programación de los eventos de riego.

\subsubsection{Disponibilidad mensual de agua}

En este módulo, se establecen límites de la cantidad de agua que se puede aplicar en cada periodo. Estos límites dependen de la concesión de uso de aguas regeneradas, de la estrategia de riego que se adopte y de las necesidades de riego del cultivo a lo largo de su ciclo productivo, calculadas a partir de las características del cultivo y de la serie histórica de datos climáticos. El límite de agua aplicable es variable a lo largo de los meses. De forma quincenal, se comprueba que la cantidad de agua aportada no supera dicho límite. En caso de haber utilizado menos agua de la establecida inicialmente, el agua no usada se podrá aplicar en los meses venideros.

\subsubsection{Programación del riego}

La programación del riego se realiza considerando desde los requerimientos teóricos de riego del cultivo, la estrategia de riego seleccionada, el sistema de riego, el balance diario de agua en el suelo hasta la limitación mensual de agua a aplicar. Las necesidades teóricas de riego se calculan al final del día previo al día de riego, a partir de los datos de las predicciones meteorológicas, como la diferencia entre la evapotranspiración del cultivo $\left(E T_{c}\right)$ y la precipitación efectiva $\left(P_{\text {eff }}\right)$ del día de riego, que es el agua de lluvia almacenada en la zona radicular y aprovechable por el cultivo, se calcula por el método del Servicio de Conservación de Recursos Naturales del USDA. Las necesidades de riego del cultivo se calculan para reponer la $E T_{c}$ diaria, calculada por el método propuesto por la FAO (Doorenbos \& Pruit, 1977):

$$
E T_{c}=E T_{0} \cdot k_{c} \cdot k_{r}
$$

Donde $E T_{0}$, se calcula con la previsión meteorológica (ver apartado 3.3.2); $k_{c}$ es el coeficiente de cultivo, cuyos valores son los propuestos por Orgaz y Fereres (2001) para olivar (Tabla 1) y $k_{r}$ es un coeficiente de cubierta que varía de 0 a 1 para árboles con menos del 60\% de cubierta y 1 cuando superan ese valor. En el caso de la finca de estudio, al tratarse de árboles adultos, este valor se considera 1.

Tabla 1. Coeficiente de cultivo $\left(k_{c}\right)$ del olivo

\begin{tabular}{cccccccccccc} 
Ene & Feb & Mar & Abr & May & Jun & Jul & Ago & Sept & Oct & Nov & Dic \\
\hline 0.65 & 0.65 & 0.65 & 0.60 & 0.55 & 0.55 & 0.50 & 0.50 & 0.55 & 0.55 & 0.60 & 0.65 \\
\hline
\end{tabular}


En cuanto a la estrategia de riego, el modelo ofrece tres posibles opciones al agricultor: riego completo $(R C)$, riego deficitario controlado (RDC) y riego deficitario sostenido (RDS). El RC considera el total de las necesidades del olivo. La estrategia de RDS distribuye equitativamente a lo largo de la campaña de riego un porcentaje de las necesidades totales del árbol. Finalmente, la estrategia de RDC también aplica un porcentaje de las necesidades de riego totales, pero con la diferencia de que estos porcentajes son variables a lo largo de la campaña, concentrado la mayor cantidad de agua en las fases fenológicas más críticas del árbol, con el objetivo de minimizar los impactos en el crecimiento del árbol, rendimiento y calidad del aceite. Estos periodos se seleccionaron siguiendo los criterios establecidos por Rallo y Cuevas (2017) y Orgaz, Fereres y Testi, (2017). Para el caso particular de Andalucía, considerando los problemas asociados a las escasez de agua y a la importancia del olivar, la estrategia recomendada es la RDC (Moriana et al., 2003; Padilla-Díaz, et al. 2016).

Para la programación del riego, se hace un seguimiento de la humedad del suelo. Para ello, se calcula el Balance de Agua en el Suelo (BAS) de forma diaria (Ec. (2)). En el caso de disponer de sondas de humedad, como sucede en la finca de estudio, el balance de agua en el suelo calculado se retroalimenta semanalmente con los datos de las sondas de humedad instaladas en campo.

$$
B A S_{d}=B A S_{d-1}+P_{e f f}+I_{a p}-E T_{c, a d j}-R-D
$$

donde $B A S_{d-1}$ es el contenido de agua en el día anterior, $l_{a p}$, el riego aplicado $(\mathrm{mm}), E T_{c, a d j}$ la evapotranspiración del cultivo ajustada $(\mathrm{mm}), R$ la escorrentía $(\mathrm{mm})$ y $D$ la percolación profunda $(\mathrm{mm})$. $R$ y $D$ son considerados nulos en este caso, ya que se trata de riego por goteo.

La $E T_{c, \text { adj }}$ está relacionada con la dificultad del cultivo para extraer agua cuando la humedad del suelo no es alta. En el modelo se considera este efecto mediante la Ec. 3 (Allen, 1998):

$$
E T_{c, a d j}=E T_{c} \cdot \frac{A T D-D_{r}}{A T D-A F A}
$$

donde $A T D$ es el agua total disponible del suelo $(\mathrm{mm}), D_{r}$, el agotamiento en la zona radicular $(\mathrm{mm})$, calculado como la diferencia entre $A T D$ y $B A S_{d-1}$, y $A F A$ es el agua fácilmente aprovechable en el suelo $(\mathrm{mm})$.

Por último, se calcula el tiempo de riego $t$ (h) según la Ec.(4):

$$
t=\frac{H_{r} \cdot A_{s} \cdot 10^{4}}{I E \cdot \sum_{i=1}^{e} q_{e} \cdot n_{e}}
$$

donde $H_{r}$ son los requerimientos de riego (mm), $A_{s}$ es el área del sector (ha), IE la eficiencia de riego, $q_{e}$ el caudal del gotero (L/h) y $n_{\mathrm{e}}$ el número de goteros del sector.

\subsubsection{Programación de la fertilización}

La planificación anual de la fertilización se basa en la evaluación del estado nutritivo del árbol, del contenido de nutrientes en suelo y de los nutrientes disueltos en el agua de riego (Fernández-Escobar, 2017). Está demostrado que las necesidades de fertilización del olivar son muy pequeñas y, en numerosas ocasiones, los nutrientes se encuentran en cantidades suficientes en el suelo para satisfacer sus necesidades. $\mathrm{Si}$, además, se tiene en cuenta que los casos que aborda este trabajo son árboles regados con aguas residuales tratadas, es posible que se estén aportando algunos nutrientes a través del riego. Sin embargo, pueden darse situaciones en las que el suelo sea pobre en algún nutriente o que éstos estén bloqueados, por lo que el árbol no los puede asimilar. Por ello, es esencial la realización del análisis foliar del árbol para así determinar si hay exceso o carencia de nutrientes y, a partir de ahí, corregir. Es por esto por lo que, en primer lugar, es necesario conocer los valores de los niveles de nutrientes en hojas (obtenidos mediante los análisis foliares realizados el año anterior en el mes de julio) y sólo en el caso de ser deficiente (ver

Tabla 2) alguno de estos niveles, se aplica dicho elemento (Fernández-Escobar, 2018). Los elementos que se analizan en este trabajo son nitrógeno $(N)$, fósforo $(P)$ y Potasio $(K)$.

Tabla 2. Interpretación de los niveles de nutrientes en hojas de olivo recogidas en julio, expresados en \% de materia seca

\begin{tabular}{lccc} 
Elemento & Deficiente & Adecuado & Tóxico \\
\hline Nitrógeno (\%) & 1,2 & $1,3-1,7$ & $>1,7$ \\
Fósforo (\%) & 0,05 & $0,1-0,3$ & -
\end{tabular}




\section{Congreso Nacional de Riegos CARTAGENA 2021}

En caso de deficiencia, la estrategia seguida se basa en la aplicación de una cantidad inicial, calculada a partir de una estimación del consumo del árbol de dicho elemento, en formato líquido (FernándezEscobar, 2017). Al año siguiente se vuelve a realizar el análisis foliar y se comprueba si es necesario aumentar o disminuir dicha dosis. En el caso del $\mathrm{N}$, si su nivel en hoja es menor de 1,3\% se aplican 0,5 $\mathrm{kg} / a ́ r b o l ~ d e ~ N$, sin superar los $150 \mathrm{~kg} / \mathrm{ha}$. En el caso del K, cuando el valor sea inferior o igual a 0,7\% en hoja, se aplicará $1 \mathrm{~kg} / a ́ r b o l$. Por último, en el caso del $\mathrm{P}$, el valor inicial de aplicación será de 0,5 $\mathrm{kg} / a ́ r b o l$. La aplicación se hace en primavera ya que su eficacia es mayor y además evita que queden restos en los goteros a final de campaña. Se recomienda que la aplicación sea semanal ya que está demostrado que su eficacia es igual que una aplicación diaria, pero se necesita menos mano de obra, aunque el usuario puede modificar esta opción y hacer coincidir la aplicación del fertilizante con la programación riego.

El siguiente aspecto considerado en el modelo es sobre la calidad de agua y los nutrientes que ya lleva en solución. En el caso de usar aguas regeneradas, el contenido en macronutrientes es considerable y debe restarse en el cálculo del fertilizante total a aplicar.

\subsection{Aplicación informática}

El modelo propuesto contempla el desarrollo de una aplicación para dispositivos móviles que implementa los módulos descritos previamente. Por otro lado, se ha desarrollado la versión beta de la aplicación en Android, la cual integra este mismo modelo y permite al usuario gestionar el riego de forma cómoda desde su smartphone. Los agricultores de la Comunidad de Regantes Tintín (Montilla) probarán la versión beta de aplicación durante la campaña de riego de 2019.
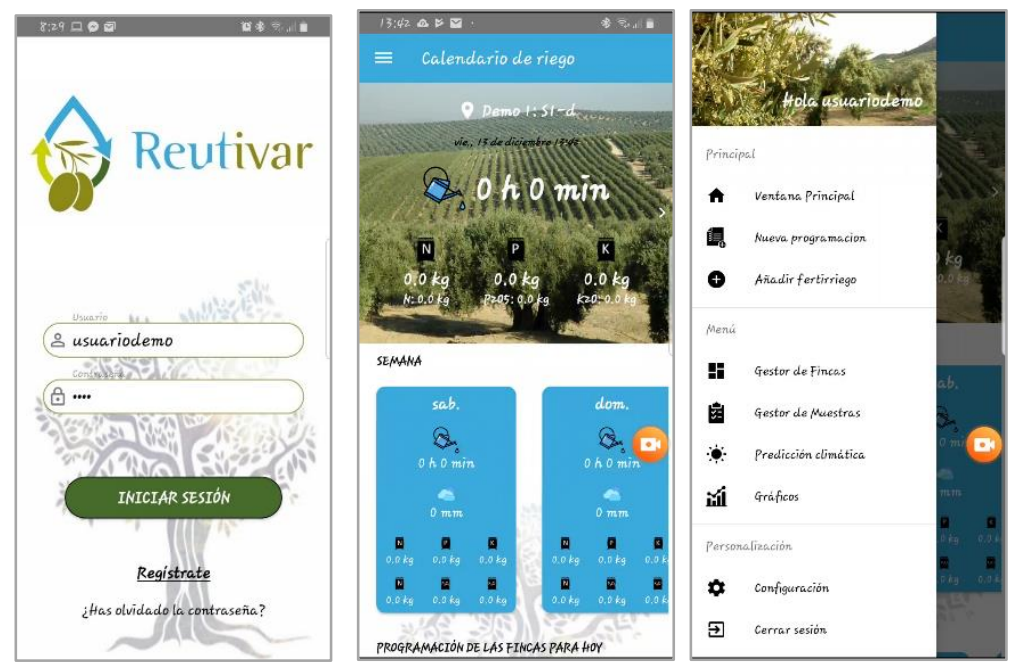

Figura 2. Interfaz gráfica de Reutivar

\section{RESULTADOS Y DISCUSIÓN}

A continuación, se muestran los resultados obtenidos al aplicar REUTIVAR a la campaña de riego 2018.

\subsection{Programación del riego}

La programación del riego para la campaña de riego 2018 se muestra en la

Figura 3. 


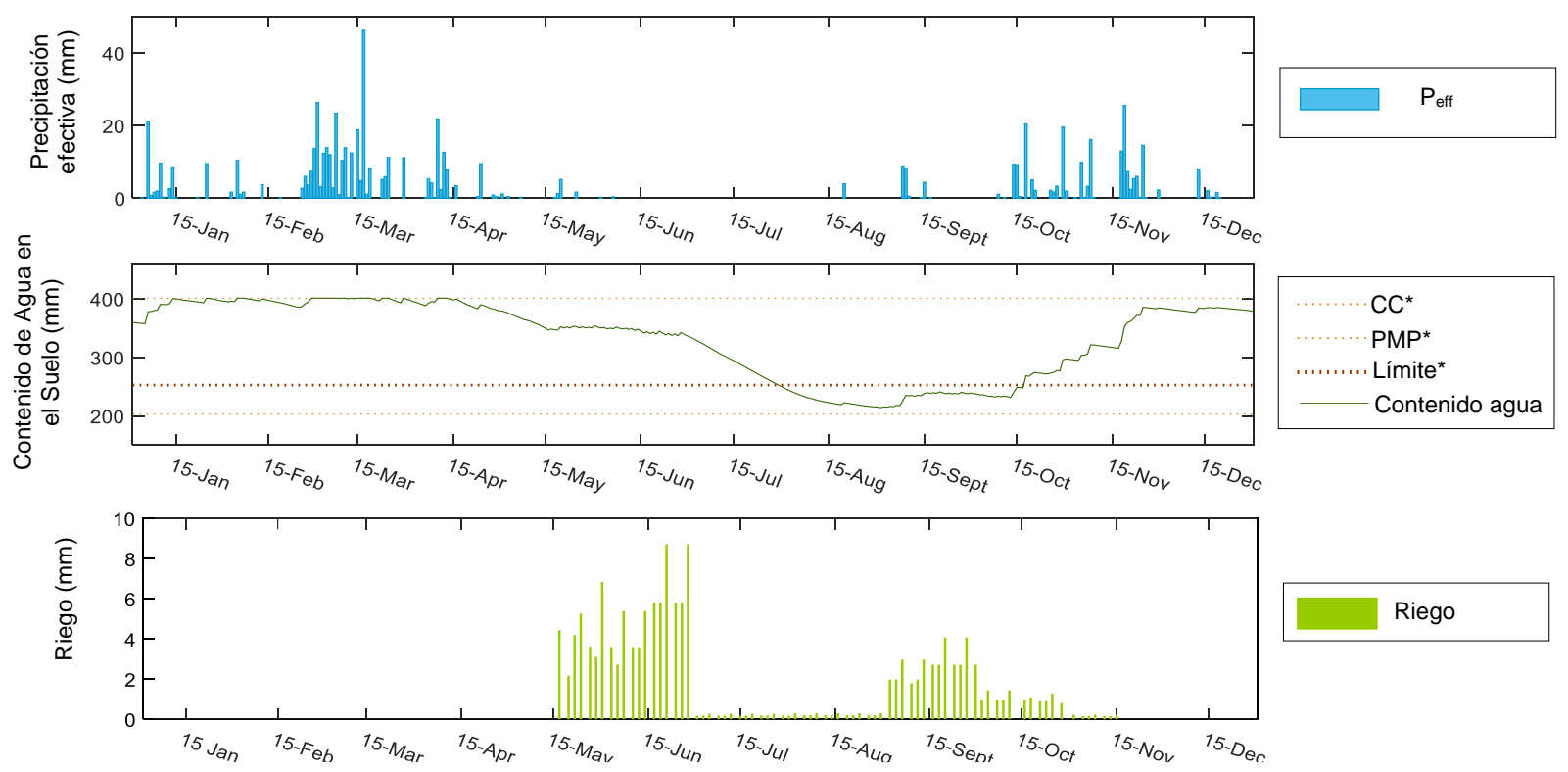

Figura 3. Distribución anual de la programación de riego propuesta, precipitación efectiva y contenido de agua en el suelo

* CC: Capacidad de Campo; PMP: Punto de Marchitez Permanente; Límite: 75\% de ATD, cuando deja de ser AFA. El modelo ofrece una programación del riego que distribuye la dotación concedida aplicando un total de $1.490 \mathrm{~m}^{3} / \mathrm{ha}$. Los momentos en los que se concentra el riego son mayo, junio y septiembre, momentos especialmente críticos al estrés hídrico (Rallo \& Cuevas, 2017), concentrándose el déficit en los meses de verano. En agosto y hasta mediados de octubre, el contenido de agua en el suelo es inferior al contenido de agua fácilmente aprovechable, por lo que el cultivo tendrá mayor dificultad para extraer el agua del suelo.

\subsection{Programación de la fertilización}

Los resultados relativos al análisis de suelo se observan en la Tabla 3.

Tabla 3. Resultados análisis de los análisis de suelo realizados en la finca de estudio

\begin{tabular}{crccccccc}
$\begin{array}{c}\text { Nombre } \\
\text { muestra }\end{array}$ & \multicolumn{1}{c}{$\begin{array}{c}\text { Espesor } \\
(\mathrm{cm})\end{array}$} & $\mathrm{pH}$ & $\begin{array}{c}\text { C.E. }(1: 5) \\
(\mathrm{dS} / \mathrm{m})\end{array}$ & Arcilla & Limo & Arena & $P(\mathrm{mg} / \mathrm{Kg})$ & $K(\mathrm{mg} / \mathrm{Kg})$ \\
\hline A1P1 & $0-15$ & 8.12 & 0.09 & 37.8 & 26.7 & 35.3 & 14.1 & 563 \\
A1P2 & $15-30$ & 8.31 & 0.10 & 38.1 & 28.0 & 33.9 & 7.7 & 454 \\
A2P1 & $0-15$ & 8.33 & 0.11 & 33.8 & 23.3 & 42.0 & 9.9 & 454 \\
A2P2 & $15-30$ & 8.20 & 0.10 & 37.4 & 20.0 & 42.7 & 5.8 & 317 \\
C1P1 & $0-15$ & 8.10 & 0.27 & 37.0 & 28.0 & 34.4 & 23.6 & 872 \\
C1P2 & $15-30$ & 8.10 & 0.48 & 34.2 & 28.6 & 36.1 & 25.7 & 794 \\
C2P1 & $0-15$ & 8.12 & 0.47 & 32.0 & 23.4 & 43.5 & 22.8 & 978 \\
C2P2 & $15-30$ & 8.00 & 0.59 & 36.1 & 21.2 & 42.1 & 27.0 & 598
\end{tabular}

De estos resultados se interpreta, en primer lugar, dado que el pH se encuentra comprendido en todas las muestras en un intervalo entre 8 y 8.3, se considera que es un suelo alcalino. En estos valores, el olivo por lo general vegeta bien (Parra, 2017). En cuanto a la conductividad eléctrica (C.E.), que proporciona información sobre el contenido de sales, se observa un contenido mayor en las muestras procedentes de las calles, siendo este ligeramente salino. Sin embargo, se debe considerar que la toma de muestras se realizó en septiembre, antes de la época de lluvias, que lavarían el suelo posteriormente, reduciendo el contenido en sales, por lo que se considera que no hay problemas de salinidad. Del análisis textural del suelo mediante el triángulo textural del USDA, se obtuvo que el suelo en todas las muestras se correspondía con el tipo franco-arcilloso.

En cuanto al análisis de macronutrientes, la cantidad de $\mathrm{P}$ en las calles es alta mientras que en los árboles es menor, pero aun así se encuentra en un rango en el que es poco probable que haya 
respuesta al abonado, especialmente para el caso del olivo, pues la importancia de este nutriente es inferior a la de otros cultivos anuales, debido a sus bajas extracciones y su facilidad de reutilización. Además, se ha demostrado que el contenido en exceso de $\mathrm{P}$ en el suelo puede inducir bloqueos de Cinc. Finalmente, en cuanto al contenido de $\mathrm{K}$, los valores en todas las muestras son altos, por lo que, del mismo modo que en el caso del P, no se espera respuesta al abonado.

Los resultados de los análisis foliares llevados a cabo en el mes de julio de 2018 para dos variedades de olivo presentes en la finca de estudio se muestran en la Tabla 4.

Tabla 4. Resultados de los análisis foliares realizados en el mes de julio en la finca de estudio,

\begin{tabular}{lccc}
\multicolumn{1}{c}{ Variedad } & Nitrógeno $(\mathrm{g} / \mathrm{100g})$ & Fósforo $(\mathrm{g} / \mathrm{100g})$ & Potasio $(\mathrm{g} / \mathrm{100g})$ \\
\hline Hojiblanca & 2,02 & 0,11 & 0,92 \\
Nevadillo azul & 1,35 & 0,13 & 0,88
\end{tabular}

Como se puede observar, en el caso de la variedad Nevadillo Azul, todos los valores se encuentran en los niveles adecuados. Por lo tanto, siguiendo los criterios comentados anteriormente y los resultados de los análisis de suelo, para la próxima campaña no se debería aplicar ningún fertilizante. En el caso de la variedad Hojiblanca, sin embargo, se observan valores adecuados de $\mathrm{P}$ y $\mathrm{K}$ en hoja, pero se observa que el valor de $\mathrm{N}$ es superior al nivel establecido. Numerosos estudios avalan la problemática ocasionada por un exceso de fertilización nitrogenada en olivar, tales como disminución de la calidad del aceite (Erel et al., 2013; Fernández-Escobar et al., 2006), mayor sensibilidad a las heladas (Fernández-Escobar, Navarro, \& Melgar, 2011) o retraso en la maduración del fruto, lo que suele relacionarse con una disminución del rendimiento graso (Fernández-Escobar, Antonaya-Baena, Sánchez-Zamora, \& Molina-Soria, 2014). Por tanto, es aconsejable que para la campaña de 2019 no se aplique ningún abono.

\section{CONCLUSIONES}

El riego de olivar con aguas regeneradas es una alternativa al uso de fuentes de agua convencionales. Sin embargo, es esencial una correcta gestión de éstas. Para ello, se ha desarrollado una aplicación para dispositivos móviles de fácil manejo para la implantación de fertirriego de precisión, que optimiza el uso de aguas regeneradas, proporcionando de forma diaria la cantidad de agua y fertilizante que es necesario aportar. De este modo, se demuestra que el uso de este tipo de aguas para riego permite el ahorro de fertilizantes, lo que proporciona beneficios significativos tanto económicos como medioambientales.

\section{AGRADECIMIENTOS}

Este trabajo forma parte del proyecto REUTIVAR, proyecto de innovación cofinanciado por la Junta de Andalucía y la Unión Europea a través del FEADER 2014-2020, en el marco de las ayudas de la Línea Olivar para el funcionamiento de grupos operativos de la Asociación Europea de Innovación (AEI) en materia de productividad y sostenibilidad agrícola.

\section{BIBLIOGRAFÍA}

Agencia Estatal de Meteorología (AEMET). (2015). AEMET OpenData. Retrieved 14 February 2019, from http://www.aemet.es/es/datos_abiertos/AEMET_OpenData

Allen, R. G. (1998). FAO Irrigation and Drainage Paper Crop by. Irrigation and Drainage, 300(56), 300. https://doi.org/10.1016/j.eja.2010.12.001

Ayoub, S., Al-Shdiefat, S., Rawashdeh, H., \& Bashabsheh, I. (2016). Utilization of reclaimed wastewater for olive irrigation: Effect on soil properties, tree growth, yield and oil content. Agricultural Water Management, 176, $163-169$. https://doi.org/10.1016/j.agwat.2016.05.035

Batarseh, M. I., Rawajfeh, A., Ioannis, K. K., \& Prodromos, K. H. (2011). Treated municipal wastewater irrigation impact on olive trees (Olea Europaea L.) at Al-Tafilah, Jordan. Water, Air, and Soil Pollution, 217(1-4), $185-196$. https://doi.org/10.1007/s11270-010-0578-7

Bedbabis, S., Ferrara, G., Ben Rouina, B., \& Boukhris, M. (2010). Effects of irrigation with treated wastewater on olive tree growth, yield and leaf mineral elements at short term. Scientia Horticulturae, 126(3), 345-350. https://doi.org/10.1016/j.scienta.2010.07.020

Bedbabis, S., Rouina, B. Ben, \& Boukhris, M. (2010). The effect of waste water irrigation on the extra virgin olive oil quality from the Tunisian cultivar Chemlali. Scientia Horticulturae, 125(4), 556-561. https://doi.org/10.1016/j.scienta.2010.04.032

Bourazanis, G., Roussos, P. A., Argyrokastritis, I., Kosmas, C., \& Kerkides, P. (2016). Evaluation of the use of treated municipal 
waste water on the yield, oil quality, free fatty acids' profile and nutrient levels in olive trees cv Koroneiki, in Greece. Agricultural Water Management, 163, 1-8. https://doi.org/10.1016/j.agwat.2015.08.023

Bueno-Delgado, M. V., Molina-Martínez, J. M., Correoso-Campillo, R., \& Pavón-Mariño, P. (2016). Ecofert: An Android application for the optimization of fertilizer cost in fertigation. Computers and Electronics in Agriculture, 121, 32-42. https://doi.org/10.1016/j.compag.2015.11.006

CHG - Confederación Hidrográfica del Guadalquivir (Spanish Government). (2016). Plan Hidrológico de la demarcación hidrográfica del Guadalquivir. Ciclo de planificación hidrológica 2015-2021, 2015-2021.

Doorenbos, J., \& Pruit, W. O. (1977). Guidelines for predicting crop water requirements. FAO Irrigation and Drainage, 24.

Erel, R., Kerem, Z., Ben-Gal, A., Dag, A., Schwartz, A., Zipori, I., ... Yermiyahu, U. (2013). Olive (Olea europaea L.) tree nitrogen status is a key factor for olive oil quality. Journal of Agricultural and Food Chemistry, 61(47), 11261-11272. https://doi.org/10.1021/jf4031585

FAO. (2012). AQUASAT database. Retrieved 12 September 2018, from http://www.fao.org/nr/water/aquastat/data/query/results.html

Fernández-Escobar, R. (2017). Fertilización. In El Cultivo del Olivo (pp. 419-460).

Fernández-Escobar, R. (2018). Trends in olive nutrition. Acta Horticulturae, 1199, $215-223$. https://doi.org/10.17660/ActaHortic.2018.1199.35

Fernández-Escobar, R., Antonaya-Baena, M. F., Sánchez-Zamora, M. A., \& Molina-Soria, C. (2014). The amount of nitrogen applied and nutritional status of olive plants affect nitrogen uptake efficiency. Scientia Horticulturae, 167, 1-4. https://doi.org/10.1016/j.scienta.2013.12.026

Fernández-Escobar, R., Beltrán, G., Sánchez-Zamora, M. A., García-Novelo, J., Aguilera, M. P., \& Uceda, M. (2006). Olive oil quality decreases with nitrogen over-fertilization. HortScience, 41(1), 215-219.

Fernández-Escobar, R., Navarro, S., \& Melgar, J. C. (2011). Effect of Nitrogen Status on Frost Tolerance of Olive Trees. Acta Horticulturae, (924), 41-45. https://doi.org/10.17660/ActaHortic.2011.924.3

González Perea, R., Fernández García, I., Martin Arroyo, M., Rodríguez Díaz, J. A., Camacho Poyato, E., \& Montesinos, P. (2017). Multiplatform application for precision irrigation scheduling in strawberries. Agricultural Water Management, 183, 194-201. https://doi.org/10.1016/j.agwat.2016.07.017

Maddock, A., Samuel Young, R., \& Reig, P. (2015). Ranking the World's Most Water-Stressed Countries in 2040. Retrieved 5 July 2018, from http://www.wri.org/blog/2015/08/ranking-world's-most-water-stressed-countries-2040

Mérida García, A., Fernández García, I., Camacho Poyato, E., Montesinos Barrios, P., \& Rodríguez Díaz, J. A. (2018). Coupling irrigation scheduling with solar energy production in a smart irrigation management system. Journal of Cleaner Production, 175, 670-682. https://doi.org/10.1016/j.jclepro.2017.12.093

Moriana, A., Orgaz, F., Pastor, M., \& Fereres, E. (2003). Yield responses of a mature olive orchard to water deficits. Journal of the American Society for Horticultural Science, 128(3), 425-431.

Orgaz, F., \& Fereres, E. (2001). El Riego. In Junta de Andalucía \& Ediciones Mundiprensa (Eds.), El Cultivo del Olivo (6ª , pp. 285-306). Madrid.

Orgaz, F., Fereres, E., \& Testi, L. (2017). El Riego. In El Cultivo del Olivo (7ª pp. 461-490).

Padilla-Díaz, C. M., Rodriguez-Dominguez, C. M., Hernandez-Santana, V., Perez-Martin, A., \& Fernández, J. E. (2016). Scheduling regulated deficit irrigation in a hedgerow olive orchard from leaf turgor pressure related measurements. Agricultural Water Management, 164, 28-37. https://doi.org/10.1016/j.agwat.2015.08.002

Pagán, F. J., Ferrández-Villena, M., Fernández-Pacheco, D. G., Rosillo, J. J., \& Molina-Martínez, J. M. (2015). Optifer: An application to optimize fertiliser costs in fertigation. Agricultural Water Management, 151, $19-29$. https://doi.org/10.1016/j.agwat.2014.11.007

Palese, A. M., Celano, G., Masi, S., Xiloyannis, C., Colturali, S., Lucano, A., ... Viale, B. (2006). Treated municipal wastewater for irrigation of olive trees: effects on yield and oil quality.

Parra, M. A. (2017). Suelo. In El Cultivo del Olivo (pp. 251-287).

Pérez-Castro, A., Sánchez-Molina, J. A., Castilla, M., Sánchez-Moreno, J., Moreno-Úbeda, J. C., \& Magán, J. J. (2017). cFertigUAL: A fertigation management app for greenhouse vegetable crops. Agricultural Water Management, 183, 186193. https://doi.org/10.1016/j.agwat.2016.09.013

Petousi, I., Fountoulakis, M. S., Saru, M. L., Nikolaidis, N., Fletcher, L., Stentiford, E. I., \& Manios, T. (2015). Effects of reclaimed wastewater irrigation on olive (Olea europaea L. cv. 'Koroneiki') trees. Agricultural Water Management, 160, 33-40. https://doi.org/10.1016/j.agwat.2015.06.003

Pratap, R. (2017). Getting started with Matlab. A quick introduction for scientist and engineers. (Oxford University Press, Ed.) (7th ed.).

Rallo, L., \& Cuevas, J. (2017). Fructificación y producción. In El Cultivo del Olivo (7a, pp. 145-186). 
Rossman, L. A. (2000). EPANET 2 Users Manual. US Environmental Protection Agency (EPA), USA. https://doi.org/10.1177/0306312708089715

Segal, E., Dag, A., Ben-Gal, A., Zipori, I., Erel, R., Suryano, S., \& Yermiyahu, U. (2011). Olive orchard irrigation with reclaimed wastewater: Agronomic and environmental considerations. Agriculture, Ecosystems and Environment, 140(3-4), 454-461. https://doi.org/10.1016/j.agee.2011.01.009 


\title{
Efecto de la frecuencia de riego en parámetros cuantitativos y cualitativos de la Vitis vinifera cv. Syrah
}

\author{
Montoro Rodríguez, A. ${ }^{1}$, Picazo Denia ${ }^{1}$, H., Mañas Jiménez, F. ${ }^{1}$
}

1 Instituto Técnico Agronómico Provincial; meli.itap@dipualba.es

Resumen: La implantación generalizada de riego por goteo en cultivos leñosos nos ha motivado al estudio de la frecuencia del riego en dichos cultivos, ya que por definición el riego por goteo se ha considerado un riego de "bajo caudal y alta frecuencia". Los cultivos leñosos presentan unas características morfológicas y estructurales muy diferentes a los cultivos herbáceos, para los que se diseñó en su origen el riego por goteo, entre los que se encuentra su sistema radicular más extenso y profundo, con una capacidad mayor de exploración del terreno. Además de ello, estudios previos [1], indican pérdidas de agua por evaporación en cada evento de riego, por lo que a priori, modificar el manejo del riego por goteo en este tipo de cultivos, reduciendo la frecuencia de riego e incrementando el número de horas del mismo, parece razonable. Es por ello que abordamos en Castilla-La Mancha, región con clima semiárido y con cerca de 160.000 ha de viñedo para vinificación en regadío [2], el estudio que se presenta, ya que pensamos que se puede mejorar la eficiencia del agua de riego en la vid, simplemente con el manejo del mismo. El ensayo se realizó en Valdeganga (Albacete) en un cultivar de la variedad Syrah, conducido en espaldera a un marco de plantación de $3 \times 1.25 \mathrm{~m}$., suelo franco arcillo arenoso y sin limitaciones de profundidad. El planteamiento del ensayo se basó en un diseño de bloques al azar cuyo factor fue la "frecuencia de riego": I1) Un riego semanal; I2) dos riegos semanales. Las programaciones de riego se ajustaron para unas necesidades hídricas de un tercio de la ETo, con balance de agua en el suelo. Durante todo el ciclo vegetativo del cultivo se ha medido semanalmente el estrés hídrico, a través de los potenciales de hoja y tallo, así como medidas de intercambio gaseoso con la finalidad de parametrizar al máximo el cultivo y poder detectar diferencias en el comportamiento fisiológico de ambos tratamientos. En cuanto al suelo, se ha medido de forma continua el contenido de agua en el mismo con sondas Sentek Drill \& Drop, a 6 profundidades diferentes (5, 15, 25, 35, 45, $55 \mathrm{~cm})$. En vendimia se analizó la producción, así como la madurez tecnológica y fenólica de la uva. Los resultados, tras un año de experimentación, nos muestran si es posible un manejo diferente, al que se está realizando actualmente, del riego por goteo en el cultivo de la vid.

Palabras clave: Vitis vinifera; frecuencia de riego; producción. 


\title{
Effect of irrigation frequency on quantitative and qualitative parameters of Vitis vinifera cv. Syrah
}

\author{
Montoro Rodríguez, A. ${ }^{1}$, Picazo Denia ${ }^{1}$, H., Mañas Jiménez, F. ${ }^{1}$
}

1 Instituto Técnico Agronómico Provincial; meli.itap@dipualba.es

\begin{abstract}
The widespread implementation of drip irrigation in woody crops has motivated us to study the frequency of irrigation in these crops since by definition drip irrigation has been considered a "low flow and high frequency" irrigation. Woody crops have morphological and structural characteristics that are very different from herbaceous crops, for which drip irrigation was originally designed, among which is their more extensive and deeper root system, with a greater capacity for exploring the terrain. In addition to this, previous studies [1], indicate losses of water by evaporation in each irrigation event, so a priori, modify the management of drip irrigation in this type of crops, reducing the frequency of irrigation and increasing the number of hours of it, it seems reasonable. That is why we approached in Castilla-La Mancha, a region with a semi-arid climate and with about 160,000 ha of vineyards for irrigated winemaking [2], the study that is presented, since we think that efficiency can be improved of irrigation water on the vine, simply by managing it. The test was carried out in Valdeganga (Albacete) on a cultivar of the Syrah variety, conducted on a trellis to a plantation frame of $3 \times 1.25 \mathrm{~m}$., Sandy clay loam soil and without depth limitations. The trial approach was based on a randomized block design whose factor was the "irrigation frequency": I1) One weekly irrigation; I2) two weekly irrigations. The irrigation schedules were adjusted for the water needs of one-third of the ETo, with a water balance in the soil. During the entire vegetative cycle of the crop, the water stress has been measured weekly, through the potential of the leaf and stem, as well as gas exchange measures to parameterize the crop as much as possible and to be able to detect differences in the physiological behavior. of both treatments. Regarding the soil, the water content in it has been continuously measured with Sentek Drill \& Drop probes, at 6 different depths $(5,15,25,35,45,55 \mathrm{~cm})$. During the harvest, the production was analyzed, as well as the technological and phenolic maturity of the grape. The results, after a year of experimentation, show us if different management is possible, from the one currently being carried out, of drip irrigation in vine cultivation.
\end{abstract}

Keywords: Vitis vinifera; irrigation frequency; production 


\section{Congreso Nacional de Riegos CARTAGENA 2021}

\section{Introducción}

Por definición el riego por goteo se considera un riego de "bajo caudal y alta frecuencia", localizado cerca del sistema radicular. Desde su origen primitivo en China, durante el siglo I a. de C., con el uso de vasijas de barro enterradas y sin esmaltar, hasta cómo lo conocemos en la actualidad, ha sufrido modificaciones técnicas en cuanto a materiales y forma de aplicar "la gota de agua" en el terreno. En la década de 1920, los productores alemanes comenzaron a utilizar tuberías perforadas para regar sus plantaciones. Una vez que los plásticos se desarrollaron y se usaron ampliamente después de la Segunda Guerra Mundial, un inventor australiano llamado Hannis Thill comenzó a usar una configuración de tubería de plástico específica con pasillos largos para distribuir el agua de riego de manera uniforme a los cultivos. En 1959, Simcha Blass y Kibbutz Hatzerim desarrollaron y patentaron el primer emisor de riego por goteo. El concepto de emisor fue desarrollado varios años antes por Simcha y su hijo Yeshayahu en Israel. En lugar de liberar agua a través de pequeños orificios bloqueados fácilmente por partículas diminutas, el agua se liberó a través de pasillos cada vez más largos, lo que disminuyó la velocidad del agua a medida que salía de la tubería [3]. A lo largo de su evolución y desarrollo, se ha pretendido siempre mejorar el sistema desde el punto de vista técnico, pero poco se ha trabajado sobre la adaptación del sistema de riego y su manejo en cada uno de los cultivos regados. Actualmente se riegan con este sistema cultivos tan diferentes como hortícolas, con un sistema radicular fasciculado, corto y poco ramificado, como por ejemplo la cebolla, hasta cultivos leñosos como por ejemplo el nogal, en el que las raíces primarias crecen como un tronco desde la base del árbol y hacia las profundidades del suelo y tienen raíces secundarias que crecen de ellas en todas direcciones hasta unos $45 \mathrm{~cm}$ del suelo, extendiéndose en distancia de dos a tres veces el diámetro de la copa del árbol. El caso que nos ocupa es el de la vid, con un sistema radicular diferente a los descritos y que podríamos catalogar como "intermedio" entre ambos, ya que se trata de un sistema radical adventicio, fasciculado y ramificado. La extensión de sistema radicular depende de la especie, marco de plantación, tipo de suelo y técnicas de cultivo, pero como generalidad podríamos decir que el $90 \%$ del sistema radical se desarrolla por encima del primer metro de suelo, estando la gran mayoría entre los 40 y $60 \mathrm{~cm}$ de profundidad.

El impacto de la dosis de riego en el cultivo de la vid (Vitis vinifera L.) y su distribución en diferentes fases del ciclo sobre los principales aspectos agronómicos y enológicos se han estudiado en profundidad [4-8]. Sin embargo, los efectos de la frecuencia de riego apenas se han estudiado en este cultivo, aunque se ha demostrado que tiene un impacto relevante en otras especies como manzano [9] y olivo [10]. La frecuencia de riego afecta la distribución espacial y temporal del agua en el suelo, ya que depende de las características hidráulicas del perfil [11]. En suelos ligeros, se han observado aumentos de rendimiento atribuidos a aportaciones de riego con frecuencias altas [12] mientras que en suelos arcillosos este efecto se ha relacionado con frecuencias de riego más bajas [13-14]. En condiciones de clima cálido y suelos de textura media (franco arcillo arenosos), las altas frecuencias de riego aumentan las pérdidas de agua debido a la evaporación en las zonas más superficiales capas del suelo (Montoro et al.2016) [1], aumentando el déficit hídrico cuando se dispone de concesiones bajas de agua.

El objetivo de este trabajo es estudiar el efecto de la frecuencia de riego en parámetros cuantitativos y cualitativos de la Vitis vinifera cv. Syrah en un viñedo cultivado en clima semiárido en Castilla-La Mancha. 


\section{Congreso Nacional de Riegos CARTAGENA 2021}

\section{Materiales y métodos (Trabajo de innovación: descripción de la innovación)}

La parcela en la que se ha llevado a cabo el ensayo está situada en la localidad de Valdeganga (Albacete), a $667 \mathrm{msm}$. La superficie total es de 10 ha de Vitis vinifera cv. Syrah injertada sobre 110 Richter y conducida en espaldera con sistema de poda Guyot. En el viñedo se acotó una zona de 0.8 ha sobre la que se realizó el estudio. La plantación tiene una edad de 16 años, a un marco de $3 \mathrm{~m}$ entre líneas de cultivo y 1,25 m entre cepas de la misma línea y regada desde el primer año de cultivo. La clasificación del suelo según FAO (1988) es Calcisol cámbico, con textura franco arenosa y sin limitaciones de profundidad para el desarrollo radicular. El clima es semiárido, con una precipitación media anual de los últimos 10 años de $356 \mathrm{~mm}$. Las condiciones climáticas de humedad y temperatura del aire, así como precipitación, fueron medidas durante el experimento con una estación agroclimática FieldClimate ${ }^{\circledR}$ localizada en la misma parcela del ensayo.

En 2021 se diseñó un ensayo experimental de bloques al azar con 3 repeticiones y 2 tratamientos: un riego por semana (R1) y dos riegos por semana (R2). Se aportó en ambos casos y con un balance semanal, un 30\% de la evapotranspiración de referencia según Penman-Monteith [15] hasta vendimia, mediante riego localizado por goteo, con dos goteros autocompensantes por planta, el R1 de caudal 4 1/h y el R2 de $81 / h$.

El estado hídrico de las plantas se realizó mediante medidas de potencial hídrico de hoja ( $\Psi 1)$ y potencial hídrico de tallo ( $\Psi$ s ) a medio día solar, al tercer día de riego en ambos tratamientos. Para ello se utilizó una cámara de presión tipo Scholander (PMS Instruments Company, Albany, Oregón, USA). El índice de área foliar se obtuvo con la relación alométrica de medida de longitud de pámpano y área foliar, obtenida el mismo año para el viñedo en estudio. Las medidas de intercambio gaseoso se realizaron con un equipo Li-Cor 6400 XT. La humedad del suelo se midió con sondas Drill\&Drop ${ }^{\circledR}$ a cinco profundidades $5,15,25,35,45$ y $55 \mathrm{~cm}$. Cuando las bayas llegaron a $23^{\circ}$ Brix de solidos solubles, se realizó la vendimia, obteniéndose los componentes del rendimiento $\left(\mathrm{n}^{\mathrm{o}}\right.$ de racimos, bayas por racimo y peso de la baya) y se analizó la madurez tecnológica y fenólica $(\mathrm{pH}$, ácido málico, ácido tartárico, ácido D-glucónico, acidez total, antocianos, índice de polifenoles totales, intesidad de color, nitrógeno fácilmente asimilable y potasio). Los resultados obtenidos se analizaron estadísticamente mediante análisis de la varianza utilizando el programa estadístico IBM SPSS v.19®.

\section{Resultados y discusión}

La Tabla 1 muestra los valores de ET0 calculados por Penman-Monteith 56 [15], precipitación, riego y agua total recibida en los tratamientos ensayados a lo largo de todo el ciclo vegetativo del cultivo, habiéndose cubierto con agua de lluvia las necesidades hídricas desde brotación hasta julio, mes en el que se iniciaron los riegos, en un estado fenológico entre baya tamaño guisante y el cierre del racimo, como se muestra en la tabla 2 , en la que se puede ver que la fecha de alcanzar los estados fenológicos fue la misma para los dos tratamientos hasta finales de julio, en el que se inició el envero antes para el tratamiento $\mathrm{R} 2$ o el de dos riegos semanales.

A pesar de haber tenido una misma cantidad de agua total recibida en los dos tratamientos, se ha apreciado un diferente comportamiento en el estado hídrico entre ambos. Así, el tratamiento R1 o de un riego semanal, se mostró ligeramente con un potencial menor que el R2 o tratamiento de dos riegos semananles, como puede observarse en la figura 1, en la que se refleja los potenciales de tallo medidos a medio día solar durante el ensayo, marcándose la diferencia entre los dos tratamientos desde el primer riego. 


\section{Congreso Nacional de Riegos CARTAGENA 2021}

Tabla 1. Demanda evaporativa de la atmósfera, precipitación, riego y agua total recibida en los tratamientos.

\begin{tabular}{lcrrr}
\hline Meses & $\begin{array}{c}\text { ET0 } \\
(\mathbf{P M})\end{array}$ & $\begin{array}{c}\text { Pe } \\
(\mathbf{m m})\end{array}$ & $\begin{array}{c}\text { Riego } \\
(\mathbf{m m})\end{array}$ & $\begin{array}{c}\text { Agua total } \\
\text { recibida } \\
(\mathbf{m m})\end{array}$ \\
\hline Octubre & 80,60 & 29,1 & 0 & 29,1 \\
\hline Noviembre & 35,10 & 67,9 & 0 & 67,9 \\
\hline Diciembre & 31,00 & 24,1 & 0 & 24,1 \\
\hline Enero & 28,70 & 61,7 & 0 & 61,7 \\
\hline Febrero & 52,70 & 16,4 & 0 & 16,4 \\
\hline Marzo & 70,50 & 16,1 & 0 & 16,1 \\
\hline Total parada vegetativa & $\mathbf{2 9 8 , 6 0}$ & $\mathbf{2 1 5 , 3}$ & $\mathbf{0}$ & $\mathbf{2 1 5 , 3}$ \\
\hline Abril & 85,40 & 65,0 & 0 & 65,0 \\
\hline Mayo & 157,10 & 33,2 & 0 & 33,2 \\
\hline Junio & 181,10 & 62,0 & 0 & 62,0 \\
\hline Julio & 231,60 & 0 & 42,70 & 42,70 \\
\hline Agosto & 196,60 & 33,4 & 85,40 & 118,8 \\
\hline Septiembre & 60,20 & $41,2\left(^{*}\right)$ & 0 & 41,2 \\
\hline Total brotación-vendimia & $\mathbf{9 1 2 , 0 0}$ & $\mathbf{1 2 8 , 6}$ & $\mathbf{1 2 8 , 0}$ & $\mathbf{3 6 2 , 9}$ \\
\hline Total & $\mathbf{1 2 1 0 , 6 0}$ & $\mathbf{4 5 0 , 3}$ & $\mathbf{1 2 8 , 0}$ & $\mathbf{5 7 8 , 2}$ \\
\hline
\end{tabular}

${ }^{*}$ ) Lluvia caída después de vendimia

Tabla 2. Fecha de Estado fenológico en los tratamientos

\begin{tabular}{l|l|l}
\hline Fecha & Tratamiento R1 & Tratamiento R2 \\
\hline $15 / 04 / 2021$ & Brotación & Brotación \\
\hline $03 / 05 / 2021$ & Hojas extendidas & Hojas extendidas \\
\hline $10 / 06 / 2021$ & Floración & Floración \\
\hline $16 / 06 / 2021$ & Cuajado & Cuajado \\
\hline $28 / 06 / 2021$ & Baya tamaño guisante & Baya tamaño guisante \\
\hline $19 / 07 / 2021$ & Cerramiento del racimo & Inicio envero \\
\hline $26 / 07 / 2021$ & Inicio de envero & Envero 20\% \\
\hline $02 / 08 / 2021$ & Envero 50\% & Envero 75\% \\
\hline $09 / 08 / 2021$ & Envero $75 \%$ & $100 \%$ enveradas \\
\hline $16 / 08 / 2021$ & $100 \%$ enveradas & Maduración \\
\hline $26 / 08 / 2021$ & Vendimia & Vendimia \\
\hline
\end{tabular}

La figura 2 muestra los valores de fotosíntesis en los tratamientos. A partir de finales de julio se aprecia una fotosíntesis ligeramente mayor en el tratamiento de dos riegos semanales, aunque no se han encontrado diferencias significativas entre tratamientos en el análisis estadístico.

El contenido de humedad del suelo se refleja en la figura 3, en la que se representa el valor medio diario en cada uno de los tratamientos, a la profundidad de $5,15,25,35,45$ y $55 \mathrm{~cm}$ y la suma total de todas ellas en el perfil. Los picos en las gráficas indican los riegos aportados. La media y resumen de todas ellas se presenta en la figura 4, en la que se observa una humedad en todo el perfil del suelo mayor en el tratamiento R1 que en el R2, la explicación que encontramos a ello puede ser debido al efecto de evaporación, que debe ser mayor en tratamientos de 2 riegos semanales que en tratamientos de 1 riego semanal (Montoro et al., 2016) [1]. 


\section{CDERY \\ XXXVIII Congreso Nacional de Riegos CARTAGENA 2021}

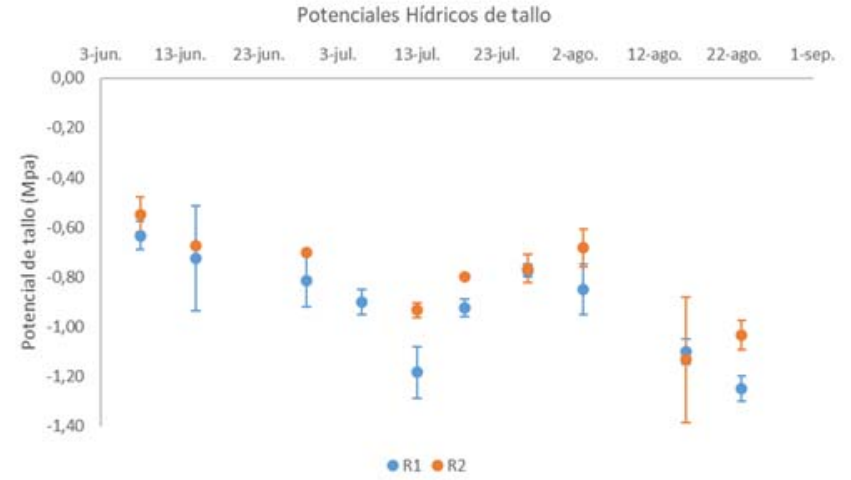

Figura 1. Potenciales hídricos de tallo tomados a medio día solar.

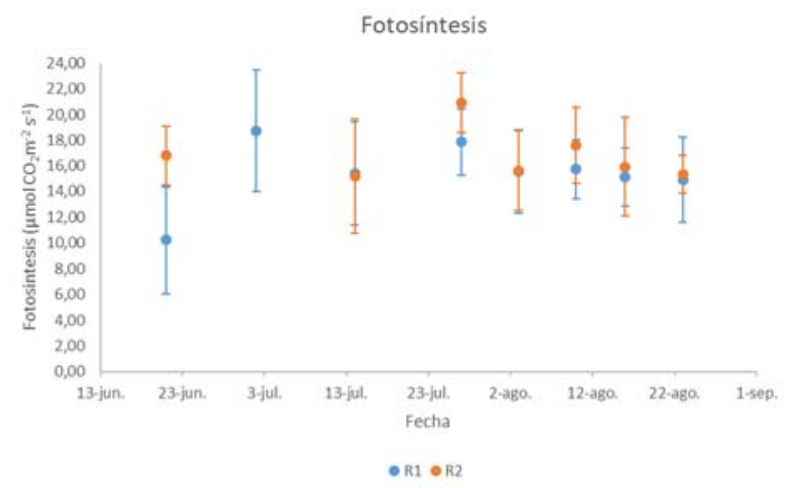

Figura 2. Fotosíntesis en los tratamientos estudiados.
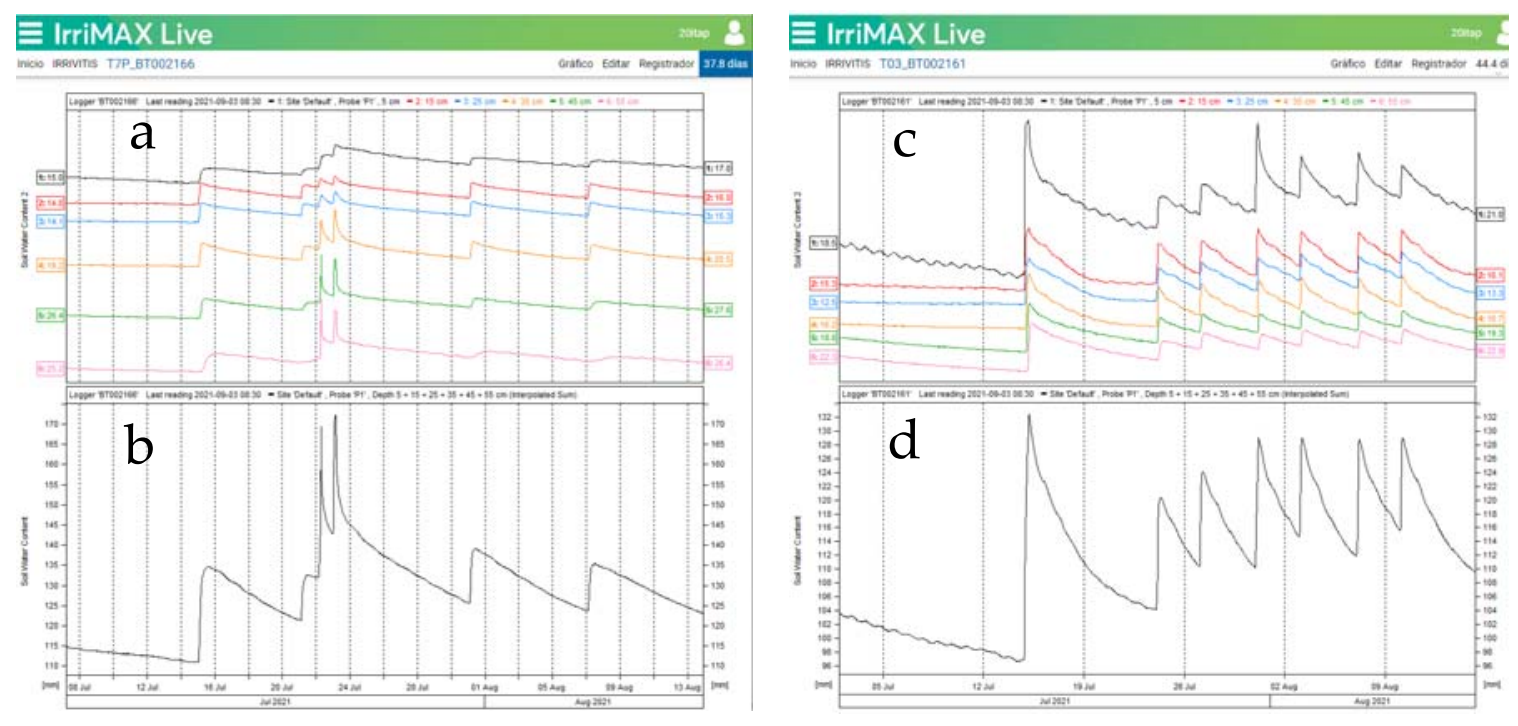

Figura 3. Contenido de humedad en el suelo en el tratamiento R1 a 6 profundidades (a) y total (b) y en el tratamiento R2 a 6 profundidades (c) y total (d).

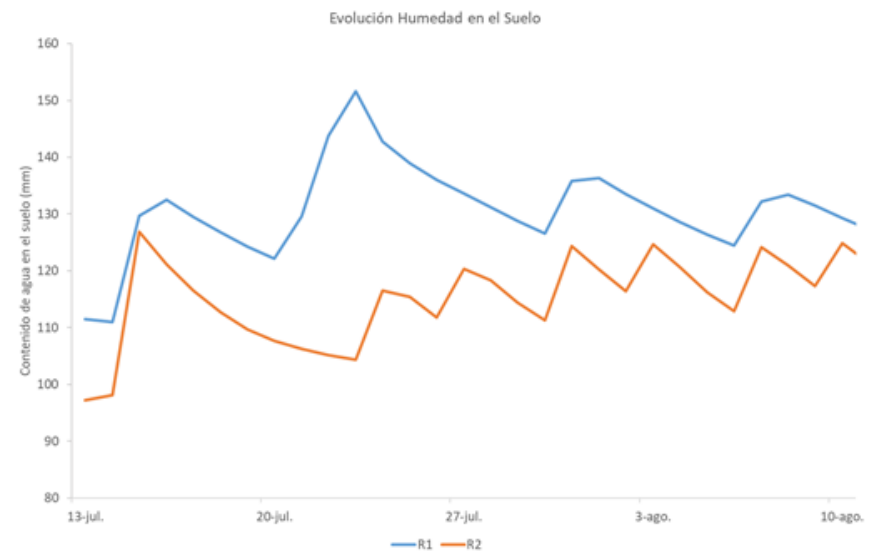

Figura 4. Comparativa del contenido total de humedad en el suelo en ambos tratamientos 


\section{Congreso Nacional de Riegos CARTAGENA 2021}

A pesar de que la fecha de vendimia estaba programada para la recolección con $23^{\circ}$ Brix, se tuvo que realizar la de los dos tratamientos a la vez, por motivos de previsión de granizo, lluvias y fuertes vientos huracanados. Se realizó el 26 de agosto, fecha en la que ninguno de los tratamientos había alcanzado los $23^{\circ}$ Brix. El R1 se encontraba en $22,7^{\circ}$ Brix y el R2 en 20,5 $5^{\circ}$ Brix, como se observa en la figura 5 , por lo que vemos que la frecuencia de riego sí que afectó a la fecha de maduración de la uva, siendo más rápida en los tratamientos de un riego semanal, que en los de 2 riegos semanales, aunque sin significación estadística. En cuanto al rendimiento, la figura 6, muestra prácticamente el mismo rendimiento en ambos tratamientos, 2,04 vs 2,16 t/ha, en R1 y R2, respectivamente.

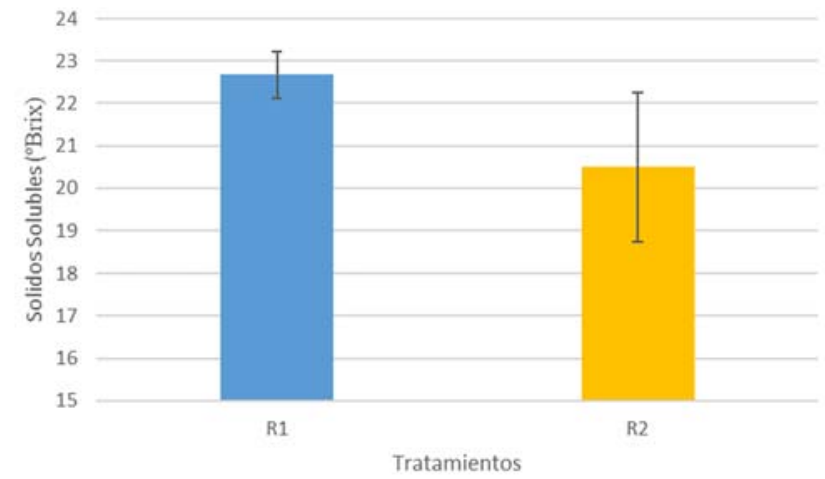

Figura 5. ${ }^{\circ}$ Brix en los dos tratamientos a misma fecha (finales de agosto).

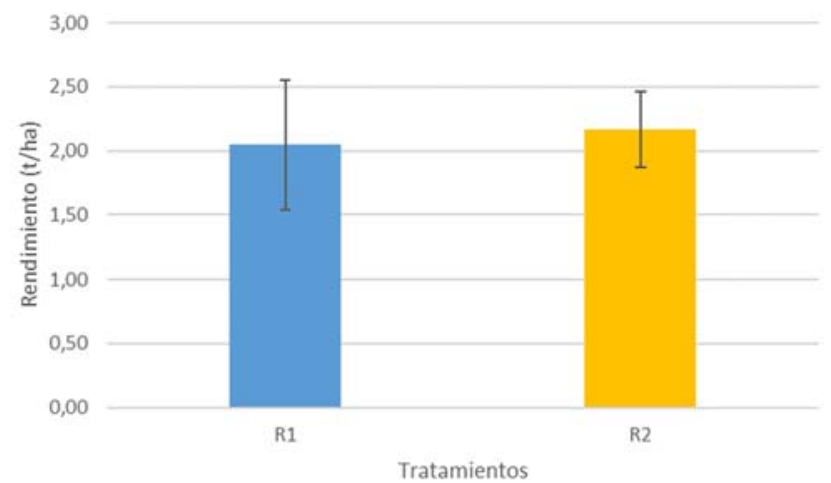

Figura 6. Rendimiento en los dos tratamientos a misma fecha (finales de agosto).

En cuanto a la acidez, los dos tratamientos tuvieron similar ácido tartárico $(5,4 \mathrm{~g} / \mathrm{l})$, pero sí que hubo una diferencia en el ácido málico ( 2,4 vs 3,1 g/l en R1 vs R2), debido quizá al diferente estado de maduración de la uva, ello produjo una acidez total también diferente, siendo mayor en el tratamiento R2 (6,4 g/l) que en el R1 (5,8 g/l). El pH fue el mismo en ambos casos, alcanzando un valor de 3,4.

Referente a la maduración fenólica, las figuras 7 y 8 muestran el valor de los antocianos e índice de polifenoles totales, observándose diferencia entre los dos tratamientos, siendo mayores los valores en ambos casos para el tratamiento de un riego semanal (R1). Esto produjo también una intensidad de color mayor en R1 que en R2 (3,58 vs 1,51).

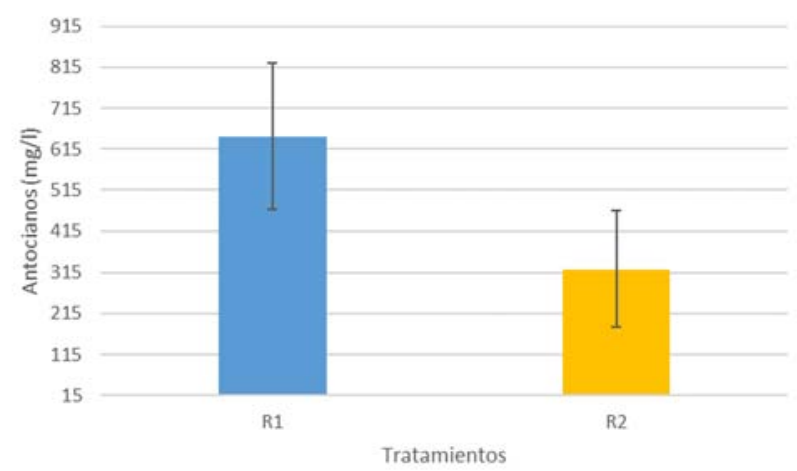

Figura 7. Antocianos en los dos tratamientos a misma fecha (finales de agosto).

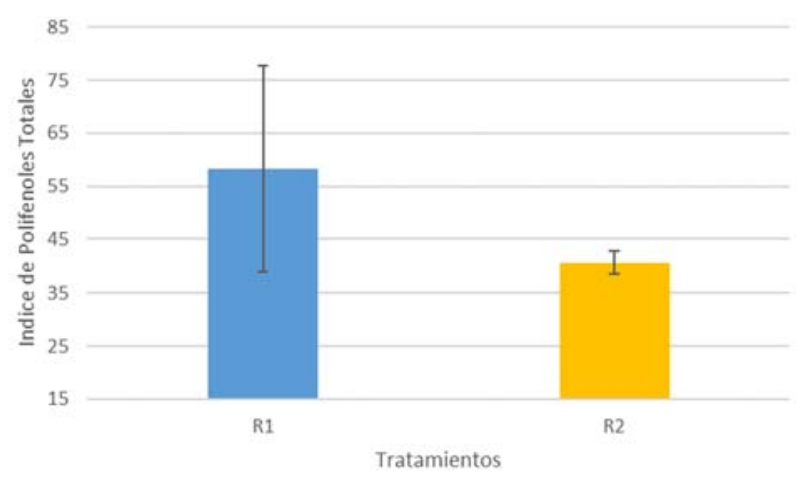

Figura 8. Índice de polifenoles totales en los dos tratamientos a misma fecha (finales de agosto). 


\section{Congreso Nacional de Riegos CARTAGENA 2021}

El nitrógeno fácilmente asimilable por las levaduras, también alcanzó valores diferentes, siendo mayor en el tratamiento de 2 riegos semanales (R2), como muestra la figura 9, aunque las diferencias encontradas no fueron significativas.

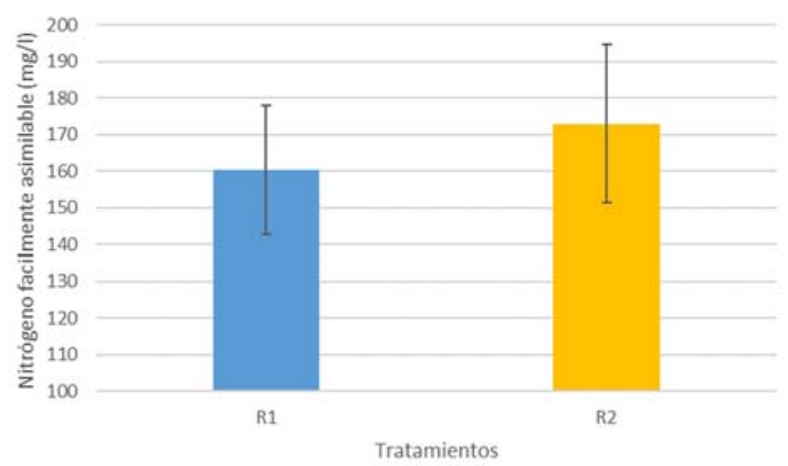

Figura 9. Nitrógeno fácilmente asimilable en los dos tratamientos a misma fecha (finales de agosto).

\section{Conclusiones}

De un solo año de estudio no se pueden obtener conclusiones firmes, pero los resultados parecen indicar que la frecuencia de riego depende del tipo de cultivo a regar, ya que, como se ha visto, en un cultivo como vid, se han obtenido buenos resultados, e incluso similares con un sólo riego semanal que con dos riegos semanales, algo impensable en cultivos hortícolas, como por ejemplo, ajo o cebolla.

La frecuencia de riego parece ser que afecta a la rapidez de la maduración, así, en nuestro caso y en el cultivo de la vid, la maduración se ha alcanzado antes en el tratamiento de un solo riego que en el de dos riegos semanales.

El rendimiento y maduración tecnológica, no se han visto afectados por las dos frecuencias de riego ensayadas (uno y dos riegos semanales). En cambio, sí que se han encontrado diferencias en la maduración fenólica entre las dos frecuencias de riego, alcanzando valores mayores en el tratamiento de un riego semanal, aunque esto ha podido estar motivado por el diferente grado de maduración de la uva.

Se requiere de los resultados de los próximos años para validar las primeras conclusiones obtenidas en este estudio.

\section{Agradecimientos}

Los autores agradecen la financiación obtenida del Ministerio de Ciencia e Innovación, a través de las ayudas a Proyectos I+D+i , en el marco de los Programas Estatales de Generación de Conocimiento y Fortalecimiento Científico y Tecnológico del Sistema I+D+i y de I+D+i orientada a los Retos de la Sociedad, al proyecto PID2019-105039RR-C43.

\section{Referencias}

1. Montoro, A.; Mañas, F.; López-Urrea., R. Transpiration and evaporation of grapevine, two components related to irrigation strategy. Agricultural Water Management. 2016. Volume 177, November 2016, Pages 193-200 . https://doi.org/10.1016/j.agwat.2016.07.005

2. MAPYA. Avance del Anuario de Estadística Agraria. 2020. https://www.mapa.gob.es/es/estadistica/temas/publicaciones/anuario-de-estadistica/default.aspx 


\section{Congreso Nacional de Riegos CARTAGENA 2021}

3. Dripdepot. The History of Drip Irrigation. https://help.dripdepot.com/support/solutions/articles/11000044434-the-historyof-drip-irrigation. 2017.

4. Kliewer, W.M.; Freeman, B.M.; Hosssom, C. Effect of Irrigation, Crop Level and Potassium Fertilization on Carignane Vines. I. Degree of Water Stress and Effect on Growth and Yield. Am J Enol Vitic. 1983. Vol 34: 186-196.

5. Poni, S.; Lakso, A.N.; Turner, J.R.; Melrous, R.E. The effects of pre- and post-veraison water stress on growth and physiology of potted Pinot Noir grapevines at varying crop levels. Vitis, 1993. Vol 32, 207-2014.

6. Ojeda, H.; Andary, C.; Kraeva, E.; Carbonneau, A.; Deloire, A. Influence of Pre- and Postveraison Water Deficit on Synthesis and Concentration of Skin Phenolic Compounds during Berry Growth of Vitis vinifera cv. Shiraz. Am J Enol Vitic., 2002. Vol. 53: 261-267.

7. Intrigliolo, D.S; Castel, J.R. Response of grapevine cv. Tempranillo to timing and amount of irrigation: water relations, vine growth, yield and berry and wine composition. Irrig Sci 2010. Vol. 28, 113-125.

8. Santesteban, L.G.; Miranda, C.; Royo, J.B. Regulated deficit irrigation effects on growth, yield, grape quality and individual anthocyanin composition in Vitisvinifera L. cv. 'Tempranillo'. Agric Water Manag, 2011. Vol 98, 1171-1179.

9. Levin, I.; Assaf, R; Bravdo, B. 1979. Irrigation, water status and nutrient uptake in an apple orchard. ISHS Acta Hort , 1979, Vol 92

10. Palomo, M.J.; Moreno, F.; Fernández, J.E.; Díaz-Espejo, A.; Girón, I.F. Determining water consumption in olive orchards using the water balance approach. Agric Water Manag, 2002. Vol 55(1), 15-35.

11. Hung, J.Y.T. Determination of emitter spacing and irrigation run time including plant root depth. In: Lamm FR (ed) Microirrigation for a changing world: conserving resources/ preserving the environment. Proceedings of the fifth international microirrigation congress, Orlando, Florida, 2-6 April, 1995. ASAE, St. Joseph, Mich., pp 292-296.

12. Myburgh, P.A. Comparing Irrigation Systems and Strategies for Table Grapes in the Weathered Granite-gneiss Soils of the Lower Orange River Region. S. Afr. J. Enol. Vitic.. 2012. Vol 33 (2), 184-197.

13. Selles G.; Ferreyra, E.; Contreras, R.E.; Ahumada, G.W.; Valenzuela, J; Bravo, R.V. Effect of three irrigation frequencies applied by drip irrigation over table grapes (Vitis vinifera L. cv. Thompson Seedless) located in the Aconcagua Valley (Chile). ISHS Acta Horticulturae. 2004. Vol 646

14. Sebastian, B.; Lissarrague, J.R.; Santesteban, L.G., et al. Effect of irrigation frequency and water distribution pattern on leaf gas exchange of cv.' Syrah ' grown on a clay soil at two levels of water availability. Agric Water Manag. 2016. Vol. 177:410418. doi: 10.1016/j.agwat.2016.08.032

15. Allen, R.G.; Pereira, L.S.; Raes, D.; Smith, M. Crop evapotranspiration. Guidelines for computing crop water requirements. FAO Irrigation and Drainage. 1998. Paper no. 56, FAO, Rome. 


\section{Congreso Nacional de Riegos CARTAGENA 2021}

\section{Plataforma de supervisión y control de riego localizado en cultivos leñosos.}

Domínguez-Niño, J.M. ${ }^{1}$, Munuera, M.T. ${ }^{2}$, Nortes, P. ${ }^{3}$, Masdemont, B. ${ }^{4}$, Buitrago, J.M. ${ }^{5}$, Ponce, L. ${ }^{6}$, Tornero, J.F. ${ }^{7}$, García, F.J. ${ }^{8}$

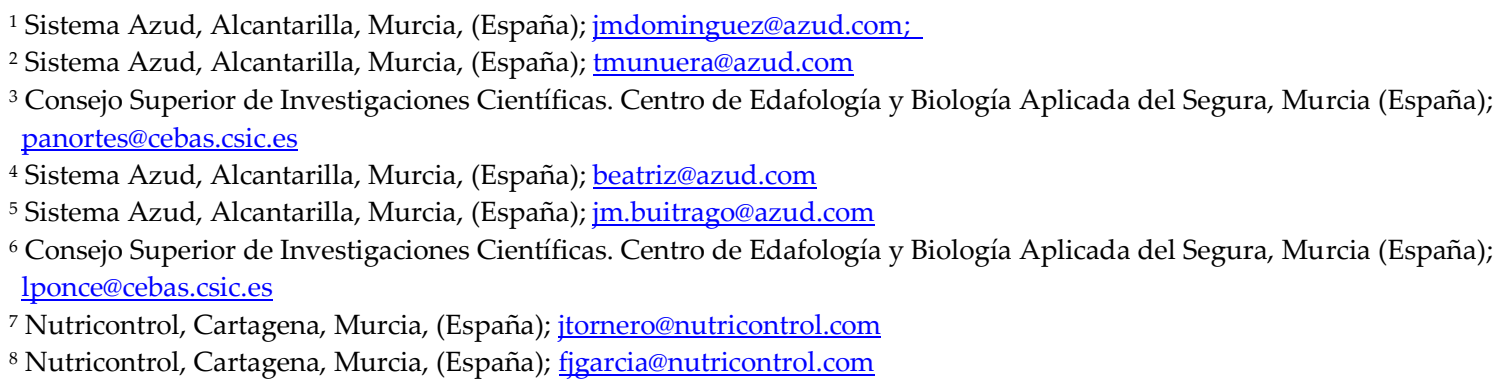

Resumen: La interpretación de sensores de humedad y la automatización del riego permiten una gestión rápida del cultivo, manteniendo unas condiciones óptimas en la zona de las raíces garantizando un adecuado crecimiento del mismo. Este trabajo trata de exponer como poner en valor las herramientas de digitalización en un cultivo leñoso regado por goteo, tomando como ejemplo el mandarino. Para ello se ha diseñado una plataforma web que permite recoger, visualizar y tomar decisiones. En concreto, gracias a la plataforma web se puede ver el comportamiento de diferentes sondas de humedad de tipo capacitivo, así como hacer un seguimiento de las lecturas de riego aplicado. Los resultados muestran que a pesar de que las sondas muestren variabilidad entre ellas, debido a sus características inherentes o propiedades del terreno en que se instalan, lo interesante es su respuesta frente al riego o un evento meteorológico y su tendencia a largo plazo. Además, se observó que durante el periodo de tiempo evaluado el caudal apenas experimentó variaciones respecto al valor teórico $(0.96 \%$ en riego superficial y $0.926 \%$ en riego subterráneo). Finalmente, gracias al conocimiento adquirido en esta instalación, se pondrá poner en práctica en otros cultivos.

Palabras clave: riego localizado; riego subterráneo; sonda de humedad, caudal; plataforma riego; monitorizar; cultivo leñoso 


\section{Platform for monitoring and control of localized irrigation in woody crops.}

Domínguez-Niño, J.M. ${ }^{1}$, Munuera, M.T. ${ }^{2}$, Nortes, P. ${ }^{3}$, Masdemont, B. ${ }^{4}$, Buitrago, J.M. ${ }^{5}$ Ponce, L. ${ }^{6}$, Tornero, J.F. ${ }^{7}$, García, F.J. ${ }^{8}$

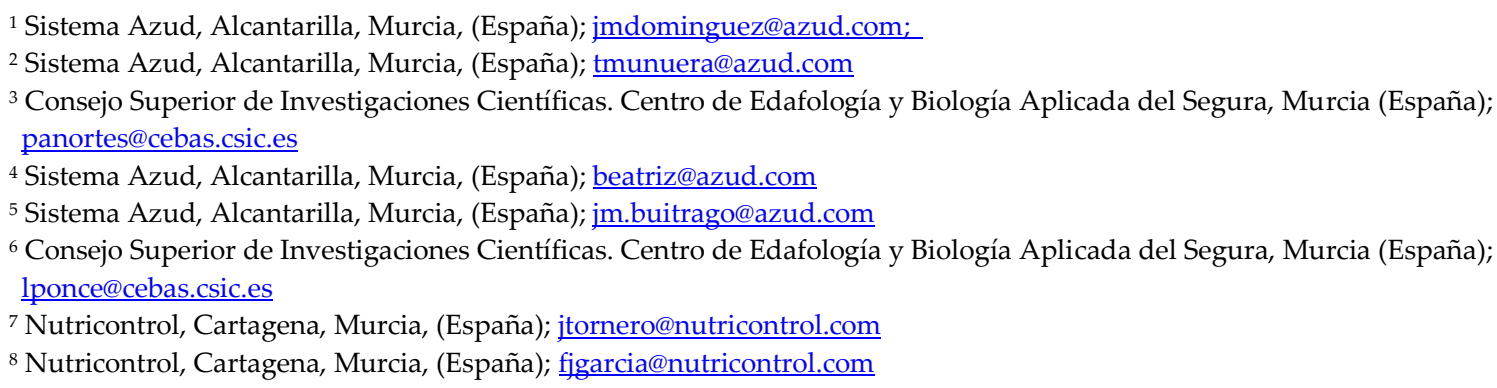

Abstract: The interpretation of moisture probes and automated irrigation allow a fast crop management, maintaining optimal conditions in the root zone and guaranteeing an adequate crop growth. This work tries to expose how to put in value the digitalization tools in a drip irrigated woody crop, taking as an example the mandarin tree. For this purpose, a web platform has been designed to collect, visualize and make decisions. In particular, thanks to the web platform it is possible to see the behavior of different capacitive moisture probes, as well as to monitor the applied irrigation. The results show that although the probes show variability among the differnt types of probes, due to their inherent characteristics or soil properties where they are installed, what is interesting is their response to irrigation or a meteorological event and their long-term trend. In addition, it was observed that during the period of time evaluated, the flow rate barely varied with respect to the theoretical value $(0.96 \%$ in surface irrigation and $0.926 \%$ in subsurface irrigation). Finally, thanks to the knowledge acquired in this installation, it will be put into practice in other crops.

Keywords: localized irrigation; subsurface irrigation; moisture probe, flow rate; irrigation platform; monitoring; woody crops 


\section{Introducción}

La agricultura es una de las actividades que más agua dulce consume en el mundo, aproximadamente el 70\% [1]. A medida que la población aumenta, también lo hace la necesidad de alimentos y, como consecuencia, la demanda de agua. Por lo tanto, es necesario desarrollar métodos para mejorar la eficiencia de la gestión del agua.

Dentro de una parcela, la monitorización y el control del riego generan beneficios como el ahorro del agua, disminución del impacto ambiental, lo que repercute en el desarrollo de una agricultura sostenible [2]. En este sentido, el riego de precisión es interesante ya que proporciona a los regantes un mayor control sobre la cantidad de agua que emplean y ayuda a optimizar parámetros como la frecuencia y duración de riego, la tasa de descarga del emisor y la ubicación de laterales en función de la parcela, suelo y cultivo [3]. Además, ayuda a reducir las pérdidas de agua por evaporación, percolación profunda y escorrentía.

En el día a día, la programación del riego optimizada, requiere de gran dedicación, constancia y experiencia de los agricultores. Por ello, se precisa de herramientas digitales que permitan liberar al agricultor de estas exigencias, haciendo que en los cultivos se aplique un riego de precisión con un esfuerzo viable. Así pues, el empleo de sondas de humedad y la automatización del riego mediante el empleo de plataformas web se presentan como la alternativa idónea para este propósito.

Las sondas de humedad son dispositivos que permiten evaluar, de forma rápida y continua, el contenido de agua del suelo a diferentes profundidades. Entre ellas, las más populares son las de tipo capacitivo dada su robustez, bajo consumo energético y bajo mantenimiento. Además del empleo de este tipo de sondas para la supervisión de la dinámica del riego, la información que generan es de gran interés en los sistemas de apoyo a la decisión (DSS) ya que permiten determinar cuándo y cuánta agua aportar en una parcela [4].

Sin embargo, su instalación en campo muestra una gran variabilidad, sobre todo en instalaciones con riego por goteo, ya que genera bulbos húmedos cuya formación está afectada por las propiedades físicas del suelo (textura, densidad aparente, contenido inicial de agua...), sistema radicular del cultivo, tasa de riego, evaporación y percolación entre otros. A pesar de estas consideraciones, el empleo de sondas de humedad para la gestión de riego es apto y por ello conocer su comportamiento es de gran utilidad.

El conocimiento de los factores implicados en las mediciones con sensores permitirá optimizar su uso, en cuanto a aspectos como su número y ubicación en el suelo, así como su interpretación e integración en plataformas que permitan hacer un seguimiento, controlar y tomar decisiones.

El objetivo del presente estudio es evaluar como las herramientas de digitalización permiten controlar y realizar un seguimiento de un cultivo leñoso regado por goteo. Para ello, se toma como referencia el comportamiento de diferentes sondas capacitivas instaladas en posiciones equivalentes y la evolución de las dosis de riego y caudales.

\section{Materiales y métodos}

\subsection{Diseño experimental y tratamientos de riego}

En ensayo se llevó a cabo en un cultivo de mandarinos (Citrus reticulata) con un marco de plantación de $6 \mathrm{~m} \times 2 \mathrm{~m}$ y orientación este-oeste con riego localizado en superficie y subterráneo $(0.40 \mathrm{~m}$ de profundidad). El suelo era de textura franca y pedregoso con un $2.6 \%$ de materia orgánica y una conductividad eléctrica de $0.29 \mathrm{mS} / \mathrm{cm}$. El sistema de riego consistió en una doble línea de emisores 
de tipo AZUD PREMIER PC AS 16 2.3L con goteros cada $0.50 \mathrm{~m}$. La distancia entre laterales y línea de cultivo fue de $1 \mathrm{~m}$.

Se ensayaron 4 tratamientos de riego, T1, riego en superficie regado al 100\% de las necesidades del cultivo durante todo el año, T2, riego en superficie, donde se aplicó una estrategia de riego deficitario controlado, con reducción del riego al 50\% de la ETc en la fase II del crecimiento del fruto, idénticos tratamientos fueron manejados en riego subterráneo, T3 y T4, respectivamente (Figura 1). El diseño experimental fue de bloques al azar con 4 repeticiones por tratamiento, de tres filas de árboles, donde se seleccionaron árboles de la fila central para el seguimiento del estado hídrico del suelo.

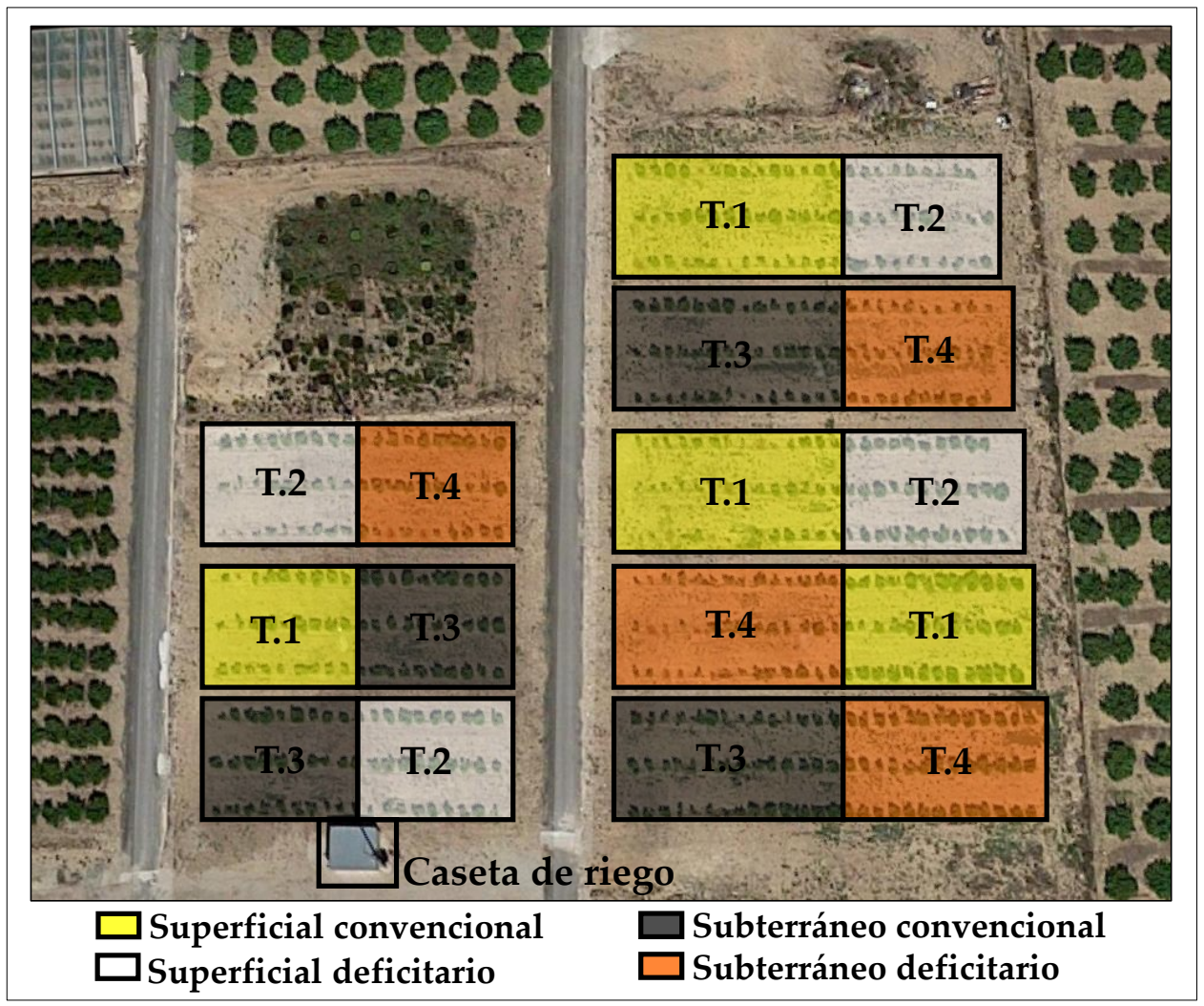

Figura 1. Esquema de la plataforma de supervisión y control de riego localizado

La programación del riego consistió en la aplicación del balance hídrico de la FAO, con periodicidad semanal, empleando la ETo de la semana anterior registrada por una estación meteorológica situada en la finca y coeficientes de cultivo teóricos. Los sectores de riego estaban controlados mediante el programador Mastia 332 3K (Nutricontrol, Murcia, España).

\subsection{Sondas de humedad empleadas y localización}

Para realizar el seguimiento del contenido volumétrico del suelo, en el ensayo se seleccionaron 3 tipos de sondas de humedad de tipo capacitivo que fueron las siguientes:

- Sonda Drill \& Drop (SENTEK Technologies): midió contenido de agua, conductividad eléctrica

y temperatura entre 0 y $80 \mathrm{~cm}$ de profundidad.

- Sonda HydraSCOUT (HSTI Soil Moisture Management): midió contenido de agua y temperatura entre 10 y $80 \mathrm{~cm}$ de profundidad. 


\section{Congreso Nacional de Riegos CARTAGENA 2021

- Sonda TEROS-12 (METER GOUP): midió contenido de agua, conductividad eléctrica y temperatura a 30 y $60 \mathrm{~cm}$ de profundidad.

Las sondas evaluadas estaban dispuestas en posiciones equivalentes respecto al gotero, concretamente en el punto medio entre dos goteros consecutivos, a $10 \mathrm{~cm}$ del lateral, tanto en la configuración de riego superficial como riego subterráneo (Figura 2).

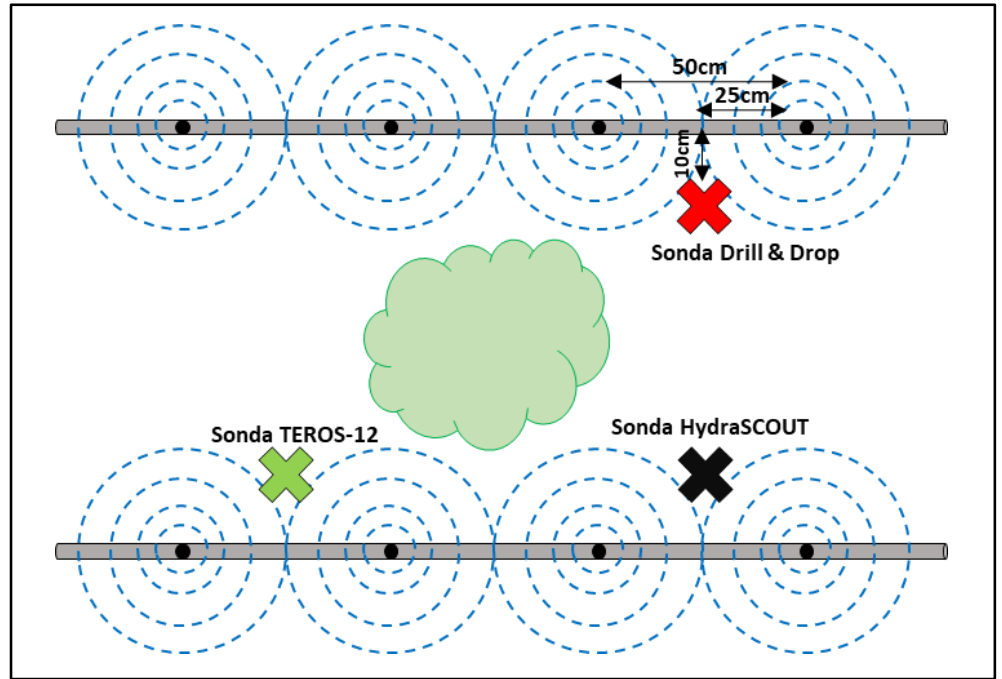

Figura 2. Disposición de las sondas de capacitancia (Drill\&Drop, HYDRASCOUT y TEROS-12)

\subsection{Sistema de control, ejecución y comunicación}

En cada sector de riego había diferentes tipos de sondas conectadas a un sistema de comunicación inalámbrico (REDIN) que almacenaba y enviaba las lecturas de las sondas de humedad al programador de riego y éste a la plataforma web donde se podían controlar y visualizar las lecturas de la señal del evento de riego y de las sondas de humedad. En la Figura 3 se observa un esquema en el que se detallan los pasos que se siguieron desde que se tomaron los datos con las sondas de humedad y contadores hasta su visualización en la plataforma web de riego.

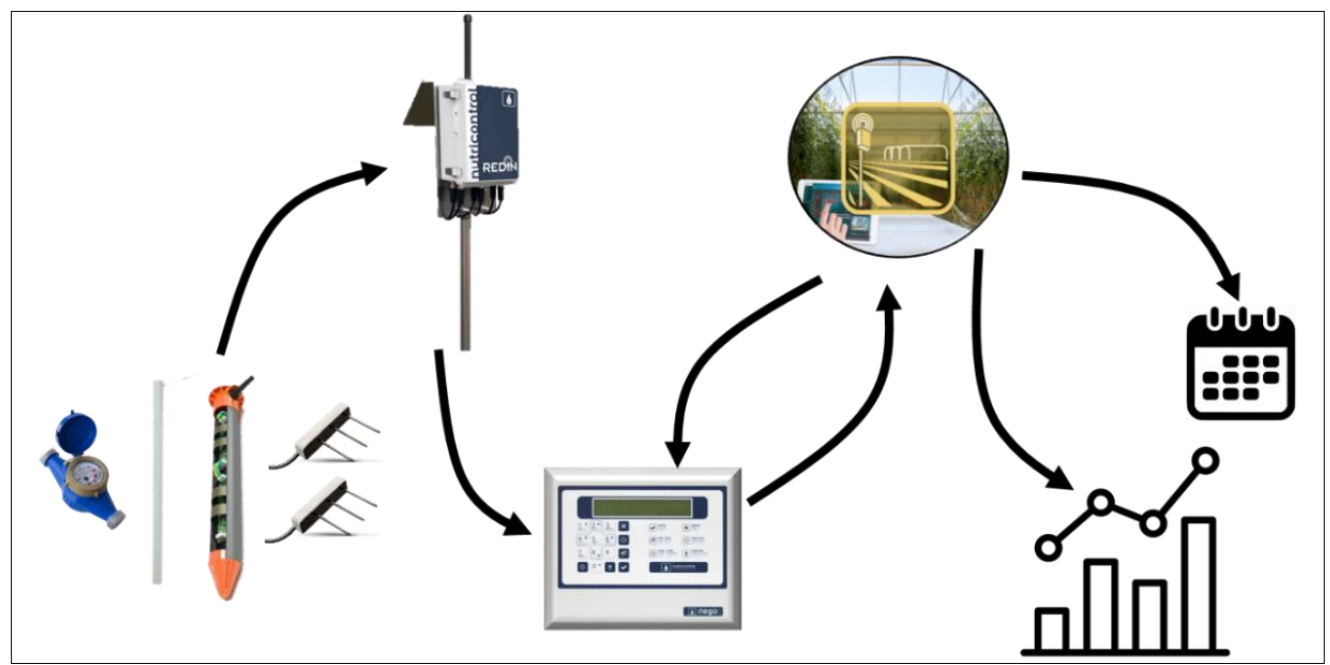

Figura 3. Esquema del sistema de control, ejecución y comunicación 


\subsection{Plataforma web para el control de riego}

La plataforma web desarrollada por Nutricontrol y junto con la colaboración de AZUD y CEBASCSIC, posibilitó conocer el comportamiento hidráulico de los diferentes sectores de una parcela en cualquier momento. Básicamente, consistió en incorporar a un controlador que inicialmente estaba diseñado para programar el riego, sondas de humedad de tipo capacitivo, cuyas lecturas junto con las de contadores se recogieron telemáticamente en una la plataforma web de riego diseñada tanto para modificar la programación de riego telemáticamente, como para registrar información acerca el estado del suelo (contenido de humedad, conductividad eléctrica y temperatura) así como dosis y caudales aplicados.

Actualmente esta plataforma web está activa y se centra en recopilar información relativa al contenido de agua, conductividad eléctrica y temperatura del suelo de un cultivo de mandarinos. Al tratarse de una plantación localizada en suelo pedregoso, presenta dificultad para la instalación de sondas y por ende manejo del riego.

La plataforma de riego desarrollada tiene como particularidad y característica diferenciadora de otras plataformas que está recogiendo lecturas de diferentes tipos de sondas capacitivas (Drill\&Drop, HydraSCOUT y TEROS-12), además de valores de caudales en cada momento del evento de riego.

\section{Resultados y discusión}

\subsection{Mediciones de contadores}

Durante el periodo en el que la plataforma de control y seguimiento del riego empezó a estar operativa hasta la actualidad, se llevó a cabo la medición de las dosis aplicadas y los caudales. En lo referente a las dosis aplicadas, variaron semanalmente de acuerdo a la programación de riego, mientras que, según se muestra en la tabla 1, los caudales de mantuvieron prácticamente constantes con variaciones entre caudal teórico y caudal medio inferiores al 1.00\%. Esto indicó que no hubo intrusión radicular o pérdidas de agua por fugas, salvo en momentos concretos cuando se realizaron labores de mantenimiento y limpieza de laterales.

Tabla 1. Variación de caudales respecto teórico en los tratamientos superficiales y los tratamientos subterráneos.

\begin{tabular}{lcc}
\hline & SUPERFICIAL & SUBTERRÁNEO \\
\hline CAUDAL TEORICO $\left(\mathrm{m}^{3} / \mathrm{h}\right)$ & 0.205 & 0.106 \\
CAUDAL PROMEDIO MEDIDO $\left(\mathrm{m}^{3} / \mathrm{h}\right)$ & 0.198 & 0.100 \\
DESVIACION CAUDAL LIMPIEZA $\left(\mathrm{m}^{3} / \mathrm{h}\right)$ & 0.053 & 0.032 \\
$\%$ VARIACION CAUDAL & 0.960 & 0.926 \\
\hline
\end{tabular}

\subsection{Mediciones con sondas de humedad capacitivas}

La respuesta de las sondas de humedad al riego y a los eventos meteorológicos variaron tanto en función del tipo sonda, como en función de la profundidad de los laterales de riego. En general, se vio que las sondas respondieron correctamente, pero con distinta intensidad en función del tipo de sonda (Figura 4).

A modo de síntesis, para comparar las sondas, se seleccionó la profundidad de $30-40 \mathrm{~cm}$ que fue común a todas las sondas, era la profundidad donde se localizaban los laterales en el riego subterráneo y fue donde se localiza la mayor proporción de las raíces. 


\section{Congreso Nacional de Riegos CARTAGENA 2021}

En el riego superficial las sondas HydraSCOUT y Drill \& Drop, respondieron de manera definida y rápida tanto a los eventos de riego como a las precipitaciones, mientras que la sonda TEROS-12 respondió de manera menos intensa y sostenida en el tiempo al riego y de manera más definida a las precipitaciones.

En el caso del riego subterráneo la sondas HydraSCOUT y TEROS-12 responden al riego y a la precipitación, pero de modo menos intensa que en el superficial. Asimismo, la sonda Drill \& Drop, mostró un comportamiento estacional, apenas mostró variaciones ante los ciclos de riego y precipitación, probablemente porque en esa profundidad está localizado el lateral y la zona se encuentra saturada.
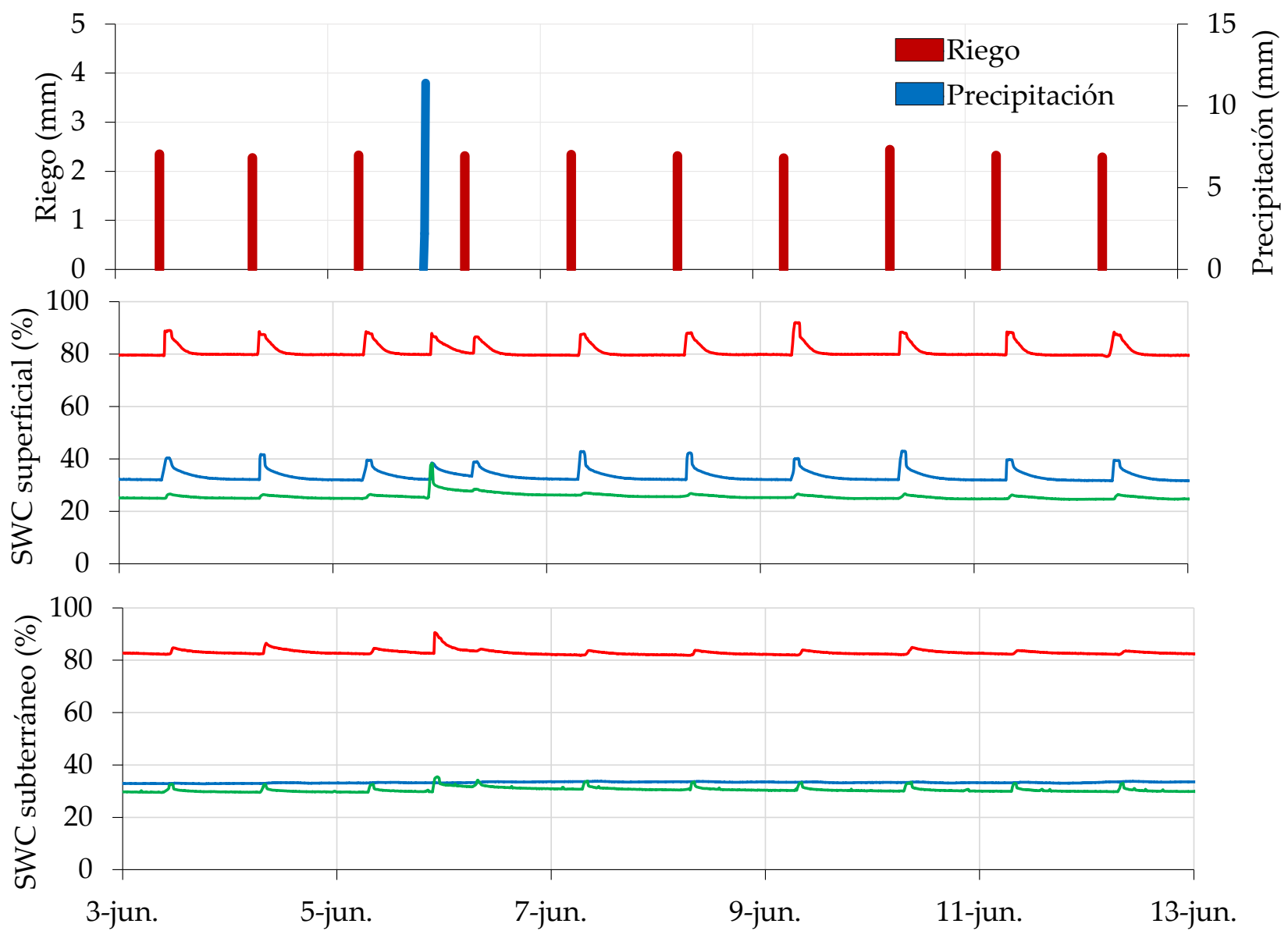

$-40 \mathrm{~cm}$ HYDRASCOUT $\quad-40 \mathrm{~cm}$ DRILL\&DROP $\quad-30 \mathrm{~cm}$ TEROS- 12

Figura 4. Dinámica del SWC de las sondas capacitivas Drill\&Drop, HYDRASCOUT y TEROS-12 en riego superficial.

En general, aunque se trate de distintas sondas de humedad ubicadas en posiciones equivalentes, hay variabilidad entre lecturas, debido al diferente volumen de agua que perciben $\left(\mathrm{V}_{\text {Hydrascout }} \approx 1.3 \mathrm{~L}\right.$, $\mathrm{V}_{\text {Drill\&Drop }} \approx 0.6 \mathrm{~L}$ y $\mathrm{V}_{\text {TEROS-12 }} \approx 1 \mathrm{~L}$ ) y por la heterogeneidad del suelo donde son instalados, debida principalmente a la presencia de gravas, la gran variabilidad de la densidad aparente, existencia de macroporos y la proximidad de las raíces del cultivo. Igualmente, la temperatura y la conductividad eléctrica pueden alterar esas mediciones. 


\section{Conclusiones}

En el presente estudio se ha puesto en marcha una plataforma de control y monitorización del riego y de sensores de humedad en una parcela de mandarinos donde había distintas configuraciones del sistema de riego por goteo, diferentes manejos y distintos tipos de sondas.

Mediante la plataforma desarrollada se ha podido dotar a un programador de riego de diferentes sensores de humedad, pudiendo conocer exhaustivamente el contenido de agua y entender lo que está pasando en el suelo.

Los resultados obtenidos hasta la fecha sugieren que el medio sobre el que están instaladas las sondas, así como el sistema de riego tienen gran relevancia. Por un lado, el suelo se caracteriza por ser muy heterogéneo, altamente variable en distancias muy pequeñas, sobre todo por la abundante presencia de gravas, provocando que los sondas no estén exactamente en condiciones de terreno equivalentes. Por otro lado, debido a las características del terreno, los bulbos húmedos que se generan no son ideales y son muy variables en cuanto a tamaño, forma y alineación respecto al gotero, haciendo que todas las sondas de humedad no se vean afectadas por el mismo volumen de agua.

Además, otra posible explicación a la variabilidad en las mediciones es debida al pequeño volumen de suelo que perciben $\left(\mathrm{V}_{\text {Hydrascout }} \approx 1.3 \mathrm{~L}, \mathrm{~V}_{\text {Drill\&Drop }} \approx 0.6 \mathrm{~L}\right.$ y $\left.\mathrm{V}_{\text {теRos-12 }} \approx 1 \mathrm{~L}\right)$, lo que hace que sean muy sensibles a las variaciones locales (textura, densidad aparente, contenido inicial de agua, sistema radicular del cultivo, tasa de riego, evaporación, percolación...). De igual manera, la temperatura y la conductividad eléctrica del suelo juegan un papel relevante.

En definitiva, dada la variabilidad del sistema, es conveniente ubicar los sensores en posiciones repetidas para que la interpretación sea más robusta. Observadas las diferentes respuestas de las sondas al riego y a los eventos meteorológicos, lo que interesa es conocer su comportamiento y dinámica en el tiempo. Además, en función de cada instalación y necesidades concretas se podrán emplear una u otra.

De acuerdo a la evolución del caudal, a diferencia de otras plataformas de riego, la plataforma desarrollada para este trabajo permitió conocer el caudal para cada evento de riego, el cual apenas sufrió variaciones a lo largo del tiempo, lo que permite al usuario a predecir operaciones de mantenimiento.

En base a todo lo indicado anteriormente, en un futuro cercano se prevé que el sistema funcione de manera desasistida de tal forma que en función de la respuesta de los sensores se active/desactive el riego y además en función de las variaciones de los caudales dé información acerca el mantenimiento de la instalación.

\section{Agradecimientos}

Este trabajo ha sido financiado por el proyecto por el Ministerio de Ciencia, Innovación y Universidades - Agencia Estatal de Investigación y cofinanciado por la Unión Europea a través del Fondo Europeo de Desarrollo Regional (FEDER), dentro de la convocatoria RETOS-COLABORACIÓN 2017 que apoya proyectos en cooperación entre empresas y organismos de investigación, cuyo objetivo es promover el desarrollo tecnológico, la innovación y una investigación de calidad (Referencia: RTC2017-6365-2).

\section{Referencias}

1. AQUASTAT database. Available online: http://www. fao.org/nr/aquastat (accessed July 2021).

2. Smith, M.; Pereira, L.S.; Berengena, J.; Itier, B.; Goussard, J.; Ragab, R.; Tollefson, L.; Van Hoffwegen, P. (Eds.). Irrigation Scheduling: From Theory to Practice. FAO Water Report 8, FAO, Rome, 1996; pp 384.

3. Skaggs, T. H.; Trout, T. J.; Rothfuss, Y. Drip irrigation water distribution patterns: effects of emitter rate, pulsing, and antecedent water. Soil Sci. Soc. Am. J. 2010, 74, pp. 1886-1896.

4. Fares, A.; Alva, A. K. Evaluation of capacitance probes for optimal irrigation of citrus through soil moisture monitoring in an entisol profile. Irrig Sci. 2000, 19, pp. 57-64. 


\title{
Integración de nuevas soluciones plásticas con propiedades an- tioxidantes en sistemas de irrigación destinados a la reutiliza- ción de agua en agricultura de precisión
}

\author{
Munuera, M.T. ${ }^{1}$ Nortes, P. ${ }^{2}$, Domínguez-Niño, J.M. ${ }^{3}$, Ponce, L. ${ }^{4}$, Masdemont, B. ${ }^{5}$, Buitrago, J.M. ${ }^{6}$.
}

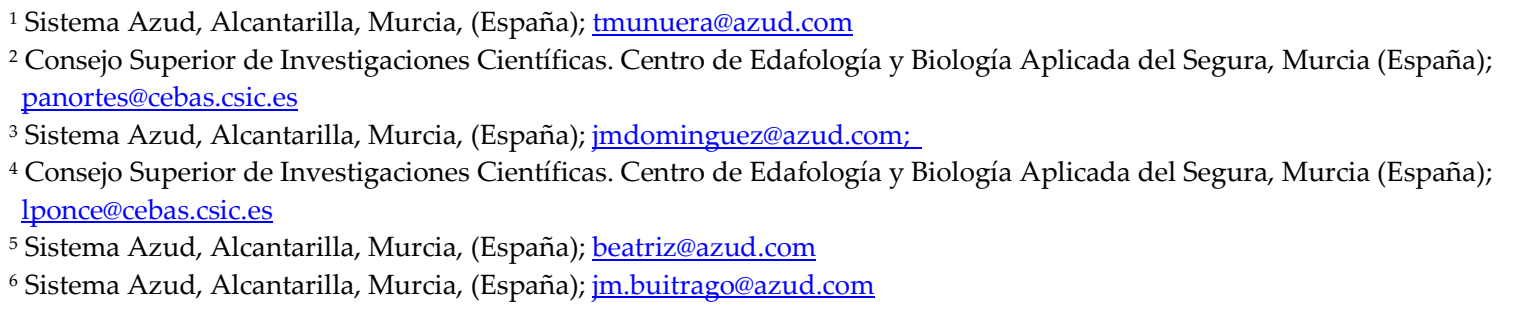

\section{Resumen:}

El uso cada vez más frecuente de aguas de alta actividad biológica, como son las aguas procedentes de depuradoras municipales, agudizan los problemas de obstrucción del emisor, lo cual conlleva para el agricultor situaciones complejas que pueden generar proliferación microbiana con reducción en la uniformidad del riego y por ende una disminución de la producción agrícola.

Desde hace años, la aplicación de nuevas tecnologías en el sector agrícola está dirigida a conseguir mayor producción trabajando con mayor precisión y control con los sistemas utilizados en riego. El desarrollo en otros sectores, como el industrial, de nuevas tecnologías puede servir como impulso en la velocidad de incorporación a la agricultura de estas soluciones. La introducción en el sector agrícola de nuevos materiales con funcionalidades antimicrobianas contrastadas puede convertirse en una línea estratégica para el desarrollo de barreras de protección frente a la obstrucción de los sistemas de irrigación sometidos a trabajar con aguas de mala calidad.

Se plantea una metodología basada en el testeo comparativo de diferentes materiales que transformados en emisores serán evaluados en la evolución del caudal emitido con agua regenerada. Una vez determinada la validez de la metodología se plantea la discriminación de los eventos necesarios para asegurar el mantenimiento de la instalación, para lo cual, se requiere continuar con el testado de los materiales.

Palabras clave: Agua Regenerada; Riego por Goteo; Microbiología 


\title{
Integration of new plastic solutions with antioxidant properties in irrigation systems for the reuse of water in precision agricul- ture
}

\author{
Munuera, M.T. ${ }^{1}$ Nortes, P. ${ }^{2}$, Domínguez-Niño, J.M. ${ }^{3}$, Ponce, L. ${ }^{4}$, Masdemont, B. ${ }^{5}$, Buitrago, J.M. ${ }^{6}$. \\ ${ }^{1}$ Sistema Azud, Alcantarilla, Murcia, (Spain); tmunuera@azud.com \\ ${ }^{2}$ Consejo Superior de Investigaciones Científicas. Centro de Edafología y Biología Aplicada del Segura, Murcia (España); \\ panortes@cebas.csic.es \\ ${ }^{3}$ Sistema Azud, Alcantarilla, Murcia, (Spain); jmdominguez@azud.com; \\ ${ }^{4}$ Consejo Superior de Investigaciones Científicas. Centro de Edafología y Biología Aplicada del Segura, Murcia (España); \\ lponce@cebas.csic.es \\ ${ }^{5}$ Sistema Azud, Alcantarilla, Murcia, (Spain); beatriz@azud.com \\ ${ }^{6}$ Sistema Azud, Alcantarilla, Murcia, (Spain); jm.buitrago@azud.com
}

Abstract: $1465 / 5000$

The increasingly frequent use of water with high biological activity, such as water from municipal treatment plants, exacerbates the problems of obstruction of the emitter, which leads to complex situations for the farmer that can generate microbial proliferation with a reduction in the uniformity of irrigation, and therefore a decrease in agricultural production.

For years, the application of new technologies in the agricultural sector is aimed at achieving greater production by working with greater precision and control with the systems used in irrigation. The development in other sectors, such as industrial, of new technologies can serve as a boost in the speed of incorporation into agriculture of these solutions. The introduction in the agricultural sector of new materials with proven antimicrobial functionalities can become a strategic line for the development of protection barriers against the obstruction of irrigation systems subjected to working with poor quality water.

A methodology is proposed based on the comparative testing of different materials that, transformed into emitters, will be evaluated in the evolution of the flow emitted with reclaimed water. Once the validity of the methodology has been determined, the discrimination of the events necessary to ensure the maintenance of the installation is proposed, for which, it is necessary to continue with the testing of the materials. e precision

Keywords: Reclaimed Water; Drip Irrigation; Microbiology 


\section{Introducción}

Europa apuesta por la reutilización de las aguas residuales tratadas en condiciones seguras y rentables, así como por soluciones que incrementen la eficiencia hídrica de cualquier uso para garantizar el suministro de agua y reducir la presión sobre unos recursos hídricos ya sobreexplotados en el continente. Fomentar con nuevos sistemas medioambientalmente sostenibles y nuevas técnicas de riego más precisas la seguridad de su reutilización en agricultura permitirá ampliar recursos en este sector y derivar otras fuentes de agua de mayor calidad a consumo, incrementando las fuentes de agua disponibles en cuencas deficitarias.

La Región de Murcia, es una de las áreas más castigadas por el déficit hídrico, por lo que viene aplicando desde hace años la reutilización de aguas residuales en la agricultura, por ello ostenta el liderazgo de proyectos destinados a la validación del uso de este recurso tanto a nivel nacional como europeo. En la mayoría de estas investigaciones, el foco de actuación está dirigido a obtener información, conocimiento o seguridad sobre su repercusión en la salud del consumidor o en la producción del cultivo. Sin embargo, no se cuantifica el impacto en el material tecnológico que habilita esta reutilización, a pesar de que, bajo estas condiciones sufre un mayor índice de reposición.

Uno de los propósitos del proyecto OXIDAGUA (DESAFIOS I+D REGION DE MURCIA) es optimizar el uso de agua regenerada en agricultura, evitando el declive progresivo del rendimiento del sistema de riego localizado por la proliferación de microorganismos. En este sentido, se ha puesto en marcha una línea de desarrollo basada en la integración, durante la fabricación del sistema de riego, de sustancias activas como parte de su composición, con el fin de crear un efecto barrera frente a agentes degradantes de la calidad de vida de los materiales destinados al goteo.

Para ello, en la primera fase de este proyecto los objetivos son:

- Cuantificar la respuesta al uso de agua regenerada de diferentes formulaciones en materiales plásticos caracterizadas como antimicrobianas.

- Determinar un sistema válido para interpretar la idoneidad de los diferentes materiales.

- Recopilar datos que nos aporten información sobre la evolución de la degeneración del sistema.

Asimismo, la presente comunicación tiene los siguientes objetivos secundarios:

- Incrementar la fiabilidad de los sistemas de riego durante más tiempo, reduciendo la huella generada por su reposición.

- Maximizar la eficiencia de riego a lo largo de la vida útil.

- Incrementar el know-how de la funcionalización de superficies plásticas en el sector que consumo más del $75 \%$ del agua.

\section{Materiales y métodos}

\subsection{Diferencia entre referencias de materiales}

Se han planteado dos ensayos en los que como única variable se ha incluido la formulación del material de fabricación de los emisores, analizando su comportamiento con agua regenerada.

En todas las formulaciones utilizadas se ha empleado un material polimérico sintético que contiene un principio activo integrado destinado a ejercer un efecto contra el crecimiento microbiano durante la vida útil prevista del producto. Estos materiales se aplican ya en diferentes sectores, industrial, cosmética, etc, pero no tienen presencia significativa en el sector agrícola. La selección de las diferentes formulaciones ha sido realizada en base a la capacidad antimicrobiana. 


\section{Congreso Nacional de Riegos CARTAGENA 2021}

Las bases plásticas elegidas entre la amplia variedad del mercado (Cloruro de polivinilo (PVC), policarbonato (PC), polipropileno (PP), poliestireno (PS), polietileno (PE/PEBD)) se han centrado en polietileno, tanto en baja como en alta densidad. El formato utilizado de estos materiales para la fabricación de las referencias ha sido pelet, aunque se suministran en diferentes formatos como polvo o líquido, empleando cada una de ellas para asegurar una incorporación perfecta.

De las referencias evaluadas la base de los aditivos testados incluye elementos comunes como cobre, plata, zinc, etc. Todas ellas vienen refrendadas por diferentes sistemas de certificación de los proveedores. Además, en su selección ha sido un criterio relevante el conseguir eficacia a una concentración aceptable económicamente. La concentración empleada para la formulación de la mezcla de inyección ha sido la recomendada por cada fabricante en su referencia.

De esta forma, los emisores han sido inyectados con las 18 referencias seleccionadas siendo testados en dos escenarios paralelos: integrados en tubería, en la Estación Depuradora de Aguas Residuales de ROLDAN - LO FERRO, Balsicas (Murcia), y de forma individual, sin integrar, en el laboratorio del Departamento de Riegos del CEBAS-CSIC (Murcia).

Es decir, se emplean 18 referencias diferentes, con y sin aditivos en la fabricación de un único modelo de emisor. A posteriori, emisores de la misma referencia son integrados en la misma línea de tubería de diámetro $16 \mathrm{~mm}$, a distancia de $0.30 \mathrm{~m}$.

\subsection{Ensayo en laboratorio}

En el ensayo en el laboratorio del Departamento de Riegos de CEBAS-CSIC se evaluó el efecto antimicrobiano de diferentes referencias una vez se han inyectado, siendo transformadas en un emisor.

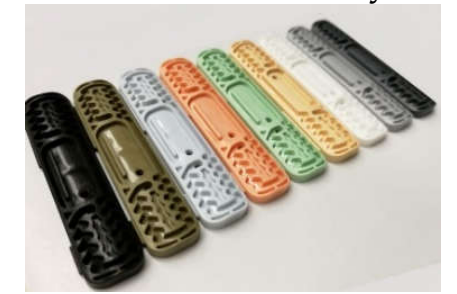

Figura 1. Emisor inyectado con diferentes referencias

Para el ensayo se utilizó la comunidad bacteriana del agua procedente del tratamiento secundario de una EDAR convencional de la Región de Murcia (Roldán - Lo Ferro - Balsicas), que presenta de forma natural una concentración media de microorganismos de $6 \log \mathrm{UFC} / \mathrm{ml}$.

El experimento consistió en poner en contacto y en agitación los diferentes emisores (conteniendo las referencias) con el agua durante un periodo de 6 días. Pasado este tiempo, se transfirieron a un tubo estéril conteniendo $20 \mathrm{~mL}$ de PBS suplementado con tween (0.1\%). A partir de cada solución, se realizaron 5 diluciones en base 10 y $100 \mu \mathrm{L}$ de cada una de ellas fueron sembradas en un medio agar nutritivo (Plate Count Agar, PCA). Las placas de PCA para el recuento fueron incubadas durante $30 \mathrm{~h}$ a $37^{\circ} \mathrm{C}$. Los resultados se expresaron en bacterias totales $\mathrm{UFC} / \mathrm{mL}$ y se evaluaron con respecto a una muestra control. Se realizaron 5 réplicas de cada uno de los ensayos, en total 330 placas.

\subsection{Ensayo en Plataforma}

El ensayo ubicado en la Plataforma de Investigación Agrícola y del Agua, de la Estación Depuradora de Aguas Residuales de ROLDAN, ha tenido como objetivo reproducir, de forma controlada y 
bajo invernadero, las condiciones de uso de agua regenerada en los emisores de un sistema de riego localizado.

Se han empleado diferentes bandejas que, ensambladas a modo de soporte estructural han actuado, como sistema de recuperación de drenajes de 3 líneas de tubería de polietileno con diámetro nominal 16 , y emisor plano integrado autocompensante de caudal nominal $2.21 \cdot \mathrm{h}^{-1}$ distanciados entre ellos 0.30 m (Figura 1)

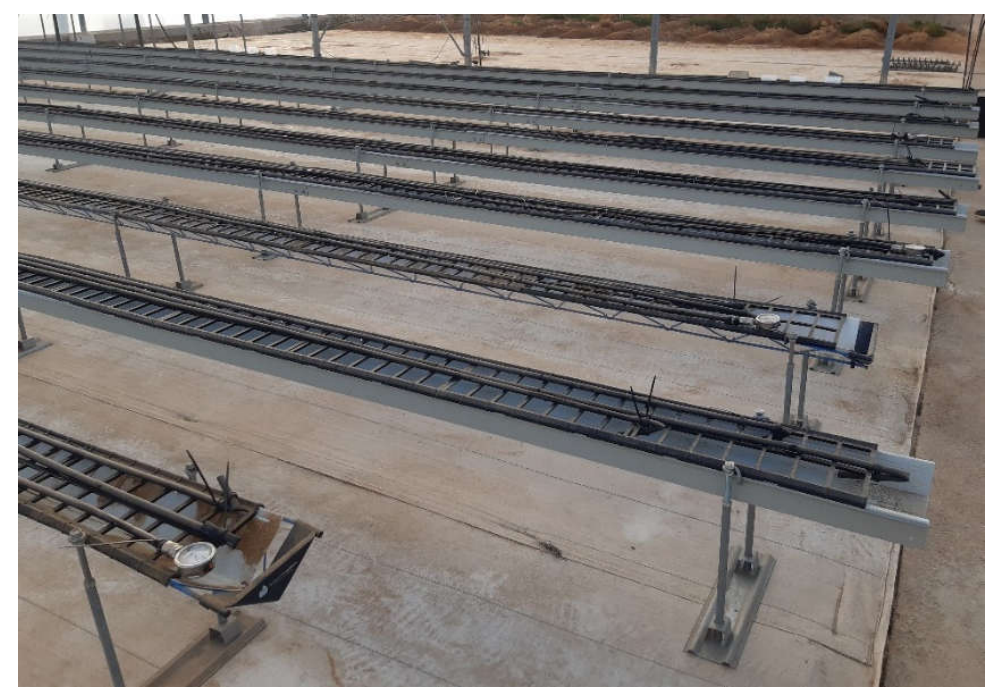

Figura 3. Sistema de riego diseñado en plataforma

La red hidráulica del ensayo se alimenta del tratamiento terciario de la estación depuradora a partir de un sistema almacenamiento de 2000 litros. La calidad del agua durante el ensayo ha sido analizada semanalmente.

En cada evento de riego una bomba de riego impulsa el agua almacenada en el depósito tras ser filtrada con un filtro de discos de limpieza manual de 130 micras a una presión de 2 bar al circuito. Se alimentan dos sectores independientes con 8 filas de bandejas, 24 líneas de tubería y con una distribución inicial de 21 líneas en el sector 1, 3 líneas alimentadas por el sector 2. La presión al final de los laterales se mantiene en 1 bar durante el riego.

Se ha programado una sucesión de riegos diarios durante 90 días, de 1,5 horas por cada evento de riego con el objetivo de alternar periodos de riego con ausencia de los mismos en el mismo día, con 4 al día, simulando las condiciones de trabajo de una explotación agrícola y a su vez someter a un proceso acelerado de las condiciones de uso de la tubería con goteo.

Los caudales de cada uno de los laterales fueron controlados con caudalímetros ultrasónicos de rango de medida de $0.2 \mathrm{l} / \mathrm{min}$ - $25 \mathrm{l} / \mathrm{min}$ con emisión de pulsos de $1 \mathrm{ml} /$ pulso, el registro de los mismos se realizó cada 5 minutos con un datalloger CR1000 (Campbell Sci.) y unidades de expansión digitales SDM-IO16A (Campbell Sci.).

Así mismo, se realizó una evaluación de los caudales instantáneos cada 15 días a partir del volumen de descarga de 6 emisores marcados en cada una de las líneas y distribuidos aleatoriamente a lo largo del ramal emisor. El tiempo de muestreo en cada emisor fue de 6 minutos, según norma ISO 9261.[1] 


\section{Congreso Nacional de Riegos CARTAGENA 2021}

\section{Resultados y discusión}

En el ensayo en laboratorio, tras el recuento en placa, solamente dos referencias (PBM2 y M3) mostraron valores de UFC/mL menores que la muestra control $\left(1.6 \times 10^{4}\right)$, sugiriendo así una ligera minimización de la proliferación microbiana, lo que permitiría, a largo plazo, incrementar el tiempo de uso y la uniformidad de los sistemas de riego conteniendo estas referencias. Por el contrario, las referencias M8 y M9 mostraron valores de UFC/mL muy superiores a la muestra control, por lo que, estas dos referencias podrían tener efectos negativos en cuanto a la uniformidad del riego a corto o largo plazo.

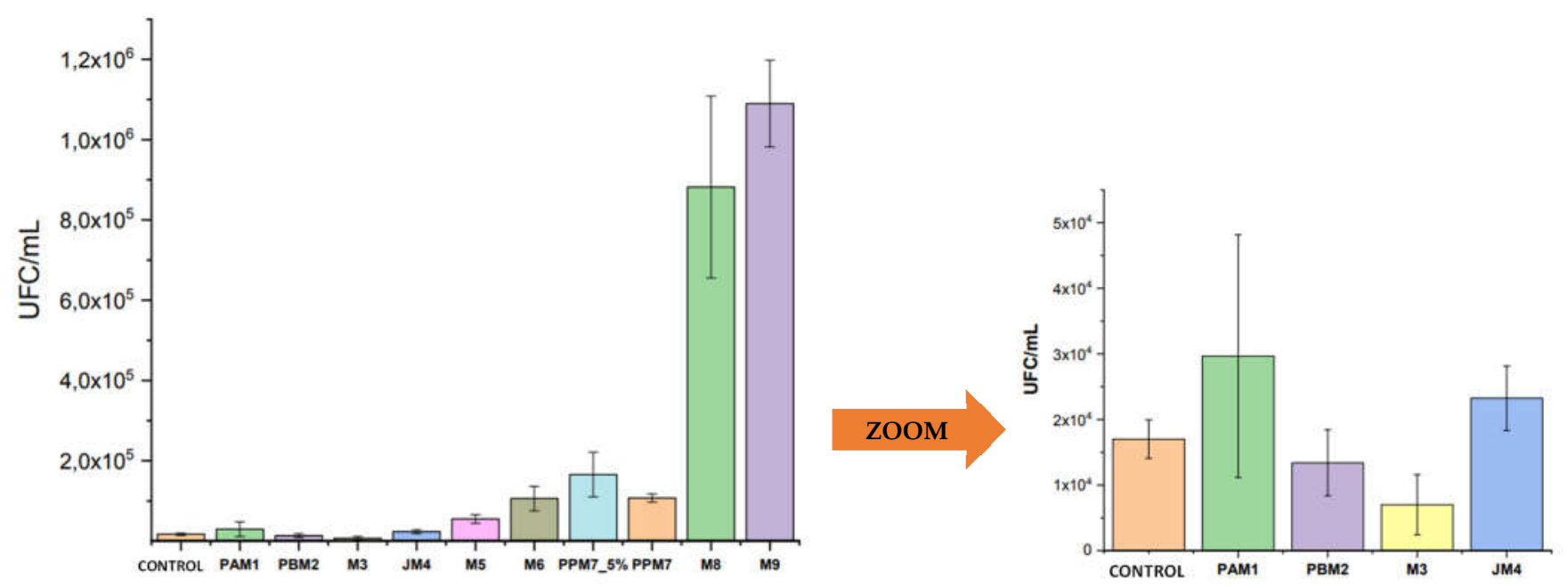

Figura 2. Proliferación microbiana de diferentes referencias

Paralelamente, y durante el periodo en el que estuvo activo el ensayo en la Plataforma de Investigación Agrícola y del Agua de Roldán, se llevó a cabo una medición de los caudales aplicados por cada uno de los 6 emisores marcados de cada una de las 18 líneas, así como el registro en continuo de los caudales totales por línea.

En lo referente a la evolución de los caudales de cada línea en las gráficas se comparó la evolución del caudal medio inicial para cada línea versus la evolución del caudal obtenido a partir del caudalímetro existente para cada línea, tomando como valores límite una variación del 7\% del caudal medio inicial, en relación a la norma ISO 9261.[1]

Como se aprecia en las gráficas una de las referencias de material que mejor se comporta en el test de placa, como M3 (línea 9), también muestra elevada uniformidad y constancia en el caudal en la línea temporal, tanto en las medidas automatizadas como manuales.

\section{Línea 9}

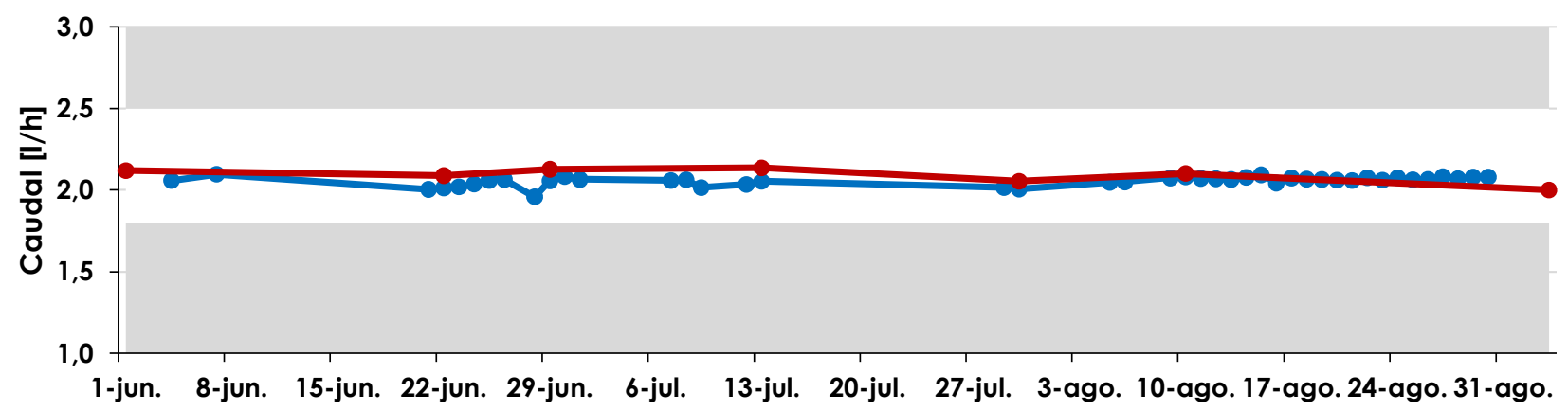




\section{Congreso Nacional de Riegos CARTAGENA 2021}

En lo referente a la evolución de los caudales por emisor en el tiempo, a continuación, se detalla la gráfica de la referencia que peor comportamiento presentó en placa (M8 línea 14), apreciando una importante reducción de caudal en los últimos 20 días en la gráfica en la que se muestra el comportamiento de cada uno de los 6 goteros por línea, al igual que una alteración importante en la evolución del caudal en la línea temporal. En general, se aprecia que el caudal tiende a disminuir en todas las líneas. En ningún caso se han realizado operaciones de mantenimiento de laterales.

Línea 14

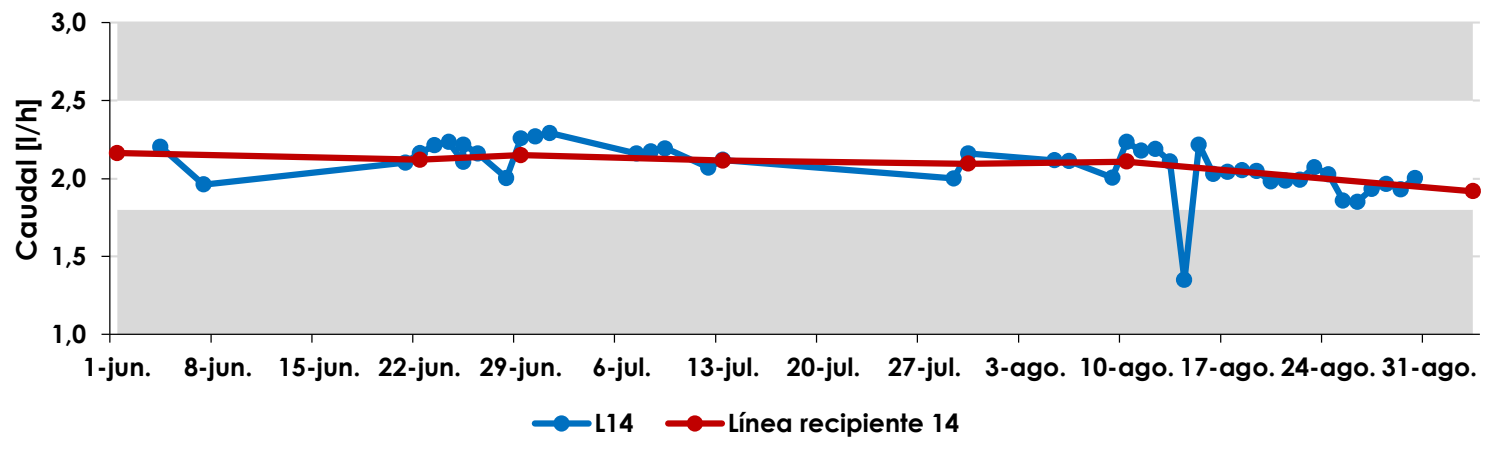

\section{Conclusiones}

El método de riego localizado se ha convertido como una herramienta imprescindible en la reutilización de aguas residuales como muestra el actual Reglamento (UE) 2020/741, sin duda apoyado por la elevada eficiencia en la aplicación y el bajo riesgo de contaminación del producto agrícola y de los operadores de campo. El uso cada vez más frecuente de aguas de alta actividad biológica, como son las aguas procedentes de depuradoras municipales, agudizan los problemas de obstrucción del emisor, lo cual conlleva para el agricultor en muchos casos una importante reducción de la uniformidad en el riego y por ende una disminución de la producción agrícola, reduciendo la eficiencia global del sistema de riego y de los sistemas de reutilización del agua.

Poder determinar unas pautas de manejo que con agua regenerada nos permita anticiparnos a posibles problemas de obstrucción es una vía interesante que sin duda puede formar parte de una herramienta digital, sin embargo, la búsqueda de elementos que, sin incrementar el costo significativamente, presenten una capacidad inhibidora de la actividad microbiana puede ser un paso relevante para la optimización del riego de precisión para lo cual es necesario continuar sometiendo estas referencias a situaciones reales y sobre todo comparativas de comportamiento con los dispositivos de riego localizado.

\section{Agradecimientos}

El trabajo recogido en este artículo forma parte de la de la convocatoria DESAFÍOS en el proyecto OXIDAGUA "Nuevos materiales con propiedades antioxidantes y regeneradoras en sistemas de irrigación dopados para reutilización de agua en agricultura de precisión" con la colaboración financiera del Instituto de Fomento de la Región de Murcia y del Fondo Europeo de Desarrollo Regional (FEDER). (Referencia: 2019.08.DEID.0016).

\section{Referencias}

1. ISO 9261 - Agricultural irrigation equipment - Emitters and emitting pipe - Specification and test methods 


\title{
Utilidad de la termografía para evaluar cambios fisiológicos en árboles de pomelo regados con agua regenerada y riego defici- tario combinado.
}

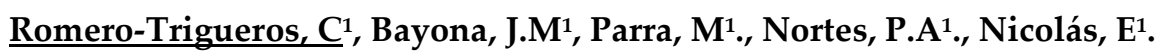

Irrigation Department, Centro de Edafología y Biología Aplicada del Segura, CSIC, P.O. Box 164, 30100, Espinardo (Murcia), Spain. cromero@cebas.csic.es

Resumen: Los cítricos son uno de los cultivos frutales comerciales más importantes a nivel mundial, incluido el sureste de España, donde el clima es semiárido y la escasez de recursos hídricos para la agricultura precisa del uso de estrategias de ahorro de agua, como el riego deficitario regulado (RDC), o fuentes de agua no convencionales, como el agua regenerada (AR). No obstante, la aplicación de estas estrategias requiere un adecuado manejo del riego y una previa caracterización del estado hídrico de la planta mediante herramientas eficaces. En este trabajo se evaluó la utilidad de la termografía para monitorear los cambios diurnos en la fisiología de árboles de pomelo regados con AR salina y/o RDC. Se midieron varios parámetros fisiológicos a nivel de hoja (potencial hídrico del tallo - $\Psi_{\text {tallo }}$-, conductancia estomática $-\mathrm{g}_{\mathrm{s}^{-}} \mathrm{y}$ clorofila total -Chl T-) e índices térmicos (temperatura del dosel -Tc-, diferencia entre la temperatura del dosel y del aire -Tc-Ta-, índice del estrés hídrico del cultivo -CWSI- e índice de conductancia estomática -IG-). En general, los resultados mostraron una significativa correlación entre los datos fisiológicos y térmicos. La Tc y la Tc-Ta se consideraron buenos indicadores para estimar

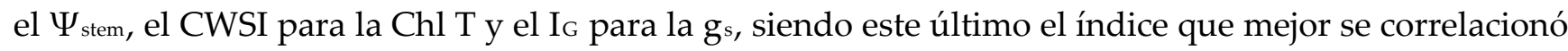
con todos los parámetros fisiológicos (mayor significación en los coeficientes de correlación) y, especialmente, con $\mathrm{g}_{\mathrm{s}}$ al mediodía. Dado que la conductancia estomática se ha definido recientemente como el mejor indicador del estado hídrico del pomelo (isohídrico), aquí nosotros sugerimos que el índice IG, medido mediante termografía, fue el indicador más útil en pomelos regados con AR y RDC.

Palabras clave: Cítricos; clorofila; conductancia estomática; CWSI; potencial hídrico del tallo; temperatura del dosel. 


\title{
XXXVIII Congreso Nacional de Riegos
} CARTAGENA 2021

\section{Thermal imaging to assess physiological changes of grapefruit trees irrigated with reclaimed water combined with deficit irri- gation}

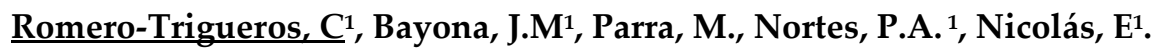

Irrigation Department, Centro de Edafología y Biología Aplicada del Segura, CSIC, P.O. Box 164, 30100, Espinardo (Murcia), Spain. cromero@cebas.csic.es

\begin{abstract}
Citrus is one of the most important commercial fruit crops worldwide, including the southeastern Spain, where climate is semi-arid Mediterranean and water is not always accessible for agriculture. In order to overcome this problematic, the use of water-saving strategies such as regulated deficit irrigation (RDI) or non-conventional water sources such as saline reclaimed water (RW) are alternatives for farmers. Nevertheless, an adequate irrigation management previous characterization of plant water status by means of reliable tools is necessary when applying these strategies. In this work, the usefulness of the thermal imaging (thermography) for monitoring the diurnal changes in the physiology of grapefruit trees irrigated with saline RW and/or RDI was assessed. Discrete physiological indicators (stem water potential $-\Psi_{\text {stem - }}$, stomatal conductance $-\mathrm{g}_{\mathrm{s}^{-}}$and leaf total chlorophyll $-\mathrm{Chl} \mathrm{T}-$ ) and thermal indices (canopy temperature -Tc-, the difference between canopy and air temperature -Tc-Ta-, crop water stress index -CWSI-, and stomatal conductance index -IG-) were measured during a daily evolution. Results, in general, showed excellent relationship between physiological and thermal data. The most suitable thermal indicators were: Tc and Tc-Ta to estimate $\Psi_{\text {stem, }} \mathrm{I}_{\mathrm{G}}$ to $\mathrm{g}_{\mathrm{s}}$, and CWSI to Chl T. Overall, IG was the index that better was related with all the physiological parameters (higher significance in the coefficients of correlation) and, specially, with $\mathrm{gs}_{\mathrm{s}}$ at midday. Since stomatal conductance was recently considered the best indicator of the grapefruit water status (isohydric), we suggest here that the $I_{G}$ index measured by thermography was the more useful thermal indicator of grapefruit trees irrigated with saline RW and RDI.
\end{abstract}

Keywords: Canopy temperature; citrus; chlorophyll; crop water stress index; stem water potential; stomatal conductance. 


\section{Introduction}

Water is essential for agricultural production. However, climate change is influencing the availability of water resources worldwide, reducing renewable surface water and groundwater resources at an alarming rate in most arid and semiarid regions [1] as the south-eastern Spain, where Citrus is one of the most important commercial fruit crops. It is estimated that by 2025, round 2 billion people will be affected by water scarcity [2], with a potential impact on agricultural production. Strategic approaches to the optimization of water management include regulated deficit irrigation (RDI), where water deficits are imposed during the phenological periods when fruit trees are less sensitive to water stress, with little impact on yield [3]. Also, non-conventional water sources, as a component of effective water conservation strategies, are required in agriculture in water-limited regions [4]. In this sense, reused reclaimed water (RW) is considered a non-expensive and reliable alternative source. This water usually contains essential nutrients, beneficial for crop growth and for the growers in economic terms, but also salts and toxic ions which discharge into the wider environment and can accumulate in soil and crops overtime, with negative consequences for soils, plant physiology and yield, and underground water bodies [5]. These impacts of RW have been studied at the plant agro-physiology and ecosystem levels [6-14] for crops such as citrus, almond and olive. Nevertheless, an adequate irrigation management previous characterization of plant water status by means of reliable tools is necessary when applying these two strategies. The selection of this kind of indicators is crucial since a balance must be found between the sensibility of measuring the crop water status and the capability to implement its measurement [15]. Stem water potential $\left(\Psi_{\text {stem }}\right)$ is considered to be the parameter par excellence for the estimation of the crop water status. However, it is a destructive, non-automatable and very time-consuming method, which implies discontinuous measurements. Besides, recently, stomatal conductance has been considered as the best and most accurate physiological indicator of crops with a near isohydric behaviour as is grapefruit irrigated with RW and RDI [14]; though, their measures are also punctual, laborious and time consuming. Other of the most extended variables used in providing insight into crop water status is plant temperature. The leaf temperature is affected by the stomatal aperture, which is influenced by plant and soil water status as well as meteorological conditions, as it acts as a cooling mechanism by controlling the evapotranspiration [14]. The higher the crop water stress, the lower the stomatal aperture in order to prevent the plant from water exhaustion, thus leading to an increase of leaf temperature and, in general, the canopy temperature (Tc), defined as the average T of multiple leaf assemblages aggregated from individual branches up to whole crowns by [16]. Then, the Tc links directly to plant water stress [17]. Other physiological traits, as $\Psi_{\text {stem }}$ or total leaf chlorophyll content (Chl T) also can influence canopy water exchanges. Though these interactions are relatively straightforward to estimate in isolated leaves, they are much more challenging to model and measure at the canopy scale. Critically, many of these properties can vary across non-homogeneous canopies as a function of canopy position, and even within species and individual crowns [18]. Several techniques can be found to measure the Tc. Infrared thermoradiometers (IRT) are widely used and one of the most popular options providing remote measurement and field installation robustness. Nonetheless, the main drawback of IRT is that both emitted and reflected radiation from the different sources covered by the field of view is integrated in the bulk measurement, thus, hampering the determination of Tc exclusively [15]. Alternatively, thermal imaging (thermography) integrate a larger number of leaves for the T measurement and could be, in some cases, more appropriate than methods that rely only in a few leaves from a specific location of the canopy as it happens with the fixed IRT [17]. For this, thermography is being widely applied, including from handheld [19], fixed on site [20] or land vehicle-attached devices 


\section{Congreso Nacional de Riegos CARTAGENA 2021}

[21] to airborne vehicles [22] and satellites [23]. To our knowledge, so far few studies have been published about the usefulness of thermography in citrus under water stress [17], and nothing under saline RW.

Here, in order to evaluate the effects of water and saline stresses on plant physiology and the suitability of different thermal indicators obtained by thermal imaging, hourly changes in the $\Psi_{\text {stem, the }}$ stomatal conductance $\left(\mathrm{g}_{\mathrm{s}}\right)$, the $\mathrm{Chl} \mathrm{T}$, and the Tc, were measured at the end of the RDI period, on DOY 257 at two times: early morning $\left(t_{1}, 08.00\right.$ GMT) and near midday $\left(t_{2}, 11.00\right.$ GMT). Then, different thermal indices (Tc-Ta, the stomatal conductance index -IG- and the crop water stress index -CWSI-) were calculated. Thus, the main aims were: i) assess the effects of irrigation with RW and RDI on plant physiology at two times of the day with different evaporative demand; ii) the suitability of Tc measurement by thermography, iii) the best thermal indicator of the plant water status, and iv) the appropriate moment to take the thermal readings. We hypothesize that the treatment that combines both stresses (RW and RDI) will be the most physiologically affected. The more useful indicator will be the one that best correlates with stomatal conductance, since grapefruit is an isohydric crop.

\section{Materials and methods}

Study area and irrigation treatments. The experiment was conducted at a commercial citrus orchard, located to the Northeast of the Murcia region in Campotéjar, $7 \mathrm{~km}$ north of Molina de Segura $\left(38^{\circ} 07^{\prime} 18^{\prime \prime} \mathrm{N}, 1^{\circ} 13^{\prime} 15^{\prime \prime} \mathrm{W}\right)$. The experimental plot of 0.5 ha was cultivated with adult 'Star Ruby' grapefruit trees (Citrus paradisi Macf) grafted onto Macrophylla rootstock (Citrus macrophylla) planted at 6 $\times 4 \mathrm{~m}$. The irrigation scheduling and experimental design are described in more detail in $[3,9,14]$. All trees received the same amount of fertilizers, which were applied through the drip irrigation system of $215 \mathrm{~kg} \mathrm{~N}, 110 \mathrm{~kg} \mathrm{P}_{2} \mathrm{O}_{5}$ and $150 \mathrm{~kg} \mathrm{~K}_{2} \mathrm{O} \mathrm{ha}^{-1} \cdot$ year $^{-1}$. Weeds were eradicated in the orchard by applying the farmers' commonly used pest control methods. The plot was always irrigated with two water sources. The first irrigation water was pumped from the Tajo-Segura canal (transfer water, TW) and, the second one, from the North of "Molina de Segura" tertiary WWTP (reclaimed water, RW). The latter had high salt and nutrient levels with a high electrical conductivity (EC) close to $4 \mathrm{dS} \cdot \mathrm{m}^{-1}$, while, for the $\mathrm{TW}$, the EC values were close to $1 \mathrm{dS} \cdot \mathrm{m}^{-1}$. Saline water was automatically mixed with water from TW at the irrigation control-head to lower its $\mathrm{EC}$ to $\approx 3 \mathrm{dS} \cdot \mathrm{m}^{-1}$ in order to establish a constant EC during the experiment. Two irrigation treatments were established for each water source: a control (C) in which the crop was irrigated according to water requirements $\left(100 \% \mathrm{ET}_{\mathrm{c}}\right)$, and a regulated deficit irrigation (RDI), applying only $50 \%$ of $E T_{c}$ during the second phase of rapid fruit growth. RDI period began on DOY 185 (4 July) and ended on DOY 260 (17 September). The daily evolution was carry out on DOY 257. The physiological and thermal measurements were carried out twice a day: at 08.00 GMT $\left(\mathrm{t}_{1}\right)$ and at $11.00 \mathrm{GMT}\left(\mathrm{t}_{2}\right)$.

Physiological crop response. Physiological data were measured in order to obtain the plant-truth data. Stomatal conductance $\left(g_{s}\right)$ and stem water potential $\left(\Psi_{\text {stem }}\right)$ were determined on eight fully-expanded leaves from the mid-shoot area of each tree per treatment (two leaves from each replicate). The $g_{s}$ was determined with a portable photosynthesis system (LI-6400 Li-Cor, Lincoln, Nebraska, USA) as described by [7]. The $\Psi_{\text {stem }}$ was determined using a pressure chamber (model 3000, Soil Moisture Equipment Corp., California, USA) as described by [10]. The osmotic water potential at full turgor ( $\left.\Psi_{100 s}\right)$ and leaf chlorophyll determination was carried out as described by [14] and [7], respectively. Osmotic adjustment was calculated by [14].

Thermal response. Average canopy temperatures (Tc) were measured using thermography twice in the course of the day (at $t_{1}$ and $t_{2}$ ) from the sunlit side of the canopy [24] in eight plants per irrigation 


\section{Congreso Nacional de Riegos CARTAGENA 2021}

treatment. One thermal image from the canopy, from each of the eight plants per treatment, was obtained from a constant distance $(\mathrm{d})$ of $0.5 \mathrm{~m}$. The selected plants were the same on which gas exchange was immediately measured. Thermal images were obtained manually with a thermal imager (ThermaCam FLIR-e50 System, Inc., Danderyd, Sweden). Camera features and input used are described by [25]. Where the canopy was imaged, dry and wet reference leaves were used to simulate leaves with fully closed and fully open stomata, respectively [24]. Wet reference leaves were sprayed with water to maintain their moisture level, and dry reference leaves were covered both sides with petroleum jelly. Thermal images were processed with ThermaCam Explorer software (FLIR Quick Report, FLIR Systems, Danderyd, Sweden). Tc for each thermal image was obtained as the average of delimited portions of mature leaves, excluding reference leaves. The temperatures of the reference leaves $\left(\mathrm{T}_{\text {wet }}\right.$ and $\left.\mathrm{T}_{\mathrm{dry}}\right)$ included in the thermal image were obtained as the mean values of each of them (see in [25]). The temperatures of the reference leaves $\left(\mathrm{T}_{\text {wet }}\right.$ and $\mathrm{T}_{\mathrm{dry}}$ ) in conjunction with $\mathrm{Tc}$ were used to obtain thermal indices: the stomatal conductance index $\left(\mathrm{I}_{\mathrm{G}}\right)$ and the crop water stress index (CWSI). The index IG = $\left(\mathrm{T}_{\mathrm{dry}}-\mathrm{Tc}\right) /\left(\mathrm{Tc}-\mathrm{T}_{\mathrm{wet}}\right)$ is theoretically proportional to stomatal conductance of water vapour (Jones et al., 2002). The CWSI $=\left(\mathrm{T}_{\mathrm{dry}}-\mathrm{Tc}\right) /\left(\mathrm{T}_{\mathrm{dry}}-\mathrm{T}_{\text {wet }}\right)[26]$ commonly varies between 0 and 1 . Values close to 0 indicate a fully transpiring leaf/crop (i.e. no stress); whereas values close to 1 indicate a non-transpiring leaf/crop (i.e. maximum stress). The air temperature was obtained from several thermoradiometers placed in the upper part of the tree canopies in the experimental plot.

Statistical analysis and experimental design. A weighted analysis of variance (ANOVA) followed by Tukey's test $(\mathrm{P} \leq 0.05)$ was used for assessing differences among treatments. Linear regressions among the physiological variables and thermal data were calculated. Pearson's correlation coefficients were used to assess the significance of these relationships. These statistical analyses were performed using SPSS (vers. 23.0 for Windows, SPSS Inc., Chicago, IL, USA). The experimental design of each irrigation treatment was 4 replicate distributed following a completely randomized design. Each replicate consisted of 12 trees, organized in 3 adjacent rows. Two trees of the middle rows from each replication were used for measurements and the rest acted as guards and were excluded from the study to eliminate potential border effects.

\section{Results and discussion}

\subsection{Effects of water and saline stress on the water relations and leaf chlorophyll}

Regarding the water relations, both water and saline stress reduced significantly the $\Psi_{\text {stem }}$ and $g_{s}$ respect to the control trees in the two samplings, mainly RW-RDI. This treatment showed the lowest

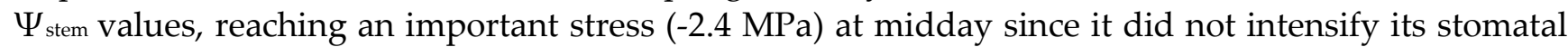
closure; that is, its $\mathrm{g}_{\mathrm{s}}$ was the same in both sampling times. Unlike, TW-RDI had high capacity to close stomata with the increase in evaporative demand at midday that protected it from a drop in $\Psi_{\text {stem }}$ (Table 1). Consequently, the correlations between stomatal conductance and water potential was higher in early morning $\left(\Psi_{\text {stem }}=13.27 \mathrm{~g}_{\mathrm{s}}-2.13, \mathrm{R}=0.71, \mathrm{p}<0.005\right)$ than at midday $\left(\Psi_{\text {stem }}=17.24 \mathrm{~g}_{\mathrm{s}}-2.79, \mathrm{R}=0.68\right.$, $\mathrm{p}<0.01)$. Chlorophyll synthesis was negatively affected by irrigation with RW but not because of RDI (Table 1). Concretely, the $\mathrm{Chl} b$ pigment was reduced to a greater extent than the Chl a pigment (by $39 \%$ the $\mathrm{Chl} \mathrm{a}$, and by $46 \%$ the $\mathrm{Chl} \mathrm{b}$ ), giving rise to a significant increase in the $\mathrm{Chl} \mathrm{a/b}$ coefficient of the RW trees respect to the control (by 13\%) (Table 2). There were no significant correlations between ChlT and $\Psi_{\text {stem }}$ or $g_{s}$. From $t_{1}$ to $t_{2}$, the TW treatments (FI and RDI) significantly decreased the $\Psi_{\text {stem }}$ and the $g_{s}$. The RW trees also reduced the $\Psi_{\text {stem, as expected, although maintained the same stomatal }}$ regulation over time (similar values of $\mathrm{g}_{\mathrm{s}}$ in both samplings) and increased the $\mathrm{Chl} \mathrm{T}$ level at $\mathrm{t}_{2}$ respect to $t_{1}$. 
Table 1. Physiological parameters: stem water potential $\left(\Psi_{\text {stem }}, \mathrm{MPa}\right)$, stomatal conductance $\left(\mathrm{g}_{\mathrm{s}}\right.$, $\left.\mathrm{mol} \cdot \mathrm{m}^{-2} \cdot \mathrm{s}^{-1}\right)$ and total leaf chlorophyll content $\left(\mathrm{Chl} \mathrm{T}, \mathrm{mg} \cdot \mathrm{g}^{-1} \mathrm{FM}\right)$, at $\mathrm{t}_{1}(08.00 \mathrm{GMT})$ and at $\mathrm{t}_{2}(11.00$ GMT) on DOY 257 for each treatment: TW-FI (transfer water-full irrigation), TW-RDI (transfer water-regulated deficit irrigation), RW-FI (reclaimed water-full irrigation) and RW-RDI (reclaimed water-regulated deficit irrigation). Each value is the average \pm SD of eight individual trees. Different letters in the same row indicate significant differences among treatments according to Tukey's test $(p<0.05)$. Asterisk indicates significant differences between time samplings for the same treatment according to repeated measures ANOVA (* $\mathrm{p}<0.05)$.

\begin{tabular}{llllll}
\hline Parameter & Sampling time & TW-FI & TW-RDI & RW-FI & RW-RDI \\
\hline \multirow{2}{*}{$\Psi_{\text {stem }}$} & $\mathbf{t}_{1}$ & $-0.68 \pm 0.02 \mathrm{c}^{*}$ & $-1.06 \pm 0.02 \mathrm{~b}^{*}$ & $-1.01 \pm 0.08 \mathrm{~b}^{*}$ & $-1.85 \pm 0.11 \mathrm{a}^{*}$ \\
\cline { 2 - 6 } & $\mathbf{t}_{2}$ & $-1.20 \pm 0.07 \mathrm{c}$ & $-1.70 \pm 0.07 \mathrm{~b}$ & $-1.66 \pm 0.10 \mathrm{~b}$ & $-2.37 \pm 0.13 \mathrm{a}$ \\
\hline \multirow{2}{*}{$\mathbf{g}_{\mathbf{s}}$} & $\mathbf{t}_{1}$ & $0.11 \pm 0.03 \mathrm{c}^{*}$ & $0.07 \pm 0.02 \mathrm{~b}^{*}$ & $0.06 \pm 0.01 \mathrm{~b}$ & $0.05 \pm 0.01 \mathrm{a}$ \\
\hline \multirow{2}{*}{$\mathbf{C h l T}$} & $\mathbf{t}_{2}$ & $0.08 \pm 0.01 \mathrm{~b}$ & $0.04 \pm 0.01 \mathrm{a}$ & $0.07 \pm 0.01 \mathrm{~b}$ & $0.05 \pm 0.01 \mathrm{a}$ \\
\cline { 2 - 6 } & $\mathbf{t}_{1}$ & $1.97 \pm 0.13 \mathrm{~b}$ & $1.64 \pm 0.25 \mathrm{~b}$ & $0.97 \pm 0.13 \mathrm{a}^{*}$ & $1.11 \pm 0.13 \mathrm{a}^{*}$ \\
\hline
\end{tabular}

Table 2. Chlorophyll a (Chl a), chlorophyll b (Chl b) and coefficient $a / b(C o e f a / b)$ at $t_{1}(08.00$ GMT) and at $t_{2}$ (11.00 GMT) on DOY 257 for each treatment: TW-FI (transfer water-full irrigation), TW-RDI (transfer water-regulated deficit irrigation), RW-FI (reclaimed water-full irrigation) and RW-RDI (reclaimed water-regulated deficit irrigation). Each value is the average \pm SD of eight individual trees. Different letters in the same row indicate significant differences among treatments according to Tukey's test $(\mathrm{p}<0.05)$. Asterisk indicates significant differences between time samplings for the same treatment according to repeated measures ANOVA $\left({ }^{*} \mathrm{p}<0.05\right)$.

\begin{tabular}{llllll}
\hline Parameter & Sampling time & TW-FI & TW-RDI & RW-FI & RW-RDI \\
\hline \multirow{2}{*}{ Chl a } & $\mathbf{t}_{1}$ & $1.50 \pm 0.10 \mathrm{c}$ & $1.24 \pm 0.19 \mathrm{~b}$ & $0.76 \pm 0.11 \mathrm{a}$ & $0.86 \pm 0.10 \mathrm{a}$ \\
& $\mathbf{t}_{2}$ & $1.48 \pm 0.12 \mathrm{c}$ & $1.14 \pm 0.14 \mathrm{~b}$ & $0.89 \pm 0.29 \mathrm{a}$ & $1.11 \pm 0.10 \mathrm{ab}$ \\
\hline \multirow{2}{*}{$\mathrm{Chl} \mathrm{b}$} & $\mathbf{t}_{1}$ & $0.47 \pm 0.04 \mathrm{c}$ & $0.39 \pm 0.06 \mathrm{~b}$ & $0.21 \pm 0.03 \mathrm{a}$ & $0.24 \pm 0.03 \mathrm{a}$ \\
& $\mathbf{t}_{2}$ & $0.47 \pm 0.03 \mathrm{c}$ & $0.35 \pm 0.05 \mathrm{~b}$ & $0.25 \pm 0.08 \mathrm{a}$ & $0.31 \pm 0.04 \mathrm{ab}$ \\
\hline \multirow{2}{*}{ Coef $\mathbf{a} / \mathbf{b}$} & $\mathbf{t}_{1}$ & $3.16 \pm 0.07 \mathrm{a}$ & $3.17 \pm 0.08 \mathrm{a}$ & $3.61 \pm 0.10 \mathrm{~b}$ & $3.53 \pm 0.11 \mathrm{~b}$ \\
& $\mathbf{t}_{2}$ & $3.18 \pm 0.11 \mathrm{a}$ & $3.22 \pm 0.11 \mathrm{a}$ & $3.61 \pm 0.12 \mathrm{~b}$ & $3.57 \pm 0.11 \mathrm{~b}$ \\
\hline
\end{tabular}

A higher content of phytotoxic elements as $\mathrm{Na}^{+}$(by 76.9 and $46.2 \%$ for RW-FI and RW-RDI, respectively) and $\mathrm{Cl}^{-}$(by 33.3 and $12.1 \%$ for RW-FI and RW-RDI, respectively) was found in the RW treatments respect to the control, although there were no significant differences among treatments. A moderate osmotic adjustment $(\mathrm{OA})$ was presented in the RW treatments $(0.20$ and $0.23 \mathrm{MPa}$ for RW-FI and RWRDI, respectively) (Table 3).

Table 3. Leaf osmotic potential at full turgor $\left(\Psi_{100 s}\right)$ at midday, osmotic adjustment (OA) and leaf phytotoxic elements on DOY 257 for each treatment: TW-FI (transfer water-full irrigation), TWRDI (transfer water-regulated deficit irrigation), RW-FI (reclaimed water-full irrigation) and RWRDI (reclaimed water-regulated deficit irrigation). Each value is the average \pm SD of four individual 
trees. Different letters in the same row indicate significant differences among treatments according to Tukey's test $(\mathrm{p}<0.05)$.

\begin{tabular}{|c|c|c|c|c|}
\hline Treatment & $\begin{array}{l}\mathrm{Cl}^{-} \\
(\%)\end{array}$ & $\begin{array}{l}\mathrm{Na}^{+} \\
(\%)\end{array}$ & $\begin{array}{l}\Psi_{100 s} \\
(\mathrm{MPa})\end{array}$ & $\begin{array}{l}\text { OA } \\
\text { (MPa) }\end{array}$ \\
\hline TW-fI & $0.33 \pm 0.08 \mathrm{a}$ & $0.013 \pm 0.001 a$ & $-1.14 \pm 0.06 a$ & - \\
\hline TW-nI & $0.25 \pm 0.05 a$ & $0.016 \pm 0.002 a$ & $-1.08 \pm 0.09 a$ & +0.06 \\
\hline RW-fI & $0.44 \pm 0.05 \mathrm{a}$ & $0.023 \pm 0.005 a$ & $-1.34 \pm 0.11 b$ & -0.20 \\
\hline RW-nI & $0.37 \pm 0.11 \mathrm{a}$ & $0.019 \pm 0.001 a$ & $-1.37 \pm 0.13 b$ & -0.23 \\
\hline
\end{tabular}

Overall, the lowest stem water potential was displayed in the RDI treatments, mainly in the trees which combined both water and saline stresses, followed by the trees full irrigated with RW. This reduction of water potential led to a stomatal closure in all stressed treatments respect to the control, according to RomeroTrigueros et al. (2021b). Leaf chlorophyll content was affected by irrigation with saline RW in both sampling times, according to the results shown in [27] for citrus seedlings and in [7,3] for mandarin and grapefruit, but not by the water stress generated with the RDI. The differences in Chl T between the TW and RW treatments were smaller at midday than at predawn since the trees irrigated with RW increased their values from $t_{1}$ to $t_{2}$ because the increase in the Tc directly affected the accumulation of chlorophyll in leaves, as reported [28] for wheat leaves. Nevertheless, there is a lack of knowledge about the diurnal changes of chlorophyll in the recent literature. When the evaporative demand was higher, at midday, the non-saline treatments (TW trees) regulated stomata to slow the drop in water potential. On the contrary, the saline RW treatments presented a slight osmotic adjustment that maintained the stomatal opening at levels similar to those obtained at predawn. Thus, the light accumulation of salts as $\mathrm{Cl}^{-}$and $\mathrm{Na}^{+}$in the $\mathrm{RW}$ leaf did not cause a specific ion effect affecting the gas exchange, if not an osmotic effect, causing a higher water deficit. These plants performed an osmotic adjustment increasing osmotic potential at full turgor, as mechanisms to adapt to osmotic stress, which maintained the leaf turgor required to keep stomata open and sustain gas exchange $[14 ; 29,30]$. Nevertheless, RW-RDI continued with a $g_{s}$ significantly lower than control, as at predawn.

\subsection{Effects of water and saline stress on the thermal indices at canopy level. Relationships between physio-} logical parameters and thermal indices.

The Tc and the difference between Tc-Ta increased significantly at $t_{2}$ in the RW-FI and mainly in both RDI treatments, respect to the control. RW-RDI reached the highest levels at $t_{2}$. The treatments TW-RDI and RW-FI had similar values of Tc at $t_{2}$; however, when the values of Tc were normalized with air temperature (Ta), the higher significantly values of Tc-Ta were found in RW-FI. Thus, the normalization of Tc by Ta showed more significant differences among treatments than the value of Tc without normalizing. The Tc increased in all trees from $t_{1}$ to $t_{2}$, as expected, and the Tc-Ta values decreased. The CWSI was also significantly higher in the RW-FI and RDI treatments, mainly in RW-RDI at $t_{1}$. The CWSI was generally similar in both sampling times. Respect to the $\mathrm{I}_{\mathrm{G}}$, all treatments decreased it $v s$ control (TW-FI>TW-RDI $>$ RW-FI $>$ RW-RDI). The $I_{G}$ index decreased from $t_{1}$ to $t_{2}$, agreement with $\mathrm{g}_{\mathrm{s}}$ data (Table 4).

Table 4. Thermal indicators: canopy temperature $\left(\mathrm{Tc}^{\circ}{ }^{\circ} \mathrm{C}\right)$, difference between canopy and air temperature $\left(\mathrm{Tc}-\mathrm{Ta},{ }^{\circ} \mathrm{C}\right)$, crop water stress index (CWSI) and stomatal conductance index $\left(\mathrm{I}_{\mathrm{G}}\right)$ at $\mathrm{t}_{1}$ 


\section{Congreso Nacional de Riegos CARTAGENA 2021

(08.0 GMT) and at $t_{2}(11.00$ GMT) on DOY 257 for each treatment: TW-FI (transfer water-full irrigation), TW-RDI (transfer water-regulated deficit irrigation), RW-FI (reclaimed water-full irrigation) and RW-RDI (reclaimed water-regulated deficit irrigation). Tc was collected by thermography. Each value is the average \pm SD of eight individual trees. Different letters in the same row indicate significant differences among treatments according to Tuckey's test $(\mathrm{p}<0.05)$. Asterisk indicates significant differences between time samplings for the same treatment according to repeated measures ANOVA $\left({ }^{*} \mathrm{p}<0.05\right)$.

\begin{tabular}{|c|c|c|c|c|c|}
\hline & & & ermography & & \\
\hline Thermal indicator & $\begin{array}{l}\text { Sampling } \\
\text { time }\end{array}$ & TW-FI & TW-RDI & RW-FI & RW-RDI \\
\hline \multirow{2}{*}{ Tc } & $\mathbf{t}_{1}$ & $31.49 \pm 1.24 \mathrm{a}^{*}$ & $33.00 \pm 1.16 \mathrm{a}^{*}$ & $32.67 \pm 1.33 a^{*}$ & $33.01 \pm 1.01 \mathrm{a}^{*}$ \\
\hline & $t_{2}$ & $33.35 \pm 1.80 \mathrm{a}$ & $35.69 \pm 1.27 \mathrm{~b}$ & $36.35 \pm 1.50 \mathrm{~b}$ & $37.97 \pm 1.45 c$ \\
\hline \multirow{2}{*}{ Tc-Ta } & $t_{1}$ & $9.37 \pm 1.95 a^{*}$ & $10.88 \pm 1.31 a^{*}$ & $10.55 \pm 0.86 a^{*}$ & $10.89 \pm 1.15 a^{*}$ \\
\hline & $t_{2}$ & $0.34 \pm 1.36 \mathrm{a}$ & $2.67 \pm 1.27 \mathrm{~b}$ & $3.31 \pm 1.55 c$ & $5.28 \pm 0.90 \mathrm{~d}$ \\
\hline \multirow{2}{*}{ CWSI } & $\mathbf{t}_{1}$ & $0.51 \pm 0.01 \mathrm{a}$ & $0.61 \pm 0.01 b$ & $0.69 \pm 0.04 b$ & $0.73 \pm 0.03 c^{*}$ \\
\hline & $t_{2}$ & $0.55 \pm 0.04 a$ & $0.61 \pm 0.03 \mathrm{ab}$ & $0.67 \pm 0.02 b$ & $0.66 \pm 0.05 b$ \\
\hline \multirow{2}{*}{$I_{G}$} & $\mathbf{t}_{1}$ & $3.62 \pm 0.02 b^{*}$ & $2.77 \pm 0.02 \mathrm{ab}^{*}$ & $2.67 \pm 0.02 a^{*}$ & $2.28 \pm 0.03 a^{*}$ \\
\hline & $t_{2}$ & $2.43 \pm 0.03 \mathrm{~d}$ & $1.69 \pm 0.03 c$ & $1.61 \pm 0.02 b$ & $1.50 \pm 0.02 \mathrm{a}$ \\
\hline
\end{tabular}

It is important to emphasize also that the CWSI (Table 4) detected the TW-RDI treatment had level of stress similar to that of RW-RDI at $t_{2}$ since it is theoretically a function of the relative transpiration [31]. This was not what the water potential measurements at leaf level reflected (Table 1) because the sensitivity of CWSI was attenuated in grapefruit trees by feedback of stomatal closure [14,32].

Significant correlations between physiological and thermal indicators were found (Table 5). The Tc and Tc-Ta indicators were significantly correlated with $\Psi_{\text {stem, }} \mathrm{g}_{\mathrm{s}}$ and $\mathrm{Chl} \mathrm{T}$ in both sampling times, being the level of significance lower for the $\mathrm{g}_{\mathrm{s}}$ at midday $\left(\mathrm{t}_{2}\right)$ and for the Chl $\mathrm{T}$ at early morning $\left(\mathrm{t}_{1}\right)$. The CWSI significantly correlated with $\Psi_{\text {stem }}$ and Chl $\mathrm{T}$ at both sampling times, and with $\mathrm{g}_{s}$ only at $\mathrm{t}_{1}$. The slopes were negative in all cases. The IG showed better relationship than the CWSI with the $g_{s}$ at $t_{2}$. Besides, its slope was positive. This is, the greater the stomatal opening, the greater the IG. Alike, the IG was also significantly correlated with $\Psi_{\text {stem }}$ and $\mathrm{Chl} \mathrm{T}$ at both sampling times. In general, the results were excellent, except when Tc, Tc-Ta and CWSI were correlated with the $\mathrm{g}_{\mathrm{s}}$ at midday because the average Tc of TW-RDI (35.69 \pm 1.27$)$ (Table 4) was lower than expected based on the $g_{s}$ data. This problem was solved by using the IG index. Therefore, our results were according to the literature which showed that infrared thermal imaging can be used to assess the crop water status under field conditions $[17,33]$.

Table 5. Coefficients of correlation $(R)$ and slope sign for linear regressions found between the thermal indicators: canopy temperature $\left(\mathrm{Tc},{ }^{\circ} \mathrm{C}\right)$, difference between canopy and air temperature $\left(\mathrm{Tc}-\mathrm{Ta},{ }^{\circ} \mathrm{C}\right)$, crop water stress index (CWSI) and stomatal conductance index $\left(\mathrm{I}_{\mathrm{G}}\right)$, with stem water potential $\left(\Psi_{\text {stem, }} \mathrm{MPa}\right)$, stomatal conductance $\left(\mathrm{g}_{\mathrm{s}}, \mathrm{mmol} \cdot \mathrm{m}^{-2} \cdot \mathrm{s}^{-1}\right)$ and total leaf chlorophyll content $\left(\mathrm{Chl} \mathrm{T,} \mathrm{mg} \cdot \mathrm{g}^{-1} \mathrm{FM}\right)$, at $\mathrm{t}_{1}(08.00$ GMT) and at $t_{2}(11.00 \mathrm{GMT})$ of grapefruits trees, regardless of irrigation treatments, on DOY $257 .{ }^{*} \mathrm{p}<0.05$, ${ }^{* *} \mathrm{p}<0.01,{ }^{* * *} \mathrm{p}<0.005$. 


\section{Congreso Nacional de Riegos CARTAGENA 2021}

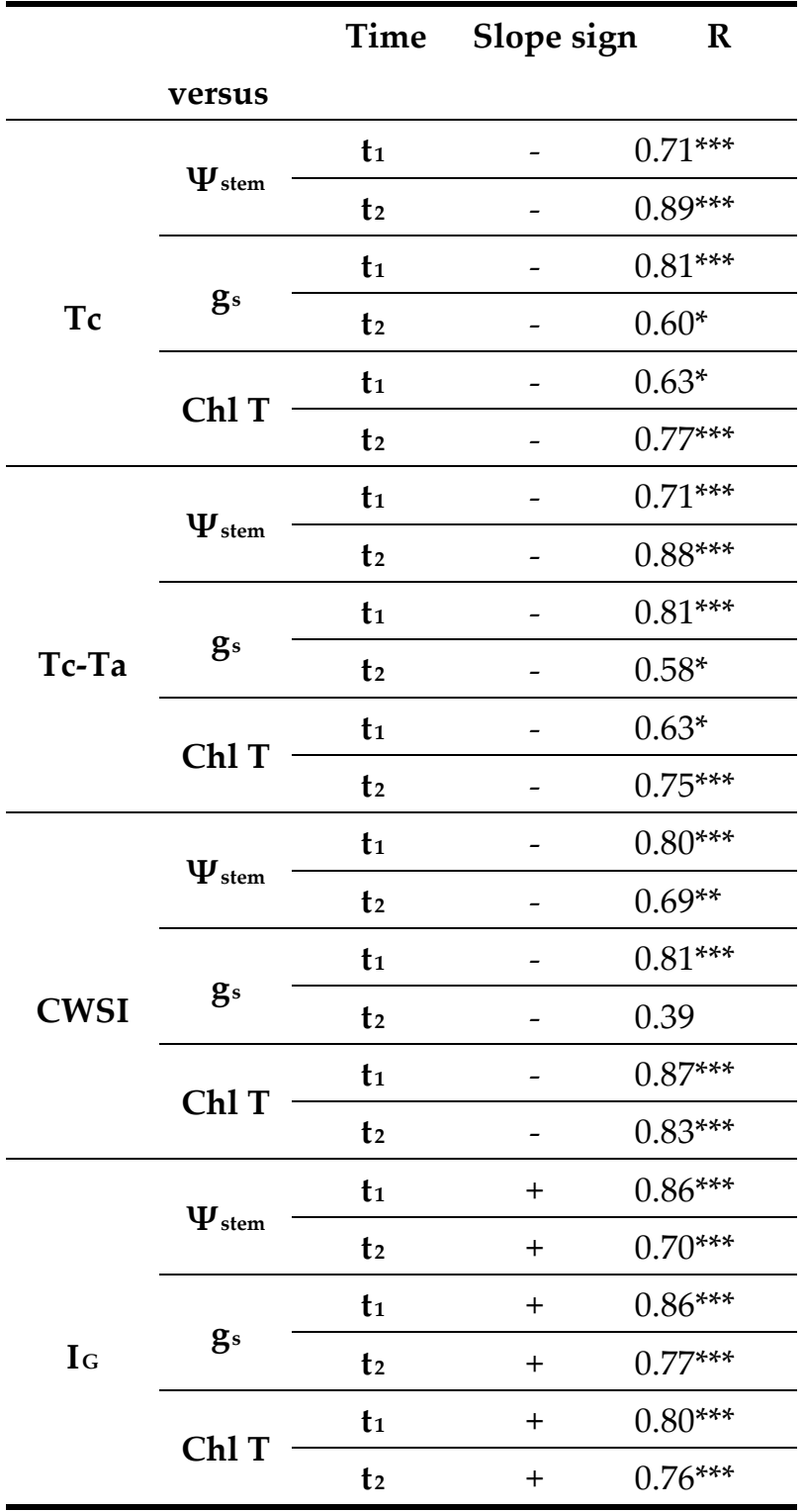

Here, data from thermography determined accurately the Tc of the grapefruits and did it agreement with the measured physiological parameters. In the particular case of the TW-RDI treatment, which important stomatal regulation from $t_{1}$ to $t_{2}(43 \%)$, the Tc values at solar noon were not as high as those of the RW-RDI treatment since this last one had a stomatal closure, of by $55 \%$ respect to the control, maintained over time $\left(t_{1}=t_{2}\right)$ that increased the Tc more than that of TW-RDI. Overall, the most suitable thermal indicators measured by thermography to estimate the diurnal changes in the physiological parameters were: Tc and Tc-Ta for stem water potential, IG for stomatal conductance and CWSI for $\mathrm{Chl} \mathrm{T}$. In addition, the IG was the index that better was related with the physiological parameters (higher significance in the coefficients of correlation) and specially with the $\mathrm{g}_{\mathrm{s}}$ at midday. As cited above, stomatal conductance was recently considered the best indicator of the water status of isohydric citrus [14]. Thus, we suggest here that the IG index measured by thermography was the more useful 
thermal indicator of grapefruits irrigated with saline RW and RDI. Finally, it was remarkable the advantage of thermography since leaf number analyzed by thermal camera was large. Besides, thermal images were taken in the same area where the physiological measurements were made, this is, from the sunlit side of the middle of the canopy, while other methods as thermometry were pointing from above of the trees, avoiding then those areas that could introduce significant noise in the results [25].

\section{Conclusions}

The usefulness of the thermal imaging (thermography) for monitoring the diurnal changes in the physiology of grapefruit trees irrigated with saline reclaimed water (RW) and/or regulated deficit irrigation (RDI) was assessed. Discrete physiological indicators as stem water potential, stomatal conductance and leaf total chlorophyll, and thermal indices (Tc, Tc-Ta, CWSI, and IG) were measured during a daily evolution. Results showed good relationships between all physiological and thermal data. Since stomatal conductance was defined the better indicator of the water status in isohydric citrus, it is suggested that the IG index is the more useful thermal indicator of the water status of grapefruits, making the thermography a promising tool for irrigation water management under these conditions of irrigation with saline RW and RDI. However, a manual segmentation for the extraction of the region of interest is required, which makes them unsuitable for continuous and autonomous measurement [34]. Future research should be directed to the design and validation of thermal image-based sensory platforms with automatic image processing.

\section{Referencias}

1. Zhao, H.R.; Qu, S.; Guo, S.; Liang, S.; Xu, M. Virtual water scarcity risk to global trade under climate change. J. Clean. Prod. 2019, 230, 1013-1026. https://doi.org/10.1016/j. jclepro.2019.05.114

2. Riemenschneider, C.; Al-Raggad, M.; Moeder, M.; Seiwert, B.; Salameh, E.; Reemtsma, T. Pharmaceuticals, their metabolites, and other polar pollutants in field-grown vegetables irrigated with treated municipal wastewater. J. Agric. Food Chem. 2016, 64 (29), 5784-5792. https://doi.org/10.1021/acs.jafc.6b01696

3. Romero-Trigueros, C.; Nortes, P.; Alarcón, J.J.; Hunink, J.E.; Parra, M.; Contreras, S.; Droogers, P.; Nicolás, E. Effects of saline reclaimed waters and deficit irrigation on Citrus physiology assessed by UAV remote sensing. Agric. Water Manag. 2017, 183, 60-69. https://doi.org/10.1016/j.agwat.2016.09.014.

4. Hristov, J.; Jesus Barreiro-Hurle, Guna Salputra, Maria Blanco, Peter Witzke, Reuse of treated water in European agriculture: Potential to address water scarcity under climate change, Agric. Water Manag. 2021, Volume 251, 106872, ISSN 0378-3774, https://doi.org/10.1016/j.agwat.2021.106872.

5. Nicolás, E.; Romero-Trigueros, C.; Nortes, P.A.; Pedrero, F.; Bayona, J.M.; Maestre-Valero, J.F.; Alarcón, J.J. Chapter 7: long-term physiological and agronomic responses of citrus irrigated with saline reclaimed water. Water Scarcity and Sustainable Agriculture in Semiarid Environment 2018 https://doi.org/10.1016/B978-0-12-813164- 0.00007-7 ISBN 978-012-813164-0.

6. Nicolás, E.; Alarcón, J.J.; Mounzer, O.; Pedrero, F.; Nortes, P.A.; Alcobendas, R.; Romero-Trigueros, C.; Bayona, J.M.; Maestre-Valero, J.F. Long-term physiological and agronomic responses of mandarin trees to irrigation with saline reclaimed water. Agric. Water Manag. 2016, 166, 1-8. https://doi.org/10.1016/j.agwat.2015.11.017.

7. Romero-Trigueros, C.; Nortes, P.A.; Pedrero, F.; Mounzer, M.; Alarcón, J.J.; Bayona, J.M.; Nicolás, E. Assessment of the viability of using saline reclaimed water in grapefruit in medium to long term. Span. J. Agric. Res. 2014a, 12 (4), $1137-$ 1148. https:// doi.org/10.1016/j.agwat.2016.09.014.

8. Romero-Trigueros, C.; Nortes, P.A., Alarcón, J.J., Nicolás, E. Determination of $15 \mathrm{~N}$ stable isotope natural abundances for assessing the use of saline reclaimed water in grapefruit. Environ. Eng. Manag. J. 2014b, 13, 2525-2530. https://doi.org/10.30638/eemj.2014.282.

9. Romero-Trigueros, C.; Parra, M.; Bayona, J.M.; Nortes, P.; Alarcón, J.J.; Nicolás, E. Effect of deficit irrigation and reclaimed water on yield and quality of grapefruits at harvest and postharvest. LWT Food Sci. Technol. 2017b, 85, 405-411. https://doi.org/10.1016/j. lwt.2017.05.001 


\section{Congreso Nacional de Riegos CARTAGENA 2021}

10. Romero-Trigueros, C.; Bayona, J.M.; Nortes, P.; Alarcón, J.J.; Nicolás, E. Determination of crop water stress index by thermometry in grapefruit trees irrigated with saline reclaimed water combined with deficit irrigation. Remote Sens. 2019a, 11 (7), 757. https://doi.org/10.3390/rs11070757.

11. Romero-Trigueros, C.; Vivaldi, G.A.; Nicolás, E.; Paduano, A.; Pedrero, F.; Camposeo, S. Ripening indices, olive yield and oil quality in response to irrigation with saline reclaimed water and deficit strategies. Front. Plant Sci. 2019b, 10, 1243. https://doi.org/ 10.3389/fpls.2019.01243.

12. Romero-Trigueros, C.; Alarcón, J.J.; Nortes, P.A.; Bayona, J.M.; Maestre-Valero, J.; Nicolás, E. Mid-long term effects of saline reclaimed water irrigation and regulated deficit irrigation on fruit quality of citrus. J. Sci. Food Agric. 2020, 100 (3), 1350-1357. doi: 10.1002/jsfa.10091.

13. Romero-Trigueros, C.; Díaz-López, M.; Vivaldi, G.A.; Camposeo, S.; Nicolás, E.; Bastida, F. Plant and soil microbial community responses to different water management strategies in an almond crop. Science of the Total Environment 2021a, 778 , art. no. 146148.

14. Romero-Trigueros, C.; Bayona, J.M.; Nortes, P.A, Alarcón, J.J.; Nicolás, E. Isohydric or anisohydric responses of two different Citrus under deficit irrigation and reclaimed water. Plant. 2021b. Accepted.

15. Giménez-Gallego, J.; González-Teruel, J.D.; Soto-Valles, F.; Jiménez-Buendía, M.; Navarro-Hellín, H.; Torres-Sánchez, R.; Intelligent thermal image-based sensor for affordable measurement of crop canopy temperature, Computers and Electronics in Agriculture, 2021, 188, 106319, ISSN 0168-1699, https://doi.org/10.1016/j.compag.2021.106319

16. Still, C.J.; Rastogi, B.; Gerald F.M.; Griffith, D.M.; Sibley, A.; et al. Imaging canopy temperature: shedding(thermal) light on ecosystem processes. New Phytologist 2021, 230, 1746-1753. doi: 10.1111/nph.17321

17. Ballester, C.; Jimenez-Bello, M.A.; Castel, J.R.; Intrigliolo, D.S. Usefulness of thermography for plant water stress detection in citrus and persimmon trees. Agric. Forest Meteorol. 2013, 168, 120-129

18. Yi, K.; Smith, J.; Jablonski, A.; Tatham, E.; Scanlon, T.; Lerdau, M.; Novick, K.; Yang, X. High heterogeneity in canopy temperature among co-occurring tree species in a temperate forest. J. Geophys. Res. Biogeosci. 2020, 125, e2020JG005892.

19. Blaya-Ros, P.J.; Blanco, V.; Domingo, R.; Soto-Valles, F.; Torres-Sanchez, R. Feasibility of low-cost thermal imaging for monitoring water stress in young and mature sweet cherry trees. Appl. Sci. 2020, 10 https://doi.org/10.3390/APP10165461.

20. Yang, W.; Wang, X.; Wheaton, A.; Cooley, N.; Moran, B. Automatic optical and IR image fusion for plant water stress analysis. In: 12th International Conference on Information Fusion. 2020, IEEE, Seattle, WA, USA, July 6-9, pp. $1053-1059$.

21. Osroosh, Y.; Khot, L.R.; Peters, R.T. Economical thermal-RGB imaging system for monitoring agricultural crops. Comput. Electron. Agric. 2018, 147, 34-43. https://doi.org/ 10.1016/j.compag.2018.02.018.

22. Blanco, V.; Blaya-Ros, P.J.; Castillo, C.; Soto-Vallés, F.; Torres-Sánchez, R.; Domingo, R. Potential of UAS-based remote sensing for estimating tree water status and yield in sweet cherry trees. Remote Sens. 2020, 12 https://doi.org/10.3390/RS12152359.

23. Zhang, L.; Zhang, Z.; Luo, Y.; Cao, J.; Tao, F. Combining optical, fluorescence, thermal satellite, and environmental data to predict county-level maize yield in China using machine learning approaches. Remote Sens. 2020, $12 \mathrm{https} / / \mathrm{doi} . \mathrm{org} /$ 10.3390/RS12010021.

24. Jones, H. G.; Stoll, M.; Santos, T.; de Sousa, C.; Chaves, M. M.; Grant, O. M. Use of infrared thermography for monitoring stomatal closure in the field: application to grapevine. J.Experiment. Bot. 2002, 53, 2249-2260.

25. Gomez-Bellot, M.P.; Nortes, P.A.; Sanchez-Blanco, M.J.; Ortuno, M.F. Sensitivity of thermal imaging and infrared thermometry to detect water status changes in Euonymus japonica plants irrigated with saline reclaimed water. Biosys. Engine. 2015, 133, 21-32. DOI10.1016/j.biosystemseng.2015.02.014

26. Idso, S.B. Non-water-stressed baselines: a key to measuring and interpreting plant water stress. Agric. Meteorol. 1982, 27, 59-70

27. Alam, A.; Ullah, H.; Attia, A.; Datta, A. Effects of Salinity Stress on Growth, Mineral Nutrient Accumulation and Biochemical Parameters of Seedlings of Three Citrus Rootstocks. Int. J. Fruit Sci. 2020, 20(4), 786-804. DOI 10.1080/15538362.2019.1674762

28. Friend, D.J. Control of chlorophyll accumulation in leaves of Marquis Wheat by temperature and light intensity.2. Chlorophyll contents relative to leaf area and thickness. Physiol. Plantarium 1961, 14, 28. DOI10.1111/j.13993054.1961.tb08134.x

29. Vivaldi, G.A.; Camposeo, S.; Lopriore, L.; Romero-Trigueros, C.; Pedrero, F. Using saline reclaimed water on almond grown in Mediterranean conditions: deficit irrigation strategies and salinity effects. Water Sci. Tech. Water Supply 2019, 19 (5), 1413-1421. https://doi.org/10.2166/ws.2019.008.

30. Vivaldi, G.A; Camposeo, S.; Romero-Trigueros, C.; Pedrero, F.; Caponio, G.; Lopriore, G., Álvarez, S. Physiological responses of almond trees under regulated deficit irrigation using saline and desalinated reclaimed water, Agric. Water Manag. 2021, 258, 107172, https://doi.org/10.1016/j.agwat.2021.107172. 


\section{Congreso Nacional de Riegos CARTAGENA 2021

31. Jackson, R.D.; Idso, S.B.; Reginato, R.J.; Pinter, P.J.; Water Resour. Res. 1981, 17(4), $1133-1138$. DOI10.1029/WR017i004p01133

32. Fereres, E.; Goldhamer, D.A. Deciduous fruit and nut trees. In: Irrigation of agricultural crops (Stewart BA \& Nielsen DR, Eds.). 1990, Am Soc Agron, Madison, WI, USA. Monograph 30, pp: 987-1017.

33. Garcia-Tejero, I.F.; Costa, J.M.; Egipto, R.; Duran-Zuazo, V.H.; Lima, R.S.N.; Lopes, C.M.; Chaves, M.M. Thermal data to monitor crop-water status in irrigated Mediterranean viticulture Agric. Water Manag. 2016, 176, 80-90 DOI10.1016/j.agwat.2016.05.008

García-Tejero, I.F.; Ortega-Arevalo, C.J.; Iglesias-Contreras, M.; Moreno, J.M.; Souza, L.; Tavira, S.C.; Duran-Zuazo, V.H. Assessing the crop-water status in almond (Prunus dulcis mill.) trees via thermal imaging camera connected to smartphone. Sensors (Switzerland) 2018, 18, 1-13. https://doi.org/10.3390/s18041050. 


\section{GRUPO TEMAS B:}

\section{Ingeniería y gestión de regadíos}

Ingeniería y Modernización del Riego: Equipos, materiales, instrumentación, etc. Métodos de riego y respuesta de los cultivos. Explotación, mantenimiento, modernización y rehabilitación de los sistemas de riego y drenaje. Ahorro de agua, energía y otros insumos. Reducción de costes de explotación. Programación de la red de riego. Modelos matemáticos. Utilización de fuentes alternativas de energía en riegos a presión. Proyectos de ingeniería de riego, experiencias y enseñanzas adquiridas de su ejecución. Aplicación práctica de técnicas experimentadas.

Gestión, Legislación, Economía del Riego y Otros: Formación del regante. Asesoría del riego. Aspectos sociales e institucionales, economía del regadío, legislación del agua y derechos de uso. Mercados del agua. Huella hídrica y agua virtual. Comunidades de usuarios y gestión integral de los recursos. Métodos de cálculo y repercusión sostenible del coste de los servicios de agua de riego, tarifas. Influencia del regadío en el ciclo del agua y la planificación hidrológica. Conservación de los recursos superficiales y subterráneos. Agricultura de regadío sostenible. Competitividad y mercados agrarios. 


\title{
Límite de la zona saturada bajo riego por goteo superficial. Mo- delo analítico y empírico.
}

\author{
del Vigo, Á(1). Zubelzu, S.(2), Juana, L. ${ }^{(3)}$.
}

1 Profesor Asociado. Universidad Antonio de Nebrija. Dpto. Ing. Industrial. C/Pirineos 55. 28040 (Madrid). avigo@nebrija.es

2 Profesor Contratado Doctor. ETSI Agronómica, Alimentaria y de Biosistemas de la U. P. de Madrid. Av. Puerta de Hierro 2. 28040 (Madrid). sergio.zubelzu@upm.es

3 Catedrático de Universidad. ETSI Agronómica, Alimentaria y de Biosistemas de la U. P. de Madrid. Av. Puerta de Hierro 2. 28040 (Madrid). luis.juana@upm.es

Resumen: Se ha desarrollado un modelo numérico capaz de calcular la evolución de la zona saturada en superficie bajo condiciones de riego por goteo superficial. Las pruebas realizadas concluyen que el modelo es robusto y eficiente con independencia de las características del suelo. Por otro lado, se ha derivado un modelo analítico simplificado que relaciona el radio de la zona saturada con el caudal aplicado, en base a cuatro parámetros del suelo que son la conductividad hidráulica en saturación, la tensión en el frente y los contenidos de humedad inicial y en saturación del suelo. Además, a partir de simulaciones realizadas con el modelo numérico para suelos del tipo Gardner, Clapp y Hornberger y Van Genuchten-Mualem, se ha obtenido un conjunto de ecuaciones empíricas que relacionan el radio máximo de la zona saturada con el caudal y los parámetros del suelo en cada uno de estos tres esquemas de caracterización. El buen ajuste de estas ecuaciones empíricas con el modelo analítico simplificado justifica su validez. La estimación del radio saturado en superficie junto con el volumen aplicado y la diferencia de contenido de humedad inicial y en saturación del suelo, permite estimar las dimensiones horizontales y verticales del bulbo, lo que es de interés para los proyectos de riego por goteo.

Este trabajo presenta las ecuaciones empíricas obtenidas para el radio máximo de la zona saturada en función del caudal y el tipo de suelo, así como su comparación con el modelo analítico simplificado.

Palabras clave: riego por goteo; tamaño del bulbo; modelo analítico; simulación; ecuaciones empíricas. 


\title{
XXXVIII Congreso Nacional de Riegos CARTAGENA 2021
}

\section{Limit of the saturated zone under surface drip irrigation. Analytical and empirical model}

\author{
del Vigo, Á(1)., Zubelzu, S.(2), Juana, L. ${ }^{(3)}$.
}

1 Profesor Asociado. Universidad Antonio de Nebrija. Dpto. Ing. Industrial. C/Pirineos 55. 28040 (Madrid). avigo@nebrija.es

2 Profesor Contratado Doctor. ETSI Agronómica, Alimentaria y de Biosistemas de la U. P. de Madrid. Av. Puerta de Hierro 2. 28040 (Madrid). sergio.zubelzu@upm.es

3 Catedrático de Universidad. ETSI Agronómica, Alimentaria y de Biosistemas de la U. P. de Madrid. Av. Puerta de Hierro 2. 28040 (Madrid). luis.juana@upm.es

Abstract: A numerical model for the analysis of soil water flow has been developed. Among others, the model is able to predict the evolution of the saturated area on the surface, under superficial drip irrigation. The tests carried out conclude that the model is robust and efficient regardless of the characteristics of the soil. On the other hand, a simplified analytical model has been derived that relates the radius of the saturated zone with the applied flow, based on four parameters of the soil, initial and the saturated soil water contents, the saturated hydraulic conductivity and the wetting front suction head. In addition, the simulations performed for soils of three different type (Gardner, Clapp and Hornberger and Van GenuchtenMualem) achieved a set of empirical equations that relate the maximum radius of the saturated zone with the applied rate flow and the soil parameters for each characterization schemes. The good agreement between these empirical equations and simplified analytical model justifies their validity. The estimation of the maximum saturated radius on the surface as a function of the applied rate flow and soil parameters is of interest for drip irrigation projects.

In this work are presented the empirical equations obtained for the maximum radius of the saturated area under the emitter and their comparison with the simplified analytical model.

Keywords: drip irrigation; bulb size; analytical model; simulation; empirical equations. 


\section{Congreso Nacional de Riegos CARTAGENA 2021}

\section{Introducción}

Los modelos empíricos son de utilidad cuando no existen datos suficientes sobre la naturaleza del suelo como para utilizar modelos analíticos o numéricos de base física, o bien, cuando se requiere una alternativa de sencilla utilización y poca complejidad matemática. La mayor parte de los modelos empíricos existentes relacionan el tamaño del bulbo (radio y profundidad) con el caudal aplicado y el tiempo, teniendo en cuenta algún parámetro del suelo de sencilla obtención experimental como la conductividad hidráulica en saturación, o los contenidos de humedad inicial y en saturación del suelo. En este sentido, algunos modelos de intereses son los modelos empíricos de Schwartzman y Zur [1], Amin y Ekhmaj [2], y otros como por ejemplo [3-6]. La mayor parte de estos modelos están inferidos de observaciones experimentales propias o recogidas de otros autores, y relacionan el radio del frente de avance con el tiempo (o volumen infiltrado).

El radio del frente de avance en superficie que predicen estos modelos es creciente con el tiempo (o volumen aplicado), lo que es una buena aproximación si el tiempo de riego no es muy elevado. Sin embargo, el radio tiende a estabilizarse a un valor constante cuando el tiempo de riego es muy grande o tiende a infinito (régimen estacionario) debido al aumento del área de infiltración, siempre que el caudal permanezca constante. En este contexto, el físico neozelandés R. A. Wooding estableció un modelo analítico a partir de la ecuación de Richards [7] cuya solución en forma de serie infinita tiende a una sencilla expresión de tan solo dos términos que relaciona el tamaño del charco límite (radio máximo, $\boldsymbol{R}_{\mathbf{0}}$ ) con el caudal aplicado $(\boldsymbol{q})$ para condiciones de régimen estacionario:

$$
q=\frac{4 k_{s}}{\alpha} R_{0}+\pi k_{s} R_{0}^{2}
$$

Donde $\boldsymbol{k}_{\boldsymbol{s}}[\mathrm{cm} / \mathrm{min}]$ es la conductividad hidráulica en saturación del suelo y $\boldsymbol{\alpha}\left[\mathrm{cm}^{-1}\right]$ es un parámetro del suelo conocido como constante de capilaridad macroscópica. El primer término de esta ecuación representa el potencial capilar de la propia succión del medio. El segundo término está relacionado con el potencial gravitatorio bajo la fuente. Notar que cuanto más grande es el radio del disco mayor es el efecto gravitatorio frente al de succión.

La limitación del modelo de Wooding se encuentra en que se asume una expresión exponencial para la conductividad hidráulica frente al contenido de humedad asociada al parámetro $\boldsymbol{\alpha}$, conocida como función del tipo Gardner [8], que permite derivar de forma analítica la ecuación (1), pero que no se ajusta a la realidad de la mayor parte de los suelos. Por otro lado, algunos autores como Pullan y Collins [9], Weir [10] o Warrick [11], han reportado un pobre ajuste del modelo de Wooding con respecto a soluciones numéricas propias para casos en los que el radio en régimen estacionario es pequeño.

En este artículo se presenta un grupo de ecuaciones empíricas que relacionan el radio límite de la zona saturada en superficie bajo riego por goteo con el caudal aplicado, la conductividad hidráulica en saturación y la diferencia entre el contenido de humedad inicial y en saturación del suelo. Estas expresiones empíricas se han inferido a partir de resultados de simulación obtenidos con un modelo numérico de elaboración propia [12-15] para suelos caracterizados con funciones del tipo Gardner [8], Clapp y Hornberger [16] y van Genuchten-Mualem [17]. Adicionalmente, se ha derivado desde la ecuación de Darcy y asumiendo hipótesis del tipo Green-Ampt un modelo analítico simplificado [18-19] que describe el caudal infiltrado desde una fuente circular y en superficie de radio constante. 


\section{Materiales y métodos}

\subsection{Modelo de simulación.}

Se ha desarrollado un código en MATLAB [15] que permite estudiar la filtración de agua a través de la ecuación de Richards. El código ha sido ampliamente validado [12,15] por comparación con soluciones analíticas conocidas, otros modelos numéricos como [20] y ensayos experimentales. Por razones de simetría, se utiliza un sistema de coordenadas cilíndricas para la resolución numérica de las ecuaciones, lo que permite reducir el número de variables espaciales y, por tanto, el tiempo de computación. La ecuación de Richards en 3-D, se resuelve en términos del potencial matricial, para cualquier función definida para la conductividad hidráulica $K(\theta)$ [cm/min]; principalmente se han utilizado los modelos de Gardner [8], Clapp y Hornberger [16] y van Genuchten-Mualem [17] para representar esta función. El modelo de simulación utiliza un esquema basado en la técnica de las diferencias finitas para integrar la ecuación de Richards en función del tiempo. Todos los detalles del modelo cómo son su esquema de discretización, el criterio de estabilidad, su validación y otras características pueden encontrarse en la bibliografía [12-15].

\subsection{Modelo analítico simplificado.}

Se ha desarrollado un modelo analítico en tres dimensiones a partir de la ecuación de Darcy y considerando hipótesis del tipo Green-Ampt que describe el volumen y caudal infiltrado desde un emisor superficial semiesférico de radio constante $\left(R_{0}\right)$. A través de argumentos de base física el modelo se ha extendido para el estudio del volumen y caudal infiltrado desde un disco saturado en superficie de radio constante. Se puede consultar todo el desarrollo, las condiciones de contorno y las hipótesis asumidas en la bibliografía [18-19]. El modelo ha sido validado por comparación con resultados de simulación obtenidos con el modelo numérico mencionado en el apartado anterior.

Como resultado del modelo analítico se ha derivado la siguiente ecuación que describe el caudal infiltrado desde el disco $(q)$ cuando el tiempo tiende a infinito, es decir, en régimen estacionario:

$$
\lim _{t \rightarrow \infty} q(t)=\sqrt{2} \pi R_{0}^{2} k_{s} \frac{\tau_{f}}{R_{0}}\left(1+\frac{2 \Delta \theta R_{0}}{\tau_{f}}\right)
$$

Donde $R_{0}$ es el radio del disco [cm] y el resto son parámetros del suelo, siendo $k_{s}[\mathrm{~cm} / \mathrm{min}$ ] la conductividad hidráulica en saturación, $\tau_{f}[\mathrm{~cm}]$ la tensión en el frente de avance y $\Delta \theta=\theta_{s}-\theta_{0}$ es la diferencia entre el contenido de humedad inicial y de saturación del suelo. Se puede expresar la anterior ecuación en magnitudes adimensionales utilizando las siguientes escalas:

$$
c_{g}=1+\frac{2 \Delta \theta R_{0}}{\tau_{f}} ; \quad V_{\text {ref }}=\frac{\sqrt{2}}{3 c_{g}} \pi \Delta \theta R_{0}^{3} ; \quad q_{\text {ref }}=\sqrt{2} \pi R_{0} \tau_{f} k_{s} \cdot c_{g} ; \quad t_{\text {ref }}=\frac{V_{\text {ref }}}{q_{\text {ref }}}
$$




$$
\lim _{t \rightarrow \infty} q^{*}=1
$$

\section{Resultados y discusión}

\subsection{Resultados de simulación y ecuaciones empíricas.}

La Figura 1 representa los resultados obtenidos de las simulaciones realizadas para suelos caracterizados respecto a las funciones de Gardner, Clapp y Hornberger y van Genuchten-Mualem al alcanzar el régimen estacionario para tres regímenes de caudal aplicado distintos $q=2,4,8 L / h$. Se representan los resultados obtenidos para el radio máximo de la zona saturada en superficie $\left(R_{0}\right)$ frente al coeficiente $\sqrt{q / \Delta \theta k_{s}}[\mathrm{~cm}]$, para cada uno de los tres catálogos mencionados:

(a)

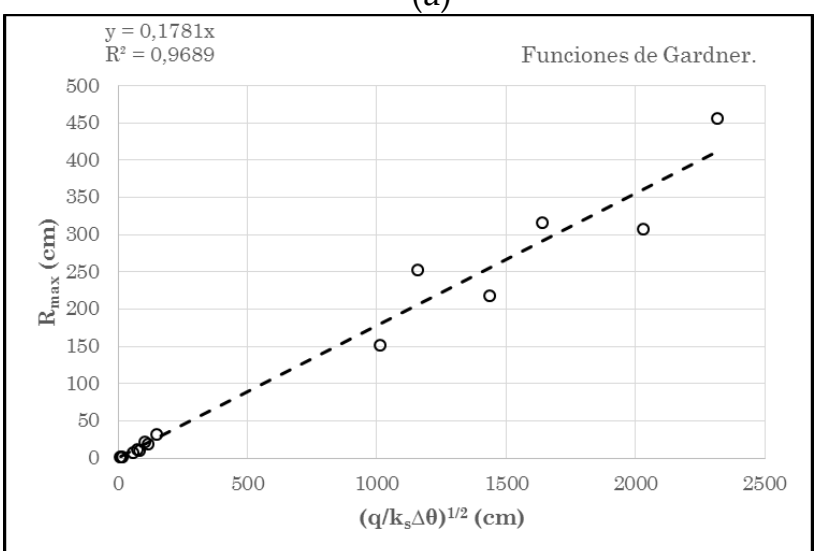

(b)

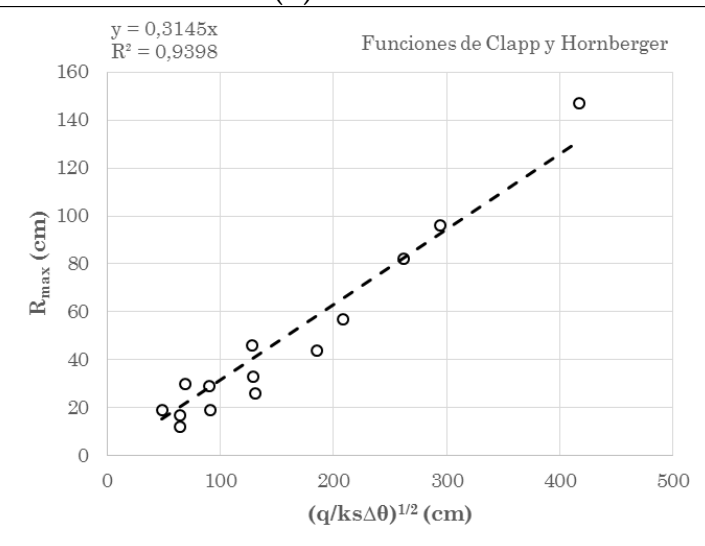

(c)

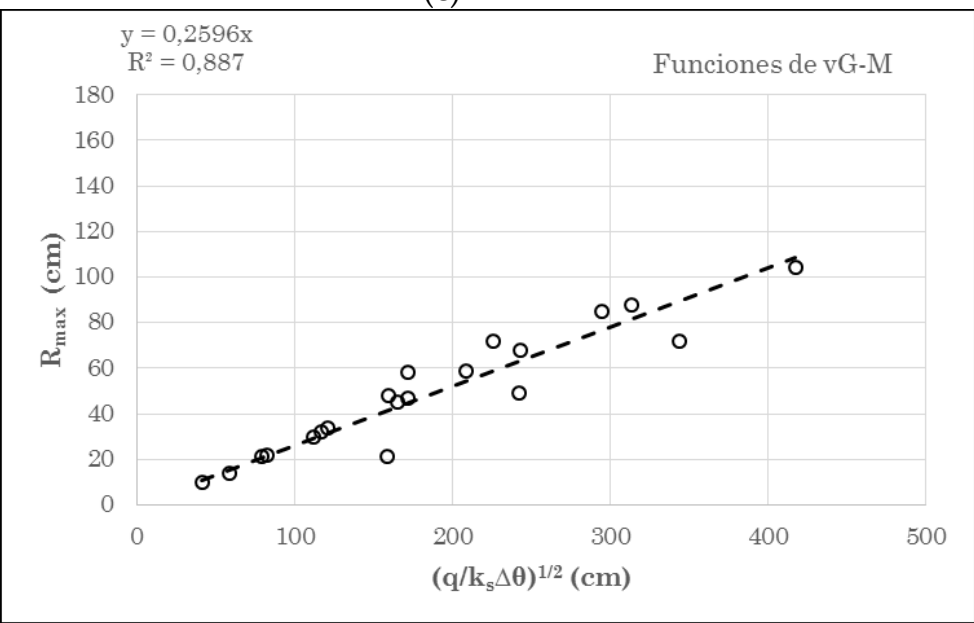

Figura 1. Resultados de las simulaciones realizadas. Radio límite de la zona saturada bajo el gotero una vez alcanzado el régimen estacionario para riego a caudal constante entre $2 \mathrm{~L} / \mathrm{h}$ y $8 \mathrm{~L} / \mathrm{h}$. Suelos de los catálogos de Mualem [21] (a), Clapp y Hornberger [16] (b) y van Genuchten-Mualem [17] (c). 
Se observa una tendencia lineal para los tres tipos de suelo. En la Tabla 1 se muestra el valor estimado de la pendiente [adim] de la recta de ajuste y su error $(\gamma \pm \Delta \gamma)$ para cada una de estas tres gráficas. La Figura 2 presenta dos ejemplos de las simulaciones realizadas para la evolución de la zona saturada en superficie frente al tiempo hasta alcanzar el radio máximo (régimen estacionario). En todas las simulaciones se ha utilizado el criterio de que el régimen estacionario (asintótico) se alcanza cuando el radio máximo permanece al menos el 30\% del tiempo total de simulación con un valor constante.

Tabla 1. Resultados del ajuste del modelo empírico. En la última columna se muestra el coeficiente de correlación lineal obtenido para cada caso.

\begin{tabular}{ccc}
\hline Catálogo & $\gamma[$ adim $]$ & {$\left[\boldsymbol{R}^{2}\right]$} \\
\hline Gardner & $0.1781 \pm 0.009$ & {$[0.97]$} \\
Clapp-Horn. & $0.3145 \pm 0.023$ & {$[0.94]$} \\
vG-M. & $0.2596 \pm 0.021$ & {$[0.89]$} \\
\hline
\end{tabular}
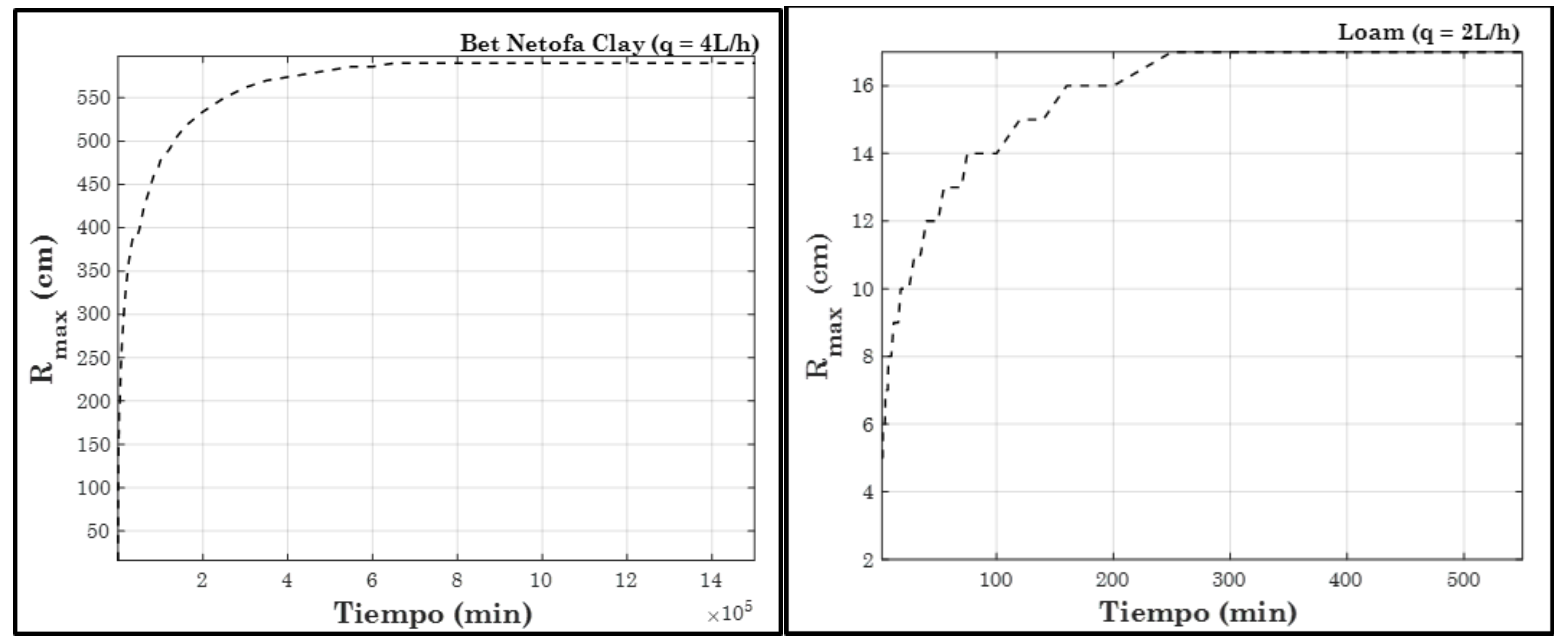

Figura 2. Ejemplos de simulación. Evolución del radio máximo en función del tiempo para dos suelos de los catálogos de Mualem (a) y Clapp-Hornberger (b). Se ha considerado que se alcanza el radio máximo (régimen estacionario) cuando este parámetro permanece constante durante al menos el 30\% del tiempo total de simulación.

\subsection{Discusión del modelo empírico.}

De las simulaciones realizadas se han extraido algunas conclusiones generales con respecto al radio de la zona saturada y que son comunes a los tres catálogos: (a) el radio del charco avanza más deprisa, para los suelos con mayor carácter arcilloso que son aquellos en los que el producto $k_{s} \Delta \theta$ es más pequeño, (b) el radio límite es mayor y se alcanza más tarde para los suelos de carácter arcilloso, es decir, cuando $k_{s} \Delta \theta$ es más pequeño, (c) el contenido de humedad inicial afecta a la evolución de la zona saturada de modo que cuanto mayor es el contenido de humedad inicial más rápido y más grande crece el charco (zona saturada), (d) la representación del radio límite para todos los tipos de suelo de un mismo catálogo sigue la tendencia $\left(k_{s} \Delta \theta\right)^{\delta}$ donde $\delta$ es en este caso un parámetro constante para 


\section{Congreso Nacional de Riegos CARTAGENA 2021}

cada catálogo, y muy próximo $-1 / 2$ independiente del caudal aplicado y (e) se ha comprobado que el caudal aplicado afecta al radio máximo como una función raíz cuadrada para los suelos de los tres catálogos. Por todo ello, se ha concluido que el modelo empírico que mejor ajusta al radio máximo del charco en función de estos parámetros el siguiente (ajuste de la Figura 1):

$$
R_{0}=\gamma \sqrt{\frac{q}{k_{s} \Delta \theta}}
$$

Siendo esta una ecuación común para los suelos caracterizados con los tres tipos de funciones y catálogos mencionados. Los valores obtenidos para el factor adimensional $\gamma$ se han presentado en la Tabla 1. Observar que el ajuste es satisfactorio a pesar de que la constante de capilaridad macroscópica $\alpha$, que está relacionada con el tamaño del poro, no aparece en el modelo. Este hecho representa que el efecto de este parámetro sobre el radio límite es pequeño; además, al estar relacionado el tamaño del poro con la diferencia de contenidos de humedad $\Delta \theta$, se puede argumentar que la información que representa $\alpha$ ya está incluida en $\Delta \theta$.

Para los suelos del tipo Gardner se ha comprobado que en la mayoría de los casos el radio obtenido es similar al que predice el modelo de Wooding, o sensiblemente superior. La desviación entre los dos modelos es en promedio inferior al $9 \%$, siendo de tan solo un $1.7 \%$ para los casos en los que el radio límite supera $10 \mathrm{~cm}$. Esto significa que el ajuste entre los dos modelos es mejor para suelos francos y arcillosos donde el tamaño del charco en régimen estacionario es mayor. Con suelos arenosos la aproximación analítica de Wooding subestima el radio límite obtenido en las simulaciones. Este hecho confirma los resultados reportados por Pullan y Collins, Weir y Warrick [9-11], que también han mencionado un pobre ajuste de la expresión de Wooding con respecto a soluciones numéricas propias bajo condiciones de radios límite pequeño. No obstante, también hay que tener en cuenta los errores de las soluciones numéricas para tiempos largos de simulación.

\subsection{Comparación del modelo empírico y analítico.}

La expresión analítica obtenida para un disco superficial de radio saturado y constante en el límite en que el tiempo tiende a infinito, ecuación (2b-REF.1), es equivalente al régimen estacionario que representa el modelo empírico (3) si se considera despreciable el primer término del factor $c_{g}$. Esto equivale a decir que el efecto de la succión es depreciable frente al gravitatorio, lo que es asumible desde un punto de vista físico en este contexto:

$$
R_{0}=\frac{1}{2^{3 / 4} \pi^{1 / 2}} \sqrt{\frac{q}{\Delta \theta k_{s}}}
$$

Lo que se corresponde a un valor para la constante $\gamma=0.3355$. Esta simplificación es asumible ya que para tiempos largos el efecto predominante en el flujo es el gravitatorio. Advertir que esta ecuación es general para cualquier tipo de suelo que pueda ser definido a través de los tres parámetros propios de las expresiones analíticas propuestas en el modelo analítico [19]. Notar que despreciando la succión, no hay dependencia entre el radio máximo que describe el modelo analítico y la tensión en el frente de 


\section{Congreso Nacional de Riegos CARTAGENA 2021}

avance que esta asociada a este modelo. Advertir que, según el modelo analítico propuesto tampoco existe dependencia entre el radio límite del régimen estacionario y el parámetro $\alpha$.

Utilizando todos los términos de la ecuación (2b-REF.1), y por tanto, asumiendo el efecto de la succión propia del suelo aparece el término de la tensión en el frente de avance $\left(\tau_{f}\right)$ en la ecuación del radio límite:

$$
R_{0}=\frac{\tau_{f}}{4 \Delta \theta}\left[\sqrt{1+\frac{8 \Delta \theta q}{\sqrt{2} \pi k_{s} \tau_{f}^{2}}}-1\right]
$$

Donde se ha omitido la solución negativa propia de esta ecuación de segundo grado. La Figura 3 compara las dos últimas expresiones sobre variables adimensionales para el radio y caudal:

$$
\begin{gathered}
R_{0}^{*}=\sqrt{q^{*}} \quad(4 b) \\
R_{0}^{*}=\sqrt{1+q^{*}}-1 \quad(5 b) \\
R_{\text {ref }}=\frac{\tau_{f}}{4 \Delta \theta} \quad ; \quad q_{\text {ref }}=\frac{\sqrt{2} \pi k_{s} \tau_{f}^{2}}{8 \Delta \theta} \quad \text { [REF.2] }
\end{gathered}
$$

(a)

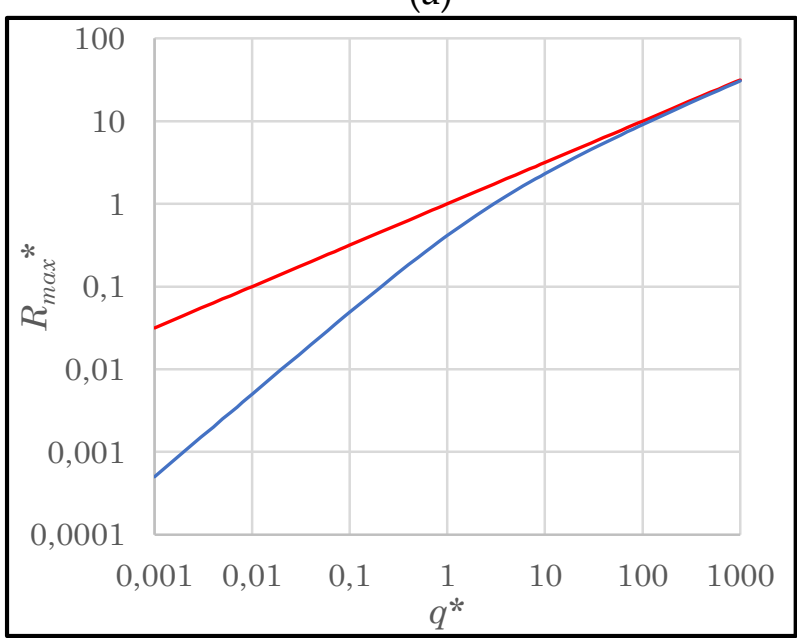

(b)

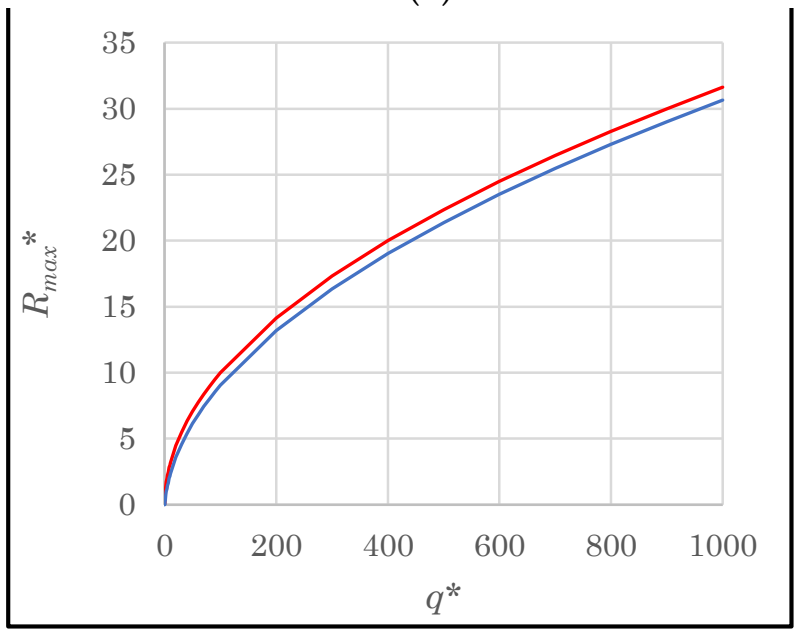

Figura 3. Comparación de las ecuaciones adimensionales (4b) en color rojo y (5b) línea azul. (a) Escala logarítmica y (b) escala decimal.

Se puede observar como el radio que representa la línea roja (4b) es mayor para todos los valores del caudal que el de la línea azul, ecuación (5b). Obviamente, al considerar el efecto de la succión (por pequeño que sea) la filtración es mayor, y por tanto el radio límite en régimen estacionario es mas pequeño. Las diferencias en términos absolutos son mayores para caudales altos, aunque no superan el 3.2\% dentro del rango de estudio. Las diferencias relativas son significativas para valores pequeños del caudal (donde el efecto de la succión es más importante) como se puede observar en el diagrama logarítmico, aunque desaparecen para valores intermedios del caudal. 


\section{Conclusiones}

Las simulaciones realizadas conducen a la conclusión de que el radio máximo de la zona saturada en superficie depende principalmente del caudal aplicado, la conductividad hidráulica en saturación, y la diferencia de los contenidos de humedad inicial y en saturación del suelo. La independencia de la expresión empírica inferida del parámetro $\alpha$ (constante de escala macroscópica de capilaridad) supone una ventaja con respecto a otros modelos de referencia como el modelo analítico de Wooding, ya que este parámetro es de obtención experimental más compleja; además, el hecho de que la solución analítica propuesta tampoco dependa de $\alpha$ justifica la validez del modelo empírico en este aspecto.

Por otro lado, es necesario recordar que la solución analítica de Wooding fue derivada para suelos caracterizados según las funciones del tipo Gardner, por lo hay que asumir que tan solo es válida en este contexto. En este sentido, se realizó un grupo de simulaciones para tres tipos de suelo caracterizado con funciones del tipo van Genuchten-Mualem en las que se encontró una desviación promedio del $48 \%$ entre el radio máximo simulado y el radio que predice la aproximación de Wooding, el cual, estaba subestimado. Recordar que según se ha reportado en [9-11] para suelos del tipo Gardner la solución de Wooding también tiende a subestimar sensiblemente su predicción del radio límite para caudales pequeños y suelos arenosos donde el tamaño del radio máximo en régimen estacionario es menor a 10 $\mathrm{cm}$. Un comportamiento similar al descrito por estos autores se ha encontrado en las simulaciones realizadas. Por otro lado, las expresiones inferidas (3) para los suelos este tipo (vG-M), generan valores para el radio máximo que no siguen ningún patrón sistemático de desviación respecto a las simulaciones realizadas de comprobación, y que según se ha visto, son en promedio inferiores al 15\%.

Observar que la desviación entre la ecuación analítica simplificada respecto al modelo empírico inferido es del 6\% para el caso de suelos del tipo Clapp y Hornberger, y del 22\% para los suelos caracterizados por funciones van Genuchten-Mualem. Es necesario recordar que la expresión analítica propuesta no sigue un patrón de caracterización del suelo similar al de estos dos modelos. Se concluye por tanto que, los dos modelos analítico (4a) y empírico (3) propuestos, pueden ser una alternativa de interés para el desarrollo y diseño de los sistemas de riego, y en particular, el posicionamiento de goteros, en los casos en que, como por ejemplo [22], se utilice el parámetro del radio máximo del charco en función del caudal aplicado para este efecto. 


\section{Congreso Nacional de Riegos CARTAGENA 2021}

\section{Referencias}

1. Schwartzman M.; Zur B. Emitter Spacing and Geometry of Wetted Soil Volume. J. Irrig. Drain. Eng. 1986. 112(3): $242-253$

2. Amin M. S. M.; Ekhmaj A. I. M. DIPAC-DripIrrigation Water Distribution Pattern Calculator. 7th International Micro-Irrigation Congress, 10-16 Sept. Pwtc, Kuala Lumpur, Malaysia. 2006.

3. Keyvan M.; Peters R.T. Wetting patterns models for drip irrigation: new empirical model. Journal of Irrigation and Drainage Engineering. 2011. 137(8): 530-36.

4. Kaul R.K.; Michael A.M. Moisture front advance under point source of water application. J Agric Eng. 1982. 19(2):1-8

5. Subbaiah R.; Pandey R.N. Soil moisture movement under trickle irrigation. J Inst Eng (India). 1991. 18:22-28

6. Zazueta F.S.; Clark G.A.; Smajstrla A.G.; Carrillo M. A simple equation to estimate soil-water movement from a drip irrigation source. Proceedings of 5 th international microirrigation congress on conserving resource/preserving the environment, ASABE, pp 581-856. 1995.

7. Wooding R.A. Steady infiltration from a shallow circular pond. Water Resour Res. 1968. 4:1259-73.

8. Gardner W.R. Some steady state solutions of unsaturated moisture flow equations with application to evaporation from a water table. Soil Sci. 1958. 85:228-232.

9. Pullan A.J. y Collins I.F. Two and three-dimensional steady quasilinear infiltration from buried and surface cavities using boundary element techniques. Water Resour Res. 1987. 23(8):1633-1644.

10. Weir G.J. Steady infiltration from small shallow circular ponds. Water Resour Res. 1987. 23:733-736.

11. Warrick A.W. Models for disk infiltrometer. Water Resour Res. 1992. 28:1319-1327.

12. del Vigo Á., Zubelzu S. \& Juana L. Numerical routine for soil dynamics from trickle irrigation. Applied Math. Model. 2020. 83: 371-385.

13. del Vigo Á., Zubelzu S. \& Juana L. Algoritmo para la resolución de la ecuación de Richards en 3-D para riego por goteo: Método, validación y resultados preliminares. XXXVII Congreso Nacional de Riegos. Don Benito. Spain. 2019a.

14. del Vigo Á., Zubelzu S. \& Juana L. Study of water infiltration in soil by Richards equations in 3D: summary and methodology validation. 11th World Congress on Water Resources and Environment. Madrid. 2019b.

15. del Vigo, Á. Simulación del flujo del agua en el suelo en riego por goteo superficial, soluciones analíticas aproximadas, caracterización del suelo y diseño de los riegos. Phd. Thesis, Universidad Politécnica de Madrid. Madrid. 2020.

16. Clapp R.B. y Hornberger G.M. Empirical equations for soil hydraulic properties. Water Resour Res. 1978. 14:601-604.

17. van Genuchten M.Th. A closed-form equation for predicting the hydraulic conductivity of unsaturated soils. Soil Sci Soc Am Proc. 1980. 44:892-898

18. del Vigo Á., Zubelzu S. \& Juana L. Soluciones analíticas aproximadas bajo hipótesis de Green-Ampt desde fuentes semiesférica y circular en superficie. Jornadas de Ingeniería del agua. Toledo. 2019c.

19. del Vigo Á., Zubelzu S. \& Juana L. Infiltration models and soil characterization for hemispherical and disc sources based on Green-Ampt assumptions. Journal of Hydrology. 2021. 595: 1259-66.

20. Šimůnek J., van Genuchten M. \& Šejna M. The HYDRUS Software Package for Simulating the Two- and Three-Dimensional Movement of Water, Heat, and Multiple Solutes in Variably-Saturated Media, Technical Manual Version 1.0. University of California Riverside. Riverside, CA, 3PC. Progress, Prague. Czech Republic. 2006.

21. Mualem, Y. A new model for predicting the hydraulic conductivity of unsaturated porous media. Water Res Jour. 1976. 12: 513.

22. Bresler, E. Analysis of trickle irrigation with application to design problems. Irrigation Science. 1978. 1: 3-17. 


\title{
LA DIGITALIZACIÓN DEL CAMPO. USO DE TELEDETEC- CIÓN Y NUEVAS TECNOLOGÍAS COMO HERRAMIENTAS SOSTENIBLES EN LA GESTIÓN DE REGADIOS MODERNI- ZADOS. PROYECTOS I+D+i: OPTIREG Y DEMETER
}

\author{
Fernández Pesado, Pedro Javier ${ }^{1}$; Rubio Melón, Ángel²; Escudero Barbero, Rosario ${ }^{3}$; Sánchez Hernández, Blanca ${ }^{4}$; \\ Cáceres Losada, Jose Luis; ; Calero Gil, Rodrigo ${ }^{6}$ \\ ${ }^{1}$ Analista (Tragsa), Cruz Roja de León 26 A. 24008 León, pfernand@tragsa.es \\ ${ }^{2}$ Coordinador de Obras (Tragsa), Cruz Roja de León 26 A. 24008 León, arubio@tragsa.es \\ ${ }^{3}$ Jefe de Departamento de Teledetección, Gerencia de Sistemas de Información Geográfica (Tragsatec), Julián Camarillo 6, 28037 Madrid, \\ reb@tragsa.es \\ 4y5 Técnicos de GIS y Teledetección, Gerencia de Sistemas de Información Geográfica (Tragsatec), Julián Camarillo 6, 28037 Madrid, bsh@tra- \\ gsa.es; jcaceres@tragsa.es \\ ${ }^{6}$ Jefe Departamento Planificación y Transferencia Tecnológica (Tragsa), Conde Peñalver 84, Madrid, rcalero@tragsa.es
}

Resumen: La actual necesidad de producir alimentos se enfrenta a su vez con la búsqueda de modelos más productivos, sostenibles, con menor impacto ambiental a un menor coste energético, hídrico y económico. La estigmatización del trabajo agrícola como principal consumidor de recursos hídricos, la población rural envejecida y la despoblación de dicho medio rural, hace que sea necesaria la búsqueda de nuevas estrategias para que la labor del empresario agrícola sea más atractiva, productiva, eficiente, sostenible, respetuosa con el medio ambiente y que se aproveche sobre todo de los avances tecnológicos.

En este marco nacen en el Grupo Tragsa dos proyectos para el desarrollo de I+D+i: En primer lugar, OPTIREG para innovación tecnológica en la optimización de la eficiencia hídrica y energética, combinando diferentes tecnologías, como el uso de teledetección por satélite, sistemas de información geográfica, RPAS y diferente sensórica. En segundo lugar, DEMETER como proyecto de innovación tecnológica para el diseño y uso de herramientas relacionadas con Big Data y Machine Learning, en la búsqueda de modelos más productivos, evaluación de comportamientos de los cultivos, predicción de cosechas o análisis de escenarios de sequía o escasez de agua. El empleo de teledetección junto con técnicas de inteligencia artificial, permite realizar herramientas más eficientes y precisas como puede ser la obtención del coeficiente Kc, indicadores de la variabilidad intra e interparcela, que redundan en un aprovechamiento máximo del agua y mejor manejo de los cultivos.

Además, se ofrece servicios personalizados a los distintos actores (Administración, Confederación, Comunidad de Regantes, explotadores agrícolas, etc.) para que sean autogestores con herramientas propias como por ejemplo la posibilidad de obtener peticiones de riego con y sin intervención de usuario (riego automático por ETP).

Palabras clave: Teledetección, ahorro, optimización, predicción, innovación, tecnología, sostenibilidad. 


\title{
THE DIGITALIZATION OF THE FIELD. USE OF REMOTE SENSING AND NEW TECHNOLOGIES AS SUSTAINABLE TOOLS IN THE MANAGEMENT OF MODERN IRRIGA- TION. R\&D\&I PROJECTS: OPTIREG AND DEMETER
}

\author{
Fernández Pesado, Pedro Javier; Rubio Melón, Ángel; Escudero Barbero, Rosario³ ${ }^{3}$ Sánchez Hernández, Blanca ${ }^{4}$ \\ Cáceres Losada, Jose Luis5; Calero Gil, Rodrigo ${ }^{6}$ \\ ${ }^{1}$ Analista (Tragsa), Cruz Roja de León 26 A. 24008 León, pfernand@tragsa.es \\ ${ }^{2}$ Coordinador de Obras (Tragsa), Cruz Roja de León 26 A. 24008 León, arubio@tragsa.es \\ ${ }^{3}$ Jefe de Departamento de Teledetección, Gerencia de Sistemas de Información Geográfica (Tragsatec), Julián Camarillo 6, 28037 Madrid, \\ reb@tragsa.es \\ ${ }_{4 y 5}^{5}$ Técnicos de GIS y Teledetección, Gerencia de Sistemas de Información Geográfica (Tragsatec), Julián Camarillo 6, 28037 Madrid, bsh@tra- \\ gsa.es; jcaceres@tragsa.es \\ ${ }^{6}$ Jefe Departamento Planificación y Transferencia Tecnológica (Tragsa), Conde Peñalver 84, Madrid, rcalero@tragsa.es
}

Abstract: The current need to produce food is faced in turn with the search for more productive, sustainable models, with less environmental impact at a lower energy, water and economic cost. The stigmatization of agricultural work as the main consumer of water resources, the aging rural population and the depopulation of this rural environment, makes it necessary to find new strategies to make the work of the agricultural entrepreneur more attractive, productive, efficient, sustainable, respectful of the environment and that takes advantage above all of technological advances.

Within this framework, two projects for the development of R\&D\&I are born in the Tragsa Group: Firstly, OPTIREG for technological innovation in the optimization of water and energy efficiency, combining differ- ent technologies such as the use of satellite remote sensing, geographic information systems, RPAS and dif- ferent sensors. Secondly, DEMETER as a technological innovation project for the design and use of tools related to Big Data and Machine Learning, in the search for more productive models, evaluation of crop behaviors, crop prediction or analysis of drought or water scarcity scenarios. The use of remote sensing together with artificial intelligence techniques, allows to make more efficient and precise tools such as obtaining the Kc coefficient, indicators of intra and interparcellan variability, which result in a maximum use of water and better management of crops.

In addition, personalized services are offered to the different actors (Administration, Confederation, Community of Irrigators, agricultural operators, etc.) so that they are self-managers with their own tools such as the possibility of obtaining irrigation requests with and without user intervention (automatic irrigation by ETP).

Keywords: Remote sensing, saving, optimization, prediction, innovation, technology, sustainability. 


\section{Congreso Nacional de Riegos CARTAGENA 2021}

\section{Introducción.}

Desde el año 2006 el Grupo Tragsa lleva la gestión y el mantenimiento de las redes de riego y distribución de agua de las CCRR de las zonas de Payuelos, Porma y Páramo Bajo de León y Zamora. En términos generales, se trata de aproximadamente 45.000 has regadas, unos 5.000 hidrantes, 24 estaciones de bombeo y $1.500 \mathrm{~km}$ de tubería enterrada, para efectuar riego sobre cultivos extensivos, donde el $78 \%$ de la superficie es de maíz y el resto de superficie se reparte entre remolacha, cereal y otros cultivos menores.

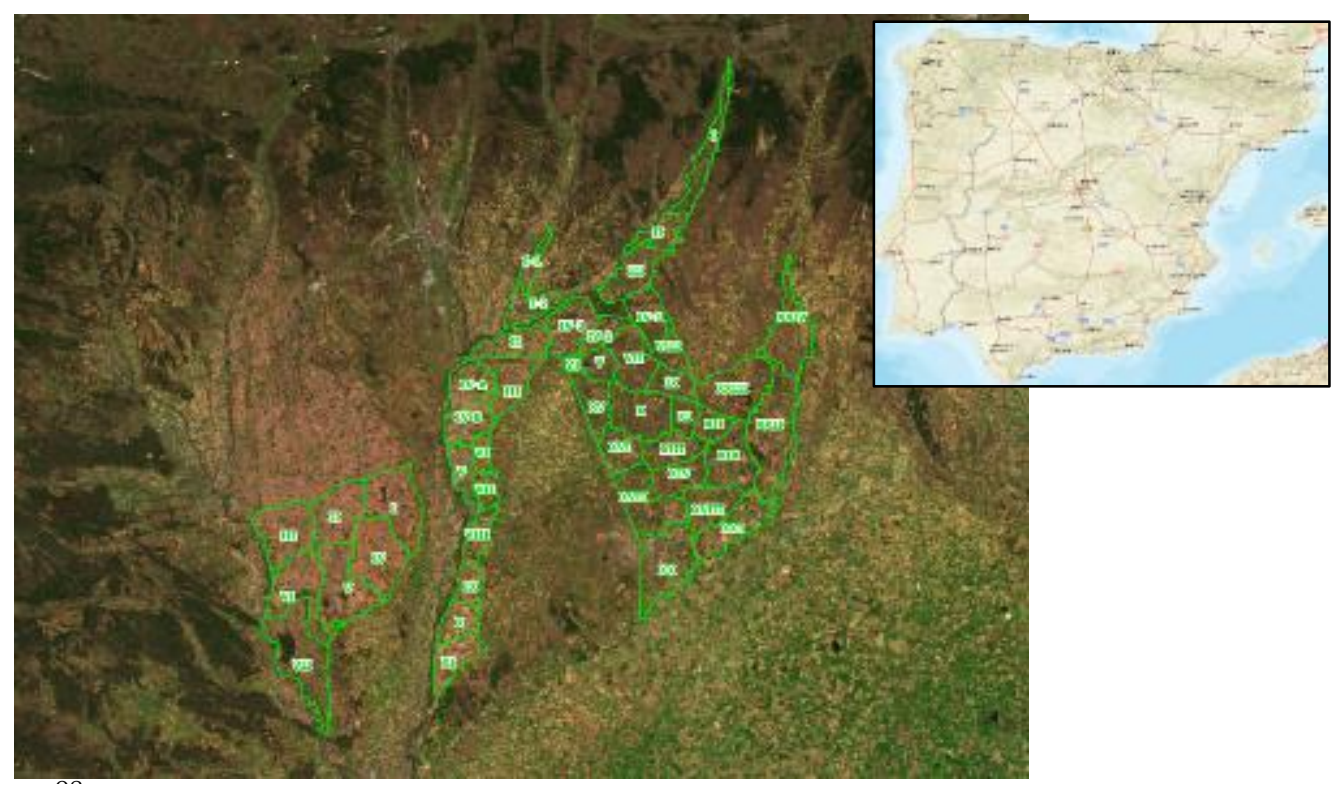

Figura 1: Localización de la zona de estudio

100

Para ayudar en la gestión del riego se desarrollaron, entre otros, una serie de servicios y productos apoyados en técnicas y metodologías de teledetección por satélite, orientados al cálculo de las necesidades hídricas de los cultivos en el marco del proyecto Optireg (2017-2018). Estos servicios se siguen ofreciendo en la actualidad no sólo a las Comunidades de Regantes, sino más directamente a los regantes. Consisten en:

- Servicios de visualización de imágenes de satélite en tiempo real a lo largo de campaña de riegos. Accesibles a través del visor: http://www.gestionregadios.com:8080/KcViewer

- Servicios de obtención de Kc/ET derivada a partir de las imágenes de satélite para el cálculo de las necesidades de riego, empleando automatismos ETL y técnicas de minería de datos para la incorporación al algoritmo de cálculo automático de riego y ejecución del mismo 


\section{ÂERYD}

CARTAGENA 2021

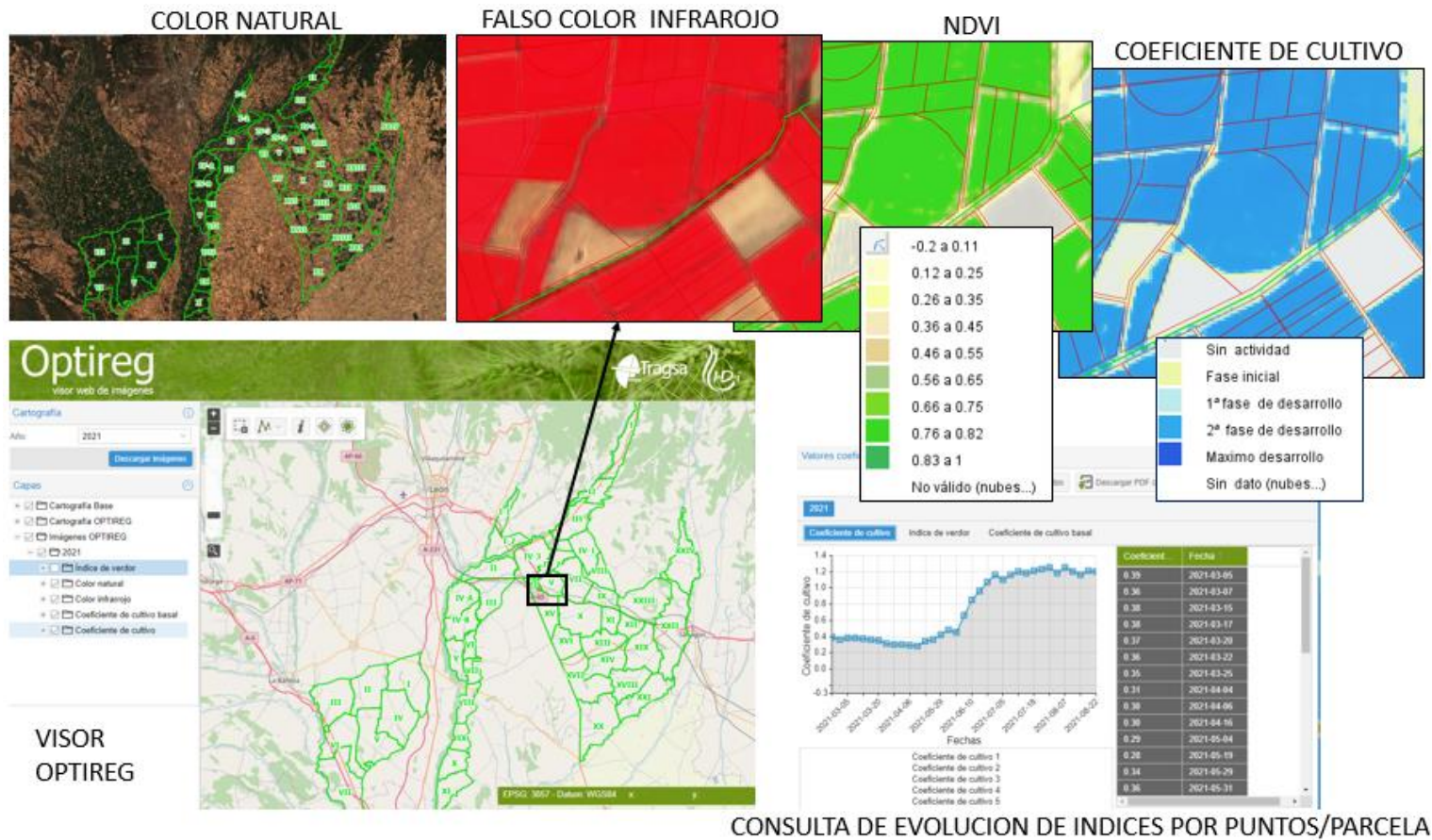

Figura 2: Servicios y productos generados en visor web Optireg

Ademas de estos servicios orientados al riego se ofrecen otros enfocados a la mejora del manejo del cultivo. Inicialmente se generaron productos que mostraban el vigor del cultivo en función al NDVI de las imágenes de satélite. Estos productos muestran las desviaciones puntuales de desarrollo que puede haber entre las distintas parcelas o zonas y funcionan como alertas de problemas en el cultivo.

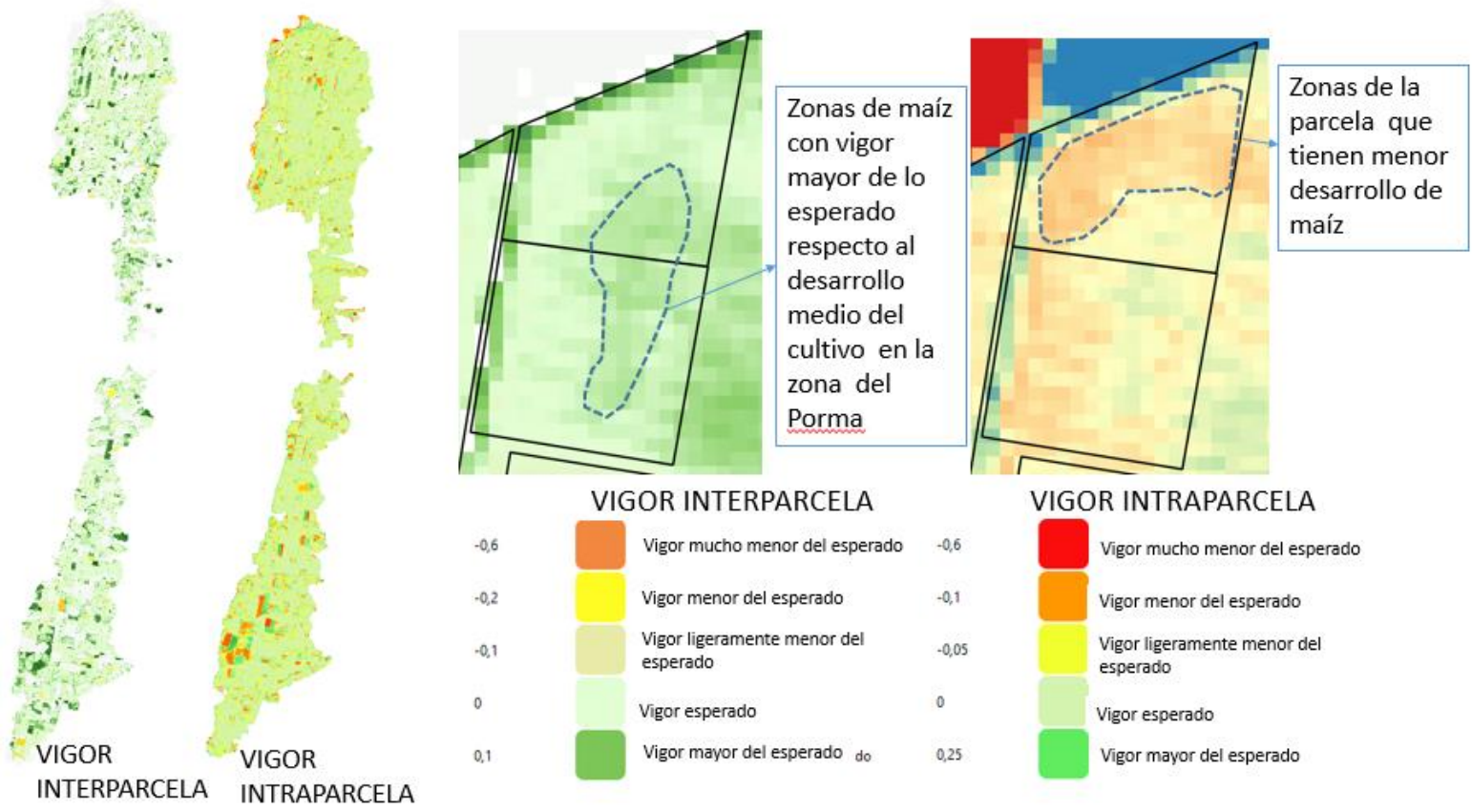

Figura 3: Productos de vigor de cultivo generados 


\section{Congreso Nacional de Riegos CARTAGENA 2021}

\section{Objetivo del trabajo.}

Con la finalidad de continuar con las mejoras de manejo del cultivo y mejoras en eficiencia hídrica y energética, en la actualidad se están desarrollando, dentro del marco del proyecto DEMETER (2020 2022), una serie de servicios adicionales apoyados en datos de teledetección para tener a disposición de los agricultores y de las propias Comunidades de Regantes. Estos servicios consisten en :

- Afinado de modelos de cálculo de necesidades hídricas.

- Aplicación de modelos de biomasa/productividad basados en datos de imágenes de satélite.

- Mejoras en el manejo del abonado nitrogenado.

El Proyecto de I+D+i DEMETER pertenece a la convocatoria europea Horizonte 2020 (H2020-DT-2018-2020, "Plataformas de integración digital para la agricultura" y pretende un despliegue a gran escala d plataformas basadas en Internet de las Cosas (IoT) de agricultura inteligente e interoperable. Estos sistemas se centrarán en el agricultor.

DEMETER demostrará el potencial real de la interoperabilidad avanzada basada en estándares entre las tecnologías IoT, al adaptar y extender los estándares existentes a un modelo de información global, al mismo tiempo que garantiza la seguridad, la privacidad y la confidencialidad empresarial en toda la cadena de valor en entornos operativos agroalimentarios.

\section{Afinado de modelos de cálculo de necesidades hídricas.}

Se han evaluado dos modelos para ver cuál proporciona mejores resultados, de acuerdo a la experiencia en la zona y a los datos disponibles de riego:

- El Modelo NDVI simplificado, que emplea la metodología FAO para estimar la evapotranspiración de los cultivos (ETc) en función de la evapotranspiración potencial (ETo) y un coeficiente de cultivo Kc, generado a partir de una serie temporal de NDVIs obtenidos de imágenes de satélite. (Calera et al, 2016).

- El Modelo SAVI MINARET, que presenta ligeras variaciones respecto del modelo anterior, teniendo en cuenta además los términos de estrés hídrico del cultivo (Ks) y coeficiente de evaporación del suelo $(\mathrm{Ke})$. En este modelo el coeficiente de cultivo se genera a partir de los índices SAVI obtenidos de las imágenes de satélite de la campaña. (Mateos et al, 2013) 


\section{Congreso Nacional de Riegos CARTAGENA 2021}

ET NDVI SIMPLIFICADO

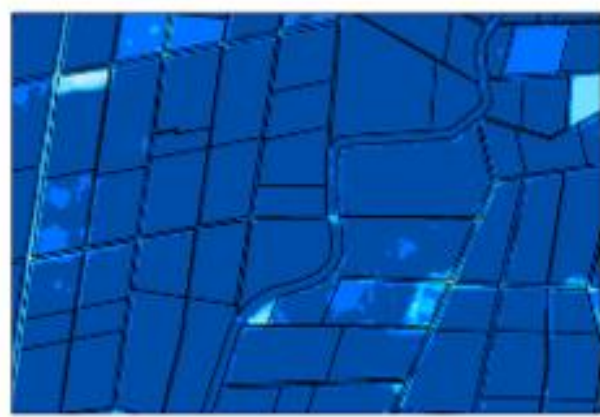

Evapotranspiración $(\mathrm{mm})$
ET MINARET

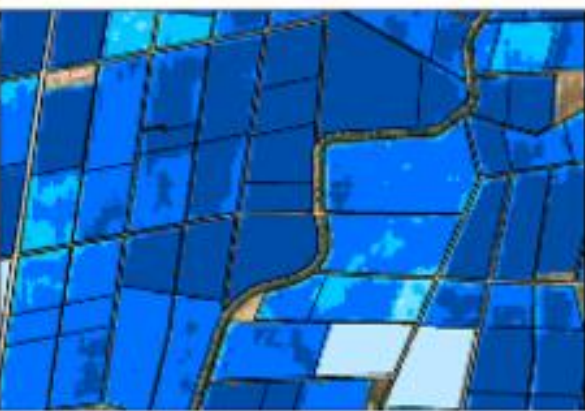

ET RIEGOS

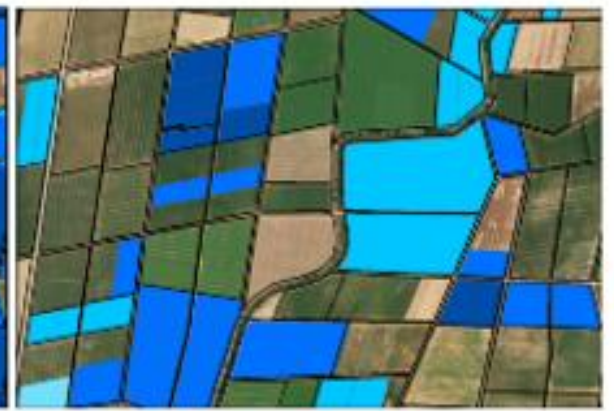

$600-700$

$0-200$

$200-300$ $300-400$

$100-500$ $500-600$

Figura 4: ET calculada con distintos modelos y ET de la que se deriva el riego real
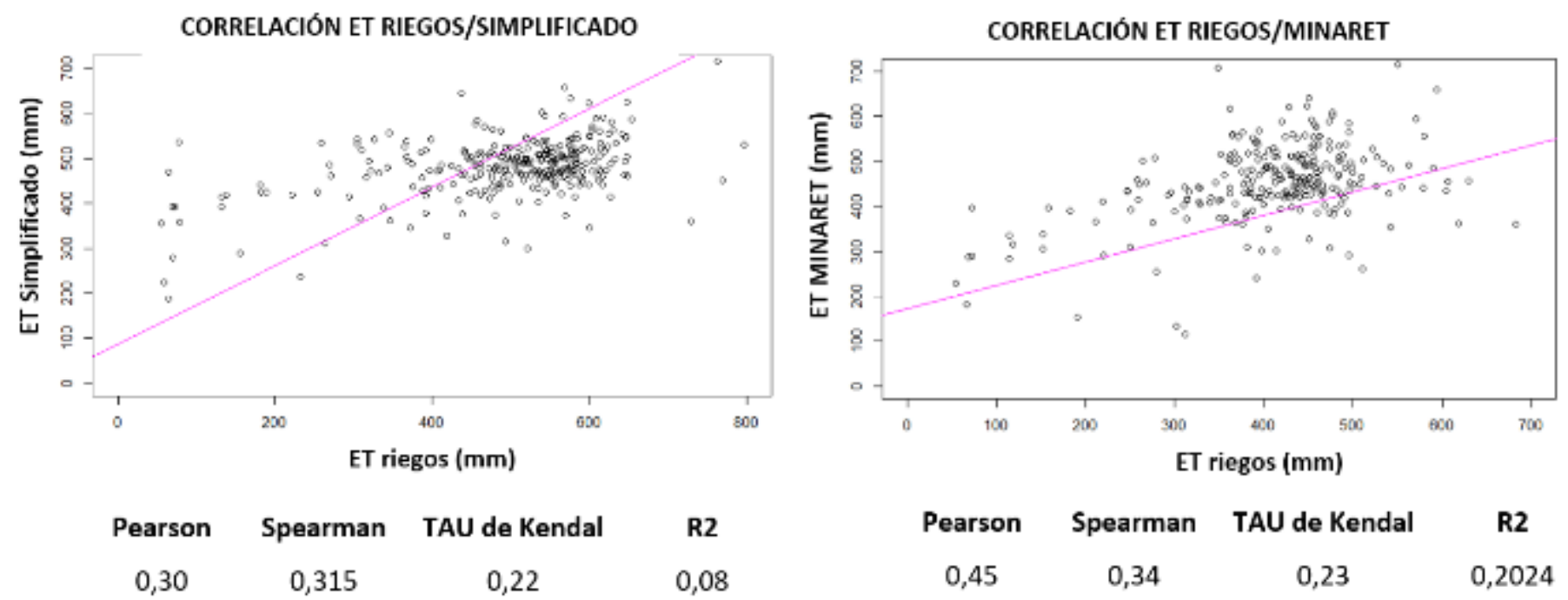

$\begin{array}{llll}0,30 & 0,315 & 0,22 & 0,08\end{array}$

Figura 5: Resultados de correlación entre de ETs

Las correlaciones existentes entre la Et calculada a partir de estos modelos y la ET del riego real permiten concluir que el la Et calculada mediante el modelo SAVI MINARET se ajusta mejor a la ET de la que derivan los datos reales de riego a nivel de parcela. 


\section{Congreso Nacional de Riegos CARTAGENA 2021}

\section{Aplicación de modelos de biomasa y rendimiento derivado.}

Se han analizado dos modelos para el cálculo de la biomasa para el maíz durante la campaña de 2019, uno basado en la eficiencia de uso de la luz absorbida (LUE) y el otro en el uso del agua transpirada (WUE) y de ellos se infiere el rendimiento por parcela.

Ambos modelos se basan en series de imágenes de satélite Sentinel-2 e índices derivados, en este caso el NDVI, y datos agroclimáticos proporcionados por estaciones SIAR; en el caso del modelo basado en la luz, la radiación diaria; y en el caso del modelo basado en el agua, la ETo diaria.

Se trabaja con los resultados de la aplicación de los modelos acumulados en un periodo de tiempo de interés para el cultivo que se define a partir de datos de imágenes de satélite en cada parcela. La aplicación de un índice de cosecha al resultado permite obtener el dato de rendimiento que se ha evaluado frente a rendimien tos reales proporcionados por cosechadoras.

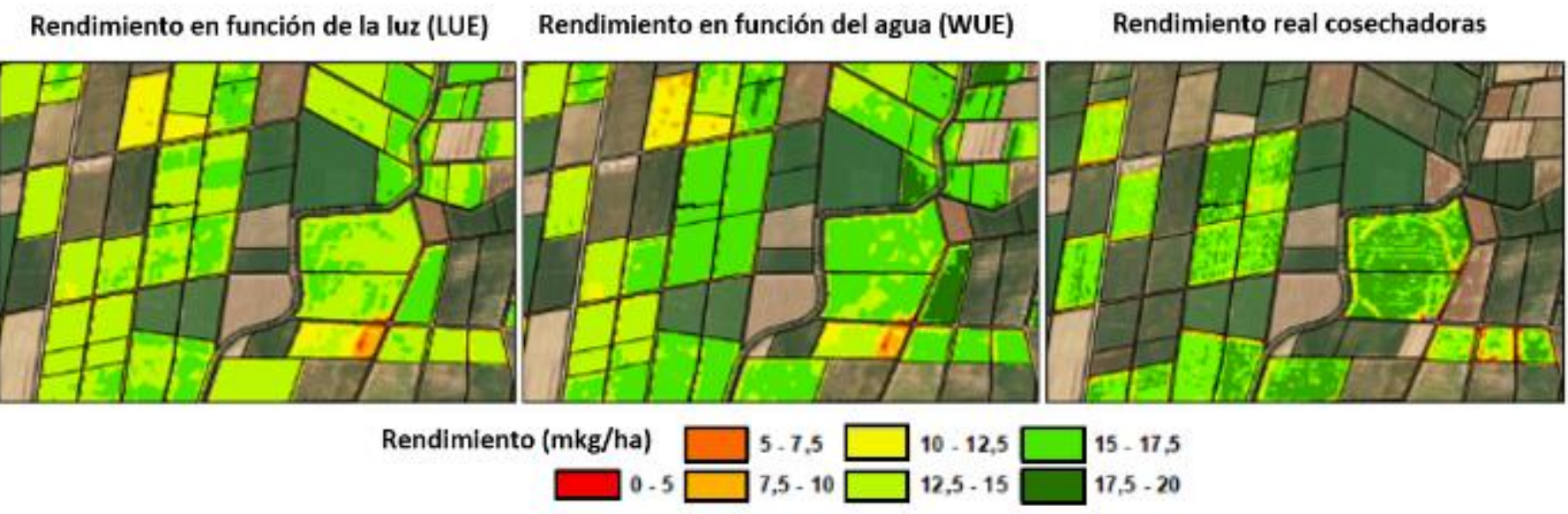

\section{Rendimiento de cultivo $=$ Biomasa $* I C$}

$$
\text { Biomasa }=\int_{\text {to }}^{t} L U E \cdot A P A R d(t) \quad \text { Biomasa }=\int_{\text {to }}^{t} W U E \cdot T c d(t)
$$

Figura 6: Rendimiento de parcelas en $\mathrm{mkg} / \mathrm{ha}$ calculado con distintos modelos y obtenido por cosechadoras

La evaluación de los resultados permite concluir que el modelo basado en la eficiencia del uso de la luz (LUE) proporciona valores de rendimientos más acordes con la realidad que el modelo basado en la transpiración del cultivo. Actualmente se trabaja en afinar aún mas los resultados de este modelo introduciéndo otras variables meteorológicas como la integral térmica. Los datos obtenidos con la aplicación de un modelo preciso son muy valiosos para la gestión de los cultivos en la zona. 


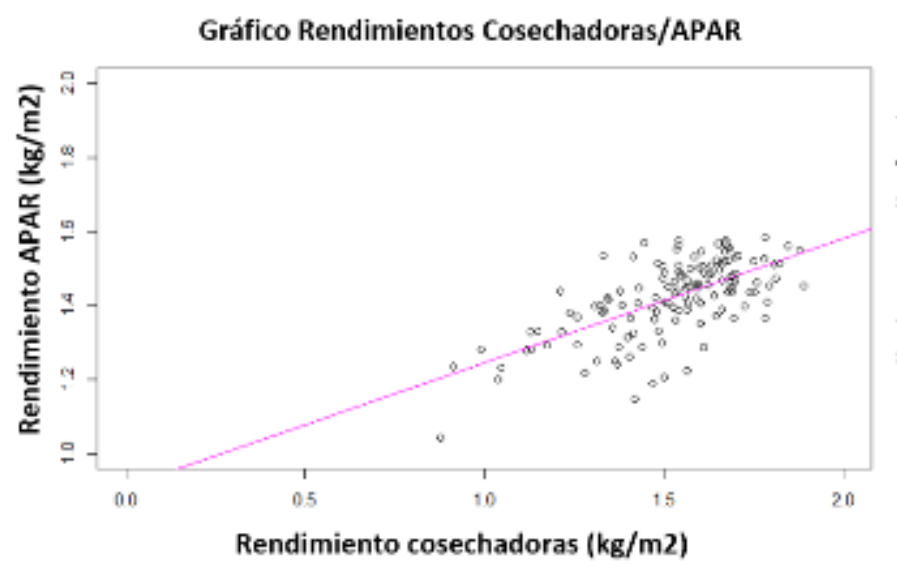

$\begin{array}{cccc}\text { Pearson } & \text { Spearman } & \text { TAU de Kendal } & \text { R2 } \\ 0,65 & 0,6 & 0,42 & 0,42\end{array}$

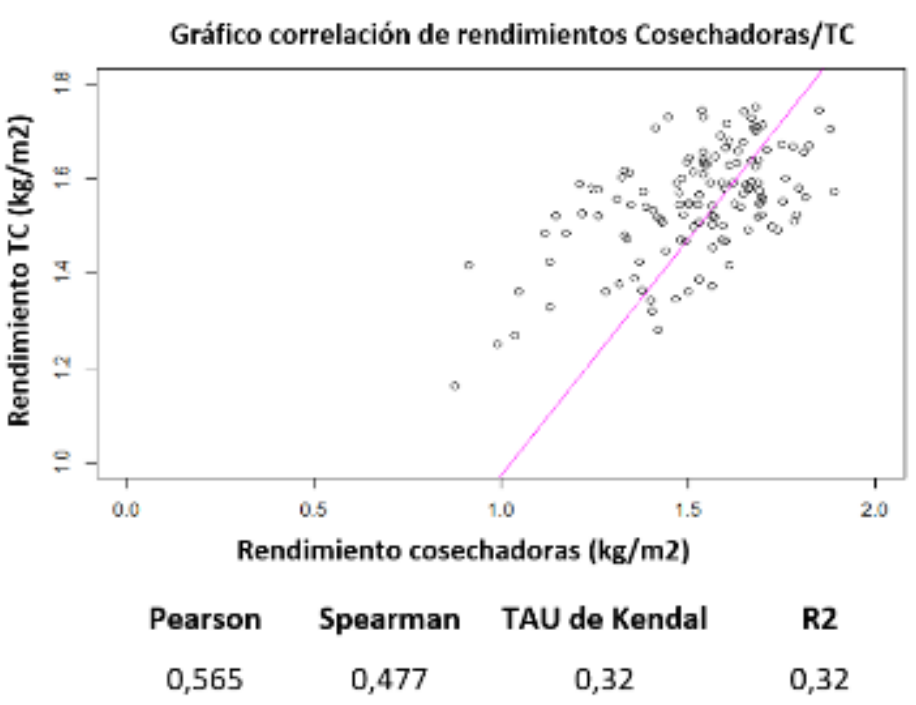

Figura 7: Resultados de correlación entre rendimientos

\section{Abonado nitrogenado.}

Esta fase se encuentra actualmente en desarrollo. Inicialmente se han recopilado estudios de suelos sobre las parcelas en las que se va a evaluar el posible uso de imágenes de satélite como información auxiliar para la ayuda en el manejo del abonado nitrogenado de las parcelas.

Se va a comprobar la relación entre diversos índices acumulados obtenidos a partir de imágenes de satélite con datos reales de abonado aplicado para emplearlos como indicativo de la necesidad de abonado. 


\section{Conclusiones.}

En paises como España, la falta de agua es el mayor factor limitante para la producción agrícola.

El nuevo mandato de la sociedad mundial y de forma más concreta en la UE, se está materializado en unas nuevas estrategias sobre biodiversidad para reintegrar la naturaleza a nuestras vidas, siendo más sostenibles en la lucha frente el cambio climático.

Las nuevas tecnologías se ponen a disposición de este nuevo mandato y el consumo de agua medido en m3 por ha debe reducirse hasta donde dicha tecnología permita.

Mediante la eficiencia hídrica podemos conseguir la meta de ahorro máximo de agua empleada en la producción agrícola, beneficiando indirectamente en la optimización y ahorro energético (sostenibilidad). La teledetección, es una tecnología que permite realizar un seguimiento del estado de los cultivos con una frecuencia casi diaria, lo que redunda en que sea la herramienta más eficiente y precisa para la obtención de una serie de indicadores de dichos cultivos y por lo tanto contribuya en gran medida a la eficiencia hídrica y energética, mejorar la distribución de las parcelas, así como la búsqueda de escenarios más productivos y la perfeccionamiento de los suelos al optimizar y racionalizar los nutrientes.

Si a los productos obtenidos mediante técnicas de teledetección y sistemas de información geográfica, los enlazamos con la interoperabilidad de los sistemas IoT distribuidos por el terreno, como sistemas de telecontrol y otros sistemas de medición, podemos conseguir que la digitalización del campo sea completa y nos estaremos acercando al rendimiento óptimo de los cultivos.

Los proyectos de innovación tecnológica OPTIREG y DEMETER y concretamente algunas de sus técnicas se aplican con éxito en diferentes Comunidades de Regantes, ayudando en primer lugar a un uso mucho más racional y eficiente de agua y electricidad, ahorro de insumos para obtener la misma cosecha o incluso mayor lo que se traduce en un beneficio máximo para el agricultor, el medio ambiente y en un mayor valor añadido de las inversiones públicas y privadas ejecutadas.

\section{Referencias}

1. Allen, R.G, B Burnett, Clarence Robinson, and M. Tasumi. “Estimating the soil surface evaporation and transpiration components from satellite images in the absence of a thermal band." Agricultural Water Management, 2008.

2. Calera, A., Campos, I. y Garrido J. “Determinación de las necesidades de agua y de Riego mediante estaciones meteorológicas y series temporalis de imágenes multiespectrales"; CENTER, 2016

3. Campoy, J. “Eficiencia de uso del agua y de la luz en cultivo de ajo mediante el uso de series temporalis de imágenes de satélite." Universidad de castilla - La Mancha, 2018.

4. Cuesta, A. “Metodología operativa para la obtención del coeficiente de cultivo desde imágenes de satélite.” ITEA: Información Técnica Económica Agraria, 2005: 101(3), 212-224.

5. Esposito, G, G Balbosa, C Cerliani, and R Balboa. "Rendimiento Potencial del Maiz." Universidad Nacional del Río Cuarto, 2016: 36.

6. Gomez, L. G. Crop yield and biomass estimation in wheat, barley and maize, using crop growth models based on satellite remote sensing. Tesis Doctoral, Universidad de Castilla - La Mancha, 2018

7. MAPA. Calendario de Siembra, Recolección y Comercialización. Madrid: Ministerio de Agricultura, Pesca y Alimentación, 2014-2016.

8. Mateos, L, M.P González-Dugo, L Testi, and F Villalobos. “Monitoring ET of irrigated crops using crop coefficients derived from time series of satellite images. I. Method validation; Monitoring ET of irrigated crop coefficients derived from time series of satellite images II. Application. “Agricultural Water Management (Agricultural Water Management), 2013.

9. Muñoz, Francisco L. “Integración de datos remotos en modelos de crecimiento y estimación de cosecha de cultivos herbáceos. Aplicación a escala local sobre trigo y maíz." Córdoba, 2011. 


\title{
Optimización de sistemas de bombeo fotovoltaico a depósitos con criterio técnico-económico.
}

\author{
Carricondo-Antón, $\mathrm{JM}^{1}{ }^{1}$, Jiménez-Bello, $\mathrm{MA}^{2}{ }^{2}$, Manzano Juárez, $\mathrm{J}^{1}$., Royuela Tomas, A $^{1}$, González Altozano, $\mathrm{P}^{3}$.
}

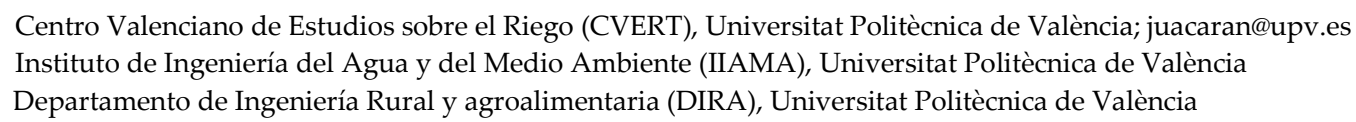

Resumen: Para el cálculo de instalaciones donde hay bombeos de agua entre dos depósitos se suele diseñar las instalaciones de bombeo fotovoltaico (FV) siguiendo las pautas de instalaciones tradicionales. Se calcula el punto de funcionamiento y se selecciona una bomba que su curva (Hm-Q) sea lo más próxima al punto de funcionamiento. El problema de esta metodología es que parte de la energía solar del día se desperdicia y podría ser utilizada para el bombeo de agua. Por ello es importante la selección del tipo y número de bombas que pueden trabajar en paralelo. Este trabajo tiene como objetivo principal desarrollar una metodología para la optimización del número de bombas que pueden trabajar en paralelo y del tamaño del generador en instalaciones de riego FV a balsas. El caso de estudio consiste en un bombeo entre dos depósitos, donde él de mayor cota abastece por gravedad una superficie de riego de 42.21 ha, en la comunidad de regantes Sector 4, próximo al municipio de Picassent perteneciente a la Comunidad Valenciana situada en el Este de España. La metodología empleada se basa en el diseño de la instalación FV (Potencia pico $(\mathrm{Pp}, \mathrm{W})$ ) y del equipo de bombeo mediante la metodología estándar. Se realiza un planteamiento de las hipótesis de bombeo con diferente número de bombas funcionando en paralelo (BFP) (de 1 a 8 bombas) donde la suma de caudales de todas las BFP de las diferentes hipótesis será igual al caudal de la hipótesis de 1 bomba. El volumen bombeado anual (VBA, $\mathrm{m}^{3} \mathrm{anno}^{-1}$ ) se calcula determinando las horas de potencia disponible $(\mathrm{HPD}, \mathrm{h}$ ) para cada hipótesis (donde Potencia neta $($ Pnet, $\mathrm{W})>$ Potencia requerida $\left.\left(\mathrm{P}_{\mathrm{b}}, \mathrm{W}\right)\right)$ para todos los días del año para conocer la variación del VBA. Seguidamente, se utilizan distintas hipótesis de factor potencia (FP) (Cociente entre $\mathrm{Pp}$ y $\mathrm{Pb}$ ) con el fin de estudiar el mínimo número de placas solares requeridas. Por último, se selecciona el número de bombas por criterio económico. Como principales resultados se obtiene un mayor aprovechamiento de la irradiancia, para la hipótesis con 1 bomba la potencia mínima requerida para que arranque la misma es de $24,4 \mathrm{~kW}$, lo que equivale a un umbral de irradiancia de 336,2 $\mathrm{Wm}^{-2}$ para el mes más desfavorable. Sin embargo, para que comience el bombeo con la hipótesis de $5 \mathrm{BFP}$, solo se requiere de 4,9 $\mathrm{kW}$, siendo el umbral de irradiancia, para el mes más desfavorable es de 65,2 $\mathrm{Wm}^{-2}$. Al aumentar el número de bombas se aumenta el VBA hasta casi un 27\%, y viendo los incrementos de bombeo a lo largo de este año en relación con las necesidades de volumen a bombear se determina que para el número óptimo de bombas que sería 5, en este caso de estudio, el FP se disminuye en un 50,7\%. La función económica nos indica el número de BFP a seleccionar, siendo la hipótesis de 5 bombas la que menor coste tiene.

Palabras clave: Bombeo fotovoltaico; Selección de bombas; Optimización riego fotovoltaico 


\title{
XXXVIII Congreso Nacional de Riegos
} CARTAGENA 2021

\section{Optimization of photovoltaic tank pumping systems with technical-economic criteria.}

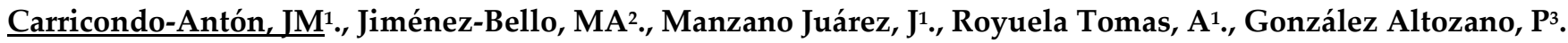

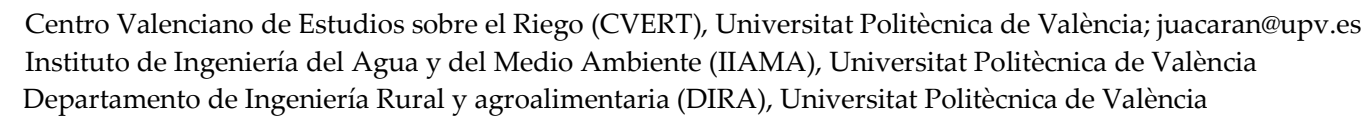

Abstract For the calculation of installations where there are water pumps between two tanks, photovoltaic (PV) pumping installations are usually designed following the guidelines of traditional installations. The operating point is calculated and a pump is selected whose curve (Hm-Q) is closest to the operating point. The problem with this methodology is that part of the day's solar energy is wasted and could be used for pumping water. For this reason, it is important to select the type and number of pumps that can work in parallel. The main objective of this work is to develop a methodology for the optimization of the number of pumps that can work in parallel and the size of the generator in PV irrigation pond irrigation installations. The case study consists of a pumping between two reservoirs, where the higher level one supplies by gravity an irrigation surface of 42.21 ha, in the Sector 4 irrigation community, close to the municipality of Picassent belonging to the Valencian Community located in the East from Spain. The methodology used is based on the design of the PV installation (Peak Power $(\mathrm{Pp}, \mathrm{W}))$ and the pumping equipment using the standard methodology. A proposal is made of the pumping hypotheses with different number of pumps operating in parallel (BFP) (from 1 to 8 pumps) where the sum of the flows of all the BFPs of the different hypotheses will be equal to the flow of the hypothesis of 1 pump. The annual pumped volume (VBA, m3year-1) is calculated by determining the hours of available power (HPD, h) for each hypothesis (where Net power (Pnet, W) $>$ Required power $(\mathrm{Pb}, \mathrm{W}))$ for all the days of the year to know the variation of the VBA. Next, different hypotheses of power factor (FP) (quotient between $\mathrm{Pp}$ and $\mathrm{Pb}$ ) are used in order to study the minimum number of solar panels required. Finally, the number of pumps is selected by economic criteria. As main results, a greater use of irradiance is obtained, for the hypothesis with 1 pump the minimum power required for it to start is $24.4 \mathrm{~kW}$, which is equivalent to an irradiance threshold of $336.2 \mathrm{Wm}^{-2}$ for the worst month. However, to start pumping with the $5 \mathrm{BFP}$ hypothesis, only $4.9 \mathrm{~kW}$ is required, the irradiance threshold being $65.2 \mathrm{Wm}-2$ for the most unfavourable month. By increasing the number of pumps, the VBA is increased to almost $27 \%$, and looking at the pumping increases throughout this year in relation to the volume needs to be pumped, it is determined that for the optimal number of pumps that would be 5 , in this case study, the FP is decreased by $50.7 \%$. The economic function indicates the number of BFP to select, being the hypothesis of 5 pumps the one with the lowest cost.

Keywords: Photovoltaic pumping; Selection of pumps; Photovoltaic irrigation optimization 


\section{Congreso Nacional de Riegos CARTAGENA 2021}

\section{1. introducción}

Los sistemas fotovoltaicos son susceptibles de aplicación para el riego solar como muestra la bibliografía [1-3]. Por lo general, para el cálculo de instalaciones donde hay bombeos de agua entre dos depósitos, en el caso de bombeo fotovoltaico, se dimensionan determinando el punto de funcionamiento y seleccionando una bomba cuya curva (Hm-Q) pase lo más cerca del mismo y con el mejor rendimiento posible. El problema de esta metodología es que durante buena parte del día la energía solar es insuficiente para mantener o bien poner en marcha la bomba y se desperdicia. Cabe la posibilidad de poner, en lugar de una única bomba, varias bombas más pequeñas conectadas en paralelo que puedan aprovechar la energía disponible con menores niveles de radiación para una misma potencia de generador fotovoltaico instalada.

El objetivo de este trabajo es proponer una metodología de dimensionado con la que llegar a establecer, tanto el número de bombas en paralelo, como la potencia del generador fotovoltaico necesario, para el funcionamiento adecuado de una impulsión a una balsa.

\section{Materiales y métodos}

\subsection{Zona de estudio}

Este estudio se ha realizado en una pequeña zona de la Comunidad de Regantes Picassent Sector 4 cercana al municipio de Picassent en la Comunidad Valenciana, en el este de España. La instalación abastece una superficie de 42,21 ha, que se riegan desde un depósito elevado de $1680 \mathrm{~m}^{3}$, situado junto al cabezal de San Rafael (coordenadas 39 22'51,46"N, $0^{\circ} 31^{\prime} 59,43^{\prime \prime} \mathrm{O}$ ), siendo la cota de su lamina libre de agua de 165.3 m.s.n.m. Esta cota permite efectuar el riego de esta zona sin necesidad de energía adicional. Este depósito es alimentado, desde el depósito del cabezal Sagrada Familia siendo la cota de su lamina libre de 142 m.s.n.m (coordenadas 39²3'13,06"N, $0^{\circ} 31^{\prime} 12,65 " \mathrm{O}$ ), también perteneciente a la comunidad de regantes. La instalación hidráulica está compuesta por una conducción de $1400 \mathrm{~m}$ de longitud de PVC de DN 400 y PN6 la cual une los dos depósitos. En la instalación se proyectó y selecciono una única bomba que requiere de una potencia de $24.4 \mathrm{~kW}$, abastecida mediante una instalación fotovoltaica compuesta de 170 paneles de $320 \mathrm{Wp}$ generando una potencia pico de $54.4 \mathrm{kWp}$ con un factor o relación Potencia generada-Potencia requerida de 2,23.

\subsection{Metodología aplicada}

En este trabajo proponemos una metodología que permita determinar tanto el número de bombas más adecuado como la potencia del generador, que garantice el suministro hídrico necesario y minimice la potencia fotovoltaica instalada.

\subsubsection{Selección de generador fotovoltaico y bomba hidráulica}

Se considera el mes más desfavorable (MUM) aquel en que la relación obtenida con la ecuación (1) es mayor.

$$
M U M_{i}=\frac{E H_{i}}{\operatorname{Gmax}_{i}}
$$

Donde $E H_{i}$ es la energía hidráulica promedio diaria mensual $(\mathrm{kWh})$ y $\operatorname{Gmax}_{i}$ es la radiación solar disponible promedio diaria mensual $(\mathrm{kWh})$. La radiación $\left(\operatorname{Gmax}_{i}\right)$ se ha obtenido a partir de los datos de irradiancia de un 


\section{Congreso Nacional de Riegos CARTAGENA 2021}

Año Meteorológico Tipo proporcionado por el Sistema de información geográfica fotovoltaica (PVGIS) del servicio de ciencia y conocimiento de la Comisión Europea (https://ec.europa.eu/jrc/en/pvgis) para la ubicación de la instalación. EHi se determina, para cada mes del año, con la expresión (2):

$$
E H_{i}=\frac{\rho \cdot g \cdot H m \cdot V}{3600}
$$

Donde $\rho$ es la densidad del agua $\left(\mathrm{kg} . \mathrm{m}^{-3}\right), g$ es la aceleración de la gravedad $\left(9.81 \mathrm{~m} \mathrm{~s}^{-2}\right), \mathrm{Hm}$ es la altura manométrica $(\mathrm{m}), V_{\text {dia }}$ es el volumen de agua a bombear diariamente $\left(\mathrm{m}^{3} \mathrm{dia}^{-1}\right)$.

Para el cálculo del volumen a bombear en cada mes usamos la siguiente ecuación:

$$
V_{\text {day }}=10^{-3} \cdot E T o \cdot K c \cdot f c_{\text {month }} \cdot \text { Area }
$$

Donde $V_{\text {day }}$ es volumen bombeado diariamente $\left(\mathrm{m}^{3} \mathrm{dia}^{-1}\right)$, ETo es la evapotranspiración de referencia (mm), Kc es el coeficiente de cultivo y $f c_{\text {month }}$ es el factor de corrección mensual propuestos para cítricos por el Institut Valencià d'Investigacions Agràries (IVIA) (www.ivia.gva.es), Area es la superficie a regar (42.21 ha).

Teniendo en cuenta las características de la impulsión, la altura manométrica (Hm) que debe suministrar el sistema de bombeo, se determina:

$$
\begin{aligned}
& H m=\left(Z_{2}-Z_{1}\right)+h r+h s \\
& h r=10.674 \cdot \frac{Q^{1.852}}{C^{1.852} \cdot D^{4.78}} \cdot L
\end{aligned}
$$

Donde $\left(Z_{2}-Z_{1}\right)$ es la diferencia de cotas $(23,3 \mathrm{~m}), h r$ son las pérdidas de carga por rozamiento determinadas según Hazen-Williams (m) (eq 5), $h s$ son las pérdidas de carga localizadas (m), $Q$ es el caudal de diseño para cada mes $\left(\mathrm{m}^{3} \mathrm{~s}^{-1}\right)$ a partir del volumen y las horas solar pico, $C$ es el coeficiente de rugosidad (en PVC, C = 150), $D$ el diámetro interno (380.4 m) y $L$ la longitud de la tubería de impulsión (1400 m).

Para el mes más desfavorable, el caudal de diseño $\left(\mathrm{Q}, \mathrm{m}^{-3} \mathrm{~s}^{-1}\right)$ se determina teniendo en cuenta que las horas de funcionamiento de la bomba ( $\mathrm{PH}$ ) son menores a las horas solar pico (HSP) para cada mes. HSP se ha calculado promediando las irradiancias diarias de cada mes $\left(\mathrm{kWh} \cdot \mathrm{m}^{-2} \cdot \mathrm{dia}^{-1}\right)$. $\mathrm{PH}$ se ha determinado sumando las horas en que la potencia requerida por las bombas es menor a la potencia generada por el generador fotovoltaico.

$$
Q=\frac{V_{d a y}}{P H}
$$

A partir de la Energía Hidráulica $\left(E H_{i}\right)$ para el mes más desfavorable, se determina la Energía Eléctrica (EE) (Eq.7), la potencia pico necesaria $\left(P_{p}\right)$ (Eq.8) y finalmente el número de paneles ( $\left.\mathrm{N}_{\text {paneles}}\right)$ (Eq.9) mediante las siguientes ecuaciones:

$$
\begin{gathered}
E E=\frac{E H_{i}}{\eta_{m b}} \\
P_{p}=\frac{E E}{P R \cdot H S P} \\
N_{\text {paneles }}=\frac{P_{p}}{P_{p_{\text {panel }}}}
\end{gathered}
$$

Siendo $\eta_{m b}$ el rendimiento del grupo motobomba y PR el rendimiento energético del sistema.

Para el cálculo del número de paneles solares (Eq.9) se escoge un panel de $320 \mathrm{Wp}$, se considera un PR = 0.4 , y un rendimiento del grupo moto-bomba de $\eta_{m b}=0.8$ 


\section{Congreso Nacional de Riegos CARTAGENA 2021}

\subsubsection{Potencia neta del generador}

En la determinación de la potencia del generador se considera el efecto de la radiación y la temperatura sobre el mismo, estos datos se trataron con una frecuencia horaria para todos los días del periodo de estudio. Los datos meteorológicos empleados se obtienen, con una frecuencia horaria de la estación agroclimática de Picassent del IVIA, perteneciente al Sistema de Información Agroclimática para el Regadío (SIAR). La temperatura de la célula (Tcel) se determina utilizando la expresión de [4]:

$$
\text { Tcel }=T+\frac{(T O N C-20) \cdot G}{800}
$$

Donde T es Temperatura en grados centígrados, TONC es la temperatura nominal de funcionamiento de la célula fotovoltaica (en este caso $45^{\circ} \mathrm{C}$ ) y $\mathrm{G}$ es la irradiancia $\mathrm{Wm}^{-2}$.

El sistema FV está formado por 170 paneles con 72 células FV de 6 pulgadas de material policristalino con una potencia de $320 \mathrm{~W}$. La potencia fotovoltaica instantánea neta disponible se determina mediante la ecuación:

$$
P_{\text {int }}=P_{p} \cdot \frac{G}{1000} \cdot\left(1+\frac{\alpha_{p}}{100} \cdot(\text { Tcel }-25)\right)
$$

Donde Pp es la potencia pico de la placa solar, G es la irradiancia $\mathrm{Wm}^{-2}$ para el año 2019, $\alpha_{p}$ es el coeficiente de variación de $\mathrm{Pp}$ con la temperatura $\left(\%{ }^{0} \mathrm{C}^{-1}\right)$ y $\mathrm{Tcel}$ es la temperatura de la célula fotovoltaica.

Por último, se debe de tener en cuenta que la potencia neta (Pnet) que las bombas pueden utilizar, se ve afectada por la eficiencia del inversor y del motor del equipo.

$$
P_{\text {net }}=P_{\text {int }} \cdot \eta_{f c} \cdot \eta_{m b}
$$

Donde $\eta_{f c}$ es la eficiencia del inversor que se considera $0.9 \mathrm{y}$ un rendimiento del grupo moto-bomba que se considera $\eta_{m b}=0.8$.

\subsection{Hipótesis de bombeo}

Para estudiar el efecto que tiene el aumento del número de bombas en paralelo en el caudal bombeado, se plantean 8 hipótesis. La hipótesis de partida con una bomba y las hipótesis 2 a 8 con un número creciente de bombas. La primera considera la bomba que sería necesaria para elevar un Q de $280 \mathrm{~m}^{3} \mathrm{~h}^{-1}$ a una $\mathrm{Hm}$ de $25.1 \mathrm{~m}$, esta sería el caso de utilizar una única bomba. La segunda hipótesis estaría formada por dos bombas de la mitad de $Q$ funcionando en paralelo, la tercera por tres bombas de un tercio del $Q$, y así sucesivamente, hasta llegar a la octava en que participan hasta 8 bombas. Las bombas consideradas son de la marca comercial Indar (https://www.ingeteam.com) para seleccionar la misma marca comercial de la instalación. El funcionamiento de las mismas se ha simulado considerando los modelos de las bombas comerciales. La selección de las bombas con los diferentes puntos de funcionamiento, según el número de bombas estudiadas, se realiza en base a la máxima eficiencia que pueden proporcionar los modelos comerciales.

En cada hipótesis, en función de la energía disponible, se irán conectando bombas hasta alcanzar la máxima energía requerida. Por ejemplo, cuando la energía requerida por una bomba para su funcionamiento a velocidad nominal sea menor que la energía suministrada por el sistema fotovoltaico esa bomba comenzara a impulsar el caudal correspondiente a la potencia transmitida al eje. Por ello, las HPD para cada bomba de cada hipótesis se producirán cuando Pnet $>\mathrm{P}_{\mathrm{b}_{\mathrm{i}}}$, siendo el caudal impulsado la suma de los caudales bombeados por las bombas de cada hipótesis. Cuando la energía suministrada por las placas solares sea superior a la requerida por dos bombas, se conectará la segunda bomba y suministrando el caudal de esas 2 bombas y así sucesivamente hasta alcanzar el número máximo de bombas de cada hipótesis. El caudal y altura manométrica de cada bomba dentro de cada 


\section{Congreso Nacional de Riegos CARTAGENA 2021}

hipótesis se calculan según la Eq.13. La Hm mínima es de $23.3 \mathrm{~m}$ con un caudal de $35 \mathrm{~m}^{3} \mathrm{~h}^{-1} \mathrm{y}$ se da en la hipótesis de 8 bombas, la Hm máxima es de $25.1 \mathrm{~m}$ y se producirá cuando se impulsan $280 \mathrm{~m}^{3} \mathrm{~h}^{-1}$ para todas las hipótesis.

$$
Q_{B^{\prime o m b a}}=\frac{Q_{I P}}{N}
$$

Donde $Q_{B o m b a}$ es el caudal que suministran las bombas de cada hipótesis en funcionamiento $\left(\mathrm{m}^{3} \mathrm{~h}^{-1}\right), Q_{I P}$ es el caudal que debería suministrar si se instalara una única bomba $\left(280 . \mathrm{m}^{3} \mathrm{~h}^{-1}\right)$ y $N$ es el número de bombas que se considera en cada una de las hipótesis (de 1 a 8 ).

Con la variación del caudal impulsado varían las pérdidas de carga, y se modifica la altura manométrica y la eficiencia de cada bomba y con ello la potencia requerida por la misma $\left(P_{b_{i}}\right)$.

$$
\mathrm{P}_{\mathrm{b}_{\mathrm{i}}}=\frac{1}{\eta_{\mathrm{i}}} \cdot \gamma \cdot \mathrm{Q}_{\mathrm{i}} \cdot \mathrm{Hm}_{\mathrm{i}}
$$

Donde $\eta_{i}$ es la eficiencia de las bombas para cada número de bombas de cada hipótesis, $\gamma$ es el peso específico del agua $\left(\mathrm{Nm}^{-3}\right), \mathrm{Q}_{i}$ es el caudal requerido para cada número de bombas de cada hipótesis $\left(\mathrm{m}^{3} \mathrm{~s}^{-1}\right)$ y $\mathrm{Hm}_{i}$ es la altura manométrica requerida para cada número de bombas de cada hipótesis (m).

El volumen semanal bombeado $\left(V_{a n ̃ o}\right)$ se calcula mediante la siguiente ecuación:

$$
V_{a \tilde{n} o}=\sum\left(I W h_{B o m b a_{i}} \cdot Q_{B_{o m b a}}\right)
$$

Siendo $V_{a n ̃ o}$ el volumen en $\mathrm{m}^{3}$ anual, $I W h_{B o m b a_{i}}$ son las horas anuales en que la potencia suministrada al número de bombas de cada hipótesis es superior a la requerida.

\subsection{Generador fotovoltaico}

El generador de partida cuenta con un número de paneles, y el Factor de Potencia (Fp) que relaciona la ponencia instalada frente a potencia requerida:

$$
F p=\frac{N_{\text {paneles }} \cdot P P_{p}}{P_{b_{i}}}
$$

Con objeto de estudiar el efecto del tamaño del generador en el funcionamiento de la instalación y en el bombeo de agua se han considerado diferentes relaciones de Fp, siendo estas $0.5,1,1.1,1.2,1.3,1.4,1.5,1.6,1.7$, $1.8,1.9,2,2.5,3,4,5,10$. Además se estudia el Fp instalado (170 paneles fotovoltaicos) con la hipótesis de 1 bomba (Fp: 2.23), de 3 bombas (Fp: 2.1), de 5 bombas (Fp: 2.06) y de 8 bombas (Fp: 1.81). Se desarrolla en el apartado 3.2.

\subsection{Selección del número de bombas por criterio económico.}

En este apartado se estudia la variación del coste económico para las diferentes hipótesis, de 1 a 8 bombas, y diferente tamaño de generador. El coste de las bombas para las hipótesis 1, 3, 5 y 8, el cual es obtenido del catálogo comercial de Indar, es de 10,777.2 $€ \mathrm{Ud}^{-1}, 4,600.6 € \mathrm{Ud}^{-1}, 3,293.5 € \mathrm{Ud}^{-1}$ y 2,703.3€ Ud $\mathrm{Ud}^{-1}$ respectivamente. El coste de cada panel fotovoltaico actualmente en la casa Solar Innova es de $124.2 € \mathrm{Ud}^{-1}$. Ambos catálogos son precios del año 2021. El cálculo económico se ha limitado al coste de las bombas y de las placas solares, sin tener en cuenta otros costes involucrados o ingresos como son los excedentes de energía. Por ello, el cálculo del coste económico de cada hipótesis $(\mathrm{CEh})$ se ha realizado mediante la siguiente ecuación, para las hipótesis con 1, 3, 5 y 8 bombas.

$$
C E_{h}=P C_{h} \times P N_{n}+P V C_{h} \times N_{\text {paneles }_{h}}
$$

Donde PCh es el coste del modelo de las bombas de cada hipótesis $\left(€ \mathrm{Ud}^{-1}\right)$, el PVCh es el coste del panel fotovoltaico $\left(€ \mathrm{Ud}^{-1}\right)$ y Npanelesh es el número de paneles fotovoltaicos de cada hipótesis para abastecer el volumen requerido. 


\section{Congreso Nacional de Riegos CARTAGENA 2021}

\section{Resultados y discusión}

\subsection{Variación del volumen impulsado con cada una de las hipótesis.}

En la figura 1 se muestra la evolución del volumen bombeado semanalmente a lo largo del año 2019 para cada una de las hipótesis planteadas. En ella destaca que el volumen impulsado con la hipótesis de partida ( 1 bomba) es significativamente inferior al del resto de hipótesis a todo lo largo del año.

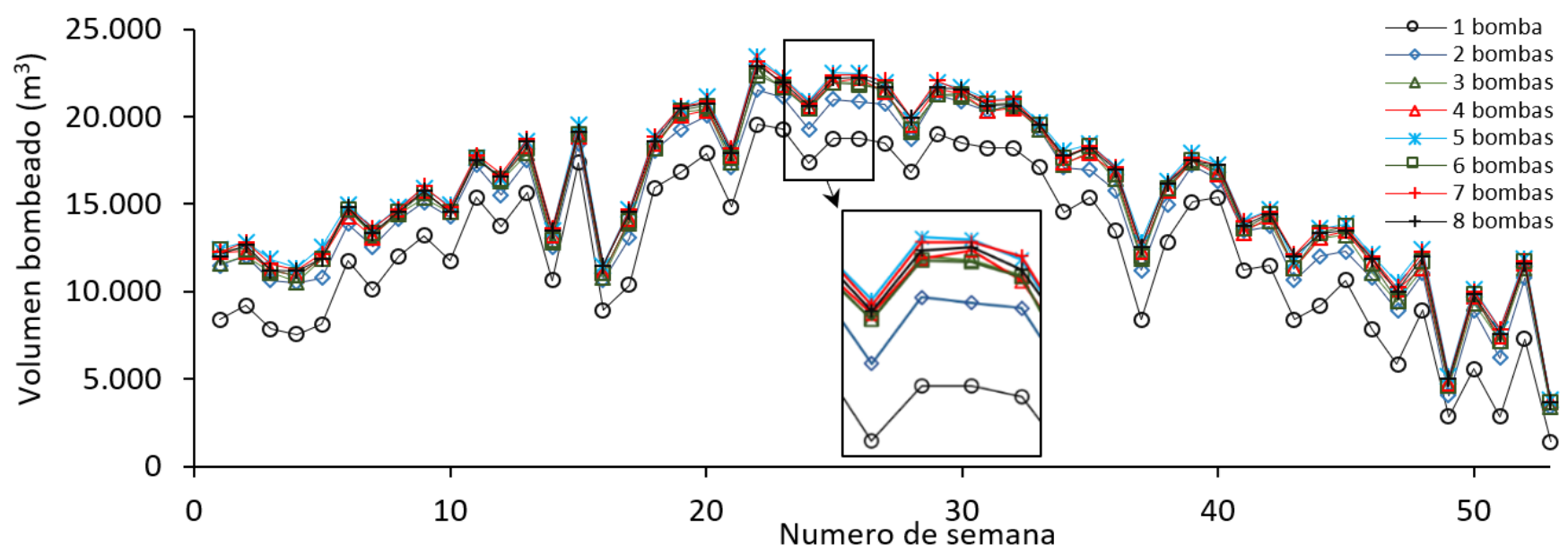

Figura 1: Volumen bombeado $\left(\mathrm{m}^{3}\right)$ para la irradiancia medida $\left(\mathrm{W} \mathrm{m}^{2}\right)$ por semana durante el año 2019.

Al aumentar el número de bombas en paralelo con cada una de las hipótesis aumenta el caudal bombeado, pero las diferencias son cada vez menores. Aunque cada bomba bombea menos caudal que en la hipótesis anterior, aumentan las horas de energía disponible (Energía suministrada-Energía requerida) y con ello el volumen bombeado $\left(\mathrm{m}^{3}\right)$. Este aumento tiene un límite, puesto que conforme aumenta el número de bombas se reduce la ganancia de volumen inyectado respecto de la hipótesis anterior. La ganancia respecto de la hipótesis con 1 bomba crece hasta la hipótesis de 5 bombas con un aumento de un $27 \%$ del volumen anual inyectado respecto de la hipótesis de partida. A partir de la hipótesis con 5 bombas la ganancia deja de crecer y se hace asintótica, lo cual muestra que el sistema de bombeo más adecuado para este caso corresponde a la hipótesis de 5 bombas en paralelo (figura 2).

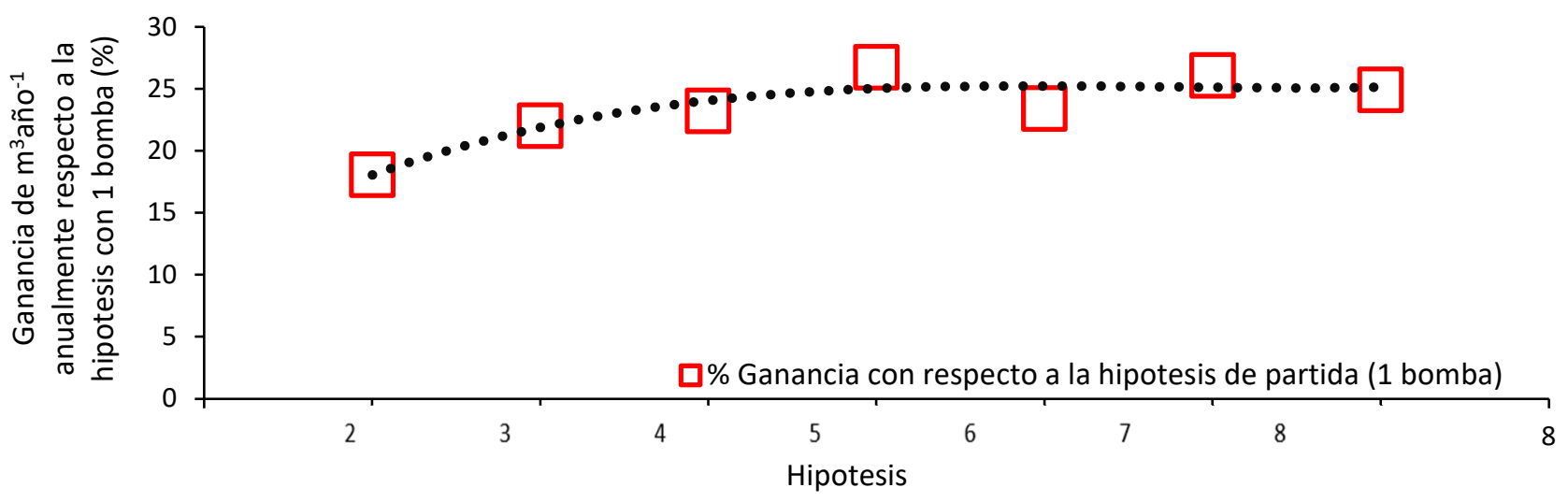

Figura 2: Porcentaje de ganancia de volumen bombeado de las hipótesis de 2 a 8 bombas respecto de la hipótesis de 1 bomba y línea de tendencia de la ganancia. 


\section{Congreso Nacional de Riegos CARTAGENA 2021}

\subsection{Variación del volumen impulsado en función de la potencia del generador fotovoltaico.}

En este apartado se estudió la variación del volumen bombeado anual para las hipótesis con 1, 3, 5 y 8 bombas en función de la potencia pico del generador fotovoltaico.

En la Figura 3 se muestra el aumento en el volumen bombeado $\left(\mathrm{m}^{3} \mathrm{año}^{-1}\right)$ al aumentar el tamaño del generador fotovoltaico para cada una de las hipótesis con 1, 3, 5 y 8 bombas en paralelo. Como era de esperar, al aumentar la potencia del generador fotovoltaico también aumenta el volumen bombeado en todas las hipótesis. Y para una potencia determinada de generador fotovoltaico, el volumen bombeado es tanto mayor cuanto mayor es el número de bombas de la hipótesis. También en esta figura se observa que la ganancia en volumen bombeado es menor conforme las hipótesis tienen mayor número de bombas. De tal forma que al pasar de la hipótesis con 1 bomba a la de 3 bombas, o de 3 a 5 , la ganancia en volumen bombeado es muy importante, pero la diferencia se reduce al pasar de 5 a 8 bombas. El efecto del tamaño del generador es muy importante (pendiente muy acusada) hasta un tamaño de generador que depende del número de bombas de la hipótesis. Se puede observar que conforme aumenta la potencia pico instalada aumenta el volumen anual impulsado. También cuando se aumenta el número de bombas que funcionan en paralelo aumentan los $\mathrm{m}^{3} \mathrm{año}^{-1}$ impulsados, pero los aumentos van disminuyendo conforme se aumenta el número de bombas que funcionan en paralelo siendo la ganancia muy reducida cuando se pasa de la hipótesis de 5 a 8 bombas funcionando en paralelo. Por ello, se vuelve a confirmar qué el óptimo para este caso de estudio sería la instalación de 5 bombas funcionando en paralelo.

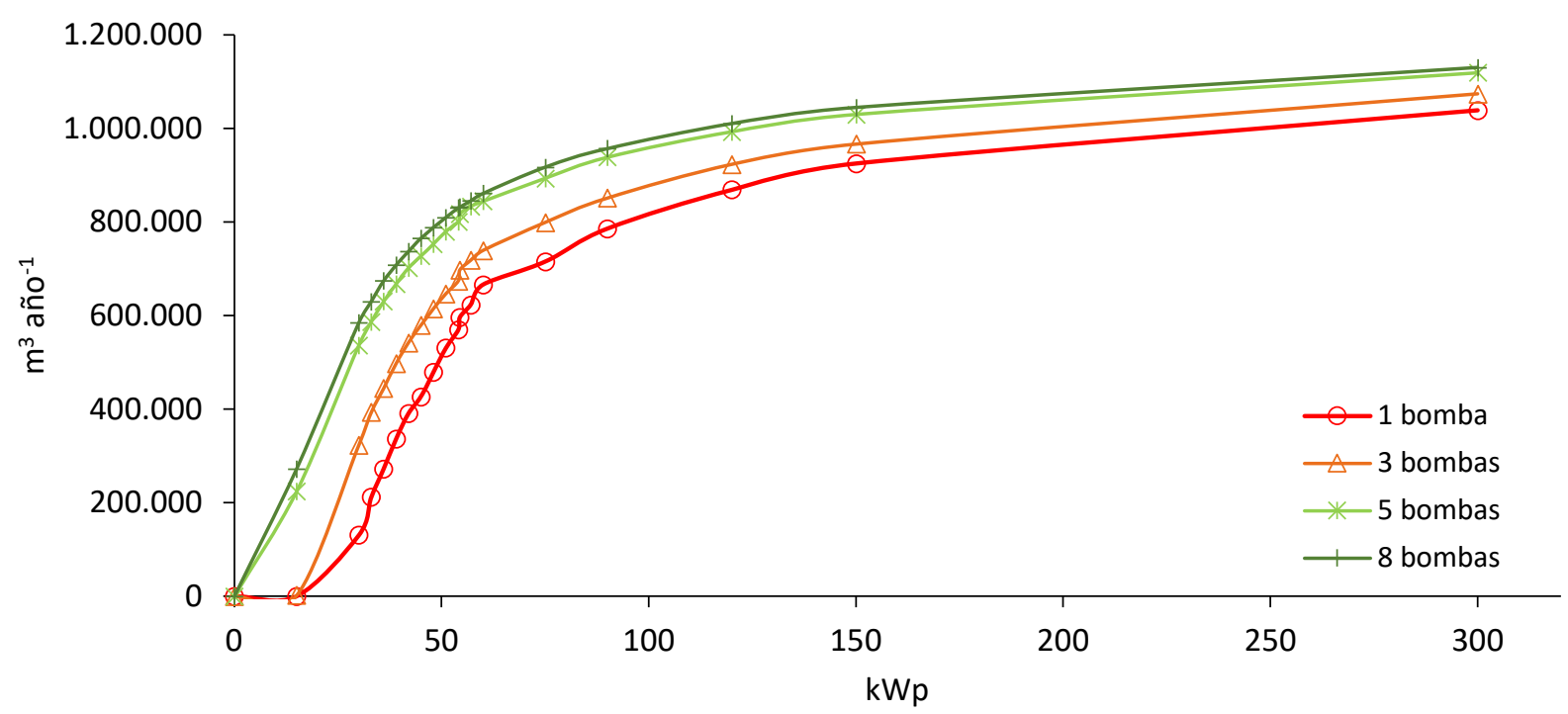

Figura 3: Volumen bombeado $\left(\mathrm{m}^{3}\right)$ frente a los $\mathrm{kWp}$ del generador fotovoltaico para diferentes factores de potencia que relacionan potencia instalada y potencia requerida.

\subsection{Variación del volumen impulsado en función del tamaño del generador FV.}

En este apartado se estudia el Fp o relación mínima que debe haber entre la potencia pico instalada y la potencia requerida por las bombas, en cada una de las hipótesis, para poder suministrar el volumen semanal necesario para abastecer la zona de regadío.

En la Figura 4 se muestra el volumen bombeado semanalmente con las hipótesis de 1, 3, 5 y 8 bombas con capacidad fotovoltaica suficiente para abastecer el volumen semanal requerido por la zona de riego. Como ya vimos en la figura 7 y también se desprende de la figura 8, el tamaño necesario de 


\section{Congreso Nacional de Riegos CARTAGENA 2021}

generador fotovoltaico aumenta conforme se reduce el número de bombas siendo necesario un Fp, o relación, de 2,23 con la hipótesis de 1 sola bomba, de 1,6 con 3 bombas, de 1,1 con 5 bombas y finalmente cuando se instalan 8 bombas sería necesario un Fp de 1. Por otro lado, también se observa que, al aumentar el número de bombas, la diferencia de Fp se va reduciendo ya que de 1 (Fp: 2.23 y $54.4 \mathrm{kWp}$ ) a 3 bombas (Fp: 1.6 y $41.3 \mathrm{kWp}$ ) se reduce el Fp en 0.63, de 3 a 5 bombas (Fp: 1.1 y $28.9 \mathrm{kWp}$ ) se reduce el Fp en 0.5 y de 5 a 8 bombas (Fp: 1.0 y $30 \mathrm{kWp}$ ) se reduce el $\mathrm{Fp}$ en 0.1 , por lo que podemos considerar que a partir de 5 bombas ya no hay reducciones significativas de la potencia fotovoltaica mínima requerida.

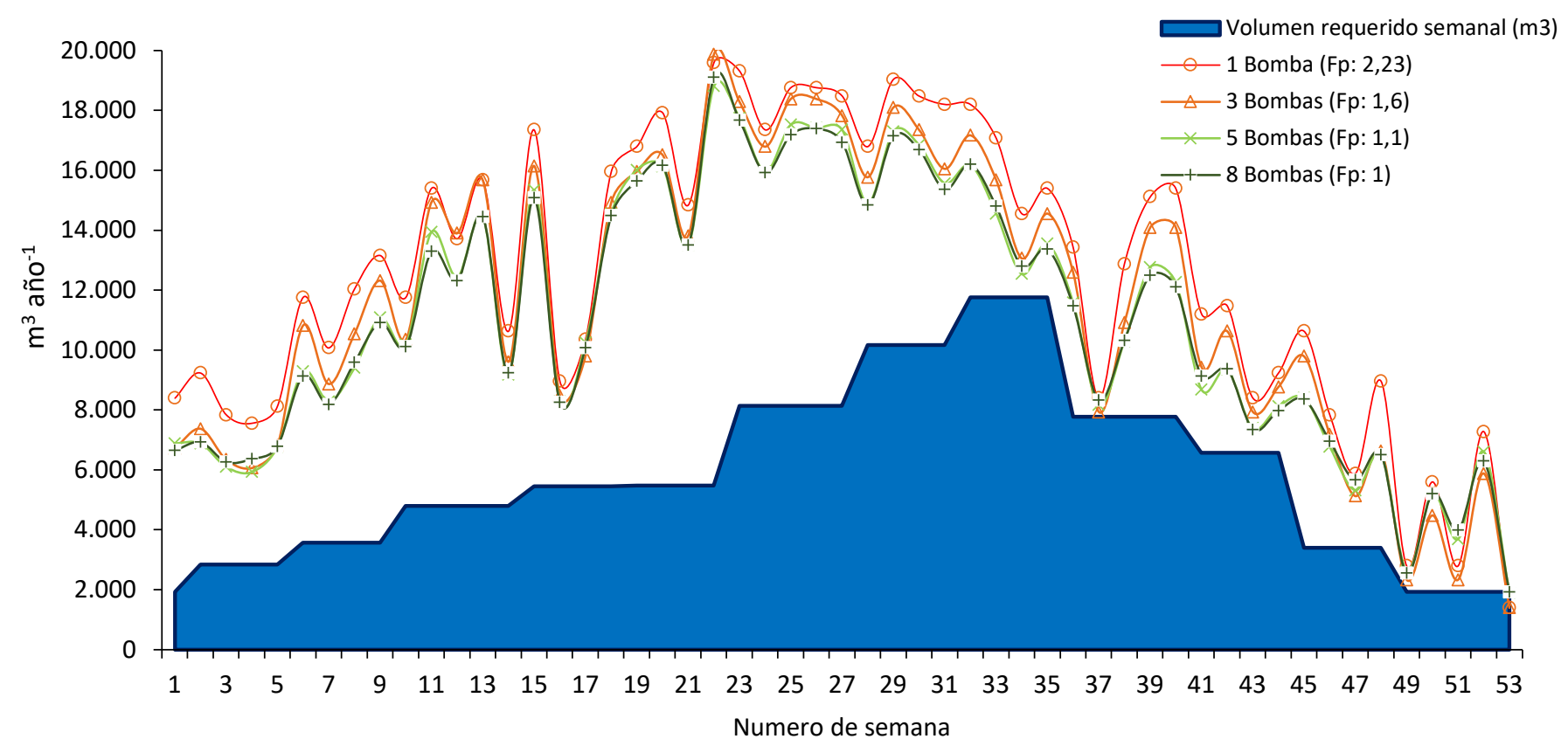

Figura 4: Volumen bombeado semanalmente $\left(\mathrm{m}^{3}\right)$ con las hipótesis de 1, 3, 5 y 8 bombas con factores de potencia 2.23, 1.6, 1.1 y 1 respectivamente para bombear el agua semanal requerida, frente al volumen semanal requerido por la zona de riego.

\subsection{Selección del número de bombas por criterio económico.}

En este apartado se describen los resultados de la selección de bombas por criterio económico como se indica en el apartado 2.5. Como muestra la figura 5 al aumentar el número de bombas se puede disminuir el número de paneles fotovoltaicos para abastecer un determinado volumen e impulsar. Como cabía esperar, al aumentar el número de bombas reduciendo su coste unitario y la reducción del número de paneles fotovoltaicos produzca una reducción del coste de instalación. Sin embargo, la pendiente de la curva comienza a aumentar a partir de la hipótesis de 5 bombas en funcionamiento. Esto es debido a dos causas, la primera es que conforme se disminuye la potencia de la bomba se va reduciendo la diferencia de precio entre las bombas y sin embargo se va aumentando el número de bombas. La segunda causa es que conforme se aumenta el número de bombas estás presentan menores eficiencias y por ello el Fp se va reduciendo, presentando solo una ganancia del 0.1 de la hipótesis de 5 a la de 8 bombas. 


\section{Congreso Nacional de Riegos CARTAGENA 2021}

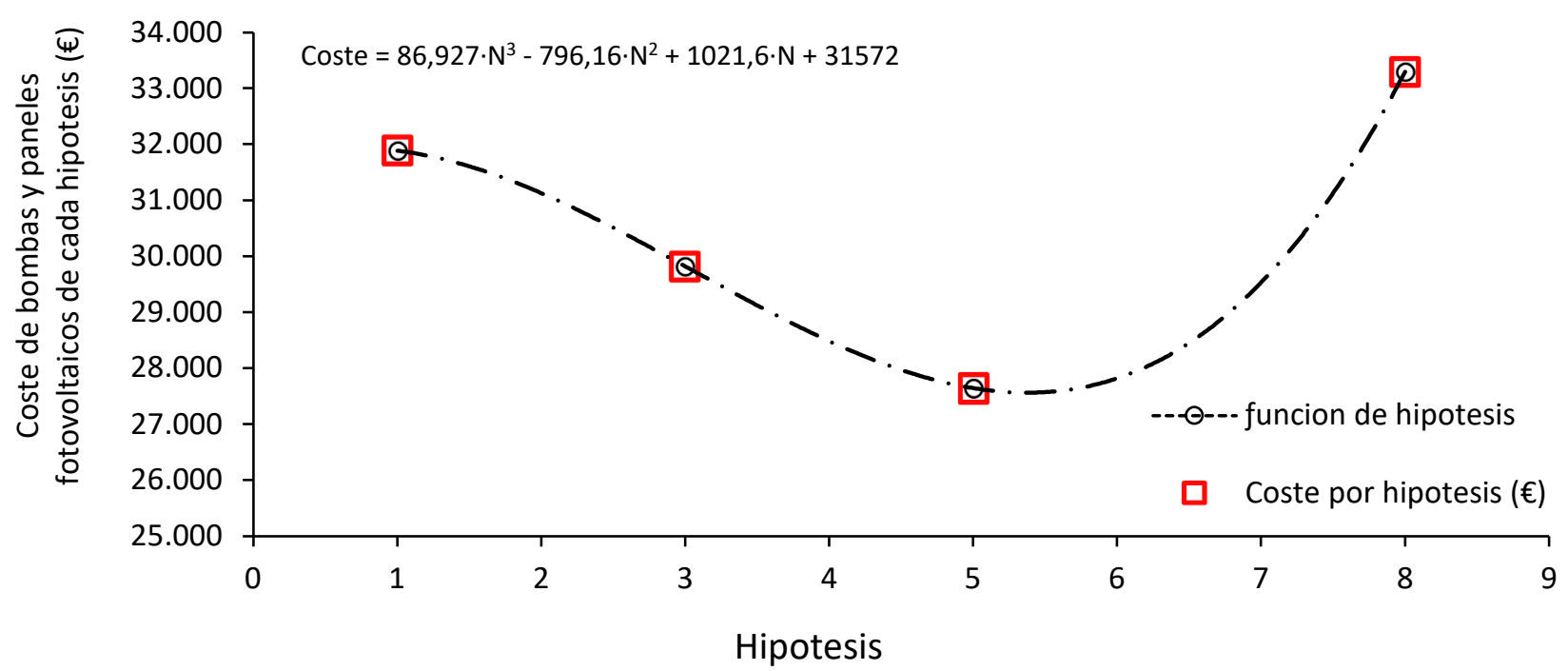

Figura 5: Coste de las bombas y paneles fotovoltaicos que los abastecen las hipótesis de 1, 3, 5 y 8, en función del número de bombas.

Por tanto, también se confirma con el criterio económico que la opción más favorable para este caso es colocar 5 bombas en paralelo. Por último, hay que tener en cuenta que la función se ha limitado al coste de las bombas y de los paneles fotovoltaicos con lo cual para futuros trabajos se debe de estudiar una función con todos los costes o ingresos que se puedan generar en la instalación fotovoltaica.

\section{Conclusiones}

En este trabajo se ha comprobado que en instalaciones fotovoltaicas aisladas de bombeo directo es preferible la colocación de varias bombas en paralelo para aprovechar mejor los momentos de menor radiación solar aumentando el volumen impulsado anualmente hasta un $27 \%$. Según los incrementos del volumen bombeado el número óptimo de bombas funcionando en paralelo sería de 5. Así mismo, el aumento del volumen bombeado, para el óptimo de 5 bombas, permite en este caso de estudio que el factor de potencia disminuya en un 50,7\%, además de disminuir el coste entre la hipótesis con 1 bomba y la hipótesis de 5 bombas de un 13.3\%.

\section{Agradecimientos}

Este estudio ha sido parcialmente financiado por el proyecto ADAPTAMED (RTI2018-101483-B-I00), financiado por el Ministerio de Ciencia e Innovación de España y con fondos de la UE FEDER

\section{Referencias}

1. Mérida García, A.; González Perea, R.; Camacho Poyato, E.; Montesinos Barrios, P.; Rodríguez Díaz, J.A. Comprehensive sizing methodology of smart photovoltaic irrigation systems, Agric. Water Manag. 229 (2020) 105888. https://doi.org/10.1016/j.agwat.2019.105888.

2. Hamidat, A.; Benyoucef, B.; Hartani, T. Small-scale irrigation with photovoltaic water pumping system in Sahara regions, Renew. Energy. 28 (2003) 1081-1096. https://doi.org/10.1016/S0960-1481(02)00058-7.

3. López-Luque, R.; x Reca, J. R. Martínez, Optimal design of a standalone direct pumping photovoltaic system for deficit irrigation of olive orchards, Appl. Energy. 149 (2015) 13-23. https://doi.org/10.1016/j.apenergy.2015.03.107.

4. Markvart, T.; Castaner, L. Practical Handbook of Photovoltaics: Fundamentals and Applications, Elsevier Science \& Technology, Kidlington, 2003. 


\title{
Predicción del volumen bombeado semanalmente con diferente número de bombas en una estación con energía fotovoltaica
}

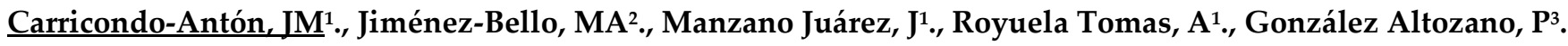

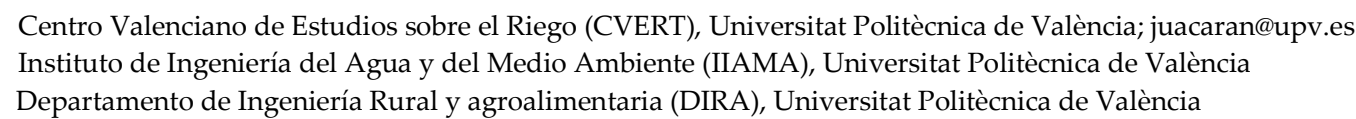

Resumen: La metodología clásica para el dimensionamiento de instalaciones de riego fotovoltaico no optimiza el número de bombas a utilizar. Para determinar el número de bombas se debe estudiar el mayor aprovechamiento de la irradiancia solar disponiendo varias bombas funcionando en paralelo y determinando a futuro los parámetros de temperatura $\left(\mathrm{T},{ }^{\circ} \mathrm{C}\right)$ e irradiancia (Irrad, $\mathrm{Wm}^{-2}$ ), los cuales son utilizados para el cálculo de la potencia neta del generador (Pnet, W) y con ello el poder obtener una predicción del volumen que se puede bombear a una semana vista. A través de la red de estaciones meteorológicas del Instituto Valenciano de Investigaciones Agrarias (IVIA) (http://riegos.ivia.es/) se han obtenido los datos meteorológicos de la zona de estudio. El objetivo es analizar en qué medida se puede aumentar el volumen bombeado $\left(\mathrm{VB}, \mathrm{m}^{3} \mathrm{~h}^{-1}\right)$ al incrementar el número de bombas instaladas en paralelo y la precisión de la estimación del VB semanalmente mediante servicios climáticos o mediante datos históricos. Este estudio se ha realizado en un bombeo del Sector 4 del Canal Júcar-Turia que abastece una superficie de 42,21 ha, en su mayoría cítricos.

Se propone un modelo basado en la estimación de los VB semanales mediante predicciones meteorológicas, estimando los parámetros de T y Irrad para calcular la Potencia Neta Generada por día y hora (PnetD,h, W). La T y Irrad se obtienen mediante datos procedentes del servicio climático Global Forecast System (GFS) (www.nco.ncep.noaa.gov) de la National Centers for Environmental Prediction (NCEP), y mediante datos históricos. Una vez determinada Pnetb, h, se calcula la potencia requerida $\left(\mathrm{PbD}_{\mathrm{D}, \mathrm{h}} \mathrm{W}\right)$ por día y hora para los diferentes grupos de bombas funcionando en paralelo (de 1 a 8 bombas). Se determina las horas de potencia disponible (HPDD,h, h) donde PnetD,h> PbD,h. Las HPDD,h de cada bomba para cada una de las 8 hipótesis multiplicadas por el caudal $\left(\mathrm{Q}, \mathrm{m}^{3} \mathrm{~h}^{-1}\right)$ de cada bomba determina el VB. Al aumentar el número de bombas en paralelo aumentan los VB anualmente respecto de la metodología clásica de instalar 1 bomba, esto es debido, al mayor aprovechamiento de la Irrad. En el caso estudiado, instalar 5 bombas en paralelo de idénticas características en lugar de una única bomba, permitiría aumentar casi el 27 \% del VB sin necesidad de modificar el generador fotovoltaico. También, los resultados demuestran que los datos del servicio climático GFS permiten mejorar la estimación del VB, a una semana vista, en comparación con el uso de datos históricos de media en un 32.2\%.

Palabras clave: Bombeo fotovoltaico; Predicción meteorológica; Predicción volúmenes bombeados 


\title{
Prediction of the volume pumped weekly with different num- ber of pumps in a station with photovoltaic energy
}

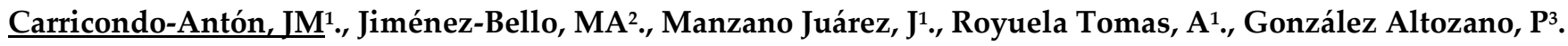

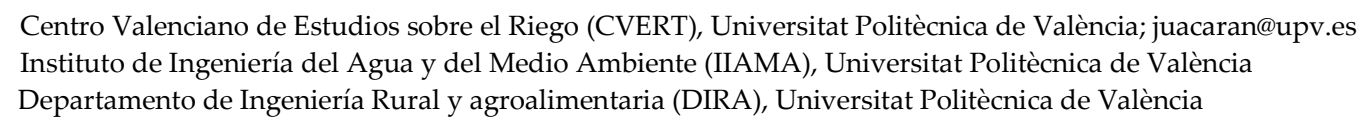

Abstract: The classical methodology for sizing photovoltaic irrigation installations does not optimize the number of pumps to be used. To determine the number of pumps, the best use of solar irradiance must be studied by having several pumps operating in parallel and determining in the future the temperature $\left(\mathrm{T},{ }^{\circ} \mathrm{C}\right)$ and irradiance (Irrad, $\mathrm{Wm}^{-2}$ ) parameters, which are used for the calculation of the net power of the generator (Pnet, $\mathrm{W}$ ) and with it the power to obtain a prediction of the volume that can be pumped within a week. Through the network of meteorological stations of the Valencian Institute of Agrarian Research (IVIA) (http://riegos.ivia.es/) the meteorological data of the study area have been obtained. The objective is to analyse to what extent the pumped volume (VB, m3h-1) can be increased by increasing the number of pumps installed in parallel and the precision of the weekly VB estimation using weather services or through historical data. This study has been carried out in a pumping of Sector 4 of the Júcar-Turia Canal that supplies an area of 42.21 ha, mostly citrus.

A model is proposed based on the estimation of weekly BV through meteorological predictions, estimating the parameters of $\mathrm{T}$ and Irrad to calculate the Net Power Generated per day and hour (PnetD, $h, W)$. The T and Irrad are obtained using data from the Global Forecast System (GFS) climate service (www.nco.ncep.noaa.gov) of the National Centers for Environmental Prediction (NCEP) and using historical data. Once PnetD, $h$ has been determined, the required power $(\mathrm{PbD}, \mathrm{h}, \mathrm{W})$ per day and hour is calculated for the different groups of pumps operating in parallel (from 1 to 8 pumps). The hours of available power (HPDD, $h, h$ ) are determined where PnetD, $\mathrm{h}>\mathrm{Pb}_{\mathrm{D}} \mathrm{h}$. The HPDD, $\mathrm{h}$ of each pump for each of the 8 hypotheses multiplied by the flow rate $\left(\mathrm{Q}, \mathrm{m}^{3} \mathrm{~h}^{-1}\right)$ of each pump determines the VB. By increasing the number of pumps in parallel, the BVs increase annually with respect to the classical methodology of installing 1 pump, this is due to the greater use of Irrad. In the case studied, installing 5 pumps with identical characteristics in parallel instead of a single pump would allow an increase of almost $27 \%$ of the BV without the need to modify the photovoltaic generator. Also, the results show that the data from the GFS climate service allows us to improve the estimation of the BV, at one week seen, compared to the use of historical data on average by $32.2 \%$.

Keywords: Photovoltaic pumping; Weather forecast; Pumped volumes prediction 


\section{Congreso Nacional de Riegos CARTAGENA 2021}

\section{Introducción}

Los procesos de modernización generan un aumento del consumo energético en las redes de distribución de agua que requieren bombeos. La energía tradicionalmente utilizada ha sido de origen no renovable basada fundamentalmente en el uso de combustibles fósiles [1,2], los cuales han sufrido un aumento de precio muy importante a lo largo de los últimos años. Para disminuir los costes de bombeo se han desarrollado sistemas de riego abastecidos de energía fotovoltaica. La metodología clásica para el dimensionamiento de instalaciones de riego fotovoltaicas se basa en determinar el mes de mayor diferencia entre la energía hidráulica requerida y la energía solar disponible; se determina el ángulo de inclinación del generador fotovoltaico para posteriormente dimensionar y configurar el generador fotovoltaico, se selecciona la bomba teniendo en cuenta que el punto de funcionamiento esté lo más próximo a la curva (H-Q) para obtener el mayor rendimiento posible y, por último, se selecciona un convertidor de frecuencia. Sin embargo, este sistema de dimensionado no optimiza los bombeos fotovoltaicos ya que desaprovecha gran parte de la radiación solar. Para realizar un mayor aprovechamiento de la irradiancia se pueden disponer de varias bombas con un funcionamiento en paralelo, produciendo que cada bomba pueda ir aprovechando la irradiancia a lo largo del día, y de la determinación a futuro de los parámetros de temperatura $\left({ }^{\circ} \mathrm{C}\right)$ e irradiancia $\left(\mathrm{W} \mathrm{m}^{-2}\right)$, los cuales son utilizados para el cálculo de la potencia neta del generador (Pnet) y con ello el poder obtener una predicción del volumen que se bombeara a una semana vista.

El objetivo del estudio es analizar la precisión de la estimación de volúmenes bombeados semanalmente, con diferente número de bombas funcionando en paralelo, mediante servicios climáticos disponibles o mediante la media de datos de medidos de los últimos 10 años y en qué medida se puede aumentar dicho volumen al incrementar el número de bombas instaladas en paralelo.

\section{Materiales y métodos}

\subsection{Zona de estudio}

Este estudio se ha realizado en una pequeña zona de la Comunidad de Regantes Picassent Sector 4 cercana al municipio de Picassent en la Comunidad Valenciana, en el este de España.

La instalación abastece una superficie de 42,21 ha, que se riegan desde un depósito elevado de 1680 m3, situado junto al cabezal de San Rafael (coordenadas 39 22'51,46"N, $0^{\circ} 31^{\prime} 59,43^{\prime \prime} \mathrm{O}$ ), siendo la cota de su lamina libre de agua de 165.3 m.s.n.m. Esta cota permite efectuar el riego de esta zona sin necesidad de energía adicional. Este depósito es alimentado, desde el depósito del cabezal Sagrada Familia siendo la cota de su lamina libre de 142 m.s.n.m (coordenadas $39^{\circ} 23^{\prime} 13,06^{\prime \prime} \mathrm{N}, 0^{\circ} 31^{\prime} 12,65 " \mathrm{O}$ ), también perteneciente a la comunidad de regantes.

La instalación hidráulica está compuesta por una conducción de $1400 \mathrm{~m}$ de longitud de PVC de DN 400 y PN6 la cual une dos depósitos. Inicialmente se ha proyectado una única bomba que requiere de una potencia de $24.4 \mathrm{~kW}$, abastecida mediante una instalación fotovoltaica compuesta de 170 paneles de $320 \mathrm{Wp}$ generando una potencia pico de $54.4 \mathrm{kWp}$ con un factor o relación Potencia generada-Potencia requerida de 2,23 . 


\section{Congreso Nacional de Riegos CARTAGENA 2021}

\subsection{Determinación de potencia neta del generador}

El volumen que impulsará la bomba depende de la irradiancia y la temperatura [3]. El volumen a impulsar se determina en este caso de estudio de dos maneras, una mediante la estimación de la potencia neta con los datos pasados (Pnet10 años) realizando la media de la irradiancia (Irrad10 años) y de tempe-

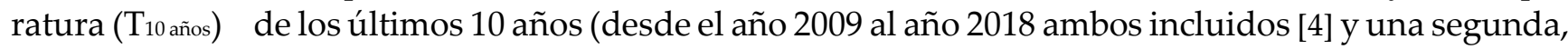
mediante la predicción de la potencia neta (Pnetpredicha) realizada con predicciones meteorológicas para los parámetros de irradancia ( $\operatorname{Irrad}_{\text {predicha }}$ y temperatura $\left(\mathrm{T}_{\text {predicha }}\right)$. Ambas con una ventana temporal de 1 semana [5-7].

Los datos históricos de irradiancia y temperatura se obtuvieron a partir de la media de los datos de temperatura $\left({ }^{\circ} \mathrm{C}\right)$ e irradiancia $\left(\mathrm{wm}^{-2}\right)$ semihoraria de los últimos 10 años para la estación climatológica más próxima a la zona de estudio (E. A. Picassent), pertenecientes al Institut Valencià d'Investigacions Agràries (IVIA) siendo su web (http://www.ivia.gva.es).

Las predicciones de irradiancia y temperatura se realizan mediante predicciones meteorológicas [7-9] del servicio climático, Global Forecast System (GFS) de la National Centers for Environmental Prediction (NCEP), perteneciente al gobierno de US, el cual permite automatizar la descarga diaria de las predicciones (https://www.noaa.gov). Este servicio, de acceso gratuito, suministra predicciones meteorológicas en tiempo real, esto permite pronosticar los volúmenes bombeados a priori, con una ventana temporal de 1 semana.

Para el cálculo de la energía disponible, donde la potencia fotovoltaica es mayor que la requerida por el bombeo, se tuvo en cuenta la eficiencia de las células fotovoltaicas que conforman el panel solar, la cual se ve afectada por la temperatura que pueden alcanzar al estar sometidas a la irradiancia. Para calcular la temperatura de la célula $\left(\mathrm{Tcel},{ }^{\circ} \mathrm{C}\right.$ ) se emplea la siguiente formula [10].

$$
T c e l=T+\frac{(T O N C-20) \cdot S R}{800}
$$

Donde $\mathrm{T}$ es Temperatura en $\left({ }^{\circ} \mathrm{C}\right)$, TONC es la temperatura nominal de funcionamiento de la célula fotovoltaica (en este caso $45^{\circ} \mathrm{C}$ ) y SR es la irradiancia solar $\left(\mathrm{Wm}^{-2}\right)$.

El cálculo de la potencia horaria neta disponible fotovoltaica para cada día de la semana se determinó mediante la ecuación:

$$
P_{D, H}=P_{p} \cdot \frac{S R}{1000} \cdot\left(1+\frac{\alpha_{p}}{100} \cdot(\text { Tcel }-25)\right)
$$

Donde Pp es la potencia pico de la placa solar y $\alpha_{p}$ es el coeficiente de variación de Pp con la temperatura $\left(\% /{ }^{\circ} \mathrm{C}\right)$. Por último, se debe de tener en cuenta que la potencia neta requerida por cada sector (Pnet) de las bombas se ve afectada por la eficiencia del inversor y del motor del equipo.

$$
P_{n e t}=P_{D, H} \cdot \eta_{f c} \cdot \eta_{m}
$$

Donde $\eta_{f c}$ es la eficiencia del inversor que es de 0.9 y $\eta_{m}$ es la eficiencia del motor que es de 0.8. 


\subsection{Determinación de la variación de volúmenes bombeados.}

Para poder realizar el análisis sobre la validación de los volúmenes bombeados se ha escogido bombas de la marca comercial Indar (https://www.ingeteam.com). Se determinan diferentes hipótesis de bombeo en paralelo, donde el número total de bombas en cada hipótesis es creciente, siendo igual el caudal total máximo por bombear. En cada hipótesis en función de la energía disponible se irán conectando bombas hasta alcanzar la máxima energía requerida.

$$
Q=\frac{Q_{I}}{N}
$$

Donde $Q$ es el caudal a impulsar que se reparten las bombas en paralelo $\left(\mathrm{m}^{3} \mathrm{~h}^{-1}\right), Q_{I}$ es el caudal que suministra la bomba instalada $\left(\mathrm{m}^{3} \mathrm{~h}^{-1}\right)$ y $N$ es el número de bombas que se plantean en las hipótesis (de 1 a 8 ).

Con la variación del caudal de la conducción varían las pérdidas de carga, modificando la altura manométrica, el rendimiento de cada bomba y con ello la potencia requerida por la bomba $\left(P_{b}\right)$.

$$
P_{b}=\frac{1}{\eta} \cdot \gamma \cdot \mathrm{Q} \cdot H m
$$

Donde $\eta$ es la eficiencia de las bombas, $\gamma$ es el peso específico del agua $\left(\mathrm{Nm}^{-3}\right)$, $Q$ es el caudal requerido $\left(\mathrm{m}^{3} \mathrm{~s}^{-1}\right)$ y $\mathrm{Hm}$ es la altura manométrica requerida $(\mathrm{m})$.

El volumen semanal bombeado $\left(V_{\text {semanal }}\right)$ se calcula mediante las horas semanales donde la energía suministrada por el sistema fotovoltaico es mayor a la energía requerida por las bombas, para cada una de las bombas y estas horas se multiplican por el $Q$ de cada bomba mediante la siguiente ecuación:

$$
V_{\text {semanal }}=\sum W h \cdot Q
$$

Siendo $V_{\text {semanal }}$ el volumen en $\mathrm{m} 3, \mathrm{Wh}$ son las horas semanales de cada bomba donde la potencia suministrada es superior a la requerida y $Q$ es el caudal que suministran las bombas en funcionamiento $\left(\mathrm{m}^{3} \mathrm{~h}^{-1}\right)$.

Una vez tenemos los volúmenes semanales para todo el año se suman y se establece el volumen suministrado por cada hipótesis (de 1 a 8 bombas), pudiendo determinar la ganancia con relación a la hipótesis de partida (1 bomba). 


\section{Congreso Nacional de Riegos CARTAGENA 2021}

\section{Resultados y discusión}

En este apartado se muestran los resultados de la variación del volumen bombeado al incrementar el número de bombas funcionando en paralelo. Posteriormente se muestra los resultados para las variables que permiten determinar el volumen bombeado, irradiancia y temperatura y con ello la Pnet para las metodologías empleadas, tanto mediante predicciones meteorológicas como usando datos históricos para su estimación. Por último, se muestran los resultados de los volúmenes bombeados, tanto de predicción mediante predicciones meteorológicas como estimación con datos históricos frente a los volúmenes bombeados con los parámetros medidos en 2019 en la zona de estudio.

\subsection{Evolución del volumen impulsado con diferente número de bombas en paralelo}

Como se puede observar en la figura 1, al aumentar el número de bombas en paralelo aumentan los volúmenes impulsados, aunque a partir de la quinta bomba, se alcanza una tendencia asintótica y no hay un aparente aumento de volumen.

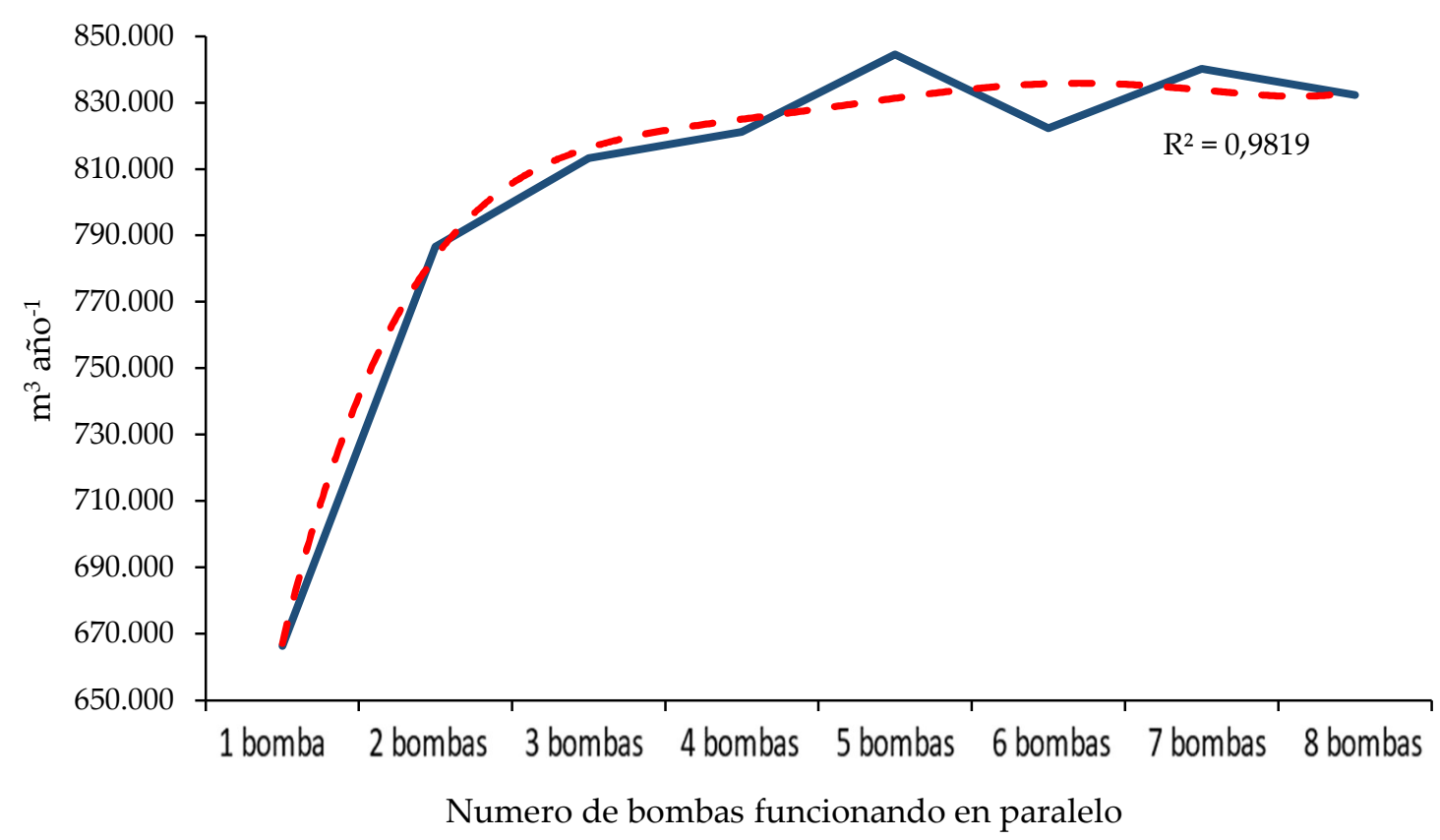

Figura 1. Aumento del volumen impulsado anualmente en $\mathrm{m}^{3}$ para las hipótesis con diferente número de bombas.

\subsection{Errores relativos para las variables temperatura, irradiancia y potencia neta}

Se calcularon los errores relativos diarios cometidos entre la temperatura, la irradiancia y la potencia neta predicha mediante predicciones meteorológicos y la estimada mediante datos históricos frente a los datos medidos de temperatura, irradiancia y la potencia neta calculada a lo largo de 2019.

Para evaluar los resultados, se ha calculado el error medio diario de 2019, el error medio en época de máximas necesidades de riego (desde el 1 de abril al 30 de septiembre de 2019), el error medio en 
época de mínimas necesidades de riego (desde el 1 de enero al 31 de marzo y del 1 de octubre al 31 de diciembre de 2019), la desviación típica, el máximo error y el mínimo error

Los errores relativos de irradiancia, temperatura y potencia neta se pueden encontrar la tabla 1.

Tabla 1. Errores relativos de temperatura, irradiancia y Pnet media diaria (\%).

\begin{tabular}{|c|c|c|c|c|c|}
\hline & 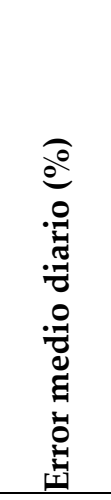 & 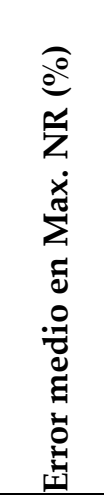 & 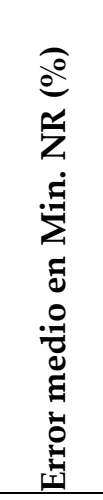 & 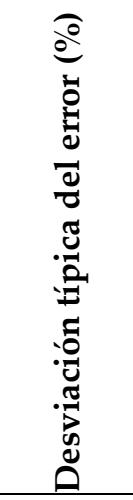 & 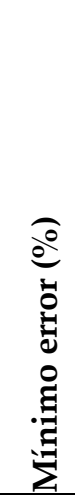 \\
\hline Irrad $_{10 \text { años }}$ & 50,63 & 52,17 & 49,10 & 176,85 & 0,07 \\
\hline Irrad $_{\text {predicha }}$ & 26,10 & 24,99 & 27,20 & 80,50 & 0,05 \\
\hline $\mathrm{T}_{10}$ años & 13,33 & 8,04 & 18,59 & 14,73 & 0,11 \\
\hline $\mathrm{T}_{\text {predicha }}$ & 7,70 & 5,03 & 10,36 & 8,69 & 0,01 \\
\hline Pnet10 años & 46,72 & 47,49 & 45,96 & 162,26 & 0,11 \\
\hline Pnetpredicha & 24,43 & 23,22 & 25,63 & 75,91 & 0,02 \\
\hline
\end{tabular}

Para todos los parámetros estadísticos presentan menores errores cuando los parámetros se han predicho con predicciones meteorológicas. Se puede observar, por ejemplo, como el error medio diario de 2019 para los parámetros Irrad predicha, $_{\text {predicha }}$ y Pnetpredicha, desciende casi un $50 \%$ respecto a estos parámetros estimados mediante datos históricos.

\subsection{Errores relativos semanales de los volúmenes bombeados}

Del mismo modo, el análisis se ha extendido a los errores relativos semanales cometidos entre el volumen calculado mediante predicciones meteorológicos o mediante datos históricos frente a los volúmenes calculados con los datos medidos en 2019.

Al igual que en el caso diario, se ha calculado el error medio semanal de 2019, el error medio en época de máximas necesidades de riego, el error medio en época de mínimas necesidades de riego, la desviación típica, el máximo error y el mínimo error. 
Tabla 2. Errores relativos de los volúmenes bombeados semanalmente (\%).

\begin{tabular}{|c|c|c|c|c|c|c|c|}
\hline & & 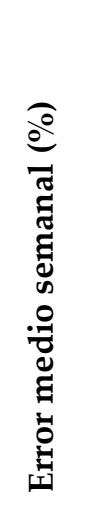 & 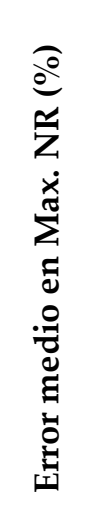 & 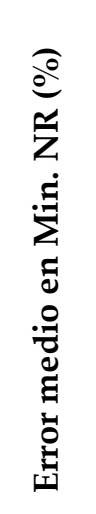 & 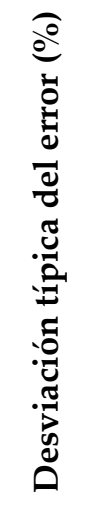 & 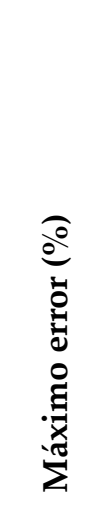 & 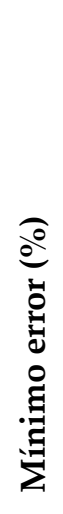 \\
\hline \multirow{2}{*}{1 bomba } & P. meteorológica & 12,7 & 12,4 & 13,3 & 12,7 & 60,0 & 0,0 \\
\hline & E. media 10 años & 15,3 & 11,1 & 19,7 & 17,7 & 88,2 & 0,0 \\
\hline \multirow{2}{*}{2 bombas } & P. meteorológica & 8,8 & 9,0 & 8,8 & 9,0 & 48,3 & 0,0 \\
\hline & E. media 10 años & 13,6 & 11,7 & 15,7 & 21,9 & 134,5 & 0,0 \\
\hline \multirow{2}{*}{3 bombas } & P. meteorológica & 8,2 & 7,6 & 9,0 & 10,5 & 57,1 & 0,0 \\
\hline & E. media 10 años & 12,3 & 11,3 & 13,3 & 20,0 & 110,2 & 0,0 \\
\hline \multirow{2}{*}{4 bomba } & P. meteorológica & 7,4 & 6,7 & 8,1 & 8,9 & 49,3 & 0,0 \\
\hline & E. media 10 años & 12,4 & 10,5 & 14,4 & 20,2 & 120,9 & 0,0 \\
\hline \multirow{2}{*}{5 bombas } & P. meteorológica & 7,2 & 6,4 & 8,0 & 8,7 & 48,9 & 0,0 \\
\hline & E. media 10 años & 11,4 & 9,9 & 13,0 & 19,1 & 110,9 & 0,0 \\
\hline \multirow{2}{*}{6 bombas } & P. meteorológica & 7,1 & 6,1 & 8,1 & 9,2 & 51,4 & 0,0 \\
\hline & E. media 10 años & 11,3 & 9,7 & 13,1 & 18,8 & 109,2 & 0,3 \\
\hline \multirow{2}{*}{7 bomba } & P. meteorológica & 7,0 & 6,2 & 7,8 & 9,4 & 55,6 & 0,0 \\
\hline & E. media 10 años & 11,8 & 10,3 & 13,4 & 19,4 & 111,9 & 0,4 \\
\hline \multirow{2}{*}{8 bombas } & P. meteorológica & 7,5 & 6,9 & 8,2 & 9,4 & 54,1 & 0,2 \\
\hline & E. media 10 años & 10,5 & 9,2 & 11,8 & 17,2 & 96,5 & 0,0 \\
\hline
\end{tabular}

Los resultados mostraron que las estimaciones del volumen bombeado mediante predicciones meteorológicas muestran menor error semanal que utilizar los datos históricos (ver tabla 2), de media un $33,2 \%$ menos para las diferentes hipótesis, como se puede ver en la figura 2. 


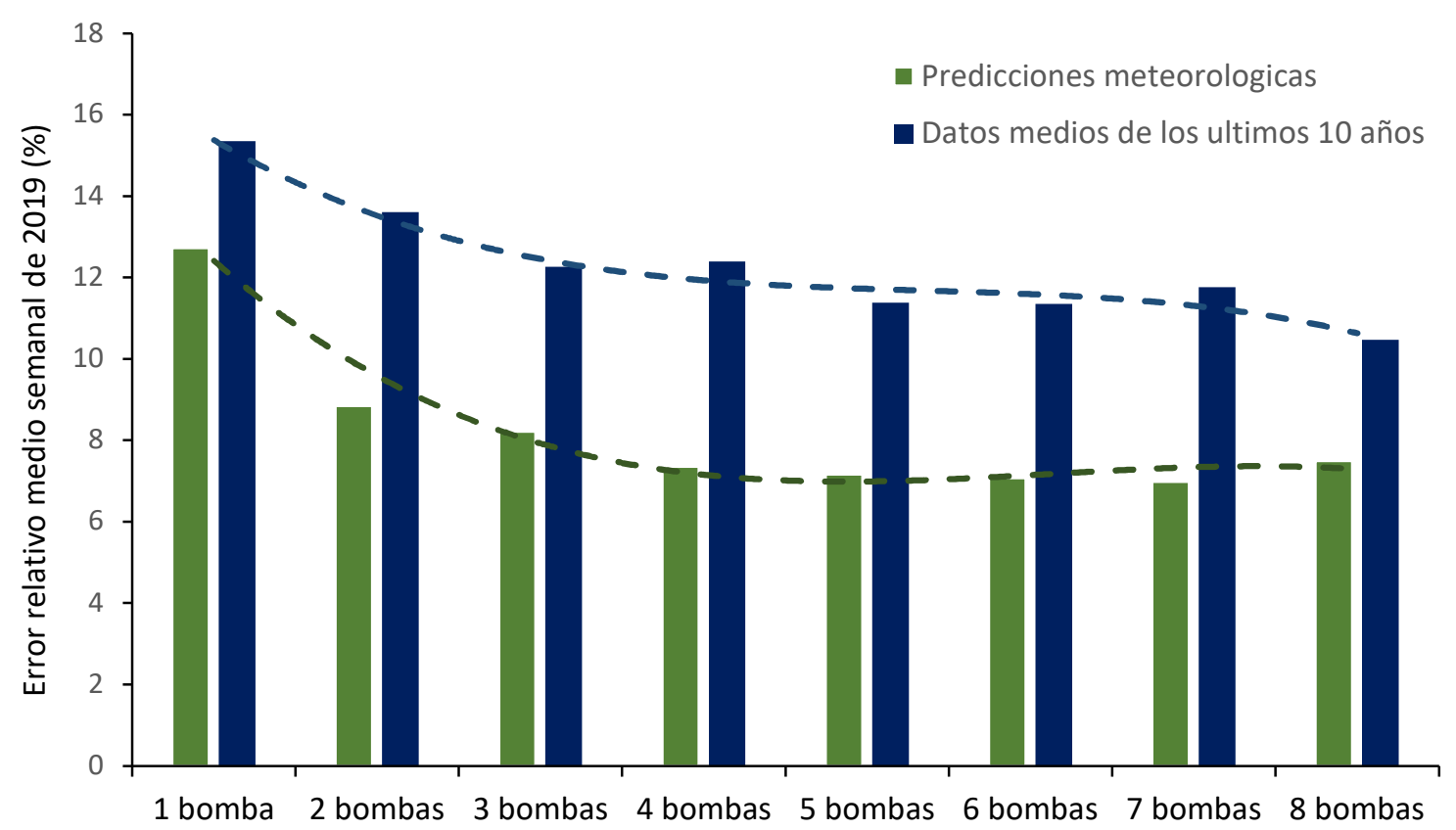

Figura 2. Media anual del error semanal del volumen bombeado mediante la irradiancia predicha con predicciones meteorológicas y de la predicha mediante los datos de los últimos 10 años frente al volumen bombeado con la irradiancia medida en el año 2019.

\section{Conclusiones}

En el caso estudiado, instalar cinco bombas en paralelo de idénticas características en lugar de una única bomba de mayor tamaño, permitiría aumentar el volumen elevado desde los $666.400 \mathrm{~m}^{3}$ hasta los $844.536 \mathrm{~m}^{3}$, lo que supone un incremento de casi el $27 \%$ del volumen bombeado sin necesidad de modificar el generador fotovoltaico instalado.

Además, se concluye que el uso de los datos del servicio climático Global Forecast System (GFS) para predecir las necesidades de bombeo, permiten mejorar la estimación del volumen bombeado a una semana vista en comparación con el uso de datos históricos. El error medio diario de 2019 para los parámetros irradiancia, temperatura y potencia neta descienden casi un $50 \%$ cuando se emplean predicciones meteorológicas frente de estos parámetros estimados mediante datos históricos. Por ello, las estimaciones del volumen bombeado mediante predicciones meteorológicas muestran de media un $33,2 \%$ menos de error relativo para las diferentes hipótesis que utilizar los datos históricos.

\section{Agradecimientos}

Este estudio ha sido parcialmente financiado por el proyecto ADAPTAMED (RTI2018-101483-B-I00), financiado por el Ministerio de Ciencia e Innovación de España y con fondos de la UE FEDER 


\section{Referencias}

1. Santra, P. Performance evaluation of solar PV pumping system for providing irrigation through micro-irrigation techniques using surface water resources in hot arid region of India, Agric. Water Manag. (2020) 106554. https://doi.org/10.1016/j.agwat.2020.106554.

2. Senthil Kumar, S.; Bibin, C.; Akash, K. ; Aravindan, K.; Kishore, M.; Magesh, G. Solar powered water pumping systems for irrigation: A comprehensive review on developments and prospects towards a green energy approach, Mater. Today Proc. 33 (2020) 303-307. https://doi.org/10.1016/j.matpr.2020.04.092.

3. Odeh, I.; Yohanis, Y.G.; Norton, B. Influence of pumping head, insolation and PV array size on PV water pumping system performance, Sol. Energy. 80 (2006) 51-64. https://doi.org/10.1016/j.solener.2005.07.009.

4. Escobar, P.; Martínez, E.; Saenz-Díez, J.C.; Jiménez, E.; Blanco, J. Profitability of self-consumption solar PV system in Spanish households: A perspective based on European regulations, Renew. Energy. 160 (2020) 746-755. https://doi.org/10.1016/j.renene.2020.06.135.

5. $\quad$ von Loeper, F.; Schaumann, P.; de Langlard, M.; Hess, R.; Bäsmann, R.; Schmidt, V. Probabilistic prediction of solar power supply to distribution networks, using forecasts of global horizontal irradiation, Sol. Energy. 203 (2020) 145-156. https://doi.org/10.1016/j.solener.2020.04.001.

6. Lan, H.; Zhang, C.; Hong, Y.Y. ; He, Y.; Wen, S. Day-ahead spatiotemporal solar irradiation forecasting using frequency-based hybrid principal component analysis and neural network, Appl. Energy. 247 (2019) 389-402. https://doi.org/10.1016/j.apenergy.2019.04.056.

7. Carricondo-Anton, J.M.; Jiménez-Bello, M.; Martínez Alzamora, F.; Sala, A. Análisis de las Predicciones Climáticas a partir de distintos Servicios Climáticos para la Programación del Riego, XXXVII Congr. Nac. Riegos. (2019).

8. Lorite, I.J.; Ramírez-Cuesta, J.M.; Cruz-Blanco, M.; Santos, C. Using weather forecast data for irrigation scheduling under semi-arid conditions, Irrig. Sci. 33 (2015) 411-427. https://doi.org/10.1007/s00271-015-0478-0.

9. Li, D.; Hendricks Franssen, H.J.; Han, X.; Jiménez-Bello, M.A.; Martínez Alzamora, F.; Vereecken, H. Evaluation of an operational real-time irrigation scheduling scheme for drip irrigated citrus fields in Picassent, Spain, Agric. Water Manag. 208 (2018) 465-477. https://doi.org/10.1016/j.agwat.2018.06.022.

10. Markvart, T. ; Castaner, L. Practical Handbook of Photovoltaics: Fundamentals and Applications, Elsevier Science \& Technology, Kidlington, 2003. 


\title{
Recuperación de humedad del suelo sobre campos agrícolas que emplean observaciones Sentinel-1 y Sentinel-2, y basado en la estimación de la rugosidad de la superficie obtenido del proceso de fotogrametría de UAV.
}

\author{
Amal Chakhar ${ }^{1}$, David Hernández-López ${ }^{1}$, Rocío Ballesteros ${ }^{1}$ and Miguel A. Moreno ${ }^{1}$ \\ 1 Instituto de Desarrollo Regional, Universidad de Castilla-La Mancha, 02071 Albacete, España; Amal.Chakhar@uclm.es; David.Hernan- \\ dez@uclm.es; Rocio.Ballesteros@uclm.es; MiguelAngel.Moreno@uclm.es.2
}

Resumen: El objetivo de este estudio es la aplicación de una metodología que permitió la estimación del contenido de humedad superficial del suelo (SSM) en un ambiente semi-árido en Tarazona de la Mancha, España. En países caracterizados por un clima árido y semiárido, la determinación precisa de las condiciones de humedad del suelo a escala de parcela es de importancia crítica, especialmente durante las primeras etapas del crecimiento de los cultivos, para programar el riego y reducir el consumo de agua. La recuperación de (SSM) se realizó combinando dos modelos de dispersión Modelo de ecuación integral IEM y Modelo de nube de agua WCM suministrados por coeficientes de retrodispersión en VV (Transmisión vertical y recepción vertical) polarización obtenida de Radar de Apertura Sintética (SAR) de banda C y un descriptor de vegetación el Índice de Vegetación de Diferencia Normalizada (NDVI) obtenido con un sensor óptico, entre otros parámetros esenciales. La inversión de estos modelos fue realizada utilizando Redes Neuronales Artificiales (ANN). Los modelos combinados fueron calibrados por Sentinel-1 (el sensor de radar) y los datos de Sentinel-2 (el sensor óptico) recolectados sobre campos de cultivo de cebada y guisantes. Para recuperar SSM, estos modelos de dispersión necesitan mediciones precisas de los parámetros de la superficie de rugosidad (altura de la raíz cuadrada media hrms y longitud de correlación L). Por lo tanto, en este trabajo, utilizamos un sistema de adquisición fotogramétrica montado en un UAV (Vehículos Aéreos No Tripulado), para reconstruir DSM (Modelos Digitales de Superficie), lo que permitió adquirir esta rugosidad del suelo a nivel de gran parte de los campos estudiados. Los resultados obtenidos mostraron que la metodología aplicada brindó una herramienta eficaz para estimar la SSM durante las principales etapas iniciales de crecimiento. Para el campo de cebada, la relación entre el SSM estimado y medido mostró $\mathrm{R} 2=0.71$ y RMSE $=0.0124$ (m3/m3). Con respecto al campo experimental de guisantes, la relación entre el SSM estimado y medido mostró $R 2=0.72$ y RMSE $=0.022(\mathrm{~m} 3 / \mathrm{m} 3)$.

Palabras clave: Humedad de suelo; Sentinel 1; Sentinel 2; IEM; WCM; Parámetros de rugosidad; Adquisición fotogramétrica; UAV. 


\section{Soil Moisture Retrieval over agricultural fields employing Sen- tinel-1 and Sentinel-2 Observations and based on the Estima- tion of Surface Roughness obtained from ground-based UAV photogrammetry process.}

Amal Chakhar ${ }^{1}$, David Hernández-López ${ }^{1}$, Rocío Ballesteros ${ }^{1}$ and Miguel A. Morenoํ․

1 Institute of Regional Development, University of Castilla-La Mancha, 02071Albacete, Spain; Amal.Chakhar@uclm.es; David.Hernandez@uclm.es; Rocio.Ballesteros@uclm.es; MiguelAngel.Moreno@uclm.es.

Abstract: The objective of this study is the application of methodology that allowed the estimation of surface soil moisture (SSM) content in semi-arid environment in Tarazona, Spain. In countries characterized by arid and semi-arid climate a precise determination of soil moisture conditions at the field scale is of critical importance especially during the first stages of crop growth in order to schedule irrigation and reduce water wastes. The retrieve of (SSM) was done by combining two scattering models IEM Integral Equation Model and WCM Water Cloud Model supplied by backscattering coefficients at VV (Vertical transmit and Vertical receive) polarization obtained from C-band Synthetic Aperture Radar (SAR) and a vegetation descriptor Normalized Difference Vegetation Index (NDVI) obtained from optical sensor, among other essential other parameters. The inversion of these models was done by the Artificial Neural Networks (ANN). The combined models were calibrated by Sentinel-1 (the radar sensor) and Sentinel-2 data (the optical sensor) collected over barley and peas crop fields. To retrieve SSM, these scattering models need accurate measurements of roughness surface parameters (height root mean square hrms and correlation length L). Therefore, in this work, we used a photogrammetric acquisition system carried on an Unmanned Aerial Vehicles UAV, to reconstruct DSM (Digital Surface Models), which allowed acquiring this soil roughness at the level of large portion of the studied fields. The obtained results showed that the applied methodology provided effective tool for estimating SSM during principal early growth stages. For the barley field, the relationship between the estimated and measured SSM showed $\mathrm{R}^{2}=0.71$ and RMSE $=0.0124\left(\mathrm{~m}^{3} / \mathrm{m}^{3}\right)$. Concerning, peas experimental field, the relationship between the estimated and measured SSM showed $\mathrm{R}^{2}=0.72$ and RMSE $=$ $0.022\left(\mathrm{~m}^{3} / \mathrm{m}^{3}\right)$.

Keywords: Soil Moisture; Sentinel 1; Sentinel 2 ; IEM; WCM; roughness parameters; photogrammetric acquisition; UAV. 


\section{Congreso Nacional de Riegos CARTAGENA 2021}

\section{Introducción}

Los programas de riego adecuados pueden aumentar la eficiencia y minimizar la pérdida de agua por evaporación o del sistema [1]. Según [2] la programación del riego consiste en aplicar la cantidad adecuada de agua en el momento adecuado para proporcionar la máxima humedad utilizable del suelo SM en la zona de la raíz de una planta. Una de las partes más difíciles de la gestión del agua de riego es decidir cuándo encender el sistema de riego y cuánto aplicar. El buen manejo del riego comienza con la medición precisa de la humedad del suelo y debe realizarse de manera regular durante la temporada de crecimiento. Las plantas son más susceptibles al daño por falta de agua durante las etapas vegetativa y reproductiva de crecimiento. Sobre esta base, la recopilación y el análisis de la tecnología de la información, la teledetección y los datos terrestres son factores clave para una gestión eficiente del agua en la agricultura [3]. La teledetección SAR se utiliza actualmente ampliamente para estimar la humedad superficial del suelo en campos agrícolas [4]-[7]. Sin embargo, la existencia de una cubierta vegetal hace que la recuperación de la humedad del suelo a partir de los datos del SAR sea más complicada porque la contribución del suelo se ve atenuada por la vegetación [8]. En este trabajo actual, se utilizó el modelo de nube de agua WCM combinado con el modelo de ecuación integral IEM para recuperar SM sobre campos experimentales de cebada y guisante. Se utilizó el WCM porque permitió estimar la contribución directa de la vegetación y la contribución del suelo que es atenuada por la vegetación y se utilizó IEM para aproximar la contribución directa del suelo. Los modelos combinados WCM e IEM se parametrizaron utilizando datos reales compuestos por coeficientes de retrodispersión en polarización VV obtenidos de Sentinel-1 y NDVI de Sentinel-2, datos de humedad del suelo y parámetros de rugosidad de la superficie (altura de la raíz cuadrada media hrms y longitud de correlación L). La metodología de recuperación aplicada se basó en trabajos previos [9], salvo que para la determinación de los parámetros de rugosidad superficial utilizamos el sistema de adquisición fotogramétrico transportado en un UAV de Vehículos Aéreos No Tripulados, para reconstruir DSM (Modelos Digitales de Superficie) que permitió la obtención de parámetros de rugosidad del suelo a nivel de gran parte de los campos estudiados y no solo la medición in situ limitada a un área muy pequeña.

\section{Materiales y métodos}

\section{1 Área de estudio}

El estudio se realizó en Tarazona de la Mancha (39.7N-38.6N and 2.53W-0.9W) que se encuentra en la región de Castilla La-Mancha, España (Figura 1). El clima es semiárido con una precipitación anual por debajo de $350 \mathrm{~mm}$ y la distribución espacial de la evapotranspiración de referencia (ETo) varió de 1151 $\mathrm{mm}$ año-1 a más de $1300 \mathrm{~mm}$ año-1 en las partes noroeste y sureste del acuífero. Su principal característica es una alta variación entre estaciones y años, según el tipo mediterráneo continental. Las

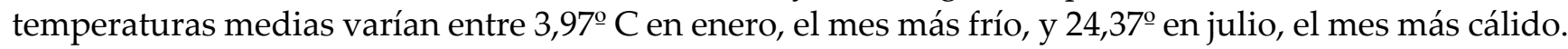
Los cultivos dominantes son el trigo, la cebada, la vid, la alfalfa, la cebolla, el ajo, adormidera y las legumbres. 


\section{Congreso Nacional de Riegos CARTAGENA 2021}

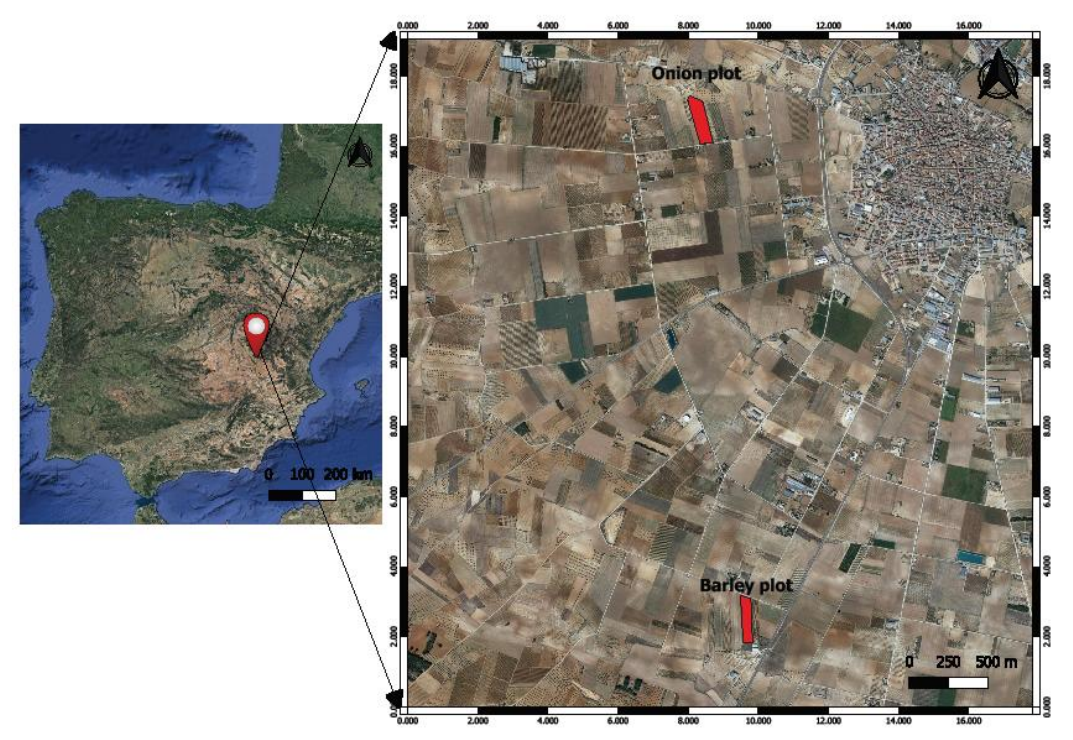

Figura 1. Presentación de la ubicación de campos experimentales.

\subsection{Metodología de recuperación de la humedad del suelo}

Con el objetivo de invertir los valores de retrodispersión obtenidos por IEM combinado con WCM y recuperar la humedad del suelo, se han utilizado numerosos algoritmos como redes neuronales Neural Networks NN [7], [9], [10], Support Vector Machine SVM [11] y tablas Look-up [12]. En el presente estudio, el enfoque aplicado de recuperación de la humedad del suelo se realizó basándose en la metodología descrita en [9]. Usamos el algoritmo NN de redes neuronales multicapa para invertir la señal VV SAR, decidimos usar solo la polarización VV porque [13] confirmó que VV por sí solo proporciona una mejor precisión en las estimaciones de humedad del suelo. Los NN fueron entrenados usando una base de datos sintética de los coeficientes de retrodispersión que han sido configurados con datos de humedad del suelo (mv), parámetros de rugosidad superficial hrms, L y NDVI. La base de datos sintética se construyó utilizando el modelo de nube de agua (WCM) combinado con el modelo de ecuación integral IEM. A continuación (Figura 2) se muestran los pasos principales del proceso de recuperación de la metodología utilizada:

Primer paso: Simulación de los coeficientes de retrodispersión VV del radar utilizando IEM y WCM.

Segundo paso: Entrenamiento y validación de las redes neuronales NN utilizando las sub-bases de datos sintéticas entrenadas y validadas, respectivamente.

Tercer paso: Aplicación de las redes neuronales entrenadas NN a la base de datos real VV para estimar la humedad del suelo. 


\section{Congreso Nacional de Riegos CARTAGENA 2021}
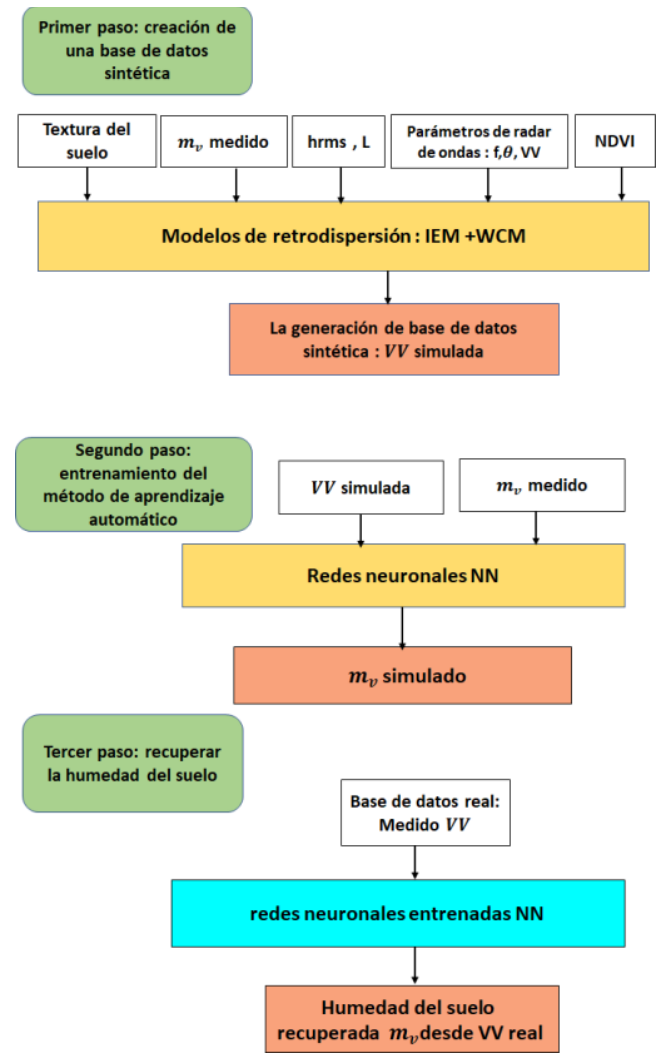

Figura 2. Metodología aplicada de recuperación de la humedad del suelo en Tarazona.

\subsection{Mediciones in situ}

\subsubsection{Humedad del suelo (mv)}

Se instaló una estación SM (Figura 3) en el campo experimental de cereales el 15/12/2020. El tipo de sensores es capacitancia medolo TEROS 10 conectado a un registrador de datos de 6 canales con posiblidad de almacenamiento de datos en la nube. En el campo de los cereales, el SM se mide continuamente cada quince minutos y los seis sensores se instalaron a una profundidad de $5 \mathrm{~cm}$. Las imágenes de Sentinel-1 se adquirieron en el paso ascendente del satélite sobre el área de estudio a las 18:00 UTC. Por lo tanto, se utilizó el promedio de los valores de humedad del suelo registrados a las 18:00 UTC de los seis sensores.

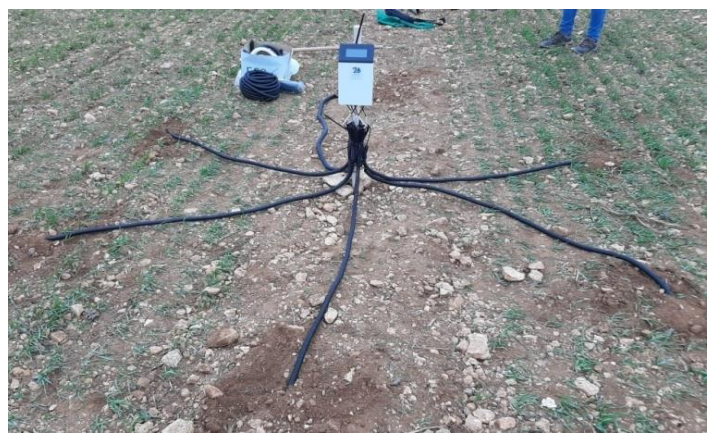

Figura 3. Sensores de humedad instalados en campo de cereales. 


\section{Congreso Nacional de Riegos CARTAGENA 2021}

Además del suelo instalado SM en el cereal, se realizaron otras mediciones de suelo in situ con el método gravimétrico clásico. El tiempo de adquisición de las muestras gravimétricas se realizó siempre dos horas más o menos como las adquisiciones de radar. En el campo de cereales se tomaron cinco muestras gravimétricas, en el campo de guisantes siete muestras gravimétricas. Estas muestras de suelo gravimétricas (Figura 4a) siempre se tomaron en el mismo lugar para mitigar los efectos de la variación del error de muestreo y para aumentar la precisión de la humedad del suelo medida. Para obtener la coordenada exacta de cada punto de muestra, se utilizó un GNSS-RTK Leica, Zeno (Figura 4 b) con una precisión promedio de $2 \mathrm{~cm}$.

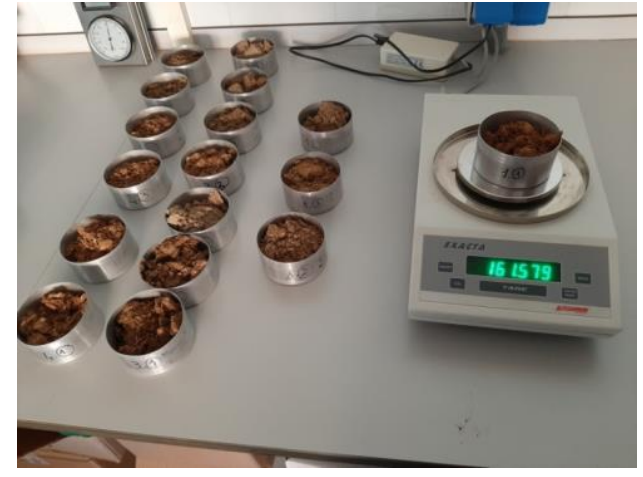

(a)

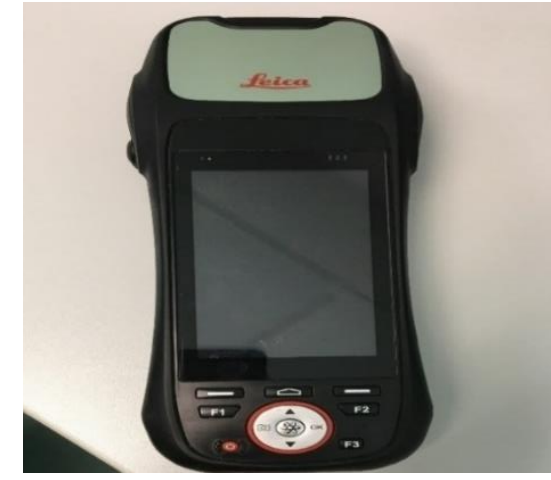

(b)

Figura 4. (a) Muestras gravimétricas y (b) el GPS de mano.

\subsubsection{Rugosidad}

En este trabajo, utilizamos un sistema de adquisición fotogramétrico transportado en un UAV, para reconstruir DSM (Modelos Digitales de Superficie) (Figura 5), que proporciona rugosidad del suelo a nivel de gran parte de los campos estudiados. Una vez que se determinaron los parámetros de rugosidad del suelo, se utilizaron como parámetros de entrada para los modelos de dispersión del suelo. La configuración para la adquisición de información sobre la rugosidad de la superficie del suelo fue realizada por un Sony personalizado montado en un dron (Figura 5). Los vuelos se planificaron a $20 \mathrm{~m}$ sobre el nivel del suelo, con un solapamiento lateral del $40 \%$ y un solapamiento frontal del $80 \%$, lo que resultó en una distancia de muestreo en el suelo (GSD) de $4 \mathrm{~mm}$.

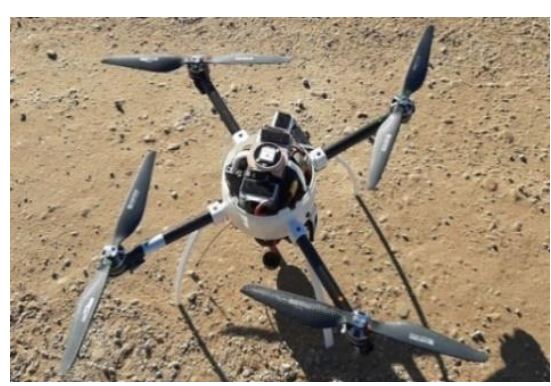

(a)

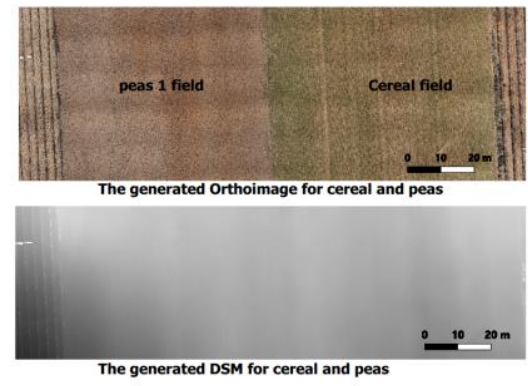

(b)

Figura 5. (a) Una foto del UAV usado "Icom3D - Carabo S3" (b) DSM y ortoimagen del cereal y guisantes de campo experimental . 


\subsection{Datos de teledetección}

\subsubsection{Conjunto de datos Sentinel-2}

Los productos Sentinel-2 fueron adquiridos en diferentes ocasiones durante el período 2020-2021. Los productos Sentinel-2 de nivel 2A (BOA) se descargaron del Centro de acceso abierto Copernicus de la Agencia Espacial Europea (ESA). El NDVI en el fondo de la atmósfera (NDVIвоA) se calculó como la siguiente ecuación:

$$
\text { NDVI }_{\text {BoA }}=\frac{\text { Band } 8-\text { Band } 4}{\text { Band } 8+\text { Band } 4}
$$

Con el objetivo de obtener la condición de la vegetación de cada campo experimental, se promediaron los valores de los píxeles del NDVI dentro de cada parcela de referencia.

\subsubsection{Conjunto de datos de Sentinel 1}

Las imágenes de Sentinel-1 se adquirieron entre 2020 y 2021. El ángulo de incidencia de Sentinel-1 sobre el sitio del estudio es de aproximadamente $38,5^{\circ}$. El conjunto de datos Sentinel-1 comprende datos de Nivel 1 de rango terrestre detectado (GRD) en modo de franja interferométrica ancha (IW) que se proyectó al rango terrestre utilizando el modelo de elipsoide terrestre WGS84. Las imágenes resultantes en polarización dual ( $\mathrm{VH}$ y VV) tenían dimensiones de $270 \times 270 \mathrm{~km}$, resolución de 10 my resolución temporal de 6 días. Las imágenes se descargaron de earthdata.nasa.gov/eosdis/daacs/asf. Todas las imágenes fueron procesadas por SNAP usando la caja de herramientas Sentinel-1. Principales correcciones realizadas: (1) Corrección de órbita, (2) Calibración radiométrica, (3) Speckle filtering, (4) Corrección geométrica. Finalmente, conversión a unidades de decibelios: El coeficiente de retrodispersión $\sigma 0$, que está en una escala lineal, se convierte en scale de decibelios $(\mathrm{dB}), \sigma^{0}(\mathrm{db})=$ $10 \log _{10} \sigma^{0}, \sigma^{0}(\mathrm{~dB})$ representa el valor del coeficiente de retrodispersión.

\section{Resultados y discusión}

En esta parte, presentamos los resultados de la simulación de los coeficientes de retrodispersión de IEM combinados con modelos de dispersión WCM con polarización VV, sobre el campo experimental de cebada y guisantes aplicando la metodología descrita en la Figura (2) y utilizando los parámetros de rugosidad medidos $\bar{L}$ and $\overline{h r m s}$. Esta experimentación duró seis meses, del 15 de diciembre hasta el 1 de junio, y realizamos un seguimiento semanal de los datos de SM porque los productos Sentinel-1 están disponibles cada 6 días. Observamos que los resultados de la modelización alcanzaron el óptimo el 26 de abril en la Figura 6 (parte izquierda) que corresponde a $\mathrm{R}^{2}=0.79$. Además, la Figura 6 (parte derecha) compara la humedad estimada con la humedad medisa con los sensors instalado en el campo, para la misma fecha. En general, según los resultados, $\mathrm{R}^{2}$ valor relativamente alto igual a 0.57 y un RMSE igual a $0.0124 \mathrm{~m}^{3} / \mathrm{m}^{3}$. 


\section{Congreso Nacional de Riegos CARTAGENA 2021}
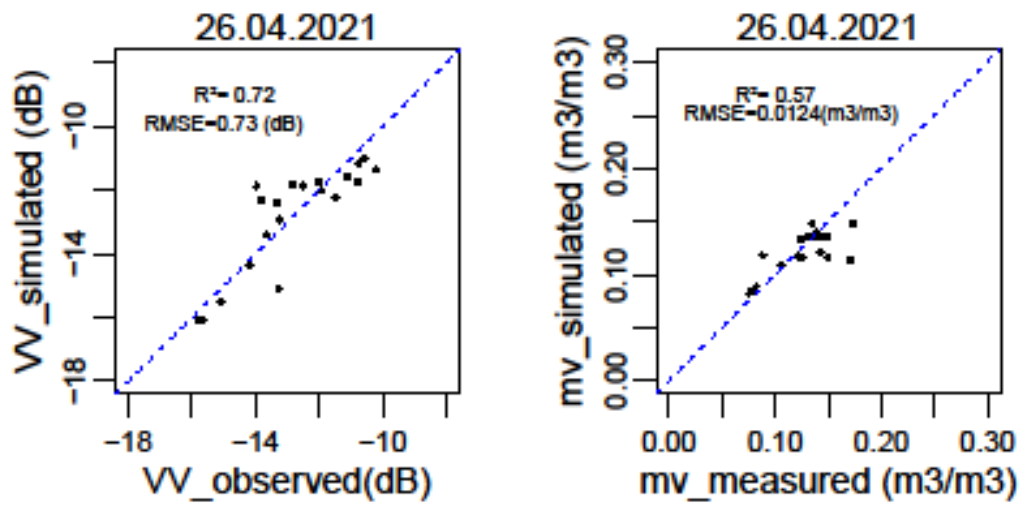

Figura 6. Comparación entre $\sigma^{0}$ observado y el estimado obtenido combinando IEM con WCM Model (parte izquierda) y comparación entre mv de humedad del suelo estimada y medida en el campo experimental de cebada (parte derecha).

Con respecto a los resultados del cultivo de guisantes, la Figura 7 (parte izquierda) muestra la relación entre el coeficiente de retrodispersión simulado en la polarización VV utilizando los modelos combinados IEM y WCM y los datos observados Sentinel-1 durante el 26 de abril que corresponde a la fecha de modelado óptima con un coeficiente de determinación $\mathrm{R}^{2}$ igual a 0.94 . En cuanto a la comparación entre la humedad simulada con la medida, hemos obtenido un alto $\mathrm{R}^{2}=0.72$ y RMSE $=$ $0.22 \mathrm{~m}^{3} / \mathrm{m}^{3}$.
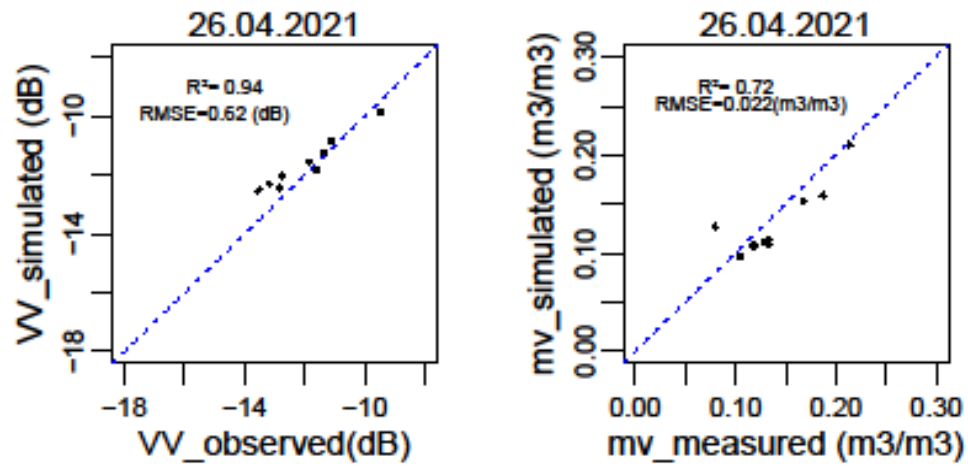

Figura 7. Comparación entre $\sigma^{0}$ observado y el estimado obtenido combinando IEM con WCM Model (parte izquierda) y comparación entre mv de humedad del suelo estimada y medida en el campo experimental de guisante (parte derecha).

Gracias a los resultados obtenidos pudimos obtener el perfil de humedad del suelo a $5 \mathrm{~cm}$ de profundidad Figura 8. De acuerdo con esta figura podemos observar que el SM está levemente subestimado luego de eventos de lluvia a fines de febrero y en abril para la cebada y finales de marzo para campo experimental de guisantes. Estos resultados mejorarán la contribución a los modelos de cultivos que necesitan SM en una capa de suelo de más de 10 $\mathrm{cm}[14]$. 


\section{Congreso Nacional de Riegos CARTAGENA 2021}

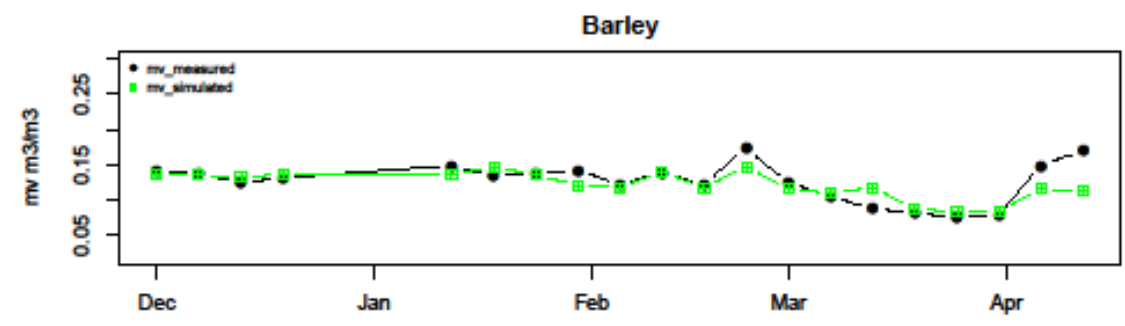

Peas
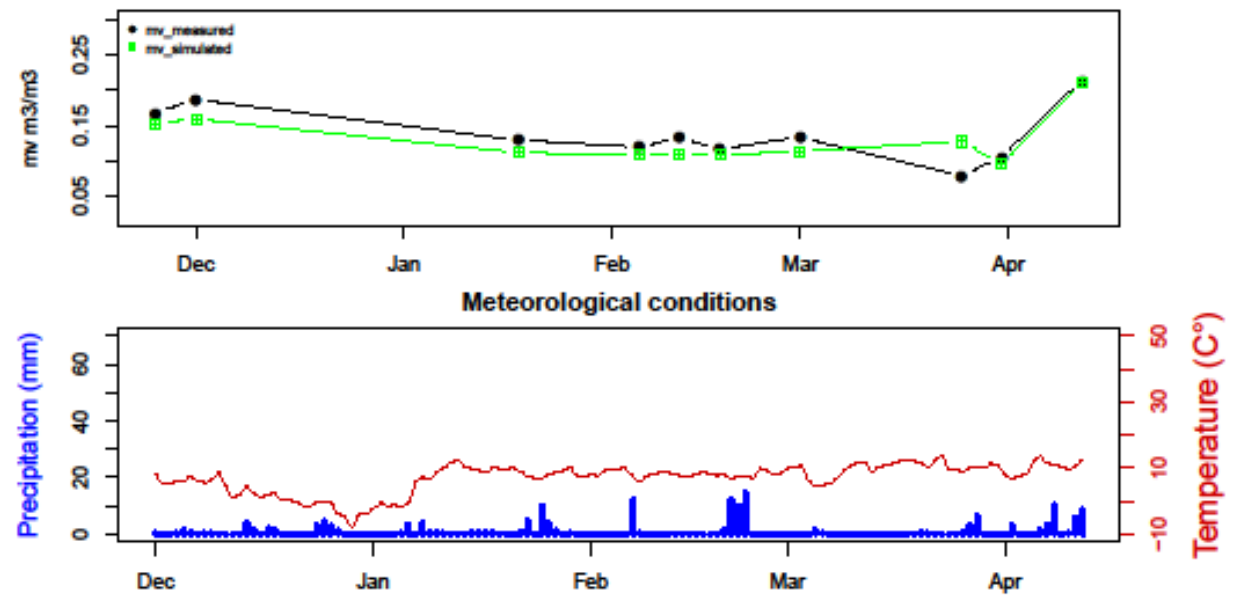

Figura 8. Serie temporal de la humedad del suelo a $5 \mathrm{~cm}$ de profundidad medida sobre un campo de cebada y guisantes.

\section{Conclusiones}

El presente estudio tuvo como objetivo aplicar una metodología operativa que ha sido probada anteriormente para las estimaciones de humedad del suelo. Pero, con el propósito de mejorar aún más los resultados de esta metodología, habíamos medido los parámetros de rugosidad (que son parámetros muy importantes para el modelo de retrodispersión IEM) mediante un sistema de adquisición fotogramétrico llevado en un UAV, para reconstruir un DSM que permitió la obtención de estos parámetros a nivel de gran parte de los campos estudiados. Por lo tanto, nuestra metodología mejorada comenzó con una medición precisa de los parámetros de rugosidad de los campos experimentales que requiere un trabajo de campo meticuloso (preparación del vuelo y equipo, elección del período del vuelo que coincide con la fecha de arado, etc.) así como procesamiento de datos para obtener el DSM y extraer las L y hrms. En segundo lugar, la parametrización del IEM con WCM para generar la base de datos sintética de la retrodispersión en la polarización VV se realizó utilizando los parámetros de rugosidad obtenidos, el SM medido, los datos de Sentinel-1 y el NDVI determinado a partir de la banda de reflectancia Sentinel-2. En tercer lugar, la base de datos sintética se dividió en un conjunto de datos de entrenamiento y validación para realizar el entrenamiento y la validación de la NN. Como paso final, el NN entrenado se aplicó a la base de datos real para probar el SM estimado. Los resultados obtenidos mostraron que la metodología aplicada brindó una herramienta eficaz para estimar la SM durante las principales etapas iniciales de crecimiento. Para el campo de cebada, la relación entre el SM estimado y medido mostró $\mathrm{R}^{2}=0.57$ y $\mathrm{RMSE}=0.0124\left(\mathrm{~m}^{3} / \mathrm{m}^{3}\right)$. Con respecto al 


\section{Congreso Nacional de Riegos CARTAGENA 2021}

campo experimental de guisantes, la relación entre el SM estimado y medido mostró $\mathrm{R}^{2}=0.72$ y RMSE $=0.022\left(\mathrm{~m}^{3} / \mathrm{m}^{3}\right)$.

\section{Referencias}

[1] G. Nikolaou, D. Neocleous, N. Katsoulas, and C. Kittas, "Irrigation of greenhouse crops," Horticulturae, vol. 5, no. 1, pp. 120, 2019, doi: 10.3390/horticulturae5010007.

[2] T. F. Scherer, D. Franzen, and L. Cihacek, “Soil, Water and Plant Characteristics Important to Irrigation," K-State Res. Exte[1] T. F. Scherer, D. Franzen, L. Cihacek, "Soil, Water Plant Charact. Important to Irrig. K-State Res. Ext., vol. 1675, no. December, pp. 18, 2017, [Online]. Available www.ksre.ksu.edu/irrigate.nsion, vol. 1675, no. December, pp. 1-8, 2017, [Online]. Available: www.ksre.ksu.edu/irrigate.

[3] R. R. Shamshiri et al., "Advances in greenhouse automation and controlled environment agriculture: A transition to plant factories and urban agriculture," Int. J. Agric. Biol. Eng., vol. 11, no. 1, pp. 1-22, 2018, doi: 10.25165/j.ijabe.20181101.3210.

[4] E. Ayari, Z. Kassouk, Z. Lili-Chabaane, N. Baghdadi, S. Bousbih, and M. Zribi, "Cereal crops soil parameters retrieval using L-band ALOS-2 and C-band sentinel-1 sensors," Remote Sens., vol. 13, no. 7, 2021, doi: 10.3390/rs13071393.

[5] N. Baghdadi, E. Saba, M. Aubert, M. Zribi, and F. Baup, "Evaluation of radar backscattering models IEM, Oh, and Dubois for SAR data in X-band over bare soils," IEEE Geosci. Remote Sens. Lett., vol. 8, no. 6, pp. 1160-1164, 2011, doi: 10.1109/LGRS.2011.2158982.

[6] M. Choker, N. Baghdadi, M. Zribi, and M. El Hajj, "Evaluation of the Oh , Dubois and IEM Backscatter," 2017, doi: 10.3390/w9010038.

[7] M. El Hajj et al., "Soil moisture retrieval over irrigated grassland using X-band SAR data," Remote Sens. Environ., vol. 176, pp. 202-218, 2016, doi: 10.1016/j.rse.2016.01.027.

[8] N. Baghdadi, N. Holah, and M. Zribi, "Calibration of the Integral Equation Model for SAR data in C-band and HH and VV polarizations," Int. J. Remote Sens., vol. 27, no. 4, pp. 805-816, 2006, doi: 10.1080/01431160500212278.

[9] M. El Hajj, N. Baghdadi, M. Zribi, and H. Bazzi, "Synergic use of Sentinel-1 and Sentinel-2 images for operational soil moisture mapping at high spatial resolution over agricultural areas," Remote Sens., vol. 9, no. 12, pp. 1-28, 2017, doi: $10.3390 /$ rs9121292.

[10] Mirsoleimani. Hamid Reza, N. B. , Mahmod Reza Sahebi, and M. El Hajj, “Bare Soil Surface Moisture Retrieval from Sentinel1 SAR Data Based on the Calibrated IEM and Dubois Models Using Neural Networks," Sensor, no. 1992, pp. 1-12, 2019.

[11] J. Ezzahar et al., "Evaluation of Backscattering Models and Support Vector Machine for the Retrieval of Bare Soil Moisture from Sentinel-1 Data," Remote Sens., vol. 12, no. 1, p. 72, 2019, doi: 10.3390/rs12010072.

[12] M. M. Rahman, M. S. Moran, D. P. Thoma, and R. Bryant, “A derivation of roughness correlation length for parameterizing radar backscatter models," Int. J. Remote Sens., no. September 2012, pp. 37-41, 2007.

[13] M. El Hajj, N. Baghdadi, M. Zribi, and H. Bazzi, "Synergic Use of Sentinel-1 and Sentinel-2 Images for Operational Soil Moisture Mapping at High Spatial Resolution over Agricultural Areas," Remote Sens., pp. 1-28, 2017, doi: 10.3390/rs9121292.

[14] T. P. Anguela, M. Zribi, S. Hasenauer, F. Habets, and C. Loumagne, "Analysis of surface and root-zone soil moisture dynamics with ERS scatterometer and the hydrometeorological model SAFRAN-ISBA-MODCOU at Grand Morin watershed (France)," Hydrol. Earth Syst. Sci., vol. 12, no. 6, pp. 1415-1424, 2008, doi: 10.5194/hess-12-1415-2008. 


\title{
Mapeo de áreas regadas usando datos geoespaciales y teledetec- ción en el municipio de Caudete de las Fuentes (Valencia).
}

\author{
López-Pérez, Esther1', Sanchis-Ibor, C. ${ }^{2}$, Jiménez Bello, M.A. ${ }^{3}$, Rubio-Martin, A. ${ }^{1}$, Macian-Sorribes, H.1 , García-Prats,
} A. ${ }^{3}$, Manzano-Juárez, J. ${ }^{4}$, García-Mollá, M. ${ }^{5}$, Pulido-Velazquez, M. ${ }^{6}$

\footnotetext{
${ }^{1}$ Técnico Superior de Investigación en el Instituto Universitario de Investigación de Ingeniería del Agua y Medio Ambiente (IIAMA), Universitat Politècnica de València Universitat, Camí de Vera s/n, 46022 València. estloppe@upvnet.upv.es; adrumar@cam.upv.es; hecmasor@upv.es

2 Técnico Superior de Investigación en el Centro Valenciano de Estudios sobre el Riego (CVER), de la Universitat Politècnica de València, Camí de Vera, s/n 46022 València. csanchis@hma.upv.es

${ }^{3}$ Profesor Contratado Doctor, Inst. U. Ingeniería del Agua y M.A (IIAMA), Universitat Politècnica de València, Camino de Vera, s/n 46022 Valencia.mijibar@dihma.upv.es

${ }^{4}$ Profesor Contratado Doctor. Centro Valenciano de Estudios sobre el Riego (CVER), de la Universitat Politècnica de València, Camí de Vera, s/n 46022 València. juamanju@agf.upv.es

${ }^{5}$ Profesora Titular. Centro Valenciano de Estudios sobre el Riego (CVER), de la Universitat Politècnica de València, Camí de Vera, s/n 46022 València.mgarmo@upvnet.upv.es

${ }^{6}$ Catedrático y Director del Inst. U. de Investigación de Ingeniería del Agua y Medio Ambiente (IIAMA), Universitat Politècnica de València Universitat, Camí de Vera s/n, 46022 Valencia. mapuve@hma.upv.es
}

Resumen: Las políticas de control del uso agrícola de aguas subterráneas mediante la inspección de contadores se han demostrado caras y poco eficientes, mientras que en algunos estudios se ha obtenido resultados prometedores mediante la teledetección. El rápido progreso de las tecnologías de teledetección ha hecho posible su aplicación para la identificación de áreas regadas, y los nuevos sensores y técnicas de inteligencia artificial abren nuevas oportunidades a mejorar su eficacia y precisión. Nuestro trabajo propone una metodología de bajo coste y eficiente para detectar viña en riego a escala de parcela con el fin de mejorar la gestión colectiva de aguas subterráneas. A partir de información oficial se ha distinguido la superficie regada con técnicas de análisis de aprendizaje automático, empleando variables que condicionan el estado hídrico de la planta para la temporada de riego 2019. La metodología calcula la humedad del suelo con el método OPTRAM (OPtical TRApezoid Model) de análisis multitemporal de imágenes procedentes de plataformas satelitales. Estos datos son integrados en un SIG junto a información climática, topográfica e información propia del cultivo. Finalmente, en base a inventarios de verdad-terreno se aplica un clasificador de aprendizaje automático para estimar la superficie regada con agua procedente del acuífero. Los resultados obtenidos presentan una precisión general del $94.7 \%$. Su evaluación aporta un error medio cuadrático de 0.163 y R-cuadrado de 0.874 . La alta precisión y los bajos niveles de error obtenidos permiten validar la metodología empleada, que presenta potencial de mejora mediante una mayor alimentación del proceso de aprendizaje automático, que se aplicará en breve a otros cultivos leñosos.

Palabras clave: área regada; teledetección; OPTRAM; agua subterránea; inteligencia artificial; gestión colectiva 


\title{
Mapping irrigated areas using geospatial data and remote sens- ing in Caudete de las Fuentes (Valencia, Spain).
}

\author{
López-Pérez, Esther1 ${ }^{1}$, Sanchis-Ibor, C², Jiménez Bello, MA ${ }^{3}$, Rubio-Martin, Adrià1, Macian-Sorribes, H. ${ }^{1}$, García- \\ Prats, A. ${ }^{3}$, Manzano-Juárez, J. ${ }^{4}$, García-Mollá, M ${ }^{5}$, Pulido-Velázquez, M $^{6}$
}

\footnotetext{
${ }^{1}$ Técnico Superior de Investigación en el Instituto Universitario de Investigación de Ingeniería del Agua y Medio Ambiente (IIAMA), Universitat Politècnica de València Universitat, Camí de Vera s/n, 46022 València. estloppe@upvnet.upv.es; adrumar@cam.upv.es; hecmasor@upv.es

2 Técnico Superior de Investigación en el Centro Valenciano de Estudios sobre el Riego (CVER), de la Universitat Politècnica de València, Camí de Vera, s/n 46022 València. csanchis@hma.upv.es

${ }^{3}$ Profesor Contratado Doctor, Inst. U. Ingeniería del Agua y M.A (IIAMA), Universidat Politècnica de València, Camino de Vera, s/n 46022 Valencia.mijibar@dihma.upv.es

4 Profesor Contratado Doctor. Centro Valenciano de Estudios sobre el Riego (CVER), de la Universitat Politècnica de València, Camí de Vera, s/n 46022 València. juamanju@agf.upv.es

${ }^{5}$ Profesora Titular. Centro Valenciano de Estudios sobre el Riego (CVER), de la Universitat Politècnica de València, Camí de Vera, s/n 46022 València.mgarmo@upvnet.upv.es

${ }^{6}$ Catedrático y Director del Inst. U. de Investigación de Ingeniería del Agua y Medio Ambiente (IIAMA), Universitat Politècnica de València Universitat, Camí de Vera s/n, 46022 Valencia. mapuve@hma.upv.es
}

\begin{abstract}
The control of groundwater for agricultural use through water meters has proven to be expensive and inefficient in numerous cases, while some studies have shown promising results using remote sensing techniques. Recent developments of remote sensing technologies have improved the capacity to detect and quantify irrigated areas, and new sensors and machine learning techniques have opened new opportunities for increasing the precision and efficiency of these methodologies. Our study proposes a cheap and efficient methodology to detect irrigated vineyards at plot scale, in order to improve the collective management of groundwater. Irrigated areas have been detected by applying machine learning techniques using determining variables of the plant water content from the dry season of 2019. The methodology calculates the soil moisture by making use of Optical TRApezoid Model (OPTRAM), supported by multitemporal analysis of satellites images. This data has been integrated into a GIS with climatic and topographic parameters, and crop data. Finally, a machine learning classifier has been applied to estimate the extent of areas irrigated with groundwater. Results show a general accuracy of $94.7 \%$. Data evaluation provides a mean square error of 0.163 and R-square of 0.874 . The high accuracy enables the validation of the described methodology, which still has potential for improvement by enlarging the learning dataset, which will soon be applied to other wood crops.
\end{abstract}

Keywords: irrigated area, remote sensing, OPTRAM, groundwater, machine learning, collective management. 


\section{Congreso Nacional de Riegos CARTAGENA 2021}

\section{Introducción}

La expansión del riego con aguas subterráneas en regiones áridas y semiáridas conlleva con demasiada frecuencia la sobreexplotación de los acuíferos, con consecuencias negativas para la viabilidad y rentabilidad de la agricultura, para el futuro de la producción de alimentos y para la sostenibilidad de los ecosistemas acuáticos [1,2]. Ante este problema, generalizado en las cuencas mediterráneas, los expertos han propuesto varios enfoques, algunos basados en la mejora de la gobernanza, otros en medidas de control y sanciones coercitivas y, cada vez más, también se aplican políticas mixtas denominadas de 'palo y zanahoria' [3-7].

En casi todos los casos, es fundamental contar con herramientas para estimar la superficie regada, ya que, sin un flujo de información adecuado sobre la evolución del uso común del recurso, es mucho más difícil desarrollar políticas impulsadas por el Estado o poner en marcha instrumentos de gestión colectiva que permitan la explotación sostenible $[8,9]$. Las metodologías aplicadas a la identificación de áreas de cultivo y superficies de riego que utilizan datos geoespaciales y sensores de observación de la Tierra son de gran utilidad en este contexto y están comenzando a aplicarse con relativo éxito en algunas regiones del mundo [10-12].

El primer mapa digital mundial de áreas regadas basado en información cartográfica fue desarrollado en 1999 por la Organización de las Naciones Unidas para la Agricultura y la Alimentación (FAO). Desde entonces, se ha ido mejorando la metodología hasta llegar a un mapa global con datos nacionales oficiales e información georreferenciada de agricultura de regadío de 187 países organizado a través de la iniciativa AQUASTAT [13].

El rápido progreso de las tecnologías de observación remota ha hecho posible su aplicación como una nueva y esencial fuente de datos para aplicaciones ambientales y para el seguimiento de cambios en la agricultura. El diseño de un mapa de superficie regada es quizás una de las aplicaciones más buscadas de la observación remota en la gestión del agua [14-16].

La teledetección mediante métodos ópticos utiliza algoritmos matemáticos que describen la relación entre la señal capturada por el sensor y el contenido de agua en la superficie. Los métodos de clasificación de series temporales de imágenes aéreas son ampliamente utilizados para el mapeo de cultivos. Estos métodos utilizan índices de vegetación en el rango óptico de la reflectancia espectral emitida por la vegetación durante su fase de desarrollo [14, 17, 18]. Recientemente, para la estimación de las áreas regadas a escala global con teledetección, se emplea la humedad del suelo captada por el sensor, resultado de aplicar modelos de superficie terrestre [19]. Otros estudios emplean para su cálculo el 'Método del triángulo' que consiste en incorporar la temperatura infrarroja superficial TIR e índices de vegetación para obtener un índice de humedad del cultivo [20, 21].

Recientemente, se ha desarrollado un nuevo modelo que relaciona datos térmicos de reflectancia de onda corta (SWIR) y datos ópticos mediante índices de vegetación. Se basa en el método del triángulo y es conocido como OPtical TRApezoid Model (OTRAM) [22]. Los buenos resultados obtenidos a pequeña escala por este método para el cálculo de la humedad del cultivo [23-25] nos han impulsado a desarrollar un método económico y eficiente para estimar áreas regadas en viñedo a través de sensores remotos. La metodología utiliza algoritmos de aprendizaje automático empleando variables condicionantes del estado hídrico del campo y el índice de humedad del cultivo. Los resultados pueden ser utilizados para mejorar la gobernanza del agua a través de una gestión colectiva transparente.

\section{Materiales y métodos.}

La metodología desarrollada parte de la integración de información geoespacial en la zona seleccionada a través de funciones de superposición de datos climáticos, topográficos, y de morfología y estado hídrico del cultivo. Esta información es incorporada en un Sistemas de Información Geográfica (SIG) en forma de capas georreferenciadas. Posteriormente los datos son analizados junto a información 


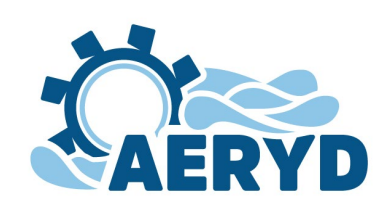

\section{Congreso Nacional de Riegos CARTAGENA 2021}

real del estado de riego de un conjunto de parcelas inventariadas mediante algoritmos de clasificación con técnicas de aprendizaje automático. Finalmente, se generan los resultados de la estimación del estado hídrico en la zona. En la presente contribución se ha empleado como área de estudio un municipio del interior de la provincia de Valencia, Caudete de las Fuentes.

\section{1. Área de estudio.}

Caudete de las Fuentes es un municipio de la comarca de Utiel-Requena (Provincia de Valencia) junto al límite entre la Comunidad Valenciana y la de Castilla-La Mancha. Este municipio se extiende sobre una superficie de $34.5 \mathrm{~km}^{2}$ de los cuales, según catastro, 2.856 ha se dedican a la producción de uva para vinificación. El clima es mediterráneo con un marcado carácter continental (Csa y Csb Köppen-Geiger). La temperatura media anual es de $14^{\circ}$ y la precipitación media anual es de $434 \mathrm{~mm}$. La parte más seca del año es de abril a septiembre y coincide con la temporada de riego, entre los meses de junio y agosto.

Los viñedos de Caudete de las Fuentes aprovechan el agua de la masa subterránea de RequenaUtiel, que está situada en la margen occidental del altiplano del mismo nombre. La masa de agua tiene una superficie de $987,9 \mathrm{~km}^{2}$ y su altitud oscila entre los 600 y los $1.200 \mathrm{~m}$ sobre el nivel del mar. En 1995, según las estadísticas de la Generalitat (VAB, 2021), la superficie regada de Requena-Utiel ocupaba $1.738 \mathrm{ha}$, de las cuales 1.279 ha eran forrajes y hortalizas de verano, y otras 449 se dedicaban al viñedo. El resto de la comarca estaba ocupada por cultivos de secano, 58.524 ha de las cuales 44.445 ha eran viñedos. Sin embargo, en 2019 la superficie regada se había ampliado significativamente hasta alcanzar las 11.660 ha de viñedos, 1.546 de almendros y 1.415 de otros cultivos, es decir se ha multiplicado por ocho en 24 años. La creación de estos nuevos sistemas de riego se llevó a cabo en la mayoría de los casos gracias a la instalación de sistemas de riego a goteo y el emparrado de la vid.

En 2016, la Confederación Hidrográfica del Júcar (CHJ) aprobó el Plan de explotación de la masa de agua subterránea Requena-Utiel, que ha establecido una dotación hídrica de $450 \mathrm{~m}$ /ha/año para cultivos leñosos para años húmedos ( $900 \mathrm{~m}^{3} / \mathrm{ha} /$ año para años secos) en la zona con concesión administrativa, [26]. Actualmente, la CHJ estima un área con derechos de agua consolidados de 19.495 ha y la administración autonómica calcula 14.621 ha de regadío (de las cuales 11.660 viñedos).

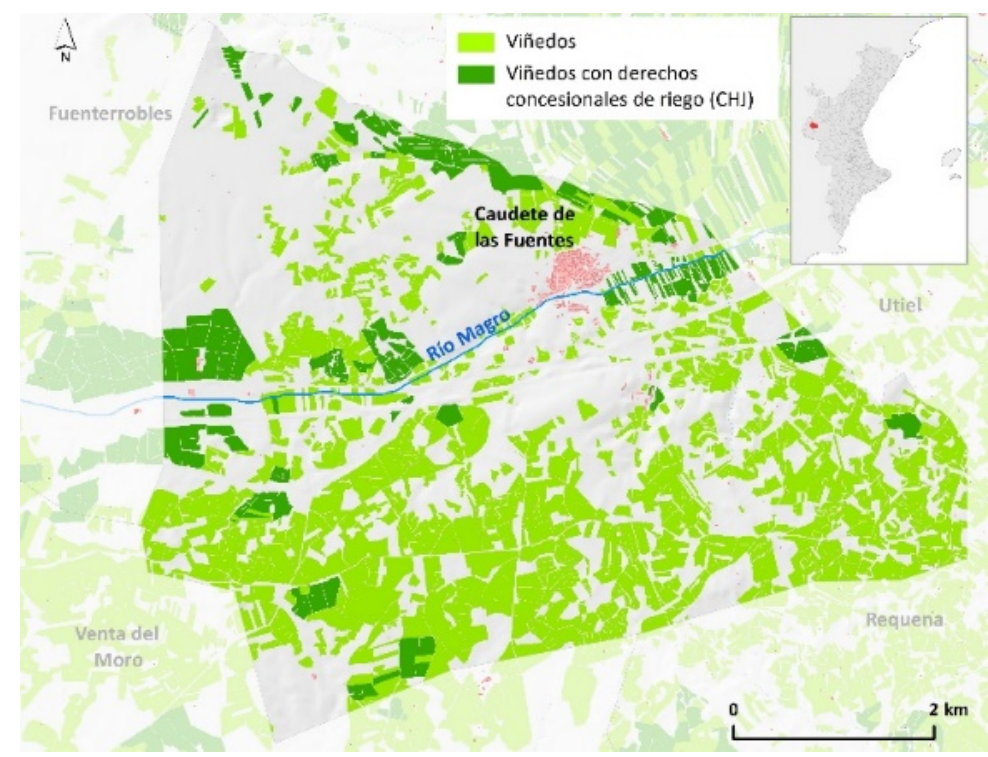

Figura 1. Mapa de localización de la zona de estudio, Caudete de las Fuentes, en la parte central del acuífero Requena-Utiel. Verde claro para viñedos de secano y regadío, y verde oscuro para viñedos que tienen derechos de agua consolidados según la CHJ. 


\section{Congreso Nacional de Riegos CARTAGENA 2021}

\subsection{Información disponible.}

El conjunto de información utilizada para la identificación de las áreas regadas parte de la cartografía oficial del registro público del Sistema de Información Geográfica de Parcelas Agrícolas (SIGPAC). El SIGPAC permite identificar geográficamente las parcelas por tipo de cultivo y aporta información gráfica y alfanumérica de cada una de ellas. A partir de esta información se delimitó geográficamente la superficie total de viñedo del municipio de Caudete de las Fuentes.

\subsubsection{Datos climáticos.}

Los datos de precipitación empleados en el análisis fueron obtenidos del satélite CHIRPS (Climate Hazards Group InfraRed Precipitation with Station data) del Servicio Geológico de los Estados Unidos (USGS) y la Universidad de California, Santa Bárbara (UCSB). CHIRPS incorpora un conjunto de datos de lluvia mensual en imágenes satelitales de resolución de $0.05^{\circ}$ y utiliza datos de estaciones in situ para crear cuadrículas de series temporales de lluvia para el análisis de tendencias y el monitoreo de sequías estacionales [27]. Partiendo del conjunto de datos, se ha filtrado una colección de imágenes mensuales y se han reducido a una sola imagen, donde cada píxel es la suma de las precipitaciones de todas las imágenes del mes. Un total de 18 imágenes fueron procesadas durante los meses de riego establecidos en el estudio.

De forma paralela, los datos diarios de temperatura de la superficie terrestre (LST) fueron tomados del espectrorradiómetro de imágenes de media resolución (MODIS). Los datos son almacenados con una resolución temporal diaria, reduciéndose a una escala mensual. Un total de 92 imágenes fueron procesadas para establecer la temperatura registrada durante los meses de riego.

\subsubsection{Datos topográficos y morfología del cultivo.}

La condición topográfica de las parcelas ha sido determinante en el análisis debido a su influencia en el almacenamiento de agua en el suelo y, por tanto, al crecimiento de la cobertura vegetal. Para ello, se utilizó el Modelo Digital de Elevación (MDE) del Instituto Geográfico Nacional Español (IGNE). A partir del MDE se obtuvo, por procesamiento digital, otros parámetros derivados como la pendiente y orientación de las parcelas. La información procesada fue incorporada al conjunto de datos. De forma adicional, y sabiendo que las unidades geomorfológicas responden de manera diferente en términos de retención de agua en el suelo, se agregó al conjunto de datos las formaciones geomorfológicas derivadas de la cartografía oficial del Plan de Acción Territorial para la prevención del riesgo de inundaciones en la Comunitat Valenciana (PATRICOVA).

Por otro lado, la morfología del cultivo también juega un papel importante en el desarrollo arbóreo de la planta y por tanto en la forma en que el estado hídrico es reflejado por sus hojas. De ese modo, se incluyó en el análisis las diferentes estructuras de plantación del viñedo presentes en la zona, como son sistema en vaso y en espaldera. Adicionalmente, y debido a que las diferentes variedades de vid presentan distintas pautas de crecimiento y requerimientos hídricos, la información varietal se incorporó al conjunto de datos. La variedad bobal es la más frecuente, seguida de garnacha tinta, merlot, messeguera y parellada.
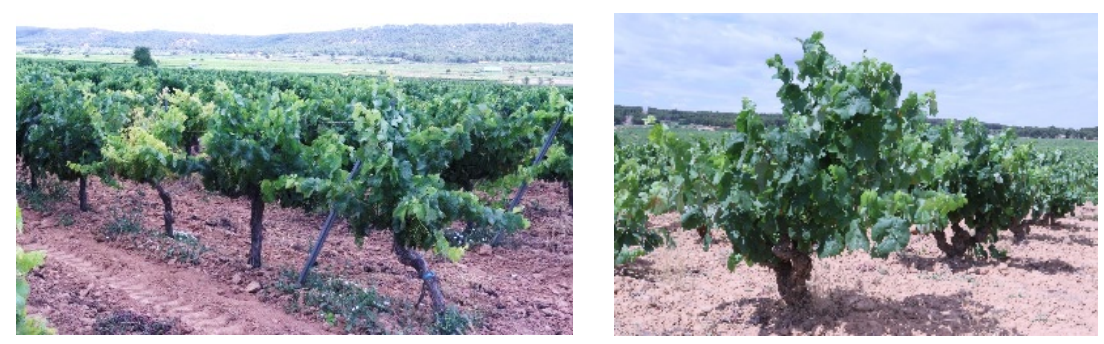

Figure 2. Morfología del cultivo en función de su plantación: sistema en espaldera y sistema en vaso, respectivamente. 


\subsection{Metodología.}

\subsubsection{Método OPTRAM.}

El modelo se basa en la relación física lineal entre la humedad del suelo (W) y la reflectancia del infrarrojo de onda corta transformado (STR) (2) y se parametriza en función de la distribución espacial del píxel entre un índice de vegetación y el STR.

$$
\mathrm{W}=\frac{\theta-\theta_{d}}{\theta_{w}-\theta_{d}}=\frac{S R T-S T R_{d}}{S T R_{w}-S T R_{d}}
$$

Donde STR está relacionado con la banda SWIR de la siguiente manera:

$$
S T R=\frac{\left(1-R_{S W I R}\right)^{2}}{2 * R_{S W I R}}
$$

$Y$ donde STRd y STR $\mathrm{w}$ son STR en seco (por ejemplo, $\theta \sim 0 \mathrm{~cm} 3 \mathrm{~cm}-3$, donde $\theta$ es el contenido de humedad volumétrica) y STR húmedo (por ejemplo, $\theta=\theta \mathrm{s} \mathrm{cm} 3 \mathrm{~cm}-3$, donde $\theta$ s es el contenido de humedad saturada), respectivamente [23].

Investigaciones recientes han mostrado que los índices de vegetación proporcionan una representación de la variabilidad de la vegetación, y esto a su vez está relacionado con el estrés hídrico del suelo [28]. Es decir, SM influye en la cantidad de agua que tiene el cultivo y esto se refleja en las características espectrales de la vegetación. Por lo tanto, se ha empleado el Índice de Vegetación Ajustado de Suelo Modificado (MSAVI2), por su mayor sensibilidad a la vegetación donde el suelo juega un papel significativo en la cobertura [29-31], y que ha sido aplicado en investigaciones recientes [24, 32].

Suponiendo una relación lineal empírica de $S T R_{d}$ y $S T R_{w}$ con la fracción de vegetación, se definen los bordes secos y húmedos del llamado trapezoide óptico como sigue (ver Fig. 3).

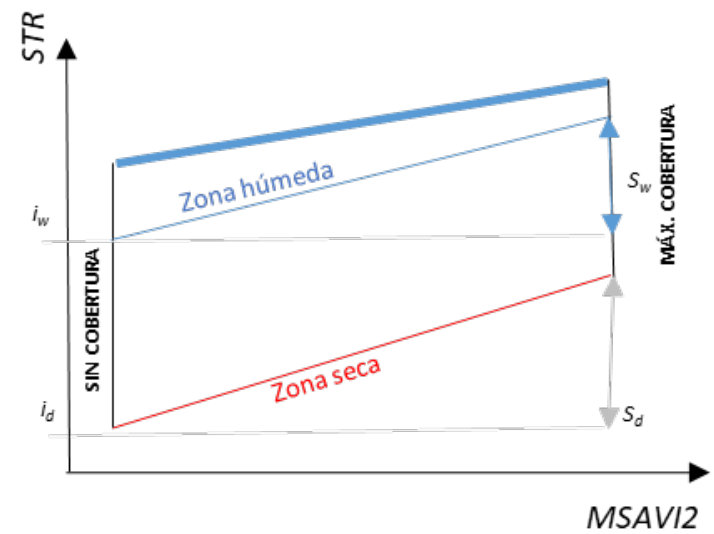

Figura 3. Esquema que ilustra los parámetros del modelo Optico TRapezoide [Eq. (4 y 5) dentro del espacio STR-MSAVI2, (Sadeghi, Jones y Philpot, 2015; Del et al., 2019).

Por lo tanto, STR responde a la relación lineal en el límite húmedo y seco, de la siguiente manera:

$$
\begin{aligned}
& S T R_{d}=i_{d}+s_{d} \text { MSAVI } \\
& S T R_{w}=i_{w}+s_{w} \text { MSAVI }
\end{aligned}
$$

Al combinar las ecuaciones, la humedad del suelo en cada píxel se puede estimar en función de STR y MSAVI2:

$$
W=\frac{i_{d}+s_{d} M S A V I-S T R}{i_{d}-i_{w}+\left(s_{d}-s_{w}\right) M S A V I}
$$




\section{Congreso Nacional de Riegos CARTAGENA 2021

A partir de la interpretación visual, los coeficientes de parametrización entre borde húmedo y seco utilizados para calcular la estimación de humedad normalizada (W), son los siguientes:

$$
\begin{aligned}
& S T R_{d}=0.15+0.7 * M S A V I \\
& S T R_{w}=0.60+0.9 * M S A V I
\end{aligned}
$$

La reflectancia es una función que depende únicamente de las propiedades del suelo y no de las condiciones atmosféricas. Por tanto, suponemos una parametrización universal válida para todas las fechas en un sitio específico [33].

\subsubsection{Random Forest Classifier}

Para la estimación del área regada se utilizó el algoritmo de Random Forest (RF) para construir un modelo clasificador a partir de las variables ambientales obtenidas con métodos ópticos de observación terrestre. RF es un conjunto de algoritmos de aprendizaje automático que consta de una gran cantidad de clasificadores de árboles de decisión, llamados estimadores, donde cada árbol produce sus propias predicciones. La precisión del clasificador de RF depende de la fuerza de los clasificadores de árboles individuales y de la dependencia entre ellos, [34]. Su arquitectura permite manejar grandes conjuntos de datos.

Se aplicó el clasificador de RF utilizando el conjunto de datos del procesamiento de datos ópticos de variables climáticas, topográficas y morfológicas del cultivo, junto a muestras de entrenamiento de un conjunto de datos del estado hídrico del riego en las parcelas del área de estudio.

\section{Resultados y discusión.}

Los valores altos de humedad del suelo en la estación seca son indicadores de la presencia de riego. Sin embargo, empleando únicamente índices de humedad del cultivo no es suficiente para identificar y delimitar las áreas regadas. Parcelas donde la topografía confiere una situación satisfactoria para que se den buenas condiciones hídricas del cultivo, como por ejemplo los barrancos y fondos de valle, hacen difícil clasificar los umbrales entre parcelas regadas y no regadas.

De un total de 2804 parcelas de viñedo, los resultados de la clasificación de suelo regado utilizando la humedad del suelo junto a la topografía, y morfología del cultivo han demostrado mejorar la caracterización de suelo regado con una precisión general del 94.7\%.

La evaluación aporta un error medio cuadrático de 0.163 y R-cuadrado de 0.874 . Los resultados de la evaluación de precisión se llevaron a cabo con una matriz de confusión [35], donde los grupos se asignan a categorías relacionadas con la categoría real probada como datos reales o de referencia. El $75 \%$ de los datos fueron para entrenamiento (227 parcelas) y los datos del $25 \%$ se utilizaron como prueba de validación (76 parcelas).

La precisión se calculó mediante errores de inclusión y exclusión en la clasificación, tabla 1.

Tabla 1. Matriz de confusión

\begin{tabular}{ccc}
\hline & Parcela No Riego & Parcela en Riego \\
\hline Parcela en No Riego & 22 & 1 \\
Parcela en Riego & 1 & 51 \\
\hline
\end{tabular}

El uso de clasificadores que determinan las condiciones hídricas de las plantas por aprendizaje automático proporciona una alta precisión para distinguir las parcelas que han sido regadas en la temporada de riego. La superficie total regada de cultivo de viñedo en el municipio de Caudete de las Fuentes fue de 566.9 ha en el periodo considerado. 


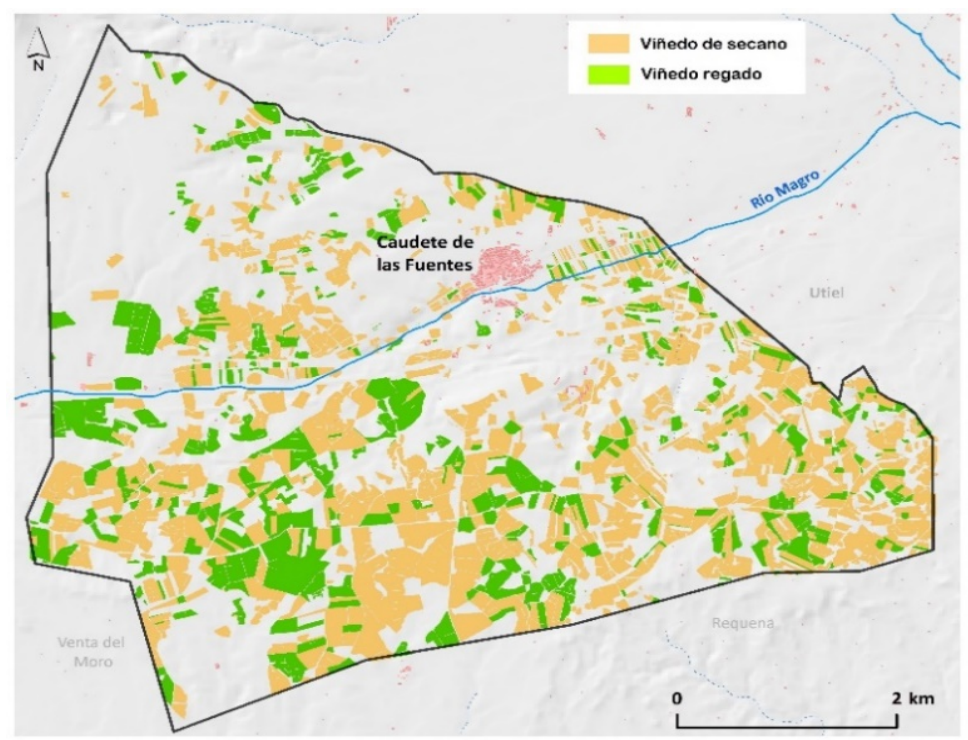

Figura 4. Mapeo de la superficie regada de viñedo en Caudete de las Fuentes para el periodo de riego de 2019.

\section{Conclusiones}

El cálculo de humedad de suelo con imágenes aéreas en el dominio óptico junto a variables que condicionan el estado hídrico del cultivo hace posible distinguir con una precisión de $94.7 \%$ la superficie regada de viñedo. Esto permite evaluar la situación actual y estudiar la evolución de los regadíos aplicando técnicas con sensores remotos.

Se debe tener en cuenta que, cuando se emplean las técnicas de inteligencia artificial, el método evalúa el error del modelo en general sobre el conjunto de datos disponible, pero no sobre cada predicción particular, por lo que el error podría ser mayor si se extrapolan los resultados.

Por tanto, la evaluación del modelo estima un error generalizado en un conjunto de datos limitado y responde a la complejidad real del problema. Para mejorar la estimación se requiere conocer toda la variabilidad existente y predecir así con más exactitud el estado de riego en la parcela.

La alta precisión y los bajos niveles de error obtenidos permiten validar la metodología empleada, que presenta potencial de mejora con una mayor alimentación del proceso de aprendizaje automático. Estas técnicas se aplicarán en breve a otros cultivos leñosos y a toda la masa de agua subterránea de Requena-Utiel.

\section{Agradecimientos.}

Este estudio ha sido financiado por el proyecto eGROUNDWATER (GA No. 1921), que forma parte del programa PRIMA, apoyado por el Programa de Investigación e Innovación Horizon 2020 de la Unión Europea.

\section{Referencias}

1. T. Gleeson, Y. Wada, M. F. P. Bierkens, and L. P. H. Van Beek, 'Water balance of global aquifers revealed by groundwater footprint', Nature, vol. 488, no. 7410, pp. 197-200, 2012, doi: 10.1038/nature11295.

2. D. S. Grogan, D. Wisser, A. Prusevich, R. B. Lammers, and S. Frolking, 'The use and re-use of unsustainable groundwater for irrigation: A global budget', Environ. Res. Lett., vol. 12, no. 3, 2017, doi: 10.1088/1748-9326/aa5fb2.

3. E. López-Gunn, ‘Groundwater governance and social capital’, Geoforum, vol. 43, no. 6, pp. 1140-1151, 2012.

4. T. L. Birkenholtz, 'Recentralizing groundwater governmentality: rendering groundwater and its users visible and governable', WIREs Water, vol. 2, no. 1, pp. 21-30, 2015, doi: 10.1002/wat2.1058. 


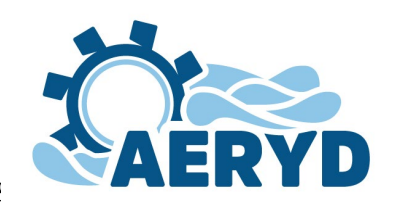

\section{Congreso Nacional de Riegos CARTAGENA 2021}

5. A. Closas, F. Molle, and N. Hernández-Mora, 'Sticks and carrots to manage groundwater over-abstraction in La Mancha, Spain', Agric. Water Manag., vol. 194, pp. 113-124, 2017, doi: 10.1016/j.agwat.2017.08.024.

6. F. Molle, E. López-Gunn, and F. van Steenbergen, 'The local and national politics of groundwater overexploitation', Water Altern., vol. 11, no. 3, pp. 445-457, 2018.

7. F. Molle and A. Closas, 'Why is state-centered groundwater governance largely ineffective? A review', Wiley Interdiscip. Rev. Water, vol. 7, no. 1, pp. 1-17, 2020, doi: 10.1002/wat2.1395.

8. Ostrom, E. (1992): Crafting Institutions for Self-Governing Irrigation Systems, San Francisco: Institute for Contemporary Studies.

9. A. AGRAWAL, 'Common Property Institutions and Sustainable Governance of Resources', WorldDevelopment Vol., vol. 29, no. 10, pp. 1649-1672, 2001, doi: 10.1177/0010836717703674.

10. S. Castaño, D. Sanz, and J. J. Gómez-Alday, 'Methodology for quantifying groundwater abstractions for agriculture via remote sensing and GIS', Water Resour. Manag., vol. 24, no. 4, pp. 795-814, 2010, doi: 10.1007/s11269-009-9473-7.

11. J. F. Brown and M. S. Pervez, 'Merging remote sensing data and national agricultural statistics to model change in irrigated agriculture', Agric. Syst., vol. 127, pp. 28-40, 2014, doi: 10.1016/j.agsy.2014.01.004.

12. D. Sanz, A. Calera, S. Castaño, and J. J. Gómez-Alday, 'Knowledge, participation and transparency in groundwater management', Water Policy, vol. 18, no. 1, pp. 111-125, 2016, doi: 10.2166/wp.2015.024.

13. S. Siebert, V. Henrich, K. Frenken, and J. Burke, 'Update of the digital global map of irrigation areas to version 5 ', Rheinische Friedrich-Wilhelms-Universituy, Bonn, Ger. Food Agric. Organ. United Nations, Rome, Italy, no. August 2014, p. 171, 2013

14. A. K. Ambika, B. Wardlow, and V. Mishra, 'Remotely sensed high resolution irrigated area mapping in India for 2000 to 2015', Sci. Data, vol. 3, pp. 1-14, 2016, doi: 10.1038/sdata.2016.118.

15. J. M. Deines, A. D. Kendall, M. A. Crowley, J. Rapp, J. A. Cardille, and D. W. Hyndman, 'Mapping three decades of annual irrigation across the US High Plains Aquifer using Landsat and Google Earth Engine', Remote Sens. Environ., vol. 233, no. October 2018, p. 111400, 2019, doi: 10.1016/j.rse.2019.111400.

16. M. F. A. Vogels, S. M. de Jong, G. Sterk, and E. A. Addink, 'Mapping irrigated agriculture in complex landscapes using SPOT6 imagery and object-based image analysis - A case study in the Central Rift Valley, Ethiopia -', Int. J. Appl. Earth Obs. Geoinf., vol. 75, no. May 2018, pp. 118-129, 2019, doi: 10.1016/j.jag.2018.07.019.

17. X. Cai, J. Magidi, L. Nhamo, and B. van Koppen, Mapping irrigated areas in the Limpopo Province, South Africa, vol. 172. 2016.

18. A. Calera, I. Campos, A. Osann, G. D'Urso, and M. Menenti, 'Remote sensing for crop water management: From ET modelling to services for the end users', Sensors (Switzerland), vol. 17, no. 5, pp. 1-25, 2017, doi: 10.3390/s17051104.

19. M. Zohaib, H. Kim, and M. Choi, 'Detecting global irrigated areas by using satellite and reanalysis products', Sci. Total Environ., vol. 677, pp. 679-691, 2019, doi: 10.1016/j.scitotenv.2019.04.365.

20. T. N. Carlson and G. P. Petropoulos, 'A new method for estimating of evapotranspiration and surface soil moisture from optical and thermal infrared measurements: the simplified triangle', Int. J. Remote Sens., vol. 40, no. 20, pp. 7716-7729, 2019.

21. T. N. Carlson, 'A brief analysis of the triangle method and a proposal for its operational implementation', Remote Sens., vol. 12, no. 22, pp. 1-9, 2020, doi: 10.3390/rs12223832.

22. M. Sadeghi, S. B. Jones, and W. D. Philpot, 'A linear physically-based model for remote sensing of soil moisture using short wave infrared bands', Remote Sens. Environ., vol. 164, pp. 66-76, 2015, doi: 10.1016/j.rse.2015.04.007.

23. E. Babaeian, M. Sadeghi, T. E. Franz, S. Jones, and M. Tuller, 'Mapping soil moisture with the OPtical TRApezoid Model (OPTRAM) based on long-term MODIS observations', Remote Sens. Environ., vol. 211, no. April, pp. 425-440, 2018.

24. E. Babaeian et al., 'A New Optical Remote Sensing Technique for High-Resolution Mapping of Soil Moisture', Front. Big Data, vol. 2, no. November, pp. 1-6, 2019, doi: 10.3389/fdata.2019.00037.

25. M. Chen et al., 'Evaluation of the OPTRAM Model to Retrieve Soil Moisture in the Sanjiang Plain of Northeast China', Earth Sp. Sci., vol. 7, no. 6, 2020, doi: 10.1029/2020EA001108.

26. C. H. del Júcar, 'PLAN DE EXPLOTACIÓN DE LA MASA DE AGUA SUBTERRÁNEA REQUENA - UTIEL', p. 13, 2016.

27. C. Funk et al., 'The climate hazards infrared precipitation with stations - A new environmental record for monitoring extremes', Sci. Data, vol. 2, no. June 2016, 2015, doi: 10.1038/sdata.2015.66.

28. L. Pádua et al., 'Vineyard variability analysis through UAV-based vigour maps to assess climate change impacts', Agronomy, vol. 9, no. 10, 2019, doi: 10.3390/agronomy9100581.

29. A. J. Richardson and C. L. Wiegand, 'Distinguishing vegetation from soil background information', Photogramm. Eng. Remote Sensing, vol. 43, no. 12, pp. 1541-1552, 1977.

30. J. Qi, A. Chehbouni, A. R. Huete, Y. H. Kerr, and S. Sorooshian, 'A modified soil adjusted vegetation index', Remote Sens. Environ., vol. 48, no. 2, pp. 119-126, 1994, doi: 10.1016/0034-4257(94)90134-1.

31. C. A. Qi J., Kerr Y., 'External_factor_consideration_in_vegetat.pdf'. 1994.

32. P. C. Towers, A. Strever, and C. Poblete-Echeverría, 'Comparison of vegetation indices for leaf area index estimation in vertical shoot positioned vine canopies with and without grenbiule hail-protection netting', Remote Sens., vol. 11, no. 9, 2019, doi: 10.3390/rs11091073. 
33. M. Sadeghi, E. Babaeian, M. Tuller, and S. B. Jones, 'The optical trapezoid model: A novel approach to remote sensing of soil moisture applied to Sentinel-2 and Landsat-8 observations', Remote Sens. Environ., vol. 198, no. September, pp. 52-68, 2017, doi: 10.1016/j.rse.2017.05.041.

34. L. Breiman, 'Random forests', Random For., pp. 1-122, 2001, doi: 10.1201/9780429469275-8.

35. R. G. Congalton, 'A review of assessing the accuracy of classifications of remotely sensed data', Remote Sens. Environ., vol. 37, no. 1, pp. 35-46, 1991, doi: 10.1016/0034-4257(91)90048-B. 


\title{
Tecnología de sensores inalámbricos para el manejo del ferti- riego en el viñedo en Galicia
}

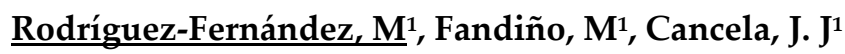

$1 \quad{ }^{1}$ GI-1716. Proepla. Depart. Ingeniería Agroforestal. Escuela Politécnica Superior de Ingeniería. Universidad de Santiago de Compostela: marta.rodriguez.fernandez0@rai.usc.es; maria.fandino@usc.es; javierjose.cancela@usc.es

Resumen: Actualmente, la gestión eficiente del uso del agua en el viñedo, es una tendencia ya implantada en el mundo vitivinícola, que cada día avanza ligada a las nuevas tecnologías, de cara a mejorar la eficiencia del riego de la vid.

En los últimos años, la tecnología inalámbrica ha revolucionado la forma de ver y comprender el manejo del viñedo, eliminando restricciones y dando más flexibilidad a la hora de implantar tecnologías sobre la viña. Gracias a esta evolución tecnológica, se han desarrollado sensores inalámbricos (WSN), que posibilitan la obtención de datos en cualquier localización a tiempo real.

En el presente estudio, se analiza la gestión del riego de un viñedo situado en Vedra (A Coruña), en las campañas 2019 y 2020. En la parcela a estudio, se encuentran instalados sensores Watermark ${ }^{\mathrm{TM}}$, que miden el potencial de agua en el suelo cada hora, a 30 y $60 \mathrm{~cm}$ de profundidad. Con los datos disponibles de lluvia y evapotranspiración del viñedo, se ha realizado un análisis de la evolución del potencial foliar a lo largo de las campañas en estudio. El potencial hídrico foliar de tallo a mediodía solar, se utilizó como estimador del estado hídrico del viñedo, buscando correlaciones entre ambos potenciales: suelo y hoja.

En las condiciones del ensayo, las medidas tensiométricas a $30 \mathrm{~cm}$, pueden ser una herramienta útil para la monitorización del riego. Si bien, se plantean distintas alternativas y mejoras del sistema que permiten el manejo del riego de la vid dentro de la eficiencia en el uso del agua, que engloba la aplicación de una viticultura de precisión.

Palabras clave: tecnología inalámbrica; sensores Watermark ${ }^{\mathrm{TM}}$; gestión del agua; riego viñedo 


\title{
XXXVIII Congreso Nacional de Riegos CARTAGENA 2021
}

\section{Wireless sensor technology for fertigation management in the vineyard in Galicia}

\author{
Rodríguez-Fernández, $\mathbf{M}^{1}$, Fandiño, $\mathbf{M}^{1}$, Cancela, J. J ${ }^{1}$
}

1 GI-1716. Proepla. Ingeniería Agroforestal. Depart. Escuela Politécnica Superior de Ingeniería. University of Santiago de Compostela: marta.rodriguez.fernandez0@rai.usc.es; maria.fandino@usc.es; javierjose.cancela@usc.es

\begin{abstract}
Currently, the efficient management of water use in the vineyard, is a trend already established in the wine world, which progresses every day linked to new technologies, order to improve the efficiency of vine irrigation. Actually, wireless technology has revolutionized the point of view of vineyard management, removing restriction and giving more flexibility when implementing technologies in the vine. This technological evolution, wireless sensors (WSN) have been developed, which make it possible to obtain data in any location in real time.

In this study, the irrigation management of a vineyard located in Vedra (A Coruña) is analysed in 2019 and 2020 seasons. In the plot under study, Watermark ${ }^{\mathrm{TM}}$ sensors are installed for measure the water potential in the soil every hour, 30 and $60 \mathrm{~cm}$ deep. With the available data in rainfall and evapotranspiration of the vineyard, an analysis of the evolution of the foliar potential throughout the seasons has been carried out. The foliar hydric potential of the stem at solar noon was used as an estimator of the hydric state of the vineyard, looking for correlations between both potentials: soil and leaf.

Under study conditions, tensiometric measurements at $30 \mathrm{~cm}$, can be a useful tool for monitoring irrigation. However, different alternatives and improvements of the system allow the management of vine irrigation within the efficiency in the use of water, which includes the application of precision viticulture.
\end{abstract}

Keywords: wireless technology; watermark ${ }^{\mathrm{TM}}$; water management; vineyard irrigation 


\section{Congreso Nacional de Riegos CARTAGENA 2021}

\section{Introducción}

La tecnología de sensores inalámbricos, se ha instalado en el campo de la viticultura como una nueva tecnología que aporta información sobre el estado del viñedo a tiempo real, que permite realizar un manejo del cultivo de forma eficiente [1].

El manejo del agua en el cultivo de la vid, se considera una herramienta importante para mejorar el desarrollo de la planta y la calidad de la uva, así como para conseguir la estabilidad en la producción a final de campaña [2].

Una de las mayores demandas de los viticultores para manejar el riego, es conocer el estado hídrico del viñedo de modo rápido, que no implique excesivo consumo de tiempo y mano de obra, tal como requiere el potencial hídrico foliar, además de ser una medida destructiva [3]. El estado hídrico de la planta depende de su desarrollo foliar, de la demanda atmosférica y del contenido de agua en el suelo [4]. Por ello, en este trabajo se plantea como objetivo el elaborar y validar los sensores inalámbricos instalados en el viñedo como una nueva tecnología que aporte información sobre el estado hídrico de la planta a partir de la disponibilidad hídrica del suelo, contrastado con la demanda ambiental y el desarrollo foliar, disponible automáticamente y con posibilidad de tener la información actualizada en tiempo real.

\section{Materiales y métodos}

\subsection{Parcela a estudio}

El viñedo a estudio se ecuentra enmarcado en la Denominación de Origen Rías Baixas (ACoruña), concretamente perteneciente a la subzona vitivinícola de Ribeira de Ulla. La parcela tiene una extensión de 12,1 ha, situada a $42^{\circ} 45^{\prime} 6^{\prime \prime}$ longitud Norte, $8^{0} 28^{\prime} 10^{\prime \prime}$ longitud Oeste y a $131 \mathrm{~m}$ sobre el nivel del mar.

El viñedo ha sido plantado en el año 2004, en toda su extensión cultivado con la variedad 'Albariño', variedad preferente en las Rías Baixas. Las vides se encuentran empalizadas en espaldera y con un sistema de poda de pulgar-vara. La distancia entre plantas es de 2,5 m entre plantas y $3 \mathrm{~m}$ entre filas. El portainjerto empleado es el 110 Ritcher y dispone de riego por goteo en toda la superficie cultivada, con un riego de campaña gestionado a criterio del viticultor.

\subsection{Dispositivo experimental}

Los puntos de muestreo de la parcela a estudio, se seleccionaron siguiendo una malla de $30 \times 30 \mathrm{~m}$, que dio a lugar a 32 puntos de muestreo que recogen el área total del viñedo, permitiendo analizar la extensión total de la parcela, de manera homogénea en cada uno de los cinco sectores de riego que presenta el viñedo.

\subsection{Mediciones}

El contenido volumétrico del agua en el suelo del viñedo, se determinó mediante sondas inalámbricas Watermark ${ }^{\mathrm{TM}}$, los sensores instalados dentro de un tubo de acceso se encuentran a 30 y 60 $\mathrm{cm}$, conectados a un nodo central que registra datos automáticamente a cada hora y diariamente durante el período a estudio (campañas 2019 y 2020).

El potencial hídrico de tallo, se medió tres veces por campaña en los meses de junio, julio y agosto, a mediodía solar, utilizando la técnica de la cámara de presión, envolviendo las hojas en bolsas opacas una hora antes de la lectura del potencial, estas medidas se llevaron a cabo en hojas sanas y adultas, 


\section{Congreso Nacional de Riegos CARTAGENA 2021}

que se encontrasen expuestas a la radiación solar directa [5,6]. Se realizaron medidas en los 32 puntos de muestreo de la parcela.

También se han recogido datos meteorológicos en las dos campañas a estudio de la estación agroclimática Pazo Galegos, gestionada meteogalicia (https://www.meteogalicia.gal/web/inicio.action). La zona vitivinícola de las Rías Baixas, se encuentra integrada en la región Atlántica, donde la climatología de la zona, se define con inviernos protagonizados por borrascas del Oeste y del Sudoeste, con frentes cálidos y aire tropical, que recaen en unas precipitaciones abundantes y temperaturas suaves.

Para evaluar la relación entre el potencial hídrico de la planta y el contenido en agua del suelo, se promediaron los datos recogidos por las sondas de 30 y $60 \mathrm{~cm}$ en los días en los que se llevaron a cabo las medidas de potencial hídrico de tallo y se analizaron los datos utilizando métodos de correlación lineal.

\section{Resultados y discusión}

Con los resultados obtenidos del seguimiento de datos de los sensores en ambas campañas, ha podido realizarse un control en los meses de mayo a septiembre, que analizado junto con las condiciones meteorológicas que se han dado en el período a estudio, ha podido observarse cómo en ambas campañas el requerimiento de agua en el suelo es mayor en los meses de julio-agosto (2019) y abriljulio (2020), coincidente con un período en los que las precipitaciones son escasas y focalizadas en días en los que se atenúan los picos medidos del potencial hídrico en el suelo.

Si bien, también puede observarse como la diferencia de los datos generados con los sensores instalados a 30 y $60 \mathrm{~cm}$ del suelo, a menor profundidad $(30 \mathrm{~cm})$ se observa una tendencia hídrica del suelo más estable, ascendente desde el mes de junio (2019) y abril (2020) hasta el mes de septiembre, por otro lado, los datos recogidos a $60 \mathrm{~cm}$ de profundidad, en la campaña 2019 registra valores ligeramente inferiores a $60 \mathrm{kPa}$, con picos focalizados en los meses de junio y septiembre, mientras que en la campaña 2020 estos sensores han presentado un brusco ascenso en el mes de abril y un fallo en la conexión de la generación de los datos del mismo en los meses de junio y agosto (Figuras 1 y 2 ).

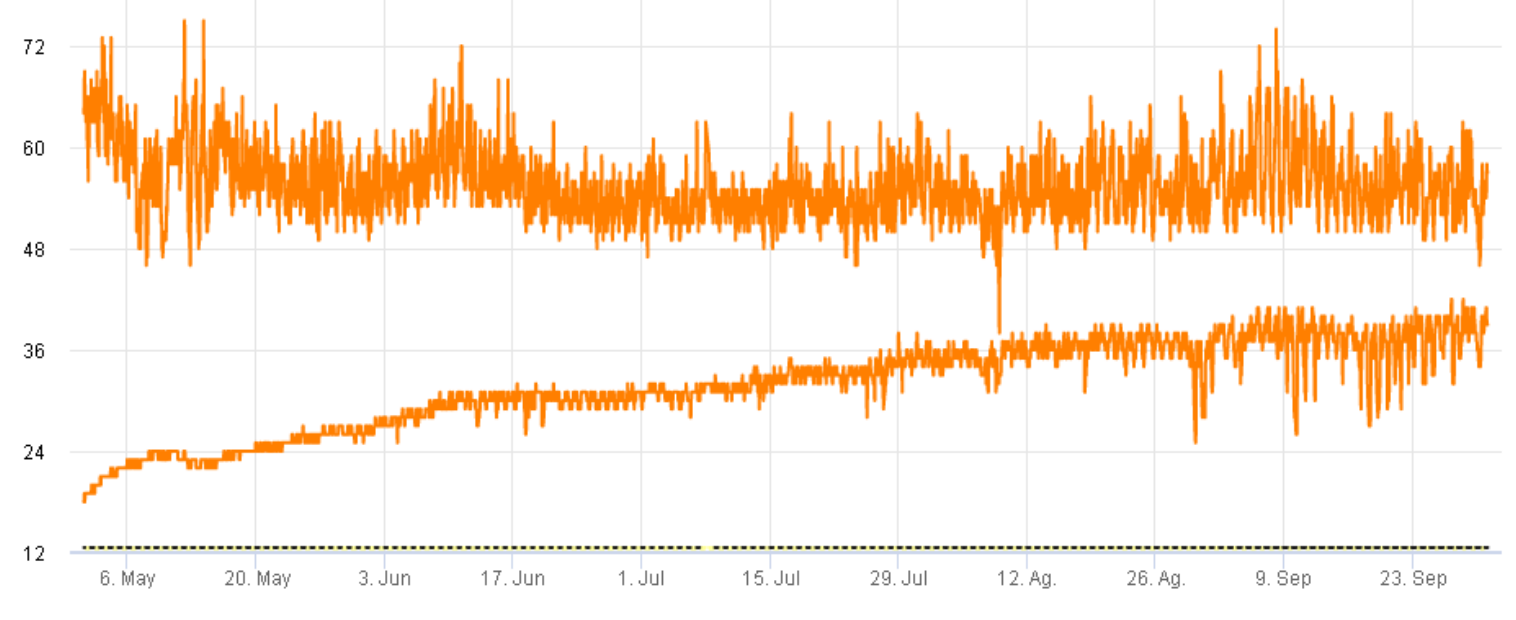




\section{Congreso Nacional de Riegos CARTAGENA 2021}

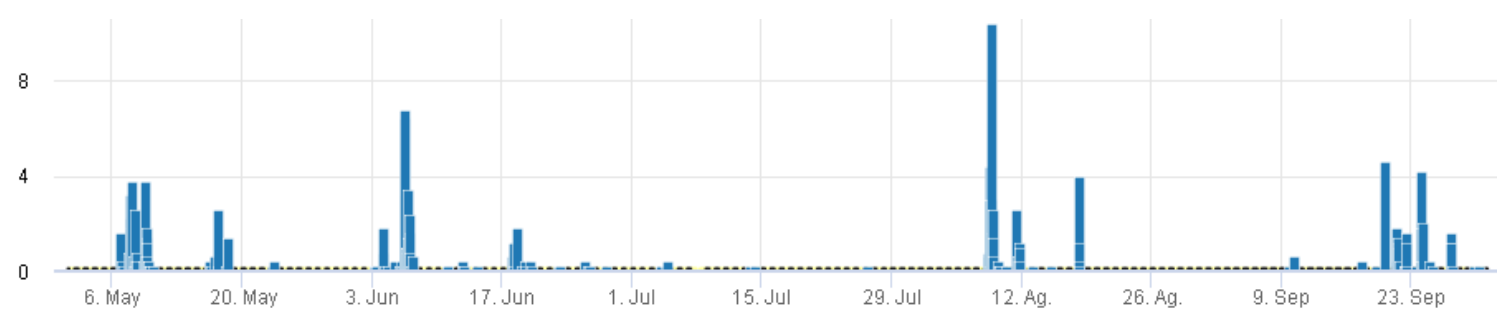

Figura 1. Registro de datos de las sondas de sensores de potencial hídrico de suelo $(\mathrm{kPa})$ a 30 y $60 \mathrm{~cm}$ de profundidad y precipitación diaria (mm)(mayo-septiembre 2019)

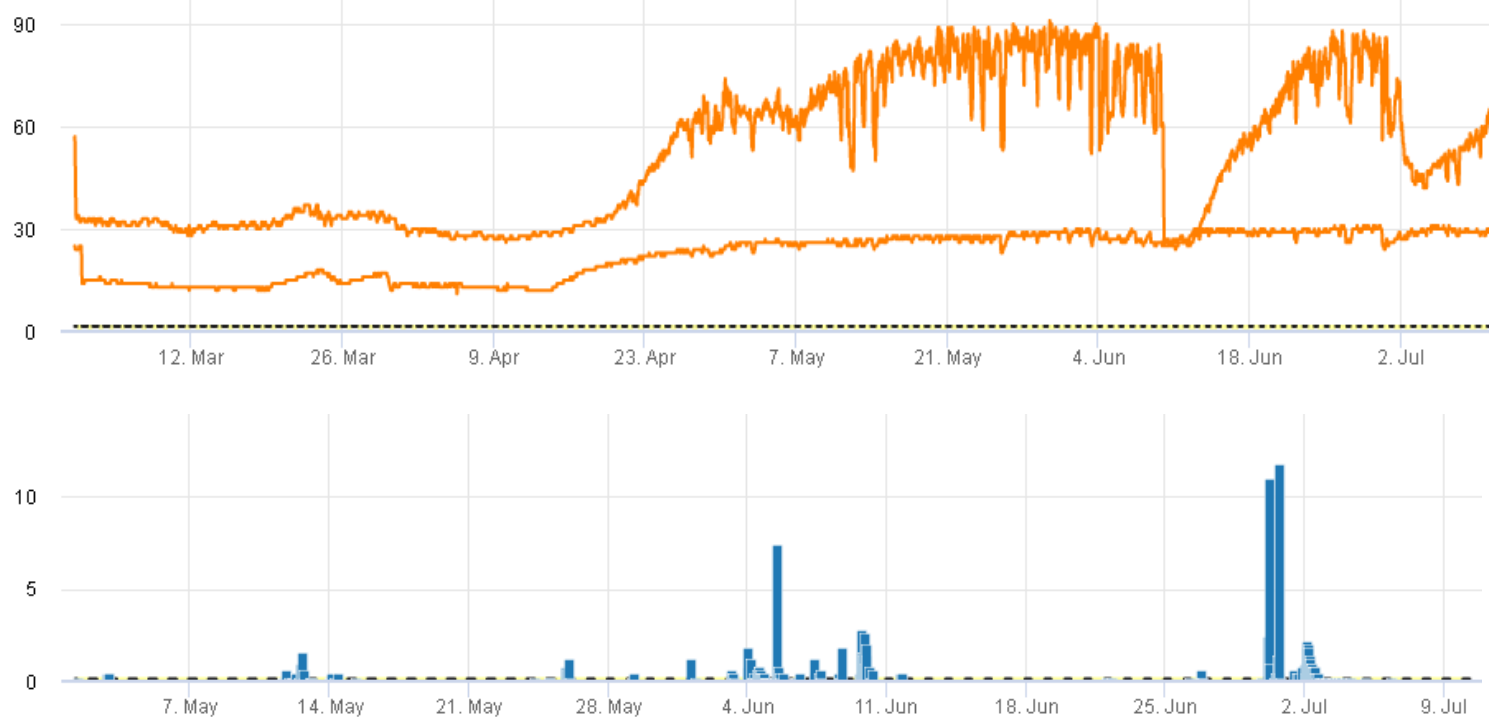

Figura 2. Registro de datos de las sondas de sensores de potencial hídrico de suelo $(\mathrm{kPa})$ a 30 y $60 \mathrm{~cm}$ de profundidad y precipitación diaria (mm) (mayo-julio 2020)

Con las relaciones lineales realizadas entre el potencial de suelo y las mediciones de potencial hídrico de tallo, se ha establecido que los sensores instalados a $30 \mathrm{~cm}$ de profundidad, son los que mejor se ajustan a las medidas realizadas en campo, con valores de $r^{2}: 0,9$ en la campaña 2019 y r²: 0,8 en 2020. Los sensores instalados a $60 \mathrm{~cm}$, también han presentado buenas relaciones, no obstante, en este caso en la campaña 2019 se ha obtenido un valor de correlación de 0,9, mientras que en 2020 este valor descendió a 0,4 influenciado por los problemas de conexión que se han dado a lo largo de la campaña a estudio (Figura 3). 

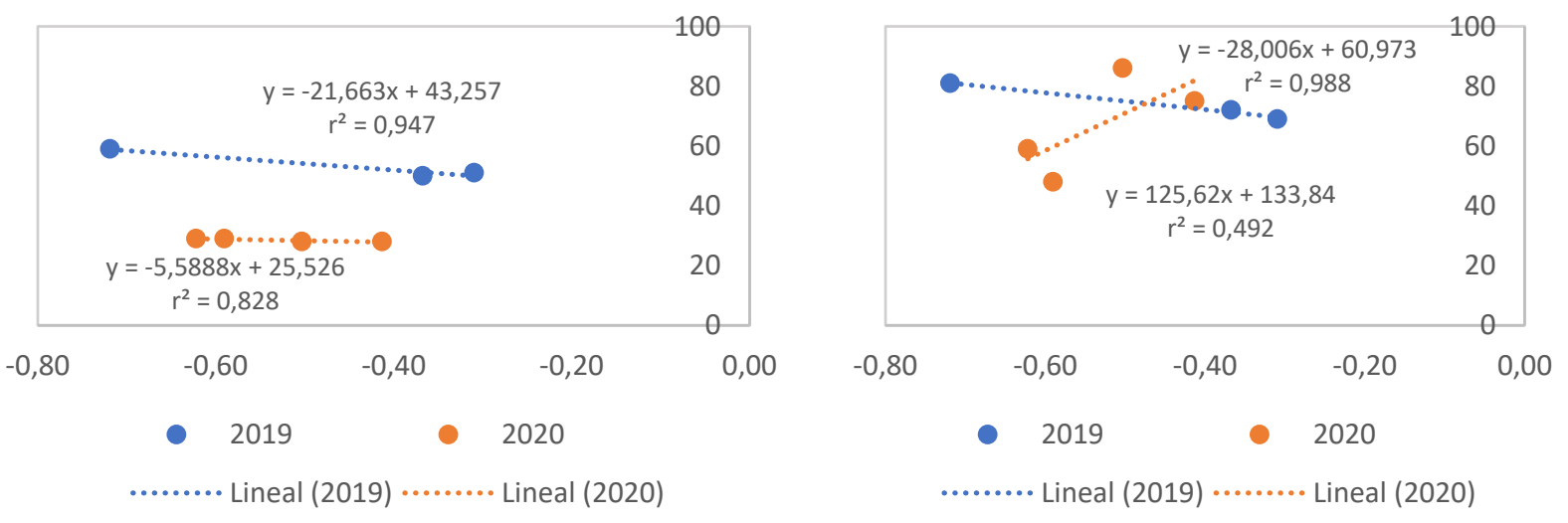

Figura 3. Relaciones lineales entre potencial hídrico de suelo $(\mathrm{kPa})$ y potencial hídrico foliar $(\mathrm{MPa})$, sensores a $30 \mathrm{~cm}$ de profundidad representados a la izquierda y sensores a $60 \mathrm{~cm}$ de profundidad representados a la derecha.

Estas relaciones determinadas entre el potencial hídrico de suelo y el potencial hídrico de tallo, también han sido estudiadas para la misma variedad 'Albariño' por otros autores [7], obteniendo también buenas relaciones entre ambas medidas.

El estudio de los sensores a distintas profundidades, también han sido analizados por distintos autores, que obtienen buenos resultados con sensores instalados en los 30 primeros $\mathrm{cm}$ del suelo [8,9]. Por otro lado, hay estudios que apuntan a que las medidas de contenido de humedad del suelo en sistemas de riego localizado, no son representativas en los primeros $\mathrm{cm}$ de suelo, debido a que el consumo de agua es más rápido que en las capas más profundas del mismo, por lo que, en este caso se considera más fiable tomar estos datos de potencial hídrico de suelo, en un rango de $60 \mathrm{~cm}$ de profundidad [10].

\section{Conclusiones}

Las conclusiones obtenidas en el presente estudio, muestran muy buenas relaciones entre los valores de potencial hídrico foliar y el potencial de agua en el suelo, evaluados mediante sensores inalámbricos instalados en el viñedo a 30 y $60 \mathrm{~cm}$ de profundidad. Estos valores obtenidos, muestran como los sensores instalados Watermark ${ }^{\mathrm{TM}}$, son una tecnología muy útil para determinar el potencial de agua en el viñedo a lo largo de la campaña, que permite la aplicación y control del riego de una forma más eficiente.

Sin embargo, las medidas analizadas en este trabajo, deben de replicarse en cuanto a campañas y profundidades de los sensores, que permitan determinar un rango mucho más estrecho en cuanto a la colocación óptima de los sensores en el viñedo. Siendo necesario ampliar la variabilidad del rango de mediciones del potencial de suelo, limitado en el estudio a valores entre 20 y $80 \mathrm{kPa}$.

\section{Referencias}

1. Blackmore, S. Precision farming: and introduction, Outlook Agr., 1994; pp. 275-280.

2. Williams, L.E., Matthews, M.A. Grapevine. In: Stewart BA, Nielsen DR (eds) Irrigation of agricultural crops agronomy monograph no. 30. ASA-CSSA-SSSA, Madison. 1990. pp 1019-1055.

3. Baena, M., Rodríguez, L., Tejero, M., Baeza, P. Estimation of the hydric state of the vineyard from the water content of the soil, environmental conditions and foliar development. In II Conference on viticulture: technical communications: Madrid, November 2016. Pp. 236-242. Polytechnic University of Madrid. 
4. Williams, L.E., Baeza, P. Relationships among ambient temperature and vapour pressure deficit and leaf and stem water potentials of fully irrigated, field-grown grapevines. American Journal of Enology and Viticulture. 2007. 58 (2) pp. $173-181$.

5. Scholander, P.H., Hammel, H.J., Bradstreet, A., Hemmingsen, E.A. Sap pressure in vascular plants. Science. 1965 pp. $339-$ 346.

6. Choné, X., Van Leeuwen, C., Dubordieu, D., Gaudillère, J.P. Stem water potential is a sensitive indicator of grapevine water status. Annals of Botany, 2001 pp. 447-483.

7. Martínez, E.M., Fandiño, M., Cancela, J.J., Rey, B.J. Evaluation of the stress of the cv. Albariño in the DO Rías Baixas. Digital magazine Interempresas Wine Industry. 2013.

8. Williams, L.E., Araujo, F.J. Correlations among predawn leaf, midday leaf, and midday stem water potential and their correlations with other measures of soil and plant water status in Vitis vinifera J. Amer. Soc. Hrtic.Sci. 2002 pp.448-454.

9. Asenjo, J.L., Yuste, J. Estimation of the hydric state of the soil bytensiomety and volumetry and its relationship with the hydric state of the vineyard. Studies of the unsaturated zone of the soil. 2003.

10. Bravdo, B., Proebsting, E.I. Use of drip irrigation in orchards. HorTechnology. 1993 pp. 44-49. 


\title{
Estudio de envejecimiento real en tuberías de PRFV en servi- cio, en redes de distribución de agua para riego.
}

\author{
Berganza López B., Chillón Moreno, JM, González Prolongo, S.
}

1 Jefe de Departamento Obras de Riego, TRAGSA; bberganz@tragsa.es

2 Jefe del Laboratorio de Instalaciones, Instituto Torroja (CSIC); jimchillon@ietcc.csic.es

3 Catedrática de Universidad. Universidad Rey Juan Carlos; silvia.gonzalez@urjc.es

\section{Resumen:}

Tras la alta tasa de incidencias ocurridas en los últimos años en el sector del regadío español con tubería de PRFV de un fabricante concreto, se ha realizado un estudio comparativo entre muestras extraídas de este fabricante y de otros 4 fabricantes (que no han presentado fallos). Para ello, se realizó la extracción de muestras representativas con una antigüedad similar (unos 10 años). El objetivo era evaluar la pérdida de prestaciones con el tiempo (envejecimiento del material) -medida a través de sus propiedades mecánicas- así como comparar los resultados obtenidos entre las tuberías que presentan fallo y las que no. También se realizó un estudio exhaustivo de la composición de los tubos y sus materiales. El desarrollo de estos trabajos se ha realizado bajo el amparo del proyecto de I+D+I TUBCAL1618 de TRAGSA. Los resultados indican que la evolución de las propiedades en el tiempo de los tubos que presentan fallo no es la esperada y sus valores absolutos están por debajo de los valores declarados por el propio fabricante (la pérdida de propiedades en el tiempo es muy superior a la declarada). Estos resultados resultan coherentes con la tasa de averías que las obras en las que están instalados están sufriendo. Además, del análisis complementario de la información de calidad disponible se ha podido comprobar la enorme variabilidad de resultados. Esto es indicativo de un pobre control de proceso durante la fabricación. En el estudio detallado de las muestras y su composición se puede comprobar, también, que hay multitud de defectos de fabricación y elección de materiales que contribuyen a los fallos anticipados.

Por el contrario, de los resultados de los ensayos mecánicos de la tubería de PRFV extraída de otros fabricantes -sin fallo- son, en general, muy buenos. La variabilidad de resultados -por fabricante- es escasa (indicando que los procesos de fabricación son mucho más estables y controlados). La pérdida de propiedades de los tubos es mucho menor, de media. Los valores obtenidos de pérdida de propiedades son muy inferiores a las curvas de referencia empleadas, por lo que el envejecimiento real es menor de lo previsto (y apunta a que su vida útil está garantizada). Los valores -en términos absolutos- obtenidos siguen siendo, además y en la mayoría de los casos, superiores a los requisitos de tubo nuevo de la norma para cada una de las referencias analizadas.

Todo esto permite corroborar que la garantía de funcionamiento de las tuberías de PRFV está directamente relacionada con la calidad en su fabricación y el cumplimiento estricto de las especificaciones a corto y largo plazo definidas por la normativa vigente y las declaraciones de los propios fabricantes.

Palabras clave: tubería de PRFV, fallo de tuberías en servicio, patología de tuberías PRFV, envejecimiento de materiales, garantía de vida útil. 


\title{
XXXVIII Congreso Nacional de Riegos
} CARTAGENA 2021

\section{Study of actual creeping in GRP pipes in service, in water dis- tribution networks for irrigation.}

\author{
Berganza López B., Chillón Moreno, JM, González Prolongo, S.
}

1 Jefe de Departamento Obras de Riego, TRAGSA; bberganz@tragsa.es

2 Jefe del Laboratorio de Instalaciones, Instituto Torroja (CSIC); jmchillon@ietcc.csic.es

3 Catedrática de Universidad. Universidad Rey Juan Carlos; silvia.gonzalez@urjc.es

Abstract: After the high rate of failures that occurred in recent years in the Spanish irrigation sector with GRP pipes from a specific manufacturer, a comparative study has been carried out between samples taken from this manufacturer and from 4 other manufacturers (who have not experienced failures). For this, representative samples were extracted with a similar age (about 10 years). The objective was to evaluate the loss of performance over time (aging of the material) -measured through its mechanical properties- as well as to compare the results obtained between the pipes that present failure and those that do not. An exhaustive study of the composition of the pipes and their materials was also carried out. The development of these works has been carried out under the R + D + I project TUBCAL1618 from TRAGSA.

The results indicate that the evolution of the properties over time of the pipes that show failure is not as expected and their actual values are below the values declared by the manufacturer itself (the creeping over time is much higher than expected). These results are consistent with the failure rate that the systems they are installed in are suffering.

Moreover, the further analysis of the quality data available has been able to verify the enormous variability of results. This is indicative of poor process control during manufacturing. The detailed study of the samples and their composition shows there are a multitude of manufacturing defects and a wrong choice of materials that contribute to anticipated failures.

On the other hand, the results of the mechanical tests of the GRP pipes extracted from other manufacturers - without failure - are, in general, very good. The variability of results -by manufacturer- is scarce (indicating that the manufacturing processes are much more stable and controlled). The loss of properties of the pipes is lower, on average. The values obtained for creeping are much lower than the reference curves used, so the actual aging is less than expected (and indicates that its design life is guaranteed). The values -in absolute terms- obtained continue to be, in addition and in most cases, higher than the new pipe requirements of the standard for each of the references analyzed.

All this allows to declare that the performance guarantee of the GRP pipes is directly related to the quality in their manufacture and the strict compliance with the short and long-term specifications defined by the current standards and the declarations of the manufacturers themselves.

Keywords: GRP pipe, failure of pipes in service, pathology of GRP pipes, creeping, guarantee of design life 


\section{Introducción}

En el período 2006-09 se llevó a cabo en España una inversión pública extraordinaria (unos 2.400 M€ previstos) en materia de modernización de regadíos. El llamado Plan de Choque de Regadíos. Esto requirió unos volúmenes muy elevados de fabricación e instalación de diferentes materiales de riego (entre ellos destacan las tuberías, por su relevancia económica). La empresa pública TRAGSA fue la responsable de ejecutar una parte importante de los trabajos encomendados (más de $1.300 \mathrm{M} €$ ).

Este período de inversión extraordinaria llevó a una gran expansión del sector productor de las tuberías empleadas en el mundo del riego (principalmente materiales plásticos). Sólo TRAGSA necesitó unos $250 \mathrm{M} €$ en tubería (un 80\% de materiales plásticos -200 M€-) de los cuales, el 50\% (unos $125 \mathrm{M} €$ ), correspondió al material que nos ocupa (PRFV). En aquel momento existían 5 fabricantes nacionales (con diferentes sistemas de fabricación) que se repartieron equitativamente la fabricación requerida.

La tubería de PRFV es un composite que aglutina diferentes componentes (resina de poliéster, fibra de vidrio y cargas inertes) para aportar, cada uno, propiedades mecánicas particulares. Cada fabricante es responsable del diseño particular del tubo que fabrica (secuencia de capas, materiales y geometría). Cada diseño, además, es característico de los diferentes sistemas de fabricación que existen y particular para las características concretas de las materias primas que utiliza.

Finalizada la ejecución de las obras encomendadas, y en la puesta en marcha, empezaron a sucederse una serie de fallos (roturas) que se consolidaron e incrementaron a lo largo del tiempo. La distribución de los mismos fue generalizada por todo el territorio nacional, pero afectando de forma única y exclusiva a una de las tipologías de tubería (sistema de fabricación) puesta en el mercado por un fabricante en concreto. Las obras más afectadas fueron 4, con $95 \mathrm{~km}$ totales de tubería de PRFV instalada y más de 450 averías acumuladas a lo largo del tiempo.

Consecuencia de las distorsiones en la gestión cotidiana de las redes distribución de riego que las roturas provocaban, así como de sus elevados costes económicos, TRAGSA decidió iniciar una investigación profunda de causas para tratar de determinar la patología subyaciente así como acotar la magnitud del problema. Para ello, suscribió sendos convenios de colaboración con el Instituto Torroja (CSIC) y la Universidad Rey Juan Carlos, bajo un proyecto de investigación (TUBCAL1618). Tras los resultados obtenidos se decidió proceder a la sustitución progresiva del material afectado como única alternativa de solución garantizada.

\section{Materiales y métodos}

El objetivo de la investigación desarrollada ha sido determinar con claridad las causas detrás de los numerosos fallos detectados en campo, que apuntaban directamente a un error sistemático en la calidad de la fabricación de la tubería. Así mismo, se ha pretendido realizar un estudio comparativo entre los diferentes fabricantes que existían entonces (5) y los diferentes métodos de fabricación (3).

Una vez descartadas las condiciones de instalación (verificando la idoneidad de los criterios de diseño empleados -hidráulicos y mecánicos-, así como la condiciones de ejecución reales) y explotación (mediante la comprobación de los históricos de funcionamiento -presiones de trabajo-) como potenciales causas de los fallos mostrados por la tubería, se puso el foco de atención sobre aspectos relacionados con la calidad de la fabricación de las mismas.

Se realizaron dos tipos de estudio sobre los diferentes fabricantes y muestras recogidas en campo (con una antigüedad similar -10 años- e instalados en condiciones parecidas). Un estudio de propiedades mecánicas ordinarias (medidas a través de los diferentes parámetros y requisitos normativos existentes -rigidez, deflexión, tracción longitudinal y tracción circunferencial), llevado a cabo en el Laboratorio de Instalaciones del Instituto Torroja (CSIC) y un estudio de microscopía y 


\section{Congreso Nacional de Riegos CARTAGENA 2021}

caracterización de los materiales, desarrollado en el Departamento de Ingeniería de Materiales de la Universidad Rey Juan Carlos.

En el mercado de tubería de PRFV existen 3 sistemas de fabricación diferentes: centrifugado (centrifugal casting), continuo (filament winding) y cruzado (crossed filament winding). Si bien todos utilizan materias primas similares, cada uno presenta particularidades propias que confieren a la tubería prestaciones mecánicas diferentes. Así pues, el sistema centrífugo (el que utilizaba el fabricante que ha presentado fallos) consiste en introducir en un molde cilíndrico -que gira a gran velocidad-, y de forma secuencial, los diferentes componentes de cada capa para ir construyendo la estructura del tubo, desde la parte exterior hacia la parte interior. Este sistema nació con vocación de uso en tuberías de saneamiento sin presión. Por este motivo, la fibra de vidrio que utiliza es del tipo cortada (a diferencia del resto de sistemas de fabricación que utilizan, también, fibra de vidrio continua). Teniendo en cuenta que la fibra de vidrio es la responsable principal de proporcional la resistencia global del tubo a presión interna, el sistema centrifugado partía en clara desventaja respecto al resto de sistemas para su competencia en tuberías a presión.

Las muestras seleccionadas se han clasificado por fabricante, siendo esto, a su vez una clasificación implícita entre las muestras que habían presentado fallo (todas de un único fabricante y sistema de fabricación) y las tuberías que presentaban, 10 años después de su instalación, un desempeño ordinario de las prestaciones esperadas (de los otros 4 fabricantes).

A continuación se presenta un resumen de las muestras analizadas:

\begin{tabular}{cccc} 
Fabricante & No muestras & Fallo & Sistema de fabricación \\
\hline A & 12 & SI & Centrifugado \\
B & 2 & NO & Continuo \\
C & 2 & NO & Continuo \\
D & 2 & NO & Cruzado \\
E & 2 & NO & Continuo
\end{tabular}

De todas y cada una de las muestras se ha obtenido la siguiente información:

1. Trazabilidad y resultados de controles internos ordinarios a tubo nuevo del fabricante (ensayos mecánicos normativos -rigidez, deflexión, tracción longitudinal y tracción circunferencial-).

2. Ensayos mecánicos a las muestras con 10 años de antigüedad -rigidez, deflexión, tracción longitudinal y tracción circunferencial- y comparación con las curvas de fluencia -pérdida de prestaciones- esperables en su vida útil (50 años).

3. Composición (\% en peso de cada material -fibra de vidrio, resina de poliéster, arena y CaCO3-).

4. Análisis en microscopía (para la determinación de defectología visible).

5. Caracterización de la resina interior y envejecimiento hidrotérmico.

Los resultados obtenidos en los ensayos mecánicos ordinarios de los tubos con 10 años de antigüedad se han comparado con los resultados obtenidos en la fabricación (controles ordinarios del fabricante de tubería nueva) para los lotes de las muestras extraídas. La variación de propiedades obtenida en el tiempo se ha comparado con la curva de regresión a largo plazo esperada (a 50 años) para comprobar si los valores reales de pérdida de prestaciones están por encima o por debajo de los valores esperados en cada caso (propiedades a largo plazo de resistencia a presión interna y rigidez). 


\section{Congreso Nacional de Riegos CARTAGENA 2021}

Por otro lado, se han comparado los valores de composición (\% en peso de cada material -fibra de vidrio, resina de poliéster, arena y/o carbonato cálcico-) entre fabricantes (y entre muestras) para evaluar las diferencias obtenidas y la estabilidad del proceso de producción de fabricante, en función de la repetitividad o variabilidad de los resultados obtenidos.

Por último, se ha realizado un estudio en detalle de microscopía para detectar los defectos de fabricación más habituales en cada sistema de fabricación, su frecuencia de ocurrencia y su relación (en cuanto a la gravedad de los mismos) con la tasa de fallo comprobada. El análisis de envejecimiento hidrotérmico aporta, además, información sobre la idoneidad (o no) de las materias primas empleadas (en especial, las resinas) por cada fabricante y su relación, también, con la tasa de fallos encontrada.

Las normativas de producto y ensayo aquí empleadas son las correspondientes al período de fabricación de los productos analizados. La UNE 53323 EX aprobada en Marzo 2001 y la UNE-EN 1796 en Octubre del 2006.

\section{Resultados y discusión}

\subsection{Trazabilidad y resultados de controles internos ordinarios}

\subsubsection{Fabricante A}

Para una misma referencia (en este caso, 400/10/5000) se puede observar la enorme variabilidad de resultados de los tubos nuevos fabricados, en fechas próximas. Se obtienen valores reales en rigidez entre 6.400 y 17.361. Así mismo, hay grandes oscilaciones -entre tubos que deberían ser iguales- en espesor (entre 9,8 y 11,1 mm) y resistencia a presión interna (entre 44 y 60,2 bar). Esto es ya, en si mismo, un indicativo notable de la variabilidad en el producto producido (reflejando un pobre control de producción) y un nivel de prestaciones completamente diferente.

\begin{tabular}{|c|c|c|c|c|c|c|c|c|}
\hline \multicolumn{9}{|c|}{ FABRICANTE A . DN 400 PN 10 SN 5000} \\
\hline & Fechas de fabricación & Ensayo & F máx (N) & $\operatorname{Pr}($ bar) & $\begin{array}{c}\text { Rigidez } \\
\left(\mathrm{N} / \mathrm{m}^{2}\right)\end{array}$ & $\begin{array}{l}\text { Espesor } \\
(\mathrm{mm})\end{array}$ & $\begin{array}{c}\text { TL } \\
(\mathrm{N} / \mathrm{mm})\end{array}$ & $\begin{array}{c}\text { Variación } \\
(\%)\end{array}$ \\
\hline LOTE 1 & 20/05/2006 - 16/10/2006 & 26/09/2006 & 5722 & 46,23 & 8270 & 10,5 & 164,4 & 4,452 \\
\hline LOTE 2 & $17 / 10 / 2006-08 / 11 / 2006$ & $17 / 10 / 2006$ & 6794 & 52,18 & 9758 & 10,4 & 227,2 & 7,704 \\
\hline LOTE 3 & 09/11/06 - 21/05/2007 & 09/11/2006 & 7624 & 53,18 & 11646 & 10,5 & 246,4 & 10,59 \\
\hline LOTE 4 & 22/05/2007 - 31/05/2007 & $22 / 05 / 2007$ & 4727 & 44 & 6400 & 9,8 & 163,9 & 2,632 \\
\hline LOTE 5 & 01/06/2007 - 21/06/2007 & 01/06/2007 & 10120 & 60,2 & 17361 & 11,7 & 181,3 & 3,863 \\
\hline LOTE 6 & 22/06/2007 - 02/10/2007 & $22 / 06 / 2007$ & 8457 & 55,6 & 13485 & 10,7 & 180 & 2,898 \\
\hline LOTE 7 & 03/10/2007 - 03/12/2007 & 03/10/2007 & 7857 & 56 & 10718 & 11,1 & 177 & 6,978 \\
\hline LOTE 8 & 04/12/2007 - 31/12/2007 & 04/12/2007 & - & - & 8458 & 10,6 & - & - \\
\hline
\end{tabular}

\subsubsection{Resto de fabricantes}

Se observa, por comparación, que los resultados de los controles internos son mucho más estables y repetidos, para referencias iguales, dentro de un mismo fabricante. Esto denota un control de proceso en la fabricación mucho más cuidado y una uniformidad mayor en el producto puesto en mercado. 


\section{Congreso Nacional de Riegos CARTAGENA 2021}

\begin{tabular}{|c|c|c|c|c|c|c|c|c|}
\hline FABRICANTE & DN & PN & SN & $\begin{array}{c}\text { FECHA } \\
\text { FABR. }\end{array}$ & $\begin{array}{c}\mathbf{R} \\
\mathbf{( N / m m 2 )}\end{array}$ & $\begin{array}{c}\text { TL } \\
\mathbf{( N / m m )}\end{array}$ & $\begin{array}{c}\text { TC } \\
\mathbf{( N / m m})\end{array}$ & e (mm) \\
\hline C & 600 & 10 & 10000 & $11 / 07 / 2012$ & 10732 & 416 & 2172,8 & 12,6 \\
\hline C & 600 & 10 & 10000 & $11 / 07 / 2012$ & 10732 & 416 & 2172,8 & 12,6 \\
\hline D & 600 & 10 & 5000 & may-03 & 5688 & - & - & 10,2 \\
\hline D & 600 & 10 & 5000 & may-03 & 5688 & - & - & 10,2 \\
\hline B & 600 & 10 & 5000 & $07 / 09 / 2004$ & 5176 & 387,4 & 3360,9 & 9,35 \\
\hline B & 600 & 10 & 5000 & $07 / 09 / 2004$ & 5611 & 394,3 & 2846,2 & 9,7 \\
\hline E & 600 & 10 & 5000 & $27 / 11 / 2005$ & 9085 & - & - & - \\
\hline E & 600 & 10 & 5000 & $27 / 11 / 2005$ & 9085 & - & - & - \\
\hline
\end{tabular}

\subsection{Ensayos mecánicos a las muestras con 10 años de antigüedad}

\subsubsection{Fabricante A}

Se presentan los resultados más significativos (aunque son todos similares), de 6 de las 12 muestras analizadas de este fabricante. En las muestras P1, P2 y P3 destaca la caída de rigidez (por encima de los valores esperados en dos de ellas -un 40 y $50 \%$ en P1 y P3-, mientras que la muestra P2 apenas cae -un $22 \%-$ ). Aquí la pérdida de resistencia a la presión es, sin embargo, bastante constante (en torno al 50\%).

\begin{tabular}{|c|c|c|c|c|c|c|c|c|c|}
\hline & \multirow{2}{*}{\multicolumn{3}{|c|}{ P1 }} & \multirow{2}{*}{\multicolumn{3}{|c|}{ P2 }} & \multirow{2}{*}{\multicolumn{3}{|c|}{ P3 }} \\
\hline & & & & & & & & & \\
\hline & $\begin{array}{c}\text { RIGIDEZ } \\
\left(\mathbf{N} / \mathbf{m}^{2}\right)\end{array}$ & $\begin{array}{c}\text { PRESIÓN } \\
\text { (bar) }\end{array}$ & $\begin{array}{c}\text { TL } \\
(\mathrm{N} / \mathrm{mm})\end{array}$ & $\begin{array}{c}\text { RIGIDEZ } \\
\left(\mathrm{N} / \mathbf{m}^{2}\right)\end{array}$ & $\begin{array}{c}\text { PRESIÓN } \\
\text { (bar) }\end{array}$ & $\begin{array}{c}\text { TL } \\
(\mathrm{N} / \mathrm{mm})\end{array}$ & $\begin{array}{c}\text { RIGIDEZ } \\
\left(\mathrm{N} / \mathbf{m}^{2}\right)\end{array}$ & $\begin{array}{c}\text { PRESIÓN } \\
\text { (bar) }\end{array}$ & $\begin{array}{c}\mathrm{TL} \\
(\mathrm{N} / \mathrm{mm})\end{array}$ \\
\hline VALOR NOMINAL & 10.000 & 10 & 160 & 5.000 & 10 & 190 & 5.000 & 10 & 250 \\
\hline ENSAYOS EN FÁBRICA & $9.758,00$ & 52,18 & 227,20 & $7.583,00$ & 42,20 & 188,80 & $9.441,00$ & 53,70 & 300,40 \\
\hline ENSAYOS ACTUALES & $5.833,00$ & 26,20 & 104,50 & $5.865,00$ & 22,20 & 137,40 & $4.657,00$ & 26,60 & 277,50 \\
\hline REQUISITO ACTUAL & $6.342,70$ & 24,52 & - & $4.928,95$ & 19,83 & - & $6.136,65$ & 25,24 & - \\
\hline PÉRDIDA DE PRESTACIONES (\%) & 40,22 & 49,79 & 54,00 & 22,66 & 47,39 & 27,20 & 50,67 & 50,47 & 7,60 \\
\hline
\end{tabular}

En las muestras M1, M2 y M3 destaca la caída de resistencia a presión interna (entre un 55 y 66\%, todas por encima de los valores esperados). Aquí la pérdida de rigidez es, sin embargo, mucho más baja en las muestras anteriores (entre un 15 y $26 \%$ ).

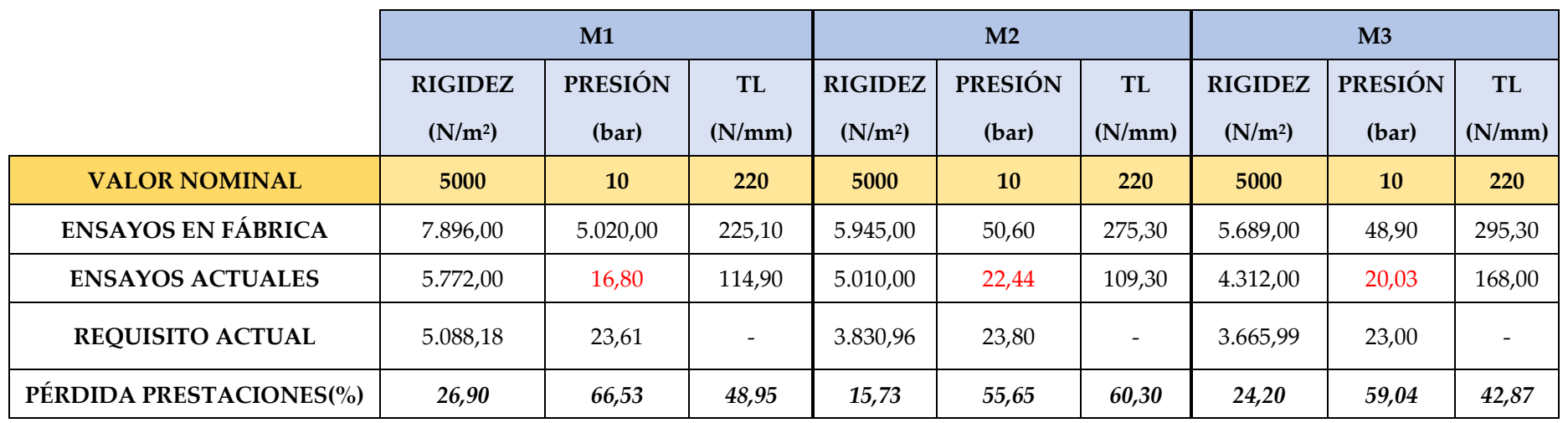




\section{Congreso Nacional de Riegos CARTAGENA 2021}

A la vista de estos datos se puede comprobar ya lo anteriormente señalado: una enorme variabilidad en el comportamiento de los tubos a medio plazo, resultado de un escaso control en la fabricación y en un diseño inapropiado. La evolución en el tiempo de propiedades iguales es muy dispar, y en muchos casos, con una pérdida de prestaciones superior a lo previsto.

\subsubsection{Resto de fabricantes}

Por el contrario, los resultados del resto de fabricantes presentan un comportamiento completamente diferente. Los valores son muy estables, dentro de un mismo fabricante y la pérdida de propiedades es mucho inferior (y siempre superior a los valores esperados). Se presentan los resultados más significativos de 2 de los otros 4 fabricantes analizados.

\begin{tabular}{|c|c|c|c|c|c|c|}
\hline \multirow[t]{2}{*}{ FABRICANTE } & \multicolumn{3}{|c|}{ B1 } & \multicolumn{3}{|c|}{ B2 } \\
\hline & $\begin{array}{c}\text { RIGIDEZ } \\
\left(\mathrm{N} / \mathrm{m}^{2}\right)\end{array}$ & $\begin{array}{c}\text { PRESIÓN } \\
\text { (bar) }\end{array}$ & $\mathrm{TL}(\mathrm{N} / \mathrm{mm})$ & $\begin{array}{c}\text { RIGIDEZ } \\
\left(\mathrm{N} / \mathrm{m}^{2}\right)\end{array}$ & $\begin{array}{c}\text { PRESIÓN } \\
\text { (bar) }\end{array}$ & $\mathrm{TL}(\mathrm{N} / \mathrm{mm})$ \\
\hline VALOR NOMINAL & 5000 & 10 & 220 & 5000 & 10 & 220 \\
\hline ENSAYOS EN FÁBRICA & $5.176,00$ & 112,29 & 387,40 & $5.611,00$ & 95,14 & 394,30 \\
\hline ENSAYOS ACTUALES & $4.866,00$ & 67,22 & 295,60 & $4.982,00$ & 58,03 & 268,20 \\
\hline REQUISITO ACTUAL & $3.201,66$ & 16,50 & - & $3.194,00$ & 16,50 & \\
\hline PÉRDIDA PRESTACIONES (\%) & 5,99 & 40,14 & 23,70 & 11,21 & 39,01 & 31,00 \\
\hline
\end{tabular}

\begin{tabular}{|c|c|c|c|c|c|c|}
\hline \multirow[t]{2}{*}{ FABRICANTE } & \multicolumn{3}{|c|}{$\mathrm{C} 1$} & \multicolumn{3}{|c|}{$\mathrm{C} 2$} \\
\hline & $\begin{array}{c}\text { RIGIDEZ } \\
\left(\mathrm{N} / \mathrm{m}^{2}\right)\end{array}$ & $\begin{array}{c}\text { PRESIÓN } \\
\text { (bar) }\end{array}$ & TL (N/mm) & $\begin{array}{c}\text { RIGIDEZ } \\
\left(\mathbf{N} / \mathbf{m}^{2}\right)\end{array}$ & $\begin{array}{c}\text { PRESIÓN } \\
\text { (bar) }\end{array}$ & TL (N/mm) \\
\hline VALOR NOMINAL & 10000 & 10 & 220 & 10000 & 10 & 220 \\
\hline ENSAYOS EN FÁBRICA & $10.732,00$ & 73,30 & 416,00 & $10.732,00$ & 73,30 & 416,00 \\
\hline ENSAYOS ACTUALES & $10.604,00$ & 71,10 & 408,00 & $10.696,00$ & 72,00 & 333,00 \\
\hline REQUISITO ACTUAL & $6.550,00$ & 17,12 & - & $6.550,00$ & 17,12 & - \\
\hline PÉRDIDA DE PRESTACIONES (\%) & 1,19 & 3,00 & 1,80 & 0,33 & 1,17 & 19,80 \\
\hline
\end{tabular}

\subsection{Ensayos de composición}

Se ha analizado la composición de las diferentes muestras (medido en \% en peso de cada material -fibra de vidrio, resina de poliéster, arena y/o carbonato cálcico-). Se observa que el fabricante A (con fallos recurrentes en su tubería) es el único que presenta carbonato cálcico en su composición (material más barato que el resto de componentes y que se utilizó como filler en proporciones muy elevadas). La proporción de fibra de vidrio, además, es notablemente más baja que en el resto de fabricantes (entre el 13-15\%, siendo el componente que aporta la resistencia a presión interna, cuando el resto incluye entre 23-26\%) y del tipo fibra cortada (en vez de fibra continua, del resto de sistemas de fabricación).

3.3.1. Fabricante A

\begin{tabular}{|l|c|c|c|}
\hline & M1 & M2 & M3 \\
\hline CONTENIDO EN FIBRAS (\%) & 12,60 & 14,00 & 15,40 \\
\hline
\end{tabular}




\section{Congreso Nacional de Riegos CARTAGENA 2021}

\begin{tabular}{|l|l|l|l|}
\cline { 2 - 4 } CONTENIDO EN CARGAS MINERALES (\%) & 56,70 & 54,70 & 52,50 \\
\hline CONTENIDO RESINA POLIESTER (\%) & 30,70 & 31,40 & 32,00 \\
\hline CONTENIDO EN CARGAS SOLUBLES & 32,80 & 35,00 & 32,30 \\
\hline
\end{tabular}

\subsubsection{Resto de fabricantes}

\begin{tabular}{|l|c|c|c|c|}
\hline & B1 & B2 & C1 & C2 \\
\hline CONTENIDO EN FIBRAS (\%) & 25,60 & 25,00 & 23,00 & 26,10 \\
\hline CONTENIDO EN CARGAS MINERALES (\%) & 43,40 & 44,10 & 48,20 & 43,80 \\
\hline CONTENIDO RESINA POLIESTER (\%) & 30,90 & 30,90 & 28,70 & 30,10 \\
\hline CONTENIDO EN CARGAS SOLUBLES & 0,20 & 0,20 & 0,40 & 0,30 \\
\hline
\end{tabular}

3.4. Análisis en microscopía (para la determinación de defectología visible).

Se ha realizado un estudio macroscópico y microscópico de las muestras con varios objetivos:

- Medir el espesor y estudiar la distribución en capas de la pared del tubo, con objeto de ver si cumplen normativa y de analizar la calidad del procesado. De hecho, los resultados se comparan con las evidencias suministradas por el propio fabricante en sus catálogos.

- Evaluar la presencia de defectos morfológicos y estructurales, como agrietamiento, porosidad, presencia de aglomerados o ausencia de capa estructural.

- Determinar la presencia de restos de corrosión biológica

\subsubsection{Resto de fabricantes}

Si bien se observan -al utilizar las mismas técnicas de análisis- algunos defectos puntuales (como presencia de pequeñas grietas por envejecimiento del material o burbujas atrapadas de aire), también se observa una mayor homogeneidad en las capas y menores contaminaciones cruzadas. Por comparación, la intensidad y frecuencia de defectos es mucho menor que en el caso del fabricante A, y las cuestiones observadas entran dentro de los parámetros esperables del normal envejecimiento del material.

\subsubsection{Fabricante A}

A continuación se presenta un resumen de lo observado. Como se puede comprobar los defectos son repetidos, diversos y de elevada importancia y repercusión en el desempeño esperado.

\begin{tabular}{|l|l|}
\hline \multicolumn{1}{|c}{ Defectología } \\
$\begin{array}{l}\text { Heterogeneidad de las capas } \\
\text { (entre tuberías y dentro de la misma } \\
\text { tubería) }\end{array}$ & $\begin{array}{l}\text { Falta de control en el procesado } \\
\text { Incorrecta dosificación }\end{array}$ \\
\hline Falta de capa estructural & $\begin{array}{l}\text { Falta de control en el procesado } \\
\text { Incorrecta dosificación }\end{array}$ \\
\hline Aglomerados de áridos & $\begin{array}{l}\text { Falta de control en el procesado } \\
\text { Incorrecta dosificación, falta de secado, } \\
\text { exceso de áridos }\end{array}$ \\
\hline Contaminación cruzada & $\begin{array}{l}\text { Falta de control en el procesado } \\
\text { Incorrecta dosificación }\end{array}$ \\
\hline Presencia de fibras y áridos en el liner & Falta de control en el procesado \\
\hline Agrietamiento generalizado del liner & $\begin{array}{l}\text { Falta de control en el procesado } \\
\text { Incorrecta dosificación } \\
\text { Incorrecta selección de la resina }\end{array}$
\end{tabular}




\begin{tabular}{|c|c|}
\hline $\begin{array}{l}\text { Corrosión bacteriológica del liner } \\
\text { interior }\end{array}$ & Incorrecta selección de la resina \\
\hline $\begin{array}{l}\text { Elevada variabilidad de la resina del } \\
\text { liner }\end{array}$ & Incorrecta selección de la resina \\
\hline $\begin{array}{l}\text { Elevada variabilidad de la resina del } \\
\text { liner con la temperatura }\end{array}$ & Incorrecta selección de la resina \\
\hline $\begin{array}{l}\text { Falta de impermeabilidad. Elevada } \\
\text { capacidad de absorción de agua del } \\
\text { liner. Embolsamientos en el liner }\end{array}$ & Incorrecta selección de la resina \\
\hline $\begin{array}{l}\text { Plastificación de la resina por } \\
\text { absorción de agua }\end{array}$ & Incorrecta selección de la resina \\
\hline
\end{tabular}

\subsection{Caracterización de la resina interior y envejecimiento hidrotérmico}

Se ha buscado la caracterización de la resina interior como elemento estructural más débil y por su importante funcionalidad como barrera a la entrada del agua al material. Para ello, se han realizado varios ensayos para evaluar su comportamiento térmico y mecánico, debido a que la resina termoestable es la más susceptible y débil mecánicamente de todos los materiales que componen la tubería. Posteriormente, se ha procedido al envejecimiento hidrotérmico para conocer cómo el material envejece con el tiempo al estar en contacto con el agua, imitando su uso.

\subsubsection{Fabricante A}

Lo primero que se aprecia es una gran variabilidad en el comportamiento de la resina interior en función de la tubería analizada, ya que puede absorber desde menos de $1 \%$ hasta casi un $8 \%$ en peso. Esta variabilidad se justifica por el agrietamiento del liner y la presencia de fibras y áridos. Por otro lado, este contenido de agua es muy elevado, para ser un material cuya principal función es ser impermeable. Además, la entrada de agua en la resina provoca su plastificación, esto es variación de sus propiedades mecánicas. Se observa cómo el módulo de almacenamiento, que mide la rigidez de la capa, varía por la absorción de agua. La resina presenta una alta variabilidad de propiedades con la temperatura, lo que las convierte en impredecibles. Esto es debido a que todos los polímeros amorfos, como resinas termoestables y elastómeros, tienen una temperatura característica, llamada temperatura de transición vítrea o $\mathrm{Tg}$, a partir de la cual cambian radicalmente sus propiedades y comportamiento.

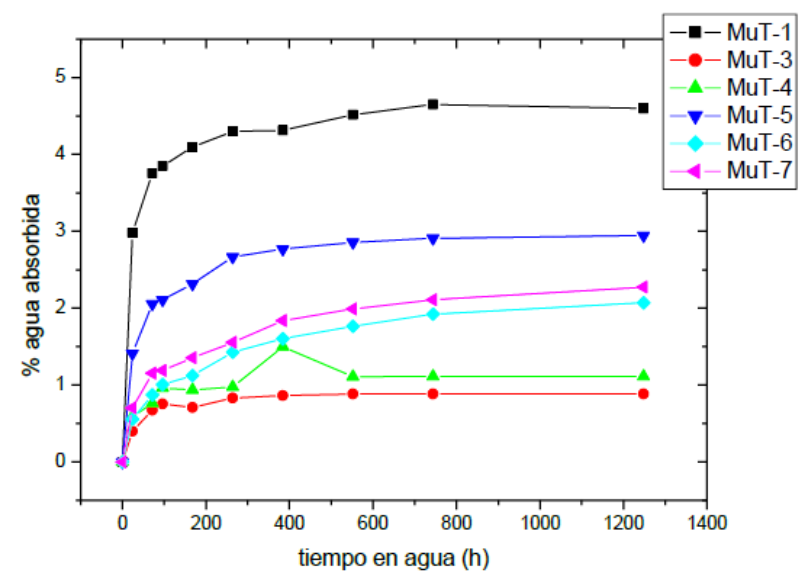

\subsubsection{Resto de fabricantes}

Las tuberías de PRFV analizadas presentan un contenido de absorción de agua a saturación comprendido entre 0,26 y 0,33 \%, muy inferior al límite máximo fijado en la Guía Cedex de 1,25\%. Además, 
no se aprecian diferencias significativas entre fabricantes en cuanto a la impermeabilidad de sus superficies interior y exterior.

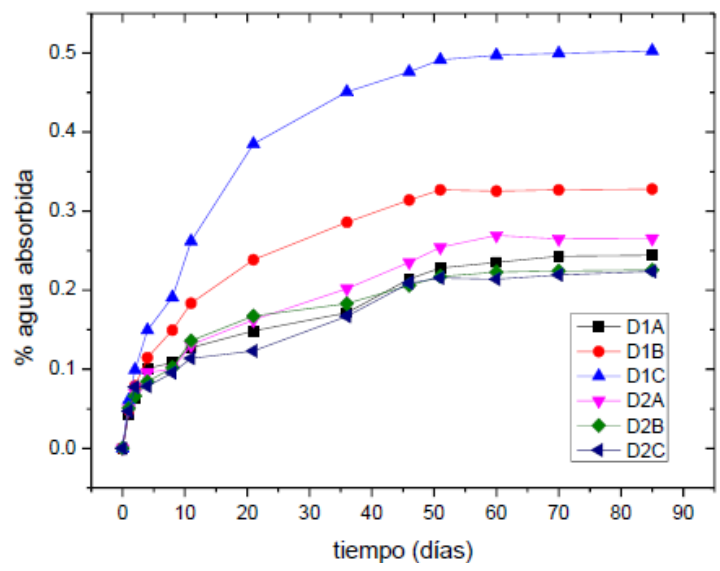

\section{Conclusiones}

- La tubería de PRFV fabricada por el método de centrifugación nació con una vocación clara de uso en tuberías sin presión (por el uso de fibra de vidrio cortada y la inexistencia de fibra de vidrio continua -para aportar resistencia a presión interna-), a diferencia del resto de sistemas de fabricación, con mejores prestaciones mecánicas para el uso en redes a presión.

- Los resultados de los controles internos del fabricante A muestran una elevada variabilidad de resultados entre tubos iguales (DN/PN/SN). Es un indicador claro de la falta de control de proceso y de la enorme heterogeneidad en el producto que salía a mercado. Las prestaciones mecánicas, por tanto, eran completamente dispares. Por comparación, el resto de fabricantes presentan valores mucho más estables y homogéneos, indicativo de procesos bien controlados.

- La composición de la tubería del fabricante A presenta valores notablemente más bajos que otros fabricantes -a igualdad de referencias- en \% de fibra de vidrio (que aporta resistencia a la presión interna) y presenta, además, un elevado contenido en carbonato cálcico (material soluble utilizado como filler que, en ocasiones, alcanza el $40 \%$ en peso en la composición del tubo). El carbonato cálcico era un producto más barato que aquellos otros componentes a los que reemplazaba en la fórmula de composición.

- Las muestras ensayadas del fabricante A para las diferentes propiedades mecánicas ordinarias, arrojan valores residuales de resistencia a presión interna y rigidez muy por debajo de los valores esperados (y declarados por el propio fabricante) para el tiempo de vida de los tubos. El resto de fabricantes, por el contrario, presenta poca pérdida de prestaciones en el tiempo y siempre por encima de los valores esperados.

- El fabricante A presenta una alta tasa de defectos diversos (heterogeneidad en las capas, aglomerado de áridos, contaminación cruzada, presencia de grietas, corrosión biológica...) que comprometen la vida útil de la tubería. Por el contrario, el aspecto de las muestras del resto de fabricantes es mucho más homogéneo y con menor tasa de defectos (cuya relevancia es, además, limitada). El fabricante A presenta una tipología de resina en el liner inadecuada para el uso pretendido (cambia sus propiedades con la temperatura y la absorción de agua).

- Los fabricantes con procesos de fabricación bien controlados ofrecen al mercado productos con las máximas garantías y cuyo desempeño es incluso mejor que el esperado (un envejecimiento menor de lo previsto). La tubería de PRFV es un producto de alto interés para el riego. 


\title{
Efecto de la modificación de la tubería de salida en filtros de arena con brazos colectores
}

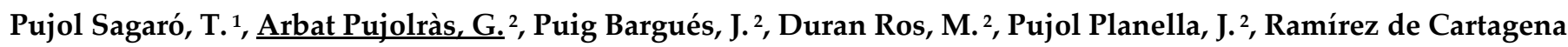 \\ Bisbe, F. ${ }^{2}$
}

Departamento de Ingeniería Mecánica y de la Construcción Industrial, Universidad de Girona, toni.pujol@udg.edu

Departamento de Ingeniería Química, Agraria y Tecnología Agroalimentaria, gerard.arbat@udg.edu, jaume.puig@udg.edu, miquel.duranros@udg.edu, joan.pujol@udg.edu, francisco.ramirez@udg.edu

Resumen: Los filtros presurizados de arena utilizados para proteger de las obturaciones las instalaciones de riego por goteo se pueden dividir en tres zonas en función de su comportamiento hidráulico: 1) entrada del agua, 2) lecho de arena, y 3) salida del agua. Estudios anteriores realizados para optimizar el funcionamiento hidráulico de este tipo de filtros se centraron en la zona de entrada y en el lecho de arena, proponiendo distintos cambios en el diseño tanto del difusor en la zona de entrada como del drenaje del lecho de arena. En el presente trabajo se analizan las consecuencias de modificar la zona de salida del agua de un filtro comercial de arena con brazos colectores sin variar su sistema de drenaje. El sistema original de salida del agua consistía en una tubería horizontal conectada a 10 brazos horizontales. Cinco diseños alternativos que diferían en su área transversal (original o doble), orientación (horizontal o vertical) y número (simple o doble) fueron numéricamente estudiados mediante dinámica de fluidos computacional en cuatro condiciones distintas de operación (dos alturas de lecho (160 y 260 $\mathrm{mm}$ ) y dos caudales (6 y $\left.12 \mathrm{~m}^{3} \mathrm{~h}^{-1}\right)$ ). La comparación de estos diseños con el comercial indicó que: 1) una tubería de salida con el doble del área transversal redujo la caída de presión total del filtro un $12 \%$ e incrementó la uniformidad del flujo del agua entre brazos colectores; 2) una doble tubería de salida conllevó un comportamiento simétrico del caudal respecto el brazo central pero no impidió que por el brazo central continuara circulando menor cantidad de agua que por los otros brazos colectores; y 3) una salida de agua vertical de igual diámetro que la comercial causó una caída de presión similar pero, en cambio, aumentó considerablemente la uniformidad del flujo entre los distintos brazos.

Palabras clave: filtración; filtro granular, riego por goteo, dinámica de fluidos computacional, modelización. 


\title{
Effect of the modification of the outlet pipe in sand filters with collector arms
}

\author{
Pujol Sagaró, T. ${ }^{1}$, Arbat Pujolràs, G. ${ }^{2}$, Puig Bargués, J. ${ }^{2}$, Duran Ros, M. ${ }^{2}$, Pujol Planella, J. ${ }^{2}$, Ramírez de Cartagena \\ Bisbe, F. ${ }^{2}$ \\ Departamento de Ingeniería Mecánica y de la Construcción Industrial, Universidad de Girona, toni.pujol@udg.edu \\ Departamento de Ingeniería Química, Agraria y Tecnología Agroalimentaria, gerard.arbat@udg.edu, jaume.puig@udg.edu, miquel.du- \\ ranros@udg.edu, joan.pujol@udg.edu, francisco.ramirez@udg.edu
}

\begin{abstract}
Pressurized sand filters that protect drip irrigation systems from clogging can be divided into three zones based on their hydraulic behaviour: 1) water inlet, 2) sand bed, and 3) water outlet. Previous studies carried out to optimize the hydraulic performance of this type of filters focused on the inlet zone and the sand bed, proposing different changes in the design of both the inlet diffuser and the drainage of the sand media. In this work, the consequences of modifying the water outlet area of a commercial sand filter with collector arms without changing its drainage system are analysed. The original water outlet system consisted of a horizontal pipe connected to 10 horizontal arms. Five alternative designs that differed in their cross-sectional area (original or double), orientation (horizontal or vertical), and number (single or double) were numerically studied using computational fluid dynamics under four different operating conditions (two bed heights (160 and $260 \mathrm{~mm}$ ) and two flow rates (6 and $\left.12 \mathrm{~m}^{3} \mathrm{~h}^{-1}\right)$ ). Comparison of these designs with the commercial one indicated that: 1) an outlet pipe with twice the cross-sectional area reduced the total pressure drop of the filter by $12 \%$ and increased the uniformity of the water flow between the collector arms; 2) a double outlet pipe entailed a symmetrical behaviour of the flow with respect to the central arm but did not prevent that less water would continue to circulate through the central arm than through the other collecting arms; and 3) a vertical water outlet of the same diameter as the commercial one caused a similar pressure drop but, on the other hand, considerably increased the uniformity of the flow between the different arms.
\end{abstract}

Keywords: filtration; granular filter, drip irrigation, computational fluid dynamics, modelling. 


\section{Introducción}

Recientemente, se ha prestado mucha atención al diseño de los elementos auxiliares internos y su efecto sobre la caída de presión en los filtros de arena utilizados en las instalaciones de riego localizado. El efecto del drenaje, que es el elemento situado en la base de arena cuyas ranuras, de menor anchura que el tamaño del medio filtrante, permiten la salida del agua filtrada ha sido estudiado por varios autores. Arbat et al. [1] demostraron la relevancia de los elementos de drenaje mediante un modelo numérico aplicado a un filtro comercial. Observaron que el flujo de agua se aceleraba dentro de la arena a medida que se acercaba a las ranuras del drenaje. Este aumento de velocidad dentro del medio poroso aumentó la caída de presión a valores mucho más altos que los esperados de la ecuación de Ergun aplicada al flujo uniforme.

Los rediseños de los elementos de drenaje de filtros comerciales también han investigados, tanto experimental como numéricamente. Bové et al. [2] llevaron a cabo un estudio de Dinámica de Fluidos Computacional (CFD) proponiendo un rediseño de un drenaje de crepinas comercial capaz de reducir la caída de presión total del filtro hasta en un 30\% para una velocidad superficial de alrededor $72 \mathrm{~m} \mathrm{~h}$ 1 . Bové et al. [3] posteriormente propusieron un tipo completamente nuevo de sistema de drenaje que maximizaba la superficie disponible conectada con la cámara de salida, ya que ocupaba toda el área de la sección transversal del filtro. Los estudios numéricos indicaron que este diseño desarrolló un flujo de agua más uniforme dentro de la arena, minimizando así las pérdidas de carga en el medio.

Mesquita et al. [4] se centraron en el diseño del difusor, por su papel en la uniformidad del flujo por encima de la región del lecho de arena. Sin embargo, el diseño de la región de salida también puede tener implicaciones importantes en el rendimiento hidráulico del filtro puesto que las características del colector de salida determinan la caída de presión y afectan a la distribución del agua a cada una de las unidades de drenaje.

El objetivo del presente trabajo fue analizar el efecto de distintos diseños de la tubería de salida en términos de 1) caída de presión total del filtro y 2) uniformidad de flujo dentro del medio poroso.

\section{Materiales y métodos}

\subsection{Diseño de la tubería de salida}

Todos los tipos de tubería de salida analizados fueron diseñados para el filtro de arena comercial FA1M del fabricante LAMA [5].

El agua filtrada se drenaba a través de 10 drenes de tipo brazo horizontal, los cuales se distribuyeron simétricamente con respecto al plano vertical central (Fig. 1). Cada brazo contenía 24 ranuras rectangulares de $79 \mathrm{~mm}$ de largo y $0,5 \mathrm{~mm}$ de ancho. Por lo tanto, el área abierta total por tubo fue igual a $960 \mathrm{~mm}^{2}$, lo que dio un área abierta total del sistema de drenaje inferior igual a $9600 \mathrm{~mm}^{2}$. En la configuración comercial, todos los brazos estaban conectados a una tubería de salida horizontal de diámetro interior $\mathrm{Do}=40,8 \mathrm{~mm}$.

Se propusieron cinco variaciones del diseño de la tubería de salida comercial, cuyas principales características se indican en la Tabla 1 (Fig. 2). Los diseños H2a y V2a tenían áreas de sección transversal el doble que las originales. El diseño H2d tenía un diámetro de sección transversal dos veces mayor que el original, por lo que tenía un área de sección transversal cuatro veces más grande que la original y dos veces mayor que la de los diseños H2a y V2a. Finalmente, se analizó el efecto de usar una salida gemela (diseño $2 \mathrm{H} ;$ Fig. 2). La longitud total del sistema de tuberías utilizado en las versiones $\mathrm{H}, \mathrm{H} 2 \mathrm{a}$ y H2d fue de $690 \mathrm{~mm}$, mientras que en las configuraciones V y V2a fue de $650 \mathrm{~mm}$, con la tubería de 
salida vertical centrada de $350 \mathrm{~mm}$ de largo. El sistema de tuberías tenía una longitud mucho mayor que la original en la caja de salida doble $2 \mathrm{H}$ (1080 $\mathrm{mm}$ de longitud total).
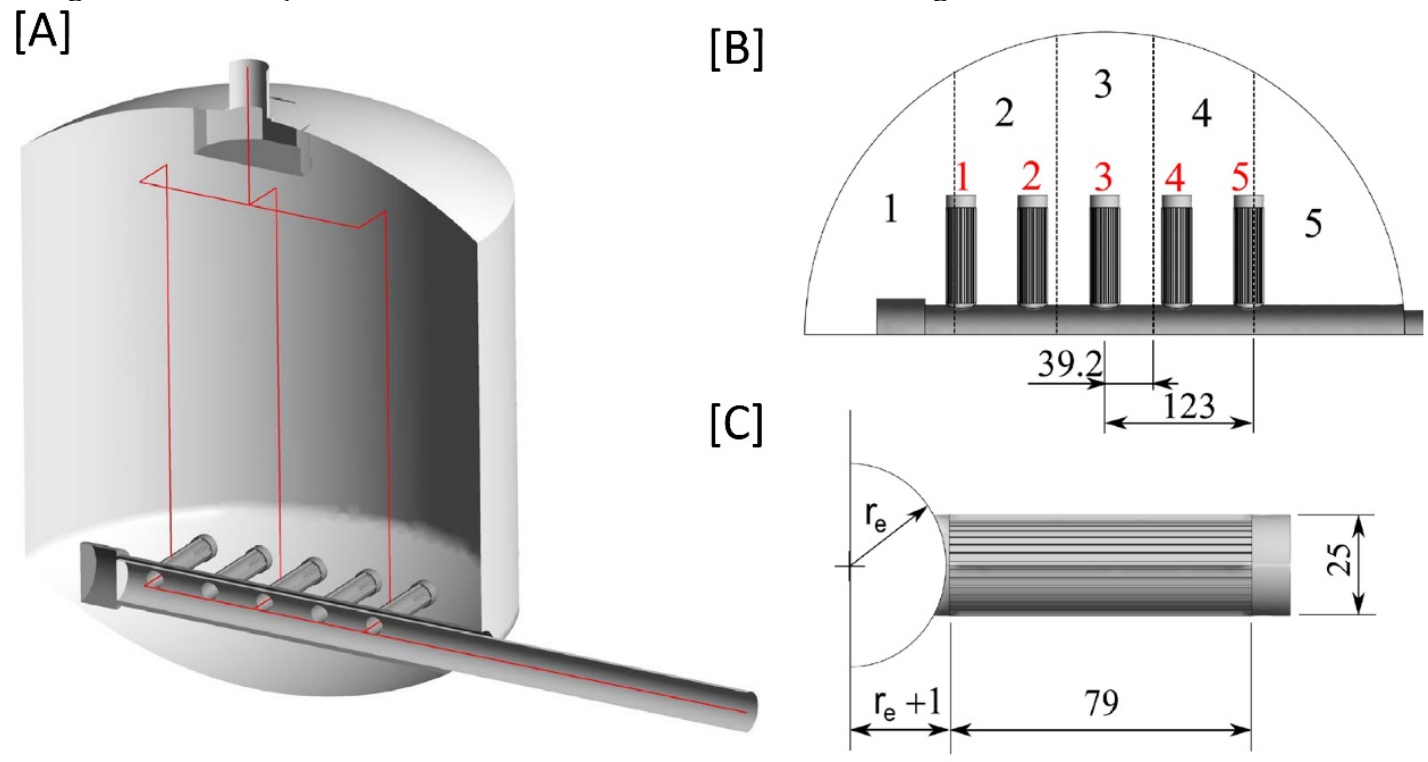

Fig. 1 - Vista de media sección del filtro comercial (caso H en la Tabla 1) donde las tres líneas rojas indican los perfiles analizados en la Sección 3 [A]. Media vista superior del colector de salida con la numeración de brazos (en rojo) y regiones de igual superficie (en negro) [B]. Dimensiones del tubo principal con $r_{e}$ el radio externo del tubo colector [C]. Dimensiones en mm.

Tabla 1. Características geométricas de los diseños de tubería de salida analizados.

\begin{tabular}{cccc}
\hline Diseño & Orientación & Diámetro interior & Área de salida \\
& & $(\mathrm{mm})$ & $\left(\mathrm{mm}^{2}\right)$ \\
\hline$H$ & Horizontal & 40,8 & 1307,4 \\
$H 2 a$ & Horizontal & 57,7 & 2614,8 \\
$H 2 d$ & Horizontal & 81,6 & 5229,6 \\
$V$ & Vertical & 40,8 & 1307,4 \\
$V 2 a$ & Vertical & 57,7 & 2614,8 \\
$2 H$ & Horizontal (2 salidas) & $2 \times 40,8$ & $2 \times 1307,4$ \\
\hline
\end{tabular}




\section{Congreso Nacional de Riegos CARTAGENA 2021}

[B] $\mathrm{H} 2 \mathrm{a}$

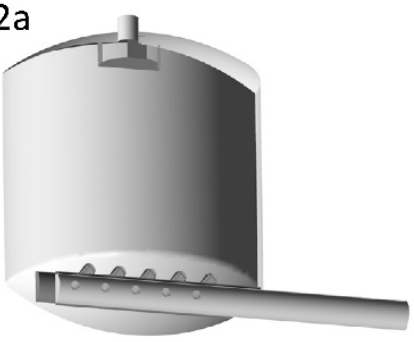

[C] $\mathrm{H} 2 \mathrm{~d}$

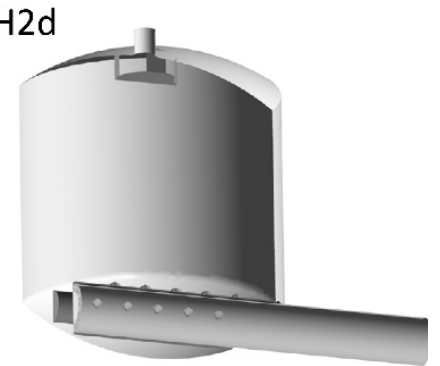

[D]

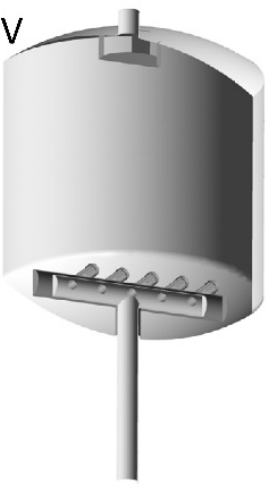

[E] V2a

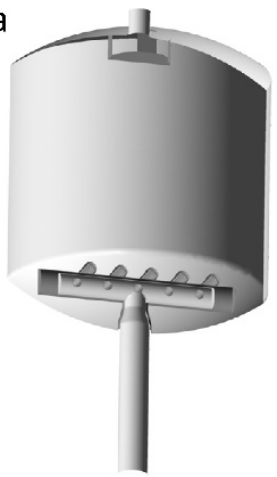

[F] $2 \mathrm{H}$

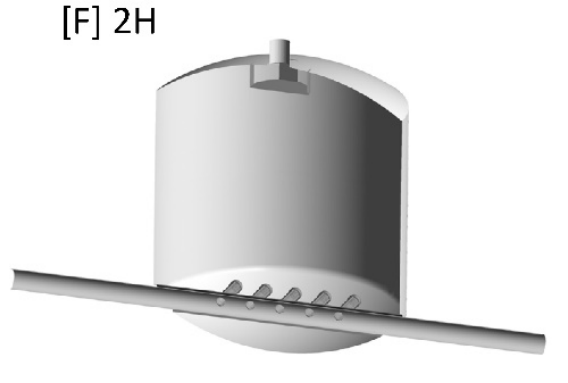

Fig. 2 - Diseños de tubería de salida analizados: caso comercial original (diámetro interior de salida Do) [A], caso H2a (D = $\sqrt{2}$ Do) [B], caso H2d $(\mathrm{D}=2 \mathrm{Do})[\mathrm{C}]$, caso $\mathrm{V}(\mathrm{D}=\mathrm{Do})[\mathrm{D}]$, caso V2a $(\mathrm{D}=\sqrt{ } 2 \mathrm{Do})[\mathrm{E}]$, caso $2 \mathrm{H}(\mathrm{D}=$ Do en ambas salidas) [F] (ver Fig. 1 y Tabla 1$)$.

\subsection{Modelo numérico}

El modelo numérico usado fue el código de dinámica de fluidos computacional (CFD) comercial ANSYS-Fluent, que utiliza el método de volumen finito para resolver las ecuaciones que gobiernan la dinámica de flujo (ANSYS, 2020). Varios autores han aplicado este software con éxito para simular el comportamiento de filtros de arena presurizados $[1,3,5,6]$. En todos los casos aquí considerados, el dominio de simulación correspondió a la mitad de todo el cuerpo ya que se aprovecharon las condiciones de simetría a lo largo del plano vertical central. Como en Pujol et al. [6], el medio filtro se dividió en tres zonas, siendo: 1) desde la entrada hasta la superficie del lecho de arena; 2) lecho filtrante; 3 ) desde la entrada del desagüe del lecho hasta la salida del colector. Las zonas 1 y 3 anteriores se definieron como regiones ocupadas solo por agua. La zona 2 se definió como un medio poroso homogéneo, por lo que se agregó un término de sumidero de impulso a la ecuación de Navier-Stokes. Este término sumidero S_i (Pa m-1) siguió de la ecuación de Ergun, estando compuesto por dos términos,

$$
S_{i}=-\frac{1}{\alpha} \mu v_{i}-C_{2} \frac{\rho}{2}|v| v_{i} \quad \text { for } i=x, y, z
$$

donde se usaron propiedades de fluido de agua constante para viscosidad $\mu(=0.001003 \mathrm{~Pa}$ s) y densidad $\left(\rho=998,2 \mathrm{~kg} \mathrm{~m}^{-3}\right), \alpha\left(\mathrm{m}^{2}\right)$ y $\mathrm{C}_{2}\left(\mathrm{~m}^{-1}\right)$ fueron la permeabilidad y el factor de resistencia inercial de la arena, respectivamente. En la ecuación (1), $v_{i}\left(\mathrm{~m} \mathrm{~s}^{-1}\right)$ fue el i-ésimo componente de la velocidad superficial del flujo cuya magnitud fue $|\mathrm{v}|$. La velocidad superficial se calculó como la velocidad sin tener en cuenta el medio poroso (es decir, sin porosidad). El flujo se consideró laminar dentro de la zona de arena. 
Todos los diseños se simularon en cuatro condiciones operativas diferentes, siendo la combinación de dos alturas de lecho de arena $\mathrm{H}_{\mathrm{s}}(160 \mathrm{~mm}$ y $260 \mathrm{~mm})$ y dos caudales volumétricos $\mathrm{Q}\left(6 \mathrm{~m}^{3} \mathrm{~h}^{-1} \mathrm{y} 12 \mathrm{~m}^{3} \mathrm{~h}^{-}\right.$ $\left.{ }^{1}\right)$. Estos valores de caudal correspondieron a velocidades superficiales del filtro iguales a $30,6 \mathrm{~m} \mathrm{~h}^{-1} \mathrm{y}$ $61,1 \mathrm{~m} \mathrm{~h}^{-1}$, respectivamente.

La configuración de los parámetros de la malla fue igual a la empleada en Pujol et al. [5,6]. Los elementos utilizados para discretizar todos los cuerpos fueron tetraedros excepto en las regiones adheridas a las paredes internas del filtro en las que se aplicó una capa de cinco prismas. El tamaño máximo de los elementos fue de $0,3 \mathrm{~mm}$ en las ranuras del desagüe, $0,8 \mathrm{~mm}$ en las paredes del desagüe, y $3 \mathrm{~mm}$ en la placa difusora, tubo de entrada y tubo de salida. En los dominios de volumen, los elementos tenían un tamaño máximo de $3 \mathrm{~mm}$ dentro de los elementos de drenaje inferior y $10 \mathrm{~mm}$ dentro del dominio del filtro. El factor de crecimiento fue del $20 \%$. Con esta configuración, el número total de elementos necesarios para mallar la mitad del filtro para el caso $\mathrm{H}$ en la Tabla 1 fue de 8,9 × 106 elementos.

\section{Resultados y discusión}

\subsection{Diseño de la tubería de salida}

La caída de presión del filtro $\Delta p_{f}$ para las cuatro condiciones de trabajo y los seis diseños de tubería de salida de las Figs. 1-2 se muestran en la Fig. 3. Para todos los casos, el valor máximo correspondió a la mayor altura del lecho de arena $(260 \mathrm{~mm})$ y caudal $\left(=12 \mathrm{~m}^{3} \mathrm{~h}^{-1}\right)$. La variación media de la caída de presión del filtro entre las configuraciones $H s=160 \mathrm{~mm}$ y $\mathrm{Hs}=260 \mathrm{~mm}$ fue $4757 \mathrm{~Pa}$ y $9525 \mathrm{~Pa}$ para caudales $\mathrm{Q}=6 \mathrm{~m}^{3} \mathrm{~h}^{-1}$ y $\mathrm{Q}=12 \mathrm{~m}^{3} \mathrm{~h}^{-1}$, respectivamente. Debe considerarse que estos valores corresponden casi exactamente a la caída de presión predicha por la ecuación (1) para una columna de arena de $260-160=100 \mathrm{~mm}$ de altura en ambos modos de velocidad superficial analizados. Esto significó que el flujo dentro de la arena fue muy uniforme, al menos a lo largo de los primeros $100 \mathrm{~mm}$. La caída de presión del filtro para los casos $H 2 a, H 2 d$ y $2 H$ fue 12,4\%, 15,6\% y 13,0\% inferior a la de la configuración original, caso H. Sin embargo, estos valores se redujeron para tener en cuenta que la tubería de salida se conectaría a una tubería existente en la instalación hidráulica de un solo tubo de diámetro interior Do. Por lo tanto, los valores de $\Delta p f$ en la Fig. 3 se modificaron restando las pérdidas de carga secundarias mínimas requeridas para conectarse al sistema de tuberías externo. Los valores del coeficiente de pérdidas secundarias se extrajeron de Çengel y Cimbala [7]. Una vez que se tuvo en cuenta esta pequeña contribución a la pérdida, la variación de la caída de presión del filtro $\Delta p f$ con respecto al valor del diseño original ( $\Delta p f, H$ en la Fig.3) reveló que los diseños $H 2 a$ y $H 2 d$ proporcionaron mejoras sustanciales (reducciones superiores al 10\%, Fig. 4). Sin embargo, el diseño $2 \mathrm{H}$ fue claramente penalizado debido a las pérdidas secundarias. La configuración del colector vertical propuesta en la Fig. 2 casi produjo un valor de $\Delta p f$ idéntico al del filtro original. 


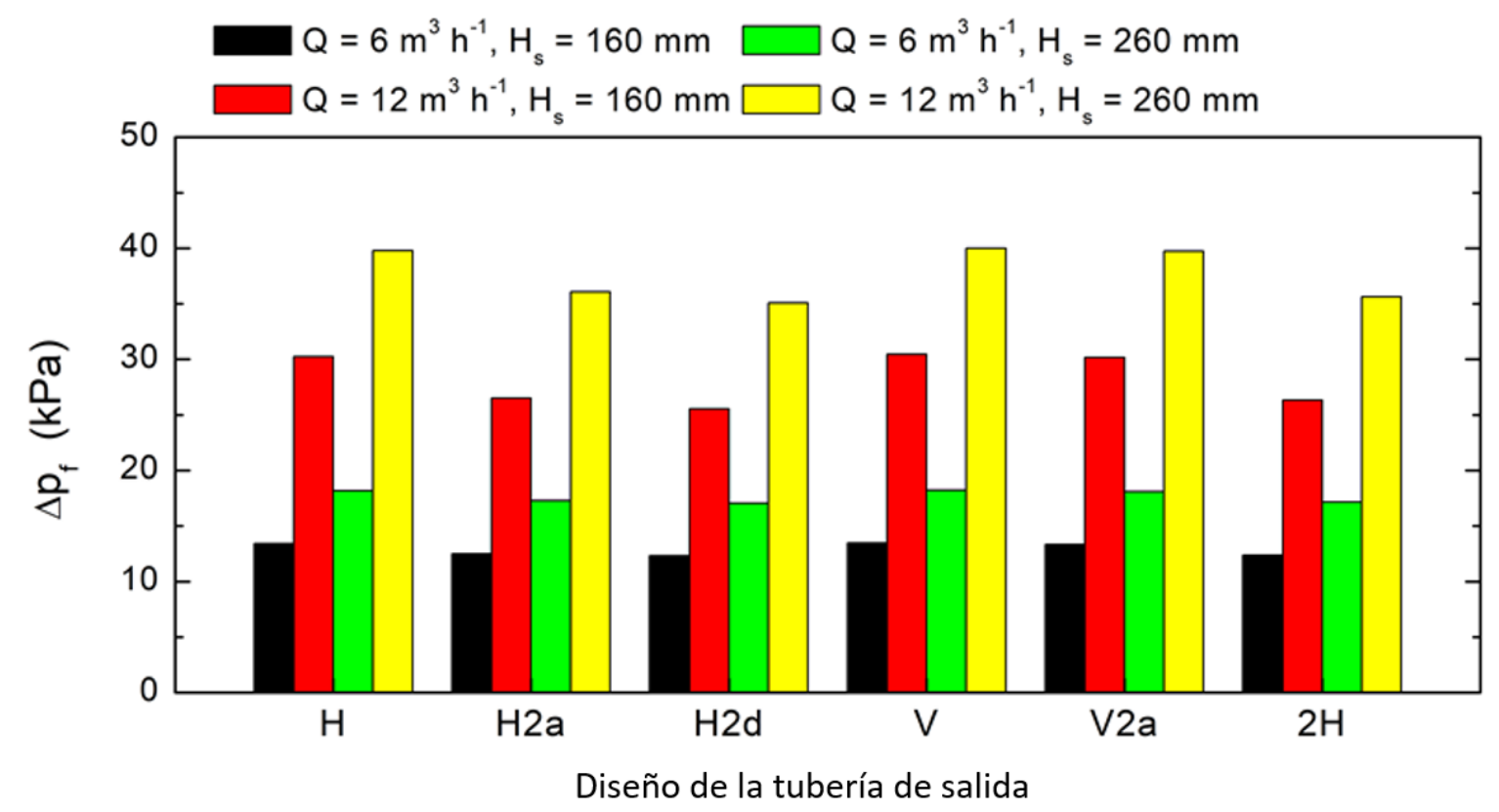

Fig. 3 - Caída de presión del filtro para filtros con diferentes diseños de tubería de salida (Tabla 1) en diferentes modos de trabajo (caudal Q y altura del lecho de arena Hs).

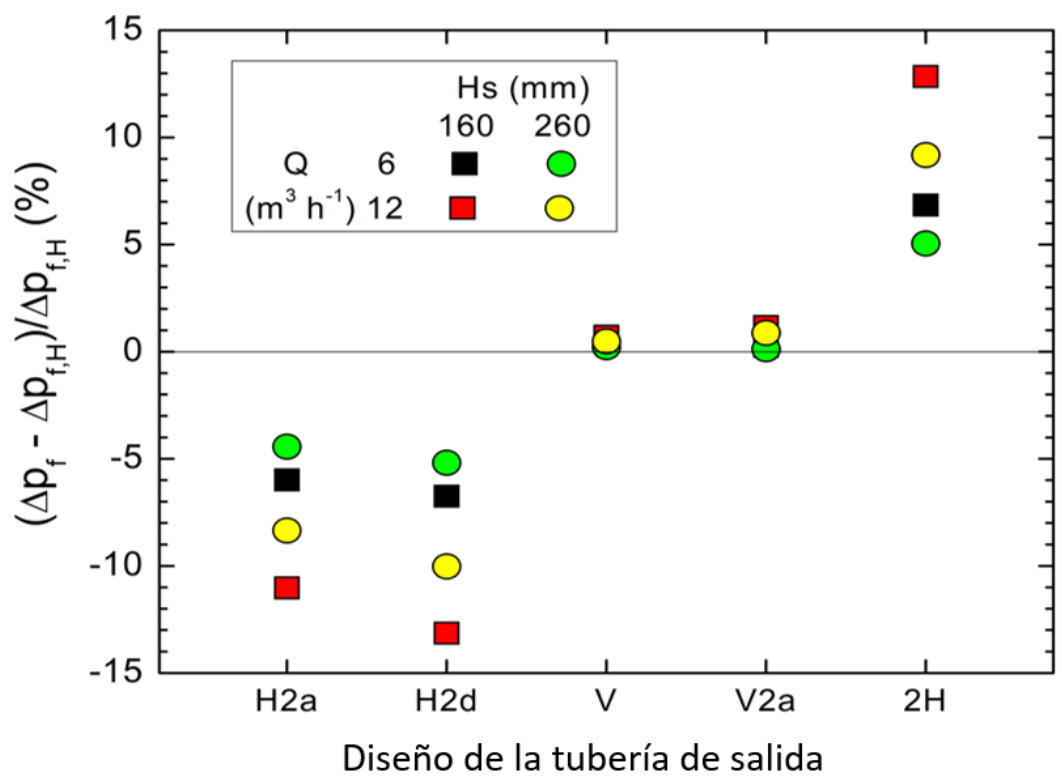

Fig. 4 - Variación (\%) de la caída de presión del filtro con respecto al filtro original con diferentes diseños de tubería de salida, incluyendo las pérdidas secundarias para adaptarse a una tubería externa de diámetro Do en diferentes modos de trabajo (caudal Q y altura del lecho de arena $\mathrm{Hs}$ ).

Cada una de las tres zonas (entrada de agua, arena, salida de agua) en las que se puede dividir el filtro contribuyó de manera diferente a las pérdidas de presión totales (Fig. 5). En aras de la concreción, los siguientes resultados se refieren al caso $\mathrm{Hs}=160 \mathrm{~mm}, \mathrm{Q}=12 \mathrm{~m}^{3} \mathrm{~h}^{-1}$, aunque las conclusiones extraídas fueron válidas para otros modos de funcionamiento. Como era de esperar, la columna de arena tuvo el aporte principal con un comportamiento que claramente se apartó del uniforme a medida que el flujo 


\section{Congreso Nacional de Riegos CARTAGENA 2021}

se acercaba a los drenes de brazo. En la Fig. 5, por conveniencia, se divide la región de arena en dos partes. La primera correspondió a los primeros $100 \mathrm{~mm}$ (desde la parte superior de la superficie del lecho de arena, $160 \mathrm{~mm}$, hasta $60 \mathrm{~mm}$ por encima del nivel de los brazos). La segunda comprendía la capa de arena desde $60 \mathrm{~mm}$ por encima de la altura de los drenes hasta el nivel de los brazos. La última región, aunque solo tenía $60 \mathrm{~mm}$ de altura, tuvo el mayor efecto sobre la pérdida de presión general (Fig. 5). Este efecto se debió al aumento en la velocidad del flujo dentro del lecho de arena, a medida que las líneas de corriente convergían hacia las ranuras del drenaje subterráneo (alta velocidad en la ecuación (1)), y también porque la trayectoria real del agua dentro de la arena no fue recta, sino que se curvó para alcanzar las aberturas del brazo de drenaje. Esto contrastó con la trayectoria casi totalmente recta de la primera región (de $160 \mathrm{~mm}$ a $60 \mathrm{~mm}$ ).

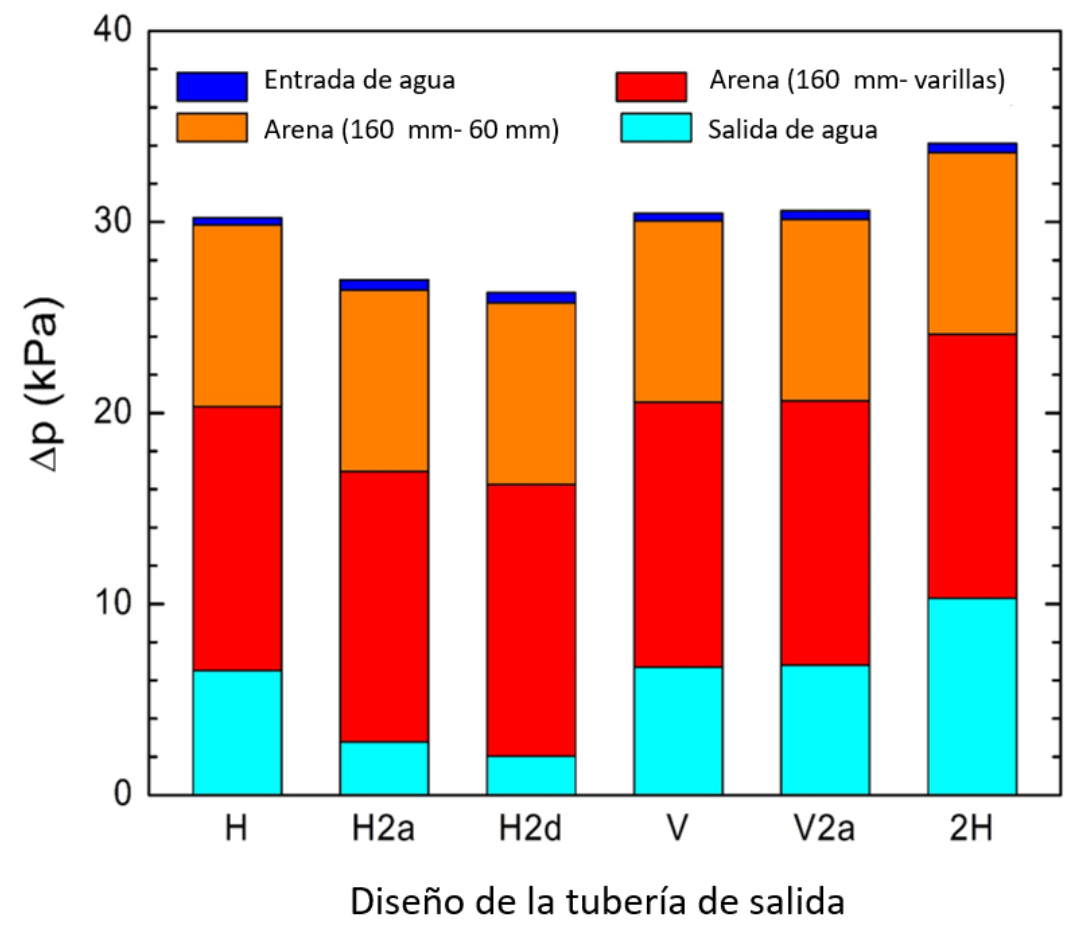

Fig. 5 - Contribución de diferentes zonas a la caída de presión total del filtro para diferentes diseños de tubería de salida, incluidas pérdidas secundarias para adaptarse a una tubería externa de diámetro Do correspondiente a Q = $12 \mathrm{~m}^{3} \mathrm{~h}^{-1}$ y Hs $=160 \mathrm{~mm}$.

La zona que menos contribuyó a la caída total de presión del filtro fue la región de entrada de agua (Fig. 5).

La zona de salida de agua, incluidos los accesorios necesarios para terminar con el mismo diámetro interior de la tubería que la comercial (caso H) tuvo una contribución notable en la caída de presión total. Para el modo de operación $\mathrm{Q}=12 \mathrm{~m}^{3} \mathrm{~h}^{-1} \mathrm{y} \mathrm{Hs}=160 \mathrm{~mm}$ fue $21 \%$ de $\Delta p f$ para el caso de referencia $(\mathrm{H})$ pero se redujo a solo $10 \%$ y $8 \%$ para diseños $\mathrm{H} 2$ a y $\mathrm{H} 2 \mathrm{~d}$, respectivamente. Las mejoras para las otras configuraciones estudiadas fueron más modestas pero aún notorias.

La reducción de las pérdidas de carga en los diseños propuestos, además de disminuir la demanda de energía, también supuso aumentar la uniformidad del flujo dentro de la arena. Esta mayor uniformidad en el flujo resultó de suma importancia para evitar la formación de caminos preferenciales dentro de la arena que acelerarían la obstrucción del filtro o afectarían negativamente el rendimiento del filtro. Por lo tanto, se investigó cómo se distribuyó el caudal total a lo largo del área de la sección transversal del 


\section{Congreso Nacional de Riegos CARTAGENA 2021}

filtro dentro de la región de arena a diferentes alturas. Las secciones horizontales se dividieron en cinco superficies de igual área (Fig. 1B) en las que se calculó el caudal (Fig. 6). La ubicación a una altura de $158 \mathrm{~mm}$ estaba a solo $2 \mathrm{~mm}$ por debajo de la capa del lecho de arena. En esa posición, el patrón fue similar para todos los diseños de tubería de salida, con la región \# 5 (la más cercana a la salida en la configuración horizontal de tubería única) teniendo la mayor disparidad de flujo (Fig. 6A). A $60 \mathrm{~mm}$ por encima del nivel del desagüe (Fig. 6B), la variación de caudal entre las tres regiones centrales y las laterales aumentó. Además, hubo una clara asimetría para el caso $\mathrm{H}$ con respecto al plano del brazo central, con las regiones \# 4 y \# 5 participando más en el flujo de agua que sus contrapartes \# 2 y \# 1 . En cambio, los diseños con doble salida y salida vertical central tuvieron un comportamiento simétrico a cualquier altura dentro del medio poroso.

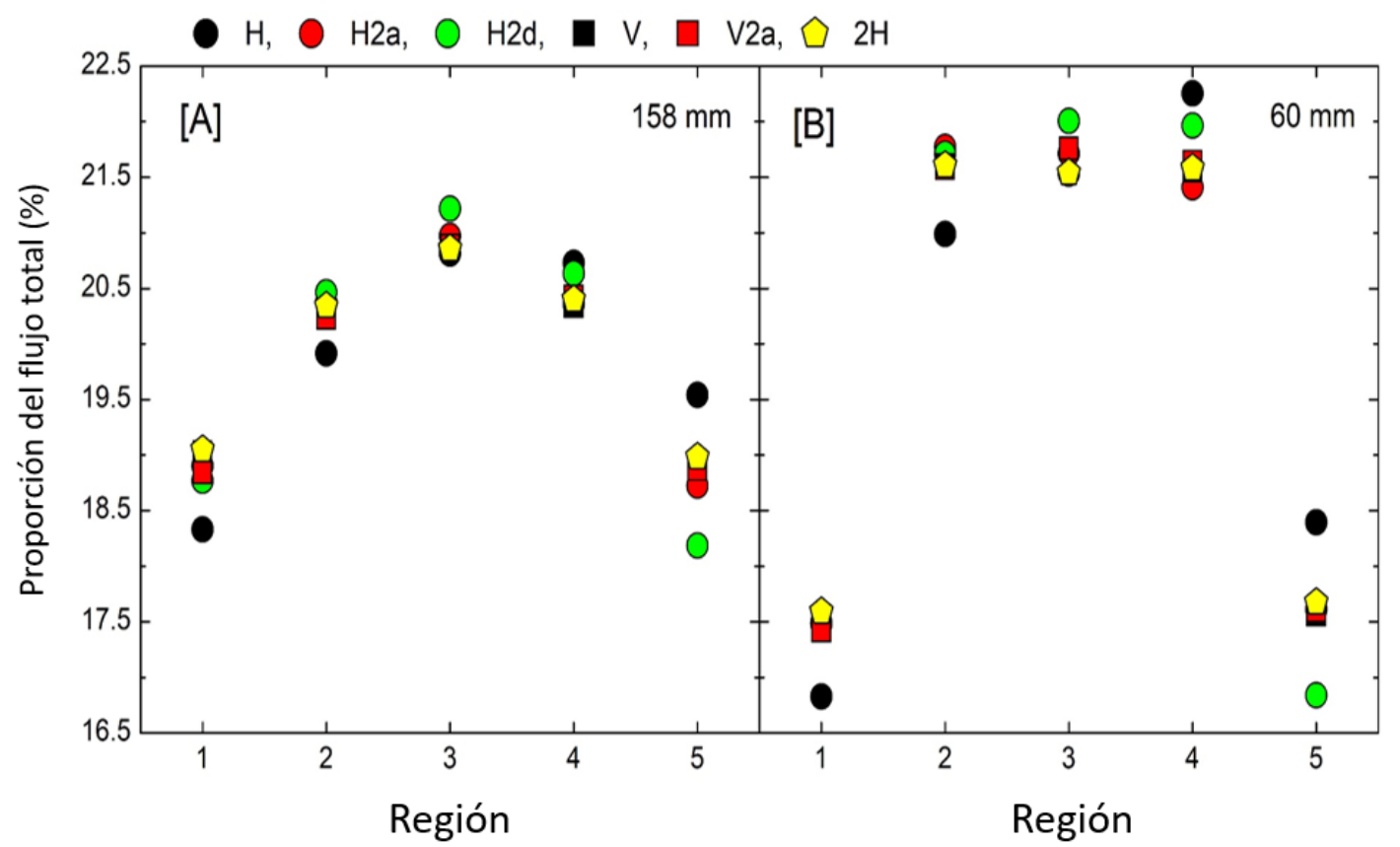

Fig. 6 - Proporción de flujo (en \% del valor total) que cruzó superficies de igual área (ver regiones en la Fig. 1B) en planos horizontales ubicados a $158 \mathrm{~mm}$ [A] y $60 \mathrm{~mm}$ [B] por encima del nivel del drenaje. Caso Q $=12 \mathrm{~m}^{3} \mathrm{~h}^{-1} \mathrm{y} \mathrm{Hs}=160 \mathrm{~mm}$.

\section{Conclusiones}

Se ha analizado numéricamente el efecto del diseño de la tubería de salida en el rendimiento hidráulico de un filtro de arena presurizado con 10 drenaje formado por brazos. Se investigaron cinco diseños que variaban en diámetro, orientación y número de salidas y se compararon los resultados con los del filtro comercial original en cuatro modos de funcionamiento. Las simulaciones indicaron que la configuración original de salida horizontal única produjo un desequilibrio en el caudal drenado por cada drenaje ( $42 \%$ de variación). Esto puede favorecer la creación de caminos preferentes dentro de la columna de arena, como se sugiere después de analizar el flujo de agua y las diferencias de presión entre diferentes sectores dentro del medio poroso.

Doblar el área de la sección transversal de la tubería de salida redujo la caída de presión del filtro hasta un $12 \%$, mejorando también el equilibrio hidráulico entre los drenajes inferiores ( $28 \%$ de variación). Un aumento adicional del área de la sección transversal de la tubería de salida (4 veces la original) solo pudo reducir la caída de presión en un 3\% con respecto duplicar el área de la sección transversal original. Además, no proporcionó una mejora relevante en el balance hidráulico de los drenajes (se 


\section{Congreso Nacional de Riegos CARTAGENA 2021}

observaron variaciones del 25\%). El cambio de la orientación de la tubería de salida a una vertical hacia abajo en la posición central no redujo las pérdidas totales de energía del filtro, pero mejoró sustancialmente la uniformidad del flujo en cada drenaje ( $21 \%$ de variación entre elementos, siendo dos veces menor que la variación del diseño comercial). Un aumento en el diámetro de la tubería de salida no modificó sustancialmente las cifras anteriores. Finalmente, una salida gemela proporcionó un comportamiento de flujo simétrico perfecto con respecto al tubo central pero no aumentó el equilibrio en comparación con el diseño de salida vertical hacia abajo, mantuvo la tubería central con menos volumen de agua drenada y, una vez incluidos todos los accesorios necesarios para conectarse a la instalación, aumentó la caída de presión general del filtro hasta un $13 \%$.

A partir de los resultados anteriores, sugerimos una revisión del diseño de la tubería de salida horizontal comercial, ya sea aumentando su diámetro al doble del original o modificando su orientación a centrada y hacia abajo. Ambos son sencillos de implementar y tienen efectos hidráulicos similares, aunque se preferiría el vertical debido a mayor efecto sobre el comportamiento simétrico.

\section{Agradecimientos}

Los autores agradecen a la Agencia Española de Investigación y al Fondo Europeo de Desarrollo Regional por su apoyo económico a través del proyecto RTI2018-094798-B-100.

\section{Referencias}

1. Arbat, G.; Pujol, T.; Montoro, L. Using computational fluid dynamics to predict head losses in the auxiliary elements of a microirrigation sand filter. Trans. ASABE 2011, 54, 1367-1376.

2. Bové, J.; Arbat, G.; Pujol, T.; Duran-Ros, M.; Ramírez de Cartagena, F.; Velayos, J.; Puig-Bargués, J. Reducing energy requirements for sand filtration in microirrigation: Improving the underdrain and packing. Biosyst. Eng. 2015, 140, 67-78, doi:10.1016/j.biosystemseng.2015.09.008.

3. Bové, J.; Puig-Bargués, J.; Arbat, G.; Duran-Ros, M.; Pujol, T.; Pujol, J.; Cartagena, F.R. de Development of a new underdrain for improving the efficiency of microirrigation sand media filters. Agric. Water Manag. 2017, doi:10.1016/j.agwat.2016.06.031.

4. $\quad$ Mesquita, M.; de Deus, F.P.; Testezlaf, R.; da Rosa, L.M.; Diotto, A. V. Design and hydrodynamic performance testing of a new pressure sand filter diffuser plate using numerical simulation. Biosyst. Eng. 2019, 183, 58-69, doi:10.1016/j.biosystemseng.2019.04.015.

5. Pujol, T.; Puig-Bargués, J.; Arbat, G.; Vegas, A.; Duran-Ros, M.; Pujol, J.; Ramírez de Cartagena, F. Numerical study of the effects of pod, wand and spike type underdrain systems in pressurised sand filters. Biosyst. Eng. 2020, 200, 338-352, doi:10.1016/j.biosystemseng.2020.10.018.

6. Pujol, T.; Puig-Bargués, J.; Arbat, G.; Duran-Ros, M.; Solé-Torres, C.; Pujol, J.; Ramírez de Cartagena, F. Effect of wand-type underdrains on the hydraulic performance of pressurised sand media filters. Biosyst. Eng. 2020, 192, 176-187, doi:10.1016/j.biosystemseng.2020.01.015.

7. Çengel, Y..; Cimbala, J.M. Fluid mechanics: fundamentals and applications. In; McGraw-Hill: New York, 2017. 


\title{
Evaluación del uso de predicciones climáticas para la operación
}

\section{de bombeos mediante energía fotovoltaica de inyección directa.}

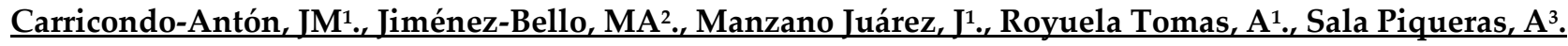

1 Centro Valenciano de Estudios sobre el Riego (CVERT), Universitat Politècnica de València; juacaran@upv.es

2 Instituto de Ingeniería del Agua y del Medio Ambiente (IIAMA), Universitat Politècnica de València

3 Instituto Universitario de Automática e Informática Industrial (AI2), Universitat Politècnica de València

Resumen: Este trabajo presenta una propuesta donde se reduce la incertidumbre en el riego fotovoltaico (FV) directo de oportunidad mediante predicciones meteorológicas (PM), pudiendo estimar con una semana de ventana temporal (VT) la irradiancia $\left(\mathrm{Wm}^{-2}\right)$, la temperatura $\left({ }^{\circ} \mathrm{C}\right)$, la velocidad del viento $\left(\mathrm{ms}^{-1}\right)$ y la humedad $\left({ }^{\%}\right.$ ) y con ello la Potencia Neta generada por día y hora (Pnetb,h, W) y la evapotranspiración de referencia (ETo). Las PM son corregidas con un filtro del Kalman para el cálculo de las horas de potencia disponible (donde Pnetb,h $>$ Potencia requerida $\left(\mathrm{Pb}_{\mathrm{D}, \mathrm{h}}\right)$ ) y de las necesidades de riego (Nr) y se compara frente a la forma tradicional de operar con los datos históricos y reemplazando la ETo sucedida en un periodo temporal. Además, se ha incorporado un modelo suelo-planta-agua el cual permite conocer el estado de humedad del suelo para establecer la programación del riego dentro de unos umbrales de humedad que no perjudiquen al cultivo. El objetivo es evaluar, en instalaciones con suministro energético $\mathrm{FV}$, una metodología de programación de riego que utiliza las PM en lugar de los datos históricos manteniendo la humedad del suelo por encima de una humedad mínima. Se aplica en un caso real de estudio de la red de riego Camí Albalat, compuesta por 4 sectores y es gestionada por la comunidad de regantes de Massalet, próximo al término municipal de Carlet (Valencia), en el este de España. El uso de las PM a 7 días permite estimar con mayor precisión la PnetD,h y las Necesidades de riego (Nr) de los cultivos, pudiendo programar con antelación el funcionamiento de la instalación. Para el caso de estudio, el error relativo diario cometido para la época de mayores $\mathrm{Nr}$ (1 de abril a 30 de septiembre) de la estimación de la Pnet y de la ETo ha sido para las PM de un 26,3\% y un 6,3\% respectivamente, frente a un error utilizando los datos históricos del 50 \% en la Pnet y del 15,2 \% para la ETo. La humedad en el sector de máximos requerimientos de $\mathrm{Pb}$ no suele alcanzar la humedad mínima establecida (es el 25\% menos de la Capacidad de Campo), esto es debido a que es el sector que aprovecha primero las horas de energía disponible. En contraposición está el sector de mínimo requerimiento de Pb que sí alcanza la humedad mínima establecida debido a que es el último sector en regarse a lo largo de la semana y por ello este sector es el que más energía eléctrica requiere. Con esto, el uso de PM ha permitido mejorar el consumo de energía FV de un 68,7 \% a un 79,3 \% y pasar del uso de energía disponible de un $11.64 \%$ a un 13.37 \% para el caso de estudio. No obstante, toda predicción está sometida a una incertidumbre y en caso de que no se cumpla se necesita una fuente de energía adicional.

Palabras clave: Riego fotovoltaico, pronóstico necesidades de riego, riego de precisión, disponibilidad de energía. 


\title{
Evaluation of the use of climate predictions for the operation of pumping using direct injection photovoltaic energy.
}

\author{
Carricondo-Antón, JM1., Jiménez-Bello, MA2., Manzano Juárez, J1., Royuela Tomas, A1., Sala Piqueras, A3.
}

1 Centro Valenciano de Estudios sobre el Riego (CVERT), Universitat Politècnica de València; juacaran@upv.es

2 Instituto de Ingeniería del Agua y del Medio Ambiente (IIAMA), Universitat Politècnica de València

3 Instituto Universitario de Automática e Informática Industrial (AI2), Universitat Politècnica de València

Abstract: This work presents a proposal where the uncertainty in direct photovoltaic irrigation (PV) of opportunity is reduced by means of meteorological predictions (PM), being able to estimate irradiance $\left(\mathrm{Wm}^{-2}\right)$, temperature $\left({ }^{\circ} \mathrm{C}\right)$, wind speed $\left(\mathrm{ms}^{-1}\right)$ and humidity $(\%)$ and with it the Net Power generated per day and hour (PnetD, h, W) and the reference evapotranspiration (ETo). The PM are corrected with a Kalman filter to calculate the hours of available power (where PnetD, $\mathrm{h}>$ Required power $(\mathrm{Pb}, \mathrm{h})$ ) and the irrigation needs (In) and it is compared against the traditional way of operate with the historical data and replacing the ETo that occurred in a temporary period. In addition, a soil-plant-water model has been incorporated which allows knowing the soil moisture status to establish the irrigation scheduling within humidity thresholds that do not harm the crop. The objective is to evaluate, in facilities with PV energy supply, an irrigation scheduling methodology that uses PM instead of historical data, keeping soil moisture above a minimum humidity. It is applied in a real case study of the Camí Albalat irrigation network, made up of 4 sectors and managed by the community of irrigators of Massalet, close to the municipality of Carlet (Valencia), in eastern Spain. The use of the 7-day PM allows the Pnetb, $h$ and In of the crops to be estimated with greater precision, allowing the operation of the installation to be programmed in advance. For the case study, the daily relative error made for the period of older In (April 1 to September 30 ) in the estimation of the Pnet and ETo has been $26.3 \%$ and $6 \%$ for the PM, 3\% respectively, against an error using the historical data of 50\% in the Pnet and $15.2 \%$ for the ETo. The humidity in the sector with maximum $\mathrm{Pb}$ requirements does not usually reach the minimum humidity established $(25 \%$ of the Field Capacity), this is due to the fact that it is the sector that takes advantage of the hours of available energy first. In contrast, there is the sector with the minimum $\mathrm{Pb}$ requirement, which does reach the minimum humidity established because it is the last sector to be watered throughout the week and therefore this sector is the one that requires the most electrical energy. With this, the use of PM has made it possible to improve the consumption of PV energy from $68.7 \%$ to $79.3 \%$ and to go from the use of available energy from $11.64 \%$ to $13.37 \%$ for the case study. However, any prediction is subject to uncertainty and if it is not fulfilled, an additional source of energy is needed.

Keywords: Photovoltaic irrigation, forecast irrigation needs, precision irrigation, energy availability. 


\section{Congreso Nacional de Riegos CARTAGENA 2021}

\section{Introducción}

Se están implementando sistemas de riego solar directo, cuando se efectúa solo si hay suficiente energía fotovoltaica es denominando Riego Fotovoltaico de Oportunidad (PVOI), presenta la problemática de la incertidumbre en el tiempo de riego (TR), ya que este depende de la irradiación. Por ello, este trabajo presenta una propuesta donde se reduce la incertidumbre del PVOI mediante predicciones meteorológicas (PM), pudiendo estimar con una semana de antelación las horas de irradiancia y la evapotranspiración de referencia (ETo). Se pretende así conocer de antemano los tiempos de energía disponible y los tiempos de energía requerida. Además, se ha incorporado un modelo suelo-planta-agua que permite conocer el estado de humedad del suelo para establecer la programación del riego dentro de unos umbrales de humedad que no perjudiquen al cultivo.

El objetivo es evaluar, en instalaciones con suministro energético fotovoltaico, una metodología de programación de riego que utiliza las PM en lugar de los datos históricos. De esta manera, se busca maximizar el uso de la irradiancia disponible por los grupos de bombeo y ajustar las dosis de riego a las estrictamente necesarias. Esta metodología se aplica en sistemas de inyección directa con múltiples hidrantes donde es fundamental conocer previamente la programación de la operación del sistema.

\section{Materiales y métodos}

\subsection{Caso de estudio}

El caso de estudio se centra en la red de riego Camí Albalat gestionada por la comunidad de regantes (CR) de Massalet. Se ubicada en el término municipal de Carlet (Valencia, 39¹3'27.45"N, $0^{\circ} 30^{\prime} 8.83$ "W), en el este de España. El cultivo de la CR son cítricos adultos que se abastecen desde el Canal Júcar-Turia. La presión mínima requerida en cada hidrante es de $28 \mathrm{~m}$, por lo que se han instalado bombas que son abastecidas energéticamente mediante una instalación fotovoltaica (FV). Para los periodos donde la energía suministrada por la instalación sea menor que la requerida, se podrá suplir mediante energía eléctrica no renovable. El suelo es Franco arenoso con una Conductividad hidráulica (Ksat) para el cálculo de la capacidad de drenaje de $800 \mathrm{~mm}$ día ${ }^{-1}$.

La red hidráulica está alimentada desde una balsa de $50.000 \mathrm{~m}^{3}$, la cual abastece mediante una conducción a dos cabezales; el de Cami Albalat que abastece 681 ha y el de Plaça Massalet que abastece 783 ha. La red de riego del cabezal de Cami Albalat, está a una cota de 42,6 m y cuenta con un total de 147 hidrantes en servicio y 198 tuberías con diámetros entre DN-90 y DN-710. El sistema de impulsión de agua que consta de 3 bombas, las cuales abastecen a 4 sectores de riego, funcionando con presión de consigna variable. Cada hectárea tiene instalados 4.200 emisores de $4 \mathrm{lh}^{-1}$ lo que equivale a un caudal por unidad de superficie de $1.68 \mathrm{lh}^{-1} \mathrm{~m}^{-2}$.

El sistema FV está formado por 912 paneles con 72 células FV de 6 pulgadas de material policristalino las cuales producen 325 W con una capacidad de generar 296,4 kW. Además, el sistema FV está formado por 3 inversores con función de variador de frecuencia. El factor o relación entre la potencia del generador FV y el sector de riego que demanda mayor Pmini es de 2,23.

\subsection{Descripción de la metodología}

Se pretende disminuir el consumo de energía eléctrica convencional y ajustar el consumo de agua al estrictamente necesario en instalaciones de riego FV, estableciendo con un tiempo de antelación el funcionamiento de las tomas o hidrantes y los grupos de bombeo, para garantizar el correcto funcionamiento del sistema. Para ello se van a utilizar las estimaciones de las necesidades de riego y la irradiancia horaria mediante el uso de las PM. La estimación de necesidades de riego, temperatura y de irradiancia se calculan mediante la metodología estándar descrita en el apartado ¡Error! No se encuentra 


\section{Congreso Nacional de Riegos CARTAGENA 2021}

el origen de la referencia.. Posteriormente se describe el cálculo de la predicción de necesidades de riego, temperatura e irradiancia mediante la metodología basada en predicciones climáticas corregidas con el Filtro de Kalman, descrito en el apartado 1.3.2. Las PM se han obtenido del servicio climático del Global Forecast System (GFS) (www.nco.ncep.noaa.gov). Del Sistema de Información Agroclimática para el Regadío (SIAR) se han obtenido los datos meteorológicos de la zona de estudio. Una vez estimada la irradiancia y la temperatura, se determina la energía que generaría el sistema FV para el segundo método (basado en predicciones). Por último, una vez conocidas la energía generada a una semana vista, los tiempos de riego de esa semana y la energía requerida por las bombas de agua, se determina la programación de los sectores de riego. Además, se establece la condición de que la humedad en el suelo no produzca estrés al cultivo y se evite el drenaje. Para ello calcula para cada día y sector la humedad del suelo $\left(\mathrm{W}_{\mathrm{t}, \mathrm{d}}\right)$.

Antes de realizar la programación del riego se determina la Capacidad de Campo de cada sector $\left(\mathrm{CC}_{\mathrm{i}}\right)$. Este término se puede sustituir por la humedad objetivo a mantener en el suelo, y la humedad para cada día de la semana $W_{\mathrm{i}, \mathrm{d}}$. Esta humedad no debe ser inferior al valor crítico que pueda causar estrés excesivo al cultivo ( $\left.\mathrm{W}_{\mathrm{i}, \text { crit }}\right)$, tal como se describe en el apartado. 1.4. Del mismo modo se determina un tiempo de riego mínimo (TRmin) que implique la conexión de las bombas, evitando que haya riegos de corta duración durante los cuales el sistema no alcance el régimen permanente.

La determinación de la programación de riego, es decir cuando riega cada sector cada semana, se realiza de la siguiente manera:

1. Se calcula el tiempo de riego semanal para cada uno de los sectores. En el caso de estudio y al tratarse de monocultivo de cítricos, se obtiene un mismo tiempo de riego para cada uno de los sectores (TRstd o TRPred_semanal).

2. Para cada sector, cada día, se calcula el tiempo de riego acumulado TRacui que al final de la semana deberá ser igual a TRstd o TRPred_semanal. Este tiempo de riego se conseguirá o bien con suministro de energía FV o bien con energía convencional.

3. Se determina la potencia horaria neta Pnet $_{D, H}$ para cada una de las horas y días de la semana.

4. Los sectores de riego se ordenan según la $P_{\min , i}$ de mayor a menor

5. Se asignan las horas de mayor $P_{n e t}$ a los sectores cuando $P_{n e t} \geq P m i n i$

6. Se comienza por el sector de mayor Pmini a realizar un bucle recorriendo las horas de cada día de la semana estableciendo las horas de riego de cada sector cuando $P_{n e t} \geq P \min i$.

7. Se determina para cada sector el tiempo de riego máximo diario TRmax,i siempre que $P_{n e t} \geq P \min n_{\text {hasta }}$ que llegue a $C_{\mathrm{i}_{1},} ; \mathrm{TRmax}_{, i}=\left\{\mathrm{TR}_{\text {std }}, \mathrm{TRPred}_{\text {semanal }}\right\}$. Si $\mathrm{W}_{\mathrm{i}, \mathrm{d}}<\mathrm{W}_{\text {crit, }}$ o si TRmax,i es positivo habrá que realizar el riego.

8. Se comprueba para ese sector si Pnet $<$ Pmini. En caso de que lo sea se asigna esa hora hasta que $\mathrm{TRacu}_{\mathrm{i}}=$ TRmax,i. Las horas utilizadas quedan descartadas para los siguientes sectores. En caso de que $P_{\text {net,i< }}$ Pmini y $\mathrm{W}_{\mathrm{i}, \mathrm{D}}<\mathrm{W}_{\text {crit,i }}$ se utiliza energía convencional.

9. El sector i no vuelve a regar hasta que TRmax,i es positivo y mayor que TRmin

10. El bucle se repite para cada día de la semana y para cada sector

Al final de la programación semanal TRacui $\leq$ TRmaxi. TRacui puede ser menor a TRmaxi cuando el suelo esté en $\mathrm{CC}_{\mathrm{i}} \mathrm{O}$ cuando TRmax,i $<\mathrm{TR}_{\min }$. Para evaluar la metodología propuesta se compara Pmini con la potencia horaria neta real que ha sucedido durante esa hora y ese día (Preald,h). Si Preald,h $>$ Pnet $d, h$ 


\section{Congreso Nacional de Riegos CARTAGENA 2021}

el sistema funciona con energía FV y se contabilizan como TRFv. En caso de que Preald,h $<$ Pnetd,h el sistema debe funcionar con energía convencional y las horas de riego se contabilizan como TRCi. Este proceso se repite para toda la campaña del riego 2019 con frecuencia semanal tomando los lunes como día de referencia.

En este trabajo se realiza un análisis comparativo de los resultados de riego en varios escenarios, dependiendo de varias opciones en cuanto a la irradiancia y el cálculo de ETo, se pretende saber qué método es mejor para disminuir la incertidumbre del sistema operativo. En cuanto al cálculo de la irradiancia, un primer escenario considera que la irradiancia de la próxima semana será igual a la radiación media de los últimos 10 años ( $\left.\operatorname{Irrad}_{10-a n ̃ o s}\right)$, mientras que una segunda opción será la que surja

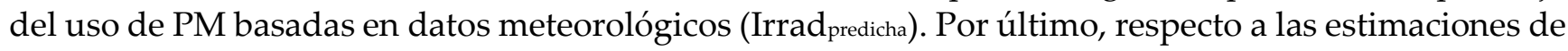
ETo, se vuelven a considerar dos opciones: siendo la primera donde la ETo es igual al valor que alcanzó dicho indicador la semana anterior y en la segunda opcion se usa el valor de ETo pronosticado [1]. En resumen, hay cuatro escenarios posibles considerando todas las opciones, SC1 (Irrad predicha y ETcPredicha),

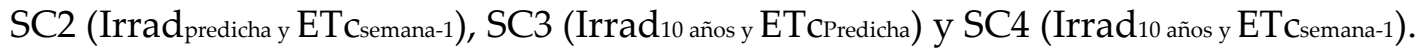

\subsection{Cálculo de Necesidades de Riego (NR).}

Para calcular las necesidades de riego, se utiliza la metodología de Penman Monteith [2] para el cálculo de la ETo. A partir de la ETo se determinan las necesidades de evapotranspiración del cultivo (ETc), utilizando para ellos los coeficientes de cultivo $(\mathrm{Kc})$, basados en los porcentajes de cubierta vegetal corregidos por un factor de corrección mensual $\mathrm{fCmes}_{\mathrm{C}}$. Se asume que todas las parcelas tienen una cubierta vegetal mayor al 70\%. Una vez calculada la ETc, a esta se le resta la precipitación efectiva $(\mathrm{Pe})$.

$$
\begin{aligned}
& E T c=E T o \cdot K c \cdot f c_{\text {mes }} \\
& N R=E T c-P_{e}
\end{aligned}
$$

Las variables para el cálculo de la ETo se obtienen mediante dos procecimientos:

1. El primero calcula la ETo mediante las PM de la Temperatura media $\left({ }^{\circ} \mathrm{C}\right)$, humedad relativa $(\%)$, velocidad del viento a 2 metros de altura $\left(\mathrm{ms}^{-1}\right)$ y radiación solar de onda corta descendente observada $\left(\mathrm{Wm}^{-2}\right)$, equivalente a la irradiancia, a una semana de ventana temporal (7 días de predicción).

2. El segundo,calcula las necesidades de riego para la próxima semana utilizando la ETo de la semana anterior, empleando los datos meteorológicos de estaciones agroclimáticas del Sistema de Información Agroclimática para el Regadío (SIAR) (http://eportal.mapa.gob.es/websiar/Inicio.aspx). Para el caso de estudio aquí considerado, se usa la corresponde a la de E.A. Carlet, situada a 3.786m del cabezal de riego Cami Albalat.

\subsubsection{Determinación de la Irradiancia y tiempos de riego mediante sistema tradicional}

En este apartado se calcula la irradiancia de la semana con la radiación media observada durante la misma semana de los últimos 10 años, la cual se midió en el plano horizontal utilizando un piranómetro modelo CMP3 (Kipp \& Zonen BV Delft, Holanda), para programar el riego de la próxima semana.

Los TR estándar (TRstd) se determinan tradicionalmente asumiendo la ETo de la semana previa, aunque en este estudio, para que ambas metodologías sean comparables, se ha decidido compensar el error de la ETo de la semana anterior en los tiempos de riego de la semana que se va a regar. Para ello se emplea la siguiente ecuación:

$$
I T_{\text {std }}=\left(E T c_{\text {semana }+1}-\left(E T c_{\text {semana-1 }}-E T c_{M \text { semana }-1}\right)-P_{\text {e semana }-1}\right) \cdot q^{-1}
$$

Donde ETcsemana+1 es la predicción de ETc para la semana próxima, ETcsemana-1 es la predicción de ETc para la semana anterior, ETcmsemana-1 es la ETc calculada mediante medidas de estación 


\section{Congreso Nacional de Riegos CARTAGENA 2021}

meteorológica de la semana anterior, $\mathrm{Pe}_{\text {semana-1 }}$ es la precipitación efectiva de la semana anterior y $q$ son los $1 \mathrm{~h}^{-1} \mathrm{~m}^{-2}$. Si TRstd es inferior a $0 \mathrm{o}$ si TR std es menor a TRmin, no se producirá riego.

\subsubsection{Predicciones de datos meteorológicos y tiempos de riego.}

Las NR de los cultivos se realiza mediante las PM del servicio climático, Global Forecast System (GFS) de la National Centers for Environmental Prediction (NCEP), perteneciente al gobierno de USA.

Para reducir la incertidumbre entre el modelo predictivo y la medida realizada en estaciones meteorológicas se ha empleado un Filtro de Kalman [3]. Las ecuaciones de dicho filtro se resuelven en dos etapas [4]. Cuando se dispone de una medida se ejecuta el paso "corrector" dado por:

$$
\begin{gathered}
K_{k}=P_{k}^{-} H_{k}^{T}\left(H_{k} P_{k}^{-} H_{k}{ }^{T}+R\right)^{-1} \\
\hat{x}_{k}=\hat{x}_{k}^{-}+K_{k}\left(z_{k}-H_{k} \hat{x}_{k}^{-}\right) \\
P_{k}=\left(I-K_{t} H_{k}\right) P_{k}^{-}
\end{gathered}
$$

Donde $P_{k}^{-}$es la matriz de varianza del estado o el error de estimación, $H_{-} k$ es la matriz de medición, $K \_$k es la ganancia de Kalman, $z \_k$ es la observación real en el instante $\mathrm{k}, x$ es el estado inicial estimado y $R$ es la matriz de varianza del ruido de medición.

Una vez se obtiene el vector corregido para las mediciones de los datos y del modelo pasado, se determina la predicción futura ajustando el modelo de los siguientes días, mediante las ecuaciones de simulación [4] lo que se suele denominar etapa de "predictor" en la literatura:

$$
\begin{aligned}
& \hat{x}_{k}^{-}=A \hat{x}_{k-1} \\
& P_{k}^{-}=A P_{k-1} A^{T}+Q
\end{aligned}
$$

Donde $P_{k}^{-}$es la matriz de varianza del estado o el error de estimación, $\hat{x}_{k-1}$ es el estado estimado en la iteración anterior (o las condiciones iniciales en la primera iteración). Si se deseara simular a varios pasos en el futuro sin observaciones intermedias, se supone en el predictor (6) $P_{k}=P_{k}^{-}$y sin ejecutar las ecuaciones del corrector (5).

Alimentando a cuatro filtros de Kalman, se obtienen (recursivamente) los cuatro parámetros de la corrección para cada una de las variables de temperatura, humedad, viento a $2 \mathrm{~m}$ e irradiancia.

Mediante los 4 parámetros se calcula la ETo mediante la metodología de Penman Monteith. Una vez conocidas la NR se determina el tiempo de riego predicho TRPred_semanal, donde se corrige cada semana con el error de la semana anterior, mediante la siguiente ecuación:

$$
I T_{\text {Pred }} \text { semanal }=\left(E T C_{K \text { semana }+1}-\left(E T c_{K \text { semana }-1}-E T c_{M \text { semana }-1}\right)-P_{e_{\text {semana }-1}}\right) \cdot q^{-1}
$$

Donde ETCKsemana+1 es la predicción de ETc para la semana próxima, ETCKsemana-1 es la predicción de ETc para la semana anterior, ETcmsemana-1 es la ETc calculada mediante medidas de estación meteorológica de la semana anterior, $\mathrm{Pe}_{\text {semana-1 }}$ es la precipitación efectiva de la semana anterior y $q$ son $\operatorname{los} 1 \mathrm{~h}^{-1} \mathrm{~m}^{-2}$ que pueden proporcionarse como caudal de riego. Si TRstd es inferior a 0 o si TRstd es menor a TRmin, no se producirá riego.

\subsection{Humedad en el suelo}

El uso adecuado del agua supone el punto de control de esta metodología, buscando mantener una alta eficiencia hídrica, se controla la humedad del suelo. Al disponer paneles FV se reduce el consumo eléctrico de energías convencionales, pero también se deben de ajustar los TR para no perder agua por drenaje si estos tiempos fueran excesivos.

La determinación de humedad del suelo para cada sector $\left(\mathrm{W}_{\mathrm{i}, \mathrm{d}}\right)$ se establece diariamente, mediante la ecuación:

$$
W_{i, d}=W_{i, d(-1)}-E T c_{M}+I+P_{e}+D P
$$




\section{Congreso Nacional de Riegos CARTAGENA 2021}

Donde $\mathrm{W}_{\mathrm{i}, \mathrm{d}(-1)}$ es la humedad del suelo del dia anterior $(\mathrm{mm})$, ETcM es la ETc calculada mediante mediciones en estaciones meteorológicas $(\mathrm{mm})$, I es el riego $(\mathrm{mm})$, Pees la precipitación efectiva $(\mathrm{mm})$ y DP es el drenaje en profundidad ( $\mathrm{mm}$ ).

En este modelo se ha simplificado no teniendo en cuenta la escorrentía superficial, al tratarse de un riego localizado. Se asume que ETсм y Pe es la misma para cada sector. El cálculo de DP se realiza cuando la humedad del suelo está entre Saturación (SAT) y Capacidad de Campo (CC), el drenaje se calcula con la siguiente ecuación [5-7].

$$
D P=0.0866 \cdot K_{s a t}{ }^{0.35} \cdot(S A T-F C)
$$

Se ha determinado la fracción de la CC de agua del suelo $\left(p_{s}, \%\right)$ para que cítricos con cobertura mayor al 70\% no sufran estrés. Esta fracción limita la mínima cantidad de agua $(\mathrm{mm})$ que debería de contener el suelo para que los cítricos no sufran estrés. Esto se ha realizado según la ecuación:

$$
W_{\text {crit }, i}=0.5+0.04 *\left(5-p_{s} \cdot E T c_{\left(m m \cdot d i a^{-1}\right)}\right)
$$

\subsection{Sistema fotovoltaico}

La eficiencia de las células FV que conforman el panel FV, se ve afectada por la temperatura que pueden alcanzar al estar sometidas a la irradiancia. Para calcular la temperatura de la célula de cada hora de cada dia de la semana $\left(\operatorname{Tcel}_{d, h}{ }^{0} \mathrm{C}\right)$ se emplea la siguiente formula.

$$
\text { Tcel }_{d, h}=T+\frac{(T O N C-20) \cdot S R}{800}
$$

Donde T es Temperatura en $\left({ }^{\circ} \mathrm{C}\right)$, TONC es la temperatura nominal de funcionamiento de la célula $\mathrm{FV}$ (en este caso $45^{\circ} \mathrm{C}$ ) y SR es la irradiancia media horaria $\left(\mathrm{Wm}^{-2}\right)$.

El cálculo de la potencia horaria neta disponible FV para cada día de la semana se determinó mediante la ecuación:

$$
P_{d, h}=P_{p} \cdot \frac{S R}{1000} \cdot\left(1+\frac{\alpha_{p}}{100} \cdot(\text { Tcel }-25)\right)
$$

Donde $P p$ es la potencia pico de la placa FV, $\alpha_{p}$ es el coeficiente de variación de $P p$ con la temperatura $\left(\% /{ }^{\circ} \mathrm{C}\right)$ y Tceld,h es la temperatura de la célula FV.

Por último, se debe de tener en cuenta que la potencia neta disponible por cada hora y día de la

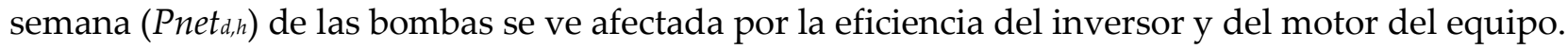

$$
P_{\text {net }, \mathrm{h}, \mathrm{h}}=P_{d, h_{i}} \cdot \eta_{f c} \cdot \eta_{m}
$$

Donde $\eta_{f c}$ es la eficiencia estimada del inversor que es de 0.9 y $\eta_{m}$ es la eficiencia estimada del motor que es de 0.8 .

Durante los periodos donde las horas y energía de riego sean mayores a las horas y energía suministradas por la instalación FV, se riega mediante energía eléctrica convencional.

\section{Resultados y discusión}

En este apartado se estudia cómo afecta la programación de riego mediante predicciones al uso de la energía FV y convencional. La evaluación de la programación de riego para cada sector se realiza estudiando las dosis de riego y el drenaje, las horas de riego regadas mediante energía convencional y energía FV y la humedad del suelo para los 4 sectores. TRmin se estableció en $0.5 \mathrm{~h}$ para evitar excesivos arranques y paros del sistema. La humedad objetivo se estableció en la $\mathrm{CC}_{\mathrm{i}}(110 \mathrm{~mm})$ y el punto de mínima humedad se estableció un $25 \%$ inferior a $\mathrm{CC}_{\mathrm{i}}$ siendo de $82.5 \mathrm{~mm}$. El drenaje se produciría debido a la precipitación ya que a la humedad del suelo se añade la precipitación superando la humedad la CC, tal como se describe en las ecuaciones 8 y 9. 


\subsection{Evaluación de los sectores según el contenido de la humedad del suelo}

En este apartado se presentan los resultados de humedad del suelo para los 2 escenarios SCE1 (figura 1) y SCE4 (figura 2).

En ambas gráficas se representa los sectores de mínimo y máximo requerimiento de potencia para que funcionen las bombas, la precipitación efectiva y la mínima humedad del suelo para que las plantas no sufran estrés. En ninguno de los 4 escenarios las plantas han sufrido estrés. Además, se puede observar qué la humedad en el sector de máximo requerimiento de potencia para el bombeo no suele alcanzar la humedad mínima establecida, esto es debido a que es el sector que aprovecha primero las horas de energía disponible.

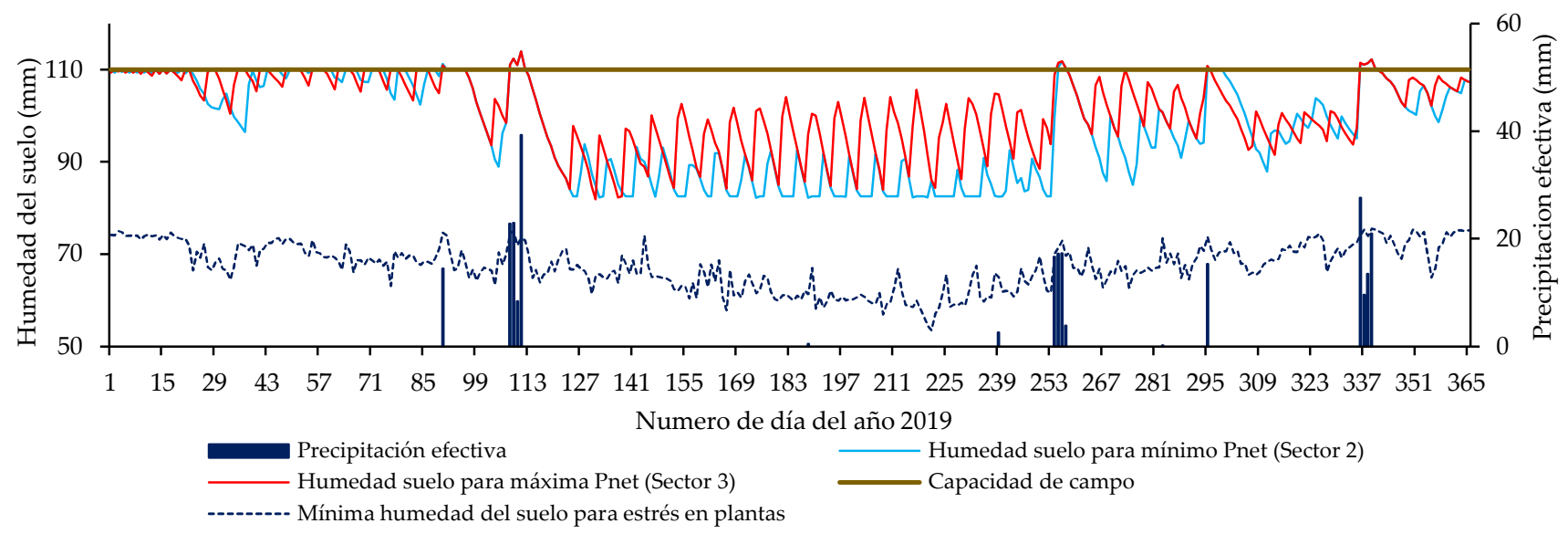

Figura 1. Capacidad de campo, Humedad del suelo mediante ETc predicha e irradiancia predicha con PM y mínima humedad de suelo para estrés en cítricos.

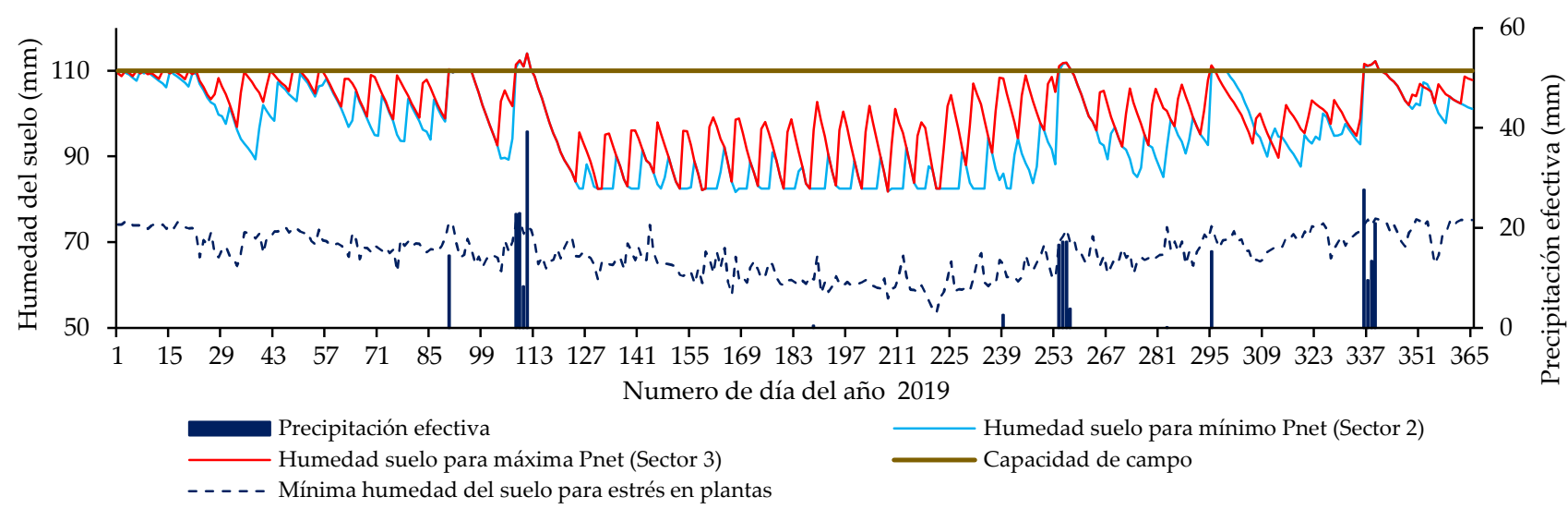

Figura 2. Capacidad de campo, Humedad del suelo mediante ETc de la semana anterior, irradiancia media de 10 años y mínima humedad de suelo para estrés en cítricos.

\subsection{Evaluación de la dosis de riego y del drenaje.}

Los consumos anuales para los 4 sectores son de 2.853,6 mm, $2869 \mathrm{~mm}, 2.877,2 \mathrm{~mm}$ y $2897 \mathrm{~mm}$ para los escenarios SCE 1, SCE2, SCE3 y SCE4 respectivamente, mostrando la menor cantidad de agua regada cuando se utiliza ETc Predicho y Irradpredicho (SCE1).

El drenaje del caso de estudio no se produce debido al riego ya que cuando se alcanza la humedad objetivo $\left(\mathrm{CC}_{\mathrm{i}}\right)$ el riego se detiene, pero en los periodos que se producen precipitaciones, el drenaje dependerá de la proximidad de la humedad objetivo a la humedad del suelo. 


\subsection{Evaluación de los sectores por el uso de energía fotovoltaica.}

Las horas anuales de funcionamiento para abastecer los 4 sectores son $1698.5 \mathrm{~h}, 1707.7 \mathrm{~h}, 1712.6 \mathrm{~h}$ y 1710.2h para los escenarios SCE 1, SCE2, SCE3 y SCE4 respectivamente, mostrando la menor necesidad de horas cuando se utilizan ETc Predicho y Irrad predicho (SCE1). La figura 3 muestra las horas de riego suministradas con energía FV y con energía convencional. La suma de las dos son las horas totales de riego que se deben de aportar a lo largo de un año para cubrir las necesidades de riego que se ha establecido.

El sector que menos horas de energía convencional ha requerido ha sido el de mayor Pmini y así sucesivamente hasta llegar al sector de menor Pmini. Las horas anuales de riego FV para abastecer los 4 sectores son $1.322,6 \mathrm{~h}, 1.236 \mathrm{~h}, 1.257,1 \mathrm{~h}$ y $1.144,6 \mathrm{~h}$ para los escenarios SCE 1, SCE2, SCE3 y SCE4 respectivamente, mostrando el mayor uso de horas de riego de energía FV cuando se utiliza ETc Predicho y Irrad $_{\text {predicted }}$ (SCE1). Por el contrario, las horas anuales de riego con energía convencional para abastecer los 4 sectores son $375,9 \mathrm{~h}, 471,8 \mathrm{~h}, 455,6 \mathrm{~h}$ y $565,7 \mathrm{~h}$ para los escenarios SCE 1, SCE2, SCE3 y SCE4 respectivamente, mostrando el menor uso de horas de riego de energía convencional cuando se utiliza ETcPredicho y Irrad predicho (SCE1).
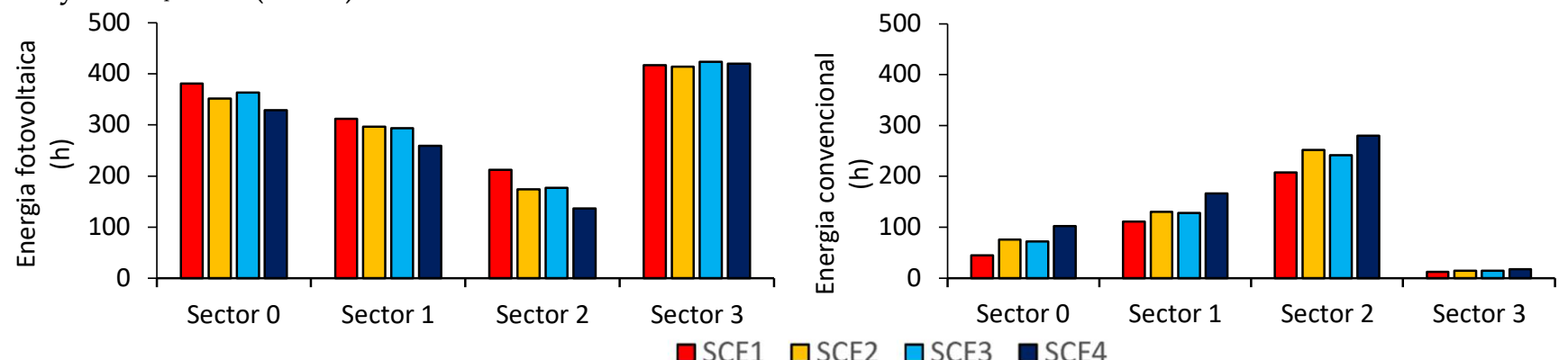

Figura 3. Horas de riego mediante energía FV y horas de riego mediante energía convencional por sectores según los diferentes escenarios SEC1, SCE2, SCE3 y SCE4.

La energía convencional se conectó en aquellas ocasiones donde la irradiancia no fue suficiente para realizar el riego ya programado mediante las predicciones tanto Irradpredicho y Irrad 10-años. Por otro lado, también se conectará la energía convencional en aquellos momentos qué la humedad del suelo sea inferior al $25 \%$ de la humedad objetivo $\left(\mathrm{CC}_{\mathrm{i}}\right)$ y no se produzca energía FV para abastecer al sistema como indica la figura 4. Aquí podemos observar como las horas de riego donde se usa energía convencional en los escenarios SCE1 y SCE2 son debidas a que la humedad desciende por debajo del 25\% de la $\mathrm{CC}_{\mathrm{i}}$ y se han de conectar las bombas mediante energía convencional. Sin embargo, para los escenarios SCE3 y SCE4 el uso de energía convencional se debe principalmente a los errores en la predicción meteorológica.
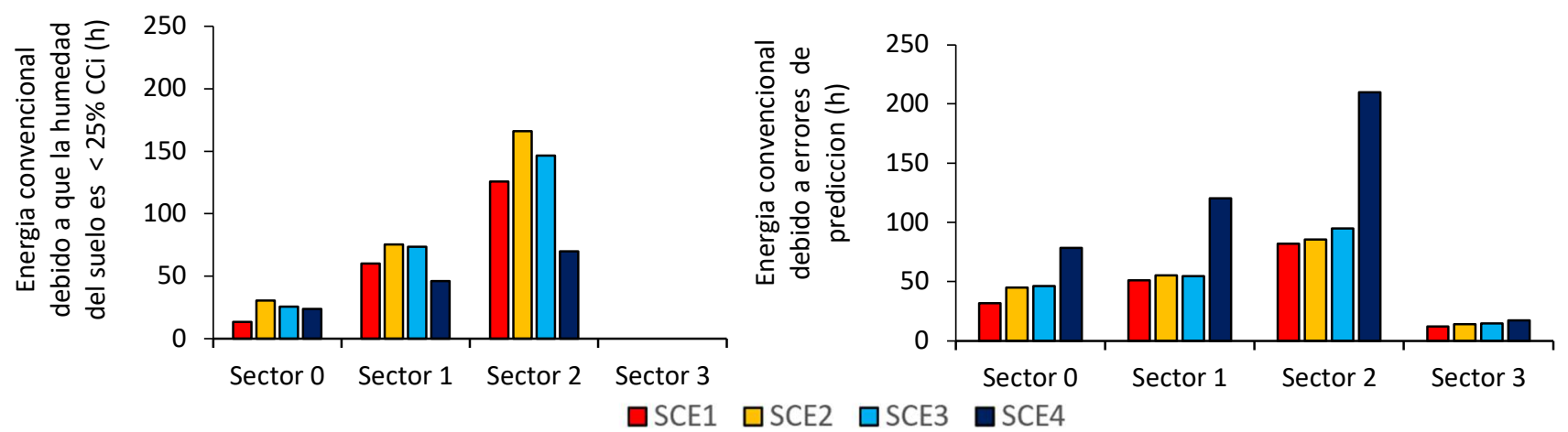

Figura 4. Horas de riego mediante energía convencional debidas a que la humedad del suelo es inferior al 25\% del CCi o debido a errores en la programación del riego por sectores según los diferentes escenarios SEC1, SCE2, SCE3 y SCE4. 
El porcentaje entre las horas de riego ejecutadas mediante energía FV frente a las horas de energía disponible son de $13.37 \%, 12.52 \%, 12.74$ y de $11.64 \%$ para los escenarios SCE1, SCE2, SCE3 y SCE4.

De aquí se determina que los mayores aprovechamientos de energía FV se dan en los escenarios

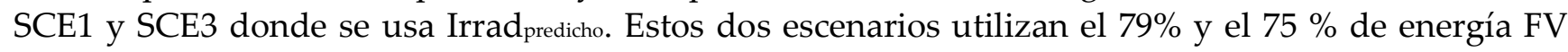
frente a SCE2 y SC4 que utilizan el 74\% y el $68 \%$ de la energía FV.

El sector 3, al ser el primero que se le asigna Pnetd,h, es el que se cubre con un mayor porcentaje de energía FV y no es necesario utilizar la energía convencional para mantener el nivel de humedad por encima de $W_{\text {criti. }}$. Solamente el error debido a la predicción, obliga al uso de energía convencional. Por otro lado, el sector 2, el sector de menor Pmini, es el que mayor uso de energía convencional hace y mayor porcentaje de ésta se debe a que no se alcanza $W_{\text {criti.i. }}$

\section{Conclusiones}

El uso de las predicciones metodológicas a corto plazo, una semana de ventana temporal de antelación, permite estimar con mayor precisión la irradiancia y las necesidades de riego de los cultivos, por lo que se puede programar con antelación el funcionamiento de la instalación. No obstante, toda predicción está sometida a una incertidumbre y en caso de que no se cumpla se necesita una fuente de energía adicional.

Esto ha permitido que la aplicación de las PM para el cálculo de la irradiancia y de las necesidades del riego (SCE1) frente al uso de los datos históricos y del cálculo de la evapotranspiración tomando como referencia lo sucedido en el pasado (SCE4) haya permitido mejorar el uso de energía renovable de un $68,7 \%$ a un $79,3 \%$ y pasar del uso de energía fotovoltaica disponible de un $11.64 \%$ a un $13.37 \%$.

Para la mejora de este último indicador se debe actuar sobre la programación del riego diseñando turnos dinámicos cuya potencia mínima de cada sector se adapte a lo largo de potencia neta.

La mejora de las predicciones acompañada junto con la reducción temporal de la ventana de predicción mejorará el porcentaje de uso de energía renovable y el aumento del uso de las horas de energía disponible.

\section{Agradecimientos}

Este estudio ha sido parcialmente financiado por el proyecto ADAPTAMED (RTI2018-101483-B-I00), financiado por el Ministerio de Ciencia e Innovación de España y con fondos de la UE FEDER

\section{Referencias}

1. Carricondo-Anton,J.M.; Jiménez-Bello,M.; Martínez Alzamora,F.; Sala ,A. Análisis de las Predicciones Climáticas a partir de distintos Servicios Climáticos para la Programación del Riego, XXXVII Congr. Nac. Riegos. (2019).

2. Allen, R.G.; Pereira, L.S.; Raes, D.; Smith, M. Crop evapotranspiration guide- lines for computing crop water requirements., (1998).

3. Kalman, R. A New Approach to Linear Filtering and Prediction Problems, Trans. ASME - J. Basic Eng. 82 (1960) $35-45$. https://doi.org/10.1115/1.3662552.

4. Albertos, P.; Sala, A. Multivariable control systems : an engineering approach, (2004).

5. Raes, D. summary simulation model of the water budget of a cropped soil, Leuven Uni, Leuven, Belgium, 1982.

6. Raes, D.; Lemmens, P. H.; Van Aelst, M.; Bulcke, V.; Smith, M. IRSIS - Irrigation scheduling information system, Dep. Land Management, Reference Manual 3, 1988.

7. Raes, D.; Geerts, S.; Kipkorir, E.; Wellens, J.; Sahli, A. Simulation of yield decline as a result of water stress with a robust soil water balance model, Agric. Water Manag. 81 (2006) 335-357. https://doi.org/10.1016/j.agwat.2005.04.006. 


\section{Estudio comparativo del comportamiento de los contadores me- cánicos frente a los contadores de ultrasonidos y caudalímetros electromagnéticos}

Madurga del Cura, Cristina1 ${ }^{1}$, Cervantes Díaz-Toledo, Alfonso², Muñoz Sopeña, Daniel², Rodríguez Fernández, Diego $^{2}$, Sánchez de Ribera González, Alejandro², Zazo Salinero, Teresa²

1 Ingeniero Agrónomo, TRAGSA - CENTER, cmadurga@tragsa.es

2 Equipo Técnico del CENTER

Resumen: Tradicionalmente se han instalado contadores mecánicos a pie de parcela, fundamentalmente por tema económico. Sin embargo, los nuevos materiales y los nuevos métodos de fabricación hacen que las nuevas tecnologías sean más accesibles, permitiendo la utilización de caudalímetros electromagnéticos y de ultrasonidos en redes de riego a pie de parcela.

El objetivo de este estudio es comparar el comportamiento de contadores mecánicos, caudalímetros electromagnéticos y de ultrasonidos bajo distintas condiciones de funcionamiento y configuraciones de montaje, así como su durabilidad siguiendo el procedimiento descrito en la norma UNE-ISO 16399 en su apartado 7.7.2 "Ensayo de resistencia a las partículas sólidas", incluido en la legislación española para contadores de riego (ICT/155/2020) que permite conocer la idoneidad o no de un equipo como contador de agua de riego al ser ensayados en condiciones reales de funcionamiento y con agua no limpia.

Para la realización de este estudio se va a analizar el comportamiento de los siguientes equipos:

- Contador mecánico tipo Woltman:

○ Eje horizontal

- Eje vertical

- Contador ultrasonidos: 2 modelos

- Caudalímetro electromagnético: 1 modelo

Todos los equipos serán DN80 con el objetivo de facilitar su comparativa.

Para cada uno de los equipos se obtendrá la curva de error bajo diferentes condiciones de funcionamiento, llevando a cabo los ensayos en el Laboratorio Central para Ensayo de Materiales y Equipos de Riego del CENTER.

Los resultados obtenidos servirán de orientación a promotores y usuarios a la hora de elegir el contador que más se adecúe a sus necesidades reales de funcionamiento.

Palabras clave: contadores; caudalímetros electromagnéticos; ultrasonidos; legislación contadores; laboratorio; ensayos; CENTER. 


\section{Comparative study of the behavior of mechanical meters com- pared to ultrasonic meters and electromagnetic flowmeters} Madurga del Cura, Cristina ${ }^{1}$, Cervantes Díaz-Toledo, Alfonso ${ }^{2}$, Muñoz Sopeña, Daniel $^{2}$, Rodríguez Fernández,
Diego $^{2}$, Sánchez de Ribera González, Alejandro², Zazo Salinero, Teresa ${ }^{2}$

1 Agricultural Engineer, TRAGSA - CENTER, cmadurga@tragsa.es

2 CENTER Technical Team

Abstract: Traditionally, mechanical meters have been installed on farm, mainly for economic reasons. However, new materials and new manufacturing methods make new technologies more accessible, allowing the use of electromagnetic flowmeters and ultrasonic meters in irritation networks with small diameters.

The aim of this study is to compare the behaviour of mechanical meters, ultrasonic meters and electromagnetic flow meters under different operating conditions and mounting configurations, as well as their durability following the procedure described in the standard UNE-ISO 16399, in its clause 7.2.2 "Resistance to solid particles test", included in the Spanish legislation for irrigation meters (ICT/155/2020). The result of this test allows knowing the suitability or not of a device as an irrigation water meter when tested under operating conditions and with not clean water.

To carry out this study, the behaviour of the following equipment is been analysed:

- Mechanical meter.

- Woltman horizontal axis.

- Woltman vertical axis

- Ultrasonic meter: 2 models

- Electromagnetic flowmeter: 1 model

All the equipment is DN80 in order to facilitate their comparison.

For each equipment, the error - curve is obtained under different operating conditions, carrying out the tests in the Central Laboratory for Testing Materials and Irrigation Equipment in the National Centre for Irrigation Technology (CENTER).

Keywords: electromagnetic flowmeter; ultrasonic meter; legislation for irrigation meters; laboratory; tests; CENTER 


\section{Introducción}

Los contadores de riego están regulados por la Orden ICT/155/2020 que establece los requisitos que deben cumplir estos equipos para poder ser comercializados e instalados en una red de riego, así como cuando ya están en funcionamiento.

En la actualidad, la mayor parte de los fabricantes de contadores los venden indistintamente para redes de agua limpia o para riego. Sin embargo, la calidad del agua para uso residencial, comercial o industria ligera difiere mucho de la del agua de riego.

Por ello, cuando en el subcomité de ISO TC/23/SC18 "Irrigation and drainage equipment and systems" se decidió redactar una norma que estableciera los requisitos mínimos de calidad que debería tener un contador para riego, desde el CENTER que lideraba este proyecto, se propuso la inclusión de un ensayo que permitiera diferenciar los contadores según su uso en función de su resistencia a las partículas sólidas. Esta norma es la ISO 16399:2014 que se adoptó como norma española en 2016 (UNE-ISO 16399:2016).

Este ensayo se ha incluido dentro de la legislación como obligatorio para los contadores de riego.

En estos momentos, la norma ISO 16399 está en proceso de revisión y es por ello que en el CENTER se están llevando a cabo numerosos ensayos con diferentes modelos y tecnologías de contadores, con el objetivo de conocer si los requisitos establecidos en la norma, relativos a la resistencia a las partículas sólidas, son adecuados o no para los equipos que hay actualmente en el mercado.

\section{Materiales y métodos}

\subsection{Equipos ensayados}

En estos momentos se están llevando a cabo un gran número de pruebas en diversos contadores de distintos modelos y tecnologías.

Las características de los equipos ensayados hasta ahora son:

Tabla 1: Contadores ensayados. Características.

\begin{tabular}{l|c|c}
\hline Tipo de contador & $\begin{array}{c}\text { Caudal permanente } \\
\left(\mathbf{Q}_{3}\right) \mathbf{~ m}^{\mathbf{3}} / \mathbf{h}\end{array}$ & $\begin{array}{c}\text { Ratio } \\
\left(\mathbf{R}=\mathbf{Q}_{3} / \mathbf{Q}_{1}\right)\end{array}$ \\
\hline Contador Woltman Eje horizontal & 100 & 200 \\
\hline Contador Woltman Eje vertical & 63 & 50 \\
\hline Contador ultrasonidos Modelo 1 & 63 & 125 \\
\hline Contador ultrasonidos Modelo 2 & 63 & 500 \\
\hline
\end{tabular}

Para cada modelo de contador se ha ensayado un mínimo de dos muestras.

Se puede observar que, además de la distinta tipología, el rango de caudales de trabajo de los equipos es completamente diferente, trabajando algunos de ellos a caudales muy bajos que no son habituales en agricultura, pero sí en agua limpia. 
 CARTAGENA 2021}

\subsection{Ensayo de resistencia a las partículas sólidas}

Este ensayo, recogido en las normas ISO 16399 e UNE-ISO 16399, permite comprobar la idoneidad o no de un contador a ser utilizado en una red de riego al someterlo al paso de agua con partículas en suspensión durante un número elevado de horas.

Aunque en el agua de riego se pueden encontrar diferentes tipos de partículas, el estandarizar este ensayo, hace que los resultados de diferentes equipos sean comparables.

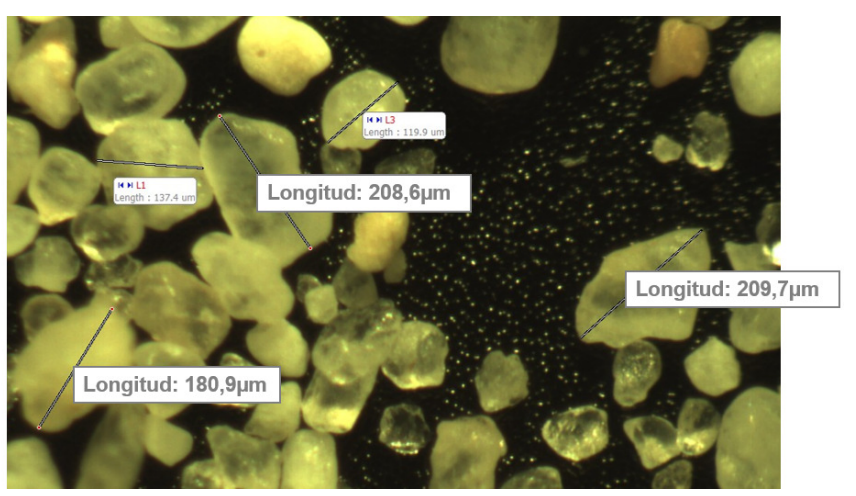

Figura 1: Partículas.

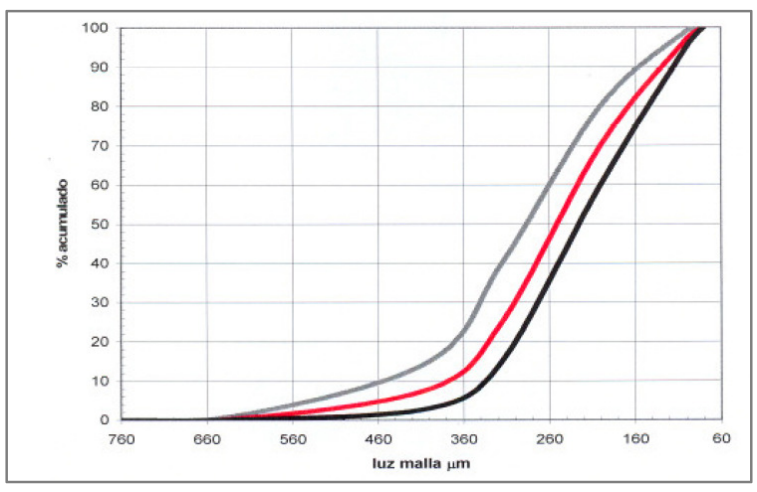

Figura 2: Distribución granulométrica.

El esquema del ensayo se muestra a continuación:

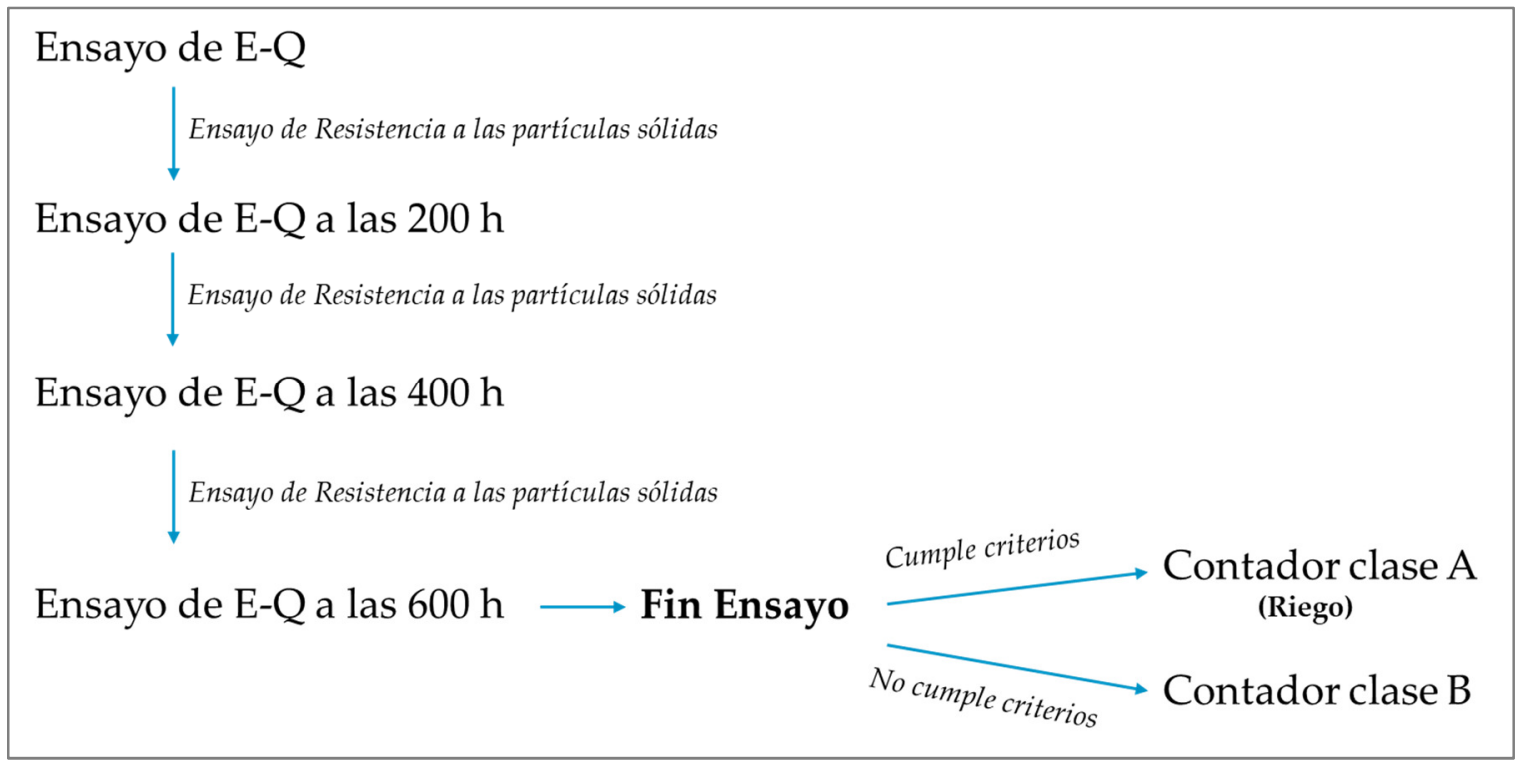

Figura 3: Esquema ensayo resistencia a las partículas sólidas.

Antes y después de cada una de las fases del ensayo de resistencia a las partículas sólidas se ha llevado a cabo la determinación de los errores (de indicación), es decir, la obtención de la curva de error en función del caudal inicial para los siguientes caudales de ensayo: 


\section{Congreso Nacional de Riegos CARTAGENA 2021}

Tabla 2: Determinación de errores (de indicación). Caudales de ensayo.

\begin{tabular}{c}
\hline ISO 16399/UNE-ISO 16399 \\
\hline $\mathrm{Q}_{1}-1,1 \mathrm{Q}_{1}$ \\
\hline $\mathrm{Q}_{2}-1,1 \mathrm{Q}_{2}$ \\
\hline $0,33\left(\mathrm{Q}_{2}+\mathrm{Q}_{3}\right)-0,37\left(\mathrm{Q}_{2}+\mathrm{Q}_{3}\right)$ \\
\hline $0,67\left(\mathrm{Q}_{2}+\mathrm{Q}_{3}\right)-0,74\left(\mathrm{Q}_{2}+\mathrm{Q}_{3}\right)$ \\
\hline $0,9 \mathrm{Q}_{3}-\mathrm{Q}_{3}$ \\
\hline $0,95 \mathrm{Q}_{4}-\mathrm{Q}_{4}$ \\
\hline
\end{tabular}

Los resultados obtenidos en esta prueba han de compararse con los errores máximos permitidos por la normativa y la legislación vigente que son:

$$
\begin{aligned}
& -\mathrm{Q}_{1} \leq \mathrm{Q}<\mathrm{Q}_{2}, \mathrm{EMP} \leq 5 \% \\
& -\mathrm{Q}_{2} \leq \mathrm{Q} \leq \mathrm{Q}_{4}, \mathrm{EMP} \leq 2 \%
\end{aligned}
$$

El error se expresa como porcentaje y equivale a:

$$
\varepsilon=\frac{\left(V_{i}-V_{a}\right)}{V_{a}} \times 100(\%)
$$

Siendo:

$$
\begin{aligned}
& \mathrm{Vi}=\text { Volumen indicado } \\
& \mathrm{Va}=\text { Volumen real }
\end{aligned}
$$

En el caso del banco del Laboratorio del CENTER, el volumen real es el indicado por las diferentes básculas, asegurando una precisión en la lectura mucho más alta que un contador o un caudalímetro patrón.

Al finalizar las $600 \mathrm{~h}$ del ensayo de resistencia a las partículas sólidas, los criterios de aceptación para la curva de error - caudal son los que se indican a continuación:

a) La variación en la curva de error no debe superar:

- $\pm 3 \%$ para caudales de la zona inferior $\left(\mathrm{Q}_{1} \leq \mathrm{Q}<\mathrm{Q}_{2}\right)$; $\mathrm{y}$

- $\pm 1,5 \%$ para caudales de la zona superior $\left(\mathrm{Q}_{2} \leq \mathrm{Q} \leq \mathrm{Q}_{4}\right)$.

Con el fin de determinar estos requisitos, se deben aplicar los valores medios de los errores en cada caudal de agua:

b) Las curvas de error no deben superar un límite de error máximo de:

- $\pm 6 \%$ para caudales de la zona inferior $\left(\mathrm{Q}_{1} \leq \mathrm{Q}<\mathrm{Q}_{2}\right)$; $\mathrm{y}$

- $\pm 2,5 \%$ para caudales de la zona superior $\left(\mathrm{Q}_{2} \leq \mathrm{Q} \leq \mathrm{Q}_{4}\right)$

\subsection{Laboratorio Central para Ensayo de Materiales y Equipos de Riego}

El Laboratorio Central para Ensayo de Materiales y Equipos de Riego, ubicado en el Centro Nacional de Tecnología de Regadíos (CENTER), órgano dependiente del Ministerio de Agricultura, Pesca y Alimentación (MAPA), dispone, entre otros, de un banco de ensayo de contadores con capacidad para realizar el ensayo de determinación de los errores (de indicación), así como un banco de durabilidad 
que permite estudiar el desgaste de los equipos con el paso del tiempo tanto con agua limpia como con agua con partículas en suspensión.

Para llevar a cabo el ensayo de resistencia a las partículas sólidas y asegurar una concentración homogénea, se dispone de cuatro agitadores que mantienen en suspensión dichas partículas.
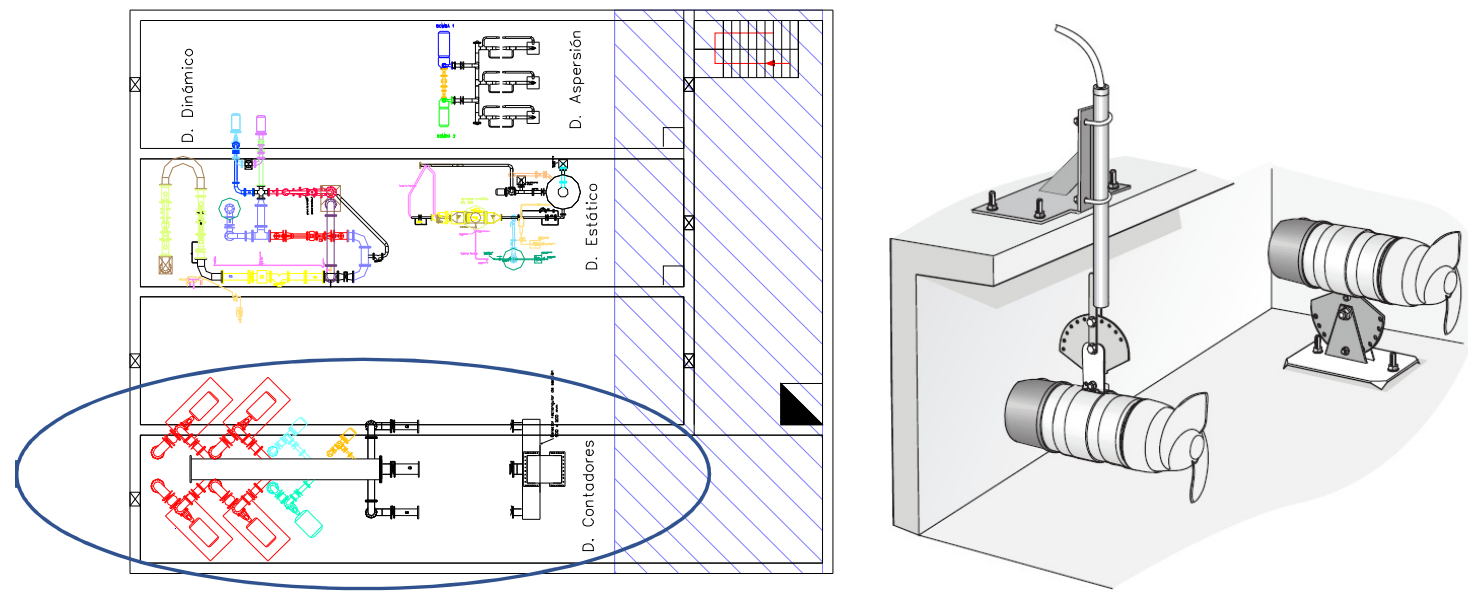

Figura 4: Banco de ensayo de resistencia a las partículas sólidas.

\section{Resultados y discusión}

\subsection{Determinación de la curva de error - caudal}

A continuación, se muestran la curva de error - caudal de una muestra de cada tipo de contador. Las líneas discontinuas rojas indican los errores máximos permitidos (EMP) marcados por la legislación vigente.

CONTADOR WOLTMAN EJE HORIZONAL

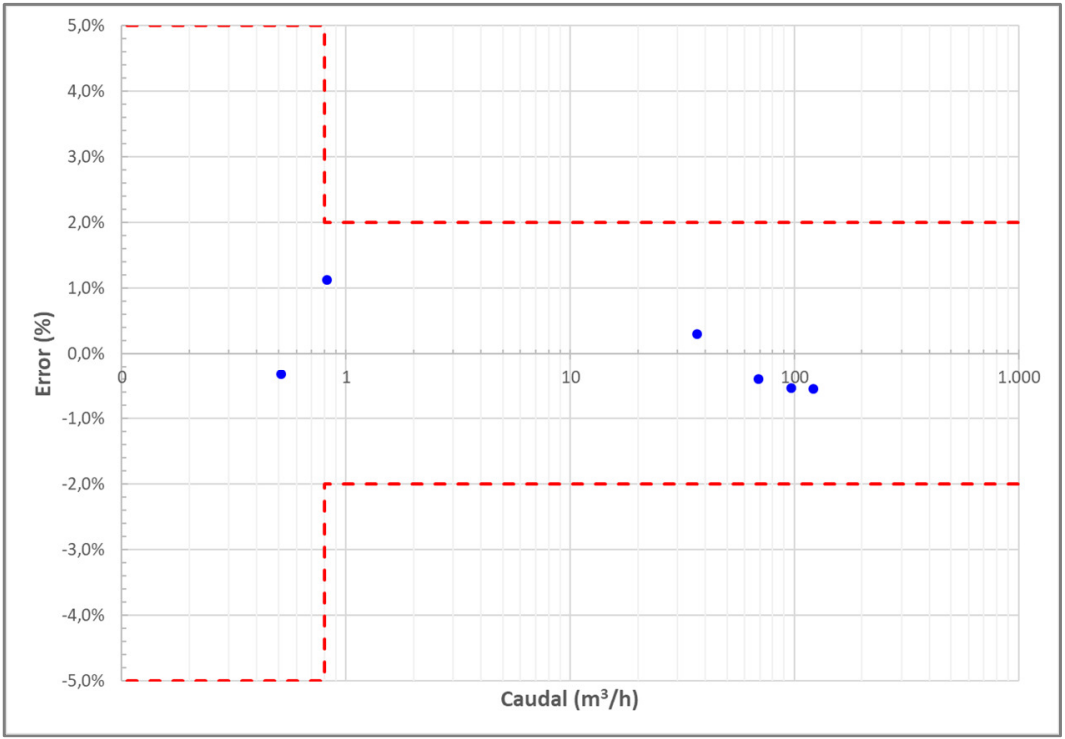

Figura 5: Curva $\mathrm{E}-\mathrm{Q}$ contador $\mathrm{Q}_{3}=100 ; \mathrm{R}=200$. 
CONTADOR WOLTMAN EJE VERTICAL

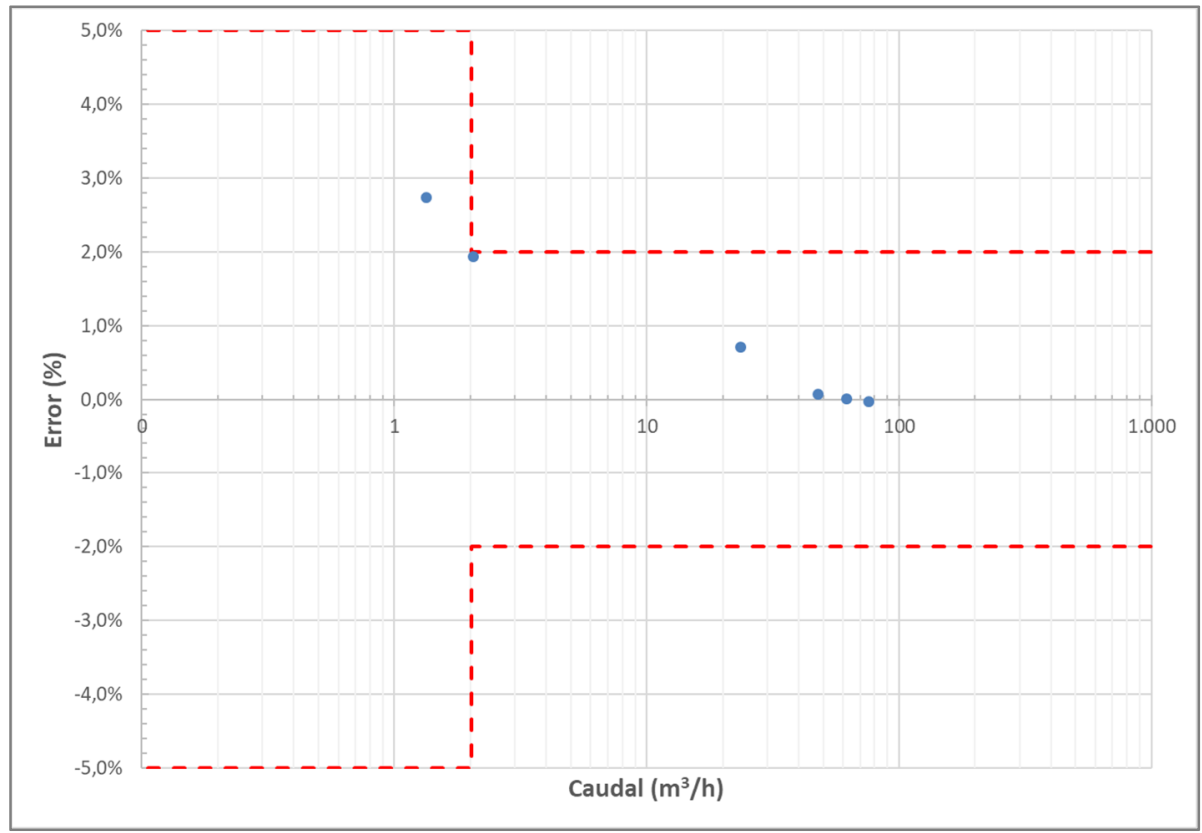

Figura 6: Curva $E-Q$ contador $Q_{3}=63 ; R=50$.

CONTADOR ULTRASONIDOS MODELO 1

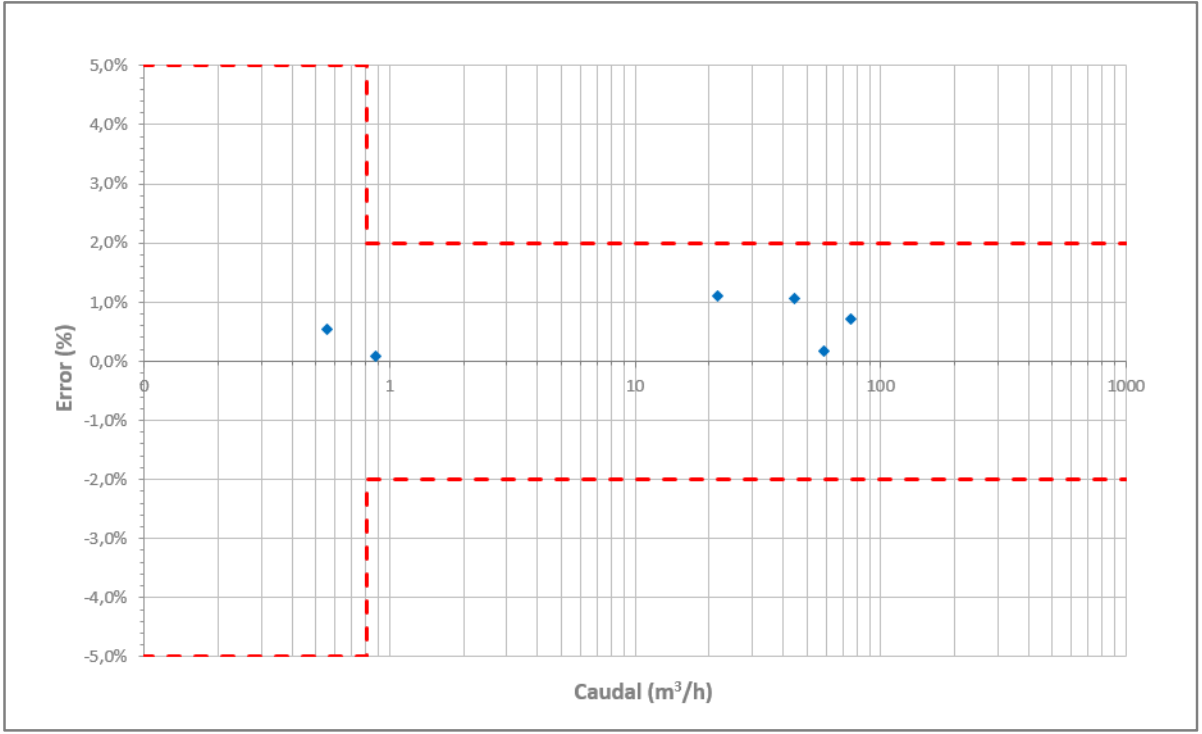

Figura 7: Curva E-Q contador $\mathrm{Q}_{3}=63 ; \mathrm{R}=125$. 


\section{Congreso Nacional de Riegos CARTAGENA 2021

\section{CONTADOR ULTRASONIDOS MODELO 2}

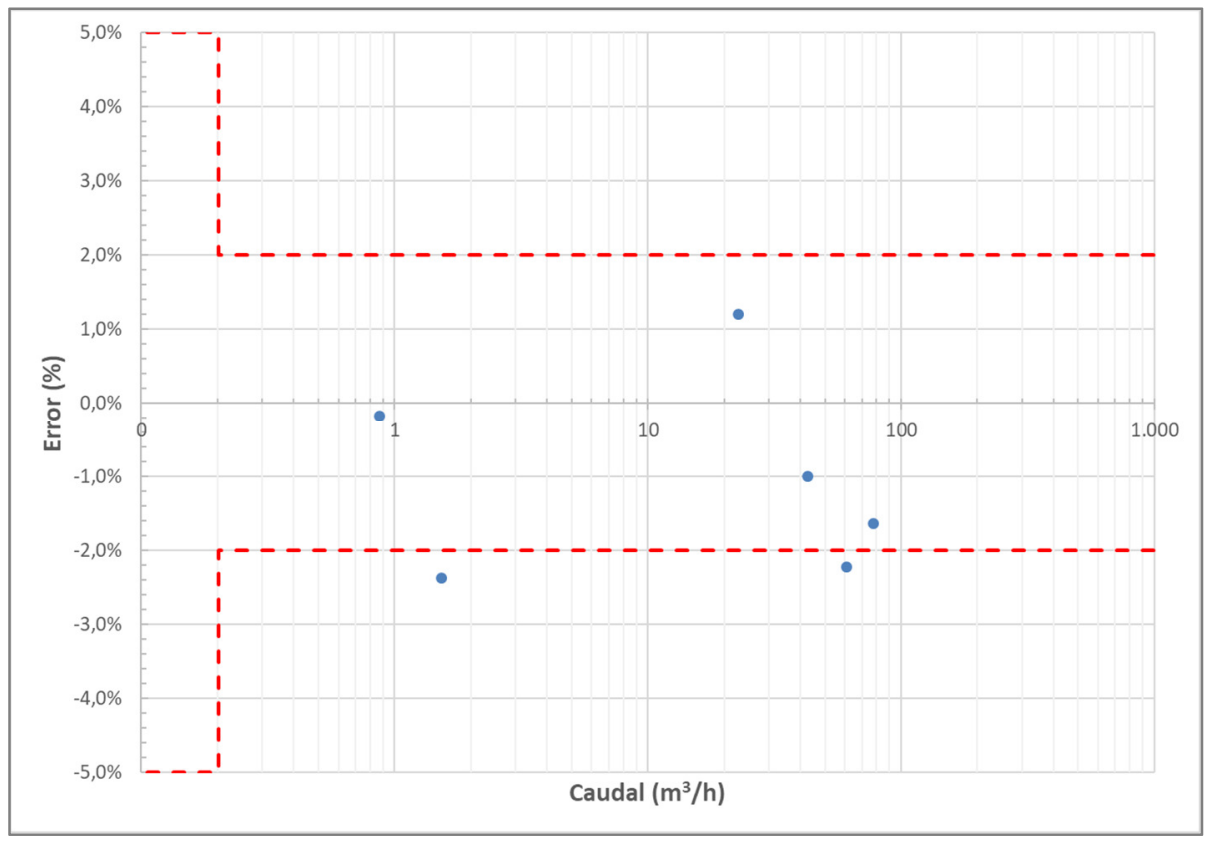

Figura 8: Curva E-Q contador $\mathrm{Q}_{3}=63 ; \mathrm{R}=500$.

En el caso de este equipo, debido a las limitaciones del banco de ensayo del laboratorio del CENTER, no se ha podido determinar el error al caudal mínimo y de transición, haciendo la prueba a un caudal superior. En cualquier caso, con los valores alcanzados en el banco, se puede estimar el comportamiento de este contador y la influencia de las partículas sólidas en su funcionamiento con el paso del tiempo.

Además, se observa que, para algunos de los caudales ensayados, el contador no cumple con los errores máximos permitidos. Sin embargo, no se realiza ningún tipo de ajuste ya que para el objetivo de este trabajo que es comprobar su comportamiento tras el ensayo de resistencia, solo influye la comparativa entre los valores iniciales y finales.

\subsection{Ensayo de resistencia a las partículas sólidas}

A continuación, y en distintas fases, todos los contadores han sido o están siendo sometidos al ensayo de resistencia a las partículas sólidas, realizando controles intermedios para controlar la evolución de la curva de error - caudal con el paso del tiempo.

En el gráfico que se muestra a continuación, correspondiente al contador tipo woltman, se indican en rojo los errores máximos permitidos en origen y, en verde, los errores máximos permitidos después del ensayo de resistencia a las partículas sólidas. 


\section{Congreso Nacional de Riegos CARTAGENA 2021

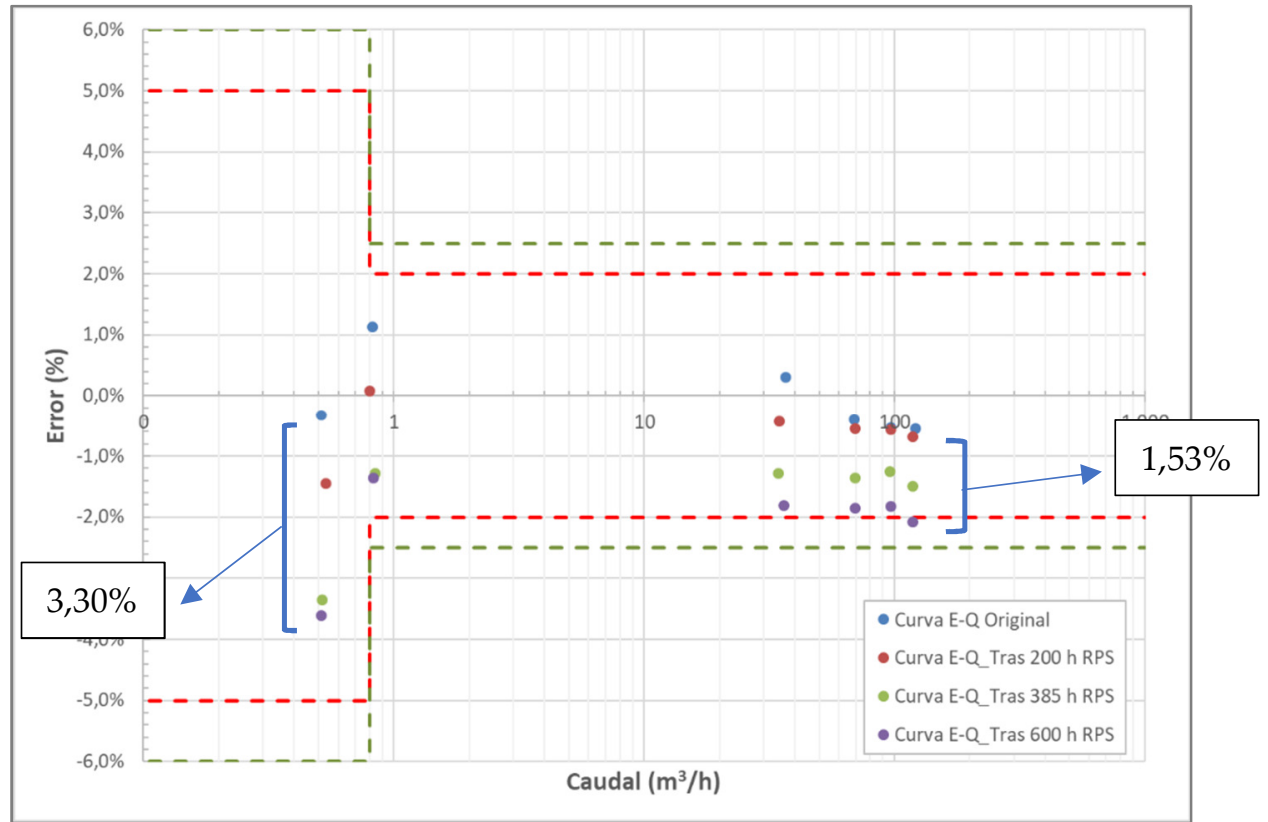

Figura 9: Curva E-Q contador $Q_{3}=100 ; R=200$ (Muestra 1). Comparativa.

Se puede observar que el contador cumple con los errores máximos permitidos, pero no cumple con los requisitos establecidos en cuanto a la variación de la curva de error, sobre todo para los caudales más bajos.

Esto mismo ocurre en las otras muestras de este modelo de contador donde también el condicionante es la variación entre la curva inicial y la curva tras el ensayo de resistencia.

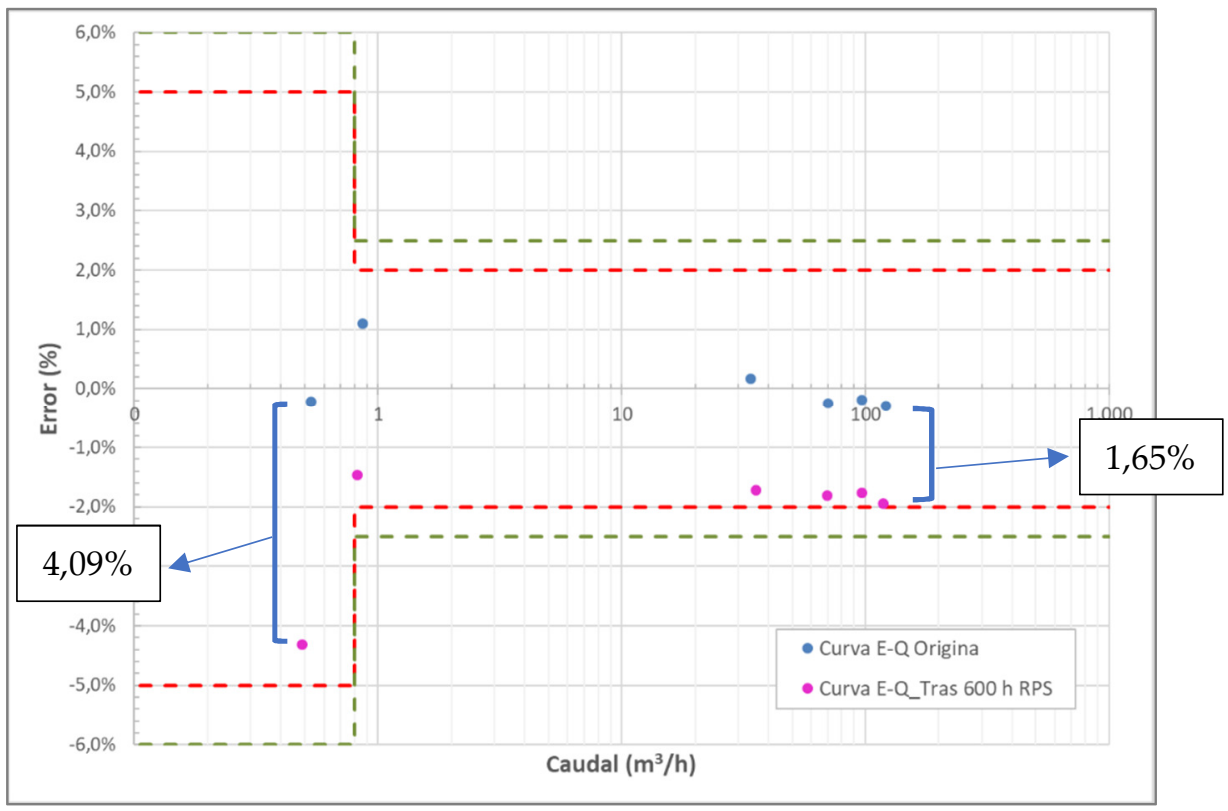

Figura 10: Curva E-Q contador $Q_{3}=100 ; R=200$ (Muestra 2). Comparativa. 
En el momento de redactar esta ponencia, el resto de contadores objeto del estudio están a falta de terminar las $600 \mathrm{~h}$ del ensayo de resistencia a las partículas sólidas por lo que los resultados se mostrarán más adelante.

\section{Conclusiones}

Aunque todavía no se ha podido terminar con todas las pruebas, los resultados obtenidos hasta el momento y la experiencia previa adquirida en el laboratorio del CENTER, permiten sacar las siguientes conclusiones:

1- Los contadores de agua, con el paso del tiempo, tienden al subcontaje, siendo el rango de caudales más bajos el más afectado en las pruebas de durabilidad tanto con agua limpia como con agua con partículas en suspensión.

2- Los rangos de caudal necesarios cuando un contador trabaja como contador de agua limpia son mucho más amplios que cuando es utilizado como contador de riego, ya que la curva de demanda suele ser mucho más variable.

El agua de riego produce mucho más desgaste que el agua limpia y, por tanto, la medición de los caudales bajos se ve afectada más rápidamente, originando que los errores de lectura superen con facilidad los errores máximos permitidos.

Todo ello lleva a plantearse la necesidad de diferenciar los contadores en función de uso.

3- La utilización de contadores en redes de riego que no son mecánicos hacen creer, a priori, que al no tener elementos móviles se verán menos afectados por el desgaste. Sin embargo, algunas tecnologías como los ultrasonidos parece que sí ven modificada considerablemente su curva de error con el paso del tiempo.

Todo esto hace necesario seguir realizando pruebas en el Laboratorio del CENTER con distintos modelos de contadores presentes en el mercado en la actualidad, con el objetivo de conocer su comportamiento y, además, comprobar si los criterios establecidos en la norma ISO 16399 han de ser revisados y adaptados a las nuevas tecnologías. 


\section{Auditorías técnicas de los sistemas de telecontrol implantados en las CCRR realizadas por el Centro Nacional de Tecnología de Regadíos (CENTER)}

Cervantes Díaz-Toledo, Alfonso ${ }^{1}$, Madurga del Cura, Cristina², Muñoz Sopeña, Daniel ${ }^{2}$, Rodríguez Fernández, Diego $^{2}$, Sánchez de Ribera González, Alejandro², Zazo Salinero, Teresa ${ }^{2}$

1 Ingeniero Técnico de Información de Gestión, TRAGSA - CENTER, acervant@tragsa.es

2 Equipo Técnico del CENTER

\section{Resumen:}

La mejora de la calidad de vida de los agricultores es uno de los objetivos fundamentales de la modernización del regadío y, por ello, se han instalado sistemas de telecontrol que permitan la aplicación de los riegos en el momento adecuado para el cultivo, el control y la gestión de toda la red en su conjunto, es imprescindible para conseguir dicho objetivo.

Estos sistemas de telecontrol funcionan perfectamente en algunas Comunidades de Regantes mientras que, en otras, diferentes motivos han ocasionado que no estén operativos al $100 \%$ o que no se estén aprovechando todas las funcionalidades para las que inicialmente fueron diseñados.

El equipo técnico del CENTER está llevando a cabo auditorías de sistemas completos de telecontrol instalados en distintas Comunidades de Regantes, comprobando in situ su funcionamiento y haciendo propuestas de reparación y mejora para asegurar su pleno rendimiento.

Estas auditorías comprenden los siguientes pasos:

1. Estudio de la documentación de proyecto y ejecución, análisis del sistema, planes de mantenimiento, etc.

2. Realización de pruebas en el laboratorio del CENTER para verificar el correcto funcionamiento de los equipos remotos instalados en la CR.

3. Pruebas en campo y análisis del funcionamiento in situ del sistema y de los diferentes equipos que lo componen.

4. Realización del informe de auditoría en base a los resultados obtenidos en las pruebas de laboratorio y de campo.

El objetivo de este trabajo es, por tanto, mostrar los resultados obtenidos en las auditorías realizadas hasta el momento, destacando la importancia de hacer un seguimiento de estos sistemas ya que, en ocasiones, pequeñas modificaciones o mantenimientos, aseguran un mejor funcionamiento y una mayor eficiencia en la aplicación de los riegos. 


\section{Norma de Interoperabilidad de los sistemas de telecontrol y su aplicación práctica en el Centro Nacional de Tecnología de Re- gadíos (CENTER)}

Cervantes Díaz-Toledo, Alfonso ${ }^{1}$, Madurga del Cura, Cristina², Muñoz Sopeña, Daniel², Rodríguez Fernández, Diego $^{2}$, Sánchez de Ribera González, Alejandro², Zazo Salinero, Teresa², Nicolae Tudorache, Adrian³ ${ }^{3}$ González Vicente, David $^{3}$

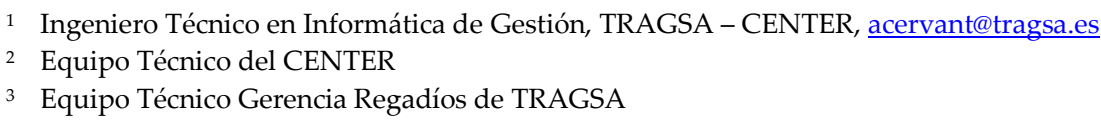

Resumen: El pasado mes de junio se publicó la norma UNE-318002-3 “Técnicas de riego. Telecontrol de zonas regables. Parte 3: Interoperabilidad", en cuya elaboración el CENTER ha participado de forma muy activa desde que en el año 2004 se comenzara a trabajar en este tema.

La interoperabilidad entre los diferentes productos destinados a la monitorización, control y gestión del regadío modernizado es un objetivo de creciente importancia debido a la heterogeneidad entre las soluciones que el mercado ofrece, sobre todo en lo referente a tecnologías y funcionalidades.

Por ello, esta norma proporciona los requisitos mínimos de estructura de datos para la transmisión de los mismos entre los diferentes equipos, dispositivos y sensores que se puedan instalar en una red de riego, aunque estos sean de diferentes empresas o utilicen softwares distintos, haciendo realidad una agricultura digital.

Parte del trabajo que conlleva la publicación de una norma es comprobar la robustez y fiabilidad de los contenidos de la misma por lo que se consideró necesario el despliegue de diferentes soluciones de mercado en una instalación de referencia. El objetivo era realizar una nueva fase de pruebas y ensayos en una instalación real al completo. Dicha instalación de referencia es la finca experimental del Centro Nacional de Tecnología de Regadíos (CENTER).

Para realizar las pruebas previstas, se han sustituido parte de las unidades remotas existentes por equipos de otros sistemas interoperables, destacando las siguientes características:

- emplean diferentes tecnologías de comunicaciones, como el GPRS y radiofrecuencia de banda libre, responden a diferentes arquitecturas, con topologías en árbol (enlaces mediante concentradoras) y en estrella (conexión directa con el software de control);

- su software de control puede estar instalado localmente o en la nube del proveedor del sistema;

El objetivo de este trabajo es mostrar la experiencia del CENTER al implantar un sistema de telecontrol interoperable y los resultados de las pruebas realizadas a lo largo de 3 campañas de riego.

Palabras clave: telecontrol, interoperabilidad, ensayos, CENTER. 


\title{
Interoperability standard for remote systems and its practical application in the National Center for Irrigation Technology (CENTER).
}

Cervantes Díaz-Toledo, Alfonso ${ }^{1}$, Madurga del Cura, Cristina ${ }^{2}$, Muñoz Sopeña, Daniel ${ }^{2}$, Rodríguez Fernández, Diego $^{2}$, Sánchez de Ribera González, Alejandro² ${ }^{2}$ Zazo Salinero, Teresa² ${ }^{2}$ Nicolae Tudorache, Adrian³ , González Vicente, David ${ }^{3}$

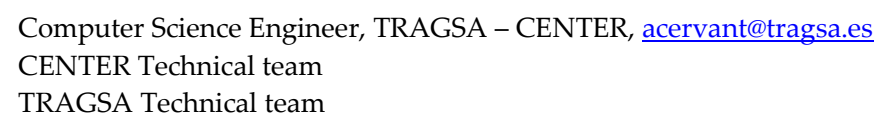

\begin{abstract}
The interoperability between the different products for the monitoring, control and management of modernized irrigation is an objective of increasing importance due to the heterogeneity between solutions that the market offers, especially with regard to technologies and functionalities.

Therefore, the standard UNE-318002-3 “Técnicas de riego. Telecontrol de zonas regables. Parte 3: Interoperabilidad" provides the minimum information structure requirements for the transmission of data between the different equipment, devices and sensors that can be installed in an irrigation network, even if they are from different companies or use different software, making it a reality a digital agriculture.

Part of the work involved in the publication of a standard is to verify the robustness and reliability of its contents, which is why it was considered necessary to deploy different market solutions in a reference facility. The objective was to carry out a new phase of test and trials in a real installation in full. This reference facility is the National Center for Irrigation Technology (CENTER).
\end{abstract}

Keywords: interoperability, remote systems, CENTER 


\section{Introducción}

Los fabricantes de sistemas de telecontrol de regadíos ofrecen soluciones diversas, sobre todo hablando de tecnologías empleadas. Dichas soluciones son cerradas para el ususario, haciéndole esclavo de su sistema.

De acuerdo con la definición de Instituto Europeo de Estándares de Telecomunicaciones (ETSI) la interoperabilidad es la capacidad de dos o más sistemas diferentes o componentes para intercambiar datos y utilizar la información intercambiada

El proyecto de interoperabilidad comenzó en el año 2008 a nivel nacional y europeo. Sin embargo, enseguida pasó a ser un proyecto internacional debido a la gran preocupación de todos los países en este tema, trabajando de forma paralela tanto en el CTN318 "Riegos" como en el ISO/TC23/SC18 "Irrigation and drainage equipment and systems". En ambos comités participan fabricantes, usuarios y diversas instituciones, públicas y privadas, que aportan sus conocimientos y permiten desarrollar una norma objetiva y útil para el sector.

En la primera fase del proyecto se definió, teóricamente, cómo abordar la interoperabilidad en el regadío. Más concretamente, en los sistemas de telecontrol, de forma que en una misma instalación pudieran convivir diferentes dispositivos.

Tras el desarrollo teórico y las comprobaciones en laboratorio y bancos de ensayo controlados, se decidió instalar en el Centro Nacional de Tecnología de Regadíos (CENTER) distintos sistemas de telecontrol interoperables y una única herramienta de gestión, con el objetivo de verificar lo indicado en la futura norma en una instalación real. Estos trabajos se han llevado a cabo durante 3 campañas de riego, desde el año 2019.

Todo ello ha permitido publicar este mismo año la norma UNE 318002-3 “Técnicas de riego. Telecontrol de zonas regables. Parte 3: Interoperabilidad" y avanzar considerablemente en el desarrollo de la futura norma internacional ISO 21622-3 "Irrigation techniques - Remote monitoring and control for irrigation - Part 3: Interoperability".

\section{Materiales y métodos}

\subsection{Finca tecnológica del Centro Nacional de Tecnología de Regadíos (CENTER)}

El CENTER es un centro de referencia en el mundo del regadío y supone el escaparate perfecto de un proyecto interoperable que ya es una realidad. La finca seleccionada se compone de cuatro redes de riego diferentes, diferenciadas por sus necesidades de presión, caudal y por el sistema de riego que emplean. El total de hidrantes de riego, compuestos por válvula y contador, asciende a sesenta y siete unidades. Además, se cuenta con otros dos puntos de control desde los que se monitorizan sensores 


\section{Congreso Nacional de Riegos CARTAGENA 2021}

que recogen propiedades relacionadas con el suelo (conductividad, humedad y temperatura) y que forman también parte de la definición del estándar.

El total de entidades de riego a controlar supone un total de setenta y cinco. Previo al inicio de las pruebas, para su control, el CENTER disponía de treinta y cuatro unidades remotas del mismo fabricante (SIGA-TRAGSA), para controlar todas estas entidades de riego.

\subsection{Unidades remotas (sistemas) interoperables instaladas}

Para realizar las pruebas previstas, se han sustituido un total de doce de las unidades remotas existentes por equipos de otros sistemas interoperables, lo que supone un treinta y cinco por ciento del total. Las nuevas remotas controlan un total de diecisiete hidrantes de riego, un veinte siete por ciento del total. Las localizaciones donde se han instalado los nuevos sistemas pueden verse en la siguiente figura. Todas las entidades de riego que no aparecen señaladas siguen estando controladas por el sistema de telecontrol original que también se ha implementado para que fuese interoperable.

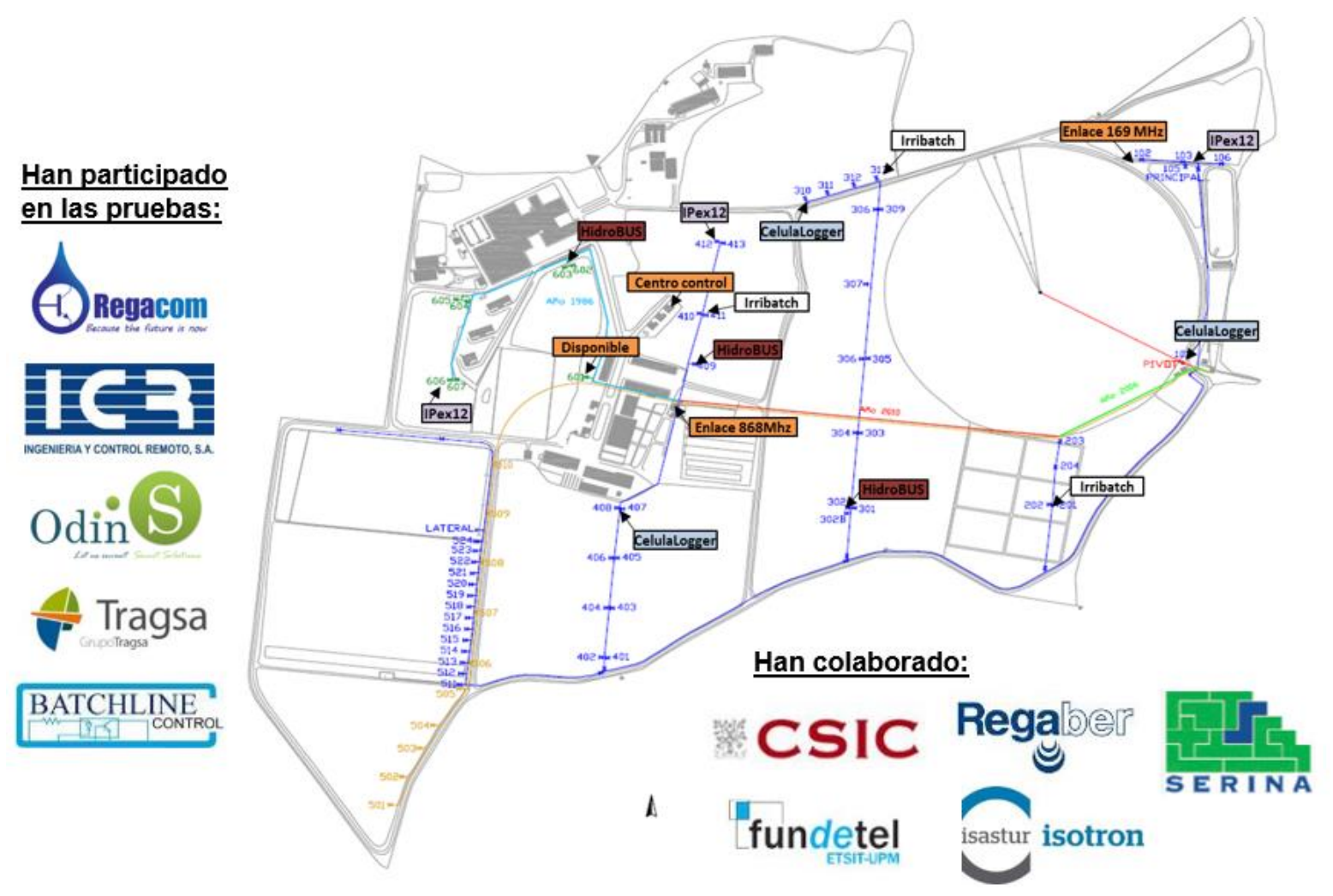

Figura 1. Despliegue de sistemas de telecontrol. 


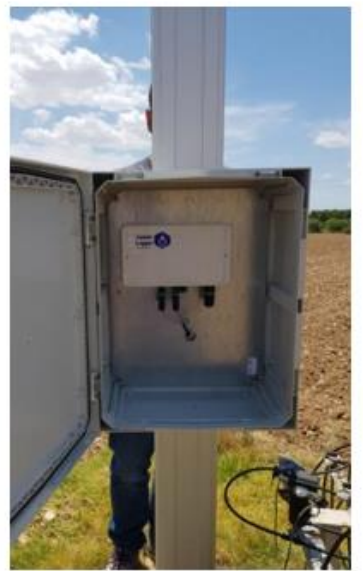

CelulaLogger

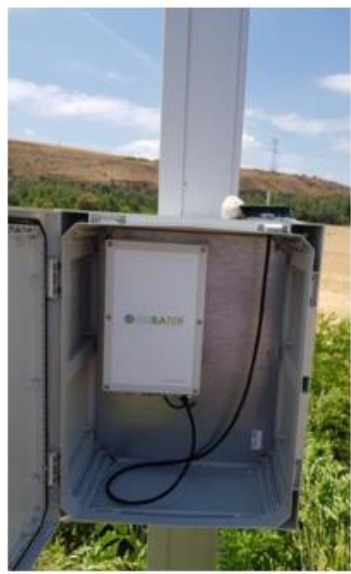

Irribatch

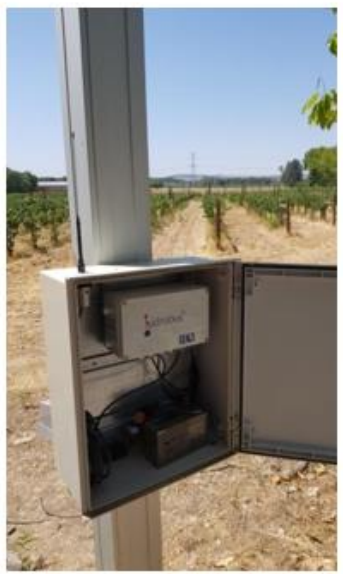

HidroBUS

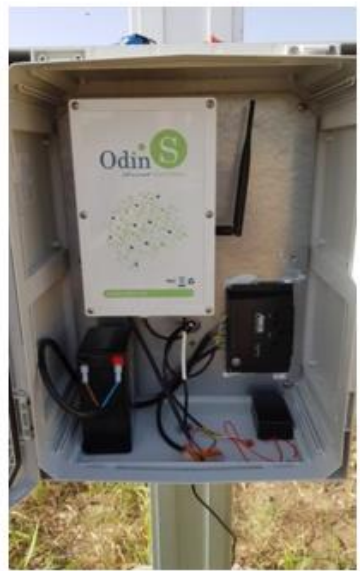

IPEx12

Figura 2. Sistemas interoperables, adicionales el existente del SIGA, instalados en el CENTER.

Tabla 1: Características de los sistemas interoperables instalados.

\begin{tabular}{l|c|c|c}
\hline \multicolumn{3}{c}{ Característcas Sistemas Interoperables } \\
\hline Sistemas & Comunicación & Arquitectura & Suministro de energía \\
\hline SIGA - Tragsa & RF 433 Mhz & Concentrador & Batería 12V 7 Ah+Panel solar 40W \\
\hline $\begin{array}{l}\text { CelulaLogger - } \\
\text { Regacom }\end{array}$ & GPRS & Directa & Pila litio o Panel solar 5W + Batería 12V \\
\hline Irribatch - Batchline & RF 869 Mhz & Concentrador & Batería 12 V 1 Ah + Panel solar 0,8 W \\
\hline Hidrobus - ICR & RF 869 Mhz & Concentrador & Batería 12V 7 Ah + Panel solar 5W o Pila \\
\hline IPEx12 - Odins & GPRS & Operador & Batería 12 V 7 Ah + Panel solar 5 W \\
\hline
\end{tabular}

Para poder ilustrar cómo beneficia la interoperabilidad en los diferentes sistemas instalados, se muestra en la tabla anterior que aún contando con diferentes tecnologías de comunicaciones (radio, GPRS), arquitecturas y sistemas de suministro de energía, no afectan a la interoperabilidad de los equipos 


\section{Congreso Nacional de Riegos CARTAGENA 2021}

\subsection{Herramientas para integración de datos y sistemas}

Para integrar los datos de todos los sistemas de telecontrol (subsistemas), se ha desplegado una herramienta de enrutamiento para realizar funciones de bróker/coordinador de mensajería en instalaciones de regadío y una herramienta de gestión para la recogida de datos e informes.

El estándar define como integrar datos de diferentes sistemas, con independencia de su origen y con mínimo impacto para el usuario. Para ello, se establecen las siguientes fronteras y niveles.

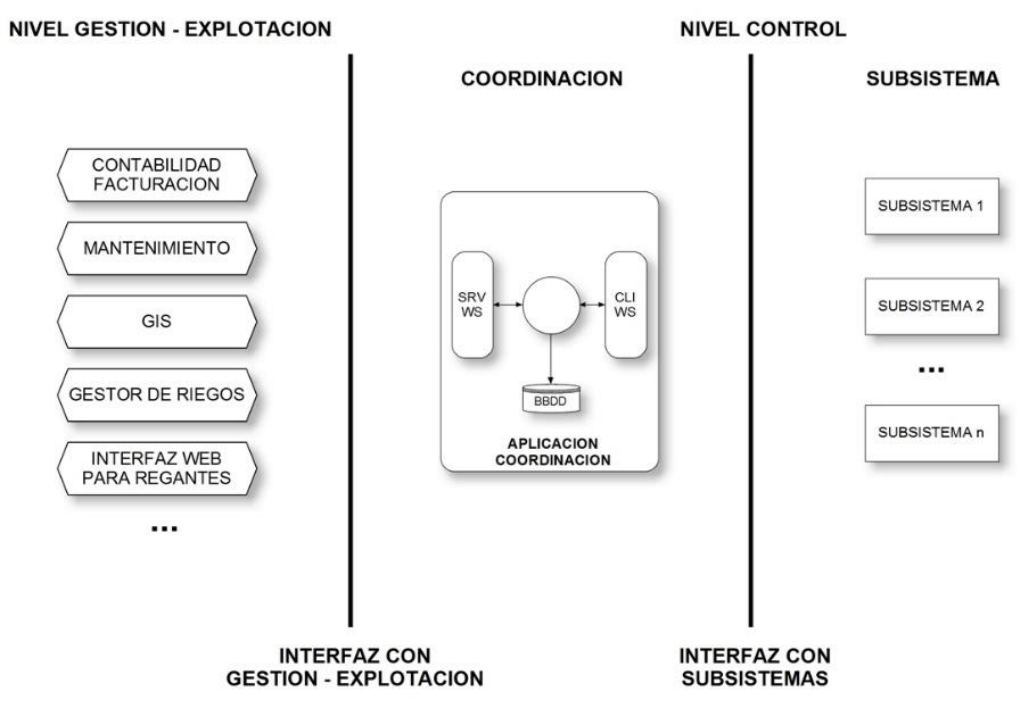

Figura 3. Arquitectura interoperable en el estándar.

\subsubsection{Bróker de coordinación}

Un bróker de mensajería es un mecanismo mediador de comunicación entre aplicaciones, que minimiza el grado de conocimiento mutuo entre aplicaciones para poder intercambiar mensajes, permitiendo su desacoplamiento. En el estándar de interoperabilidad esta herramienta recibe el nombre de bróker de coordinación.

¿Cómo funciona y cuáles son las funciones del bróker de coordinación?

El bróker de coordinación es un elemento software que proporciona interoperabilidad entre los sistemas de control y los sistemas de gestión, realizando las siguientes funciones básicas:

1. Mapeado de las entidades hidráulicas y asociación de éstas con los subsistemas que las controlan.

2. Enrutar las peticiones (lecturas, escrituras, programas de riego).

3. Transformar las peticiones al protocolo que soporte el destinatario. 


\section{Congreso Nacional de Riegos CARTAGENA 2021}

4. Recoger las respuestas y devolvérselas al emisor, transformándolas si es necesario.

5. Guardar información de las entidades de riego (identificación, localización, datos de diseño, datos para comunicar).

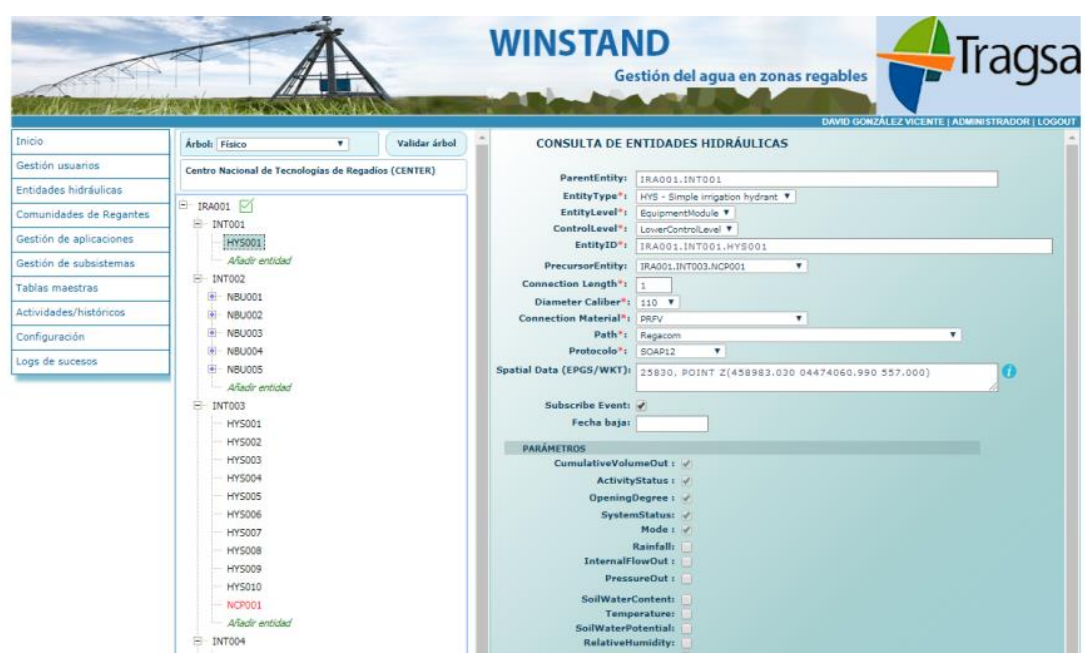

Figura 4. Interfaz de coordinación desarrollada.

En la norma se indica una definicion genérica no vinculada a ninguna tecnología concreta, pero para poder ponerlo en práctica, se han utilizado dos de las tecnologías actuales existentes como son SOAP y REST. REST es un lenguaje muy empleado en el mundo IoT. En el standard existe la documentación necesaria para que cualquier empresa interesada, pueda desarrollar su propio coordinador.

\subsection{Herramienta de gestión}

Para finalizar, el despliegue se completa con una herramienta de gestión utilizada a día de hoy en diferentes Comunidades de Regantes. Dicha herramienta se emplea para:

- Monitorizar el estado y recoger datos (valores de propiedades) de todos los hidrantes de la finca, así como de los puntos de control existentes.

- Enviar diferentes tipos de programa de riego.

- Monitorizar el resultado de los programas de riego ejecutados, revisando su duración, condición de finalización y consumo de agua asociado. 


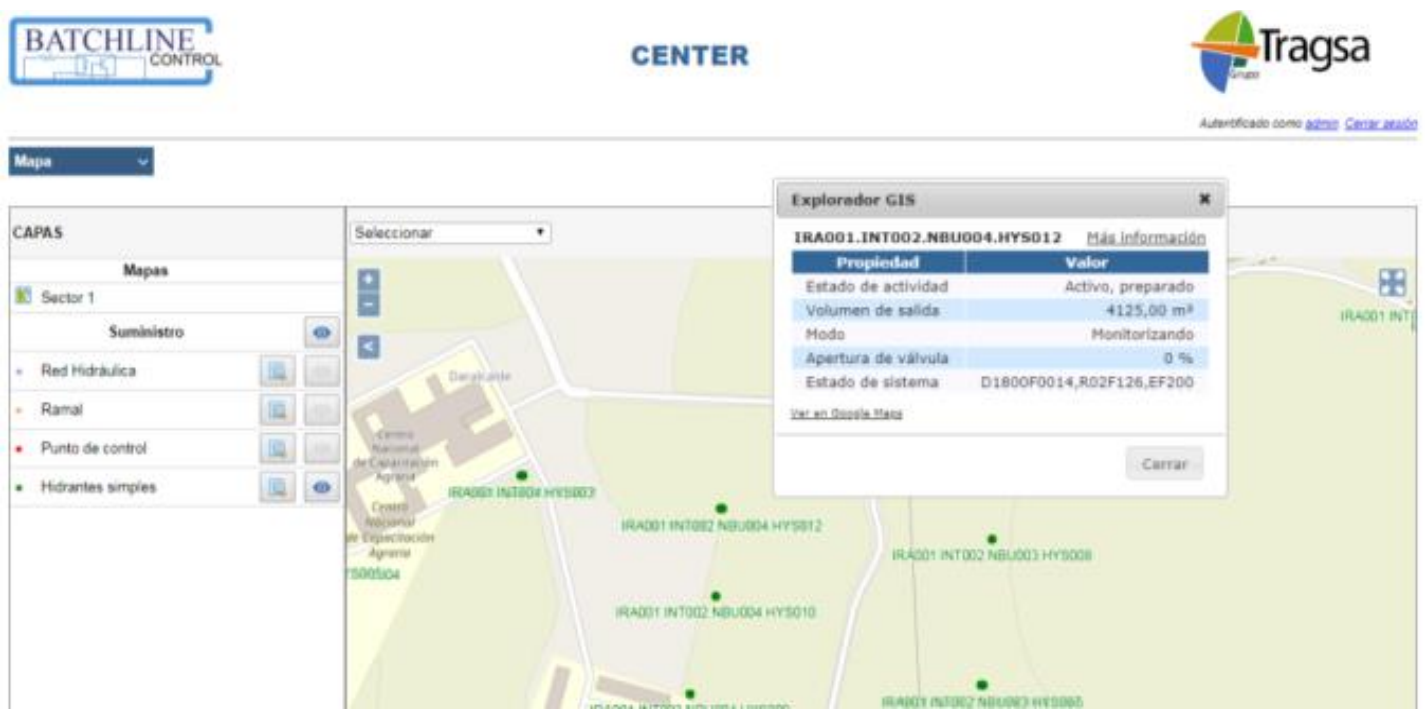

Figura 5. Aplicación de gestión implementada.

El desarrollo a nivel de software de esta aplicación lo realizó Batchline, pero al igual que sucede con el coordinador, cualquier empresa puede adaptar su producto a la norma interoperable.

\section{Resultados y discusión}

El calendario de pruebas se inició en junio de 2019, después la instalación de los nuevos equipos de control y todas las herramientas informáticos descritas. La primera campaña de riego finalizó a inicios del mes de noviembre. Para los dos años posteriores, se establecieron las mismas fechas como inicio y fin para el tiempo de estudio.

Dentro del primer año, se consideró la primera quincena como periodo de adaptación y ajuste de los despliegues. Los meses de noviembre no forman parte de la fase de estudio al ser un período poco representativo debido a la baja actividad de riego en ese tiempo. Así pues, los meses representativos para el estudio han sido los cuatro meses centrales de cada año teniendo en cuenta tres prioridades:

- Primera: responder a las necesidades de gestión del CENTER, cuyos aspectos centrales son el envío de programas de riego, monitorización y la recepción de informes de los datos obtenidos.

- Segunda: ensayar todas las posibilidades de intercambio en aquellos sistemas que lo soporten. Adicionalmente a las mencionadas en el punto anterior, el estándar incluye otras que son relevantes para la gestión del riego, destacando la sincronización de contadores, el paro o la cancelación de programas en ejecución. También se realizan pruebas relacionadas con las entidades de riego como son el alta y baja de entidades de riego.

- Tercera: desarrollar el mayor número posible de pruebas. Cubriendo las necesidades básicas reflejadas en las prioridades anteriores, se intenta realizar el mayor número posible de pruebas para asegurar que los resultados obtenidos son significativos. 


\section{Congreso Nacional de Riegos CARTAGENA 2021}

- Cuarta: realizar pruebas de fiabilidad en todos los componentes desplegados. Para ello, se emplean las peticiones masivas para el refresco de los datos, soportados por la herramienta de gestión. La prioridad es comprobar la estabilidad de los diferentes elementos al lanzarles una cantidad importante de peticiones.

Durante las tres campañas de riego se ha hecho un seguimiento de todas las pruebas realizadas, mostrándose a continuación, un resumen de los resultados generales del 2019 que son los más representativos al ser el primer año.

Tabla 2: Peticiones tramitadas.

\begin{tabular}{l|c|c}
\hline \multicolumn{3}{c}{ Peticiones tramitadas } \\
\hline Peticiones tramitadas & 2507 & \\
\hline Resultado 1: éxito & 1785 & $71,2 \%$ \\
\hline Resultado 2: éxito parcial & 574 & $22,9 \%$ \\
\hline Resultado 3: fallo & 148 & $5,9 \%$ \\
\hline
\end{tabular}

A efectos de interoperabilidad, tanto los resultados de tipo 1 como los de tipo 2 (éxito y éxito parcial), se consideran satisfactorios. Por ello, se puede concluir que la interoperabilidad ha funcionado correctamente en el 94,1\% durante el periodo de pruebas.

Tomando como referencia los cuatro meses de mayor actividad, principalmente el verano, el porcentaje medio de fallo en 2019 es del 5,9\% (148 errores sobre 2507 peticiones tramitadas), si bien se observa una tendencia a la baja en el porcentaje de errores registrados en los siguientes años reduciendose a un 5,5\% en el 2020 y a un 5,3\% en el 2021 Ha de tenerse en cuenta que dentro de los errores incluidos en el resultado 3 , se incluyen sólo aquellos que no han sido generados por pruebas erróneas y que son debidos a:

- Fallos de comunicaciones: cuando las peticiones no se tramitan correctamente;

- Fallo específico de comunicaciones por timeout: cuando las peticiones realizadas no reciben respuesta en el tiempo estipulado por el emisor, asimilándose a un error de interfaz interoperable;

- Problemas de seguridad: cuando uno de los componentes interoperables bloquea la tramitación de peticiones debido a criterios de seguridad informática (autenticación, direccionamiento, etcétera), asimilándose a un error de interfaz interoperable;

- Errores de implementación: cuando la interfaz interoperable ha funcionado correctamente pero el destinatario no interpreta correctamente una petición bien formulada.

La distribución concreta que se ha producido por tipos de error se muestra en la tabla siguiente: 


\section{Congreso Nacional de Riegos CARTAGENA 2021}

Tabla 3: Clasificación de errores.

\begin{tabular}{l|c|c}
\hline \multicolumn{3}{c}{ Clasificación de errores } \\
\hline Total de errores & 148 & \\
\hline Fallo de comunicación y Timeout & 33 & $22,3 \%$ \\
\hline Problema de seguridad & 34 & $23,0 \%$ \\
\hline Errores de implementación & 81 & $54,7 \%$ \\
\hline
\end{tabular}

\section{Conclusiones}

Tras tres campañas de riego utilizando herramientas y sistemas interoperables que han hecho posible la monitorización de los parámetros básicos del riego, como son las presiones y volúmenes suministrados, la ejecución, con éxito, de numerosos programas de riego, la recogida de sus informes, la sincronización de contadores y la recogida de datos históricos, entre otras funcionalidades, se pueden sacar las siguientes conclusiones:

1- En una red de riego real se puede implementar un sistema de telecontrol totalmente interoperable, no sólo en instalaciones nuevas sino también en sistemas que ya están en funcionamiento.

2- La interoperabilidad favorece el desligamiento entre usuarios y fabricantes de sistemas de telecontrol, permitiendo la elección de la mejor solución, fomentando la competitividad y mejora de los productos ofertados, además de la apertura del mercado de prestación de servicios de explotación y mantenimiento, reducción del abandono de los sistemas y ptenciación del uso de las informaciones que de ellos se puede extraer.

3- Los sistemas interoperables facilitan el manejo y la gestión al usuario ya que podrá adquirir datos de diferentes sistemas de control en una única herramienta de gestión, favoreciendo la toma de decisiones y el control de su instalación.

4- Los fabricantes de telecontrol también se verán beneficiados al poder incluir una funcionalidad que ofrece muchas posibilidad a los usuarios.

5- Tanto la norma UNE 318002-3 “Técnicas de riego. Telecontrol de zonas regables. Parte 3: Interoperabilidad" ya publicada, como la futura norma internacional ISO 21622-3 "Irrigation techniques - Remote monitoring and control for irrigation - Part 3: Interoperability" establecen los requisitos mínimos que debe cumplir un sistema para ser interoperable pero no obligan a los fabricantes a modificar su hardware o su software de control. Únicamente se solicita una capa intermedia que sea capaz de traducir sus mensajes para que sean entendibles por la aplicación de coordinación.

Acabada la fase de desarrollo y pruebas y una vez publicada la norma, se emplaza a los fabricantes de sistemas de telecontrol y a los desarrolladores de herramientas de gestión a implementar el estándar en sus productos. Del mismo modo, se emplaza también a los promotores y proyectistas a tener en cuenta criterios de interoperabilidad en la fase de diseño y desarrollo de proyectos relacionados con el control y la gestión de instalaciones de regadío. 


\title{
Nuevo enfoque en metodología de transferencia en los regadíos.
}

\author{
Jarén Morilla $C^{1}$, Salvatierra Bellido $B^{1}$, López Rodríguez $\mathbf{M}^{1}$
}

\begin{abstract}
Instituto de Investigación y Formación Agraria de Andalucía, Rancho de la Merced (IFAPA, sede Chipiona-Cádiz); cristina.jaren@juntadeandalucia.es, benito.salvatierra@juntadeandalucia.es, manuel.lopez.rodriguez@juntadeandalucia.es
\end{abstract}

Resumen: La transferencia de tecnología de forma amplia se suele enunciar como el proceso por el que se transfieren habilidades, conocimientos, formas de hacer, instrumentos... Con una conceptualización industrial, la transferencia de tecnología se dibuja como un proceso cuasi lineal desde los centros de conocimiento (universidades,...), donde algo que se descubre, que puede tener una utilidad, es introducido/vendido en un sector determinado. Muchas veces sin tener claro que esa nueva utilidad sea realmente la respuesta a una necesidad. El modelo simple sería "tengo un útil, ¿cómo vendo esto?".

Esta forma de realizar la transferencia ha hecho que, en muchos casos, el objeto de dicha transferencia no sea muy proclive a seguir las recomendaciones/transferencia que se les proponen. El sector agrario cada vez tiene menos peso en la economía y trabajo de los países desarrollados. En dicho sector, las innovaciones no aparecen con la celeridad que se produce en otros sectores, de ahí su desfase. Pero al mismo tiempo, cada vez más, juega un papel muy importante en las nuevas demandas de la sociedad como el medio ambiente y el cambio climático.

Los organismos de transferencia agro-alimentaria han realizado su labor con un modelo similar al de las industrias clásicas. En este trabajo se propone y se pone en práctica una metodología de transferencia que va más allá de las bondades del modelo de abajo a arriba donde el agricultor es el eje principal de la acción) utilizado en los últimos tiempos, se emplea además una visión desde lo general a lo concreto y se suman elementos de más horizontalidad analizando/integrando diversos aspectos que al final inciden en la rentabilidad y sostenibilidad de la explotación.

Para ello, se ha puesto el foco en una zona regable, el sector B-XII en Lebrija y se han unido cuatro proyectos que trataban partes aparentemente individuales para hacer un enfoque común de los mismos sin perder el trabajo de lo concreto pero desde una óptica que se inicia en lo general. Los proyectos han sido sobre riego, nitratos, suelos y teledetección. Al mismo tiempo, se han realizado convenios de colaboración con cooperativas, la comunidad de regantes y agricultores a los que se les ha realizado una monitorización de sus labores.

Este tipo de trabajo permite calar con mayor celeridad en los "modus operandi" de los técnicos y posteriormente de los agricultores con un mensaje claro donde el objetivo es mejorar la rentabilidad (entendida en un sentido amplio económica, social y ambiental) de la explotación.

Palabras clave: Transferencia; riego; horizontalidad; integración. 


\title{
Nuevo enfoque en metodología de transferencia en los regadíos.
}

\author{
Jarén Morilla $C^{1}$, Salvatierra Bellido $\mathbf{B}^{1}$, López Rodríguez $\mathbf{M}^{1}$
}

Instituto de Investigación y Formación Agraria de Andalucía, Rancho de la Merced (IFAPA, sede Chipiona-Cádiz); cristina.jaren@juntadeandalucia.es, benito.salvatierra@juntadeandalucia.es, manuel.lopez.rodriguez@juntadeandalucia.es

Abstract: The transfer of technology in a broad way is usually enunciated as the process by which skills, knowledge, ways of doing, instruments are transferred ... With an industrial conceptualization, technology transfer is drawn as a quasi-linear process from knowledge centers ( universities,...), where something that is discovered, that may have a utility, is introduced / sold in a certain sector. Many times without being clear that this new utility is really the answer to a need. The simple model would be "I have a tool, how do I sell this?".

This way of carrying out the transfer has meant that, in many cases, the object of said transfer is not very inclined to follow the recommendations / transfer that are proposed to them. The agricultural sector has less and less weight in the economy and work of developed countries. In this sector, innovations do not appear with the speed that occurs in other sectors, hence their lag. But at the same time, increasingly, it plays a very important role in the new demands of society such as the environment and climate change.

Agro-food transfer agencies have carried out their work with a model similar to that of classical industries. In this work, a transfer methodology is proposed and put into practice that goes beyond the benefits of the bottom-up model where the farmer is the main axis of action) used in recent times, a vision is also used from the general to the concrete and elements of more horizontality are added analyzing / integrating various aspects that ultimately affect the profitability and sustainability of the exploitation.

For this, the focus has been placed on an irrigable area, the B-XII sector in Lebrija and four projects that dealt with apparently individual parts have been joined to make a common approach to them without losing the work of the concrete but from a perspective that starts in general. The projects have been on irrigation, nitrates, soils and remote sensing. At the same time, collaboration agreements have been made with cooperatives, the community of irrigators and farmers who have been monitored for their work.

This type of work allows to penetrate more quickly the "modus operandi" of the technicians and later of the farmers with a clear message where the objective is to improve the profitability (understood in a broad economic, social and environmental sense) of the exploitation.

Keywords: Transferencia; riego; horizontalidad; integración. 


\section{Congreso Nacional de Riegos CARTAGENA 2021}

\section{Introducción.}

En el punto actual donde disponemos de mucha tecnología, la eficiencia en la aplicación de insumos, agua de riego (necesidades de la planta para su normal desarrollo/agua utilizada), fertilizantes y fitosanitarios es aún muy baja en término medio.

Los modelos de transferencia tradicionalmente se han desarrollado a partir de experiencias aisladas, en parcelas pequeñas o individuos no muy representativos de lo que se quería difundir (más si es una nueva forma de hacer). Normalmente, los individuos objeto tienen muy poca confianza, bien porque no se transmite adecuadamente o bien por la precariedad que genera la parcialidad de muchas experiencia.

Actualmente se disponen de herramientas que hacen posible un análisis global de amplias zonas que ayudan en la estrategia para introducir una tecnología.

En el B-XII con 14.643 has y 1.143 [1]parcelas se desarrolla una agricultura muy puntera donde se suceden a lo largo del año, cultivos hortícolas de consumo directo, tomate industrial, algodón, cereales,... con unos problemas de homogeneidad de producción, uso de insumos, cantidad de agua y de impacto ambiental, muy comunes todos en las zonas regables del Guadalquivir.

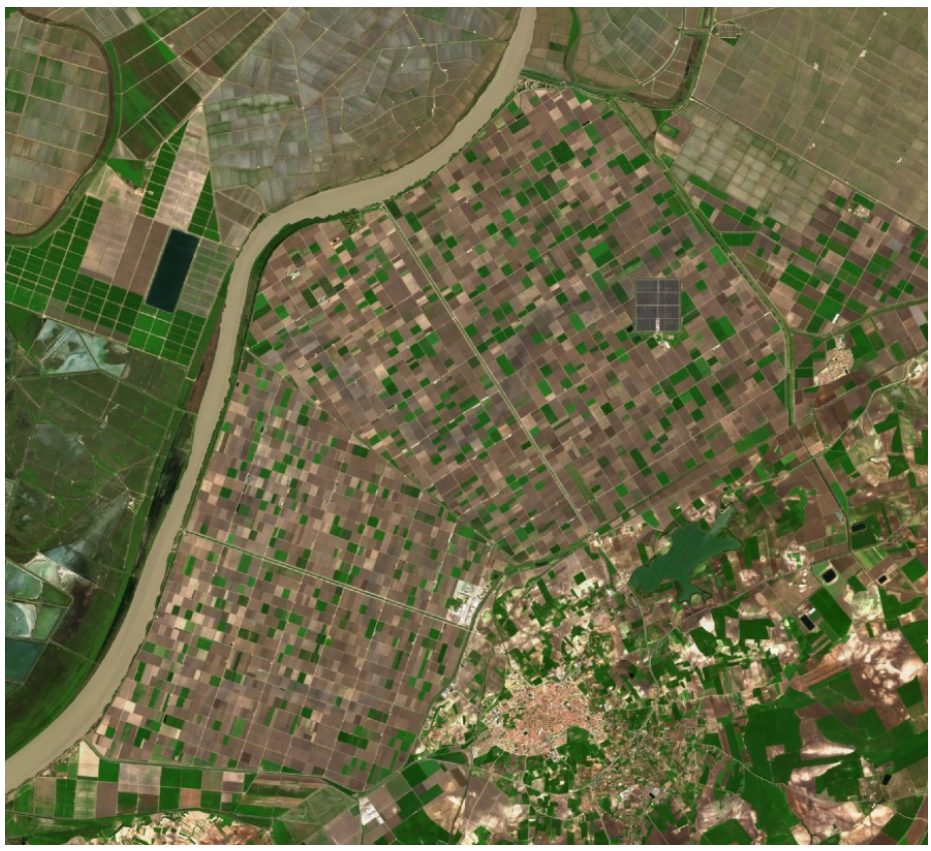

Figura 1. Imagen satélite de la zona regable sector B-XII.

Atendiendo a al Real Decreto 261/1996, de 16 febrero,[2] sobre protección de las aguas contra la contaminación producida por los nitratos procedentes de fuentes agrarias, esta zona, además sufrir episodios de restricciones de agua, en 2020, en dicho sector por pertenecer a unas de las zonas indicadas, se decide realizar un ensayo en una parcela de tomate de industria en el cual se establecen cuatro tratamientos experimentales [3]. Dichos tratamientos son el resultado de combinar 
un manejo sostenible cuyas pautas establecía el IFAPA y otro convencional bajo las indicaciones del propio agricultor coincidiendo en el manejo tradicional que el ejercía sobre sus parcelas.

De este dicho ensayo surgieron conclusiones muy interesantes que establecen el punto de partida del presente trabajo. Dichas conclusiones quedan relegadas a las características del ensayo en cuanto a superficie, dando lugar igualmente a la incógnita de la similitud de dichos resultados en condiciones más reales en cuanto a dicha superficie de cultivo se refiere.

Por todo ello, el objetivo pasó a ser el de realizar un diagnóstico de la zona y cambiar formas de operar con la fertirrigación para lograr mejoras económicas y ambientales en el desarrollo de la zona regable.

De esta forma, recogeríamos los diferentes escenarios en cuanto a riego y fertirrigación se refiere llevados a cabo en la zona para poder así extrapolar las conclusiones a escenarios reales de cultivo.

La metodología que se propone es fruto de aunar las herramientas y recursos que disponemos para poderlo fundir en una única visión generalizada de los cultivos en su escenario cotidiano.

En los últimos años, el equipo de trabajo del IFAPA Rancho de la Merced, ha estado realizando trabajos tendentes a mejorar la eficiencia del riego y de disminución del impacto del abonado en el medio, así como trabajos sobre el comportamiento de los suelos y más recientemente de teledetección (dron y satélites). A pesar de que los resultados obtenidos son muy prometedores y en algunos casos corroboran resultados ya muy antiguos, la realidad al analizar la zona elegida es que la eficiencia del riego es muy baja y el impacto en el uso de insumos es muy elevado en general.

Conscientes de esta realidad, en el último año se plantea una nueva metodología que pretende abordar el agrosistema del B-XII de forma global, tal cual es, y movilizando al mayor número de técnicos y agricultores que permitan la difusión de los resultados obtenidos con unas mayores posibilidades de éxitos y adelantándonos a un cambio en las formas de hacer que hagan del agrosistema B-XII un ejemplo de buen hacer en la agricultura sin por ello renunciar a la rentabilidad que como buenos agentes económicos los agricultores pretenden.

Así, el objetivo que planteamos con este nuevo enfoque es acelerar la transferencia de tecnología en el sector agrícola.

\section{Materiales y métodos.}

Para poder llevar a cabo el objetivo propuesto, el IFAPA Rancho de la Merced sede de Chipiona, ha hecho uso de herramientas de colaboración como son los convenios con empresas y los seminarios de discusión [4]para poder realizar la recopilación de información de primera mano como puede ser la de los propios técnicos encargados de las parcelas elegidas, que, a su vez, están en permanente contacto con los agricultores.

Dichas colaboraciones han tenido lugar mediante un convenio de colaboración con COALSA (agrupación de cooperativas algodoneras), Comunidad de Regantes Sector BXII y cooperativa Las Marismas de Lebrija S.C.A. Con esta última se ha realizado el seminario de discusión.

Además, se ha utilizado como material de apoyo el uso de programas de software libre como es Qgis donde se puede volcar la información recogida por imágenes satelitales, vuelos de dron y otras fuentes de información que se pueden obtener de manera gratuita y que complementan la visión 


\section{Congreso Nacional de Riegos CARTAGENA 2021}

global que queremos obtener de las parcelas. El uso de drones para el control de pequeñas parcelas demostrativas ofrece unas imágenes con una resolución óptima en comparación con las proporcionadas por los satélites que la captan a un tamaño de pixel más grande y por lo tanto la información que aportan es de menor exactitud.

Se decide trabajar con los cultivos de algodón y tomate de industria por tratarse de los más representativos de la zona.

La metodología llevada a cabo con todo lo mencionado anteriormente se detalla en el siguiente esquema:

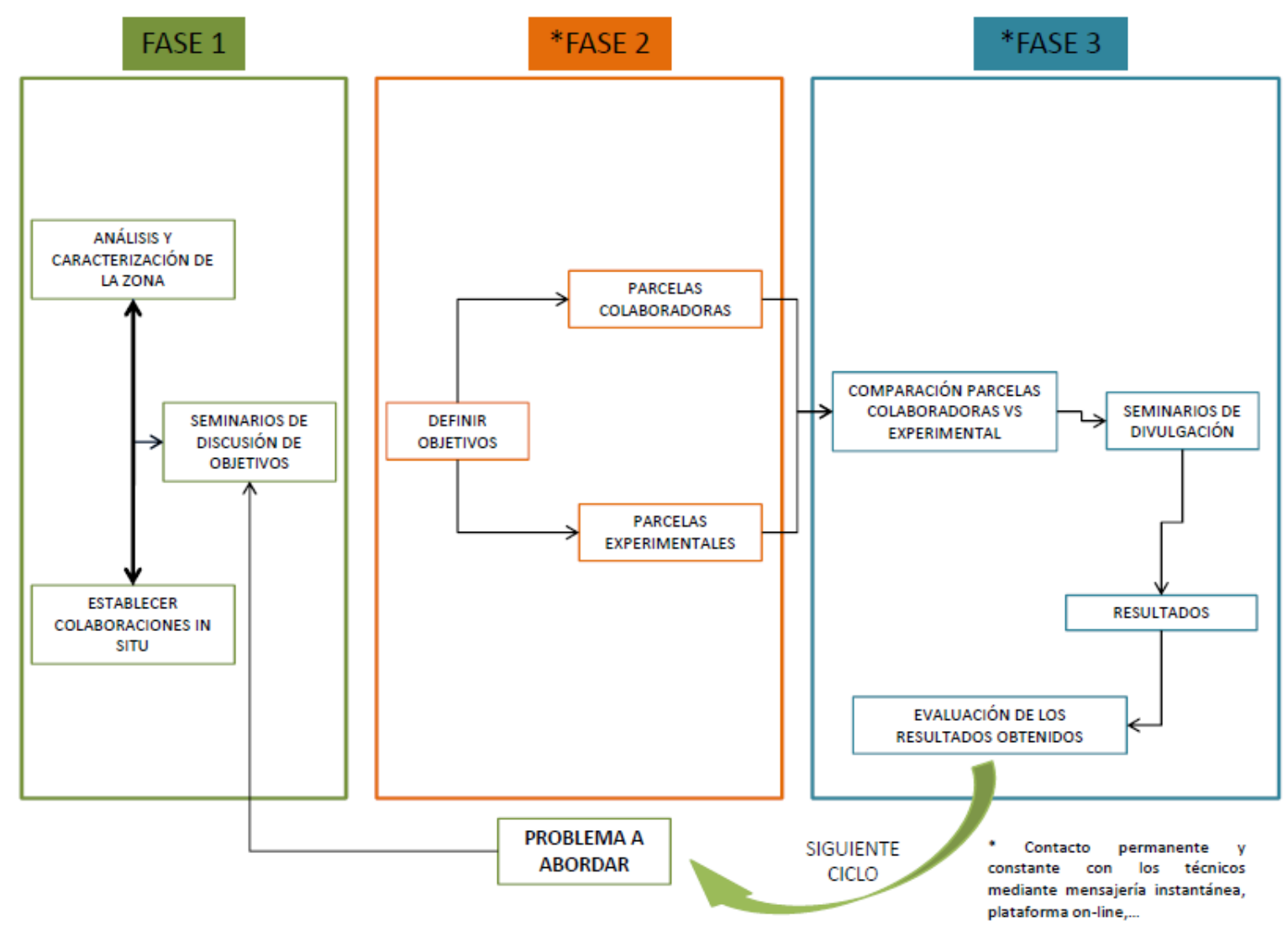

Figura 2. Esquema de la metodología empleada.

Se trata de reuniones mensuales donde se establece contacto directo con los técnicos que están a pie de campo de las parcelas colaboradoras elegidas en los convenios. En estos encuentros se revisa la información recopilada y se muestran observaciones que hasta la fecha se han ido realizando de manera general. También se resuelven dudas planteadas y se dan nociones acerca del manejo del riego y de la fertirrigación en base a la información recopilada.

Todo ello va apoyado en herramientas informáticas como es el uso de un espacio de trabajo online común, pero a la vez privado para cada técnico donde se puede incorporar la información requerida y realizar comentarios exclusivos y concretos para cada parcela. A su vez, se incorpora a 
cada carpeta una imagen por satélite donde se va detallando el índice de vigor de cada parcela solicitando por parte del técnico la descripción de la misma en caso de que se observen diferencias. También esta metodología se apoya en la realización de videoconferencias con los propios técnicos y el uso de mensajería instantánea para dar indicaciones de carácter general.

La duración de este seminario es la propia de los cultivos sobre los que se esté trabajando que en el caso que nos ocupa sería el de tomate de industria y algodón.

Una vez concluidos los cultivos se procede a una última reunión donde se pone en común las conclusiones obtenidas de manera general e incluso la posibilidad de plantear nuevas líneas de trabajo para el ciclo siguiente y que puede dar lugar a la realización de cambios importantes sobre el manejo de la fertirrigación y el riego en los cultivos estudiados.

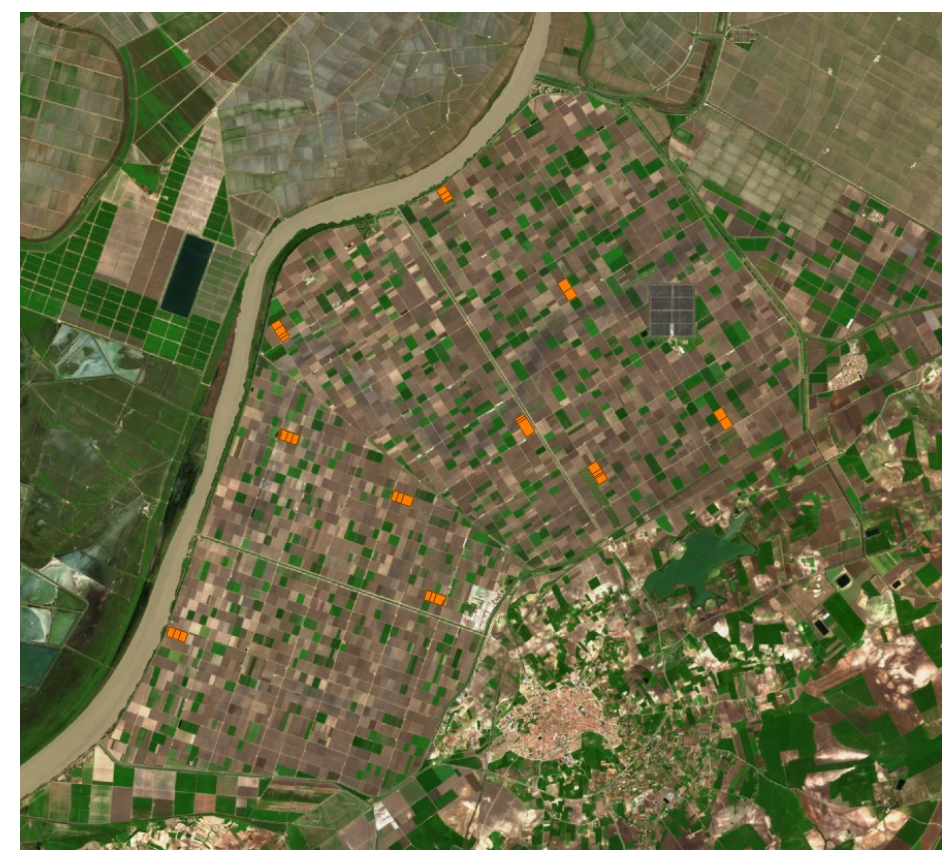

Figura 3. Ubicación de las parcelas colaboradoras de tomate de industria en el sector B- XII.

\section{Resultados y discusión.}

Como ya se ha comentado la zona de actuación pertenece a una de las zonas declaradas como vulnerables en la contaminación por nitratos y a su vez está sometida cada año a restricciones de agua de riego con toda la incertidumbre que ello conlleva a la hora de organizar los cultivos de la zona.

En base a estas dos premisas, eficiencia del agua de riego entendida como el agua de riego aprovechada realmente por la planta y el uso excesivo de insumos que incrementan los costes del cultivo y favorecen la contaminación del agrosistema, se decide actuar para transferir una metodología de aplicación de estos dos factores mediante el uso de prácticas más correctas de los mismos que ayuden a velar por el buen estado ambiental de la zona así como la rentabilidad de los cultivos.

Se definen dos líneas de trabajo complementarias que son el riego y la fertilización que se trabajan sobre una parcela experimental. En el caso del riego se establece la pauta de aportar la dosis de agua 
calculada expresamente en cada momento del ciclo del cultivo y por lo tanto aumentando la frecuencia del riego [5-7]. La fertilización se pauta en función de los requerimientos nutricionales de la planta a lo largo del cultivo a una dosis inferior a la propuesta por la producción integrada [8] donde además, se elimina el aporte de abonado de fondo y se establece la frecuencia de fertirrigación manteniendo una proporción 10-80-10 con respecto al riego, donde el aporte de nutrientes se realiza en cada riego y a lo largo del tiempo que dura el mismo, salvo un tiempo mínimo inicial para la estabilización del sistema de riego y otro final para la limpieza de dicho sistema.

En las parcelas colaboradoras se establecen los criterios de similitud de superficie cultivada, fecha de plantación, cultivar, existencia de drenes,... con respecto a la parcela experimental pero el manejo es el propio del agricultor.

Mediante el empleo de sistemas de información geográfica y teledetección se comparan los resultados obtenidos de la parcela experimental con el resto de parcelas colaboradoras obteniendose así una serie de conclusiones que se trasladan los técnicos responsables de dichas parcelas.

La siguiente imagen muestra los resultados obtenidos concretamente en las parcelas de tomate de industria estudiadas.

Los resultados esperados de la aplicación de esta metodología de trabajo son básicamente, pero no por ello menos importante, el contabilizar el número de agricultores deciden incorporar esas buenas prácticas en riego y fertilización al comprobar en parcelas similares a las suyas que no sólo la producción se mantiene o incluso es mayor, sino que además, el gasto en insumos es menor por lo que al final, la rentabilidad aumenta sin sacrificar el coste ambiental, logrando de esta forma que la zona cambie en un periodo de varios años tanto el perfil del manejo del riego como el de abonado lo que a su vez se traducirá en una mejora ambiental de la zona pero no por ello una disminución de la rentabilidad.

La figura siguiente muestra los resultados de producción en tomate de industria recogidos a través de la información facilitada por los técnicos colaboradores.

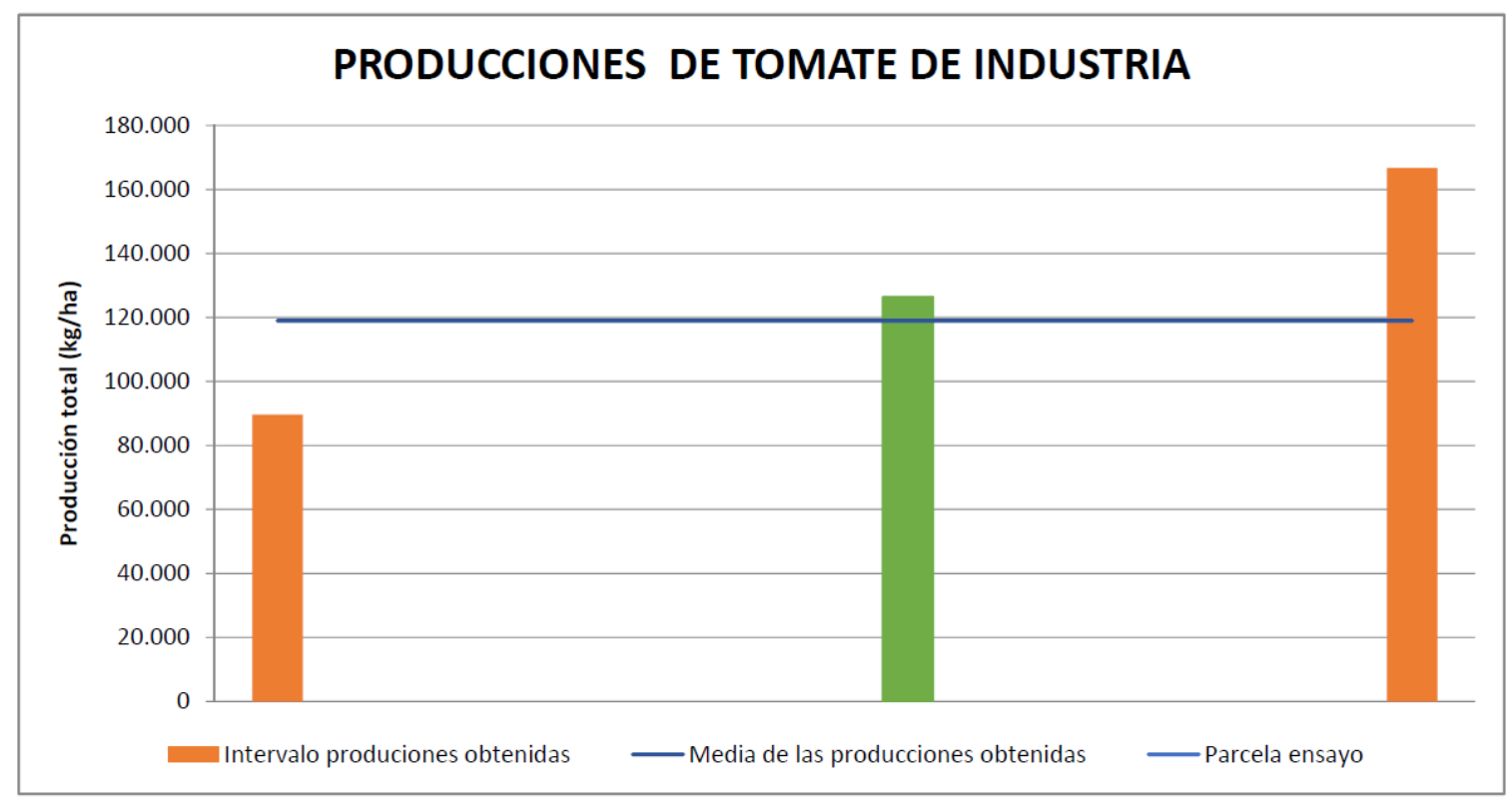

Figura 4. Producciones obtenidas en las parcelas colaboradoras con tomate de industria. 
La producciones obtenidas en las parcelas colaboradoras de tomate de industria están comprendidas entre los 85.000 y los $165.000 \mathrm{~kg} / \mathrm{ha}$, quedando la establecida como parcela experimental con una producción que supera a la homóloga manejada por propio agricultor de la parcela, en una producción en un 30\%. También se puede observar como la producción de la parcela manejada bajo los criterios del IFAPA queda por encima de la media obtenida en la zona.

\section{Conclusiones}

El hecho de actuar sobre parcelas grandes de extensión y características similares a las de la zona, así como la integración de las técnicas, hace que el agricultor perciba mayor realismo en los trabajos y esté más dispuesto a colaborar en la adopción de nuevas formas de hacer sobre los cultivos. Además, al involucrarlos en la propia metodología [9] ven de primera mano la veracidad de los resultados animándose a adoptar la propuesta como forma de hacer.

Esta metodología requiere que se repita de manera cíclica para poder ir identificando y ajustando problemáticas que existan o que puedan ir surgiendo.

El indicador en el éxito de la transferencia deberá ser el número de agentes que hacen suya la técnica propuesta en un área determinada. Lo cual requiere de unos plazos de tiempo mayores a los de una sola campaña.

\section{Referencias}

1 Comunidad de Regantes del Sector BXII del bajo Guadalquivir. Septiembre, 2021. http://www.crsectorb12.es

España. Real Decreto 261/1996, de 16 febrero, sobre protección de las aguas contra la contaminación producida por los nitratos procedentes de fuentes agrarias. Boletín Oficial del Estado, de 11 marzo de 1996, núm. 61.

Salvatierra, B., Jarén, C., López, M., Vanderlinden, K. (2021). Optimización del riego y la fertirrigación en cultivo del tomate de industria. Agricultura,1048 (marzo), 50-56. http://www.revistaagricultura.com.

Salvatierra, B. El seminario continuo de asesoramiento al regante como formato de formación para la transferencia en riegos. Instituto de Investigación y Formación Agraria, Pesquera, Alimentaria y de la Producción Ecológica, IFAPA, 2010.

Organización de las Naciones Unidas para la Alimentación y la Agricultura, 2006. Evapotranspiración del cultivo. Guía para la determinación de los requerimientos de agua de los cultivos. Estudios de Riego y Drenaje 56.

Hanson, B. y D. May. 2006. Coeficientes de cultivo para tomate procesado con riego por goteo. Gestión agrícola 81: $381-399$.

Campillo, C. et al. Manual práctico de riego tomate de industria. Centro de Invetigaciones Científicas y Tecnológicas de Estremadura, CICYTEX, 2015.

Orden de 2 de octubre de 2008. Reglamento Específico de Produccción Integrada de Tomate para Transformación Industrial. Boletín Oficial de la Junta de Andalucía, 203, de 10 de octubre de 2008, 13-24.

Kamruzzaman, M.; Daniell, K.A. ; Chowdhury, A.;Crimp, S.;James, H., 2020. How can agricultural extension and rural advisory services support innovation to adapt to climate change in the agriculture sector?. Advancements in Agricultural Development, 1 (1), 48-62. 


\title{
Evaluación económica del impacto sobre la agricultura de rega- dío del Vinalopó-Alacantí de la sustitución de recursos subte- rráneos por recursos del trasvase Júcar-Vinalopó
}

\author{
Calatrava, J. ${ }^{1}$ Martínez-Granados ${ }^{2}$, Richart, V.J. ${ }^{3}$
}

Escuela Técnica Superior de Ingeniería Agronómica, Universidad Politécnica de Cartagena, Cartagena; j.calatrava@upct.es

Escuela Técnica Superior de Ingeniería Agronómica, Universidad Politécnica de Cartagena, Cartagena; david.martinez@upct.es

Junta Central de Usuarios del Vinalopó, L'Alacantí y Consorcio de Aguas de la Marina Baja, Aspe, Alicante; vicente@juntacentral.es

Resumen: El sistema de explotación Vinalopó-Alacantí (SEVA) está localizado al sur de la Demarcación Hidrográfica del Júcar. En el SEVA coexisten una importante agricultura de regadío con una elevada población residente y una notable actividad turística concentrada en la costa Sur de la provincia de Alicante. Esto genera una situación de competencia por los recursos hídricos entre los usos urbanos y los agrarios que suponen aproximadamente un $40 \%$ y un $55 \%$ del consumo de agua respectivamente. La principal fuente de suministro de agua en la zona son las aguas subterráneas provenientes de diferentes acuíferos, la mayoría de ellos sobreexplotados y, al sur del sistema, el Trasvase Tajo-Segura. Para paliar la sobreexplotación de los acuíferos de la zona, el Plan Hidrológico del Júcar de 1998 y el Plan Hidrológico Nacional plantearon la sustitución de bombeos por recursos superficiales del río Júcar a través de la Conducción Júcar-Vinalopó, lo que supone duplicar o triplicar, según zonas regables, el coste del agua para riego, resultando en la inoperatividad, hasta la fecha, de la infraestructura. En este sentido, el objetivo de este trabajo es evaluar el impacto económico sobre el regadío del Vinalopó-Alacantí de la sustitución de recursos subterráneos por los provenientes del río Júcar. Para ello, se ha utilizado un modelo agro-económico no-lineal calibrado en base a la asignación real de cultivos de la zona. Los resultados muestran como el incremento del coste de suministro del agua resultante conllevarían una reducción de la demanda de agua y la superficie regada de más de un $35 \%$ con respecto a la situación actual, afectando principalmente a cultivos extensivos, viñedo para vinificación, olivar y cítricos, pero también a algunos cultivos frutales y hortícolas. Además, el impacto económico no se repartiría homogéneamente, sino que sería especialmente severo en los regadíos del Alto Vinalopó y del Pinós y Albatera.

Palabras clave: Trasvases inter-cuencas; sobreexplotación de acuíferos; modelos agro-económicos; demanda de agua. 


\title{
Economic assessment of the impact on the Vinalopó-Alacantí irrigated agriculture of substituting groundwater pumping by resources from the Júcar-Vinalopó water transfer system
}

\author{
Calatrava, J. ${ }^{1}$, Martínez-Granados ${ }^{2}$, Richart, V.J. ${ }^{3}$ \\ Escuela Técnica Superior de Ingeniería Agronómica, Universidad Politécnica de Cartagena, Cartagena; j.calatrava@upct.es \\ Escuela Técnica Superior de Ingeniería Agronómica, Universidad Politécnica de Cartagena, Cartagena; david.martinez@upct.es \\ Junta Central de Usuarios del Vinalopó, L'Alacantí y Consorcio de Aguas de la Marina Baja, Aspe, Alicante; vicente@juntacentral.es
}

\begin{abstract}
The Vinalopó-Alacantí exploitation system (SEVA in its Spanish acronym) is located in the south of the Júcar hydrographic basin. In the SEVA an important irrigated agriculture coexists with a high resident population and a notable tourist activity concentrated on the southern coast of the province of Alicante. This generates a situation of competition for water resources between urban and agricultural uses, which account for approximately $40 \%$ and $55 \%$ of water consumption respectively. The main sources of water supply in the area are groundwater from different aquifers, most of which are overexploited and, to the south of the system, the Tajo-Segura Transfer. In order to alleviate the overexploitation of the aquifers in the area, the 1998 Júcar Hydrological Plan and the 2001 National Hydrological Plan proposed the replacement of groundwater pumping by resources from the River Júcar transferred through the Júcar-Vinalopó Pipeline what would double or triple, depending on the areas to be irrigated, the cost of water for irrigation, resulting in the inoperability, to date, of the infrastructure. In this sense, the aim of this work is to evaluate the economic impact on irrigation in the Vinalopó-Alacantí area of the substitution of groundwater resources for those coming from the river Júcar. For this purpose, a non-linear agro-economic model, calibrated on the basis of the real allocation of crops in the area, has been used. The results show how the resulting increase in the cost of water supply would lead to a reduction in water demand and irrigated surface area of more than $35 \%$ compared to the current situation, mainly affecting extensive crops, vineyards for vinification, olive groves and citrus fruits, but also some fruit and vegetable crops. Moreover, the economic impact would not be evenly distributed, but would be particularly severe in the irrigated areas of Alto Vinalopó and Pinós and Albatera.
\end{abstract}

Keywords: Inter-basin water transfers; aquifer overexploitation; agro-economic models; water demand. 


\section{Congreso Nacional de Riegos CARTAGENA 2021}

\section{Introducción}

El sistema de explotación Vinalopó-Alacantí (SEVA) está localizado al sur de la Demarcación Hidrográfica del Júcar (Figura 1). Se trata de una cuenca hidrográfica con una extensión total de 2,786 $\mathrm{km}^{2}$ y que incluye territorio de la Comunidad Valenciana, Castilla-La Mancha y la Región de Murcia. En el SEVA coexisten una importante agricultura de regadío con una elevada población residente y una importante actividad turística concentrada en la costa Sur de la provincia de Alicante. Esto genera una situación de competencia por los recursos hídricos entre los usos urbanos y los agrarios que suponen aproximadamente un $40 \%$ y un $55 \%$ del consumo de agua respectivamente.
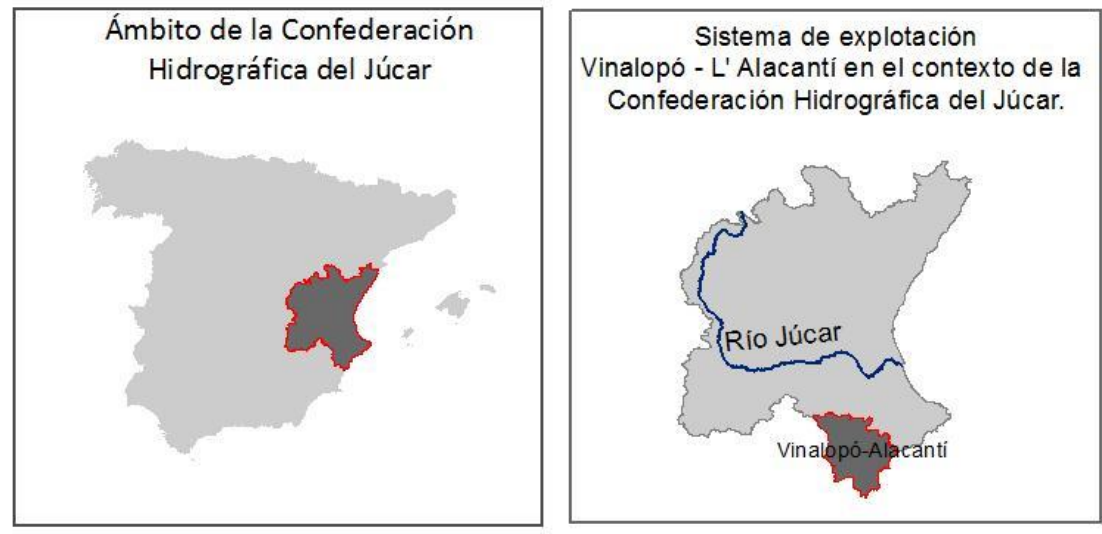

Figura 1. Localización del sistema de explotación Vinalopó-Alacantí (Fuente: Junta Central de Usuarios del Vinalopó, L'Alacantí y Consorcio de Aguas de la Marina Baja)

La principal fuente de suministro de agua en la zona son las aguas subterráneas provenientes de diferentes acuíferos, la mayoría de ellos sobreexplotados. Para el conjunto del SEVA, se estima un consumo de $113 \mathrm{hm}^{3}$ anuales de aguas subterráneas, con una recarga media anual estimada en $48 \mathrm{hm}^{3}$, lo que supone una sobreexplotación equivalente a $65 \mathrm{hm} 3 /$ año de extracciones no renovables que se constituye como uno de los principales problemas medioambientales de la zona.

El Plan Hidrológico de la Demarcación Hidrográfica del Júcar de 1998 [1], y derivado de ello el Plan Hidrológico Nacional [2], planteó la sustitución de bombeos por recursos superficiales del río Júcar, trasvasados a través de la Conducción Júcar-Vinalopó, como una de las soluciones para paliar la sobreexplotación de acuíferos en la zona. En su concepción inicial, la toma del trasvase en el Río Júcar se situaba en Cortes de Pallás y contemplaba que los recursos trasvasados se destinasen tanto a usos urbanos como de regadío. Finalmente, la toma del trasvase se situó cerca de la desembocadura del río Júcar, donde la calidad del agua es significativamente peor, por lo que el destino de los recursos a trasvasar se limitaría al regadío.

El regadío en el SEVA incluye tanto una importante producción hortofrutícola, en la que destacan cultivos como la uva de mesa, el viñedo para vinificación, el granado, los cítricos y los hortícolas protegidos, como cultivos extensivos (principalmente cereales) y una importante superficie regada de olivar y almendro.

La superficie de regadío actual abarca 40.674 hectáreas [3] que se reparten entre diez Unidades de Demanda Agraria (UDA) que se nutren de recursos hídricos de diferentes orígenes entre los que se incluyen los subterráneos, el Acueducto Tajo-Segura (ATS), la reutilización de aguas residuales urbanas y una mínima aportación de recursos superficiales (Tabla 1). Según el plan hidrológico del Júcar [3], la disponibilidad media de recursos hídricos para el regadío del SEVA asciende a 147,42 hm³/año en alta (Tabla 1). 
Tabla 1. Superficie neta regada y disponibilidad media del agua en las UDAs del SEVA.

\begin{tabular}{|c|c|c|c|c|c|}
\hline \multirow{2}{*}{$\begin{array}{l}\text { Unidad de Demanda Agraria } \\
\text { (UDA) }\end{array}$} & \multirow{2}{*}{$\begin{array}{c}\text { Superficie } \\
\text { neta (ha) }\end{array}$} & \multicolumn{4}{|c|}{ Disponibilidad media de agua (hm³/año en alta) } \\
\hline & & Superficial & Subterránea & Reutilizada & Tajo-Segura \\
\hline $\begin{array}{l}\text { UDA 082070A: Riegos de la cabecera } \\
\text { del Monnegre }\end{array}$ & 1148 & 0,35 & 3,20 & 0,04 & 0,00 \\
\hline UDA 082071A: Riegos del Jijona & 502 & 0,66 & 1,09 & 0,00 & 0,00 \\
\hline $\begin{array}{l}\text { UDA 082072A: Riegos de Levante } \\
\text { MI: Huerta de Alicante y Bacarot }\end{array}$ & 1127 & 0,79 & 0,00 & 1,03 & 5,74 \\
\hline UDA 082073A: Riegos del Alacantí & 4597 & 0,07 & 13,03 & 6,63 & 0,00 \\
\hline $\begin{array}{l}\text { UDA 082074A: Riegos mixtos del } \\
\text { Alto Vinalopó }\end{array}$ & 751 & 1,25 & 0,57 & 0,00 & 0,00 \\
\hline $\begin{array}{l}\text { UDA 082075A: Riegos subterráneos } \\
\text { del Alto Vinalopó }\end{array}$ & 10097 & 0,30 & 30,06 & 2,60 & 0,00 \\
\hline $\begin{array}{l}\text { UDA 082076A: Riegos del Medio } \\
\text { Vinalopó }\end{array}$ & 9424 & 0,50 & 27,50 & 1,71 & 0,00 \\
\hline $\begin{array}{l}\text { UDA 082077A: Riegos del Bajo Vi- } \\
\text { nalopó }\end{array}$ & 1428 & 0,05 & 4,97 & 0,31 & 1,63 \\
\hline $\begin{array}{l}\text { UDA 092001A: Riegos de Levante } \\
\text { MI: Camp d'Elx }\end{array}$ & 7458 & 0,00 & 0,00 & 10,93 & 28,17 \\
\hline $\begin{array}{l}\text { UDA 092002A: Riegos del Pinós y } \\
\text { Albatera }\end{array}$ & 4142 & 0,00 & 4,24 & 0,00 & 0,00 \\
\hline TOTAL & 40674 & 3,97 & 84,66 & 23,25 & 35,54 \\
\hline
\end{tabular}

Fuente: Elaboración propia con datos de [3] y [4].

En cuanto al coste de los recursos hídricos, el coste medio en alta en cada UDA depende del mix de recursos hídricos utilizados y del coste de bombeo en cada zona, el cual oscila entre 0,094 y 0,191 $€ / \mathrm{m}^{3}$, con un valor medio para el SEVA de $0,156 € / \mathrm{m}^{3}$. Al coste en alta hay que añadir los costes del peaje del postrasvase Tajo-Segura y los costes de distribución dentro de las diferentes zonas regables.

La substitución de recursos subterráneos por recursos del Júcar supondría duplicar o triplicar, según zonas, el coste del agua para riego, lo que ha supuesto, hasta la fecha, la inoperatividad de la infraestructura. En este sentido, el objetivo de este estudio es evaluar el impacto económico sobre la agricultura de regadío del Vinalopó-Alacantí de la sustitución de recursos subterráneos por los no convencionales transferidos a través de la Conducción Júcar-Vinalopó.

\section{Materiales y métodos}

El impacto económico sobre el regadío del Vinalopó-Alacantí de las alternativas analizadas se ha evaluado utilizando un modelo no-lineal de optimización que simula las decisiones de asignación de tierra y agua entre los cultivos de regadío de cada una de las diez Unidades de Demanda Agraria (UDA) de la zona de estudio y genera indicadores económicos de uso del agua. La estructura de dicho modelo agro-económico es la del modelo descrito en [5], pero todos sus parámetros técnicos y económicos han sido adaptados a las características de la zona de estudio. La función objetivo del modelo maximiza el margen neto de las actividades de cultivo en regadío en cada UDA, mientras que las restricciones representan la disponibilidad de recursos (superficie regable y recursos hídricos provenientes de diferentes fuentes de suministro). El modelo ha sido calibrado utilizando el enfoque de calibración mediante Programación Matemática Positiva propuesto por [6].

El modelo calibrado se ha utilizado para simular y evaluar dos escenarios: 


\section{Congreso Nacional de Riegos CARTAGENA 2021}

- Escenario 1: Situación actual de disponibilidad de recursos hídricos y coste de dichos recursos, de acuerdo con lo establecido en el plan hidrológico del Júcar vigente [3];

- Escenario 2: Sustitución de bombeos de los acuíferos del Subsistema por recursos del trasvase Júcar-Vinalopó, considerando un coste de suministro en alta a soportar por los regantes de 0,31 $€ / \mathrm{m}^{3}$, y un volúmen total a trasvasar previsto de $46,20 \mathrm{hm}^{3} /$ año en alta, de acuerdo con lo establecido en el escenario 2 de sustitución de bombeos definido en el plan hidrológico del Júcar vigente [3].

\section{Resultados y discusión}

La Tabla 2 muestra los resultados del modelo agro-económico calibrado para el escenario actual o de referencia (escenario 1). De acuerdo con la simulación de la asignación de superficie a actividades de cultivo realizada, el valor total de la producción agraria en el sistema Vinalopó-Alacantí es de aproximadamente 552 millones de euros al año, para un uso de recursos hídricos de aproximadamente $133 \mathrm{hm}^{3}$ anuales y una superficie regada de algo más de 38.000 hectáreas. Como resultado de esta actividad agraria se genera un margen neto de aproximadamente 135 millones de euros anuales y un uso de mano de obra en las explotaciones agrarias equivalente a más de 11.500 puestos de trabajo a tiempo completo. Los resultados presentados en la Tabla 2 presentan notables diferencias entre Unidades de Demanda Agraria (UDA) debido no solo a las diferencias de tamaño de las mismas sino también a diferencias en las orientaciones técnicas agrarias predominantes y a diferencias en la gestión de los recursos hídricos.

Tabla 2. Resultados del modelo agro-económico para el escenario actual.

\begin{tabular}{|c|c|c|c|c|c|c|}
\hline UDA/ZONA & $\begin{array}{c}\text { Agua } \\
\text { utilizada } \\
\left(\mathbf{h m}^{3} / \mathbf{a n ̃ o}\right)\end{array}$ & $\begin{array}{c}\text { Valor } \\
\text { marginal } \\
\text { del agua } \\
\left(€ / \mathrm{m}^{3}\right)\end{array}$ & $\begin{array}{c}\text { Valor de la } \\
\text { producció } \\
\text { n agraria } \\
\text { (M€/año) }\end{array}$ & $\begin{array}{c}\text { Margen } \\
\text { neto de } \\
\text { explotació } \\
\text { n (M€/año) }\end{array}$ & $\begin{array}{c}\text { Superficie } \\
\text { regada } \\
\text { (hectáreas) }\end{array}$ & $\begin{array}{c}\text { Mano de } \\
\text { obra } \\
\text { utilizada } \\
\text { (UTA/año) }\end{array}$ \\
\hline 082073A & 16,30 & 0,15 & 98,79 & 24,64 & 4.597 & 2.046 \\
\hline 082074A & 2,95 & 0,13 & 4,95 & 1,43 & 751 & 98 \\
\hline 082075A & 31,45 & 0,14 & 61,64 & 17,72 & 10.097 & 1.082 \\
\hline 082076A & 21,83 & 0,16 & 123,46 & 27,83 & 9.424 & 2.736 \\
\hline 082077A & 6,49 & 0,16 & 32,54 & 7,34 & 1.428 & 713 \\
\hline 092002A & 7,08 & 0,14 & 16,01 & 3,58 & 1.513 & 276 \\
\hline Subtotal UDAS del TJV & 86,09 & 0,15 & 337,40 & 82,53 & 27.810 & 6.950 \\
\hline 082070A & 3,79 & 0,09 & 7,80 & 2,49 & 1.148 & 149 \\
\hline 082071A & 1,53 & 0,16 & 3,96 & 1,70 & 502 & 57 \\
\hline 082072A & 6,28 & 0,11 & 30,93 & 7,54 & 1.127 & 626 \\
\hline 092001A & 35,53 & 0,11 & 172,57 & 40,87 & 7.458 & 3.757 \\
\hline Subtotal resto de UDAs & 47,12 & 0,11 & 215,25 & 52,60 & 10.235 & 4.589 \\
\hline TOTAL SUBSISTEMA & 133,21 & 0,13 & 552,65 & 135,14 & 38.045 & 11.539 \\
\hline
\end{tabular}

Nota: Volúmenes de agua en alta (bruta). Denominación de las UDAs: 082073A: Riegos del Alacantí; 082074A: Riegos mixtos del Alto Vinalopó; 082075A: Riegos subterráneos del Alto Vinalopó; 082076A: Riegos del Medio Vinalopó; 082077A: Riegos del Bajo Vinalopó; 092002A: Riegos del Pinós y Albatera; 082070A: Riegos de la cabecera del Monnegre; 082071A: Riegos del Jijona; 082072A: Riegos de Levante MI: Huerta de Alicante y Bacarot; 092001A: Riegos de Levante MI: Camp d'Elx. Fuente: Elaboración propia.

El valor marginal de uso del agua de riego oscila entre 0,09 y $0,16 € / \mathrm{m}^{3}$, dependiendo de la UDA que se considere (Tabla 2). Estos valores sugieren que el incremento del coste de suministro del agua 


\section{Congreso Nacional de Riegos CARTAGENA 2021}

resultante de sustituir la extracción de recursos subterráneos por agua proveniente del Júcar produciría una reducción en la demanda de agua por parte del regadío de la zona, ya que la disposición a pagar por el agua de riego es inferior al coste de suministro propuesto para el trasvase Júcar-Vinalopó. Como consecuencia de lo anterior, sería esperable una reducción en la superficie regada y en la producción y el empleo agrario.

En la Tabla 3 se muestra la variación porcentual de los resultados generados por el modelo para el escenario 2 con respecto a los obtenidos para el escenario actual. La Tabla 3 muestra, en primer lugar, como las UDAs que no recibirían recursos del TJV no se verían obviamente afectadas en este segundo escenario. En el caso de las UDAs afectadas por el TJV, el escenario 2 de sustitución de bombeos analizado reduciría la demanda de agua en un 34,5\% con respecto a la situación actual como consecuencia del incremento del coste de suministro del agua de riego. Esta reducción en el uso de recursos hídricos causaría, en el conjunto de las 6 UDAs afectadas por el TJV, una reducción del 36,7\% en la superficie media regada (10.215 hectáreas menos), del $14,6 \%$ en la producción agraria $(49,4$ millones de euros/año menos), del $10 \%$ en el margen neto de las explotaciones $(8,2$ millones de euros/año menos) y del 13,4\% en el empleo agrario (935 UTAs anuales menos).

La reducción de la superficie regada, aunque afecta a la mayoría de los cultivos en mayor o menos medida, corresponde principalmente a cultivos extensivos (cereales, forrajeros, leguminosas), el viñedo para vinificación, el olivar y los cítricos, aunque también afecta significativamente, aunque en porcentajes menores, a frutales como el granado y hortícolas como la zanahoria, la alcachofa, el puerro e incluso a la lechuga. El incremento que se observa en el valor marginal de uso del agua de riego (Tabla 3) se debe a la reducción de la superficie cultivada y la demanda de agua como consecuencia del incremento del coste del agua de riego.

Tabla 3. Variación porcentual de los resultados del modelo agro-económico en el escenario de trasvase Júcar- Vinalopó con respecto de la situación actual.

\begin{tabular}{ccccccc}
\hline UDA/ZONA & $\begin{array}{c}\text { Agua } \\
\text { utilizad } \\
\text { a }\end{array}$ & $\begin{array}{c}\text { Valor } \\
\text { marginal } \\
\text { del agua }\end{array}$ & $\begin{array}{c}\text { Valor de la } \\
\text { producción } \\
\text { agraria }\end{array}$ & $\begin{array}{c}\text { Margen } \\
\text { neto de } \\
\text { explotación }\end{array}$ & $\begin{array}{c}\text { Superficie } \\
\text { regada }\end{array}$ & $\begin{array}{c}\text { Mano de } \\
\text { obra } \\
\text { utilizada }\end{array}$ \\
\hline 082073A & $-4,11 \%$ & $20,00 \%$ & $-1,09 \%$ & $-0,90 \%$ & $-3,01 \%$ & $-0,74 \%$ \\
082074A & $-10,17 \%$ & $15,38 \%$ & $0,70 \%$ & $-0,36 \%$ & $-6,66 \%$ & $2,73 \%$ \\
082075A & $-47,79 \%$ & $92,86 \%$ & $-32,97 \%$ & $-17,55 \%$ & $-55,10 \%$ & $-36,12 \%$ \\
082076A & $-35,87 \%$ & $93,75 \%$ & $-14,64 \%$ & $-9,67 \%$ & $-32,70 \%$ & $-13,62 \%$ \\
082077A & $-35,75 \%$ & $93,75 \%$ & $-11,72 \%$ & $-14,82 \%$ & $-32,66 \%$ & $-7,53 \%$ \\
092002A & $-51,13 \%$ & $121,43 \%$ & $-38,33 \%$ & $-31,13 \%$ & $-60,44 \%$ & $-37,97 \%$ \\
Subtotal UDAS del TJV & $\mathbf{- 3 4 , 5 6 \%}$ & $\mathbf{6 6 , 6 7 \%}$ & $\mathbf{- 1 4 , 6 4 \%}$ & $\mathbf{- 9 , 9 7 \%}$ & $\mathbf{- 3 6 , 7 3 \%}$ & $\mathbf{- 1 3 , 4 4 \%}$ \\
\hline Subtotal resto de UDAs & $\mathbf{0 , 0 0 \%}$ & $\mathbf{0 , 0 0} \%$ & $\mathbf{0 , 0 0} \%$ & $\mathbf{0 , 0 0 \%}$ & $\mathbf{0 , 0 0} \%$ & $\mathbf{0 , 0 0} \%$ \\
\hline TOTAL SUBSISTEMA & $\mathbf{- 2 2 , 3 4 \%}$ & $\mathbf{4 6 , 1 5 \%}$ & $\mathbf{- 8 , 9 4 \%}$ & $\mathbf{- 6 , 0 9 \%}$ & $\mathbf{- 2 6 , 8 5 \%}$ & $\mathbf{- 8 , 1 0 \%}$ \\
\hline
\end{tabular}

Nota: Agua en alta. Denominación de las UDAs: 082073A: Riegos del Alacantí; 082074A: Riegos mixtos del Alto Vinalopó; 082075A: Riegos subterráneos del Alto Vinalopó; 082076A: Riegos del Medio Vinalopó; 082077A: Riegos del Bajo Vinalopó; 092002A: Riegos del Pinós y Albatera. Fuente: Elaboración propia.

Asimismo, el impacto económico negativo del incremento del coste del agua no sería homogéneo en toda la zona (Tabla 3). Mientras que en los Riegos del Alacantí y en los Riegos mixtos del Alto Vinalopó el impacto económico sería más limitado, en los Riegos del Medio Vinalopó y del Bajo Vinalopó sería mayor debido a una reducción de la superficie regada de aproximadamente un tercio de la actual. El impacto económico sería especialmente grave en el caso de los Riegos subterráneos del 


\section{Congreso Nacional de Riegos CARTAGENA 2021}

Alto Vinalopó y en los Riegos del Pinós y Albatera debido a una reducción de la superficie regada que supera con creces el $50 \%$.

\section{Conclusiones}

De acuerdo con los resultados obtenidos, el valor total de la producción agraria en el sistema Vinalopó-Alacantí asciende a aproximadamente 552 millones de euros, lo que supone una media de 14.526 euros por hectárea. En términos de margen neto, esto supone aproximadamente 135 millones de euros anuales o 3.552 euros por hectárea. Asimismo, las más de 38.000 hectáreas regadas con recursos propios de la demarcación generan un total de 2,77 millones de jornales cada año, incluyendo trabajo familiar y asalariado en las explotaciones agrarias, lo que equivale a más de 73 jornales por hectárea de regadío. Los resultados obtenidos ponen de manifiesto la importancia económica del regadío en el sistema Vinalopó-Alacantí, Aunque existen notables diferencias entre las diferentes Unidades de Demanda Agraria del subsistema debido a las diferentes orientaciones productivas predominantes en cada una de ellas.

Los resultados obtenidos para el conjunto de las seis UDAs afectadas por la sustitución de bombeos por recursos del trasvase Júcar-Vinalopó, muestran como el incremento del coste de suministro del agua resultante reducirían la demanda de agua y la superficie regada en más de un tercio con respecto a la situación actual. Los cultivos más afectados serían los cultivos extensivos, el viñedo para vinificación, el olivar y los cítricos, aunque también afectaría de manera significativa a algunos frutales y cultivos hortícolas. El impacto económico previsto (una caída del 14,6\% en la producción agraria y del 13,4\% en el empleo agrario) no se repartiría de manera homogénea, sino que sería especialmente grave en los regadíos de aguas subterráneas del Alto Vinalopó y del Pinós y Albatera y, en menor medida, en los regadíos del Medio y Bajo Vinalopó, siendo más reducido en el Alacantí y en los regadíos mixtos del Alto Vinalopó.

\section{Agradecimientos}

La realización de este trabajo ha sido posible gracias a la financiación proporcionada por la Fundación PRIMA a través del proyecto WATERMED 4.0 (Proyecto número 1821).

\section{Referencias}

1. CHJ. Plan Hidrológico de cuenca del Júcar; Confederación Hidrográfica del Júcar: Valencia, España, 1998.

2. MIMAM. Plan Hidrológico Nacional; Ministerio de Medio Ambiente: Madrid, España, 2001.

3. CHJ. Plan Hidrológico de la Demarcación Hidrográfica del Júcar. Ciclo de planificación hidrológica 2015-2021; Confederación Hidrográfica del Júcar: Valencia, España, 2015.

4. CHJ. Documentos iniciales del tercer ciclo de planificación hidrológica (2021-2027); Confederación Hidrográfica del Júcar: Valencia, España, 2019.

5. Calatrava, J.; Martínez-Granados, D. Water buybacks to recover depleted aquifers in south-east Spain. Int. J. Water Resour. Dev. 2019, 35(6), 977-998.

6. Gohin, A.; Chantreuil, F. La programmation mathématique dans les modèles d'exploitation agricole. Principes et importance du calibrage. Cahiers d'Économie et Sociologie Rurales 1999, 52, 59-77. 


\title{
Desarrollo de una plataforma IoT para la gestión del riego de precisión
}

\author{
Puig Pérez-Barquero, Francisco ${ }^{1}$, Rodríguez Díaz, Juan Antonio², González Perea, Rafael 3, Camacho Poyato, Emi- \\ lio $^{4}$
}

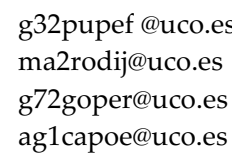

Resumen: Hoy en día el riego de precisión es cada vez más importante debido a la necesidad de optimizar el uso de los recursos agua y la energía, los cuales son cada vez más limitantes. Sin embargo, aplicar un riego de precisión no es una tarea fácil para la mayoría de los agricultores, ya que es necesario conocer los factores que influyen en el crecimiento del cultivo. El avance tecnológico está permitiendo que cada vez sea más factible medir, recopilar datos y analizar el manejo del riego, utilizando diferentes tipos de sensores y servidores, de esta manera se pueden calcular de forma automática las necesidades de riego y aplicar el agua de forma precisa justo cuando es más necesaria. No obstante, la mayoría de las plataformas IoT son sistemas cerrados que no permiten la integración con plataformas y sensores de terceros y se limitan a mostrar los valores de estos sensores de manera gráfica, sin entrar en el cálculo de las necesidades del cultivo y, por tanto, no son del todo útiles para funcionar como sistemas de apoyo a la toma de decisiones. El presente trabajo pretende mostrar la metodología para el desarrollo de una plataforma IoT de bajo coste para el riego de precisión, así como la integración de diferentes estrategias de riego en la misma. Para desarrollar la plataforma se ha utilizado el framework Django, de código abierto. Con el fin de conectar diferentes sensores a la plataforma se ha diseñado un dispositivo de toma de datos, de código abierto y eficiente energéticamente, que soporta una gran cantidad de protocolos de comunicación. Finalmente se ha calculado una programación de riego para una finca de estudio. Dicha finca consta de 44 hectáreas de almendros en intensivo y organizados en dos sectores de riego. Las estrategias se han desarrollado con el lenguaje de programación Python y se conectan automáticamente a la red de estaciones meteorológicas de la AEMET y a la página web de elTiempo.es para obtener tanto datos climáticos de la serie histórica como las predicciones para los próximos días. Todos estos datos se muestran en la plataforma de forma gráfica, a través de la cual también se pueden modificar las variables relacionadas con el sistema hidráulico, el cultivo y la explotación

Palabras clave: Riego de precisión, Cultivo del Almendro, TIC's, Software, Aplicación Web 


\title{
XXXVIII Congreso Nacional de Riegos
} CARTAGENA 2021

\section{Developing an IoT platform for smart irrigation management}

\author{
Puig Pérez-Barquero, Franciscoํㅜ, Rodríguez Díaz, Juan Antonio², González Perea, Rafael ${ }^{3}$, Camacho Poyato, Emi- \\ lio $^{4}$
}

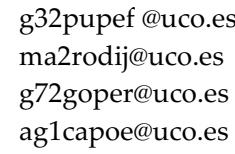

\begin{abstract}
Nowadays the smart irrigation is becoming increasingly important due to the need to optimise the use of water and energy resources, which are becoming more and more limiting. However, applying smart irrigation is not an easy task for most farmers, as it is necessary to know the factors that influence crop growth. Technological advances are making it increasingly feasible to measure, collect data and analyse irrigation management, using different types of sensors and servers, so that irrigation needs can be calculated automatically, and water can be applied precisely when it is most needed. However, most IoT platforms are closed systems that do not allow integration with third-party platforms and sensors and are limited to displaying the values of these sensors graphically, without entering the calculation of crop needs, and therefore are not entirely useful to work as decision support systems. This paper aims to show the methodology for the development of a low-cost IoT platform for smart irrigation, as well as the integration of different irrigation strategies in it. The open-source Django framework has been used to develop the platform. In order to connect different sensors to the platform, an open source, energy-efficient data acquisition device has been designed, which supports a large number of communication protocols. Finally, an irrigation schedule has been calculated for a study farm. This farm consists of 44 hectares of intensive almond trees organised in two irrigation sectors. The strategies have been developed with the Python programming language and are automatically connected to the AEMET weather station network and to the elTiempo.es website to obtain both weather data from the historical series and forecasts for the coming days. All this data is displayed graphically on the platform, through which the variables related to the hydraulic system, the crop and the farm can also be modified.
\end{abstract}

Keywords: Smart Irrigation, Almond trees, TIC's, Software, Web Platform 


\section{Introducción}

En España, al igual que ocurre en el resto de los países de la cuenca mediterránea, el agua es un recurso escaso, frágil e irregularmente distribuido. A la escasez de precipitaciones, la elevada evapotranspiración, la alta variabilidad espacial y temporal de las lluvias, la desigual distribución de los recursos hídricos y la frecuencia de las sequias, se unen problemas como son el aumento de la presión sobre los recursos hídricos, el déficit creciente que sufren algunas cuencas y la salinización o contaminación de acuíferos [1].

La agricultura de regadío es el principal consumidor de agua, suponiendo un $82 \%$ del total del agua consumida, según estimaciones del Instituto Nacional de Estadística (INE) en 2018. Por ello, en la actualidad, y más aún en el futuro, la agricultura de regadío se llevará a cabo bajo un escenario de escasez de agua. El suministro insuficiente de agua para el riego serä la norma más que la excepción, y la gestión del riego pasará de enfatizar la producción por unidad de área, hacia la maximización de la producción por unidad de agua consumida (Fereres \& Soriano, 2007). Para el cálculo de las estrategias de riego de precisión es necesario conocer los parámetros que afectan a la distribución de agua en el suelo y la planta. Sin embargo, conocer estos parámetros y calcular el balance de agua en el suelo no es una tarea fácil para la mayoría de los agricultores.

El desarrollo tecnológico, que implica la mejora y la disminución del coste de los sensores, supone un cambio importante en la agricultura. El IoT (Internet of Things) surge como la opción natural para las aplicaciones de gestión inteligente del agua [2]. Con el uso de esta tecnología se pueden desarrollar estrategias de riego de precisión, de manera autónoma, que permitan un mayor control de los diferentes factores que afectan al riego y mejoren la gestión de agua y energía en la explotación. Esto reduce costes, mejora la aplicación del riego y disminuye el impacto medioambiental, siendo cada vez más imprescindible su uso en la agricultura. Sin embargo, la mayoría de las plataformas y sensores comerciales son sistemas cerrados, que no permiten la integración con sensores y plataformas de terceros, lo que limita en gran medida su potencial.

El presente trabajo pretende mostrar la metodología que se ha seguido para el desarrollo de un sistema IoT, de bajo coste y de código abierto, para la automatización de las estrategias de riego de precisión en una finca comercial de almendros. Este sistema permite la integración con diferentes plataformas IoT y soporta una gran cantidad de sensores comerciales.

\section{Materiales y métodos (Trabajo de innovación: descripción de la innovación)}

\section{1. Área de estudio}

El proyecto se ha llevado a cabo en una finca de almendros situada en Córdoba, España. El clima en esta zona se caracteriza por inviernos suaves, con temperaturas que rondan los $10^{\circ} \mathrm{C}$ y veranos calurosos, con temperaturas medias superiores a los $27^{\circ} \mathrm{C}$. Las precipitaciones anuales rondan los $592 \mathrm{~mm}$, pudiendo llegar algunos años a superar los $1.000 \mathrm{~mm}$. El terreno presenta una textura que varía entre franco-arcillosa y franco-arenosa, en función de la zona.

Dicha finca consta de dos variedades de almendro, Soleta y Lauranne, distribuidas en dos parcelas con una superficie productiva de 22 y 21 hectáreas respectivamente. La plantación es de tipo intensiva con un marco de 6 × 3,5 metros. El riego es por goteo, con un caudal de gotero de 1,2 L/h,_y está dividido en dos sectores, uno para cada variedad de almendro, y cada uno consta de dos bombas. Una de las bombas se encargará de llevar el agua del río Guadalquivir hasta un depósito de un millón de litros. La segunda bomba es utilizada para aplicar riego a los distintos sectores. Ambas bombas se alimentan 
mediante energía fotovoltaica. La finca cuenta también con un sistema de fertirriego, de modo que le aplican los fertilizantes directamente en el agua de riego.

Las características del sistema de riego por sectores se representan en la Tabla 1. Los valores de uniformidad y eficiencia de riego se han obtenido de un ensayo de campo que realizó la Universidad de Córdoba

Tabla 1. Características del sistema de riego por sectores. Fuente: elaboración propia.

\begin{tabular}{ccccc}
\hline Sector & No Goteros & $\begin{array}{c}\text { Caudal Gote- } \\
\text { ros (1/h) }\end{array}$ & $\begin{array}{c}\text { Uniformi- } \\
\text { dad del } \\
\text { riego (\%) }\end{array}$ & $\begin{array}{c}\text { Eficiencia del riego } \\
\text { (\%) }\end{array}$ \\
\hline 1 & 87000 & 1.18 & 95.5 & 90 \\
2 & 93000 & 1.15 & 90.4 & 90 \\
\hline
\end{tabular}

\subsection{Materiales}

\subsubsection{Dispositivos IoT}

Para permitir la conexión de los sensores con la plataforma IoT se han desarrollado unos dispositivos de toma de datos, compatibles con diferentes sistemas de comunicación y protocolos de salida. Estos dispositivos se caracterizan por:

- Amplio rango de instalación: Los dispositivos han sido desarrollado con el objetivo de soportar un gran rango de sistemas de comunicación, ya que se suelen instalar en lugares remotos, en los que muchas veces no hay conexión a internet. Estos sistemas de comunicación son: GSM, Sigfox, LoraWAN, NB-IoT, Bluetooht y Wi-Fi. En este trabajo se ha optado por utilizar la tecnología SigFox.

- Eficientes energéticamente: Debido a la dificultad para acceder a los dispositivos, estos deben ser autosuficientes energéticamente. Estos tienen una batería de Li-Ion recargable de $2600 \mathrm{mAh}$ y 3.7V que se recarga a través de un panel solar de $250 \mathrm{~mA}$.

- Compatibles con una gran variedad de sensores: Para conseguir medir una mayor cantidad de parámetros que afectan a el riego, es necesario que los dispositivos sean compatibles con la gran mayoría de sensores comerciales. Entre los protocolos que soporta se encuentran: SDI-12 (Serial Digital Interface), RS-485, I2C (Inter-Integrated Circuit) y SPI (Serial Peripheral Interface). Los dispositivos también son compatibles con sensores analógicos.

Estos dispositivos se han programado con el software Arduino y envía los valores tomados por los sensores cada $15 \mathrm{~min}$ a la plataforma IoT. 


\subsubsection{Sensores de suelo}

El cálculo de la humedad en la zona radicular se ha realizado mediante dos sensores (Figura 1), que miden la humedad de suelo, la conductividad eléctrica y la temperatura, instalados a 30 y $45 \mathrm{~cm}$.

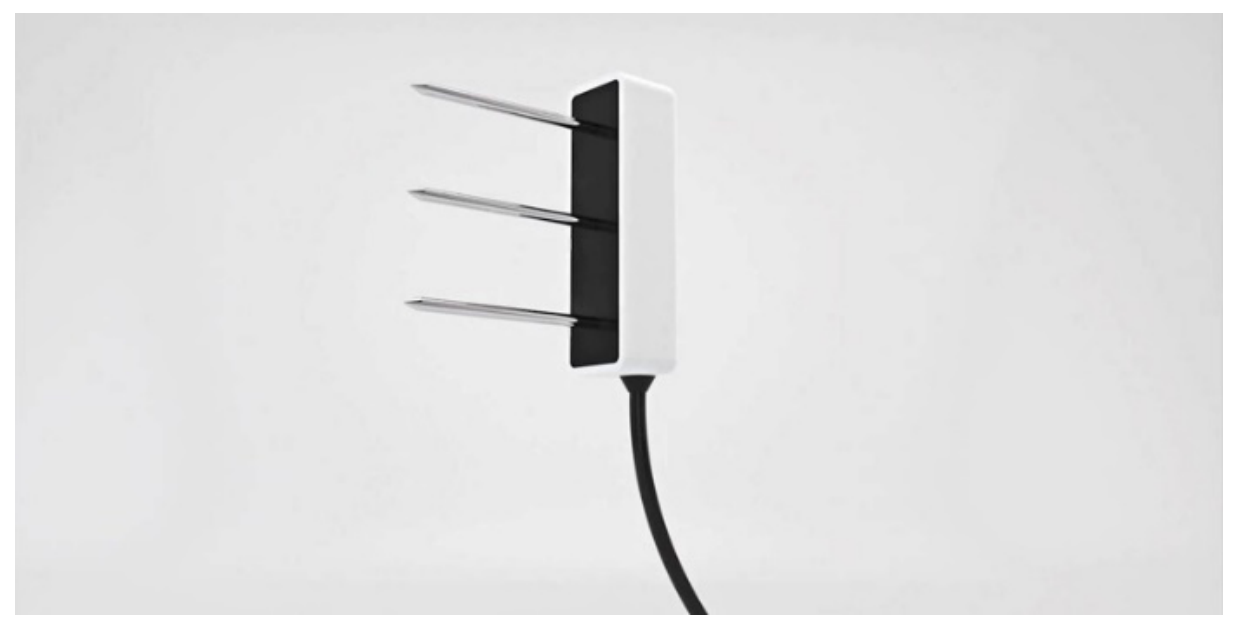

Figura 1. Sonda de humedad Teros 12.

Estos sensores se comunican con el dispositivo de toma de datos mediante el protocolo de comunicación SDI-12.

\subsubsection{Servidor}

Se ha utilizado la Raspberry Pi 3 Model B+ como servidor (Figura 2). La Raspberry es un ordenador de placa reducida, de bajo coste y consumo reducido, lo que lo hace ideal para utilizarlo como servidor para proyectos en desarrollo.

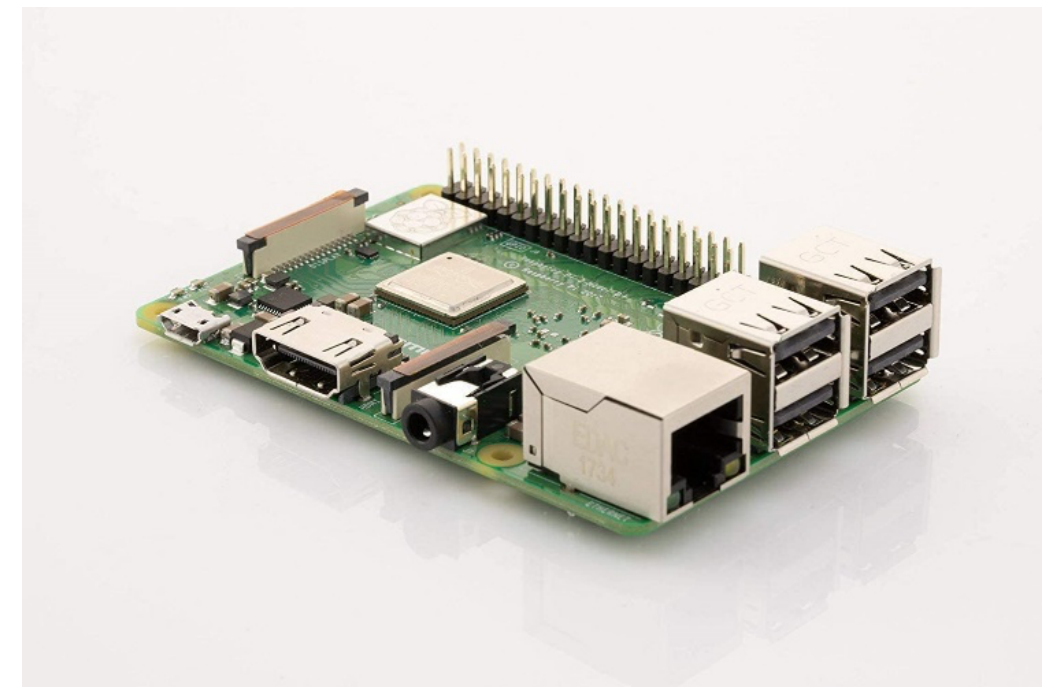

Figura 2. Raspberry Pi 3 Model B+ 


\section{Congreso Nacional de Riegos CARTAGENA 2021}

\subsection{Metodología}

La metodología se puede dividir en dos partes, el desarrollo del sistema IoT y el cálculo de la programación de riego.

La arquitectura del sistema IoT (Figura 3) se puede dividir en tres capas:

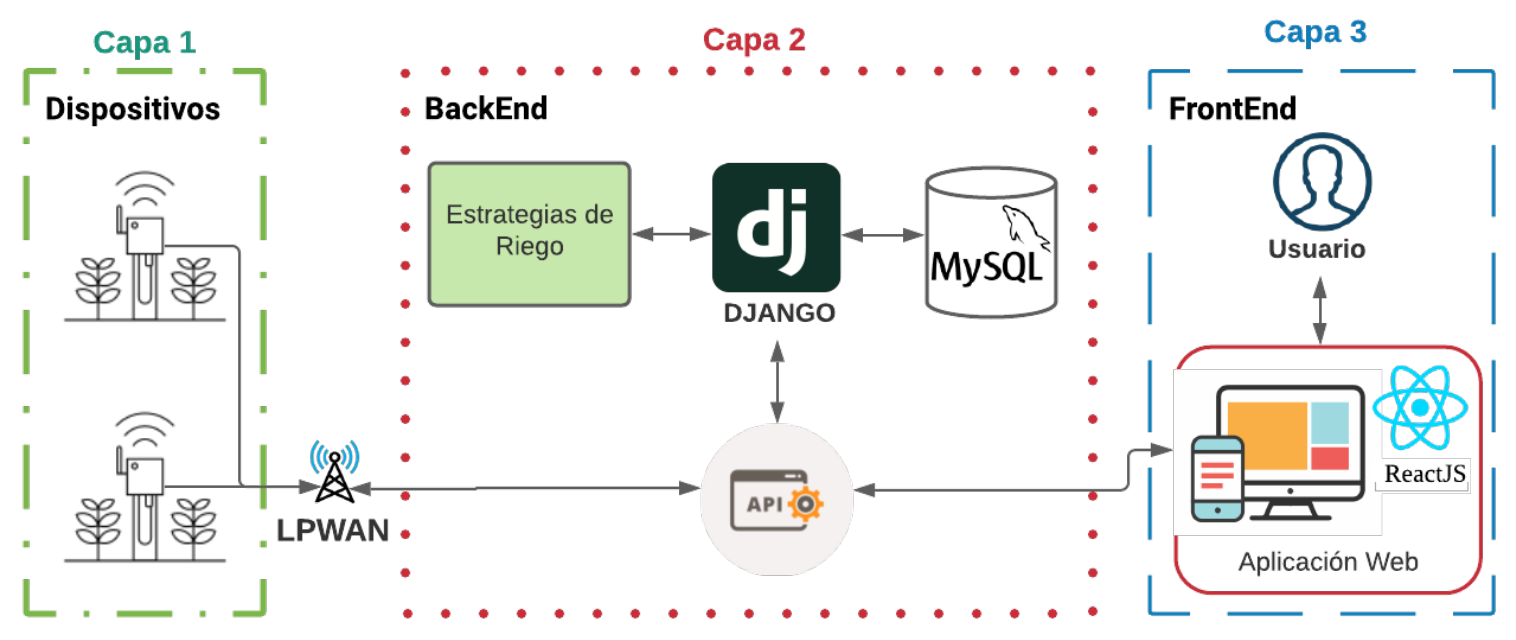

Figura 3. Arquitectura del sistema IoT. Fuente: elaboración propia.

La capa 1 representa los dispositivos de toma de datos descritos en el apartado anterior. Estos dispositivos se conectan con la API REST (Application Programming Interface. REpresentational State Transfer) del backend a través de los sistemas de comunicación LPWAN.

La capa 2 representa el backend de la plataforma. Se ha utilizado el framework de Django (https://docs.djangoproject.com/), de desarrollo web y de código abierto, escrito en Python, que sigue un patrón de diseño conocido como Modelo-Vista-Controlador (MVC). En esta capa se encuentran el algoritmo de riego de precisión, desarrollado en el lenguaje de programación Python, en el que se calculan las diferentes estrategias de riego. Para comunicar las tres capas, se ha desarrollado una API REST utilizando la herramienta "Django Rest Framework".

La última capa es el frontend que contiene la interfaz gráfica de la aplicación e interactúa con la segunda capa a través de su API REST. Para su desarrollo se ha utilizado la librería ReactJS.

Todo el sistema se ha desarrollado de manera que se puede desplegar tanto en la nube como insitu, en cualquier miniordenador. 


\subsubsection{Programación de riego}

En la aplicación se puede escoger entre dos tipos de estrategias: 1- Reponer al 100\% las necesidades de agua, 2- Riego deficitario controlado (RDC). La Figura 4 muestra un esquema del cálculo de la programación del riego en función de la estrategia escogida

Para la programación del riego de precisión se ha utilizado la metodología propuesta por la Organización de las Naciones Unidas para la Agricultura y la Alimentación (FAO) [3].

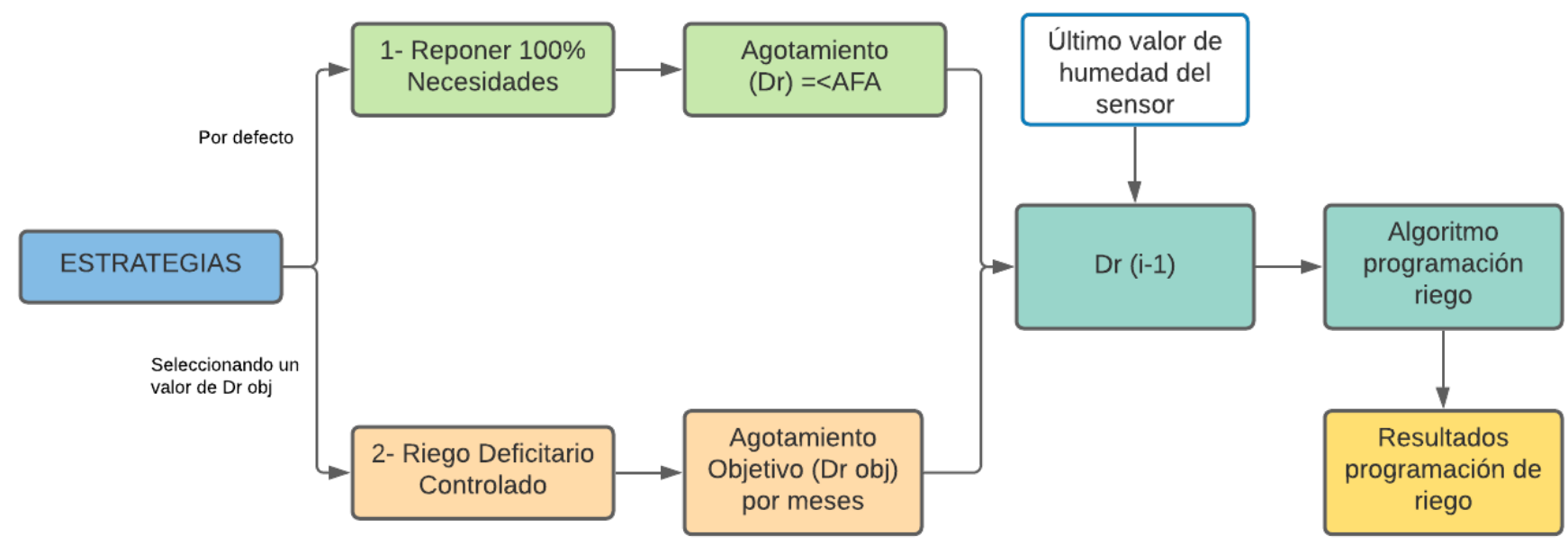

Figura 4. Esquema de la programación del riego para las diferentes estrategias. Fuente: elaboración propia

Como se observa en el esquema de la figura anterior, la programación de riego por defecto utiliza la estrategia de reponer $100 \%$ las necesidades hídricas y calcula el tiempo de riego que el sistema debe estar funcionando, para que el agotamiento de humedad en el suelo sea igual o menor al Agua Fácilmente Aprovechable (AFA). Este proceso lo repite para cada día de los próximos siete. De esta forma, aplicando el algoritmo utilizado para la programación de riego, que se explicará en el siguiente apartado, se obtiene la lámina bruta y el tiempo de riego necesarios para que el suelo no presente agotamiento de humedad.

Si se quisiera realizar un RDC se asigna un valor de agotamiento objetivo que establece el nivel máximo de agotamiento que el suelo debe presentar. De esta manera se puede reducir los aportes hídricos en aquellos periodos fenológicos en los que aplicar un déficit hídrico controlado no afecte sensiblemente a la producción y a la calidad de la cosecha, mientras que en el resto del ciclo del cultivo se garantice el $100 \%$ de las necesidades hídricas.

$D_{r, i-1}$ se calculará todos los días a partir de los valores que presenten los sensores de humedad instalados en la finca 


\section{Congreso Nacional de Riegos CARTAGENA 2021}

\subsubsection{Algoritmo Programación Riego}

El diseño del algoritmo de programación del riego va a seguir el esquema mostrado en la figura 5

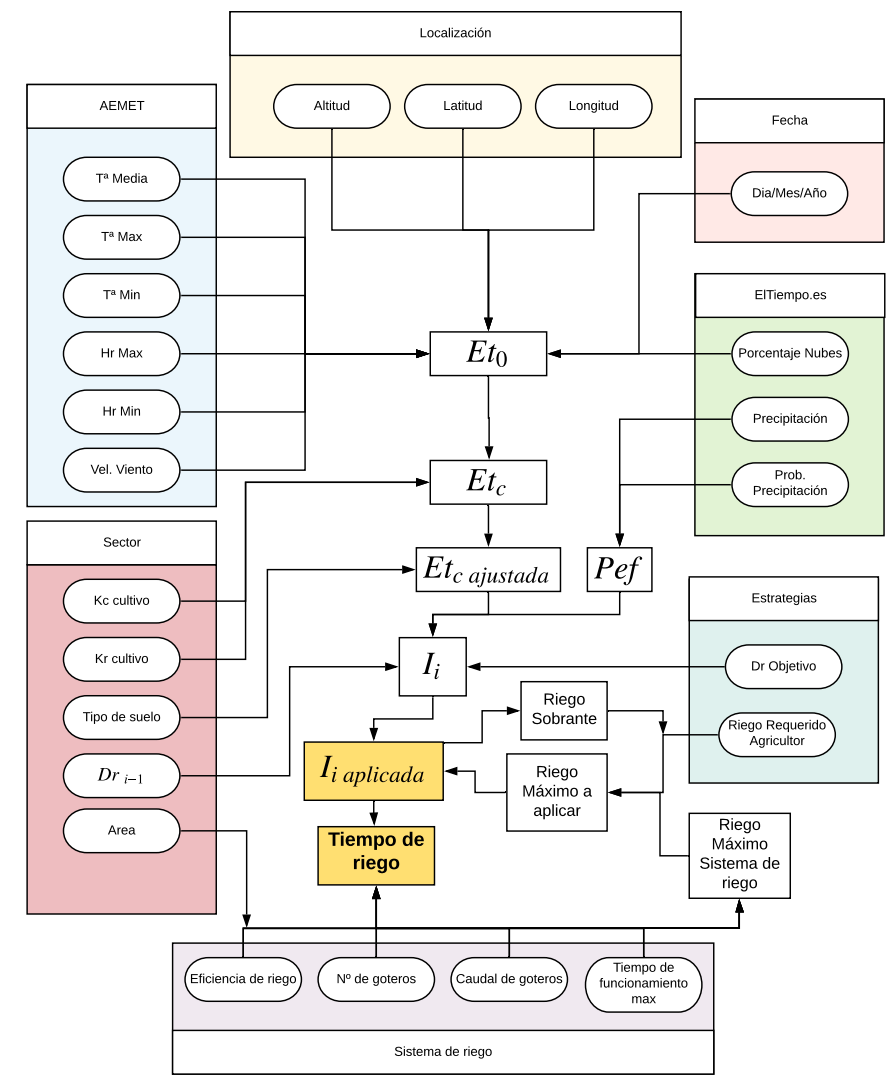

Figura 5. Esquema del diseño de la programación del riego. Fuente: elaboración propia

En primer lugar, se calcula la evapotranspiración de referencia $\left(E T_{0}\right)(\mathrm{mm})$ que depende únicamente de los valores climatológicos de la zona de estudio, los cuales se obtienen a través de la API de la AEMET OpenData

En segundo lugar, se calcula la evapotranspiración del cultivo $\left(E T_{c}\right)(\mathrm{mm})$ que utiliza el valor del coeficiente del cultivo $(\mathrm{Kc})$ y la $E T_{0}$ calculada anteriormente. El valor de $E T_{c}$ es menor cuando la cantidad de agua en el suelo está por debajo del Agua Disponible Total (ADT), ya que la transpiración del cultivo se reduce, por lo que debe ser ajustado en función del tipo de suelo, dando lugar a la evapotranspiración del cultivo ajustada $\left(E T_{\text {c ajustada }}\right)(\mathrm{mm})$.

Tras esto se realiza un balance de agua en el suelo para calcular la lámina neta de riego $\left(I_{i}\right)(\mathrm{mm})$, considerando las entradas (precipitación efectiva) y las salidas (evapotranspiración del cultivo.). Para el balance de agua es necesario el agotamiento del suelo del día anterior $\left(D r_{i-1}\right)(\mathrm{mm})$, que informa sobre la humedad del suelo, y el agotamiento del suelo al que se quiere llegar $\left(D r_{\text {objetivo }}\right)(\mathrm{mm})$.

Una vez calculada $I_{i}$, se calcula el tiempo que el sistema de riego debe de estar funcionando. Estas variables van a depender de las limitaciones del sistema hidráulico (Área, eficiencia del riego, n⿳o de goteros, caudal de goteros y tiempo de funcionamiento máximo) y de las limitaciones de agua que el agricultor especifique (riego requerido). Los parámetros referentes a la localización, sistema de riego y a las estrategias, se encuentran almacenados en la base de datos y pueden ser modificados desde la aplicación para ajustar la programación del riego a cualquier sector, cultivo y necesidades del agricultor 


\section{Congreso Nacional de Riegos CARTAGENA 2021}

\subsubsection{Despliegue}

Finalizado el diseño de la aplicación, es necesario pasar a la fase de producción (Figura 6). Esta fase consiste en desplegar la web en un servidor para que esté operativa las 24 horas y pueda ser accesible desde cualquier parte

Como ya se ha comentado, se ha optado por la Raspberry pi 3+ como servidor y se ha utilizado la herramienta Docker, que permite la automatización y el despliegue de la aplicación en diferentes dispositivos. La aplicación se ha desarrollado para ser lo más eficiente posible, permitiendo su funcionamiento en este "miniordenador". La elección de este servidor atiende a aspectos económicos.

\section{Resultados y discusión (Trabajo de innovación: resultados obtenidos en ensayo o en explotación comer-} cial)

El sistema IoT ha sido probado durante una campaña de riego completa. La aplicación web ha facilitado la visualización tanto de los valores de los sensores (Figura 7) como de las estrategias calculadas por el algoritmo de riego (Figura 8).

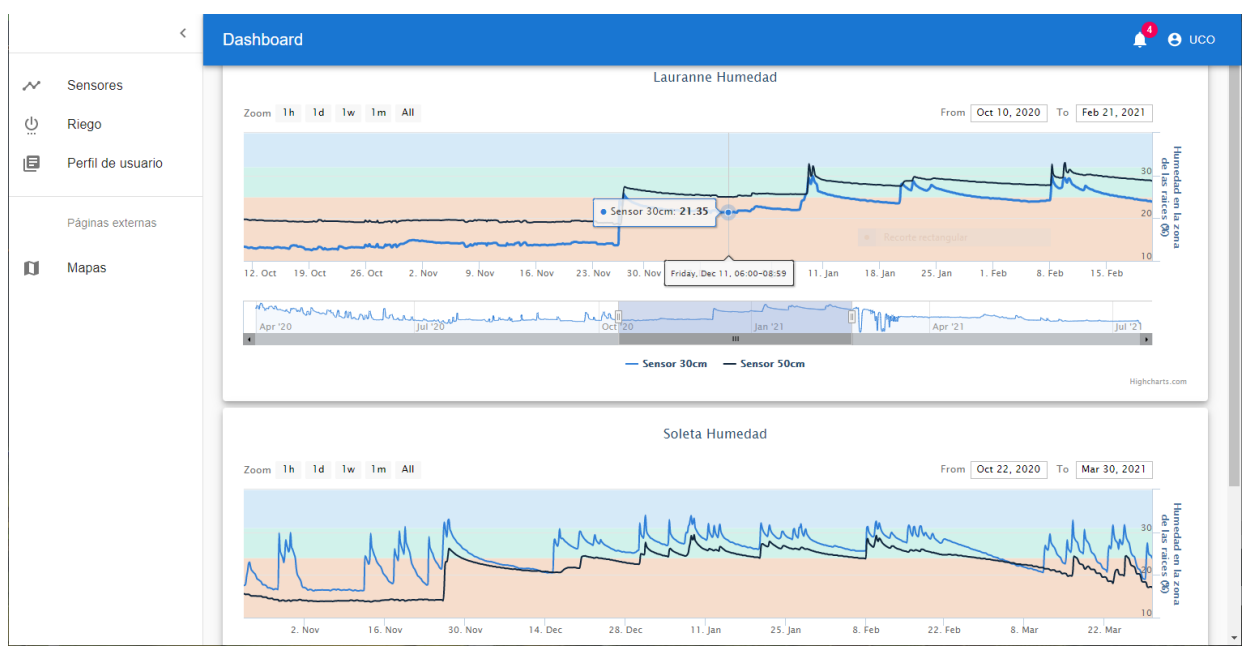

Figura 7. Página principal de la aplicación web. Fuente: elaboración propia

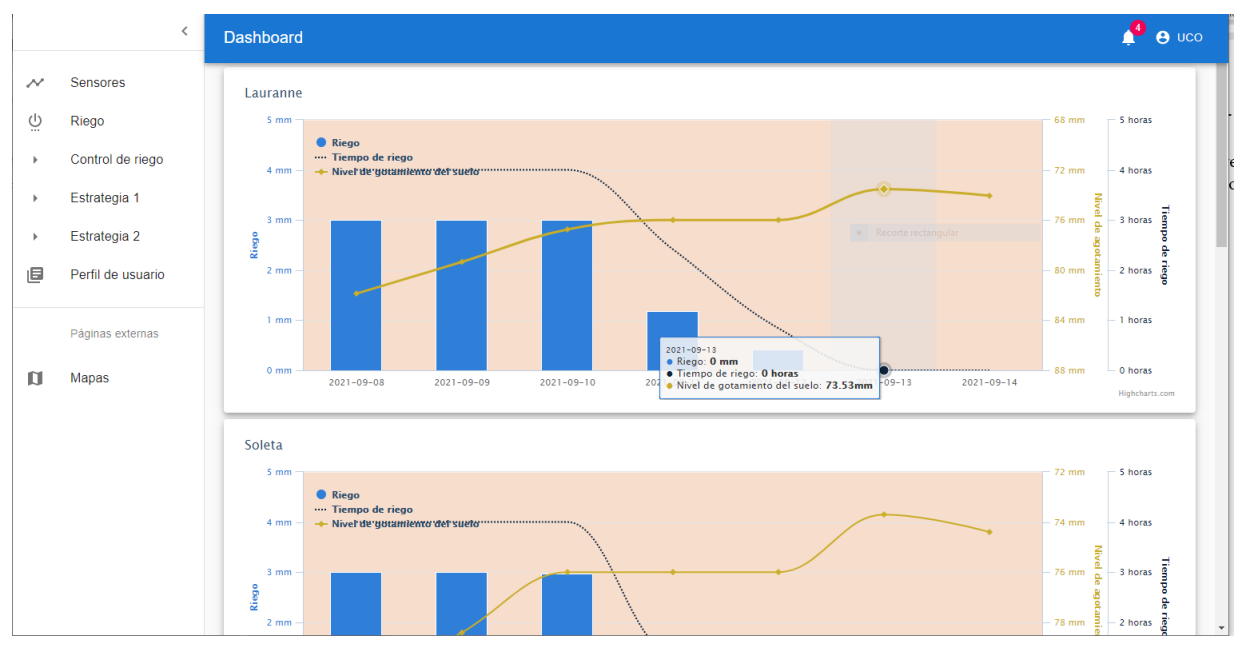

Figura 8. Página de estrategias de la aplicación web. Fuente: elaboración propia 


\section{Conclusiones}

En este trabajo se ha desarrollado un sistema IoT para controlar en tiempo real un riego de precisión, permitiendo una programación óptima, sencilla y personalizada para diferentes estrategias.

Se ha automatizado el cálculo de las necesidades de riego según la metodología de FAO. haciendo uso de las APIS de la AEMET y elTiempo.es, la aplicación realiza una predicción semanal de la variación de la humedad en el suelo.

La aplicación web implementa también el cálculo del tiempo que el sistema de riego debe funcionar a diario para aplicar el riego de precisión.

La aplicación ha sido desarrollada haciendo uso de dos de las herramientas más utilizadas hoy en día en desarrollo web (ReactJS y Django). Esto permite que dicho proyecto sea ampliamente escalable y útil de cara al mundo profesional.

Finalmente, la aplicación se ha pasado a modo producción y se ha instalado en un miniordenador, permitiendo así la instalación rápida, económica y segura en la explotación.

\section{Referencias}

1. García Morillo, J.; Rodríguez Díaz, J.; Montesinos, P., Hacia el riego de precisión en el cultivo de fresa en el entorno de Doñana, [Tesis doctoral]. 2015

2. Kamienski, C.; Soininen, J.P.; Taumberger, M; Dantas, R; Toscano, A.; Salmon Cinotti, T; Filev Maia, R.; Torre Neto, A, Smart Water Management Platform: IoT-Based Precision Irrigation for Agriculture, Sensors 2019, 19, 276.

3. Allen, R.G., Pereira, L.S., Raes, D., Smith, M. Crop evapotranspiration - guidelines for computing crop water requirements. FAO Irrigation and drainage paper 1998; 56. Food and Agriculture Organization, Rome.

4. Fereres, E., Soriano, M.A. Deficit irrigation for reducing agricultural water use. Journal of Experimental Botany 2007, Volume 58, Issue 2, 1, 147-159 


\title{
Rentabilidad del uso de agua marina desalinizada en la produc- ción de tomate de invernadero en Almería
}

\author{
Martínez-Granados, D. ${ }^{1}$, Marín-Membrive, P. ${ }^{2}$, Calatrava, J. ${ }^{3}$ \\ Investigador, E.T.S. de Ingeniería Agronómica, Universidad Politécnica de Cartagena, Cartagena; david.martinez@upct.es \\ Investigadora, Departamento de Ingeniería, Universidad de Almería, La Cañada de San Urbano, Almería; patriciamarin@ual.es \\ Catedrático de Universidad, E.T.S. de Ingeniería Agronómica, Universidad Politécnica de Cartagena, Cartagena; j.calatrava@upct.es
}

Resumen: La elevada rentabilidad del regadío en el sudeste de España, unida a unas condiciones climáticas semiáridas, hace que la demanda de agua para riego supere con mucho a la disponibilidad de recursos hídricos, generando una situación de escasez crónica. En este contexto, el reciente desarrollo de la disponibilidad de agua marina desalinizada (AMD) tiene indudables ventajas, al suponer un incremento de la disponibilidad de agua para riego, una mejora de su calidad y una mayor garantía del suministro. Por el contrario, el AMD tiene como mayores inconvenientes su elevado coste y unos mayores costes de fertilización, lo que puede, en principio, reducir la rentabilidad de las explotaciones. En ese sentido, el objetivo de este estudio es analizar la rentabilidad del riego con AMD en el cultivo de tomate en invernadero, uno de los principales cultivos hortícolas del sudeste español, tanto sobre enarenado como en sistemas hidropónicos con reutilización de drenajes.

La información sobre la respuesta agronómica de ambos sistemas de cultivo a los diferentes tipos de agua de riego utilizados (tres mezclas diferentes de AMD con diferentes conductividades eléctricas) procede de un ensayo experimental con tomate bajo plástico realizado dentro de las actividades del proyecto LIFE+ DESEACROP. Para analizar el impacto de los diferentes tratamientos de riego sobre la rentabilidad del cultivo, se ha realizado una caracterización técnico-económica del proceso estándar de producción de tomate para los dos sistemas de producción considerados a partir de estudios previos y de la consulta a técnicos, caracterización en la que se ha integrado la información técnica proveniente del ensayo experimental para calcular diferentes indicadores y ratios económicos.

Los resultados obtenidos muestran cómo el uso exclusivo de AMD para la producción de tomate supone un incremento del $5 \%$ de los costes de fertilización en hidropónico y del 14\% en enarenado y un incremento del $49 \%$ en el coste del agua de riego en cultivo hidropónico y del $54 \%$ en enarenado. Esto se traduce en un incremento de los costes de producción del $6 \%$ en hidropónico y del $4 \%$ en enarenado, incrementos que se ven reducidos de manera significativa cuando se utiliza una mezcla de AMD con aguas subterráneas. Pese a ello, la menor conductividad eléctrica del AMD mejora notablemente los rendimientos del cultivo generando un incremento de su rentabilidad en ambos sistemas de cultivo.

Palabras clave: desalinización; cultivos protegidos; hidropónico; calidad del agua de riego; costes de producción; evaluación económica. 


\title{
Profitability of using desalinated seawater in greenhouse to- mato production in Almeria
}

\author{
Martínez-Granados, D. ${ }^{1}$, Marín-Membrive, P. ${ }^{2}$, Calatrava, J. ${ }^{3}$
}

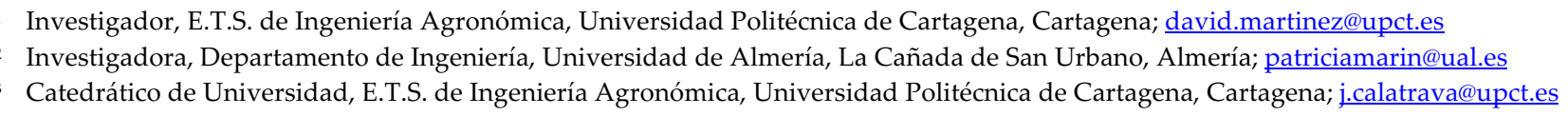

\begin{abstract}
The high profitability of irrigation in south-eastern Spain, coupled with semi-arid climatic conditions, leads to the demand for irrigation water far exceeding the availability of water resources, generating a situation of chronic water shortage. In such context, the recent development of the availability of desalinated seawater (DSW) has undoubted advantages, since it increases the availability of water for irrigation, improves its quality and guarantees a better supply. On the other hand, the main disadvantages of DSW are its high cost and higher fertilization costs, what could, in principle, reduce farm profitability. In this sense, the objective of this study is to analyse the profitability of irrigation with DSW in greenhouse tomato cultivation, one of the main horticultural crops in south-eastern Spain, both on traditional sanded soils and in hydroponic systems with reuse of drainage.
\end{abstract}

The information on the agronomic response of both cropping systems to the different types of irrigation water used (three different DSW mixtures with different electrical conductivities) comes from an experimental trial with tomato under plastic carried out within the activities of the LIFE+ DESEACROP project. To analyse the impact of the different irrigation treatments on crop profitability, a technicaleconomic characterization of the standard tomato production process for the two production systems considered has been carried out based on previous studies and the consultation with technicians, characterization in which the technical information from the experimental trial has been integrated to calculate different indicators and economic ratios.

The results obtained show that the exclusive use of DSW for tomato production increases fertilization costs by $5 \%$ in hydroponics and $14 \%$ in soil production and increases the cost of irrigation water by $49 \%$ in hydroponics and $54 \%$ in soil cultivation. This translates into an increase in production costs of $6 \%$ in hydroponics and $4 \%$ in soil cultivation, increases that are significantly reduced when using a mixture of DSW with groundwater. Despite this cost increase, the lower electrical conductivity of DSW significantly improves crop yields and thus increases profitability for both cropping systems.

Keywords: desalination; protected cultivation; hydroponic; irrigation water quality; production costs; economic assessment. 


\section{Congreso Nacional de Riegos CARTAGENA 2021}

\section{Introducción}

El sudeste de España es una de las regiones con mayor escasez de agua de toda Europa. La elevada rentabilidad de la actividad agrícola, unida a unas condiciones climáticas semiáridas, hace que la demanda de agua para riego supere con mucho a la disponibilidad de recursos hídricos [1], generando una situación de escasez crónica que repercute principalmente sobre la agricultura.

Las respuestas ante esta situación de escasez hidrológica han sido de diversa naturaleza. En primer lugar, la escasez de agua ha incentivado la adopción generalizada de modernos sistemas de riego presurizado, habiéndose producido en paralelo la modernización de gran parte de las infraestructuras de distribución de agua, maximizando su eficiencia a niveles difícilmente mejorables desde un punto de vista técnico [2] y generando importantes beneficios para la agricultura de regadío [3].

La segunda de las respuestas al problema de la escasez de agua en el Sudeste Español ha sido la transferencia de recursos desde otras zonas, a través de los trasvases Negratín-Almanzora y Tajo-Segura, que aportan importantes volúmenes al abastecimiento y al regadío del sudeste de España. Sin embargo, no existen expectativas razonables al respecto de la construcción de nuevos trasvases. Además, las previsiones futuras de disminución de las aportaciones hídricas plantean escenarios claros de reducción de las aportaciones de estos trasvases [4].

En tercer lugar, se ha producido un importante desarrollo de recursos hídricos no convencionales, incluyendo un elevado nivel de reutilización de las aguas residuales urbanas e industriales para aprovechamientos de riego, tanto en la cuenca del Segura como en la provincia de Almería [5, 6], así como el reciente y creciente recurso a la desalinización de agua marina $[7,8]$.

Pese a todas estas actuaciones, la escasez de recursos hídricos continúa siendo una realidad en el sudeste español. Además, las previsiones son que esta escasez se intensifique a medio plazo como consecuencia del cambio climático, con escenarios que prevén una reducción de las aportaciones hídricas medias en régimen natural de entre el 5 y el 11\% [5, 9], lo que supone una amenaza para la continuidad de la agricultura de regadío en muchas zonas. Las opciones de actuación a nivel de explotación pasan por el uso de estrategias de riego más sostenibles basadas en técnicas de riego deficitario controlado, los sistemas de telecontrol para optimizar la gestión del riego, y el recurso a nuevos cultivos o variedades menos demandantes de agua [10,11].

A nivel institucional, el escaso margen existente para mejorar la distribución y aplicación de agua o para incrementar los recursos procedentes de la reutilización (limitados por el consumo urbano e industrial), reduce las alternativas que permitan incrementar la resiliencia de la agricultura de regadío frente al progresivo agotamiento de los sistemas hidrológicos y afrontar la escasez, actual y futura, de agua en el sudeste español. Frente a otras opciones de gestión de la demanda de agua mediante mecanismos económicos, la principal apuesta de la planificación hidrológica nacional para el sudeste ha sido el desarrollo de la disponibilidad de agua de mar desalinizada. Efectivamente, a través del Programa AGUA, España ha hecho en los últimos tres lustros fuertes inversiones para la construcción de plantas desalinizadoras, con el fin de cubrir el déficit hídrico estructural, atendiendo la demanda del regadío y garantizando el suministro urbano.

En la actualidad, en todo el sudeste español, se están suministrando alrededor de $168 \mathrm{hm} /$ año de AMD para riego desde las siete Instalaciones Desalinizadoras de Agua de Mar (IDAM) de las provincias de Alicante, Almería y Murcia que suministran para uso agrícola (Torrevieja, Escombreras, Valdelentisco, Águilas-Guadalentín, Cuevas de Almanzora, Carboneras y Campo de Dalías). En el caso de la cuenca del Segura, durante los primeros años de operación de las IDAM, la demanda de AMD para uso agrícola fue reducida, manteniéndose entre 20 y $25 \mathrm{hm}^{3} /$ año hasta 2012. A partir de 2013, el uso de AMD desalinizada empieza a crecer, alcanzando los 139 hm³/año en 2016, con previsiones de alcanzar 


\section{Congreso Nacional de Riegos CARTAGENA 2021}

los $175 \mathrm{hm} 3 /$ año en pocos años. Este auge del uso del AMD para el riego agrícola en el sudeste español se explica por varias circunstancias favorables: el gran número de IDAMs financiadas por el Programa AGUA, que además utilizan tecnologías actuales y bastante eficientes, lo que reduce el coste de producción del AMD; la creciente necesidad de aportar nuevos recursos hídricos que ayuden a paliar el déficit estructural de agua; y la elevada rentabilidad de la agricultura de regadío en determinadas zonas.

Este hecho tiene indudables ventajas para el regadío del sudeste español, ya que supone una mayor cantidad de agua disponible para la producción agrícola, una mejora de la calidad del agua de riego en algunas zonas y un incremento de la garantía del suministro. Por el contrario, el agua marina desalinizada tiene como mayor inconveniente el elevado coste de su suministro, lo que reduce la rentabilidad de la actividad agraria. Asimismo, el AMD presenta también problemas que derivan, principalmente, de su baja concentración en nutrientes como calcio, magnesio y sulfato, que son esenciales para el desarrollo de los cultivos, y cuya presencia en las aguas continentales hace innecesario su aporte mediante fertilización [12-14]. Estas carencias obligan a realizar aportes de estos nutrientes, lo que incrementa los costes de la fertilización y tiene un impacto claro sobre la rentabilidad de las explotaciones [15].

En ese sentido, el objetivo de este estudio es analizar la rentabilidad y productividad de los principales factores de producción del riego con agua marina desalinizada en el cultivo de tomate en invernadero, uno de los principales cultivos hortícolas del sudeste español, tanto sobre enarenado como en sistemas hidropónicos con reutilización de drenajes prestando especial atención al impacto del coste del AMD y de la fertilización.

\section{Materiales y métodos}

La información sobre la respuesta del cultivo de tomate al riego con agua marina desalinizada, tanto sobre enarenado como en sistemas hidropónico con reutilización de drenajes, proviene de un ensayo experimental llevado a cabo en un invernadero tipo Almería, con ventilación cenital y lateral natural automatizada y sin calefacción, localizado en la Fundación Finca Experimental UALANECOOP, Retamar (Almería). Dicho ensayo se enmarca dentro de las actividades del proyecto LIFE+ DESEACROP (Desalinated Seawater for Alternative and Sustainable Soilless Crop Production) que se centra en la demostración del uso de técnicas de manejo eficiente y sostenible del agua marina desalinizada en sistemas de producción de tomate sin suelo de la horticultura almeriense. Con dicho objetivo en mente, las actividades experimentales del mencionado proyecto incluyeron diferentes tratamientos de riego utilizando diferentes tipos de agua en sistemas hortícolas protegidos, desarrollándose el cultivo tanto sobre suelo como en hidropónico. Los ensayos experimentales se han realizado durante dos ciclos otoño-invierno de tomate (Solanum lycopersicum L. cv. Ramyle) y dos ciclos primavera-verano de tomate (Solanum lycopersicum L. cv. Ramyle).

Para analizar el efecto del sistema de cultivo se han considerado [16]: 1) un sistema de cultivo hidropónico sobre sustrato de fibra de coco con reutilización de los drenajes; y 2) un sistema de enarenado tradicional de la zona sin reutilización de drenajes. Para analizar el efecto del riego con agua marina desalinizada, frente a las fuentes de suministro habitual en la zona, se han considerado tres tipos tratamientos de riego [17]: 1) agua marina desalinizada proveniente de la IDAM de Carboneras (tratamiento T1); 2) una mezcla de agua subterránea y AMD con una conductividad eléctrica de 1,5 dS/m (tratamiento T2); y 3) una mezcla de agua subterránea y AMD con una conductividad eléctrica de $3 \mathrm{dS} / \mathrm{m}$ (tratamiento T3).

Para analizar el impacto de los diferentes tratamientos de riego considerados sobre la rentabilidad del cultivo analizado, se ha partido de una caracterización técnico-económica del proceso estándar de 


\section{Congreso Nacional de Riegos CARTAGENA 2021}

producción de tomate para los dos sistemas de producción considerados. Dicha caracterización se ha realizado a partir información secundaria proveniente de estudios previos [18-20] y de la consulta a técnicos, y se ha contrastado con el proceso de producción llevado a cabo en el ensayo experimental para asegurar su compatibilidad. La caracterización técnico-económica de los procesos de producción en términos de cantidad y calidad de la producción, uso de insumos (incluyendo mano de obra), costes de producción, dinámica del proceso de producción, etc. requiere de la obtención de una amplia información de las diferentes labores u operaciones que se llevan a cabo durante el ciclo de cultivo. Para ello, las operaciones de cultivo se han organizado por meses, empezando inmediatamente después de la recolección y finalizando en la recolección de la siguiente campaña, y se han desagregado por tipos de operaciones (labores de preparación del terreno y del cultivo, labores culturales, aplicación del riego y de diversos tratamientos y tareas de recolección). Asimismo, se ha caracterizado la estructura productiva de una explotación estándar de la zona de estudio en términos de infraestructuras, sistemas de cultivo y riego, etc.

La caracterización técnico-económica del proceso productivo realizada para cada uno de los sistemas de cultivo considerados se ha utilizado para analizar el impacto sobre su rentabilidad del uso de cada tipo de recursos hídricos (tratamientos) considerados en el estudio. Para ello, se ha recogido información del ensayo experimental que se ha integrado en dicha caracterización técnico-económica y se han calculado una serie de indicadores y ratios económicos. Se presentan en este trabajo los resultados correspondientes a la media para los cuatro ciclos de cultivo de los diferentes tratamientos ensayados.

\section{Resultados y discusión}

\subsection{Rendimientos}

La Tabla 1 resume los valores medios de los indicadores calculados. Para interpretarlos correctamente, es importante considerar que los rendimientos del cultivo obtenidos en las actividades experimentales del proyecto están por debajo de los rendimientos normales del tomate en Almería. Esto se debe a la necesidad de incorporar más de dos ciclos productivos en la vida del proyecto, lo que llevó a la decisión de plantar cuatro ciclos productivos cortos en lugar de dos largos. Además, la necesidad de encajar dos ciclos productivos de tomate en un año llevó a terminar la recolección del cultivo antes de lo que es habitual en las explotaciones comerciales, para dar espacio y tiempo a la preparación del siguiente ciclo experimental. Esto ha dado lugar a un rendimiento medio anual del cultivo $\left(11 \mathrm{~kg} / \mathrm{m}^{2}\right)$ inferior al habitual en la zona que es de $19 \mathrm{~kg} / \mathrm{m}^{2}$ al año [21].

Los rendimientos medios de tomate en la Tabla 1 muestran un impacto positivo tanto de la calidad del agua como del uso de sistemas productivos sin suelo. El aumento del rendimiento medio del cultivo al pasar de T3 a T2 es significativo, mientras que la diferencia entre T2 y T1 es menor. El aumento del rendimiento de los cultivos al regar con agua menos salina es significativamente mayor para la producción sin suelo con recirculación de los flujos de drenaje $(\mathrm{H})$ que para el cultivo en enarenado. La mayor diferencia en el rendimiento de los cultivos entre T2 y T3 para el cultivo sin suelo $(\mathrm{H})$ con respecto al cultivo en suelo $(S)$ puede explicarse por la naturaleza más compleja de la tecnología de cultivo sin suelo. Los sistemas tradicionales de producción en suelo de la zona se desarrollaron para adaptarse a suelos pobres y recursos hídricos de mala calidad y, por tanto, los rendimientos se ven menos afectados por la salinidad del agua, que reduce significativamente los rendimientos en el cultivo sin suelo. 


\section{Congreso Nacional de Riegos CARTAGENA 2021}

\subsection{Costes de producción}

Los costes de producción, tanto directos como indirectos, son mayores para el cultivo sin suelo $(\mathrm{H})$ que para el cultivo tradicional en suelo (S), como se muestra en la Tabla 1. Por su parte, un mayor uso de AMD incrementa solamente los costes directos (T1>T2>T3). Las diferencias en los costes directos se explican por el mayor coste del AMD, el mayor consumo de agua, energía y fertilizantes de la producción sin suelo $(\mathrm{H})$ y el coste de las labores de recolección que depende del rendimiento del cultivo. El sistema de producción sin suelo tiene la ventaja de evitar la percolación de nutrientes al suelo, ya que el drenaje se recircula, pero al mismo tiempo consume más agua, fertilizantes y energía. Por otro lado, el rendimiento de los cultivos también aumenta con la producción sin suelo. Las diferencias en los costes indirectos se explican por el coste de amortización del sustrato y del sistema de recirculación de los drenajes.

Debido a lo comentado anteriormente, los costes unitarios de producción por kilogramo son menores para la producción sin suelo $(\mathrm{H})$ en T1 y T2, mientras que son mayores para el agua más salina (T3) debido a los menores rendimientos obtenidos. Un patrón similar se observa cuando se examina el coste unitario de la mano de obra. Por otro lado, los costes unitarios de agua, energía y fertilización son mayores para la producción sin suelo $(\mathrm{H})$ que para la producción en suelo (S). Esto se debe a que el consumo de agua, energía y fertilizantes es significativamente mayor en la producción sin suelo, a pesar de los mayores rendimientos que proporciona este sistema productivo. Sin embargo, el coste de estos insumos es relativamente pequeño en comparación con otros insumos como el capital y la mano de obra y se ve compensado, en general, por el mayor rendimiento de los cultivos que proporcionan los sistemas sin suelo.

\subsection{Productividades de los factores de producción}

La Tabla 1 muestra en primer lugar que tanto la productividad de la tierra como la del trabajo son mayores en la producción sin suelo $(\mathrm{H})$ para las calidades de agua T1 y T2. De nuevo, los resultados para T3 en la producción sin suelo son peores que en la producción con suelo tradicional, debido a las diferencias antes mencionadas en el rendimiento de los cultivos. Para cada sistema productivo, tanto la productividad de la tierra como la del trabajo aumentan con la calidad del agua (T1 $>$ T2 $>$ T3).

Por el contrario las productividades tanto de agua como de energía son mayores para la producción en suelo tradicional que para la produccón sin suelo, lo que se debe a las mayores necesidades de agua y energía de la producción sin suelo. El incremento de los rendimientos en hidropónico con respecto al cultivo en enarenado es menor que los incrementos en el consumo de agua y energia asociados. Finalmente, se observa cómo, para un mismo sistema productivo, las productividades aumentan con la calidad del agua (T1>T2>T3).

\subsection{Indicadores de rentabilidad}

En cuanto a las diferentes indicadores de rentabilidad calculados, su interpretación debe considerar que algunas de ellas toman valores negativos debido a los rendimientos inferiores a los habituales, ya comentados, obtenidos en los experimentos del proyecto. Para todas las medidas de rentabilidad consideradas (tierra, agua y energía), la rentabilidad por unidad aumenta con la calidad del agua (T1 $>\mathrm{T} 2>\mathrm{T} 3$ ). Todas las medidas de rentabilidad son también mayores para la producción sin suelo $(\mathrm{H})$ para T1 y T2, pero lo contrario ocurre para T3, debido al impacto de la baja calidad del agua en los rendimientos de los cultivos para la producción sin suelo (Tabla 1). 


\section{Congreso Nacional de Riegos CARTAGENA 2021}

Tabla 1. Indicadores económicos calculados para las diferentes estrategias analizadas

\begin{tabular}{|c|c|c|c|c|c|c|c|}
\hline & \multirow{2}{*}{ INDICADOR } & \multicolumn{6}{|c|}{ ESTRATEGIAS } \\
\hline & & H-T1 & H-T2 & H-T3 & S-T1 & S-T2 & S-T3 \\
\hline $\begin{array}{l}\text { Rendimiento del } \\
\text { cultivo }\end{array}$ & $\begin{array}{l}\text { Rendimiento medio del cultivo } \\
\qquad(\mathrm{kg} / \mathrm{ha})\end{array}$ & 66438 & 64375 & 44675 & 55378 & 54311 & 47353 \\
\hline \multirow{8}{*}{ Costes } & Costes directos $(€ /$ ha $)$ & 39837 & 39712 & 37458 & 36577 & 36494 & 35280 \\
\hline & Costes indirectos $(€ /$ ha $)$ & 11897 & 11897 & 11897 & 10158 & 10158 & 10158 \\
\hline & Costes de producción totales ( $€ /$ ha) & 51734 & 51609 & 49355 & 46735 & 46652 & 45438 \\
\hline & $\begin{array}{c}\text { Costes unitarios de producción } \\
(€ / \mathrm{kg})\end{array}$ & 0,7787 & 0,8017 & 1,1048 & 0,8439 & 0,8590 & 0,9596 \\
\hline & Costes unitarios del agua $(€ / \mathrm{kg})$ & 0,0169 & 0,0166 & 0,0169 & 0,0148 & 0,0138 & 0,0112 \\
\hline & Costes energéticos unitarios $(€ / \mathrm{kg})$ & 0,0173 & 0,0185 & 0,0239 & 0,0009 & 0,0009 & 0,0009 \\
\hline & $\begin{array}{l}\text { Costes unitarios de fertilización } \\
(€ / \mathrm{kg})\end{array}$ & 0,0415 & 0,0435 & 0,0591 & 0,0328 & 0,0348 & 0,0336 \\
\hline & $\begin{array}{l}\text { Coste unitario de la mano de obra } \\
\qquad(€ / \mathrm{kg})\end{array}$ & 0,3509 & 0,3597 & 0,4813 & 0,4046 & 0,4109 & 0,4566 \\
\hline \multirow{4}{*}{ Productividades } & Productividad de la tierra $(€ /$ ha) & 55458 & 53736 & 37292 & 46226 & 45336 & 39528 \\
\hline & Productividad del agua $\left(€ / \mathrm{m}^{3}\right)$ & 23,60 & 22,01 & 17,06 & 27,03 & 26,58 & 25,82 \\
\hline & $\begin{array}{c}\text { Productividad de la mano de obra } \\
(€ / \text { día })\end{array}$ & 142,7 & 139,2 & 104,1 & 123,8 & 121,9 & 109,7 \\
\hline & Productividad de la energía $(€ /$ kWh $)$ & 5,34 & 4,98 & 3,86 & 108,12 & 106,31 & 103,28 \\
\hline \multirow{6}{*}{ Rentabilidades } & Margen bruto por hectárea $(€ /$ ha) & 15621 & 14024 & -166 & 9649 & 8842 & 4247 \\
\hline & Margen neto por hectárea $(€ /$ ha) & 4451 & 2854 & -11336 & 218 & -589 & -5184 \\
\hline & $\begin{array}{l}\text { Margen bruto por unidad de agua } \\
\qquad\left(€ / \mathrm{m}^{3}\right)\end{array}$ & 6,65 & 5,74 & $-0,08$ & 5,64 & 5,18 & 2,77 \\
\hline & $\begin{array}{l}\text { Margen neto por unidad de agua } \\
\qquad\left(€ / \mathrm{m}^{3}\right)\end{array}$ & 1,89 & 1,17 & $-5,19$ & 0,13 & $-0,35$ & $-3,39$ \\
\hline & $\begin{array}{c}\text { Margen bruto por uso de energía } \\
(€ / \mathrm{kWh})\end{array}$ & 1,50 & 1,30 & $-0,02$ & 22,57 & 20,73 & 11,10 \\
\hline & $\begin{array}{l}\text { Margen neto por uso de energía } \\
(€ / \mathrm{kWh})\end{array}$ & 0,43 & 0,26 & $-1,17$ & 0,51 & $-1,38$ & $-13,54$ \\
\hline \multirow{3}{*}{$\begin{array}{l}\text { Uso de mano de } \\
\text { obra }\end{array}$} & $\begin{array}{l}\text { Uso de mano de obra por hectárea } \\
\text { (días/ha) }\end{array}$ & 389 & 386 & 358 & 373 & 372 & 360 \\
\hline & $\begin{array}{l}\text { Uso de mano de obra por unidad de } \\
\left.\text { agua (días } / \mathrm{m}^{3}\right)\end{array}$ & 0,1653 & 0,1581 & 0,1640 & 0,2183 & 0,2180 & 0,2354 \\
\hline & $\begin{array}{l}\text { Uso de mano de obra por } \mathrm{kWh} \\
\text { (días } / \mathrm{kWh} \text { ) }\end{array}$ & 0,0374 & 0,0358 & 0,0371 & 0,8733 & 0,8721 & 0,9415 \\
\hline
\end{tabular}

\subsection{Impacto social}

Pasando a los indicadores sociales que contemplan la demanda de mano de obra por unidad de los diferentes factores de producción, la Tabla 1 muestra que la mejora de la calidad del agua mediante el uso de AMD y el uso de sistemas productivos sin suelo con recirculación de drenaje da lugar a un 


\section{Congreso Nacional de Riegos CARTAGENA 2021}

ligero aumento del uso de mano de obra por hectárea, pero con diferencias muy pequeñas para las diferentes fuentes de agua (T1, T2 y T3). Por el contrario, el uso más intensivo del agua y de la energía en los sistemas de cultivo sin suelo reduce el uso de mano de obra por $\mathrm{m}^{3} \mathrm{y}$ por $\mathrm{kWh}$ con respecto al cultivo de suelo convencional.

\section{Conclusiones}

En este trabajo se presentan resultados de la evaluación del impacto económico del riego con agua marina desalinizada en el cultivo de tomate en invernadero, tanto sobre enarenado como en sistemas hidropónicos con reutilización de drenajes, de la provincia de Almería. Los resultados presentados se centran en el análisis de las diferentes estrategias analizadas en las actividades experimentales del proyecto DESEACROP, en las que se ha comparado el uso de diferentes fuentes de agua en sistemas protegidos de producción de tomate, tanto tradicionales como sin suelo.

Los resultados obtenidos ponen de manifiesto, en primer lugar, como el uso de AMD incrementa los costes de producción pero también los rendimiento de los cultivos, al reducirse la salinidad del agua, dando lugar a una mayor rentabilidad de los mismos. El uso exclusivo de AMD para la producción de tomate supone un incremento del $5 \%$ de los costes de fertilización en hidropónico y del $14 \%$ en enarenado y un incremento del $49 \%$ en el coste del agua de riego en cultivo hidropónico y del $54 \%$ en enarenado. Esto se traduce en un incremento de los costes de producción del $6 \%$ en hidropónico y del $4 \%$ en enarenado, incrementos que se ven reducidos de manera significativa cuando se utiliza una mezcla de AMD con aguas subterráneas. Pese a ello, la menor conductividad eléctrica del AMD mejora los rendimientos del cultivo generando un incremento de su rentabilidad. Asimismo, todas las productividades calculadas aumentan con la mejora de la calidad del agua gracias al mayor uso de AMD.

En cuanto al sistema de cultivo, el cultivo sin suelo es más intensivo en cuanto al uso de insumos, especialmente agua, energía y fertilizantes, lo que se traduce en mayores costes de producción que se compensan con un mayor rendimiento de los cultivos y una mayor rentabilidad de los mismos. Sin embargo, el rendimiento y la rentabilidad de los cultivos cuando se utiliza más agua salina son mayores para el sistema de producción tradicional en suelo. La materialización de los beneficios potenciales de la producción sin suelo en términos de rendimiento y rentabilidad de los cultivos requiere, por tanto, la utilización de recursos hídricos de mejor calidad. Asimismo, el uso de sistemas de producción sin suelo aumenta la productividad de la tierra y del trabajo con respecto a los sistemas de suelo tradicionales, pero da lugar a productividades más bajas de los factores agua y energía.

En cuanto a la demanda de mano de obra, tanto el uso de sistemas de producción sin suelo como el riego con AMD aumenta las necesidades de de mano de obra por hectárea, pero reduce el uso de mano de obra por $\mathrm{m}^{3} \mathrm{y}$ por $\mathrm{kWh}$.

En resumen, los resultados de las actividades experimentales del proyecto sugieren que tanto el uso de AMD como los sistemas de producción sin suelo aumentarían la rentabilidad de las explotaciones en la zona de estudio. Sin embargo, la materialización de los beneficios potenciales de la producción sin suelo requiere el uso de recursos hídricos de mejor calidad. En la zona de estudio, donde los recursos hídricos naturales disponibles son altamente salinos, la mejora de la calidad del agua de riego implica el uso de AMD. De lo contrario, el sistema tradicional de producción en suelo con enarenado, mejor adaptado a los suelos pobres y al agua de mala calidad, sería más rentable.

Sin embargo, desde el punto de vista de la sociedad, las ventajas de la producción sin suelo y del AMD son ambiguas. Mientras que el uso de AMD mejora la productividad de los insumos y, por tanto, la eficiencia en el uso de los recursos, el uso de sistemas de producción sin suelo reduce la 


\section{Congreso Nacional de Riegos CARTAGENA 2021}

productividad del agua y la energía, que son recursos escasos. Si nos fijamos en la generación de mano de obra, tanto la producción sin suelo como el AMD generan menos mano de obra por uso de agua y energía. La intensificación de la producción de tomate mediante el uso de tecnologías de producción sin suelo aumenta el uso de recursos productivos muy limitantes (agua y energía) sin que el aumento de la producción y la generación de empleo resultantes lo compensen. Sin embargo, esto podría ser compensado por la reducción de la lixiviación y, por tanto, de la contaminación del suelo y del agua, un efecto que no se evalúa aquí.

Es necesario indicar, finalmente, que los resultados de este trabajo se ven afectados cuantitativamente por las restricciones específicas del entorno experimental que dieron lugar a rendimientos de los cultivos inferiores a la media de la zona, pero siguen siendo válidos cualitativamente en lo que se refiere a la influencia de los factores (calidad del agua y sistema de cultivo) analizados.

\section{Agradecimientos}

Este trabajo ha sido financiado por la Unión Europea a través del Proyecto LIFE+ DESEACROP (LIFE16 ENV/ES/000341).

\section{Referencias}

1. Urquijo, J.; De Stefano, L. Perception of Drought and Local Responses by Farmers: A Perspective from the Jucar River Basin, Spain. Water Resour Manag 2016, 30, 577-591.

2. Soto-García, M.; Martínez-Alvarez, V.; García-Bastida, P.A.; Alcon, F.; Martin-Gorriz, B. Effect of water scarcity and modernisation on the performance of irrigation districts in south-eastern Spain. Agr Water Manage 2013, 124, 11-19.

3. Berbel, J.; Gutiérrez-Martín, C., Eds. Efectos de la modernización de regadíos en España. Serie Economía nº 30; Cajamar Caja Rural: Almería, España, 2017.

4. Senent-Aparicio, J.; López-Ballesteros, A.; Cabezas, F.; Pérez-Sánchez, J.; Molina-Navarro, E. A Modelling Approach to Forecast the Effect of Climate Change on the Tagus-Segura Interbasin Water Transfer. Water Resour Manage 2021, 35, 37913808.

5. CHS. Plan Hidrológico de la Cuenca del Segura 2015-2021; Confederación Hidrográfica de la Cuenca del Segura: Murcia, España, 2015.

6. Valera, D.L.: Belmonte, L.J.; Molina-Aiz, F.D.; López, A. Greenhouse Agriculture in Almería. A Comprehensive Techno-Economic Analysis; Cajamar Caja Rural: Almería, España, 2016.

7. Martínez-Álvarez, V.; González-Ortega, M.J.; Martin-Gorriz B.; Soto-García, M.; Maestre-Valero, J. F. The use of desalinated seawater for crop irrigation in the Segura River Basin (south-eastern Spain). Desalination 2017, 422, 153-164.

8. Melgarejo-Moreno, J.; López-Ortiz, M. I.; Fernández-Aracil, P. Water distribution management in South-East Spain: A guaranteed system in a context of scarce resources. Sci Total Environ 2019, 648, 1384-1393.

9. CEDEX. Evaluación del cambio climático en los recursos hídricos en régimen natural en España; Centro de Estudios y Experimentación de Obras Públicas: Madrid, España, 2011.

10. Fereres, E.; Soriano, M.A. Deficit irrigation for reducing agricultural water use. J Exp Bot 2007, 58(2), 147-159.

11. Ruiz-Sanchez, M. C.; Domingo, R.; Castel, J.R. Review. Deficit irrigation in fruit trees and vines in Spain. Span J Agric Res 2010, 8(S2), 5-20.

12. Yermiyahu, U.; Tal, A.; Ben-Gal, A.; Bar-Tal, A.; Tarchitzky, J.; Lahav, O. Rethinking desalinated water quality and agriculture. Science, 2007, 318, 920-921.

13. Ben-Gal, A.; Yermiyahu, U.; Cohen, S. Fertilization and blending alternatives for irrigation with desalinated water. J Environ Qual 2009, 38, 529-536.

14. Martínez-Alvarez, V.; Martin-Gorriz, B.; Soto-García, M. Seawater desalination for crop irrigation - A Review of current experiences and revealed key issues. Desalination 2016, 381, 58-70.

15. Maestre-Valero, J.F.; Martin-Gorriz, B.; Soto-García, M.; Martinez-Mate, V.; Martínez-Álvarez, V. Producing lettuce in soilbased or in soilless outdoor systems. Which is more economically profitable? Agr Water Manage 2018, 206, 48-55.

16. UAL. Deliverable DB1.1: Report on the configuration of the demonstrative plots; LIFE+ DESEACROP Project, Reference LIFE 16ENV-ES-000341, Universidad de Almería: Almería España, 2018. 


\section{Congreso Nacional de Riegos CARTAGENA 2021}

17. UAL. Deliverable DB2.1: Report on irrigation treatments and procedures to the water quality adjustments; LIFE+ DESEACROP Project, Reference LIFE 16-ENV-ES-000341, Universidad de Almería: Almería, España, 2018.

18. MAGRAMA. Estudios de Costes y Rentas de las Explotaciones Agrarias: Resultados técnico-económicos; Ministerio de Agricultura, Alimentación y Medio Ambiente: Madrid, España, 2015.

19. Junta de Andalucía. Anuario de estadísticas agrarias y pesqueras de Andalucía; Consejería de Agricultura, Ganadería, Pesca y Desarrollo Sostenible, Junta de Andalucía: Sevilla, España, 2018.

20. Calatrava, J.; Martínez-Granados, D. La productividad económica en los sistemas agrarios intensivos del Mediterráneo. In El regadío en el Mediterráneo Español. Serie Monografías nº 38; Garrido, A., Pérez Pastor, A., Eds.; Cajamar Caja Rural: Almería, España, 2019; pp. 97-124.

21. Valera D.; Belmonte L.J.; Molina F.D.; López A. Los invernaderos de Almería: análisis de su tecnología y rentabilidad; Cajamar Caja Rural: Almería, España, 2014. 


\section{GRUPO TEMAS C:}

\section{Balsas de Riego}

Infraestructura especialmente relevante y representativa del regadío del sureste español. En esta sesión se incluirán trabajos referidos a: El papel de las Balsas de riego como elemento de regulación, Importancia de la Seguridad en su explotación, Propuestas de clasificación y planes de emergencia, Tecnologías específicas de balsas (coberturas de sombreo, geomembranas, etc.) y otras cuestiones de interés relacionadas con estas infraestructuras. 


\title{
XXXVIII Congreso Nacional de Riegos CARTAGENA 2021
}

\section{Estudio comparativo de punzonamiento en láminas sintéticas para impermeabilización de balsas}

\author{
Climent Vicent, Pau ${ }^{1}$, Moreno Marín, Francisco José ${ }^{1}$, Murillo Silva, Claudio ${ }^{1}$
}

1 Renolit Ibérica S.A.; Pau.Climent@renolit.com

Resumen: Los nuevos Planes Hidrológicos plantean una reducción del agua disponible para riego en las próximas décadas. En este escenario, es imprescindible que las infraestructuras hidráulicas maximicen su eficiencia, o dicho de otra manera que minimicen sus pérdidas. Las balsas de riego son estructuras construidas con la máxima economía de materiales. En este sentido, el diseño geométrico de la balsa se suele llevar a cabo bajo el principio de balance neto de tierras: en la medida de lo posible, las tierras excavadas se deben utilizar en los diques de cierre y terraplenes para evitar o minimizar los préstamos. Como resultado, las estructuras de cierre son heterogéneas y contienen partículas de distinto tamaño y naturaleza, por lo que las láminas de impermeabilización se colocan sobre un soporte que puede dar lugar a punzonamientos. La resistencia o susceptibilidad a dicho punzonamiento no depende solamente del sustrato, sino también de las condiciones de operación de la balsa y del tipo de lámina. Mediante ensayos de laboratorio se ha simulado el comportamiento de geomembranas de PVC y PEAD frente a este fenómeno para conocer la magnitud de las perforaciones que podrían sufrir bajo distintas condiciones. En base a estos resultados y a la bibliografía existente se discuten las consecuencias que se derivan de las pérdidas de agua esperables a través de las zonas punzonadas y sus efectos a nivel de seguridad estructural de la balsa y de disponibilidad de recurso.

Palabras clave: impermeabilización, geomembranas, láminas, balsas, punzonamiento, pérdidas 


\title{
Aumento de la durabilidad de láminas de PVC-P utilizadas para la impermeabilización de balsas de riego con tecnologías de lacado
}

\author{
Climent Vicent, Pau, Moreno Marín, Francisco José, Murillo Silva, Claudio, Hans Tanghe
}

1 Renolit Ibérica S.A.; Pau.Climent@renolit.com

Resumen: Las geomembranas de PVC-P se han utilizado para impermeabilizar obras hidráulicas desde los años 40 del siglo XX. En España, las balsas para riego agrícola han sido uno de los campos en los que se ha utilizado este material con mayor profusión. Las barreras geosintéticas han permitido construir balsas impermeables con unos costes muy competitivos y unos niveles de seguridad elevados, pero en ciertos casos con una vida útil limitada, por lo que la durabilidad de los materiales se ha convertido en una cuestión clave a la hora de asegurar la viabilidad de los proyectos de construcción de balsas. A día de hoy, existe un stock importante de láminas instaladas en balsas con 30 y 40 años de antigüedad, lo cual ha permitido (1) conocer los principales procesos de degradación de estos materiales e (2) introducir mejoras en el diseño y fabricación de estos materiales. La tecnología de lacado, consistente en la aplicación de una fina película en la superficie de la lámina, ha permitido aumentar la durabilidad de las geomembranas de PVC de manera radical. Ensayos de envejecimiento acelerado demuestran que la aplicación de estas lacas puede llegar a doblar la vida útil de la lámina, ya que son capaces de desacelerar distintos procesos de degradación. Las balsas de Llanos de Mesa y Valle Molina, en la isla de Tenerife, han adoptado esta tecnología, lo cual ha permitido a sus propietarios disponer de garantías de hasta 20 años de duración, maximizando el retorno de la inversión y resultando en una mayor eficiencia en el uso de recursos.

Palabras clave: impermeabilización, geomembranas, láminas, balsas, durabilidad, lacado 


\title{
XXXVIII Congreso Nacional de Riegos
} CARTAGENA 2021

\section{Durability extension in PVC-P liners used for waterproofing ir- rigation reservoirs with lacquering technology}

\author{
Climent Vicent, Pau, Moreno Marín, Francisco José, Murillo Silva, Claudio, Hans Tanghe
}

1 Renolit Ibérica S.A.; Pau.Climent@renolit.com

\begin{abstract}
PVC-P geomembranes have been used to waterproof hydraulic works since the 1940s. In Spain, agricultural irrigation reservoirs has been one of the fields in which this material has been used with greatest profusion. Geosynthetic barriers have enabled the construction of watertight reservoirs with very competitive costs and high levels of safety, but in certain cases with a limited service life, so the durability of the materials has become a key issue when appraising the viability of reservoir construction projects. To date, there is an important stock of liners installed in rafts 30 and 40 years old, which has allowed (1) to understand the main degradation processes of these materials and (2) to introduce improvements in the design and manufacturing of these materials. Lacquering technology, consisting of the application of a thin film on the surface of the sheet, has made it possible to radically increase the durability of PVC geomembranes. Accelerated aging tests show that the application of these lacquers can double the useful life of the sheet, since they are capable of slowing down different degradation processes. The Llanos de Mesa and Valle Molina rafts, on the island of Tenerife, have adopted this technology, which has allowed their owners to have guarantees of up to 20 years, maximizing the return on investment and resulting in a greater efficiency in the use of resources.
\end{abstract}

Keywords: waterproofing, geomembranes, liners, ponds, reservoirs, durability, lacquering, coating 


\section{Congreso Nacional de Riegos CARTAGENA 2021}

\section{Geomembranas para impermeabilización de balsas: cómo y por qué se degradan}

La construcción de balsas ha acompañado el desarrollo humano desde el neolítico, con los primeros asentamientos humanos en comunidades agrícolas y ganaderas. El motivo fundamental de la construcción de balsas es la gestión del recurso hídrico: almacenar agua permite disponer de ella dónde y cuándo se necesita, con independencia de los regímenes fluviales, pluviales o cualquiera sea la fuente de aportación. En la actualidad la razón de ser de las balsas sigue siendo la misma, aunque la manera de construirlas es completamente distinta. La aparición de los materiales plásticos, capaces de crear una barrera impermeable con muy poco espesor, revolucionó la construcción de balsas, ya que permitió construir balsas sin necesidad de emplazarlas en terrenos de baja permeabilidad o de utilizar soluciones de impermeabilización complejas con materiales naturales, como la argamasa o los paquetes de arcilla [1]. El uso de materiales sintéticos, producidos en condiciones controladas, permitió también un control de calidad más exhaustivo y suprimió la heterogeneidad de prestaciones asociada al uso de materiales naturales como las arcillas, que eventualmente resultó en mayores niveles de seguridad para la balsa.

Alrededor de 1940 se empezaron a utilizar láminas de PVC plastificado (PVC-P) y otros polímeros como elemento impermeable en la construcción y renovación de obras hidráulicas [2]. Desde entonces el uso de dichos materiales, conocidos en la actualidad como geomembranas, se ha perfeccionado y tecnificado hasta convertirse en un elemento fundamental en las obras hidráulicas modernas, con infinidad de casos de éxito en los que las láminas llevan décadas en uso con un perfecto funcionamiento [3-5].

Las geomembranas pueden estar formuladas con distintos polímeros, pero todos ellos comparten una problemática: son compuestos orgánicos que se degradan y pierden propiedades con el tiempo [6]. En el caso de las geomembranas de PVC, el proceso de degradación es más complejo que en otros materiales, puesto que su envejecimiento no depende solamente de la degradación del polímero, sino también de la pérdida de plastificante [7]. Cuando hablamos de geomembranas de PVC, en realidad nos referimos a geomembranas de PVC plastificado (PVC-P), en contraposición al PVC rígido o noplastificado (PVC-U) utilizado en múltiples aplicaciones de uso común, como las cañerías domésticas. Con la adición de los plastificantes se consigue un producto flexible, con gran capacidad de adaptación al soporte y excelentes propiedades mecánicas, pero cuando éste se pierde el PVC recupera su estado rígido. Así pues, la degradación de las láminas de PVC depende de:

- Degradación de la resina de PVC: en el caso del PVC se trata de una deshidrocloración, y para que este proceso tenga lugar debe haber aporte de oxígeno y energía. En geomembranas utilizadas en balsas, esto puede suceder durante la soldadura de la lámina si la temperatura es excesiva, pero sobretodo como consecuencia de la exposición a la radiación solar de la parte de la lámina que queda expuesta en los taludes de la balsa. Durante este proceso, se produce una escisión de las cadenas poliméricas, por lo que el polímero pierde peso molecular y reduce sus prestaciones. La manifestación más clara de este proceso es la aparición de fisuras superficiales en la lámina, así como un cambio de color hacia tonos más amarillentos. El remedio típico utilizado en la industria para mitigar este fenómeno ha sido la aditivación con estabilizantes.

- Pérdida de plastificante: el proceso general consiste en una migración del plastificante desde el interior de la lámina hacia el medio externo, que en una balsa puede ser el agua (parte sumergida) o el aire (parte emergida). Además, ciertos microorganismos pueden también extraer el plastificante. La velocidad con la que se da este fenómeno depende de varios factores, entre ellos el tipo de plastificante, las condiciones ambientales, el espesor de la lámina, etc. La principal consecuencia, como se ha comentado, es la rigidización de la 


\section{Congreso Nacional de Riegos CARTAGENA 2021}

lámina, que se vuelve más frágil y más susceptible a la rotura; aunque también da lugar a una retracción isotrópica por la pérdida de masa asociada a la pérdida de plastificante. Para reducir la pérdida de plastificante la solución tradicional ha sido una buena selección de plastificantes, buscando por un lado una baja solubilidad y por otro una tipología poco proclive a la extracción por microorganismos.

Aunque se trata de mecanismos de degradación distintos, estos dos procesos ocurren de manera simultánea en láminas utilizadas en balsas de riego, que es el objeto de este artículo. La experiencia ha demostrado que, en la mayoría de casos, la degradación de las partes emergida y sumergida tiene un comportamiento distinto:

- En la parte sumergida el agua reduce el aporte de radiación solar, por lo que el polímero prácticamente no sufre degradación, pero sí tiene lugar una pérdida de plastificante. En plastificantes lineales utilizados por algunos fabricantes en el pasado sí se observaron pérdidas importantes por solubilidad [9], pero hoy en día no suele ser un mecanismo dominante. Los estudios realizados en aplicaciones no expuestas demuestran que láminas de PVC correctamente formuladas con plastificantes de alto peso molecular pueden retener concentraciones de plastificante elevadas durante cientos de años [10], manteniendo su flexibilidad y prestaciones. No obstante, en la parte sumergida de balsas sí cobra mayor importancia la extracción de plastificante por microorganismos.

- En la parte emergida, cercana a la coronación de taludes, es donde la lámina acostumbra a presentar mayor nivel de degradación. Esto se debe a que en esta zona sí tiene lugar ambos procesos de degradación simultáneamente. La radiación solar aporta energía necesaria para la degradación del polímero y a la vez hace que la lámina alcance mayor temperatura, lo cual acelera la pérdida de plastificante por evaporación. La temperatura es un factor que influye drásticamente en la velocidad a la que se dan estas reacciones [11].

\section{La tecnología de lacado y su efecto en geomembranas de PVC-P}

El uso de láminas sintéticas para impermeabilización no es ni mucho menos exclusivo de las balsas de riego. La experiencia adquirida por RENOLIT en la impermeabilización de otras aplicaciones expuestas como piscinas y cubiertas, ha permitido aplicar al campo de las balsas el uso de tecnologías innovadoras para aumentar la durabilidad de las geomembranas de PVC.

Los mecanismos de degradación arriba expuestos han sido ampliamente estudiados y la industria ha ido encontrando soluciones, principalmente incorporando aditivos a la formulación: estabilizantes térmicos para evitar la degradación, pigmentos para modificar la temperatura de la lámina, biocidas, etc. Aunque estos aditivos sin duda consiguen efectos beneficiosos, su introducción lleva aparejada un aumento de coste y en ocasiones efectos secundarios en forma de pérdida de prestaciones, por lo que la cantidad de aditivos siempre ha tenido unas concentraciones máximas admisibles. Otra solución clásica para aumentar la durabilidad de las láminas ha sido aumentar su espesor. Como regla general, doblar el espesor de una lámina doblaría también su vida útil, pero esto también tiene un impacto significativo en el coste del producto.

En este contexto, en el que la limitación en el uso de aditivos impedía obtener grandes mejoras en la durabilidad de las láminas, RENOLIT desarrolló el uso de lacas. La tecnología de lacado consiste en la aplicación de una fina capa en la superficie de la lámina durante su producción, quedando ésta permanentemente unida a la lámina de PVC propiamente dicha. Esta capa, al ser de un material diferente al de la lámina, permite la utilización de materiales con propiedades distintas, que mejoran las prestaciones de esta. 


\section{Congreso Nacional de Riegos CARTAGENA 2021}

En lo que concierne a la durabilidad de la lámina, los principales efectos de las lacas desarrolladas por RENOLIT son tres:

1. Efecto barrera: al estar aplicada en la superficie, la laca crea una barrera que permite alterar las condiciones con las que la lámina interactúa con el medio. Este aspecto es fundamental, ya que todos los mecanismos de degradación expuestos arriba tienen lugar siempre a través de la interface que supone la superficie de la lámina.

2. Absorción de UV: debido a la composición del material de base de la laca, es posible añadir una mayor concentración de pigmento, que permiten aumentar la protección contra la radiación ultravioleta (UV). Dentro del espectro de la radiación solar, la radiación UV es la que aporta mayor cantidad de energía, por lo que es la parte del espectro que más influye en el proceso de degradación.

3. Reducción de la temperatura: el material con el que se producen estas lacas permite no sólo aumentar la concentración de pigmento, sino además utilizar otros tipos más innovadores. Para conseguir una buena absorción de UV la solución tradicional pasaba por el uso de negro de humo. Este pigmento, utilizado también en otras geomembranas como las de polietileno o polipropileno, permite absorber gran cantidad de UV, pero debido a su color oscuro aumenta también la temperatura de la lámina. Por el contrario, el uso de pigmentos minerales alternativos ha permitido mantener las propiedades de absorción de UV a la vez que aumentar la reflexión de la parte infrarroja (IR) del espectro solar, mejorando así la capacidad de reflexión y reduciendo la temperatura de la lámina. Ante el ojo humano, una lámina gris claro clásica y una lámina gris claro lacada tienen exactamente la misma apariencia pero, a igualdad de condiciones, la temperatura de la lámina lacada es significativamente inferior (hasta $10^{\circ} \mathrm{C}$ en horas centrales del día en Barcelona). Esta reducción de la temperatura tiene un efecto claro: la lámina se degrada más lentamente.

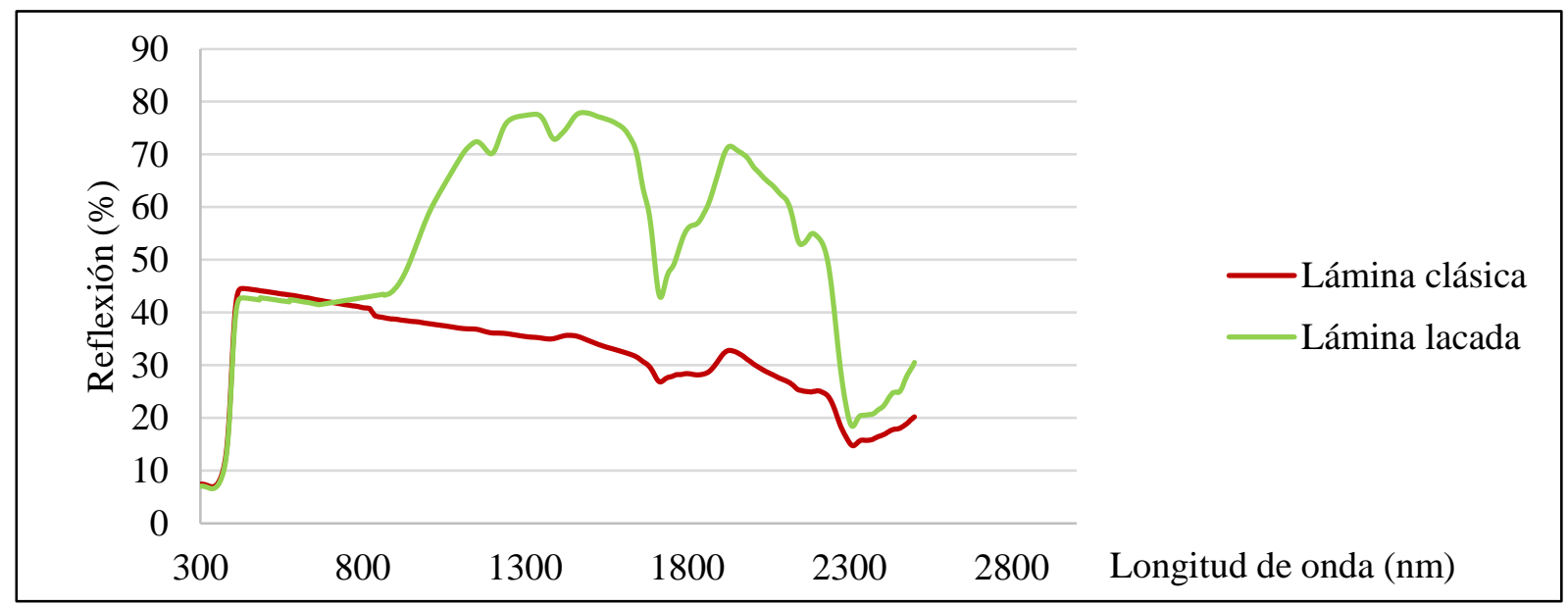

Figura 1. Espectros de reflexión de una lámina clásica de color gris claro y una equivalente con laca

Además, cabe destacar que las lacas se aplican en condiciones controladas en fábrica, no necesitan ningún tipo de mantenimiento (más allá del de la propia lámina) y no afectan las condiciones ni la calidad de la soldadura.

\section{Resultados}




\section{Congreso Nacional de Riegos CARTAGENA 2021}

\subsection{Envejecimiento acelerado en laboratorio}

La degradación de las geomembranas utilizadas en la impermeabilización de balsas es un proceso que, si se trata de productos adecuadamente formulados, tiene lugar durante décadas hasta que el producto alcanza el final de su vida útil. Existe abundante bibliografía que recoge casos de éxito en los que las geomembranas han estado (o siguen estando) en uso después de 40 años [3-5].

Para poder simular estos procesos en un intervalo de tiempo más reducido, se han venido desarrollando ensayos de laboratorio de envejecimiento acelerado. Estos ensayos tratan de simular las condiciones de degradación que ocurren en el medio natural mediante la aplicación intensificada de alguno/s de los factores que originan la degradación (p.e. temperatura, humedad, espectro de la radiación,...). La última versión de la norma EN 13361, que regula el marcado CE para geomembranas utilizadas en balsas [12], recoge en su Anexo A un resumen de los ensayos más adecuados para cada tipo de geomembrana. Cabe mencionar que, aunque los ensayos de envejecimiento acelerado permiten conocer en un menor tiempo el comportamiento del producto frente a ciertas acciones, dicha intensificación los hace más agresivos que la realidad, alterando en ocasiones los procesos de degradación. Así pues, los resultados siempre deben interpretarse con cautela y en base a un análisis crítico, idealmente contrastado y calibrado con casos reales.

El ensayo de proliferación de microorganismos según la norma EN 12225, permite conocer la velocidad con la que ciertos microorganismos pueden extraer el plastificante. En la figura de abajo se compara la efectividad del uso de biocidas con la de la aplicación de una laca de tan sólo $5 \mu \mathrm{m}$ de espesor a la hora de prevenir este proceso, y se comprueba que la laca es mucho más efectiva en el largo plazo, ya que reduce la pérdida de peso por extracción de plastificante al crear un efecto barrera.

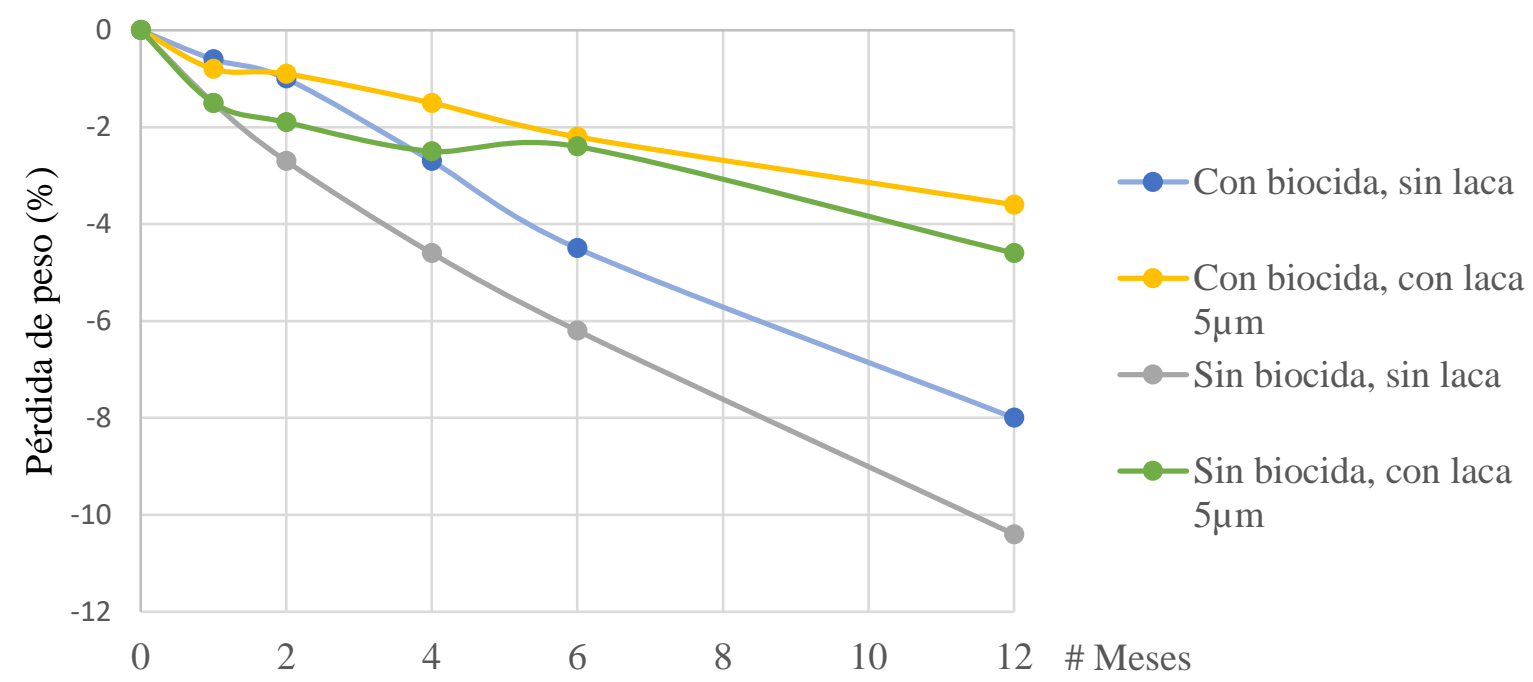

Figura 2. Pérdida de plastificante en ensayo de proliferación de microorganismos según EN 12225

Por otro lado, el ensayo 2 SUN se ha convertido en uno de los más avanzados de la industria a la hora de determinar el envejecimiento de geomembranas sometidas a la radiación solar. Este ensayo consiste en la aplicación de luz, calor y también tiene la opción de aplicar ciclos de humedad, lo cual somete a las láminas a condiciones de envejecimiento especialmente severas. En la normativa [12] se propone el ensayo EN 12224 para determinar la resistencia a la radiación UV, pero el 2 SUN presenta grandes ventajas sobre este otro ensayo, por utilizar lámparas de Xenon y por someter a la lámina a 
radiación continuada. Con carácter general, se puede estimar que 1000h de exposición en el ensayo 2 SUN equivaldrían a 2-3 años de uso en una balsa en el sur de Europa.

En el gráfico inferior se comparan los resultados obtenidos para una misma lámina con y sin laca. Se observa que la laca reduce la velocidad con la que se produce la pérdida de plastificante, de manera que transcurridas 5000 horas ( $\approx 10-15$ años) la pérdida de plastificante en una lámina lacada es un $40 \%$ menor respecto a una normal. Además, las lámparas Xenon utilizadas en el ensayo 2 SUN emiten menos radiación infrarroja que la radiación solar real, por lo que cabe pensar que la diferencia en condiciones de operación puede ser aún mayor.

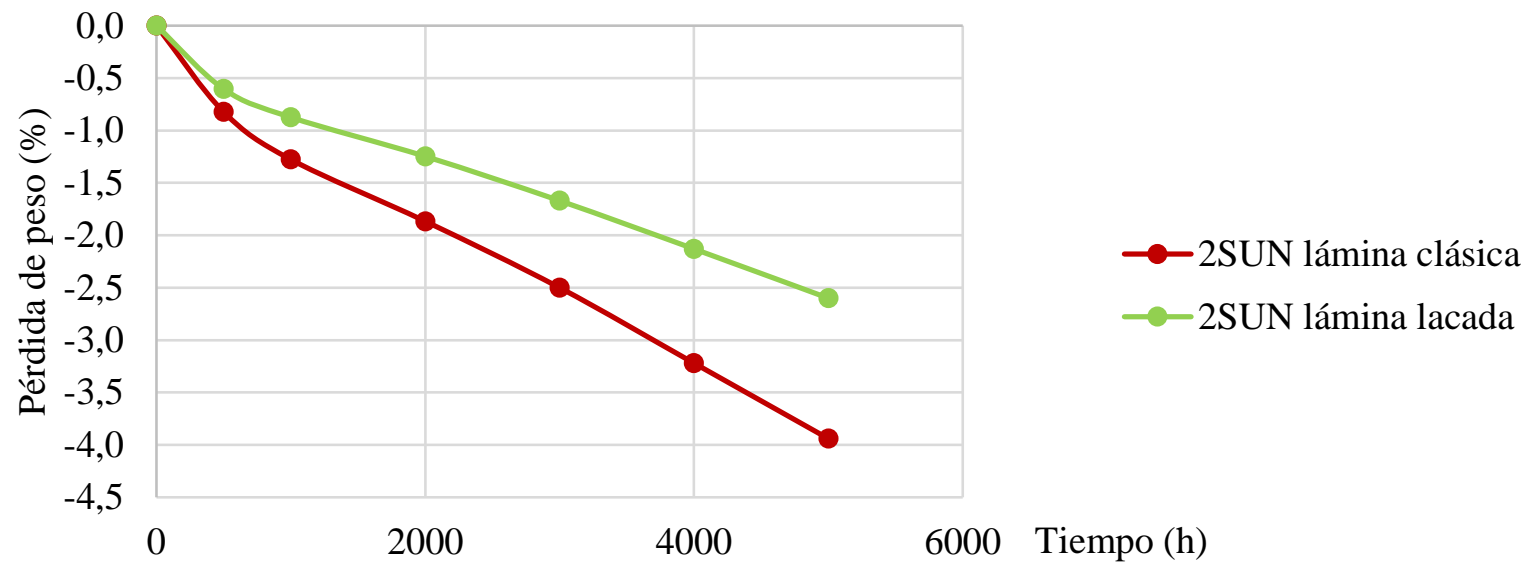

Figura 2. Pérdida de plastificante en láminas de $1.2 \mathrm{~mm}$ de color gris claro en el ensayo de $2 \mathrm{SUN}$

\subsection{Resultados de campo, la experiencia en Canarias}

Más allá de los resultados de laboratorio, las láminas incorporando tecnología de lacado ya han recorrido un cierto camino en aplicaciones reales. Por ejemplo, las láminas lacadas se han venido utilizando para la impermeabilización de piscinas desde hace más de 20 años, y para impermeabilización de cubiertas desde hace más de 10 años. En el ámbito de las obras hidráulicas, los primeros proyectos en incorporar dicha mejora estuvieron vinculados a centrales hidroeléctricas, en los cuales se incorporó el lacado para aumentar la durabilidad de la lámina en geografías con radiación solar severa como Oriente Medio. Este tipo de lacado se conoce como "tecnología de escudo solar" o SST por sus siglas en inglés (Solar Shield Technology).

En balsas de riego, la primera experiencia en España con tecnología SST se llevó a cabo en el año 2019, durante la re-impermeabilización de la Balsa de Valle Molina, en Tenerife. Esta balsa se construyó en 1985, contando para la impermeabilización del vaso con una lámina de PVC-P de 1,5 mm. Tras más de 30 años en servicio, la lámina instalada en la parte superior de los taludes había dado signos de envejecimiento, pero la lámina de la parte inferior de los taludes y del fondo presentaba aun unas propiedades aceptables. Así pues, la propiedad (BALTEN) decidió acometer una re-impermeabilización parcial de la balsa, conservando las zonas en buen estado y renovando únicamente las más deterioradas.

Dado que la lámina original había tenido una durabilidad muy elevada, la propiedad se interesó por las mejoras tecnológicas disponibles en el mercado para conseguir maximizar la vida útil de la nueva geomembrana. La experiencia de RENOLIT en las islas Canarias permitió desarrollar la conocida como formulación Barlovento, con una durabilidad contrastada en balsas situadas en el exigente clima subtropical del archipiélago. La combinación de la formulación Barlovento, junto con la aplicación de las lacas SST permitió ofrecer garantías extendidas con un periodo de validez de 15 años. Tal como se 


\section{Congreso Nacional de Riegos CARTAGENA 2021}

aprecia en la fotografía inferior, se instalaron unos $28.000 \mathrm{~m} 2$ de lámina RENOLIT ALKORPLAN Hydro R de 1,5 mm armada con malla de poliéster, en color gris claro y con tecnología de lacado SST en el anillo superior de la balsa.

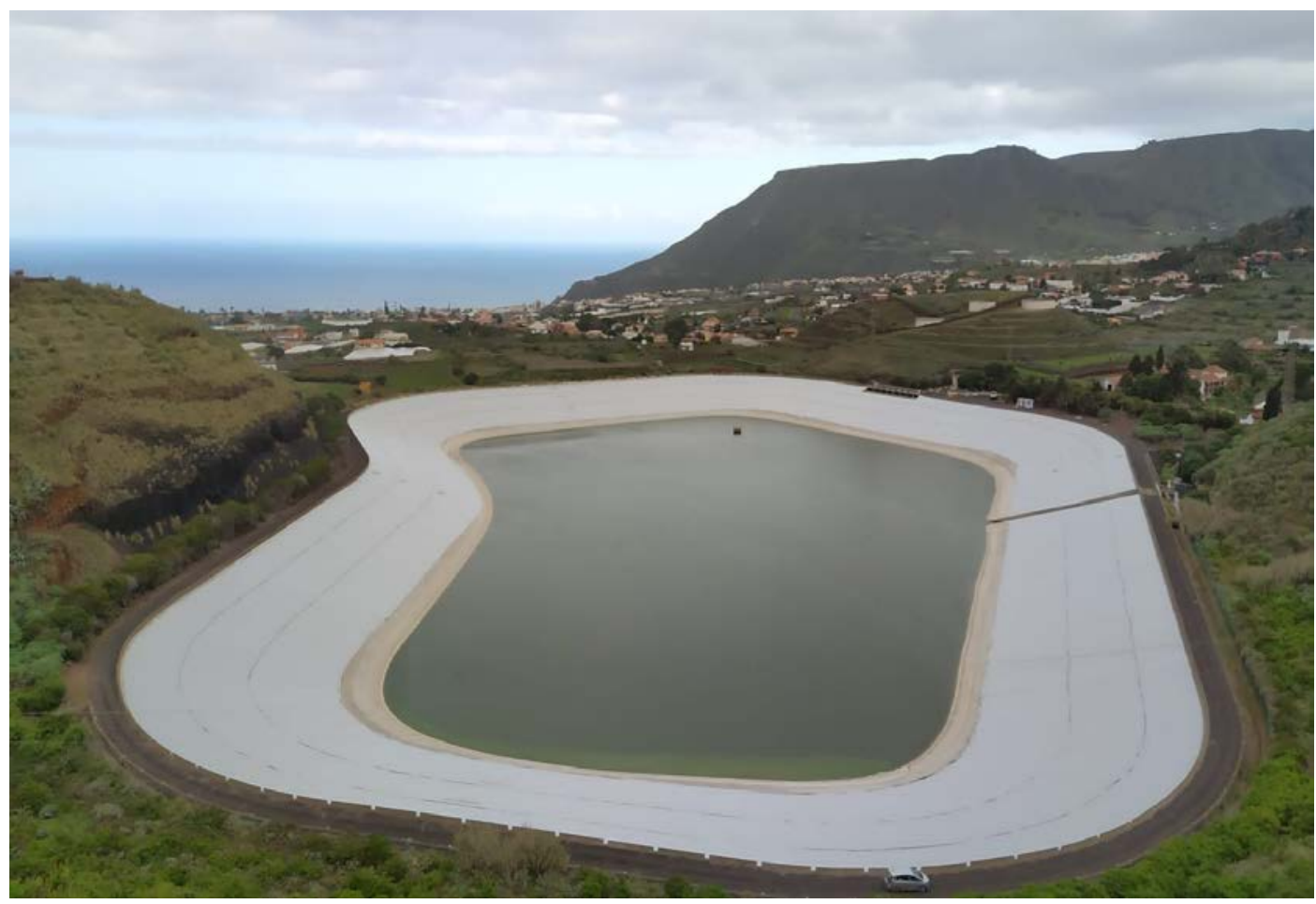

Figura 3. Vista de la balsa de Valle Molina tras la re-impermeabilización parcial, nótese el cambio de tonalidad entre la lámina original en el fondo y la nueva en el anillo superior.

La balsa de Llanos de Mesa, también en Tenerife, tiene una capacidad de $176.000 \mathrm{~m}^{3}$ y $15 \mathrm{~m}$ de columna de agua, se construyó entre 1986 y 1989 y se impermeabilizó con una lámina de PVC de 1,5 mm que había llegado ya al final de su vida útil. En el año 2020 BALTEN sacó a concurso público la reimpermeabilización total de la balsa. En el lote correspondiente al suministro de material se incluyó un criterio que valoraba la extensión de la garantía desde el periodo base de 10 años. Gracias a la tecnología de lacado SST y a la experiencia adquirida, RENOLIT fue capaz de ofrecer una garantía de 20 años para sus láminas RENOLIT ALKORPLAN Hydro R y RF de 1,5 mm. En este caso, se trataba de una lámina armada con malla de poliéster en el fondo $\left(8.000 \mathrm{~m}^{2}\right)$ y un geocompuesto en los taludes $\left(19.000 \mathrm{~m}^{2}\right)$, que incorporaba un geotextil de polipropileno laminado en su parte trasera, ambas con tecnología SST.

Aunque el lapso de tiempo transcurrido desde la instalación de estas geomembranas es aún demasiado corto para extraer conclusiones, la experiencia hasta el momento ha sido muy positiva y los resultados iniciales auguran un comportamiento muy favorable. Además, la propiedad puede ahora tener la confianza que la durabilidad de la lámina está avalada no sólo por los resultados de una innovación tecnológica, sino también por una garantía del fabricante. 


\section{ÄARYD}

XXXVIII Congreso Nacional de Riegos CARTAGENA 2021

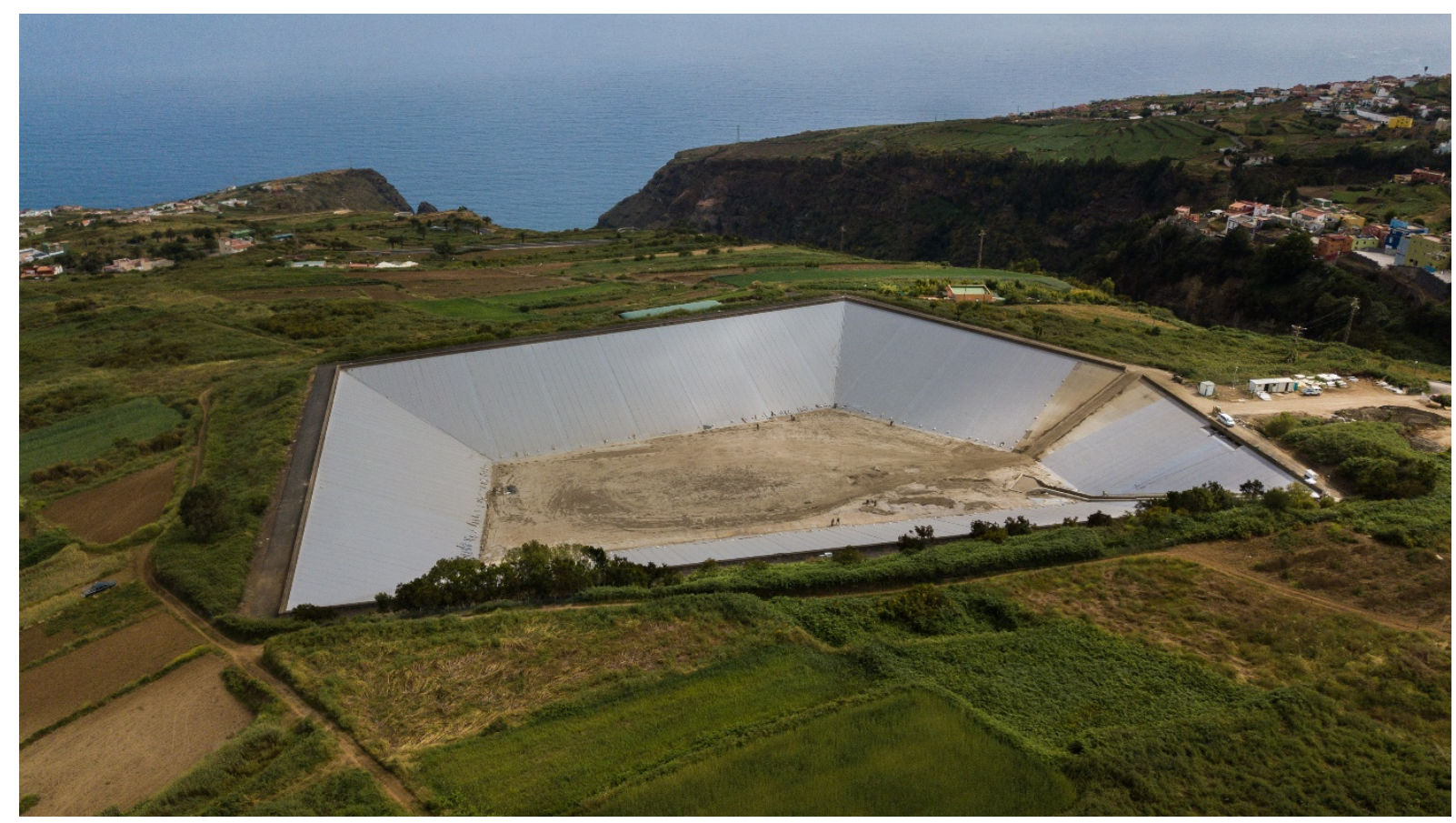

Figura 4. Balsa de Llanos de Mesa durante su re-impermeabilización. Se aprecia como el fondo y parte de los taludes no están aún impermeabilizados.

\section{Conclusiones}

Tras haber sido desarrollada en otros ámbitos, la tecnología de lacado ha llegado por fin a las geomembranas de PVC-P utilizadas para la impermeabilización de obras hidráulicas. La aplicación de la laca tiene un triple efecto sobre la lámina: crea un efecto barrera, mejora la absorción de UV y reduce la temperatura. Con estos efectos se consigue tanto reducir la desplastificación en las zonas sumergidas como combatir los efectos de la radiación solar en las zonas expuestas, consiguiendo así una extensión de la vida útil de la lámina de entre un $40 \%$ y un 100\% comparado con las correspondientes láminas tradicionales.

Estas mejoras en la durabilidad de la geomembrana son rápidamente aprovechables por los propietarios de las balsas donde se aplican, ya que permiten ofrecer garantías de hasta 20 años incluso en climas severos, reduciendo así el riesgo de las inversiones. Ya esxisten en España dos grandes balsas impermeabilizadas con láminas lacadas con tecnología SST y con su correspondientes garantías extendidas.

De cara a posibles futuras innovaciones, la protección superficial ofrecida por la tecnología de lacado podría permitir una reducción de espesor de la lámina para conseguir una misma vida útil objetivo. En cualquiera de los dos casos (i.e. mismo producto con mayor durabilidad o producto menos grueso para una misma vida útil) esta innovación representa una mayor eficiencia en el uso de recursos, en consonancia con las estrategias marcadas por los Objetivos de Desarrollo Sostenible [13], con los que tanto las balsas de riego como sus geosintéticos deberán alinearse.

\section{Referencias}

1. De Cea J C, 2021, Curso de seguridad de balsas para regadío. Proyecto, diseño, construcción, explotación y rehabilitación de balsas de tierra, CICCP

2. Koerner R M, 2012, Designing with Geosynthetics - 6th Edition Vol. 1, Xlibris 


\section{Congreso Nacional de Riegos CARTAGENA 2021}

3. Cazzuffi D and Gioffrè D, 2020, Lifetime assessment of exposed PVC-P geomembranes installed on Italian dams Geotextiles and Geomembranes 48 (2020) 130-136

4. Blanco M et al., 2016, Evolution over time of PVC-P Geomembrane used at Barlovento Reservoir, EuroGeo 6 Proceedings, $\mathrm{p}$ 631-641

5. Blanco M et al, 2018, Durability of Reinforced PVC-P Geomembranes installed in Reservoir in Easter Spain, Geosynthetics International, 2018, 25, No. 1

6. Scheirs J., 2000, A Guide to Polymeric Geomembranes, Wiley Series in Polymer Science

7. Fayoux D and Van Der Sype D, 2000, Durability of PVC-P Geomembranes, Assessment after very long UV Exposure, EuroGeo 2

8. Blanco $\mathrm{M}$ et al, 2016, Performance of Geomembranes seldom used un Hydraulic Works, installed in the experimental field of El Saltadero, EuroGeo 6 Proceedings, p 417-426

9. Crespo M., et al. 2017, Performance throughout 30 years of the PVC-P geomembrane installed in 'La Florida' reservoir, GeoAfrica 2017

10. Benneton J P, 1994, PVC-P Geomembranes Behaviour in a Ten-Year Water Laboratory Test, $5^{\text {th }}$ International Conference in Geotextiles, Geomembranes and Related Products, Singapore, 5-9 September 1994

11. R. M. Koerner, Y. G. Hsuan and G. R. Koerner, 2016, Lifetime Predictions of Exposed Geotextiles and Geomembranes, GeoAmericas 2016

12. UNE EN 13361:2018 Barreras geosintéticas. Requisitos para su utilización en la construcción de embalses y presas.

13. Touze N, 2021, Healing the world, a geosynthetics solution, Geosynthetics International, 28, No.1 


\title{
Evolución de las geomembranas de PVC-P instaladas en las bal- sas de la Isla de Tenerife. Importancia de los plastificantes en la vida útil de la geomembrana.
}

\author{
Vara Mora, Tatiana ${ }^{1}$, Cabrera Romero, M Dolores $^{1}{ }^{1}$, Solera Martínez, Rosario ${ }^{2}$, Mateo Sanz, Beatriz \\ 1 EPEL BALTEN; t.vara@balten.es \\ 2 Laboratorio Central de Estructuras y Materiales, CEDEX; Rosario.Solera@cedex.es
}

Resumen: En los años 80 del siglo XX, el Excmo. Cabildo Insular de Tenerife promovió las dos grandes iniciativas de carácter hidráulico que se desarrollaron en la Isla: el "Plan de Balsas del Norte de Tenerife (1980-1990)" con la construcción de 10 balsas en la vertiente norte de la isla y el "Programa de Reutilización de las aguas depuradas de las ciudades de Santa Cruz y La Laguna (1984-1994)", con la construcción de 2 balsas y $70 \mathrm{~km}$ de conducciones de impulsión y transporte en la vertiente sur y 1 balsa y $12 \mathrm{~km}$ de conducciones en vertiente norte. El éxito de este Plan de Balsas dió pie a la construcción de más balsas para poder cubrir las necesidades hídricas de la isla, contando en actualidad con un total de 21 balsas gestionadas por la EPEL BALTEN. Desde noviembre de 1989 se vienen realizando ensayos en las geomembranas instaladas en los embalses de Tenerife conforme al convenio suscrito con el Laboratorio Central de Estructuras y Materiales (CEDEX). la superficie impermeabilizada con láminas de PVC-P. asciende al 62,41\%. En este trabajo se exponen los comportamientos de las distintas geomembranas de PVC-P instaladas en las balsas de Tenerife. Se contrastan geomembranas con la misma formulación pero situadas con distintas condiciones de radiación solar, humedad y tensiones soportadas para comprobar que la formulación tiene un efecto significativo sobre el comportamiento de la degradación de la geomembrana, especialmente a largo plazo. Ya que los Plastificantes son aditivos que se incorporan a la geomembrana de PVC para darle flexibilidad, por lo que su pérdida ocasiona una rigidez en el material, haciéndolo quebradizo. La naturaleza de estos plastificantes es determinante para la vida útil o durabilidad de la geomembrana.

Palabras clave: impermeabilización; geomembrana PVC-P, balsas, plastificantes. 


\title{
Reimpermeabilización, casos prácticos
}

\author{
Vara Mora, Tatiana ${ }^{1}$, Dolores Cabrera, $\mathbf{M}^{\mathrm{a}}$ Dolores $^{1}$, Solera Martínez, Rosario ${ }^{2}$, Mateo Sanz, Beatriz
}

1 EPEL BALTEN; t.vara@balten.es

2 Laboratorio Central de Estructuras y Materiales, CEDEX; Rosario.Solera@cedex.es

Resumen: Cuando en los años 80 se impermeabilizó con geosintéticos, estos materiales resultaron una técnica novedosa y única para poder superar la permeabilidad de los terrenos volcánicos de Tenerife. Ante la necesidad de realizar trabajos de seguimiento del comportamiento de los distintos materiales se contactó con el Centro de Estructuras y Materiales de Obras Públicas (CEDEX) dependiente del Ministerio de Fomento ya que, su Laboratorio Central de Estructuras y Materiales, en el sector de Materiales, disponía de los medios especializados para la realización de los mismos. Gracias a los resultados obtenidos en los 31 años de convenios se ha podido planificar y programar las distintas actuaciones en las pantallas de impermeabilización de los embalses de Canarias. Los condicionantes que nos encontramos y que tenemos que tener en cuenta a la hora de reimpermeabilizar son: Comportamiento del material, Material instalado anteriormente, Tipología de la balsa y Ciclo del agua. De esta forma hemos conseguido: A) Rentabilización de la obra Pública, B) Planificación y programación de las actuaciones en las pantallas y C) Incremento de la vida útil de las pantallas, siempre en la franja de seguridad que nos ampara los ensayos realizados por el CEDEX, "no es gastar más ni menos, es gastar bien"

Palabras clave: reimpermeabilización; balsa; geosintéticos. 


\title{
CRITERIOS TÉCNICOS PARA LA CONSTRUCCIÓN Y EXPLOTACIÓN DE LAS BALSAS DE SEIASA
}

\author{
Hernández Redondo, J.A. ${ }^{1}$ Majuelos Moraleda, $\mathbf{M}^{2}$ \\ 1 SEIASA. Subdirector de Obras y Explotación; j.hernandez@seiasa.es \\ 2 SEIASA. Departamento Técnico; m.majuelos@seiasa.es
}

Resumen: SEIASA, Sociedad Mercantil Estatal de Infraestructuras Agrarias, S.A. ha construido, en el marco de los convenios de modernización de regadíos establecidos con las Comunidades de Regantes, 156 balsas y actualmente están en construcción otras cinco. De estas balsas SEIASA es el titular.

De la experiencia obtenida en la elaboración de los proyectos, la dirección de las obras y la explotación de las mismas, podemos extraer y compartir algunos criterios que pueden contribuir a la construcción y explotación de balsas más seguras. Sin ser exhaustivos expondremos los criterios constructivos fundamentales y las líneas generales del seguimiento de la explotación de las balsas. Repasando las principales causas de colapso observadas establecemos los criterios seguidos para la construcción y las pautas en la observación de los puntos críticos de las infraestructuras.

Palabras clave: Seiasa, balsa, construcción, explotación. 


\title{
XXXVIII Congreso Nacional de Riegos CARTAGENA 2021

\section{TECHNICAL CRITERIA FOR THE CONSTRUCTION AND OPERATION OF THE SEIASA WATER RESERVOIR}

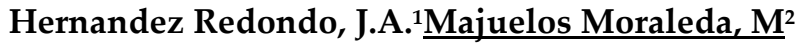 \\ 1 SEIASA. Subdirector de Obras y Explotación; j.hernandez@seiasa.es \\ 2 SEIASA. Departamento Técnico; m.majuelos@seiasa.es
}

\begin{abstract}
SEIASA, Sociedad Mercantil Estatal de Infraestructuras Agrarias, S.A. has built, within the framework of the irrigation modernisation agreements established with the Irrigation Communities, 156 water reservoirs and another five are currently under construction. SEIASA is the owner of these reservoirs.

From the experience gained in the preparation of the projects, the management of the works and their operation, we can extract and share some criteria that can contribute to the construction and operation of safer reservoirs. Without being exhaustive, we will outline the fundamental construction criteria and the general guidelines for monitoring the operation of ponds. Reviewing the main causes of collapse observed, we establish the criteria followed for construction and the guidelines for observing the critical points of the infrastructures.
\end{abstract}

Keywords: Seiasa, water reservoir, construction, operation. 


\section{Introducción}

Las balsas de tierra, nombradas a veces como balsas de materiales sueltos, o como balsas de agua, forman parte fundamental de las instalaciones de modernización de regadíos. En España es innegable su importancia en los últimos 60 años. Hasta 2008 no existe una referencia normativa a las balsas y es en el RD 9/2008, de modificación del Reglamento del Dominio Público Hidráulico, donde se recoge la definición:

"Balsa: Obra hidráulica consistente en una estructura artificial destinada al almacenamiento de agua situada fuera de un cauce y delimitada, total o parcialmente, por un dique de retención".

También se recoge la de "Presa: Estructura artificial que, limitando en todo o en parte el contorno de un recinto enclavado en el terreno, esté destinada al almacenamiento de agua dentro del mismo. A los exclusivos efectos de seguridad, también se entenderán como tales las balsas de agua."

Aun hoy, no existen muchas referencias normativas sobre balsas, su construcción, explotación o mantenimiento, si bien la experiencia es abundante. El citado RD del año 2008, en su artículo 364, recoge la necesidad de redacción de tres Normas Técnicas de Seguridad, que serán aprobadas, cuando proceda, por Real Decreto:

- Norma Técnica de Seguridad para la clasificación de las presas y para la elaboración e implantación de los planes de emergencia de presas y embalses.

- Norma Técnica de Seguridad para el proyecto, construcción y puesta en carga de presas y llenado de embalses.

- Norma Técnica de Seguridad para la explotación, revisiones y puestas fuera de servicio de presas.

SEIASA, Sociedad Mercantil Estatal de Infraestructuras Agrarias, pertenece al grupo Patrimonio del Estado (Ministerio de Hacienda) y es desde el año 2000 empresa instrumental del Ministerio de Agricultura, Pesca y Alimentación, dependiente de la actual Dirección General de Desarrollo Rural, Innovación y Formación Agroalimentaria, para la modernización y consolidación de los regadíos contemplados en el Plan Nacional de Regadíos y declarados de interés general.

En SEIASA participamos en la supervisión de los proyectos, dirigimos las obras y somos los titulares de las mismas por un periodo de 50 años, si no son amortizadas de forma anticipada, lo que implica una importante responsabilidad en su explotación. En la actualidad disponemos de 156 balsas en explotación y 5 en ejecución.

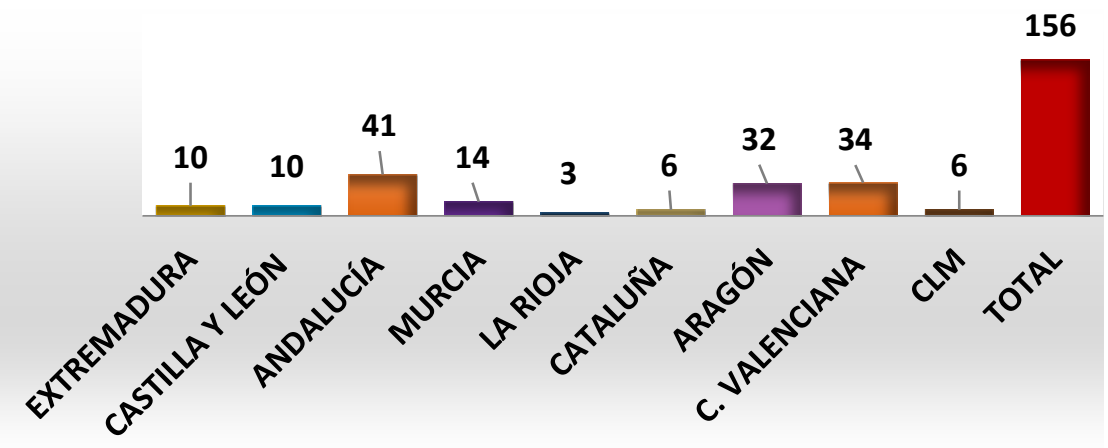

Figura 1. Balsas en explotación, 2021 


\section{Congreso Nacional de Riegos CARTAGENA 2021}
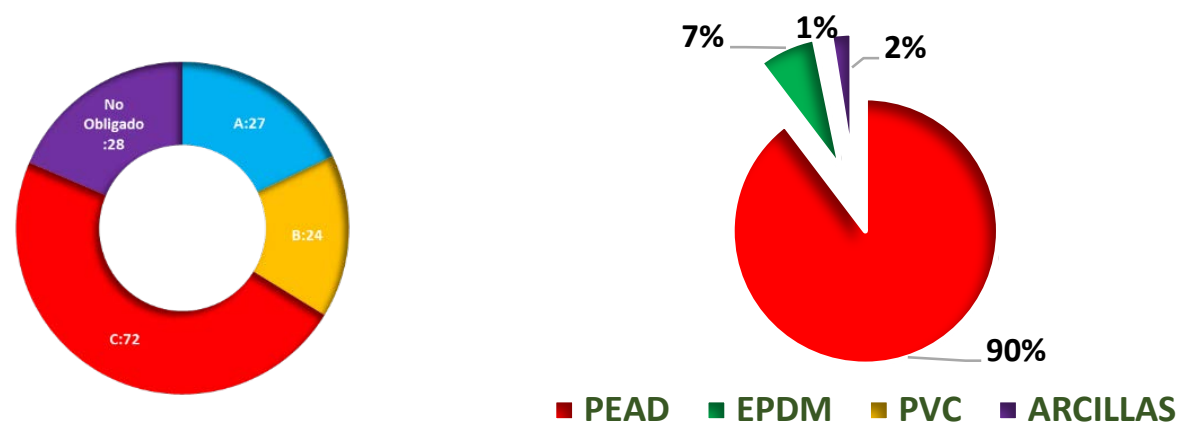

Figura 2. Clasificación de las balsas y tipo de impermeabilización

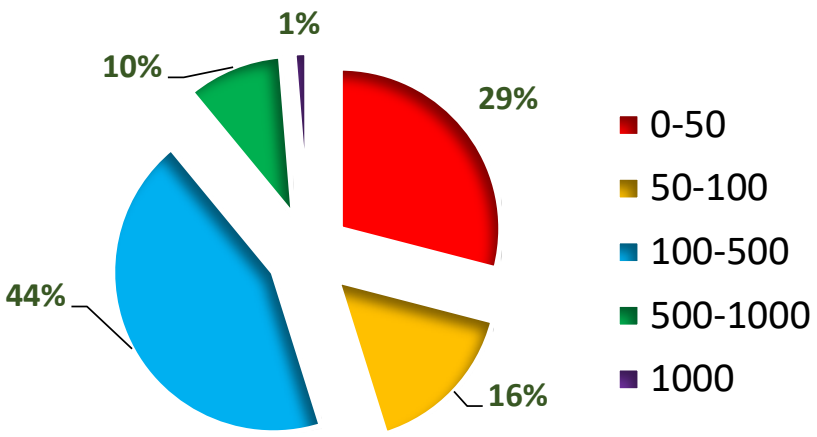

Figura 3. Volúmenes, en miles de $\mathrm{m}^{3}$.

De esta experiencia en el proyecto, construcción y explotación podemos extraer algunos criterios que pueden contribuir a la construcción y la explotación de balsas más seguras.

\section{Criterios para la Construcción}

Se trata de construir balsas seguras que cumplan satisfactoriamente y por largo tiempo, su función, por lo que ha de tenerse en cuenta que esta seguridad está íntimamente relacionada con los siguientes aspectos [1]:

- Criterios de proyecto, sobre todo en determinados puntos críticos.

- Control exhaustivo durante la ejecución, especialmente de los puntos críticos detectados.

- Normas de Explotación o unas Normas eficaces de Vigilancia y Mantenimiento.

Dado que, a pesar de todo, el riesgo cero no existe, la obra puede fallar e interesa analizar cuáles serían sus consecuencias, para así poder adoptar medidas eficaces que disminuyan al máximo los daños, especialmente los referidos a la pérdida de vidas humanas: esto se recogerá en el Plan de Emergencia. [2]:

El Análisis de las patologías e incidencias en las balsas, la observación de los accidentes y el estudio de sus causas nos debería permitir [3]:

- Conocer la problemática real desde un punto de vista estructural y funcional.

- Determinar los puntos críticos y los secundarios para categorizar la inspección en las labores de explotación, vigilancia y mantenimiento. 
- Establecer las patologías y puntos críticos que pueden afectar en mayor y menor medida a la balsa y a los que se les deberá prestar especial atención tanto a nivel de proyecto y ejecución como a nivel de explotación.

Fundamentalmente se han observado las siguientes causas de colapso:

- Sobrevertido (diseño erróneo del aliviadero, por lluvia extrema, error humano, etc.). Causa principal de colapso en PRESAS, pero escasa en BALSAS.

- Deslizamientos, diseños erróneos, inestabilidad geotécnica y/o geológica, falta de mantenimiento, acción sísmica, etc. Escasa incidencia en balsas.

- Erosión interna. Causa principal de colapso en BALSAS. Asociadas a las obras de toma y/o a través de las vías preferentes en el contacto con las conducciones o estructuras que atraviesan el dique.

- A través de la masa del dique. Escasa incidencia en balsas.

Pueden establecerse las siguientes patologías, probabilidades y soluciones de los colapsos [4]:

- Caso general de rotura en la geomembrana. Baja probabilidad de accidente grave. Dren chimenea y de vaso.

- Rotura en la unión de la geomembrana con la obra de toma. Alta probabilidad de accidente grave. Dren de envuelta.

- Rotura o Fugas en tuberías a presión en contacto con el terreno u hormigonadas. Muy alta probabilidad de accidente grave. Estructura de protección.

Referido a los modos de fallo por Erosión Interna, principalmente pueden presentarse [5]:

- Tubificación a través de las vías preferentes existentes junto a las estructuras que atraviesan el dique.

- Tubificación a través del cuerpo del dique.

- Tubificación a través de la cimentación.

- Tubificación debido a filtraciones de conducción en presión dentro del dique.

- Tubificación debido filtraciones canalizadas por conducción sin presión.

- Tubificación causada por fauna o flora.

- Tubificación causada por filtraciones exteriores.

La SOLUCIÓN que debe adoptarse se basa en:

- Impedir que los materiales erosionados sean evacuados (retener la materia sólida arrastrada).

- Impedir que el agua que atraviese los filtros tenga capacidad erosiva (gradiente muy bajo).

Estas soluciones se concretan en:

\section{DREN DE ENVUELTA}

- Los drenes de envuelta permiten que en caso de filtración, el agua sea drenada, pero no arrastre el material, protegiendo y avisando de la filtración. 


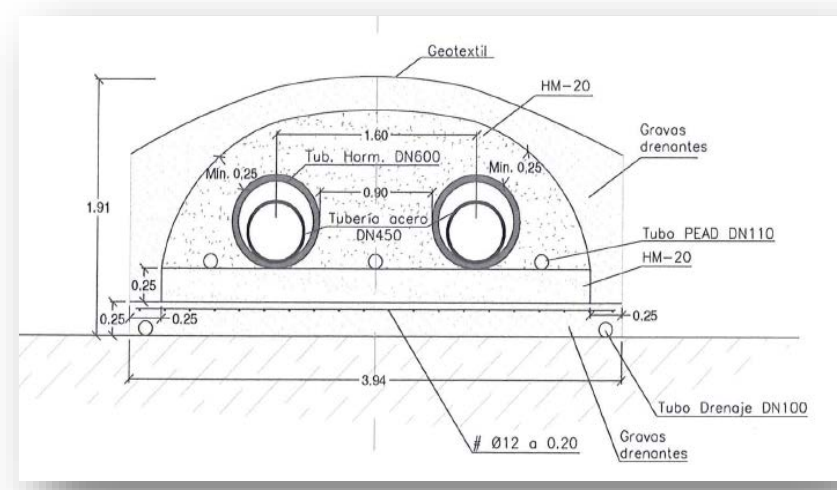

Figura 4.Dren de envuelta

\section{DREN DE CHIMENEA}

- La ejecución de un dren chimenea en el talud en terraplén protege al talud exterior de cualquier tipo de filtración que lo podría colapsar.

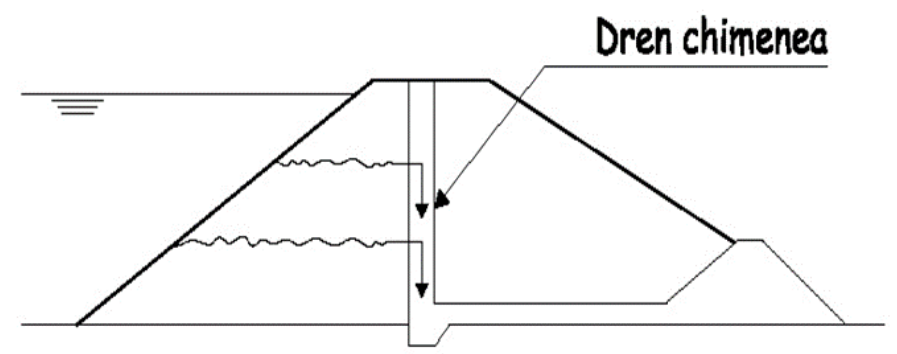

Figura 5. Dren chimenea [6]:

\section{DRENES DE VASO}

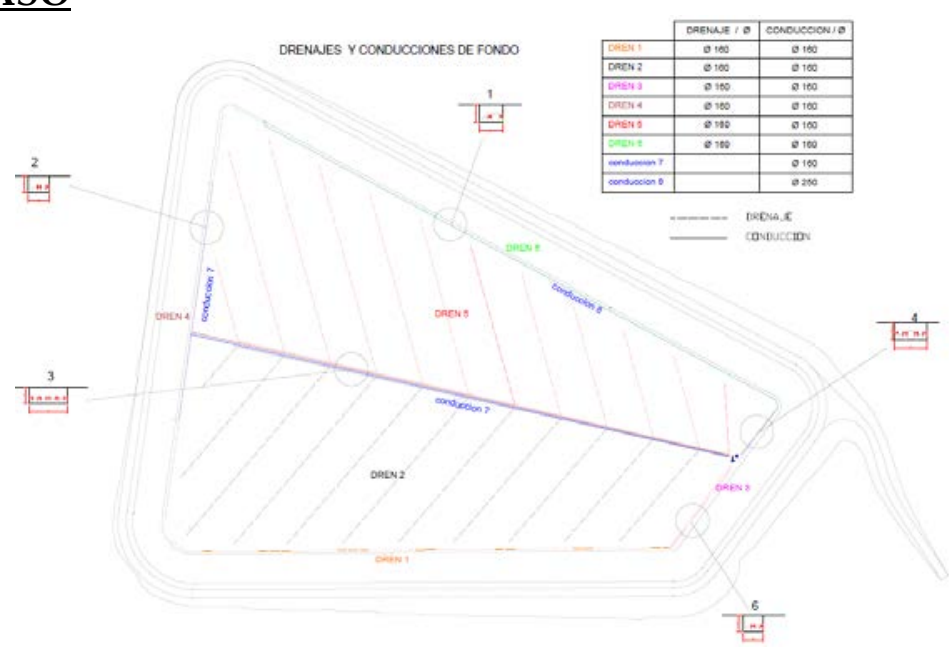

Figura 6. Dren de vaso 


\section{PROTECCIÓN DE TUBERIAS}

- Nunca colocar tuberías en presión en contacto con el terreno, siempre irán alojadas en galería o conducción de protección.

\section{DOBLE VALLADO}

- Realizar un cerramiento de la superficie ocupada, pie de talud exterior y ortor en el perímetro interior del camino de coronación

\section{DESAGÜE DE EMERGENCIA}

- En el tiempo acorde a la infraestructura y al punto de entrega

Todos los modos de fallo (excepto las filtraciones de conducción en presión dentro del dique), necesitan necesariamente una rotura o fallo de la pantalla impermeabilizante.

\section{Criterios para la explotación}

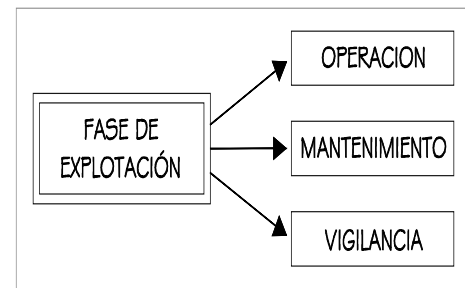

Figura 7. Fase de explotación [7]:

- Operación. Este aspecto se refiere al uso del recurso en sí, y al empleo de la balsa y de sus elementos para conseguir la finalidad de su uso.

- Mantenimiento. Este aspecto se refiere a la conservación de todos aquellos elementos que componen la balsa a lo largo del tiempo manteniéndolos en condiciones idóneas de funcionamiento.

- Vigilancia. Este aspecto se refiere a la observación continuada y atenta de la balsa y su entorno a lo largo del tiempo, en busca de anomalías que indiquen un mal funcionamiento de algún elemento, o la aparición de alguna irregularidad, que revele un comportamiento anómalo de la balsa, pudiendo prevenir anticipadamente situaciones de riesgo para la balsa. Dentro de este aspecto se incluye el control de aquellos elementos contenidos dentro de la auscultación.

Según la Normativa de Presas, aplicada a balsas, las que cumplan determinadas condiciones deberán solicitar ante la administración competente la correspondiente clasificación frente al riesgo potencial.

Si es clasificada en las categorías A o B, deberán elaborar el preceptivo Plan de Emergencia, que deberá formar parte de las Normas de Explotación. 
En este apartado solo se recoge lo referente al:

\section{PLAN DE CONTROL, INSPECCIÓN Y VIGILANCIA}

El PLAN tiene por objeto definir las actuaciones que deberán llevarse a cabo y la organización y medios que serán necesarios, para mantener, en condiciones adecuadas de uso y por consiguiente de seguridad, la balsa como infraestructura de riego.

Debe entenderse la vigilancia en sus dos principales facetas:

- De mantenimiento, que será llevada a cabo por el equipo habitual del manejo de las instalaciones en explotación.

- De seguridad, que será realizada por un equipo experto y con los conocimientos precisos de los puntos débiles de la balsa.

Se centra en el seguimiento ordinario que durante la explotación deberá realizar el personal que maneja las instalaciones, es decir, tiene un carácter eminentemente preventivo. No obstante, recoge el procedimiento a seguir en aquellas ocasiones en que se consideren necesarias acciones correctivas o mejorativas, si procede.

Formará parte de las NORMAS DE EXPLOTACION.

\section{LABORES DE INSPECCIÓN, CONTROL Y VIGILANCIA}

El Director del Plan, junto con el Responsable de su ejecución, determinará, con la periodicidad que se estime adecuada en función de las características de la Balsa, todas aquellas labores necesarias para el correcto mantenimiento de la misma. Establecerá así mismo, las pautas a seguir en situaciones extraordinarias, como puedan ser las ocasionadas por fenómenos meteorológicos o geológicos fuera de lo normal.

En función de la información obtenida en el seguimiento del PLAN, se elaborarán nuevas pautas para el periodo siguiente.

Semanalmente (incluso de forma diaria):

- Inspección visual de taludes exteriores, arquetas de recogida de drenes y arquetas de registro de válvulas y de llenado.

- Inspección visual de la coronación de la balsa, de los anclajes de la lámina y de las superficies impermeabilizadas que no estén sumergidas.

- Inspección visual de los cerramientos, accesos y elementos de seguridad.

\section{Mensualmente:}

- Control de ventosas, válvulas, tornillería...

- Control de automatismos y elementos de auscultación.

- Control de elementos de desagüe y aliviaderos (completando todo su recorrido). 


\section{Congreso Nacional de Riegos CARTAGENA 2021}

\section{Semestralmente:}

- Control general de la obra: estructura, impermeabilización, elementos hidráulicos, calidad de las aguas y urbanización.

\section{Anualmente:}

- Control de la impermeabilización (juntas, uniones, piezas especiales, estado de las superficies...). En este control se tomaran muestras de los materiales de impermeabilización para su ensayo, si así se ha establecido anteriormente o lo aconsejara la inspección, y a partir de los resultados obtenidos se determinará la periodicidad de los siguientes.

- Control de las cotas (planimetría de coronación, arquetas, casetas, cunetas...). Si visualmente se aprecian desniveles.

- Control de elementos hidráulicos (presiones, estanqueidades, maniobra de válvulas...).

Anualmente se elabora el informe que recoge todas las actuaciones y observaciones realizadas y se añade al archivo de la obra.

\section{ORGANIZACIÓN}

\section{Director del Plan}

- Responsable de dirigir todas las actuaciones, valorar la información recibida en el desarrollo del Plan, adoptar nuevas actuaciones, determinar las actuaciones a seguir en los casos de incidencias o situaciones exraordinarias y eleborar los informes anuales.

\section{Responsable del Plan}

- Ejecutar el Plan establecido, coordinando las labores de los operarios asignados, y centralizando la información obtenida para su remisión al DIRECTOR DEL PLAN. Participará en la valoración de la información obtenida, junto con el DIRECTOR.

\section{Administrativo}

- Desarrollar las labores administrativas derivadas del plan, en especial las de recopilación de partes y su organización.

\section{Operario}

- Será el encargado de la vigilancia, el control y las inspecciones asignadas en el PLAN, cumplimentando los partes a tal fin elaborados.

\section{Especialistas}

- Seran los profesionales externos que puedan adscribirse al Plan para la realización de operaciones de reparación, de mejora o de asesoramiento en situaciones de incidencias o extraordinarias. 


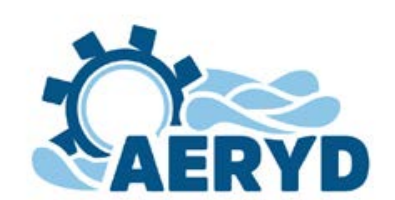

\section{Congreso Nacional de Riegos CARTAGENA 2021}

\section{Conclusiones}

Las 156 balsas que actualmente están en explotación y de las que SEIASA es titular, nos han permitido extraer conclusiones importantes aplicables a la construcción y explotación de otras nuevas.

La mayoría de estas conclusiones corroboran las recogidas en las Tesis Doctorales de J. SánchezRomero, "Criterios de seguridad en balsas de tierra para riego," Universitat Politècnica de València, 2014 y F. A. Zapata Raboso, “Análisis del comportamiento histórico de balsas de tierra en la Provincia de Alicante. Criterios de Diseño. Universidad Politécnica de Valencia, 2003. Y guías (J. Adalid, C. Ferrer, and J. Torregrosa, Guías para el proyecto, construcción, explotación, mantenimiento, vigilancia y planes de emergencia de las balsas de riego con vistas a la seguridad. Valencia: Consellería de Medi Ambient, Aigua, Urbanismo i Habitatge).

Algunas de estas conclusiones se han expuesto en este trabajo:

\section{Respecto a la construcción:}

$>$ La ejecución de dos tuberías (explotación y desagüe), que puedan ambas servir para el doble propósito y también para el desagüe de emergencia).

$>$ La protección de estas tuberías, evitando el contacto con el dique (galería, otras tuberías).

$>$ La ejecución de drenes estructurales y de vaso (Chimenea, envuelta, de vaso).

$>$ La protección de la balsa y del vaso, fundamentalmente frente a animales (doble cerramiento).

\section{Respecto a la explotación:}

La importancia de la elaboración e implantación de un Plan de Control, Inspección y Vigilancia para el mantenimiento, específico para cada una de las balsas. Este plan se ha revelado importante para la anticipación de incidencias que son fácilmente subsanables y que de no haberse detectado a tiempo podrían haber causados importantes daños y, desde luego, habrían ocasionado mayores gastos.

\section{Referencias}

[1, 2, 3, 4, 5, 7] F.J. Sánchez-Romero, “Criterios de seguridad en balsas de tierra para riego," Universitat Politècnica de València, 2014.

[6] J. Adalid, C. Ferrer, and J. Torregrosa, Guías para el proyecto, construcción, explotación, mantenimiento, vigilancia y planes de emergencia de las balsas de riego con vistas a la seguridad. Valencia: Consellería de Medi Ambient, Aigua, Urbanisme i Habitatge https://www.cma.gva.es/comunes_asp/documentos/agenda/Cas/62949-balsas_indices.pdf, 2009. 


\title{
Reflexiones sobre la Elaboración e Implantación de Planes de Emergencia en Balsas
}

\author{
Sánchez-Romero, F.J. ${ }^{\mathrm{a} 1}$, Pérez-Sánchez, M. ${ }^{\mathrm{b}}$, Redón-Santafé, M. ${ }^{\mathrm{a} 2}$, Torregrosa Soler J.B. a3 , Ferrer Gisbert, C. ${ }^{\mathrm{a}}$, Fe-

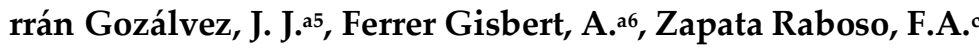
a Rural and Agroalimentary Engineering Department. Universitat Politècnica de València. Camino de Vera s/n 46022 . España. ${ }^{a 1}$ fco- sanro@agf.upv.es, a2 miresan@agf.upv.es, a3 jbtorreg@fis.upv.es, a4 caferrer@agf.upv.es,a5 jjferran@agf.upv.es, a6 aferrerg@agf.upv.es
b. Hydraulic Engineering and Environment Department. Universitat Politècnica de València. Camino de Vera s/n 46022 . España. mopesan1@upv.es.
c. Agriculture, Rural Development, Climate Emergency and Ecological Transition. C/Profesor Sala,2 Alicante. zapata_fra@gva.es

Resumen: Las balsas de tierra impermeabilizadas con geomembranas son obras muy seguras, tanto por la tipología constructiva empleada, como por su tipo de explotación, tal y como demuestra la experiencia y la escasez de incidencias. En cualquier caso se debe ser consciente que cualquier infraestructura puede colapsar y causar daños, y en el peor de los casos la pérdida de vidas humanas. Aunque la probabilidad de colapso nula no existe, es obligación tanto de los usuarios, técnicos implicados el intentar conseguirla.

El desarrollo de las sociedades exige mayores niveles de seguridad, y en este sentido tanto para las balsas de tierra como para cualquier otro tipo de infraestructura, las exigencias en seguridad cada vez son mayores.

La seguridad en las balsas de tierra viene determinada por tres pilares fundamentales que son:

1. Criterios de proyecto y control durante la ejecución, en ciertos puntos críticos.

2. Mantenimiento de la seguridad a lo largo del tiempo, lo que requiere de unos planes eficaces de Vigilancia y Mantenimiento, dentro de unas normas de Explotación, acordes con las entidades titulares que las tienen que implementar.

3. En el peor de los casos, la infraestructura puede fallar, por lo que interesa analizar cuáles serían sus consecuencias y hacerlo con el suficiente detalle para que puedan adoptarse medidas eficaces que aminores, e incluso anulen los daños, y en especial de vidas humanas.

Esta preocupación por la seguridad en las balsas, se vio establecida con la inclusión de las balsas en el Real Decreto 9/2008. Una mala concepción de la seguridad en balsas ha querido trasladar a estas infraestructuras, los criterios y planteamientos de las presas, lo cual ha provocado una gran confusión, tanto administrativa como técnica, e incluso un rechazo del sector a la exigencia del establecimiento de un marco normativo para este tipo de infraestructuras.

En la presente ponencia se establecen una serie de reflexiones sobre los contenidos de los Planes de Emergencia, estableciendo la diferencia entre su aplicación a presas y balsas, las implicaciones sociales que pueden derivarse de los mismos, así como cuáles deben ser los criterios a seguir para incrementar la seguridad real de las balsas.

Palabras clave: Balsas, Emergencia, Normas Técnicas 


\title{
Reflections on the Elaboration and Implementation of Emer- gency Plans in Agricultural Water Reservoirs.
}

\author{
Sánchez-Romero, F.J.a1, Pérez-Sánchez, M. ${ }^{b}$, Redón-Santafé, M.a2 , Torregrosa Soler J.B. a3 , Ferrer Gisbert, C.a , Fer- \\ rán Gozálvez, J. J.a5, Ferrer Gisbert, A.a6, Zapata Raboso, F.A.c \\ a Rural and Agroalimentary Engineering Department. Universitat Politècnica de València. Camino de Vera s/n 46022 . España. ${ }^{\mathrm{a} 1}$ fco- \\ sanro@agf.upv.es, a2 miresan@agf.upv.es, a3 jbtorreg@fis.upv.es, a4 caferrer@agf.upv.es,a5 jjferran@agf.upv.es, a6 aferrerg@agf.upv.es \\ b. Hydraulic Engineering and Environment Department. Universitat Politècnica de València. Camino de Vera s/n 46022. España. \\ mopesan1@upv.es. \\ c. Agriculture, Rural Development, Climate Emergency and Ecological Transition. C/Profesor Sala,2 Alicante. zapata_fra@gva.es
}

\begin{abstract}
Agricultural Water Reservoirs waterproofed with geomembranes are very safe works, both because of the construction technology used and the type of operation, as shown by experience and the scarcity of incidents. In any case, one must be aware that any infrastructure can collapse and cause damage, and in the worst case, the loss of human lives. Although the probability of zero collapse does not exist, it is the obligation of both the users and the technicians involved to try to achieve it.

The development of societies demands higher levels of safety, and in this sense, both for Agricultural Water Reservoirs and for any other type of infrastructure, the safety requirements are increasingly higher.
\end{abstract}

Safety in Agricultural Water Reservoir is determined by three fundamental pillars:

1. Criteria for design and control during execution, at certain critical points.

2. Maintenance of safety over time, which requires effective surveillance and maintenance plans, within the framework of operating standards, in accordance with the entities that have to implement them.

3. In the worst case scenario, the infrastructure may fail, so it is important to analyze the consequences and to do so in sufficient detail so that effective measures can be adopted to reduce or even eliminate the damage, especially in terms of human lives.

This concern for raft safety was established with the inclusion of rafts in Royal Decree 9/2008. A bad conception of safety in Agricultural Water Reservoir has wanted to transfer to these infrastructures, the criteria and approaches of dams, which has caused great confusion, both administrative and technical, and even a rejection of the sector to the demand for the establishment of a regulatory framework for this type of infrastructure.

This paper sets out a series of reflections on the contents of the Emergency Plans, establishing the difference between their application to dams and agricultural reservoirs, the social implications that may derive from them, as well as the criteria to be followed in order to increase the real safety of reservoirs.

Keywords: Agricultural Water Reservoirs, Emergency, Technical Standard 


\section{Congreso Nacional de Riegos CARTAGENA 2021}

\section{Introducción}

Aunque desde el punto de vista Administrativo, " A efectos de seguridad, los diques de cierre de las balsas son presas, y las balsas son embalses", la diferente naturaleza de las infraestructuras e idiosincrasia del sector requiere enfoques diferentes en materia de seguridad, para que realmente sean efectivos y puedan implantarse en el sector.

El "éxito" logrado en la solución de las emergencias que se tienen noticia en balsas, sin la aplicación de ningún protocolo escrito ni la activación de mecanismos de comunicación complejos, se debe a una serie de características de las infraestructuras que vale la pena resaltar y que deberían ser tenidas en cuenta:

- Las balsas en sus más de 60 años de existencia han demostrado un comportamiento "noble" debido a su propia naturaleza, tanto estructural como social.

- Excelente comportamiento estructural con un protagonismo indiscutible de las barreras geosintéticas, que se traduce en unas obras hidráulicas de gran seguridad, siendo incrementada ésta a lo largo de los años debido al análisis exhaustivo del comportamiento estructural observado, introduciendo los drenes estructurales.

- En el caso de las balsas dotadas con dren chimenea y dren de envuelta, estos no solo advierten de las filtraciones, sino que además protegen de la erosión interna, tanto de las potenciales filtraciones que se produzcan en el cuerpo del dique, como de las ocurridas a lo largo de las vías preferentes asociadas a las estructuras que atraviesan el dique, todo lo cual prácticamente anula la probabilidad de una rotura de la balsa [1].

A pesar de todo la obra puede fallar, por lo que interesa saber las consecuencias, y hacerlo con el suficiente detalle para que puedan adoptarse medidas eficaces que aminoren, e incluso anulen los daños, y especialmente el de vidas humanas.

\section{Diferencias entre balsas y presas}

Aunque las balsas y presas se tratan de obras con ciertas analogías, presentan notables diferencias, que obliga a un tratamiento diferente tanto en temas de seguridad estructural como de seguridad frente a posibles colapsos de estas infraestructuras.

La naturaleza de las balsas para riego es totalmente diferente a las presas por diferentes razones como [2] [3] [4]:

- En relación a los caudales recibidos o aportados, las presas reciben caudales muy variables y con una gran incertidumbre, ya que cortan cauces naturales y su cálculo presenta una gran incertidumbre en algunos casos. Los caudales de entrada y salida de las balsas son caudales regulados dentro de un rango conocido e incluso controlados por el ser humano, lo que permite su regulación a voluntad.

Los aliviaderos en presas son elementos fundamentales en la seguridad, mientras que en balsas al estar los caudales de entrada regulados y conocidos, hacen que los aliviaderos (obligatorios) sean elementos no tan importantes en la seguridad como lo podrían ser otros elementos (drenes estructurales, drenes de fondo, etc..).

- Presentan tipologías estructurales totalmente diferentes, solo asimilables a las presas de tierra. Existiendo una gran diferencia en relación a su tamaño, siendo las presas de dimensiones del orden de los centeneras de $\mathrm{Hm}^{3}$ y las balsas de dimensiones mas "modestas" dentro de un amplio rango pero del orden de miles de $\mathrm{m}^{3}$. 


\section{Congreso Nacional de Riegos CARTAGENA 2021}

- En presas la impermeabilización se centra en el dique de cierre y en su cimentación, confiando en el resto del vaso la impermeabilización al terreno que lo conforma. En balsas la impermeabilización se extiende a todo el vaso, siendo habitualmente de tipo artificial.

- Las balsas se construyen donde se necesitan, siendo su emplazamiento más común fuera de los cauces, con el material existente sin que exista generalmente una elección del lugar en base a criterios de impermeabilidad, resistentes, etc... como en presas ni una selección del material para la ejecución de los diques. Precisamente este aspecto exige en las balsas la ejecución de una pantalla impermeabilizante (generalmente geomembranas) para proteger al dique anárquicamente heterógeneo de posibles filtraciones. En caso de filtración desde el vaso de la balsa (por ejemplo por rotura de la geomembrana), este flujo de agua producirá preferentemente una tubificación, sin llegar a saturar el dique, que en el peor de los casos podría desembocar en orificio y finalmente en una brecha de rotura. Actualmente es común ejecutar drenes estructurales como del dren de envuelta y el dren chimenea que protegen al dique de posibles filtraciones y que disminuyen en gran medida la probabilidad de rotura.

- Respecto a su número es España existen 1300 presas mientras que el número de balsas no se sabe exactamente, cifrándose entre 50000 y 80000, incluso algunos autores opinan que podría llegar a las 100000.

- Para presas en la mayoría de casos el coste del agua es nulo, mientras que para balsas el agua suele tener un coste, por lo que no puede existir ningún tipo de pérdidas por infiltración.

- Para presas es abundante la normativa, bibliografía y experiencia tanto a nivel nacional e internacional. Sin embargo, para balsas no existe prácticamente normativa aplicable ni bibliografía específica, siendo un tipo de construcción y su problemática casi específicamente asociada a España, ya que ha sido en este tipo de infraestructura pionera a nivel mundial. Es verdad que a día de hoy este tipo de obras empieza a ser común en países en procesos de modernización de las superficies de regadío. La casi nula existencia de normativa y bibliografía a propiciado la extrapolación de conceptos y soluciones de las presas a las balsas, no siendo en la mayoría de los casos las soluciones más adecuadas e idóneas desde el punto de vista de la seguridad.

- El encuadre sociológico y económico de cada una de las infraestructuras es totalmente diferente. Las presas son explotadas por la propia Administración, empresas hidroeléctricas con suficientes recursos tanto materiales, humanos y económicos. Sin embargo las balsas quedan enmarcadas dentro de un sector agrario, donde la escasez de recursos es la tónica general.

- En presas la operación, vigilancia y mantenimiento es más complicada que en balsas, que suelen tener explotaciones más simples y sencillas.

- La forma de rotura de presas principalmente es por sobrevertido y en segundo lugar por erosión interna o tubificación, mientras que para las balsas la principal es por erosión interna, siendo secundaria por sobrevertido.

- La capacidad destructiva de las presas es mucho mayor que las balsas, aunque al estar las balsas cerca de zonas pobladas y vulnerables, los potenciales daños que pueden ocasionar pueden ser importantes en algunos casos.

Aunque las balsas de riego y las presas son obras hidráulicas, presentan importantes diferencias entre ellas que determinan el modo de proyectas y construirlas, de explotarlas y de los criterios de actuación ante situaciones de emergencia. 


\section{Consideraciones.}

En relación al posible fallo y aminoración de los posibles daños producidos, la normativa española obliga a la elaboración e implantación de unos Planes de Emergencia. Esta obligatoriedad nace de la “Directriz Básica de Planificación de Protección Civil ante el Riesgo de Inundaciones" publicada en el año 1996 [5]. Esta directriz define el concepto y las funciones básicas de los Planes de Emergencia en Presas y propone las diferentes escalas de Clasificación en función de los daños provocados por la posible rotura (A, B y C), obligando a todas aquellas que sean A y B, a elaborar e implantar un Plan de Emergencia.

En este sentido en el año 2001 el Ministerio publicó la “Guía para la elaboración de Planes de Emergencia para presas" [6], para posteriormente en el año 2010 "adaptar" esta Guía a balsas, publicando la "Guía para la elaboración de Planes de emergencia en balsas" . Esta última Guía "adaptada" a las balsas, aunque supone una aproximación al entorno agrario, debe ser matizada en algunos aspectos. La inclusión de las balsas en el marco normativo a raíz de su aparición en el Real Decreto del 2008 [7] obliga a todas aquellas con un Volumen mayor que $100000 \mathrm{~m}^{3} \mathrm{o}$ una altura mayor que 5 metros a presentar propuesta de Clasificación.

No obstante los seres humanos, no entienden si el agua que les afecta en una potencial inundación como fallo de una infraestructura hidráulica, proviene de una Presa o de una Balsa, es decir lo que le importa es la altura de la lámina de agua y su velocidad. Para las Balsas y dentro del entorno que las caracteriza, se deberían plantear e implantar unos Planes de Emergencia eficaces y redunden en aumentar la "Seguridad Real".

Si analizamos el éxito de aplicación de la normativa tanto a Presas como Balsas, los resultados a día de hoy no son nada esperanzadores.

- En Presas en 25 años de aplicación de la normativa aproximadamente el $100 \%$ de todas ellas están clasificadas, siendo un 53\% clasificadas como A ó B. Un $72 \%$ de las clasificadas como A ó B, tiene el Plan de Emergencia Elaborado y en fase de aprobación (50\% de PE aprobados) [8]. No existen datos oficiales de la implantación de Planes de Emergencia de Presas, pero se estiman en un $12 \%$ ( $\approx 100$ Presas) los Planes implantados. Es decir, que la propia normativa, pensada para presas y creada desde el enfoque de las Presas NO está teniendo los resultados esperados, y a día de hoy gran parte del parque nacional de Presas NO dispone de Planes de Emergencia elaborados y mucho menos implantados.

- Para Balsas NO se disponen datos oficiales accesibles ni a nivel nacional ni autonómico, pero las noticias que se tienen del número de balsas clasificadas respecto al total a clasificar estarían del orden entre el 1-5\% del total, siendo muy reducido el número de balsas con Planes de Emergencia elaborados e implantados, y casi anecdótico las balsas con Planes de Emergencia implantados.

Este fracaso en la aplicación de la normativa tanto a nivel de Presas como en Balsas demuestra que el enfoque actual debería ser replanteado, tanto el proceso administrativo-burocrático, como las exigencias y requerimientos por parte de la Administración, estableciendo procedimientos más ágiles y siempre teniendo en cuenta la realidad del sector al que va dirigido y que finalmente todos estos documentos sean eficaces para el objetivo de aminorar los daños y proteger a la población potencialmente afectada.

En este sentido existen algunos aspectos para Balsas que se deberían analizar, replantear y reconsiderar su aplicación. Estos aspectos son: 


\section{Congreso Nacional de Riegos CARTAGENA 2021}

\section{Respecto a la Clasificación y Elaboración de los Planes de Emergencia}

- La obligatoriedad de Clasificar a todas las Balsas con alturas mayores que 5 metros, obligaría a elaborar una propuesta de clasificación para un número de balsas entre 25000 y 50000 , de las que la gran mayoría (>50\%) se clasificarían como A ó B, por lo que serían miles de Balsas (>10000) [9] [10] para las que habría que elaborar el Plan de Emergencia e implantarlo. Actualmente con los mecanismos actuales sería imposible llevar a cabo esta ardua tarea.

- Las NTS de Presas gradúa las exigencias en seguridad (coeficientes de seguridad, períodos de retorno, etc..) según la clasificación de la Presa, lo que implica diferentes niveles de seguridad. La aplicación de coeficientes menores de seguridad para Balsas (o Presas) clasificadas como C compromete a la obra durante toda su vida, ya que un cambio de clasificación por modificación de su entorno, podría aumentar la clasificación, y además si los criterios de diseño no han sido holgados, la Balsa (o Presa) pasaría a una situación de inseguridad.

- Las Balsas son construcciones que en muchas zonas de España se ubican en zonas habitadas, por lo que cualquier modificación de su entorno (construcción de nuevas infraestructuras, edificaciones, etc...), podría llevar a un cambio de categoría. En caso de un aumento de la categoría (por ejemplo de C a A ó B) y exigencia de un Plan de Emergencia y posibles modificaciones en la Balsa, para aumentar su nivel de seguridad, ¿quién debería realizarlo, el titular de la Balsa o el responsable de las nuevas infraestructuras?. Este aspecto controvertido ha sido debatido en numerosos foros, sin que exista un criterio a día de hoy.

- Aunque los conceptos de Altura movilizable y Volumen movilizable se manejan habitualmente en la modelización de las roturas en balsas, no quedan reflejados ni definidos en ninguna normativa, por lo que en casos de balsas enterradas parcialmente o totalmente, que cumplan con alguno de los requisitos para ser clasificadas y dependiendo del criterio de la Administración competente, se exige su clasificación y por tanto la simulación de una rotura irreal, que podría obligar a la elaboración e implantación de un PE.

- Las hipótesis de rotura que habitualmente se manejan en Presas, no se ajustan a las Balsas, ya que para Balsas no existe una Avenida Extrema (excepto la que podemos considerar como lluvia sobre la Balsa para el cálculo del aliviadero), y además existen diferencias significativas al considerar una rotura por sobrevertido o por tubificación.[11] Además al estar las balsas ubicadas en puntos altos y collados de donde pueden partir una o varias vaguadas, suele implicar el estudio de varias roturas a lo largo del dique con características diferentes de tiempo de formación y anchura media de brecha. Este aspecto en un estudio riguroso de todas las posibles roturas e hipótesis implica un esfuerzo adicional de trabajo y recursos que se puede ver ampliado por ubicaciones con geometrías complejas, rotura encadenada y/o inducida de otras balsas, obstrucciones en la propagación de la onda de rotura e inundación de llanuras (flujos bidimensionales). En contraposición, para Presas no suele existir diferencia entre la rotura por sobrevertido o tubificación, y la propagación generalmente se realiza por un cauce definido y preferentemente mediante un flujo unidireccional [12].

- En la zonificación territorial de la potencial rotura tanto la propuesta de Clasificación como el Plan de Emergencia se tratan de ejercicios teóricos, intentando determinar, en las condiciones más adversas posibles, cuál sería la envolvente de la máxima zona afectada que se podría originar, qué afecciones se producirían y qué posibles daños se podrían ocasionar. La utilización de modelos matemáticos complejos, no implica necesariamente la 


\section{Congreso Nacional de Riegos CARTAGENA 2021}

modelización correcta de una realidad compleja. En Balsas donde los recursos actuales son limitados y existe un gran número de estas infraestructuras, los métodos simplificados manuales tanto en la Clasificación como en los Planes de emergencia, deben ser una herramienta útil que permita el estudio de la hipotética rotura, estableciéndose metodologías simples que permitan el análisis de este fenómeno de una manera rápida y fiable.

- A efectos burocráticos la Clasificación simplemente es la justificación de la categoría de la Presa o Balsa. Esta clasificación se puede realizar con gran detalle, calculando y representando mapas de inundación de todas las zonas afectadas e hipótesis, y sentando las bases para el posterior desarrollo del Plan de Emergencia, o justificando la clasificación mediante juicio ingenieril, y en todo caso empleando métodos simplificados justificados. En los casos donde la clasificación sea obvia, el propio juicio ingenieril debe ser suficiente para poder formular la Clasificación debiéndose crear mecanismos y formularios simples de aplicación.

Respecto a la Elaboración e Implantación de los Planes de Emergencia

- La causa principal de rotura para Presas es el Sobrevertido, mientras que para Balsas es la Tubificación. Este tipo de rotura se produce progresivamente en unos intervalos de tiempo lo suficientemente grandes para su posible detección temprana y la toma de medidas inmediatas por el equipo de Explotación. Las medidas a tomar en caso de una incidencia serán:

- Interrupción del llenado.

- Vaciado.

- Aviso urgente (si procede) a los organismos implicados (112) y/o elementos afectados.

Esta oportunidad de tiempo en la toma de medidas y de aviso, íntimamente ligada a una vigilancia de la obra, posibilita una gran variedad de sistemas de aviso a la población, así como el uso de sistemas de comunicación convencionales.

Las experiencias extraídas de las diferentes situaciones de emergencia de las que se tienen noticias, es que las medidas adoptadas para disminuir los posibles daños, han sido eficaces, resolviendo las situaciones de emergencia satisfactoriamente, sin la causa de daños personales, y en la mayoría de los casos sin aviso a instancias superiores o solo con aviso a Protección Civil.

- En Presas las situaciones de emergencia (Sobrevertido por Avenida) suelen estar asociadas a factores meteorológicos que pueden llegar a alterar las comunicaciones y por tanto sí que parece recomendable el uso de sistemas redundantes y con fiabilidad extrema. En Balsas las situaciones de emergencia suelen venir causadas a procesos de tubificación (no asociadas a factores meteorológicos extremos), por lo tanto parece más razonable que se utilicen las comunicaciones que habitualmente se utilizan por las entidades explotadoras (teléfono móvil principalmente, teléfono convencional, fax, internet, etc.) y que además el personal de la entidad está familiarizado con su uso. En este sentido la "Guía de Implantación para Planes de Emergencia en Presas" recomienda tener en cuenta el uso de las tecnologías aplicables en el momento de la implantación, ya el desarrollo de la tecnología permite un mayor número de posibilidades a la hora de la implantación.

- Los sistemas de aviso a la población deben responder al objetivo esencial de aviso a la población para su autoprotección, y dependiendo de cada infraestructura se podrá contar con un tipo de sistema único o una solución mixta [6]. En este sentido existen varias alternativas 


\section{Congreso Nacional de Riegos CARTAGENA 2021}

como sistemas acústicos, telefónicos, luminosos, apps, avisos personalizados, que pueden ser implantados.

- La "Guía para la elaboración de Planes de Emergencia en balsas" para cada Escenario de rotura, indica como y con quién debe comunicar el Director del Plan de Emergencia. Con el fin de simplificar las actuaciones y centrarse en la situación de emergencia parece más eficaz la comunicación con un solo organismo (Protección Civil), y que Protección Civil comunique al resto de organismos en función del Escenario. Se tienen noticias de situaciones de emergencia solucionadas eficazmente solo con el aviso a Protección Civil.

- En Balsas prácticamente no existe auscultación, siendo casi imposible fijar umbrales, siendo el Director del Plan de Emergencia, apoyado por su equipo, quien determine el paso de un Escenario a otro. Además existe una lista interminable de indicadores dentro de la "Guía para la elaboración de Planes de Emergencia en balsas", difíciles de interpretar. Estos indicadores deberían simplificarse a un número menor y fácilmente interpretable por el Director del Plan y equipo.

Respecto a la Implantación de los Planes de Emergencia

- Las inundaciones naturales (que pueden producir un sobrevertido en Presas) son un fenómeno periódico de origen natural, por lo que la población que permanece en la zona afectable, a lo largo de su vida tendrá que hacer frente a este fenómeno varias veces. Esta población está acostumbrada y por lo tanto es fácil ante la implantación de un Plan de Emergencia que reconozca el riesgo y dispuesta a contribuir. Sin embargo en las inundaciones por rotura en Balsas, es un fenómeno que posiblemente no se produzca nunca, y además tenemos la posibilidad de reducir la probabilidad para que no ocurra este fenómeno. Las zonas afectadas en este caso suelen ser zonas que nunca se han inundado. En este sentido habría que repensar el enfoque de la divulgación de la información a la población y posiblemente buscar alternativas para una divulgación más eficaz.

- Las NTS de Presas exigen que el Plan de Emergencia esté elaborado e implantado antes de la primera puesta en carga. Actualmente las tramitaciones suelen ser muy largas, del orden de años, lo que puede implicar un retraso para este tipo de obras, y por lo tanto una pérdida de oportunidad para la ejecución de estas infraestructuras.

- Según la Directriz cualquier anomalía o acontecimiento extraordinario que aconseje una intensificación de la vigilancia debe ser puesta en conocimiento de los organismos implicados. En Balsas son muy comunes incidencias y patologías que mal interpretadas podrían desencadenar alarmas injustificadas y colapso en la Administración. Se deberían buscar alternativas que permitan flexibilizar este tipo de situaciones.

\section{Reflexiones Finales}

Todo ello implica que se deba replantear el enfoque que actualmente se está aplicando, basado en:

1. El enfoque actual se traduce en una maraña burocrática lenta, ineficaz y de dudosa eficacia real para las posiblemente 50000-80000 balsas estimadas en España, debiéndose reflexionar sobre que tamaño (capacidad y/o altura de dique) se les exige aplicar la normativa. En este sentido una posible solución sería:

- A corto plazo, sólo contabilizar $\mathrm{V}>100000 \mathrm{~m}^{3}$ o H>10 m.

- Aplicación por fases:

- Fase a corto plazo: Actuación sobre las balsas en las que la Administración ejerza como entidad explotadora, y todas aquellas balsas de mayor entidad. En esta fase 


\section{Congreso Nacional de Riegos CARTAGENA 2021}

también se deberían incluir aquellas balsas, con conocimiento de la Administración, que por su situación y estado de conservación, estén generando una situación de riesgo no aceptable.

- Fase a medio plazo: En esta fase se analizarían todas aquellas balsas con volúmenes superiores a $100000 \mathrm{~m}^{3} \mathrm{o}$ alturas superiores a $10 \mathrm{~m}$, tanto públicas como privadas.

- Fase a largo plazo: En esta fase se analizarían el resto de balsas.

2. Es fundamental la incorporación de la gestión de la emergencia desde las primeras incidencias por parte de Protección Civil, como ha quedado demostrado en diversos incidentes, donde Protección Civil gestionó y organizó el aviso a los puntos e infraestructuras afectadas por toda la zona inundada eficazmente, siendo buenos ejemplos de eficacia por parte de los Organismos preparados para ello.

3. La incorporación de Protección Civil activa desde el principio de la Emergencia, tomando el control de las comunicaciones y avisos. Lo que implica eliminar el aviso en la primera media hora por parte del Director del Plan de Emergencia.

4. Eliminación del sistema de aviso a la población mediante sirenas y sustitución por sistemas asociados a las nuevas tecnologías de comunicación y drones o aquellos que considere más adecuados Protección Civil.

5. Integración de los Planes de Emergencia dentro del sistema de Explotación de la Balsa. Los equipos de explotación e técnicos relacionados con la obra, han resuelto de forma eficaz la emergencia. Estos equipos son conocedores de la obra y de su entorno, lo que permite una respuesta rápida y eficaz frente a cualquier evento.

6. Mismos criterios de Seguridad para Balsas que dependan de la Administración central y Autonómica, en un mismo territorio.

7. Habría que reflexionar sobre los recelos y desconfianza que se está creando entre la población en contra de las obras hidráulicas, pudiendo acarrear mayores daños de los que se intenta resolver, creando finalmente un rechazo tanto de la población en general como de las propias entidades a este tipo de exigencias. El sistema actual con reparto de trípticos de la zona inundable crea una falsa alarma injustificada, que indirectamente genera una oposición a la obra hidráulica en general, y a las balsas en particular, paradójicamente creado por el propio sector hidráulico. Se trata de proteger a la población NO de alarmar a la población.

8. Desde el punto de vista de Seguridad, se debería realizar un mayor esfuerzo en la fase de Explotación, debiéndose garantizar unos planes de Vigilancia y Explotación efectivos y que realmente aseguren un buen estado de la infraestructura y un aviso en caso de emergencia. En este sentido es importante que se busquen mecanismos para la rehabilitación de balsa, que permitan la reimpermeabilización y que por lo tanto realmente se aumente el nivel de Seguridad. Una balsa de más de 20 años, con una geomembrana envejecida, NO es más segura por que tengamos un documento como el Plan de Emergencia. La Administración debería implicarse para desarrollar sistemas que permitan la financiación para la sustitución de las geomembranas envejecidas y aumento del nivel de seguridad en general, pudiéndose vincular estos trabajos a la implantación de los Planes de Emergencia.

9. Las futuras NTS de Balsas se deberían adaptar a la realidad del sector, y resolver los impedimentos que a día de hoy retrasan alarmantemente el establecimiento de un marco normativo para las Balsas, que finalmente permita un desarrollo y explotación sostenible tanto del sector como del parque de balsas. También sería necesario la elaboración de diferentes guías, documentos y metodologías 


\section{Congreso Nacional de Riegos CARTAGENA 2021}

que permitan de una manera eficaz, segura y sencilla regularizar y normalizar estas infraestructuras.

Es necesario precisamente por la seguridad, la simplificación y el replanteamiento de las Propuestas de Clasificación, Planes de Emergencia y sobre todo su Implantación, en Balsas, para que sean realmente eficaces.

\section{Agradecimientos}

Este trabajo fue apoyado por el proyecto SISIFO (Desarrollo de herramientas analíticas para caracterIzar la Sostenibilidad de los sistemas hidráulicos Indicadores que definen Objetivos de desarrollo sostenible) PID2020-114781RA-I00 del Plan Estatal de Investigación Científica y Técnica e Innovación 2017-2020.

\section{Referencias}

[1] J. Adalid, C. Ferrer, and J. Torregrosa, Guías para el proyecto, construcción, explotación, mantenimiento, vigilancia y planes de emergencia de las balsas de riego con vistas a la seguridad. Valencia: Consellería de Medi Ambient, Aigua, Urbanisme i Habitatge https://www.cma.gva.es/comunes_asp/documentos/agenda/Cas/62949-balsas_indices.pdf, 2009.

[2] J. M. Gonzalez Ortega, "Reflexiones acerca de la situación actual y la seguridad de las balsas en España.," in X Jornadas de Presas. Valladolid., 2010, pp. 1-10.

[3] J. M. Gonzalez Ortega, R. Segura Graiño, and F. J. Sánchez Cabezas, "Situación actual de las balsas y los pequeños embalses en España.," in II Congreso In-ternacional de Impermeabilización sobre Proyecto, Construcción e Impermeabilización de balsas (Palma de Mallorca, Abril de 2009), 2009.

[4] F.-J. Sánchez-Romero, "Criterios de seguridad en balsas de tierra para riego," Universitat Politècnica de València, 2014.

[5] Gobierno de España, Directriz Básica de Planificación de Protección Civil ante el Riesgo de Inundaciones. 1995, p. 29.

[6] Ministerio de Medio Ambiente de España, Guía técnica para la elaboración de los planes de emergencia de presas. 2001, p. 164.

[7] Gobierno de España, Real Decreto 9/2008, de 11 de enero, por el que se modifica el Reglamento del Dominio Público Hidráulico, aprobado por el Real Decreto 849/1986, de 11 de abril. 2008, pp. 3141-3149.

[8] MITECO, "No Title," 2020. [Online]. Available: https://www.miteco.gob.es/es/agua/temas/seguridad-de-presas-y-embalses/gestion-seguridad-presas/planes.aspx. [Accessed: 20-Sep-2021].

[9] F. A. Zapata Raboso, "Análisis del comportamiento histórico de balsas de tierra en la Provincia de Alicante. Criterios de Diseño.," Universidad Politécnica de Valencia, 2003.

[10] F.-J. Sánchez-Romero, "Water management and safety issues in Agricultural Water Reservoirs in Spain."

[11] F. J. Sánchez-Romero et al., "Estudio numérico para la elaboración de mapas de inundación considerando la hipótesis de rotura en balsas para riego ," Ing. del agua, vol. Vol. 23, N, 2019.

[12] F. J. Sánchez-Romero et al., "Planes de Emergencia en Balsas: La influencia del coeficiente de rugosidad en la definición de los grados de afección por hipótesis de rotura en balsas." 


\section{Contribución a la caracterización geométrica de balsas como he- rramienta para el cálculo de indicadores de sostenibilidad}

Sánchez-Romero, F.J.a1, Pérez-Sánchez, M. ${ }^{b}$, Redón-Santafé, M.a2 , Torregrosa Soler J.B. ${ }^{a 3}$, Ferrer Gisbert, C. ${ }^{a 4}$, Ferrán Gozálvez, J. J.a5, Ferrer Gisbert, A.a6, Zapata Raboso, F.A.c

a Departamento de Ingeniería Rural y Agroalimentaria. Universitat Politècnica de València. Camino de Vera s/n 46022. España.a ${ }^{a}$ fcosanro@agf.upv.es, a2 miresan@agf.upv.es, a3 jbtorreg@fis.upv.es, a4 caferrer@agf.upv.es, a5 jjferran@agf.upv.es, a6 aferrerg@agf.upv.es

b. Departamento de Ingeniería Hidráulica y Medio Ambiente. Universitat Politècnica de València. Camino de Vera s/n 46022. España. mopesan1@upv.es.

c. Consellería de Agricultura, Desarrollo Rural, Emergencia Climática y Transición Ecológica. C/Profesor Sala,2 Alicante. zapata_fra@gva.es

Resumen: Las balsas a diferencia de las presas presentan desde un punto de vista geométrico elementos y formas similares que pueden ser estudiadas y caracterizadas para la obtención de relaciones y expresiones útiles para la planificación y análisis de diferentes aspectos. En el presente artículo se pretende recopilar y analizar las diferentes relaciones geométricas en balsas. En primer lugar se realiza una recopilación con las relaciones entre las diferentes variables encontradas en la bibliografía especializada. A partir de la información recopilada por la Generalitat Valenciana de aproximadamente unas 50 balsas, se han obtenido diferentes relaciones entre las variables. Estas relaciones permiten que de una manera aproximada y en fase de predimensionado de una balsa o gestión del territorio, la estimación rápida de diferentes parámetros como la superficie ocupada en función del volumen, superficie impermeabilizada y otro tipo de variables útiles tanto para los proyectistas, gestores y Comunidades de Regantes. El desarrollo y utilización de este tipo de herramientas analíticas debe permitir la caracterización de este tipo de infraestructura dentro de los sistemas hidráulicos, proporcionando indicadores que permitan una mejor planificación y gestión en base a Objetivos de desarrollo Sostenible.

Palabras clave: Balsas, geometría, superficie impermeabilizada 


\title{
Contribution to the geometric characterization of Agricultural Water Reservoirs as a tool for the calculation of sustainability indicators.
}

Sánchez-Romero, F.J.a1, Pérez-Sánchez, M. ${ }^{b}$, Redón-Santafé, M.a2 , Torregrosa Soler J.B. a3 , Ferrer Gisbert, C.a4, Ferrán Gozálvez, J. J. ${ }^{\mathrm{a}}$, Ferrer Gisbert, A. ${ }^{\mathrm{a}}$, Zapata Raboso, F.A.c

a Rural and Agroalimentary Engineering Department. Universitat Politècnica de València. Camino de Vera s/n 46022. España. ${ }^{a 1}$ fcosanro@agf.upv.es, a2 miresan@agf.upv.es, a3 jbtorreg@fis.upv.es, a4 caferrer@agf.upv.es,a5 jjferran@agf.upv.es, a6 aferrerg@agf.upv.es

b. Hydraulic Engineering and Environment Department. Universitat Politècnica de València. Camino de Vera s/n 46022. España. mopesan1@upv.es.

c. Agriculture, Rural Development, Climate Emergency and Ecological Transition. C/Profesor Sala,2 Alicante. zapata_fra@gva.es

\begin{abstract}
The Agricultural Water Reservoirs, unlike dams, present from a geometrical point of view similar elements and shapes that can be studied and characterized in order to obtain relations and expressions useful for the planning and analysis of different aspects. In this article we intend to compile and analyze the different geometric relationships in Agricultural Water Reservoirs. First of all, a compilation of the relationships between the different variables found in the specialized literature is made. From the information compiled by the Generalitat Valenciana of approximately 50 Agricultural Water Reservoirs, different relationships between the variables have been obtained. These relationships allow, in an approximate way and in the pre-dimensioning phase of a Agricultural Water Reservoirs or management of the territory, the fast estimation of different parameters such as the occupied surface in function of the volume, waterproofed surface and other types of useful variables for designers, managers and Irrigation Communities. The development and use of this type of analytical tools should allow the characterization of this type of infrastructure within the hydraulic systems, providing indicators that allow better planning and management based on Sustainable Development Objectives.
\end{abstract}

Keywords: Agricultural Water Reservoirs, geometric, waterproofed surface 


\section{Introducción}

La estimación de los diferentes parámetros que definen características significativas de las balsas en fase de predimensionado de una infraestructura de este tipo o como conocimiento para la gestión del territorio son herramientas muy útiles para los técnicos implicados.

En este sentido Aguiar[1] proponen una serie de relaciones en base a un conjunto de balsas ya construidas, relacionando la capacidad del embalse $\left(\mathrm{m}^{3}\right)$ con el movimiento de terreno a desplazar $\left(\mathrm{m}^{3}\right)$ y con la superficie impermeabilizada $\left(\mathrm{m}^{2}\right)$ y de terreno ocupado $\left(\mathrm{m}^{2}\right)$. Estas relaciones son presentadas mediante curvas sin expresión directa y sólo válidas hasta balsas de $30000 \mathrm{~m}^{3}$.

Zapata [2] propone en base a un conjunto de balsas construidas en la provincia de Alicante, Murcia, Valencia y Huelva algunas relaciones del mismo tipo con el propósito de utilizarlas para el análisis de un censo efectuado mediante fotografía aérea en la provincia de Alicante en el año 2003.

Actualmente por parte de las diferente Comunidades Autónomas se está llevando a cabo el Registro de este tipo de infraestructuras (con mayor o menor éxito), además en algunas Comunidades se están realizando Revisiones de Seguridad. Todos estos trabajos están permitiendo conocer de un mayor número de balsas sus características geométricas y por tanto mejorar este tipo de relaciones y expresiones.

La determinación de relaciones matemáticas entre las variables geométricas permite en fase de predimensionado y proyecto de una balsa por ejemplo conocer cuanta superficie es necesaria para su construcción, información muy importante para la compra de terrenos por parte de la Comunidad de Regantes y/o entidad promotora. Además la aplicación de estos expresiones a datos obtenidos mediante fotografía aérea, y para el parque de balsas de un determinado territorio, permite estimar capacidades de almacenamiento y superficie de lámina instalada. Estos parámetros son importantes conocer para la gestión y ordenación del territorio. Por ejemplo el conocimiento de la superficie de lámina instalada, debe permitir una mejor planificación de posibles mecanismos administrativos y ayudas financieras para la reimpermeabilización y rehabilitación de balsas.

El objetivo principal del presente estudio, es a partir de la información disponible obtener relaciones entre los diferentes parámetros, que mejoren las estimaciones, persiguiendo la obtención de relaciones simples y máximos índices de correlación.

\section{Materiales y métodos}

Se parte de los datos recogidos de 48 balsas (ampliando los utilizados por otros investigadores ya comentados anteriormente), situadas principalmente en la provincia de Alicante según la Tabla 1 y analizados en [3].: 


\section{Congreso Nacional de Riegos CARTAGENA 2021}

Tabla 1. Datos del conjunto de balsas utilizado.

\begin{tabular}{|c|c|c|c|c|c|c|c|c|c|c|c|c|c|c|c|c|c|c|c|c|c|c|c|c|c|c|c|c|c|c|}
\hline 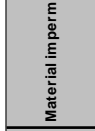 & 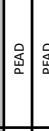 & $\frac{a}{2}$ & & & & & & & 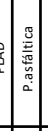 & $\frac{\vdots}{2}$ & $\frac{1}{2}$ & 絗 & 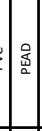 & & 焉 & & & $\stackrel{0}{a}$ & & 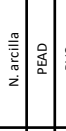 & 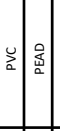 & 妾道 & 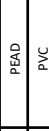 & & $\frac{9}{2}$ & & | & & & \\
\hline 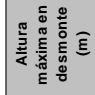 & & & & & & & & & & & $\mid$ & $\stackrel{\sim}{\sim}$ & & & . & & & & & & & & & & & & & & & \\
\hline 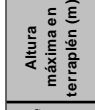 & & & & & & $\because 7$ & & & 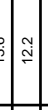 & $\exists$ & & & $\stackrel{\sim}{\sim}$ & $\because=$ & $\approx$ & & & $\Rightarrow \approx$ & & $\approx$ & $\therefore \approx$ & 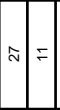 & & & & & 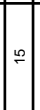 & & & $=$ \\
\hline 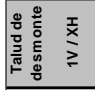 & - & 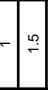 & F & 4 & 告 & & مُ ٌْ & & -1 & ఝ & . & N & & $\sim \sim \sim$ & -1 & & N & & & $\exists$ & & -1 & $\sim$ & & & $\infty$ & -7 & & & $\sim$ \\
\hline 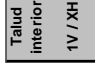 & $\sim$ & & 舟 & $m$ & $\stackrel{\leftrightarrow}{|c|}$ & $\forall \stackrel{\sim}{\sim}$ & & קִ & $\stackrel{n}{n}$ & & $\infty$ & $m$ & + & $\stackrel{\sim}{\infty}$ & $\infty$ & صู & $\stackrel{\sim}{\sim}$ & $\sim m$ & 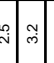 & $\stackrel{n}{\sim}$ & & 跑 & & $\sim$ & & $ナ \stackrel{\sim}{\mathrm{N}}$ & & & & $\sqrt{3}$ \\
\hline 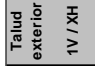 & 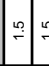 & $=\sim$ & $\sim$ & 4 & 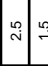 & $\sim$ & 赵 & $\oiiint$ & $\stackrel{2}{2}$ & & 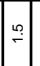 & $\sim$ & & 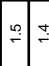 & $\rightarrow$ & 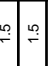 & $\sim$ & $\sim \sim$ & 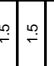 & $\stackrel{n}{\sim}$ & $\sim \sim$ & 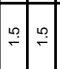 & 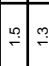 & 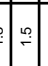 & $\sim \sim$ & $\because \subsetneq$ & & & & ? \\
\hline 旁 & + & $\infty$ & \begin{tabular}{|lll}
\multirow{i}{*}{} & +
\end{tabular} & t) & 00 & $m$ & 足 & $>0$ & $\circ \stackrel{0}{\circ}$ & g. & . & r & 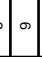 & $\infty$ & (ด) & $+\infty$ & 0. & 0. & 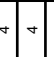 & \begin{tabular}{l|ll} 
& + \\
$\circ$ & + & \\
\end{tabular} & \begin{tabular}{l|l|}
\multirow{2}{*}{} & $\infty$ \\
\multirow{n}{*}{} & $\infty$
\end{tabular} & \begin{tabular}{|l|l|}
$\circ$ & + \\
\end{tabular} & 0 & : & $\approx$ & 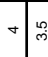 & $\infty$ & & & . \\
\hline 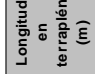 & 品 & & & 营总 & & : & & & $:$ & 告 & $\stackrel{\circ}{\circ}$ & 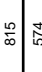 & & : & 声 & & 哈 & 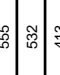 & of & $: \approx$ & & & 志 & & & จุ : & $\stackrel{9}{\nearrow}$ & & & 志 \\
\hline 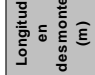 & 5 & & & 品 & & & & $0 \stackrel{\circ}{\mathscr{g}}$ & 刍 & & & 壳 & & \begin{tabular}{|l|l|}
$\tilde{g}$ \\
$\tilde{g}$
\end{tabular} & 9 & & 㞻 & $\circ{ }_{0}^{\circ}$ & & 表骂 & & $\stackrel{N}{N}$ & 寻号 & 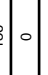 & & $\vec{z}$ & 8 & & & 赵 \\
\hline 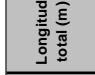 & 8 & 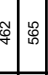 & व: & : & & & & $\approx$ & 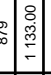 & 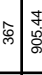 & & 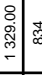 & & 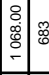 & 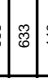 & & : 8 & 에 & $\approx$ & & & $\stackrel{\infty}{\infty}$ & 或总 & & & 吕: & $|\vec{b}|$ & & & : \\
\hline $\begin{array}{l}\bar{E} \\
\bar{E} \\
\end{array}$ & 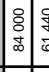 & 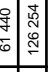 & 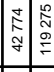 & & 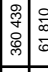 & 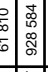 & 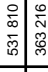 & 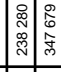 & 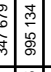 & 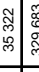 & \begin{tabular}{|c|}
0 \\
0 \\
$a$ \\
\\
\end{tabular} & & 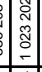 & 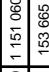 & 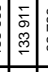 & 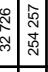 & 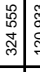 & 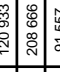 & 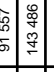 & 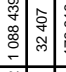 & 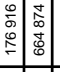 & 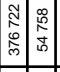 & \begin{tabular}{|l|l} 
\\
$\vdots$ \\
0 \\
0 \\
0
\end{tabular} & 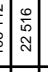 & 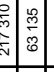 & 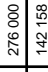 & \begin{tabular}{|l|}
$\mid$ a \\
a \\
\end{tabular} & : & & 商总 \\
\hline 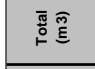 & 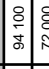 & 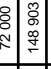 & & & & 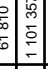 & & & 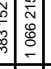 & & $\mid$ & 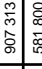 & & 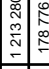 & 辛 & & & $\begin{array}{l}0 \\
0 \\
0\end{array}$ & 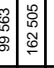 & 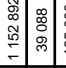 & 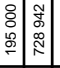 & 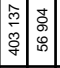 & 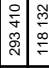 & 嵒 & 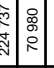 & & 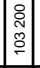 & & & 㝵题 \\
\hline 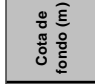 & 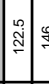 & : & 㱩 & 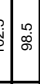 & 声题 & 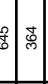 & 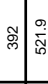 & $\begin{array}{ll}0 \\
0 \\
0 \\
0 \\
0\end{array}$ & 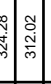 & 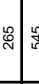 & 敏 & $\vec{F}$ & 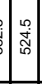 & 品爱 & $\approx$ & & 号 & : & 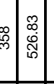 & 声和 & ڤั & 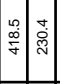 & 离 & : & 象 & $\Rightarrow$ & | & J & & 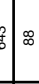 \\
\hline 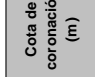 & :워 & & & 뷔워 & & 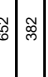 & & & & & & & & & $\approx$ & & & 80 & & & & & 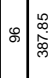 & 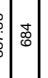 & & & & & & : \\
\hline 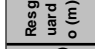 & 告. & -1 告 & \begin{tabular}{l|lll}
0 \\
0
\end{tabular} & 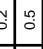 & $\begin{array}{lll}0 & 0 \\
\end{array}$ & $\circ \sim$ & \begin{tabular}{l|l}
-1 \\
\hdashline
\end{tabular} & 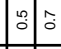 & - & -7 & 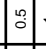 & $\Rightarrow$ & 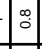 & $\Rightarrow \stackrel{\circ}{\circ}$ & בְ. & : & 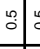 & : & 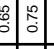 & 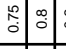 & $\begin{array}{ll}0 \\
:\end{array}$ & \begin{tabular}{|l|l} 
\\
0 \\
0
\end{tabular} & 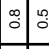 & \begin{tabular}{|l|l|l|} 
\\
\end{tabular} & 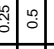 & 0.0 & $\hat{\circ}$ & 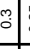 & & $\begin{array}{c}0-1 \\
\end{array}$ \\
\hline 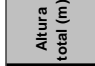 & $\stackrel{\infty}{\infty} \infty$ & $\infty$ & 0 & $\infty$ & $\Rightarrow$ & $\rightarrow$ & $\approx \simeq$ & 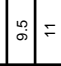 & $\Rightarrow=$ & 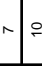 & : & $\Rightarrow=$ & $=$ & . & $=$ & $\wedge$ 绐 & 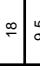 & 0 & : & 9 & $=\frac{n}{0}$ & $\begin{array}{lll} & 0 \\
& 0 & 0 \\
\end{array}$ & $\therefore={ }_{\infty}^{\infty}$ & $\begin{array}{l}\infty \\
0 \\
0\end{array}$ & 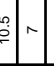 & \% & $\approx$ & g & & $\Rightarrow$ \\
\hline 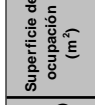 & 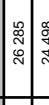 & 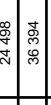 & 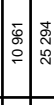 & 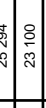 & 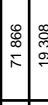 & \begin{tabular}{l|l}
0 \\
0 \\
0
\end{tabular} & & 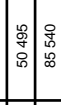 & 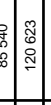 & & : & 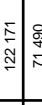 & $\begin{array}{l}0 \\
\vdots \\
0 \\
0 \\
0\end{array}$ & 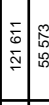 & 量 & & & 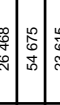 & 党: & 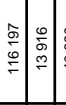 & & 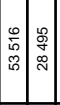 & 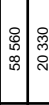 & 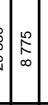 & 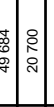 & 总 & $\mid$ & & & 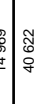 \\
\hline 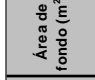 & 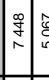 & 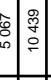 & 表尔 & 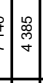 & $\begin{array}{lll}0 & 0 \\
0 & 0 \\
\Rightarrow & 0 \\
0 & 0\end{array}$ & 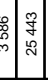 & 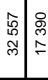 & 年 & $\begin{array}{l}2 \\
2 \\
2\end{array}$ & 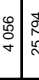 & $\mid$\begin{tabular}{l}
0 \\
0 \\
0 \\
\hdashline
\end{tabular} & 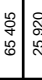 & 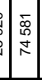 & 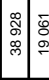 & 告 & 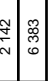 & & 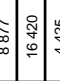 & 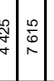 & 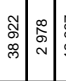 & 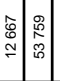 & 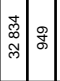 & \begin{tabular}{l|l} 
\\
$\vdots$ \\
$\vdots$
\end{tabular} & 索 & \begin{tabular}{l}
0 \\
\hdashline \\
\hdashline
\end{tabular} & $\mid$ & $\mid$ & & & 嶑舜 \\
\hline 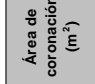 & $\mid$\begin{tabular}{l|l} 
\\
0 \\
0 \\
0
\end{tabular} & & & 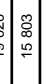 & & 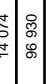 & & 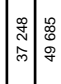 & $\begin{array}{l}0 \\
\vdots \\
\vdots \\
0 \\
0\end{array}$ & 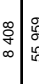 & $\mid$ & 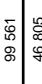 & 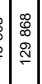 & 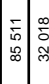 & 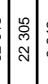 & 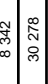 & & 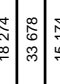 & 空 & 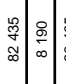 & 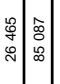 & 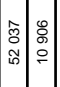 & 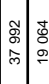 & & 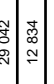 & $\mid \begin{array}{l}\mathbf{0} \\
\mathbf{0} \\
\vec{f}\end{array}$ & $\mid$ & & & 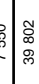 \\
\hline $2 \frac{0}{9}$ & 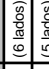 & 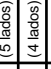 & $\sqrt{2}$ & & \begin{tabular}{|l|}
$\frac{\pi}{2}$ \\
$\frac{a}{2}$ \\
\end{tabular} & & 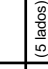 & 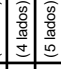 & & 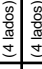 & & 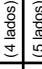 & 70 & 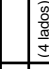 & 吾 & 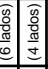 & & 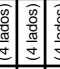 & 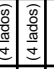 & \begin{tabular}{|l|} 
\\
0 \\
0 \\
0 \\
\end{tabular} & 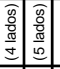 & 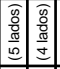 & & 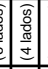 & 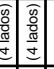 & 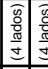 & \begin{tabular}{|l|} 
\\
$\frac{0}{0}$ \\
\end{tabular} & & & 递 \\
\hline$\frac{\frac{\pi}{\alpha}}{\frac{\pi}{2}}$ & 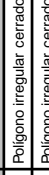 & | & 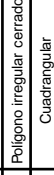 & & & & 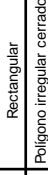 & 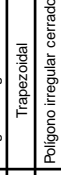 & & бేّ & & & 鳣 & 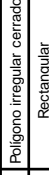 & 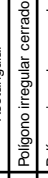 & | & & 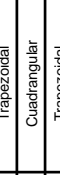 & 这 & 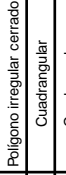 & 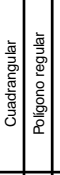 & 造 & 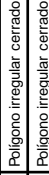 & 要 & 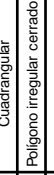 & 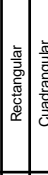 & 产 & & 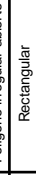 & 竧 \\
\hline 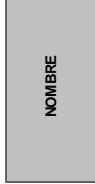 & 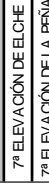 & 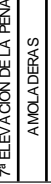 & & & & 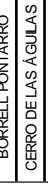 & & 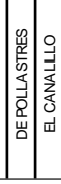 & 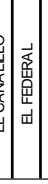 & & 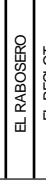 & & & 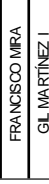 & 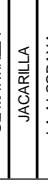 & 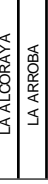 & & 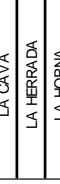 & $\begin{array}{lll} & \\
\end{array}$ & 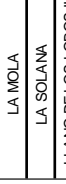 & 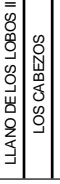 & 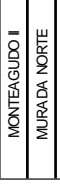 & 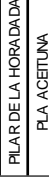 & $\mid$ & 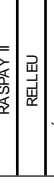 & 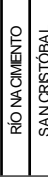 & | & & 焉 & 焉 \\
\hline
\end{tabular}




\section{Congreso Nacional de Riegos CARTAGENA 2021}

\section{Resultados y Discusión}

A continuación se presentan los resultados obtenidos para las diferentes parámetros analizados 3.1. Superficie Ocupada

Respecto a la Superficie Ocupada puede ser estimada mediante la figura 1 y ecuación (6).

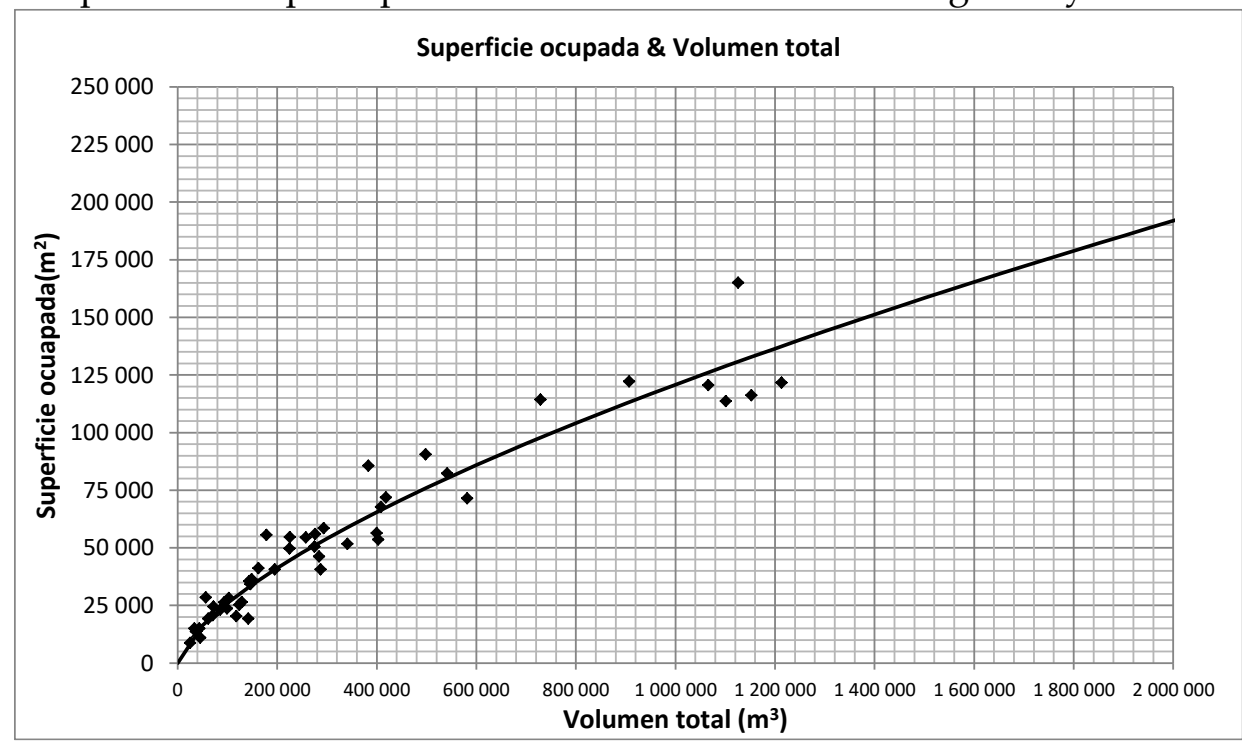

Figura 1. Relación entre la superficie ocupada y el volumen total.

$$
S_{\text {ocupada }}=11.937 \cdot V_{T}^{0.667} R^{2}=0.935
$$

donde $S_{\text {ocupada }}$ es la superficie ocupada por la balsa en $\mathrm{m}^{2}$ y $\mathrm{V}_{\text {т }}$ es el volumen total hasta la cota de coronación en $\mathrm{m}^{3}$.

La relación entre la $S_{\text {ocupada }}$ y el volumen útil queda expresada en la figura 2 y ecuación (7).

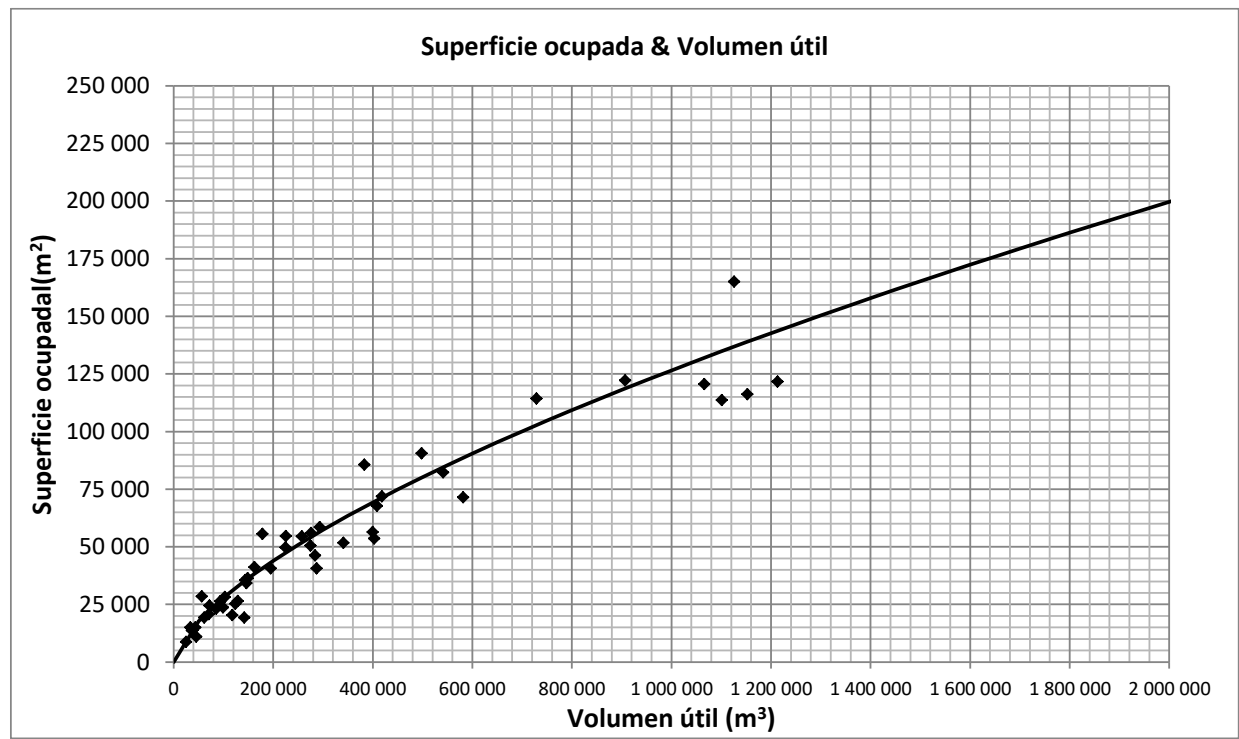

Figura 2. Relación entre la superficie ocupada y el volumen útil.

$$
S_{\text {ocupada }}=14.394 \cdot V_{u}^{0.657} R^{2}=0.93
$$

donde $V_{u}$ es el volumen útil de la balsa en $\mathrm{m}^{3}$. 


\section{Congreso Nacional de Riegos CARTAGENA 2021}

\subsection{Superficie Coronación}

En relación a la superficie de coronación $\left(S_{c}\right)$ ésta puede relacionarse con los volúmenes, así como con la superficie impermeabilizada $\left(S_{\text {impermeab }}\right)$, según las siguientes figuras y ecuaciones.

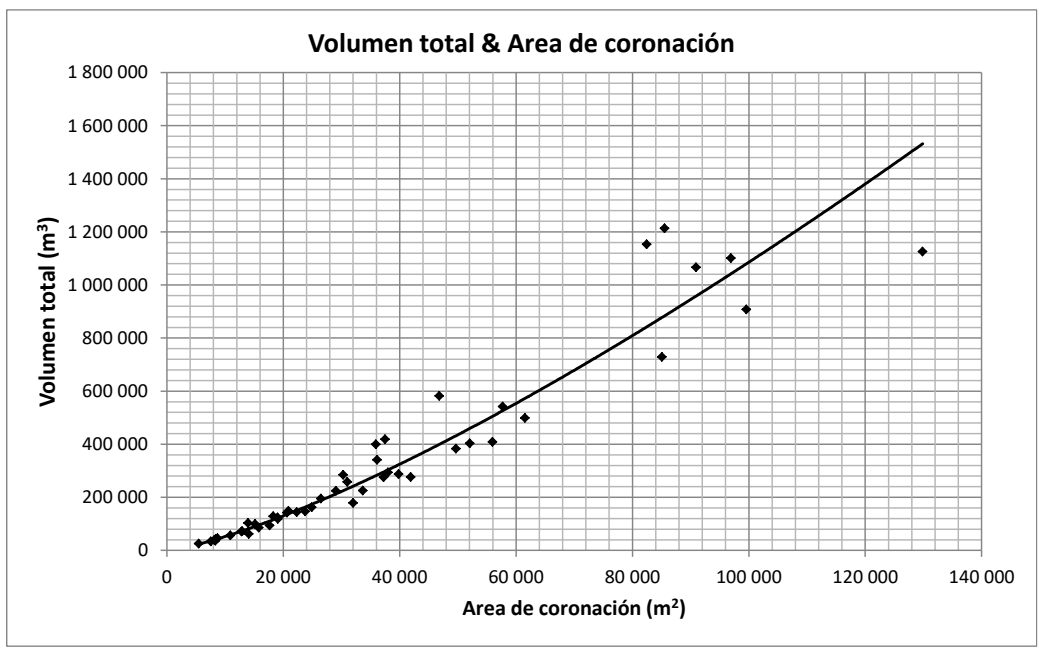

Figura 3. Relación entre la superficie de coronación y el volumen total.

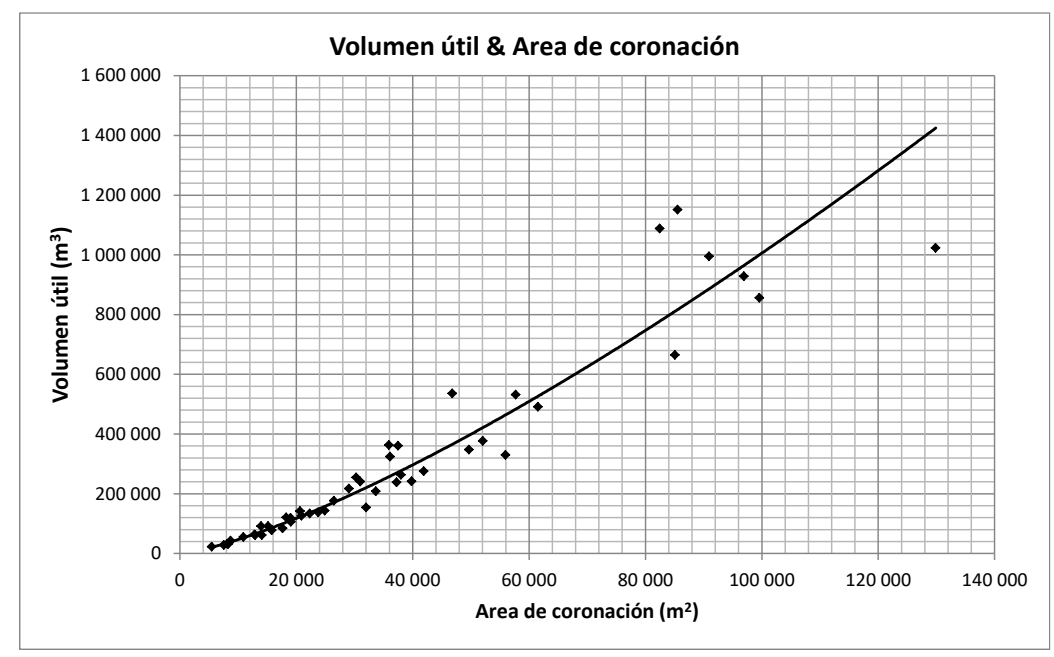

Figura 4. Relación entre la superficie de coronación y el volumen útil.

$$
\begin{array}{ll}
V_{T}=0.2811 \cdot S_{c}^{1.3174} & R^{2}=0.973 \\
V_{u}=0.2193 \cdot S_{c}^{1.3323} & R^{2}=0.971
\end{array}
$$




\section{Congreso Nacional de Riegos CARTAGENA 2021}

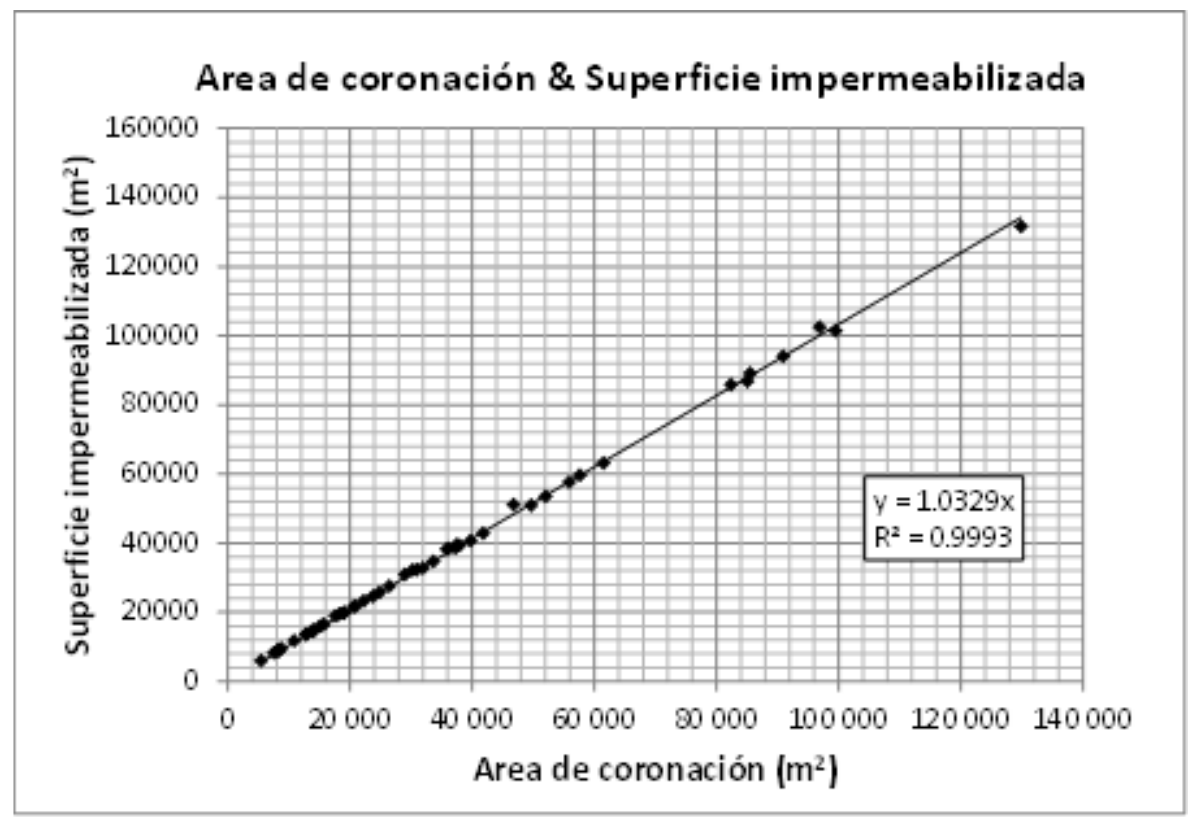

Figura 5. Relación entre la superficie ocupada y superficie de impermeabilizada.

$$
S_{\text {impermeab }}=1.0329 \cdot S_{c} \quad R^{2}=0.9993
$$

\subsection{Otras Relaciones}

Otro tipo de relaciones, útiles en el predimensionado de este tipo de infraestructuras se recogen en las siguientes figuras:

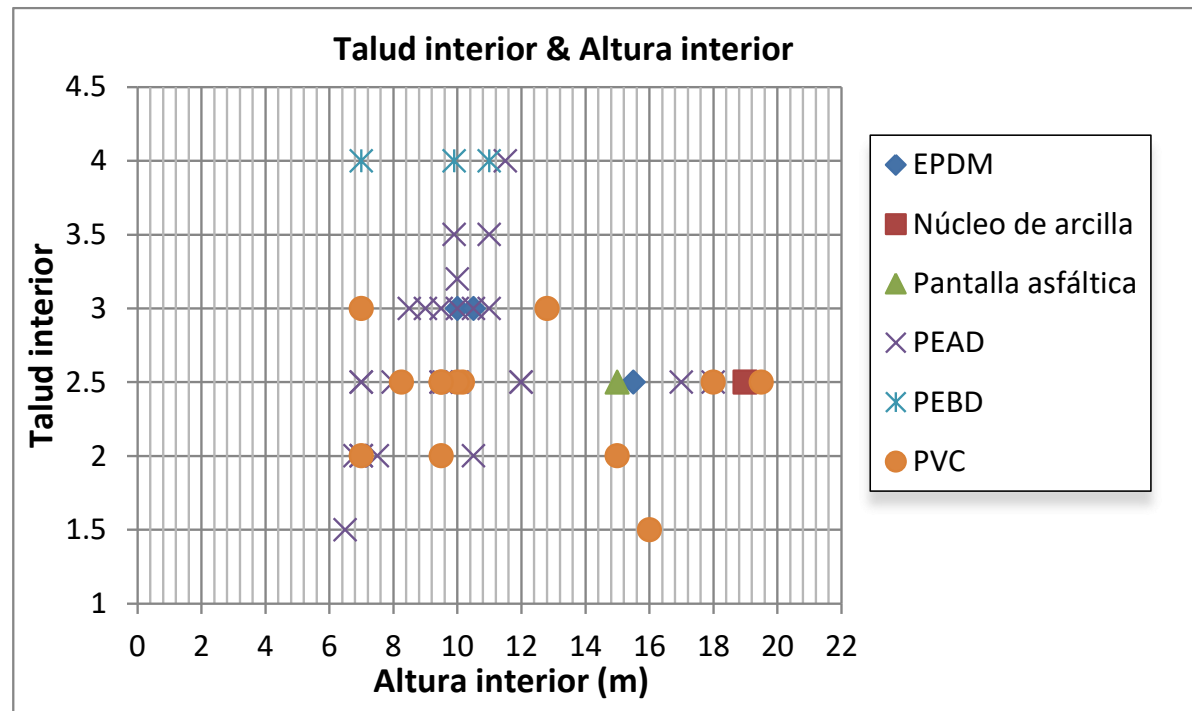

Figura 6. Relación entre el talud interior y la altura máxima interior. 


\section{Congreso Nacional de Riegos CARTAGENA 2021}

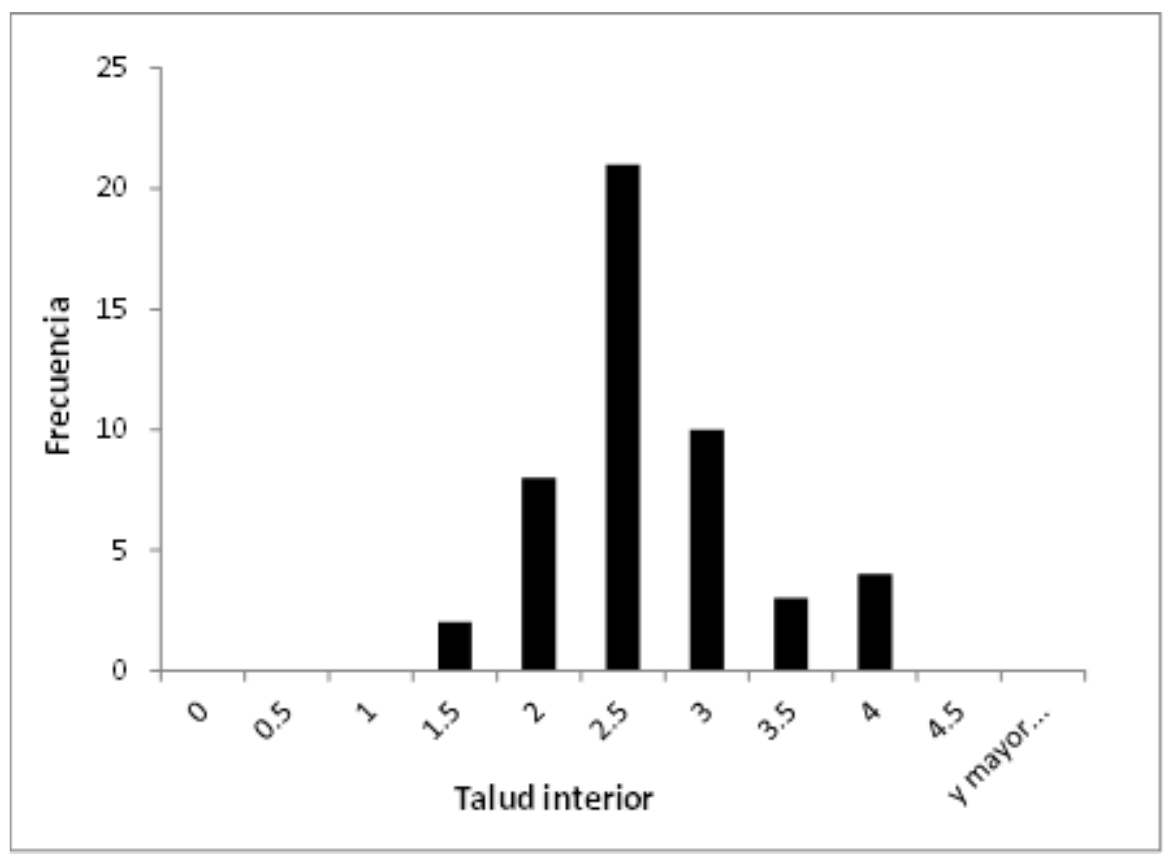

Figura 7. Frecuencias para el talud interior.

El Fetch queda definido como la distancia en la cual el viento puede actuar sobre una masa de agua. Para balsas esta definición se interpreta como la distancia normal desde la orilla opuesta en la dirección del viento hasta la estructura que se quiere diseñar. Este parámetro puede ser relacionado con el volumen útil y superficie de coronación según las siguientes figuras y ecuaciones:

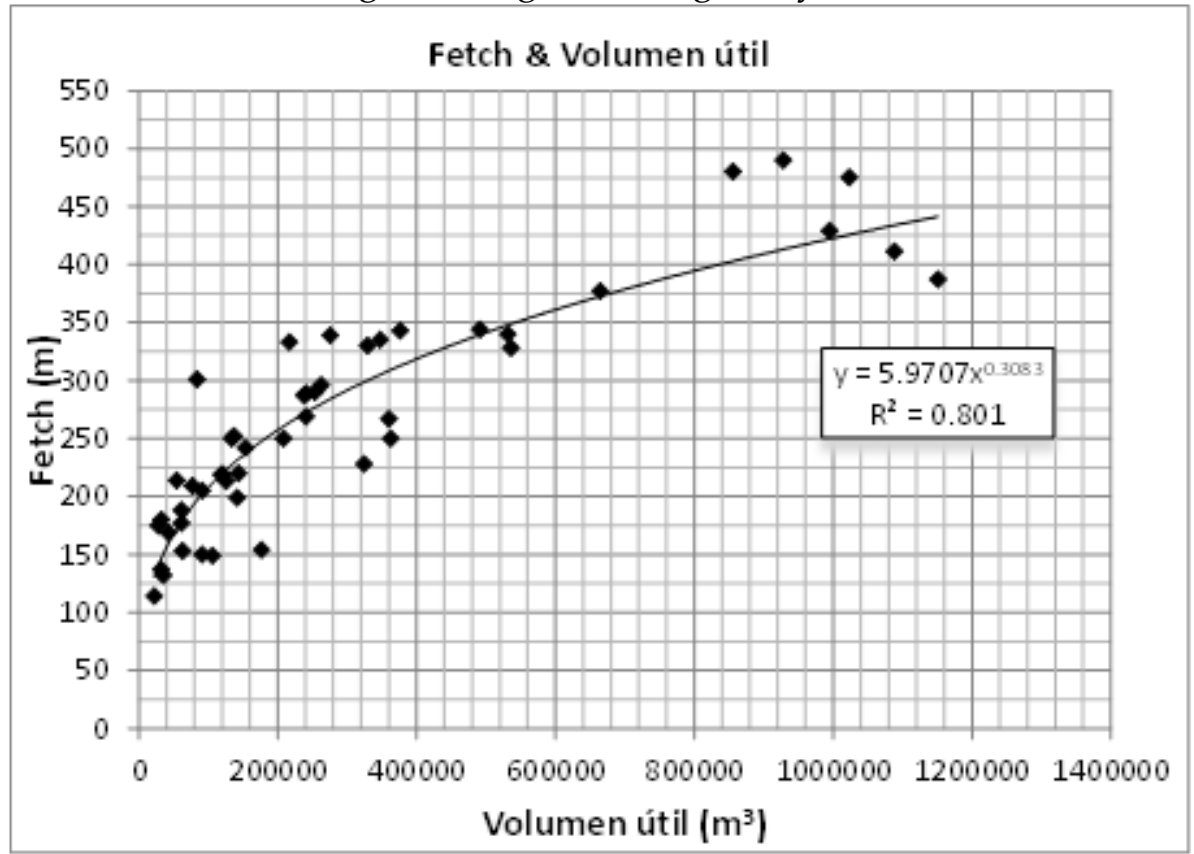

Figura 8. Fetch en relación al Volumen útil. 


\section{Congreso Nacional de Riegos CARTAGENA 2021}

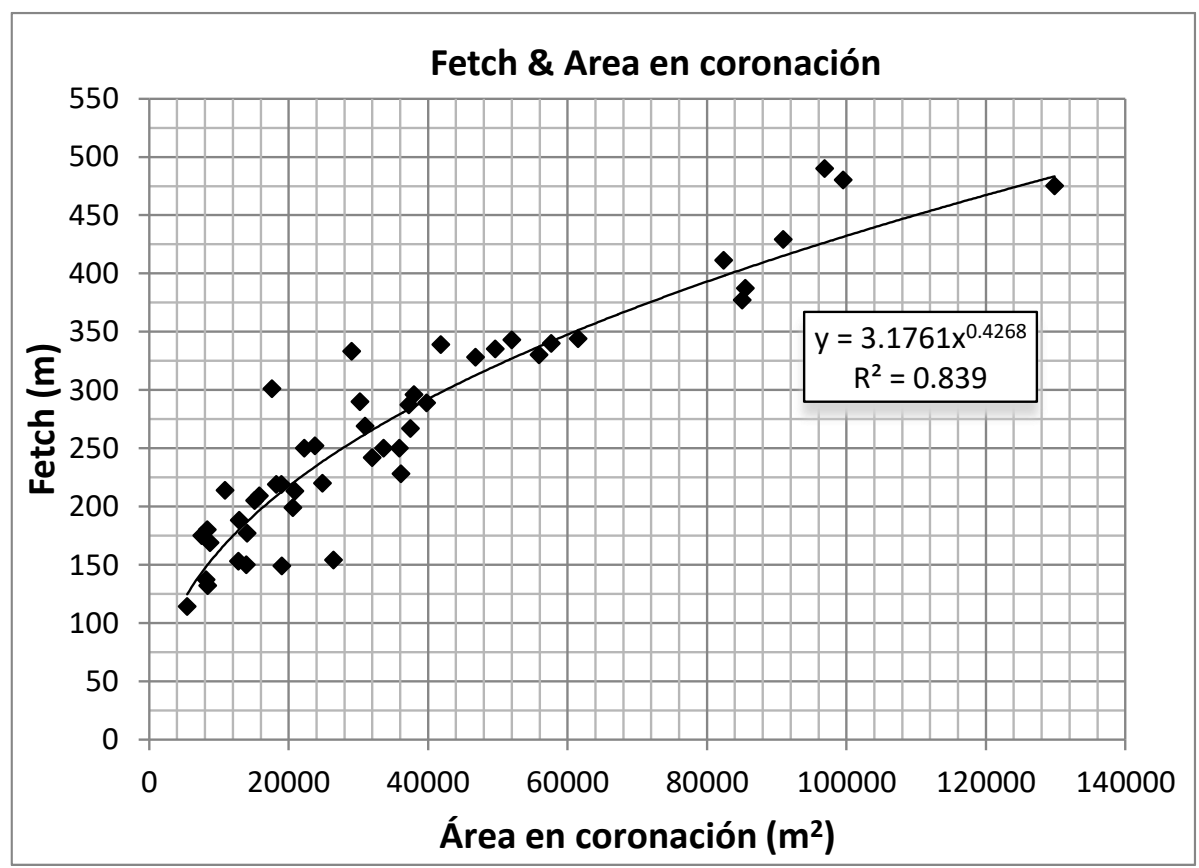

3.4. Ejemplo de Aplicación.

Figura 9. Fetch en relación a la Superficie de Coronación

A partir de los datos del censo obtenidos por [2] para la provincia de Alicante y extrapolando al resto de España y un coste de $6 € / \mathrm{m}^{2}$ de sustitución del paquete de geosintéticos, es posible estimar el coste de reimpermeabilización en función del número de balsas.

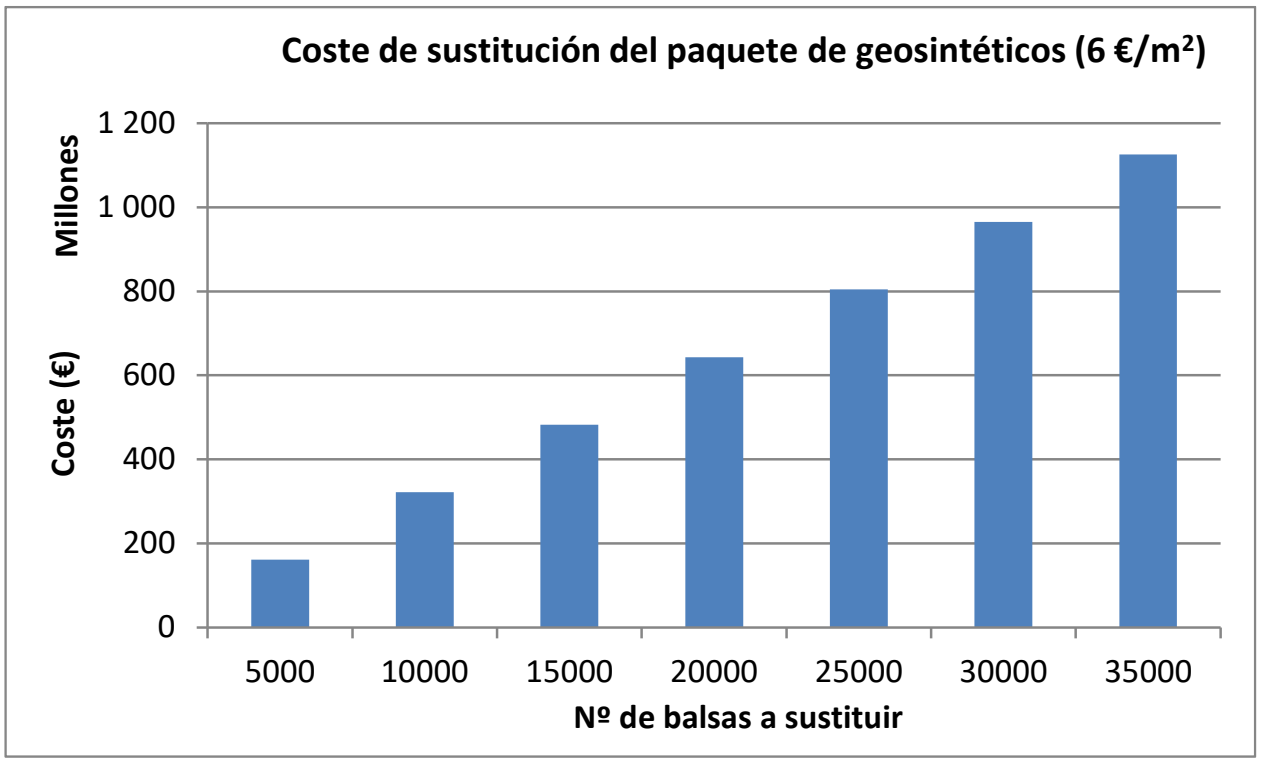

Figura 10. Estimación coste de reimpermeabilización en función del número de balsas. 


\section{Congreso Nacional de Riegos}

CARTAGENA 2021

\section{Conclusiones}

A partir de los datos obtenidos para un conjunto de 50 balsas, recopiladas por la Generalitat Valenciana, ha sido posible obtener las diferentes relaciones entre los parámetros característicos geométricos de una balsa. En este sentido es posible por ejemplo mediante la medición de las diferentes características mediante fotografía aérea la estimación de las variables geométricas más significativas, así como la extrapolación a la totalidad de balsas del territorio, mejorando así la gestión y planificación del territorio.

Este tipo de herramientas deben permitir en fase de predimensionado, la estimación de los diversos parámetros significativos para la toma de decisiones.

Los presentes y futuros trabajos de recopilación de la información de estas infraestructuras en el territorio (Registro), ya sea mediante fotografía aérea o fichas técnicas in situ, podrán apoyarse en estas expresiones y estudios, para la caracterización general del parque de balsas existente.

Este estudio debe ser la base para estudios más detallados y diseño de metodologías que también permitan la estimación de la altura de los diques, a partir tanto de fotografía aérea como de información topográfica accesible.

\section{Agradecimientos}

Este trabajo fue apoyado por el proyecto SISIFO (Desarrollo de herramientas analíticas para caracterIzar la Sostenibilidad de los sistemas hidráulicos Indicadores que definen Objetivos de desarrollo sostenible) PID2020-114781RA-I00 del Plan Estatal de Investigación Científica y Técnica e Innovación 2017-2020.

\section{Referencias}

[1] E. Amigó and E. Aguiar, “Manual para el diseño, construcción y explotación de embalses impermeabilizados con geomembranas," Cons. Agric. y Aliment. Gob. ..., 1994.

[2] F. A. Zapata Raboso, "Análisis del comportamiento histórico de balsas de tierra en la Provincia de Alicante. Criterios de Diseño.," Universidad Politécnica de Valencia, 2003.

[3] F.-J. Sánchez-Romero, “Criterios de seguridad en balsas de tierra para riego," Universitat Politècnica de València, 2014. 


\section{Nuevas Funciones de las Balsas de Riego en una Transición hacia una agricultura más sostenible, en la Provincia de Ali- cante.}

Zapata Raboso, F.Ac,a (P) Cabañero Fernández, J.d1 , Ferrán Gozálvez, J.J.a1 , Ferrer Gisbert ,A a2 , Ferrer Gisbert, C.a3, Mascarell Gómez, A.d2, Pérez Sánchez, M. ${ }^{b 1}$, Redón-Santafé, M. ${ }^{44}$, Sánchez Romero F.J. ${ }^{a 5}$, Torregrosa Soler J.B. ${ }^{a b}$, Vinaches Ramis, J.a,e

a. Departamento de Ingeniería Rural y Agroalimentaria. Universitat Politècnica de València. Camino de Vera s/n 46022. Valencia

a1 jjferran@agf.upv.es , a2 aferrer@agf.upv.es , a3 caferrer@agf.upv.es , a4miresan@agf.upv.es,

a5 fcosanro@agf.upv.es, a6jbtorreg@fis.upv.es

b. Departamento de Ingeniería Hidráulica y Medio Ambiente. Universitat Politècnica de València. Camino de Vera s/n 46022. España. ${ }^{b 1}$ mopesan1@upv.es

c. Generalitat Valenciana: Servicio del ciclo integral del agua c/Democracia, 77. Ciudad administrativa 9 d'octubre Torre 146018 Valencia zapata_fra@gva.es

d. Grusamar, Consultoría e Ingeniería Dirección de Oficinas Centrales: Parque Empresarial Barajas Park, C/ San Severo 18 ,28042 Madrid (España)

d1 javier.cabanero@elsamex.com , d2 alba.mascarell@grusamar.com>

e. Proiatec ingeniería Calle Cervantes no 5 bajo 03570 Villajoyosa (Alicante); proiatec@proiatec.com

\section{Resumen:}

Son bien conocidas las funciones de las balsas de tierra, como infraestructuras imprescindibles en la modernización, consolidación y sostenibilidad de regadíos, desde finales de los años 60 del siglo pasado.

Actualmente, dichas funciones están plenamente vigentes, pero además, se amplían las mismas como infraestructuras básicas para la regulación de recursos en el ámbito comarcal, independientemente de su origen. Las nuevas funciones que cumplirán las balsas son: Regulación de volúmenes de aguas superficiales, derivadas de ríos, sin interferir en las dinámicas naturales de los mismos. Acoplar la oferta y la demanda de aguas residuales y desaladas, haciendo posible, además, la utilización de fuentes de energía renovables. Contribuir como micro-humedales, en combinación con la actividad agraria, en el aumento de la biodiversidad.

Palabras clave: Balsas, Agricultura, riego, Sostenibilidad, Reutilización, Aguas residuales, Desalación, Ríos, Presas. 


\section{Congreso Nacional de Riegos CARTAGENA 2021}

\section{New Functions of the irrigation reservoirs in a Transition towards a more sustanaible agriculture, in the Province of Ali- cante (Spain)}

Zapata Raboso, F.Ac,a (P) Cabañero Fernández, J.d1, Ferrán Gozálvez, J.J.a1 , Ferrer Gisbert ,A a2, Ferrer Gisbert, C.a3, Mascarell Gómez, A. ${ }^{d 2}$, Pérez Sánchez, M. ${ }^{b 1}$, Redón-Santafé, M. ${ }^{44}$, Sánchez Romero F.J. ${ }^{a 5}$, Torregrosa Soler J.B. ${ }^{a 6}$, Vinaches Ramis, J.a,e

a. Department of Rural and Agri-Food Engineering. Universitat Politècnica de València. Camino de Vera s/n 46022. Valencia a1jjferran@agf.upv.es, a2 aferrer@agf.upv.es , a3 caferrer@agf.upv.es , a4miresan@agf.upv.es,

a5 fcosanro@agf.upv.es, a6 jbtorreg@fis.upv.es

b. Department of Hydraulic Engineering and Environment. Universitat Politècnica de València. Camino de Vera s/n 46022. España. b1 mopesan1@upv.es

c. Generalitat Valenciana: Department of the integral water cycle c/Democracia, 77. Ciudad administrativa 9 d'octubre Torre 146018 Valencia zapata_fra@gva.es

d. Grusamar, Consulting and Engineering Dirección de Oficinas Centrales: Parque Empresarial Barajas Park, C/ San Severo 18 ,28042 Madrid (España)

d1 javier.cabanero@elsamex.com , d2 alba.mascarell@grusamar.com>

e. Proiatec ingeniería Consulting and Engineering. Calle Cervantes no 5 bajo 03570 Villajoyosa (Alicante);proiatec@proiatec.com

Summary:

The functions of earth reservoirs are well known, as essential infrastructures in the modernization, consolidation and sustainability of irrigation systems, since the end of the 60s of the last century.

Currently, these functions are fully in force, but they are also expanded as basic infrastructures for the regulation of resources at the regional level, regardless of their origin. The new functions that the earth reservoirs will fulfill are: Regulation of surface water volumes derived from rivers, without interfering with their natural dynamics. Coupling the supply and demand of wastewater and desalinated, also making possible the use of renewable energy sources. Contribute as micro-wetlands, in combination with agricultural activity, in increasing biodiversity.

Keywords: Reservoirs, Agriculture, Irrigation, Sustainability, Reutilization, Wastewater, Desalination, Rivers, Dams. 


\section{Introducción}

El excelente clima, y la bondad de los suelos en las zonas áridas de la provincia de Alicante, exige el aprovechamiento de cualesquiera recursos hidráulicos disponibles: superficiales, subterráneos, aguas residuales y aguas saladas, que permitan contribuir, a la garantía y seguridad alimentaria; uno de los retos del siglo XXI.

Tradicionalmente, las balsas de riego han venido asociadas a la regulación de las aguas subterráneas y a las aguas regenaradas procedentes de la Estaciones Depuradoras de Aguas Residuales (EDAR).

Como es bien sabido el uso de recursos no convencionales (aguas residuales y desaladas), presenta la necesidad de ejecución de infraestructuras hidráulicas complementarias, que superan en la mayoría de los casos, en cuanto a inversión, las estrictas instalaciones de las EDAR y las desaladoras. Si se pretende incorporar la Reutilización de las aguas residuales y desaladas al riego, es condición necesaria, pero en absoluto suficiente la depuración en condiciones aptas para la agricultura y la desalación en su caso. La condición suficiente, se obtiene, si además se coloca el recurso a pie de parcela. Esto supone, en la mayoría de los casos, la ejecución de conducciones de transporte hasta cabecera de las zonas regables, y balsas de acumulación que acoplen la oferta de las aguas a la demanda del riego; y todo ello a un coste energético, asumible por la agricultura. Esta última fase, de puesta del agua en parcela supone muchas veces, costes importantes que pueden llegar a superan las instalaciones de depuración y desalación, pero que en ningún caso pueden ser obviadas, si se pretende el uso "real" de los potenciales recursos de las aguas residuales y desaladas.

En cuanto a las aguas superficiales, complementar las funciones de las presas en la regulación de las aguas superficiales.

En el presente artículo se desarrollan dichas funciones, implementándose para el caso concreto de la Provincia de Alicante.

\section{Funciones.}

[En cuanto a las aguas residuales]

a) Ajuste de la oferta a la demanda. Los volúmenes depurados y regenerados, son prácticamente constantes a lo largo del año. En la época estival, pueden ser absorbidos en su totalidad por la superficie regable, es más, suele ocurrir, que la demanda de agua para el riego, supere la oferta de suministro de la EDAR, mientras que en las épocas invernales prácticamente todo el volumen regenerado, es vertido al mar, dándose la paradoja, que, siendo el volumen total anual regenerado superior al requerido para el riego, exista un déficit en los periodos punta de riego. A modo de ejemplo, si el volumen medio de depuración de una EDAR comarcal, es de 25.000 m3/día; para un periodo de tres meses, sin prácticamente demanda al riego, condición que se verifica en otoño/invierno, supone un vertido al mar, y una pérdida de recurso para el riego, del orden de 2,25 hm3, que, a su vez, sería la capacidad de la balsa a proyectar.

b) Incorporación de las energías renovables. 
En el caso de que la ubicación de la EDAR, se encuentre en una cota que garantice presión suficiente para el riego (caso de la EDAR de Benidorm) (ver Figura.- 1), no es necesario energía complementaria; aunque esta situación no es la más habitual.

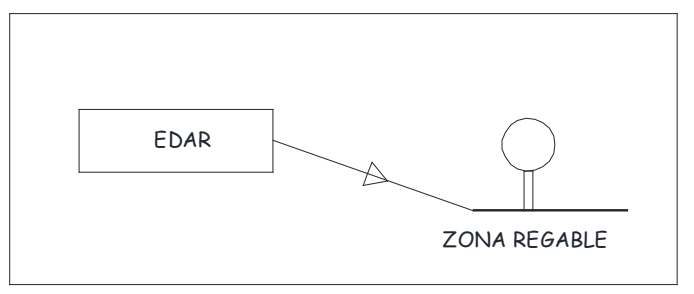

Figura.- 1 Esquema de emplazamiento de EDAR, en la que no es necesario aporte adicional de energía para el riego.

La situación más usual, es que las EDAR/desaladoras, se encuentren en cotas bastante inferiores a la zona regable, lo cual hace necesario, la adición de energía complementaria hasta alcanzar la misma. Actualmente, el tipo de energía utilizada, es la convencional obtenida de la red eléctrica. Las potencias y energías necesarias, son importantes, llegando a costes del orden de 50 céntimos de euro el metro cúbico. Una solución para reducir el coste de la energía, es la implantación de energía renovable solar. Esta solución presenta varios problemas que pasamos a enunciar:

i. El emplazamiento de las EDAR, hace prácticamente imposible, en las cercanías a la misma, la ejecución de una balsa con las dimensiones suficientes para almacenar los volúmenes necesarios para que los equipos, funcionen en horas de sol, e independientemente de los caudales salientes de la EDAR.

ii. Además, las potencias necesarias para el bombeo, exigen la ocupación de superficies que no están disponibles en las inmediaciones de la balsa, para el emplazamiento del huerto solar.

La solución, consiste en la ejecución de una primera elevación de poca altura, mediante energía convencional, que permita el funcionamiento del bombeo, según los volúmenes salientes de la EDAR, hasta encontrar un emplazamiento donde se pueda construir, tanto la balsa, con las dimensiones necesarias, como la superficie suficiente para la instalación de los huertos solares, que denominamos etapa 1 (ver. Figura.- 2) desde esta balsa, ya exclusivamente, mediante energía renovable solar, se eleva el agua hasta la zona regable (etapa 2). Esta solución, permite abaratar energéticamente el coste de la elevación independientemente de la altura, prácticamente a cero. Este procedimiento, está planificado para algunas EDAR de la ciudad de Alicante, como por ejemplo Orgegia.

También permite de idéntica manera la racionalización energética de las desaladoras de agua de mar, si es el caso. 


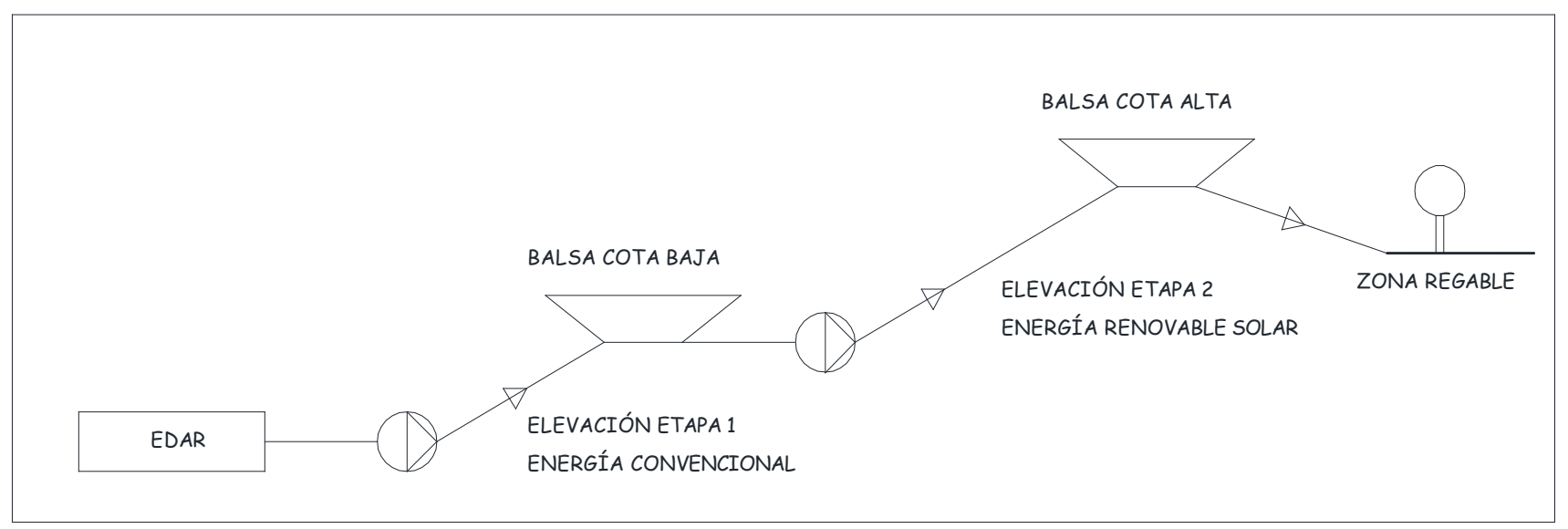

Figura.- 2 Solución a la utilización de energía renovable solar, hasta alcanzar la balsa de dominio de la zona regable

[En cuanto a las aguas superficiales]

Dado el estado del arte actual en la construcción de balsas de cara a su seguridad, que ha derivado hacia la tendencia de construcción de balsas de mayor capacidad, encuentra un nicho nuevo, junto con las presas en la regulación de las aguas superficiales. Estas nuevas funciones podemos agruparlas en los siguientes puntos:

i. Regular volúmenes, en emplazamientos fuera de cauce, donde no resulte aconsejable la construcción de presas.

ii. Dada la actual política de seguridad de presas, en determinadas épocas del año (hacia finales del verano), las Confederaciones Hidrográficas, marcan unas cotas de embalse que no pueden ser superadas en ningún caso, incluidas las presas de fábrica, en previsión de la llegada de las torrenciales lluvias otoñales mediterráneas. Esto, lleva a realizar desembalses en estas fechas, perdiéndose los volúmenes almacenados por encima de esta cota de seguridad, al no existir aguas abajo, vasos en los que almacenar estos excedentes. La situación se agrava aún más, cuando, al menos en parte, el agua almacenada, ha sido mediante bombeos de escorrentías, procedentes de otras cuencas, este por ejemplo, es el caso de las presas de Amadorio y Guadalest, que dada las escasas aportaciones de sus cuencas, funcionan más a modo de balsa de regulación/almacenamiento, que de presa propiamente dicha, almacenando los volúmenes de otra cuenca más rica, la del Algar

iii. Por otra parte, la mejora en el aprovechamiento de las escorrentías superficiales, redunda en una explotación más racional de las aguas subterráneas. 
La aplicación práctica de los puntos indicados, se manifiesta en: la nueva balsa de Relleu de $170.000 \mathrm{~m}^{3}$ y la Balsa de Alfondóns, de $300.000 \mathrm{~m}^{3}$ en Villajoyosa, en la Cuenca del Amadorio, y la futura balsa, actualmente en fase de redacción de proyecto, de la balsa de Massatava, con una capacidad superior al millón de metros cúbicos en la cuenca del Guadalest. Además, estas balsas cumplen las funciones tradicionales inherentes a suministrar los volúmenes necesarios directamente a las zonas regables.

[En cuanto a contribuir a mejorar la calidad ambiental]

Las balsas, junto con la actividad agraria de regadío, cumplen además las siguientes funciones en relación a la calidad ambiental:

i. Permitir el arrastre de solidos del río y no interferir en los procesos naturales del mismo, al estar emplazadas fuera del cauce.

ii. Disminuir los vertidos de las EDAR, al mar, hasta prácticamente cero.

iii. Permitir libremente el tránsito de la fauna piscícola del río.

iv. Incorporar el agua residual al riego, contribuyendo a una gestión sostenible de un recurso escaso, ajustando la oferta de las EDAR, con la demanda del riego.

v. Permitir la incorporación de las aguas desaladas al riego.

vi. Permitir la utilización de energías renovables para el bombeo de las aguas procedentes de las EDAR y desaladoras hasta la zona regable, a un coste energético, prácticamente nulo.

vii. Crear microzonas húmedas, que contribuyen junto con la actividad agraria, al incremento de la biodiversidad, principalmente las aves.

\section{Conclusiones.}

Estas nuevas funciones, de:

i. contribuir a la reutilización, prácticamente total de los efluentes de las EDAR al riego, con vertido cero al mar, con costes energéticos mínimos, gracias a la implantación de energía renovable solar, que permite, por una parte, racionalizar todos los recursos existentes, independientemente de su procedencia y por otra, incrementar las garantías del recurso al sector agrario.

Se quiere destacar que la reutilización de las aguas residuales y desaladas "real", no es posible, sin la ejecución de las infraestructuras de transporte y regulación de dichas aguas hasta la cabecera de la zona regable, a un coste asumible por el sector agrario; cuyo coste de ejecución de dichas infraestructuras, puede supera ampliamente al de las propias infraestructuras e instalaciones de depuración y desalación.

ii. Su contribución, junto con las presas, a mejorar la racionalización en el uso de las aguas superficiales y subterráneas.

iii. Su indiscutible valor como infraestructura que contribuye al incremento de la biodiversidad. 
Refuerzan, la necesidad, ya indiscutible, de este tipo de obras hidráulicas de riego, para el mantenimiento de una agricultura sostenible, que garantice la seguridad alimentaria, en perfecta armonía con el entorno ambiental.

\section{Referencias}

Obras en servicio, en ejecución, en planificación y redacción de proyecto de la Generalitat Valenciana, en el ámbito de la Provincia de Alicante. 


\section{GRUPO TEMAS FORO EMPRESARIAL DE INNOVACIÓN:}

Foro Empresarial de Innovación para la Eficiencia en el Uso del Agua en la Agricultura 


\title{
Uso del PVC Orientado como herramienta de ahorro energético en las obras de Modernización del Regadío de la Z.R de la C.R del Trasvase Tajo-Segura de Librilla. Sectores 2 y 3
}

\author{
Rincón Benito, Marcos (1) (P)
}

1Asistencia Técnica, Molecor, marcos.rincon@molecor.com

\section{Introducción.}

La modernización del sistema de riego es crucial para el mantenimiento de la actividad agrícola en el ámbito del área regable de la Comunidad de Regantes de Librilla. Su déficit hídrico, consecuencia del estructural que padece el sureste español y del sistema de riego que se emplea en la actualidad, obliga a disponer de uno con la mayor eficiencia posible, que asegure el máximo aprovechamiento de los recursos disponibles. Además, aunque diferentes programas de reabastecimiento de agua estatales o autonómicos fueran capaces de equilibrar el balance hídrico, el coste del $\mathrm{m}^{3}$, como ya está ocurriendo, no permite el mal- gasto del recurso que supone el riego por inundación comparado con otros sistemas de mayor eficiencia intrínseca.

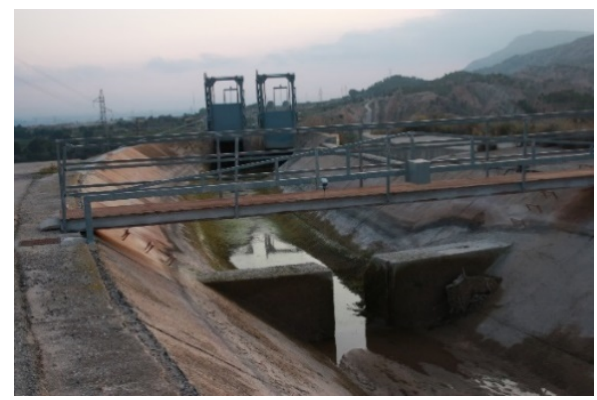

Por otra parte, el agricultor, para acometer reconversiones varietales y cambios de cultivo, que son necesarios para mantener la rentabilidad de la actividad agraria, ha de disponer de un sistema de riego adecuado.

La modernización debía plantearse desde la perspectiva de la instalación de un riego localizado que cubría la superficie regable, abastecido mediante redes de distribución de agua a presión.

El objeto de la obra pasa por optimizar el uso de los recursos actualmente disponibles, incrementar la capacidad de regulación estacional, optimizar las infraestructuras de abastecimiento de agua y energía, con objeto de reducir los costes de impulsión, asegurar el suministro de agua en parcela y automatizar e infor- matizar las infraestructuras hidráulicas, facilitando el control de consumos y la gestión administrativa del agua.

2. Diferenciación de actuaciones y sectores 


\section{Congreso Nacional de Riegos CARTAGENA 2021}

El área regable de la Comunidad está perfectamente definida por el Canal del Trasvase Tajo-Segura Margen Derecha al noroeste, la Rambla de Belén al noreste, el Río Guadalentín al sureste y la Rambla de Algeciras al suroeste;

Analizada el área regable de la Comunidad, con una superficie modernizable total de 2.811,9214 ha, зpara acometer las actuaciones previstas, se dividió en cuatro sectores de riego independientes, cada uno con su toma en el Canal del TTS.

En el presente documento se hablará de sendas actuaciones independientes acometidas en los sectores 2 y 3 .

El Sector 2 , cuenta con una superficie modernizable de 879,5 ha, repartidas en una Zona de Impulsión de 219,3 ha y 371 parcelas reunidas en 43 hidrantes y una Zona de Gravedad de 660,1789 ha y 868 parcelas en 90 hidrantes.
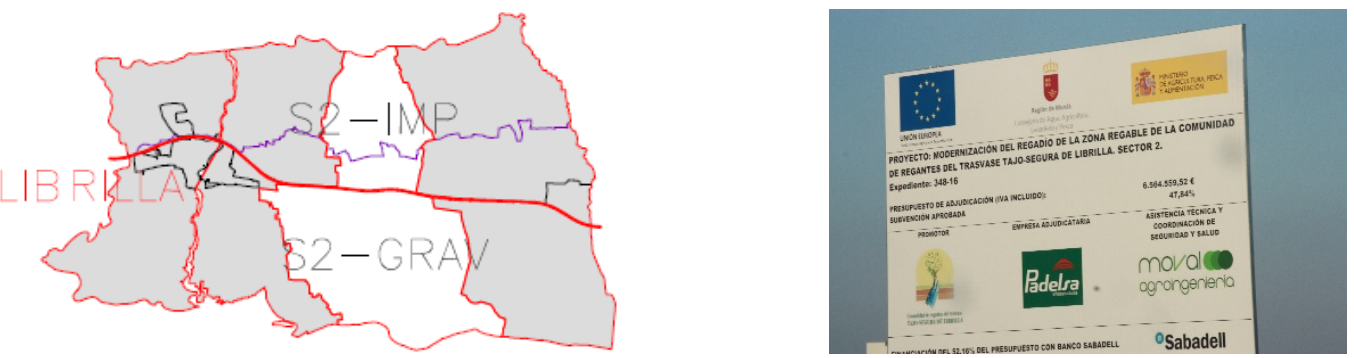

Las obras fueron promovidas a instancia de la Comunidad de Regantes de Aguas del Trasvase TajoSegura de Librilla (Murcia). El proyecto fue redactado por la ingeniería Water Technologies y supervisado por Moval Agroingeniería, quienes a su vez asumieron la Dirección de Obra y la coordinación de seguridad de las obras que fueron ejecutadas por Padelsa. Las obras comenzaron en el año 2018 y finalizaron en Julio del 2020.

El Sector 3 , contaba con una superficie modernizable de 595,88 ha, repartidas en una Zona de Impulsión de 243,9 ha y 574 parcelas reunidas en 67 hidrantes y una Zona de Gravedad de 351,94 ha y 863 parcelas en 97 hidrantes.
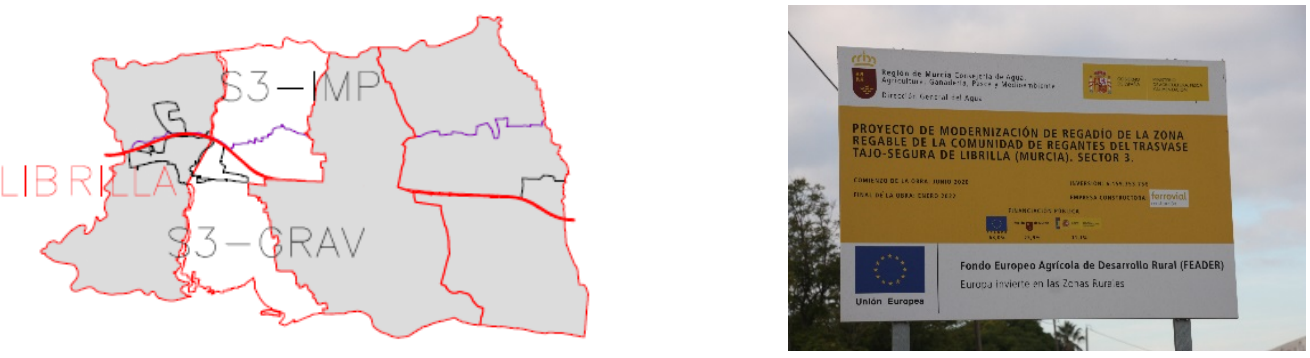

Las obras fueron promovidas a instancia de la Consejería de Agua, Agricultura, Ganadería y Pesca de la Región de Murcia. El proyecto fue redactado por la ingeniería Water Technologies y supervisado por Moval Agroingeniería, quienes a su vez asumieron la Dirección de Obra y la coordinación de seguridad de las obras que fueron ejecutadas por Ferrovial. Las obras comenzaron en junio del año 2020 y tienen prevista su finalización en enero del 2022. 
En ambos casos la supervisión y control se han llevado a cabo por los Servicios Técnicos de la Consejería de la R.M en colaboración con el Servicio Técnico de la Comunidad de Regantes de Librilla.

\section{Diseño de la red y descripción de las obras}

La instalación partirá en cada Sector de un embalse de regulación, que en los Sector 2 y 3 han sido motivo de proyecto aparte y realizado y financiado por la Consejería de agua, Agricultura, Ganadería y Pesca de la Región de Murcia, que se abastecerán desde las correspondientes tomas automatizadas del Canal del TTS.

Cada Sector ésta dividido en dos Zonas, una que necesita aporte de energía (impulsión) y otra que riega por gravedad, y en cada una de ellas, aparte de la automatización, se distinguen dos tipos de actuaciones: la distribución en alta, que comprende todos los elementos desde la toma en el TTS hasta la acometida de los hidrantes colectivos, y la distribución en baja, que considera los necesarios para llegar desde estos últimos hasta todas y cada una de las fincas consideradas.

Para el cálculo de necesidades de agua, se considera representativa del área regable una plantación adulta de limoneros, formada al 60/40 por las variedades Verna y Fino. El diámetro probable del bulbo, dada la textura del terreno, se ha estimado en $1,37 \mathrm{~m}$, lo que supone un área mojada por emisor de 1,47 $\mathrm{m}^{2}$. Con una disposición de 8 emisores de 4 l/h por árbol, considerando un marco de plantación de 5,5x5,5, se obtiene un porcentaje de suelo mojado del $35 \%$. De esta forma se dedujo un módulo de riego de 1,057 1/m²h y así se deduce que es conveniente hacer 3 turnos de riego diarios por cada Zona de cada Sector, y si la JER es de 18 horas, se dispondrá de 6 horas por turno.

La dotación de la que se dispone varía entre los $8.802 .300 \mathrm{~m}^{3} /$ año y $7.310 .740 \mathrm{~m}^{3} / \mathrm{año}$. Esta cifra está conformada por la dotación que tiene la CCRR del Trasvase Tajo-Segura, las escorrentías que se recogen en la PRESA DE LA RAMBLA DE ALGECIRAS, las correspondientes a la concesión de las aguas residuales regeneradas de la EDAR de Librilla. Esta dotación tiene la particularidad de que el reparto es igualitario stanto en calidad como en cantidad, en función de la superficie de cada comunero. Esta singularidad hizo que la automatización prevista fuera a nivel de parcela.
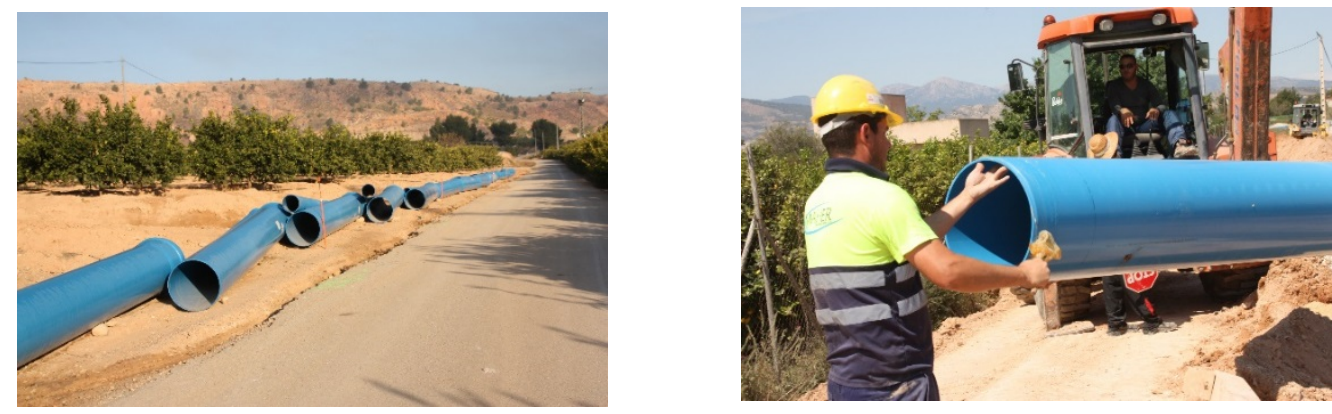

Las parcelas situadas en una franja de aproximadamente $50 \mathrm{~m}$ por debajo de la cota media de cada embalse necesitan del aporte de energía al sistema de riego para su buen funcionamiento. Por lo tanto, los sectores se han dividido en dos Zonas, una que funcionará por impulsión y otra por gravedad. 


\begin{tabular}{ccc}
\hline & SECTOR 2 & SECTOR 3 \\
\hline & \multicolumn{2}{c}{ Superficie (ha) } \\
\cline { 2 - 3 } Impulsión & 219,4 & 243,9 \\
Gravedad & 660,2 & 351,94 \\
Total & 879,6 & 595,84 \\
\hline
\end{tabular}

El funcionamiento de una red en impulsión directa supone el aporte de energía eléctrica para permitir el funcionamiento del equipo de impulsión, que se instalará en los mismos edificios que los cabezales de filtrado. Se utilizará de forma mixta energía de red y energía solar fotovoltaica tanto en la Zona de Impulsión como en la Zona de Gravedad.

A partir del cabezal de filtrado, se ha instalado en cada Zona de riego una red de tuberías principales y terciarias, de diferentes materiales, diámetros y timbrajes, que lleva el agua, filtrada y medida, desde el punto de suministro hasta todas y cada una de las fincas. Las redes principales son ramificadas y rematan en unas casetas o arquetas prefabricadas en donde se albergan los elementos de medición y de automatización en campo de las parcelas (entre 6 y 14 de ellas por caseta o arqueta). Desde las casetas o arquetas hasta las parcelas se han instalado tuberías terciarias independientes para cada una de ellas.

Entre todos los embalses se instalarán tuberías de comunicación para asegurar el trasiego si fuera necesario, que funcionarán por gravedad en el sentido de circulación de agua por el canal y en impulsión aprovechando los grupos motobomba.

\subsection{Cabezales de las Zonas impulsadas}

Bombeos: Con el fin de simplificar trabajos de mantenimiento y de reparación e incluso de reposición de algún grupo motobomba y aunque ello signifique sacrificar algún punto porcentual en cuanto a rendi- miento, se instalaron dos equipos de impulsión exactamente iguales en ambos sectores que cubre distintos turnos de riego, es decir, distintas demandas de caudal y presión. El turno 1 formado por tres grupos motobomba centrífugos horizontales en paralelo en el Sector 2 proporciona 743,719 $\mathrm{m}^{3} / \mathrm{h}$ a una altura manométrica de 69,65 m.c.a mientras que en el Sector 3 el turno 1 proporciona $857,714 \mathrm{~m}^{3} / \mathrm{h}$ a una altura manométrica de 70 m.c.a. Los turnos de bombeo 2 y 3 son cubiertos en ambos sectores por otros tres grupos motobomba centrífugos horizontales de las mismas características, pero con motores de $55 \mathrm{~kW}$ de potencia nominal en paralelo.

Todos los grupos motobomba de cada equipo estarán provistos de un variador de frecuencia hibrido capaz de hacer funcionar los grupos motobomba tanto con la energía de red como a partir de la corriente continua de la energía solar fotovoltaica.

Se instaló una válvula de alivio rápido de presión, que alivia las presiones en el sistema cuando superan un máximo predefinido, abriéndose totalmente y cerrando a continuación con suavidad, con la repetitividad necesaria hasta bajar la presión al nivel de régimen de trabajo, con lo cual constituye un elemento de seguri- dad ante la presencia de sobrepresiones por transitorios rápidos. Así pues, se instaló una válvula de alivio rápido de $200 \mathrm{~mm}$ en derivación, precedida por otra de mariposa para facilitar operaciones de manteni- miento, que verterá por gravedad a un canal principal de riego tradicional próximo al almacén del cabezal. 


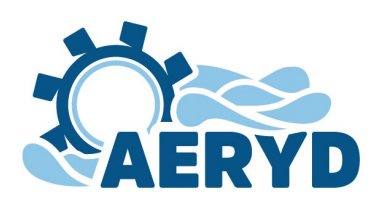

\section{Congreso Nacional de Riegos CARTAGENA 2021}

A la salida de los cabezales se instaló un caudalímetro electromagnético de $400 \mathrm{~mm}$ de diámetro, con el fin de obtener lectura del caudal instantáneo y el volumen suministrado.

Además del bombeo que da servicio a las zonas impulsadas se incluyeron el encargado del aprovechamiento del agua procedente del lavado de filtros en la zona de gravedad en ambos sectores y finalmente, el destinado al aprovechamiento de las aguas residuales regeneradas de la EDAR municipal, que desde su balsa de regulación también se impulsarán hasta el embalse del Sector 3 por el mismo motivo.

En la estación de filtrado de la Zona de Gravedad el agua de la limpieza de filtros se envía a una arqueta de decantación, con un cuerpo de regulación de un volumen de 8,25 $\mathrm{m}^{3}$. Este volumen se vuelve a inyectar a la red de gravedad mediante un grupo motobomba, una vez decantada. Para inyectar este volumen de manera que no se produzcan arranques continuos en el aprovechamiento de estos recursos, se instalará una electro- bomba centrífuga de eje vertical de pequeño caudal, concretamente de 3,5 1/s $\left(12,6 \mathrm{~m}^{3} / \mathrm{h}\right)$, que podrá evacuar el volumen regulado en 0,65 h. La presión necesaria para dicha inyección en la entrada de la instalación de filtrado de la Zona de Gravedad del Sector 2, tendrá que ser superior a 55,5 m.c.a y de 51,5 m en el Sector 3, que es la diferencia de cota entre la lámina de agua superior del embalse de regulación y la del colector de entrada.
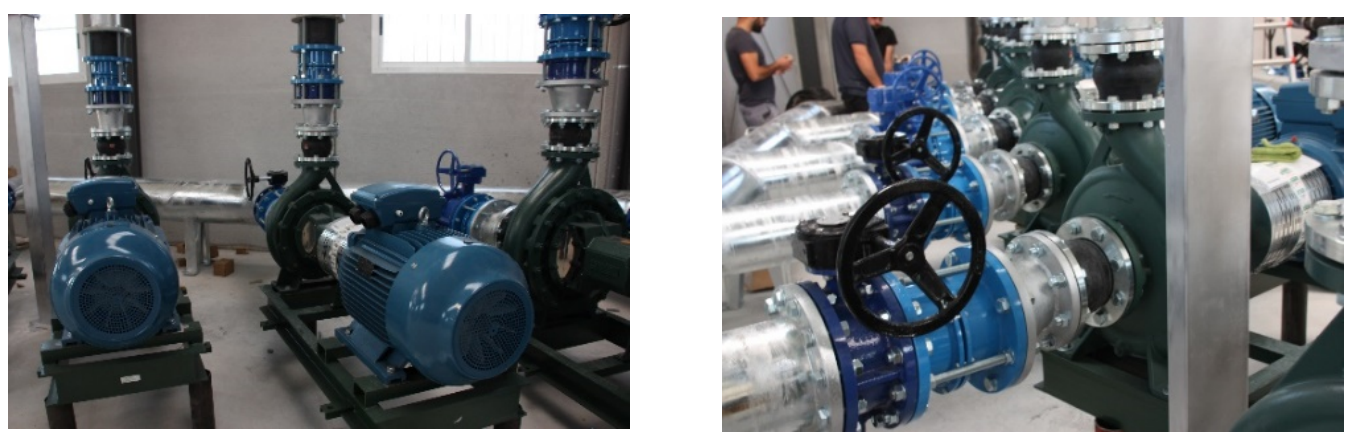

Equipo de filtrado: Formado por 2 baterías de 24 unidades cada una de filtros auto limpiantes de anillas de 3" con un paso de 100 micras, o sistema equivalente que deberá mantener una superficie filtrante de 24,24 m2, todo ello sobre colectores de polipropileno de PN10 y 300 mm de diámetro o de material de igual o mejor fiabilidad.

El lavado se produce secuencialmente de forma automática cuando el presostato diferencial dé lecturas iguales o superiores a $0,5 \mathrm{~kg} / \mathrm{cm}^{2}$.

El sistema de recuperación del agua de limpieza de filtros consiste en la prolongación del colector de salida hasta la coronación del embalse, con 100 m de tubería de PEAD DN110.

Edificio de las estaciones de bombeo: Las bombas y el equipo de filtrado se alojarán en un edificio a pie del embalse con estructura metálica de 25x10 metros en planta para los Sectores 2 y3, cerramiento vertical mediante panel visto prefabricado de hormigón armado y cubierta metálica tipo sándwich. 

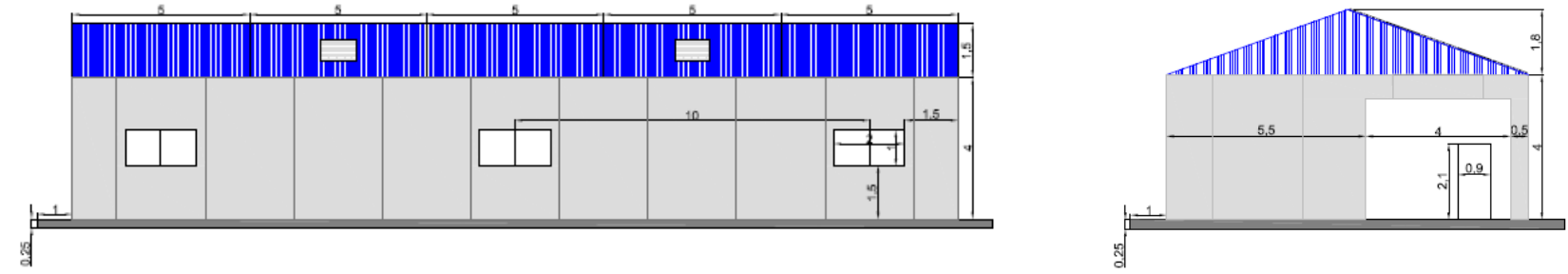

\subsection{Cabezales de las Zonas por gravedad}

Edificio: el equipo de filtrado y demás elementos se alojarán en un edificio con estructura metálica de 20x10 metros en planta y las mismas características constructivas.

Equipo de filtrado: están formados por 2 baterías en el Sector 3 y 5 baterías en el Sector 2 de 32 unidades de filtros de anillas auto limpiantes de 3" y con un paso de filtración de 100 micras o sistema equivalente, todo ello sobre colectores de polipropileno de PN10 y $350 \mathrm{~mm}$ de diámetro.

Se construyó una arqueta semienterrada de recogida del agua de limpieza de filtros de 8,25 $\mathrm{m}^{3}$ de capacidad de regulación y se instalará un grupo motobomba de impulsión multicelular de eje vertical, capaz de inyectar un caudal nominal de $12,6 \mathrm{~m}^{3} / \mathrm{h}$ a una presión de 60 m.c.a en el colector de entrada del equipo de filtrado, con una potencia nominal de $4 \mathrm{~kW}$.

Se instaló también una válvula de alivio de $250 \mathrm{~mm}$ de diámetro que vierte a la arqueta de recuperación del agua de lavado de filtros.

A la salida del cabezal se instaló un caudalímetro electromagnético de $600 \mathrm{~mm}$ de diámetro, con el fin de obtener lectura del caudal instantáneo y el volumen suministrado.

\subsection{Suministro de Energía}

El suministro de energía de red a los cabezales de impulsión se hizo con una línea aérea de media tensión de 312,2 metros para el Sector 2 y de 407,6 m para el Sector 3, línea subterránea de media tensión de entrada al centro de transformación del tipo intemperie compacto (CTIC), de $250 \mathrm{KVA}$ de potencia, e instalación en baja tensión.

El suministro de energía solar fotovoltaica en la zona de impulsión se hará a partir de sendas plantas aisladas de suelo de 594 paneles para el Sector 2 y 378 para el Sector 3 de $300 \mathrm{Wp}$, de una potencia de 178,2 kWp, que será capaz de proporcionar anualmente 257.570,2 kWh/año en el S2 y 145.880,8 kWh/año en el S3. El suministro de los cabezales de la Zona de Gravedad de menor demanda energética se hizo de igual manera para ambos sectores, mediante una planta solar fotovoltaica de techo, formada por 40 paneles de 300 Wp y una

potencia de $12 \mathrm{kWp}$, capaz de proporcionar la energía eléctrica necesaria para todos los puntos de consumo del edificio a lo largo del día, y conectada a la red para garantizar el suministro cuando no haya producción solar. La energía sobrante fotovoltaica se inyectará a la red, compensando el consumo.

Desde el centro de transformación y desde cada cuadro central de las plantas generadoras de energía fotovoltaica, bien sean de suelo o de techo, parten las líneas de acometida en baja tensión hasta los Cuadros Generales de Protección de las estaciones de bombeo de los cabezales de la Zona de Impulsión y al cabezal de filtrado de las Zonas de Gravedad. 


\subsection{Redes principales de distribución de agua}

Tuberías: Para llevar el agua desde los cabezales hasta los hidrantes colectivos de cada una de las dos Zonas, se proyectan redes de distribución ramificadas.

La presión necesaria en cada hidrante serán las alturas piezométricas calculadas para cada uno, más la pérdida de carga considerada en su interior (5 m.c.a).

La dotación de riego adoptada de 1,057 1/ $\mathrm{m}^{2}$.h es el resultado del diseño agronómico estudiado.

En el proyecto se incluyó un estudio comparativo entre los diferentes materiales que se pueden utilizar para las conducciones, teniendo en cuenta su precio instalado y el zanjeo, anclajes y capacidad hidráulica. De él se deduce que, para diámetros de $140 \mathrm{~mm}$ o superiores, el material indicado es el PVC-O serie 500, y entre 125 mm y 90 mm, tomado como diámetro inferior admisible, el material idóneo es el PEAD PE100.

Las mediciones de tubería por materiales instaladas son:

- SECTOR 2: $25.283 \mathrm{~m}$ de longitud en PVC-O serie 500 y $4.673 \mathrm{~m}$ en PEAD (PE-100)

- SECTOR 3 :22.301 m de longitud en PVC-O serie 500 y 4.479 m en PEAD (PE-100)

\begin{tabular}{|c|c|c|c|c|c|c|c|c|c|}
\hline \multicolumn{9}{|c|}{ TUBERÍAS RED PRINCIPAL PVC-O SECTOR 2} & \multirow{3}{*}{$\begin{array}{c}\text { TOTAL } \\
\text { MEDICIÓN } \\
\text { PVC-O (m) }\end{array}$} \\
\hline \multirow{2}{*}{ RED } & \multirow{2}{*}{ TIMBRAJE } & \multicolumn{6}{|c|}{$\varnothing$} & & \\
\hline & & 140 & 160 & 200 & 225 & 250 & 315 & & \\
\hline \multirow{2}{*}{ IMPULSIÓN } & PN12,5 & 209 & 102 & 958 & & 837 & 36 & & \multirow{11}{*}{25.283} \\
\hline & PN16 & 413 & 448 & 365 & 227 & 451 & 153 & & \\
\hline \multirow{2}{*}{ GRAVEDAD } & PN12,5 & 1.498 & 1.048 & 276 & 1.089 & 691 & 3.154 & & \\
\hline & PN16 & 143 & 617 & 1.081 & 213 & 419 & & & \\
\hline \multicolumn{2}{|c|}{ TOTAL (m) } & 2.263 & 2.215 & 2.680 & 1.529 & 2.398 & 3.343 & & \\
\hline \multirow{2}{*}{ RED } & \multirow{2}{*}{ TIMBRAJE } & \multicolumn{6}{|c|}{$\emptyset$} & \multirow[b]{2}{*}{800} & \\
\hline & & 355 & 400 & 450 & 500 & 630 & 710 & & \\
\hline \multirow{2}{*}{ IMPULSIÓN } & PN12,5 & 657 & 576 & & & & & & \\
\hline & PN16 & 621 & & & & & & & \\
\hline \multirow{2}{*}{ GRAVEDAD } & PN12,5 & 1.003 & 913 & 654 & 1.320 & 2.338 & 1.378 & 441 & \\
\hline & PN16 & 710 & 244 & & & & & & \\
\hline \multicolumn{2}{|c|}{ TOTAL (m) } & 2.991 & 1.733 & 654 & 1.320 & 2.338 & 1.378 & 441 & \\
\hline
\end{tabular}

\begin{tabular}{|c|c|c|c|c|c|c|c|c|}
\hline \multicolumn{8}{|c|}{ TUBERÍAS RED PRINCIPAL PVC-O SECTOR 3} & \multirow{3}{*}{$\begin{array}{c}\text { TOTAL } \\
\text { MEDICIÓN } \\
\text { PVC-O (m) }\end{array}$} \\
\hline \multirow{2}{*}{ RED } & \multirow{2}{*}{ TIMBRAJE } & \multicolumn{6}{|c|}{$\varnothing$} & \\
\hline & & 140 & 160 & 200 & 225 & 250 & 315 & \\
\hline \multirow{2}{*}{ IMPULSIÓN } & PN12,5 & 606 & 147 & 236 & 845 & 275 & 875 & \multirow{14}{*}{22.301} \\
\hline & PN16 & 721 & 358 & 349 & 1.195 & 183 & 143 & \\
\hline \multirow{2}{*}{ EDAR } & PN12,5 & & & & & & 1.600 & \\
\hline & PN16 & & & & & & 2.404 & \\
\hline \multirow{2}{*}{ GRAVEDAD } & PN12,5 & 1.427 & 705 & 584 & 2.077 & 216 & & \\
\hline & PN16 & 149 & & & & & & \\
\hline \multicolumn{2}{|c|}{ TOTAL (m) } & 2.903 & 1.209 & 1.169 & 4.116 & 673 & 5.021 & \\
\hline \multirow{2}{*}{ RED } & \multirow{2}{*}{ TIMBRAJE } & \multicolumn{6}{|c|}{$\emptyset$} & \\
\hline & & 355 & 400 & 450 & 500 & 630 & 800 & \\
\hline \multirow{2}{*}{ IMPULSIÓN } & \begin{tabular}{|l|} 
PN12,5 \\
\end{tabular} & 146 & 98 & & & & & \\
\hline & PN16 & & & & & & & \\
\hline \multirow{2}{*}{ GRAVEDAD } & \begin{tabular}{|l|} 
PN12,5 \\
\end{tabular} & 1.795 & 667 & 862 & 420 & \begin{tabular}{|l|}
3.221 \\
\end{tabular} & & \\
\hline & PN16 & & & & & & & \\
\hline \multicolumn{2}{|c|}{ TOTAL (m) } & 1.942 & 764 & 862 & 420 & 3.221 & 0 & \\
\hline
\end{tabular}

\begin{tabular}{|c|c|c|c|c|c|c|c|}
\hline \multicolumn{7}{|c|}{ TUBERÍAS RED PRINCIPAL PEAD } & \multirow{3}{*}{$\begin{array}{c}\text { TOTAL } \\
\text { MEDICIÓN } \\
\text { PEAD (m) }\end{array}$} \\
\hline \multirow{2}{*}{ RED } & \multirow{2}{*}{ TIMBRAJE } & \multicolumn{5}{|c|}{$\varnothing$} & \\
\hline & & 90 & 110 & 125 & & & \\
\hline \multirow{2}{*}{ IMPULSIÓN } & PN10 & & 286 & 668 & & & \multirow{5}{*}{4.673} \\
\hline & PN16 & 112 & 519 & 547 & & & \\
\hline \multirow{2}{*}{ GRAVEDAD } & PN10 & 41 & 981 & 1.208 & & & \\
\hline & PN16 & 311 & & & & & \\
\hline \multicolumn{2}{|c|}{ TOTAL (m) } & 464 & 1.786 & \multicolumn{3}{|l|}{2.423} & \\
\hline \multicolumn{7}{|c|}{ TUBERÍAS RED PRINCIPAL PEAD } & \multirow{10}{*}{4.479} \\
\hline \multirow{2}{*}{ RED } & \multirow{2}{*}{ TIMBRAJE } & \multicolumn{5}{|c|}{$\varnothing$} & \\
\hline & & 90 & 110 & 125 & 315 & 500 & \\
\hline \multirow{2}{*}{ IMPULSIÓN } & PN10 & 206 & 96 & 179 & & & \\
\hline & PN16 & 401 & 348 & 375 & & & \\
\hline \multirow{2}{*}{ EDAR } & PN10 & & & & & 91 & \\
\hline & PN16 & & & & 91 & & \\
\hline \multirow{2}{*}{ GRAVEDAD } & PN10 & 468 & 1.269 & 956 & & & \\
\hline & \begin{tabular}{|l|} 
PN16 \\
\end{tabular} & & & & & & \\
\hline \multicolumn{2}{|c|}{ TOTAL (m) } & 1.075 & 1.713 & 1.510 & 91 & 91 & \\
\hline
\end{tabular}



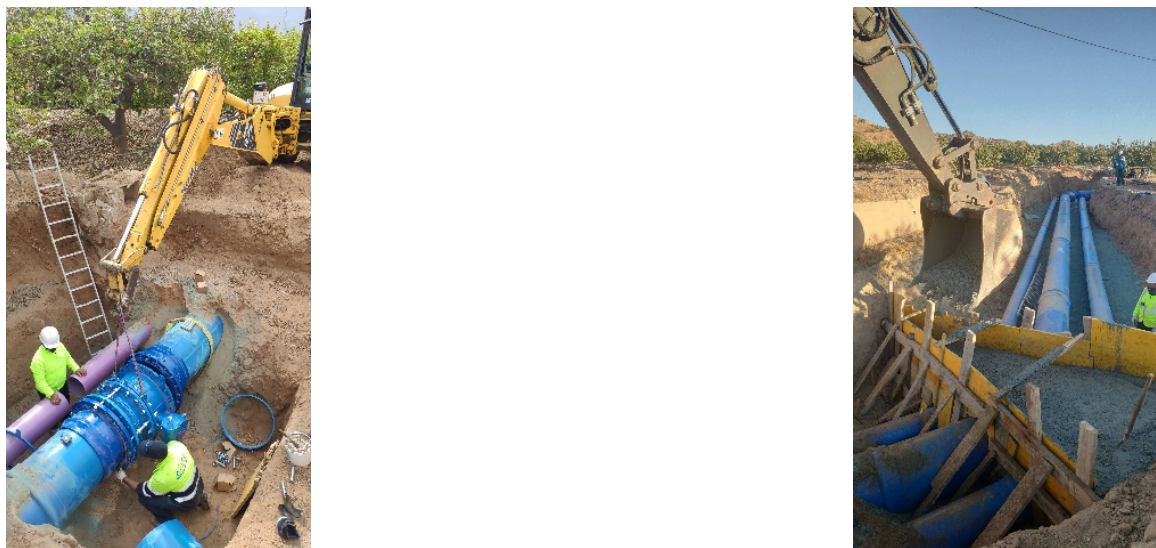

Hidrantes colectivos e individuales: Se han instalado 133 hidrantes colectivos en el sector 2 y 158 en el Sector 3. Se cuenta además con un total de 574 hidrantes individuales en la Zona de Impulsión y de 863 en la

de Gravedad del Sector 2 y 371 en la Zona de Impulsión y 868 en la de Gravedad en el Sector 3.

Los Individuales están formados por un contador con emisor de pulsos y una electroválvula hidráulica de membrana con un piloto reductor de presión, que sirve para controlar el flujo de agua de riego que abastece a una finca determinada, en el ámbito del hidrante colectivo al que pertenece.

Los hidrantes colectivos están formados por válvulas de descarga, válvulas de mariposa, filtros cazapiedras, colectores multitoma, ventosas y manómetros o presostatos. Además de los accesorios y piezas especiales necesarios para su instalación o conexión.

Tuberias Terciarias: son las encarg

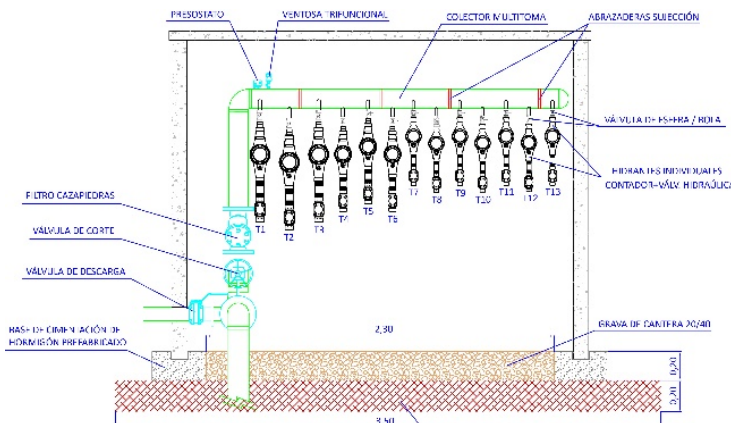

finca. Son de PEAD de diámetros comprendidos entre $32 \mathrm{~mm}$ y $250 \mathrm{~mm}$ con una longitud aproximada

cela o

km en el Sector 2 y 193 km en el Sector 3 de tal manera que la presión mínima disponible en el punto

más alto de cada parcela será de 25 m.c.a.

\subsection{Tubería de impulsión y grupo de bombeo edar del Sector 3}

En el embalse de la EDAR se recogen las aguas de la misma, con un caudal ficticio continuo de 11,01 1/s, pero la posibilidad de aumento de concesión y la necesidad de tener que vaciar la balsa en aproximada- mente 2 días, hace que se considere un caudal de 90 l/s. Para su aprovechamiento es necesaria una impulsión que las lleve al embalse de regulación del Sector 3, el más asequible, para desde allí distribuirlas a los demás embalses, si conviene para unificar su calidad. 
En este caso se dispone en la parcela de energía de red suficiente para suministrar al equipo de impulsión formado por tres grupos motobomba centrífugos horizontales en paralelo, capaces de bombear cada uno un caudal de 31,1 1/s a una altura de 127 m.c.a con motor eléctrico de $55 \mathrm{~kW}$ de potencia nominal y variadores de frecuencia. La tubería de impulsión, de 4.340 m de longitud total es de PVC-O PN 16/12,5, de 315 mm de diámetro.
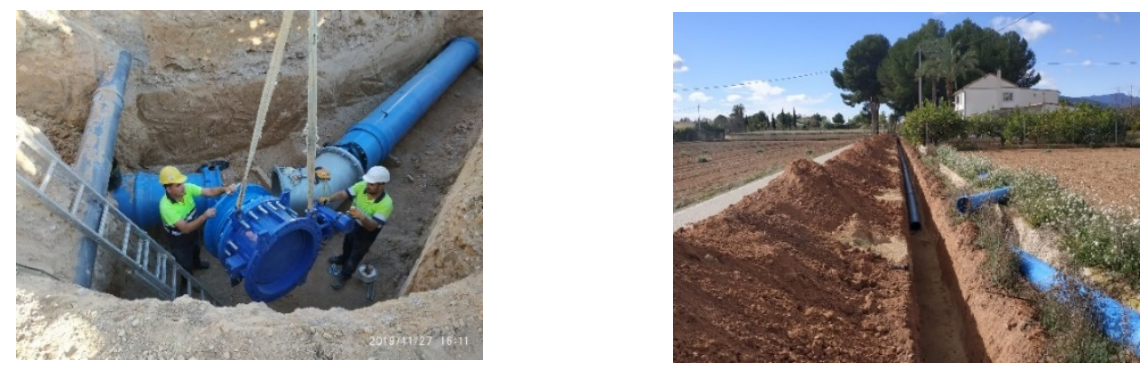

\subsection{Tubería de trasiego entre Sectores de riego:}

De una longitud de 1.924,50 m, formada por tubos de PVC-O de $400 \mathrm{~mm}$ de diámetro PN12,5. Para poder llevar agua desde el embalse de regulación del Sector 1 hasta él del Sector 2 por gravedad y desde éste último hasta el primero, bien por gravedad si las láminas de agua de ambos lo permiten o mediante los equipos de impulsión del Sector 2 si no es así, se instalará una tubería de PVC-O de $400 \mathrm{~mm}$ de diámetro en PN12,5 entre las arquetas de salida de ambos embalses, que tendrá una longitud total de 1.924,5 m, cuya traza puede coincidir con alguna línea de la red de distribución de las Zonas de Impulsión de cualquiera de los dos Sectores, o con la tubería de transporte a EF-2. De momento solo se ha instalado la parte que corresponde al ámbito del Sector 2, ya que el tramo desde el Sector 2 al Sector 3, e incluso el tramo desde es Sector 4 al Sector 3 ya estaban realizados.

\subsection{Automatización}

Se han instalado unidades remotas para control de hidrantes y valvulería, que comunicarán con unidades concentradoras (una en la zona de impulsión y otra en la de gravedad) vía radio.
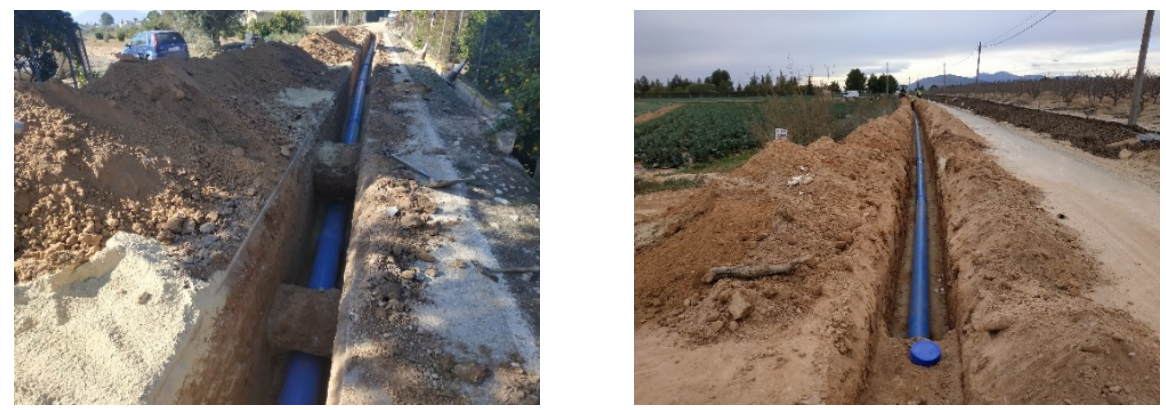

Desde un Centro de Control ubicado en la oficina central de la Comunidad, sita en C/ Murcia, no 32, Librilla (Murcia), se comandan y gestionan todos los elementos a automatizar, acción que es redundante, (wifi y gprs) desde las concentradoras instaladas en las edificaciones que alojan las estaciones de filtrado, donde se dispone de energía procedente de la red eléctrica o solar fotovoltaica. 


\section{Congreso Nacional de Riegos CARTAGENA 2021}

\section{Conclusiones}

Creemos necesario recordar que el ahorro y eficiencia energética de una Modernización de Regadíos comienzan en la fase de diseño de la actuación, tanto del esquema hidráulico como en la elección de los materiales de la red, y esta actuación es un buen ejemplo de ello.

De no ser así, se estará condenado únicamente a la adopción de medidas sólo paliativas que tendrán una menor repercusión en la factura eléctrica, que, desde luego, no desdeñamos, pero consideramos insuficientes.

Medidas tales como la ejecución de balsas de acumulación para aprovechar el caudal que se pueda bombear en horas con menor coste energético el aprovechamiento, donde sea posible, de los desniveles naturales que puedan reducir los costes de impulsión, el uso de energías renovables y por fin, el uso de materiales eficientes que permitan, debido a sus características intrínsecas, el transporte del agua de riego con la menor pérdida de carga posible, han de primar a la hora de la valoración de la alternativa a acometer.

Es pues el marco actual, el más apropiado para el uso del PVC-O y sus accesorios en las redes hidráuli- cas de las nuevas modernizaciones. Un material, que debido a sus propiedades genera una menor pérdida de carga y consecuentemente de energía respecto otros materiales y permite un ahorro considerable de la potencia necesaria a instalar y posteriormente contratar y del propio consumo de energía en estas actuaciones.

\section{Referencias}

1. Water Technologies. Proyectos constructivos de los Sectores 2 Y 3. Proyecto de Modernización del Regadío de la Zona Regable de la Comunidad de Regantes del Trasvase Tajo - Segura de Librilla. sector 3 y Proyecto de Modernización del Regadío de la Zona Regable de la Comunidad de Regantes del Trasvase Tajo-Segura de Librilla. sector 2. 


\title{
XXXVIII Congreso Nacional de Riegos CARTAGENA 2021

FEI-02-2021

Trabajo de Innovación

\section{ELIMINACIÓN DE LAS PÉRDIDAS DE AGUA EN EMBALSES CON EL USO COMBINADO DE IMPERMEABILIZACIÓN Y CUBIERTAS FLOTANTES}

\author{
Autores: Quintero, Mauro (1) (P), Sánchez, C. (2), Soria, I. (3)
}

\author{
1 Jefe Producto, Sotrafa, geosinteticos@sotrafa.com \\ 2 Responsable Comercial Geo, Sotrafa, cs-geo@sotrafa.com \\ ${ }^{3}$ Responsable Comercial Geo, Sotrafa, is-geo@sotrafa.com
}

\section{Geomembrana de polietileno alta densidad, la solución idónea a largo plazo para evitar pérdidas de agua de riego embalsada.}

El revestimiento del fondo y taludes de los embalses permite eliminar las pérdidas de agua por filtración. La cubrición del embalse con una geomembrana flotante, elimina las importantes pérdidas de agua por evaporación en la cuenca mediterránea, así como mantener la calidad del agua en ausencia de algas, polución y concentración de sales.

"Abstract" HDPE Geomembranes are the most suitable solution to storage water irrigation.

\section{1- MAYOR DEMANDA HÍDRICA CONLLEVA MEJOR GESTIÓN DEL AGUA}

España tiene un sector agrícola de los más importantes a nivel mundial, tanto por extensión como por su tecnificación. Según datos de FAO AQUASTAT 2015 en España hay 2.349.745 Ha de Riego (localizado y por aspersión). Esto implica una gran demanda hídrica que unida a la cada vez mayor escasez de agua, nos obliga a optimizar este recurso tan preciado.

El sistema de riego ha tenido una evolución en los últimos años pasando de riego a manta, por aspersión, a la implantación cada vez más extensa del riego por goteo tanto para agricultura intensiva como la extensiva.

Además, nos fijamos como objetivo eliminar las pérdidas de agua por filtración tanto en la red de abastecimiento como en los embalses reguladores de almacenamiento. Y en los últimos años se está dando un paso más hacia reducir o eliminar las pérdidas de agua por evaporación, cuyo ratio es del $1,8 \mathrm{~m}^{3} / \mathrm{m}^{2 \star}$ año en las regiones de Murcia, Almería y Jaén.

Desde SOTRAFA, fabricante especializado en la fabricación de films para la agricultura intensiva y extensiva, optimizando a través de los acolchados, dobles cámaras y cubiertas de invernadero aumentando el rendimiento y precocidad en las cosechas, también ha desarrollado una gama de geomembranas impermeabilizantes en base a polietileno de alta densidad, fabricadas con la última tecnología en ancho de $7,5 \mathrm{~m}$ para impermeabilizar embalses de riego y cubiertas flotantes antievaporación. 


\section{2- NORMATIVA PARA IMPERMEABILIZACION DE EMBALSES DE RIEGO}

Dada la importancia de este tipo de infraestructuras hidráulicas en España, contamos con la norma UNE EN 104427 - Febrero 2010, que define las características que deben cumplir las geomembranas aplicadas a la impermeabilización de los embalses, así como procedimientos para la preparación de la superficie, puntos de anclaje de la barrera impermeabilizante e instalación de la geomembrana uniendo los paños entre sí por termofusión. La expectativa de vida útil de las geomembranas expuestas a la intemperie es superior a 20 años.
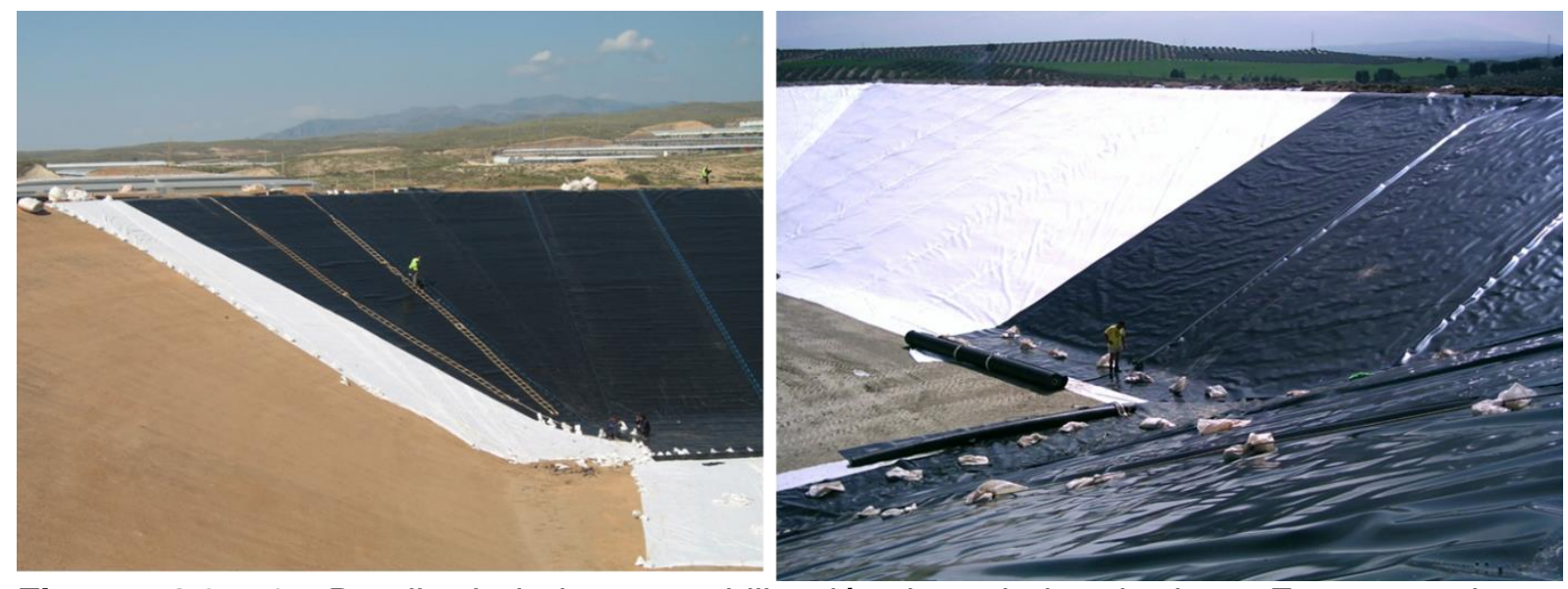

Figuras 1,2 y 3. Detalle de la impermeabilización de embalse de riego. Fotos superiores, compactación, refinado superficie, geotextil de protección y sobre él la geomembrana ALVATECH PEAD, de espesor 1,5 mm ó $2 \mathrm{~mm}$ según envergadura del embalse.

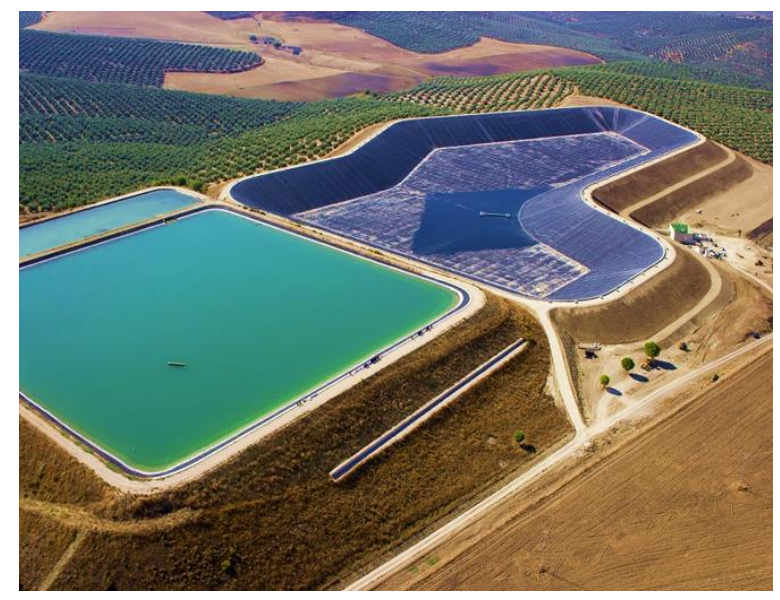

\section{3- CUBIERTAS FLOTANTES}

Datos de la Región de Murcia, para comprender la pérdida de agua por evaporación:

- Ratio de evaporación > 1.800 mm/año

- Solo en la Cuenca del Segura (Murcia) hay 13.000 embalses con $5.000 \mathrm{Ha}$ de superficie de agua.

- En estos embalses la pérdida de agua por evaporación es 60 Hm³/año 
El sistema de cubrición de embalses mediante una geomembrana ALVATECH PEAD, instalada posteriormente sobre la impermeabilización, es una práctica muy extendida no solo en España sino todos los países de clima árido con alto consumo de agua.

Esta solución permite eliminar completamente la pérdida de agua por evaporación, mantener la calidad de agua sin necesidad de aportar alguicidas, manteniendo constante la concentración sales.

La vida útil de la cubierta flotante es superior a los 15 años, y el retorno de la inversión está entre 5 y 6 años, considerando el coste completo de la cubierta flotante y por otro lado el ahorro en agua no evaporada, supresión de alguicidas y reducción del mantenimiento de sistema riego.

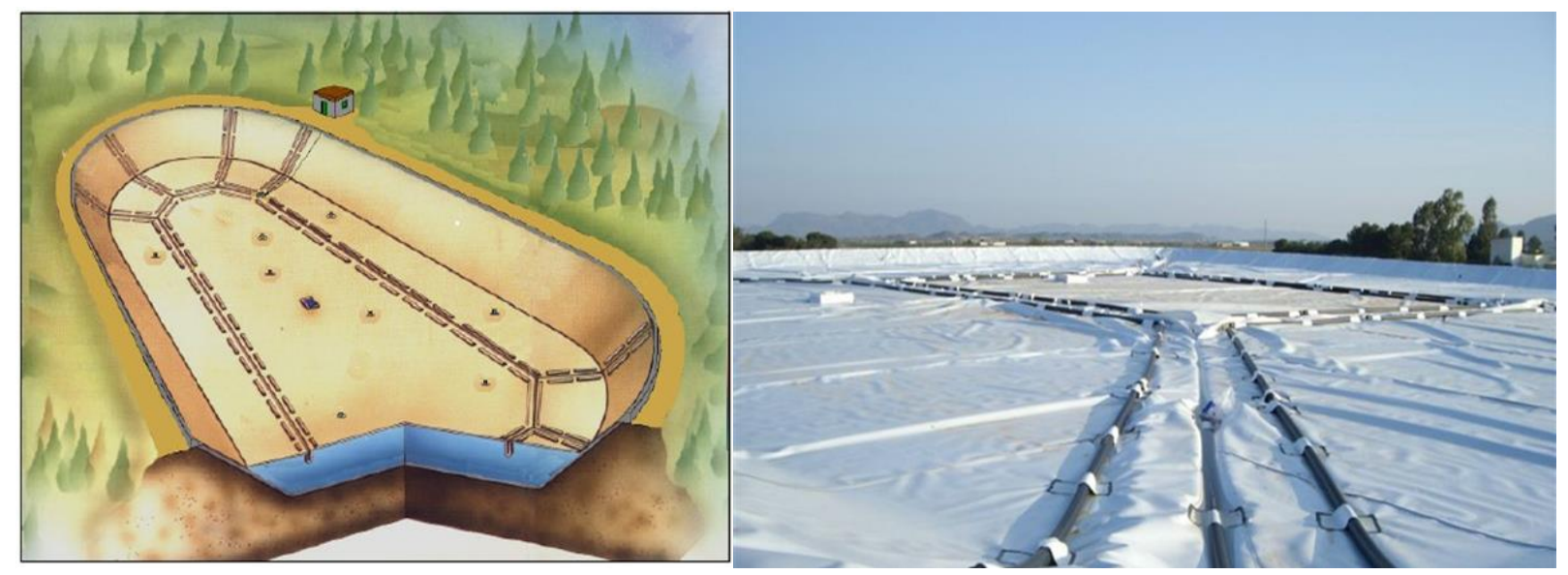

Figuras 4 y 5. Detalle de la cubierta flotante del embalse de riego, con el sistema de lastres y flotadores que permiten plegar la geomembrana cuando el embalse está lleno de agua.

\section{4- JUSTIFICACIÓN ECONÓMICA RETORNO A 4 AÑOS, EXPECTATIVA DE VIDA 20 AÑOS}

\begin{tabular}{|c|c|}
\hline INVERSIÓN PREVISTA & $65.815,50 €$ \\
\hline \multicolumn{2}{|l|}{ AHORRO PREVISTO } \\
\hline \multicolumn{2}{|l|}{ AGUA } \\
\hline Volumen total embalsado & $62.475,73 \mathrm{~m} 3$ \\
\hline Superficie evaporación & $10.745,60 \mathrm{~m} 2$ \\
\hline Evaporación media anual según ministerio de fomento & $1.600,00 \mathrm{~mm} / \mathrm{m} 2$ \\
\hline Coeficiente corrector vientos persistentes $+/-10 \%$ & $-\%$ \\
\hline Coeficiente corrector zonas elevadas $+/-10 \%$ & $-\%$ \\
\hline Coeficiente corrector fuerte insolación $+/-10 \%$ & $-\%$ \\
\hline Evaporación media anual corregida & $1.600,00 \mathrm{~mm} / \mathrm{m} 2$ \\
\hline Volumen agua evaporada & $17.192,96 \mathrm{~m} 3$ \\
\hline \% mejora evaporación cubierta & $100,00 \%$ \\
\hline Volumen agua ahorrada & $17.192,96 \mathrm{~m} 3$ \\
\hline Coste agua & $0,30 € / \mathrm{m} 3$ \\
\hline Total ahorro agua evaporada & $5.157,89 €$ \\
\hline
\end{tabular}




\begin{tabular}{|c|c|}
\hline \multicolumn{2}{|l|}{ ALGUICIDAS } \\
\hline Volumen total embalsado & $62.475,73 \mathrm{~m} 3$ \\
\hline Coste alguicidas por $1.000 \mathrm{~m} 3$ embalsado & $80,00 €$ \\
\hline Total ahorro alguicidas & $4.998,06 €$ \\
\hline \multicolumn{2}{|l|}{ FILTRADO (ESTIMACIÓN) } \\
\hline Superficie de riego por goteo & $120.000,00 \mathrm{~m} 2$ \\
\hline Coste de sustitución goteros obstruidos & $100,00 € /$ ha \\
\hline Total ahorro mantenimiento & $1.200,00 €$ \\
\hline \multicolumn{2}{|c|}{ SEDIMENTACIÓN EN FONDO + PERDIDA DE CAPACIDAD DE EMBALSE } \\
\hline Superficie de fondo & $7.002,21 \mathrm{~m} 2$ \\
\hline Sedimentación anual & $3,00 \mathrm{~cm}$ \\
\hline Volumen de sedimento & $210,07 \mathrm{~m} 3$ \\
\hline Volumen acumulado en 10 años, perdida de capacidad & $2.100,66 \mathrm{~m} 3$ \\
\hline Coste limpieza manual & $18,00 € / \mathrm{m} 3$ \\
\hline Total ahorro limpieza fondos repercusión anual & $3.781,20 €$ \\
\hline \multicolumn{2}{|l|}{ TOTAL AHORRO ANUAL ESTIMADO } \\
\hline Evaporación & $5.157,79 €$ \\
\hline Alguicidas & $4.998,06 €$ \\
\hline Filtrado & $1.200,00 €$ \\
\hline Sedimentación & $3.781,20 €$ \\
\hline Mejora en salinidad de agua & $? €$ \\
\hline Mejora en seguridad y salud & $? €$ \\
\hline TOTAL AHORRO ANUAL ESTIMADO & $15.137,14 €$ \\
\hline \multicolumn{2}{|l|}{ PERIODO DE RETORNO } \\
\hline & 4,35 AÑOS \\
\hline
\end{tabular}

\section{5- CONCLUSIONES:}

Evidentemente la optimización del agua disponible pasa por un uso responsable, pero también depende en gran medida de la calidad de las infraestructuras hidráulicas. En este apartado las geomembranas impermeabilizantes tienen un papel esencial aportando una buena solución duradera en el tiempo.

Las normativas existentes a tal efecto, permiten proyectar embalses asegurando un correcto diseño y una buena ejecución. Estando perfectamente regulada y delimitada la responsabilidad del fabricante, empresa instaladora y control de calidad a pie de obra. 


\title{
La amplitud de coberturas de seguro para balsas de riego
}

\author{
Salinas Poch, C. (P) ponente ${ }^{1}$ \\ ${ }^{1}$ Director General Comercial de EPGSalinas, Corredores de Seguros; carlos.salinas@epgsalinas.com
}

\section{Problemática abordada}

Las balsas de riego son infraestructuras estratégicas y relevantes dentro de la actividad de una comunidad de regantes en el proceso de sondeo, captación, almacenamiento y distribución de agua para riego. Precisan, desde distintos puntos de vista, de un tratamiento particular:

- Desde el punto de vista constructivo y de explotación, con la particularidad precisa que garantice su solidez, viabilidad, sostenibilidad y seguridad, en un momento como el actual en que la escasez del recurso hídrico hace aún más notable la gestión de su almacenamiento y regulación.

- Legislativamente, tal es su importancia y peculiaridad, que en breve se espera una reglamentación expresa de seguridad de balsas, para diferenciarla de la recientemente publicada de presas y embalses. [1]

- Y como no, desde el punto de vista asegurador, se presenta el importante reto de garantizar la integridad de esta infraestructura para la continuidad de la actividad de la comunidad de regantes, ya sean por los daños que propiamente sufra la balsa, como los daños a terceros en procesos largos y complejos que comprometen el patrimonio de la entidad.

El seguro se presenta como una excelente herramienta de protección y hay que verla como una auténtica inversión a largo plazo.

\section{Descripción de la innovación}

La verdadera innovación radica en dar la mejor respuesta a las múltiples casuísticas de siniestros de daños propios e incidentes de responsabilidad civil, en todas las fases del seguro:

- Asesorar en el trabajo previo de análisis del riesgo y en la mejor opción de contratación, desde la experiencia y conocimiento de las comunidades de regantes y la agricultura de regadío

- Contar con un producto asegurador para balsas de riego, un producto especializado que tiene las correctas coberturas, definiciones y clausulado.

- Gestionar de manera eficiente el siniestro en el momento de la verdad, cuando ocurre el incidente.

\subsection{Análisis del riego}

En materia de gestión de riesgos y seguros, la tarea inicial radica en ayudar a la comunidad de regantes a identificar cuáles son los incidentes que, por su frecuencia e intensidad, pueden afectar al desarrollo de su actividad. A modo de semáforo (ver figura 1), se van evidenciando los que, por mayor frecuencia e impacto, tienen que ser transferidos al seguro (rojo y amarillo) y cuales podrían ser sumidos con los propios medios a su disposición (verde).

Esta orientación nos llevará la mejor gestión del riesgo, toma de decisiones y herramientas, entre ellas las aseguradoras. [2] 


\section{Congreso Nacional de Riegos CARTAGENA 2021}

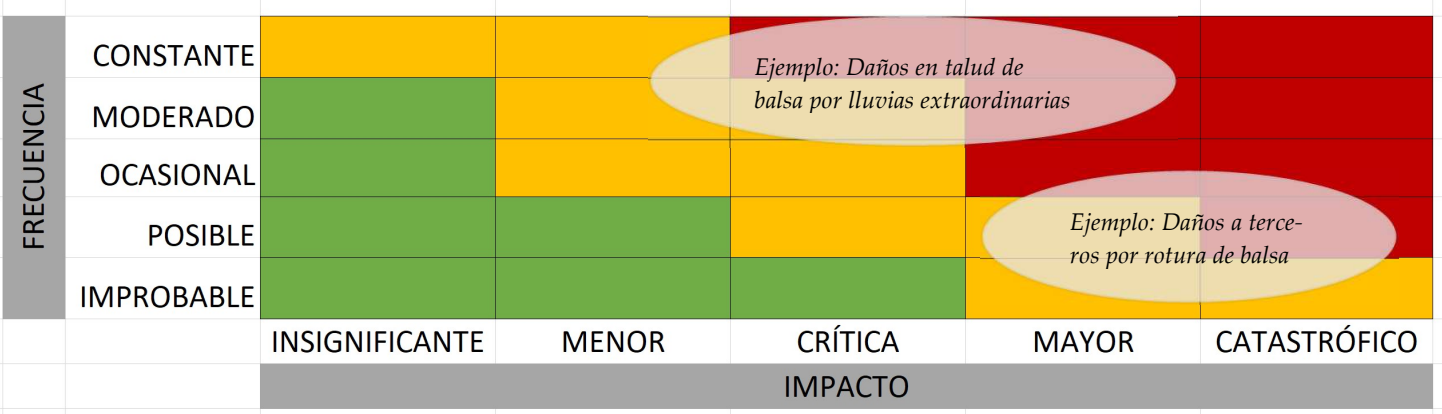

Figura 1: Ejemplo de matriz de riesgos a partir del análisis de los mismos

En balsas de riesgo, relacionando su capacidad y altura, que conllevan a su clasificación, se sitúan los distintos tipos de balsas. Cada tipo es susceptible de causar distintos daños en base a la vulnerabilidad y exposición de personas, bienes materiales y medioambientales. [2]

Según nuestra experiencia en la gestión de siniestros de balsas de riego, los de daños propios son más frecuentes en cuanto a número de siniestros, si bien los de daños a terceros (RC: responsabilidad civil) son de mayor intensidad en cuanto a pago de indemnizaciones.

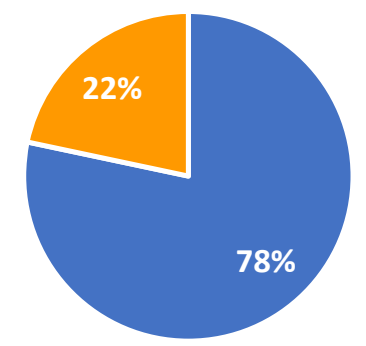

- DAÑOS PROPIOS I RC

Figura 2: Distribución según la frecuencia del tipo de siniestro de balsa de riego tramitado por EPGSalinas

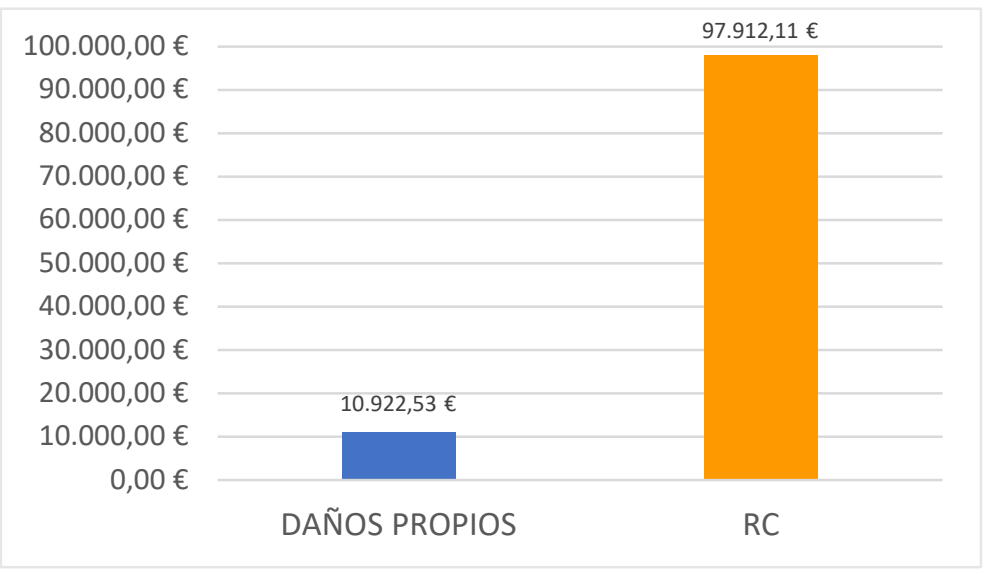

Figura 3: Coste medio de indenimización por tipo de siniestro de balsa de riego tramitado por EPGSalinas 


\subsection{Las coberturas de seguro para balsas de riego}

\subsubsection{Cobertura de daños propios para balsas de riego}

- $\quad$ Riesgo asegurado: Balsa/presa/embalse de agua para riego y todas las instalaciones relacionadas con la misma.

- Suma asegurada: El valor total de la balsa, incluida obra civil, impermeabilización, aliviadero, sistemas de regulación, cerramiento y vallado, etc.

- Coberturas: La compañía aseguradora indemniza el coste de reparación o reposición a nuevo del bien dañado o destruido (Indemnización a valor de reposición a nuevo 100\%) en caso de:

- Incendio y gastos aplicables, como desescombro y demolición, bomberos, rellenado de equipos de extinción de incendios, etc. (Aplicando su correspondiente tasa especial de Consorcio de Compensación de Seguros).

- Riesgos extraordinarios (a cargo del Consorcio de Compensación de Seguros). Acontecimientos extraordinarios cubiertos:

- Los siguientes fenómenos de la naturaleza: terremotos, maremotos, inundaciones extraordinarias (incluidas las producidas por embates de mar), erupciones volcánicas, tempestad ciclónica atípica (incluyendo los vientos extraordinarios y los tornados) y caídas de cuerpos siderales y aerolitos.

- Los ocasionados violentamente como consecuencia de terrorismo, rebelión, sedición, motín y tumulto popular.

- Hechos o actuaciones de las Fuerzas Armadas o de las Fuerzas y Cuerpos de Seguridad en tiempo de paz.

- Dato básico para cotizar: Valor de la instalación (balsa y sus equipamientos). Al ser un seguro multirriesgo, además del valor de la balsa, se facilita también el valor del resto de infraestructura y equipamientos con que cuenta la comunidad de regantes para el desarrollo de su actividad.

\subsubsection{Cobertura de responsabilidad civil para balsas de riego.}

- $\quad$ Riesgo asegurado: Titularidad, propiedad y explotación de balsa/presa/embalse de almacenamiento de agua para riego.

- $\quad$ Suma asegurada: A elección y según nivel de franquicia. $300.000 €, 600.000 €, 1.000 .000 € 1.200 .000 €$, $1.800 .000 €, 2.000 .000 €, 3.000 .000 €$

- Coberturas:

- Responsabilidad civil de explotación: Cobertura por daños originados por la propia balsa/presa/embalse, su vallado, etc., y los trabajos propios de su actividad.

- $\quad$ Responsabilidad civil patronal: Cobertura por daños personales a los empleados (y de forma subsidiaria a los empleados de contratistas o subcontratistas) como consecuencia de un accidente laboral.

- $\quad$ Responsabilidad civil subsidiaria de contratistas y subcontratistas: Cobertura por hechos derivados de la actuación de contratistas o subcontratistas y que puedan corresponder de forma subsidiaria al asegurado.

- Responsabilidad civil profesional: Cobertura por hechos derivados de la actuación del Director de Explotación y del Director del Plan de emergencia de su equipo, conforme a sus competencias, atribuciones y responsabilidades legalmente atribuidas.

- Defensa y fianzas: Cobertura para la defensa personal del asegurado por abogados y procuradores en procedimientos civiles y criminales, la constitución de fianzas, así como el pago de gastos judiciales.

- $\quad$ Dato básico para cotizar: capacidad de la balsa (en m3). 
Adicionalmente, el titular de la balsa conoce si está clasificada, ya que como hemos expuesto anteriormente, es un factor relevante para determinar el grado de riesgo de la balsa en función de su capacidad y altura.

- No requieren clasificación. Altura inferior a 5 metros o capacidad inferior a $100.000 \mathrm{~m} 3$

- Requieren clasificación. Altura superior a 5 metros y capacidad superior a 100.000 m3.

\section{Clasificación:}

- Tipo A. Aquellas cuya rotura o funcionamiento incorrecto puede afectar gravemente a núcleos urbanos o a servicios esenciales, así como producir daños materiales o medioambientales muy importantes.

- Tipo B. Aquellas cuya rotura o funcionamiento incorrecto puede afectar a un número reducido de viviendas u ocasionar daños materiales o medioambientales importantes.

- Tipo C. Aquellas cuya rotura o funcionamiento incorrecto puede producir daños materiales de moderada importancia y solo incidentalmente pérdidas de vida humanas.

Pendientes de Clasificar. Aquellas balsas que están obligadas según sus características a ser clasificadas pero aún no tiene asignada una clasificación.

\subsubsection{Cobertura de responsabilidad medioambiental para balsas de riego}

- $\quad$ Riesgo asegurado: Titularidad, propiedad y explotación de balsa/presa/embalse de almacenamiento de agua para riego.

- Suma asegurada: Límite independiente para responsabilidad civil general y para responsabilidad medioambiental y por contaminación, esta última por cada una de las balsas.

- Coberturas: La compañía aseguradora garantiza el pago de indemnizaciones al asegurado frente a cualquier pérdida (indemnizaciones a terceros, gastos de limpieza, gastos legales, gastos de aminoración) inesperada e involuntaria que estuviera legalmente obligado a pagar como resultado de reclamaciones o pérdidas resultantes de:

- Daños a los recursos naturales incluyendo los gastos necesarios para proceder a la reparación del medioambiente dañado en sus tres grados de reparación conforme a la Ley 26 / 2007, por contaminación o por cualquier otra causa derivada de la actividad desarrollada.

Por daños a los recursos naturales se entiende el daño físico o la destrucción real de agua, suelo o especies protegidas o hábitats naturales respecto de los cuales el asegurado es legalmente responsable conforme a la Directiva de la Unión Europea 2004/35/CE sobre responsabilidad medioambiental y/o cualquier legislación local equivalente y en concreto la Ley 26/2007 de Responsabilidad por Daños al Medioambiente.

- Costes de prevención. Costes de medidas tomadas para prevenir la inminente ocurrencia del daño.

- Defensa y fianzas. Cobertura para la defensa personal del asegurado por abogados y procuradores en procedimientos civiles y criminales, la constitución de fianzas, así como el pago de gastos judiciales.

- $\quad$ Dato básico para cotizar: capacidad de la balsa (en m3).

Un factor relevante para determinar el grado de riesgo medioambiental es la existencia espacios protegidos en la zona geográfica donde se ubique la balsa/presa/embalse, como: 


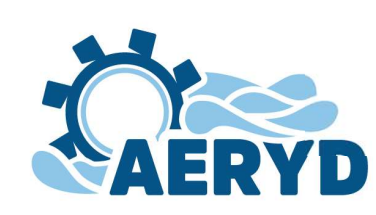

\section{Congreso Nacional de Riegos CARTAGENA 2021}

- ZEPA: Zona de Especial Protección para las Aves. (Figura 2).

- LIC: Lugar de Interés Comunitario. (Figura 2)

- PEIN: Espacio natural protegido incluido en el Plan de Espacios de Interés Natural. (Figura 3).

- HUMEDAL: Zona de tierras, generalmente planas, en la que la superficie se inunda permanente o intermitentemente con interés biológico. (Figura 4)

- ZONA PROTEGIDA: Zona protegida por otra causa no descrita en los apartados anteriores.

- ZONA PIV: Existencia de viviendas, polígono industrial y/o infraestructuras de servicios esenciales en un radio de 150 metros.

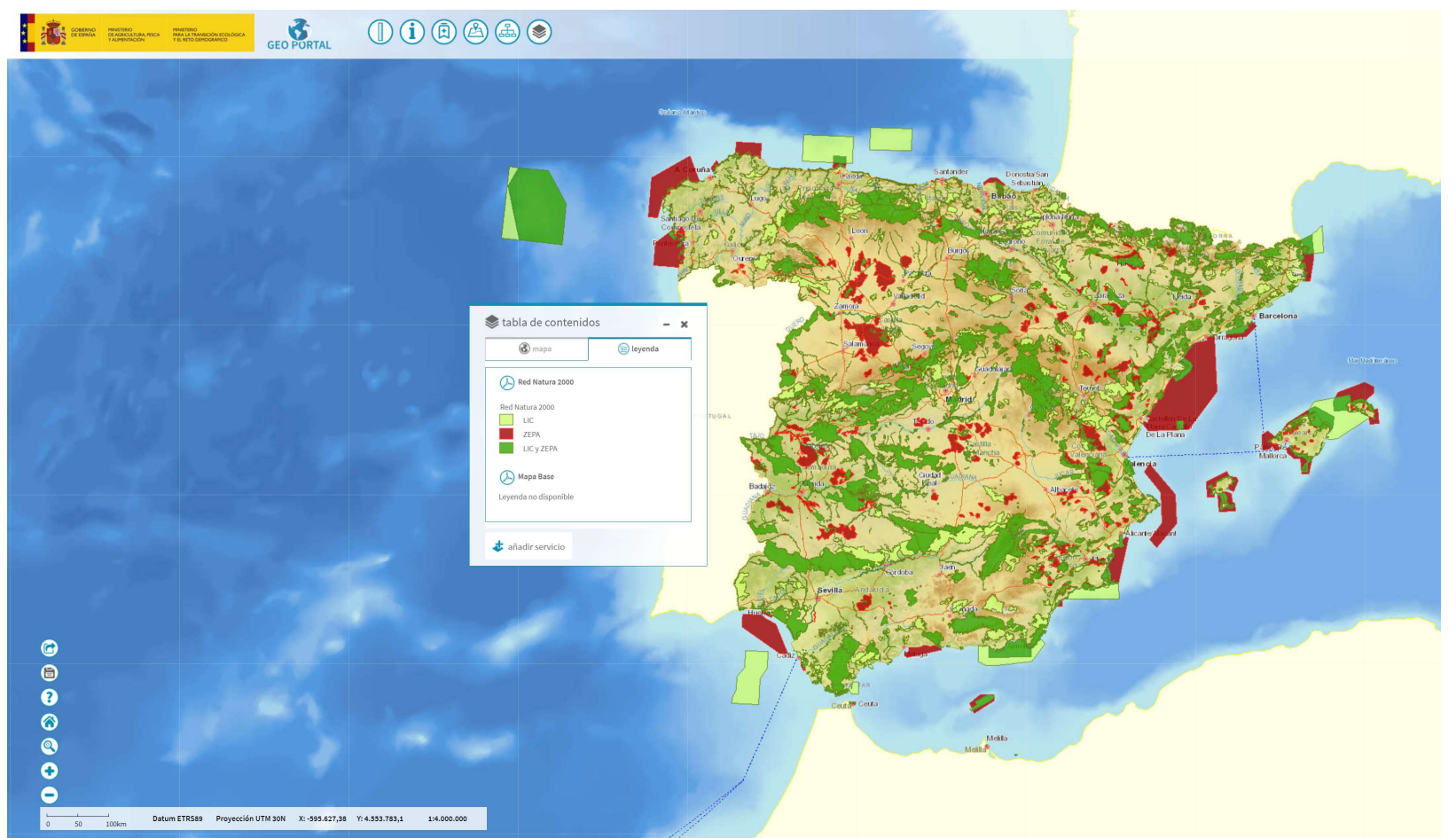

Figura 4: zonas LIC, ZEPA, LIC y ZEPA según Red Natura 2000. Geoportal del Ministerio Agricultura, Pesa y

Alimentación. https://sig.mapama.gob.es/geoportal/ 


\section{IAERYD CARTAGENA 2021

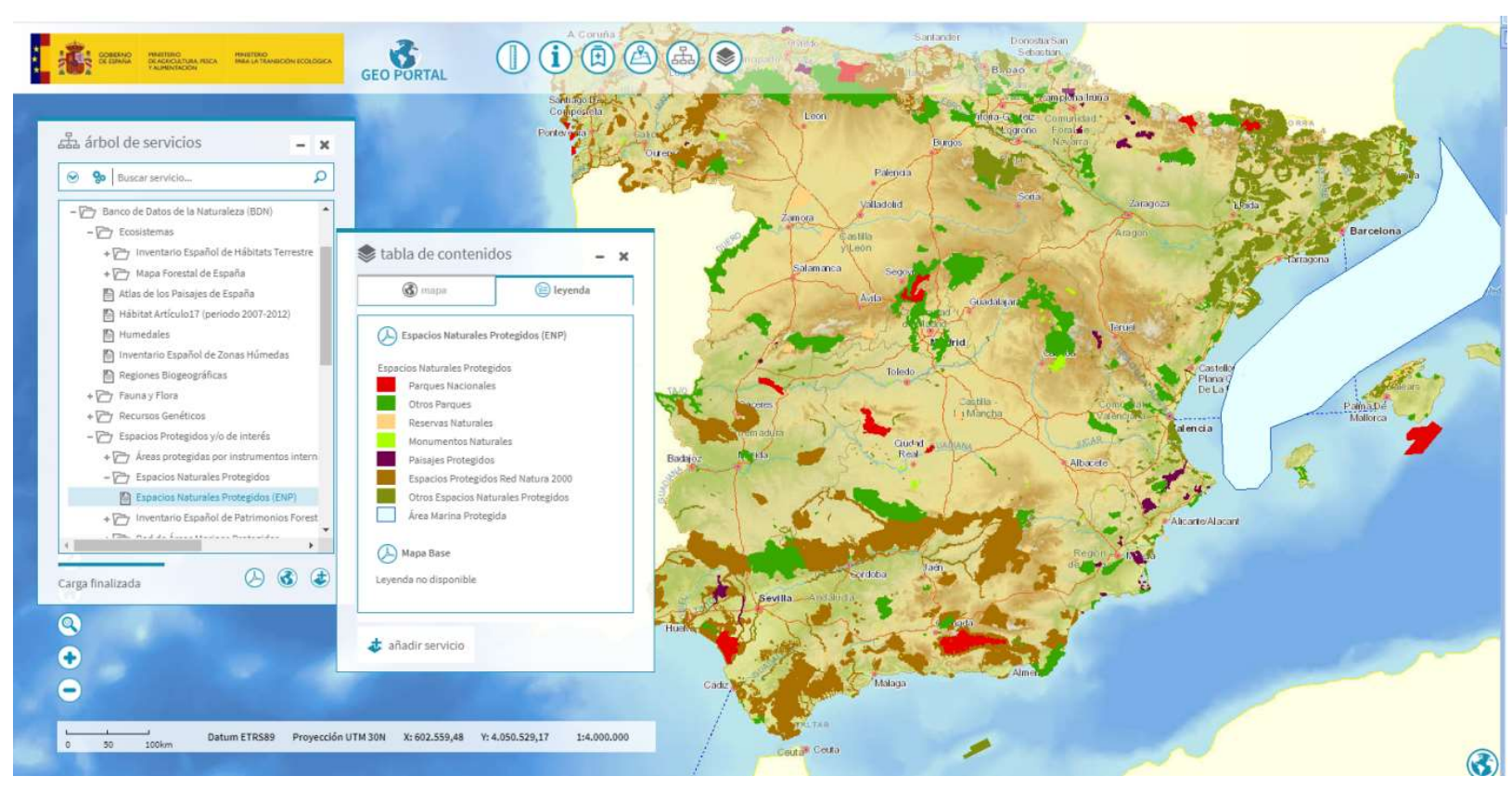

Figura 5: zonas Espacios Naturales Protegidos según Banco de Datos de la Naturaleza. Geoportal del Ministerio Agricultura, Pesca y Alimentación. https://sig.mapama.gob.es/geoportal/

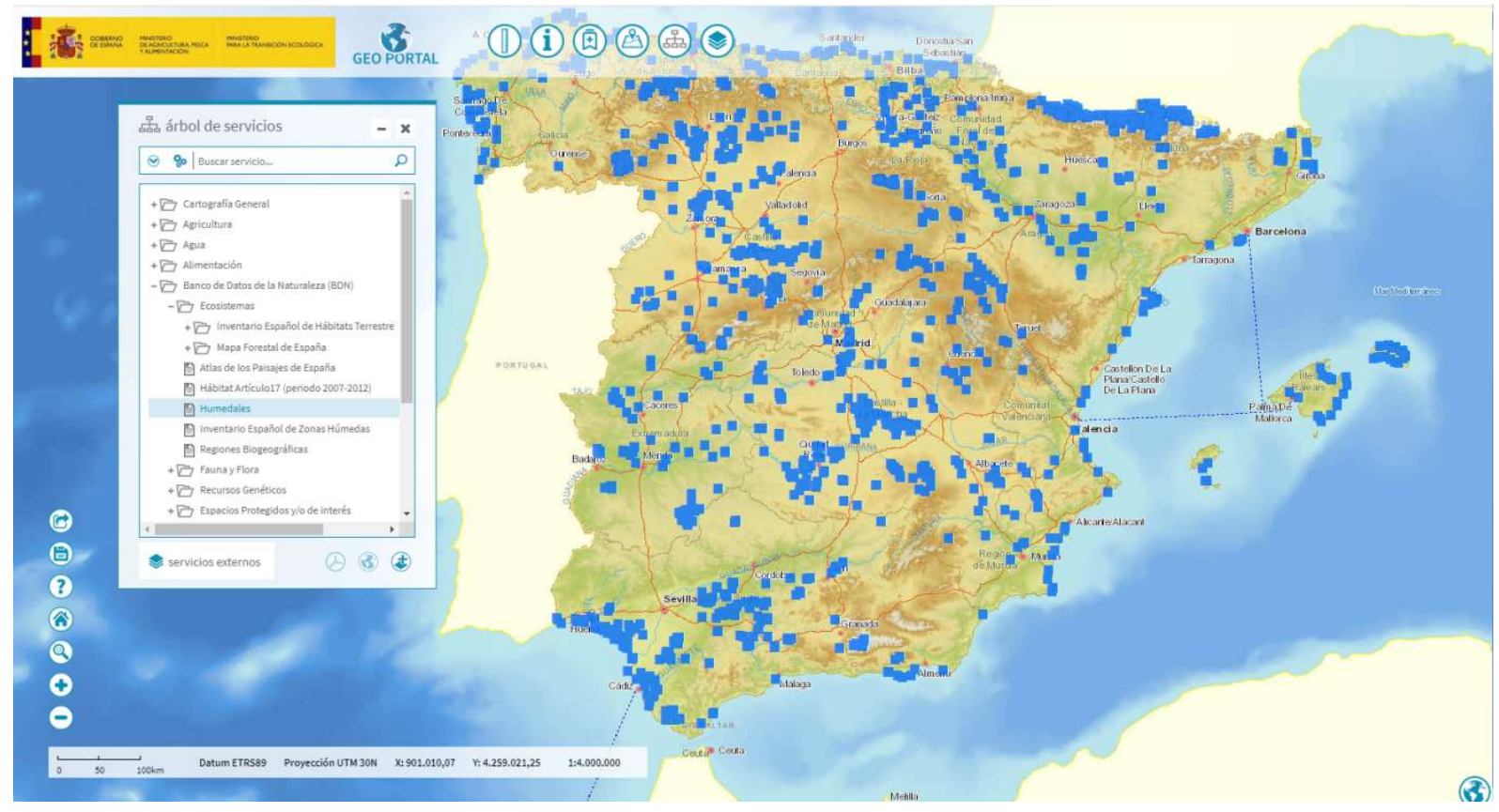

Figura 6: zonas Humedales según Banco de Datos de la Naturaleza. Geoportal del Ministerio Agricultura, Pesca y Alimentación. https://sig.mapama.gob.es/geoportal/ 


\section{Congreso Nacional de Riegos CARTAGENA 2021}

\subsection{El siniestro.}

Cuando ocurre un siniestro, siendo un momento clave en la vida de la póliza de seguro, es fundamental seguir una serie de pasos y plazos establecidos, siempre de la mano del mediador de seguros de la póliza, que acompañará a la comunidad de regantes en la atención inmediata del siniestro, su tramitación y la mejor consecución del mismo. Son relevantes las tareas de lectura e interpretación de garantías y clausulado de la póliza, seguimiento de informes periciales, y otras labores propias como interlocutor entre el cliente y la aseguradora, siempre en defensa del asegurado y en comunicación directa y especializada.

\subsubsection{Caso real 1:}

- Causa y descripción: Rotura de balsa de riego con una brecha de 5-6 metros por la que se produce la pérdida de $180.000 \mathrm{~m} 3$ de agua almacenada (en una hora aproximadamente se produce el vaciado de la misma).

- Daños provocados: La onda hidráulica provoca daños materiales importantes a terceros a lo largo de $4 \mathrm{~km}$, con una superficie total afectada de 27,53 has de:

- Cultivos

- Infraestructuras

- Daños al Dominio Público Hidráulico (cauce de un arroyo)

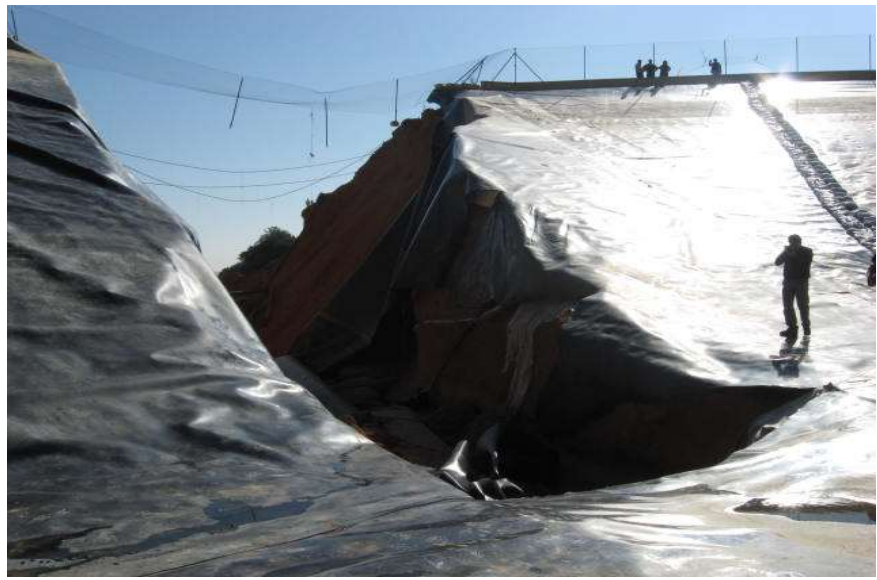

Figura 7: imagen de la brecha abierta en la balsa de riego

\subsubsection{Caso real 2:}

- Causa y descripción: La avería del sistema automatizado de regulación del trasvase de agua de una balsa de $450.000 \mathrm{~m} 3$ a la de $80.000 \mathrm{~m} 3$ (sonda de presión y boya de control de nivel de agua) produce el desbordamiento de la balsa de capacidad de $80.000 \mathrm{~m} 3$, por encima del rebosadero.

- Daños provocados: Daños a terceros en fincas colindantes de dos comuneros, con arrastre de tierras.

\subsubsection{Caso real 3:}

- Causa y descripción: Intensas precipitaciones provocan que el agua se infiltre por el terreno y además, que descienda por la pendiente en forma de escorrentía, produciendo disgregación de material y movimientos superficiales. 


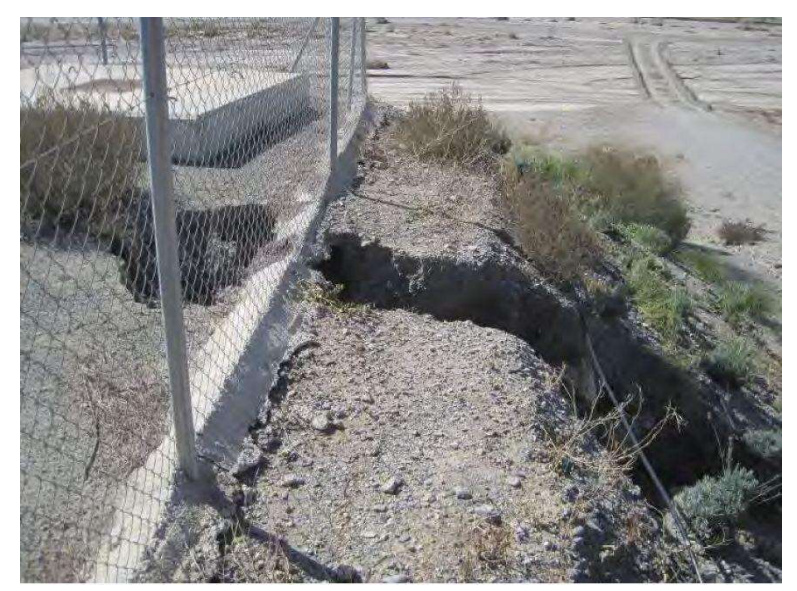

Figura 8: socavón en coronación de balsa y pérdida de pendiente

- Daños provocados: Daños propios en taludes y coronación de las balsas (perdida de pendiente y socavones) por la garantía consorciable de inundación extraordinaria.

\subsubsection{Tipos de siniestros.}

Los siniestros de balsas de riego, cuyas casuísticas y circunstancias son múltiples, podríamos clasificarlos en:

1. Siniestros de daños activos, que provoca la balsa propiamente dicha, hacia el exterior. Ejemplo: por rotura o desbordamiento de la balsa.

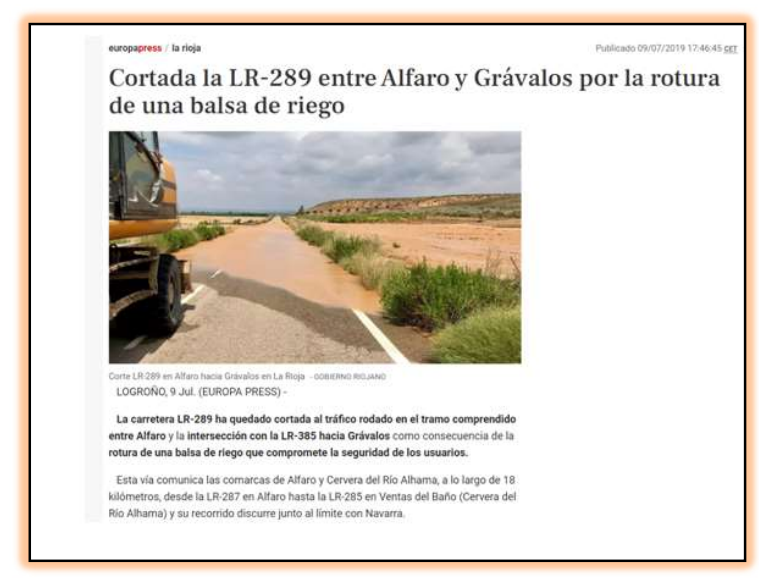

Figura 9: Cortada la LR-289 entre Alfaro y Grávalos por la rotura de una balsa de riego

(9 de julio de 2019). Europapress, La Rioja. Recuperado de http://www.europapress.es/

2. Siniestros de daños pasivos, en que ningún hecho fortuito y accidental de la balsa produce el daño; es decir, la propia balsa no causa el daño. Ejemplo: personas ahogadas en la balsa. 


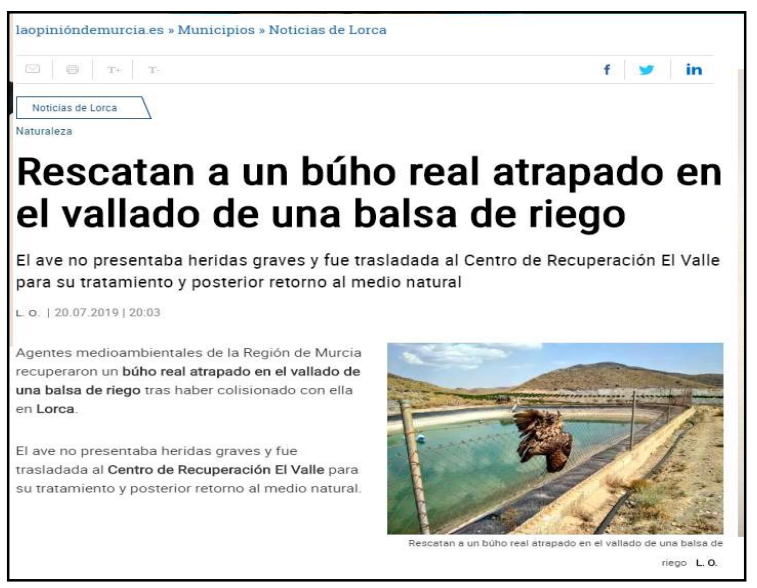

Figura 10: L.O. Rescatan a un búho real atrapado en el vallado de una balsa de riego (20 de julio de 2019). La Opinión de Murcia, Municipios. Recuperado de http://www.laopiniondemurcia.es/

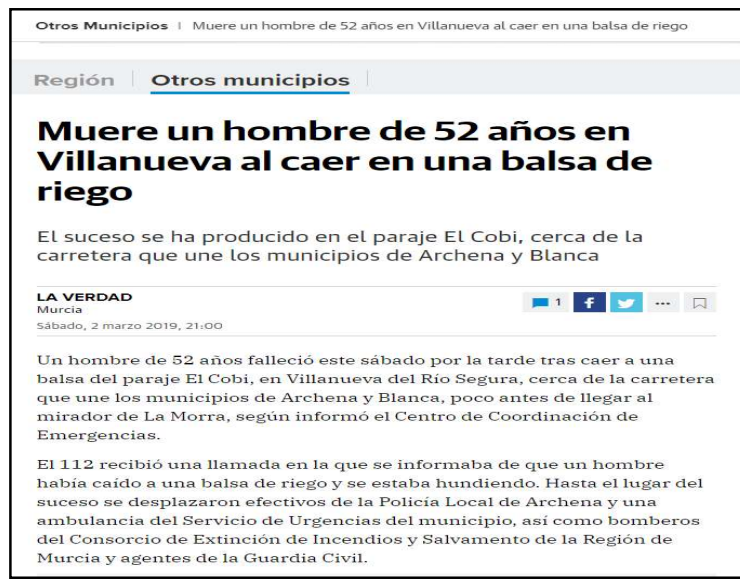

Figura 11: Muere un hombre de 52 años en Villanueva al caer en una balsa de riego (2 de marzo de 2019). La Verdad, Murcia. Recuperado de http://www.laverdad.es/

\section{Resultados obtenidos en ensayo o en explotación comercial.}

El éxito del seguro de balsas radica en ser único en el mercado asegurador, específico para este riesgo en concreto. Nuestra especialización se basa en más de 35 años asegurando comunidades de regantes, a través de un completo programa de seguros, entre los que se encuentra el de balsas.

Somos referentes en el aseguramiento del sector de la agricultura de regadío, contando en la actualidad con más de 400 comunidades de regantes que son clientes de EPGSalinas. Son ya más de 500 balsas aseguradas por todo el territorio español, que representan en torno a $85 \mathrm{hm} 3$ de capacidad de almacenamiento de agua en balsas aseguradas, con una media alrededor de $170.000 \mathrm{~m} 3$ por balsa y un promedio de 7,5 metros de altura. Las balsas clasificadas del tipo A, representan el $33 \%$ del total de las aseguradas clasificadas.

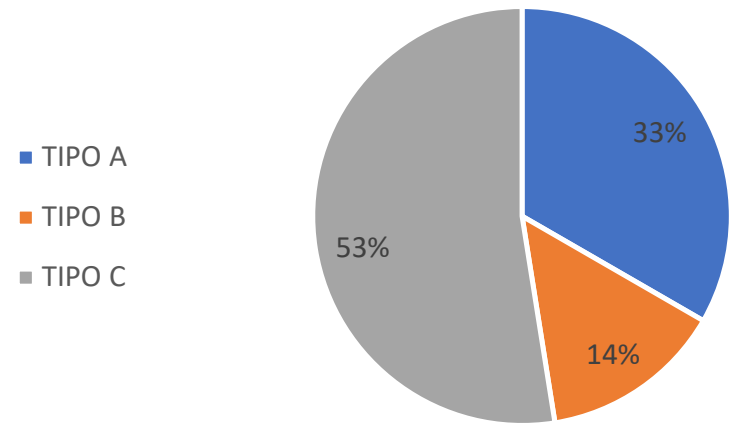

Figura 12: Distribución de la tipología de balsas clasificadas aseguradas a través de EPGSalinas 


\section{Congreso Nacional de Riegos CARTAGENA 2021}

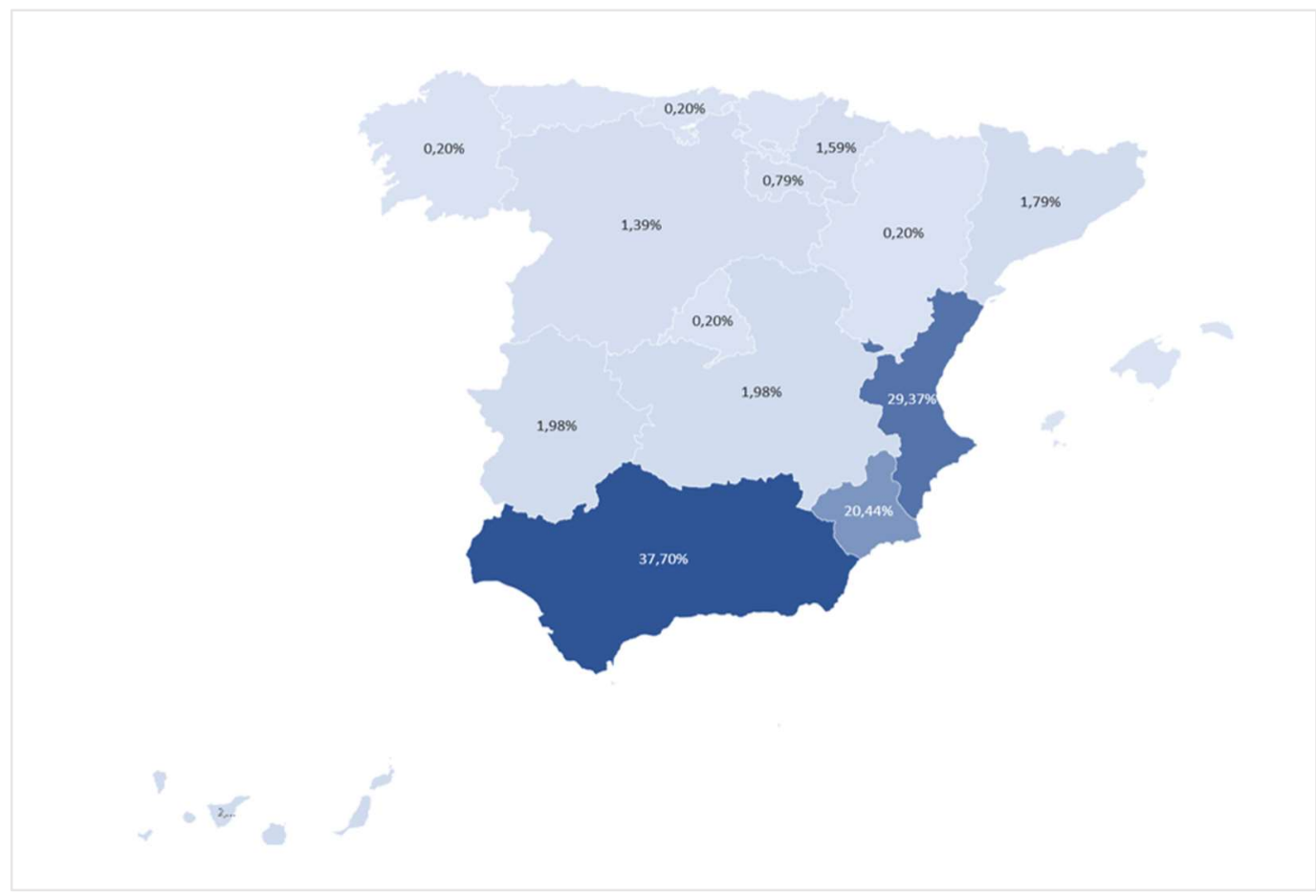

Figura 13: Distribución de las balsas aseguradas a través de EPGSalinas

\section{Conclusiones}

1. Hay que ser consciente de que a pesar del exhaustivo control de la seguridad y mantenimiento de las balsas de riego, los siniestros de balsas por rotura o mal funciomamiento suceden, accidental y fortuitamente, y hay que estar preparados.

2. Los siniestros de responsabilidad civil y medioambiental son muy diferentes a los siniestros de daños propios, con particularidades como temporalidad, complejidad y ponen en juego el patrimonio y la reputación.

3. Hay que estar bien asegurados: la importancia de encontrar seguros especializados.

4. Además de estar bien asegurados, es fundamental estar bien asesorados. Es relevante la labor del corredor de seguros, en continua innovación en cuanto a soluciones aseguradoras y servicios.

5. Visión $360^{\circ}$ de los riesgos de las comunidades de regantes: todos los riesgos asegurados bajo un programa específico de seguros.

\section{Referencias}

1. De Cea, Juan Carlos (Dirección General del Agua MITERD, Comisión de normas de grandes presas, experto de la CR en seguridad de infraestructuras). Evolución de la normativa en seguridad de balsas de riego. Jornada sobre la Gestión de la Seguridad en Balsas de Riego. Madrid, 2021

2. Espejo Almodóvar, Fernando (profesor titular de la Universidad de Salamanca). Propuestas de clasificación de balsas. Aplicación práctica del marco normativo. Jornada sobre la Gestión de la Seguridad en Balsas de Riego. Madrid, 2021 


\section{Telecontrol y automatización de ramales terciarios en redes de distribución a lámina libre.}

\section{Tejero Juste, M. 1, Gracia Force, E ${ }^{1}$}

${ }^{1}$ Departamento Técnico y Comercial. Riegosalz. C/ La Ontina, 3. Ontinar de Salz (Zaragoza) comercial@riegosalz.com

Palabras clave: gestión de canales; acequias; redes de distribución; riego tradicional; telecontrol.

Las Comunidades de Regantes con distribución a lámina libre y riego tradicional, distribuyen sus aguas a los comuneros mediante una red de acequias que parten de un canal principal y que se ramifican hasta llegar a las parcelas. El reparto de ese agua se realiza, tradicionalmente, de forma manual; mediante la modificación de la apertura de las compuertas y tajaderas dispuestas a lo largo de la red. Ésta es una operación que demanda mucha mano de obra y en la que cualquier cambio o adaptación supone un esfuerzo importante de coordinación entre regantes y personal de gestión. La falta de elasticidad provoca que la operativa del riego no se planifique desde un punto de vista de optimización del uso del agua sino desde una perspectiva de ahorro de mano de obra.

Con nuestras compuertas automatizadas Ziquilink podemos automatizar y telecontrolar estos nodos tanto en la red primaria como en la secundaria y en todas las compuertas de parcela. Esto permite una total flexibilidad del riego a lo largo de las $24 \mathrm{~h}$ del día y asegura la máxima eficiencia del uso del agua al coordinar y encadenar el riego de distintos usuarios del ramal terciario sin pérdidas de tiempo y agua. Este control consigue un escenario homólogo al que sucede en las zonas de riego presurizado de última generación, en las que la Comunidad de Regantes controlan la apertura y consumo de los hidrantes y hasta los sectores de riego en parcela.

COMPUERTAS AUTOMATIZADAS ZIQUILINK

La gama de compuertas automatizadas Ziquilink están fabricadas en acero inoxidable e incorporan un sistema de motorización, telecontrol y energización en el mismo conjunto. Permiten el telecontrol para: apertura "Todo o nada", control de posición o regulación automática de una variable. Todo telecontrolado desde un servidor accesible en todo momento a través de web o app.

\section{INNOVACIÓN}

El uso de estas compuertas automáticas Ziquilink permite automatizar y telecontrolar los ramales terciarios (compuertas de parcela) de forma equivalente a los hidrantes de una red a presión. Tiene las siguientes características:

- Facilidad de instalación. Son elementos de bajo peso y tamaño. Baja o nula necesidad de obra civil. Instalación y puesta en marcha en pocas horas.

- $\quad$ Sistema escalable. El sistema puede crecer ilimitadamente.

- $\quad$ Sistema ampliable. De 1 a 4 equipos por nodo.

- Bajo Mantenimiento. Los componentes y materiales utilizados reducen el mantenimiento al mínimo y la necesidad de técnicos especializados.

- Versatilidad. Funciones de apertura/cierre, control de posición y regulación de caudal.

- Adaptación. Control de compuertas de captación, desagüe y retención. 
- Control a tiempo real. Comunicación inmediata GPRS/3G con App Android, iOS y PC. Redundancia mediante SMS y aviso por Voz.

- Bajo consumo. El diseño de la electrónica y periféricos está optimizado para un bajo consumo y gran autonomía.

- Accionamiento de emergencia. Además del control electrónico, el sistema dispone de accionamientos electromecánico y manual.

- Sistema redundante de seguridad con duplicidad de sensores.

- Diseño compacto. El conjunto completo se suministra en un bloque (compuerta, motorización alimentación y control).

- Eficiencia mecánica. Compuerta de mínima resistencia. Motorización optimizada.

- Sin pérdida de carga. El diseño de la compuerta permite mantener la rasante del canal.

- Favorece la autolimpieza y evita la acumulación de sedimentos.

- Aplicable a aguas de baja calidad. Todos los elementos en contacto con el agua son resistentes a la corrosión.

https://riegosalz.com/ziquilink-compuerta-automatizada-telecontrolada/ 


\title{
Remote control and automation of tertiary branches in free sheet distribution networks.
}

\author{
Tejero Juste, M. 1, Gracia Force, E1
}

${ }^{1}$ Departamento Técnico y Comercial. Riegosalz. C/ La Ontina, 3. Ontinar de Salz (Zaragoza) comercial@riegosalz.com

Keywords: channel management; ditches; distribution networks; traditional irrigation; remote control.

The Communities of Irrigators with distribution to free sheet and traditional irrigation, distribute their waters to the comuneros through a network of ditches that start from a main channel and that branch until they reach the plots. The distribution of this water is traditionally carried out manually; by modifying the opening of the gates and slasters arranged along the network. This is an operation that demands a lot of labor and in which any change or adaptation involves an important coordination effort between irrigators and management personnel. The lack of elasticity means that irrigation operations are not planned from a point of view of optimizing water use but from a labor-saving perspective.

With our Ziquilink automated gates we can automate and remote control these nodes in both the primary and secondary networks and in all plot gates. This allows total flexibility of irrigation throughout the 24 hours of the day and ensures maximum efficiency of water use by coordinating and chaining the irrigation of different users of the tertiary branch without loss of time and water. This control achieves a scenario similar to that which happens in the areas of pressurized irrigation of the latest generation, in which the Community of Irrigators control the opening and consumption of hydrants and even the irrigation sectors on plots.

ZIQUILINK AUTOMATED GATES

The Ziquilink range of automated gates are made of stainless steel and incorporate a motorization, remote control and energization system in the same set. They allow remote control for: "All or nothing" opening, position control or automatic regulation of a variable. All remotely controlled from a server accessible at all times through web or app.

INNOVATION

The use of these Ziquilink automatic gates makes it possible to automate and remote control the tertiary branches (plot gates) in an equivalent way to the hydrants of a pressure network. It has the following characteristics:

- Ease of installation. They are elements of low weight and size. Low or no need for civil works. Installation and commissioning in a few hours.

- Scalable system. The system can grow unlimitedly.

- Expandable system. From 1 to 4 computers per node.

- Low Maintenance. The components and materials used reduce maintenance to a minimum and the need for specialized technicians.

- Versatility. Opening/closing functions, position control and flow regulation.

- Adaptation. Control of collection, drainage and retention gates.

- Real-time control. Immediate GPRS/3G communication with Android, iOS and PC App. Redundancy through SMS and Voice notification. 
- Low consumption. The design of the electronics and peripherals is optimized for low consumption and great autonomy.

- Emergency drive. In addition to electronic control, the system has electromechanical and manual drives.

- $\quad$ Redundant safety system with duplication of sensors.

- Compact design. The complete assembly is supplied in a block (gate, motorization power and control).

- Mechanical efficiency. Gate of minimum resistance. Optimized motorization.

- No pressure loss. The design of the gate allows to maintain the grade of the channel.

- It favors self-cleaning and prevents the accumulation of sediments.

- Applicable to low quality water. All elements in contact with water are resistant to corrosion.

https://riegosalz.com/ziquilink-compuerta-automatizada-telecontroladal 


\section{Problemática abordada}

Las Comunidades de Regantes con distribución a lámina libre y riego tradicional, distribuyen sus aguas a los comuneros mediante una red de acequias que parten de un canal principal y que se ramifican hasta llegar a las parcelas. El reparto de ese agua se realiza, tradicionalmente, de forma manual; mediante la modificación de la apertura de las compuertas y tajaderas dispuestas a lo largo de la red. Ésta es una operación que demanda mucha mano de obra y en la que cualquier cambio o adaptación supone un esfuerzo importante de coordinación entre regantes y personal de gestión. La falta de elasticidad provoca que la operativa del riego no se planifique desde un punto de vista de optimización del uso del agua sino desde una perspectiva de ahorro de mano de obra.

Algunas comunidades avanzadas, como la de la Huerta de Pina de Ebro, afrontaron mejoras en la operación de la red de riego mediante la automatización y telecontrol de los elementos de regulación de la red Primaria (Azud, compuertas transversales, etc) y de la red secundaria (compuertas de derivación de acequias). Con eso se consigue un control avanzado de la red por parte de los gestores, que permite optimizar las tareas de reparto del agua hacia las tuberías de la red secundaria. Pero en esa situación queda pendiente resolver la última acción: el control del riego en cada parcela.

Cuando un regante desea regar, debe pactar con el personal técnico unas condiciones de horario y caudal y después debe acudir a la parcela para mover sus tajaderas y prepararlas para el riego. Una vez finalizado éste, el regante debe volver para cerrar la entrada de agua en el campo. Por lo tanto, es un proceso que involucra mucha mano de obra, precisa que el regante esté en el momento preciso en el campo (a la hora que sea), y si esa vigilancia se descuida, se puedan producir pérdidas operacionales de entre un 8 y un $15 \%$.

\section{Descripción de la innovación}

Riegosalz y la Comunidad de Regantes de la Huerta de Pina desarrollaron un proyecto de cooperación cuyo objetivo principal es conseguir las herramientas necesarias para que el proceso del riego de las parcelas se pudiera realizar de forma automática mediante el telecontrol de las compuertas de parcela, de la misma forma que en las redes presurizadas se controlan los hidrantes de cada parcela.

Con las compuertas automatizadas

ZIQUILINK 3 se pueden automatizar y telecontrolar los nodos tanto en la red primaria como en la secundaria, y en todas las compuertas de parcela.

Este sistema, que consiste en unos equipos de control automático de apertura y cierre de compuertas para la gestión de entrada de agua en las parcelas, permite al agricultor llevar a cabo esta tarea, que hasta ahora se realizaba de forma manual, a distancia, realizando en remoto las maniobras de las compuertas de las arquetas de reparto de la parcela, de manera automática a través de la programación de este sistema por medio de la información recibida mediante un centro de control.

Los equipos Ziquilink unidos al telecontrol de las compuertas automáticas del canal principal y canales secundarios, hace que el riego de los ramales terciarios en redes de distribución a lámina libre se pueda realizar ahora de forma totalmente automática y programada, sin intervención física del agricultor ni del gestor de la comunidad, al igual que en las comunidades con sistemas de riego presurizados. 


\section{Congreso Nacional de Riegos CARTAGENA 2021}

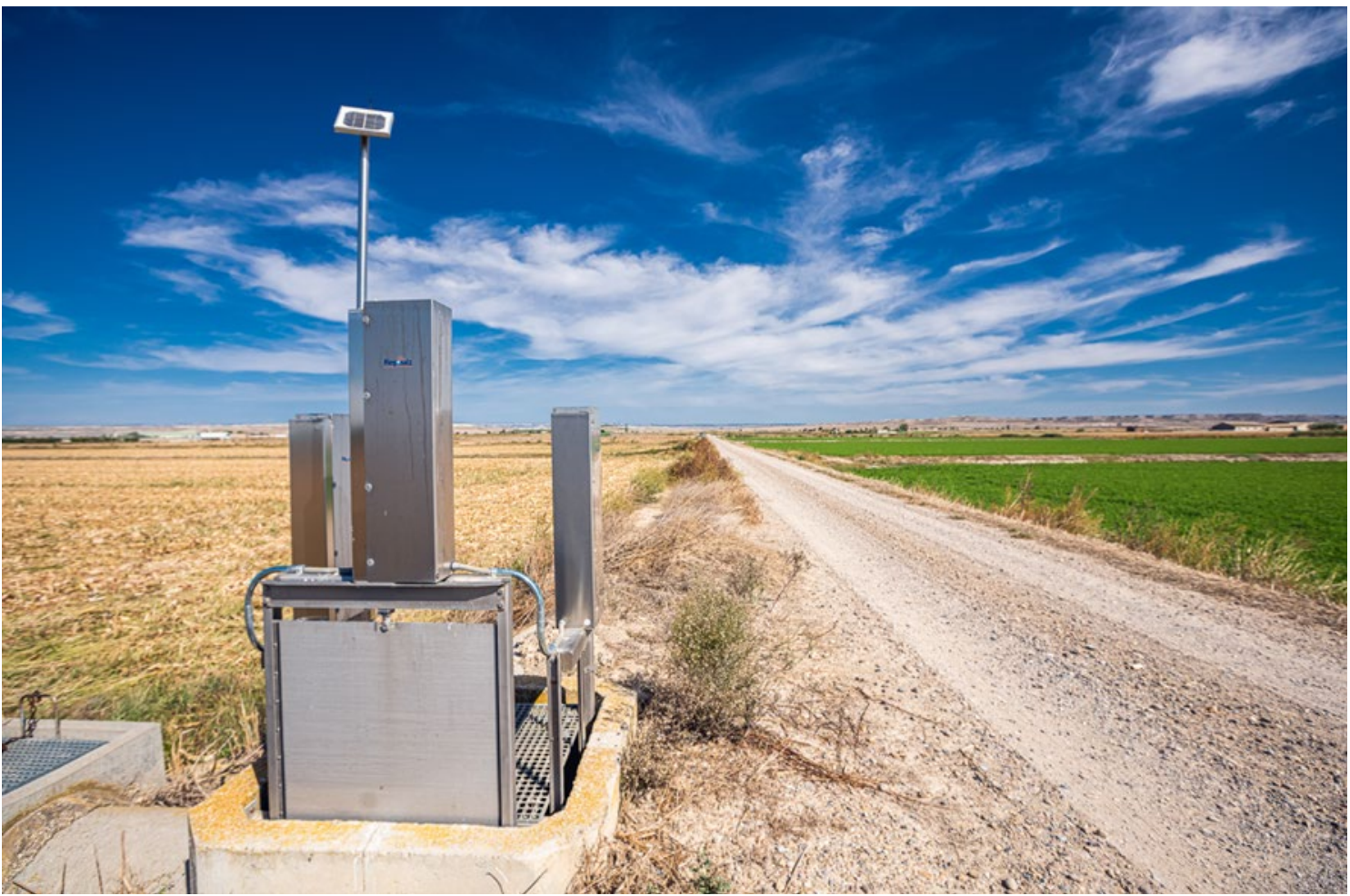

Figura 1. Nodo de 3 compuertas Ziquilink para regar parcelas a la derecha e izquierda del camino.

\section{COMPUERTAS AUTOMATIZADAS ZIQUILINK}

La gama de compuertas automatizadas Ziquilink están fabricadas en acero inoxidable e incorpora un sistema de motorización, telecontrol y energización en el mismo conjunto. Permiten el telecontrol para: apertura "Todo o nada", control de posición o regulación automática de una variable. Todo telecontrolado desde un servidor accesible en todo momento y desde cualquier lugar a través de web o app. con CloudCôntrol, el sistema de control y monitorización de automatizaciones de riegos multiplataforma propiedad de Riegosalz.

El telecontrol se realiza por medio de un módem GSMGPRS/3G incluido en cada equipo que permite varias vías de conexión al usuario:

- A través de la aplicación CloudCôntrol para Android e iOS con comunicación a tiempo real para gestión de órdenes, configuración históricos y con notificaciones inmediatas de cambios de estado.

- Puesto central de control sobre PC con gestión continua de la comunicación completa con las remotas.

- Comunicación redundante para emergencias por medio de teléfono móvil (SMS y VOZ) directo entre el equipo y el usuario.

CloudCôntrol de Riegosalz permite la interconexión con otros SCADAS. 
Para conjuntos de compuertas Ziquilink, se ofrece la alternativa de comunicación vía Radio.
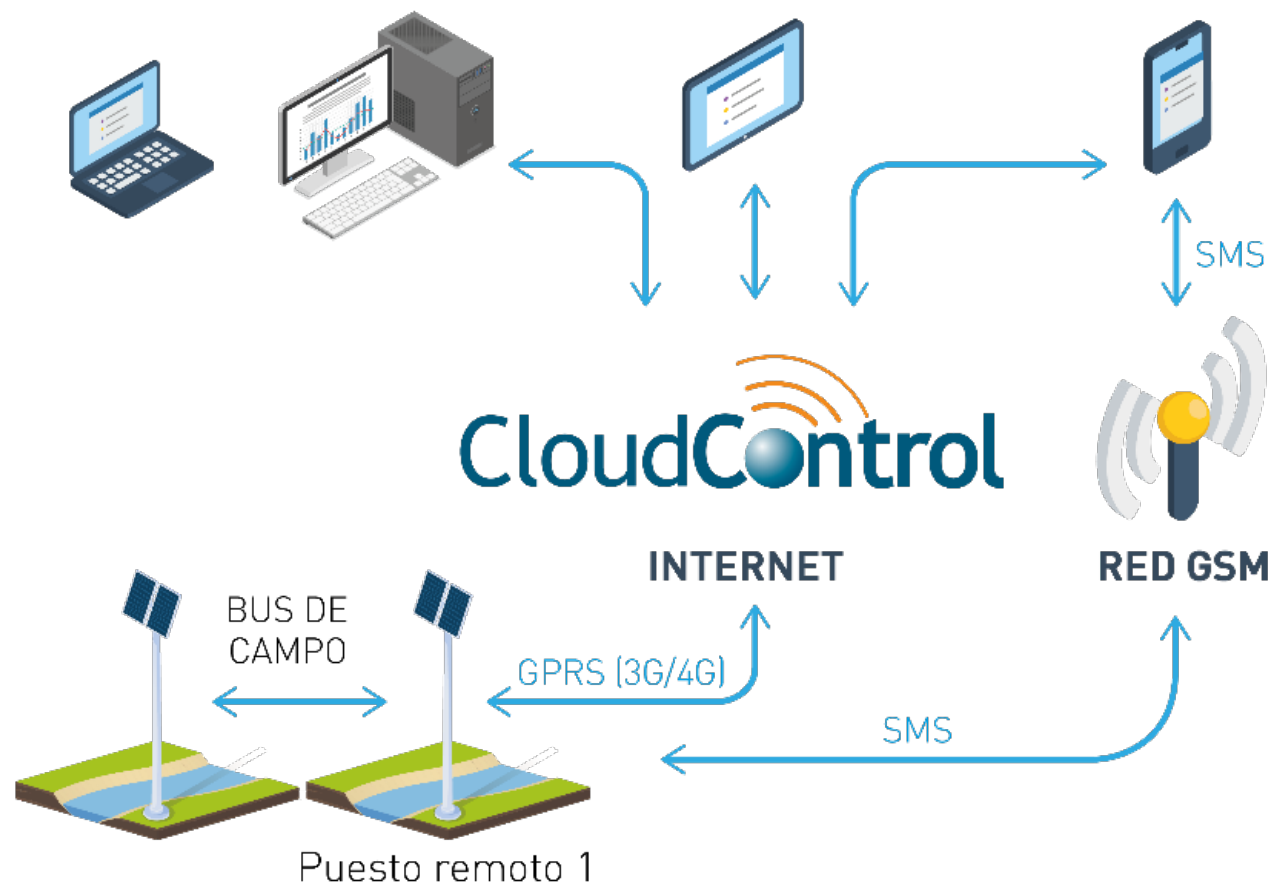

Figura 2. Esquema del Cloud Control.

\section{Compuertas}

Las compuertas son del tipo "canal", con hoja plana deslizante estanca a tres caras. Dimensiones de hoja y altura de marco: variable según modelo. Estanqueidad simple en un único sentido a favor de la corriente mediante junta de neopreno tipo nota musical en cierre inferior. Fabricada en acero inoxidable AISI-304. Guías deslizantes con plástico técnico. Puente mecanizado para atornillar accionamiento. Compuerta preparada para encofrar o para atornillar a muro frontal.

\section{Sistema de motorización de compuerta}

La motorización del sistema Ziquilink permite una carrera de compuerta regulable de hasta 800 $\mathrm{mm}$ con control de posición y atasco.

\section{Sistema de alimentación con energía solar fotovoltaica}

La compuerta automática Ziquilink se alimenta a $12 \mathrm{Vdc}$ desde la batería y el panel solar incorporados. Con opción de alimentación 230VAC.

\section{Equipo de control Ziquilink GPRS(3G) Maestro y Esclavo}

El diseño del sistema Ziquilink GPRS(3G) permite controlar VARIAS compuertas CONTIGUAS hasta un máximo de 4 con una misma tarjeta de comunicación.

\section{Regulación automática}

En el caso de la regulación automática, el usuario determina una consigna de nivel o caudal a medir y el sistema modifica el grado de apertura de la compuerta mediante un ajuste proporcional hasta alcanzar el nivel deseado en la canalización. Si las condiciones de caudal cambian y eso hace que el nivel medido se desvíe del de consigna por encima de un margen permitido, el sistema corregirá inmediatamente ese efecto mediante el movimiento de la compuerta. La regulación de nivel, combinada con una 


\section{CXERY}

CARTAGENA 2021

sección de aforo aguas abajo, permite controlar el caudal entregado por una compuerta de forma precisa.

\section{Control de nivel}

En el caso del modelo Ziquilink REGULACIÓN, se añade una sonda de nivel piezorresistiva con precisión milimétrica y un sensor de nivel máximo que controla el riesgo de desbordamiento; actuando sobre la compuerta de forma electromecánica sin presencia de operarios.

\section{Accionamientos alternativos o de emergencia}

El conjunto de control automático se completa con sistemas electromecánicos y manuales de emergencia para que, en caso de error humano, fallo electrónico o eléctrico, éstos actúen de forma preconfigurada para llevar el canal a una situación de seguridad. Además, desencadenará los avisos de alarma correspondientes.

\section{Operación del sistema en modo local}

A pesar de que las compuertas se equipan con sistemas automáticos y telemando, siempre hay que tener previsto opciones de operación sobre los elementos de terreno. El sistema de Riegosalz prevé varios modos de operación, un modo de actuación con botones de acción y un modo de actuación manual para caso de emergencia.

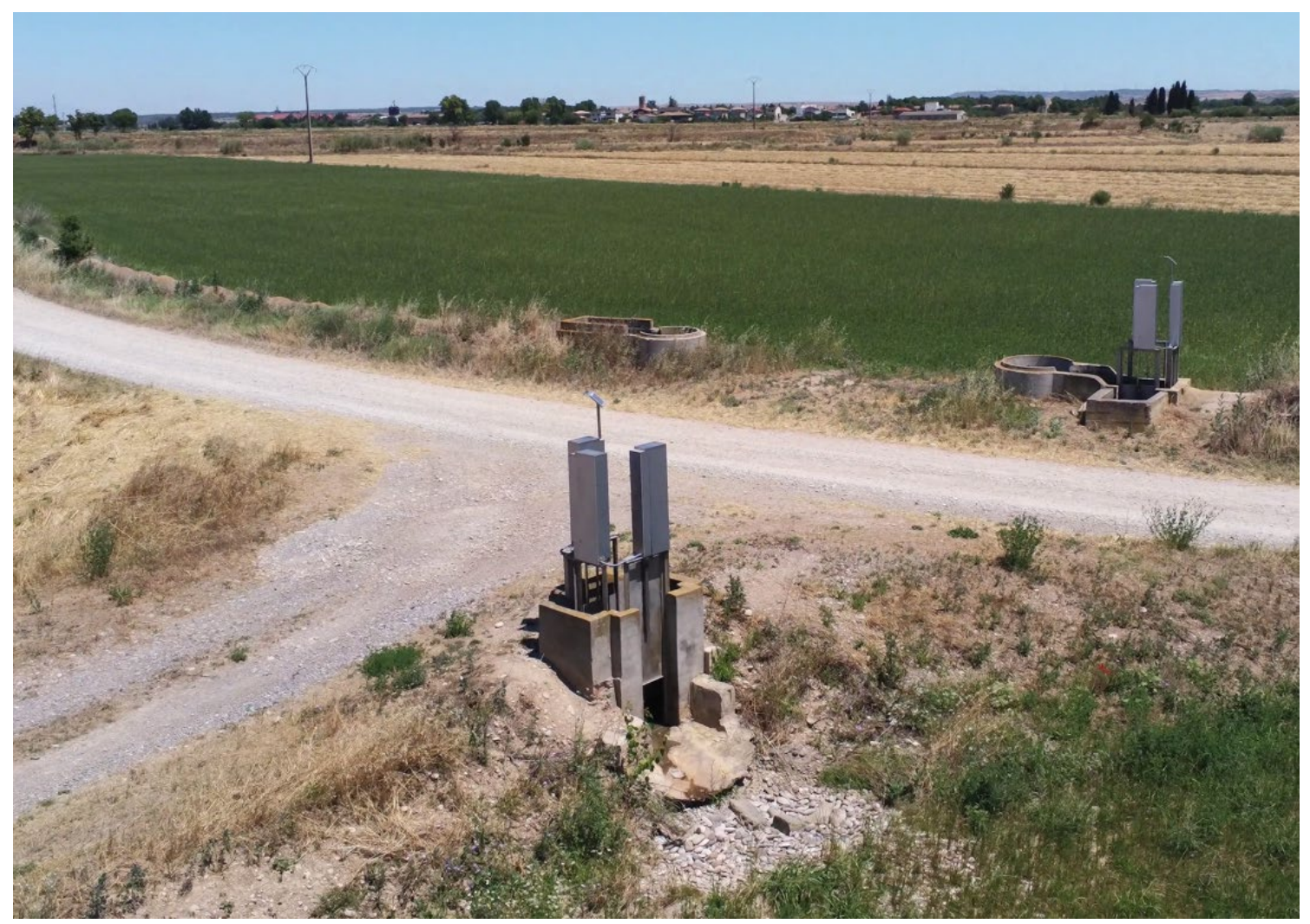

Figura 3. 2 nodos de 3 compuertas Ziquilink en sifones a ambos lados de un camino.

\section{INNOVACIÓN}

El uso de estas compuertas automáticas Ziquilink permite automatizar y telecontrolar los ramales terciarios (compuertas de parcela) de forma equivalente a los hidrantes de una red a presión.

Las compuertas Ziquilink tienen las siguientes características: 
- Facilidad de instalación. Son elementos de bajo peso y tamaño. Baja o nula necesidad de obra civil. Instalación y puesta en marcha en pocas horas.

- Sistema escalable. El sistema puede crecer ilimitadamente.

- Sistema ampliable. De 1 a 4 equipos por nodo.

- Bajo Mantenimiento. Los componentes y materiales utilizados reducen el mantenimiento al mínimo y la necesidad de técnicos especializados.

- Versatilidad. Funciones de apertura/cierre, control de posición y regulación de caudal.

- Adaptación. Control de compuertas de captación, desagüe y retención.

- Control a tiempo real. Comunicación inmediata GPRS/3G con App Android, iOS y PC. Redundancia mediante SMS y aviso por Voz.

- Bajo consumo. El diseño de la electrónica y periféricos está optimizado para un bajo consumo y gran autonomía.

- Accionamiento de emergencia. Además del control electrónico, el sistema dispone de accionamientos electromecánico y manual.

- Sistema redundante de seguridad con duplicidad de sensores.

- Diseño compacto. El conjunto completo se suministra en un bloque (compuerta, motorización alimentación y control).

- Eficiencia mecánica. Compuerta de mínima resistencia. Motorización optimizada.

- Sin pérdida de carga. El diseño de la compuerta permite mantener la rasante del canal.

- Favorece la autolimpieza y evita la acumulación de sedimentos.

- Aplicable a aguas de baja calidad. Todos los elementos en contacto con el agua son resistentes a la corrosión.

\section{Resultados obtenidos en explotación comercial}

Las compuertas automáticas para control de ramales terciarios se han instalado en dos ramales de la red de distribución de la Huerta de Pina y en diez fincas particulares de las provincias de Zaragoza y Lleida. Asimismo, se están ejecutando sesenta y tres instalaciones en ramales terciarios de redes de distribución en zonas regables de Chile.

La utilización en los prototipos de la Huerta de Pina ha permitido validar dos tecnologías de comunicación:

- Comunicación GPRS/3G para control de puntos aislados o independientes.

- Comunicación Radio LORA para redes de control con equipos numerosos.

También se han podido validar el diseño de los elementos de campo como:

- Motorización.

- Sensorización.

- Alimentación eléctrica.

- Electrónica de control para nodos de hasta tres compuertas. 


\section{CXerro}

CARTAGENA 2021

La automatización de los ramales terciarios ha permitido desarrollar la labor del riego de forma tele controlada y autónoma desde la plataforma de gestión de la Comunidad de Regantes. La experiencia resultante es:

- El riego se ha podido realizar de forma programada y concatenando el resto de los elementos de la red para aportar un caudal ajustado a los valores óptimos para cada parcela.

- No ha sido necesaria la labor humana salvo para las tareas de programación y supervisión.

- La programación ha permitido flexibilizar el riego y encajarlo en la franja horaria más adecuada.

- Las maniobras encadenadas han permitido gestionar cada ramal sin pérdida de tiempo ni agua.

- El ajuste del caudal a las necesidades de la parcela ha permitido disminuir el tiempo de riego, minimizar las pérdidas por percolación profunda y reducir el intervalo entre riegos.

- El cultivo no ha sufrido ningún tipo de estrés ni por defecto ni por exceso de riego.

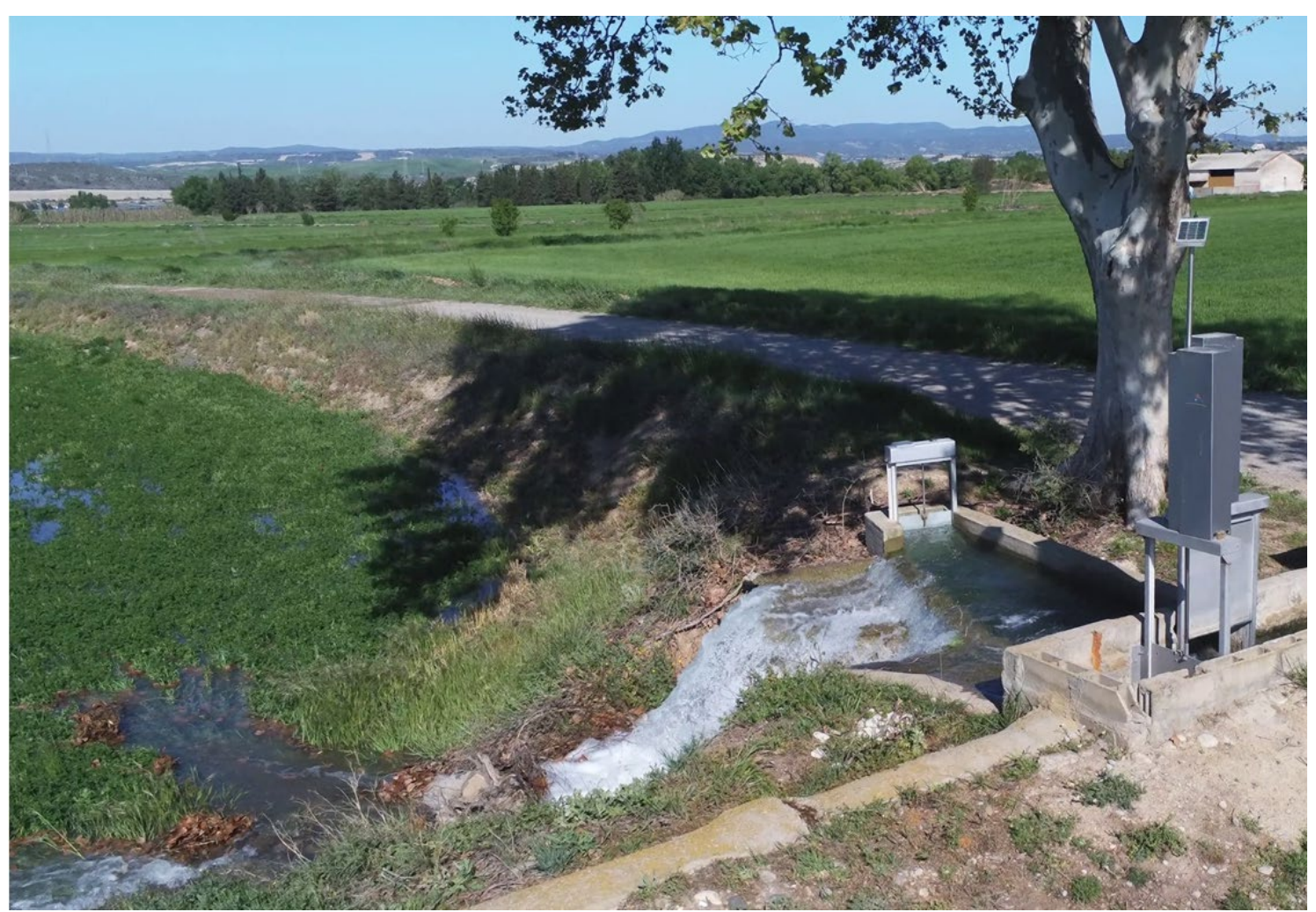

Figura 4. Nodo de 2 compuertas Ziquilink de derivación y 1 compuerta Ziquilink regando finca usando aliviadero.

\section{Conclusiones}

Los sistemas de riego tradicional necesitan herramientas de control y gestión para poder optimizar el uso del agua y de la mano de obra en las operaciones.

Las compuertas automáticas en los ramales terciarios permiten alcanzar un grado de automatización equivalente a las redes de riego presurizado.

La experiencia de la Comunidad de Regantes de Pina se está extendiendo a otra fincas y redes de distribución de España y Latinoamérica. 


\section{Cabezal compacto para un control inteligente de la bionutrición y el riego}

\section{Martínez Tornero, José Francisco}

1 jtornero@nutricontrol.com

\section{Resumen:}

En los últimos años, la demanda de los consumidores y mercados hacia productos más sanos y cultivados de manera respetuosa con el medio ambiente, ha hecho que la agricultura experimente una evolución hacia sistemas más eficientes, precisos, tecnificados y sostenibles, para lo que es necesario poder disponer del control y de los datos para optimizar el uso de todos los recursos empleados en la producción.

Estos cambios han generado nuevas demandas para aquellas empresas que somos lideres en le desarollo de todo tipo de soluciones para la tecnificación del campo y la mayoría de estos retos gracias al uso de la tecnología, son resueltos de manera exitosa, mejorando los procesos exixtentes.

Otros aspectos que hemos identificado consecuencia, en muchos casos, de esa tecnificación son: (i) la necesidad de un mayor conocimento para el manejo de todos los datos que se generán, (ii) la aparición de diferentes sistemas de recogida de datos, (iii) el uso de nuevos fertilizantes orgánicos y bio estimulantes más respetuosos con el medio ambiente pero a la vez más dificles de manejar en los sistemas de riego, (iv) sistemas de cultivo intensivos y con variedades más exigentes, (v) las nuevas exigencias de los nuevos consumidores y la legislación vigente, mucho más exigentes con los recursos empleados en la producción, (vi) unido al precio de la energía y el agua que se ha incrementado de forma considerable (además del deficit de esta última), y (vii) todo ello sin dejar de perder rentabilidad en los cultivos y a la vez, ser respetuosos con el medio natural.

Por todo lo mencionado, se nos planteo el reto de aportar una solución integral que pueda mejorar o resolver en gran medida, las nuevas exigencias y permitir evolucionar hacia una agricultura mucho más sostenible y rentable. De ahí, y con la experiencia internacional de más de 30 años en el sector, decidimos desarrollar un sistema compacto e inteligente que intregrara todos los dispositivos necesarios para el manejo de forma autónoma y precisa del riego y la fertirrigación. Facilmente exportable y sencillo de montar, incorporandole una gran cantidad de sensórica que nos permitiera obtener una gran cantidad de datos que nos ayudaran a tomar las decisiónes más oportunas en cada monento para marcar una estrategia de manejo más rentable y adaptada a los nuevos productos y, sobre todo, nos marcamos el reto de integrar diferentes dispositivos bajo una única plataforma, con el fin de mejorar la experiencia del usuario final de forma intuitiva y amigable, eliminando así la problemática de tener que gestionar plataformas diferentes para dispositivos que tienen el mismo fin.

Tambien incorporamos la opción de poder compartir los datos generados por el sistema inteligente con otras plataformas o con los propios sistemas de gestión de las explotaciones agrícolas ya que estamos convencidos de que la comunicación abierta nos hace avanzar a todos. 
Palabras clave: sensórica; manejo del riego; digitalización de la agricultura; agricultura de precisión 


\section{Cabezal compacto para un control inteligente de la bionutrición y el riego.}

\section{Problemática abordada}

Nos encontramos la realidad de una nueva agricultura, mucho más digital, con un mayor requerimiento de información, de datos y, sobre todo, el reto de conseguir mantener los mismos rendimientos, pero bajo el paraguas de la sostenibilidad.

Las explotaciones agrícolas ya se comportan como una fábrica en la que debemos conocer todo aquello que se está utilizando (fertilizantes, agua, mano de obra, etc) todo aquello que requiere la planta y sobre todo poder medir y controlar aquello que se aporta para conseguir una producción sostenible.

Este modelo de agricultura sostenible, también es un reto para los equipos que tradicionalmente controlaban y aportaban todo lo necesario para los cultivos, por diversos motivos:

- Las dotaciones de agua son cada vez menores.

- La calidad del agua es menos óptima para los cultivos.

- El coste del agua se ha incrementado en los últimos años como consecuencia de su déficit y por la incorporación de agua desalada.

- Los suelos son más pobres en M.O.

- Las limitaciones en los aportes de fertilizantes convencionales, principalmente nitrogenados..

- El uso de nuevos abonos orgánicos y bioestimulantes mejoradores del suelo, con densidades y texturas diferentes a los convencionales, con volúmenes de aporte diferentes y por lo general, de un mayor coste.

- El perfil de agricultor está cambiando y empieza a valorar poder disponer de más tiempo para su vida personal y exige un mayor control y precisión a tiempo real.

- La aparición de diferentes sistemas ocasionando que las explotaciones dispongan de sistemas distintos que no interactúan entre ellos y no permiten disponer de un control integral del cultivo.

- El aumento de cultivos de alto valor y también más sensibles y exigentes en necesidades hídricas y requerimientos nutricionales (berries, aguacate, etc) junto con sistemas de cultivo más intensivos.

- La legislación también está evolucionando y empieza a ser más restrictiva y exigente en las aportaciones de agua, fertilizantes y materias activas para el control de plagas y enfermedades.

- El consumidor final también ha variado y empieza a exigir y valorar como se ha producido y que recursos se han consumido en aquello que van a comprar (huella hídrica). 
Todo lo anterior, ha requerido aportar soluciones mucho más precisas y completas que permitan a los agricultores abordar este nuevo escenario, pudiendo manejar todos los elementos de una instalación de riego de una forma integrada y precisa para disponer en todo momento de un control total del riego, la fertirrigación y el estado fitosanitario del cultivo.

\section{Descripción de la innovación}

Ante este nuevo reto, Nutricontrol decidió abordar la problemática para estar nuevamente del lado de una agricultura de precisión y sostenible, poniendo en valor y aglutinando todo el conocimiento, tecnología y experiencia acumulada en los últimos 30 años en el control de riego, el clima y la fertirrigación.

La prioridad fue buscar una solución holística a todo lo expuesto en el apartado anterior y englobarlo todo bajo una única plataforma y equipo compacto de fácil instalación y manejo.

Para ello, desarrollamos todo un sistema inteligente y compacto alimentado con diferentes tipos de tecnología para un control total de todo aquello que influye de manera directa sobre la rentabilidad de un cultivo y el manejo de la explotación (Figura 1).

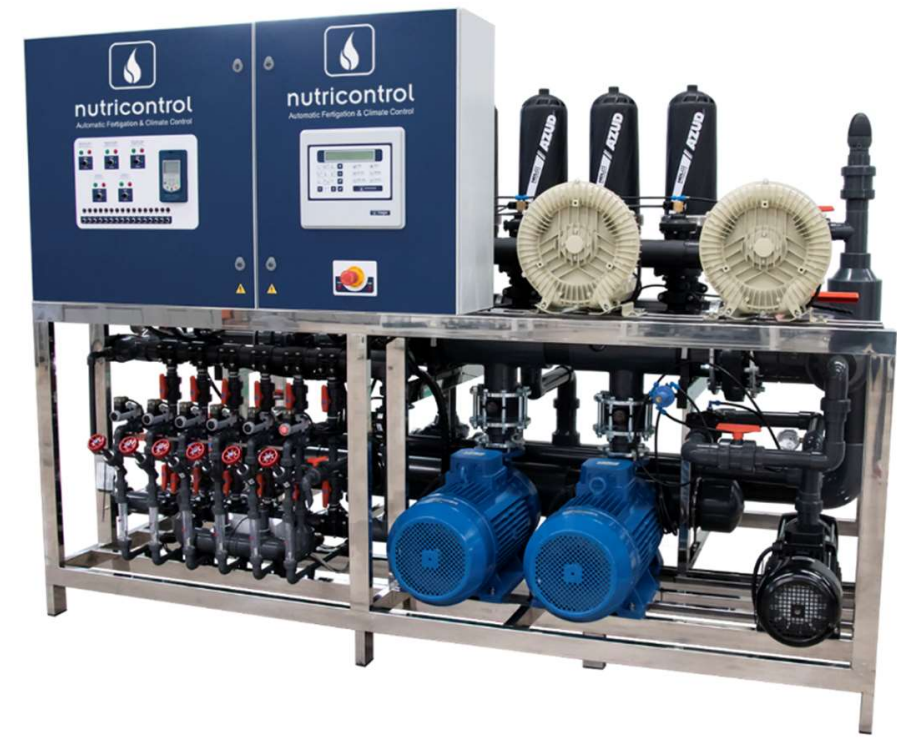

Figura 1. Solución de cabezal compacto inteligente.

El equipo desarrollado integra, bajo una única estructura compacta, todos los elementos necesarios para un control inteligente de todo el sistema de riego, fertirrigación y clima:

- Controlador de riego (Mithra Riego; Figura 2) capaza de manejar hasta 3 cabezales de riego de forma totalmente independientes, comandar hasta 200 válvulas ya sea por cable o de forma inalámbrica y controlar todos los elementos de la instalación. También es posible ampliar las prestaciones del mismo, únicamente a través de un código sin necesidad de cambiar el equipo o mandarlo a fábrica. 


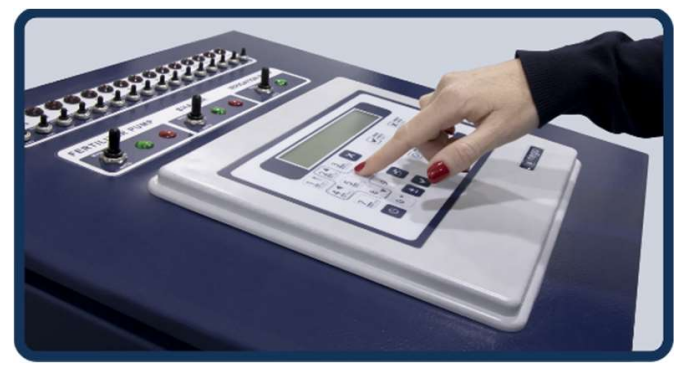

Figura 2. Controlador de riego Mithra

- Sistema de bombeo para presurizar la instalación siempre manejado con variadores que controla el mismo sistema de control de riego (Mithra Riego) con diferentes consignas de presión dependiendo del sector de riego.

- Sistema de filtrado de anillas aire - agua (Azud) dimensionado según las características de la instalación, fuente de agua y los volúmenes de agua a tratar.

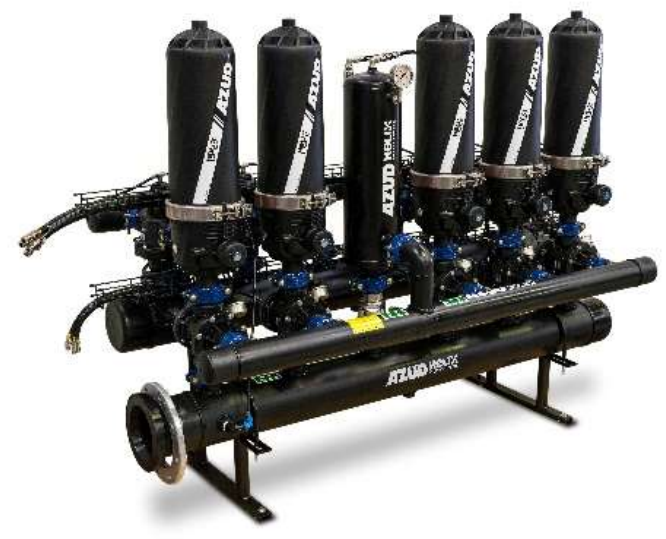

Figura 3. Sistema de filtrado de anillas aire - agua

- Contador de agua con emisor de pulsos para controlar los volúmenes de riego aportados y permitir un riego por volumen. Podemos disponer de los volúmenes de agua consumidos por cada sector o válvula.

- Equipo de fertirrigación con hasta 9 líneas de inyección que controla de forma automática el pH y la CE de hasta 20 recetas de abonado diferentes. Sistema multi inyección para poder aportar diferentes abonos a la vez y controlando en todo momento el $\mathrm{pH}$ de la mezcla para evitar precipitados.

- Sistema de inyección analógico: la inyección de los fertilizantes podemos controlarla con dos sistemas dependiendo del caudal a inyectar.

Si es necesario inyectar cantidades inferiores a $600 \mathrm{~L} / \mathrm{h}$, se controlará de forma automática con una nueva válvula motorizada (NUCON) desarrollada bajo las especificaciones de Nutricontrol para un control mucho más preciso y lineal de la $\mathrm{CE}$, el $\mathrm{pH}$ y el aporte de los fertilizantes. 
Si los caudales de inyección son mayores, podemos llegar a una inyección de hasta 1800 1/h por cada línea de inyección.

En ambos casos, hemos desarrollado un sistema de inyección que permite inyectar una mayor cantidad de abono y que, además, está diseñado para poder trabajar con abonos orgánicos, eliminando los riegos de obturaciones del sistema como consecuencia de las densidades, impurezas y texturas de estos abonos orgánicos y bioestimulantes.

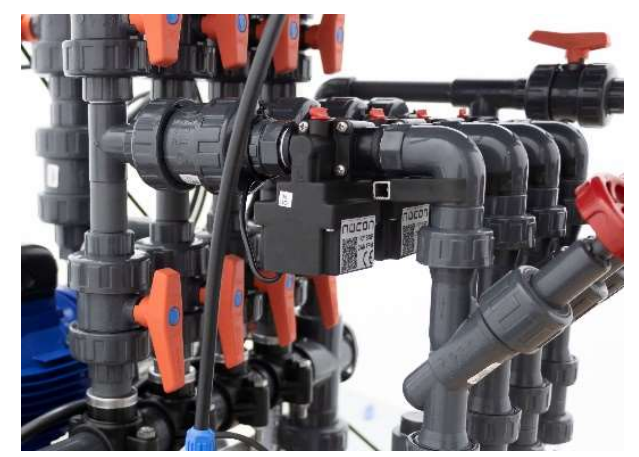

Figura 4. Sistema de inyección con válvulas Nucon.

- Contadores de abono por ultrasonidos. Estos contadores nos permiten realizar un abonado mucho más preciso, conociendo y aplicando exactamente las dosis necesarias en cada momento. Combinado junto con el contador de abono, podemos realizar un abonado por volumen y lo más importante, repartirlo durante todo el tiempo de riego para un reparto más uniforme a lo largo del bulbo húmedo.

- Sensores de suelo: El equipo permite programar el riego en función a parámetros de suelo obtenidos a través de diferentes sensores que midan la humedad del suelo (\%) o el potencial matricial. También podemos tener lectura de la $\mathrm{T}^{\mathrm{a}} \mathrm{y}$ la $\mathrm{CE}$ del suelo y cálculos como el agua disponible, punto de recarga, punto de marchitez, etc.

- Sensores de clima: Podemos también programar el riego en función a factores ambientales como la radiación o como la ETo o la ETc. Y cálculos como el DPV, punto de rocío, horas frio, DH, etc

- Con los valores de los sensores de clima, también disponemos de sistemas predictivos para ciertas enfermedades y ciertos cultivos, integral térmica, etc.

- Imágenes de satélite, que permiten disponer de valores como el NDVI, índice usado para estimar la cantidad, calidad y desarrollo de la vegetación con base a la medición de la intensidad de la radiación de ciertas bandas del espectro electromagnético que la vegetación emite o refleja y nos permite identificar problemas o nos ayuda a tomar decisiones de por dónde empezar a comprobar.

También podemos disponer de índices de humedad, integral térmica o necesidades de riego. 
- Comunicación web: Toda la información generada, que registrada en un servidor en la nube pudiendo consultar y cambiar parámetros desde cualquier dispositivo móvil om Pc con acceso a internet.

- Comunicación con otros dispositivos: Otra de las ventajas de disponer de todos los datos en la nube, es que podemos comunicarlos con otros dispositivos instalados en la explotación e interactuar entre ellos. Es posible que el agricultor disponga de sistemas de monitoreo (datalogger) y que la información recogida por estos dispositivos, pueda ser compartida bajo la misma plataforma que gestiona el riego, un mismo usuario y sin necesidad de tener que acceder a diferentes plataformas con usuarios y formas de operar diferentes.

- Compartir los datos con otros sistemas: El sistema desarrollado por Nutricontrol permite compartir los datos generados a través de la API (Application Programming Interface) para poder incorporarlo al sistema SCADA de cada cliente y poder hacer un uso más eficiente de los datos.

\section{Resultados obtenidos}

Con la integración de todos los sistemas y tecnologías anteriormente descritas, hemos conseguido dar solución a muchos de los problemas que aparecían a la hora de poder implementar tecnología que nos ayude a una agricultura de mayor precisión y sostenibilidad.

Entre los problemas que se han podido solventar o mejorar se encuentran:

- 3.1. Una mayor internacionalización de las soluciones tecnológicas;

El hecho de haber estandarizado la fabricación y haberlo hecho escalable y compacto, permite poder exportar la tecnología de una manera más sencilla y fácil para el cliente final. Dispone de un único proveedor y de un producto que el cliente lo recibe montado, probado y programado de fábrica, lo que reduce los imprevistos del montaje y la mano de obra en un 35\% con respecto a una instalación tradicional. Ya que en ocasiones es difícil encontrar mano de obra especializada. Además de asegurarnos la compatibilidad de funcionamiento de todos los elementos.

\section{- 3.2. Una mayor eficiencia energética;}

El uso de variadores para controlar las bombas de riego de forma autónoma desde el equipo y con consignas diferentes de presión dependiendo del sector, combinado con el uso de sensores de humedad de suelo o potencial matricial, optimiza el consumo eléctrico y el diseño de la instalación de riego, ya que permite modificar las estrategias de riego en función a dichos sensores, optimizar los tiempos y frecuencias de riego, consiguiendo ahorros energéticos de entre un 20 y un $40 \%$ con respecto al manejo de un cabezal de riego tradicional.

El optimizar los tiempos de riego, ajustarlos y no aplicar el riego más de lo estrictamente necesario, conlleva también un aumento de la vida útil de la instalación y de todos sus elementos, ya que estamos reduciendo las horas de funcionamiento de cada uno de ellos. 


\section{Congreso Nacional de Riegos CARTAGENA 2021

Tabla 1. Ejemplo de ahorro energético obtenido en 1 ha de cítricos

\begin{tabular}{cccc}
\hline Cultivo & $\begin{array}{c}\text { Coste energé- } \\
\text { tico } € / \text { ha }\end{array}$ & $\begin{array}{c}\text { \% ahorro } \\
\text { energético }\end{array}$ & $\begin{array}{c}\text { Ahorro } \\
(€ / \text { ha })\end{array}$ \\
\hline $\begin{array}{c}\text { Cítricos } \\
1 \text { ha }\end{array}$ & 917,28 & $35 \%$ & 321,0 \\
\hline
\end{tabular}

Precio del kW/h: 0,15€

- 3.3. Optimización del agua de riego;

La instalación de sensores de suelo para medir el agua útil disponible, la capacidad de campo, punto de marchitez, unto de recarga y conocer la profundidad del perfil de riego, permite conocer la disponibilidad y el consumo necesario para el cultivo en cada momento y en función a su estado fenológico. El uso de estos sensores de suelo, junto con el de variables climáticas que nos permiten conocer y calcular parámetros como la Etc, junto con el uso de contadores, permiten modificar los tiempos, frecuencias y dosis de agua de riego, pudiendo aportar lo estrictamente necesario en cada momento del ciclo del cultivo, evitando perdidas por escorrentías o percolación.

También nos permite conocer cuando está activo el sistema radicular y conocer el momento óptimo de aplicación de los fertilizantes.

El ahorro de agua con el uso de sensores de suelo y clima, permite ahorrar en general, entre un 20 y un $40 \%$ con respecto a los planes de riego tradicionales. 
Tabla 2. Ahorro hídrico con sensorización en diferentes cultivos

\begin{tabular}{llc}
\hline \multicolumn{1}{c}{ CULTIVO } & \multicolumn{2}{c}{$\begin{array}{c}\text { NECESIDADES HÍDRI- } \\
\text { CAS } \\
\text { Ahorro 20\% (€/ha) }\end{array}$} \\
\hline AGUACATE & 3.400 & 680 \\
\hline ALMENDRO SETO & 2.600 & 520 \\
\hline ARÁNDANOS & 2.280 & 456 \\
\hline CIRUELA & 2.000 & 400 \\
\hline FRESA & 2.280 & 456 \\
\hline LIMÓN & 2.400 & 480 \\
\hline MANZANA & 2.960 & 592 \\
\hline MELOCOTÓN & 2.800 & 560 \\
\hline MELÓN & 2.400 & 480 \\
\hline NARANJO & 2.800 & 560 \\
\hline OLIVO & 1.600 & 320 \\
\hline PERA & 1.600 & 320 \\
\hline UVA & 2.480 & 496 \\
\hline PATATA & 1.200 & 240 \\
\hline
\end{tabular}

*Precio del agua $0,4\left(€ / \mathrm{m}^{3}\right)$

También el uso de sistemas de filtrado de alta eficiencia (aire/agua) permite disminuir los tiempos de limpieza, consiguiendo un ahorro de hasta un $80 \%$ del agua empleada en la limpieza con respecto a sistemas de filtrado estándar.

\subsection{Ahorro de fertilizantes}

El poder combinar en las lecturas diferentes valores de CE en la solución nutritiva de abonado, los contadores de abono en cada línea de inyección y los valores de CE en suelo a través de sensores de suelo, permite ajustar el aporte de fertilizantes según las necesidades de cada momento del cultivo. Controlar la CE de una solución nutritiva de abonado es fundamental para mantener niveles elevados de rentabilidad y productividad, ya que determinados niveles de CE dificultan la absorción de los abonos disminuyendo la productividad, incluso pudiendo llegar a ocasionar contaminación de las aguas subterráneas o un empobrecimiento del suelo. 
Tabla 3. Ahorro obtenido por el control de la CE para diferentes cultivos

\begin{tabular}{|c|c|c|c|}
\hline \multirow{3}{*}{ CULTIVO } & \multicolumn{3}{|c|}{$\mathrm{CE}$} \\
\hline & \multirow{2}{*}{$\begin{array}{c}\mathrm{CE} \\
\text { ideal }\end{array}$} & \multicolumn{2}{|c|}{ Pérdidas $(25 \%)$} \\
\hline & & $\mathrm{CE}$ & $€ /$ ha \\
\hline AGUACATE & 0,9 & 1,7 & 5.276 \\
\hline $\begin{array}{l}\text { ALMENDRO } \\
\text { SETO } \\
\end{array}$ & 1,0 & 1,9 & 2.164 \\
\hline $\begin{array}{l}\text { ARÁNDA- } \\
\text { NOS }\end{array}$ & 0,7 & 1,4 & 14.736 \\
\hline CIRUELA & 1,0 & 1,9 & 4.098 \\
\hline FRESA & 0,7 & 1,2 & 15.218 \\
\hline LIMÓN & 1,1 & 2,2 & 3.927 \\
\hline MANZANA & 1,0 & 2,2 & 6.290 \\
\hline $\begin{array}{l}\text { MELOCO- } \\
\text { TÓN } \\
\end{array}$ & 1,1 & 1,9 & 4.759 \\
\hline MELÓN & 1,5 & 3,8 & 2.979 \\
\hline NARANJO & 1,1 & 2,2 & 1.843 \\
\hline OLIVO & 1,8 & 3,7 & 939 \\
\hline PERA & 1,0 & 2,2 & 3.695 \\
\hline UVA & 1,0 & 2,7 & 6.914 \\
\hline PATATA & 1,1 & 2,5 & 3.652 \\
\hline
\end{tabular}

*Precios percibidos por los agricultores 2019/2020 (MAPA)

$\mathrm{Al}$ igual ocurre con el $\mathrm{pH}$, es fundamental mantener niveles ácidos en el abonado (5,5-6,5) para conseguir que la mayor parte de los elementos nutritivos estén disponibles para ser absorbidos por la planta.

\subsection{Eliminación de las obsturaciones del sistema y mayor presición de inyección;}

Uno de los retos que nos encontrábamos cuando se requería el aporte de abonos orgánicos, eran los problemas de obturación del sistema de fertirrigación sobre todo a nivel de valvulería y emisores.

Para evitar obturaciones del sistema de inyección y aplicación de los fertilizantes, se desarrolló una válvula (Figura 5) de un paso de líquido mayor a las utilizadas hasta el momento, pero sin perder precisión en la inyección y control de la $\mathrm{CE}$ y el $\mathrm{pH}$. 


\section{Congreso Nacional de Riegos CARTAGENA 2021

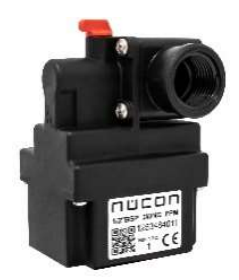

Figura 5. Válvula de control de inyección (Nucon)

La válvula dispone de un control analógico y lineal, mucho más preciso y estable que el control por pulsos utilizado comúnmente. Incluso con un sistema de seguridad de cierre en el caso de un corte de corriente eléctrico que evitaría que la válvula se quedara abierta ocasionado el vaciado de los tanques de abonado.

Esta válvula permite un control muy preciso de caudales de abono de entre 50 y $600 \mathrm{~L} / \mathrm{h}$ por cada línea de inyección, ideal para culticos sensibles a los cambios de $\mathrm{CE} \mathrm{o} \mathrm{pH.}$

Con este sistema de inyección, combinado con el sistema de filtrado aire/agua, resolvimos el problema de las obturaciones del sistema de inyección con el uso de abonos orgánicos y aumentamos la precisión en el control continuo de la CE.

\subsection{Reducción de los tratamientos y la aplicación de materias activas;}

El poder medir parámetros como la Ta , la HR (\%), radiación, la humectación en hoja, etc, nos permite desarrollar modelos predictivos de enfermedades lo que nos puede llevar a realizar los tratamientos únicamente en los momentos de mayor probabilidad del desarrollo.

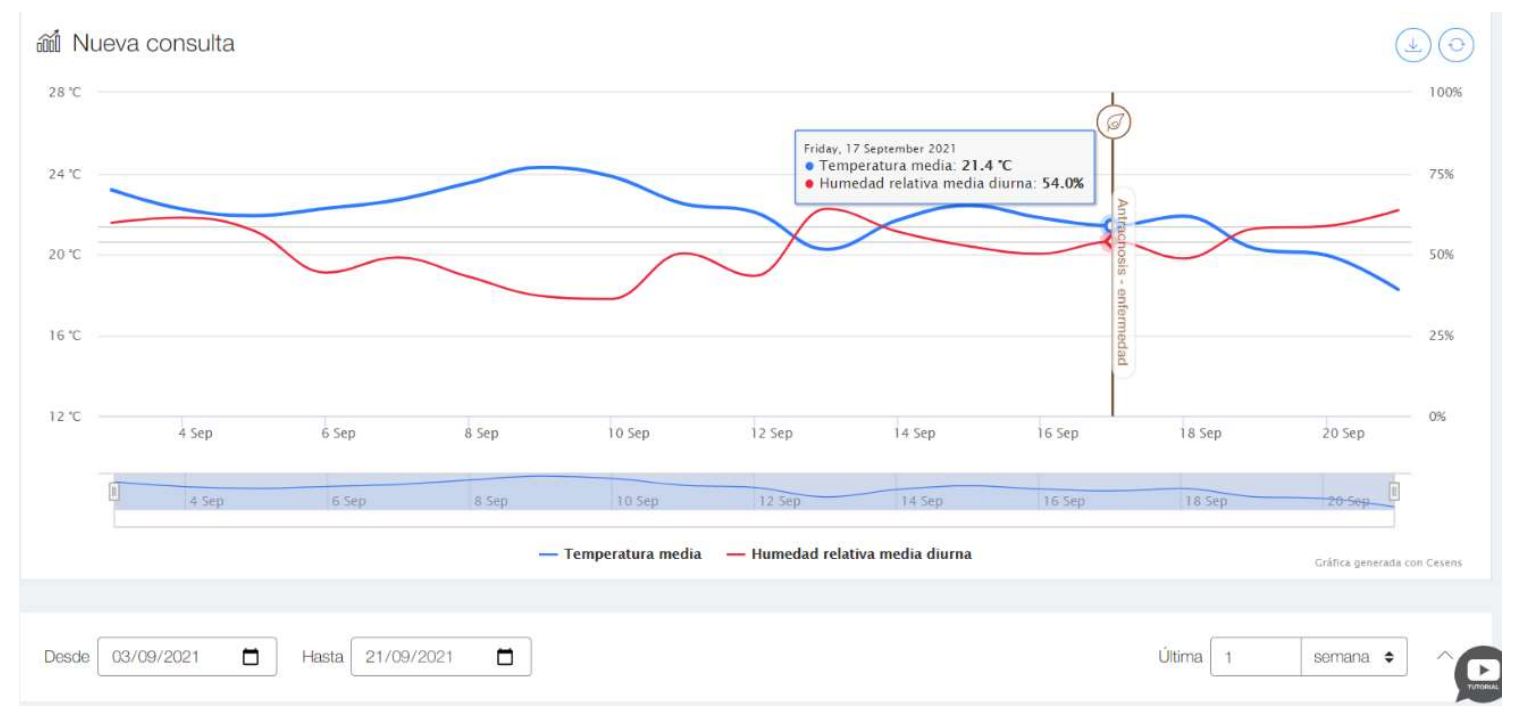

Figura 6. Evolución de temperatura y humedad y probabilidad de aparción de Antacnosis.

También, el cálculo de la integral térmica nos puede ayudar a calcular los ritmos vitales de plagas y enfermedades. Insectos, hongos y bacterias también responden y se desarrollan en función de una integral térmica. De esta forma, según las previsiones meteorológicas podemos 


\section{Congreso Nacional de Riegos CARTAGENA 2021}

anticiparnos a la aparición de una plaga o enfermedad y hacer el tratamiento oportuno de forma preventiva únicamente si se dan las condiciones idóneas.

\subsection{Control integral bajo una única plataforma;}

La plataforma web permite controlar todos los parámetros propios del cabezal, pero también posibilita poder conectar otros dispositivos bajo un mismo usuario.

Podemos disponer de datalogger repartidos por la explotación, monitorizando diferentes parámetros a lo largo de la misma y tenerlos vincularlos dentro de la misma plataforma web de control del riego y la fertirrigación para poder consultarlos de forma conjunta sin necesidad de disponer de diferentes plataformas.

Esto permite facilitar la experiencia de usuario en el manejo y consulta de los datos, no perder tiempo innecesario pasando de una plataforma a otra, y sobre todo, poder disponer y trabajar con los datos de varios dispositivos de forma autónoma y sencilla, tal y como se aprecia en la Figura 7.
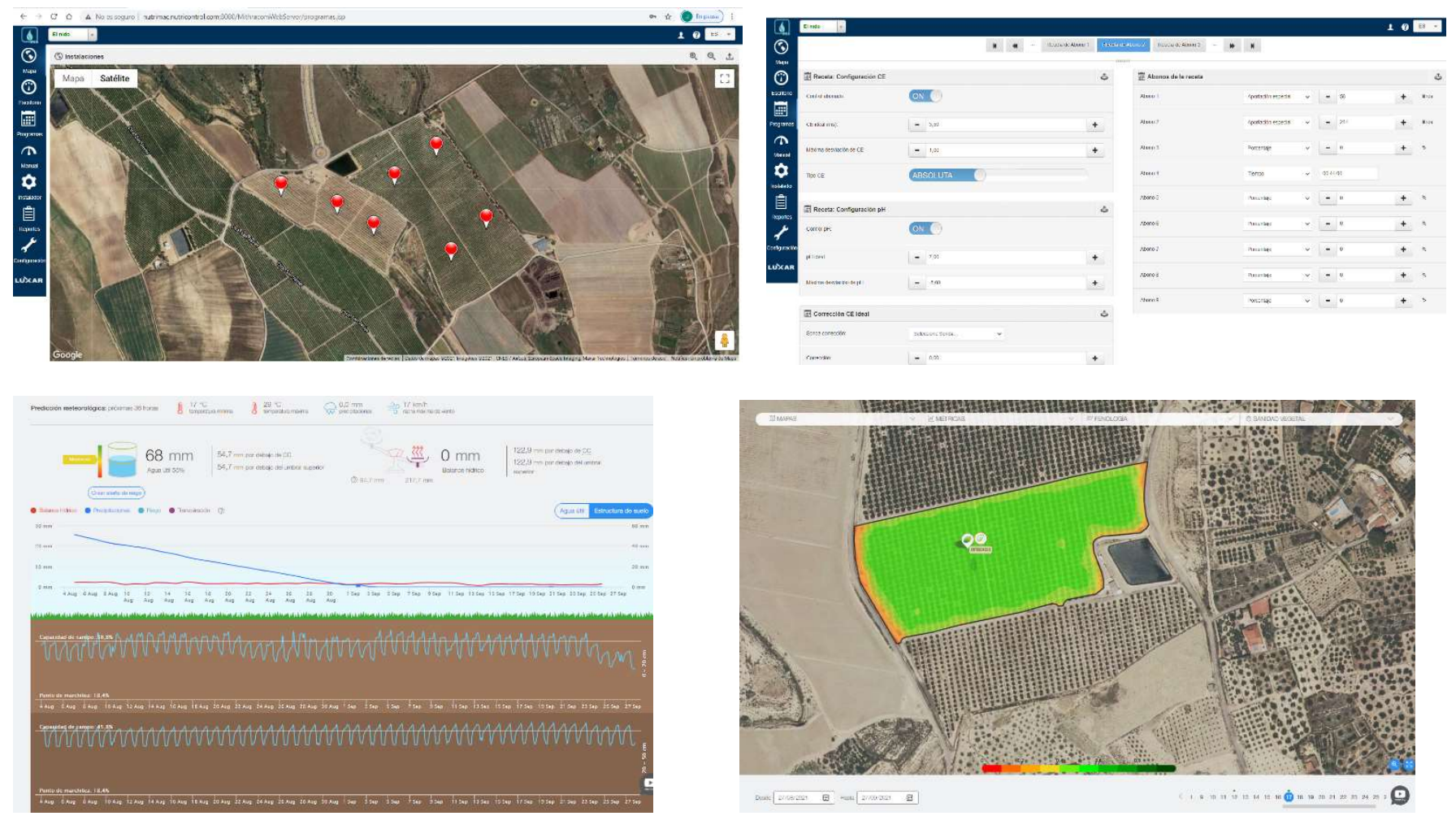

Figura 7. Integración de todas las medidas y control en plataforma web. 


\section{Conclusiones}

Nos encontramos en un cambio hacia la digitalización del campo y hacia una democratización de los datos por lo que, tenemos que aportar soluciones de valor y precisas que nos permitan elegir las estrategias más adecuadas para el manejo del riego y la fertirrigación.

Además, tenemos que apoyarnos en la aplicación de la tecnología y en el desarrollo de nuevos productos y sistemas encaminados a evolucionar y movernos para ser el cambio que queremos ver en la agricultura. Adaptándonos a las nuevas necesidades de la sociedad sin perder competitividad y que el agricultor pueda seguir siendo agricultor. Todo esto es imposible de alcanzar sin la utilización y desarrollo de tecnología en todos los procesos de producción de una explotación agrícola, la incorporación de sensórica y un trabajo posterior de analisis y evaluación de los datos generados con los sistemas instalados.

Para facilitar este trabajo, reducir costes energéticos, de fertilizantes y agua, se ha integrado toda la sensórica en un cabezal compacto que ha permitido ahorros energéticos de hasta un $35 \%$, un $20 \%$ en consumos hídricos y un $25 \%$ en ahorro de fertilizantes, constatado en diferentes cultivos. Asimismo, se ha facilitado al agricultor una plataforma amigable de fácil consulta que integra toda la información de los sensores, modelos predictivos y volcado sobre planos, para facilitar la toma de decisiones y cumplir con ello los objetivos de sostenibilidad marcados. 


\title{
Innovar para una Agricultura Circular. Única Estrategia So- tenible
}

\author{
Juárez, J. ${ }^{1}$, Munuera Pérez, M T. ${ }^{2}$, Masdemont Hernández, B. ${ }^{3}$
}

\footnotetext{
1 Sistema Azud, Alcantarilla, Murcia, (España); jjuarez@azud.com

${ }^{2}$ Sistema Azud, Alcantarilla, Murcia, (España); tmunuera@azud.com

${ }^{3}$ Sistema Azud, Alcantarilla, Murcia, (España); beatriz@azud.com
}

\section{Resumen:}

Surgir en una de las regiones más áridas de Europa, en un contexto de profunda escasez de recursos hídricos convencionales ha impulsado desde sus orígenes la misión de AZUD, que siempre ha estado ligada a "La Cultura del Agua".

Cada uno de los pasos que ha dado en estos últimos 30 años ha marcado su trayectoria convirtiéndose en una de las empresas líderes en la eficiencia en el uso de agua dentro del sector agrícola, industrial y medioambiental. Crecer de forma continua y progresiva, ha sido el reto de AZUD, apostando como clave en su estrategia a largo plazo, por una inversión continua en I+D+i.

Actualmente AZUD, apuesta por liderar la transformación radical de los sistemas de aplicación de agua en agricultura, industria y medioambiente, convencida de que solo con la integración de todos los agentes y herramientas se garantizará una gestión del agua más inteligente, más circular.

Inmersos en esta filosofía mantiene activos proyectos destinados a desarrollar sistemas de filtración autolimpiantes de alto rendimiento, regeneración de aguas y su uso reglado en agricultura, líneas de fabricación de tubería de micoirrigación de alta velocidad, sistemas de riego inteligentes para riego subterráneo, dispositivos de acondicionamiento de purines y valorización de residuos mediante filtración por discos, aditivación de emisores con efecto inhibidor de biofilm, o repelentes de agentes dañinos de efecto mecánico, utilización de ciclodextrinas con efecto inhibidor de intrusión radicular, etc.....

La experimentación más básica realizada en diferentes ámbitos en colaboración con universidades y centros de investigación de todo el país, les permite no solo abrir nuevos campos de ideas, detectar necesidades del sector, creando estrechas alianzas con empresas que enriquecen hoy su negocio actual, sino generar líneas futuras de desarrollo que son incorporadas al día a día del usuario.

Palabras clave: agricultura de precisión; riego; reutilización; valorización 


\section{Problemática abordada}

La ONU asegura que en 2050 se espera que la población mundial llegue a 9.000 millones y que para su alimentación será necesario incrementar la producción de los cultivos en un 50\%, por lo que los gobiernos de todo el mundo impulsan estrategias para producir más, optimizando la gestión de los recursos, y consumir menos, generando menor impacto ambiental, con el fin de alcanzar un equilibrio sostenible a través de un nuevo modelo económico más circular. Además, un nuevo consumidor ha irrumpido en la sociedad con un perfil más exigente, mucho más concienciado e informado en sistemas de producción y en su impacto ambiental y en su salud, demandando una correcta gestión de los recursos en la agricultura.

La FAO insiste en que este desafío sólo será factible a través de estrategias de diversificación en la agricultura, por lo que es preciso investigar para desarrollar soluciones innovadoras y viables que provoquen una nueva revolución agrícola, que generen un incremento en la producción sostenible de alimento aplicando prácticas agrícolas resilientes, que contribuyan al mantenimiento de los ecosistemas, fortalezcan la capacidad de adaptación al cambio climático, a los fenómenos meteorológicos extremos, las sequías, etc. y cooperen en la conservación de suelos, optimizando los recursos productivos.

Desde que los sistemas de riego por goteo revolucionaron la agricultura, el sector agrícola ha participado año tras año en el incremento de los rendimientos que la sociedad demanda, optimizando recursos cada vez más escasos, y convirtiéndose en una herramienta estratégica imprescindible para conseguir una agricultura sostenible $\mathbf{y}$ eficiente ya que consume el $\mathbf{8 0} \%$ de un escaso recurso; el agua.

Las empresas dedicadas a la optimización del uso del agua dirigen sus desarrollos a la implementación de tecnología para incrementar su rendimiento, adaptándose a los requerimientos de diferentes escenarios en todo el mundo: cultivos dispares, distintas estaciones de producción, variabilidad en la calidad y cantidad de los recursos disponibles, etc... siendo ya una realidad al alcance del usuario final una amplia gama de sistemas muy eficientes dirigidos al control de la aplicación del agua y de los nutrientes en la explotación, y sobre todo a extraer el máximo aprovechamiento de unos recursos que hasta hace unos años se rehusaban.

En el sector agrícola y ganadero, la recuperación y gestión de los residuos ha pasado de ser una preocupación para convertirse en una etapa productiva más; una nueva tendencia de un sector que, empujado por normativas cada vez más exigentes, consume anualmente más de doscientos millones de toneladas de nutrientes de procedencia mineral fósil (IFA; Asociación Internacional de la Industria de Fertilizantes).

Esta nueva visión de economía circular se presenta como una importante oportunidad para que las soluciones más innovadoras den un paso hacia adelante y abandonen las plataformas de investigación convirtiéndose en aplicaciones confiables y desarrollos de empresas. De esta forma, desde AZUD estamos colaborando en un gran número de proyectos dirigidos a la puesta en marcha de instalaciones autosostenibles que innovan para romper el modelo convencional de producción y avanzar hacia una agricultura circular que minimice su impacto ambiental y maximice la reutilización de los residuos, desarrollando diferentes soluciones avanzadas que 
contribuyan a mejorar y optimizar la eficiencia del uso del agua, la reutilización y la valorización de subproductos procedentes de la producción agrícola-ganadera. Un ejemplo de ello, son proyectos de I+D+i como DIRELMIVID (2I20SAE0007), actualmente en ejecución, o ya finalizados como BIOREFINA (ITC-20161161), ó REUSAGUA (2I16SAE00165) con impacto directo en el sector a través de soluciones ya aplicadas en el mercado como el caso de la Gestión Ambiental de ESTANCIAS DEL LAGO expuesto a continuación.

\section{Descripción de la innovación}

Concienciado e influido por un nuevo escenario social, el grupo de empresas del complejo agroindustrial San Pedro de ESTANCIAS DEL LAGO (Uruguay), destinado a la producción de leche en polvo, se planteó un modelo sostenible de producción agrícola alineado con las tendencias en economía circular y eficiencia en el uso de los recursos para la producción intensiva de leche en polvo. El plan; alimentación de ganado con forraje cultivado en proximidad, mediante recuperación y gestión de residuos orgánicos y efluentes del propio proceso productivo. Incluyendo además, la generación y el autoconsumo de la energía eléctrica y térmica requeridas en distintos procesos, a partir de biogás.

El concepto, lógico, conlleva alta complejidad por la integración de todas las etapas del proceso productivo de forma equilibrada y sostenible, desde la siembra, la generación de alimento para el ganado, hasta la producción y envasado de leche en polvo. Todo ello, mediante la optimización y revalorización de recursos y subproductos.

\begin{tabular}{|l|r|l|}
\hline \multicolumn{3}{|c|}{ DATOS DE LA INSTALACIÓN } \\
\hline Vacas estabuladas & 15.600 & un \\
\hline Vacas en ordeñe & 13.000 & un \\
\hline Explotación agrícola & 16.000 & $\mathrm{ha}$ \\
\hline Generación de efluentes & 930.000 & $\mathrm{~m}^{3} /$ año \\
\hline
\end{tabular}

Fig. 1. Datos de la instalación

En esta línea de minimización de la huella de la actividad y del impacto ambiental, la interrelación entre los flujos de entrada y salida de las diferentes plantas ha sido una pieza clave. Por ello, se trazó un sistema efectivo de recogida de efluentes de diferentes procesos (agua de la planta de procesamiento de leche en polvo, agua de lavado de las plataformas de ordeñe, agua de enfriamiento, agua de los establos, agua de lavado por flushing, residuos y desechos de comida, desechos de animales, etc.).

Se trata de efluentes cargados de restos orgánicos generados en distintos procesos de la explotación, por tanto, con distintas calidades de agua. Su aprovechamiento se realiza a través de sistemas de irrigación con el fin de producir alimento para el ganado como soja, trébol persa o maíz. La complejidad de la explotación requiere una solución articulada por diferentes tecnologías y aplicaciones de ingeniería. AZUD formó parte de estas soluciones permitiendo el acondicionamiento de estas corrientes para su reutilización en riego.

El esquema de flujo comienza con la dirección de los efluentes a la planta de generación de biogás donde. Tras la digestión anaerobia el efluente se separa mecánicamente dando lugar a dos corrientes, una compuesta por material sólido y otra líquida. 
Los sólidos suponen $142 \mathrm{Tn} /$ día y contienen entre un $60 \%$ y un 70\% de humedad. Esta corriente es diferenciada según el tamaño de la fibra y se emplea como cama de vacas o bien como fertilizante sólido. Por otra parte, la corriente líquida, que supone más de $2.500 \mathrm{~m}^{3} /$ día, se almacena en balsas de acondicionamiento, durante 15 días y se utiliza tanto en fertirrigación y como en diversos procesos de la planta mezclada al $50 \%$.

La corriente líquida del efluente digerido y acondicionado tiene como destino su empleo como solución nutritiva de los cultivos de la explotación y completando el círculo.

Para permitir la aplicación de este efluente a través del sistema de riego es necesario su acondicionamiento previo. Se requiere una filtración para garantizar que no ingresen partículas al interior del sistema de irrigación que puedan llegar a obturarlo.

Aunque la concentración de sólidos en suspensión del fluido digerido se reduce a su paso por las balsas de almacenamiento, el riesgo de obstrucciones en el sistema se evalúa considerando la naturaleza de estos sólidos que son de origen orgánico e inestables, así como las condiciones de almacenamiento a las que son sometidos, pues resultan determinantes ya que favorecen su proliferación.

\begin{tabular}{|c|c|c|c|}
\hline $\begin{array}{c}\text { EFLUENTE } \\
\text { DIGERIDO }\end{array}$ & $\begin{array}{c}\text { EFLUENTE LÍQUIDO } \\
\text { SEPARADO }\end{array}$ & $\begin{array}{c}\text { SALIDA BALSA } \\
\text { FACULTATIVA }\end{array}$ & $\begin{array}{c}\text { SALIDA BALSA } \\
\text { PARA RIEGO }\end{array}$ \\
\hline $400-500 \mathrm{mg} / \mathrm{l}$ & $250-350 \mathrm{mg} / \mathrm{l}$ & $100-200 \mathrm{mg} / \mathrm{l}$ & $<60 \mathrm{mg} / \mathrm{l}$ \\
\hline
\end{tabular}

Fig. 2 Contenido de carga orgánica de diseño

Todas estas características suponen un reto técnico y requieren, para garantizar la efectividad del proceso de adecuación del agua a los niveles de calidad requeridos, la aplicación de nuevas tecnologías que aporten garantías de mantenimiento de la calidad del agua durante la fase de filtración y una alta capacidad de regeneración de los medios filtrantes durante la fase de autolimpieza.

La solución aportada por AZUD permite garantizar la calidad del agua requerida por la aplicación manteniendo como objetivo la sostenibilidad del proceso y la viabilidad a lo largo de toda la vida útil de los componentes pertenecientes al sistema de riego de la instalación.

Apostando por diferentes tecnologías en función de las condiciones de partida y de los objetivos buscados, el innovador proceso de tratamiento seleccionado incluye dos sistemas de filtración instalados en serie, con funciones claramente diferenciadas, y adecuados tanto a los niveles de carga como a las características del material particulado en suspensión contenido en el agua.

- SISTEMA FILTRACION 1: AZUD LUXON LKM con superficie de $26.400 \mathrm{~cm}^{2}$ y grado de filtración en malla de 800 micras.

- SISTEMA FILTRACION 2: AZUD HELIX AUTOMATIC AA con superficie unitaria de $64.800 \mathrm{~cm}^{2}$ y grado de filtración en disco de 200 micras. 


\section{CXeAro}

CARTAGENA 2021
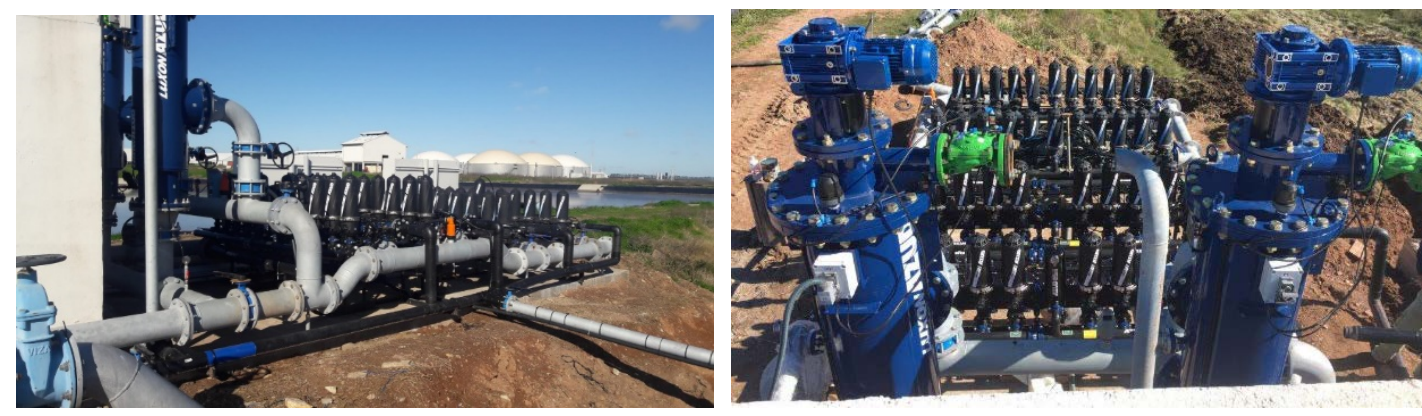

Fig. 3 Imagen de la Estación de acondicionamiento

Fruto de la investigación y la innovación, AZUD dispone de un diseño exclusivo del elemento filtrante instalado en todos sus sistemas de filtración donde incluye la tecnología patentada HELIX que permite que el fluido que entra al filtro adquiera un movimiento helicoidal alejando las partículas de la superficie filtrante, lo que tiene un efecto de retardo de la colmatación, de esta forma permite un mayor aprovechamiento del agua y una menor generación de aguas de rechazo.

El funcionamiento de los filtros de discos consta de dos procesos diferenciados: la filtración y el contralavado (figura 4). Durante la fase de filtración, el agua circula del exterior al interior de la columna de discos comprimida. De esta forma, las partículas quedan atrapadas en todos los discos. En función de sus dimensiones, las partículas quedarán retenidas en la superficie más externa de la pila de discos o bien sobre la superficie interna de cada uno, sobre los canales grabados en ellos. La coexistencia de ambos tipos de estrategias de filtrado permite que la capacidad de retención de los discos sea muy elevada independientemente de la geometría y la naturaleza de las partículas. También permite que éstos sean capaces, no sólo de retener sólidos superiores a un tamaño definido, es decir, al grado de filtración, sino también un elevado porcentaje de sólidos con un tamaño inferior, lo que reduce drásticamente la concentración de partículas en suspensión (figura 4a).

Durante la fase de contralavado, el agua filtrada cambia su sentido de paso y circula de dentro hacia afuera consiguiendo, gracias al diseño interno del elemento filtrante, que la columna de discos se despresurice. El agua es proyectada a través de las boquillas creando un efecto tangencial de limpieza de los discos (figura $4 \mathrm{~b}$ ).
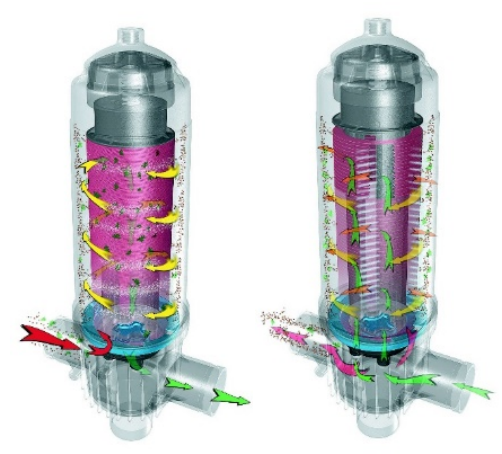

Figura 4. Funcionamiento de filtros de discos: a) filtración; b) contralavado. 


\section{Resultados obtenidos}

De las 16.000 hectáreas cultivadas en el complejo, el 13\% son de regadío.

La superficie de riego se divide en dos partes "El Mirador" con una extensión de 1.140 ha y riego sectorizado con aspersión a través de 17 equipos de pívots fijos, y "San Pedro" con una extensión de 958 ha y riego a través de 15 equipos de pívots fijos.

Los datos recogidos en el tiempo transcurrido desde su puesta en marcha, y la mínima frecuencia de operaciones no programadas de mantenimiento avala que la solución aportada por AZUD permite garantizar la calidad del agua requerida por la aplicación manteniendo como objetivo la sostenibilidad del proceso y la viabilidad a lo largo de toda la vida útil de los componentes pertenecientes al sistema de riego de la instalación.

El aprovechamiento de los nutrientes se realiza a través del agua filtrada, con garantía de calidad desde el punto de vista de ingeniería de aplicación, y con un caudal instantáneo de $300 \mathrm{~m} 3 / \mathrm{h}$, inyectandose en la red de transporte y distribución del agua para el riego de los cultivos forrajeros.

El primer sistema AZUD LUXON, retiene los sólidos de mayor tamaño presentes en la fuente de agua. El volumen de estos sólidos junto con sus características morfológicas y grado de adhesividad implican un alto grado de adherencia y una elevada capacidad tapizante de los mismos sobre el medio filtrante, por tanto, la elevada superficie filtrante instalada $\left(26.400 \mathrm{~cm}^{2}\right)$ unida a las características del elemento filtrante, un cilindro de acero inoxidable con una superficie microperforada -no trenzada-, así como las características del proceso de limpieza, que emplea el barrido por cepillo para la liberación de los sólidos retenidos sin vías de paso reducidas al no requerir boquillas de succión, permiten una alta efectividad en el proceso de filtrado, una reducida frecuencia de activación del proceso de autolimpieza y una elevada efectividad en la eliminación de sólidos de la superficie filtrante y su extracción al exterior de sistema.

La segunda etapa, AZUD HELIX AUTOMATIC AA, garantiza tanto la protección de los sistemas de emisión de agua pertenecientes al sistema de riego como el suministro del caudal demandado sin provocar interacciones hidráulicas asociadas al proceso de autolimpieza, gracias al sistema de limpieza asistido por aire, automático que permite trabajar con elevadas cargas de sólidos, incluso siendo éstos de naturaleza compleja, (sólidos orgánicos, filamentosos, deformables...).

Los equipos con sistema de limpieza apoyado por aire asistido (AA) resuelven de forma efectiva la problemática habitual ligada a los procesos de filtración de aguas verdes, realizando la limpieza de los elementos filtrantes con una elevada eficacia y un reducido consumo de agua, con tan solo 2 minutos para la limpieza de la totalidad de los elementos filtrantes de esta instalación, alcanzando un consumo extremadamente reducido de agua, 400 litros utilizados en cada ciclo completo de limpieza, y trabajando a presiones de operación no condicionadas por los requerimientos específicos del proceso de autolimpieza.

Esta innovación, puesta en el mercado, es un sistema es modular y eficiente respecto al espacio ocupado, la mano de obra y el consumo energético. Además, optimiza el rendimiento por litro de fertilizante producido, ya que permite que el balance de volumen de agua rechazada frente al volumen de agua filtrada presente una ratio superior a 100/10, permitiendo la producción continua de fertilizante para la inyección mediante riego. 
El estudio de los rendimientos productivos obtenidos en la campaña de 2017-2018, muestra siempre un valor superior en la producción de forraje en aquellas zonas que fueron regadas con el fertilizante generado en la propia explotación respecto al riego convencional, tanto en trébol persa $(2 \%)$ como en maíz $(10 \%)$.
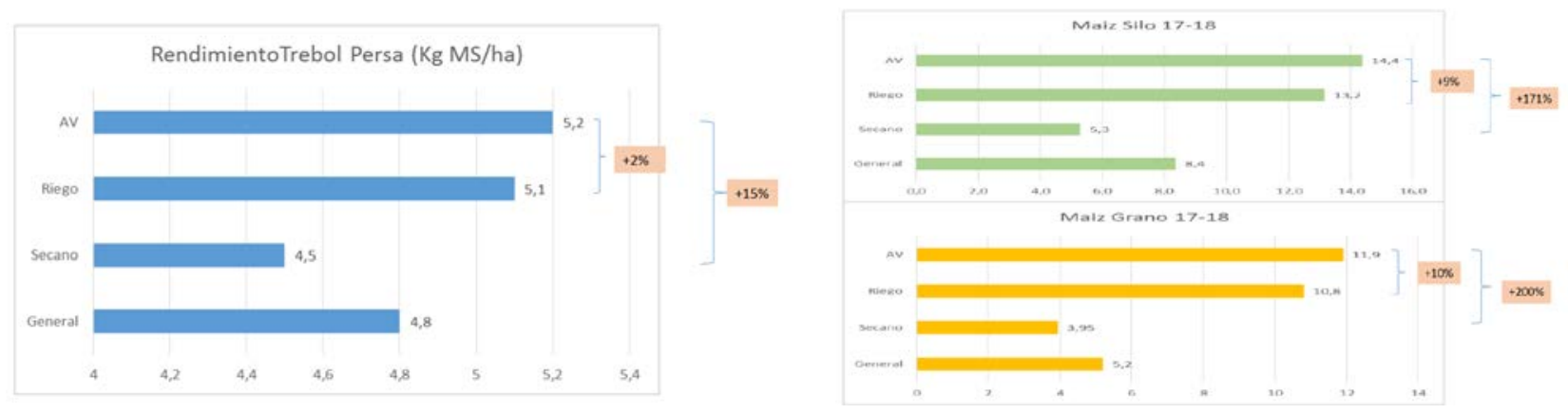

Fig 5. Rendimiento cultivos 2017/2018

\section{Conclusiones}

El proyecto ESTANCIAS DEL LAGO ha conseguido reducir la huella ambiental de su actividad agrícola y ganadera manteniendo la calidad de su producto así como su competitividad en los mercados internacionales y asociar su imagen al éxito de la Gestión Ambiental y la Responsabilidad Social.

Este éxito se debe a una visión sostenible de su proceso productivo y a un diseño integrador e inclusivo de etapas y subproductos que ha encontrado el equilibrio contrarrestando el impacto ambiental generado por la agricultura, mejorando la producción de los cultivos, reduciendo la aplicación de fertilizantes químicos y regenerando biológicamente los suelos afectados.

Para este objetivo, las soluciones innovadoras de AZUD han contribuido a optimizar la reutilización del agua y han permitido la revalorización de subproductos y efluentes procedentes de la producción agrícola-ganadera.

Los principales resultados a destacar:

- El riego con efluentes es viable gracias a su acondicionamiento con las soluciones avanzadas de filtración de AZUD que garantizan una alta efectividad del proceso de filtrado, una elevada eficiencia de regeneración de los sistemas de filtrado y una reducida frecuencia de activación del proceso de limpieza. Por tanto, consiguen minimizar la generación de residuos, mejorar la calidad del agua, proteger los sistemas de riego y, en definitiva, la eficiencia del proceso, el ahorro de recursos y la reducción del impacto industrial en el entorno.

- El aprovechamiento de los residuos y la obtención de "biofertilizante" con alta carga orgánica, nitrógeno, fósforo y potasio de origen renovable procedente de las deyecciones ganaderas propias y producido en la misma explotación, ha permitido a ESTANCIAS DEL LAGO reducir la adquisición y consumo de fertilizantes minerales de origen fósil en un $70 \%$. 


\begin{tabular}{|l|r|l|}
\hline Leche producida & $\mathbf{4 5 0 . 0 0 0}$ & L/día \\
\hline Leche en polvo & 20.000 & Tn/año \\
\hline Producción propia de grano & 17.000 & Tn/año \\
\hline Biocombustibles Generación de energía térmica & 2.300 & Tn/año \\
\hline Biofertilizantes sólidos & 230 & Tn/día \\
\hline
\end{tabular}

Fig. 6 Datos de producción

- Los análisis realizados indican que el efluente líquido:

o Promueve el equilibrio nutricional del suelo, aumenta su fertilidad y estimula los microorganismos beneficiosos, por tanto, aumenta su calidad sin dejar residuos tóxicos.

o Es rico en minerales, aminoácidos, vitaminas y hormonas, mejora el balance nutricional en la planta haciéndola más resistente al ataque de plagas y enfermedades, por tanto, puede considerarse un fertilizante efectivo y un firme competidor de los fertilizantes minerales.

En resumen, este caso demuestra que la producción intensiva sostenible es posible, pero es necesario la inclusión e integración de diferentes tecnologías e ingenierías, ya que es imprescindible la asociación de múltiples actores.

La agricultura y la ganadería pueden ser procesos circulares siempre que se apliquen los sistemas de tratamiento adecuados, por ello, el proyecto ESTANCIAS DEL LAGO no es una excepción. AZUD, cuenta con diferentes plataformas de trabajo con aguas complejas que contienen partículas cuyos tamaños llegan a oscilar desde $20 \mathrm{~mm}$ hasta por debajo de 5 micras dónde la concentración de sólidos en suspensión puede alcanzar los $35.000 \mathrm{mg} / \mathrm{l}$. Sin duda, uno de los puntos críticos del proceso reside en la estabilidad de los digeridos pero el sistema de filtración en serie propuesto por AZUD ha demostrado su capacidad de resiliencia y adaptación a las diversas condiciones de trabajo con garantía de éxito, un logro conseguido gracias a la participación de un gran equipo.

\section{Agradecimientos}

El trabajo recogido en este artículo forma parte de la de la convocatoria INTECONECTA en el proyecto BIOREFINERÍA DE PRODUCTOS FERTILIZANTES PARA AUTO CONSUMO EN EXPLOTACIONES HORTOFRUTÍCOLAS. enmarcado dentro de la convocatoria FEDER INNTERCONECTA 2016, subvencionado por el CDTI, apoyado por el Ministerio de Economía y Competitividad y cofinanciado con Fondos Estructurales de la Unión Europea dentro del Programa Operativo de Crecimiento Inteligente 2014-2020, así como del proyecto estratégico Ris3MUR REUSAGUA, financiado por la Consejería de Empresa, Industria y Portavocía (Gobierno de Murcia) en el marco del Programa Operativo FEDER 2014-2020. 
XXXVIII Congreso Nacional de Riegos CARTAGENA 2021

FEI-08-2021

Trabajo de Innovación

\section{CORENET- COREGEST}

SERVICIOS Y SISTEMAS PARA TRANSFORMACION DIGITAL DE LAS COMUNIDADES DE REGANTES
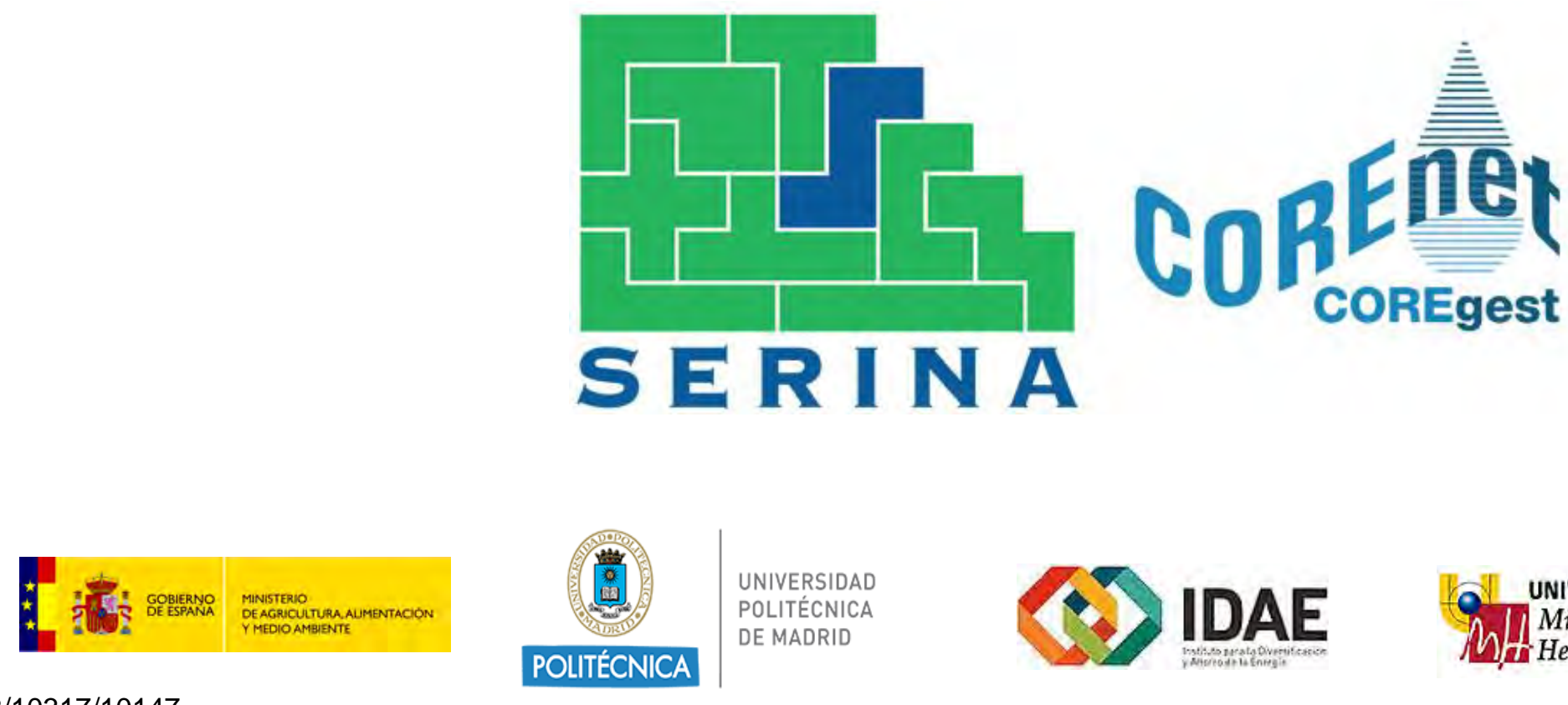

C) IDAE

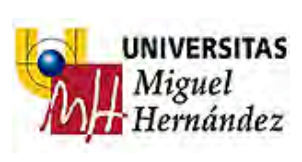

2. 


\section{Congreso Nacional de Riegos CARTAGENA 2021}

- Desde 1997 ayudando a las Comunidades de Regantes en la aplicación de Tecnologías de la Información para mejorar su funcionamiento.

- Experiencia con todo tipo de Comunidades (tradicionales y modernizadas) en toda España.

- Actividad constante de mejora de las herramientas y actividad de I+D en colaboración con los centros de investigación más importantes.

- Continuidad

- Apoyo a la Comunidad continuo. 

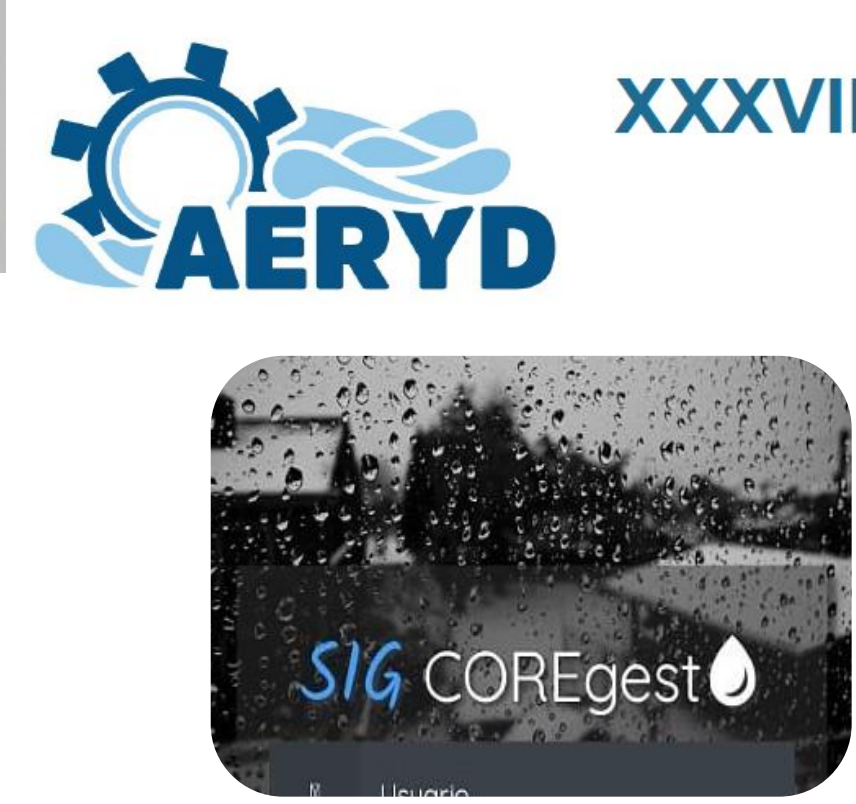

Gestión y

Mantenimiento del

Parcelario

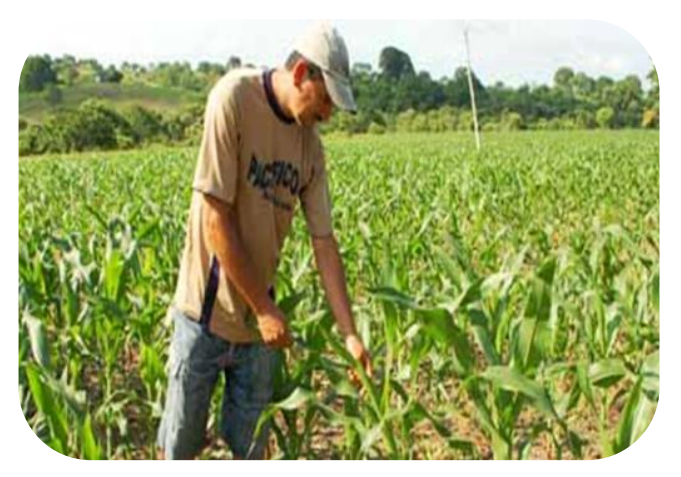

Procedimientos de relación con el regante

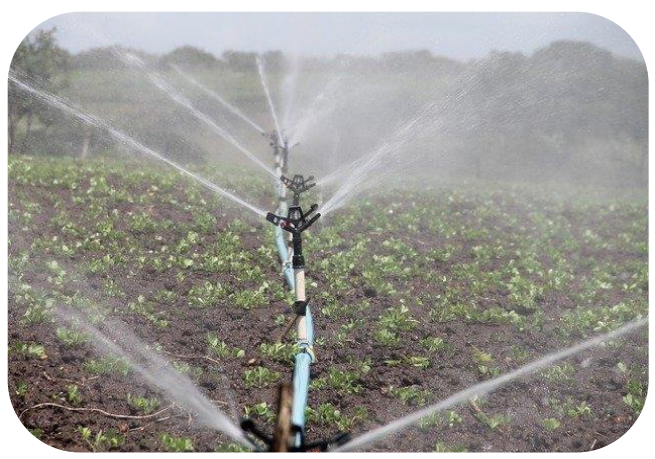

Procedimientos de gestión del agua

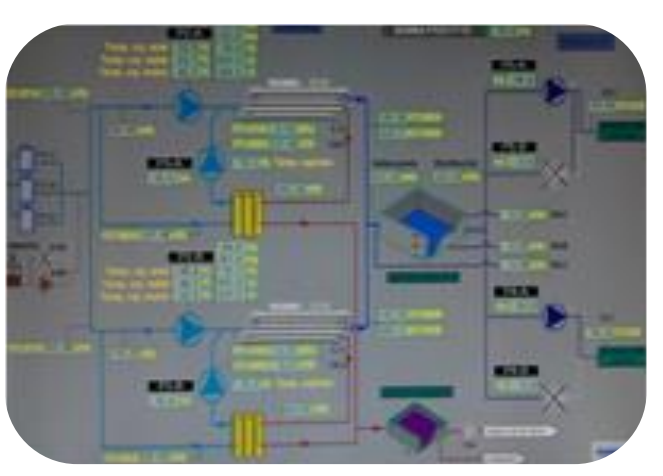

Información de gestión suministrada por automatismos y sensores. IOT

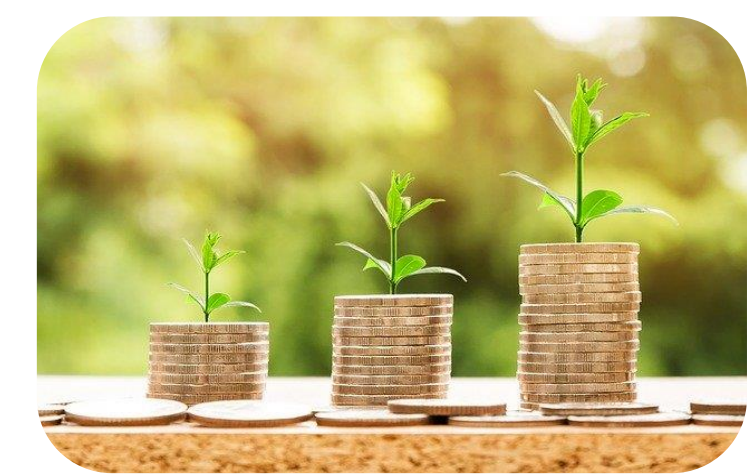

Procedimientos de

Facturación, Recaudación y control de costes

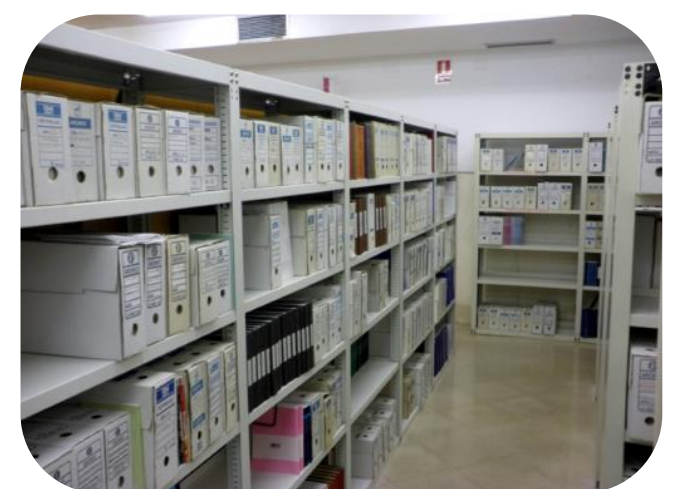

Procedimientos de gestión de documentación

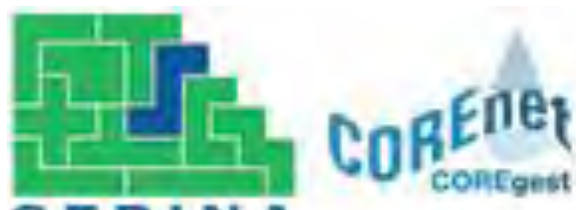

SERINA
A SCRATS

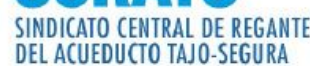

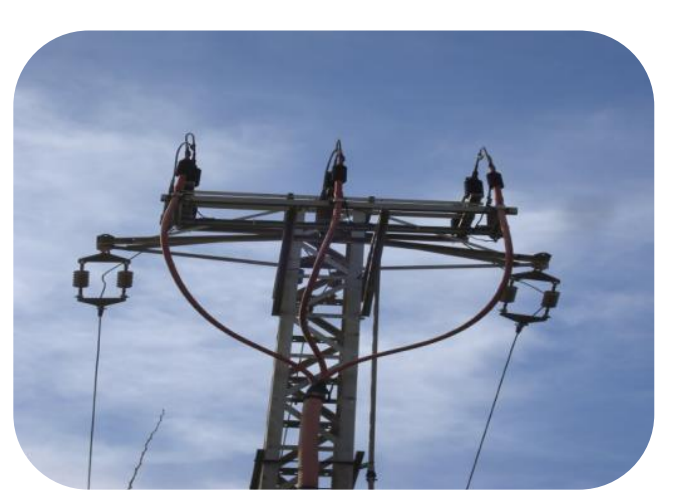

Procedimientos de gestión de energía.

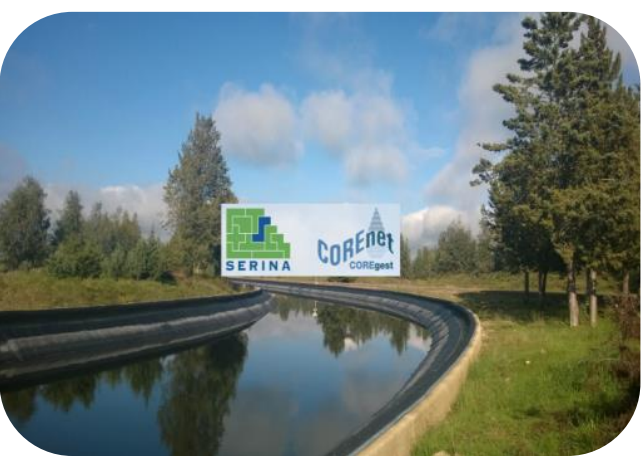

Procedimientos de mantenimiento de infraestructuras y gestión del personal 


\section{HERRAMIENTAS PARA SOPORTE DE LA COMUNIDAD}

-MODULOS SELECCIONABLES EN FUNCION DE LAS NECESIDADES DE CADA COMUNIDAD

-MODULOS ADAPTABLES EN FUNCION DE LAS NECESIDADES DE CADA COMUNIDAD

-INTERCAMBIO DE INFORMACIÓN CON AUTOMATISMOS , SERVICIOS DE INFORMACIÓN EXTERNOS Y DISPOSITIVOS IOT

-INTEGRACIÓN DE INFORMACIÓN

CORENET WEB
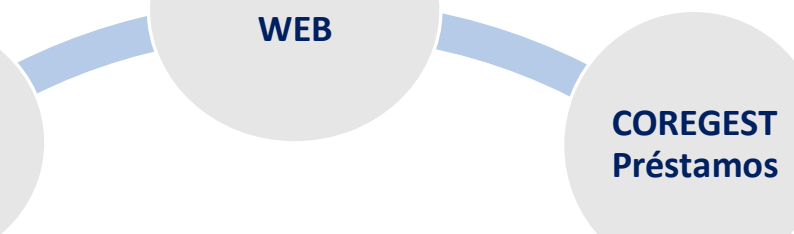

COREGEST

Préstamos
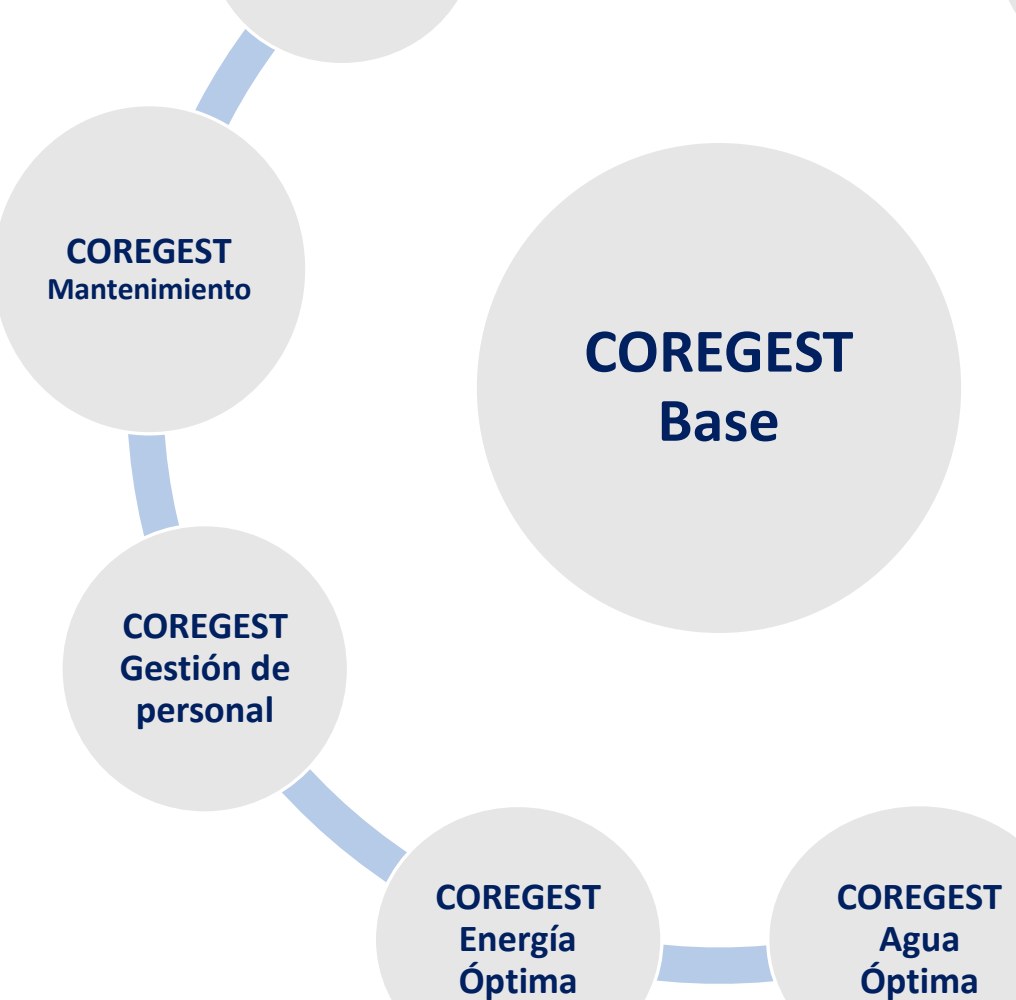

COREGEST

Cultivos

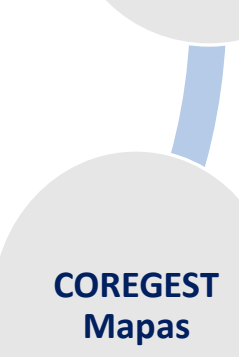




\section{COMUNIDAD GENERAL}

- Automatizar la gestión de ventas de agua desde la CG a C. de Base (toma única).

Permitir una gestión de asignaciones de agua a los regantes totalmente flexible $y$ transparente.

- Simplificar el proceso de venta de agua al regante incluyendo ventas por Internet.

- Gestionar ventas de agua con y sin IVA (posibilidad desgravación para empresas) Herramientas de gestión adicionales tales como Gestión Documental, Registro de Entrada-Salida electrónico

- Permitir, en siguientes fases del proyecto venta de agua por Internet, Gestión de Mantenimiento, WebGIS, gestión del canal y uso óptimo del agua.

Riegos de Levante Margen Izquierda del

\section{Segura}

COMUNIDADES
El Canal
Bacarot
60 y 70 de Levante
Tercero de Levante
60 y 70 La Peña
Crevillente
Orihuela

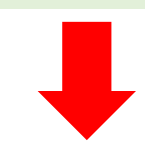

Regantes 

CARTAGENA 2021

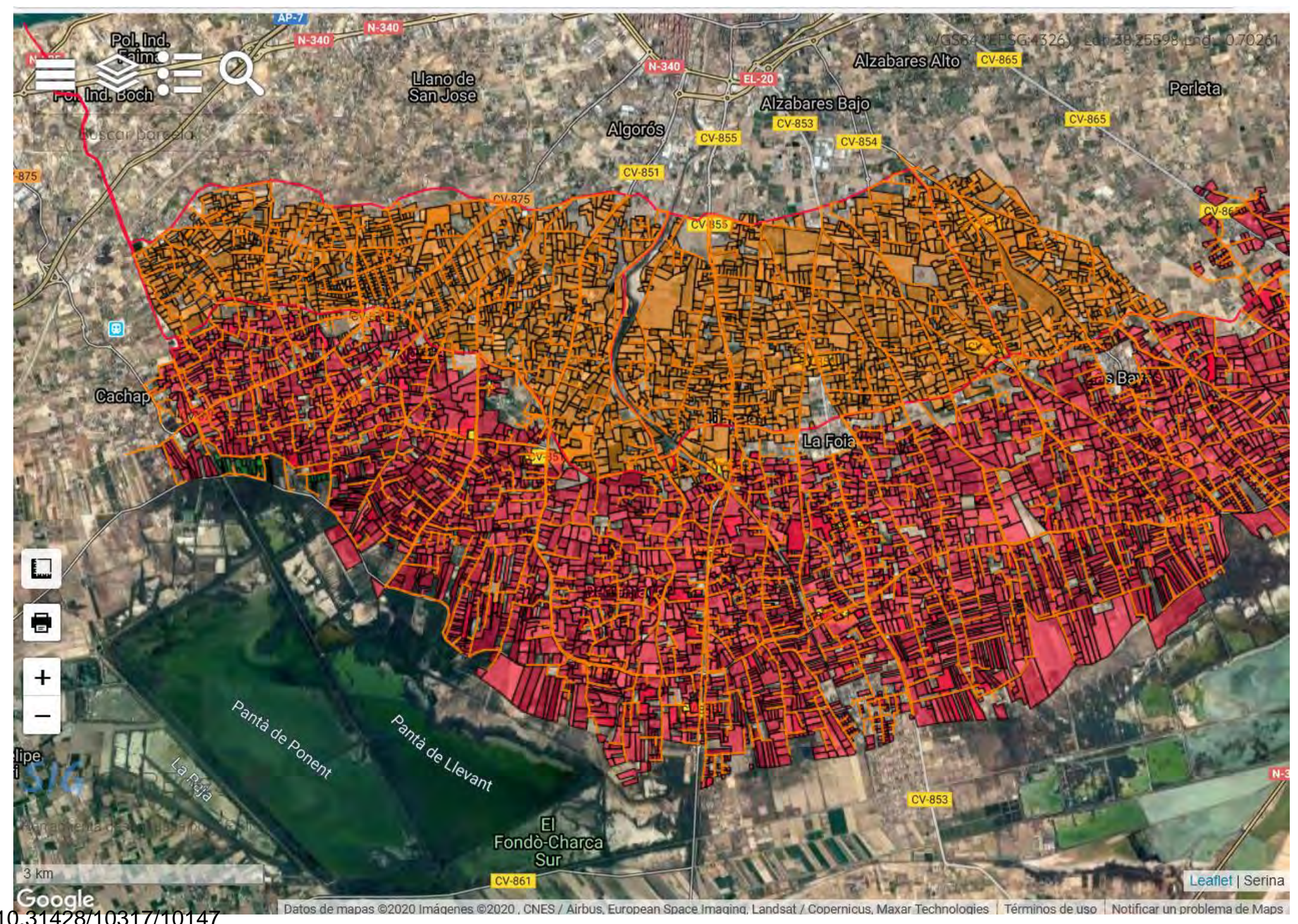

COMUNIDAD GENERAL

Riegos de Levante Margen Izquierda del Segura 